\title{
FutureGen Project Report
}

\author{
Prepared for: \\ U.S. Department of Energy
}

Type of Report:

Reporting Period Start Date:

Reporting Period End Date:

Principal Author(s):

Date Report Issued:

DOE Award Number:
Final Technical Report

July 13, 2009

August 30, 2010

Jim Cabe, Battelle

Mike Elliott, Battelle

December, 2013

DE-FE0000587

\section{Prepared by: \\ FutureGen Industrial Alliance}

\section{Disclaimer:}

This report was prepared as an account of work sponsored by an agency of the United States Government. Neither the United States Government nor any agency thereof, nor any of their employees, makes any warranty, express or implied, or assumes any legal liability or responsibility for the accuracy, completeness, or usefulness of any information, apparatus, product, or process disclosed, or represents that its use would not infringe privately owned rights. Reference herein to any specific commercial product, process, or service by trade name, trademark, manufacturer, or otherwise does not necessarily constitute or imply its endorsement, recommendation, or favoring by the United States Government or any agency thereof. The views and opinions of authors expressed herein do not necessarily state or reflect those of the United States Government or any agency thereof. 


\begin{abstract}
This report summarizes the comprehensive siting, permitting, engineering, design, and costing activities completed by the FutureGen Industrial Alliance, the Department of Energy, and associated supporting subcontractors to develop a first of a kind near zero emissions integrated gasification combined cycle power plant and carbon capture and storage project (IGCC-CCS). With the goal to design, build, and reliably operate the first IGCC-CCS facility, FutureGen would have been the lowest emitting pulverized coal power plant in the world, while providing a timely and relevant basis for coal combustion power plants deploying carbon capture in the future.
\end{abstract}

The content of this report summarizes key findings and results of applicable project evaluations; modeling, design, and engineering assessments; cost estimate reports; and schedule and risk mitigation from initiation of the FutureGen project through final flow sheet analyses including capital and operating reports completed under DOE award DE-FE0000587. This project report necessarily builds upon previously completed siting, design, and development work executed under DOE award DE-FC2606NT4207 which included the siting process; environmental permitting, compliance, and mitigation under the National Environmental Policy Act; and development of conceptual and design basis documentation for the FutureGen plant. For completeness, the report includes as attachments the siting and design basis documents, as well as the source documentation for the following:

- Site evaluation and selection process and environmental characterization

- Underground Injection Control (UIC) Permit Application including well design and subsurface modeling

- FutureGen IGCC-CCS Design Basis Document

- Process evaluations and technology selection via Illinois Clean Coal Review Board Technical Report

- Process flow diagrams and heat/material balance for slurry-fed gasifier configuration

- Process flow diagrams and heat/material balance for dry-fed gasifier configuration

- Full capital cost report and cost category analysis (CAPEX)

- Full operating cost report and assumptions (OPEX)

Comparative technology evaluations, value engineering exercises, and initial air permitting activities are also provided; the report concludes with schedule, risk, and cost mitigation activities as well as lessons learned such that the products of this report can be used to support future investments in utility scale gasification and carbon capture and sequestration.

Collectively, the FutureGen project enabled the comprehensive site specific evaluation and determination of the economic viability of IGCC-CCS. The project report is bound at that determination when DOE formally proposed the FutureGen 2.0 project which focuses on repowering a pulverized coal power plant with oxy-combustion technology including CCS. 


\section{Table of Contents}

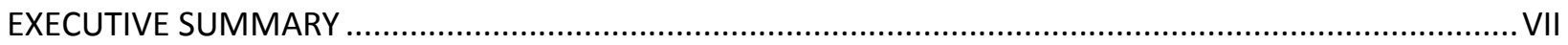

ACRONYMS AND ABBREVIATIONS ................................................................................

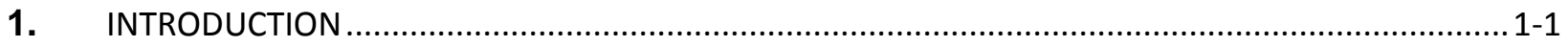

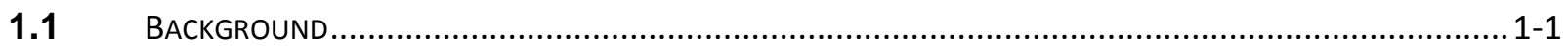

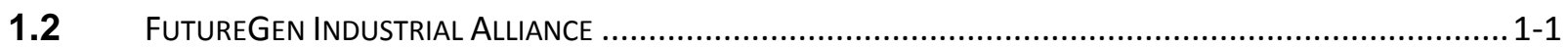

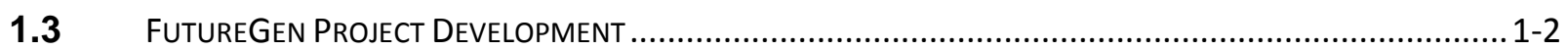

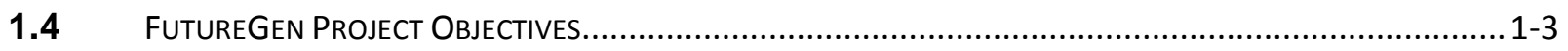

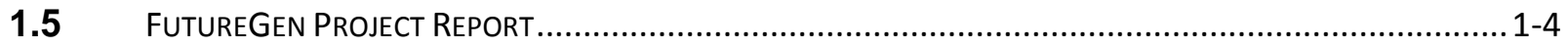

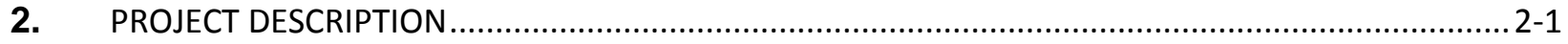

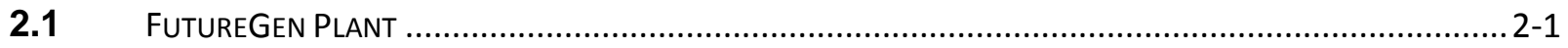

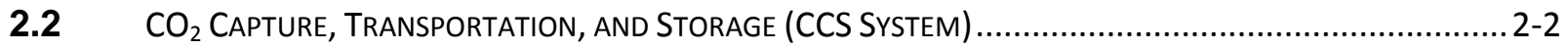

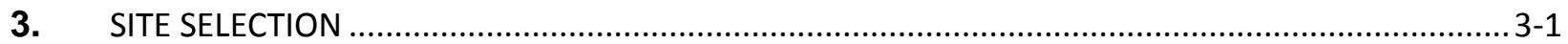

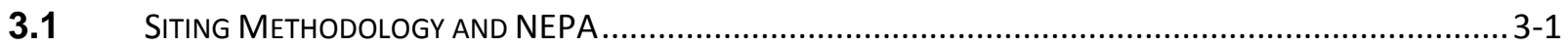

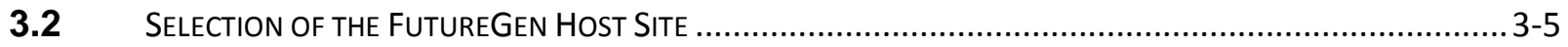

3.3 DESCRIPTION OF THE MATTOON, ILLINOIS FUTUREGEN SITE .................................................

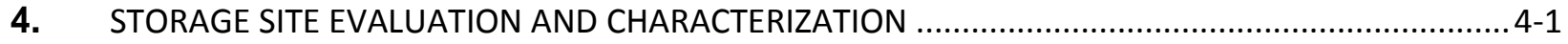

4.1 MATTOON AND THE Mt. SIMON STORAGE RESERVOIR ..........................................................

4.2 UNDERgRound INJECTION CONTROL (UIC) PERMitTING ......................................................4-6

4.2.1 Hydrogeologic Characterization of the Mattoon Injection and Confining Zones .............. 4-6

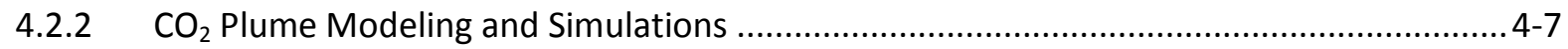

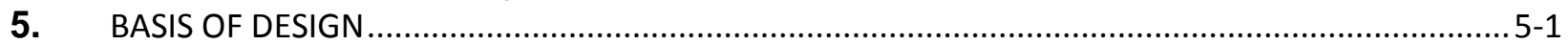

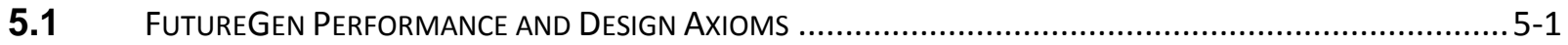

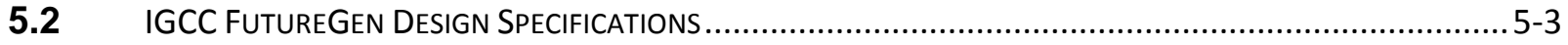

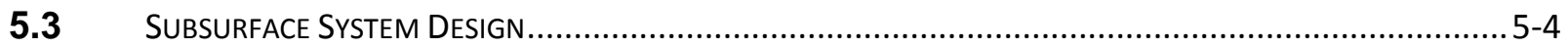

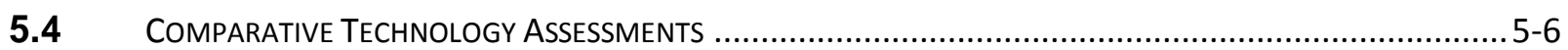

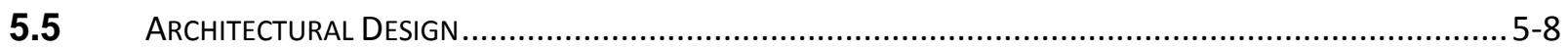

6. PROCESS EVALUATIONS, CONFIGURATION, AND HEAT \& MATERIAL BALANCE DEVELOPMENT ..6-1

6.1 CLEAN COAL REVIEW BOARD REPORT ........................................................................

7. PROJECT LIFE CYCLE COST ESTIMATE METHODOLOGY AND OVERVIEW.................................

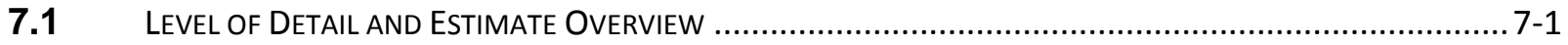

7.2 TECHNICAL REQUIREMENTS AND ENABLING ASSUMPTIONS .....................................................

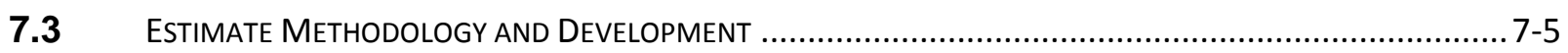

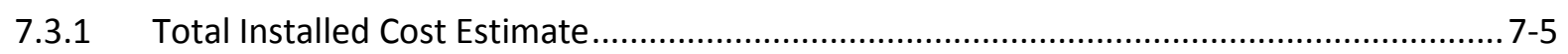

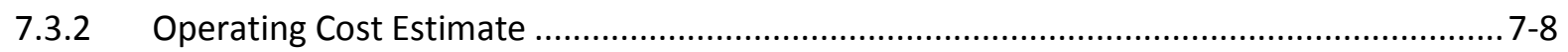

7.3.3 Post-Operations Cost Estimate ...............................................................

7.3.4 Value Engineering and Final Review ..............................................................

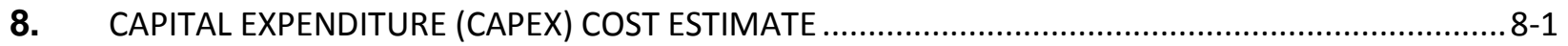

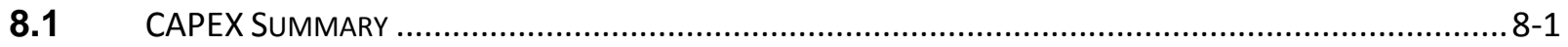

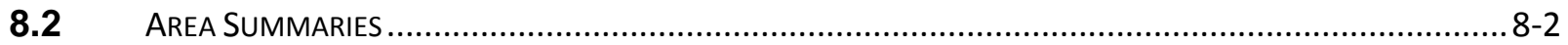

9. IGCC AND CCS OPERATIONS AND MAINTENANCE (OPEX) COST ESTIMATE .............................. 9-1

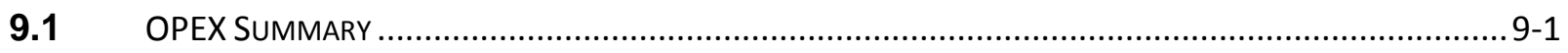




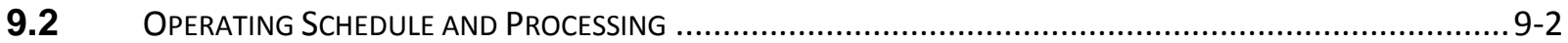

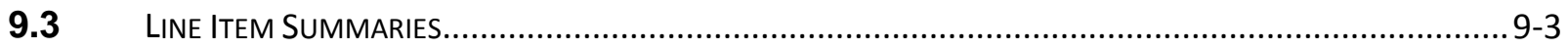

10. POST-OPERATIONS AND PROJECT CLOSEOUT ...................................................................... 10-1

11. ENGINEERING AND OPERATIONAL ASSESSMENTS …......................................................11-1

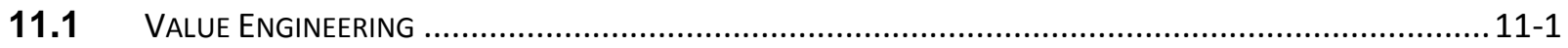

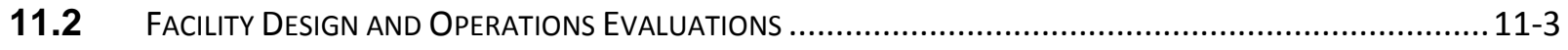

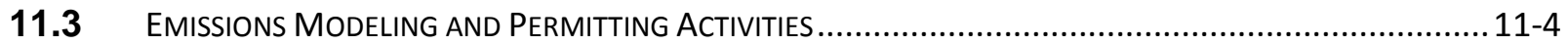

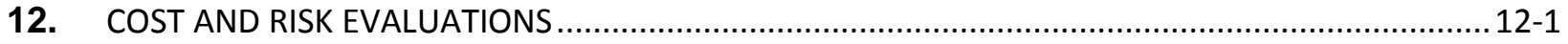

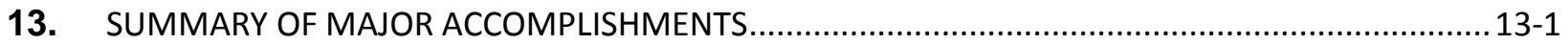

\section{Attachments}

ATTACHMENT 1 -SITE SELECTION REPORT

ATtACHMENT 2 - Underground InJection Control (UIC) Permit Application

ATTACHMENT 3 -DESIGN BASIS DOCUMENT

ATtACHMENT 4 - CleAn CoAl ReVIeW BoARd TeChNical Report

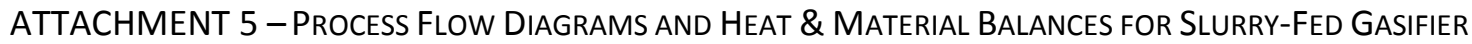

ATtACHMENT 6 - Process Flow Diagrams and HeAt \& Material BalanCES For Dry-Fed Gasifier

ATTACHMENT 7 - CAPITAL EXPENDITURE (CAPEX) COST ESTIMATE REPORT

ATTACHMENT 8 -OPERATING EXPENDITURE (OPEX) COST ESTIMATE REPORT 


\section{LIST OF TABLES}

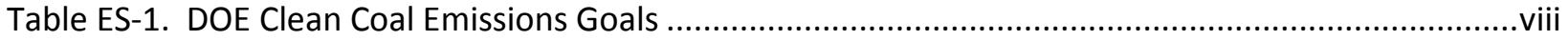

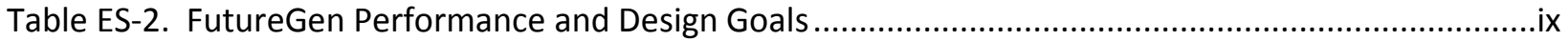

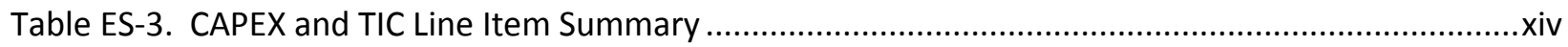

Table ES-4. Summary of FutureGen Operating Costs ...............................................................................

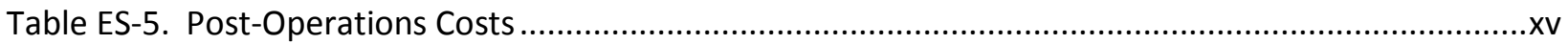

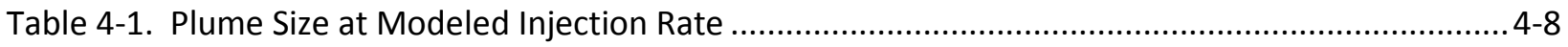

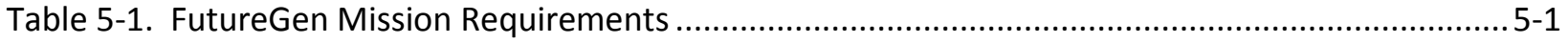

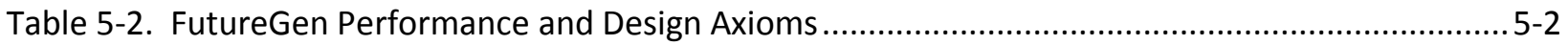

Table 5-3. FutureGen Technical Design Specifications ${ }^{a}$.........................................................................

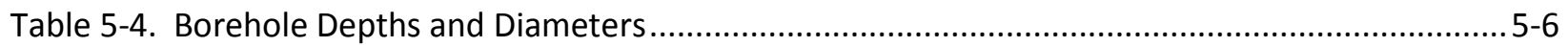

Table 6-1. Material Balance and Flow Rate at Design ........................................................................... 6-2

Table 6-2. Material Balance and Flow Rate for Alternate Coal Ranks ................................................ 6-2

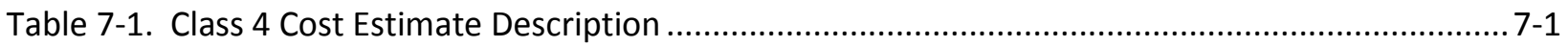

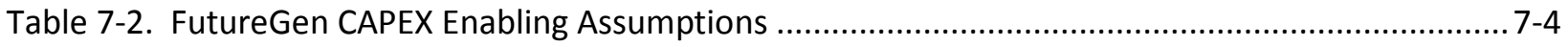

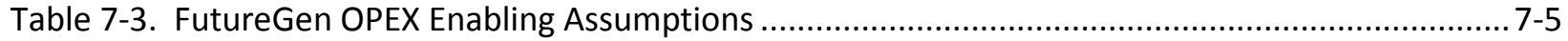

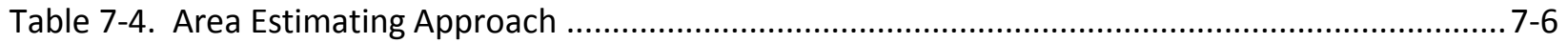

Table 8-1. CAPEX for Slurry-Fed and Dry-Fed Configurations................................................................ 8-2

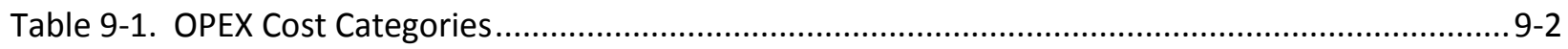

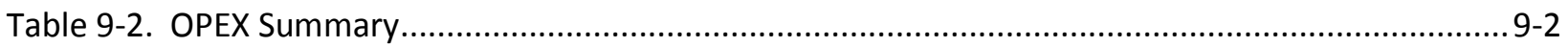

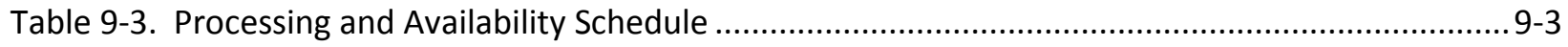

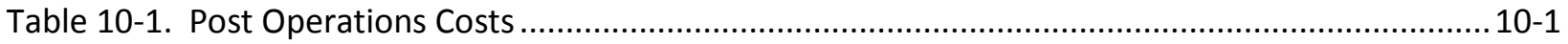

Table 11-1. Value Engineering and Trade-off Evaluations ..............................................................11-2

Table 12-1. FutureGen Alliance Inputs and Summary for Monte Carlo Analysis..................................12-1 


\section{LIST OF FIGURES}

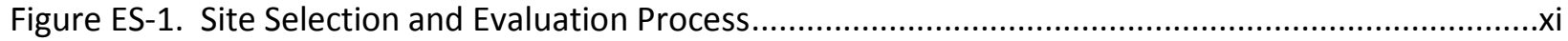

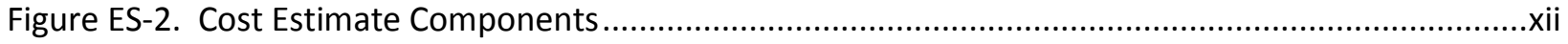

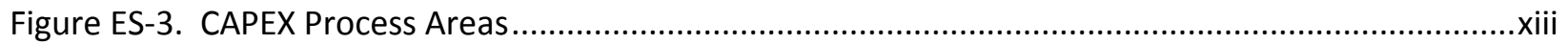

Figure 2-1. Simplified Block Flow Diagram of an IGCC Plant with $\mathrm{CO}_{2}$ Capture................................... 2-1

Figure 2-2. Components of a Generic Sequestration System ......................................................... 2-3

Figure 3-1. Proposed Sites for the FutureGen Project ..................................................................... $3-2$

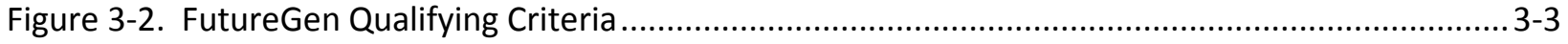

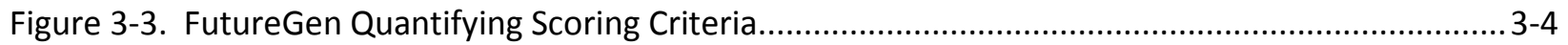

Figure 3-4. Mattoon, Illinois FutureGen Plant and Injection Site ..................................................... 3-6

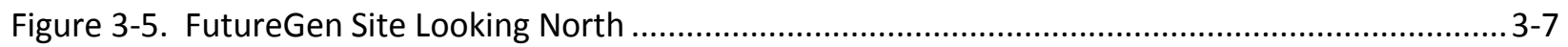

Figure 3-6. FutureGen Site with New Crop Planted.............................................................................

Figure 4-1. 20-yr and 50-yr Modeled $\mathrm{CO}_{2}$ Plume Size...................................................................... 4-2

Figure 4-2. Seismic Profiles Acquired at the Mattoon FutureGen Site ............................................... 4-3

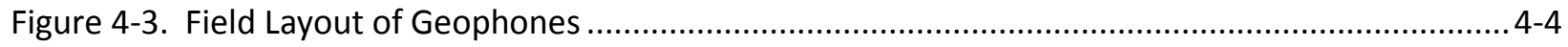

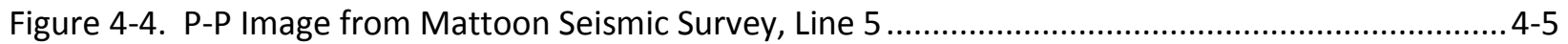

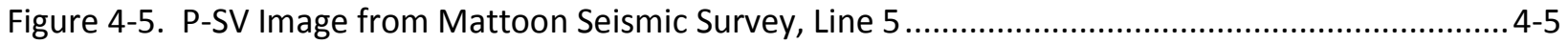

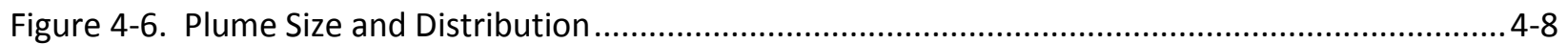

Figure 4-7. Injection Model Scenario: Layers 4c-6f (748-ft)............................................................. 4-9

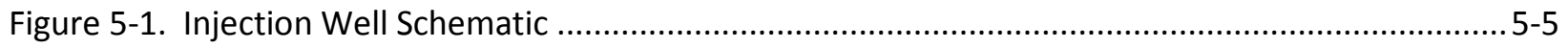

Figure 5-2. Artist rendering of FutureGen visitor center ................................................................. 5-9

Figure 5-3. FutureGen control room building - 3D rendering ........................................................ 5-10

Figure 5-4. FutureGen control room building - architectural plan, first floor ..................................... 5-11

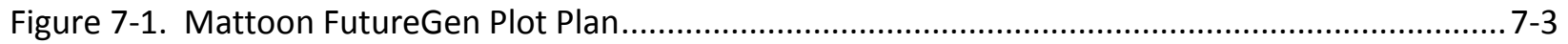

Figure 7-2. Example of Area Estimate Bid Logic............................................................................... 7-7

Figure 7-3. CAPEX and Total Install Cost Estimate Logic ..................................................................

Figure 7-4. OPEX and Total Operating Cost Estimate Logic ..........................................................

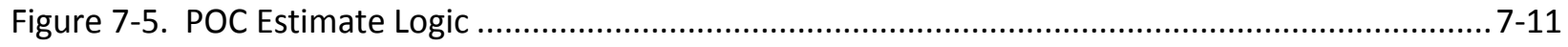

Figure 7-6. Cost Estimate Review Process .................................................................................... 7-11

Figure 11-1. FutureGen Plant Alignment and Sources................................................................. 11-5

Figure 11-2. Cold Plant Start-Up Sequence of Operations............................................................... 11-6 


\section{EXECUTIVE SUMMARY}

The FutureGen Integrated Gasification/Combined Cycle (IGCC) Carbon Capture and Storage (CCS) project was a collaborative partnership of global stakeholders, both public and private, involved in the effective use of coal for electricity production. This project was focused on an IGCC/CCS configuration until 2010, when the scope was changed to an oxycombustion/CCS configuration and renamed "FutureGen 2.0." This report summarizes the collaborative efforts of the original FutureGen project, which was exclusively an IGCC/CCS configuration, from site selection activities starting in 2005 through the conceptual design and cost estimate in 2010.

In response to a 2003 federal call to investigate and promote the development of clean coal power production, the FutureGen Industrial Alliance (the Alliance) was formed to evaluate the technical and economic feasibility of generating electricity from a first-of-a-kind (FOAK) clean coal power plant. At project initiation, the Alliance was composed of 12 major industrial companies that produce coal and generate coalfueled power on six continents. With coal-fueled electricity generation providing nearly half of the domestic supply of power ${ }^{1}$ and approximately 40 percent of the worldwide supply, ${ }^{2}$ the FutureGen project was the first attempt in the world to site, permit, design, construct, and operate a fully integrated coal-fueled power plant with near-zero emissions, including the capture and permanent storage of the carbon dioxide $\left(\mathrm{CO}_{2}\right)$ produced by the power plant.

As originally envisioned, the Alliance, in cooperation with the U.S. Department of Energy (DOE), was responsible for all aspects of the FutureGen project design and development, including power plant and sequestration $^{3}$ site selection; power plant and sequestration system design, cost estimating, construction, and operations; risk and liability management; and overall project management. As a compendium of information, analyses, and documentation from project initiation and siting through the site-specific design phase of the FutureGen IGCC/CCS project, the following project report was prepared by the Alliance to summarize the work conducted by the Alliance and its subcontractors in the development of the first comprehensive and supportable site selection and project cost estimate provided to DOE for the FutureGen IGCC/CCS project. Accordingly, the report includes substantial technical contributions from URS (Washington Division: Houston office); siting and project development support from Coles Together (Coles County, Illinois); as well as those activities completed by the Alliance and numerous others. The work contained herein was executed under the original FutureGen cooperative agreement (DE-FC26-06NT42073) and the FutureGen restart agreement (DE-FE0000587).

The FutureGen IGCC/CCS project not only produced a defensible siting process, a robust engineering and design effort, and a detailed cost estimate, it provided a comprehensive and applicable path to the development and deployment of integrated power production and carbon capture technologies. The following summarizes the activities and details considered most relevant in the execution of siting, designing, engineering, and costing the FutureGen project. Each of the following sections also includes a condensed discussion of the key lessons learned. The lessons learned are subjective and represent the opinions of the project team.

\footnotetext{
${ }^{1}$ U.S. Energy Information Administration, Annual Energy Outlook 2011. DOE/EIA-0383(2011), April 2011.

2 U.S. Energy Information Administration, International Energy Outlook 2011. DOE/EIA-0484, September 2011.

3 The term "sequestration" has since been changed to "storage."
} 
This report provides a narrative of the work completed for the FutureGen project, and is a collection of the substantial amount of technical design, engineering, and development work previously completed by the Alliance, their respective subcontractors, collaborative partners, and the DOE. Further description or details are added to this report to clarify this previous work such as siting and subsurface evaluations; design basis and engineering analyses; capital and operating reports; as well as others which are included in entirety as attachments to this report. In some cases, these reports contain proprietary information that was provided to the Alliance by technology providers. In those cases, the proprietary information is redacted or provided as an amended version with the relevant details disclosed.

The Alliance completed considerable work in other important areas, such as vendor due diligence and communications, equipment and materials specifications, stakeholder support, and site-specific communications among others. These are captured in other documents outside the scope of this report.

\section{Basis of Design}

Under guidance provided by DOE's National Energy Technology Laboratory for a near-zero emissions gasification and power generation facility, the Alliance designed the FutureGen project to nominally produce $275 \mathrm{MW}(\mathrm{e})$, while meeting the programmatic emissions targets provided in Table ES-1.

Table ES-1. DOE Clean Coal Emissions Goals

\begin{tabular}{|l|}
\hline \multicolumn{1}{|c|}{ Emissions Goals ${ }^{\mathrm{a}}$} \\
\hline Greater than 99 percent removal of sulfur \\
\hline Greater than 90 percent mercury removal \\
\hline $\begin{array}{l}\text { Less than } 0.05 \text { pounds of nitrogen oxides }\left(\mathrm{NO}_{x}\right) \text { emitted per million British thermal } \\
\text { units (BTU) }\end{array}$ \\
\hline Less than 0.005 pounds of particulate matter (PM) emitted per million BTU \\
\hline Capture and sequester 90 percent of the $\mathrm{CO}_{2}$ produced at the plant \\
\hline${ }^{\mathrm{a}}$ FutureGen Alliance Initial Conceptual Design Report. Rev. 2. May 2007.
\end{tabular}

The Alliance refined these targets further for project-specific design basis documents such as the environmental impact statement (EIS), surface facility engineering design data, capital cost report, and the operating cost report; the targets are offered in the following design axioms as proposed by the Alliance. 
Table ES-2. FutureGen Performance and Design Goals

\begin{tabular}{|c|c|c|}
\hline & Performance Target & Design Axioms ${ }^{a, b}$ \\
\hline \multirow{2}{*}{$\begin{array}{l}\text { Facility } \\
\text { Related }\end{array}$} & $\begin{array}{l}\text { IGCC configuration, rated } \\
\text { nominally at } 275 \mathrm{MW}(\mathrm{e})\end{array}$ & $\begin{array}{l}\text { Capability to fully load an F-Class combustion gas turbine on at least } \\
\text { one coal type. }\end{array}$ \\
\hline & $\begin{array}{l}\text { Gasify multiple coal types and } \\
\text { ranks }\end{array}$ & $\begin{array}{l}\text { Capability to gasify a range of coal types from sub-bituminous to } \\
\text { bituminous. }\end{array}$ \\
\hline \multirow{5}{*}{$\begin{array}{l}\text { Emissions } \\
\text { Related }\end{array}$} & $\begin{array}{l}\text { Greater than } 99 \text { percent removal } \\
\text { of sulfur }\end{array}$ & $\begin{array}{l}\text { Emit at the heat recovery steam generator }(\mathrm{HRSG}) \text { stack an amount } \\
\text { equal to or less than } 1 \text { percent of sulfur }\left(\mathrm{as} \mathrm{SO}_{\mathrm{x}}\right) \text { in the coal feed, or less } \\
\text { than } 15 \mathrm{ppmv} \text {, whichever is greater. }\end{array}$ \\
\hline & $\begin{array}{c}\text { Greater than } 90 \text { percent mercury } \\
\text { removal }\end{array}$ & $\begin{array}{l}\text { Remove more than } 90 \text { percent of the mercury contained in the coal fed } \\
\text { to the gasifier. }\end{array}$ \\
\hline & $\begin{array}{l}\text { Less than } 0.05 \text { pounds of } \\
\text { nitrogen oxide emitted per } \\
\text { million BTU coal }\end{array}$ & $\begin{array}{l}\text { Emit at the HRSG stack an amount of } \mathrm{NO}_{\mathrm{x}} \text { equal to or less than } 0.05 \\
\text { pounds of } \mathrm{NO}_{\mathrm{x}} \text { per million BTU of coal gasified., }\end{array}$ \\
\hline & $\begin{array}{l}\text { Less than } 0.005 \text { pounds of PM } \\
\text { emitted per million BTU coal }\end{array}$ & $\begin{array}{l}\text { Emit at the HRSG stack an amount of PM equal to or less than } \\
0.005 \text { pounds per million BTU of coal gasified. }\end{array}$ \\
\hline & $\begin{array}{l}\text { Capture } 90 \text { percent of the } \mathrm{CO}_{2} \\
\text { produced at the plant }\end{array}$ & $\begin{array}{l}\text { Capture } 90 \text { percent of the carbon in the sour syngas stream from the } \\
\text { gasifier. Sequester at least } 1 \text { million metric tons of } \mathrm{CO}_{2} \text { per year in a } \\
\text { deep saline geologic formation. }\end{array}$ \\
\hline
\end{tabular}

The final technology configuration(s) and flow sheet analyses confirmed that the design axioms could be met by the proposed design.

\section{Observations and Lessons Learned - Performance Targets}

- Gasifying multiple coal types required a non-optimized design, additional equipment resulting in higher cost, or significant turndown on the combustion turbine generator (CTG) for lower rank coals. Fuel flexibility would also affect the plant on-stream factor when transitioning between coal types. The plant heat rate and gross-to-net capacity penalty to accommodate fuel flexibility was noticeable. As described in the Value Engineering section (11.1), the Alliance evaluated the impact to capital costs by optimizing the design for a single coal (Illinois 6); the concluding recommendation was to optimize the design to a single coal, but maintain the capability to process other ranks. These value engineering exercises recommended a revised axiom:

"The FutureGen design is optimized for a single coal type, Illinois \#6. While this doesn't preclude use of other coal types, no equipment or capacity will be installed for other coal types."

- The IGCC gross and net output varied considerably based on technology configuration and coal type. In each case, the gross output of the facility was greater than $275 \mathrm{MW}$; however, the net power output varied as much as $45 \mathrm{MW}$. The terminology used to initially define the project's electrical output, Nominally Rated at $275 \mathrm{MW}$, should be amended such that future performance targets capture the objective of the gasification process (nominal syngas production), and the objectives of power production: capacity and efficiency. 
- Preliminary plant permitting activities and best available control technology analysis had been initiated, requiring site-specific design details such as stack, flare, and vent locations and impacts to dispersion models based on local conditions and the current plot plan. The initial performance targets did not have provisions for "off-spec" or "off-design" operations, which were considerable given the proposed availability and capacity factors of early year operations. The performance goals should specify that targets are for commercial operation after startup periods are complete.

- The carbon capture specification was based on sour syngas from gasifier, not carbon in the coal. This was done so that carbon in the gasifier byproducts would not count against the total. This provision was felt to be appropriate considering the range of gasifier technologies available. That said, this target did not provide for startup and shut down operations such as natural gas combustion during startup, flaring, operation of auxiliary boiler, etc. This caused some difficulty in determining the accounting system and "rules" necessary to ensure that the intent of the target was met. The performance target for carbon capture should provide some detail about the intent of the target and the contributors to the carbon total. This is especially important for FOAK facilities and less important for future commercial facilities.

- The fuel flexibility performance target made it challenging to meet capital cost targets in most areas of the plant, not just the gasifier and CTG. The target had significant impacts on the acid gas removal unit and sulfur removal unit / tail gas treatment unit designs and costs, the coal yard, etc. Future performance targets for fuel flexibility should account for the significant economic impact of this feature and either 1) accept that a premium price will be paid for such a facility and that the gas treatment train may require parallel units, or 2 ) allow significant plant de-rating and possible nonattainment of emissions targets during processing of some fuel types.

\section{Siting and Site Selection}

The FutureGen site selection process was initiated in December 2005. The Alliance Siting Team and support staff developed and issued the draft FutureGen Alliance Request for Proposals for the FutureGen Facility Host Site in February 2006, and the final FutureGen Alliance Request for Proposals for the FutureGen Facility Host Site in March 2006, ${ }^{4}$ after receiving and incorporating public comments. Twelve proposals representing seven different states were received for consideration. Through a rigorous qualitative and quantitative screening process, the Alliance carried four candidate sites forward for analysis. This process included full characterization of the four candidate sites under federal National Environmental Policy Act (NEPA) requirements, as well as the evaluation of site-specific characteristics. The matrix developed for the final determination of site suitability and preferential ranking of the sites included contributions from multiple sources including original site proposals; the best and final offer submissions from site proponents; Alliance due diligence analyses of the legal and financial aspects of each site; studies related to sequestration site and reservoir, transmission, and permitting; site-specific studies on power plant construction, transmission, and operations; consideration of site preparation requirements; and evaluations of representative power markets. A copy of the final, completed matrix is included in the reference folder. Figure ES-1 provides the framework developed and executed by the Alliance during the site selection process.

\footnotetext{
${ }^{4}$ FutureGen Industrial Alliance: Final Request for Proposals for the FutureGen Facility Host Site. March 7, 2006.
} 


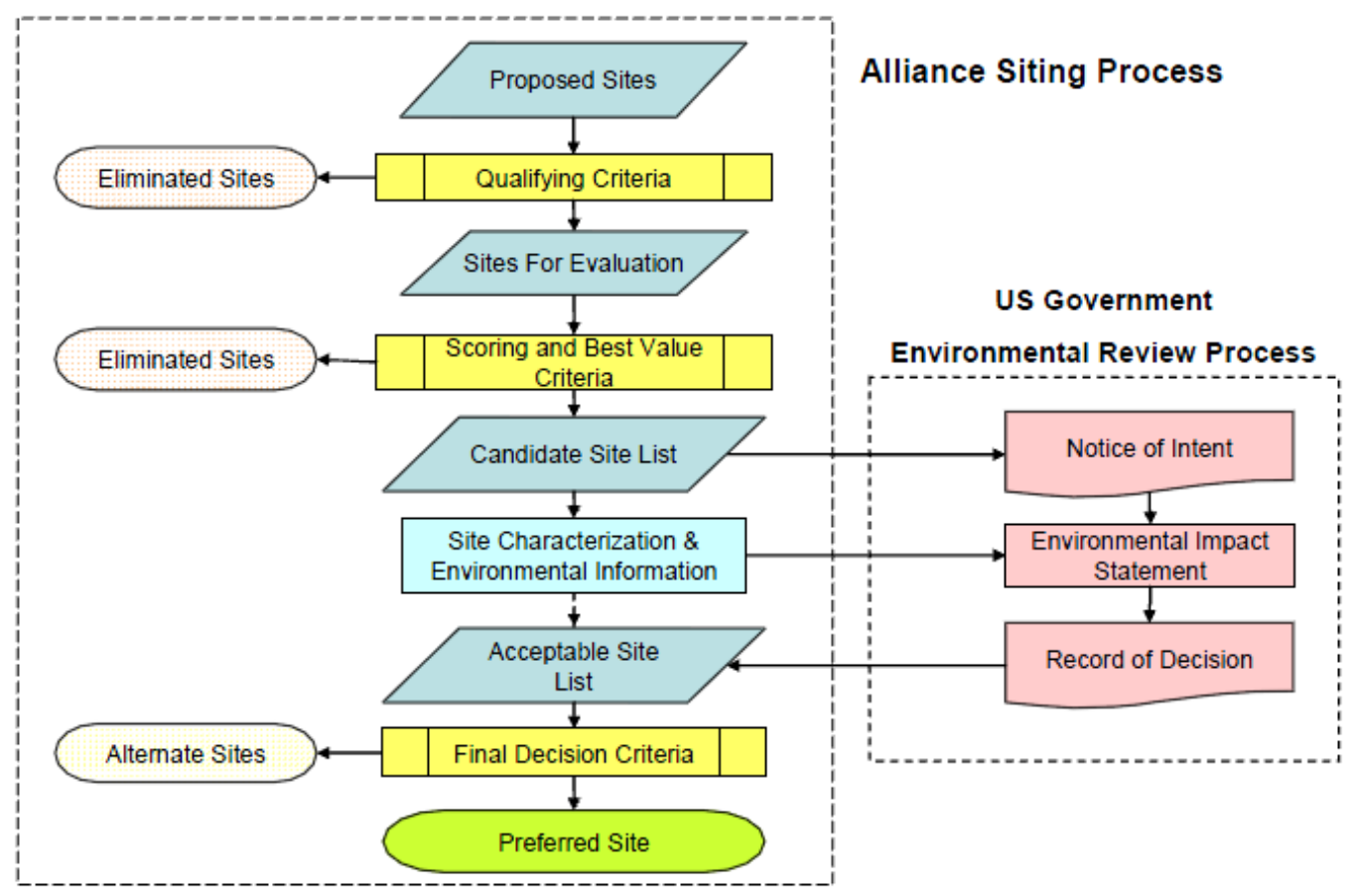

Figure ES-1. Site Selection and Evaluation Process ${ }^{5}$

With the final determination that each of the final four candidate sites could support the project, the Alliance announced in December 2007 that the Mattoon, Illinois site provided the best overall comparative value, having fully considered the environmental, cost, and risk characteristics of each site (both to cost and schedule). The record of decision (ROD) was issued by the federal government in July 2009, confirming compliance with NEPA requirements; the ROD indicated that each candidate site would be acceptable to host the FutureGen project. Section 3. provides additional information on siting and the site selection process.

Observations and Lessons Learned - Siting and Site Selection

- Develop a siting evaluation and selection plan with input from a wide range of disciplines prior to drafting requests for proposals.

- While confidentiality is necessary to maintain fair competition, the overall process should be as open and transparent as possible.

- A robust siting process wherein all pertinent information is fully disclosed is necessary to gain and keep stakeholder support.

- Clear legal title or purchase option to the property is imperative to minimizing ownership risk. This enabled the Alliance to quickly establish plant boundaries and design specifics related to site control, access points (rail and road entrance), egress, and utility connections. It also limits third party interests or claims on the property.

- Clear legal control or exercisable options for ownership of subsurface (sequestration) pore space is imperative to enabling control over the $\mathrm{CO}_{2}$ plume boundaries.

\footnotetext{
${ }^{5}$ Included in Section 1 of the FutureGen Request for Proposals for the FutureGen Facility Host Site, March 7, 2006.
} 
- Clear understanding of $\mathrm{CO}_{2}$ pipeline route access and ownership is important for sites where the $\mathrm{CO}_{2}$ injection site is separated from the power plant.

- Siting in a location with meaningful $\mathrm{CO}_{2}$ storage legislation (at the state level) has a clear advantage, addressing aspects of indemnification and storage liability.

- Siting in a location with clear state-level guidelines and processes streamlines the permitting process.

- It is advantageous to minimize off-site requirements (easements for pipeline and utility corridors) and injection well locations. Fully evaluate the risks to public, cost, and schedule.

- Access and rights to utilities such as plant make-up water, natural gas, and power are important in the siting process.

- Electrical tie-in requirements and timelines are important to plant cost and schedule. The process, cost, and schedule for the power transmission system upgrades (via the regional transmission organization) should be understood during the siting process.

- The absence of pre-existing penetrations into the primary seal (storage reservoir) is advantageous.

- Sites considering $\mathrm{CO}_{2}$ storage vs. $\mathrm{CO}_{2}$ utilization (e.g., enhanced oil recovery) should fully vet potential take-off agreements, impacts to financial considerations, and overall levelized cost of electricity.

\section{Cost Estimate}

The FutureGen team prepared a Class 4 cost estimate methodology based on the Association for the Advancement of Cost Engineering guidance. ${ }^{6}$ Developed to accommodate the first "total project cost estimate," components of the cost estimate are aligned with four key areas and are provided in Figure ES-2: project initiation (Budget Period (BP)-0 and BP-1); total installed cost (TIC) which includes capital expenditures (CAPEX) and pre-commissioning costs; total operating expenditures (OPEX) including Alliance operations, owner costs, and permitting; and post-operations cost (POC).

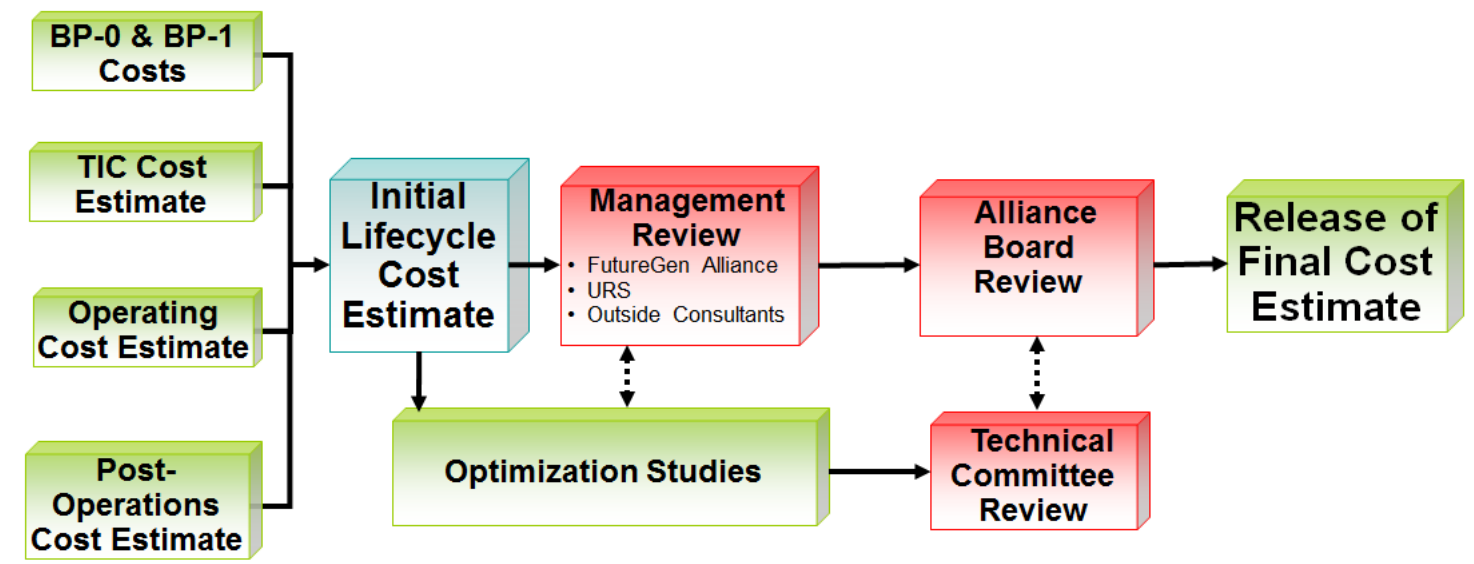

Figure ES-2. Cost Estimate Components

Prefacing the formal cost estimate activities, a complete set of process flow diagrams and the corresponding heat and material balance were developed for three representative coal types and two different types of coal gasifiers, enabling the estimate team to fully characterize the technology selections, likely configurations, and equipment sizing. The ensuing reference plant proposed for the cost estimate was

${ }^{6}$ AACE International Recommended Practice No. 18R-97, Cost Estimate Classification System - As Applied in Engineering, Procurement, and Construction for the Process Industries. 2005. 
expected to be reasonably representative of the final plant configuration; given the early stage of design development; however, it was understood that the final configuration (and therefore cost) of the facility would change as the design was completed.

With costs estimated for the reference plant design, each cost area was subjected to a Monte Carlo analysis to quantify the risks and impacts associated with the cost estimate (see Section 12. ). This was a multi-step process starting with the unmitigated overnight CAPEX estimate, applying the estimate-driven risks identified by the estimating team, applying confidence limits and ranges for each island, and then incorporating event-driven risks to arrive at the additional contingency necessary to provide assurance that the project can be delivered within budget. An independent analysis of the final cost estimate indicated that, based on an assessment of project documentation and interviews with the design and estimating team, appropriate estimating methods, techniques, and procedures were utilized in preparing the estimates.

\section{CAPEX and Total Installed Cost}

The FutureGen CAPEX was based on a facility design that was segmented into 15 process areas, distinguishable by the red lettering in Figure ES-3. Several different estimating strategies were needed to estimate the costs for each area as accurately as possible. These tools included "Similar Plant," EPC Bid, Aspen Capital Cost Estimator (ACCE ${ }^{\mathrm{TM}}$ - formerly Kbase ${ }^{\mathrm{TM}}$ and Icarus), WINEST, and Factored Estimates. The tools were tailored and used to provide the most representative and defensible cost estimate for each area.

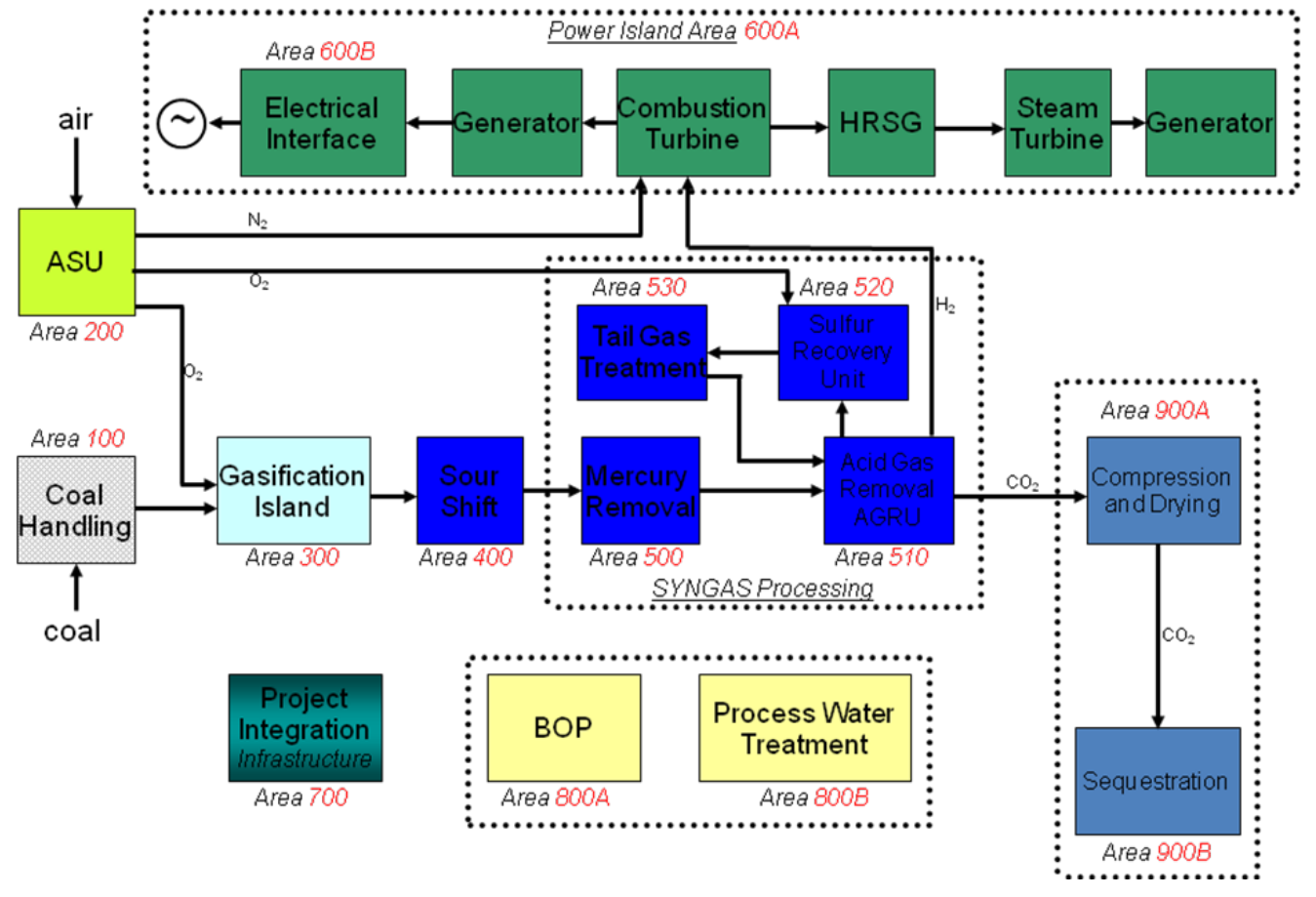

Figure ES-3. CAPEX Process Areas

The CAPEX values, summarized in Table ES-3, include an estimate for a slurry-fed gasifier configuration and a dry-fed gasifier configuration, as it was not decided at the time of cost estimate report which technology would ultimately be deployed for the FutureGen project. The values provided are from the draft 2009 
project cost estimate issued to DOE and January 2010 update, $^{7}$ and are based on an estimate of costs as of the second quarter of 2009 (2Q2009).

Table ES-3. CAPEX and TIC Line Item Summary

\begin{tabular}{|c|c|c|c|c|c|}
\hline \multirow{2}{*}{ Line } & & \multicolumn{2}{|c|}{$\begin{array}{c}\text { 2Q2009 } \\
\text { Slurry-Fed Gasifier }\end{array}$} & \multicolumn{2}{|c|}{$\begin{array}{c}\text { 2Q2009 } \\
\text { Dry-Fed Gasifier }\end{array}$} \\
\hline & Direct Costs & $\$$ & $1,010,081,000$ & $\$$ & $1,166,428,000$ \\
\hline 2 & Indirect Costs & $\$$ & $267,954,735$ & $\$$ & $265,493,742$ \\
\hline 4 & Total Field Costs & $\$$ & $1,278,035,735$ & $\$$ & $1,431,921,742$ \\
\hline 5 & Home Office Engineering & $\$$ & $109,308,385$ & $\$$ & $109,727,385$ \\
\hline 6 & Total Field and Home Costs & $\$$ & $1,387,344,120$ & $\$$ & $1,541,649,127$ \\
\hline 7 & Insurance & $\$$ & $13,458,558$ & $\$$ & $13,477,942$ \\
\hline 8 & Bonds & $\$$ & $3,212,955$ & $\$$ & $3,164,660$ \\
\hline 9 & Freight & $\$$ & $28,133,700$ & $\$$ & $27,540,600$ \\
\hline 10 & Cost Provisions & $\$$ & $141,453,000$ & $\$$ & $156,907,000$ \\
\hline 11 & Total CAPEX & $\$$ & $1,573,602,333$ & $\$$ & $1,742,739,329$ \\
\hline 12 & Fee & $\$$ & $96,627,855$ & $\$$ & $95,589,855$ \\
\hline 13 & Total Contract Value & $\$$ & $1,670,230,188$ & $\$$ & $1,838,329,184$ \\
\hline 14 & Alliance Operations & $\$$ & $28,400,000$ & $\$$ & $28,400,000$ \\
\hline 15 & $\begin{array}{l}\text { Engineering, Licensing, and } \\
\text { Construction Management }\end{array}$ & $\$$ & $69,326,630$ & $\$$ & $75,326,630$ \\
\hline 16 & Permitting & $\$$ & $6,500,000$ & $\$$ & $6,500,000$ \\
\hline 17 & First Fills & $\$$ & $16,516,452$ & $\$$ & $16,342,524$ \\
\hline 18 & License Fees \& Prelim Eng. & & uded in Line 15) & $(\ln$ & uded in Line 15) \\
\hline 19 & Initial Spares & & (Included in TIC) & & (Included in TIC) \\
\hline 20 & Owner Costs & $\$$ & $120,727,442$ & $\$$ & $126,553,514$ \\
\hline 21 & Pre-operational Costs & $\$$ & $13,217,302$ & $\$$ & $13,217,302$ \\
\hline 22 & TOTAL INSTALLED COST & $\$$ & $1,804,174,932$ & $\$$ & $1,978,100,000$ \\
\hline
\end{tabular}

The CAPEX estimate includes costs for the surface facility (IGCC), subsurface facility (including $\mathrm{CO}_{2}$ injection wells, monitoring wells, and all related monitoring, verification, and accounting (MVA) capital requirements), and supporting infrastructure. The division between CAPEX and OPEX for the purpose of the estimate was plant commissioning; equipment check-out was contained in the CAPEX, with plant startup costs captured in the OPEX.

\section{OPEX}

The OPEX produced for the FutureGen facility was based on the same plant specifications and design provided for in the CAPEX. The baseline operating plan called for 4 years of plant operations followed by 2 years for MVA of the $\mathrm{CO}_{2}$ sequestration site. Therefore, the OPEX estimate includes all of the operations and maintenance (O\&M) costs associated with the full 48-month operating period, as well as the POCs associated with $\mathrm{CO}_{2}$ monitoring and project closeout, although the POCs were reported separately. The estimate was relative to 2 Q2009 dollars; however, where appropriate, certain costs such as labor, fuel, and consumables were escalated to determine total project cost associated with the OPEX.

\footnotetext{
${ }^{7}$ FutureGen Alliance. 2009 Project Cost Estimate: Volume I, Capital Costs. January 29, 2010.
} 
Two estimates were developed, representing the slurry-fed and dry-fed gasifier configurations. Many of the costs were similar in both configurations, drawing on the same resources independent of the technology selection. Examples of such costs include O\&M labor, all subsurface O\&M, and certain owner costs. The summary data provided in Table ES-4 is categorized by fixed and variable costs, determining the total nonfuel-related O\&M expenditures; the fuel costs were added to capture the total O\&M costs. It is noted that the OPEX estimate was based on utilization of a single coal type (Illinois 6).

Table ES-4. Summary of FutureGen Operating Costs ${ }^{8}$

\begin{tabular}{|l|r|r|}
\hline Cost Category & Slurry Fed Total & Dry Fed Total \\
\hline Fixed O\&M & \$215 M & \$236 M \\
\hline Variable O\&M & $\$ 53 \mathrm{M}$ & \$53 M \\
\hline Total Non-Fuel O\&M & $\mathbf{\$ 2 6 8 ~ M}$ & $\mathbf{\$ 2 8 9} \mathbf{M}$ \\
\hline Fuel & $\$ 108 \mathrm{M}$ & $\$ 101 \mathrm{M}$ \\
\hline Total O\&M & $\mathbf{\$ 3 7 6} \mathbf{M}$ & $\mathbf{\$ 3 9 0 ~ \mathbf { ~ }}$ \\
\hline Coal Processed (short tons) & $2,445,000$ & $2,292,000$ \\
\hline $\mathrm{CO}_{2}$ Sequestered (MT) & $4,393,251$ & $4,118,336$ \\
\hline
\end{tabular}

\section{Post-Operations Costs}

The POC estimate includes 2 years of MVA for the sequestration site, the associated reporting, and project closeout costs. The POCs for the subsurface facility include the following activities: closure in place of the $\mathrm{CO}_{2}$ pipeline; limited O\&M for the injection well; plugging and abandonment of all deep wells; continuation of the comprehensive $\mathrm{CO}_{2}$ monitoring program initiated during the CAPEX and OPEX phase; field labor, travel, and overhead expenses; project indirect costs; and home office costs.

The cost estimate specified that the plant transition after operations is a zero cost item. That is, it does not take credit for any resale revenues of the facility after the 4 years of operation, nor does it assume costs associated with a plant closure after operations. It is expected that the plant will retain capital value after the 4-year operating period. The POCs are shown in Table ES-5.

Table ES-5. Post-Operations Costs

\begin{tabular}{|l|r|}
\hline \multicolumn{1}{|c|}{ Item } & \multicolumn{1}{c|}{ 2Q2009 } \\
\hline Subsurface & $\$ 17,000,000$ \\
\hline Owner Costs & $\$ 6,345,781$ \\
\hline Total & $\mathbf{\$ 2 3 , 3 4 5 , 7 8 1}$ \\
\hline
\end{tabular}

\section{Observations and Lessons Learned - Cost Estimate}

- Cost position can be improved by purchasing major equipment outright and assigning the license/contract to an engineering, procurement, and construction (EPC) contractor if amenable to the technology provider. This avoids fees associated with an EPC purchase of equipment (percent of capital). However, it requires more contracting and administrative infrastructure for the owner.

- The purchasing structure is different for gasification equipment compared to normal power plant equipment. Technology providers are not willing to give firm pricing (e.g., lump sum/turnkey). In a

${ }^{8}$ FutureGen Alliance. Project Cost Estimate Vol. II - Operating Costs. DES-OPEX-02 Rev. 2. February 2010. 
competitive environment, this will delay finalization of even the preliminary design of the balance of plant until the FEED studies are complete and the gasification system has been selected. There are a limited number of gasifier technology providers and each has a different preferred method of providing their technology. Some prefer to provide a design package and technology license while others are teamed with an EPC contractor and prepared to provide the entire gasification island.

- Pre-approval of all EPC contractors and subcontractors through a structured evaluation process is recommended to determine capabilities and expertise; this helps to avoid a bid-based evaluation only.

- Perform due diligence on vendors that will be supplying major pieces of equipment and understand nuances of that equipment when it is operating both on and off specification.

- Include senior operations staff and leadership as early as possible. This enables on-site training for personnel and construction management assistance to the project team as units and processes are turned over. Senior operations staff should also be included early in the design stage to develop operating strategies (O\&M, cold startup, warm restart) that can be included or addressed in the plant design.

- Scope and invest in a complete process simulator and ensure pre-commissioning labor hours are available for engineering and operator training.

- Include insurance providers early in project development to help mitigate and reduce risk.

- Expect unplanned/forced outages and compromised availability in the first 3-6 months of commercial operation. Historical startup curves of FOAKs are relevant and should indicate a prolonged acceptance testing period after mechanical completion is declared for major equipment.

- For a commercially dispatched facility, be willing to evaluate utilization of natural gas for power production when the gasification plant is not available. This goes against the FutureGen axioms, but is relevant for other utilities or facilities involved in poly-generation.

- Consider "over the fence" terms for isolated or distinguishable services, for example, oxygen delivery, zero liquid discharge, and high purity water production.

- Recognize that the plant has two separate processes, gasification and power production, which have inherent differences, including risk/safety/health, engineering, and environmental. Management must provide support and leadership to ensure an integrated team and clear communication. 


\section{Acronyms and Abbreviations}

\begin{tabular}{|c|c|}
\hline AACE & Association for the Advancement of Cost Engineering \\
\hline AGRU & acid gas removal unit \\
\hline ASU & air separation unit \\
\hline BACT & best available control technology \\
\hline BAFO & best and final offer \\
\hline BGS & below ground surface \\
\hline $\mathrm{BP}$ & budget period \\
\hline BTU & British thermal unit \\
\hline CAPEX & capital expenditures \\
\hline CCS & carbon capture and storage \\
\hline CTG & combustion turbine generator \\
\hline DEIS & draft environmental impact analysis \\
\hline DOE & U.S. Department of Energy \\
\hline ECM & engineering construction management \\
\hline EIA & U.S. Energy Information Administration \\
\hline EIS & environmental impact statement \\
\hline EPC & engineering, procurement, and construction \\
\hline FEED & front-end engineering design \\
\hline FEIS & final environmental impact statement \\
\hline FEL & front-end loading (engineering level) \\
\hline FOAK & first-of-a-kind \\
\hline FSCA & full scope cooperative agreement \\
\hline HRSG & heat recovery steam generator \\
\hline I\&C & instrumentation and control \\
\hline ICDR & initial conceptual design report \\
\hline IEPA & Illinois Environmental Protection Agency \\
\hline IGCC & Integrated Gasification/Combined Cycle \\
\hline LAER & lowest achievable emission rate \\
\hline LSCA & limited scope cooperative agreement \\
\hline LTSA & long-term service agreement \\
\hline MBTU & million British thermal units \\
\hline
\end{tabular}


MMT

MVA

$\mathrm{MW}(\mathrm{e})$

NETL

NEPA

O\&M

OPEX

PFD

PM

POC

ppm

ppmv

ppmvd

PRB

$\mathrm{RFI}$

RFP

ROD

SCR

SRU

STG

TEG

TIC

UIC

ZLD million metric tons

monitoring, verification, and accounting

mega-watt electrical (power)

National Energy Technology Laboratory

National Environmental Policy Act

operations and maintenance

operating expenditures

process flow diagram

particulate matter

post-operations cost

parts per million

parts per million by volume

parts per million, volumetric dry

Powder River Basin

request for information

request for proposal

record of decision

selective catalytic reduction

sulfur removal unit

steam turbine generator

triethylene glycol

total installed cost

underground injection control (permit)

zero liquid discharge 


\section{Introduction}

The FutureGen Integrated Gasification/Combined Cycle (IGCC) Carbon Capture and Storage (CCS) project was conceptualized as a first-of-a-kind (FOAK) clean coal power plant that would operate as a "near-zero emissions" facility, deploying the most advanced technical controls available for emissions control and abatement. As described in the initial conceptual design report (ICDR Vol. I: Rev. 2, May 2007), the advancement, consolidation, and use of these technologies in one facility was ambitious. While research and development had significantly advanced technologies to support gasification, electricity generation, and emissions control including carbon dioxide $\left(\mathrm{CO}_{2}\right)$ capture and permanent storage, these technologies had not been demonstrated at a scale and fidelity consistent with industrial power production. Many stakeholders contributed to the FutureGen project, including but not limited to the FutureGen Industrial Alliance (Alliance) and Alliance member companies; the U.S. Department of Energy (DOE), particularly the National Energy Technology Laboratory (NETL); and various subcontractors. All stakeholders were focused on the timely delivery of a coal-fueled energy production facility that would provide a pathway to affordable, near-zero emissions electricity generation. The FutureGen project represented that full-scale demonstration, and was considered essential to proving the technical, economic, and commercial viability of generating power with full emissions control including $\mathrm{CO}_{2}$.

\subsection{Background}

Under guidance promulgated in the 2001 National Energy Policy, ${ }^{1}$ it was recommended that the DOE provide $\$ 2$ billion over a 10-year period to fund clean coal technology research and development, with the intent to align federal energy policy directly with state and federal regulations on widespread emission reductions. The energy policy development group specifically addressed the advantages of coal gasification (IGCC), enabling the continued use of the substantial domestic reserves of coal, in an environmentally preferable manner. In February 2003, President Bush announced that the United States would sponsor the FutureGen Initiative-a \$1 billion, 10-year project to build and operate the world's first coal-based, nearzero emissions power plant that would have broad international, public, and private sector partners. ${ }^{2}$

\section{$1.2 \quad$ FutureGen Industrial Alliance}

In response to the call for the FutureGen Initiative, the Alliance consortium incorporated in July 2005. In structuring the company, and to capitalize on the strengths of each member company, the Alliance formed a Board of Directors composed of one voting member from each of the companies. Representing domestic and foreign commitments to the strategic development of clean coal-based resources, the Board of Directors not only provided programmatic and project oversight, they worked to ensure that the project represented the highest degree of transferability.

The Alliance also formed a Technical Committee that included an engineer or scientist from each of the participating members. Broadly, the Technical Committee was tasked with ensuring that the FutureGen project could meet the mission-specific objectives set forth by the DOE while advancing IGCC/CCS technologies toward commercial deployment. Accordingly, one of their first responsibilities was to provide

\footnotetext{
${ }^{1}$ National Energy Policy: Report of the National Energy Policy Development Group. May 2001.

${ }^{2}$ Clean Energy and Climate Change: George W. Bush Whitehouse Archives. Accessed at: http://georgewbushwhitehouse.archives.gov/ceq/clean-energy.html. 11/15/2011.
} 
a comprehensive assessment of the current state-of-technology for IGCC and CCS systems and processes, and the likelihood of their implementation into the FutureGen plant. Complementing the technology readiness evaluation, the Technical Committee also began to formulate the criteria the Alliance would use to assess potential technology configurations, and to determine what plant operating characteristics would be required to meet the mission objectives.

Where appropriate, the Technical Committee formed subcommittees to provide more in-depth analysis of specific aspects of the project and facility design and engineering. Examples include subcommittees for subsurface characterization, subsurface design and engineering evaluations, and surface facility design and engineering. This enabled the participation of technology and location-specific expertise from the member companies and supporting contractors, and ultimately provided for the siting and design of a FutureGen plant that encompassed the broadest range of applicable knowledge in these respective areas.

\section{$1.3 \quad$ FutureGen Project Development}

Having secured federal financial support and scope, the Alliance, with programmatic guidance from NETL, began a rigorous feasibility and conceptual design assessment, as well as a site selection process under a limited scope cooperative agreement (LSCA) executed in December 2005. By mid-2006, the Alliance had issued and received 12 proposals from seven different states to host the FutureGen project. ${ }^{3}$ Each of the 12 proposals was assessed against project siting criteria, and utilized two evaluation teams: one to consider criteria related to the power plant, and one to consider criteria related to the geologic storage (sequestration) site. After weighting, scoring, and ranking the proposed sites, the Alliance provided four candidate sites for detailed analysis in the draft environmental impact statement (DEIS). DOE issued the three-volume DEIS in June 2007. ${ }^{4}$ After soliciting and incorporating public comments as appropriate, the final environmental impact statement (FEIS) was issued by DOE in November 2007 (DOE/EIS-0394). ${ }^{5}$ In the FEIS, DOE indicated that all four candidate sites could support the proposed action. The Alliance, in turn, would be able to select the final FutureGen site from the proposed sites once DOE issued the record of decision (ROD). Section 3. includes further discussion of both the National Environmental Policy Act (NEPA) siting analysis and the final site selection analysis.

Concurrent with the siting analysis and conceptual design, the Alliance executed a full scope cooperative agreement (FSCA) in March 2007. The agreement included finalizing the site selection process, fulfilling the NEPA requirements, and initiating the preliminary design of the plant using site-specific details (the results of which would be determined by the site selection analysis and issuance of the ROD). Subsequent phases of the project, including final design, construction, and operations, would also have been captured under the FSCA.

Citing project cost concerns, DOE allowed the FSCA to expire in June 2008, and replaced it with an LSCA that included scope to complete the preliminary design as well as a revised project cost estimate. Based on the results of these efforts, the Alliance and DOE would then decide how best to proceed to successive phases of the project. Additionally, as part of the design and costing effort, the Alliance would evaluate aspects of the project specific to operating and technology that could inherently improve reliability and availability, and

\footnotetext{
3 DOE/EIS-0394D: FutureGen Project Draft EIS. June 2007.

${ }^{4}$ U.S Department of Energy. Notice of Availability of the Draft Environmental Impact Statement for the FutureGen Project. Federal Register, 72 FR 30572, June 1, 2007.

${ }^{5}$ DOE/EIS-0394: FutureGen Project Final EIS. November 2007. Accessed at: http://www.netl.doe.gov/technologies/coalpower/futuregen/EIS/. 11/17/2011.
} 
reduce overall cost. Considerations included relaxing the 90 percent $\mathrm{CO}_{2}$ capture goal in operational years one and two to accommodate unknown integration and $\mathrm{CO}_{2}$ storage issues that might be expected from an FOAK power plant; designing and costing the combined cycle power plant to operate on natural gas for power production during construction of the gasification plant and whenever syngas was not available; and optimizing the design of the plant based on a single coal type. Where applicable, details of these assessments are included in this report as they played a significant role in the final determination of project overall cost and viability.

In August 2010, DOE announced that the FutureGen project would be re-scoped as a clean coal development project, but not necessarily IGCC. Therefore, the activities providing the basis of this report came to a natural conclusion. Though the Alliance and DOE continue to lead in the advancement of the integrated oxy-combustion/ $\mathrm{CO}_{2}$ capture and sequestration project, the following project report is bound at the terminus by that re-scoping.

\section{$1.4 \quad$ FutureGen Project Objectives}

Proposed as a $275 \mathrm{MW}(\mathrm{e})^{6}$ IGCC power plant, the FutureGen project was designed to gasify pulverized coal, converting it to a hydrogen-rich syngas stream of sufficient quantity to fully load an F-Class industrial combustion turbine to generate electricity. Design specifications included the capture of at least 90 percent of the $\mathrm{CO}_{2}$ in the syngas from the gasifier, compressing the $\mathrm{CO}_{2}$ to a supercritical fluid, and transporting the $\mathrm{CO}_{2}$ to an underground injection site for permanent storage in a deep saline formation. As a mission to build, operate, and standardize a first generation IGCC/CCS power plant, the FutureGen project would have produced a working industrial power generation facility and research platform that could continuously provide relevant data and information for subsequent facilities. Though "boilerplate" IGCC reference plant designs were commercially available, the FutureGen project represented a significant departure from the routine development and execution of a power plant project.

First and foremost, the FutureGen project had to be designed, permitted, and operated to ensure success in meeting the rigorous emissions goals established by DOE for a near-zero emissions gasification and power generation facility. This included greater than 99 percent sulfur removal, greater than 90 percent mercury removal, and the ambitious goal of capturing and storing a minimum of 90 percent of the $\mathrm{CO}_{2}$ produced at the plant. ${ }^{7}$

Second, because the FutureGen project would be a FOAK facility, the Alliance had to develop and implement novel methodologies for the disciplined screening and assessment of potential sites that could support both the power plant and CCS activities, as well as for the alternative technology configurations. The framework(s) developed for each of these activities was independently evaluated by technical experts in the respective fields so that they could serve as reasonable structures for future deployments.

Third, as a consortium of a broad range of invested parties, the Alliance not only had to prove the viability of selected technologies in a single plant at commercial scale, they also had to provide enough flexibility to accommodate the development of globally transferable near-zero emissions technologies that could be economically dispatched into a representative power market. At the project level, this was best represented by maintaining strong international support and representation within the Alliance, as well as a high degree

\footnotetext{
${ }^{6}$ Nominal, or nameplate, capacity rating.

${ }^{7}$ FutureGen Alliance. ICDR, Rev. 2. May 2007.
} 
of stakeholder involvement and communication. At the technology level, this was demonstrated by employing sound science and engineering practices, executing design and costing efforts for multiple coal types and gasifier configurations, and the routine use of the technical and economic community at the regional, national, and international level.

Finally, because of the high visibility of the FutureGen project and in consideration of building and operating a FOAK IGCC/CCS facility, the Alliance frequently and candidly conducted risk, risk mitigation, and environmental, health, and safety analyses, addressing the identifiable types of credible concerns. While not unique in application, the level of rigor applied to these efforts enabled the Alliance to understand the risks involved in building and operating the IGCC/CCS facility; and of greater consequence, how to design and operate a plant that could avoid or mitigate these risks, thereby protecting the public.

\section{$1.5 \quad$ FutureGen Project Report}

This report is intended to provide an inclusive accounting of project activities from inception through the issuance of full site specific cost reports. Due to the significant investment already made by the Alliance, their collaborative partners, subcontractors, and DOE, previously executed scope that resulted in the formal production of studies and reports is relied upon and referenced. When appropriate, these documents are included as attachments in entirety or as amended. Reference documentation may also be provided via a weblink, as would be the case for publicly available information. For clarity, further description or detail may accompany this previously completed work. Assessments or evaluations that have not been publicly released are included to the extent practical with the exception of information proprietary to technology providers that was provided to the Alliance or DOE under non-disclosure agreements. This is particularly true for aspects of the Air Separation Unit (ASU), gasifier, and portions of the acid gas recovery process units. Certain portions of the sulfur recovery unit, particularly final process configuration, are also under non-disclosure.

Due to the number and volume of supporting documents, references and referenced reports are provided separately as attachments. This report begins by introducing the FutureGen project, the structure of the Future Industrial Alliance (Section 1); and an overall project description for the plant and CCS systems (Section 2). The site selection process and results follow in Section 3. Relevant information compiled and disclosed in the environmental information volume, DEIS, and FEIS is referenced, as they were instrumental in the evaluations of the respective sites for both the IGCC and the CCS infrastructure. Where fitting, sitespecific information is provided, clarifying the FutureGen Alliance's final determination of site suitability based on cost, risk, and benefit, as well as DOE's final determination of suitability, which culminated in the ROD. The Mattoon property description is included, as is the finalized plot plan that was used for the costing effort and initial permitting activities.

As an extension of the siting and characterization process, Section 4 includes site-specific evaluations of sequestration and carbon storage aspects for the Mattoon site. This section also includes a discussion of the underground injection control (UIC) permit application.

Section 5 provides the basis of design, design option evaluations, and the final design configuration for the FutureGen plant. This section begins with the general design basis assumptions and performance axioms for the proposed IGCC/CCS project. The section also contains a significant level of detail on the Alliance's evaluations of proposed technologies and/or technology configurations conducted for equipment selection, 
configuration, and integration to the overall process design prior to the costing effort. Design of the $\mathrm{CO}_{2}$ injection wells and supporting systems is included in Section 5 as well.

A significant level of effort was completed to evaluate both gasifier and acid gas recovery units. Though largely based on proprietary vendor supplied information, the evaluations conducted as part of the Illinois Clean Coal Review Board (CCRB) supported work enable the down-selection of major plant technologies; their incorporation into process flow diagrams and accompanying heat and material balances; and development of initial operating scenarios. The CCRB work is captured in Section 6 while the CCRB report in entirety as well as the accompanying process diagrams and material balances are included as attachments.

The cost estimate methodology and cost estimate plan is included in Section 7, noting that they were developed prior to issuance or receipt of any request for information (RFI) or request for proposal (RFP) from participating vendors. The cost estimate was based on an "island approach," enabling the identification and assignment of physical boundaries, the infrastructure contained within those boundaries, and the key material take-offs. As proposed, the scope associated with each island would be assigned to a specific contractor through separate bid processes. However, to ensure overall project continuity, the Alliance anticipated using a single integrating contractor responsible for overall continuity between islands, as well as the balance of plant.

The cost estimate portion of the report includes estimates for capital expenditures (CAPEX, Section 8), operating expenditures (OPEX, Section 9), and post-operations costs (POC, Section 10) for the surface and subsurface portions of the project. Results of the cost estimate at the area level are included. The design basis includes the throughput and composition requirements of major streams, the design coal compositions for each coal type, and de-rating allowances. The overall process flow sheets, heat and material balance, and descriptions of each process island are provided and described with a level of detail commensurate with the stage of design at the time the project cost estimate was provided to DOE. This includes, where applicable, equipment sizes, throughputs, and capacities. Consistent with the project cost estimate reports for CAPEX and OPEX, information is provided for slurry-fed and dry-fed gasifier configurations, as the Alliance completed full flow sheet analyses of both technologies to accommodate an Association for the Advancement of Cost Engineering (AACE) Class 4 cost estimate.

With a fixed, baseline plot plan, and having completed the costing exercise, the Alliance conducted value engineering assessments on multiple aspects of the facility that, if executed, could mitigate capital and operating expenses from the plant. Included here are several studies conducted to evaluate design and engineering considerations, as well as the studies executed under State of Illinois and Southern Illinois University grant programs. Concurrently, the Alliance initiated site-specific emissions modeling and profiling in support of the New Source Review and prevention of significant air quality deterioration analysis, which require the installation and operation of the best available control technology (BACT). Descriptions of each of these are provided in Section 11.

Section 12 includes summary level information regarding internal and external reviews of the cost estimate reports, risk and contingency assessments, and the analysis of financial (pro-forma) models provided by the Alliance to the DOE.

The report concludes with a summary of major accomplishments in Section 13. These key attributes and findings frame and define the technical and non-technical aspects of the project that were not only relevant to the original FutureGen project, but would have broad applicability to the development, execution, and 
operation of an FOAK power plant project regardless of location or technology selection. As the first comprehensive effort to site, design, and cost a utility sized coal fired power plant with integrated carbon capture and storage, the analyses and efforts of the original project have been instrumental to the development of the current FutureGen project, with many of the key findings being incorporated into the new plant configuration and location. 


\section{Project Description}

Fundamentally, the FutureGen project would have been coal-fueled power plant that produced hydrogen $\left(\mathrm{H}_{2}\right)$ for use in a combustion turbine, thereby generating electricity for commercial sales. Additionally, the FutureGen project would have separated and captured $\mathrm{CO}_{2}$ produced by the plant, which could have been delivered (via pipeline) to a wellhead for injection and permanent geologic storage.

\section{$2.1 \quad$ FutureGen Plant}

The simplified block flow diagram in Figure 2-1 captures the essential elements of the facility, with the three functional blocks representing the gasification portion (yellow), the gas processing portion (green), and the combined-cycle power plant (blue).

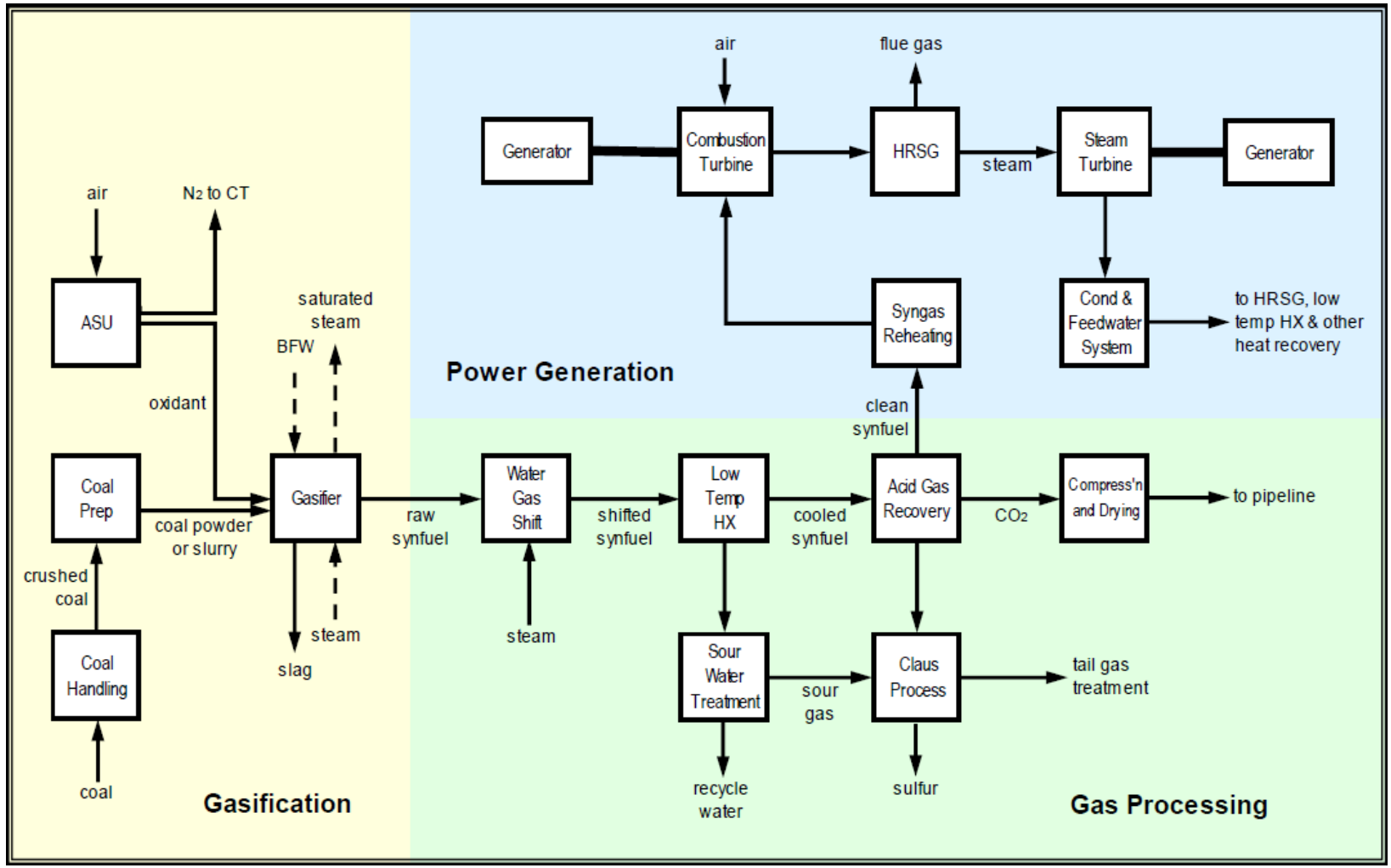

Figure 2-1. Simplified Block Flow Diagram of an IGCC Plant with $\mathrm{CO}_{2}$ Capture

Though many of the technologies considered for the plant had already gained commercial acceptance (e.g., steam turbine generator (STG), coal handling equipment, Claus process for sulfur recovery), the FutureGen facility proposed and designed for the Mattoon, Illinois site represented the first fully integrated IGCC/CCS facility in the world. As shown in Figure 2-1, the gasification and gas processing sections of the facility have more distinct unit processes than the power generation section of the plant; this is a function of the gasification process, which retains the chemical energy found in the coal until it can be used in the combustion turbine. 
The gasification of coal has significant advantages compared to conventional combustion practices; the most significant is that it can substantially reduce the overall emissions profile from a coal-fueled facility. To understand this, it's useful to consider how the energy conversion processes vary between the two. Conventional combustion releases the chemical energy found in coal through complete oxidation; this typically requires an extensive "post-combustion" clean-up process such as particulate control, mercury removal, and desulphurization for emissions management. Gasification, on the other hand, converts the coal into a gaseous fuel stream (syngas) through partial oxidation. The resulting syngas contains a very high percentage of the primary contaminants found in coal that are of concern when considering overall emissions such as sulfur and mercury, but these contaminants are removed in the "pre-combustion" gas processing steps, as outlined in Figure 2-1. Because the contaminants are removed prior to combustion, the overall size of emissions control equipment and total emissions can be considerably less when compared to conventional combustion practices.

An additional process germane to the FutureGen project enabled the production and separation of $\mathrm{CO}_{2}$ from the syngas. Formed in the water-gas shift, the reaction of water (steam) and $\mathrm{CO}$ in the presence of a catalyst yields additional $\mathrm{H}_{2}$ as well as $\mathrm{CO}_{2}$. The $\mathrm{CO}_{2}$ produced in the water-gas shift is then removed from the syngas in the acid gas removal unit (AGRU); the AGRU is the same technology that removes most of the sulfur in the syngas as well. Once captured and removed from the syngas, the sulfur is processed in the Claus reactor, which produces elemental sulfur, while the $\mathrm{CO}_{2}$ is compressed to form a liquid (supercritical), supplied to a pipeline, and ultimately injected through a well into a deep geologic formation for permanent sequestration.

Finally, once through the AGRU, the resulting syngas, primarily consisting of $\mathrm{H}_{2}$ and small amounts of other gases, is heated and supplied to the combustion turbine to generate electricity. To maximize the overall efficiency of the plant, waste heat from the combustion turbine, as well as steam harvested from the gasification and gas processing process units, is used to drive a steam turbine, which also generates electricity. Considering the extensive level of integration between the power plant and the gasification and gas processing units, the overall complexity of the facility is significant.

\section{$2.2 \mathrm{CO}_{2}$ Capture, Transportation, and Storage (CCS System)}

The $\mathrm{CO}_{2}$ produced at the plant would have been transported via pipeline to a well distribution system, and injected into the storage reservoir. Figure 2-2 depicts a $\mathrm{CO}_{2}$ transportation and storage system, generically presenting key components of that system, including pipeline, injection, and monitoring wells; $\mathrm{CO}_{2}$ injection zones; and the primary seals. Sections 4 and 5.2 provide further details of the FutureGen design of the CCS system. 


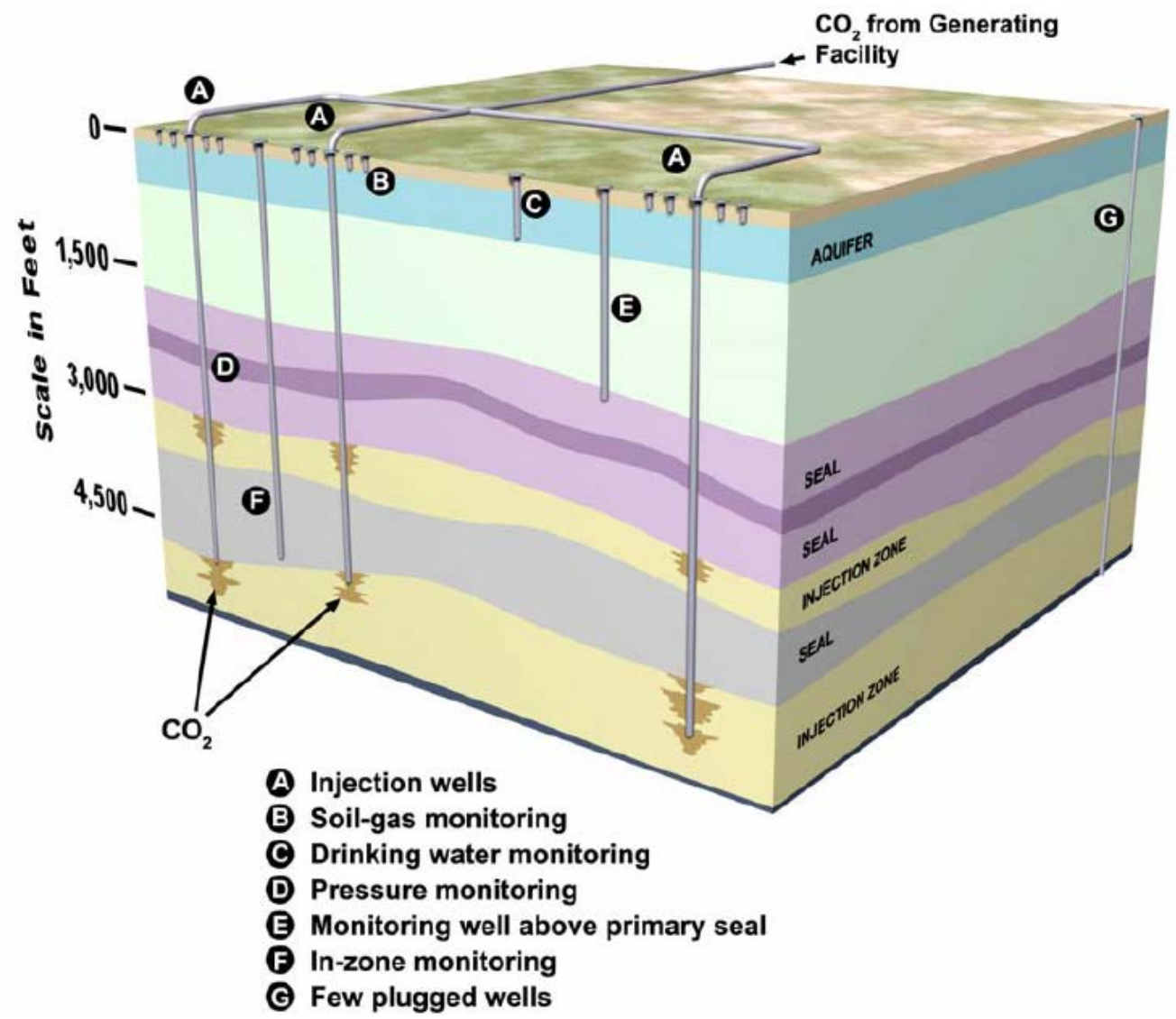

Figure 2-2. Components of a Generic Sequestration System

Each component in the sequestration system design is site-specific, and the Mattoon site would have enabled the Alliance to capitalize on several aspects of the proposed CCS system. Beginning with the discharge of supercritical $\mathrm{CO}_{2}$ from the FutureGen plant's $\mathrm{CO}_{2}$ compressor, the pipeline segment required to transport the liquid $\mathrm{CO}_{2}$ would have been short, never leaving the FutureGen property. The short pipeline run would not only have limited the capital expense required for construction of the pipeline, it would have eliminated the risk of pressure loss in the pipeline, which is more likely in longer pipeline segments. As such, the discharge pressure of the $\mathrm{CO}_{2}$ compressor could be operated to closely match the wellhead conditions required for injection. Additionally, co-locating the plant, transportation, and injection systems on one contiguous piece of property would have mitigated issues of pipeline and access right-of-way, environmental health and safety, and public protection.

The $\mathrm{CO}_{2}$ distribution and injection system of the FutureGen project was proposed to contain one primary injection well, and four monitoring wells in varying placements. The primary injection well targeted the Mt. Simon Formation, and was proposed to be at a total depth of approximately 8000 feet below surface. 
The four monitoring wells consisted of:

- an "in-reservoir" monitoring well to evaluate reservoir changes in pressure and geochemical conditions as the injection of $\mathrm{CO}_{2}$ took place;

- a primary seal monitoring well just above the caprock encompassing the storage reservoir, enabling the Alliance to continuously monitor for $\mathrm{CO}_{2}$ migration out of the reservoir; and

- two seismic monitoring wells located within 1200 feet of the primary injection well and instrumented to continuously evaluate the seismic conditions of the reservoir as over 1 million tons of $\mathrm{CO}_{2}$ per year was injected into the Mt. Simon Formation.

The FutureGen project planned to conduct a robust monitoring, verification, and accounting (MVA) program. Implemented over the 4-year injection period and a 2-year post-injection time frame, the MVA program addressed research objectives in several areas. These objectives included establishing the baseline conditions; tracking and characterizing the size of the plume; examining the geochemical effects caused by the interaction of $\mathrm{CO}_{2}$ and the Mt. Simon Formation; and detecting any $\mathrm{CO}_{2}$ leakage above the Mt. Simon caprock that could influence the drinking water aquifer or activities conducted at the surface. 


\section{Site Selection}

Initiated by the LSCA in December 2005, the FutureGen Alliance began the initial stages of a site selection process that would culminate in the selection of a single site that offered the best overall value in terms of environmental, safety, technical, and economic factors.

\subsection{Siting Methodology and NEPA}

To execute a national-level search for the most appropriate site that would accommodate both the surface facility (IGCC) and the subsurface storage site (sequestration reservoir), an Alliance Siting Team was created, composed of scientists, engineers, Alliance committee member experts, and Alliance Technical Committee members for the surface and subsurface facilities. Tasked with developing criteria for evaluating each proposed alternative site, the Siting Team crafted the following three types of measurements for assessing site suitability:

- Qualifying criteria - Criteria that each site would have to meet before being considered further. Failure to meet any criterion resulted in disqualification.

- Quantifying criteria - Criteria that would allow sites to be scored and ranked based on the extent to which they possessed desirable features.

- Best value criteria - Criteria that could not be quantitatively scored, but that represented factors the Alliance would consider when choosing a site that could best fulfill the project's mission.

Prior to issuance of the FutureGen Alliance Request for Proposals (RFPs) for the FutureGen Facility Host Site, the Alliance also sought and received input from additional stakeholders such as DOE, regulatory agencies, and environmental groups. The draft RFP was issued in February 2006 for public review and comment; the final RFP was revised based on that feedback and was issued in March 2006. ${ }^{1}$ The Alliance received 12 proposals to host the FutureGen project, representing locations in seven different states. Figure 3-1 provides the locations of the proposed sites.

\footnotetext{
${ }^{1}$ FutureGen Alliance. FINAL: Request for Proposals for FutureGen Facility Host Site. March 7, 2006.
} 


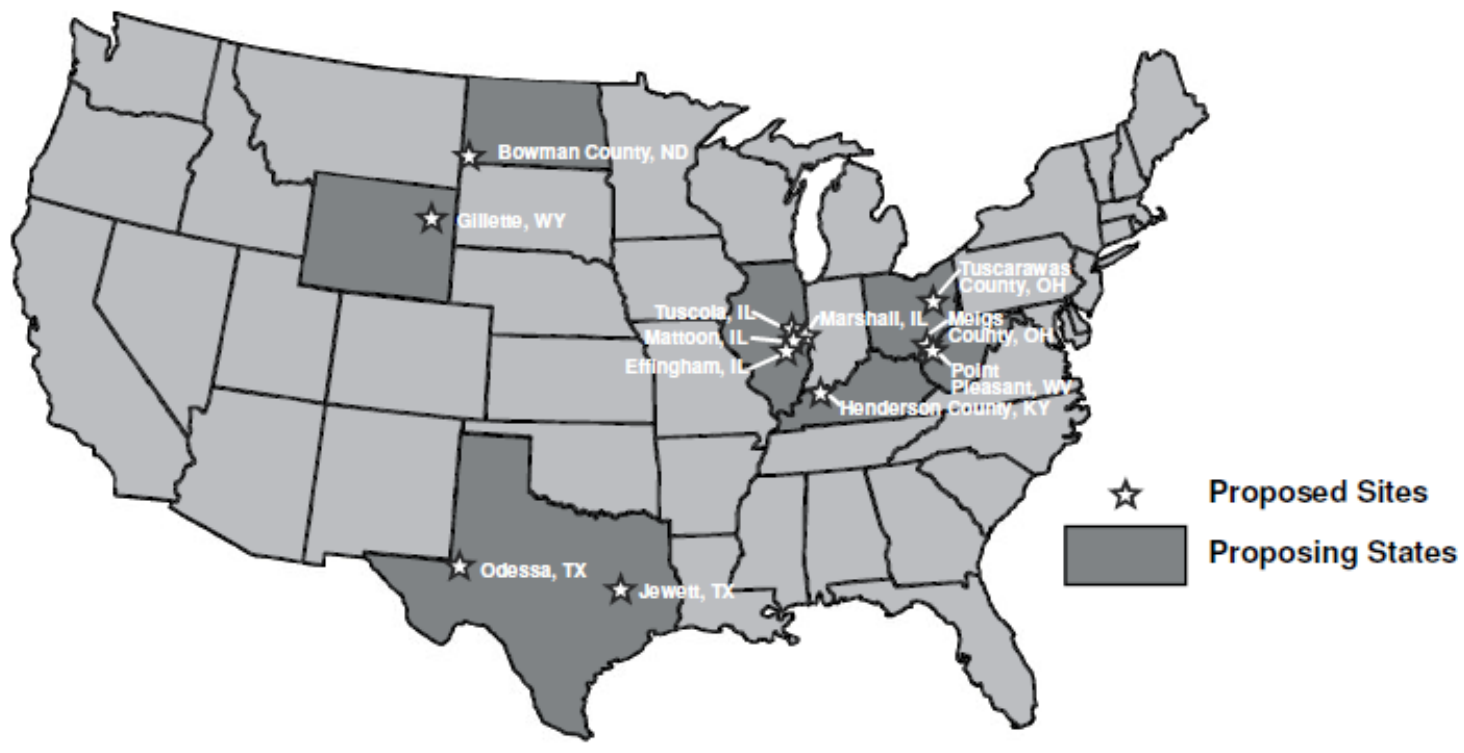

Figure 3-1. Proposed Sites for the FutureGen Project

Given the inherent complexity of each aspect of the project (surface and subsurface), the Alliance formed two proposal evaluation teams: one team evaluating criteria as it applied to the surface facility, and one team evaluating the criteria as it applied to the subsurface portion of the project. Working independently, the siting teams reviewed each of the 12 proposals to assess their compliance with the qualifying criteria found in Figure 3-2. 


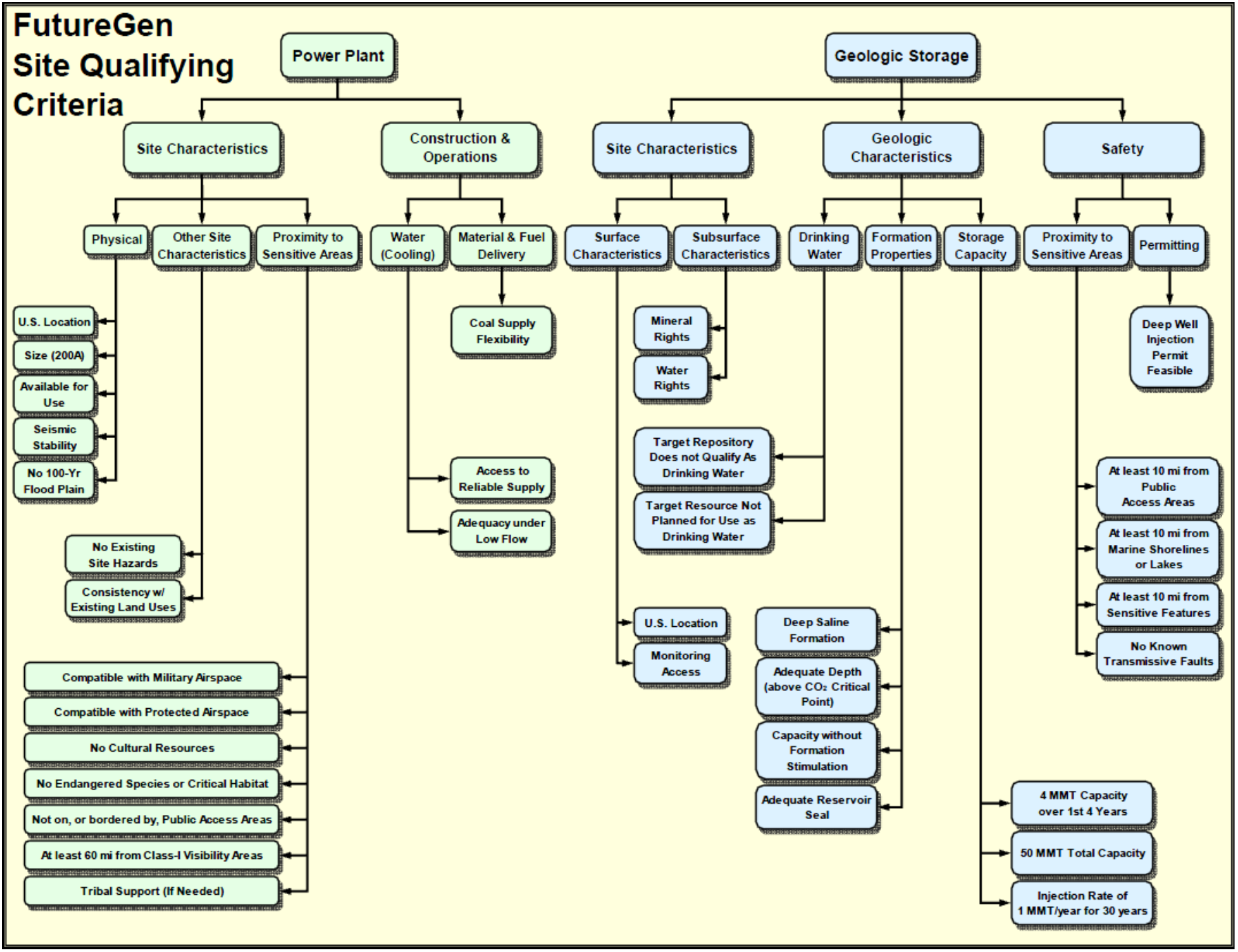

Figure 3-2. FutureGen Qualifying Criteria

Following review of the proposals, as well as clarifying responses asked to each of the sites, the evaluation teams determined that 4 of 12 sites could not satisfy all of the qualifying criteria. These sites were eliminated from further review, while the remaining 8 sites were carried forward for the quantitative analysis using the scoring criteria found in Figure 3-3. 


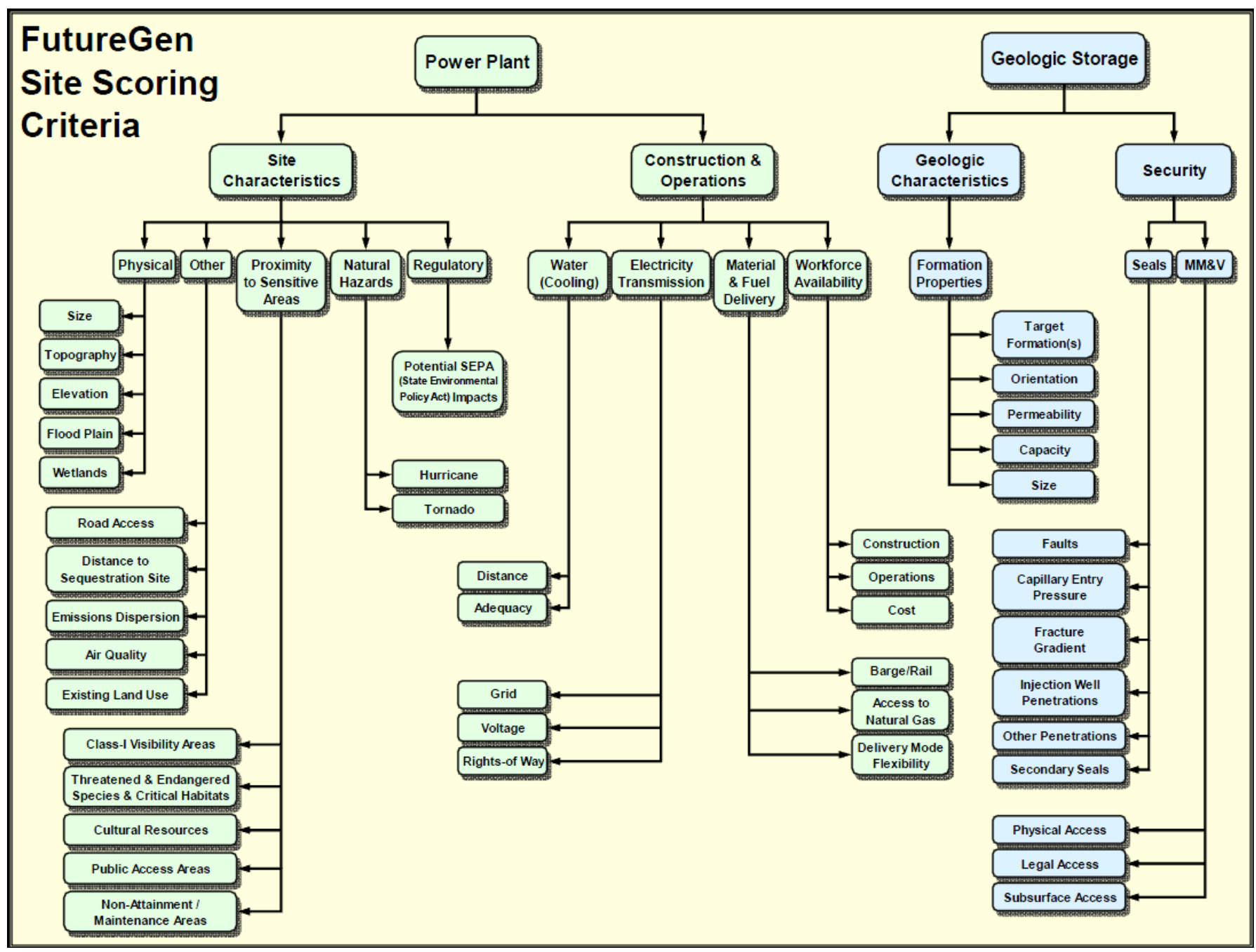

Figure 3-3. FutureGen Quantifying Scoring Criteria

The scores were then independently derived (each scoring team member individiually scored and ranked each site) and tabulated, giving a final score for each site based on its strengths and weaknesses. The Alliance also conducted a non-numeric review of each site's "best value criteria," which characterized aspects of the sites that were difficult to quantify, such as known markets for power or hydrogen, land ownership and proximity to senstitive receptors, recycling and disposal paths, and other considerations. Once compiled and summarized, the final ranking of the sites was considered to be unbiased and reflective of a site's overall suitability to host the FutureGen project by offering:

1. an acceptable location for siting, constructing, and operating the power plant;

2. at least one acceptable targeted geologic formation for sequestration; and

3. minimal risk for schedule delay and/or project failure.

Of the eight sites that were scored and ranked, four were removed from further consideration, and four were carried forward as viable candidates that would be characterized in the environmental impact statement (EIS) as part of the federal NEPA process. The final four sites were Mattoon, Illinois; Tuscola, 
Illinois; Jewett, Texas; and Odessa, Texas. Additional information regarding the siting methodology and analysis can be found in the FutureGen EIS in Section 3.2.

Concurrent with issuance and review of the draft EIS, but prior to receipt of the ROD, the Alliance conducted a final round of inquiries with the remaining four sites. This activity culiminated in the "best and final offer" (BAFO) that each candidate site provided to the Alliance to aid in their final deliberations on site selection. While the information contained in the BAFOs could not be publicly disclosed, the details contained therein enabled the Alliance to conduct a robust comparative assessment capturing the site-specific detail of approximately 80 separate line items, including aspects of land and right-of-way ownership, impacts to capital and operating costs, potential revenue(s) and incentives, and legal considerations. Because the siteselection process is highly competitive, and to maintain the integrity of each site's respective offer, the final tabulations, ranking, and selection of the preferred site was done by Alliance management in a closed-door meeting.

\subsection{Selection of the FutureGen Host Site}

In December 2007, the Alliance announced that the Mattoon, Illinois site would be the preferred site to host the FutureGen project, pending the outcome of the review of the FEIS and corresponding ROD. The Mattoon Final Site Selection Report is included in Attachment 1 of this report. In selecting the Mattoon site, the Alliance acknowledged that each of the candidate sites was likely to be acceptable to DOE and could individually offer significant benefits. However, the Mattoon site specifically represented the best overall value to the project by offering the following ${ }^{2}$ :

- The Alliance would have clear legal title to the power plant and injection site, minimizing land ownership risk and concerns.

- Power plant and injection location(s) are co-located on the same continguous piece of property, reducing capital and operating expenses and improving public access and educational opportunities.

- The Mt. Simon Formation is regionally extensive, is considered to represent a key geologic storage reservoir in the U.S., contains multiple caprock seals, and few existing penetrations into the formation or caprock.

- The site is located near supporting infrastructure to accommodate the large, capital project (rail, road, water, and transmission).

The ROD was issued July 2009 and indicated that each of the candidate sites would be acceptable alternatives to host the FutureGen project, confirming compliance with federal NEPA guidelines. Additional information regarding the NEPA process and the siting methdology can be found in the FEIS. ${ }^{3}$

\subsection{Description of the Mattoon, Illinois FutureGen Site}

The selected host site for the FutureGen project was located approximately $2.5 \mathrm{mi}$. west of Mattoon, Illinois, and was composed of 419 acres of predominantly agricultural use land. As previously discussed, due to the size of the property, the Alliance was able to co-locate both the surface facility (IGCC) and the sequestration site on the same contiguous parcel, reducing both the cost and risk of the project.

\footnotetext{
${ }^{2}$ FutureGen Alliance. Final Site Selection Report. December 18, 2007. Included as Attachment 1 to this report.

${ }^{3}$ DOE/EIS-0394: FutureGen Project Final EIS. November 2007. Accessed at: http://www.netl.doe.gov/technologies/coalpower/futuregen/EIS/. 11/17/2011.
} 
From a constructability standpoint, the Mattoon site offered several benefits. Bordered on the northeast by Highway 121 and surrounded by county roads, the site had proximity to rail (Canadian National Railroad at the northeast corner of the property), and major transportation corridors of Interstate-57 running northsouth and Interstate-70 running east-west were located within. As is pertinent to any power plant project, the Mattoon site also provided clear access to, and supply of, make-up water for the plant, as well as reasonable access to local electrical transmission distribution infrastructure. Figure 3-4 highlights the general location of the site on the state map, the site itself (blue outline), and the proposed corridors for water, wastewater, and natural gas supply to the site (green). Figure 3-5 is a photo of the harvested site, and Figure 3-6 is a photo of the site as it appeared in the spring with a new crop started.

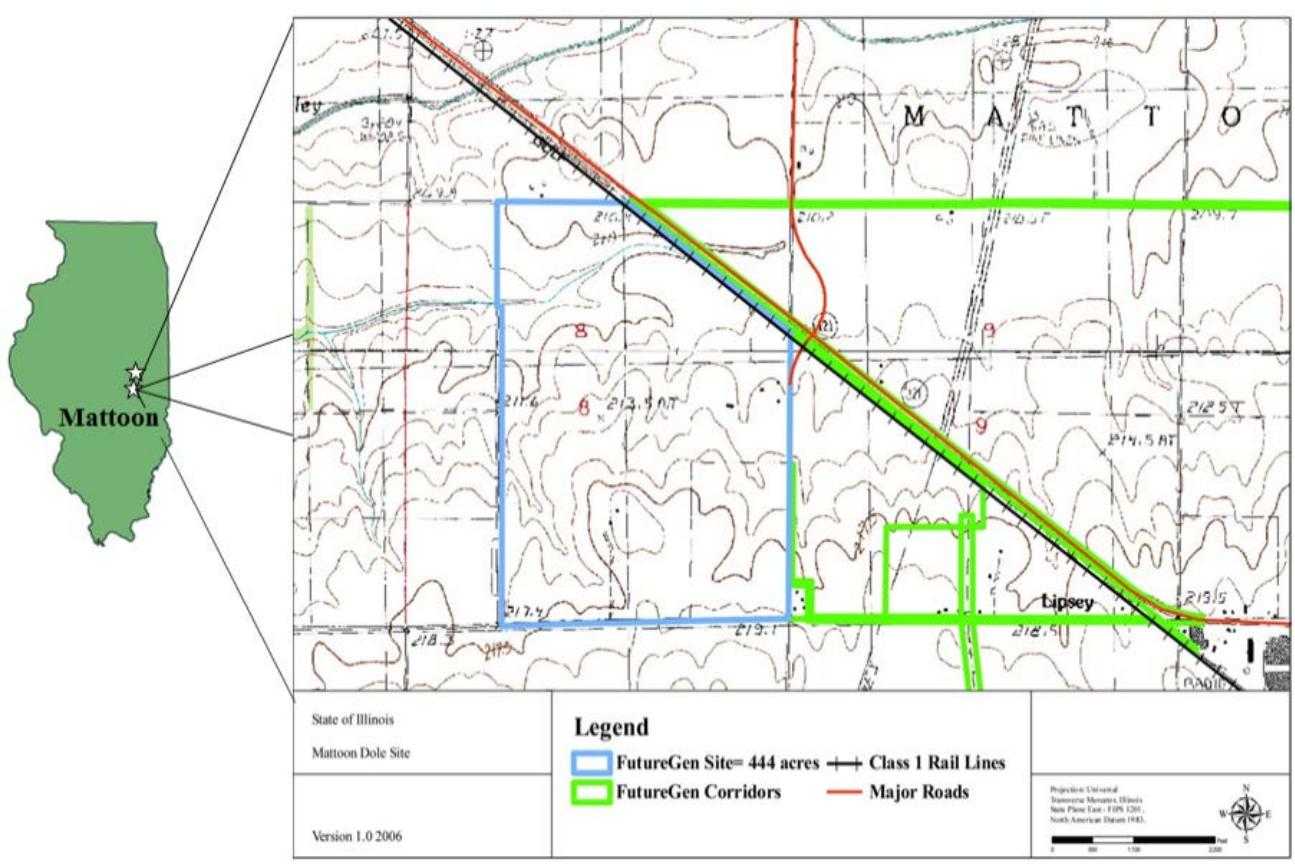

Figure 3-4. Mattoon, Illinois FutureGen Plant and Injection Site 


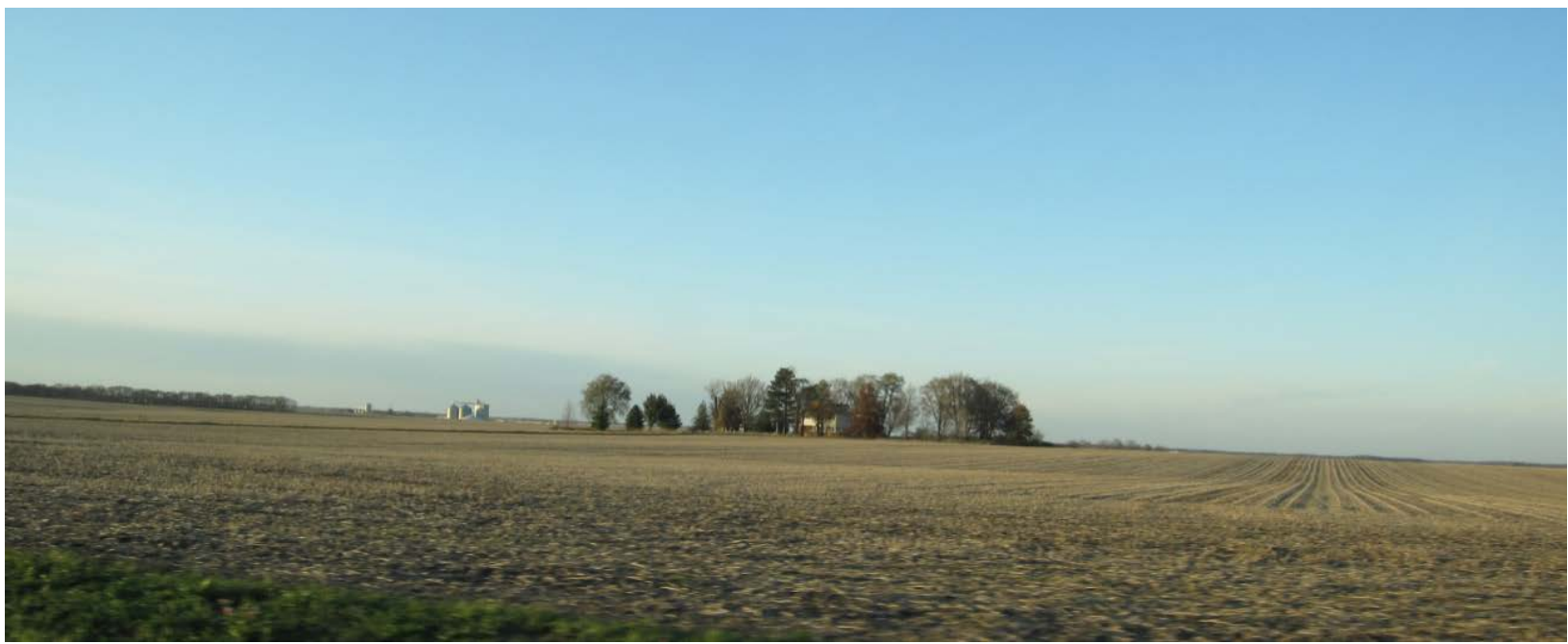

Figure 3-5. FutureGen Site Looking North

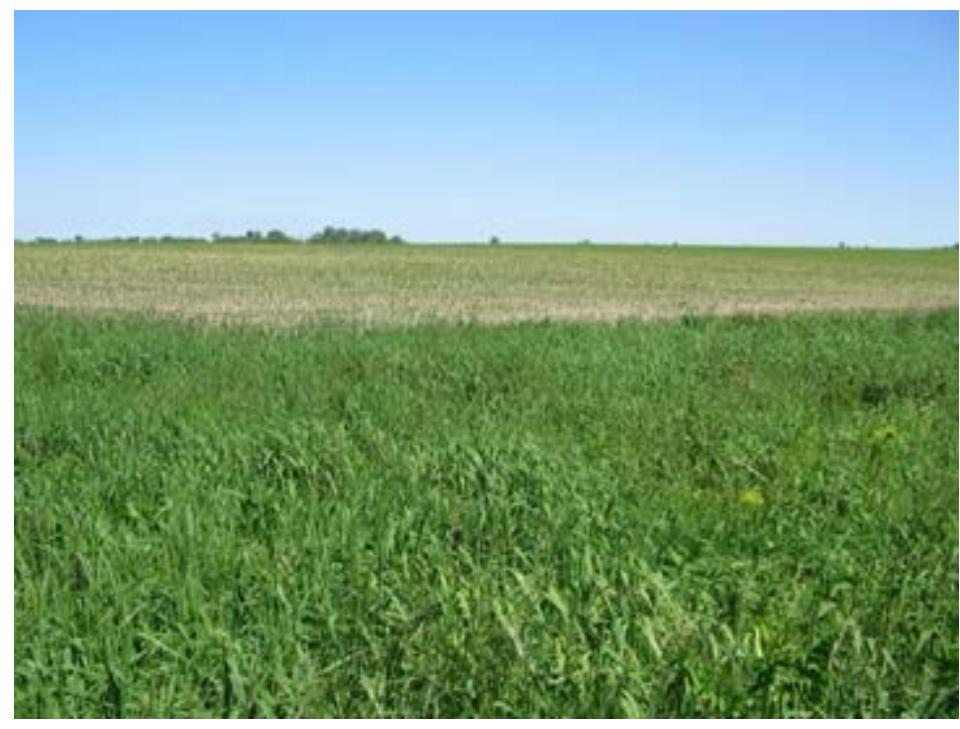

Figure 3-6. FutureGen Site with New Crop Planted

In addition to being the best overall site from a technical standpoint, the Mattoon FutureGen site would have likely capitalized on several non-technical aspects of the location as well. For example, the project had gained substantial support at the local, regional, and state level. As mentioned previously, the site was close to several universities, colleges, and trade schools that could have served as key institutional locations for the education and advancement of IGCC/CCS technologies and personnel. Further, in alignment with project goals to develop and operate a coal-fired facility with the lowest environmental footprint, the FutureGen facility at Mattoon intended to use only municipal grey water as its primary make-up water source, thereby eliminating potential impacts to local freshwater sources. Finally, though difficult to quantify, in targeting the Mt. Simon Formation for sequestration, the FutureGen project would have had a very high degree of transferability, as the Mt. Simon Formation was not only one of the most important storage reservoirs in the U.S., it was representative of the vast majority of geologic storage reservoirs being considered for carbon sequestration globally. 


\section{Storage Site Evaluation and Characterization}

The FutureGen project had an objective to store (sequester) 1 million tons (1 million metric tons (MMT)) of $\mathrm{CO}_{2}$ per year into a deep saline reservoir. As previously discussed, given the degree of investigation afforded to the siting process, which included subsurface characterization, each of the target formations was determined to be a reasonable alternative by addressing key geologic criteria, including but not limited to the following:

- High storage capacity (in excess of project goals) was available.

- Formation permeability and porosity would support planned injection rates but limit migration.

- Primary seal(s) of the reservoirs were thick, expansive, and void of additional penetrations.

- There was little to no evidence of active or hydraulically transmissive faults.

\subsection{Mattoon and the Mt. Simon Storage Reservoir}

As a well-known formation, Mt. Simon had been thoroughly investigated prior to its consideration for the FutureGen project, with a significant body of work already completed by the Illinois State Geologic Survey, Midwest Geological Sequestration Consortium, and those involved in natural gas storage and delivery. As such, the Alliance was able to focus its subsurface characterization work on determining the site-specific potential impacts of sequestration; two examples include the reservoir-modeling simulations using the proposed $\mathrm{CO}_{2}$ injection rates, and seismic evaluations to provide geologic insights to the $\mathrm{Mt}$. Simon Formation and Eau Claire caprock.

Equipped with data and information regarding the physical properties of the targeted reservoir, the Alliance conducted several numerical simulations to predict the distribution and fate of the $\mathrm{CO}_{2}$ injected into the $\mathrm{Mt}$. Simon Formation. The model, Subsurface Transport Over Multiple Phases (STOMP), solves for and describes the migration $\left(\mathrm{CO}_{2}\right.$ plume size) and fate of $\mathrm{CO}_{2}$ as it's injected into the $\mathrm{Mt}$. Simon based on parameters such as viscosity, solubility, relative permeability, and density. Detailed descriptions of the formation characteristics can be found in the UIC Permit Application (Section 2). ${ }^{1}$

For the EIS, two injection rates were considered that represented the reasonable bounds of $\mathrm{CO}_{2}$ output from the plant. Though ultimately dependent on many factors such as the rank and type of coal being gasified, availability of the plant, and overall capture efficiency, the bounding injection rate investigated was 7551 tons ( 6850 metric tons) per day, or an annual injection rate of 2.8 million tons ( $2.5 \mathrm{MMT}$ ) per year. For the second case, the model considered a continuous injection rate of 1.1 million tons (1 MMT) per year. This corresponded to the minimum rate of sequestration that the project expected over the first 4-year operating period, and directly aligned with the FutureGen programmatic goals for sequestration. In any scenario, the upper modeling limit was held to 55 million tons ( $50 \mathrm{MMT}$ ) of $\mathrm{CO}_{2}$ injected into the Mt. Simon Formation.

It was expected that once the project was approved for the next phase, a characterization well would have been drilled at the Mattoon site. The ensuing analytic work on the borehole and core samples would have provided much-needed corroborative evidence for the characterization of the Mt. Simon Formation at the site, as well as representative data that would be used to update the injection and plume models, formation

\footnotetext{
${ }^{1}$ FutureGen Alliance. Underground Injection Control Permit Application. April 19, 2010. Included as Attachment 2 in this report.
} 
characteristics, seals, and additional subsurface data requirements. The additional analytic work would have also enabled further investigation into the pressure constraints of the Mt. Simon formation, which for the purposes of modeling was held to a single-pressure boundary acknowledging that the pressure front of the injection plume would be of a larger diameter than the proposed plume boundary, but it was not quantified. As will be discussed in Section 4.2 because the Area of Review (AOR) was conservation at 2.5 miles and initial injection models indiacted a plume size of approximately 1 mile, the pressure boundary was likely to fall well within the AOR constraint though this was not specifically modeled.

The following figure is an example of a calculated 20-year (yellow radius is equivalent to $2.5 \mathrm{MMT}$ for 20 years), and 50-year (red radius is equivalent to $1 \mathrm{MMT}$ for 50 years) plume size at the Mattoon site based on $\mathrm{CO}_{2}$ injection modeling conducted in $2007 .^{2}$

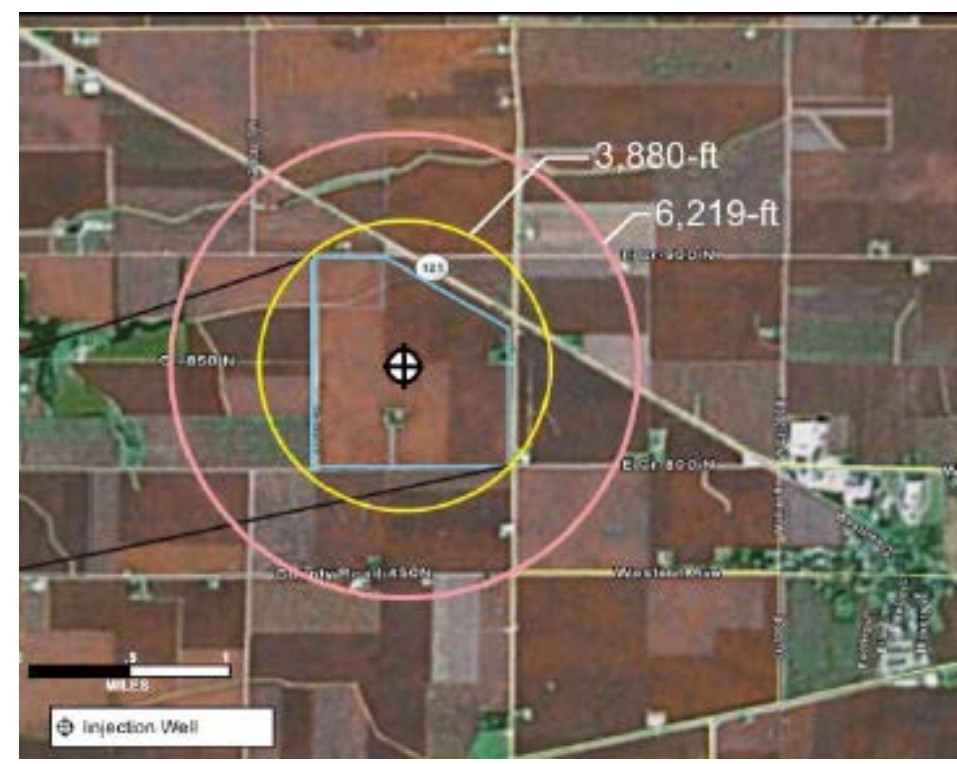

Figure 4-1. 20-yr and 50-yr Modeled $\mathrm{CO}_{2}$ Plume Size

In response to the original FutureGen host site RFP, the site proponent provided the Alliance with a substantial amount of descriptive information about the Mt. Simon target formation, as well as additional details addressing geologic storage criteria. ${ }^{3}$ Among the deliverables was an investigation into formation and caprock faulting and fracture zones, which, if present, could affect the injection field and integrity of caprock seal. To accommodate the analysis, the site proponent had a 2D seismic survey done, verifying at a rudimentary level that no faulting was present, at least on the single seismic line that was acquired.

Once the Mattoon site was selected as the preferred location to host the FutureGen project, the site proponent executed a second, more detailed seismic survey that was completed in June 2008. The results of that survey were used to corroborate the previous 2D findings, as well as to further describe the features of the Mt. Simon Formation and the bounding caprock layers by acquiring almost 30 linear miles of seismic data along seven different profiles that traversed the FutureGen site. Figure 4-2 illustrates the seven profiles acquired in that effort, with the blue tangents representing the three-component $(3 \mathrm{C})$ lines, and the red tangents as the normal 2D lines.

${ }^{2}$ FutureGen Alliance. ICDR, Rev. 2. May 2007.

${ }^{3}$ FutureGen Alliance. Request for Proposals for FutureGen Facility Host Site: Part 4.0-Geologic Storage Criteria. March 2006. 


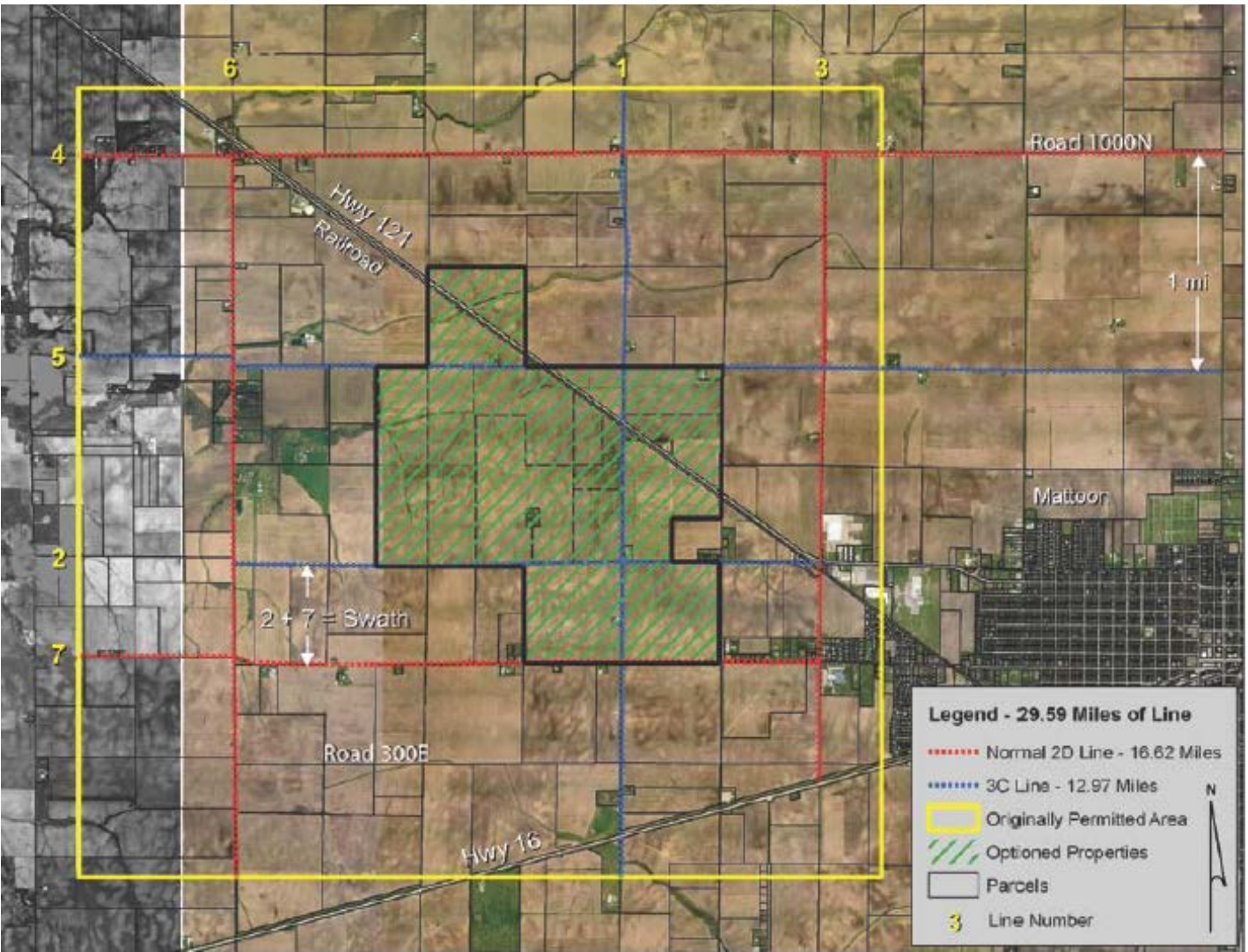

Figure 4-2. Seismic Profiles Acquired at the Mattoon FutureGen Site

The seismic data was acquired using industry standard techniques. Large, truck-mounted vibrators were strategically positioned to provide vertical compression energy, which traveled down into the earth much like a wave. With this technique, as the energy travels through the earth, varying layers of rock and material impede upon that energy wave, causing it to reflect back toward the surface of the earth. At the surface, geophones (instruments that convert ground movement to an electrical signal) can then measure the degree and intensity of that reflection as it moves back to the surface. Figure 4-3 provides a view of how the geophones are spatially oriented in the field during the seismic testing; during acquisition of a single line, multiple geophone locations are required. 

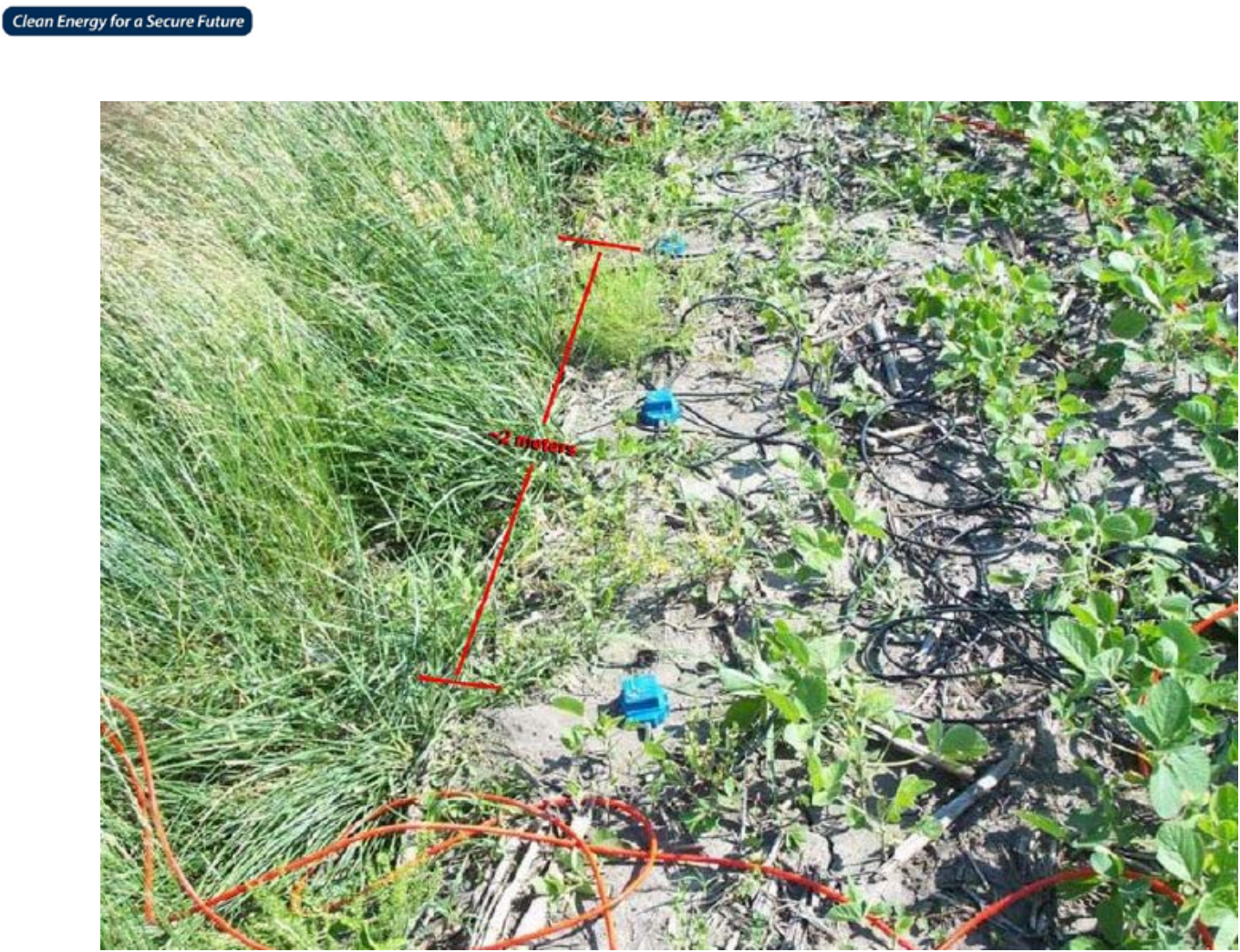

Figure 4-3. Field Layout of Geophones

Data processing and interpretation of the seismic survey was completed by Fairfield Industries (renamed FairfieldNodal in 2010), a recognized worldwide leader in geophysics and seismic data processing. A first interpretation, called a "brute stack analysis," provided a rough estimate of the quality of the data collected, indicating that once a full analysis had been conducted, the Alliance should have high-quality images of both the storage reservoir and the caprock seal. Additionally, findings supported the 2D survey done in 2006, indicating there was no evidence of faulting in either the storage reservoir or the caprock seal.

A second interpretation of the seismic data was executed in late $2008 .{ }^{4}$ This analysis compiled data from the vertical geophones capturing compression (P-P) waves, and included 13 miles of (3C) geophones capturing converted-shear (P-SV) images. With the addition of $3 \mathrm{C}$ data, interpreters can more effectively describe the type of wave and the direction of wave propagation, enabling a more thorough description of subsurface lithology as well as other features.

The following images show the depth-registered interpretation of the Mattoon seismic profile, and include both P-P images and P-SV images. In Figure 4-4 and Figure 4-5, starting from the top and working toward the bottom, the blue line represents the base of the Knox Formation; this is effectively the top of the Eau Claire caprock seal. The Eau Claire Formation is represented by the span between the blue and green lines, with the green line representing the boundary between the top of the Mt. Simon Formation and the bottom of the Eau Claire caprock. The Mt. Simon Formation is then the span between the green line and the yellow line, with the yellow line representing the boundary between the bottom of the Mt. Simon Formation and the top of the underlying Pre-Cambrian basement formation.

${ }^{4}$ Data processing and interpretation provided by Bob A. Hardage. December 8, 2009. 


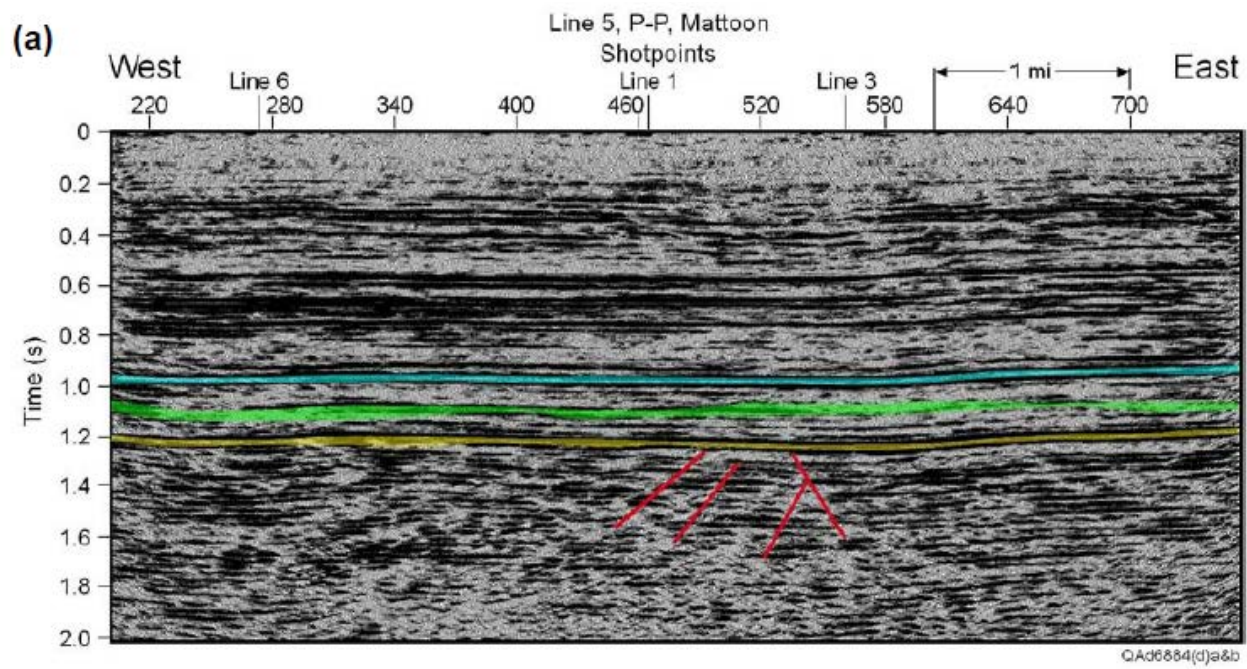

Figure 4-4. P-P Image from Mattoon Seismic Survey, Line 5

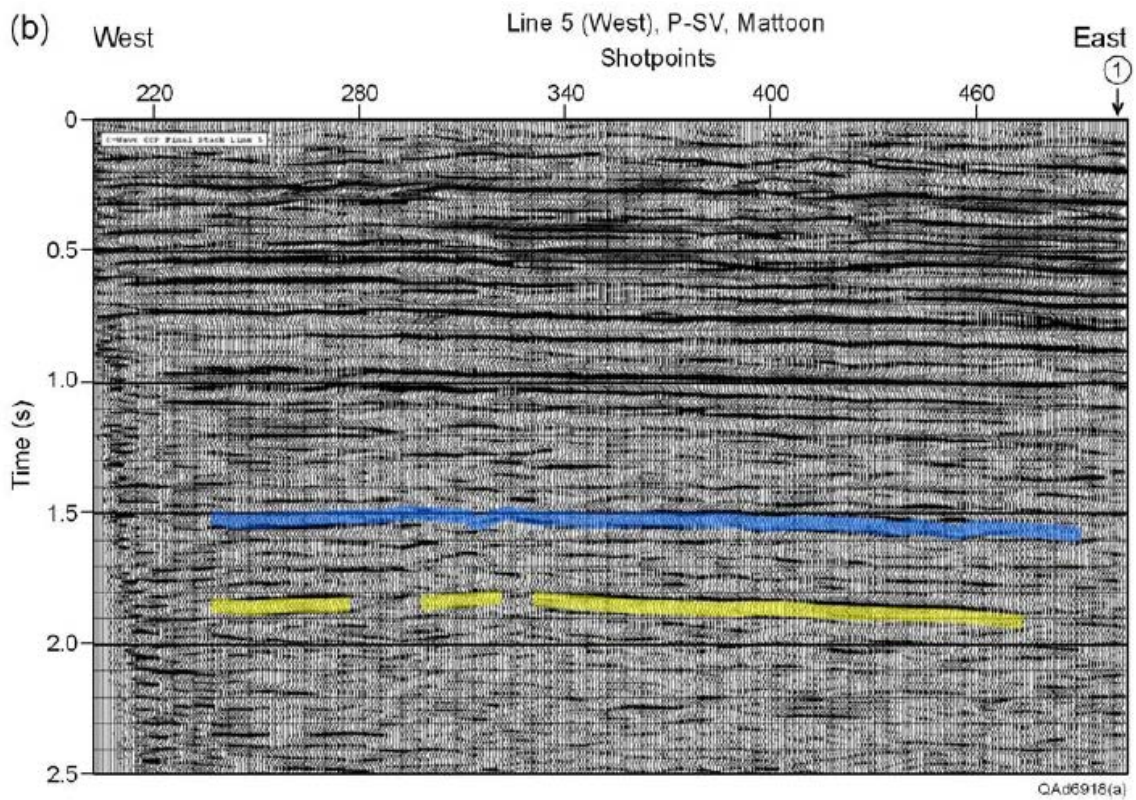

Figure 4-5. P-SV Image from Mattoon Seismic Survey, Line 5

The seismic evaluation concluded with an interpretation of fault potential at the Mattoon site. Though discontinuities (potential faulting) did appear in the Pre-Cambrian basement formation (highlighted in red in Figure 4-4), there was no compelling evidence in any of the profiles to conclude that these extended into the Mt. Simon Formation or caprock seal.

A final note in the analysis provided a clear path for further reconciliation of the seismic work with the known geologic conditions at the Mattoon site, predicated on the drilling of a characterization well. This effort would enable calibrating the seismic data obtained through imaging, with actual physical logs and other "in-hole" activities such as vertical seismic profiling and borehole core sampling. 


\subsection{Underground Injection Control (UIC) Permitting}

The Alliance filed the initial UIC permit application on September 30, 2009, and the revised permit application on April 19, 2010. ${ }^{5}$ The Draft Class I UIC permit was issued by the Illinois Environmental Protection Agency (IEPA) June 26, 2010, approving the application. ${ }^{6}$ In the permit application, the Alliance fully disclosed specifics related to the hydrogeologic characterization of the injection and confining zones; well construction (Section 5.3 of this report); modeling of the $\mathrm{CO}_{2}$ reservoir (Section 4.2.2 of this report); and operations, monitoring, and reporting activities expected during the project. Due to the re-scoping of the FutureGen project, the application was ultimately withdrawn by the Alliance; however, the following appended information details the relevant aspects of the permit application and the approved draft permit issued by the IEPA.

The draft permit issued by the IEPA conditionally approved the injection of supercritical $\mathrm{CO}_{2}$ into the Mt. Simon sandstone formation at the Mattoon site (pending approval of the final UIC permit). The permit specified the construction and operation of up to two injection wells, with a requirement to operate only one injection well at a time, enabling the Alliance reasonable flexibility in such cases where a single well might be off-line for repair, inspection, or other operational or maintenance purposes. The permit also specified an injection rate not to exceed 6312 metric tons per day, noting that the final heat and material balance calculated approximately 5900 metric tons per day, and a total injection mass of 50 MMT. In accordance with the monitoring program detailed in the application, the draft permit allowed the construction and operation of up to two injection zone monitoring wells in the Mt. Simon formation, and the construction of four shallow monitoring wells in the lowermost sections of the drinking water aquifer located at the site.

Building on the seismic evaluations, the UIC permit application also provided detailed hydrogeologic characteristics of the injection zone (Mt. Simon formation), as well as the upper and lower confining zones which would have providing 'sealing' for the $\mathrm{CO}_{2}$ storage reservoir. Actual depths and defining formation attributes would have been confirmed or verified after drilling, geophysical logging, and hydraulic testing of the injection well. Additional details found in the UIC permit application addressed the potential sources of groundwater at the Mattoon site including both brackish water (non-potable aquifers) as well as underground sources of drinking water. The draft permit clarified the procedures and policies that would govern the injection and sequestration of $\mathrm{CO}_{2}$, and included provisions detailed in the State of Illinois administrative codes (35 III. Adm. Code 702, 704, and 730), as well as federal guidelines such as the Safe Drinking Water Act and United States Environmental Protection Agency Region V guidance. Additional information can be found in the UIC permit application (Attachment 2 of this report).

\subsubsection{Hydrogeologic Characterization of the Mattoon Injection and Confining Zones}

The Mt. Simon sandstone is a well characterized band of medium to coarse-grained quartz sandstone ranging from approximately 7,500 to 9,000 feet below ground surface (bgs) at the Mattoon injection location. Interspersed with fine to medium-grained sandstones, the Alliance intended to target a coarsegrained arkosic interval located near the bottom of the formation based on geophysical well log data (specifically porosity data) obtained from the Weaber-Horn \#1 well which is approximately 36 miles southwest of the Mattoon site.

\footnotetext{
${ }^{5}$ FutureGen Alliance. Underground Injection Control Permit Application.

${ }^{6}$ IEPA. July 26, 2010. Permit No. UIC-013-FIA; Log No. UIC-144.
} 
The high porosity zone in the Weaber-Horn well is relatively thick at $125 \mathrm{feet}$, and contains an average porosity in excess of 20 percent. Extrapolated using regional correlations, this high-porosity zone can range from 20 to 400 feet in thickness, and it was concluded that finding an appropriately analogous zone at the Mattoon injection site was highly probable.

The UIC permit application also provided relevant details regarding the integrity of the sealing formation(s) and the potential for fractures to develop as a result of the high pressure injection of $\mathrm{CO} 2$ into the Mt. Simon. For conservative purposes, the maximum injection pressure was conservatively set at 85 percent of the .8 pound per square inch per foot (psi/ft) gradient as required by State of Illinois regulation. With fracture stimulation commonly requiring a gradient of $1.0 \mathrm{psi} / \mathrm{ft}$ in the Illinois basin, limiting injection pressures to significantly below fracture opening and closure pressures, the risk of accidental overpressure and induced fracturing in the formation, seals, or casing cements is greatly reduced.

Once the initial well was developed at Mattoon, additional subsurface characterization work would have been completed using actual drilling results and geophysical logging including effective porosity, hydraulic conductivity, capacity, and formation flow among others.

The primary confining zone of the Mt. Simon sandstone is the immediately overlying Eau Claire formation; two additional secondary sealing formations are located above the Eau Claire. Regionally, the Eau Claire formation is used as a primary caprock seal for a number of natural gas storage fields in the Illinois Basin, consisting predominantly of thick shale deposits. Extensive study and use of the Eau Claire particularly at the Manlove and Herscher gas storage fields indicates that the shale beds are an effective seal, and capable of preventing the upward migration of natural gas from the Mt. Simon into overlying formations.

The basement formation, or lower confining zone, is Precambrian age granite. With the $\mathrm{CO} 2$ being injected above the formation and the inherent buoyancy of the $\mathrm{CO} 2$, aspects of formation fracturing, porosity, and permeability are minimized. Though there was no publically available literature or data addressing characteristics of the granitic basement formation in Illinois, modeling results and extrapolated research on granites indicated the physical integrity of the lower confining zone would not be compromised during injection.

\subsection{2 $\quad \mathrm{CO}_{2}$ Plume Modeling and Simulations}

$\mathrm{CO}_{2}$ plume modeling was routinely updated throughout the FutureGen siting and design processes as new information became available, such as the geophysical log data from the nearby Weaber-Horn Well \#1. Equipped with log data on the physical properties of the targeted reservoir, the Alliance conducted multiple simulations to predict the distribution and fate of the $\mathrm{CO}_{2}$ injected into the Mt. Simon Formation at the Mattoon FutureGen site. Using the STOMP simulator, the models quantified the migration $\left(\mathrm{CO}_{2}\right.$ plume size) and fate of $\mathrm{CO}_{2}$ injected into the $\mathrm{Mt}$. Simon Formation based on parameters such as viscosity, solubility, relative permeability, and density.

The baseline modeling scenario completed for the UIC permit application, "Plant-Lifetime Injection Scenario," was based on a continuous injection rate of approximately 1.95 MMT per year for 25.6 years, giving a total injection volume of $50 \mathrm{MMT}$ of $\mathrm{CO}_{2}$ into a highly permeable 260 -ft thick arkosic interval located towards the base of the Mt. Simon Formation. Table 4-1 provides the plume radii for the modeled injection scenario at selected times. 
Table 4-1. Plume Size at Modeled Injection Rate

\begin{tabular}{|c|c|c|}
\hline $\begin{array}{c}\text { Time } \\
\text { (years) }\end{array}$ & $\begin{array}{c}\text { Radius } \\
\text { (feet) }\end{array}$ & $\begin{array}{c}\text { Radius } \\
\text { (miles) }\end{array}$ \\
\hline 5 & 2237 & 0.42 \\
\hline 10 & 2831 & 0.54 \\
\hline 20 & 3303 & 0.63 \\
\hline 50 & 4251 & 0.81 \\
\hline
\end{tabular}

Complementary to the injection simulations, were plume distribution models that considered injection over the same time constraints as indicated in the Table 4-1. As illustrated in the following Figure 4-6, after injection stops at year 25.6, the $\mathrm{CO}_{2}$ plume relaxes under the influence of buoyancy. The models also indicate that the $\mathrm{CO}_{2}$ is rendered relatively immobile in the injection formation of the Mt. Simon and dispersion of the plume is limited both vertically under the confining layer, and horizontally within the Mt. Simon itself.
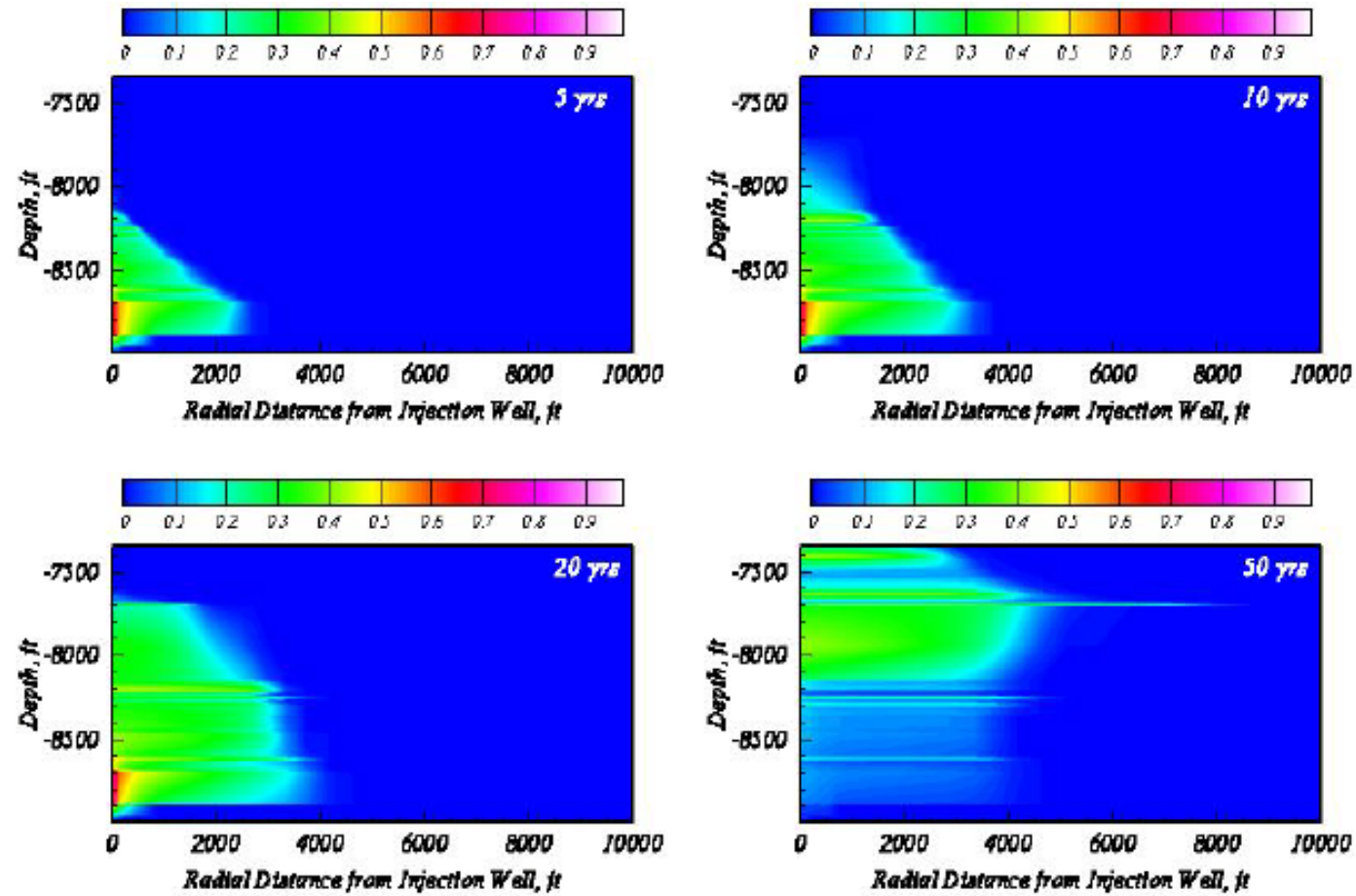

Figure 4-6. Plume Size and Distribution

In addition to those provided in the UIC permit application, additional simulations were conducted throughout the course of the project as plant operating conditions became better defined, and as exploratory evaluations were considered such as changes to injection rates, duration of injection, and targeted intervals within the Mt. Simon. These modeling efforts also provided substantive indications that 
the 2.5 mile AOR as prescribed by the State of Illinois for Class I Injection Wells was reasonably conservative and that the actual plume would be well inside of that boundary. ${ }^{7}$

Using the model described above to evaluate $\mathrm{CO}_{2}$ plume size for different durations of injection (i.e., different amounts of $\mathrm{CO}_{2}$ injected), additional scenarios evaluated injection into multiple intervals within the Mt. Simon formation to examine lateral distribution characteristics of the plume. For this simulation, three different injection durations were modeled targeting a larger 748-ft interval in the Mt. Simon. Much like the previous example, each injection period was followed by a post-injection period where the plume would relax in the formation. The corresponding plumes were calculated and plotted on the FutureGen plot plan for each of the three injection scenarios (duration and volume as provided in Figure 4-7), assuming a total of a 50 -year span from the start of injection.

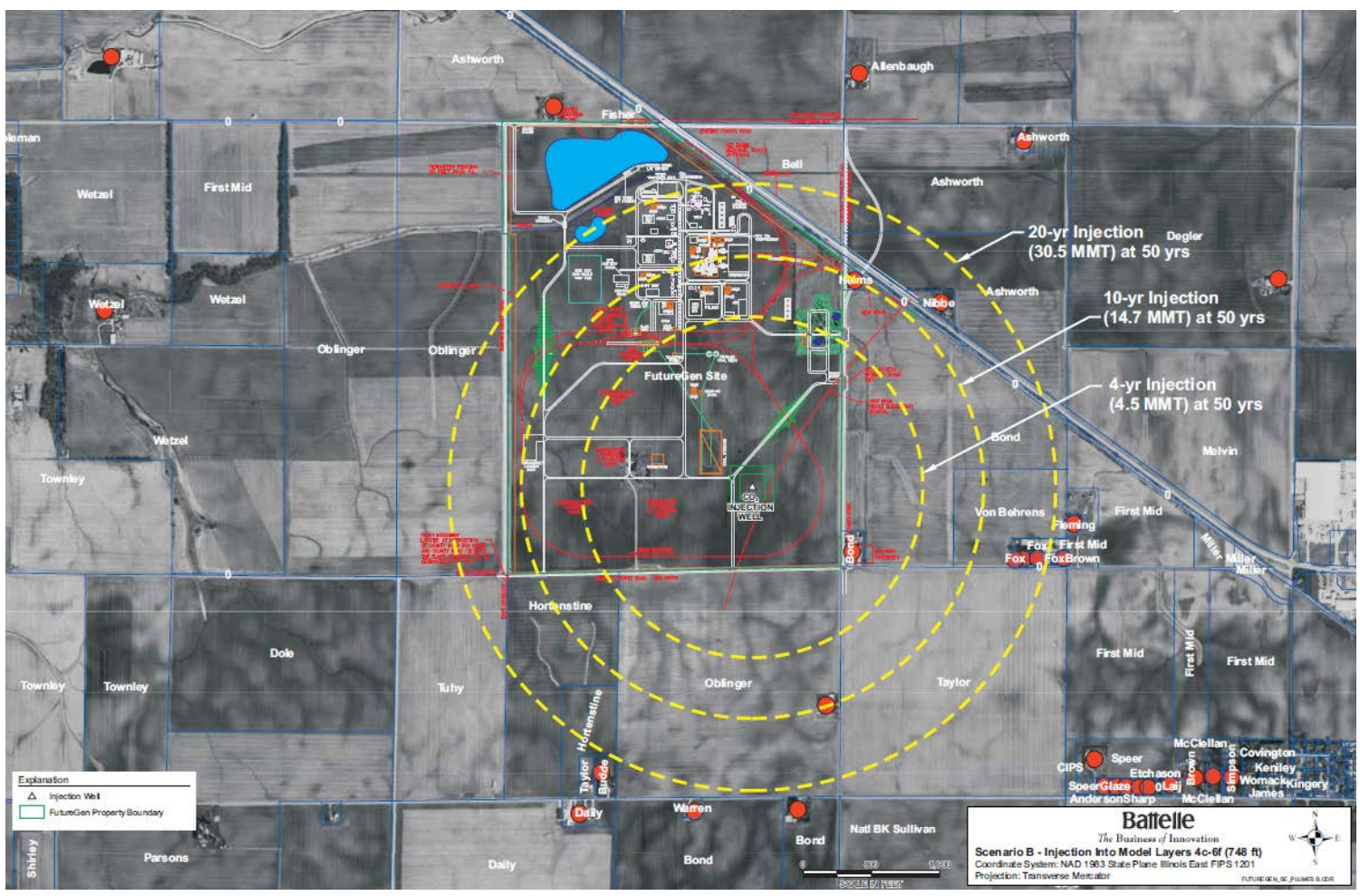

Figure 4-7. Injection Model Scenario: Layers 4c-6f (748-ft)

\footnotetext{
${ }^{7}$ This has since been changed, and is currently administered under the State of Illinois Class VI well classification.
} 


\section{Basis of Design}

The FutureGen plant was designed to facilitate the research, development, and demonstration of technologies that could progress coal-to-energy power generation toward near-zero emissions. When successfully built and operated, the FutureGen plant would have provided a basis for reliable, environmentally friendly, coal-fueled power plants that could compete economically with other carbonbased technologies, both domestically and internationally.

\subsection{FutureGen Performance and Design Axioms}

To enable the progression of readily transferable technologies, and to ensure that the FutureGen plant would be deploying those representing the most advanced state of the technology, the Alliance conducted several engineering and techno-economic evaluations prior to advancing any firm design or performance axioms. Essentially running in parallel, the first of those efforts was an internal technology readiness assessment in late 2006. This assessment enabled the Alliance to broadly evaluate not only those technologies deployable for commercial operation in the FutureGen plant, but also those emerging technologies that could foreseeably improve capital or operating costs of future plants and could be candidates for development testing at the FutureGen site.

The first formal evaluation report, the ICDR, was issued in May 2007. The ICDR included a detailed synopsis of criteria considered in the technology screening and ranking process conducted by the Alliance Technical Committee, Alliance support staff, DOE, and independent technical experts. Predicated on successfully meeting the non-negotiable mission requirements listed in Table 5-1, the evaluations formed the basis of the FutureGen design and performance axioms, which could be applied to any potential technology configuration.

Table 5-1. FutureGen Mission Requirements

\begin{tabular}{|l|}
\hline \multicolumn{1}{|c|}{ FutureGen Mission Requirements } \\
\hline Capture 1 million metric tons of $\mathrm{CO}_{2}$ per year \\
\hline $\begin{array}{l}\text { Demonstrate technology progression toward near-zero } \\
\text { emission coal-fueled, commercial power plants }\end{array}$ \\
\hline $\begin{array}{l}\text { Demonstrate economic progression toward lower cost of } \\
\text { electricity for advanced commercial power plants }\end{array}$ \\
\hline Demonstrate commercial scale power generation \\
\hline $\begin{array}{l}\text { Demonstrate the capability to gasify bituminous and sub- } \\
\text { bituminous coal }\end{array}$ \\
\hline a FutureGen Alliance. $I C D R$, Rev. 2 May 2007
\end{tabular}

Framed by the mission requirements, the Alliance and supporting staff developed the operational and performance goals for the FutureGen project. To do so, the Alliance used the relevant field experience of participating member companies, and conducted due diligence trips to assess existing IGCC plants located in other parts of the world. Collectively, and in consideration of objectives that would reflect the FutureGen project as well as those of maturing technologies found in an " $n$ th" plant, the Alliance established the following performance and design axioms (Table 5-2). 
Table 5-2. FutureGen Performance and Design Axioms

\begin{tabular}{|c|c|}
\hline Evaluation Criteria & Performance and Design Axioms ${ }^{a}$ \\
\hline Integration & Full IGCC integrated with CCS at commercial scale \\
\hline Fuel Flexible & $\begin{array}{l}\text { Capability to gasify a range of coal types from sub-bituminous to } \\
\text { bituminous }\end{array}$ \\
\hline Commercial Application & $\begin{array}{l}\text { Capability to fully load an F-Class combustion gas turbine on } \\
\text { syngas (hydrogen) with at least one coal type }\end{array}$ \\
\hline $\mathrm{CO}_{2}$ Capture and Storage & $\begin{array}{l}\text { Sequester at least } 1 \text { million metric tons } \mathrm{CO}_{2} \text { per year in a deep } \\
\text { saline geologic formation }\end{array}$ \\
\hline $\mathrm{CO}_{2}$ Capture Fraction & $\begin{array}{l}\text { Capture } 90 \text { percent of the carbon in the sour syngas stream from } \\
\text { the gasifier }\end{array}$ \\
\hline Emissions Goals & $\begin{array}{l}\text { Meet or exceed the criteria as defined in the EIS and DOE Clean } \\
\text { Coal Emissions Goals }\end{array}$ \\
\hline Cost of Electricity & $\begin{array}{l}\text { Path of development to target } 10 \text { percent increase in the cost of } \\
\text { electricity with } \mathrm{CO}_{2} \text { capture compared to non-capture IGCC }\end{array}$ \\
\hline
\end{tabular}

${ }^{\mathrm{a}}$ FutureGen Alliance. ICDR, Rev. 2. Volume 1 and Volume 2. May 2007.

Accordingly, to be eligible for the FutureGen mission, any technology or process had to comply with these axioms. Additional criteria evaluated included aspects of risk as it pertained to the mission, budget, and schedule; vendor alignment and willingness to participate; and the number and degree of innovations incorporated.

Despite the inherent complexity of the facility, the preceding constructs positioned the Alliance to objectively evaluate approximately 30 potential IGCC technology configurations for the FutureGen facility. The first qualitative down-selection process yielded 12 candidate technology configurations. Process simulation tools were then used to model the material and energy flows for each of the remaining candidates, enabling the development of budgetary estimates for total capital cost, annualized operations and maintenance (O\&M) costs, and fuel requirements. The simulations were also used to calculate the likely gross and net power outputs of each configuration, and were the basis for estimating potential electricity revenue. These quantitative steps yielded three technology configurations that were carried forward for a full conceptual design evaluation, culminating in the FutureGen Power Plant Conceptual Design Case Studies, which was offered as part of the ICDR.

It is important to note that the configurations evaluated were intended only to represent the types of technologies that could be deployed in the FutureGen project; they were not intended to offer an opinion of exclusivity or reflect a preferred vendor status. Simply, the ICDR and conceptual design studies functioned to identify and quantify the vendor specific constraints, risks, and benefits associated with each technology configuration so that when the Alliance issued a firm RFP (or request for quotation), they had reasonable assurance that the selections could be deployed and were capable of meeting the mission and performance goals of the project. The most substantive findings were then carried throughout the design and costing process. Examples include the development of a single gasifier train that could still meet the operational goals for capture and sequestration (as opposed to a two-train parallel system for improved availability); designing to a narrower range of coal types but providing scheduling flexibility for lower British thermal unit (BTU) value coal types; and using proven oxygen and $\mathrm{CO}_{2}$ separation technologies in the backbone of the facility. The Alliance also considered advanced technologies for smaller, engineering-scale type applications. 


\subsection{IGCC FutureGen Design Specifications}

To accommodate a uniform analysis encompassing multiple gasifier types and coal ranks, and to provide prescriptive information to potential vendors, the Alliance developed the following set of technical specifications, framing the expected design, engineering, and operational targets for the FutureGen facility.

Table 5-3. FutureGen Technical Design Specifications ${ }^{a}$

\begin{tabular}{|c|c|c|}
\hline \multicolumn{2}{|c|}{ Design Basis } & Specification \\
\hline \multirow{4}{*}{ Fuel Utilization } & Coal Feed Rate & 210,000 to $340,000 \mathrm{lb} / \mathrm{hr}$ \\
\hline & Coal Analysis & $\begin{array}{l}\text { Accommodate the following fuel specifications for Northern } \\
\text { Appalachia, Illinois 6, and Powder River Basin (PRB) }\end{array}$ \\
\hline & Fuel Flexible & $\begin{array}{l}\text { Designed to Illinois 6; feed rates adjusted to gasifier } \\
\text { limitations for Northern Appalachia and PRB coals }\end{array}$ \\
\hline & Syngas Production & $\begin{array}{l}\text { Provide } 1920 \text { million British thermal units per hour (MBTU/hr) } \\
\text { (lower heating value) to the combustion turbine for base case } \\
\text { coal (Illinois 6) }\end{array}$ \\
\hline \multirow{4}{*}{ Equipment } & Train Arrangement & $\begin{array}{l}\text { Single train (air separation unit (ASU), gasifier, } \mathrm{AGRU}, \mathrm{CO}_{2} \\
\text { compression) }\end{array}$ \\
\hline & Generating & $\begin{array}{l}1 \text { on } 1 \text { ( } 1 \text { combustion turbine generator (CTG) and } 1 \mathrm{STG} \text { ) } \\
\text { gross output of at least } 275 \mathrm{MW}(\mathrm{e})\end{array}$ \\
\hline & Turndown & 60 percent on all major equipment \\
\hline & Availability & $\begin{array}{l}\text { Two } 28 \text { day outages per year; or consistent with storage goal } \\
\text { of } 1 \text { MMTPY }\end{array}$ \\
\hline \multirow{6}{*}{ Product } & Syngas & $\begin{array}{l}\text { As delivered from the gasifier; sufficient to supply } 1920 \\
\text { MBTU/hr to the CTG }\end{array}$ \\
\hline & \multirow{4}{*}{ Carbon Dioxide } & $>95$ mol\% $\mathrm{CO}_{2}$ purity; $<100$ ppmv $\mathrm{H}_{2} \mathrm{~S}$ \\
\hline & & 2200 psig at compressor discharge \\
\hline & & $>90$ percent removal from syngas on an instantaneous basis \\
\hline & & 1 MMTPY (approximately 7000 TPD maximum delivery rate) \\
\hline & Sulfur & $\begin{array}{l}>99.9 \text { wt } \% \text { removed or }<15 \text { ppmvd in treated syngas, } \\
\text { whichever is greater }\end{array}$ \\
\hline \multirow{4}{*}{ Environmental } & Air & Envelope defined by EIS specification \\
\hline & Liquid & Zero liquid discharge facility \\
\hline & Slag & Classified for secondary utilization \\
\hline & Noise & OSHA standard for abatement inside plant boundary \\
\hline $\begin{array}{l}\text { Environmental } \\
\text { Cont. }\end{array}$ & Noise & $\begin{array}{l}\text { Site design to incorporate rail and transfer location noise } \\
\text { abatement }\end{array}$ \\
\hline
\end{tabular}

${ }^{a}$ Compiled and condensed from FutureGen Alliance: FutureGen Design Data, Rev. D. January 2008.

Collectively, the preceding technical specifications provided the bounding conditions for all ensuing engineering and design activities, and were conditionally captured in the bottom-up cost estimate for the two gasifier configurations (slurry-fed and dry-fed) evaluated in the CAPEX report and OPEX report. The design bases were maintained in the Design Basis Document ${ }^{1}$ that was updated routinely as vendor responses and process details became apparent. Note this is a draft document representative of the state of design at the conclusion of the FutureGen 1.0 project.

\footnotetext{
${ }^{1}$ FutureGen Alliance Design Basis Document, Rev. D. Included as Attachment 3 of this report.
} 


\subsection{Subsurface System Design}

The construction and operation of the injection and monitoring wells is described extensively in Section 3 and 4 of the UIC permit application, ${ }^{2}$ including the design and construction specifications for up to two injection wells; two injection zone monitoring wells; and four shallow groundwater monitoring wells.

The injection well(s) were designed to accommodate the injection of supercritical $\mathrm{CO}_{2}$ into the Mt. Simon Formation at an approximate depth of 7353 to 8996 feet bgs. The injection well was designed to extend 100 feet below the base of the Mt. Simon Formation. Therefore, the total depth of the well was estimated to be 9096 feet ( 9100 feet). The Mt. Simon Formation was quite extensive at the FutureGen site with an estimated thickness of more than 1600 feet, though the Alliance would have targeted specific injection intervals within in that after geologic characterization and analysis of drilling logs. The proposed well design included three primary casing strings of varying lengths and diameter, and the corresponding cementing used to fill the annulus between the casing strings. Final construction of the wells would have been contingent upon the findings and analysis obtained during drilling, such as evaluation of drilling logs, core samples, and injection zone testing.

The longest casing string penetrates the Mt. Simon sandstone formation, and has perforations in the lowermost section permitting the distribution of the supercritical $\mathrm{CO}_{2}$. The tubing, or centermost pipe run, runs from the wellhead down the length of the well, and contains the supercritical $\mathrm{CO}_{2}$. The $\mathrm{CO}_{2}$ flows out of the tubing and into the lowermost casing string, where it is distributed into the formation through the perforations. A sealbore packer prevents the supercritical $\mathrm{CO}_{2}$ fluid from migrating up into the casing string. Additionally, the annulus between the tubing and casing string is filled with a fluid such as potassium chloride or sodium chloride, and pressurized so that the annular pressure is greater than the injection zone pressure, thereby preventing fluid flow back up the well casing.

The UIC permit application provided a full description of the casing program anticipated for the FutureGen project. Two injection well construction diagrams were offered in the permit application, as the final configuration was contingent on the findings obtained during drilling of the well. Figure 5-1 provides a diagram of the one of the primary injection well casing plans, which includes depth, cementing, and casing descriptions for each of the casing lengths; Table 5-4 includes the estimates for casing depth and diameter.

\footnotetext{
${ }^{2}$ FutureGen Alliance. Underground Injection Control Permit Application.
} 


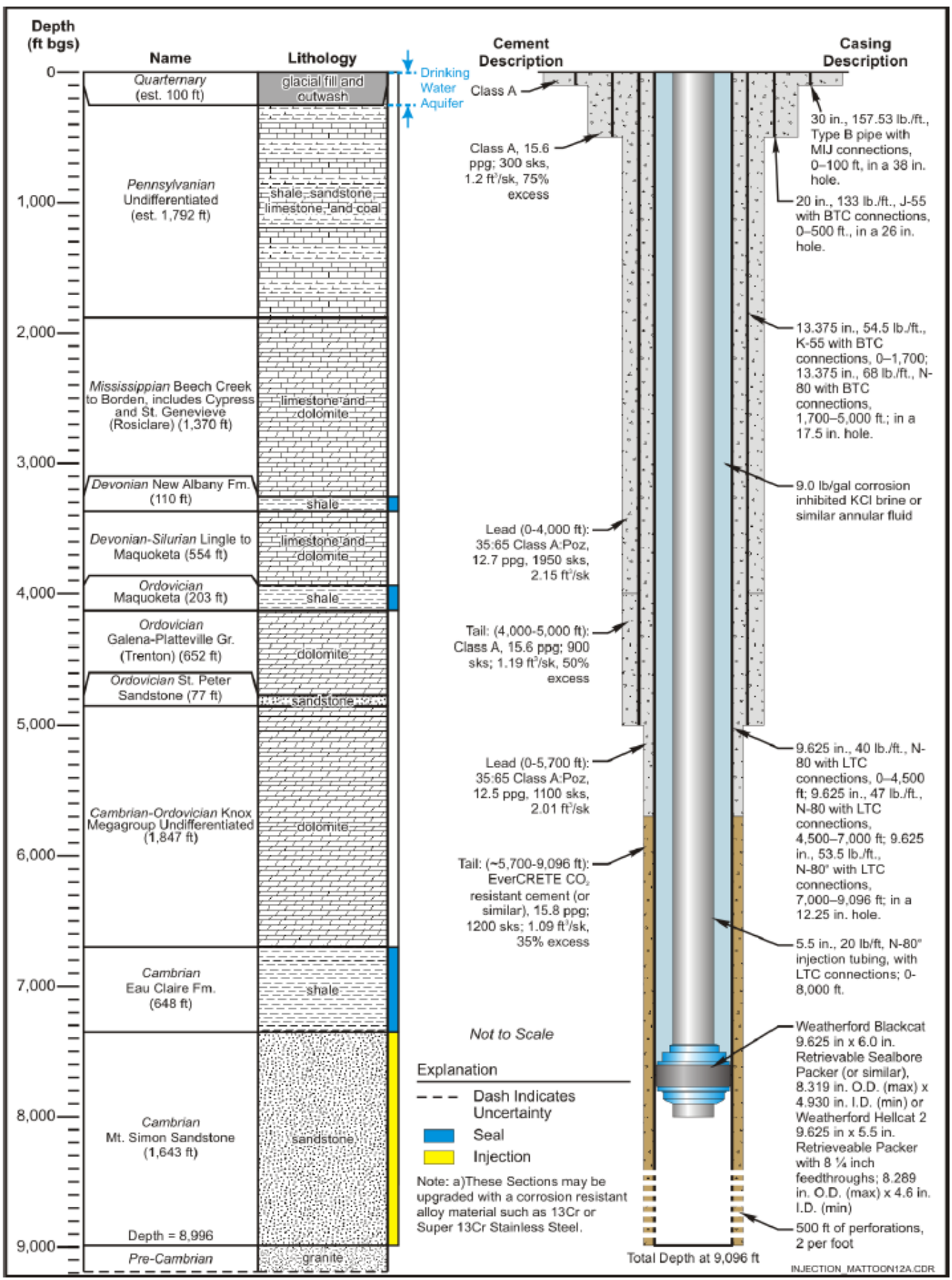

Figure 5-1. Injection Well Schematic 
Table 5-4. Borehole Depths and Diameters

\begin{tabular}{|c|c|c|c|}
\hline Casing String & $\begin{array}{c}\text { Casing Depth } \\
\text { (ft) }\end{array}$ & $\begin{array}{c}\text { Borehole Diameter } \\
\text { (inches) }\end{array}$ & $\begin{array}{c}\text { Casing Outside } \\
\text { Diameter } \\
\text { (inches) }\end{array}$ \\
\hline Conductor & 100 & 38 & 30 \\
\hline Surface & 500 & 26 & 20 \\
\hline Intermediate & 5000 to 7000 & 17.5 & 13.375 \\
\hline Long String & 9096 & 12.25 & 9.625 \\
\hline Tubing & 8000 & NA & 5.5 \\
\hline
\end{tabular}

As part of the routine operation of the storage site, the Alliance would have implemented a rigorous monitoring program. Section 6 of the UIC permit application details the monitoring, integrity testing, and contingency programs that the Alliance would have been responsible for during operation of the storage site.

\subsection{Comparative Technology Assessments}

Framed by the performance and design specifications, the Alliance conducted multiple technology assessments examining the potential trade-offs and impacts of technology or configuration options that could be deployed in the FutureGen facility. The analyses were not conducted to down-select potential vendors. Rather, the intent was to recognize strengths and weaknesses associated with potential equipment selections; understand what should be represented in the FutureGen facility; and survey a range of operational flexibility prior to generating the process flow diagrams (PFDs) and heat and material balances that would inform the project cost estimate activities. The individual evaluations contain proprietary information received from vendors or technology providers such that they cannot be included or attached to this document, however, an appended version of each of the studies is included in the following narrative.

$\mathrm{CO}_{2}$ Compressor Evaluation: The $\mathrm{CO}_{2}$ compressor evaluation directly addressed responses received from vendors during the RFI process. The main focus of the review was to determine aspects of risk, reliability, and basic mechanical attributes of different compressor types that would be considered for the project. Responses were received by three candidate technologies; all three were found to be technically acceptable for the project pending further review and clarification.

$\mathrm{CO}_{2}$ Dehydration Report: The analysis investigated relaxing the $\mathrm{CO}_{2}$ product dryness specification as offered in the ICDR (from 100 ppmv to $1250-2100$ ppmv) without compromising the operation or integrity of downstream $\mathrm{CO}_{2}$ pipeline. The analysis also considered the impact of integrating water removal with $\mathrm{CO}_{2}$ compression. The potential to eliminate a separate triethylene glycol (TEG) dehydration unit between the compressor and pipeline was determined to be feasible using a fourth-stage $\mathrm{CO}_{2}$ recycle stream, with approximately a 1 percent increase in compression horsepower. Ultimately, it was decided to leave the dryness specification at 100 ppmv, and include a TEG unit for water removal.

ASU Integration Study: Integrating the air separation unit (ASU) with the extraction air from the combustion turbine generator (CTG) has been demonstrated to reduce the power demand of the ASU and increasing overall IGCC plant efficiency. The analysis considered the impact of varying integration rates (0 percent, 25 percent, and 50 percent) on power output, heat rate, fuel gas consumption, and potential impacts to 
reliability of the industrial gas turbines. The analysis also considered aspects of intercooling which would be required before introducing the CTG extraction air to the ASU's booster air compressor, heat recovery, and impact to heat rate. The study concluded that integration of the ASU and CTG was not preferred because of startup and operability risks, but that recovery of bleed air energy by other means should be considered depending on the technology selection.

Steam Drive/Steam Cycle Report: The impact of using steam drives (vs. electric motor drives) was analyzed in this report, focusing primarily on the large compressors in the FutureGen plant: the $34 \mathrm{MW}$ main air compressor on the ASU, and the $22 \mathrm{MW} \mathrm{CO}_{2}$ compressor. Steam turbine performance and economics were evaluated for six different configurations and two steam cycle configurations (reheat vs. non-reheat steam cycle), and concluded with a comparative assessment with standard motor driven machines. It was decided to retain electrical motors for the large drivers because utilizing steam drives resulted in higher CAPEX, no efficiency gain, and some operational issues.

SRU Range Evaluation: This study examined sulfur removal unit (SRU) performance due to variations in feedstock compositions from the AGRU and sour water stripper/ammonia stripper, and to determine if a single unit design could accommodate the entire range of likely fuels. The analysis included predicted performance of the SRU unit bound by Illinois 6 coal (highest mean sulfur composition), and PRB (highest nitrogen/sulfur ratio and highest turndown percentage). An ancillary sulfur/ammonia burner simulation evaluated low syngas $\mathrm{H}_{2} \mathrm{~S}$ feed concentrations and the potential for supplemental hydrocarbon fuel use (to maintain temperature), supplemental sulfur additions, or operational changes to the Claus reactors in the formation of elemental sulfur. Processing Illinois No.6 coal at full rate presented no operational problems. The acid gas and ammonia streams can be fed to the burner without bypass. At a temperature in excess of $2400^{\circ} \mathrm{F}$, ammonia destruction is ensured and a sulfur recovery of $>96 \%$ was predicted. Processing PRB coal, particularly at reduced throughput, would require operational and design adjustments in the SRU and increase the cost of the SRU system and operations.

CTG Turbine Inlet Cooling: This analysis examined the impacts to CTG output, and gross CTG heat rate by using inlet air cooling at the FutureGen candidate host sites to improve warm weather performance. CTG performance was modeled both with and without evaporative inlet air cooling in 10 degree increments above $50-60^{\circ} \mathrm{F}$, capturing annualized generation (CTG only), incremental fuel consumption, and potential impacts to revenue and cost of operations. Depending on the site location and the plant capacity factor, the simple payback of installing evaporative cooling ranged from 1.1 to 3.8 years. Based on this, inclusion of turbine inlet coolers was recommended for consideration after finalizing the site location and the operating projections.

CTG-NOx and SCR Evaluation: The evaluation examined the potential capital and operational impacts of the CTG when tuned for varying levels of NOx in the turbine exhaust (15, 25, and $50 \mathrm{ppm})$. Strategies for NOx control included use of an ammonia-based SCR, increased diluent flow at the CTG (nitrogen and water vapor), or a combination of both. Based on a proposed stack limit of $15 \mathrm{ppm}$ and variations in CTG tuning, NOx limits were found to be achievable under a relatively wide range of hydrogen firing conditions using diluent only which would inherently increase the duty on the air separation unit as diluent flow increased, and the increase in steam demand would also contribute to a slightly higher net heat rate. The study also enumerated the potential tradeoffs in maintaining compressor surge margin, maximum firing temperature, and the likelihood of requisite CTG compressor air extraction based on the variations in tuning conditions based on CTG operational philosophy. 
Tail Gas Treatment: Two options for tail gas treatment system were evaluated to determine whether they could meet the 99 percent sulfur recovery requirement, and the 90 percent carbon capture requirement. The first configuration recycled the tail gas back to the front end of the AGRU allowing the gaseous stream to be reprocessed. The second configuration included tail gas treatment, and incineration of the remaining gas stream. In each configuration, three different syngas compositions were considered with varying methane and $\mathrm{CO}$ conversion levels. For the non-recycle configuration, incinerator emission calculations were performed based on the three potential coal fuel types, and compared with and without the tail gas treatment unit. The study concluded that recycling of the tail gas from the Claus unit was the most effective way to meet the emissions objectives of the FutureGen project.

\subsection{Architectural Design}

Architectural designs were developed for the visitor center and the control room building with the intention of providing a showcase facility for tours and education. A rendering of the visitor center is shown in Figure 5-2 and the control room building is shown in Figure 5-3 and Figure 5-4. 
2 future Gen"

Clean Energy for a Secure future

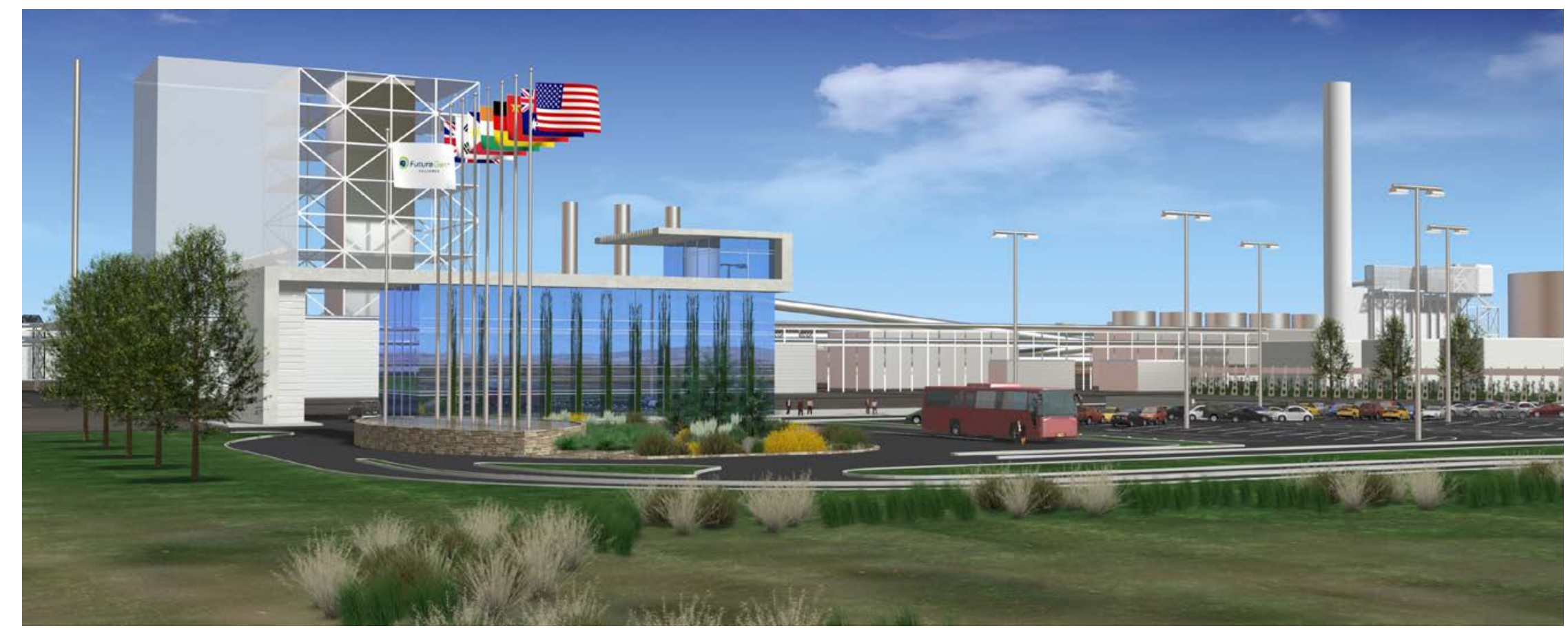

Figure 5-2. Artist rendering of FutureGen visitor center 
2 future Gen"'

A L L I A N C E

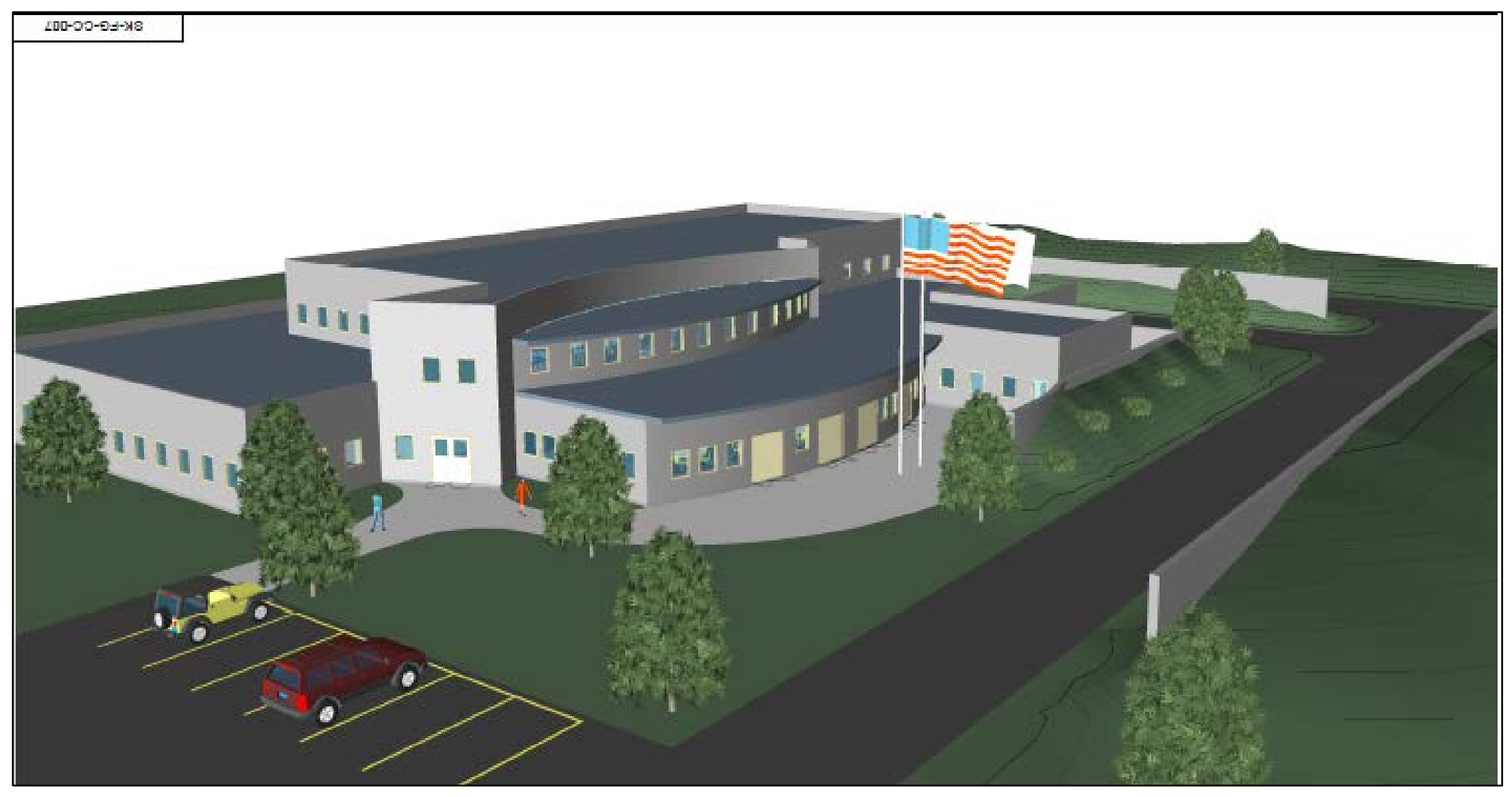

Figure 5-3. FutureGen control room building $-3 D$ rendering 
(2) FutureGen"

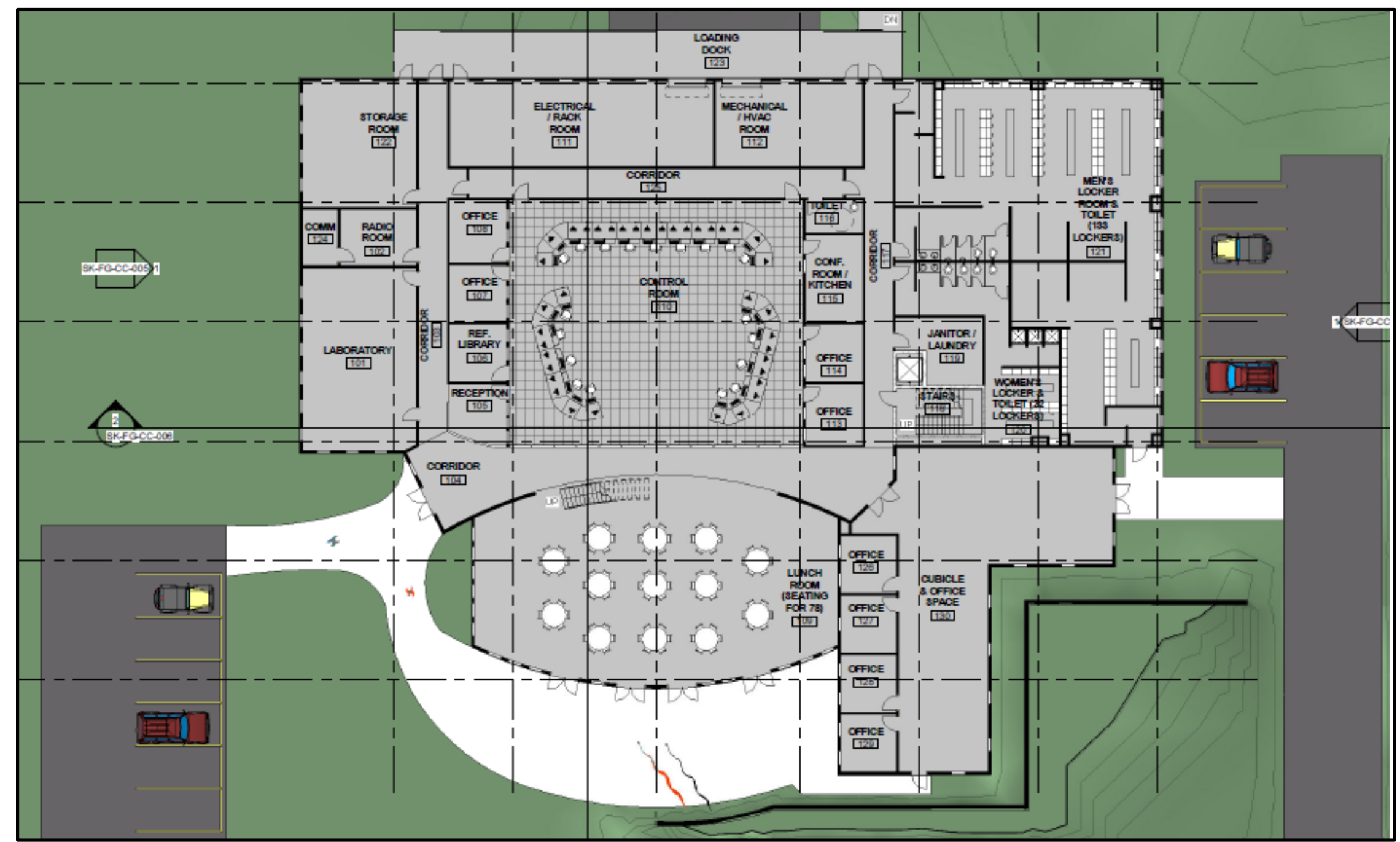

Figure 5-4. FutureGen control room building - architectural plan, first floor 


\section{Process Evaluations, Configuration, and Heat \& Material Balance Development}

To accommodate development of the PFDs and accompanying heat and material balances (HMBs), the Alliance conducted evaluations of gasifier technologies including variations to fuel feed (slurry-fed and dryfed), as well as variations to syngas cooling (quench or syngas cooling). Additional evaluations were conducted on potential variations of syngas conditioning such as sulfur and $\mathrm{CO}_{2}$ removal, as well as preliminary evaluations of plant and environmental control strategies based on the fixed plot plan and process configuration.

\subsection{Clean Coal Review Board Report}

Activities discussed in the preceding are found in the technology and process evaluations completed as part of the State of Illinois Clean Coal Review Board (CCRB) Report issued June 16, 2009. ${ }^{1}$ That report, as redacted, can be found in Attachment 4. The individual tasks executed as part of the CCRB report are provided in the following abbreviated synopsis:

Task 1: To engineer and develop the process configuration and perform technical evaluations on the FutureGen IGCC power plant gasifying Illinois 6 coal. Subtasks included evaluation of gasifier technologies, acid gas removal assessments, development of PFDs, and plant HMBs. Secondary activities included evaluation of overall plant efficiency, integration of subsystems, and overall operations and optimization based on the Mattoon site.

Task 2: Building on defined PFDs and HMBs, the approach to Task 2 was to identify and quantify key environmental considerations. The subtasks included optimizing site-specific water and wastewater use; production, characterization, and disposal of solids, solid wastes, and byproducts; and integrated trace metals distribution and critical control point analysis.

Task 3: These activities included the analysis of site and plant-specific variables as well as plant control mechanisms to initiate the evaluation and determination of key criteria for BACT (best available control technology), PSD (prevention of significant deterioration) requirements, and AQRV (air quality related value) including attainment status and regulatory applicability. Completion of the objectives in Task 3 required use of established plot plan configurations, identification of all plant and balance of plant interface, and development of an operations plan.

There were numerous iterations of the PFDs and HMBs throughout the project. Once developed, the PFDs and $\mathrm{HMBs}$ continued to be refined as the process configuration and operational scenarios were better defined or substantiated with vendor-supplied information. For clarity, only the final PFDs and HMBs that were utilized to frame the CAPEX and OPEX are included in this report. The PFD and HMB for the slurry-fed gasifier configuration are contained in Attachment 5 of this report. The PFD and the HMB for the dry-fed gasifier configuration are contained in Attachment 6 of this report. Note that the PFDs and HMBs contain redacted portions that are proprietary to technology providers, including the gasifier and certain aspects of syngas treatment. Additional information on process descriptions can be found in Section 8.2

Table 6-1 includes selected streams from the respective material balances developed for each of the gasifier configurations.

\footnotetext{
${ }^{1}$ FutureGen Alliance. Clean Coal Review Board Report. June 19, 2009. Included as Attachment 4 in this report.
} 
Table 6-1. Material Balance and Flow Rate at Design

\begin{tabular}{|c|c|c|c|c|}
\hline Plant Configuration & $\begin{array}{c}\text { Fuel Feed Rate } \\
(\mathrm{lb} / \mathrm{hr})\end{array}$ & $\begin{array}{c}\text { Oxygen Feed Rate } \\
(\mathrm{lb} / \mathrm{hr})\end{array}$ & $\begin{array}{c}\mathrm{CO}_{2} \text { to Injection Well } \\
(\mathrm{lb} / \mathrm{hr})\end{array}$ & $\begin{array}{c}\text { Net Station Power } \\
(\mathrm{MW})\end{array}$ \\
\hline Slurry-Fed Gasifier & $268,933^{2}$ & 218,557 & 538,051 & 244 \\
\hline Dry-Fed Gasifier & $252,105^{3}$ & 188,345 & 500,120 & 199 \\
\hline
\end{tabular}

The difference in net power output between the two designs is primarily due to different outputs of the steam turbine generator. Both designs result in a fully-loaded combustion turbine generator at $232 \mathrm{MW}$. The different STG output is from the generation and utilization of high-pressure steam for power production from the syngas cooler in the slurry fed configuration. ${ }^{4}$ While the slurry-fed design produces more net power, it also consumes more fuel / coal. The dry-fed configuration can produce the required level of syngas (LHV) to fully load the combustion turbine using less coal and oxygen, but due to the full quench the dry-fed configuration recovers less process heat and therefore has lower steam turbine output as designed.

It is also noted that given the level of design, neither the slurry-fed nor dry-fed gasifier configuration were fully optimized. The achievable performance would have been expected to be improved as the design was refined, particularly in terms of reducing the demands of parasitic loads. Further refinement of each configuration based on a single coal type would yield improvements to the gross and net power outputs, as well as station heat rate.

Additionally, because the Alliance had originally intended to run all three representative coal types in the facility including Illinois, Pittsburgh, and PRB, HMBs were also developed for two other coal ranks in the slurry-fed configuration for comparative purposes, and to enable an evaluation of operational impacts. Table 6-2 contains selected streams from the respective material balances developed for the varying coal types.

Table 6-2. Material Balance and Flow Rate for Alternate Coal Ranks

\begin{tabular}{|c|c|c|c|c|c|}
\hline $\begin{array}{c}\text { Plant } \\
\text { Configuration }\end{array}$ & Fuel Type & $\begin{array}{c}\text { Fuel Feed Rate } \\
\text { (lb/hr) }\end{array}$ & $\begin{array}{c}\text { Oxygen Feed Rate } \\
\text { (lb/hr) }\end{array}$ & $\begin{array}{c}\mathrm{CO}_{2} \text { to Injection Well } \\
\text { (lb/hr) }\end{array}$ & $\begin{array}{c}\text { Net Station Power } \\
\text { (MW) }\end{array}$ \\
\hline \multirow{2}{*}{$\begin{array}{c}\text { Slurry-Fed } \\
\text { Gasifier }\end{array}$} & Pittsburg 8 & 217,334 & 200,350 & 517,716 & 226 \\
\cline { 2 - 7 } & Powder River Basin & 311,295 & 222,828 & 526,988 & 211 \\
\hline
\end{tabular}

Noting that due to modification of the cooperative agreement, work completed in support of the cost estimate such as the process evaluations were ultimately bound to a single coal type for the two gasifier configurations. Therefore, heat and material balances for the alternate coal ranks were not completed for the dry-fed configuration. Similar impacts could be expected however in the dry-fed configuration respective of the energy properties of the alternative coal ranks.

\footnotetext{
${ }^{2}$ FutureGen Alliance Heat and Material Balance. Rev C. Document No: 29207-000-21-ENG-05-200-0001. December 18, 2009. Included in Attachment 5 of this report.

${ }^{3}$ FutureGen Alliance Heat and Material Balance. Rev. D. Document: 29207-000-21-ENG-05-200-004. December 3, 2009. Included in Attachment 6 of this report.

${ }^{4}$ FutureGen Alliance. Clean Coal Review Board Report: Gasification Technology Evaluation Summary. June 16, 2009.
} 


\section{Project Life Cycle Cost Estimate Methodology and Overview}

Based on the preceding, the Alliance produced a preliminary design report and factored cost estimate capturing the design and costing elements of total installed cost for capital expenditures (CAPEX), operating cost (OPEX), and post-operations cost (POC) for slurry-fed and dry-fed gasifier configurations. Where appropriate, aspects that would influence the project life cycle cost were also incorporated, such as owner's costs and contingencies for estimate-driven and event-driven risks. The cost estimate methodologies are presented in this section. The results of the CAPEX cost estimate also are summarized in Section 8. , with the details provided in Attachment 7. The results of the OPEX cost estimate are summarized in Section 9. , with the details provided in Attachment 8. The results of the POC estimate are summarized in Section 10.

\subsection{Level of Detail and Estimate Overview}

The following details constitute the first cost estimate developed for the FutureGen facility based on a robust FEL-2 facility design for the two gasifier technologies at the Mattoon site. The budget estimate was proposed as a Class 4 factored cost estimate using the AACE guidance, which can have a range of estimate accuracies. The level of estimate chosen for this activity was -15 percent to +30 percent, and was consistent with most aspects of the FEL-2 level of design. The AACE classification guidance for a Class 4 cost estimate is provided in Table 7-1.

Table 7-1. Class 4 Cost Estimate Description ${ }^{1}$

\begin{tabular}{|c|c|}
\hline \multicolumn{2}{|c|}{ Class 4 Cost Estimate } \\
\hline $\begin{array}{l}\text { ANSI Standard Reference Z94.2-1989 Name: } \\
\text { Budget estimate (typically - } 15 \% \text { to + 30\%). } \\
\text { Alternate Estimate Names, Terms, Expressions, Synonyms: } \\
\text { Screening, top-down, feasibility, authorization, factored, } \\
\text { pre-design, pre-study. } \\
\text { Description: } \\
\text { Class } 4 \text { estimates are generally prepared based on limited } \\
\text { information and subsequently have fairly wide accuracy } \\
\text { ranges. They are typically used for project screening, } \\
\text { determination of feasibility, concept evaluation, and } \\
\text { preliminary budget approval. Typically, engineering is from } \\
1 \% \text { to } 15 \% \text { complete, and would comprise at a minimum } \\
\text { the following: plant capacity, block schematics, indicated } \\
\text { Iayout, process flow diagrams (PFDs) for main process } \\
\text { systems, and preliminary engineered process and utility } \\
\text { equipment lists. } \\
\text { Level of Project Definition Required: } \\
1 \% \text { to } 15 \% \text { of full project definition. } \\
\text { Effort to Prepare (for Us\$20mm project): } \\
\text { Typically, as little as } 20 \text { hours or less to perhaps more than } \\
300 \text { hours depending on the project and the estimating }\end{array}$ & $\begin{array}{l}\text { End Usage: } \\
\text { Class } 4 \text { estimates are prepared for a number of purposes, } \\
\text { such as but not limited to, detailed strategic planning, } \\
\text { business development, project screening at more } \\
\text { developed stages, alternative scheme analysis, } \\
\text { confirmation of economic and/or technical feasibility, and } \\
\text { preliminary budget approval or approval to proceed to next } \\
\text { stage. } \\
\text { Estimating Methods Used: } \\
\text { Class } 4 \text { estimates virtually always use stochastic } \\
\text { estimating methods such as equipment factors, Lang } \\
\text { factors, Hand factors, Chilton factors, Peters-Timmerhaus } \\
\text { factors, Guthrie factors, the Miller method, gross unit } \\
\text { costs/ratios, and other parametric and modeling } \\
\text { techniques. } \\
\text { Expected Accuracy Range: } \\
\text { Typical accuracy ranges for Class } 4 \text { estimates are - } 15 \% \text { to } \\
\text {-30\% on the low side, and }+20 \% \text { to }+50 \% \text { on the high side, } \\
\text { depending on the technological complexity of the project, } \\
\text { appropriate reference information, and the inclusion of an } \\
\text { appropriate contingency determination. Ranges could } \\
\text { exceed those shown in unusual circumstances. }\end{array}$ \\
\hline
\end{tabular}

${ }^{1}$ AACE International Recommended Practice No. 18R-97, Cost Estimate Classification System - As Applied in Engineering, Procurement, and Construction for the Process Industries. 2005. 


\subsection{Technical Requirements and Enabling Assumptions}

To reflect the total estimated life cycle costs for the project, the Alliance framed the estimates with the following provisions:

- BP-0 included costs associated with project definition, NEPA/siting activities, the initial conceptual design, and program management.

- The CAPEX included costs for the surface facility, the subsurface facility, and all supporting infrastructure required for operations prior to commissioning.

- The total installed cost (TIC) reflects the sum of the CAPEX and the owner's costs prior to the start of operations.

- The OPEX included costs for the commissioning and operation of the plant for 4 years.

- Post-operations costs cover the 2 years of MVA operations, and project closeout costs.

The FutureGen facility would have had significant value at the end of the 4 years of operation as a commercial power plant and integrated CCS facility; however, the facility's final disposition was neither known nor proposed when the estimate was developed. Therefore, costs, revenues, and residual values associated with the facility were not included in the cost estimate, and transition to a new operator was considered a reasonable assumption.

The CAPEX, OPEX, and POC estimates were bound by enabling assumptions found in Table 7-2 (CAPEX) and Table 7-3 (OPEX), noting that the POC assumptions are collectively captured in the CAPEX and OPEX as well. The final plot plan proposed for the CAPEX estimate is included in Figure 7-1. For clarity, the basis of each assumption is provided when the supporting detail is considered material. 
ALLIANCE

Clean Energy for a Secure Future

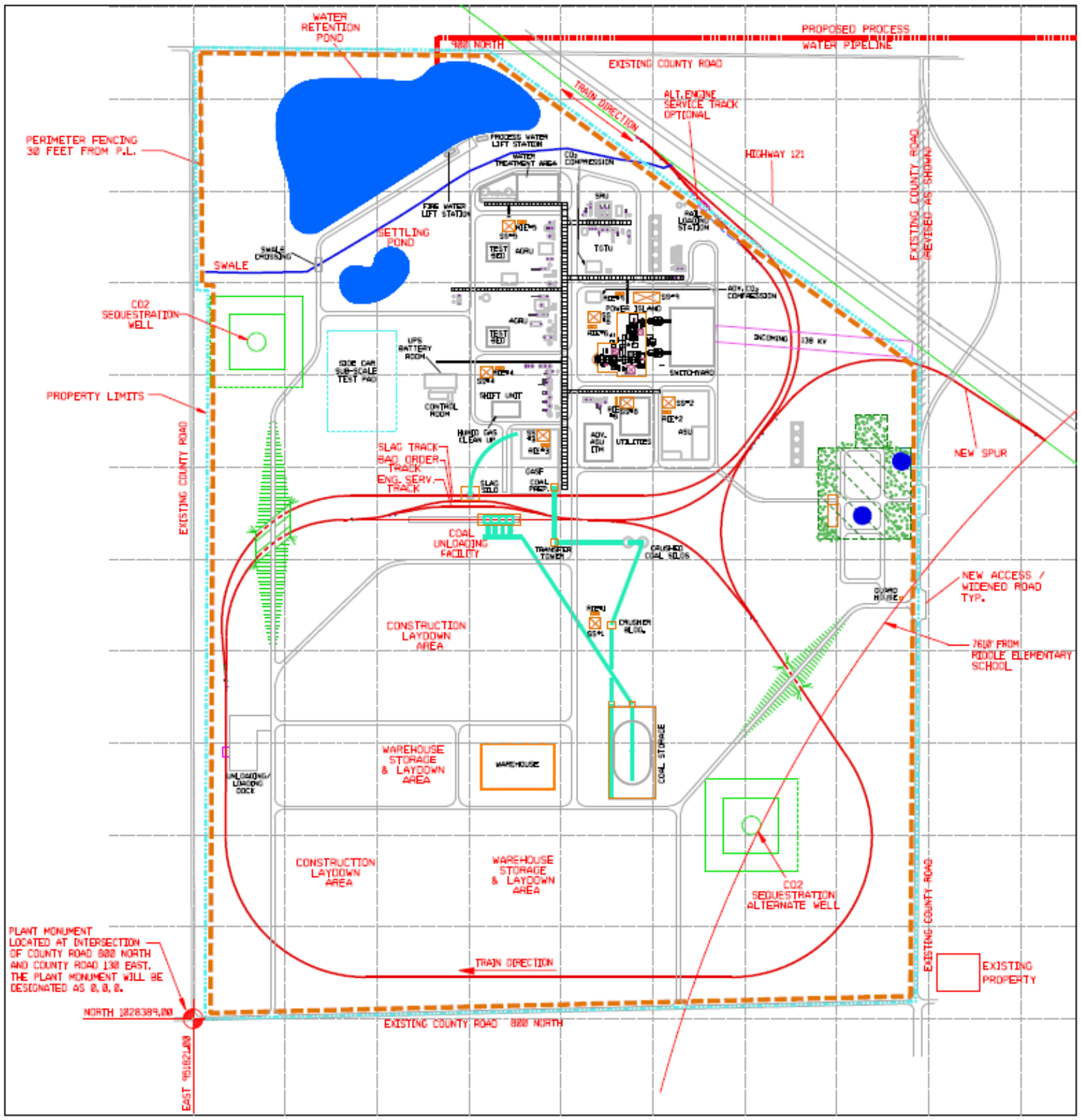

Figure 7-1. Mattoon FutureGen Plot Plan 
Table 7-2. FutureGen CAPEX Enabling Assumptions

\begin{tabular}{|c|c|c|c|}
\hline & No. & Assumption & Basis \\
\hline & 1 & Axioms will be fully implemented into the design. & Governance for the engineering and design basis. \\
\hline & 2 & $\begin{array}{l}\text { SCR (selective catalytic reduction) equipment will be installed in } \\
\text { the HRSG (heat recovery steam generator) stack to reduce } \mathrm{NO}_{x} \\
\text { emissions to } 5 \mathrm{ppm} \text {. }\end{array}$ & $\begin{array}{l}\text { For optimum performance of the combustion gas } \\
\text { turbine, an SCR is required to meet the targeted } \mathrm{NO}_{x} \\
\text { emissions as defined by the EIS and ROD. }\end{array}$ \\
\hline & 3 & $\begin{array}{l}\text { The CAPEX estimate will be segregated at mechanical } \\
\text { completion and at turnover. This break allows for a clear } \\
\text { understanding of the cost of commissioning and startup of the } \\
\text { plant from the traditional elements that define the completion } \\
\text { of construction. }\end{array}$ & $\begin{array}{l}\text { Construction traditionally is completed at mechanical } \\
\text { completion. At this point, specialist personnel trained in } \\
\text { the commissioning and startup of process and power } \\
\text { facilities are introduced into the project with the goal of } \\
\text { turnover of a complete facility. }\end{array}$ \\
\hline & 4 & $\begin{array}{l}\text { Major islands (gasification, ASU, and power block) will be } \\
\text { purchased under separate engineering, procurement, and } \\
\text { construction (EPC) contracts. The engineering construction } \\
\text { management (ECM) company will provide site prep, integration } \\
\text { engineering, and balance of plant engineering. The ECM will } \\
\text { serve as the main automation contractor for the project and will } \\
\text { work with process-control system suppliers to provide the } \\
\text { distributed control system, safety instrumented system, and } \\
\text { data warehouse. }\end{array}$ & $\begin{array}{l}\text { Due to the unique contracting nature of the gasification, } \\
\text { ASU, and power island, each was treated as a separate } \\
\text { EPC contract. Proposals were solicited from the } \\
\text { gasification and ASU suppliers to provide EPC quotes. } \\
\text { The power island was estimated by the URS Corporation } \\
\text { (URS) power engineering group. }\end{array}$ \\
\hline & 5 & Contracts will be awarded by the FutureGen Alliance. & Reduces contractor fees \\
\hline & 6 & FutureGen will hold the labor agreement for the site. & $\begin{array}{l}\text { Minimizes competition for resources among the } \\
\text { construction contractors }\end{array}$ \\
\hline & 7 & $\begin{array}{l}\text { CAPEX owner costs will include the first full charge of all feed } \\
\text { stocks and consumables required to initiate operations at the } \\
\text { site. }\end{array}$ & Basis of Estimate \\
\hline CAPEX & 8 & $\begin{array}{l}\text { Contingency was agreed upon by the Alliance consistent with } \\
\text { industry practice and based on the degree of design uncertainty } \\
\text { of each area or island contract. }\end{array}$ & Basis of Estimate \\
\hline & 9 & $\begin{array}{l}\text { A data warehouse will be purchased and will store historical } \\
\text { data to be retrieved by others. It will not be a central storage } \\
\text { for all unit operations functions for the life of the project. The } \\
\text { data warehouse will retain a defined period of operations, } \\
\text { typically a month of operations of the total surface and } \\
\text { subsurface facilities. }\end{array}$ & Basis of Estimate \\
\hline & 10 & $\begin{array}{l}\text { The plant will be designed to process the base case throughput } \\
\text { for Illinois } 6 \text { coal and an allowable turndown to } 70 \text { percent for } \\
\text { PRB coal. }\end{array}$ & $\begin{array}{l}\text { This is the optional case from the coal parametric study } \\
\text { and gasifier RFP. The lower turndown for the PRB coal } \\
\text { was chosen because of the dramatic impact to the capital } \\
\text { cost of the ASU ( } \$ 10 \mathrm{M} \text { from going from } 87 \text { percent to } \\
70 \text { percent for PRB) and the gasification island (TBD). }\end{array}$ \\
\hline & 11 & The plant will be operated for 4 years following turnover. & $\begin{array}{l}\text { The 4-year period is based on } 1 \text { year of shake down and } \\
\text { commissioning and running multiple coal types to } \\
\text { demonstrate the operability and meet sequestration } \\
\text { targets. }\end{array}$ \\
\hline & 12 & $\begin{array}{l}\text { The cost of the subscale research and development facility was } \\
\text { not included in the estimate. The plot plan will have room for } \\
\text { subscale testing areas near the applicable processing islands. } \\
\text { Future installation of the following subscale systems was } \\
\text { assumed: ion-transport membrane oxygen system near the ASU, } \\
\text { fuel cells near the power island, and Ramgen compressors near } \\
\text { the } \mathrm{CO}_{2} \text { compression facility. }\end{array}$ & Basis of Estimate \\
\hline & 13 & $\begin{array}{l}\text { The post-operations scenario is uncertain at this time. The plant } \\
\text { is assumed to have no value or burden at the end of the fourth } \\
\text { year of operations, although in reality it will. }\end{array}$ & Basis of Estimate \\
\hline & 14 & $\begin{array}{l}\text { Labor rates for construction craft, union operators, maintenance } \\
\text { staff, and non-union engineers were based on labor surveys } \\
\text { conducted by URS and are valid for the estimate. }\end{array}$ & Basis of Estimate \\
\hline
\end{tabular}


Table 7-3. FutureGen OPEX Enabling Assumptions

\begin{tabular}{|c|c|c|c|}
\hline & No. & Assumption & Basis \\
\hline & 1 & $\begin{array}{l}\text { The "break" between the CAPEX and OPEX costs is at } \\
\text { mechanical completion. CAPEX includes all costs before and } \\
\text { during activities associated with mechanical completion. } \\
\text { OPEX includes all costs after mechanical completion. }\end{array}$ & \\
\hline & 2 & $\begin{array}{l}\text { Cost estimate was based on Illinois } 6 \text { only coal feed } \\
\text { assumptions for slurry fed and dry fed gasifier options. }\end{array}$ & $\begin{array}{l}\text { Agreement with Technical Committee and in response to RFIs } \\
\text { issued to gasification vendors. }\end{array}$ \\
\hline & 5 & $\begin{array}{l}\text { Plant availability was determined from the fuel processing } \\
\text { schedule: } 2285 \text { for Year } 1 ; 4435 \text { for Year 2; } 5174 \text { for Year 3; } \\
\text { and } 6300 \text { for Year } 4 \text {. }\end{array}$ & $\begin{array}{l}\text { Modified based on surveys of other plants and technology } \\
\text { provider information such as planned maintenance outages. }\end{array}$ \\
\hline & 6 & $\begin{array}{l}\text { No credit or debit was assumed for the subscale system } \\
\text { loads. }\end{array}$ & $\begin{array}{l}\text { In general, installed subscale equipment will be power neutral, } \\
\text { or be capable of operating without significantly impacting } \\
\text { station heat rate. }\end{array}$ \\
\hline OPEX & 8 & $\begin{array}{l}\text { Fixed maintenance costs (labor and materials) are } \\
\text { estimated as a percentage of direct field cost. EPRI (TAG) } \\
\text { terminology is used to determine the split between labor } \\
\text { and materials (40:60) based on guidance from the Alliance } \\
\text { Technical Committee, vendor input, and historical } \\
\text { information from operating IGCCs. }\end{array}$ & $\begin{array}{l}\text { Fixed maintenance costs include all materials and labor that is } \\
\text { not part of the maintenance labor retained by the plant. Plant } \\
\text { supplied labor depends on the complexity and maturity of the } \\
\text { technology. }\end{array}$ \\
\hline & 9 & $\begin{array}{l}\text { Long-term service agreements (combustion turbine) are } \\
\text { included as part of the variable maintenance costs } \\
\text { associated with surface maintenance. }\end{array}$ & $\begin{array}{l}\text { Listed in services subcontracts line item; provided on a per } \\
\text { fired hour basis. }\end{array}$ \\
\hline & 10 & $\begin{array}{l}\text { Plant availability was evaluated among representative peers } \\
\text { and through vendor responses to RFPs. The plant is } \\
\text { intended to operate with high capacity factors when } \\
\text { available. Startups will be taken into account based on the } \\
\text { outage time. That is, hot restarts, warm restarts, and cold } \\
\text { restarts will require increasing amounts of time and } \\
\text { resources to complete. }\end{array}$ & $\begin{array}{l}\text { The plant is not anticipated to have reserve shut down hours, } \\
\text { which would reduce the capacity factor. }\end{array}$ \\
\hline & 11 & $\begin{array}{l}\text { Labor rates: union operators and maintenance staff. Non- } \\
\text { union engineers. Labor rates received from the State of } \\
\text { Illinois will be used. URS labor rates for construction have } \\
\text { also been received. }\end{array}$ & \\
\hline & 12 & $\begin{array}{l}\text { The mean coal compositions in the design basis will be used } \\
\text { for processing calculations }\end{array}$ & Recommendation of Technical Committee \\
\hline & 13 & $\begin{array}{l}\text { The plant will be allowed to run and dispatch power } \\
\text { whenever it is available. That is, it will not have to sit idle } \\
\text { due to an over-supply of power in the area. }\end{array}$ & \\
\hline
\end{tabular}

\subsection{Estimate Methodology and Development}

The cost estimate provided to DOE was all-inclusive from a project standpoint, such that it accounted for itemized costs in the following four areas: project initiation costs including all design and engineering costs, TIC, OPEX, and POC. The logic used to arrive at each area estimate was varied, but relative to the process design maturity and amount of available information for each area.

\subsubsection{Total Installed Cost Estimate}

The cost estimate was based on a reference FutureGen plant configuration using the FEL-2 design and engineering effort, as well as technical input received from potential suppliers of the major islands and equipment for the facility. Due to the overall complexity of the plant, the estimate required the use of 
several different estimating resources, including Aspen's ACCE $^{\mathrm{Tm}}$ software $^{2}$ (formerly Kbase ${ }^{\mathrm{Tm}}$ ), WinEst ${ }^{\circledR}{ }^{3}$, Similar Plant (a proprietary factored approach methodology), and factored estimating tools to develop the TIC. The application of each of these tools depended on the area, as each tool has its strengths. Tools were selected to maximize the accuracy of the estimate for a given area. Budgetary quotes were received for major equipment as well as some complete areas or contract elements. Where supplier quotations were unattainable, cost estimates were developed by extrapolating historical information. Table 7-4 provides the estimating tool and approach used for each area estimate.

Table 7-4. Area Estimating Approach

\begin{tabular}{|c|l|c|c|}
\hline \multicolumn{2}{|c}{ Area } & Estimate Tool & $\begin{array}{c}\text { Estimate } \\
\text { Approach }\end{array}$ \\
\hline 100 & Coal Handling Island & Similar Plant & Priced Equipment \\
\hline 200 & Air Separation Unit Island & EPC Bid & Vendor Quote \\
\hline 300 & Gasification Island & EPC Bid & Vendor Quote \\
\hline 400 & Shift Reaction & ACCE & Priced Equipment \\
\hline 500 & Mercury Removal & ACCE & Priced Equipment \\
\hline 510 & Acid Gas Removal & ACCE & Priced Equipment \\
\hline 520 & Sulfur Removal & ACCE & Priced Equipment \\
\hline 530 & Tail Gas Treatment Unit & ACCE & Priced Equipment \\
\hline $600 \mathrm{~A}$ & Power Island & Similar Plant & Priced Equipment \\
\hline $600 \mathrm{~B}$ & Grid Interface & Similar Plant & Priced Equipment \\
\hline 700 & Project Integration & WinEst & Priced Material \\
\hline $800 \mathrm{~A}$ & Balance of Plant & ACCE & Priced Equipment \\
\hline $800 \mathrm{~B}$ & Process Water Treatment Island & ACCE & Priced Equipment \\
\hline $900 \mathrm{~A}$ & CO ${ }_{2}$ Compression Island & ACCE & Priced Equipment \\
\hline $900 \mathrm{~B}$ & Sequestration & Factored & Priced Equipment \\
\hline & & & \\
\hline
\end{tabular}

The TIC estimate was completed for two different process technologies: one for slurry-fed gasification and one for a dry-fed gasification configuration, as the gasifier technology had not been selected at the time the estimates were completed. Initial estimates were completed as overnight 1Q2008\$. To clarify the potential impacts of the various technologies, the costs for the aforementioned technologies were estimated separately. The steps for the TIC estimate are as follows:

1. Separate cost estimates were completed for each plant area as well as the subsurface activities, BP0 , and BP-1 costs. Figure 7-2 shows how area costs were binned depending on the methodology.

\footnotetext{
${ }^{2}$ Aspen ACCE ${ }^{\mathrm{TM}}$ is the former Aspen Kbase ${ }^{\mathrm{TM}}$ software. It is designed for use throughout the estimating life cycle to generate both conceptual and detailed estimates. Equipment, with associated plant bulks, is represented by design-based installation models.

${ }^{3}$ WinEst Pro $^{\circledR}$ Construction Estimating Software
} 


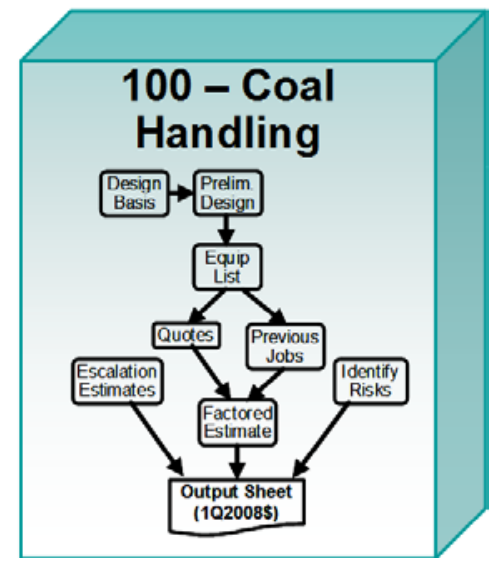

Figure 7-2. Example of Area Estimate Bid Logic

2. The individual area estimates were summed to arrive at the unmitigated CAPEX (CAPEX before any risk contingency costs have been added).

3. The owner's costs were added to the CAPEX to arrive at the unmitigated TIC.

4. Estimate-driven risks were quantified to evaluate the uncertainty of the estimate. This was reported internally as a bracketed range of costs (+/- estimate), and comparatively assessed against the proposed accuracy of the estimate.

5. Event-driven risks such as inflation, abnormal escalation, design changes, and delays were quantified to evaluate additional uncertainties in the estimate. Similar to the estimate-driven risk analysis, the initial event-driven risk analysis was initially reported as a bracketed range of costs (+/- estimate).

6. Depending on the availability of risk information, a probability model was used to develop a cost estimate with a given probability (P85 cost estimate), and reported as the as-spent TIC estimate.

The logic to arrive at the CAPEX and TIC is provided in Figure 7-3. 


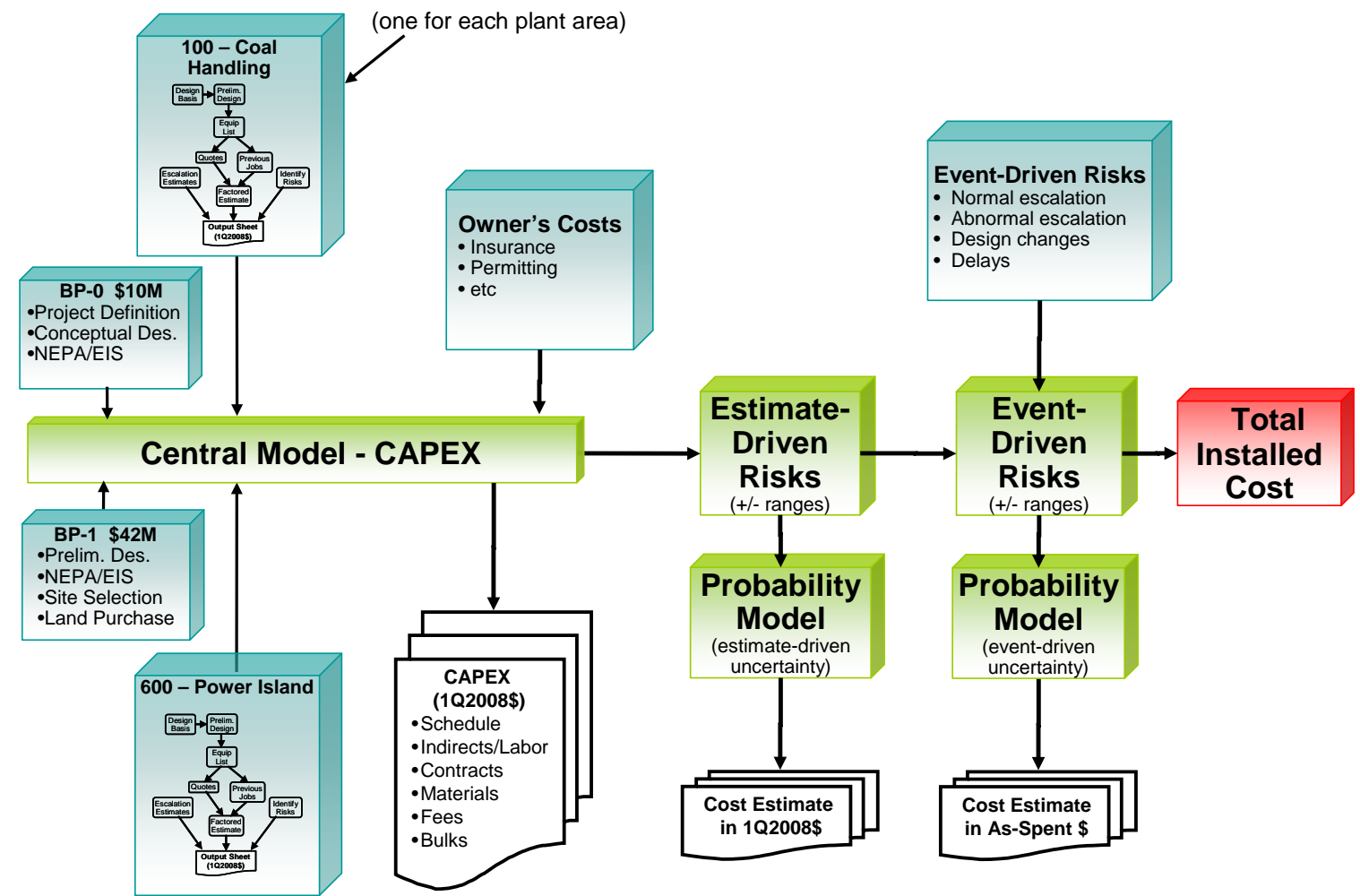

Figure 7-3. CAPEX and Total Install Cost Estimate Logic

\subsubsection{Operating Cost Estimate}

The estimates for the total operating cost and the POC were developed using the same methodology as the TIC estimate, and were based on the reference design activities. The OPEX estimate provides costs for a full 4 years ( 48 months) of O\&M. Due to the overlap of CAPEX and OPEX related costs during the start-up and commissioning period, costs related to plant personnel labor prior to the mechanical completion of the plant are contained within the CAPEX estimate. Specifically, this captures the costs related to hiring, training, and development of plant management, engineering, operations, and maintenance staff in the year(s) prior to mechanical completion of the plant. This is further characterized in Section 8 . of this estimate.

The steps of the OPEX and total operating cost estimate are as follows:

1. A schedule was developed for the staff training, commissioning, and plant operations. As previously indicated, the schedule overlapped with the CAPEX schedule because on-site plant personnel training started prior to mechanical completion of the plant.

- A separate staffing plan was developed for plant startup and check-out, which is contained in the CAPEX.

o A staffing plan was developed for base operations; this included labor costs associated with onsite maintenance staff in addition to operators.

2. Fully burdened labor costs for each job category were gathered from both internal sources and State of Illinois labor reports. 
3. Fuel, consumables, and utility (natural gas, water, electricity, etc.) needs were obtained from the heat and material balance for the respective configuration and fuel type. These contained both fixed and variable costs.

4. Availability and electricity generation was determined using historical start-up curves and allowances for full commissioning, and incorporating two planned outages each year during the spring and fall when the demand for power is traditionally lower.

5. Factored maintenance labor and material costs were gathered from a variety of sources as described later in this document.

6. Contractual service agreements such as the CTG long-term service agreement (LTSA) were calculated based on fired hours. Other service contracts were estimated based on the level of labor and materials that would be required for non-routine systems outside of costs captured in the factored maintenance estimate (e.g., AGRU solvent performance evaluation).

7. Subsurface $O \& M$ estimates were developed based on routine inspections, well testing/workovers, and MVA activities for the sequestration facilities.

8. Owner's costs were added to the OPEX to arrive at the unmitigated total operating cost.

9. Similar to the CAPEX estimate, risk analyses were completed for two separate groups of risks, estimate-driven risks and event-driven risks, to arrive at the total operating cost estimate.

The logic used to arrive at the total operating cost estimate is provided in Figure 7-4. 

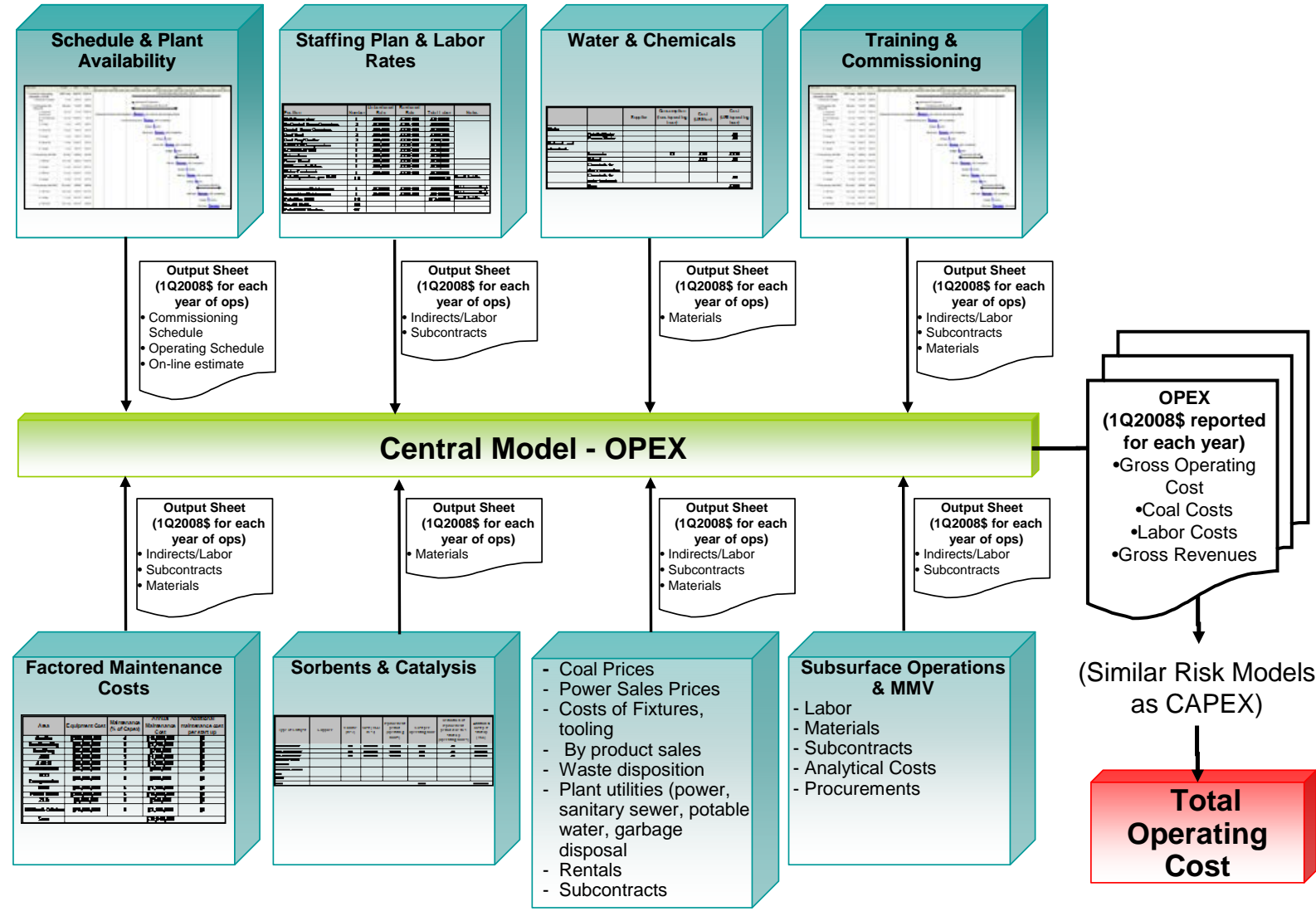

(Similar Risk Models as CAPEX)

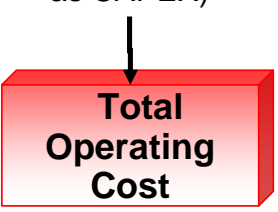

Figure 7-4. OPEX and Total Operating Cost Estimate Logic

\subsubsection{Post-Operations Cost Estimate}

The POC estimate included the costs for 2 years of MVA activities for the sequestration site, the associated reporting, and project closeout costs. The POC for the subsurface facility included the following major activities: closure in place of the $\mathrm{CO}_{2}$ pipeline; limited O\&M for the injection well; plugging and abandonment of all deep wells; continuation of the comprehensive $\mathrm{CO}_{2}$ monitoring program initiated during the CAPEX and OPEX phase; field labor, travel and overhead expenses; and project indirects and home office costs.

As indicated in Section 7.2 , the cost estimate assumes that the transition of the plant operations is a zero cost item; it does not take credit for any residual value of the facility after the 4 years of operation, nor does it assume costs associated with a plant closure after operations. This is a conservative assumption because the plant will retain significant book value after the 4-year operating period. The POCs are shown in Figure 7-5. Owner's costs are included and represent activities and costs incurred by the Alliance after full-scale operation of the FutureGen plant is completed. 


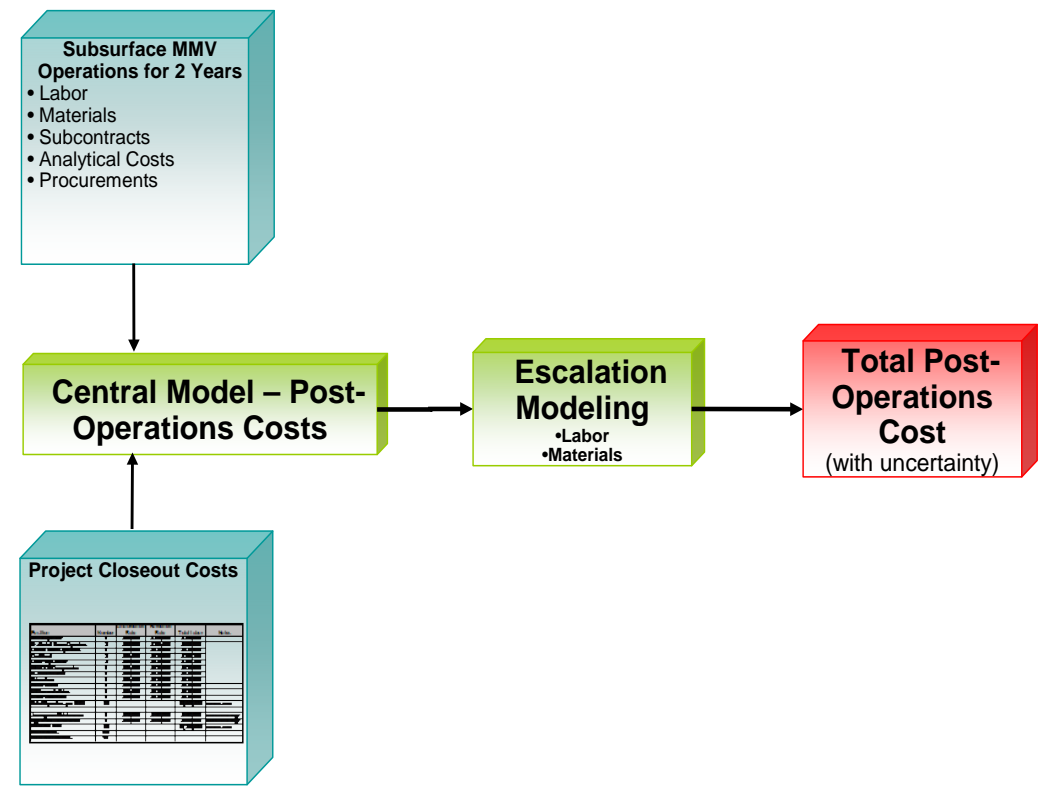

Figure 7-5. POC Estimate Logic

\subsubsection{Value Engineering and Final Review}

For completeness, each area estimate underwent several reviews, both internal and external, prior to issuance. The review team was made up of senior managers from the participants and external consultants. Value engineering studies and Technical Committee reviews were completed in parallel with the management review. The final consolidated life cycle cost estimate was compared with previous order-ofmagnitude estimates for continuity, and released to Alliance management and the Alliance Board for final review. With consolidated findings from the value engineering and management reviews, the final CAPEX, OPEX, and combined total project cost estimate was provided in 202009 dollars. The estimate review process is provided in Figure 7-6.

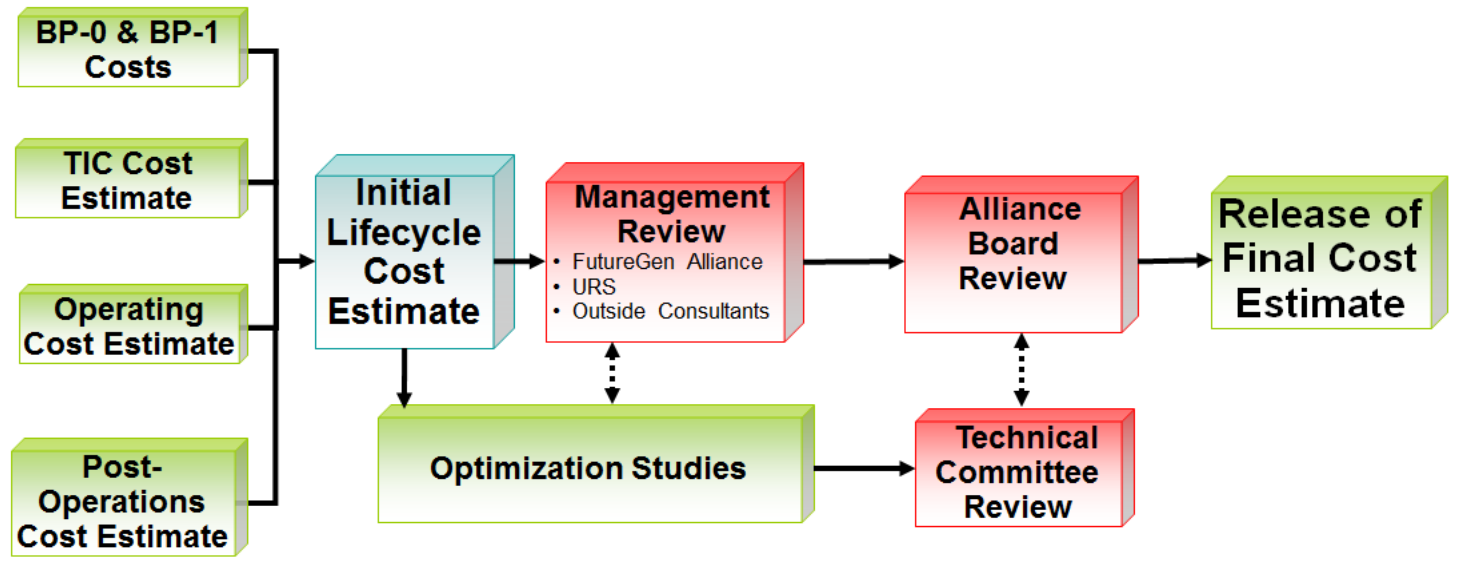

Figure 7-6. Cost Estimate Review Process 


\section{Capital Expenditure (CAPEX) Cost Estimate}

The following provides summary level details of the CAPEX developed for the FutureGen project at the Mattoon, Illinois site. The complete CAPEX report is provided in Attachment 7 of this report. As discussed previously, the FutureGen plant was designed to produce electrical power with near-zero emissions by gasification of coal with oxygen to produce a syngas consisting primarily of hydrogen, carbon monoxide, carbon dioxide, water vapor, and hydrogen sulfide.

The carbon monoxide is converted to hydrogen and carbon dioxide by the water-gas shift reaction, and then systematically cooled and treated to separate the carbon dioxide and hydrogen sulfide from the syngas. The carbon dioxide, having been removed from the syngas, is compressed and sequestered in a saline aquifer; the hydrogen sulfide is converted into elemental sulfur in a Claus unit.

The remaining fuel stream consisting primarily of hydrogen, is mixed with a diluent (nitrogen), and fed to the CTG to generate electrical power. Hot combustion gases from the CTG discharge to the HRSG, which transfers the heat of combustion into water to produce steam. Steam from the HRSG is combined with other steam sources from the gasification and syngas cooling processes, and is fed to the STG which generates additional electrical power.

\subsection{CAPEX SUmmary}

The cost estimate was completed for two different process technologies: one for slurry-fed gasification and one for a dry-fed gasification configuration. To clarify the potential impacts of the various technologies, the costs for each configuration were estimated separately. Table 8-1 provides the roll-up summary CAPEX estimate for the two configurations by Area. ${ }^{1}$

${ }^{1}$ FutureGen Alliance. 2009 Project Cost Estimate: Volume I, Capital Costs. January 29, 2010. Included in Attachment 7 of this report. 
Table 8-1. CAPEX for Slurry-Fed and Dry-Fed Configurations

\begin{tabular}{|c|c|c|c|}
\hline Area Number & Area & $\begin{array}{l}\text { 2Q2009 Slurry- } \\
\text { Fed Gasifier }\end{array}$ & $\begin{array}{c}\text { 2Q2009 Dry-Fed } \\
\text { Gasifier }\end{array}$ \\
\hline 100 & Coal Handling Island & $\$ 128,564,646$ & $\$ 128,503,030$ \\
\hline 200 & Air Separation Unit Island & Note A & Note A \\
\hline 300 & Gasification Island & Note A & Note A \\
\hline 400 & Shift Reaction & $\$ 66,363,000$ & $\$ 70,129,000$ \\
\hline 500 & Mercury Removal & $\$ 4,079,000$ & $\$ 3,578,000$ \\
\hline 510 & Acid Gas Removal & $\$ 158,692,000$ & $\$ 152,441,000$ \\
\hline 520 & Sulfur Removal & $\$ 26,436,000$ & $\$ 26,976,000$ \\
\hline 530 & Tail Gas Treatment Unit & $\$ 15,308,000$ & $\$ 16,360,000$ \\
\hline $600 \mathrm{~A}$ & Power Island & $\$ 354,457,000$ & $\$ 340,871,000$ \\
\hline $600 \mathrm{~B}$ & Grid Interface & $\$ 37,362,000$ & $\$ 37,355,000$ \\
\hline 700 & Project Integration & $\$ 320,008,000$ & $\$ 319,481,000$ \\
\hline $800 \mathrm{~A}$ & Balance of Plant & $\$ 23,854,000$ & $\$ 21,775,000$ \\
\hline $800 \mathrm{~B}$ & Process Water Treatment Island & $\$ 8,004,000$ & $\$ 9,343,000$ \\
\hline $900 \mathrm{~A}$ & $\mathrm{CO}_{2}$ Compression Island & $\$ 43,569,000$ & $\$ 43,304,000$ \\
\hline $900 \mathrm{~B}$ & Sequestration & $\$ 68,795,000$ & $\$ 68,795,000$ \\
\hline
\end{tabular}

Table Note A: Packaged TIC cost information for the ASU and Gasifier Islands (Area 200 and 300) are redacted due to proprietary information.

All plant areas were affected by the gasifier technology selection with the exception of the coal handling and sequestration areas (Areas 100 and 900B), as summarized in Table 8-1. The gasifier selection (slurry-fed or dry-fed gasifier) resulted in different heat and material balances, which in turn affected the flow sheets and accompanying equipment sizing. Nevertheless, the designs are very similar, and the same approach for determining CAPEX costs was used for both process configurations.

\subsection{Area Summaries}

The following sections present a summary explanation of each area, and the significant items within each area that contributed to the CAPEX estimate.

\section{Area - Coal Handling and Storage}

The coal-handling and storage area includes the enclosed coal-unloading building, coal-unloading conveyor, fully enclosed coal storage, coal reclaim system, coal-crushing system, transfer towers, crushed coal silos, and storage hoppers. A detailed vendor cost estimate for the coal-handling system was received, which included most of the items necessary to be considered a "package unit."

Significant cost savings were experienced in the coal-handling area because of a refined design that incorporated value-engineering modifications, such as reducing the on-site coal storage from 30 days to 15 days, and maintaining a 3-day reserve fuel pile. This was considered reasonable given the proximity to fuel resources. An additional modification to the design was the option to eliminate the thaw shed, which would have been most relevant for high-moisture coal, but not necessarily a requirement. 


\section{Area - Air Separation Unit}

The ASU was one of the islands that had a supplier-provided TIC estimate. The estimate was validated against other industrial ASU quotations on a "per ton of $\mathrm{O}_{2}$ produced" basis. Primary pieces of equipment include the main air compressor, cold box, heat exchange and condensing equipment, and distillation columns. Additional pumping and compression is also required for oxygen and nitrogen.

The bid received was all-inclusive with the exception of the process cooling system, for which labor and material were estimated separately. Because the estimate was for a package-unit, the home engineering costs were lowered to 1 percent, and the insurance, bonds, and fee were excluded the in EPC contract. It is noted that a value engineering study considered an "over the fence" contract for oxygen and nitrogen supply; the costs associated with that moved the CAPEX cost to an OPEX fixed cost, which did not appreciably influence the overall project costs.

\section{Area - Gasification}

The gasification area estimates were based on TIC bids from the slurry-fed and dry-fed licensor/EPC contractors, respectively. The primary piece of equipment in this area was the gasifier, and where applicable the quench system (dry-fed configuration only). Secondary systems included the syngas scrubber and the slag and black water handling systems. Additional equipment packages such as the vent blower, vent knock-out drum, and vent stack were added during the estimate design.

Similar to the gasification area, the estimates were for packaged units, which reduced the home engineering costs to 1 percent, and the insurance, bonds, and fee were excluded in the EPC contract.

\section{$400,500,510,520$, and 530 Areas - Syngas Processing}

The 400 Area syngas conditioning process begins with the syngas cooler (slurry-fed option), followed by syngas scrubber and shift reactors. The area also contains the process zero liquid discharge (ZLD) system associated with the shift reactors, and the sour water treatment system. The 500 Area includes the mercury removal system (Area 500); the acid gas removal unit (Area 510), which separates hydrogen and sulfur from the syngas; the sulfur recovery unit (Area 520), which converts hydrogen sulfide to elemental sulfur; and the tail gas treatment unit (Area 530), which returns any remaining sulfur back to the acid gas removal unit (Area 510). The platform for developing the estimate for these areas was ACCE $^{\mathrm{T}}$; ; the templates were augmented by direct equipment quotes as available.

\section{$\underline{600 A}$ Area - Power Island}

Area 600A includes the CTG, HRSG, SCR system, STG, cooling towers that supply the surface condenser, and the ZLD water treatment system. With the exception of the ZLD system, the 600A area estimate was based a common configuration ( 1 CTG and 1 STG) for analogous natural gas-fired combined-cycle power plants. The CTG was an industrial Frame 7B type design, modified for hydrogen service. The HRSG was a single reheat design that contained the SCR system and supplied $1800 \mathrm{psig} / 1000^{\circ} \mathrm{F}$ steam to the STG. The STG proposed was a three section, axial exhaust machine that exhausted steam to the water-cooled surface condenser. The area also contained the generator step-up transformers, deaerator, large boiler feed water pumps, and a hot oil loop that was used for syngas and diluent heat exchange systems. 
Specifications for most of the equipment were provided via vendor quotations, and were included as part of the similar plant estimate.

\section{$\underline{600 B}$ Area - Switchyard, Substation, and Grid Interface}

The primary cost for this area was developed during a system impact study conducted by the regional power marketer, and addressed the appropriate strategies to tie into the existing $138 \mathrm{kV}$ power system. Supplemental equipment required for the interface with the grid was estimated via Similar Plant methodology. The cost of the interface to the $138 \mathrm{kV}$ power transmission line, including "dead-end tower" structures and metal tangent line poles (with foundations), are part of the power marketer's estimate supplied during the system impact study.

\section{$\underline{700 \text { Area - Project Integration }}$}

Area 700 was defined as the integration or interface area. The 700 Area contains all activities and systems that interface and all functional activities that integrate the discrete process units and areas. This includes civil work (cut, grade, piles, caps, foundations, etc.); area lighting; grounding; pipe rack and primary pipe runs; security and cable systems (both electrical and instrumentation); underground piping such as electrical, instrumentation and control $(I \& C)$, water, natural gas and $\mathrm{CO}_{2}$ pipelines; all above ground piping for utilities (cooling, process, high purity, and fire water); and the remaining electrical distribution interfaces. Also included in this area are buildings and support structures such as fencing and roads. The platform for developing this estimate was WinEst.

\section{$800 \mathrm{~A}$ and $800 \mathrm{~B}$ Area - Balance of Plant and Water Treatment}

The 800 Area is not a contiguous area, as it includes structures, piping, and equipment associated with remaining utilities and most of the water production and treatment aspects of the facility. Included here are storage buildings for water treatment and lube oil; two prefabricated substations; and equipment/materials for process, cooling, and high purity water production. The bulk of the equipment was priced based on vendor quotes, with piping, with the mechanical, electrical, and I\&C quantified using $A C C E^{\mathrm{T}}$.

\section{$\underline{900 \mathrm{~A}-\mathrm{CO}_{2} \text { Compression }}$}

This area includes the $\mathrm{CO}_{2}$ compression and drying equipment, and the ancillary support structures such as buildings and instrument enclosures. This area also includes the high-pressure $\mathrm{CO}_{2}$ pipeline that delivers the supercritical fluid to the $900 \mathrm{~B}$ Area. The $\mathrm{CO}_{2}$ compressor was priced based on quotation, with piping, mechanical, electrical, and I\&C quantified using $A C C E^{T m}$.

\section{B - Sequestration}

The primary method used to develop the cost estimate was vendor quotes. Where vendor quotations were unattainable, cost estimates were developed based on extrapolation of historical invoices, quotations for similar work previously performed, and professional judgment. Primary components of the 900B Area include the primary $\mathrm{CO}_{2}$ injection well, four monitoring wells (injection reservoir, primary seal monitoring, and two seismic monitoring wells), well characterization and bore testing, and baseline MVA activities. 


\section{Summary}

The FutureGen CAPEX was found to be within the parameters of similar facilities recently estimated, nearing conclusion, or completed by the Alliance members. The featured estimate was presented to the Alliance Board of Directors and was found to align with the aforementioned results. The accuracy of the estimate was well within the parameters of Class 4 estimates as defined by AACE and, in certain aspects, exceeded the requirements by obtaining vendor quotations for pricing the major pieces of equipment in the facility.

Finally, the CAPEX and supporting documentation were subject to independent third-party review and comment regarding the estimate, level of supporting documentation, and processes and procedures executed in the development of the CAPEX report. The analysis concluded that, based on the evaluation of the estimate and supporting documentation, the CAPEX could be considered an advanced Class 4 estimate, or a less advanced Class 3 estimate. Further, the reviewers concluded that the project team had used an appropriate basis for establishing project scope and activities, and had used the appropriate estimating methods, techniques, and procedures in preparing the CAPEX estimate. 


\section{IGCC and CCS Operations and Maintenance (OPEX) Cost Estimate}

The OPEX for the FutureGen facility was generated based on the plant specifications and design described in the CAPEX. The complete OPEX report is included in Attachment 8 of this report. The OPEX also contains the POCs associated with $\mathrm{CO}_{2}$ monitoring as well as costs required for project closeout. The OPEX cost estimate presented is the overnight cost in 202009 dollars. $^{1}$

\subsection{OPEX SUmmary}

The baseline FutureGen plan calls for a full 4 years of plant operations, followed by 2 years for MVA of the $\mathrm{CO}_{2}$ sequestration site. The 2 years of monitoring is considered to be POC, and the estimate for this activity is reported separately from the OPEX. Two estimates were developed, representing both slurry-fed and dryfed gasifier configurations. In both configurations, many of the costs are similar as they draw on the same resources independent of the technology selection. Examples of such costs include O\&M labor, all subsurface $O \& M$, and certain owner costs. For comparison, summary tables for both slurry-fed and dry-fed configurations are provided regardless of the variance.

The O\&M costs include operating labor costs; maintenance costs; costs for fuel, consumables, and byproduct disposition; and owner costs. The O\&M costs are categorized by fixed and variable costs to determine total non-fuel-related O\&M expenditures; and then fuel costs are provided to capture the total O\&M costs. Table 9-1 provides the specific line items as they were categorized in the OPEX, and Table 9-2 provides the cost roll-up for each respective cost category (fixed or variable).

\footnotetext{
${ }^{1}$ FutureGen Alliance. 2009 Project Cost Estimate: Vol. II, Operating Costs. January 29, 2010. Included in Attachment 8 of this report.
} 
Table 9-1. OPEX Cost Categories

\begin{tabular}{|l|l|c|}
\hline \multicolumn{1}{|c|}{ Ad } & \multicolumn{1}{|c|}{ Activity } & Cost Type \\
\hline $\mathbf{0 1}$ & Surface Operations Labor & Fixed O\&M \\
\hline 0101 & Operations Labor & Fixed O\&M \\
\hline 0102 & Administrative \& Support Labor & Fixed O\&M \\
\hline $\mathbf{0 2}$ & Surface Maintenance & (Itemized below) \\
\hline $\mathbf{0 2 0 1}$ & On-site Maintenance Labor & Fixed O\&M \\
\hline $\mathbf{0 2 0 2}$ & Services Subcontracts & Variable O\&M \\
\hline $\mathbf{0 2 0 3}$ & External Maintenance Labor & Fixed O\&M \\
\hline $\mathbf{0 2 0 4}$ & Maintenance Materials (Excluding GT/Well) & Fixed O\&M \\
\hline $\mathbf{0 3}$ & Subsurface Operations \& Maintenance & Fixed O\&M \\
\hline $\mathbf{0 3 2 1}$ & CO Pipeline (Labor Subcontract \& Materials) & Fixed O\&M \\
\hline $\mathbf{0 3 2 4}$ & Subsurface Maintenance (Injection Well Workover) & Fixed O\&M \\
\hline $\mathbf{0 3 2 5}$ & Subsurface Maintenance (Monitoring Well Workover) & Fixed O\&M \\
\hline $\mathbf{0 3 5 1}$ & Subsurface MMV & Fixed O\&M \\
\hline $\mathbf{0 3 3 1}$ & Field Labor OHD \& Expenses & Fixed O\&M \\
\hline $\mathbf{0 3 6 1}$ & Indirects \& Home Office Costs-Sequestration & Fixed O\&M \\
\hline $\mathbf{0 4}$ & Consumables & Variable O\&M \\
\hline $\mathbf{0 5}$ & Byproduct Disposition & Variable O\&M \\
\hline $\mathbf{0 6}$ & Fuel (Coal) Purchases & Fuel \\
\hline $\mathbf{0 7}$ & Owner Costs & Fixed O\&M \\
\hline
\end{tabular}

Table 9-2. OPEX Summary

\begin{tabular}{|l|r|r|}
\hline Cost Category & Slurry Fed Total & Dry Fed Total \\
\hline Fixed O\&M & $\$ 215 \mathrm{M}$ & $\$ 236 \mathrm{M}$ \\
\hline Variable O\&M & $\$ 53 \mathrm{M}$ & $\$ 53 \mathrm{M}$ \\
\hline Total Non-Fuel O\&M & $\$ 268 \mathrm{M}$ & $\$ 289 \mathrm{M}$ \\
\hline Fuel & $\$ 108 \mathrm{M}$ & $\$ 101 \mathrm{M}$ \\
\hline Total O\&M & $\$ 376 \mathrm{M}$ & $\$ 390 \mathrm{M}$ \\
\hline
\end{tabular}

\subsection{Operating Schedule and Processing}

As the OPEX cost categories were entirely dependent on a declaration of plant availability, the first activity was to complete the commissioning, start-up, and operating schedules for the plant. In consultation with member companies, and based on a review of historical information, the estimate assumed a full 1-year checkout and commissioning period following mechanical completion. The first half ( 6 months) of the commissioning period would represent equipment checkout and commissioning with an estimated availability of 10 percent. The second half of the first year would be integrated testing, where several shutdowns and restarts were assumed with an estimated availability of 50 percent. Accordingly, the estimate assumed a first year average availability of 30 percent. The estimate assumed that commissioning will be done using Illinois 6 coal. This was followed by 3 years of full operations after the 1 -year commissioning and integrated testing period. The estimate assumed that Illinois 6 coal will be used during the 3 years of operation as well. Additional coal(s) may have been consumed or trialed during the 4-year operating time period, but it was not accounted for in the estimate. 
The planned maintenance outages are driven primarily by the gasification island maintenance requirements, and in certain years by the combustion turbine. As planned, semi-annual maintenance outages would have occurred during the "shoulder" months in the spring and fall. Initially, these outages were expected to be approximately 28 days long. Depending on factored hours and starts, it was anticipated that combustion inspections and/or hot-gas-path inspections (if needed) would coincide with planned outages. The initial outage period was planned to occur at the end of the commissioning period (i.e., at the end of Year 1, Q4). Subsequent outages were planned on a semi-annual basis, with a goal of moving to one planned outage each year from 2-3 weeks. The future planned outage schedules would be predicated on the technologies ultimately selected for the plant, and the maintenance requirements. The operating schedule developed for the cost estimate is shown in Table 9-3.

Table 9-3. Processing and Availability Schedule

\begin{tabular}{|c|c|c|c|c|c|c|c|c|}
\hline & \multirow{2}{*}{\multicolumn{2}{|c|}{$\begin{array}{c}\text { Start Up/ } \\
\text { Commissioning }\end{array}$}} & \multirow{2}{*}{\multicolumn{2}{|c|}{ Integrated Testing }} & \multirow{2}{*}{\multicolumn{4}{|c|}{ Year 2}} \\
\hline & & & & & & & & \\
\hline & Q1 & Q2 & Q3 & Q4 & Q1 & Q2 & Q3 & Q4 \\
\hline Run Weeks & 13 & 13 & 13 & 9 & 13 & 9 & 13 & 9 \\
\hline Scheduled Outage (weeks) & & & & 4 & & 4 & & 4 \\
\hline Coal Type & Illinois 6 & Illinois 6 & Illinois 6 & Illinois 6 & Illinois 6 & Illinois 6 & Illinois 6 & Illinois 6 \\
\hline Availability (100\% equivalent) & $10 \%$ & $10 \%$ & $50 \%$ & $50 \%$ & $60 \%$ & $60 \%$ & $60 \%$ & $60 \%$ \\
\hline $\begin{array}{l}\text { Available Hours ( } 100 \% \\
\text { equivalent) }\end{array}$ & 218 & 218 & 1092 & 756 & 1310 & 907 & 1310 & 907 \\
\hline Yearly Operations (hours) & & & & 2285 & & & & 435 \\
\hline Scheduled Outages (hours) & & & & 672 & & 672 & & 672 \\
\hline Cumulative Run Time (hours) & 218 & 437 & 1529 & 2285 & 3595 & 4502 & 5813 & 6720 \\
\hline
\end{tabular}

\begin{tabular}{|l|r|r|r|r|r|r|r|r|}
\cline { 2 - 10 } \multicolumn{1}{c|}{} & \multicolumn{4}{c|}{ Year 3 } & \multicolumn{4}{c|}{ Year 4 } \\
\cline { 2 - 10 } \multicolumn{1}{c|}{} & \multicolumn{1}{c|}{ Q1 } & \multicolumn{1}{c|}{ Q2 } & \multicolumn{1}{c|}{ Q3 } & \multicolumn{1}{c|}{ Q4 } & \multicolumn{1}{c|}{ Q1 } & \multicolumn{1}{c|}{ Q2 } & \multicolumn{1}{c|}{ Q3 } & \multicolumn{1}{c|}{ Q4 } \\
\hline Run Weeks & 13 & 9 & 13 & 9 & 13 & 11 & 13 & 13 \\
\hline Scheduled Outage (weeks) & & 4 & & 4 & & 2 & & \\
\hline Coal Type & Illinois 6 & Illinois 6 & Illinois 6 & Illinois 6 & Illinois 6 & Illinois 6 & Illinois 6 & Illinois 6 \\
\hline Availability (100\% equivalent) & $70 \%$ & $70 \%$ & $70 \%$ & $70 \%$ & $75 \%$ & $75 \%$ & $75 \%$ & $75 \%$ \\
\hline $\begin{array}{l}\text { Available Hours (100\% } \\
\text { equivalent) }\end{array}$ & 1529 & 1058 & 1529 & 1058 & 1638 & 1386 & 1638 & 1638 \\
\hline Yearly Operations (hours) & & & & 5174 & & & & 6300 \\
\hline Scheduled Outages (hours) & & 672 & & 672 & & 336 & & \\
\hline Cumulative Run Time (hours) & 8249 & 9307 & 10,836 & 11,894 & 13,532 & 14,918 & 16,556 & 18,194 \\
\hline
\end{tabular}

Plant availability shown in the tables is based on several factors. Data was gathered from gasification vendors, and commercial plant operating data was reviewed. The maximum plant average availability selected was 75 percent, and planned outages were reduced to one in the final year of operation. While information from gasification and turbine vendors indicated that higher availability was likely, particularly as the plant matures, considering the complexity of the facility it was determined that 75 percent availability represented an achievable target and reflected what would be commercially acceptable.

\subsection{Line Item Summaries}

The following provides the summary-level detail for each of the line item costs found in the OPEX. Where appropriate, the distinctions between the technology selections that led to a significant difference in operating costs are described. 


\section{Surface Operations Labor}

The FutureGen plant staff estimate was developed based on input from IGCC operators. The organization was divided into Operations (shift workers); Administration; Environmental, Safety, Health, and Quality (ESH\&Q); Maintenance (found in Surface Maintenance); and Technical Services (engineering). Total plant staffing considered in the estimate was 90 . Complete shift coverage requires slightly more than four shifts. This was achieved by having four shifts and making up the balance with premium (overtime) hours for the shift workers.

It was expected that the dedicated, on-site maintenance staff would conduct the routine maintenance activities. Subcontractors would perform specialized activities, such as turbine maintenance and gasifier rebuilds. The costs for the subcontractor maintenance are included elsewhere in the OPEX estimate (a subsection of Surface Maintenance).

Since most of the operations staff would be hired prior to plant commissioning, a staff hiring and training schedule was developed to allow full capture of the staffing costs in the time leading up to commissioning. All of the costs related to staffing, training, and development prior to commercial operations were captured in the CAPEX cost estimate as a pre-operational cost.

\section{Surface Maintenance}

The maintenance labor and material costs were handled separately for the surface and subsurface (sequestration) facilities. Surface facility maintenance costs included on-site maintenance labor costs, services subcontracts, external maintenance labor via subcontracts, and maintenance materials.

The core maintenance staff consisted of 13 full-time staff; this did not include the Instrument and Control technicians and pipefitters who were included as part of the surface operations labor.

Several service contracts would be set up to maintain various parts of the surface facility, with the largest subcontract estimated to be for the LTSA with the CTG vendor. The LTSA was based on fired hours on the CTG such that the total costs increased as the plant availability increased.

The balance of maintenance costs for the surface facility was estimated using a factored estimate for slurryfed and dry-fed gasifier configurations. Maintenance factors were developed for each island and adjusted using information from subject matter experts, as well as peer-reviewed information from operating IGCC personnel. The overall maintenance cost was estimated as a percentage of the capital cost (direct field cost) based on inputs from internal and external subject matter experts. As the dry-fed configuration carried a higher direct field cost, it was slightly more expensive to maintain. In both cases, the split of total maintenance costs was set at 40 percent labor and 60 percent materials based on the EPRI TAG, ${ }^{2}$ noting that in areas of less complexity or well established technical maturity, much of the planned maintenance is expected to be performed by the on-site maintenance staff, with the balance to be completed by subcontractors.

\footnotetext{
2 Electric Power Research Institute. Technical Assessment Guide, Electricity Supply-1993, Nonutility/Nonmember Edition, EPRI TR-
} 102276-V1R7, June 1993. 


\section{Subsurface Operations and Maintenance}

The operations costs for the subsurface facility included the following major activities: $\mathrm{CO}_{2}$ pipeline inspections; O\&M for the injection well; O\&M for the monitoring wells; implementation of a comprehensive $\mathrm{CO}_{2}$ monitoring program; field labor, travel, and overhead expenses; project indirects; and home office costs.

The $\mathrm{CO}_{2}$ pipeline from the surface facility compressors to the injection well required annual corrosion inspections; the cost category captured the costs of performing annual corrosion inspection of exposed section(s) of the pipeline (i.e., near wellhead and manhole access points) using ultrasonic mapping.

Injection well cost categories included annual well testing, annual well workovers, annual equipment replacement, field offices and utilities, and system maintenance. The field office and utility costs for the sequestration site were captured in this cost category and are not included in the others.

Similar to the injection well, this cost category covered activities for the four deep monitoring wells (one injection reservoir monitoring well, a primary seal monitoring well, and the two seismic monitoring wells), and included annual well testing, annual well workovers, and annual equipment replacement.

The remaining cost category addresses the MVA implemented during operations to accomplish the following objectives: track the migration of the $\mathrm{CO}_{2}$ plume over time; determine geochemical effects caused by the interaction of $\mathrm{CO}_{2}$ and the $\mathrm{Mt}$. Simon Formation; and detect $\mathrm{CO}_{2}$ leakage above the caprock, in the drinking water aquifer, and at the ground surface.

\section{Consumables}

Consumables were defined as non-maintenance items consumed as part of plant operations. There were three minor differences in consumable costs when evaluating the slurry-fed and dry-fed configurations. These were due to a variance in the estimated total make-up water flow requirement for each technology, and a distinction in the parasitic load, which affects the need for purchased electricity during start-ups. Costs for consumables were gathered for the following categories: process and potable water, water treatment chemicals, catalysts and sorbents, purchased electricity, diesel (for firewater pumps), and natural gas for the package boiler and CTG.

\section{Byproduct Disposition}

This category captures costs related to the characterization and disposal of three solid byproduct streams produced during normal operations: 1) ZLD solids from the cooling tower water system, 2) ZLD solids from the process water system, 3) and other miscellaneous solid wastes (maintenance wastes, etc.).

Cost estimates were received for non-hazardous special wastes such as the ZLD solids as well as waste char and ash at $\$ 30$ per ton; hazardous wastes such as activated or impregnated carbon from filtering process at $\$ 300$ per ton; and non-hazardous wastes that required analyses at $\$ 100$ per ton. Disposal costs were based on the rate of production from the heat and material balances, and included transportation where appropriate. Solid wastes would be disposed of in landfills consistent or compliant with the waste classification. 
The cost estimate also considered that additional solids such as slag may be utilized by others for road building, aggregate, or other approved end uses, as well as recovered elemental sulfur which could be utilized in the fertilizer industry. Neither credit for sales of product nor disposal cost was assumed for the estimate.

\section{Fuel (Coal) Purchases}

The coal costs consisted of the base coal costs and the shipping costs of the coal types. While the shipping costs vary significantly among the coal types due to the distance from the mine mouth to the FutureGen plant in Illinois, for the purposes of the estimate only the costs associated with Illinois 6 coal pricing were developed. The coal purchase prices were evaluated using EIA estimates for the operating period, by recommendation of the Technical Committee to levelize what have been widely varying prices observed over the past several years coinciding with the development of the cost reports. The annual EIA estimated prices over the 4-year operating period (2015 to 2018) were gathered and used to determine the delivered price of Eastern Interior high sulfur bituminous coal. ${ }^{3}$ Due to differences in fuel throughput between the two gasifiers, the slurry-fed gasifier configuration was expected to have slightly higher fuel costs.

\section{Owner Costs}

The owner costs consisted of labor; insurance; bonds, taxes, and fees; permits; legal fees; and stakeholder support costs. The owner costs prior to plant startup were included in the CAPEX estimate. The OPEX estimate includes owner costs for the 4 years of plant operations.

Owner labor costs consisted of salaries, travel, and subsistence for the FutureGen CEO, administrative assistants, financial staff, chief operating officer, chief technology officer, and external affairs staff.

The plant insurance costs were on an "All Risks" basis and were estimated to be approximately 1 percent of the direct field cost. This included all property, boiler and machinery, liability (including directors and officers), and a pro-rated deductible. Business interruption insurance was not included in the estimate, nor was it considered to be required.

There were no OPEX costs for bonds, taxes, or fees. This assumption was based on the following: 1) the bonding costs were assumed to be part of the insurance costs; 2) FutureGen Industrial Alliance, Inc. was a tax-exempt non-profit corporation under 501(c) (3) of the Internal Revenue Code such that it would not have local, state, or federal taxes; and 3) the fees associated with technology licenses were assumed to be up-front fees and are included in the CAPEX costs.

The substantial permitting costs are included in the CAPEX (construction, wastewater, etc.). Emissions taxes would be imposed as part of the air permit; these would be fixed rates per mass of pollutant emitted. Air permitting information was combined with the mass flows and operating hours for each coal type to arrive at the total emissions costs per year. The emissions rates were calculated conservatively, and based on the design axioms for $\mathrm{NO}_{x}, \mathrm{SO}_{\mathrm{x}}$, and mercury emissions.

Legal support to the FutureGen Alliance was required during operations for contract support, council for facility operation, insurance coverage, etc.

${ }^{3}$ http://www.eia.doe.gov/oiaf/aeo/supplement/index.html. 


\section{(2) Future Gen" \\ ALLIANCE

Remaining costs reflected office rental costs, subcontracts for public relations and communications, and miscellaneous supplies and overheads. 


\section{Post-Operations and Project Closeout}

The FutureGen project would have concluded with 2 years of post-operational activities, primarily focused on continuing the MVA program and on administrative details such as project reporting and execution of project closeout requirements. Additional aspects of project closeout were considered from a cost perspective, acknowledging that it was unknown what commercial value could be realized in the remaining FutureGen plant and sequestration system once the project concluded, or if portions of the project would remain commercially available and utilized. Therefore, to provide a conservative estimate, the project assumed that the following activities could take place: closure in place of the $\mathrm{CO}_{2}$ pipeline, routine but limited maintenance for the injection well(s), plugging and abandonment of all deep reservoir monitoring wells, and the associated labor and expenses incurred in the completion of these activities. Table 10-1 provides the estimated POCs for the 2-year time frame.

Table 10-1. Post Operations Costs

\begin{tabular}{|l|r|}
\hline Item & \multicolumn{1}{|c|}{$\mathbf{2 Q 2 0 0 9}$} \\
\hline Sub-surface & $\$ 17,000,000$ \\
\hline Owner Costs & $\$ 6,345,781$ \\
\hline Total & $\mathbf{\$ 2 3 , 3 4 5 , 7 8 1}$ \\
\hline
\end{tabular}

Of the subsurface POCs, the MVA program was estimated to be slightly over half of the remaining costs. The program and schedule for implementation was consistent with the MVA program that was conducted during the operations (injection) period and included surface $\mathrm{CO}_{2}$ emissions monitoring, drinking water aquifer monitoring well assessment, primary seal and injection reservoir well monitoring, geophysical logging, and seismic profiling. Once these activities had been completed, well closure would have commenced in accordance with the Class I UIC permit.

The post-operations owner's costs were limited to funding the Alliance executive staff, insurance for staff and remaining activities, and professional services subcontracts such as legal, financial, and accounting support. 


\section{Engineering and Operational Assessments}

With a firm plot plan, complete heat and material balances, and an initial cost estimate based on 1Q2008 dollars, the Alliance scoped and performed several trade-off analyses focused on site-specific approaches that could improve the cost position of the plant from modifications to plant design, construction, and operations if implemented. Concurrently, the Alliance began developing operating strategies and protocols to maximize the thermal and electrical efficiencies of the plant, and identify and quantify sources and quantity of emissions from the plant. This included evaluations of planned start-up and shut-down procedures, identification and classification of transient operations, and dispersion modeling in support of IEPA permitting requirements. The following sections describe relevant activities included in these efforts.

\subsection{Value Engineering}

The Alliance staff, working with the Technical Committee and subcontractors, identified 21 cost-saving opportunities. For parity, all options were considered regardless of plausibility or likelihood of implementation. Evaluated quantitatively to determine overall impact to cost, and qualitatively to assess technical and political risk, the opportunities were then ranked and prioritized based on the resulting impact to the project. After vetting, the list was reduced to 14 potential actions that could be deployed to reduce the overall cost of the project. Table 11-1 provides an abridged version of all 21 opportunities assessed and monetary impacts to the project estimates, and indicates whether they were recommended for further investigation or incorporation into the final design. 
Table 11-1. Value Engineering and Trade-off Evaluations

\begin{tabular}{|c|c|c|c|c|}
\hline Item & Description & Impact to CAPEX & Impact to OPEX & $\begin{array}{l}\text { Recommendation } \\
\text { to Implement }\end{array}$ \\
\hline 1 & Alternative acid gas scrubbing technologies & None & \$7M per year savings & No \\
\hline 2 & Reduce the $90 \%$ carbon capture mandate & $\$ 1.6 \mathrm{M}$ & 7.6 $\mathrm{MW}$ reduction & No \\
\hline 3 & Oxygen and nitrogen over the fence & $\begin{array}{l}\text { Eliminate capital for } \\
\text { Area } 200\end{array}$ & $\$ 3.2 \mathrm{M}$ per month increase & No \\
\hline 4 & $\begin{array}{l}\text { Relax the ZLD mandate (treat process water } \\
\text { only) }\end{array}$ & $\$ 24.9 M$ & $\$ 1.5 \mathrm{M}$ over 4 years & Yes \\
\hline 5 & Eliminate Thaw Shed & $\$ 11 \mathrm{M}$ & $\begin{array}{l}\text { Eliminate intermittent } \\
\text { power consumption }\end{array}$ & Yes \\
\hline 6 & Optimize plant for Illinois 6 coal & $\begin{array}{l}\text { Slurry Fed: } \$ 19.8 \mathrm{M} \\
\text { Dry Fed: } \$ 40.9 \mathrm{M}\end{array}$ & $\begin{array}{l}\text { Eliminate coal drying } \\
\text { penalty for dry fed and } \\
\text { Simplifies operation of } \\
\text { SRU with low sulfur coal. }\end{array}$ & Yes \\
\hline 7 & Over the fence water supply and treatment & $\$ 31.8 \mathrm{M}$ & $\begin{array}{l}\$ 17 \mathrm{M} \text { increase over } 4 \\
\text { years }\end{array}$ & Yes \\
\hline 8 & Sparing philosophy of recycle compressors & $\$ 11.6 \mathrm{MM}$ & - & Yes \\
\hline 9 & $\begin{array}{l}\text { Natural gas to the turbine/duct burner to } \\
\text { increase availability }\end{array}$ & $\begin{array}{l}\text { \$1M increase to } \\
\text { CAPEX }\end{array}$ & $\begin{array}{l}\$ 21 \mathrm{M} \text { additional revenue } \\
\text { over } 4 \text { years }\end{array}$ & Yes \\
\hline 10 & Increase design life from 25 to 30 years & $\$ 2 M$ & - & Yes \\
\hline 11 & $\begin{array}{l}\text { Combine the } \mathrm{H}_{2} \mathrm{~S} \text { flash gas and tail-gas } \\
\text { compressors }\end{array}$ & $\$ 2.1 \mathrm{MM}$ & $\$ 15 \mathrm{~K}$ per year increase & Yes \\
\hline 12 & Reduce coal storage & $\$ 12.4 \mathrm{MM}$ & - & Yes \\
\hline 13 & Revisit relevant design codes and standards & $\$ 1.2 \mathrm{MM}$ & - & Yes \\
\hline 14 & Use $\mathrm{CO}_{2}$ as a refrigerant & $\$ 6 \mathrm{M}$ & $\$ 2.4 \mathrm{M}$ per year increase & No \\
\hline 15 & Use integral gear $\mathrm{CO}_{2}$ compressors & $\$ 10.5 \mathrm{MM}$ & Parasitic power reduction & Yes \\
\hline 16 & Nitrogen as stripping gas in concentrator & $\begin{array}{l}\$ 4 \mathrm{M} \text {, offset by } \\
\text { increase in nitrogen } \\
\text { purity requirement }\end{array}$ & - & No \\
\hline 17 & Review entire Area 700 & $\$ 51.8 \mathrm{MM}$ & - & Yes \\
\hline 18 & Craft retention package & $\$ 19 \mathrm{MM}$ & - & Yes \\
\hline 19 & Reduce rail system for smaller unit train & $\$ 1.8 \mathrm{M}$ & - & No \\
\hline 20 & $\begin{array}{l}\text { Purchase pre-owned equipment (auxiliary } \\
\text { instrument air skid, package boiler, emergency } \\
\text { generators, etc.) }\end{array}$ & $\$ 1.5 \mathrm{MM}$ & - & Yes \\
\hline 21 & $\begin{array}{l}\text { Design for, but do not include, carbon capture } \\
\text { in the CAPEX during startup. Include as a cost } \\
\text { when plant is stabilized and operating then } \\
\text { implement sequestration. }\end{array}$ & $\begin{array}{l}\text { Evaluated but against } \\
\text { axioms }\end{array}$ & $\begin{array}{l}\text { Evaluated but against } \\
\text { axioms }\end{array}$ & No \\
\hline
\end{tabular}

The 2009 CAPEX and OPEX incorporated several of the above findings, and assumed that had the project continued to the next phase, additional findings from the evaluations would likely have been considered as the project was better defined. While aspects of the remaining analyses demonstrated that the cost position of the project could be improved significantly, their risk profiles were considered too high to 
warrant further investigation, or they were simply indefensible from an axiom standpoint, as described in Table 5-2.

\subsection{Facility Design and Operations Evaluations}

At various times during the project, the Alliance conducted assessments to better understand equipment nuances, potential cost impacts of operations (both on-specification and off-specification), and for comparative purposes. Many of these are described previously in Section 5.4 (Comparative Technology Evaluations), Section 6.1 (CCRB Report), and Section 11.1 (Value Engineering). Numerous others fell outside of that scope, but were conducted to address specific aspects of design, capital, and operating conditions. The following includes narrative of the assessments, and relevant findings or impacts to the plant.

Start-Up and Trip Assessment: The power-block start-up assessment was conducted to quantify what would happen in the event of a trip and restart under various conditions (hot, warm, or cold), and the impact to the OPEX portion of the cost estimate. Using historically relevant material (IGCC availabilities), the Alliance made assumptions about causes of plant trips and availability by unit process, which rolled up into the yearover-year OPEX estimate. Secondarily, the assessment helped to quantify aspects of consumables such as total fuel consumed in restarts, potential revenue streams from NGCC operations (megawatt-hours), and cost implications of reserving firm pipeline capacity.

Oxygen and Diluent Storage: Consistent with the effort to improve plant availability, particularly in the first years of commissioning and operations, the Alliance evaluated optimizing the storage capacity of oxygen and diluent in the event of an ASU trip. The findings also helped to strategize CTG operations, and aspects of flaring that would be required during a forced outage depending on the source of the outage and expected duration. Consistent with the findings addressed in the Start-Up and Trip Assessment, preliminary estimates suggested maintaining on-site storage of liquid oxygen and liquid nitrogen for up to 8 hours of minimum firing rate consumption for the gasifier and CTG.

Supercritical $\mathrm{CO}_{2}$ and Corrosion Potential: The corrosion study was initiated to investigate the behaviors of mild steel in supercritical $\mathrm{CO}_{2} / \mathrm{H}_{2} \mathrm{O}$ solutions. Addressing wellbore and pipeline design, relaxing the $\mathrm{H}_{2} \mathrm{O}$ could potentially have eliminated the dehydration system proposed for the FutureGen plant, reducing the CAPEX and OPEX cost estimates. Preliminary results indicated that a water content of approximately 780 ppmw did not demonstrate surface corrosion, while the coupon at 1300 ppmw did. Continuing studies would have addressed varying the water content between $800-1300$ ppmw, as well as secondary evaluation regarding the impacts due to the inclusion of $\mathrm{H}_{2} \mathrm{~S}$.

Fuel Feed Rate and Gross Power Output by Coal Type: The heat rate evaluation addressed observations of the Technical Committee, which identified a possible discrepancy in the calculated heat rate(s) of the FutureGen plant respective of the coal type. To address the observations, the material balances of all three coal cases were re-checked against their design bases. Additionally, the parasitic loads for the three cases, originally taken to be approximately equal, were differentiated to account for differing loads of the ASU and $\mathrm{CO}_{2}$ compressors. In summary, it was determined that the bituminous coal(s) HMBs were prepared representing the most conservative conditions (hottest ambient temperatures), while the PRB case had been prepared using a conventional average day design due to known firing limitations of the CTG when gasifying PRB coal. The findings closely resembled those found in Table 6-1, with the exception of the Illinois 6 case, which under further refinement was able to show an approximate 1 percent improvement. Final heat and material balances produced used average day design limitations. 


\subsection{Emissions Modeling and Permitting Activities}

Several studies were initiated as part of the site characterization and permitting process to quantify and establish appropriate controls for emissions from the FutureGen plant at Mattoon. Emissions characterization required making basic plant configuration and alignment assumptions, as well as operational scenarios. In consideration of the facility design used for the CAPEX and OPEX which included the facility plan from Figure 7-1, and the block flow diagram following in Figure 11-1, 32 distinct locations were initially modeled as emission sources and used to evaluate potential sources and distance to receptors. Numerous emission sources were located outside of the physical plant boundary limit as well including coal receiving and transfer locations, cooling towers (drift), the emergency diesel generator, and others. Compiled results were used to begin drafting of the air permitting and BACT analysis, as well as provide baseline data for comparative determinations against other previously permitted CTGs and IGCC plants.

Building on vendor-supplied information in conjunction with technology-specific studies and the CCRB report as described in Section 6.1 , the Alliance began drafting and evaluating operational scenarios that would assist with the overall emissions characterization work such as the preliminary plant start-up and controlled shut-down emissions evaluation. One of the start-up sequences evaluated was the cold start-up of the plant, which is included in Figure 11-2. For each of the steps in the start-up protocol, both the duration of the event and the valve alignment were considered enabling determinations of volumetric and molar flow of syngas as well as the anticipated level of gas conditioning completed prior flaring or oxidation. The report quantified usage rates of consumables such as natural gas, syngas, and nitrogen used in start-up and shut-down procedures, as well as help to identify appropriate control strategies that could be deployed to minimize flaring and release of criteria pollutants associated with bringing the plant up to stable operations. Findings also helped to appropriately size the auxiliary steam supply system which could be used to preheat lower pressure steam systems, shift reactors (via nitrogen heating), and for nitrogen oxide control as the combustion turbine began operation. 


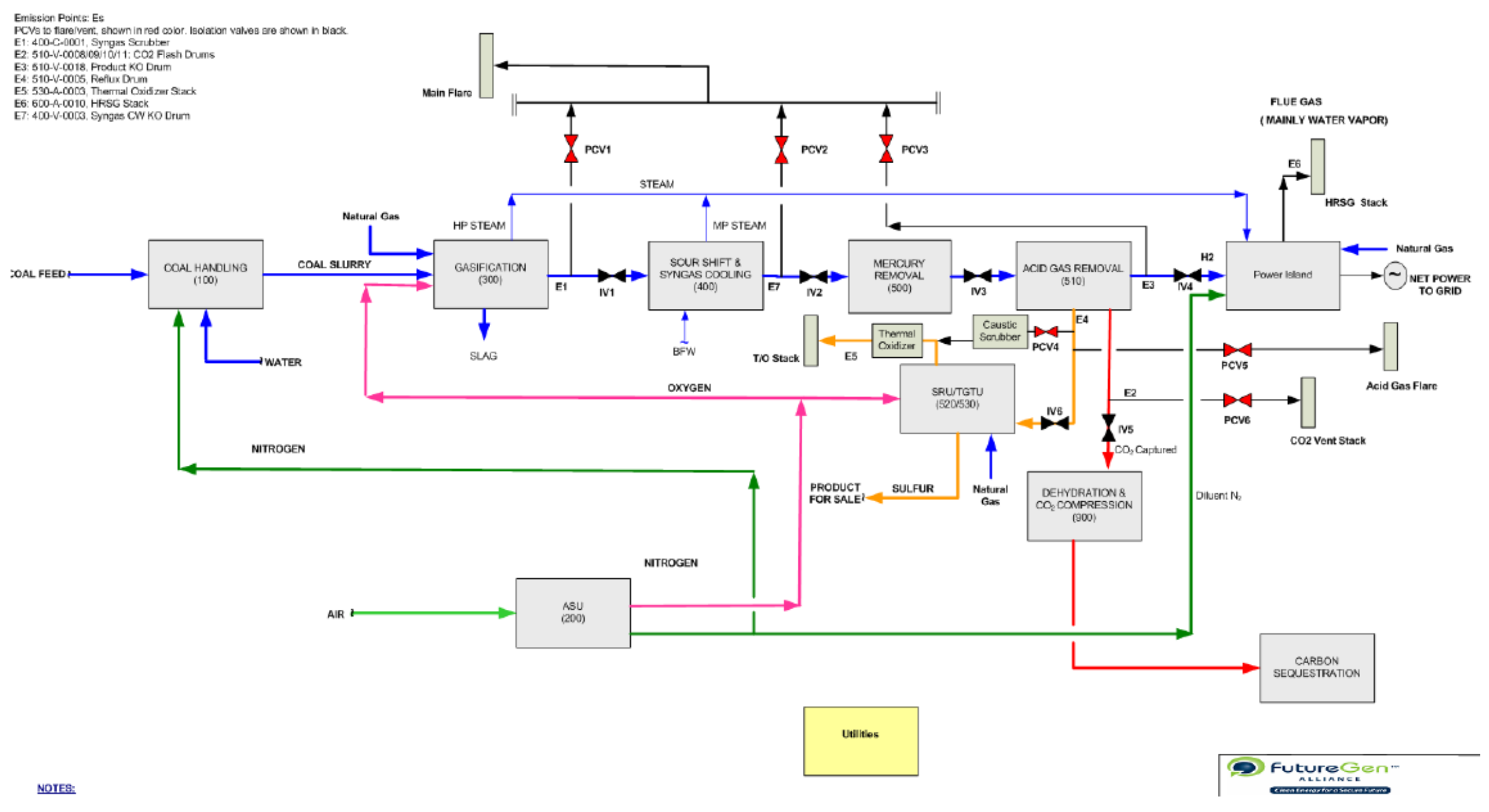

Figure 11-1. FutureGen Plant Alignment and Sources 


\section{2 futureGen" \\ A L L I A N C E}

\section{FutureGen Cold Startup Timeline}

\begin{tabular}{|c|c|}
\hline Steps & Actions \\
\hline 0 & Bring up the auxiliary boiler \\
\hline 1 & Warm up and pressurize gasifier with sub-stoichiometric combustion of NG (44 hrs) \\
\hline 2 & Estabish circulation in TGTU contact condenser, TG compressor runs on recycle with nitrogen \\
\hline 3 & Heat up SRU with NG (34 hrs), heat up hydrogenation reactor in TGTU (DMDS injection). \\
\hline 4 & Heat up area 400 with nitrogen ( $8 \mathrm{hrS}$, DMDS injection) \\
\hline 5 & Feed area 400 with NG-syngas from gasifier ( 4 hrs to stablize 4 hrs continue operation, DMDS injection) \\
\hline 6 & Bring up the propane refigeration system ( $2 \mathrm{hrs}$ ) \\
\hline 7 & AGRU absorbers pressurized and solvent circulation established (4 hrs) \\
\hline 8 & Feed areas 500 and 510 with NG-Syngas to establish gas load in AGRU ( 4 hrs) \\
\hline 9 & Caustic scrubber on circulation and ready to receive acid gas \\
\hline 10 & Switch gasiiner fuel gadually from NG to coal and achieve stable operation ( $8 \mathrm{hrs}$ ) \\
\hline 11 & Startup power island with NG ( $3 \mathrm{hrs}$ ) \\
\hline 12 & Power island switch to $\mathrm{H} 2$ fuel ( $1 \mathrm{hr})$ \\
\hline 13 & CO2 dehydration unit, compression and injection systems ready \\
\hline 14 & Feed CO2 product to $\mathrm{CO} 2$ compressor \\
\hline 15 & Feed SRU with acid gas and achieve stable SRU and TGTU operation ( $3 \mathrm{hrs}$ ) \\
\hline
\end{tabular}

SRU and TGTU operation ( 3 hrs

\section{List of abbreviations / notations}

NG: Natural Gas

DMDS: Dimethyl Disuline

Indicates that the system is ready at the end of corresponding hour

color bar Indcates continuous operation on actions stated

hicates transtion operation swiching from NG to coal

ndcates continuous stable operation on coal feed

Note: Al system is deaned, purged with nitrogen, air and mosture free.

ASU, utity systems, and stemn system (uSing auxitary boder) are ready at time 0

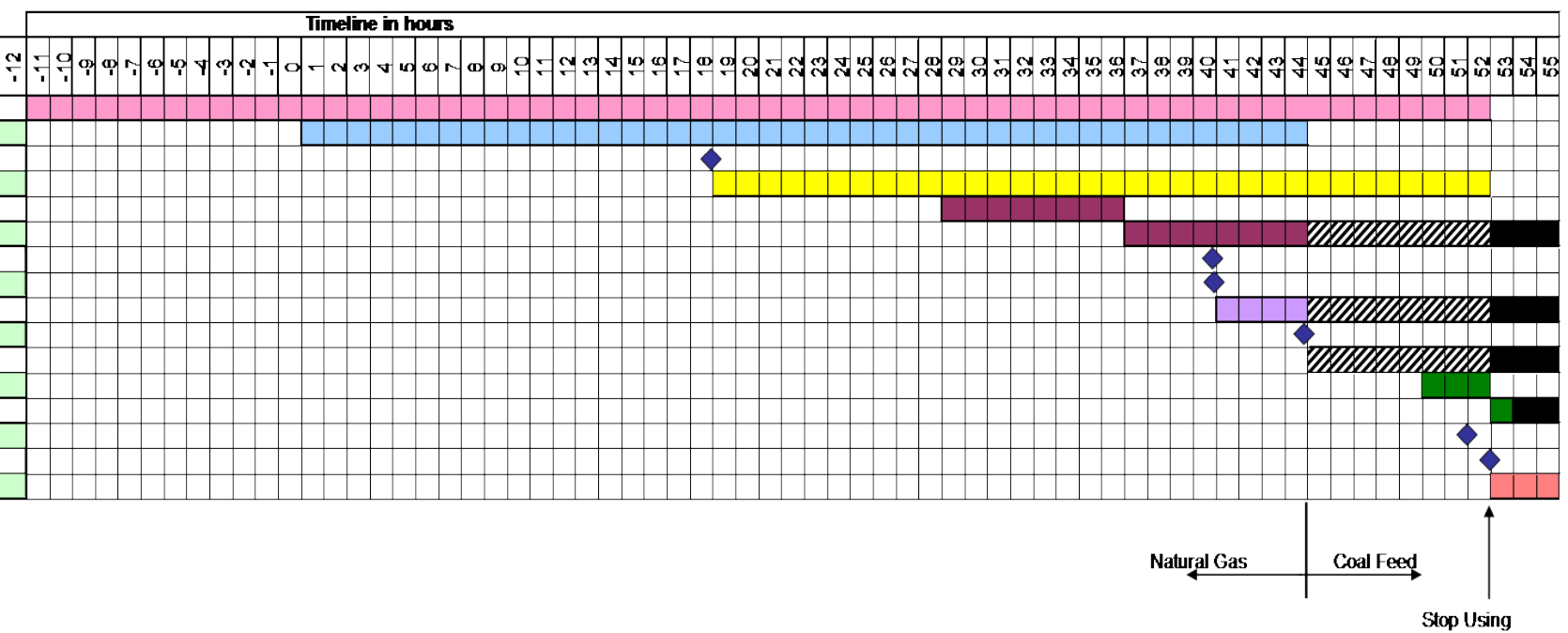

Caustic Scrubber

Figure 11-2. Cold Plant Start-Up Sequence of Operations 
The Alliance also initiated a BACT review. Though neither the gasifier nor CTG technology had been selected at the time the review was commissioned, the Alliance assumed that the emission units (processes) would essentially be the same regardless of the final configuration. To complement the BACT review, the Alliance performed baseline emission calculations on both a slurry-fed and dry-fed gasifier configurations, and on each of the representative Frame 7 CTGs when combusting hydrogen and when combusting natural gas. The draft BACT analysis addressed the proposed controls for the following unit processes:

- combined cycle combustion turbines with HRSGs;

- gasifier process flare;

- acid gas removal unit flare;

- sulfur recovery unit thermal oxidizer;

- material handling systems including coal receiving, handling and storage, slag handling, storage and disposal;

- cooling tower;

- auxiliary boiler;

- diesel-fired fire pump; and

- diesel-fired emergency generator.

When evaluating air pollution control technologies, the U.S. Environmental Protection Agency recommends a "top-down" approach. This approach to BACT involves determining the most stringent control technique available, lowest achievable emission rate (LAER), for a similar or identical emission source. If it can be shown that the LAER is technically, environmentally, or economically impractical on a case-by-case basis for the particular source, then the next most stringent level of control is determined and similarly evaluated. The process continues until a control technology and associated emission level is determined which cannot be eliminated by any technical, environmental, or economic objections. Each of the pollutants subject to the BACT determination, defined as those exceeding the prevention of significant deterioration major source threshold level, were subject to the evaluation including oxides of nitrogen (NOx), sulfur dioxide $\left(\mathrm{SO}_{2}\right)$, carbon monoxide $(\mathrm{CO})$, particulate matter $(\mathrm{PM})$, particulate matter smaller than 10 micrometer $(\mu \mathrm{m})$ and $2.5 \mu \mathrm{m}$ in diameter (PM10/PM2.5). 


\section{Cost and Risk Evaluations}

Several activities were conducted to assess the potential impacts of estimate and event-driven risks to the FutureGen project; these included in-house identification and valuation of project risks via the FutureGen Project Risk Register, Consequence Based Risk Ranking Study, ${ }^{1}$ and a probability based evaluation of the FutureGen 2009 cost estimate. Table 12-1 includes the cost information and ranges for the probability evaluation completed by the Alliance.

Table 12-1. FutureGen Alliance Inputs and Summary for Monte Carlo Analysis

\begin{tabular}{|c|c|c|c|c|c|c|c|c|c|}
\hline Area & Description & $\begin{array}{l}\text { Contingency } \\
\text { in Base Cost } \\
\text { Estimate }\end{array}$ & $\begin{array}{l}\text { Confidence } \\
\text { Level of } \\
\text { Estimate }\end{array}$ & & Jwer Range & & $\begin{array}{l}\text { reliest Value } \\
\text { Contingency) }\end{array}$ & & oper Range \\
\hline 100 & Coal Handling & $15 \%$ & $70 \%$ & $\$$ & $115,708,181$ & $\$$ & $128,564,646$ & $\$$ & $147,031,433$ \\
\hline 200 & ASU & $5 \%$ & $70 \%$ & & Note A & & Note A & & Note A \\
\hline 300 & Gasification & $10 \%$ & $50 \%$ & & Note A & & Note A & & Note A \\
\hline 400 & Shift & $5 \%$ & $65 \%$ & $\$$ & $65,035,740$ & $\$$ & $66,363,000$ & $\$$ & $73,629,513$ \\
\hline 500 & Mercury & $5 \%$ & $70 \%$ & $\$$ & $3,956,630$ & $\$$ & $4,079,000$ & $\$$ & $4,523,088$ \\
\hline 510 & AGRU & $12 \%$ & $60 \%$ & $\$$ & $138,692,000$ & $\$$ & $158,692,000$ & $\$$ & $217,371,153$ \\
\hline 520 & SRU & $12 \%$ & $65 \%$ & $\$$ & $24,936,000$ & $\$$ & $26,436,000$ & $\$$ & $31,847,233$ \\
\hline 530 & $\begin{array}{c}\text { Tail Gas Treatment } \\
\text { Unit }\end{array}$ & $12 \%$ & $65 \%$ & $\$$ & $13,777,200$ & $\$$ & $15,308,000$ & $\$$ & $19,206,822$ \\
\hline $600 \mathrm{~A}$ & Power Island & $5 \%$ & $70 \%$ & $\$$ & $319,011,300$ & $\$$ & $354,457,000$ & $\$$ & $414,385,894$ \\
\hline $600 \mathrm{~B}$ & Switchyard & $5 \%$ & $70 \%$ & $\$$ & $33,625,800$ & $\$$ & $37,362,000$ & $\$$ & $91,273,495$ \\
\hline 700 & Integration & $15 \%$ & $60 \%$ & $\$$ & $288,007,200$ & $\$$ & $320,008,000$ & $\$$ & $374,501,816$ \\
\hline 800 & Utilities & $5 \%$ & $70 \%$ & $\$$ & $21,468,600$ & $\$$ & $23,854,000$ & $\$$ & $27,544,018$ \\
\hline $800 \mathrm{~B}$ & Process Water & $5 \%$ & $70 \%$ & $\$$ & $7,203,600$ & $\$$ & $8,004,000$ & $\$$ & $9,242,153$ \\
\hline $900 \mathrm{~A}$ & $\mathrm{CO}_{2}$ Compression & $8 \%$ & $70 \%$ & $\$$ & $27,200,000$ & $\$$ & $43,569,000$ & $\$$ & $61,882,867$ \\
\hline $900 \mathrm{~B}$ & Sequestration & $16 \%$ & $70 \%$ & $\$$ & $61,915,500$ & $\$$ & $68,795,000$ & $\$$ & $96,037,023$ \\
\hline Comm & Comm/Startup & $20 \%$ & $50 \%$ & $\$$ & $31,428,000$ & $\$$ & $34,920,000$ & $\$$ & $64,289,838$ \\
\hline Owner & Owner Costs & $0 \%$ & $55 \%$ & $\$$ & $114,665,000$ & $\$$ & $120,700,000$ & $\$$ & $175,441,301$ \\
\hline Pre & Precommissioning & $0 \%$ & $50 \%$ & $\$$ & $11,895,572$ & $\$$ & $13,217,302$ & $\$$ & $39,261,910$ \\
\hline Sched & Schedule Delays & $0 \%$ & $20 \%$ & $\$$ & $(500,000)$ & $\$$ & - & $\$$ & $90,000,000$ \\
\hline Esc & Escalation & $0 \%$ & $50 \%$ & $\$$ & $(85,000,000)$ & $\$$ & - & $\$$ & $85,000,000$ \\
\hline \multirow{2}{*}{\multicolumn{4}{|c|}{$\begin{array}{l}\text { Total } \\
\text { Relative Change from Likeliest Value }\end{array}$}} & $\$$ & $1,548,015,965$ & $\$$ & $1,804,148,603$ & $\$$ & $2,523,242,583$ \\
\hline & & & & & $-17 \%$ & & & & $40 \%$ \\
\hline \multicolumn{4}{|c|}{ Absolute Change from Likeliest value } & & $(\$ 256,132,638)$ & & & & $\$ 719,093,980$ \\
\hline
\end{tabular}

Table Note A: Cost information for the ASU and Gasifier Islands (Area 200 and 300) are redacted due to proprietary information.

Note that the risk analysis was completed as an 'area-by-area' evaluation prior to finalizing the cost estimates as captured in the final CAPEX and OPEX reports. As a result, the $\$ 1.8$ billion used as the value for the highest likelihood reference case in the risk assessment, is slightly different than the final CAPEX value

\footnotetext{
${ }^{1}$ Consequence Based Risk Ranking Study for the Proposed FutureGen Project Configurations. Oct. 23, 2006. Quest Consultants, Inc. Norman, OK. Found in DOE/EIS-0394D: FutureGen Project Draft EIS. June 2007.
} 


\section{(2) Future Gen" \\ ALLIANCE

due to a minor difference in owner costs, as well as rounding. The final CAPEX cost estimate of $\$ 1.8$ billion overnight capital includes estimate-driven contingency.

Among the more relevant findings, the Alliance considered the single largest impact to the estimate (lowest level of confidence) to be associated with the combined impacts of scheduling delays and escalation associated with that. 


\section{Summary of Major Accomplishments}

The following summarizes the major accomplishments achieved by the Alliance, their respective subcontractors, and DOE in executing programmatic and project goals defined by the FutureGen IGCC/CCS project. With regard to the project timeline, it's useful to recognize that the majority of the activities were executed between 2006 and 2008. This is significant considering that the Alliance effort began in mid-2005, with no known site or facility design, but culminated with an approved ROD in full compliance with NEPA; a draft UIC permit for $\mathrm{CO}_{2}$ injection; a comprehensive FEL-2 design and Class 4 cost estimate; control and ownership of both surface and subsurface rights; and broad stakeholder approval at the local, state, and federal level.

The level of rigor and objectivity applied to the site selection process was matched only by the degree of timeliness. The period from the issuance of the original siting RFP to the selection and characterization of the four candidate sites via the DEIS was 18 months. With the FEIS following 5 months later, the Alliance, in full compliance with NEPA guidelines, was not only able to select four sites capable of supporting the FutureGen project mission, but to comprehensively evaluate and determine that the Mattoon site provided the best overall value to the project. As indicated previously, the Alliance received an ROD approving the findings disclosed in the FEIS.

Complementing the ROD, the Alliance also received a draft UIC permit from IEPA for injection of $\mathrm{CO}_{2}$ into the Mt. Simon Formation at the Mattoon site. Issuance of the draft UIC permit was based on the comprehensive Class I UIC permit application submitted by the Alliance which detailed the design, construction, and operation of the carbon capture storage site system including the rigorous monitoring and reporting protocols that would have been implemented. The IEPA Class I UIC permitting process and administrative requirements preceded the EPA's transition to Class VI UIC permits in December 2010 which specifically addressed carbon dioxide injection and geologic sequestration. Had the Alliance continued with the project, they would have been required to fulfill the obligations of the newly developed Class VI UIC well permit.

The Alliance produced the first comprehensive design and cost estimate for a fully integrated IGCC power plant with a dedicated CCS system, including valuations of capital requirements (CAPEX), as well as operating and maintenance requirements (OPEX) for the project lifecycle. At the time the estimates were being developed, the Alliance had not made a formal technology selection with regard to the gasifier. Accordingly, the CAPEX and OPEX estimates assessed both slurry-fed and dry-fed configurations, with each configuration supported by a complete heat and material balance, and the corresponding process flow sheets reflective of utilizing a single coal rank (Illinois 6). In advancing one of the design axioms, the Alliance also completed preliminary heat and material balances for comparative purposes utilizing two additional coal ranks that could be used in the plant including Pittsburgh 8 and PRB.

Strengthening the validity of the CAPEX estimate, more than 85 percent of the costs associated with major pieces of equipment were based on actual priced equipment and vendor supplied quotes. Similar plant or factored estimate practices were limited to those areas where significant in-house costing efforts had been previously completed, and were restricted to routine processes such as coal handling, grid interface, and portions of the power island. Additionally, the third party assessment completed by Deloitte indicated that based on the level of design, the CAPEX and OPEX were reasonable estimates within the proposed range of uncertainty, and that an appropriate basis had been used in the estimation process. 
The Alliance moved from a conceptual study (ICDR) to a defensible, all-in capital, operating, and postoperations cost estimate containing the relevant details that enabled the development of pro-forma models. The financial modeling for the project included sensitivity analysis around carbon pricing both with and without federal legislation, debt structure and servicing, escalation rates, load-weighted energy market analysis specific to the two electricity hubs that the FutureGen plant could service, levelized cost of electricity, as well as others. If the project had proceeded, these analyses would have contributed directly to the structuring of eventual commercial financing, and a likely power purchase agreement.

The Alliance put significant effort into valuating "below the line" aspects of the cost estimate, as the application of standard contingency factors did not adequately capture and quantify risk in terms of the potential cost impact. With the intent to provide a cost probability distribution beyond the inherent range offered as part of the Class 4 estimate, the Alliance conducted assessments at each area level, adjusting contingency based on the level of understanding, complexity, and confidence. These findings were independently evaluated by third party who determined the key indicators of uncertainty were primarily related to schedule slip, escalation, and overall plant integration (Area 700).

The Alliance advanced the design and engineering of the FutureGen IGCC/CCS project well beyond the $\mathrm{HMBs}$, and a paper study of steady-state operations. Executing multiple operability assessments, the Alliance quantified aspects of plant start-up, shut down, and transient operations including evaluations of equipment and process modifications, abatement strategies, and operating plans (e.g., vent vs. flare). The final design as offered for the cost estimate and preliminary permitting activities represented the most efficient configuration in an alignment that could control emissions production and release within the bounds of the expected goals of the project.

As a clean coal project, FutureGen maintained broad support at the local, state, and federal levels throughout the project timeline. The commitment to stakeholder engagement and involvement manifested itself in several aspects of the project. As a living laboratory, the plant and CCS systems were designed to support public accessibility and education and included a site visitor center, observation locations for both the power plant and sequestration locations at the site, and a locally sited educational facility. From a siting perspective, the DEIS moved expediently through the public comment period, ultimately obtaining an ROD that approved all four candidate sites, and the technologies that could be developed there.

Project support was also apparent by the willingness of local landowners, Coles Together, and the State of Illinois to ensure that the Alliance was able to secure both property and storage rights for the FutureGen plant and CCS systems. Finally, though the FutureGen plant was a coal burning power plant, the project was widely considered as a fundamental and necessary step toward the advancement of fossil based power production with as few societal impacts as the state of the technology would allow. 


\section{ATTACHMENT 1}

\section{SITE SELECTION REPORT}




\section{(2) future Gen" A L L I A N C E \\ Clean Energy for a Secure Future}

\section{Final Site Selection Report}

December 18, 2007 

Acknowledgment: This material is based upon work supported by the U.S. Department of Energy under Award Number DE-FC26-06NT42073.

Disclaimer: This report was prepared as an account of work sponsored by an agency of the United States Government. Neither the United States Government nor any agency thereof, nor any of their employees, makes any warranty, express or implied, or assumes any legal liability or responsibility for the accuracy, completeness, or usefulness of any information, apparatus, product, or process disclosed, or represents that its use would not infringe privately owned rights. Reference herein to any specific commercial product, process, or service by trade name, trademark, manufacturer, or otherwise does not necessarily constitute or imply its endorsement, recommendation, or favoring by the United States Government or any agency thereof. The views and opinions of authors expressed herein do not necessarily state or reflect those of the United States Government or any agency thereof.

FUTUREGEN INDUSTRIAL ALLIANCE, INC. 1001 PENNSYLVANIA AVENUE, NW

$6^{\mathrm{TH}}$ FLOOR WASHINGTON DC 20004

202-429-8430

Email: info@FutureGenAlliance.org

Homepage: www.FutureGenAlliance.org 



\section{Final Site Selection Report}

December 18, 2007

Submitted by:

FutureGen Industrial Alliance, Inc. 



\section{SUMMARY}

FutureGen is a government-industry cost-shared project to design, build, and operate a first-of-a-kind coal-fueled, near-zero emission power plant. The FutureGen power plant will produce electricity and hydrogen from coal while capturing and permanently storing carbon dioxide $\left(\mathrm{CO}_{2}\right)$ in a deep geologic formation. On December 2, 2005, the U.S. Department of Energy (DOE) entered into a cooperative agreement with the FutureGen Industrial Alliance, Inc. (Alliance) to begin the FutureGen host site selection process and prepare a conceptual design for the facility.

The Alliance implemented a thoughtfully structured, openly competitive siting process to identify the site that could best meet the goals of the FutureGen project. This process involved the issuance of a Request for Proposals from potential site hosts, a rigorous evaluation of the 12 proposals received, and the identification of four candidate sites for full consideration by the Alliance and DOE. The four sites under consideration to host the FutureGen facility are located in Mattoon, Illinois; Tuscola, Illinois; Jewett, Texas (also referred to as Heart of Brazos); and Odessa, Texas.

In accordance with the National Environmental Policy Act, DOE prepared a Draft and a Final environmental impact statement (EIS) to evaluate the potential environmental impacts of constructing and operating the FutureGen project at each of the four sites. In the Final EIS, DOE stated that its preferred alternative is to provide financial assistance to the FutureGen project and tentatively found that all four sites were acceptable. The Alliance expects that, in the near future, DOE will issue a Record of Decision that states that it will implement its preferred alternative and confirms that each of the four sites is acceptable. The Alliance will implement miti measures specified in the DOE Record of Decision.

After extensive review and evaluation of the advantages and disadvantages of the four candidate sites both individually and in comparison to one another, the Alliance voted to select Mattoon as the host site for the FutureGen facility, pending the outcome of DOE's Record of Decision. While the Alliance believes that all of the candidate sites are acceptable and offer significant benefits to the FutureGen project, the Alliance believes the Mattoon site provides many advantages, among which are the following:

- The Mattoon site proponent can provide clear legal title to the power plant site, including the injection site, which results in minimal land ownership risk.

- Onsite $\mathrm{CO}_{2}$ injection eliminates the need for an extended length, offsite $\mathrm{CO}_{2}$ pipeline, which reduces capital and operating costs while still providing an excellent test of the integration of the power plant with $\mathrm{CO}_{2}$ injection and sequestration. This site will provide both operating- and construction-related integration efficiencies that will reduce costs and staffing requirements.

- With both power production and injection on the same site, public access and educational opportunities will be exceptional.

- The Mt. Simon geologic injection formation is regionally extensive and is widely considered to be one of the most important geologic storage reservoirs for anthropogenic $\mathrm{CO}_{2}$ in the U.S.

- The thick geologic injection formation, multiple thick overlying and low permeability formations which provide multiple seals, and lack of penetrations into both the primary or secondary seals substantially decrease geologic risk. 
- There is a secure water source from two wastewater treatment facilities, which when combined with the construction and operation of an onsite reservoir, will ensure an adequate water supply to the plant.

- The site is near interstate highways which connect to major waterways to provide an opportunity for modular construction of the facility.

- There is very strong community support for the FutureGen project in Mattoon and surrounding communities.

- Enhanced, site-specific environmental mitigation measures will be implemented to reduce, to the fullest extent practicable, potential impacts from light, noise, and odors and to increase the compatibility of the plant with the surrounding area.

- There is a good potential for self-sufficient post-project operation of the plant because of the power plant's projected revenue potential and the projected low operating cost of the FutureGen plant at this site.

Balancing overall cost and associated financial risks, and other risks and benefits such as legal issues, water issues, geologic conditions, sequestration opportunities, construction issues, and environmental issues, Mattoon would best serve the overall project mission. 


\section{TABLE OF CONTENTS}

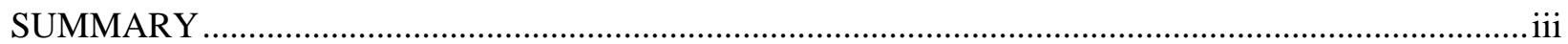

ACRONYMS AND ABBREVIATIONS …......................................................................................... vii

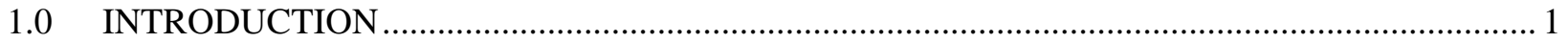

2.0 FUTUREGEN FACILITY SITING PROCESS ..................................................................... 1

3.0 CAPITAL AND OPERATING COSTS, EXPECTED REVENUES, AND INCENTIVES ............. 3

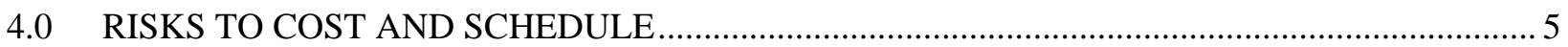

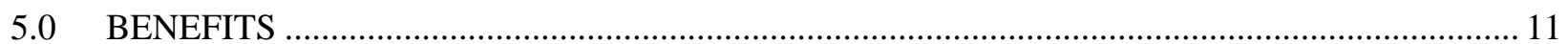

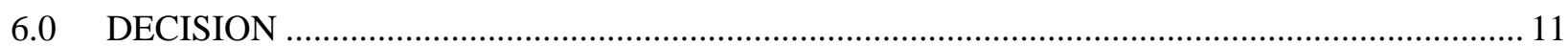

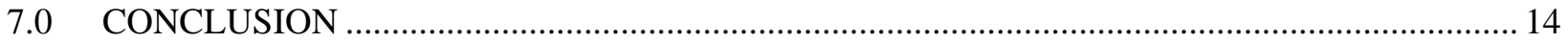





\section{ACRONYMS AND ABBREVIATIONS}

BAFO

$\mathrm{CO}_{2}$

DOE

EIS

MMT

MMV

MW

NEPA

TDCJ
Best and Final Offer

carbon dioxide

U.S. Department of Energy

environmental impact statement

million metric tons

monitoring, mitigation, and verification

megawatt

National Environmental Policy Act

Texas Department of Criminal Justice 



\subsection{INTRODUCTION}

FutureGen is a government-industry cost-shared project to design, build, and operate a first-of-a-kind coal-fueled, near-zero emission power plant. The FutureGen power plant will produce electricity and hydrogen from coal while capturing and permanently storing carbon dioxide $\left(\mathrm{CO}_{2}\right)$ in a deep geologic formation. The nominally rated 275-megawatt (MW) prototype power plant will operate as a production plant, generating commercially significant levels of electric power. It will also provide a large-scale engineering laboratory for testing new and clean power generation, $\mathrm{CO}_{2}$ capture, and coal-to-hydrogen technologies, as well as including syngas slip-stream access for testing and developing new technologies. The FutureGen program intends to build and operate the cleanest coal-fueled power plant in the world.

The project is being jointly funded by the U.S. Department of Energy (DOE) and the FutureGen Industrial Alliance, Inc. (Alliance). There were four candidate sites under consideration to host the FutureGen facility. The sites are located in Mattoon, Illinois; Tuscola, Illinois; Jewett, Texas (also referred to as Heart of Brazos); and Odessa, Texas.

The Alliance engaged in a detailed discussion of the strengths and weaknesses of each site individually and performed a side-by-side comparison of the sites looking specifically at costs (including uncertainties), risks to cost and schedule, and other benefits. After this extensive review and evaluation of the advantages and disadvantages of the four candidate sites both individually and in comparison to one another, the Alliance Board of Directors voted to select Mattoon as the host site for the FutureGen facility, pending the outcome of future DOE decisionmaking.

This report summarizes the siting process that was used to identify candidate sites and, ultimately, to select one of those sites as the host site. In addition, the report provides an overview of the costs, revenues, and incentives; risks to cost and schedule; and other benefits associated with constructing and operating FutureGen at each of the candidate sites. With that background, the report then provides the rationale for selecting Mattoon as the host site. DOE reviewed and approved the final site selection process.

\subsection{FUTUREGEN FACILITY SITING PROCESS}

The Alliance implemented a thoughtfully structured, openly competitive siting process to identify the site that could best meet the goals of the FutureGen project. The process used is summarized below.

\section{Request for Proposals}

On December 2, 2005, DOE entered into a cooperative agreement with the Alliance to begin the FutureGen host site selection process and prepare a conceptual design for the facility. As a result, the Alliance created a process to identify candidate sites for the proposed FutureGen facility. This process involved developing over 75 different siting criteria, issuing a Request for Proposals, and evaluating the proposals received using a scoring system, including a visit to each proposed site.

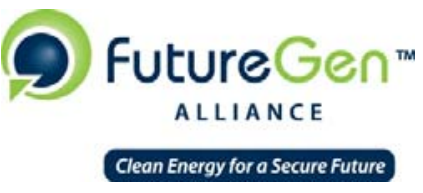




\section{Candidate Site List}

In July 2006, the Alliance identified four candidate sites to host the FutureGen facility, out of 12 sites for which proposals were submitted. The candidate sites were selected after completion of a rigorous proposal evaluation process, which was independently audited by DOE. The Candidate Site List, and supporting rationale, was submitted to DOE for inclusion into the agency's National Environmental Policy Act (NEPA) compliance process. The Alliance's Report to the U.S. Department of Energy on the Results of Site Offeror Proposal Evaluation, dated July 21, 2006, provides additional detail.

\section{Environmental Impact Statement}

In accordance with its NEPA regulations, DOE analyzed the potential environmental impacts of siting and constructing the FutureGen facility at each of the four candidate sites and documented these analyses in the FutureGen Draft Environmental Impact Statement (DOE/EIS-0394D, May 2007) (Draft EIS). The Draft EIS was the subject of public hearings at the four sites. DOE considered the public comments received on the Draft EIS and issued the FutureGen Final Environmental Impact Statement (DOE/EIS0394F, November 2007) (Final EIS). A Notice of Availability of the Final EIS was published by the U.S. Environmental Protection Agency on November 16, 2007 (72 Fed. Reg. 64618, 64619 [November 16, 2007]), beginning the minimum 30-day waiting period required by NEPA regulations.

\section{Record of Decision}

In the Final EIS, DOE stated that its preferred alternative is to provide financial assistance to the FutureGen project and tentatively found that all four sites were acceptable. The Alliance expects that, in the near future, DOE will issue a Record of Decision that states that it will implement its preferred alternative and confirms that each of the four sites is acceptable. The Alliance will implement mitigation measures specified in the DOE Record of Decision.

\section{Data Analysis}

The Alliance considered the costs, risks, and benefits associated with the construction and operation of the FutureGen facility at each of the four candidate sites. All phases (construction, operation, postoperation, and long-term monitoring) and significant components (power plant, utility requirements, and sequestration) of the plant were evaluated - over 120 different factors. The data for this analysis was derived from several sources including, but not limited to:

- $\quad$ Best and Final Offer (BAFO) submissions from the proponents of the candidate sites; ${ }^{1}$

- Original site proposals; and

- Alliance due diligence efforts, including legal and financial analyses.

\footnotetext{
${ }^{1}$ BAFO Directions were provided to the site proponents in draft on May 30, 2007. These directions were modified after consideration of comments received from the site proponents, and final directions were sent to the site proponents on June 15, 2007. The BAFO directions describe the general factors the Alliance intends to consider in its final siting decision. BAFOs were submitted by the site proponents on August 1, 2007.
}

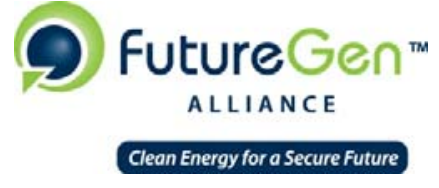




\subsection{CAPITAL AND OPERATING COSTS, EXPECTED REVENUES, AND INCENTIVES}

For each of the candidate sites, the Alliance considered the expected capital and operating costs, potential revenues, and potential incentives offered by the site proponents. Capital costs are those that will need to be expended over a 44-month construction period for (1) purchasing or leasing land for the power plant and/or injection site, required rights-of-way for utilities and a $\mathrm{CO}_{2}$ pipeline, and subsurface rights needed for $\mathrm{CO}_{2}$ sequestration; (2) preparing the power plant site for construction (e.g., road access, grading, natural gas pipeline work); (3) constructing the power plant (e.g., cost of construction labor and weatherdriven costs); (4) sequestration design and construction (e.g., site characterization, building the $\mathrm{CO}_{2}$ pipeline system and infrastructure, and monitoring infrastructure); and (5) environmental mitigation (e.g., noise attenuation barriers and odor controls). Operating costs are those that will need to be expended for the 4-year operations period of the power plant (e.g., coal and other consumables), the 4-year operations period of the sequestration system (e.g., $\mathrm{CO}_{2}$ pipeline operations and maintenance and monitoring, mitigation, and verification (MMV)), and the 2-year post-operation period (e.g., continued MMV, injection well closure, and $\mathrm{CO}_{2}$ pipeline closure).

The operation of the FutureGen facility is expected to generate revenue from the sale of electricity and of co-products such as elemental sulfur and slag. In addition, $\mathrm{CO}_{2}$ sales would be possible if the plant were located at one candidate site - Odessa.

The site proponents offered various economic incentives in their best and final offers. In particular, both Illinois and Texas offered several million dollars in contributions and grants. Some of the grants require applications to be filed and/or certain conditions to be met.

The site proponents in both states also offered in-kind contributions. These include MMV services valued at least \$1 million annually. Other in-kind contributions offered include equipment, research, and services.

The following addresses the expected costs, revenue, and incentives for each site.

\section{Mattoon}

- Capital costs are comparatively high and are driven by construction labor, grid upgrades, and weather-driven requirements.

- Operating costs are comparatively low and are driven by coal delivered costs, $\mathrm{CO}_{2}$ pipeline operations and maintenance, and operations labor.

- Total revenue is expected to be \$216 million over 4 years, of which \$215 million is expected to come from electricity sales.

- The value of incentive contributions and grants is \$21 million.

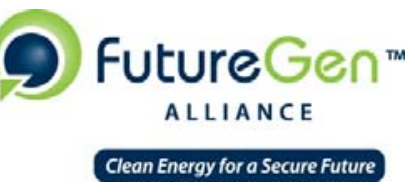




\section{Tuscola}

- Capital costs are comparatively high and are driven by construction labor, grid upgrades, weather-driven requirements, and the potential future need for a process water treatment facility.

- Operating costs are comparatively low and are driven by coal delivered costs, water, and operations labor.

- Total revenue is expected to be \$216 million over 4 years, of which \$215 million is expected to come from electricity sales.

- The value of incentive contributions and grants is $\$ 21$ million.

\section{Jewett}

- Capital costs are comparatively high and are driven by the need for a process water treatment facility and a $\mathrm{CO}_{2}$ pipeline system.

- Operating costs are comparatively high and are driven by coal delivered costs, water treatment costs, and sequestration requirements.

- Total revenue is expected to be $\$ 231$ million over 4 years, of which $\$ 230$ million is expected to come from electricity sales.

- The value of incentive contributions and grants is $\$ 20$ million.

- Texas offered the Alliance franchise tax credits (based on electricity sales), subject to a cap. Although the Alliance is not subject to the franchise tax, the Alliance extensively analyzed the ability to sell the credits to entities that are subject to the tax in order to realize value from the credits. However, the value of any such credits to the Alliance is highly uncertain because of the unique nature of the credits, the lack of tried and tested state regulations implementing the credits, the unknown extent of the available market for the credits, and the uncertainty of electricity sales during the initial part of the facility's operating period. In addition, there is a risk that entities that are eligible for a franchise tax credit may not be eligible for the offered school district tax abatements.

\section{Odessa}

- Capital costs are comparatively low and are driven by process water treatment facility requirements, weather-driven requirements, and sequestration design and construction.

- Operating costs are comparatively high and are driven by coal delivered costs, water and water treatment requirements, and sequestration requirements.

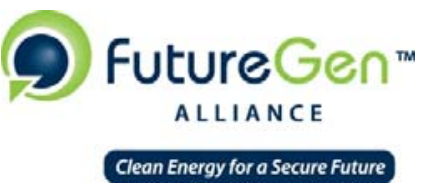


- Total revenue is expected to be $\$ 201$ million over 4 years, of which $\$ 190$ million is expected to come from electricity sales and $\$ 10$ million is expected to come from $\mathrm{CO}_{2}$ sales.

- The value of incentive contributions and grants is $\$ 25$ million.

- Texas offered the Alliance franchise tax credits (based on electricity sales), subject to a cap. Although the Alliance is not subject to the franchise tax, the Alliance extensively analyzed the ability to sell the credits to entities that are subject to the tax in order to realize value from the credits. However, the value of any such credits to the Alliance is highly uncertain because of the unique nature of the credits, the lack of tried and tested state regulations implementing the credits, the unknown extent of the available market for the credits, and the uncertainty of electricity sales during the initial part of the facility's operating period. In addition, there is a risk that entities that are eligible for a franchise tax credit may not be eligible for the offered school district tax abatements.

With respect to cost and cost components, there is no one site that clearly stands out as the best. For this reason, the other differentiating factors included in the overall siting analysis magnify in importance.

\subsection{RISKS TO COST AND SCHEDULE}

In considering risks to cost and schedule, the Alliance considered legal issues, water issues, geologic conditions and sequestration, construction capability, and environmental issues at each site.

Legal issues refer to the ability to obtain clear, unencumbered title to the proposed power plant site and the ability to obtain the necessary easements or other rights for utility corridors, the $\mathrm{CO}_{2}$ pipeline, the installation of monitoring equipment as required over the 6-year plume, and the use of geologic reservoirs for the permanent storage of injected $\mathrm{CO}_{2}$.

Water issues refer to the volume of water that is available, the ability to access the water when needed, and the quality of the water.

Geologic conditions and sequestration refer to the general characteristics of the target formation to store $\mathrm{CO}_{2}$, including permeability, thickness and other factors that might impact design of the sequestration and monitoring systems, the number and thickness of caprock seals, and scientific research opportunities.

Construction capability refers to the availability of construction labor and opportunities to maximize construction efficiencies to avoid schedule delays.

Environmental issues refer to the land use of the surrounding area and the presence or absence of any sensitive receptors or resources in the area.

The following addresses these factors for each site.

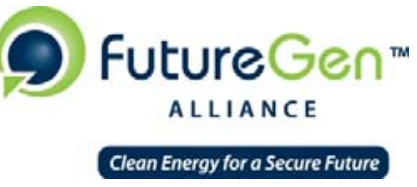




\section{Mattoon}

- Legal issues: The Alliance would generally be able to acquire marketable title (or equivalent site control) to the proposed 419-acre power plant site, which includes the injection site. The site proponent is or will be in control of all necessary utility and transportation corridors; no $\mathrm{CO}_{2}$ corridor is required. Modeling results suggest that the 6-year $\mathrm{CO}_{2}$ plume would remain on the proposed site or within adjacent acreage controlled by the site proponent. As a charitable organization, the Alliance is highly likely to be eligible for a property tax exemption.

- Water issues: Process water would be supplied from effluent from city wastewater treatment plants in Mattoon and Charleston, Illinois. With the construction of a 7- to 10-acre reservoir on the site, process water would be available in sufficient quantities even in dry conditions. The quality of the water is good, although it will need additional treatment.

- Geologic conditions and sequestration: The geologic features of the injection reservoir and seals combine to produce a sequestration setting that is chemically, physically, and structurally robust. The target formation is the regionally extensive Mt. Simon sandstone formation. The Mt. Simon at the Mattoon site is the deepest reservoir as compared to the other sites. The reservoir caprock is the thick Eau Claire shale that serves as a competent caprock for natural gas storage reservoirs elsewhere in Illinois. Multiple secondary seals also exist at the site to provide backup to the main seal. The tectonic setting is stable and in a compressive regional stress regime, which further increases the likelihood that any undetected fracture zones at the site would be sealing. A recent seismic survey near the site shows no obvious faults within the sequestration area. No existing wellbores penetrate the primary seal within the 50-million metric ton (MMT) plume footprint, eliminating a potential leakage risk and well remediation expenses. Reservoir simulations conducted using reservoir property data supplied by the site proponent show that a single well would support a design basis injection rate of 2.5 MMT annually. However, because the reservoir property data used in the simulations were obtained from a well located over 50 miles away, there is uncertainty in achieving the modeled injectivity rate of 2.5 MMT annually in a single well under actual reservoir permeability conditions at the site. Additional simulations were conducted assuming the use of as little as one-third of the total reservoir thickness and still resulted in the ability to inject at a 2.5-MMT annual rate. Further, low injectivity could be mitigated by the installation of a second injection well or by installing a horizontal well at additional cost. Considering all of these factors, this site has a low probability of encountering geologic conditions that would make it impracticable to engineer a sequestration system to achieve the required $\mathrm{CO}_{2}$ injection rate.

- Construction capability: Having the power plant and injection infrastructure located on the same site would allow for construction and operation integration efficiencies by being able to use the same team for surface and subsurface activities. In addition, the site is located near interstate highways which connect to major waterways to provide an opportunity for modular construction of the facility. Labor rates are higher in Illinois than in Texas, and the Illinois sites could experience weather-related construction delays. Because the Mattoon site is located near residences, the ability to work around the clock may also be limited. The nearest transmission line is a 138-kV line, and the lower voltage increases the potential for system congestion. A 345-kV 
line is located approximately 16 miles away; a tie-in to that line could require 4 to 5 years for permitting and construction, adversely affecting the FutureGen schedule.

- Environmental issues: The current land use is agricultural. The surrounding area is rural with a low population density. Two residences are located adjacent to the site. An elementary school is located approximately 2 miles southeast of the proposed site. Enhanced, site-specific environmental mitigation measures would be implemented to reduce potential light, noise, and odor impacts to the local community to the fullest extent practicable. In addition, as required by DOE in its Record of Decision, the Alliance would consider other environmental mitigation measures such as (but not limited to) enclosing or shielding some components of the plant and landscaping around the perimeter of the plant site to partially screen the plant from nearby residences.

\section{Tuscola}

- Legal issues: The Alliance would have clear title to the proposed 349-acre power plant site. Some existing easements (e.g., natural gas lines) would affect the placement of the power plant on the site, or would require that the easements be modified. The Alliance would also have clear title to the 10-acre injection site located approximately 11 miles south of the power plant site. With one exception, all property owners above the 6-year plume have signed options for storage deeds for the area between 3,500 and 8,000 feet below the surface and have also agreed to surface access for MMV, including drilling monitoring wells. The 6-year plume could come within 600 feet or less of an existing shallow gas storage field, requiring extra diligence during drilling to ensure the integrity of the gas storage field; indemnification of the owner of the gas storage field may also be required. The site proponent does not have complete control over the rights-of-way needed for utilities, transportation corridors, and the $\mathrm{CO}_{2}$ pipeline; use of eminent domain to obtain the required rights is likely. As a charitable organization, the Alliance is highly likely to be eligible for a property tax exemption.

- Water issues: Process water would be supplied from the Kaskaskia River through a pipeline controlled by the Lyondell-Equistar Company. A sufficient volume is available and the water quality is good. Lyondell-Equistar is in the process of being sold to another company and the Alliance has been unable to reach an agreement regarding the future availability of river access. Should the pipeline and existing water treatment plant become unavailable, the Alliance would need to find another access route to the Kaskaskia River water.

- Geologic conditions and sequestration: Similar to Mattoon, the target formation would be the regionally extensive Mt. Simon formation with geologic features and seals combining to produce a sequestration setting that is chemically, physically, and structurally robust. The reservoir caprock is the thick Eau Claire shale that serves as a competent caprock for natural gas storage reservoirs elsewhere in Illinois. Multiple secondary seals also exist at the site to provide backup to the main seal. The tectonic setting is stable and in a compressive regional stress regime, which further increases the likelihood that any undetected fracture zones at the site would be sealing. A recent seismic survey near the site shows no obvious faults within the sequestration area. The principal difference from the Mattoon site is a shallow ( $<2$ degree) dip of the reservoir to the 
southeast. This would cause an asymmetrical distribution of the $\mathrm{CO}_{2}$, extending the plume farther to the northwest and expanding the acreage beyond the estimates made with a simple, radially symmetric reservoir model. The Tuscola site is also surrounded by mature and abandoned petroleum exploration and production wells, one of which penetrates the New Albany secondary seal above the 50-MMT plume footprint. However, none of the known wells penetrates the primary seal. Similar to the Mattoon site, there is uncertainty in achieving the modeled injectivity rate of 2.5 MMT annually in a single well because of uncertainty in reservoir permeability in this deep reservoir. Because of the limited acreage offered for the sequestration site, installation of a second injection well would not be a mitigation option due to pressure interference over short inter-well distances. Installing a horizontal well at additional cost would be the only corrective option for low injectivity at the Tuscola site.

- Construction capability: The site is located near interstate highways which connect to major waterways to provide an opportunity for modular construction of the facility. Labor rates are higher in Illinois than in Texas, and the Illinois sites could experience weather-related construction delays. There is a large natural gas mainline located on the property that would need to be moved prior to construction. The nearest transmission line is a $138-\mathrm{kV}$ line, and the lower voltage increases the potential for system congestion. A 345-kV line is located approximately 17 miles away; a tie-in to that line could require 4 to 5 years for permitting and construction, adversely affecting the FutureGen schedule.

- Environmental issues: The current land use is agricultural. The site is located adjacent to an existing industrial area. Three residences, which would be purchased, are located adjacent to the site; 7 other residences are located within 0.5 miles of the site. As required by DOE in its Record of Decision, the Alliance would consider other environmental mitigation measures such as (but not limited to) enclosing or shielding some components of the plant and landscaping around the perimeter of the plant site to partially screen the plant from nearby residences.

\section{Jewett}

- Legal issues: The Alliance would have clear title to the proposed 400-acre power plant site. However, existing encumbrances (e.g., oil and gas leases) may affect use of the site, and the Alliance would need to negotiate with leaseholders to restrict the leaseholders' activities so as not to interfere with construction or operation of the FutureGen plant. The injection site would be located approximately 50 miles away on 800 acres of land owned by and leased from the Texas Department of Criminal Justice (TDCJ). ${ }^{2}$ The TDCJ owns only $1 / 8^{\text {th }}$ of the mineral interests in the subsurface area. However, Texas case law has been interpreted to require permission from only the surface owner (not the mineral owner) for right to inject and store $\mathrm{CO}_{2}$ in a subsurface formation that is not productive of oil and gas. The possibility exists that an affected mineral owner could seek a storage fee or damages, if provable. Modeling results show that the 6-year $\mathrm{CO}_{2}$ plume (encompassing approximately 1,650 acres) may not remain on the 800-acre site. Rights-of-way would not be required for utility or transportation corridors. The Alliance would construct and operate the 59-mile $\mathrm{CO}_{2}$ pipeline. Rights-of-way have not been obtained, but

${ }^{2}$ Use of the TDCJ property as the injection site for Jewett is the reference case. Use of property owned by the Hill Family as the injection site raised concerns regarding faulting in the area, concerns that are not present on the TDCJ property. 
common practice in Texas indicates that such rights would be granted. If the use of eminent domain were required, the Alliance would need to become or work with a common carrier.

- Water issues: Process water is proposed to be provided from a combination of onsite and offsite groundwater wells and blowdown water. Mine water is also available. Sufficient volume is available from a variety of sources, although the quality of blowdown and mine water is poor and other sources were not quantified by the site offeror. In all cases, the Alliance would need to reach agreement with NRG regarding the use of the water from their offered and/or identified sources.

- Geologic conditions and sequestration: The primary target formation is the highly porous and permeable Woodbine sandstone that provides high capacity for $\mathrm{CO}_{2}$ injection. Although highly permeable, the Woodbine is also the thinnest of the proposed reservoirs (600 feet total) and so generates the largest plume footprint of the sites. The site also has the heterogeneous Travis Peak sandstones that provide opportunities for research on low permeability, very deep ( $>10,000$ feet) reservoirs. The primary seal is the thick Eagle Ford shale that is immediately overlain by another thick secondary seal, the Austin chalk. The injection site is in an area of active oil and gas exploration and production. There are numerous wells in the area, although none would intersect the 6-year plume. Several existing wells would require remediation should plant operations continue. The closest seismic line, located less than 0.1 mile from the proposed TDCJ injection site, shows no clearly identifiable faults. However, the Jewett site is in a regional stress regime that is extensional in nature. Although the likelihood is low, should presently undetected faults and fracture zones exist at the site, these structures would be at somewhat higher risk of opening under stresses and frictional changes induced from $\mathrm{CO}_{2}$ injection.

- Construction capability: The site is located near interstate highways which connect to major waterways to provide an opportunity for modular construction of the facility. NRG, which operates the adjacent Limestone coal-fired power plant, is building a third unit, which is expected to be completed in 2012. This could put a strain on the availability of construction labor for the FutureGen plant. The proximity of the NRG Limestone plant could also provide synergies with FutureGen that have not been identified or valued. A 345-kV transmission line is located adjacent to the proposed power plant site, reducing the potential for congestion.

- Environmental issues: The proposed plant site is located adjacent to an operating lignite mine and an operating coal-fired power plant. There are no residences near the proposed power plant site. The proposed injection site is located on property which also houses several thousand state prisoners. According to Census data, approximately 100 people reside above the modeled 6-year plume; 7,000 currently reside above the modeled 50-MMT plume.

\section{Odessa}

- Legal issues: The proposed plant site is currently subject to oil and gas leases, pipelines, and other encumbrances, and the Alliance would need to negotiate with leaseholders to restrict their activities so as not to interfere with construction or operation of the FutureGen plant. The proposed injection site would be located approximately 80 miles away on land owned by and

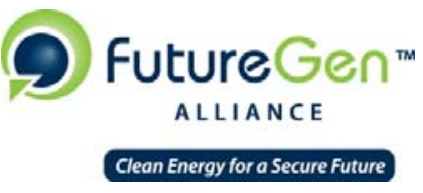


leased from the University of Texas System; four well sites would be leased for a total of 648 acres. Modeling results show that the 6 -year $\mathrm{CO}_{2}$ plume would remain within the 648 leased acres. The site proponent obtained a letter of commitment from the affected landowner for a transmission line easement; no other utility or transportation rights-of-way would be required. To the extent that new $\mathrm{CO}_{2}$ pipelines are required, they would be sited, constructed, and operated by third parties which, as common carriers, may be able to use eminent domain to obtain the necessary easements if necessary.

- Water issues: Process water would be supplied by the City of Odessa through a new water pipeline to the proposed site. There is adequate volume available, although the quality of the water is poor.

- Geologic conditions and sequestration: The targeted injection zone is the Delaware Mountain Group sandstones. This porous sandstone interval is overlain by dominantly non-porous and impermeable carbonates of the Goat Seep Limestone. The primary seal is a very thick (700 feet) anhydrite mixed with minor amounts of carbonate and halite followed by another thick anhydrite (500 feet) of the Salado Formation. The Odessa injection reservoir is the shallowest of the sites and is also of the lowest overall permeability, based on data provided by the site proponent. Hence, achieving the targeted 1-MMT annual injection rate would require multiple vertical wells and/or a horizontal well. The low permeability and the option to mix horizontal and vertical wells to meet injectivity requirements offer significant scientific research opportunities unique to the Odessa site. Based on available seismic data, there is no evidence of faults cutting the primary caprock seal or any of the overlying formations. There are numerous caprock penetrations in the general area due to oil and gas exploration, but there is sufficient acreage to allow the required number of vertical and/or horizontal wells to be positioned to avoid plume contact with existing wells. The $\mathrm{CO}_{2}$ produced at the FutureGen plant would be co-mingled with $\mathrm{CO}_{2}$ produced elsewhere before injection. The sequestration system design basis was established at $1 \mathrm{MMT}$ of $\mathrm{CO}_{2}$ to be injected annually and any additional produced $\mathrm{CO}_{2}$ would be sold. The costs of a dedicated $\mathrm{CO}_{2}$ pipeline to eliminate co-mingling and the additional wells needed to allow the sequestration of more than $1 \mathrm{MMT}$ of $\mathrm{CO}_{2}$ annually have not been estimated but would be high because of the large distance ( $>50$ miles) between the plant and sequestration site.

- Construction capability: This site poses the least risk of construction labor shortages and allows for the most predictable construction schedule. The plant would tie into a double-circuit $138-\mathrm{kV}$ transmission line. Being located in a relatively unpopulated area, the West Texas transmission system has limited capacity and is not highly networked. This increases the potential for congestion with new generation. Based on information from the Texas BAFO, 4,500 MW of commercial windpower is being developed in the region. However, the region has been designated as a Certified Renewable Energy Zone, which allows grid upgrades in the area to be given priority. In addition, a utility joint venture has been formed specifically to increase the transmission capacity in Certified Renewable Energy Zones, including West Texas. Although the potential for congestion exists at this site, the situation could improve substantially by the time the FutureGen plant is online. Due to the absence of a major waterway in the vicinity, this site offers the least opportunity for modular construction as compared to the other three sites. 
- Environmental issues: The proposed power plant site is in a rural area and is currently partially used for natural gas activities. The area surrounding the site to the east, west, and north is dominated by ranching and oil and gas activities. Industrial facilities and the largely abandoned town of Penwell are located adjacent to the site, to the south. There are 4 residences (which may be abandoned) located within 0.5 miles of the proposed power plant site.

All sites pose advantages and disadvantages with respect to risks to cost and schedule. Overall, the Alliance believes that selection of the Mattoon site will pose the least risk because of certainties in obtaining legal control of the site and necessary easements, the availability of process water for the facility, and the soundness of the geologic target formation.

\subsection{BENEFITS}

- All sites enjoy strong stakeholder support for the FutureGen plant.

- The use of eminent domain is available in both states, although it is likely that the states would decline to use that power except as a last resort. In Texas, the use of a general eminent domain (e.g., to resolve title issues) requires that the necessary funds be authorized and appropriated by the Texas legislature.

- All sites offer opportunities for co-product sales such as elemental sulfur and slag; Odessa offers the opportunity for $\mathrm{CO}_{2}$ sales.

- All sites provide important scientific research opportunities and transferability of geologic sequestration results.

- All sites offer a high potential for university involvement for both the power plant and geologic sequestration components of the project.

- By virtue of specially enacted state legislation, both states would take "all rights, title, and interest” in the $\mathrm{CO}_{2}$ injected into the target formation and both states offer liability protection to the Alliance. The Illinois statute states that Illinois will take ownership of "all sequestered gases" and that the state will "indemnify, hold harmless, defend, and release the Alliance and member companies from any public liability for damages arising once the gas is injected into the wellhead.” Legal counsel believes that the Texas statute will be interpreted to include other gases that are included within the $\mathrm{CO}_{2}$ stream.

All sites offer significant benefits to the Alliance and the FutureGen project, with no one site having a particular advantage over the others with respect to the benefits.

\subsection{DECISION}

The Alliance selects Mattoon as the host site for the FutureGen facility. Although, as discussed above, all candidate sites are acceptable and offer significant benefits to the FutureGen project, the Alliance believes the Mattoon site provides many clear advantages and minimal disadvantages.

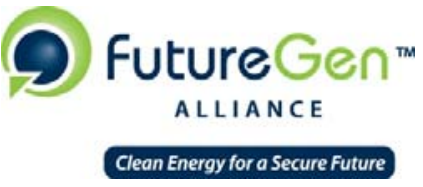




\section{Legal Issues}

- The Mattoon site proponent can provide clear legal title to the power plant site, including the injection site, which results in minimal land ownership risk.

Water

- There is a secure water source from two city wastewater treatment facilities, which when combined with the construction and operation of an onsite reservoir, will ensure an adequate water supply to the plant.

\section{Geologic Conditions and Sequestration}

- Onsite injection eliminates the need for an extended length, offsite $\mathrm{CO}_{2}$ pipeline, which reduces capital and operating costs while providing an excellent test of the integration of the power plant with $\mathrm{CO}_{2}$ injection and sequestration. In addition, onsite injection configures the FutureGen plant in a manner that appears to be a high-probability design (onsite or near-onsite injection) for future near-zero emission power plants.

- With both power production and injection on the same site, public access and educational opportunities will be exceptional.

- The Mt. Simon geologic injection formation is regionally extensive and is widely considered to be one of the most important geologic storage reservoirs for anthropogenic $\mathrm{CO}_{2}$ in the U.S. In addition, the Mt. Simon formation is representative of the majority of U.S. and world geologic storage capacity and provides a favorable geologic setting for groundbreaking research.

- The thick geologic injection formation, multiple thick overlying and low permeability formations which provide multiple seals, and lack of penetrations to both the primary or secondary seals substantially decrease geologic risk.

- The Mattoon site would have the smallest $\mathrm{CO}_{2}$ plume footprint of all the candidate sites.

- The Mattoon site provides unfettered access to conduct a world-class monitoring program.

- This site presents the fewest issues for continuing operations because there are no wells that penetrate the caprock seals within the modeled 50-year $\mathrm{CO}_{2}$ plume and there are no reservoir capacity issues. The site proponent controls a significant portion of the land area above the 50year plume.

\section{Construction Capability}

- There is a highly skilled construction labor force available in the region.

- Onsite injection offers both construction and operational efficiencies by being able to use the same team for surface and subsurface activities.

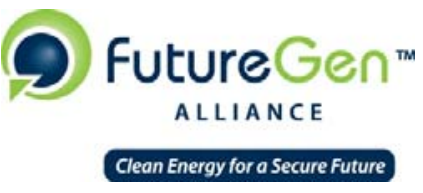


- The site is near interstate highways which connect to major waterways to provide an opportunity for modular construction of the facility.

- All necessary utilities - rail, transmission, and natural gas - are adjacent or close by the site.

\section{Environmental Issues}

- The potential for environmental impacts is low. The power plant/injection site is cropland that has been farmed extensively, reducing the potential for undiscovered cultural, historic, or natural resources. Utility corridors will be located primarily along existing rights-of-way which also reduces the potential for undiscovered resources.

- Enhanced environmental mitigation measures will be implemented to reduce, to the fullest extent practicable, potential impacts from light, noise, and odors and to increase the compatibility of the plant with the surrounding area. In addition, as required by DOE in its Record of Decision, the Alliance will consider other environmental mitigation measures such as (but not limited to) enclosing or shielding some components of the plant and landscaping around the perimeter of the plant site to partially screen the plant from nearby residences.

\section{Cost}

- The Mattoon site offers significant coal transportation cost advantages, including the opportunity to transport all coal types economically.

- There is a good potential for self-sufficient post-project operation of the plant because of the power plant's projected revenue potential and projected low operating cost of the FutureGen plant at this site.

- The incentives provided by Illinois and the local community are significant and certain.

\section{Other Considerations}

- Illinois has enacted meaningful $\mathrm{CO}_{2}$ storage legislation to benefit the Alliance, including a level of liability protection.

- The Mattoon site is located in a business enterprise zone which creates a favorable tax environment.

- The Illinois Geologic Survey is strongly supportive of the project and has offered to provide valuable MMV services during and after the project period.

- The state has enacted legislation to provide a streamlined environmental permitting process for the FutureGen project.

- There is ready access to world-class universities and research institutions that focus on coal and carbon sequestration.

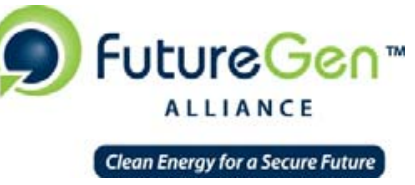


- There is very strong community support for the FutureGen project in Mattoon and surrounding communities.

\subsection{CONCLUSION}

As described above, the Alliance has undertaken a rigorous, open site selection process that has been approved by DOE. After careful consideration of the advantages and disadvantages offered at each of the four candidate sites, the Alliance believes that the Mattoon site can best meet the goals of the FutureGen project within the current schedule and budget. 


\section{ATTACHMENT 2}

\section{UIC Permit Application}




\section{(2) futureGen" \\ A L L I A N C E \\ Clean Energy for a Secure Future \\ Underground Injection Control (UIC) \\ Permit Application \\ for the}

FutureGen Electric Power and Hydrogen Generating Plant

in

Coles County, Illinois

April 19, 2010 
Acknowledgment: This material is based upon work supported by the U.S. Department of Energy under Award Number DE-FC26-06NT42073.

Charitable Status: FutureGen Industrial Alliance, Inc. (the "Alliance") is a tax-exempt non-profit corporation under 501(c) (3) of the Internal Revenue Code. As such, any reduction in fees that vendors charge to the Alliance or actual donations made by vendors to the Alliance (a "charitable contribution"), may be tax deductible on the vendor's federal income tax return, based on the vendor's particular tax situation. We recommend you consult with your tax advisor to determine the availability of this benefit. The Alliance would be able to assist in providing appropriate documentation, where possible.

Disclaimer. This report was prepared as an account of work sponsored by an agency of the United States Government. Neither the United States Government nor any agency thereof, nor any of their employees, makes any warranty, express or implied, or assumes any legal liability or responsibility for the accuracy, completeness, or usefulness of any information, apparatus, product, or process disclosed, or represents that its use would not infringe privately owned rights. Reference herein to any specific commercial product, process, or service by trade name, trademark, manufacturer, or otherwise does not necessarily constitute or imply its endorsement, recommendation, or favoring by the United States Government or any agency thereof. The views and opinions of authors expressed herein do not necessarily state or reflect those of the United States Government or any agency thereof.

Contact Information:

FutureGen Industrial Alliance, Inc.

1001 Pennsylvania Avenue, NW

Sixth Floor

Washington, D.C. 20004

202-429-8430

Email: info@FutureGenAlliance.org

Homepage: www.FutureGenAlliance.org 


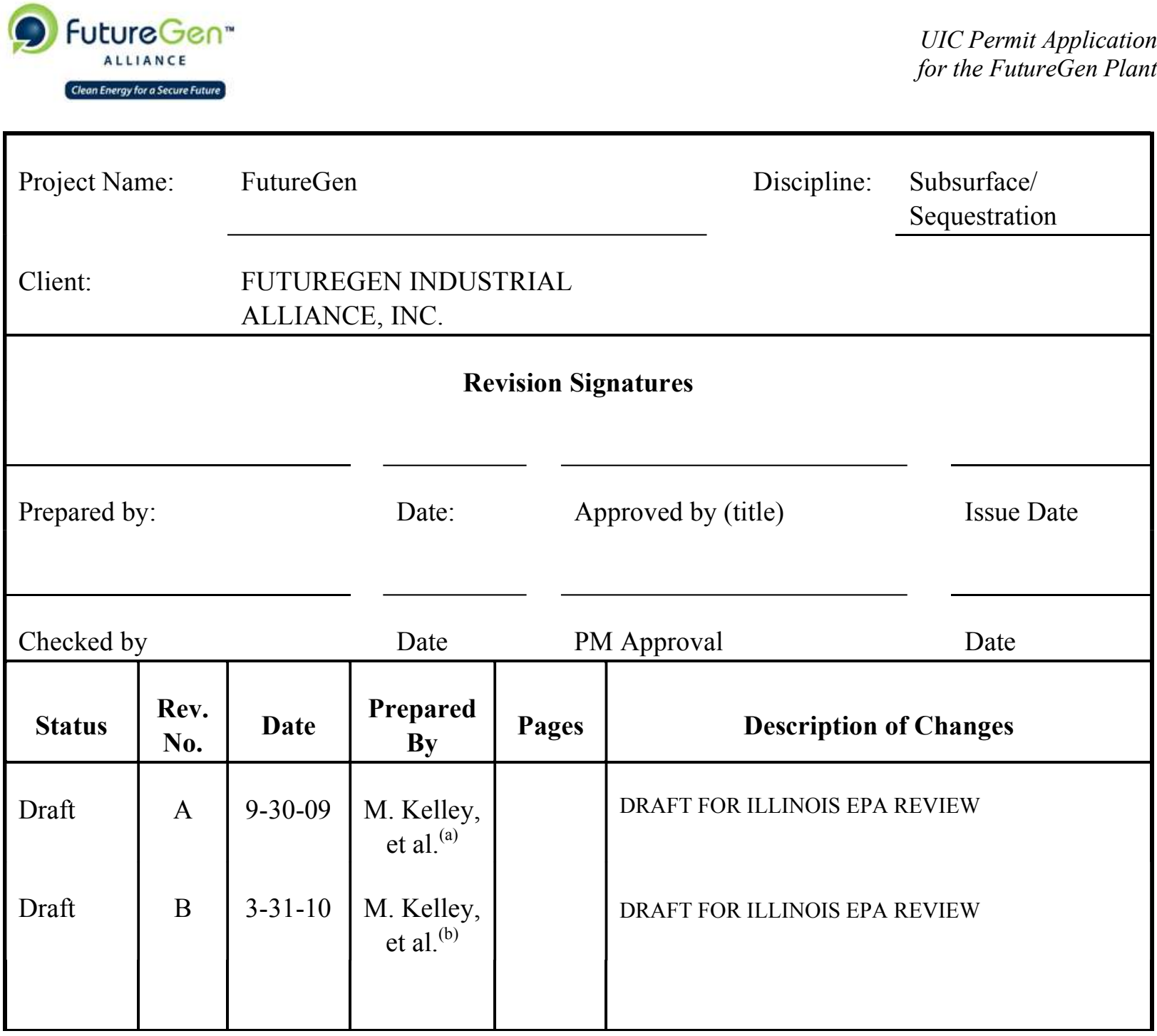

(a) Document authors include: Homero Casteneda (Battelle), John Coll, P.E. (Battelle), Michael Elliott (PNNL), Chris Gardner (Battelle), Christopher Murray, PhD (PNNL), Mark Stewart (PNNL), Timothy Williams (Battelle), Signe Wurstner (PNNL), Martin Zilka, P.E. (Battelle), and Patrick Engineering.

(b) Document authors include: Homero Casteneda (Battelle), John Coll, P.E. (Battelle), Michael Elliott (PNNL), Chris Gardner (Battelle), Christopher Murray, PhD (PNNL), Mark Stewart (PNNL), Timothy Williams (Battelle), Signe Wurstner (PNNL), Martin Zilka, P.E. (Battelle), and Patrick Engineering. 


\section{EXECUTIVE SUMMARY}

The FutureGen Project was conceived to support the initiatives and recommendations of the National Energy Policy (NEP) to foster technology for future low carbon emission power plants over the next decade, and to provide breakthroughs that would greatly reduce greenhouse gas emissions over the longer term. The lead organization for the project is the National Energy Technology Laboratory (NETL), a multi-purpose laboratory operated by the U.S. Department of Energy's (DOE's) Office of Fossil Energy. NETL has a mission to solve the environmental, supply, and reliability constraints of producing and using fossil energy resources to promote a stronger economy and a more secure future for America. The DOE goal for this project is to prove the technical feasibility and potential economic viability of co-production of electricity and hydrogen fuel from coal while capturing and sequestering carbon dioxide $\left(\mathrm{CO}_{2}\right)$ and greatly reducing other air emissions. The FutureGen Alliance, Inc., formed to partner with DOE on the FutureGen Project, is a non-profit consortium of some of the largest coal producers and electricity generators in the world. Member companies include Alpha Natural Resources, Anglo American Services Limited, BHP Billiton Energy Coal Inc., China Huaneng Group, CONSOL Energy, E.ON U.S. LLC, Peabody Energy Corporation, Rio Tinto Energy America Services, and Xstrata Coal. Collectively, these member companies have global operations serving customers across several continents, including Asia, Australia, Canada, Continental Europe, the People's Republic of China, South Africa, South America, and the United States.

This document seeks to obtain an Underground Injection Control (UIC) permit from the Illinois Environmental Protection Agency (IEPA) to authorize deep well injection of $\mathrm{CO}_{2}$ captured from the planned FutureGen Electric and Hydrogen Generating Plant (FutureGen facility), to be located in Coles County, Illinois. The Mattoon Site was initially considered for the FutureGen project after being proposed by a group consisting of the State of Illinois (through the Illinois Department of Commerce and Economic Opportunity), the City of Mattoon, Coles County, and Coles Together (an economic development organization). The proposed FutureGen facility is a prototype electric power and hydrogen generating plant that would employ coal gasification technology integrated with combined-cycle electricity generation to produce approximately 275 megawatts (MW) of electrical output. Low carbon emissions would be achieved by injecting the $\mathrm{CO}_{2}$ captured from the plant into deep wells for permanent geologic storage (sequestration), resulting in one of the cleanest coal-fueled power system in the world. The FutureGen Site consists of approximately 444 acres (180 hectares) of farmland located approximately 1 mile (1.6 kilometers) northwest of the City of Mattoon, in Coles County, Illinois. The proposed power plant and sequestration site would be located on the same parcel of land. The proposed site is bordered to the northeast by State Route 121 , to the north by E. County Rd. $900 \mathrm{~N}$, to the west by N. County Rd. $130 \mathrm{E}$, to the south by E. County Rd. $800 \mathrm{~N}$, and to the east by N. County Rd. 200E (Dole Road). A location map is shown in Figure ES-1.

The concept of geologic sequestration is illustrated in Figure ES-2. $\mathrm{CO}_{2}$ emissions would be separated at the plant, compressed into a (supercritical) liquid state, and delivered to a deep injection well via an underground pipeline. $\mathrm{CO}_{2}$ would be separated during the second stage of the syngas cleanup process (Section 4.2 of this application document provides more details about the operational areas of the power plant and their functions). The injection well would 


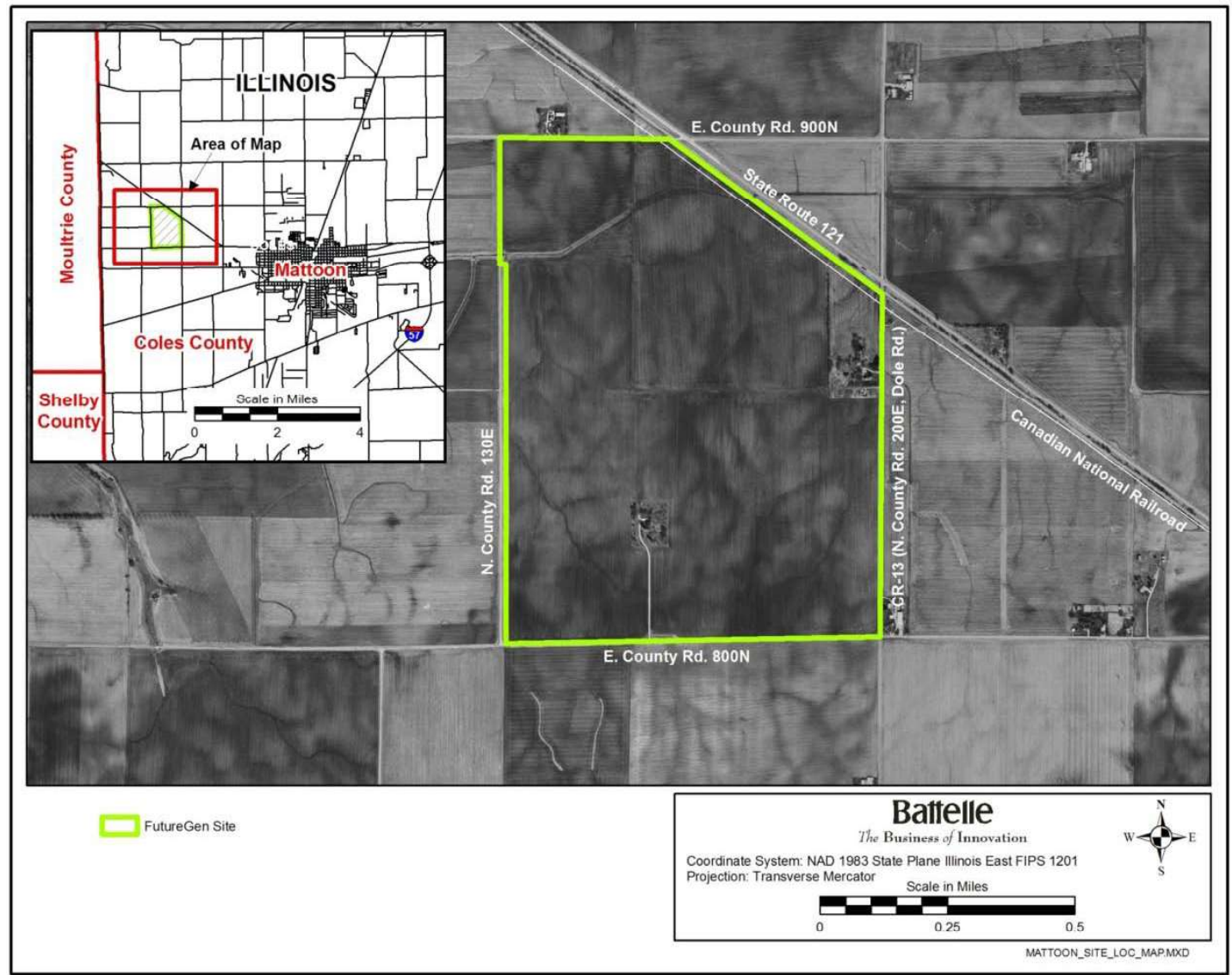

Figure ES-1. Location of the FutureGen Site, Coles County, Illinois

deliver the $\mathrm{CO}_{2}$ stream deep underground to a porous and permeable geologic formation containing only saltwater where it would be permanently stored. To ensure that the $\mathrm{CO}_{2}$ remains permanently in place, the storage layer is immediately overlain by a low permeability confining layer, or caprock, that prevents upward migration of the $\mathrm{CO}_{2}$ out of the storage reservoir. The storage reservoir underlying the FutureGen site is the approximately 1,600 ft thick Mt. Simon Sandstone. Overlying the Mt. Simon Formation is the approximately 500 to 700 $\mathrm{ft}$ thick low-permeability Eau Claire Formation, consisting primarily of shale and siltstone. Further protection against upward migration is provided by additional low-permeability formations, referred to as secondary seals, which occur above the Eau Claire caprock; these include the Ordovican-age Maquoketa Formation and the Devonian-age New Albany Formation. Low permeability granite rock underlies the Mt. Simon Formation, which will further help contain the injected $\mathrm{CO}_{2}$ within the Mt. Simon Sandstone. Both the Mt. Simon Formation and the Eau Claire Formation extend over much of the Midwestern United States. Based on data from the Illinois Geological Survey (ISGS), the Mt. Simon is estimated to occur between depths of 7,353 and $8,996 \mathrm{ft}$ (1.39 to 1.7 miles) below ground surface (bgs) at the planned FutureGen site in Coles County. The Eau Claire Formation is estimated to occur between depths of 6,705 and $7,353 \mathrm{ft}$ bgs (1.27 to 1.39 miles). The actual depth interval for the Mt. Simon Formation, as well as the actual depths for the injection interval(s) within the Mt. Simon, will be identified after drilling, geophysical logging, and hydraulic testing are completed on the injection well and/or characterization wells. Section 3.9 of this permit application describes examples of 


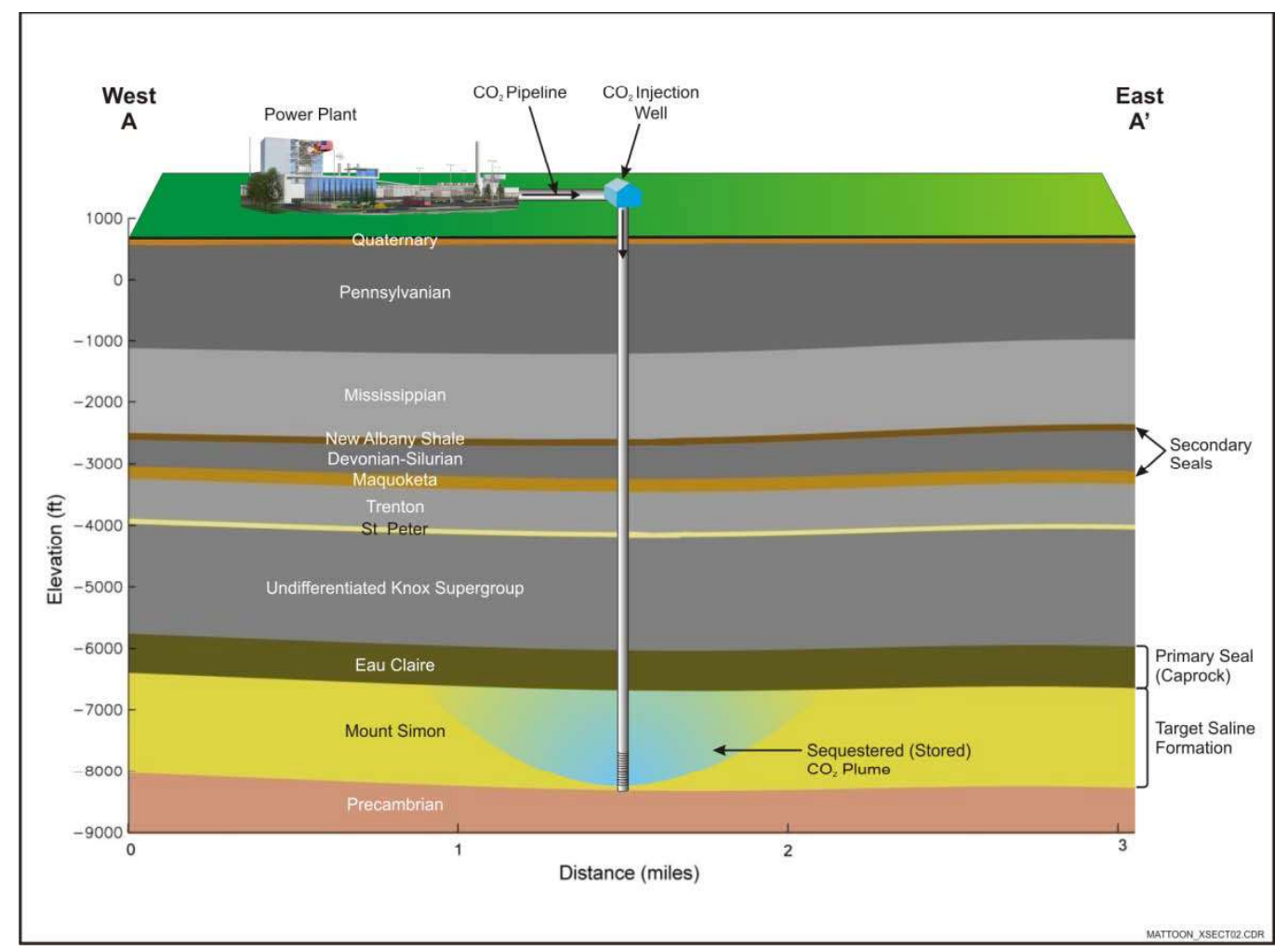

Figure ES-2. Illustration of Geologic Sequestration

characterization activities (geophysical logging, coring, testing) that may be conducted during drilling. The Mt. Simon Formation does not contain useable (potable) water and thus is not an underground source of drinking water (USDW). In general, useable groundwater in the vicinity of the site is normally obtained from sand and gravel deposits that are contained within the unconsolidated Quaternary-age sands and gravels above bedrock. In the vicinity of the planned site, these materials range in depth from about 25 to $125 \mathrm{ft}$ bgs (see Section 2.7.2). As part of this permit application, a well search was conducted for a 2.5 mile area surrounding the site (i.e., the area extending 2.5 miles in all directions from the site) to identify all water wells near the site; results of this search confirmed that groundwater in the county is normally obtained from sand and gravel aquifers that are contained in unconsolidated material above bedrock (see Section 5).

Two seismic surveys have already been conducted at the FutureGen site to help characterize the geology beneath the site and to evaluate its suitability for injecting and storing $\mathrm{CO}_{2}$. Most recently in 2008, 29.6 miles of two-dimensional (2D) seismic data were acquired, including 16.6 miles with standard geophones and 13.0 miles using three-component (3C) geophones. The $3 \mathrm{C}$ geophones allowed for enhanced analysis because they record reflected shear wave (P-SV) images as well as the compressional wave (P-P) images recorded using the standard geophones. Interpretations of both the P-P and P-SV data provide no evidence that faults are present that cut the Mt. Simon interval and breach its top seal (see Section 2). This is an important finding because it suggests that faults that could act as natural leakage pathways and allow $\mathrm{CO}_{2}$ to migrate out of the storage reservoir are not present. These findings are consistent with an earlier, less extensive 2D seismic survey that was conducted by the ISGS. Further 
interpretation of the 2D seismic data will be possible once the well is drilled and a specific type of geophysical log is run to provide velocity data for the subsurface layers.

In addition to an absence of faults in the vicinity of the site, the well search that was conducted for this application determined that there are no unplugged wells within the $2 \frac{1}{2}$ mile Area of Review (AOR) that penetrate the injection zone (Mt. Simon Formation) or the Primary Seal (Eau Claire Formation) (Section 5.5.2). The deepest unplugged well located in the AOR is a gas well that has a depth of $3,254 \mathrm{ft}$, and is located approximately 2.8 miles from the center of the FutureGen site. The deepest plugged well is a dry and abandoned well that is $3,585 \mathrm{ft}$ deep, and approximately 0.7 miles from the injection site. Thus, no wells are present in the vicinity of the site that could be potential pathways for $\mathrm{CO}_{2}$ migration out of the storage reservoir.

Approximately 1.95 million metric tons [MMT] of $\mathrm{CO}_{2}$ per year would be sequestered at this site over a 4-year period. This estimate is based on a peak daily production rate of 6,312 metric tons per day (the actual $\mathrm{CO}_{2}$ production rate may be less depending on coal type and gasifier technology that is employed) and assumes two 28-day plant shutdowns per year. A rate of 6,312 metric tons per day corresponds to an estimated volumetric flow rate of $394,949 \mathrm{ft}^{3} /$ day; the volumetric flow rate is an estimate because the actual density of the product is uncertain (Section 7.3). Reservoir modeling and well design analyses indicate that the $\mathrm{CO}_{2}$ output from the plant can be injected into a single deep well in the Mt. Simon Formation (Section 3); however, a second (backup) well is planned in the event that a single well cannot accommodate $100 \%$ of the plant output of $\mathrm{CO}_{2}$ or if the primary well needs to be taken out of service for an extended period of time. Preliminary locations for the primary and alternate injection wells have been identified on the plant property; however, these may need to be adjusted to accommodate changes to the plot plan for the power plant. Consequently, an area UIC permit is being requested so that the well can be placed anywhere on the plant property. The injection well will inject $\mathrm{CO}_{2}$ through tubing (i.e., pipe) that extends to the injection interval(s) within the Mt. Simon Formation. The tubing string will include a packer, positioned near the bottom of the string but above the injection interval, to ensure $\mathrm{CO}_{2}$ exits the well only at the injection interval(s). Above the packer, the tubing string will be surrounded by annular fluid to help reduce differential pressure across the packer and tubing and to allow a means for monitoring for leaks in the tubing and/or packer. The injection tubing will be 5-1/2 inch outer diameter (O.D.) inside of a 9$5 / 8$ inch O.D. long-string casing that extends to the bottom of the Mt. Simon Formation and is cemented to surface. Both the primary injection well and the alternate well will be located on the FutureGen site property. The expected area of the Mt. Simon Formation containing $\mathrm{CO}_{2}$ after 4 years of injection at this rate is approximately 306 acres; this is equivalent to a circular area with a radius of 0.39 miles.

Monitoring will be a major component of the geologic sequestration program at the FutureGen site. Numerous types of monitoring will be undertaken, including methods to measure the amount of $\mathrm{CO}_{2}$ injected, methods to image and track the location of $\mathrm{CO}_{2}$ within the storage reservoir, methods to detect the potential for $\mathrm{CO}_{2}$ leakage at the land surface, and methods to monitor for impacts to USDWs. Most types of monitoring will begin before $\mathrm{CO}_{2}$ injection starts to establish baseline conditions that can be used as a reference for comparison to monitoring data collected after injection begins. In accordance with the UIC permit application instructions, this document describes specific aspects of the monitoring program, including: regular sampling and analysis of the injection fluid (Section 6.1), the program for monitoring the injection process (i.e., injection rate, pressure, temperature) (Section 6.2.1), and the planned USDW monitoring 
program (Section 6.2.2 and 6.2.3). It also includes the planned program for monitoring the integrity of the injection wells to ensure that they continue to operate properly and do not leak $\mathrm{CO}_{2}$ into the zones outside the storage reservoir (Section 6.3) and a plan to monitor the potential for corrosion of key well components such as casing and tubing (Section 6.5). A comprehensive monitoring program is currently being developed that will determine other types of monitoring that will be conducted in addition to the types required by this UIC permit application. Some types of monitoring may require wells to be installed in the Mt. Simon storage reservoir; therefore, a design for injection reservoir monitoring wells has been included in this document (Section 4) in accordance with the IEPA instructions for preparing a UIC permit application. These wells would be similar in depth to the injection wells but would be used to support monitoring rather than for injection.

DOE-sponsored activities under the FutureGen Project would include 4 years of plant operation and $\mathrm{CO}_{2}$ injection plus 2 years of additional monitoring of the sequestered $\mathrm{CO}_{2}$ afterwards. After the DOE-sponsored research activities (see Section 2.2) conclude, it is generally expected that the plant would continue to operate for at least 20 to 30 years and possibly up to 50 years. The FutureGen Alliance and DOE will develop a disposition plan that addresses the future management and operation of the power plant after their involvement ends. 


\section{CONTENTS}

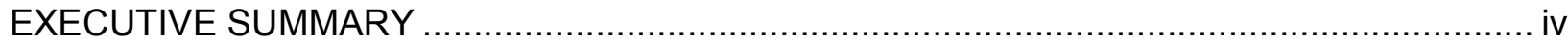

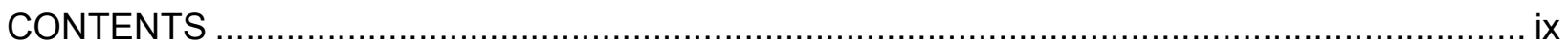

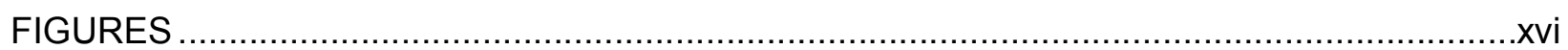

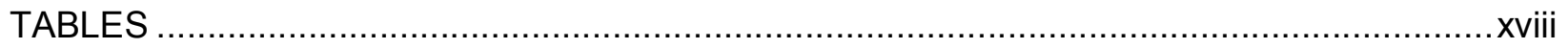

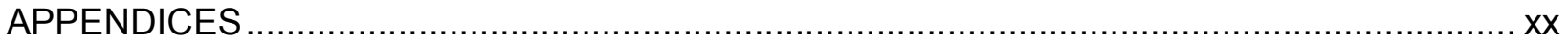

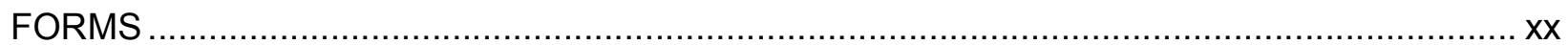

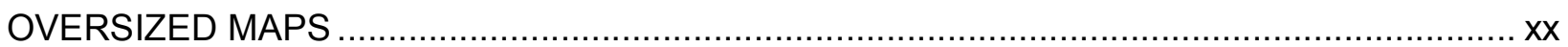

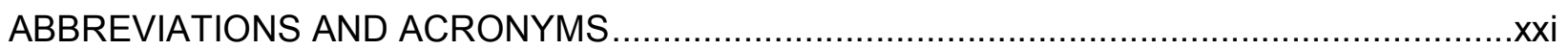

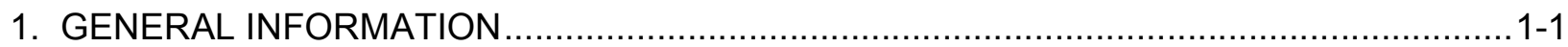

2. HYDROGEOLOGIC INFORMATION (Form 4a) .................................................. $2-4$

2.1 Elevation of Land Surface at Well Location ............................................................ 2-4

2.2 Faults, Known or Suspected Within the Area of Review .....................................2-4

2.3 Maps and Cross Sections as Required by Section 730.114 (a) or $730.134(a) \ldots \ldots \ldots . .2-4$

2.4 Injection Zone ......................................................................................... $2-4$

2.4.1 Geologic Name(s) of Injection Zone ................................................ $2-9$

2.4.2 Depth Interval of Injection Zone Beneath Land Surface ............................. 2-9

2.4.3 Characteristics of the Injection Zone ..................................................... $2-11$

2.4.3.1 Lithologic Description...................................................... $2-11$

2.4.3.2 Injection Zone Thickness Available to Accept Waste .....................2-11

2.4.3.3 Fracture Pressure at Top of Injection Zone ............................... 2-12

2.4.3.4 Effective Porosity ..................................................................... 2-12

2.4.3.5 Intrinsic Permeability................................................................ $2-13$

2.4.3.6 Hydraulic Conductivity or Permeability ...................................... 2-14

2.4.3.7 Storage Coefficient ............................................................. 2-15

2.4.3.8 Seepage Velocity (ft/yr) and Flow Direction of Formation Water ....2-15

2.4.4 Characteristics of Injection Zone Formation Water ................................... $2-18$

2.4.4.1 Temperature .................................................................... $2-18$

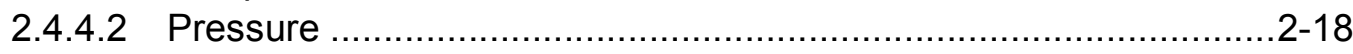

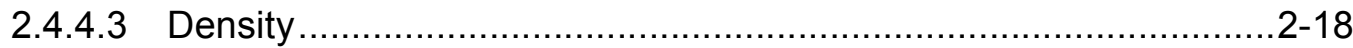

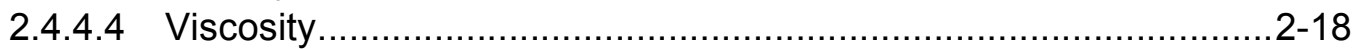

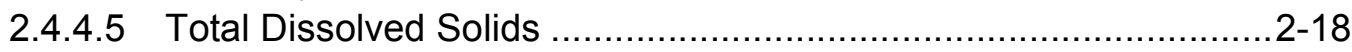

2.4.4.6 Potentiometric Surface ........................................................ 2-20

2.4.5 Additional or Alternative Zones Considered for Injection............................2-20

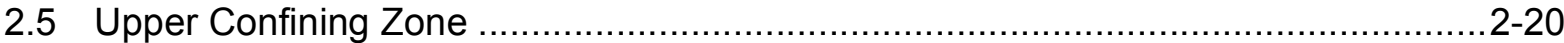

2.5.1 Geologic Name(s) of Confining Zone ................................................2-20

2.5.2 Depth Interval of Upper Confining Zone Beneath Land Surface ..................2-20

2.5.3 Characteristics of Confining Zone ......................................................... 21

2.5.3.1 Lithologic Description.......................................................... 2-21

2.5.3.2 Fracture Pressure at Depth ................................................. 2-21

2.5.3.3 Intrinsic Permeability ....................................................... 2 -22

2.5.3.4 Hydraulic Conductivity .....................................................2-22 
2.5.3.5 Alternative Confining Zones Proposed, Include Explanation and Depth Interval(s) ....................................................22

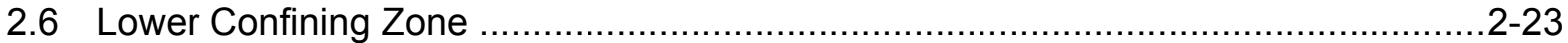

2.6.1 Geologic Name(s) of Confining Zone ...............................................2-23

2.6.2 Depth Interval of Lower Confining Zone Beneath Land Surface ..................2-23

2.6.3 Characteristics of Confining Zone ................................................... $2-23$

2.6.3.1 Lithologic Description.......................................................... 23

2.6.3.2 Fracture Pressure at Depth ..............................................2-23

2.6.3.3 Intrinsic Permeability...................................................... $2-23$

2.6.3.4 Hydraulic Conductivity ..................................................... $2-24$

2.6.3.5 Alternative Confining Zones Proposed ....................................2-25

2.7 Overlying Sources of Groundwater at the Site .....................................................2-25

2.7.1 Characteristics of the Aquifer Immediately Overlying the Confining Zone ....2-25

2.7.1.1 Elevation at Top of Aquifer ..................................................2-25

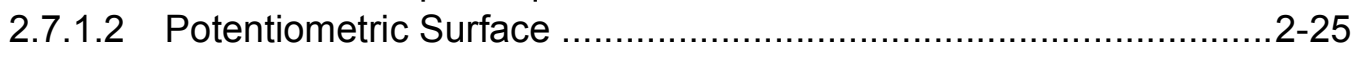

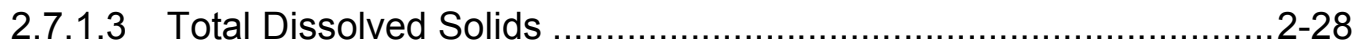

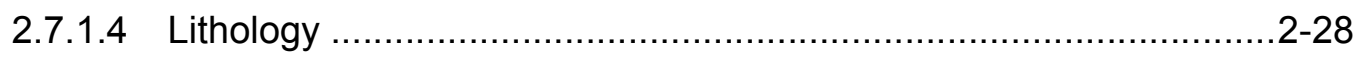

2.7.1.5 Aquifer Thickness ........................................................... $2-28$

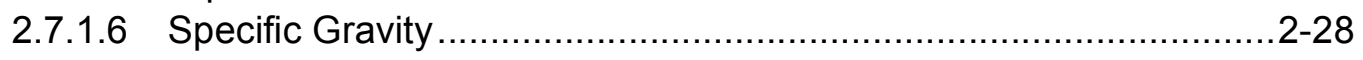

2.7.2 Underground Sources of Drinking Water..............................................2-28

2.7.2.1 Maps and Cross Sections Required by 730.114(a)(4) or

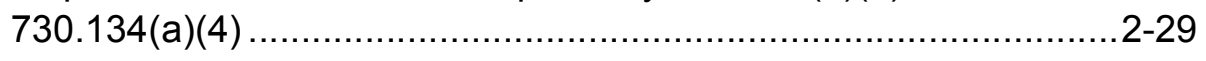

2.7.2.2 Lowest Depth of Underground Source of Drinking Water

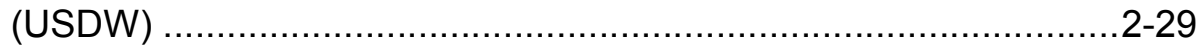

2.7.2.3 Elevation of Potentiometric Surface of Lowest USDW Referenced to Mean Sea Level .............................................2-29

2.7.2.4 Distance to Nearest Water Supply Well.....................................2-31

2.7.2.5 Distance to Nearest Downgradient Water Supply Well ................. 2-31

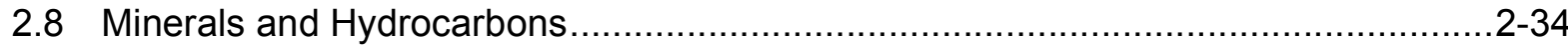

2.8.1 Mineral or Natural Resources Beneath or Within 5 miles of the Site............2-34

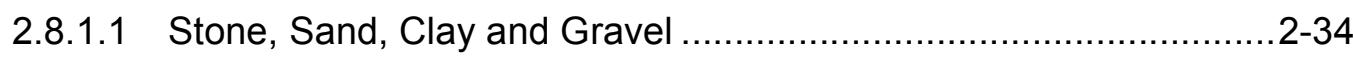

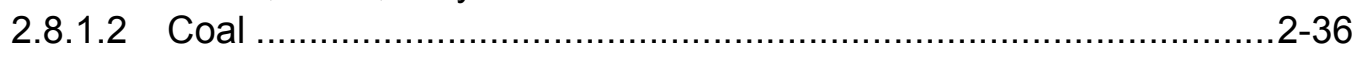

2.8.1.3 Oil and Gas ........................................................................

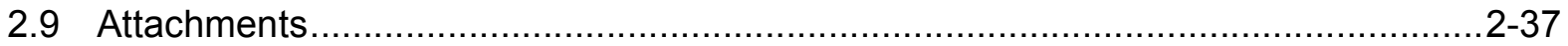

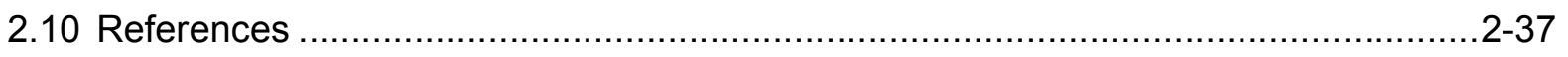

3. INJECTION WELL DESIGN, CONSTRUCTION TESTS, AND LOGS (Form 4b)...............3-3

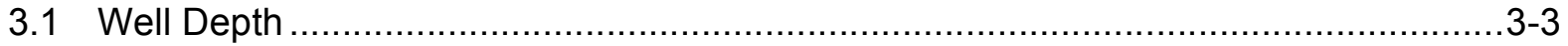

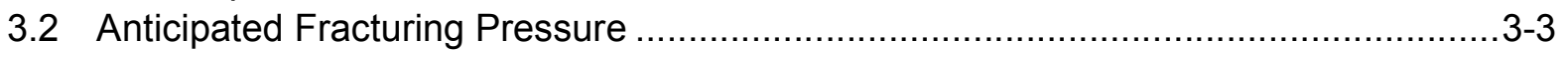

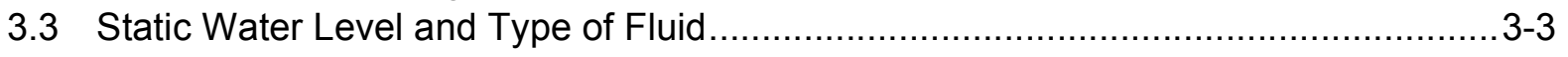

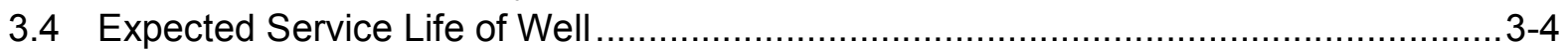

3.5 Injection Well Completion ............................................................................ $3-5$

3.6 Schematic or Other Appropriate Drawing of the Surface and Subsurface

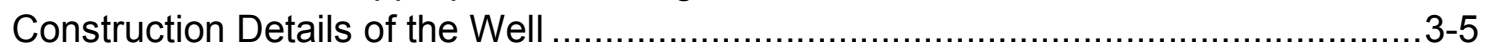

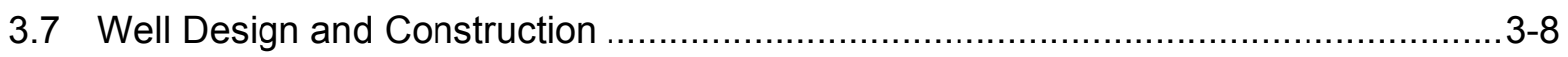

3.7.1 Well Hole Diameters and Corresponding Depth Intervals .......................... 3-8 


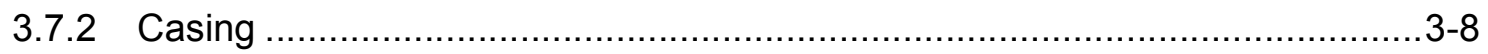

3.7.2.1 Conductive Casing.............................................................. $3-9$

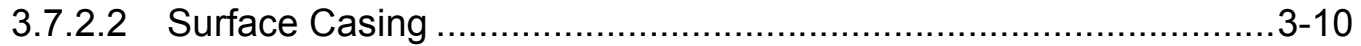

3.7.2.3 Intermediate Casing(s) ........................................................... $3-12$

3.7.2.4 Long-String Casing .................................................................... $3-14$

3.7.2.5 Other Casing ....................................................................... $3-14$

3.7.3 Injection Tubing ……...................................................................

3.7.3.1 Maximum Allowable Suspended Weight Based on Joint Strength of Injection Tubing ........................................................ 3-17

3.7.3.2 Weight of Injection Tubing String (Axial Load) in Air .....................3-18

3.7.4 Cement ........................................................................

3.7.4.1 Conductive Casing ................................................................ $3-18$

3.7.4.2 Surface Casing .................................................................. $3-18$

3.7.4.3 Intermediate Casing ............................................................... $3-18$

3.7.4.4 Long-String Casing ................................................................. $3-19$

3.7.4.5 Other Casing ....................................................................... $3-20$

3.7.4.6 Cementing Techniques, Equipment Positions, and Staging

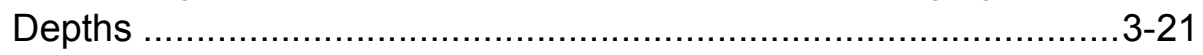

3.7.4.7 Perforation Depths ………………………….......................

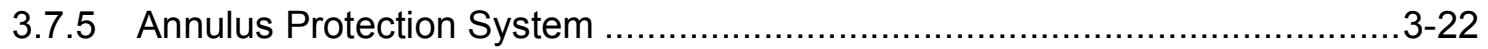

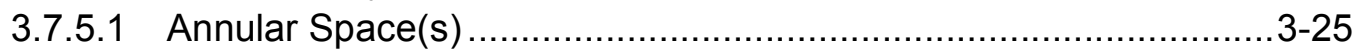

3.7.5.2 Type of Annular Fluid(s) ....................................................... $3-25$

3.7.5.3 Specific Gravity of Annular Fluid(s) ………................................ $3-25$

3.7.5.4 Type of Additive(s) and Inhibitor(s) .......................................... $3-25$

3.7.5.5 Expansion Coefficient of Annular Fluid(s)................................... $3-26$

3.7.5.6 Packer or Fluid Seal ............................................................ $3-26$

3.7.5.6.1 Packer(s) .............................................................. $3-26$

3.7.5.6.2 Fluid Spotting Procedure, Frequency, and Quantity .....3-26

3.8 Information on Well Drilling Company Used During Construction .............................3-27

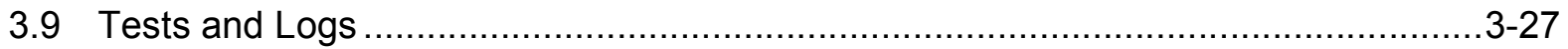

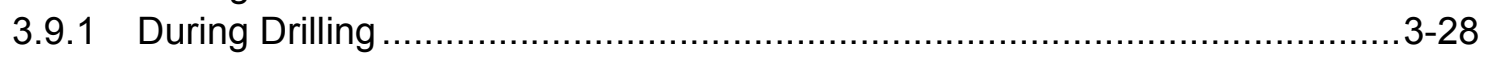

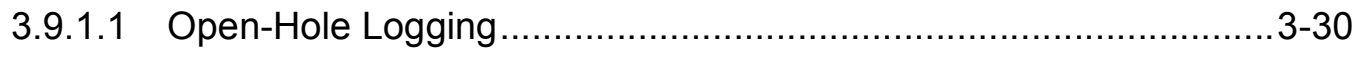

3.9.1.2 Rock Coring and Analysis...................................................... $3-32$

3.9.1.3 Fluid Sampling ................................................................. $3-33$

3.9.1.4 Open-Hole Injection Testing to Determine Formation Fracture

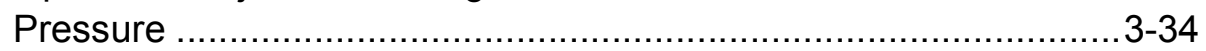

3.9.1.5 Other Types of Open-Hole Reservoir Tests ...............................3-35

3.9.1.6 Cased-Hole Logging ...............................................................3-35

3.9.2 During and After Casing Installation Drilling …........................................3-35

3.9.2.1 Well Completion................................................................... $3-35$

3.9.2.2 Injection Testing................................................................ $3-36$

3.9.3 Demonstration of Mechanical Integrity ………....................................3-37

3.9.4 Copies of the Logs and Tests Listed Above ............................................3-38

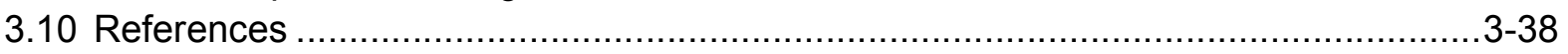


4. OPERATION PROGRAM AND SURFACE FACILITIES (Form 4C) ...............................4-3

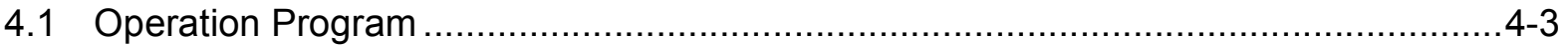

4.1.1 Area Injection Project ………......................................................... 4

4.1.1.1 Maximum Fluid to be Injected Per Day .......................................4-3

4.1.1.2 Years Remaining in Area Injection Project .....................................4-3

4.1.1.3 Anticipated Total Number of Injection Wells Required .....................4-3

4.1.1.4 Injection Wells Operate With/Without Common Manifold .................4-3

4.1.1.5 Number of Injection Zone Monitoring Wells, Include List and Schematics ................................................................................ $4-4$

4.1.1.6 Number of, Name, and Location of Injection Wells Currently In Project.............................................................................

4.1.2 Single Injection Well ........................................................................ 4

4.1.2.1 Number or Name of Well ......................................................... $4-4$

4.1.2.2 Location ............................................................................. 4

4.1.2.3 Expected Service Life ........................................................... $4-8$

4.1.2.4 Operation During 24-Hour Period .................................................4-8

4.1.2.5 Operation Days Per Month ......................................................... $4-8$

4.1.2.6 Injection Pressure, Average, and Maximum ...................................4-8

4.1.2.7 Injection Rate, Average, and Maximum .........................................4-8

4.1.2.8 Casing Tubing Annulus Pressure, Average, and Maximum .............4-9

4.1.2.9 Other Annulus Pressure ........................................................... $4-9$

4.1.2.10 Number of Injection Zone Monitoring Wells, Include

Schematics .......................................................................... 4

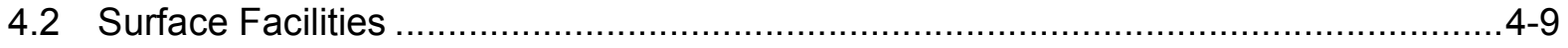

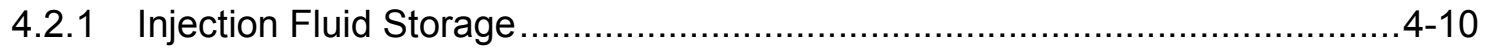

4.2.1.1 Storage Capacity in Days and Gallons ..................................... 4-10

4.2.1.2 Type of Storage Facility(s) ....................................................4-10

4.2.1.3 Storage Capacity in Case of Well Failure ……............................4-10

4.2.2 Holding Tanks and Flow Lines ..........................................................4-10

4.2.3 Process and Instrumentation Diagram Attachment .....................................4-11

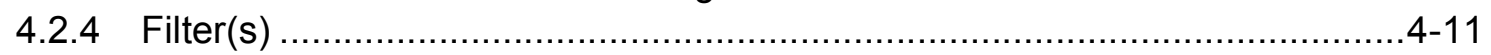

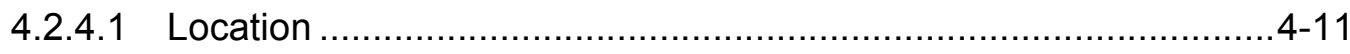

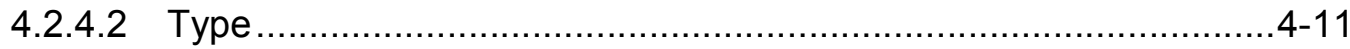

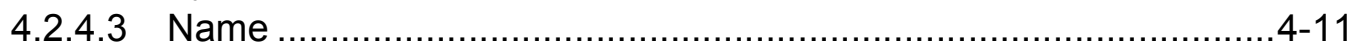

4.2.4.4 Model Number ................................................................ $4-11$

4.2.4.5 Capacity, Gallons Per Minute ................................................. $4-11$

4.2.4.6 Pore Size, microns............................................................ $4-11$

4.2.5 Injection Pump(s).....................................................................

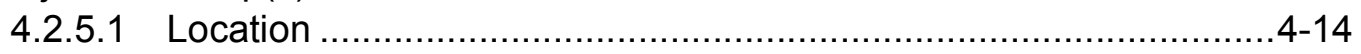

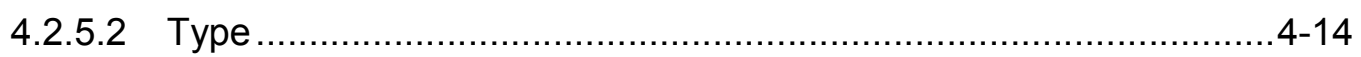

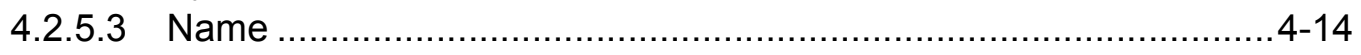

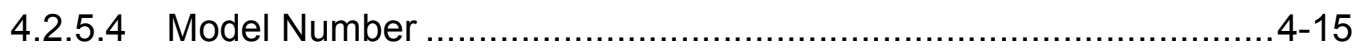

4.2.5.5 Capacity, Gallons Per Minute ……………………………..... $4-15$

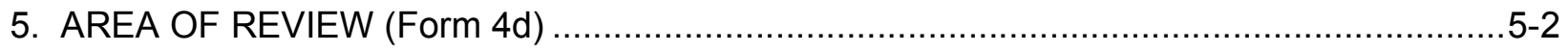

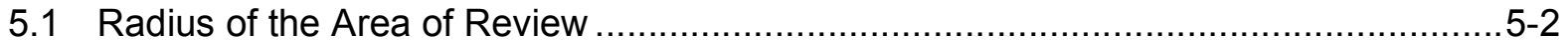


5.2 Method of Radius Determination ............................................................... 5-2

5.3 Map with Information Required by Section 730.114(a)(2) or 730.134(a)(2) ...............5-2

5.4 Description of Anticipated Injection Fluid Movement During the Life of the Project.

5.4.1 Simulation Software Description and General Assumptions ........................5-4

5.4.2 Site Specific Assumptions and Methodology ............................................5-5

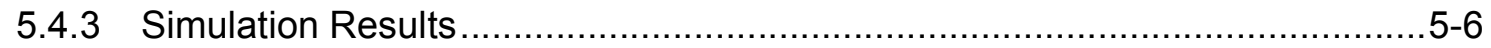

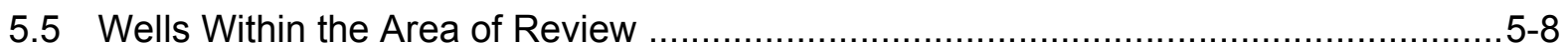

5.5.1 Tabulation of Well Data Required by $730.114(a)(3)$ or $730.134(a)(3) \ldots \ldots \ldots \ldots . .5-8$

5.5.2 Number of Wells Within $2 \frac{1}{2}$ Miles of Injection Well Penetrating Within 300 Feet of the Uppermost Injection Zone ............................................... 5-9

5.5.2.1 Properly Plugged and Abandoned ............................................. $5-9$

5.5.2.2 Temporarily Abandoned …………………….......................... $5-9$

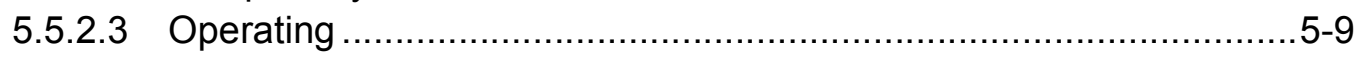

5.5.2.4 Improperly Sealed, Completed, or Abandoned............................... 5-9

5.5.3 Plugging Affidavits for All Plugged Wells.................................................. 5-9

5.5.4 Proposed Corrective Action for Unplugged Wells Penetrating the

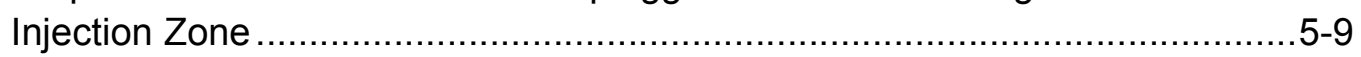

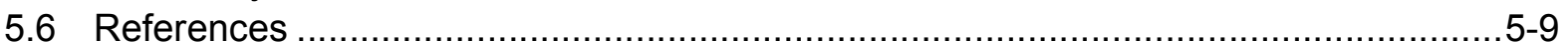

6. MONITORING, INTEGRITY TESTING, AND CONTINGENCY PLAN (Form 4e)..............6-2

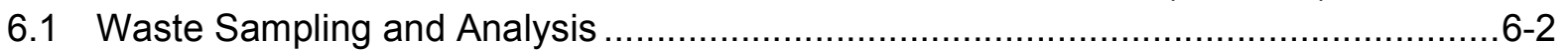

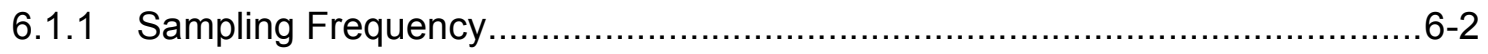

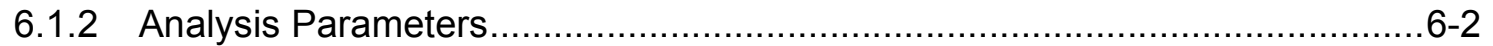

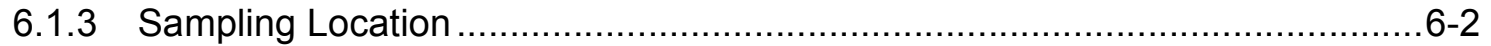

6.1.4 Detailed Waste Analysis Plan................................................................. $6-3$

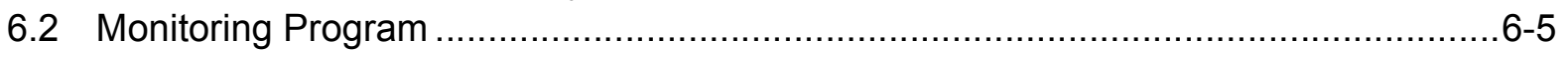

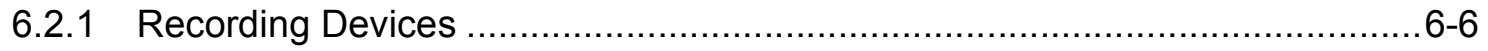

6.2.1.1 Injection Pressure Gauges ……………................................6-6

6.2.1.2 Casing-Tubing Annular Pressure Gauges ...................................6-7

6.2.1.3 Flow Meters ................................................................................

6.2.1.4 pH Recording Devices ............................................................ $6-8$

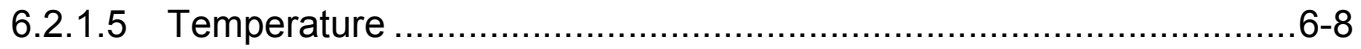

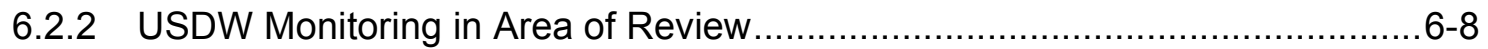

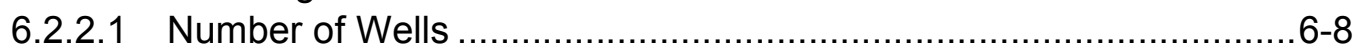

6.2.2.2 Type of Wells ......................................................................

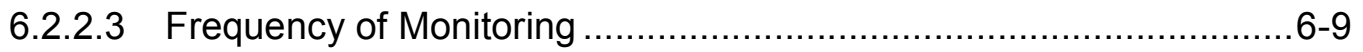

6.2.2.4 Types of Samples ..................................................................

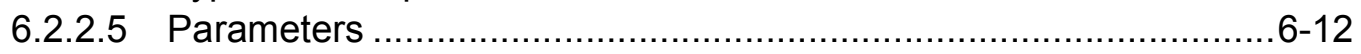

6.2.2.6 Map of Well Location and Logs ...............................................6-12

6.2.3 Detailed Groundwater Monitoring Plan................................................... $6-14$

6.2.3.1 Project Definition and Objectives ..............................................6-14

6.2.3.2 Geochemical Parameters ......................................................... $6-14$

6.2.3.3 Groundwater Sample Collection ................................................ 6-15

6.2.3.3.1 Water Level Measurements ....................................6-15

6.2.3.3.2 Well Purging Procedures …………………………....6-16 
6.2.3.4 Sample Collection Procedures ……………….......................... 6-17

6.2.3.5 Sample Chain of Custody ……………....................................

6.2.3.6 Field Quality Control ...............................................................

6.2.3.7 Laboratory Quality Control ...................................................... $6-18$

6.2.3.8 Data Review and Validation ...................................................... $6-18$

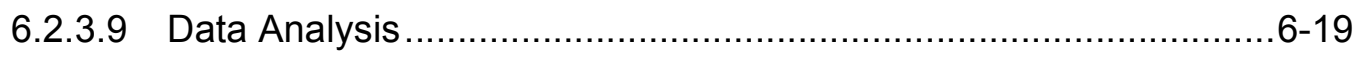

6.2.3.9.1 Determination of Background Values..........................6-19

6.2.3.9.2 Comparisons to Background Values ............................6-19

6.2.3.9.3 Criteria for Determining when Background Values are Exceeded and Response Actions ..............................6-20

6.3 Mechanical Integrity Tests During Service Life of Well.........................................6-20

6.3.1 Continuous Monitoring of Annular Pressure ............................................6-20

6.3.2 External Mechanical Integrity Testing .................................................... 6-21

6.3.2.1 Temperature Logging ………………………....................... $6-21$

6.3.2.2 Pulsed Neutron Capture (PNC) Logging ………........................6-22

6.3.2.3 Radioactive Tracer Logging .....................................................6-23

6.4 Contingency Plan for Well Failure or Shut In ...................................................6-27

6.4.1 Description of Control and Alarm System for the Well Monitoring

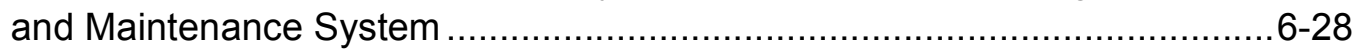

6.4.1.1 Control System Overview ………………….......................... $6-28$

6.4.1.2 Annular Fluid Pressure Control.................................................6-28

6.4.1.3 Injection Process Control ........................................................... 6-29

6.4.2 Automatic Shutdown Procedure ............................................................ $6-30$

6.4.2.1 Process Alarms (Non-shutdown) …………….......................... $6-30$

6.4.2.2 Shutdown Alarms ............................................................... $6-30$

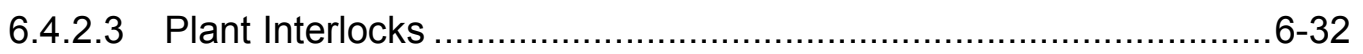

6.4.2.4 Automatic Shutdown Sequence ............................................... 6-32

6.4.3 Persons Designated to Oversee Well Operations .......................................6-32

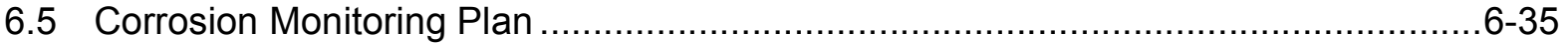

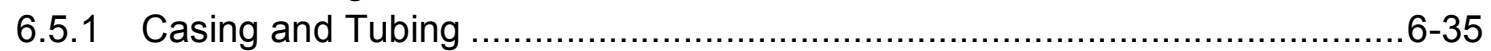

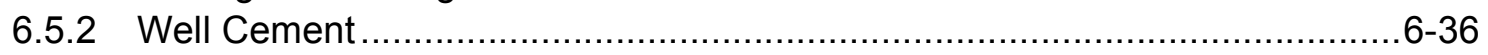

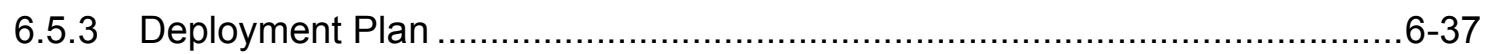

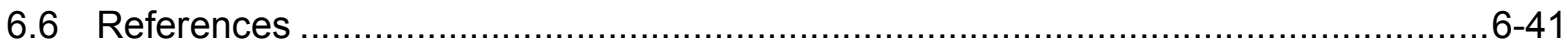

7. CHARACTERISTICS, COMPATIBILITY AND PRE-INJECTION TREATMENT OF

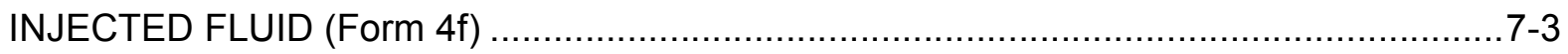

7.1 Component Streams Forming Injection Fluid ……............................................

7.2 Source and Generation Rate of Component Streams ............................................

7.3 Volume of Injection Fluid Generated Daily and Annually.........................................

7.4 Physical and Chemical Characteristics of Injection Fluid ........................................

7.4.1 Generic Waste/Fluid Name .....................................................................

7.4.2 Fluid Phase

7.4.3 Complete Waste Analysis.....................................................................

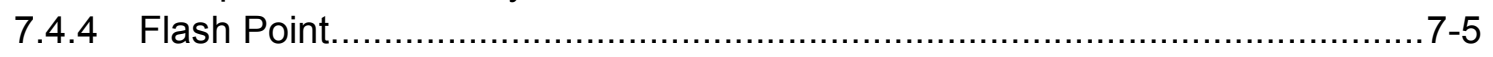

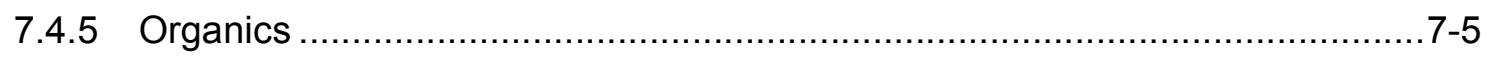

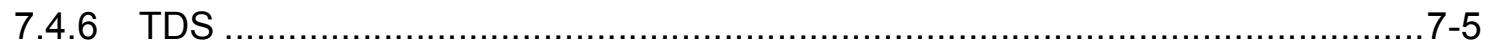




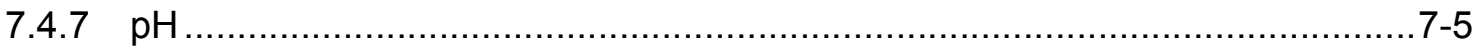

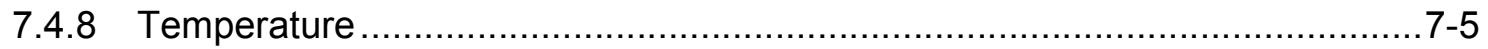

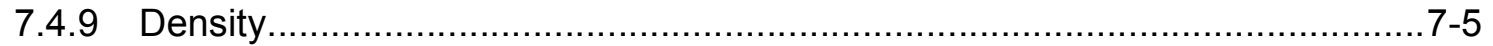

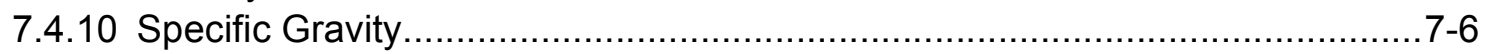

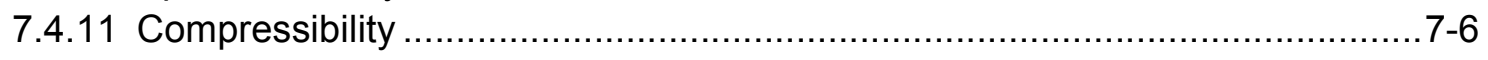

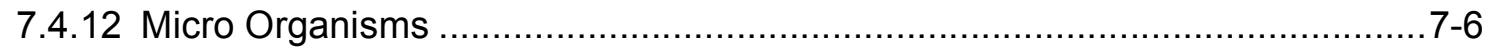

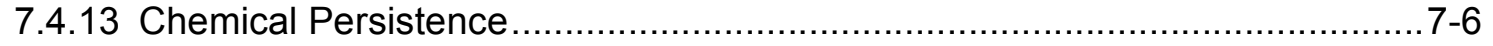

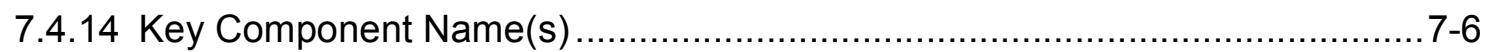

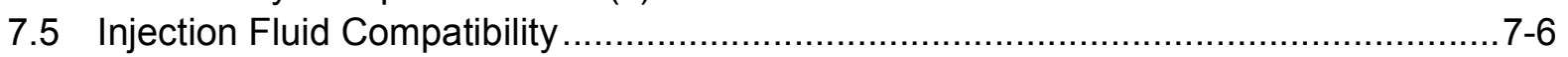

7.5.1 Compatibility with Injection Zone ...........................................................

7.5.2 Compatibility with Minerals in the Injection Zone ........................................ 7-7

7.5.3 Compatibility with Minerals in the Confining Zone ........................................77

7.5.4 Compatibility with Injection Well Components .............................................

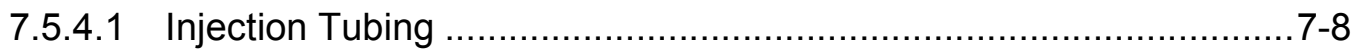

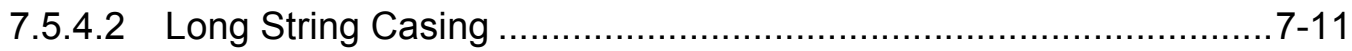

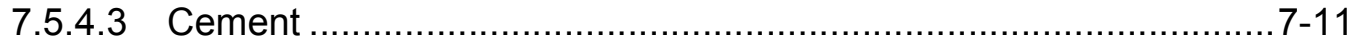

7.5.4.4 Annular Fluid..........................................................................

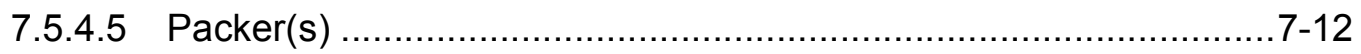

7.5.4.6 Well Head Equipment ..........................................................

7.5.4.7 Holding Tanks(s) and Flow Lines ............................................. $7-13$

7.5.5 Compatibility with Filter and Filter Components ......................................

7.5.6 Full Description of Compatibility Concerns …………...................................

7.5.7 Pre-Injection Fluid Treatment ............................................................

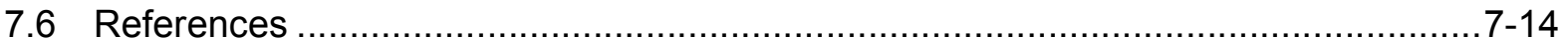

8. PLUGGING AND ABANDONMENT PROCEDURES (Form 4g) ……......................... 8 -2

8.1 Description of Plugging Procedures for Injection Well........................................... 8-2

8.1.1 Injection Well Abandonment During Construction ...................................... 8-2

8.1.2 Injection Well Abandonment After Injection ............................................ 8-5

8.1.3 Type and Quantity of Plugging Materials, Depth Intervals …....................... 8-5

8.1.4 Detailed Plugging and Abandonment Procedures......................................8-5

8.1.5 Cost Estimate for Plugging and Abandonment.......................................... 8-6

8.2 Description of Plugging Procedures for Injection Reservoir Monitoring Well............... 8-7

8.2.1 Injection Reservoir Monitoring Well Abandonment During Construction .........8-8

8.2.2 Injection Reservoir Monitoring Well Abandonment After Construction .............8-9

8.2.3 Type and Quantity of Plugging Materials, Depth Intervals …....................... 8-9

8.2.4 Detailed Plugging and Abandonment Procedures.................................... 8-9

8.2.5 Cost Estimate for Plugging and Abandonment...................................... 8-10

8.3 Description of Plugging Procedures for USDW Well ............................................. 8-10

8.3.1 USDW Well Abandonment During Construction ........................................ 8-10

8.3.2 USDW Well Abandonment After Construction .......................................... 8-11

8.3.3 Type and Quantity of Plugging Materials, Depth Intervals ......................... 8-11

8.3.4 Detailed Plugging and Abandonment Procedures.....................................8-11

8.3.5 Cost Estimate for Plugging and Abandonment.........................................8-12 


\section{FIGURES}

Figure ES-1. Location of the FutureGen Site, Coles County, Illinois ES-V

Figure ES-2. Illustration of Geologic Sequestration. ES-vi

Figure 1-1. Area of Review Map for the FutureGen Site ..1-4

Figure 2-1. Seismic Program Implemented at Mattoon Shown on an Aerial Photograph of the Area

Figure 2-2. Line 1. (a) No interpretation. (b) With interpretation. Intra-basement faults are shown in red. Blue horizon $=$ Base of Knox. Green horizon $=$ Top of Mt. Simon. Yellow horizon $=$ Top of Precambrian.

Figure 2-3. Line 2. (a) No interpretation. (b) With interpretation. Intra-basement faults are shown in red. Blue horizon $=$ Base of Knox. Green horizon $=$ Top of Mt. Simon. Yellow horizon $=$ Top of Precambrian.

Figure 2-4. Line 5. (a) No interpretation. (b) With interpretation. Intra-basement faults are shown in red. Blue horizon $=$ Base of Knox. Green horizon $=$ Top of Mt. Simon. Yellow horizon $=$ Top of Precambrian.

Figure 2-5. Index Map Showing Location of Perpendicular Cross-Sections in Figures 2-6 and 2-7 that Illustrate the Structural Dips and the Stratigraphic

Thickness of Units at the Mattoon Site

Figure 2-6.

Figure 2-7.

West-East Structural Cross-Section through the Mattoon Site.

$2-10$

Figure 2-8.

North-South Structural Cross-Section through the Mattoon Site

Thickness Map of Mt. Simon Sandstone for the Mattoon Area

Porosity Estimated from the Sonic Log for the Humble Weaber-Horn \#1

Figure 2-14. Thickness Isopach Map for Eau Claire Shale, the Upper Confining Zone for the Mt. Simon Sandstone at the Mattoon Site....

Figure 2-15. Structural Contour Map for the Elevation of the Top of the PrecambrianAge Granitic Basement, Relative to Mean Sea Level.

Figure 2-16. Structural Contour Map for the Elevation of the Top of the PrecambrianAge Granitic Basement, Relative to Mean Sea Level...................................2-25

Figure 2-17. Thickness Map of the Ironton/Galesville formation in Illinois.........................2-26

Figure 2-18. Thickness Map of the Franconia Formation in Illinois ..................................2-27

Figure 2-19. Mattoon Cross Section A-A' ............................................................... $2-32$

Figure 2-20. Mattoon Cross Section B-B' ....................................................................

Figure 2-21. GFLOW Contour Map of the Estimated Water Table Beneath the Mattoon Injection Site (Dashed blue lines represent the water table, 10-foot, [3.05 $\mathrm{m]}$ contour interval.)......................................................................... 24

Figure 2-22. Locations of Water Wells and Residences ........................................... 2-35

Figure 3-1. Injection Well Schematic (5,000 ft Intermediate Casing String) ..................... 3-6

Figure 3-2. Injection Well Schematic $(7,000 \mathrm{ft}$ Intermediate Casing String) ........................ $3-7$

Figure 3-3. Influences on $\mathrm{CO}_{2}$ Pressure versus Depth from Delivery to the Wellhead to Injection at Depth of Target Formation 
Figure 3-4. Process Flow Diagram for $\mathrm{CO}_{2}$ Injection Well Maintenance and Monitoring

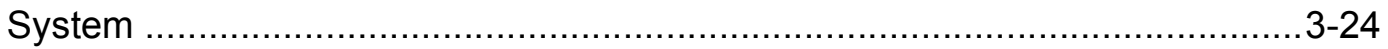

Figure 4-1. Location of Injection Wells and Injection Reservoir Monitoring Wells ...............4-5

Figure 4-2. Monitoring Well Construction Diagram (5,000 ft Intermediate Casing) .............4-6

Figure 4-3. Monitoring Well Construction Diagram (7,000 ft Intermediate Casing) .............4-7

Figure 4-4. Process Areas and their Flowsheet Relationships .................................. 4-10

Figure 4-5. FutureGen Process Flow Diagram - $\mathrm{CO}_{2}$ Compression and Injection Wells ....4-12

Figure 4-6. FutureGen Process Flow Diagram $-\mathrm{CO}_{2}$ Dehydration ................................4-13

Figure 4-7. FutureGen Preliminary Plot Plan ........................................................ $4-16$

Figure 4-8. $\quad$ Dresser-Rand DATUM Compressor (@2009 Dresser-Rand) ........................4-16

Figure 5-1. Well Locations (Also attached as an oversized map) ...................................5-3

Figure 5-2. Gas-Phase Saturation Profiles at 5, 10, 20, and 50 Years for the Modeled Injection Scenario (Injection of 50 MMT over 25.6 years.) ..............................5-8

Figure 6-1. Double-Ended Sample Cylinder Provided by Atlantic Analytical Laboratory ......6-4

Figure 6-2. Atlantic Analytical Gas Sampling Instruction Sheet ...................................6-5

Figure 6-3. Illustration of Bottomhole Monitoring Installations ......................................6-7

Figure 6-4a. Example Monitoring Well Construction Details for Wells Constructed at the

Bedrock Interface... ......................................................................... 6-10

Figure 6-4b. Example Monitoring Well Construction Details for Wells Constructed in the

Shallow Bedrock....................................................................................6-11

Figure 6-5. USDW Monitoring Well Locations (Locations are tentative, pending the final location of the injection well) .....................................................6-13

Figure 6-6. Temperature Logging Procedure ....................................................

Figure 6-7. $\quad$ Radioactive Tracer Tool for Injection Logging (From U.S. EPA, 1994) ..........6-26

Figure 6-8. $\quad$ WMMS Control System Block Diagram..................................................6-29

Figure 6-9. Process Flow Diagram for $\mathrm{CO}_{2}$ Injection Well Maintenance and Monitoring

System ......................................................................................... $6-31$

Figure 6-10. A 3D View from a Multi-Arm Caliper (MAC) Tool Shows an Enlarged OD

Caused by Perforating the Well (Source Halliburton).....................................6-38

Figure 6-11. Output from Halliburton's CAST-V Acoustic Monitoring Tool .........................6-40

Figure 6-12. Corrosion Coupon Illustration in Pipeline ..................................................6-41

Figure 7-1. Expected Penetration Times (0.5 inch) for Four Materials Assuming

General Corrosion Process (Red Lines Bracket Anticipated Bottomhole

Temperature)

Figure 7-2. Expected Penetration Time for Injection Tubing Four Materials Assuming

Pitting Corrosion ............................................................................. $7-11$

Figure 7-3. Illustration of the Wellhead and Christmas Tree...................................... $7-13$

Figure 8-1. Plugging Scenarios for Injection Abandonment During Construction................8-4 


\section{TABLES}

Table 1-1. Organization of this Document Compared to IEPA Instructions for UIC Permit Applications............................................................................... $1-1$

Table 2-1. Projected Stratigraphy for the Mattoon Site .............................................2-11

Table 2-2. Estimated Elevation and Thickness - Franconia Formation ...........................2-25

Table 3-1. Load Scenarios Evaluated ...................................................................

Table 3-2. Borehole Diameters and Depths for Casing Strings for the $\mathrm{CO}_{2}$ Injection Well ........................................................................................................

Table 3-3. Casing Program for the $\mathrm{CO}_{2}$ Injection Well (5,000 ft Intermediate Casing

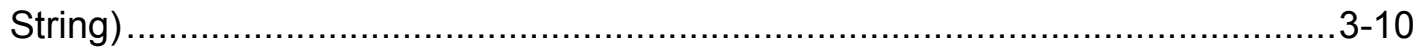

Table 3-4. Casing Program for the $\mathrm{CO}_{2}$ Injection Well (7,000 ft Intermediate Casing

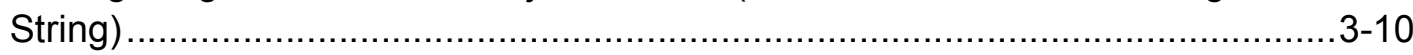

Table 3-5. Properties of Well Casing Materials ..................................................... $3-11$

Table 3-6. Conductor Casing Load Scenarios................................................... $3-11$

Table 3-7. Minimum Design Factors and Corresponding Scenarios for Conductor

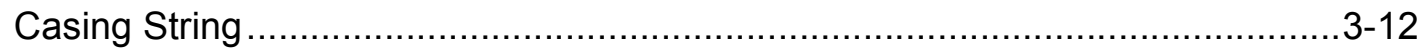

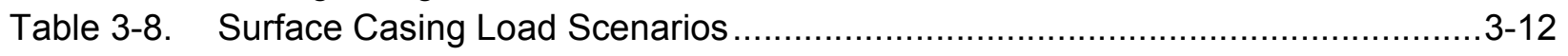

Table 3-9. Minimum Design Factors and Corresponding Scenarios for Surface Casing

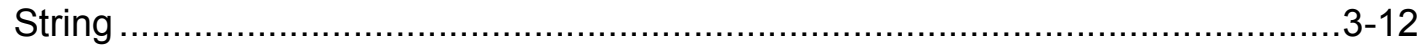

Table 3-10. Intermediate Casing Load Scenarios ................................................... $3-13$

Table 3-11. Minimum Design Factors and Corresponding Scenarios for Intermediate

Casing String ........................................................................................ $3-14$

Table 3-12. Long String Casing Load Scenarios .......................................................... -14

Table 3-13. Minimum Design Factors and Corresponding Scenarios for Long String

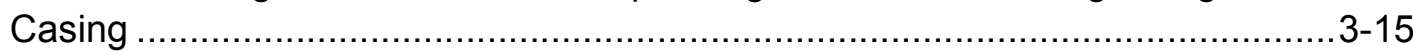

Table 3-14. Flow Rates and Limiting Pressures for Hydraulic Calculations .......................... 3-15

Table 3-15. Summary Results of Thermohydraulic Evaluation ....................................... $3-17$

Table 3-16. Properties of Tubing Material ...................................................................

Table 3-17. Cement Program for the $\mathrm{CO}_{2}$ Injection Well ................................................... 3-19

Table 3-18. Properties of the EverCRETE Cement System .......................................... 3-20

Table 3-19. Additional Cementing Equipment Required for Each Casing String...................3-21

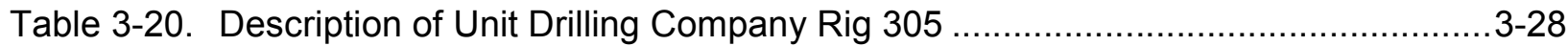

Table 3-21. Preliminary Logging and Testing Program ..............................................29

Table 3-22. Preliminary Core Analysis Program ........................................................... $3-33$

Table 3-23. Possible Intervals for Fluid Sampling During Drilling...................................3-34

Table 3-24. Test Intervals for Microhydraulic Fracture Testing During Drilling Using

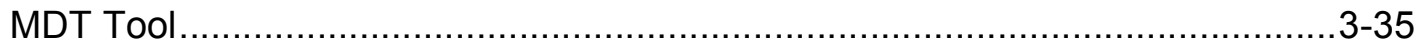

Table 4-1. Location of Primary Injection and Backup Wells ......................................... 4-8

Table 5-1. Summary of Hydrologic Properties for the Mt. Simon .................................. 5-6

Table 5-2. Summary of Initial Conditions................................................................ $5-6$

Table 5-3. Plume Radii (miles) for Modeled Injection Scenario at Selected Times ............... 5-7

Table 6-1. Analytes to be Measured in the $\mathrm{CO}_{2}$ Stream.............................................. $6-2$

Table 6-2. Physical Characteristics of $\mathrm{CO}_{2}$ Stream 911 (Vapor Stream Leaving Knockout Drum) ….......................................................................... $6-3$ 
Table 6-3. Estimated Composition of CO2 Stream 911 (Vapor Stream Leaving

Knockout Drum) - Gasifier Technology \#1

Table 6-4. Estimated Composition of $\mathrm{CO}_{2}$ Stream 911 (Vapor Stream Leaving Knockout Drum) - Gasifier Technology \#2

Table 6-5. Sample Container, Holding Time, and Preservation Methods for Laboratory

Analytes

Table 6-6. Analytical Laboratories .....

Table 6-7. Description of WMMS Instrumentation, Well \#1 and Common Equipment........

Table 6-8. Major Responsibilities for Individuals Overseeing Well Operations 6-32

Table 6-9. Examples of Wireline Tools for Monitoring Corrosion of Casing and Tubing ......6-38

Table 7-1. Volumetric Flow Rate Estimates $.7-3$

Table 7-2. Physical and Chemical Characteristics of Injection Fluid .................................. $7-4$

Table 7-3. Composition of Three Stainless Steel Alloys ................................................. $7-8$

Table 7-4. Operating Conditions for Corrosion Modeling Analyses.................................... 7-9

Table 7-5. Expected Life (100\% penetration of 0.5 inch) for Four Materials Assuming General Corrosion ............................................................................... $7-10$

Table 7-6. Expected Penetration Time for Injection Tubing Assuming Pitting Corrosion ......7-10

Table 7-7. Materials Specification of Wellhead and Christmas Tree ................................. 7-12

Table 7-8. Material Classes from API 6A (Specification for Wellhead and Christmas Tree Equipment)....................................................................................

Table 8-1. Cement Plugs and Quantities Assuming Drilling Terminates Before Well is

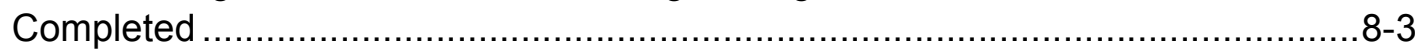

Table 8-2. Cement Types and Quantities for Abandonment After Injection ...........................8-5

Table 8-3. Itemized Plugging and Abandonment Costs (Single Injection Well)..................... 8-7

Table 8-4. Cement Plugs and Quantities Assuming Drilling Terminates Before Well is Completed

Table 8-5. Cement Types and Quantities for Abandonment After Injection 


\section{APPENDICES}

APPENDIX 3-1: Well Cementing Plan

APPENDIX 3-2: Material Safety Data Sheets for Annular Fluid Additives and Inhibitors

APPENDIX 3-3: Example Packers for Above Packer Monitoring and Below Packer Monitoring

APPENDIX 5-1: Tables Listing Oil and Gas Wells and Water Wells in the Area of Review

APPENDIX 5-2: Plugging Affidavits for Wells in the Area of Review

APPENDIX 6-1: Gauge Specifications

APPENDIX 6-2: Mechanical Integrity Testing Procedures

\section{FORMS}

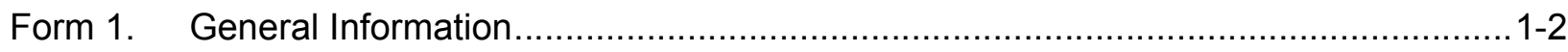

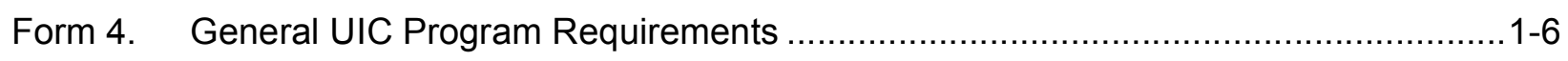

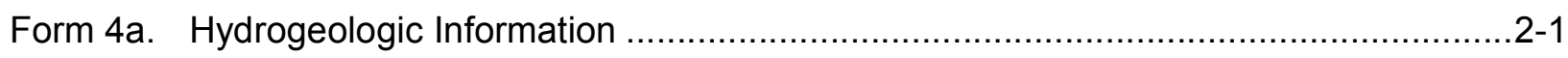

Form 4b. Injection Well Design, Construction Tests And Logs....................................... $3-1$

Form 4c. Operation Program and Surface Facilities ..................................................... $4-1$

Form 4d. Area of Review .........................................................................................

Form 4e. Monitoring, Integrity Testing and Contingency Plan ......................................6-1

Form 4f. Characteristics, Compatibility and Pre-Injection Treatment of Injection Fluid ...........7-1

Form 4g. Plugging and Abandonment Procedure .................................................... $8-1$

\section{OVERSIZED MAPS}

1-1. Area of Review Map for the FutureGen Site (provided in plastic sleeve)

4-5. FutureGen Process Flow Diagram - $\mathrm{CO}_{2}$ Compression and Injection Wells (provided in plastic sleeve)

4-6. FutureGen Process Flow Diagram - $\mathrm{CO}_{2}$ Dehydration (provided in plastic sleeve)

4-7. FutureGen Preliminary Plot Plan (provided in plastic sleeve)

5-1. Well Locations (provided in plastic sleeve) 


\section{ABBREVIATIONS AND ACRONYMS}

$\Sigma$

${ }^{\circ} \mathrm{C}$

${ }^{\circ} \mathrm{F}$

$\mu \mathrm{m}$

$13 \mathrm{Cr}$

$13 \mathrm{Cr} 95$

1D

2D

3D

$3 C$

$\mathrm{AAL}$

ADM

AOR

APT

$\mathrm{Ar}$

B

B

$\mathrm{Ba}$

bbl

Bc

bgs

BHCT

BNST

$\mathrm{Br}^{-}$

BTC

BTU

C

c.u.

$\mathrm{Ca}$

$\mathrm{CaCl}_{2}$

$\mathrm{CBL}$

$\mathrm{CH}_{4}$

$\mathrm{Cl}$

$\mathrm{CO}$

$\mathrm{CO}_{2}$

cos

$\mathrm{cp}$

$\mathrm{C}_{\mathrm{p}}$

$\mathrm{C}_{\mathrm{v}}$ sigma

degree Celsius

degree Fahrenheit

micrometers

$13 \%$ chromium stainless steel tubing

one-dimensional

two-dimensional

three-dimensional

three-component

Atlantic Analytical Laboratory

Archers Daniel Midland

area of review

annular pressure test

argon

body

buttress

barium

barrel

Bearden unit of slurry consistency

below ground surface

bottomhole circulating temperature

bottomhole static temperature

bromine

buttress thread casing and coupling

British thermal unit

carbon

capture units

calcium

calcium chloride

cement bond log

methane

chlorine

carbon monoxide

carbon dioxide

carbonyl sulfide

centipoises

specific heat capacity at constant pressure

specific heat capacity at constant volume 


$\mathrm{Cp} / \mathrm{Cv}$
$\mathrm{Cr}$
$\mathrm{Cr} 13 \%$
$\mathrm{Cs}$
CUSUM
$\mathrm{C}_{\mathrm{v}}$

DCS
DOE
DSI

\section{ECS}

$E S H \& Q$

$\mathrm{F}^{-}$

$\mathrm{Fe}$

FIPS

$\mathrm{ft}$

FutureGen facility

gal
Gd
GFLOW
gpd
gpd/ft
gpm
$\mathrm{H}$
$\mathrm{H}_{2}$
$\mathrm{H}_{2} \mathrm{O}$
$\mathrm{H}_{2} \mathrm{~S}$
$\mathrm{HCO}_{3}^{-}$
$\mathrm{HDPE}^{-}$
$\mathrm{He}$
$\mathrm{HMI}$
$\mathrm{HNBR}$
$\mathrm{HNO}$
$\mathrm{HP}$
I.D.
IEPA
IL DCEO
ILL
ISGS
ISWS

specific heat capacity ratio

Chromium

$13 \%$ chromium material

Cesium

combined Shewart-cumulative sum

specific heat capacity at constant volume

Distributed Control System

U.S. Department of Energy

dipole sonic shear imager

elemental capture spectroscopy

Environmental Safety Health \& Quality

fluorine

Iron

Federal Information Processing Standards

feet

FutureGen Electric and Hydrogen Generating Plant

gallon

Gadolinium

Groundwater Flow Analytic Element Model

gallons per day

gallon per day per foot

gallon per minute

hydrogen

hydrogen

water

hydrogen sulfide

bicarbonate

high density polyethylene

helium

Human Machine Interface

hydrogenated nitrile butadiene rubber

nitric acid

high pressure

inner diameter

Illinois Environmental Protection Agency

Illinois Department of Commerce and Economic Development

Illinois

Illinois State Geological Survey

Illinois State Water Survey 


\begin{tabular}{|c|c|}
\hline $\begin{array}{l}\text { Puture Gen" } \\
\text { ALLIANCE } \\
\text { Clean Enery for a Secure future }\end{array}$ & $\begin{array}{l}\text { UIC Permit Application } \\
\text { for the FutureGen Plant }\end{array}$ \\
\hline $\mathrm{J}$ & joint \\
\hline J-55 & $\begin{array}{l}\text { General purpose pipe manufactured to API specification } 5 \text { CTminimum } \\
\text { yield strength of } 55,000\end{array}$ \\
\hline JFE & $\begin{array}{l}\text { premium tubing connection, exceeds API class } 1 \text { requirements for } \\
\text { compression and torque, bending and external pressure resistance }\end{array}$ \\
\hline $\mathrm{K}$ & hydraulic conductivity \\
\hline k & intrinsic permeability \\
\hline $\mathrm{K}$ & potassium \\
\hline K-55 & $\begin{array}{l}\text { General purpose pipe manufactured to API specification } 5 \text { CT. Typically } \\
\text { used in casing applications. }\end{array}$ \\
\hline $\mathrm{KCl}$ & potassium chloride \\
\hline KDHE & Kansas Department of Health \& Environment \\
\hline $\mathrm{kg}$ & kilograms \\
\hline $\mathrm{km}$ & kilometer \\
\hline $\mathrm{kPa}$ & kilopascal \\
\hline $\mathrm{kPa} / \mathrm{m}$ & kilopascal per meter \\
\hline ksi & kilopound per square inch \\
\hline$k-s-P$ & relative permeability-saturation-capillary pressure function \\
\hline L-80 & $\begin{array}{l}\text { Pipe manufactured to API specification } 5 C T \text {. It is a controlled yield } \\
\text { strength material with a hardness testing requirement typically used in } \\
\text { wells with sour }\left(\mathrm{H}_{2} \mathrm{~S}\right) \text { environments. }\end{array}$ \\
\hline $\mathrm{lb}$ & pound \\
\hline lbf & pound-foot \\
\hline $\mathrm{lb} / \mathrm{ft}^{3}$ & pound per cubic foot \\
\hline lbm & pound-mass \\
\hline Ibmole & pound-mole \\
\hline LP & low pressure \\
\hline LT-4 & Annular Fluid Storage Tank Level Transmitter \\
\hline LT-7 & Accumulator Fluid Level Transmitter \\
\hline LTC & long, round thread casing and coupling \\
\hline LV-7 & Accumulator Tank Fluid Level Control Valve \\
\hline $\mathrm{m}$ & meter \\
\hline $\mathrm{mA}$ & milliampere \\
\hline MAC & Multi-Arm Caliper \\
\hline MCr13\% & modified Cr13\% \\
\hline MCRWD & Moultrie County Rural Water District \\
\hline $\mathrm{mD}$ & milliDarcies \\
\hline MDT & Schlumberger's Modular Reservoir Dynamics Tester \\
\hline $\mathrm{Mg}$ & magnesium \\
\hline $\mathrm{mg} / \mathrm{L}$ & milligrams per liter \\
\hline MIJ & metal-to-metal seal integral-joint connector \\
\hline $\min$ & minute \\
\hline mmBTU & one million British Thermal Units \\
\hline
\end{tabular}

Page xxiii 19 April 2010




\begin{tabular}{|c|c|}
\hline MMT & million metric ton \\
\hline $\mathrm{Mn}$ & manganese \\
\hline Mo & molybdenum \\
\hline $\mathrm{MPa}$ & mega Pascal \\
\hline $\mathrm{ms}$ & milliseconds \\
\hline $\mathrm{m} / \mathrm{s}$ & meters per second \\
\hline $\mathrm{ms} / \mathrm{ft}$ & milliseconds/ft \\
\hline MSDS & Material Safety Data Sheet \\
\hline MSL & mean sea level \\
\hline MT & metric ton \\
\hline MW & megawatt \\
\hline $\mathrm{N}_{2}$ & nitrogen \\
\hline $\mathrm{N}-80$ & $\begin{array}{l}\text { General purpose pipe manufactured to API specification } 5 \mathrm{CT}, 80,000 \mathrm{ps} \\
\text { minimum yield strength }\end{array}$ \\
\hline NACE & National Association of Corrosion Engineers \\
\hline $\mathrm{NaCl}$ & sodium chloride \\
\hline NE & northeast \\
\hline NEP & National Energy Policy \\
\hline NETL & National Energy Technology Laboratory \\
\hline $\mathrm{Ni}$ & nickel \\
\hline No. & number \\
\hline NPT & National pipe thread fitting \\
\hline NW & northwest \\
\hline O.D. & outer diameter \\
\hline $\mathrm{O}_{2}$ & oxygen \\
\hline ORP & oxidation/reduction potential \\
\hline$P$ & phosphorus \\
\hline P\&ID & Process and Instrumentation Diagram \\
\hline $\mathrm{Pa}$ & Pascal \\
\hline PAL-1 & Nitrogen Bank 1 Low Pressure Switch \\
\hline PAL-2 & Nitrogen Bank 2 Low Pressure Switch. \\
\hline Paleosol & ancient topsoil/organic layer \\
\hline PEF & photoelectric factor \\
\hline PFD & Process Flow Diagram \\
\hline $\mathrm{pH}$ & \\
\hline PIC-3 & Annular Fluid Pressure Controller \\
\hline PLC & Programmable Logic Controller \\
\hline PNC & pulsed neutron capture \\
\hline PNNL & Pacific Northwest National Laboratory \\
\hline Poz & Pozzolan \\
\hline P-P & compressional wave \\
\hline ppg & pound per gallon \\
\hline ppm & parts per million \\
\hline
\end{tabular}




\begin{tabular}{|c|c|}
\hline psi & pounds per square inch \\
\hline P-SV & reflected shear wave \\
\hline PT-13 & Annular Pressure Injection Well \\
\hline PT-14 & $\mathrm{CO}_{2}$ Injection Pressure \\
\hline PT-3 & Annular Fluid Expansion Tank Pressure \\
\hline PT-9 & Annular Supply Pressure \\
\hline PV & plastic viscosity \\
\hline PVC & polyvinyl chloride \\
\hline QC & quality control \\
\hline $\mathrm{R}$ & Rankine \\
\hline RAT & radioactive tracer \\
\hline $\operatorname{Re}$ & Reynolds number \\
\hline RTDB & real time database \\
\hline RTU & remote terminal unit \\
\hline s & second \\
\hline S & sulfur \\
\hline $\mathrm{SCr} 13 \%$ & super $\mathrm{Cr} 13 \%$ \\
\hline SE & southeast \\
\hline SEM/EDS & scanning electron microscopy/energy dispersive spectrometer \\
\hline SFL & spherically focused resistivity \\
\hline Si & silicon \\
\hline sks & sacks \\
\hline $\mathrm{SO}_{4}$ & sulfate \\
\hline SOI & silicon on insulator \\
\hline SR & State Route \\
\hline STOMP & Subsurface Transport Over Multiple Phases \\
\hline TBD & to be determined \\
\hline TD/PBTD & total depth or plugged-back depth \\
\hline TDAS & Tubular Design and Analysis System \\
\hline TDS & total dissolved solids \\
\hline TEG & triethylene glycol \\
\hline Th & thorium \\
\hline $\mathrm{Ti}$ & titanium \\
\hline TIC & turbulence inducer \\
\hline TT-5 & Annular Fluid Storage Tank Temperature \\
\hline TT-8 & Annular Fluid Tank Temperature \\
\hline $\mathrm{T}_{\mathrm{y}}$ & point yield point \\
\hline$U$ & uranium \\
\hline U.S. EPA & United States Environmental Protection Agency \\
\hline UCA & Ultrasonic Cement Analyzer \\
\hline $\mathrm{UCl}$ & Ultrasonic Casing Imager \\
\hline
\end{tabular}


UIC

UNIT

USDW

USI

WMMS

XRD

yr

Z

ZLD
Underground Injection Control

Unit Drilling Company

underground source of drinking water

Ultrasonic Imager

Well Maintenance and Monitoring System

x-ray diffraction

year

compressibility factor

Zero Liquid Discharge 


\section{GENERAL INFORMATION}

This document is organized according to Illinois Environmental Protection Agency's (IEPA's) instructions for preparing an underground injection control (UIC) application. The instructions are contained in a number of forms that, taken together, describe the information required in the UIC permit application. To facilitate regulatory review of the permit application, this document has been divided into sections corresponding to each of the forms, as shown in Table 1-1.

Table 1-1. Organization of this Document Compared to IEPA Instructions for UIC Permit Applications

\begin{tabular}{|l|l|l|}
\hline $\begin{array}{c}\text { Section in this } \\
\text { Document }\end{array}$ & \multicolumn{1}{|c|}{$\begin{array}{c}\text { IEPA Instructions } \\
\text { (Form Number) }\end{array}$} & \multicolumn{1}{c|}{ Contents } \\
\hline 1 & Forms 1 and 4 & General Information \\
\hline 2 & Form 4a & Hydrogeologic Information \\
\hline 3 & Form 4b & $\begin{array}{l}\text { Injection Well Design, Construction Tests, and } \\
\text { Logs }\end{array}$ \\
\hline 4 & Form 4c & Operation Program and Surface Facilities \\
\hline 5 & Form 4d & Area of Review \\
\hline 6 & Form 4e & $\begin{array}{l}\text { Monitoring, Integrity Testing, and Contingency } \\
\text { Plan }\end{array}$ \\
\hline 7 & Form 4f & $\begin{array}{l}\text { Characteristics, Compatibility, and Pre-Injection } \\
\text { Treatment of Injection Fluid }\end{array}$ \\
\hline 8 & Form 4g & Plugging and Abandonment Procedure \\
\hline
\end{tabular}

Note: The UIC Permit Application also requires a Well Completion Report (Form 4h), which will be prepared and submitted to the IEPA following completion of the drilling of the injection well.

Forms 1 (General Information) and 4 (General UIC Program Requirements) provide general information about the project and are included in this section of the document. Forms 1 and 4 are standalone and, as completed, satisfy the General Information requirements of the UIC application. Unlike Forms 1 and 4, Forms 4 a through $4 \mathrm{~g}$ do not contain information about the project but rather provide a cross-walk between specific information requirements on each form and section numbers in this report where the information can be found. These forms have been included at the front of each section of this document to further facilitate review of the document. (It should be noted that Forms $4 \mathrm{a}$ through $4 \mathrm{~g}$ contain a signature line that has not been completed per direction from the IEPA; instead, the signatures have been provided on Forms 1 and 4 where required.) 
I. Is this facility a proposed stationary source which is one of the 28 industrial categories listed in the instructions and which will potentially emit 100 tons per year of any air pollutant regulated under the Clean Air Act and may affect or be located in an attainment area? (Form 5)

Based on preliminary estimates of maximum air emissions that would be expected from the facility, emissions of one or more criteria pollutants are projected to exceed 100 tons per year during startup operations or during steady-state operations following startup. An air permit will be obtained from the Illinois EPA for this facility.

$\mathrm{X}$

$\mathrm{J}$. Is this facility a proposed stationary source which is NOT one of the 28 industrial categories listed in the instructions and which will potentially emit 250 tons per year of and air pollutant regulated under the clean Air Act and may affect or be located in an attainment area? (Form 5)

III. NAME OF FACILITY FUTUREGEN Electric Power and Hydrogen Generating Plant

IV. FACILITY INFORMATION

CONTACT (Name and Title) Iohn David Brown, Contracting Officer

PHONE (202) 280-6019 (Carole Plowfield)

MAILING ADDRESS 101 Pennsylvania Avenue N.W.

Suite $600.6^{\text {th }}$ Floor

Washington, D.C. 20004

LOCATION

The FutureGen Site consists of approximately 444 acres ( 180 hectares) of farmland located approximately 1 mile ( 1.6 kilometers) northwest of the City of Mattoon, in Coles County, Illinois. The power plant and sequestration site would be located on the same parcel of land. The

proposed site is bordered to the northeast by State Route (SR) 121 and a Canadian National Railroad.

COUNTY

SIC CODES (First)

Coles County.

(Second)

(Third)

(Fourth)

$\underline{4911}$

OPERATOR (Name)

FutureGen Industrial Alliance, Inc.

Is the operator also the owner? Yes_ $\mathrm{X}$ No

STATUS OF OPORATOR

Federal

Public (Specify)

State

$\mathrm{X}$ Other (Specify)

Private

The FutureGen Alliance, Inc. is structured as a non-profit 501 (c)(3) organization.

OPERATOR PHONE same as above STREET or PO BOX same as above
(City/Town) same as above

(State \& Zip Code) same as above 
V. EXISTING ENVIRONMENTAL. PERMITS (There are no existing permits for this facility.)

NPDES N N/A

UIC $\quad$ This application requests a UIC Permit

RCRA N/A

OTHER (Specify) N N/A

OTHER (Specify) N/A

VI. MAP (Location) A topographic map extending 2.5 miles beyond the property boundary is provided as Figure 1-1. Also an oversized version of this map is provided as an attachment to this document.

VII. NATURE OF BUSINESS (Location) The proposed FutureGen facility is a prototype electric power and hydrogen (H2) generating plant that would employ coal gasification technology integrated with combined-cycle electricity generation and sequester carbon dioxide (CO2) emissions. The project would also include an ongoing research program, which would be the principal feature of the prototype plant. The power plant would be a 275 -megawatt (MW) output Integrated Gasification Combined-Cycle (IGCC) system. $\mathrm{CO} 2$ capture and geologic storage would occur at a rate of at least 1.1 million tons ( 1 million metric tons [MMT]) of $\mathrm{CO} 2$ per year.

\section{CERTIFICATION (see instructions)}

I certify under penalty of law that this document and all attachments were prepared under my direction or supervision in accordance with a system designed to assure that qualified personnel properly gather and evaluate the information submitted. Based on my inquiry of the person or persons who managed the system, or those persons directly responsible for gathering the information, the information submitted is, to the best of my knowledge and belief, true, accurate, and complete. I am aware that there are significant penalties for submitting false information, including the possibility of fine and imprisonment for knowing violations.

NAME \& OFFICAL TITLE John David Brown, Contracting Officer PIIONE (28!) 552-2146

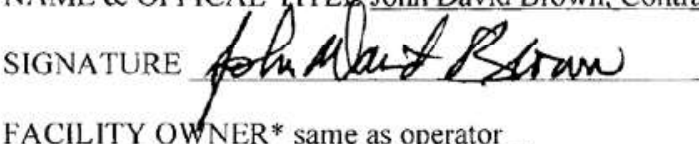

FACILITY OWNER* same as operator

SIGNATURE* same as operator

* required if owner is different than operator

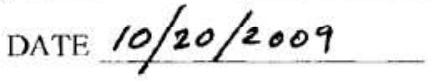

PHONE same as operator

DATE same as operator 


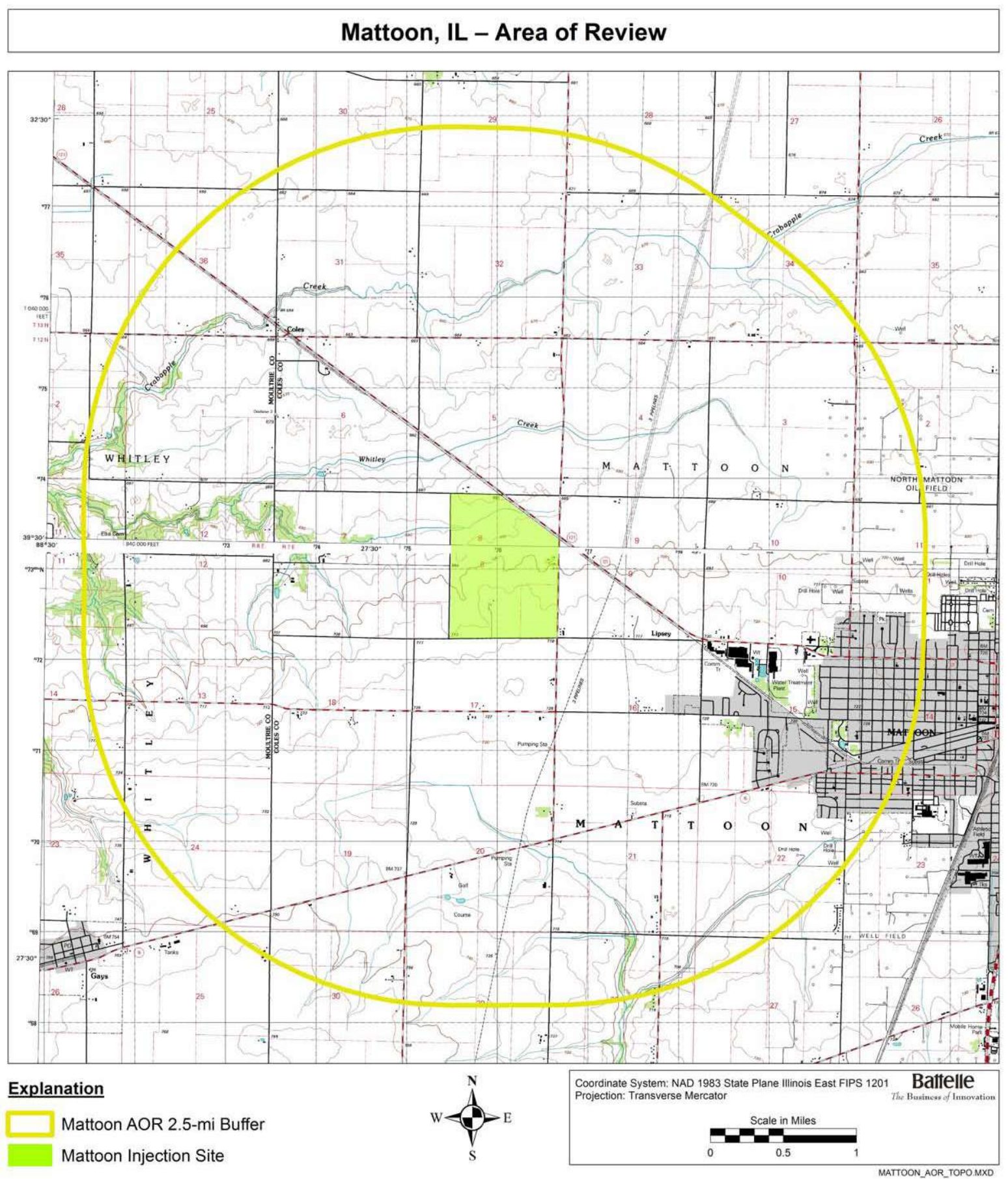

Figure 1-1. Area of Review Map for the FutureGen Site (Also attached as an oversized map) 


\section{DRAFT UIC PERMIT FORMS}

\section{ILLINOIS ENVIRONMENTAL PROTECTION AGENCY \\ UNDERGROUND INJECTION CONTROL PERMIT APPLICATION GENERAL UIC PROGRAM REQUIREMENTS}

USEPA ID NUMBER not applicable FORM 4

$\begin{array}{ll}\text { IEPA ID NUMBER } & 0290255208 \\ \text { WELL NUMBER } & \text { FutGen-INJ-1 and FutGen-INJ-2 }\end{array}$

I. Well Status

Operating

II. Type of Permit Individual:

New $X \quad$ Renewal Emergency

Permit Number

$\begin{array}{ll}\text { Area: } & \begin{array}{l}\text { Number of Wells } \\ \text { New }\end{array} \text { - } 2 \text { Renewal } \\ \text { Emergency }\end{array}$

Permit Number

III. Class I Non Hazardous

IV. Location of Well (if area permit is requested, give approximate center of area)

A. Township-Range-Section system of the Bureau of Land Management of the US Government (specify distance, direction and number; circle pertinent direction where applicable)

4 feet south and 500 feet west of the _NE_ corner of the _ NW quarter of the $\bar{S}$ E_ quarter of Section _ 8 _ , Township_ 12 north, Range $\overline{7}$ east of the 3rd_Principal Meridian,___ Coles___ County, Illinois.

B. Latitude $39^{\circ} 29^{\prime} 52.46^{\prime \prime}$ C. Longitude $88^{\circ} 26^{\prime} 28.60^{\prime \prime}$

(degs. mins. secs.) (degs. mins, secs.)
Closest Municipality_Mattoon, Illinois (Name \& County)

Note: location description corresponds to approximate center of site

V. Land Ownership

(Enter name of the site landowner if not the applicant or operator)
A. Name and Title
B. Phone Number

C. Street, PO Box or Route

\begin{tabular}{llll}
\hline D. City or Town & E. State & F. County & G. Zip Code
\end{tabular}

H. Lease is to terminate on (month, day, year)

VI. Attachments (see instruction sheet)

A. Application Forms (enter form numbers) 1, 4, 4a, 4b, 4c, 4d, 4e, 4f, 4g 
B. Are five (5) copies of the Feasibility Report attached? Yes_X_No (explain)

C. Are five (5) copies of the Well Completion Report attached? Yes ___ No_ X _... (explain) The Well Completion Report is not provided at this time since the injection wells have not yet been drilled. The Well Completion Report will be provided after the wells have been drilled.

D. Has the applicant applied to proper local government unit(s) to secure siting approval? Yes__ No X_ (explain) There is no official siting approval required for the injection wells by Coles County or the City of Mattoon. Furthermore, The Future Gen Alliance will secure subsurface storage rights for properties that overly the portion of the Mt. Simon Formation that will store injected carbon dioxide. Thereofore, any injected waste (i.e., carbon dioxide) will be slored in areas controlled by the FutureGen Alliance and as such a formal siting approval is not required per Illinois Environmental Protection Act. Are two (2) copies of siting approval attached? Yes ___ No $\mathrm{X}_{\text {_ }}$ (explain)

E. Is a certification of financial responsibility to close, plug and abandon the well(s) attached? Yes ____. No _._. _ _ (explain) Per the Illinois EPA, cerification of financial responsibility will be submitted after the IEPA reviews and approves the well plugging and abandonment cost estimate provided in this UIC permil application.

F. If the land is leased, is a copy of the lease agreement attached? Yes__ No ______ (explain) Not applicable; land is owned by applicant.

VII. Illinois State Legislative Requirements (see instruction sheet)

(Applicable to hazardous waste disposal sites except those publicly-owned sewage works or the disposal or utilization of sludge from publicly-owned sewage works.)

This application is for a non-hazardous UIC permit, therefore, this section does not apply.

A. Is the proposed or existing hazardous waste disposal site located:

1. Above an active in inactive shaft or tunneled mine or within 2 miles of an active fault in the earth's crust or active quarry doing blasting? Yes No. Not applicable

2. In a county populated with less than 225,000 :

a. Within $1 \frac{1}{2}$ miles of the corporate limits as defined on June 30 , 1978 of any municipality?

Yes __ No ___ Not applicable

If "yes", has approval been given by the governing body of the municipality in an official action?

Yes No Not applicable

b. Within 1000 feet of an existing private well or the existing source Of a public water supply measured from the boundary of the actual active permitted site and excluding existing private wells on the property of the permit applicant?
Yes No Not applicable

B. Is the proposed or existing well a pollution control facility? Yes Have the requirements of SB172 been met? Yes Attach a dated copy of the approval by the county board or city council No Not applicable No Not applicable

VIII. Certification

I certify under penaity of law that this document and all attachments were prepared under my direction or supervision in accordance with a system designed to assure that qualified personnel properly gather and evaluate the information submitted. Based on my inquiry of the person or persons who manage the system, or those persons directly responsible for gathering the information, the information submitted is, to the best of my knowledge and belief, true, accurate, and complete. I am aware that there are significant penalties for submitting false information, including the possibility of fine and imprisonment for knowing violations.

Jo wn DAvin BRown.Contracting Offied $\frac{(281) 552-2146}{\text { Phone Number }}$




\title{
DRAFT UIC PERMIT FORMS
}

\author{
ILLINOIS ENVIRONMENTAL PROTECTION AGENCY \\ UNDERGROUND INJECTION CONTROL PERMIT APPLICATION
}

\section{FORM 4a - HYDROGEOLOGIC INFORMATION}

\author{
USEPA ID NUMBER not applicable \\ IEPA ID NUMBER 0290255208 \\ WELL NUMBER _FutGen-INJ-1 and FutGEN-INJ-2
}

Location in Application

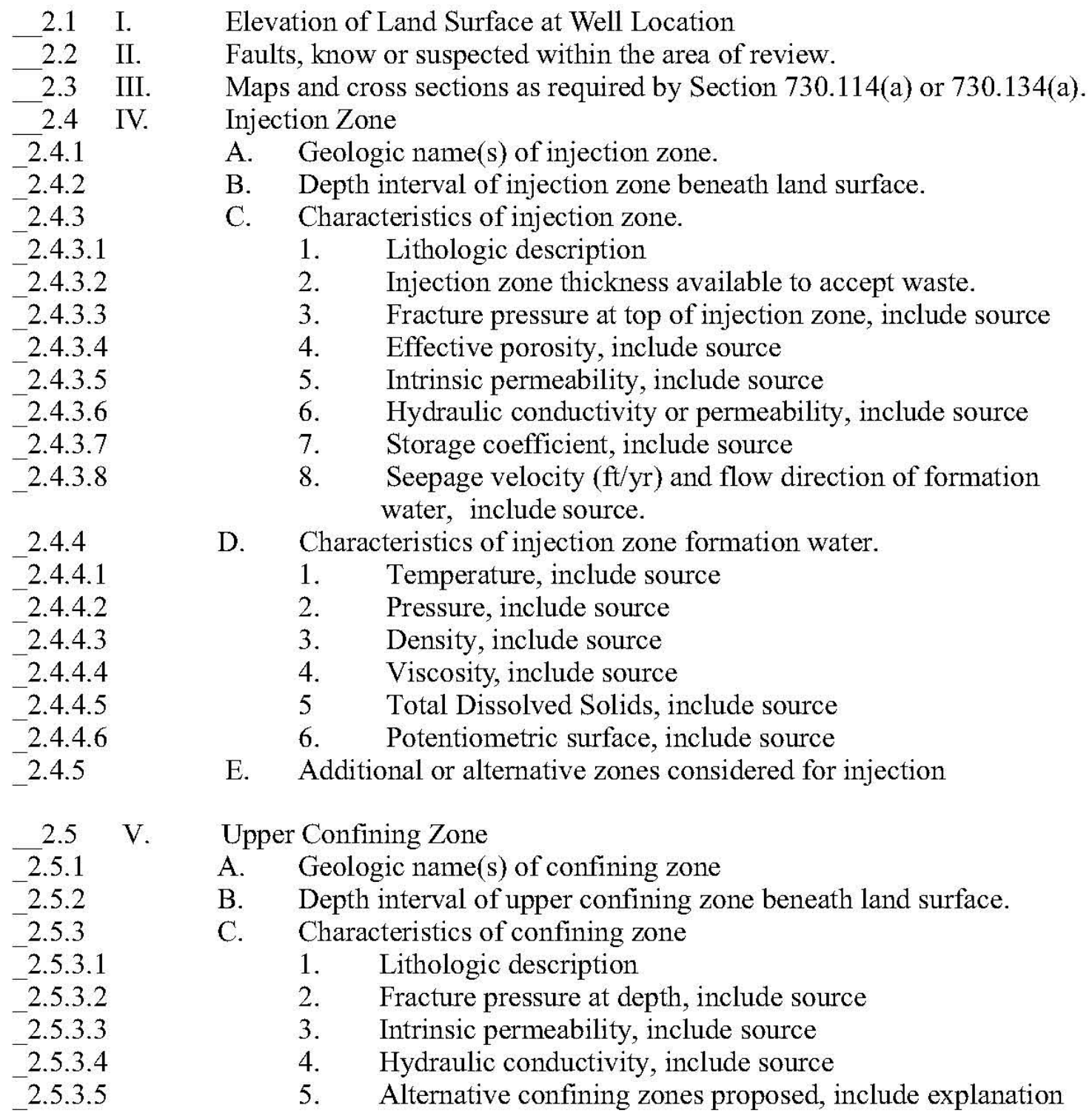


and depth interval(s)

2.6 VI. Lower Confining Zone

2.6.1

A. Geologic name(s) of confining zone

2.6 .2

2.6 .3

2.6.3.1

2.6.3.2

B. Depth interval of lower confining zone beneath land surface

C. Characteristics of confining zone

1. Lithologic description

2. Fracture pressure at depth, include source

2.6.3.3

3. Intrinsic permeability, include source

2.6.3.4

4. Hydraulic conductivity, include source

2.6.3.5

5. Alternative confining zones proposed, include explanation and depth interval(s)

2.7 VII. Overlying Sources of Groundwater at the Site

A. Characteristics of the aquifer immediately overlying the confining zone

1. Elevation at top of aquifer, include source

2. Potentiometric surface, include source

3. Total Dissolved Solids, include source

4. Lithology, include source

5. Aquifer thickness

6. Specific gravity, include source

B. Underground Sources of Drinking Water (USDW)

1. Maps and cross sections required by 730.114(a)(4) or 730.134(a)(4)

2. Lowest depth of USDW

3. Elevation of potentiometric surface of lowest USDW referenced to mean sea level

4. Distance to nearest water supply well

5. Distance to nearest down gradient water supply well

2.8 VIII. Minerals and Hydrocarbons

2.8 .1

A. Mineral or natural resources beneath or within 5 miles of the site, include types and depth intervals 


\section{(2) Future Gen"m \\ ALLIANCE \\ Clean Energyfora Secure fiture}

UIC Permit Application

for the FutureGen Plant

\section{Certification}

I certify under penalty of law that this document and all attachments were prepared under my direction or supervision in accordance with a system designed to assure that qualified personnel properly gather and evaluate the information submitted. Based on my inquiry of the person or persons who managed the system, or those persons directly responsible for gathering the information, the information submitted is, to the best of my knowledge and belief, true, accurate and complete. I am aware that there are significant penalties for submitting false information, including the possibility of fine and imprisonment for knowing violations.

Name \& Official Title

Phone Number

Note: per direction from the Illinois EPA, a signature is not required on this form. 


\section{HYDROGEOLOGIC INFORMATION (Form 4a)}

\subsection{Elevation of Land Surface at Well Location}

The elevation of the land surface at the proposed location of the carbon sequestration site is approximately 698 feet (ft) above mean sea level (MSL).

\subsection{Faults, Known or Suspected Within the Area of Review}

In order to examine the potential for faulting within the area of review (AOR), 29.6 miles of twodimensional (2D) seismic data were recently acquired and interpreted. Of that survey, 16.6 miles were recorded with standard geophones, while 13.0 miles were recorded using threecomponent geophones that allowed for recording reflected shear wave (P-SV) images as well as the compressional wave (P-P) images recorded using the standard geophones (Figure 2-1).

The P-SV data are used to confirm the acoustic variability of the Mt. Simon Sandstone and provide an indication of the internal heterogeneity of the sequestration target beyond that provided by P-P data.

Interpretations of both the P-P and P-SV data provide no evidence that faults traverse the Mt. Simon interval and breach its top seal. The P-P images provide the best resolution of the structural configuration of the Eau Clair, Mt. Simon, and Precambrian basement, and are presented here. Figure 2-2, Figure 2-3, and Figure 2-4 depict P-P images for lines 1, 2, and 5, which are located east, south, and north of the FutureGen site, respectively. The figures show that faults have been interpreted in the Precambrian basement beneath the Mt. Simon reservoir, but that the faults do not appear to penetrate the Mt. Simon or the Eau Claire sealing unit.

\subsection{Maps and Cross Sections as Required by Section 730.114(a) or $730.134(a)$}

A location map and two perpendicular cross-sections are presented in Figure 2-5, Figure 2-6, and Figure 2-7. The cross-sections include available log control, geologic units, and lithology from the surface to the lower confining bed below the injection zone. Note that there is no deep well control in the Mattoon area, so no well locations are displayed on the cross-sections. Structure maps of the deeper horizons were provided as digital grids by the Illinois State Geological Survey (ISGS) (Appendix, Mattoon Subsurface Data package submitted by Illinois State Geological Survey, Sections 1_1_6_struc_resvr, 1_3_2_struc_seal, and 1_3_3_isopach_seal). The structure grids were based on regional mapping performed by the ISGS. The structure grids were incorporated into a solid earth model using the EarthVision ${ }^{\circledR}$ software package, and then used to estimate the tops and thicknesses of the stratigraphy beneath the Mattoon Site, as well as to produce the required maps and cross-sections.

\subsection{Injection Zone}

The injection zone will be in the Mt. Simon Formation. The Mt. Simon is Upper Cambrian in age, deposited on Precambrian basement rocks and overlain by a thick, impermeable shale referred to as the Eau Claire Formation. The Mt. Simon is regionally extensive in Illinois, 


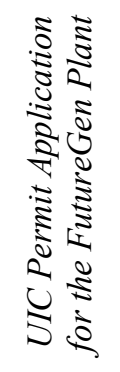

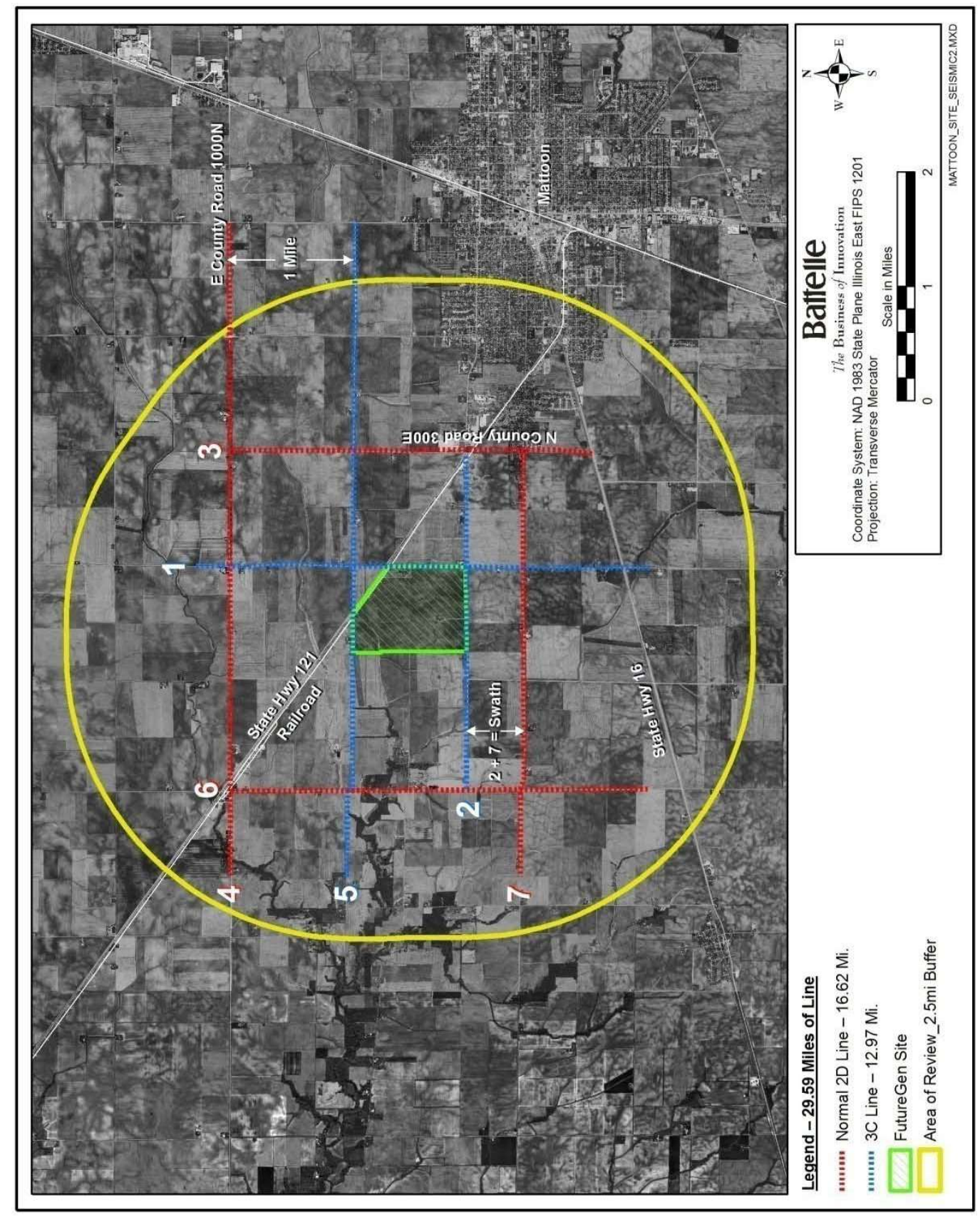

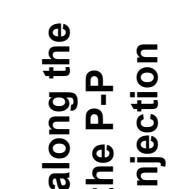

웅 웅

ฮ 증ํㅇ 눈응응 응 웡 흥 흥

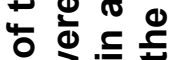
둥 के

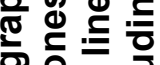
잉 응 증 응 응 응 응도

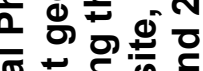

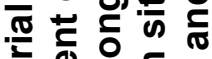
d ष웡워 든 을 잉 인 ธ ํํㄹ 롤

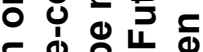
요요 을 은 톤 心的焉 ธ워 \& 운 응 잉 끌토 응 듕

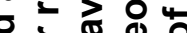

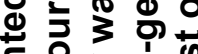

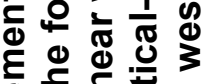
흥 응 응 ह 도ㅇㅝㅓㅇ 은 흥응 든 율 옹 。웡 은 응 응 혼 응 के 응 ह व

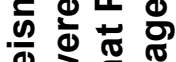
ल 3 ह $\therefore$ \& సं 웡 ๑) 응 윽 응 $\frac{3}{0}$ 은 웡 정 음 은 긍

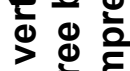
츨 
(a)

Line 1, P-P, Mattoon
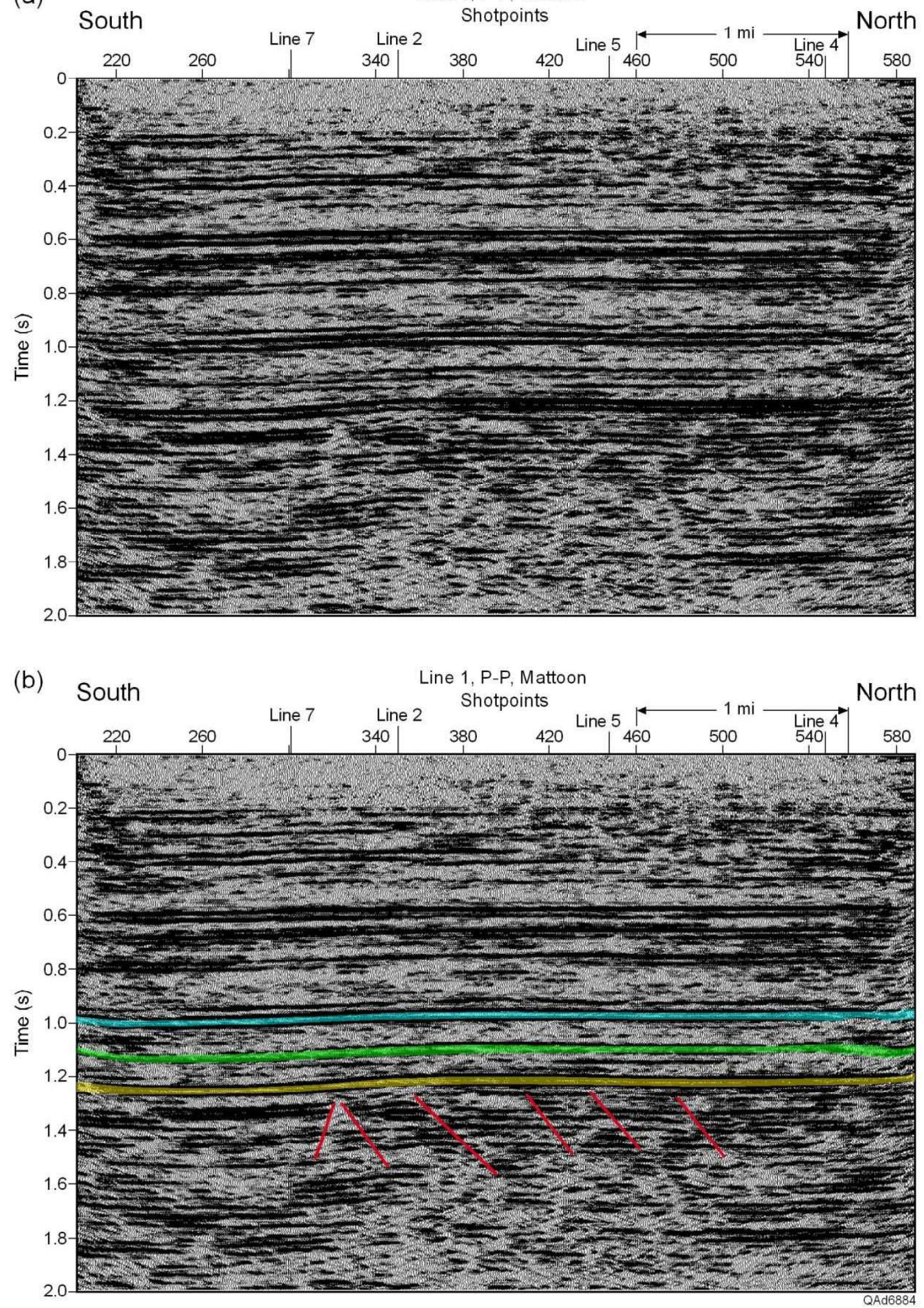

Figure 2-2. Line 1. (a) No interpretation. (b) With interpretation. Intra-basement faults are shown in red. Blue horizon $=$ Base of Knox. Green horizon $=$ Top of Mt. Simon. Yellow horizon $=$ Top of Precambrian. 

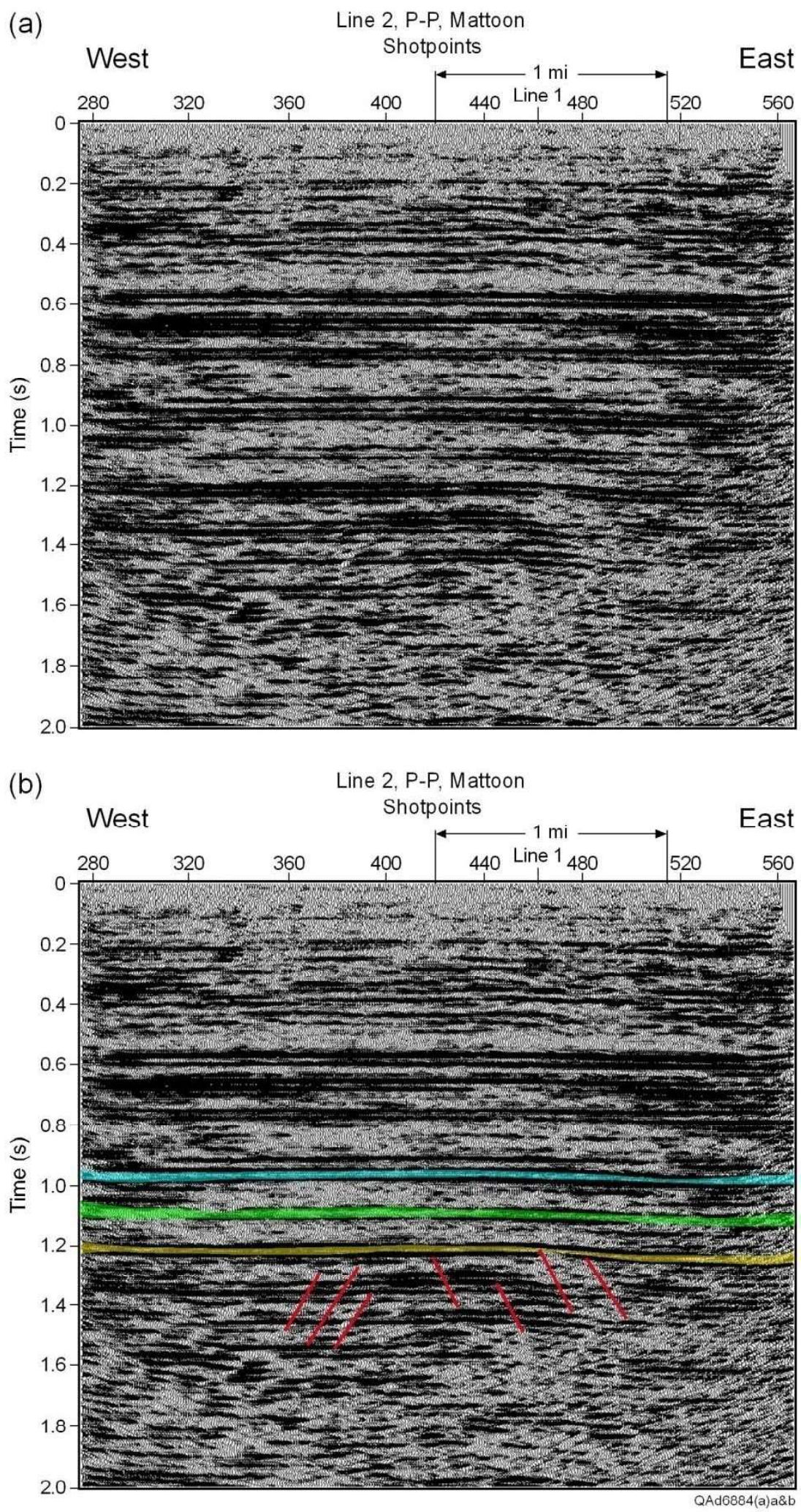

Figure 2-3. Line 2. (a) No interpretation. (b) With interpretation. Intra-basement faults are shown in red. Blue horizon $=$ Base of Knox. Green horizon $=$ Top of Mt. Simon. Yellow horizon $=$ Top of Precambrian. 

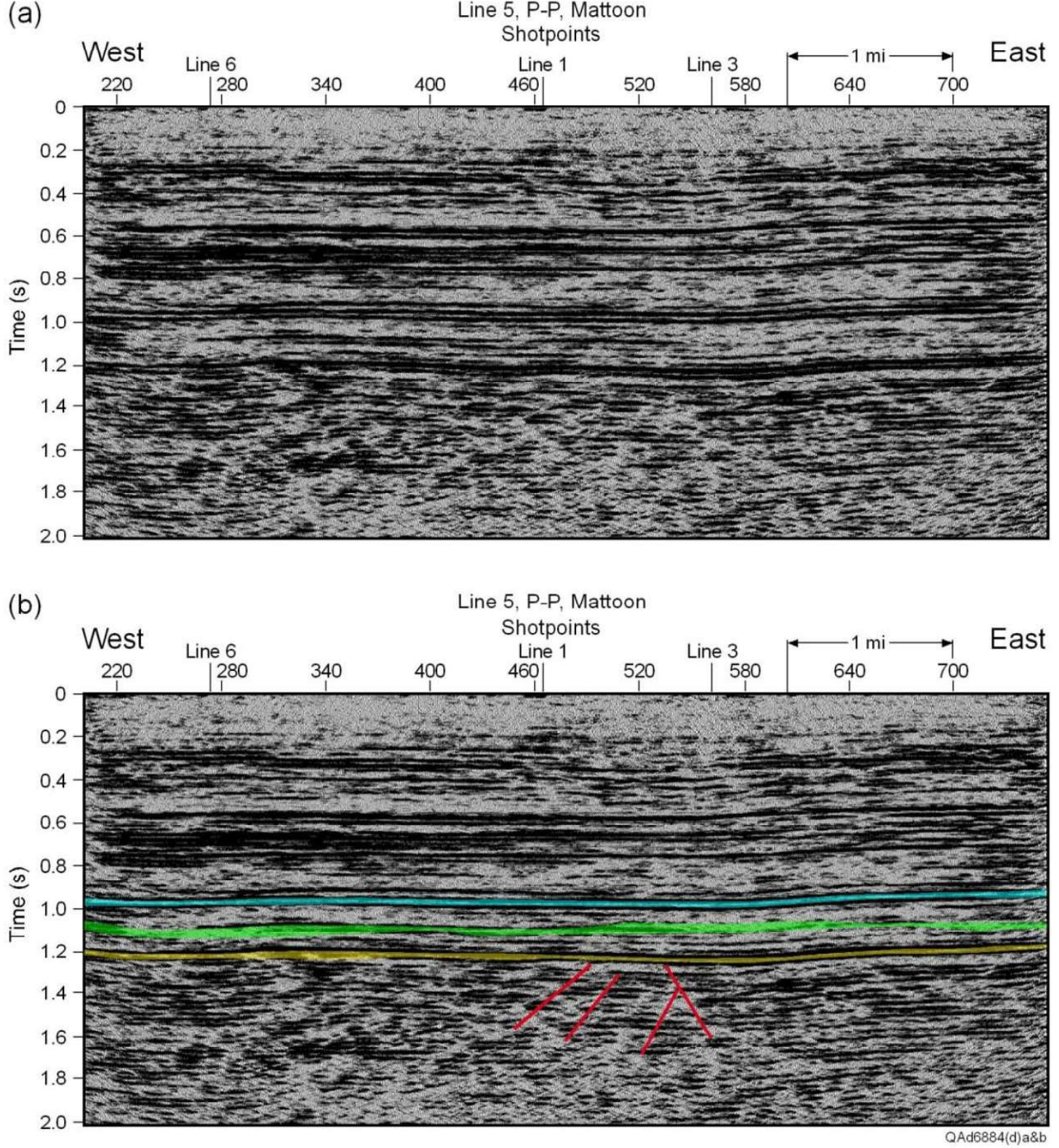

Figure 2-4. Line 5. (a) No interpretation. (b) With interpretation. Intra-basement faults are shown in red. Blue horizon $=$ Base of Knox. Green horizon = Top of Mt. Simon. Yellow horizon $=$ Top of Precambrian.

varying in thickness from less than 150 meters $(\mathrm{m})(500 \mathrm{ft})$ to more than $780 \mathrm{~m}(2,600 \mathrm{ft})$ thick (Morse and Leetaru, 2005). Where present on anticlinal structures, the Mt. Simon Sandstone has been used for numerous gas storage projects in the State of Illinois, with the overlying Eau Claire shale providing an effective seal (Morse and Leetaru, 2005).

Deposition of the Mt. Simon is normally ascribed to tidal environments in shallow marine settings (e.g., Driese et al., 1981; Sargent and Lasemi, 1993). Detailed study of core samples from Manlove Field, a gas storage field, by geologists from the ISGS supported a shallow subtidal depositional environment for the Mt. Simon in east-central Illinois (Morse and Leetaru, 2005). 


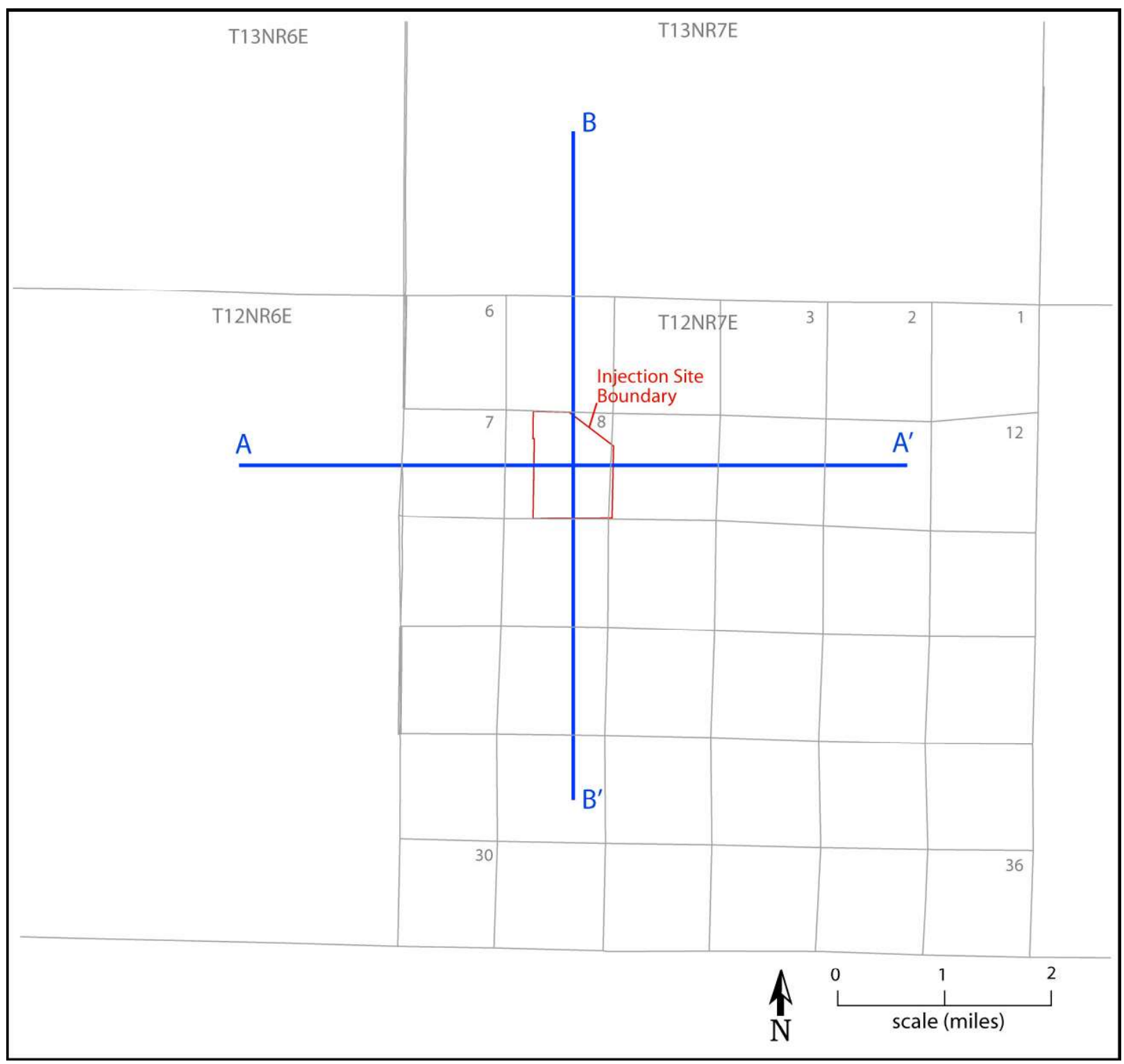

Figure 2-5. Index Map Showing Location of Perpendicular Cross-Sections in Figures 2-6 and 2-7 that Illustrate the Structural Dips and the Stratigraphic Thickness of Units at the Mattoon Site

\subsubsection{Geologic Name(s) of Injection Zone}

The injection zone for the sequestration of $\mathrm{CO}_{2}$ is the Cambrian Mt. Simon Sandstone.

\subsubsection{Depth Interval of Injection Zone Beneath Land Surface}

The sequestration zone for the Mattoon Site is the Mt. Simon Sandstone, in the interval between 7,353 and 8,996 ft below ground surface (bgs) (Table 2-1). Structure maps of the deeper horizons were provided as ArcGIS digital grids by the ISGS (Appendix, Mattoon Subsurface Data package submitted by Illinois State Geological Survey, Sections 1_1_6_struc_resvr, 1_3_2_struc_seal, and 1_3_3_isopach_seal). The structure grids were based on regional 


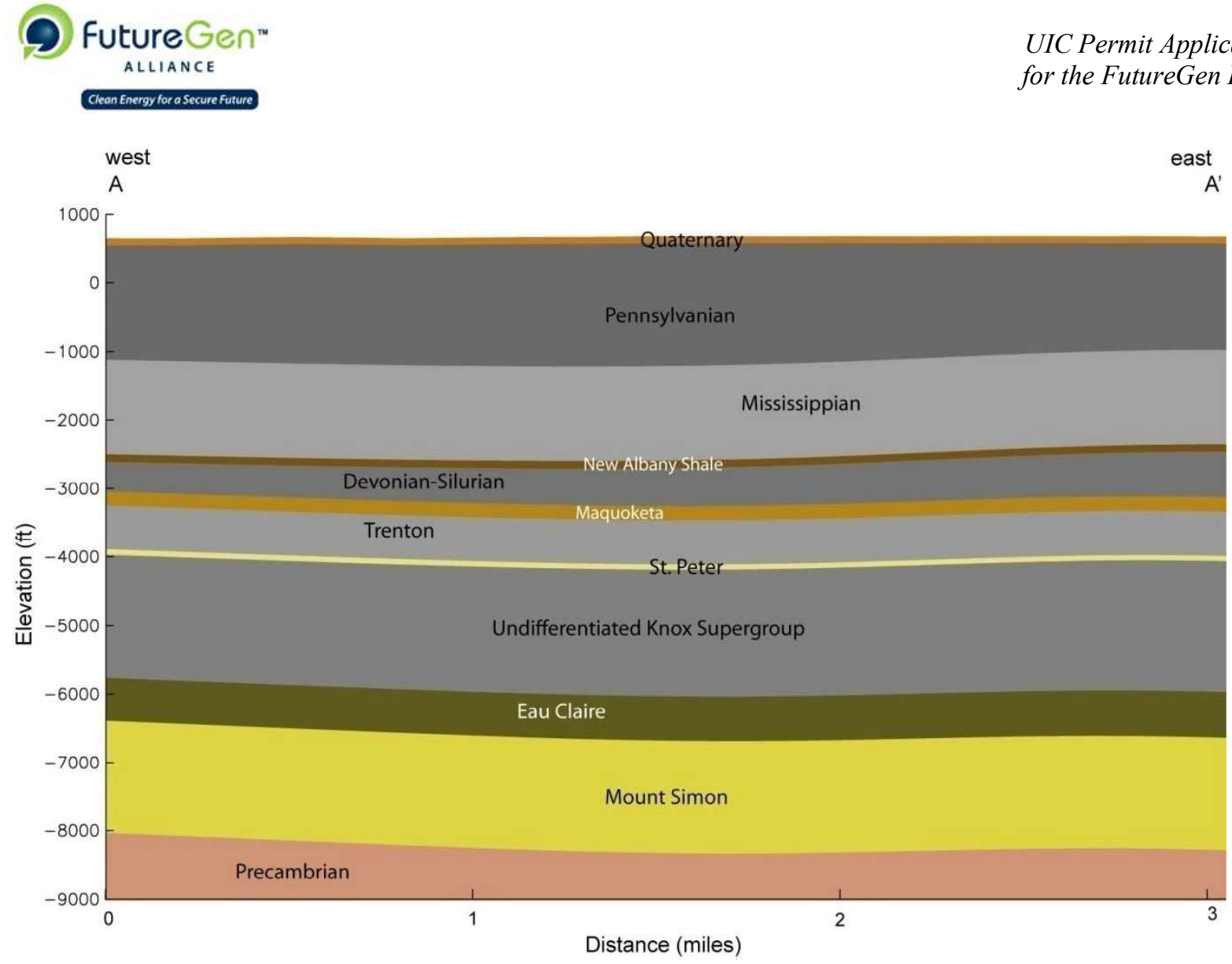

Figure 2-6. West-East Structural Cross-Section through the Mattoon Site

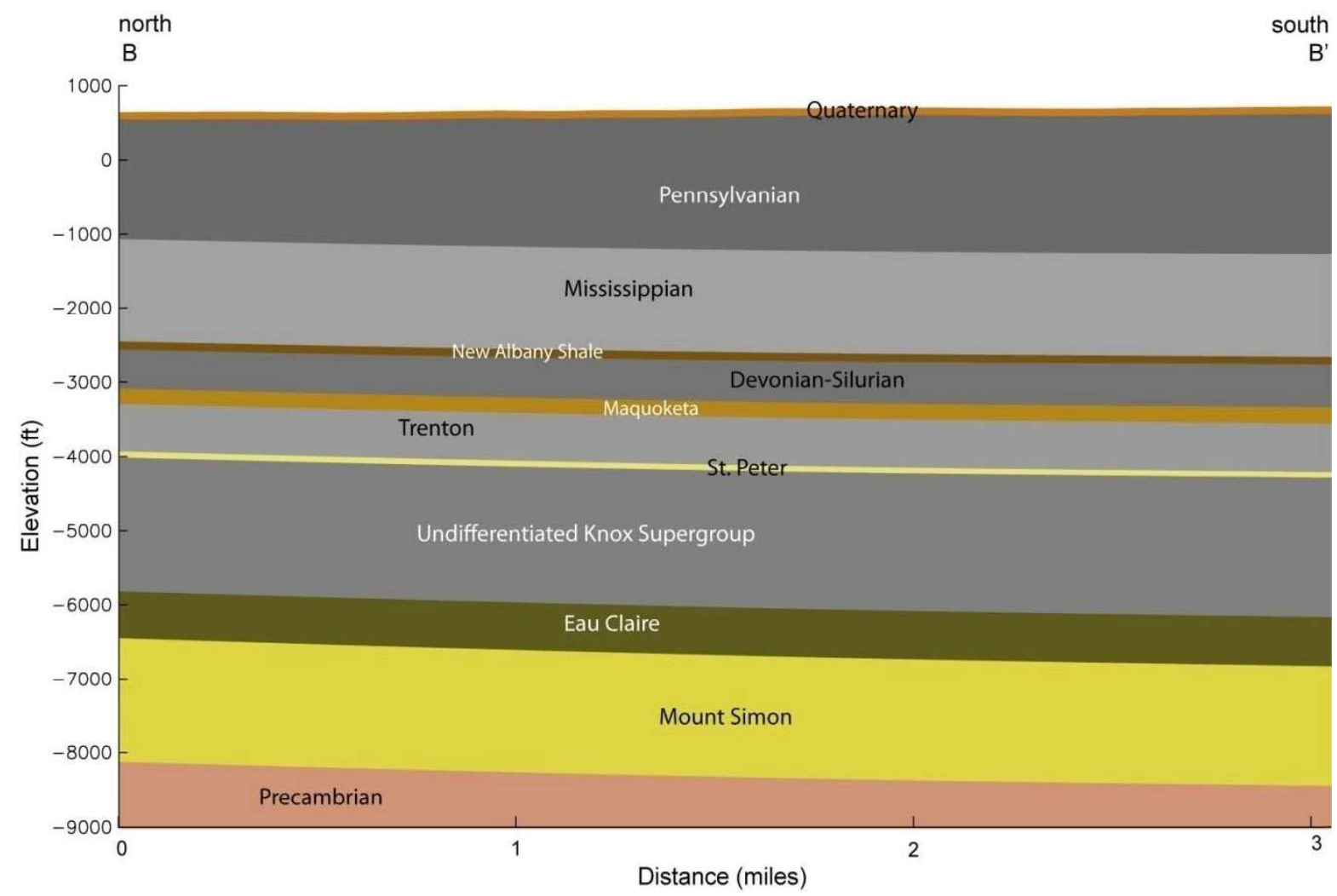

Figure 2-7. North-South Structural Cross-Section through the Mattoon Site 
Table 2-1. Projected Stratigraphy for the Mattoon Site

\begin{tabular}{|l|c|c|c|c|}
\hline \multicolumn{1}{|c|}{ Geologic Unit } & Elevation (ft) & Depth (ft) & $\begin{array}{c}\text { Thickness } \\
\text { (ft) }\end{array}$ & Comment \\
\hline Quaternary & 698 & 0 & 100 & \\
\hline Pennsylvanian & 598 & 100 & 1,792 & \\
\hline Mississippian & $-1,194$ & 1,892 & 1,370 & \\
\hline New Albany Shale & $-2,564$ & 3,262 & 110 & Seal \\
\hline Devonian Silurian & $-2,674$ & 3,372 & 554 & \\
\hline Maquoketa & $-3,228$ & 3,926 & 203 & Seal \\
\hline Trenton & $-3,431$ & 4,129 & 652 & \\
\hline St Peter & $-4,083$ & 4,781 & 77 & \\
\hline Undifferentiated Knox & $-4,160$ & 4,858 & 1,847 & \\
\hline Eau Claire & $-6,007$ & 6,705 & 648 & Seal \\
\hline Mt. Simon & $-6,655$ & 7,353 & 1,643 & Reservoir \\
\hline Precambrian & $-8,298$ & 8,996 & & \\
\hline
\end{tabular}

mapping performed by the ISGS. The structure grids were incorporated into a solid earth model using the EarthVision ${ }^{\circledR}$ software package, and then used to estimate the tops and thicknesses of the stratigraphy beneath the Mattoon Site.

The primary zone for sequestration will not be the entire thickness of the Mt. Simon, but a relatively coarse-grained arkosic interval that is usually present in the lower portion of the Mt. Simon (Leetaru et al., 2005). Estimated depths for that interval at the Mattoon Site are from 8,698 to $8,958 \mathrm{ft}$. The actual depth interval for injection will be identified after drilling, geophysical logging, and hydraulic testing of the injection well.

\subsubsection{Characteristics of the Injection Zone}

\subsubsection{Lithologic Description}

The Mt. Simon Sandstone is primarily a medium- to coarse-grained quartz sandstone with some conglomeratic beds (Leetaru et al., 2005). Zones of fine- to medium-grained feldspathic sandstone are also present. The coarser-grained beds tend to have better sorting and higher porosity, with lower concentrations of feldspar. Cementation in the Mt. Simon Sandstone consists primarily of euhedral quartz overgrowths (Morse and Leetaru, 2005), with euhedral feldspar overgrowths present in the more feldspathic intervals. Diagenetic clay minerals are rare; scanning electron microscope imagery indicated that most of the clay is illite (Morse and Leetaru, 2005).

\subsubsection{Injection Zone Thickness Available to Accept Waste}

Regional mapping of the Mt. Simon Sandstone by the ISGS suggests that the total thickness of the Mt. Simon in the Mattoon area is approximately 1,400 to 1,700 $\mathrm{ft}$ (Leetaru et al., 2005, Figure 3-14), although there is no nearby control that has penetrated the Mt. Simon. Estimated thickness of the Mt. Simon based on the structure grids provided by the ISGS (Figure 2-8) is $1,643 \mathrm{ft}$. 
Data from the Weaber-Horn \#1 well, the closest well that fully penetrates the Mt. Simon with geophysical porosity logs, indicates that there is a thick high-porosity zone near the base of the formation that would be the primary injection target. The Weaber-Horn \#1 well is located approximately 36 miles southwest of the Mattoon Site, in Louden Oil Field, Fayette County, Illinois. The high-porosity zone in the Weaber-Horn well is approximately $125 \mathrm{ft}$ thick, with average porosity in excess of $20 \%$. Based on regional correlations, Leetaru et al. (2005) described the basal arkose-rich interval that forms this high-porosity zone as varying from 20 to $400 \mathrm{ft}$ in thickness.

Encountering porous zones with significant thickness is highly probable based on the thickness and porosity of high-porosity zones in the Weaber-Horn \#1 well, and in Mt. Simon gas storage fields in the Illinois Basin (Morse and Leetaru, 2005).

Because of the lack of nearby well control, detailed hydrologic testing and geophysical well log analysis will be required to identify the thickness and porosity of intervals within the Mt. Simon after drilling the injection well at the Mattoon Site.

\subsubsection{Fracture Pressure at Top of Injection Zone}

Because the actual pressures that would cause new or existing fractures to open are not known, the maximum injection pressure is conservatively set at $85 \%$ of the 0.8 pound per square inch per foot (psi/ft) gradient that is required by Illinois regulation. Leetaru et al. $(2005$, p. 312) stated that fracture stimulation companies commonly use a fracture gradient of $1.0 \mathrm{psi} / \mathrm{ft}$ in stimulating wells in the Illinois Basin.

Once the initial Mt. Simon well is drilled at the Mattoon Site, additional subsurface characterization would be conducted. Fracture opening/closure pressures will be determined and would be used in refining the safe injection pressure. Requiring injection pressures to be substantially below the fracture opening and fracture closure pressures greatly lowers the risk of accidental overpressure and induced fracturing of the formation, seal, or cements in wellbores, as well as lowering the risk of opening existing fractures.

\subsubsection{Effective Porosity}

Estimation of porosity for the Mt. Simon at the Mattoon Site is based on analogy with the closest well with geophysical logs through the Mt. Simon, the Humble Oil Weaber-Horn \#1 well. There is a sonic porosity log available for that well, but no core or effective porosity measurements. The use of the Weaber-Horn \#1 well as an analog appears to be very appropriate as the depth of the top of the Mt. Simon in the Weaber-Horn \#1 well is at 7,010 ft bgs, which is similar to the expected depth of the Mt. Simon at the Mattoon Site $(7,353 \mathrm{ft})$.

Porosity data were estimated by the ISGS from the Weaber-Horn \#1 sonic log using an assumed matrix velocity of 52.6 milliseconds per foot ( $\mathrm{ms} / \mathrm{ft})$, corresponding to a consolidated sandstone matrix. The median of the estimated porosities $(0.121)$ indicates that about half of the Mt. Simon porosity is in excess of $12 \%$. The median permeability corresponds to an estimated permeability of approximately 14.5 milliDarcies $(\mathrm{mD})$ using the regression equation described in Section 2.4.3.5. The estimated values of the porosity and permeability of the Mt. Simon suggest that it should be very suitable for injection of $\mathrm{CO}_{2}$. Figure 2-9 provides a histogram of the porosity calculated from the Weaber-Horn \#1 sonic log. 


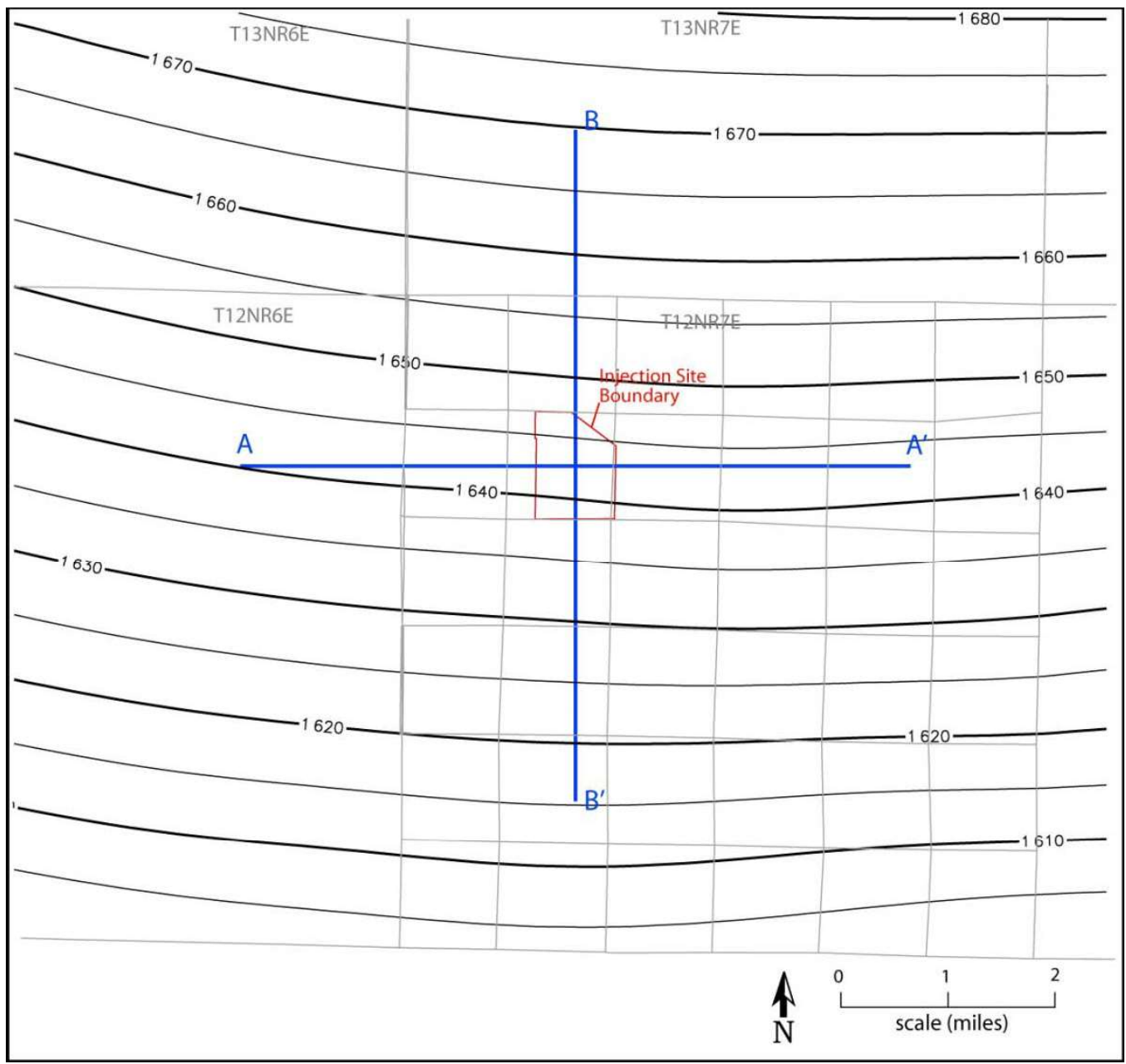

Figure 2-8. Thickness Map of Mt. Simon Sandstone for the Mattoon Area

Analysis of the Hinton No. 7 well, a deep well in the Manlove Gas Storage Field in Champaign County, Illinois, indicates that the porosity did not change substantially with depth in the reservoir (Leetaru et al., 2005). The median porosity found for the upper, middle, and lower zones in the Mt. Simon in that well varied from 9.3 to 10\% (Leetaru et al., 2005), similar to that found for the Mt. Simon in the Weaber-Horn \#1 well.

After drilling of the injection well at the Mattoon Site, a full suite of geophysical logs (including neutron, density, and sonic logs) will be run through the injection interval. Together with detailed laboratory core analysis, this will allow quantitative evaluation of the porosity of the injection interval in the Mt. Simon.

\subsubsection{Intrinsic Permeability}

There are no direct measurements of intrinsic permeability for the Mt. Simon near the Mattoon Site. In order to estimate the Mt. Simon permeability for the analog well used in Section 2.4.3.4 (Weaber-Horn \#1, Louden Field, Fayette County, Illinois), the ISGS used a regression equation developed from a porosity-permeability database that includes data from throughout the Illinois Basin (Appendix, Mattoon Subsurface Data package submitted by Illinois State Geological Survey, 1_2_7_perm_resvr_mattoon.doc). The regression equation used a reduced major axis 


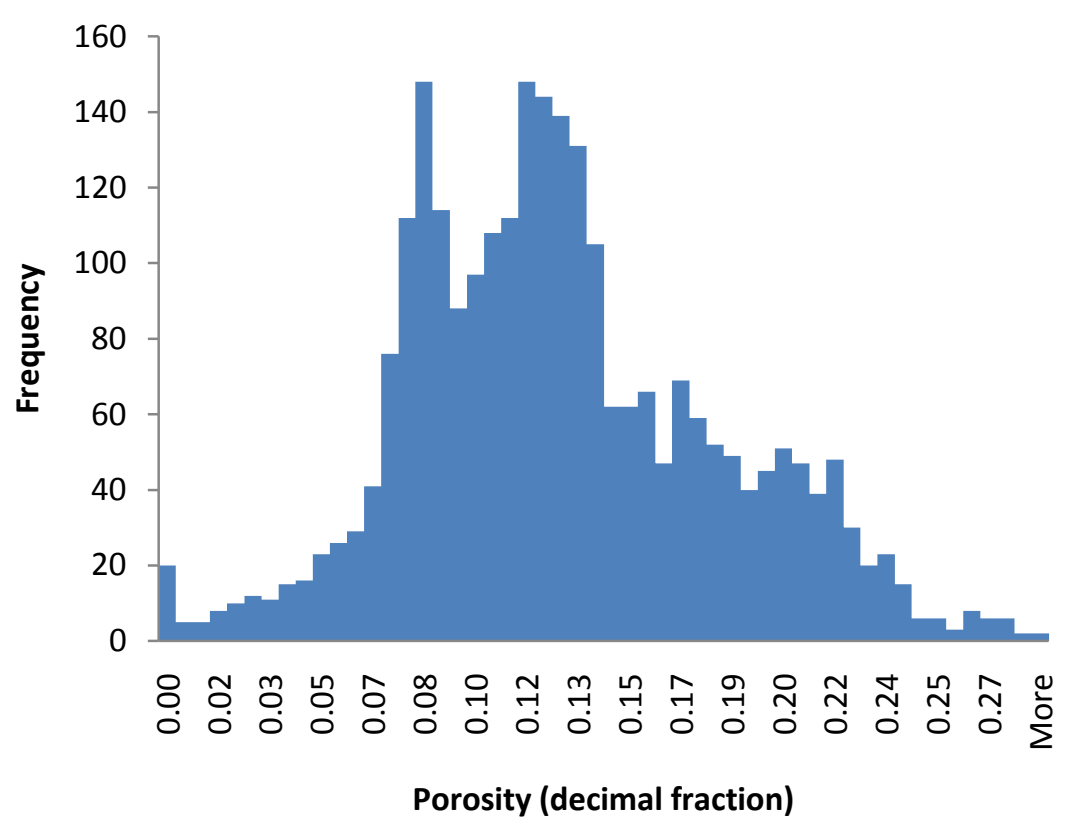

Figure 2-9. Porosity Estimated from the Sonic Log for the Humble Weaber-Horn \#1

algorithm that is appropriate when both variables are subject to error and it is not clear which variable should be considered the dependent variable (Davis, 2002). The equation relates the log of permeability to the porosity, yielding the following equation:

$$
\log (k)=0.268 \text { porosity }(\phi)-2.08
$$

where permeability $(\mathrm{k})$ is measured in $\mathrm{mD}$ and porosity is measured in percent. In order to avoid extrapolation beyond the range of the core permeability data, the maximum permeability retained from the regression equation was set to 2,600 $\mathrm{mD}$. This regression equation was used to transform porosity values from the Mt. Simon in the Weaber-Horn \#1 well to estimates of permeability.

Analysis of the estimated permeability for the Mt. Simon in the Weaber-Horn \#1 well indicated an average permeability of $384 \mathrm{mD}$ and a median permeability of $14.5 \mathrm{mD}$. The large magnitude of the average relative to the median permeability shows that the permeability estimates are positively skewed, which is usually the case for permeability data (Davis, 2002). There were approximately $592 \mathrm{ft}$ of Mt. Simon in the Weaber-Horn \#1 well with permeability exceeding a cutoff of $20 \mathrm{mD}$; average and median permeabilities were 839 and $232 \mathrm{mD}$, respectively, for those high permeability intervals.

As mentioned above, a full suite of geophysical logs (including neutron, density, and sonic logs) will be run through the injection interval. These log data, together with detailed laboratory core analyses and petrophysical analyses, will allow quantitative evaluation of the intrinsic permeability of the injection interval in the Mt. Simon at the Mattoon Site.

\subsubsection{Hydraulic Conductivity or Permeability}

There are no direct measurements of hydraulic conductivity for the Mt. Simon near the Mattoon Site. The hydraulic conductivity was estimated using the intrinsic permeability (k) values 
estimated in Section 2.4.3.5, and the following equation for hydraulic conductivity $(\mathrm{K})$ taken from Freeze and Cherry (1979):

$$
\mathrm{K}=\mathrm{k \rho g} / \mu
$$

where $\rho=$ fluid density, $\mathrm{g}=$ gravitational acceleration, and $\mu=$ dynamic viscosity.

The fluid density and dynamic viscosity are discussed in Sections 2.4.4.3 and 2.4.4.4, respectively. The gravitational acceleration constant is 9.81 meter per second squared $\left(\mathrm{m} / \mathrm{s}^{2}\right)$. For the median permeability of the Mt. Simon in the Weaber-Horn \#1 well of $14.5 \mathrm{mD}$, the estimated hydraulic conductivity equals $2.6 \times 10^{-7}$ meter per second $(\mathrm{m} / \mathrm{s})$. For the average permeability of $384 \mathrm{mD}$, the estimated hydraulic conductivity is $6.9 \times 10^{-6} \mathrm{~m} / \mathrm{s}$. For the $592 \mathrm{ft}$ of rock in the Mt. Simon in the Weaber-Horn well with an estimated intrinsic permeability greater than a cutoff of $20 \mathrm{mD}$ (Section 2.4.3.5), the median permeability of $232 \mathrm{mD}$ would correspond to an estimated hydraulic conductivity of $4.2 \times 10^{-6} \mathrm{~m} / \mathrm{s}$, while the average permeability of 839 $\mathrm{mD}$ would correspond to an estimated hydraulic conductivity of $1.5 \times 10^{-5} \mathrm{~m} / \mathrm{s}$.

\subsubsection{Storage Coefficient}

There are no direct measurements of storativity for the Mt. Simon near the Mattoon Site. The storativity was estimated using the following equation for storativity taken from Freeze and Cherry (1979):

$$
S=\rho g b(\alpha+n \beta)
$$

where $\rho=$ fluid density, $g=$ gravitational acceleration, $b=$ formation thickness, $\alpha=$ rock compressibility, $n=$ porosity and $\beta=$ fluid compressibility.

The fluid density is discussed in Section 2.4.4.3, the gravitational acceleration constant is 9.81 $\mathrm{m} / \mathrm{s}^{2}$, and $b$ was set at the estimated thickness of the Mt. Simon in Table 2-1 (1,643 ft). The estimated values of $\alpha$ and $\beta$ assume a temperature $\left(61.5^{\circ} \mathrm{C}\right)$ and pore pressure $(24.4 \mathrm{MPa})$ corresponding to those expected at the center of the Mt. Simon, estimated to be about 8,175 $\mathrm{ft}$ bgs. The estimated rock compressibility at that depth, based on linear interpolation from Table 3 of Huang and Rudnicki (2006), is $1.7 \times 10^{-10}$ Pascal $(\mathrm{Pa})^{-1}$. The estimated brine compressibility for that same temperature and pressure, based on linear interpolation from Table 6 of Huang and Rudnicki (2006), is equal to $2.1 \times 10^{-9} \mathrm{~Pa}^{-1}$. Calculation of storativity using those input parameters and the equation above yielded an estimate of 0.0023 (dimensionless value).

\subsubsection{Seepage Velocity (ft/yr) and Flow Direction of Formation Water}

The groundwater flow directions and velocity in the Mt. Simon are poorly understood in the Mattoon area due to a lack of deep well control. Bond (1972) suggested that flow in the Mt. Simon in southern Illinois was generally to the south, with a possible discharge area in the Rough Creek Fault Zone in the deeper part of the basin. Estimated flow rates in the Mt. Simon were very slow, on the order of inches per year (Bond, 1972). Bond (1972) indicated that conclusions about flow in the Mt. Simon in the deeper portions of the Illinois Basin were questionable due to the sparseness of the data and the sensitivity of the calculations to interpretations of drill-stem test results.

Gupta and Bair (1997) evaluated flow directions in the Mt. Simon using a three-dimensional (3D) steady state, variable density finite difference flow model for midcontinent basins, including 
the eastern portion of the Illinois Basin. Their conceptual flow model (Figure 2-10) suggested that flow in the Mt. Simon was directed away from structural arches and towards the deeper portions of structural basins. Specifically, they suggested that flow directions in eastern Illinois would be towards the deeper portions of the Illinois Basin (Figure 2-10). Velocity vectors provided by numerical modeling that they conducted for the study supported the conceptual flow model, with flow patterns in the Illinois Basin directed westward from the uplifted Cincinnati Arch region towards the center of the Illinois Basin. The results of Gupta and Bair (1997), taken together with the structural map of the Mt. Simon Formation in the Illinois Basin produced by the ISGS (Figure 2-11), generally agree with the conclusions of Bond (1972), suggesting that flow in the Mt. Simon in the Mattoon area should be generally to the south, towards the center of the Illinois Basin.

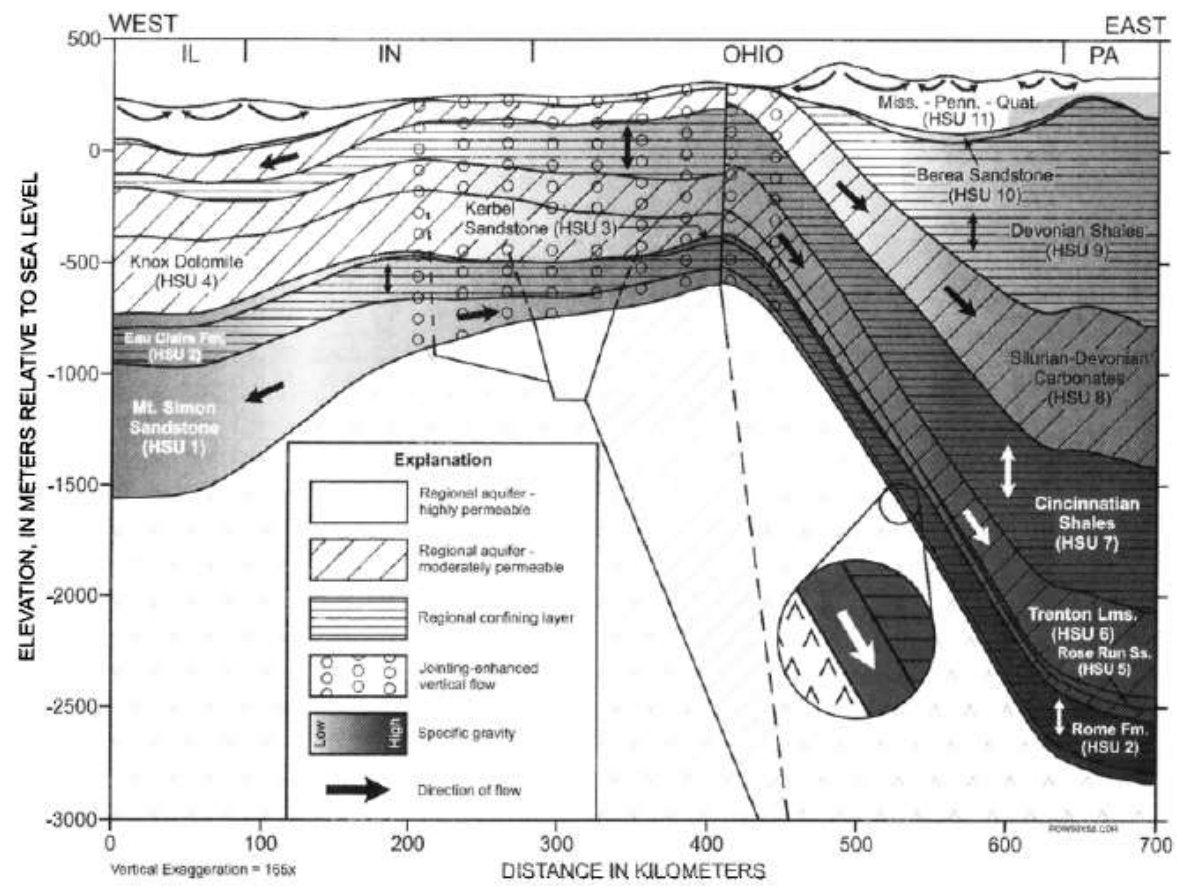

Figure 2-10. Conceptual Flow Model for the Midcontinent Basins and Arches (from Gupta and Bair, 1997)

Evidence for vertical flow in the Mt. Simon in the northeastern Illinois Basin was presented by Gupta and Bair (1997) (Figure 2-12). A drill stem test in that area suggested upward flow from the Mt. Simon and vertical flow vectors calculated from their numerical modeling supported that conclusion (Gupta and Bair, 1997). Leetaru et al. (2005) suggested that this vertical movement from the Mt. Simon into the Eau Claire would support a hypothesis proposed by Bredehoeft et al. (1963) to explain the high brine concentrations found in many deep basins, including the Illinois Basin. That hypothesis suggests that confining layers like the Eau Claire function as osmotic barriers, allowing water to move upward from the permeable units, but leaving behind the salt. Leetaru et al. (2005) point out that this would be a very slow process, taking place over hundreds of thousands of years.

This summary provides the best information currently available for the expected flow in the Mt. Simon, however, none of it is local and most of it is based on data and modeling from the surrounding region. Extensive hydraulic testing of the Mattoon injection well and monitoring of 


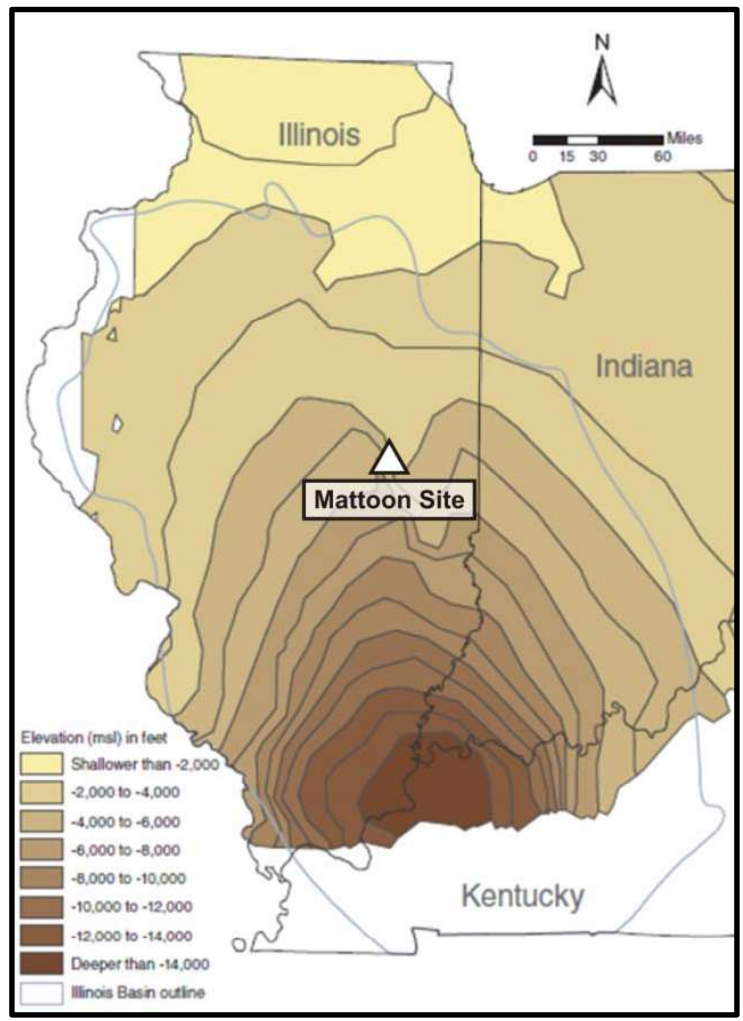

Figure 2-11. Regional Structure Map for the Mt. Simon Formation in the Illinois Basin (from Leetaru et al., 2005)

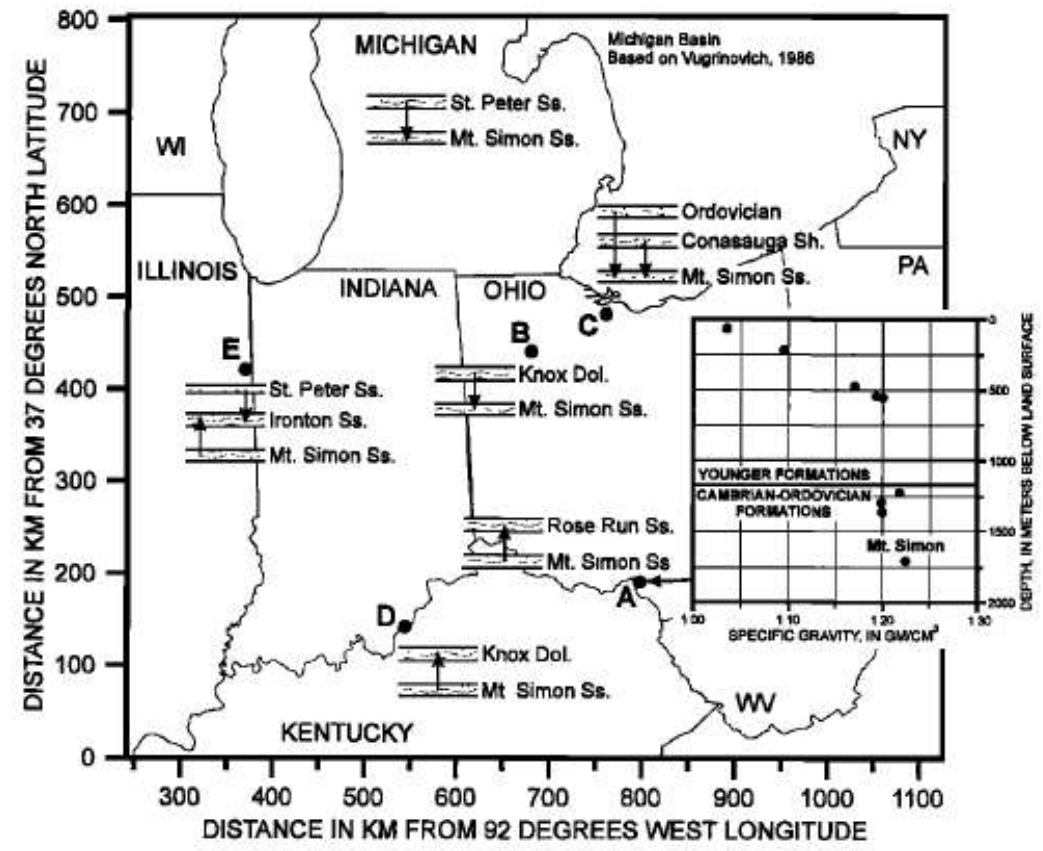

Figure 2-12. Evidence for Vertical Flow in the Mid-continent Basins and Arches (from Gupta and Bair, 1997) 
The carbon dioxide $\left(\mathrm{CO}_{2}\right)$ plume will be used to provide more quantitative and local information on flow directions and velocity in the Mt. Simon at the Mattoon Site.

\subsubsection{Characteristics of Injection Zone Formation Water}

\subsubsection{Temperature}

Based on the expected depth interval for the Mt. Simon (Table 2-1), the formation temperature in the Mt. Simon should vary from 57 degrees Celsius $\left({ }^{\circ} \mathrm{C}\right)\left(134\right.$ degrees Fahrenheit $\left.\left[{ }^{\circ} \mathrm{F}\right]\right)$ at the top of the formation to $63^{\circ} \mathrm{C}\left(145^{\circ} \mathrm{F}\right)$ at the base. The estimated temperatures are based on the assumption of a geothermal gradient of $1^{\circ} \mathrm{F} / 100 \mathrm{ft}$ from a near-surface datum of $16.7^{\circ} \mathrm{C}\left(62^{\circ} \mathrm{F}\right)$ at $100 \mathrm{ft}$ (Leetaru et al., 2005, p. 310). These temperatures are well above the threshold required to maintain the injected $\mathrm{CO}_{2}$ in a supercritical state $31.1^{\circ} \mathrm{C}\left(87.9^{\circ} \mathrm{F}\right)$.

\subsubsection{Pressure}

Pressures within the Mt. Simon Formation should vary from 3,184 psi at the top to 3,895 psi near the base. This assumes a freshwater pressure gradient of $0.433 \mathrm{psi} / \mathrm{ft}$, based on Leetaru et al. (2005) and the estimated elevations of the top and base of the Mt. Simon given in Table 2-1.

\subsubsection{Density}

No nearby data are available for the density of the interstitial water in the Mt. Simon at the Mattoon Site, so the density was estimated using a correlation between relative density and total dissolved solids (TDS) established for the Illinois Basin (Bond, 1972). The estimation of the TDS value for the Mattoon Site is provided in Section 2.4.4.5, where it is estimated to be approximately 130,000 parts per million (ppm), or its equivalent unit, microgram per liter (mg/L) (Figure 2-13). Using the correlation provided in Bond (1972, Figure 9) and a TDS value of $130,000 \mathrm{mg} / \mathrm{L}$, the relative density of the interstitial water in the Mt. Simon is estimated to be 1.09 , which corresponds to a density of approximately $1,090 \mathrm{~kg} / \mathrm{m}^{3}$.

\subsubsection{Viscosity}

Viscosity data are not available for the formation fluid in the Mt. Simon Sandstone in the area of the Mattoon Site. Assuming that sodium chloride is the dominant salt present in the brine, the viscosity of the formation fluid was estimated using tables published in Kestin et al. (1981). The tables in that publication provide estimates of the viscosity based on the expected salinity, temperature, and pressure of the solution. Based on the temperature, pressure, and salinity estimates provided in Sections 2.4.4.1, 2.4.4.2, and 2.4.4.5, respectively, the estimated viscosity ranges from $5.48 \times 10^{-4}$ to $6.23 \times 10^{-4} \mathrm{~Pa} \mathrm{~s}\left(5.48 \times 10^{-1}\right.$ to $6.23 \times 10^{-1}$ centipoises [cp]). The average of that range, $5.85 \times 10^{-4} \mathrm{~Pa} \mathrm{~s}\left(5.85 \times 10^{-1}\right.$ centipoises $)$, was used in the calculation of the hydraulic conductivity of the Mt. Simon (Section 2.4.3.6) and the Eau Claire formations (Section 2.5.3.4).

\subsubsection{Total Dissolved Solids}

Salinity data from the Mt. Simon Sandstone are sparse in the Illinois Basin, with the few measurements available confined to natural gas storage fields in which the Mt. Simon is the storage reservoir (Leetaru et al., 2005).

The salinity of the Mt. Simon at the Mattoon Site was estimated from a regional Mt. Simon map published by the ISGS (Leetaru et al., 2005). Based on the location of the Mattoon Site on the 


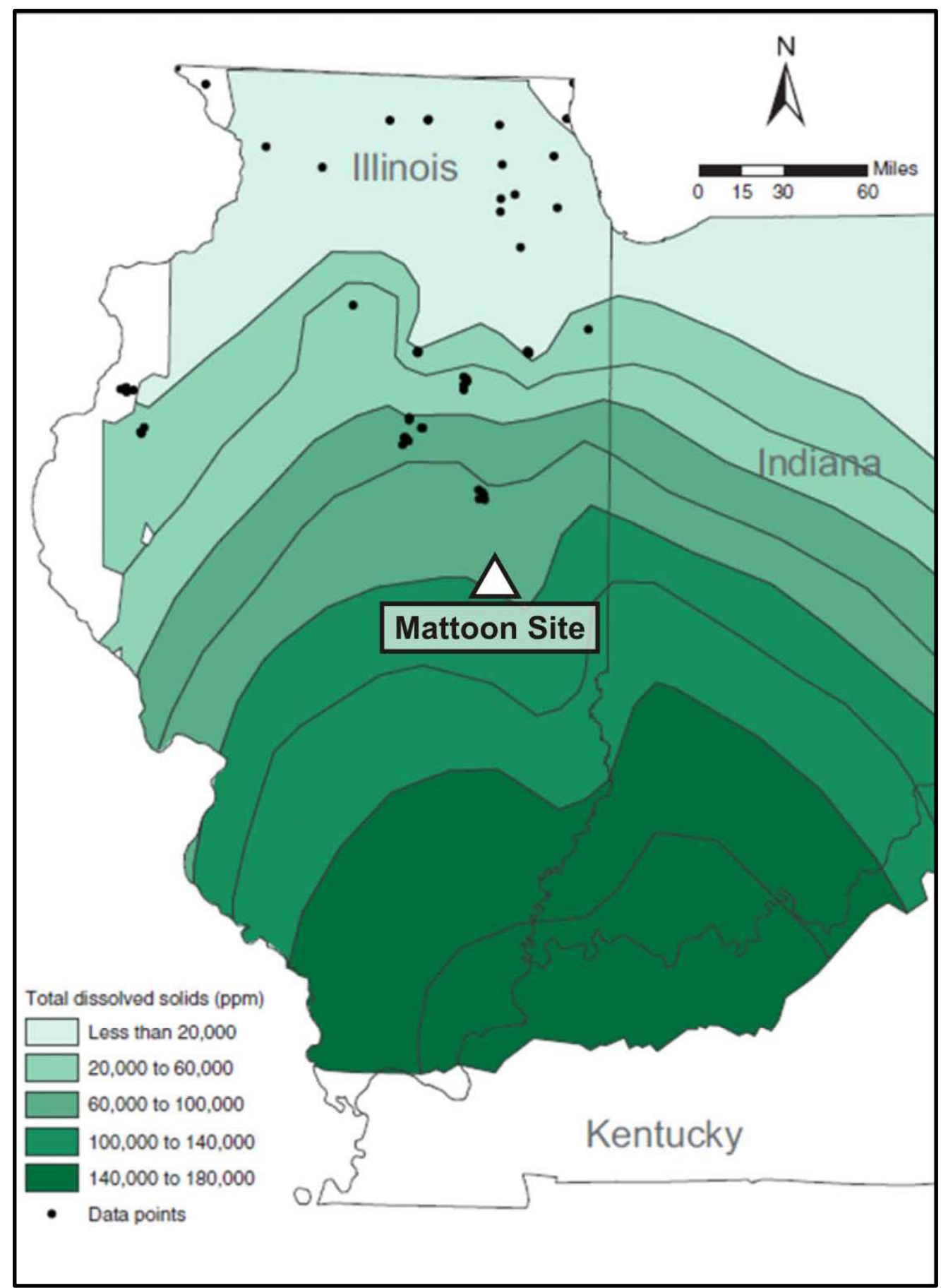

Figure 2-13. Total Dissolved Solids Map for the Mt. Simon Sandstone (from Leetaru et al., 2005, Figure 3-32) 
map (Figure 2-13), the salinity was estimated to be between 100,000 and 140,000 ppm. A salinity value of 130,000 ppm (Appendix, Mattoon Subsurface Data package submitted by Illinois State Geological Survey, 1_1_3_ReservoirGeology_Mattoon.doc) was used in modeling the injection and transport of $\mathrm{CO}_{2}$ at the site (see Section 5.4), and in calculations of the density and viscosity of the injection zone formation water (Sections 2.4.4.3 and 2.4.4.4, respectively).

\subsubsection{Potentiometric Surface}

No penetrations of the Mt. Simon exist in the Mattoon area, so the elevation of the potentiometric surface is not accurately known. A drillstem test from the Weaber-Horn \#1 well had a pressure gradient essentially equivalent to a freshwater gradient of $0.433 \mathrm{psi} / \mathrm{ft}$ (9.79 kiloPascal $[\mathrm{kPa}] / \mathrm{m})$ (Appendix, Mattoon Subsurface Data package submitted by Illinois State Geological Survey, 1_2_3_pressure_resvr_mattoon.doc). Assumption of a freshwater gradient for the Mt. Simon Sandstone at the Mattoon location suggests that the potentiometric surface should be equal to the ground surface.

Hydraulic testing of the initial well at the Mattoon Site will be used to quantify the potentiometric surface of the Mt. Simon.

\subsubsection{Additional or Alternative Zones Considered for Injection}

No other injection zones are being considered for this project.

\subsection{Upper Confining Zone}

At least three sealing units should overlie the Mt. Simon Formation at the Mattoon Site. The most important of these is the Cambrian-age Eau Claire Formation, which directly overlies the Mt. Simon and is discussed in detail below. The Ordovican-age Maquoketa Formation and the Devonian-age New Albany Formation provide important secondary seals for the Mt. Simon and are briefly discussed in Section 2.5.3.5.

The Eau Claire Formation provides the primary seal for a large number of gas storage fields in the Illinois Basin (Morse and Leetaru, 2005). It is a regionally extensive unit, and a regional cross-section shows that the Eau Claire should consist of a thick section of shale in the central Illinois basin (e.g., Leetaru et al., 2005, Figure 3-9). The Eau Claire has been extensively studied at Manlove and Herscher gas storage fields, where it provides an effective seal for gas storage in the Mt. Simon (Morse and Leetaru, 2005). The middle section of the Eau Claire, in particular, has been shown to consist of shale beds that provide an effective seal, preventing the upward migration of gas from the Mt. Simon into overlying formations (Morse and Leetaru, 2005).

\subsubsection{Geologic Name(s) of Confining Zone}

The main confining zone will be the Cambrian-age Eau Claire Formation. An isopach map based on projection of regional well control by the ISGS indicates that the Eau Claire should be approximately $648 \mathrm{ft}$ thick at the Mattoon Site (Figure 2-14).

\subsubsection{Depth Interval of Upper Confining Zone Beneath Land Surface}

The estimated depth to the top of the Eau Claire Formation is approximately 6,705 $\mathrm{ft}$ (Table 21), with the base expected at 7,353 ft. 


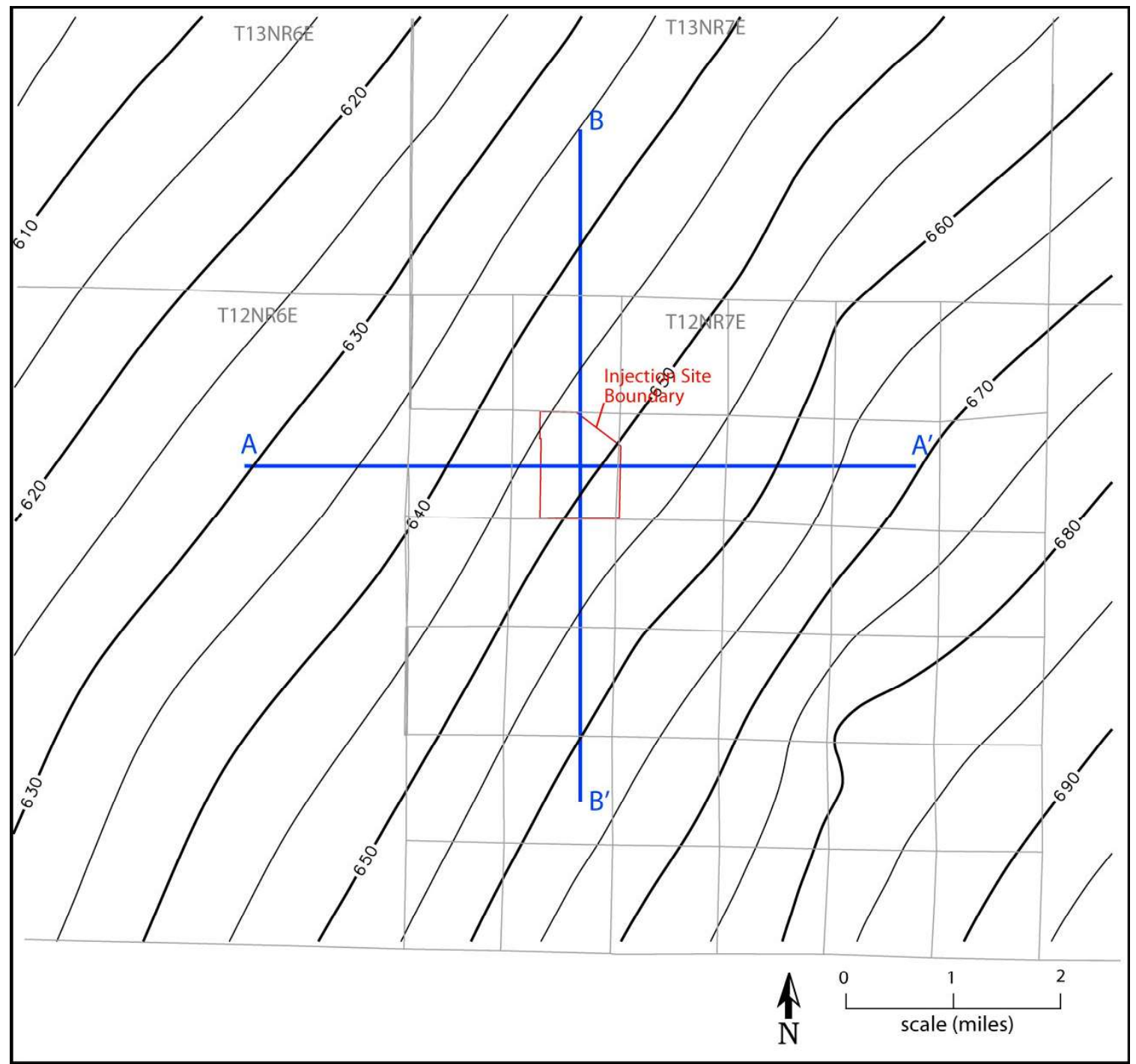

Figure 2-14. Thickness Isopach Map for Eau Claire Shale, the Upper Confining Zone for the Mt. Simon Sandstone at the Mattoon Site

\subsubsection{Characteristics of Confining Zone}

\subsubsection{Lithologic Description}

The Eau Claire Formation consists of siltstone or shale in the central part of the Illinois basin, and a mixture of dolomite and limestone interbedded with fine-grained clastic rocks in the southern portion of the basin (Leetaru et al., 2005). A cross-section of the Cambrian System in the Illinois basin suggests that the Eau Claire is a thick, regionally extensive shale unit in the central Illinois Basin (Leetaru et al., 2005, Figure 3-9). Shales in the middle portion of the Eau Claire are known to provide an effective seal for many Mt. Simon gas storage fields in Illinois (Morse and Leetaru, 2005).

\subsubsection{Fracture Pressure at Depth}

Because the actual pressures that would cause new or existing fractures to open in the Eau Claire are not known, the maximum injection pressure will be set conservatively, at $85 \%$ of the 
$0.8 \mathrm{psi} / \mathrm{ft}$ gradient that is required by Illinois regulation. Leetaru et al. (2005, p. 312) reported that fracture stimulation companies commonly use a fracture gradient of $1.0 \mathrm{psi} / \mathrm{ft}$ when stimulating wells in the Illinois Basin.

Once the initial Mt. Simon well is drilled at the Mattoon Site, additional subsurface characterization will be conducted. Fracture opening/closure pressures would be determined and would be used in refining the safe injection pressure. Limiting injection pressures to substantially below the fracture opening and fracture closure pressures greatly lowers the risk of accidental overpressure and induced fracturing of the formation, the seal, or cements in wellbores, as well as lowering the risk of opening existing fractures.

\subsubsection{Intrinsic Permeability}

The permeability of the seal is the main control on slow permeation that can ultimately result in seal failure. The thick primary seal in the Eau Claire is a mix of low permeability lithologies that serves as a competent caprock in 38 natural gas storage reservoirs in Illinois (FutureGen Alliance, 2006). According to the ISGS in material provided to support the Mattoon Environmental Information Volume (Appendix, Mattoon Subsurface Data package submitted by Illinois State Geological Survey, 1_3_4 Seal_Geolog_Mattoon.doc), the primary Eau Claire seal was studied in detail by Peoples Gas Light and Coke before they installed the Manlove Gas Storage Field, $93.3 \mathrm{~km}$ (58 miles) north of the Mattoon site. The Eau Claire at the Manlove field has porosities ranging from less than $1 \%$ to as much as $10 \%$, with corresponding vertical permeabilities that range from less than 0.00001 to $0.0005 \mathrm{mD}$ (Appendix, Mattoon Subsurface Data package submitted by Illinois State Geological Survey, 1_3_4 Seal_Geolog_Mattoon.doc). Extensive pressure testing of the Mt. Simon Formation at Manlove Gas Storage Field indicated that the Eau Claire Formation provided an effective seal for the Mt. Simon (Morse and Leetaru, 2005) and the field has received extensive use as a gas storage facility.

\subsubsection{Hydraulic Conductivity}

There are no direct measurements of hydraulic conductivity for the Eau Claire near the Mattoon Site. The hydraulic conductivity was estimated using the intrinsic permeability (k) values estimated in Section 2.5.3.3, and the equation for hydraulic conductivity in Section 2.4.3.6 of the Eau Claire would be estimated to range from $<1.8 \times 10^{-13}$ to $9.0 \times 10^{-12} \mathrm{~m} / \mathrm{s}$.

The fluid density and dynamic viscosity are discussed in Sections 2.4.4.3 and 2.4.4.4, respectively. The gravitational acceleration constant is $9.81 \mathrm{~m} / \mathrm{s}^{2}$. For the range of intrinsic permeability given in Section 2.5.3.3 $(<0.00001$ to $0.0005 \mathrm{mD})$, the hydraulic conductivity of the Eau Claire would be estimated to range from $<1.8 \times 10^{-13}$ to $9.0 \times 10^{-12} \mathrm{~m} / \mathrm{s}$.

After drilling of the injection well at the Mattoon Site, a full suite of geophysical logs including neutron, density, and sonic logs will be run through the injection interval. Together with detailed laboratory core analysis and petrophysical analysis, as well as the analysis of drill stem test results, this will allow quantitative evaluation of the porosity, intrinsic permeability, and hydraulic conductivity of the Eau Claire.

\subsubsection{Alternative Confining Zones Proposed, Include Explanation and Depth Interval(s)}

Two secondary shale seals above the Eau Claire provide backup to the main seal (Table 2-1) (Appendix, Mattoon Subsurface Data package submitted by Illinois State Geological Survey, 
1_3_6 Seal Porosity and Diagenesis_Mattoon.doc). The Devonian-Mississippian-age New Albany Shale at an expected depth of 3,262 ft and the Ordovician-age Maquoketa Shale at an expected depth of 3,926 ft are both dominantly marine shales with vertical permeabilities to water of $0.001 \mathrm{mD}$ or less. The New Albany shale, in particular, is characterized by thick black, organic-rich shale (Leetaru et al., 2005), with vertical permeabilities of less than $0.0001 \mathrm{mD}$, and is a regional seal to hydrocarbon accumulations (FutureGen Alliance, 2006) as well as several gas storage facilities in Illinois (Appendix, Mattoon Subsurface Data package submitted by Illinois State Geological Survey, 1_3_6 Seal Porosity and Diagenesis_Mattoon.doc). The thickness of the New Albany is expected to be about $110 \mathrm{ft}$ at the Mattoon Site, and the thickness of the Maquoketa is expected to be about $200 \mathrm{ft}$ (Table 2-1).

\subsection{Lower Confining Zone}

The lower confining zone is the Precambrian-age granite basement. Figure 2-15 depicts a structural elevation map for the top of the basement. The $\mathrm{CO}_{2}$ injection interval will be above the lower confining zone and, due to the buoyancy of the injected $\mathrm{CO}_{2}$, the fracture pressure, porosity, and permeability of the granite will not impact injection or fluid migration. Modeling results that illustrate the buoyant nature of the $\mathrm{CO}_{2}$ within the Mt. Simon can be seen in Section 5.4, and indicate that the physical integrity of the lower confining zone should not be an issue during injection of $\mathrm{CO}_{2}$ at the Mattoon Site.

\subsubsection{Geologic Name(s) of Confining Zone}

The lower confining zone is the Precambrian-age granite basement.

\subsubsection{Depth Interval of Lower Confining Zone Beneath Land Surface}

There is no nearby well control to determine the depth of the granite basement. Given the estimate of the top and thickness of the Mt. Simon, the granite basement is expected to be encountered at a depth of approximately 8,996 ft (Table 2-1). The Precambrian-age basement will constitute the base of sediment at the Mattoon Site, so there is no thickness given for the lower confining zone.

\subsubsection{Characteristics of Confining Zone}

\subsubsection{Lithologic Description}

The Precambrian basement in the Illinois Basin consists of rhyolitic and dacitic volcanic deposits and chemically similar shallow granitic plutons that formed between 1.42 and 1.5 billion years ago (Bickford et al., 1986).

\subsubsection{Fracture Pressure at Depth}

The authors know of no data on the fracture pressure of granites in Illinois. Given the buoyant nature of the $\mathrm{CO}_{2}$ plume, the fracture pressure of the granite should not have any effect on migration of the $\mathrm{CO}_{2}$.

\subsubsection{Intrinsic Permeability}

The authors know of no data on the intrinsic permeability of granites in Illinois. Although granites generally have very low effective porosity and permeability (Domenico and Schwartz, 1990), the porosity and permeability will vary depending on the grain size, mineralogy, and degree of weathering and fracturing of the granite. No data are available for those 


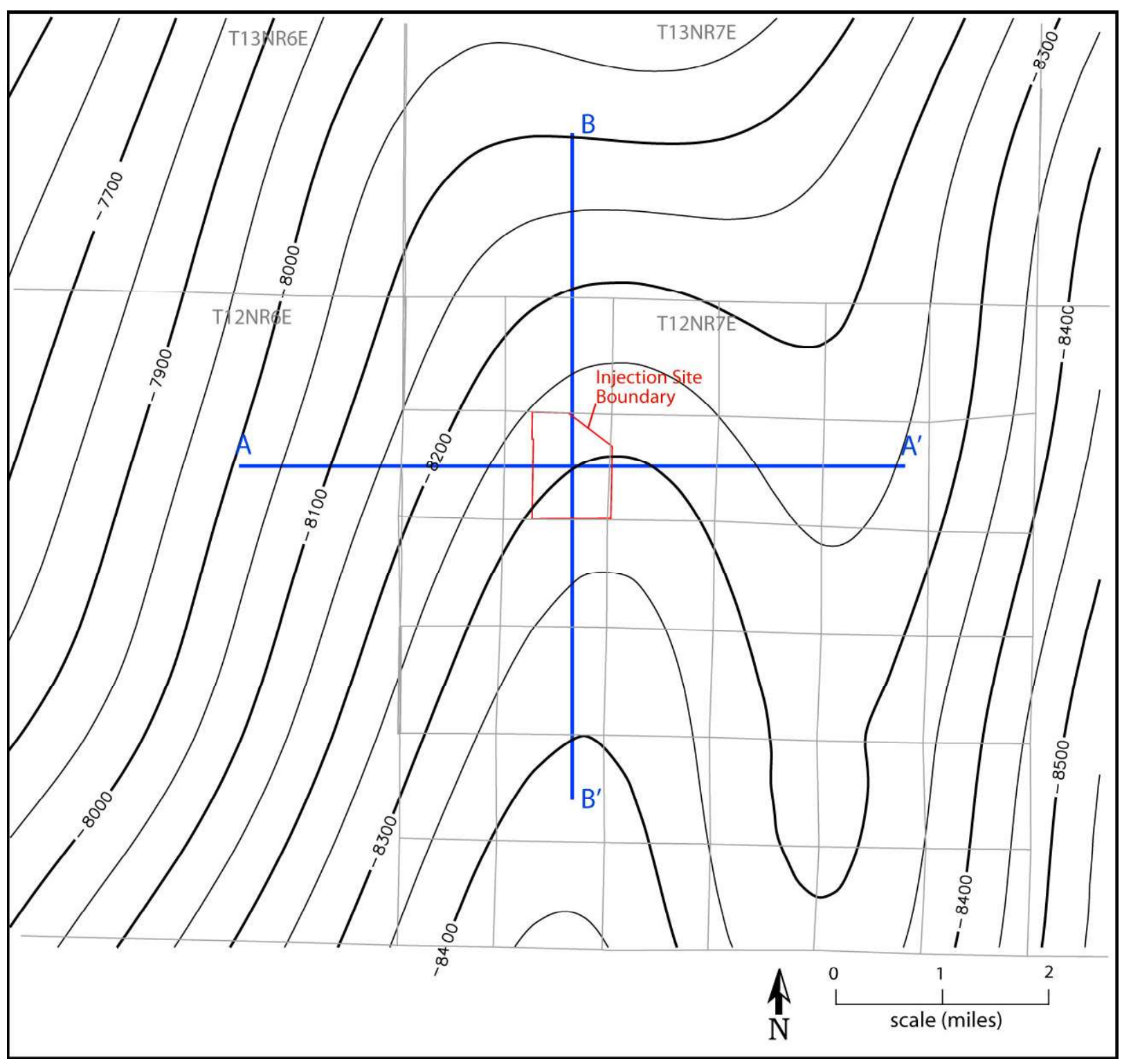

Figure 2-15. Structural Contour Map for the Elevation of the Top of the Precambrian-Age Granitic Basement, Relative to Mean Sea Level

characteristics of the Precambrian basement in the Mattoon area, so the intrinsic permeability of the lower confining unit could not be estimated.

\subsubsection{Hydraulic Conductivity}

The authors know of no data on the hydraulic conductivity of granites in Illinois. Granites generally have extremely low hydraulic conductivity, varying from $3 \times 10^{-14} \mathrm{~m} / \mathrm{s}$ for unfractured igneous rocks to $3 \times 10^{-4} \mathrm{~m} / \mathrm{s}$ for fractured igneous rocks (Domenico and Schwartz, 1990, Table $3-2$, p. 65). The hydraulic conductivity will depend on the permeability of the granite. As noted in Section 2.6.3.3, the intrinsic permeability will vary depending on the grain size, mineralogy, and degree of fracturing in the granite (Domenico and Schwartz, 1990). No data 
are available for those characteristics of the Precambrian basement in the Mattoon area, so the hydraulic conductivity of the lower confining unit could not be estimated.

\subsubsection{Alternative Confining Zones Proposed}

There are no alternative confining zones expected below the Precambrian-age granitic basement. Given the silica-rich nature of the basement in the eastern granite-rhyolite province, Bickford et al. (1986) suggest that the granitic rocks are sitting atop older Proterozoic crust that would also be expected to have a granitic composition.

\subsection{Overlying Sources of Groundwater at the Site}

\subsubsection{Characteristics of the Aquifer Immediately Overlying the Confining Zone}

At the Mattoon site, the confining zone immediately above the Mt. Simon Sandstone is the Eau Claire shale. Throughout the northern half of Illinois, the geologic unit overlying the Eau Claire shale is the Ironton and Galesville sandstone. However, based on a published IEPA isopach map (Figure 2-16), the Ironton/Galesville is most likely absent in the Mattoon area (Student et al., 1981). In the absence of the Ironton/Galesville, the geologic unit immediately overlying the Eau Claire shale at the Mattoon site would be the Cambrian-age Franconia formation, which underlies all of Illinois and is estimated to be $300 \mathrm{ft}$ thick at the site. The Franconia formation generally consists of glauconitic argillaceous shaly-sandstone and dolomite, and is a waterbearing formation. An isopach map of the estimated thickness of the Franconia formation in Illinois is included and shown in Figure 2-17 (Student et al., 1981). This map also illustrates the trend in TDS that typically occurs in the Franconia formation. In the southern half of the state (including Mattoon), the TDS is typically $>10,000 \mathrm{mg} / \mathrm{L}$.

\subsubsection{Elevation at Top of Aquifer}

The top of the Franconia Formation has an estimated elevation of 5,707 ft below MSL at the Mattoon site location. This estimated elevation is based on a set of formation structure contour maps that were provided by the ISGS, and input by Battelle into the EarthVision ${ }^{\circledR}$ software model. The output data from the model were used to estimate the elevations of various stratigraphic units, referenced from a point at the center of the site. The elevation of the top of the Franconia Formation was then estimated as shown in Table 2-2 (based on the EarthVision ${ }^{\circledR}$ output data and the thickness map in Figure 2-17).

Table 2-2. Estimated Elevation and Thickness - Franconia Formation

\begin{tabular}{|c|c|c|}
\hline $\begin{array}{c}\text { Estimated Thickness } \\
\text { (ft) }\end{array}$ & $\begin{array}{c}\text { Estimated Bottom Elevation } \\
\text { (ft below MSL) }\end{array}$ & $\begin{array}{c}\text { Estimated Top Elevation } \\
\text { (ft below MSL) }\end{array}$ \\
\hline 300 & 6,007 & 5,707 \\
\hline
\end{tabular}

\subsubsection{Potentiometric Surface}

Insufficient data are available regarding the potentiometric surface of the Franconia Formation, as there are very few wells that penetrate this formation in the region around the site. An estimate of the potentiometric surface of the Midwest Bedrock Aquigroup (which includes the water-bearing units immediately above the Eau Claire shale) is contained in the ISGS report "Geology, Hydrology, and Water Quality of the Cambrian and Ordovician Systems in Northern 


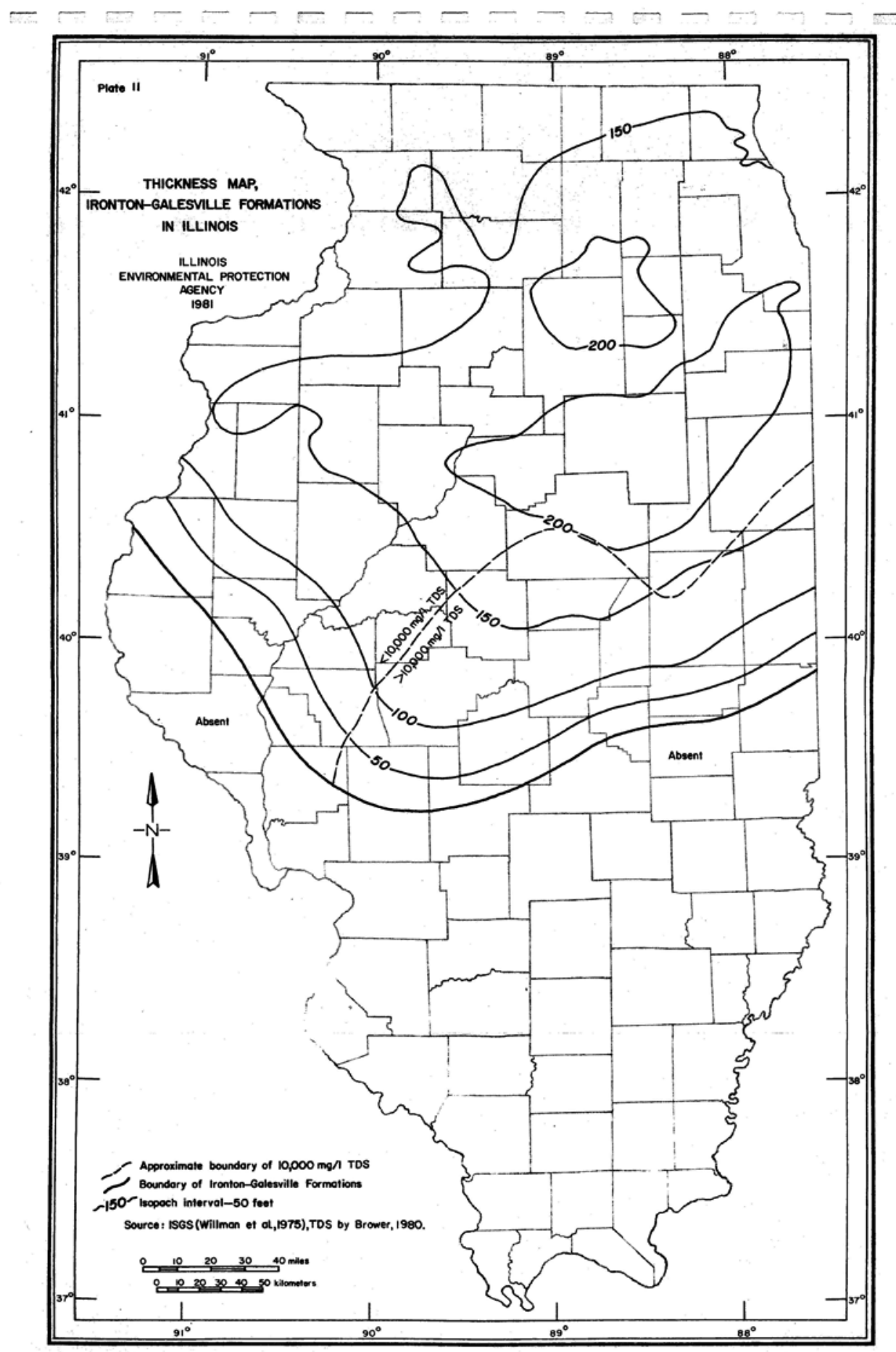

Figure 2-16. Thickness Map of the Ironton/Galesville formation in Illinois (Student et al., 1981) 


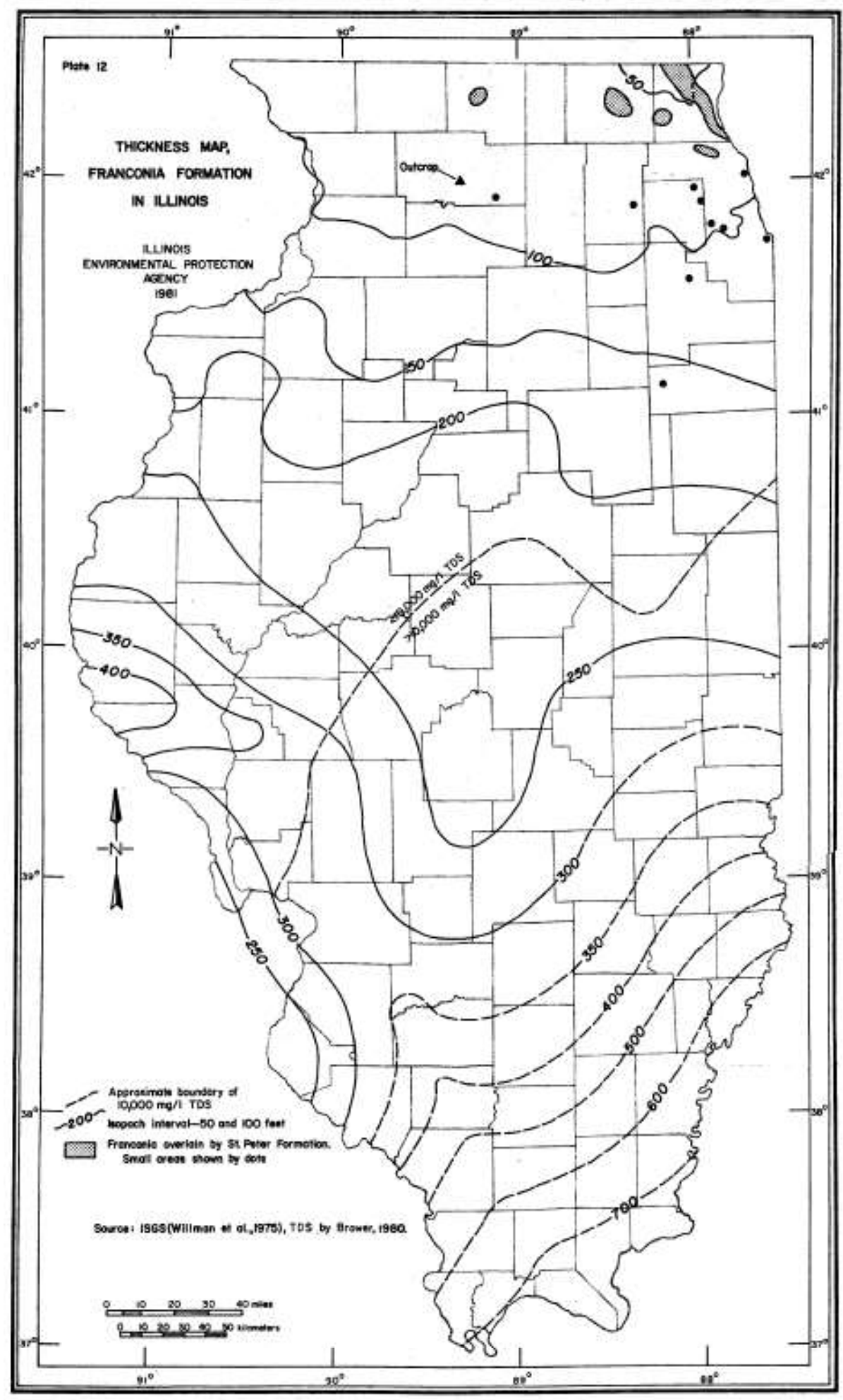

Figure 2-17. Thickness Map of the Franconia Formation in Illinois (Student et al., 1981) 
Illinois" (ISGS, 1985, pg 68, Figure 26). This publication includes limited data for the central portion of Illinois, but does include an estimated potentiometric surface level of $500 \mathrm{ft} \mathrm{MSL}$ for the Midwest Bedrock Aquigroup in northwestern Coles County.

\subsubsection{Total Dissolved Solids}

Limited information is available regarding the TDS concentrations in the groundwater in the Franconia Formation at the Mattoon site. The closest data on TDS in the Franconia comes from a well in Douglas County to the north of the site. This well was installed into the Franconia Formation to a depth of $3,095 \mathrm{ft}$ and included a brine analysis with TDS listed as $27,000 \mathrm{ppm}$ (Student et al., 1981).

\subsubsection{Lithology}

The Franconia Formation generally consists of glauconitic, argillaceous sandstone and dolomite. From north to south in Illinois, the lower part of the formation becomes increasingly shaly and the upper part grades to silty and sandy dolomite. In central and southern Illinois, the glauconitic sandstone is absent, and the silty, shaly sandstone is overlain directly by relatively pure dolomite (Willman et al., 1975).

\subsubsection{Aquifer Thickness}

The Franconia Formation is approximately $300 \mathrm{ft}$ thick underneath the site (Willman et al., 1975). The Franconia Formation occurs at a depth of approximately 6,405 to $6,705 \mathrm{ft} b g s$, and an elevation of approximately -5707 to $-6007 \mathrm{ft} \mathrm{MSL}$ (refer to Table 2-1, using an estimated grade elevation for the center of the Mattoon site of $698 \mathrm{ft} \mathrm{MSL).}$

\subsubsection{Specific Gravity}

The authors know of no information regarding the specific gravity of the Franconia Formation.

\subsubsection{Underground Sources of Drinking Water}

Groundwater resources in the area immediately surrounding and including the proposed power plant site are available in limited quantities based on information obtained from the ISGS's Water Well Database, and referenced in Section 6 of the "Mattoon Site Environmental Volume" (FutureGen Alliance, Inc., 2006). In general, groundwater in the vicinity of Mattoon is normally obtained from sand and gravel deposits that are contained within the unconsolidated Quaternary-age material above bedrock. The sand and gravel deposits for the vicinity of the proposed power plant site range in depth from about 25 to $125 \mathrm{ft}$ bgs. The sand and gravel deposits are sufficient groundwater sources when small or large diameter drilled wells are constructed for domestic and farm uses. Bedrock is indicated by a boring on the southwest border of the site to be approximately $90 \mathrm{ft}$ below the surface.

According to Allen Wehrmann, Senior Hydrologist and Director for the Center for Groundwater Science of the Illinois State Water Survey (ISWS) in 2006, there is no identified major shallow aquifer present at the proposed site. The shallow groundwater at the site exists in sporadic sand and gravel lenses, or discontinuous layers of sand. There were no specific data available on the recharge capacity and transmissivity of the sand and gravel deposits located in the vicinity of the proposed power plant site. Mr. Wehrmann stated that the only transmissivity data the ISWS had available for the area was for three public wells located in Cooks Mills, Illinois and one public well located in Mattoon, Illinois. Cooks Mills is located approximately 5 miles north of 
the proposed power plant site, and in, 1979, transmissivity values were obtained for each well. The transmissivity values of the three wells were 7,920 gallons per day per foot (gpd/ft), 13,200 $\mathrm{gpd} / \mathrm{ft}$, and 12,160 gpd/ft with well depths of $33 \mathrm{ft}, 30 \mathrm{ft}$, and $28 \mathrm{ft}$, respectively. The public well in Mattoon was located approximately four miles southeast of the proposed power plant site, and in 1939 the transmissivity was obtained. The transmissivity of the well was $10,000 \mathrm{gpd} / \mathrm{ft}$, with a total well depth of $56 \mathrm{ft}$. Recharge capacity information for the proposed power plant site and local vicinity was unavailable. However, based on a potential yield of 50,000 gallons (gals) per day per square mile, Mr. Wehrmann estimated that the vicinity of the proposed power plant site might exhibit a recharge capacity equal to or less than approximately one inch per year. According to Bill Wallace of the Moultrie County Rural Water District, public water supply is provided to the proposed site area by Moultrie County Rural Water District (MCRWD). The water service extends to County Road 200E by means of a 4 inch water main. MCRWD obtains its water supply from wells that are owned by the City of Sullivan, Illinois, which is located approximately 12 miles northwest of the proposed plant site. The area in the vicinity of the proposed power plant site does not consume significant quantities of water from MCRWD.

\subsubsection{Maps and Cross Sections Required by 730.114(a)(4) or 730.134(a)(4)}

Refer to Figure 2-6 and Figure 2-7, which include the deep stratigraphy that separates the upper Quaternary deposits from the deeper injection zone, and to Figure 2-18 and Figure 2-19 depicting cross-sections through the unconsolidated deposits which constitute the lowest underground source of drinking water (USDW).

\subsubsection{Lowest Depth of Underground Source of Drinking Water}

Public water supplies in Coles County are generally obtained from surface water, with a small amount obtained from groundwater. Groundwater in the county is normally obtained from sand and gravel aquifers that are contained in unconsolidated material above bedrock. The sand and gravel deposits in the vicinity of the proposed power plant site range in depth from approximately 25 to $125 \mathrm{ft}$ bgs (ISGS Water Well Database).

The FutureGen Alliance Environmental Impact Statement states that potable water is not likely to be found below $175 \mathrm{ft}$ at the site. Water well data from private wells in the vicinity of the site, provided by the ISGS, confirms that any water tested below $175 \mathrm{ft}$ was found to be too mineralized for potable use. Therefore, the lowest USDW is considered to be the unconsolidated deposits of sand and gravel above bedrock. The ISGS water well database for a well located approximately 3 miles to the northeast of the site (well log \# 120290173200 , drilled in 1962) indicated a depth to bedrock of $105 \mathrm{ft}$ bgs at that location.

\subsubsection{Elevation of Potentiometric Surface of Lowest USDW Referenced to Mean Sea Level}

The review of available ISGS water well log data within the AOR indicates that the well data are highly variable and the manner of logging field data was inconsistent. Many of the well logs for the wells screened in the lowest USDW did not list a static water level. The water level data that were obtained from the well logs was highly variable when comparing wells screened within the same approximate range of depth. For those wells screening groundwater between 100 to 175 $\mathrm{ft}$ bgs, reported static water levels in the lowest USDW ranged from 16 to $35 \mathrm{ft}$ bgs from five wells (approximate elevation 682 to $663 \mathrm{ft} \mathrm{MSL}$ ). For those wells screening groundwater at less 
than $100 \mathrm{ft}$ bgs, reported static water levels in the lowest USDW ranged from approximately 9 to $26 \mathrm{ft}$ bgs from seven wells (approximate elevation 689 to $672 \mathrm{ft}$ MSL).

Observations from a review of three ISGS water-well database logs, for wells located adjacent to the south and east of the site, indicated the following:

- Well 1 adjacent to the south of the site (database \# 12029226 3500):

- Total depth: $89 \mathrm{ft}$ below grade;

- Best determination of stratigraphy from driller log: clay till down to $65 \mathrm{ft}$; sand and gravel 65 to $89+\mathrm{ft}$; water-bearing sand and gravel from 79 to $89 \mathrm{ft}$. Static water level $19 \mathrm{ft}$ below casing top (this indicates a confined sand layer, with a usable quantity of water available in the unit). Well was pumped for $3 \mathrm{hr}$ at 6 gallons per minute (gpm) - pumping level $32 \mathrm{ft}$.

- Well 2 is adjacent to the east/north of the site (database \# 120290110700 ):

- Total depth: $85 \mathrm{ft}$ below grade;

- Best determination of stratigraphy from driller log: clay till down to $77 \mathrm{ft}$; waterbearing sand 77 to $85+\mathrm{ft}$. Static water level is $26 \mathrm{ft}$ below casing top (this indicates a confined sand layer). Could have potential for a usable quantity of water - well was pumped down to a pumping level of $60 \mathrm{ft}$, but no pumping rate or duration of pumping was noted.

- Well 3 is adjacent to the east/south of the site (database \# 12029224 7500):

- Total depth: $38 \mathrm{ft}$ below grade;

- Best determination of stratigraphy from driller log: various thin stringers of sand and clay; water-bearing gray sand from 19 to $20 \mathrm{ft}$.

The ISGS and Patrick Engineering, Inc., performed seven shallow test soil borings within and bordering the site in September and November of 2006. These borings were designated B1M, $\mathrm{B} 2 \mathrm{M}, \mathrm{B} 3 \mathrm{M}, \mathrm{B} 4 \mathrm{M}, \mathrm{B} 5 \mathrm{M}, \mathrm{B} 6 \mathrm{M}$, and B7M. The depth of the borings ranged from 30 to $90 \mathrm{ft}$ bgs, and the depth to first saturated soil samples ranged from approximately 8.0 to $14.6 \mathrm{ft}$ bgs. No wells were installed in these borings and no direct groundwater level information was available on these logs. Bedrock was encountered (at $83.6 \mathrm{ft}$ ) only in boring B1M, which extended to a total depth of $90 \mathrm{ft}$ bgs.

The ISGS well logs for nearby wells appear to support what was observed in on-site borings $\mathrm{B} 2 \mathrm{M}$ and B5M - that there is a relatively deep layer of confined water-bearing sand within the glacial deposits which lie above the bedrock surface. However, this layer may not be continuous throughout the entire site (as noted absent at the same elevation in ISGS log for $\mathrm{B} 1 \mathrm{M})$. It was also observed that there is a deep layer of thin organic topsoil noted in the on-site boring logs at an approximate elevation of $640 \mathrm{ft} \mathrm{MSL}$. It occurs at approximately the same elevation in all three of the deepest on-site borings - B1M, B2M, and B5M. This is a paleosol (ancient topsoil/organic layer) that can be used as a reference marker bed. In some locations on site, there is water-bearing sand deposited directly on top of the paleosol (B2M, B5M), and in other locations there is till deposited directly on top of the paleosol (B1M - the ISGS descriptive log for B1M appears to indicate a till deposit on top of the paleosol). These observations confirm the inconsistent nature of glacial deposits at the site, and the lack of a continuous deep 
aquifer layer throughout the entire site. Also, the shallower water-bearing sands that do occur appear to be discontinuous (pinching-out) in some places (B6M). The long distance between available boring data makes it difficult to confirm continuity in the layers within the site. Refer to shallow cross sections A-A' and B-B' (Figure 2-18 and Figure 2-19, respectively). These crosssections illustrate the available on-site boring data in the form of boring diagrams located at various locations and elevations within the site. As indicated, the borings were widely spaced.

The variability of data prohibits development of a potentiometric surface map for groundwater within the USDW. However, an estimated regional groundwater table contour map was previously prepared (by E. Mehnert, Sr. Geohydrologist with the ISGS for the Mattoon EIV submittal) for both the Tuscola and Mattoon injection well candidate sites, using Groundwater Flow Analytic Element Model (GFLOW) modeling software (Haitjema Software, Bloomington, IN). The input data were adopted from a calibrated model for a watershed in northern Champaign County (Mehnert et al., 2006), which is approximately 30 miles (48 km) north of Mattoon. The contour map of the water table was estimated with the following inputs:

- Hydraulic conductivity $=37.5 \mathrm{ft} /$ day $(11.4 \mathrm{~m} / \mathrm{day})$

- $\quad$ Aquifer thickness $=50 \mathrm{ft}(15.2 \mathrm{~m})$

- Recharge $=0.00091$ foot $/$ day $\left(2.8 \times 10^{-4} \mathrm{~m} /\right.$ day $)$

Figure 2-21 shows the estimated contours for the GFLOW water table map. This contour map indicates that shallow groundwater beneath the Mattoon site flows north-northwest toward Whitley Creek. The GFLOW water table map is a regional estimate of shallow groundwater flow direction. As previously indicated, direct field data are not available to develop a localized contour map of the shallow groundwater at the Mattoon site.

\subsubsection{Distance to Nearest Water Supply Well}

Based on the ISGS water well database, there is a water supply well on the proposed site of the FutureGen power plant. It is a private well listed as a water supply well and has a depth of 113 $\mathrm{ft}$ (ISGS database well \#1202 9236 5300). This well will be properly abandoned since the occupant will be relocated. Figure 2-21 shows three additional wells on site. These are not water wells but represent the three geotechnical borings conducted by ISGS and Patrick Engineering in September 2006. Based on a potable water survey of residences within a one mile radius of the site, the closest active water supply well to the site is located approximately one mile to the west of the site, servicing the Wetzel residence. The property is shown on Figure 2-21 as are all the residences within a one mile radius from the site. With the exception of the Wetzel residence, potable water is supplied to these residences by the City of Mattoon or by the MCRPWD.

\subsubsection{Distance to Nearest Downgradient Water Supply Well}

Since a hydrogeological study has not been performed at the site, the local groundwater gradient is not yet known with accuracy. However, the regional GFLOW water table map shown in Figure 2-21 indicates shallow groundwater flow to the northwest. The nearest downgradient water supply well is approximately 2.4 miles northwest of the site boundary, located within Township 13N, Range 5E, Section 31 (ISGS database well \#1202 9016 1100). This well was drilled to a depth of $150 \mathrm{ft}$ bgs, and encountered bedrock at a depth of $90 \mathrm{ft}$ bgs. Other wells 


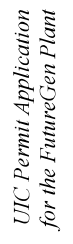

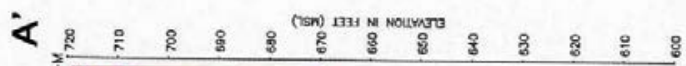

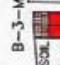
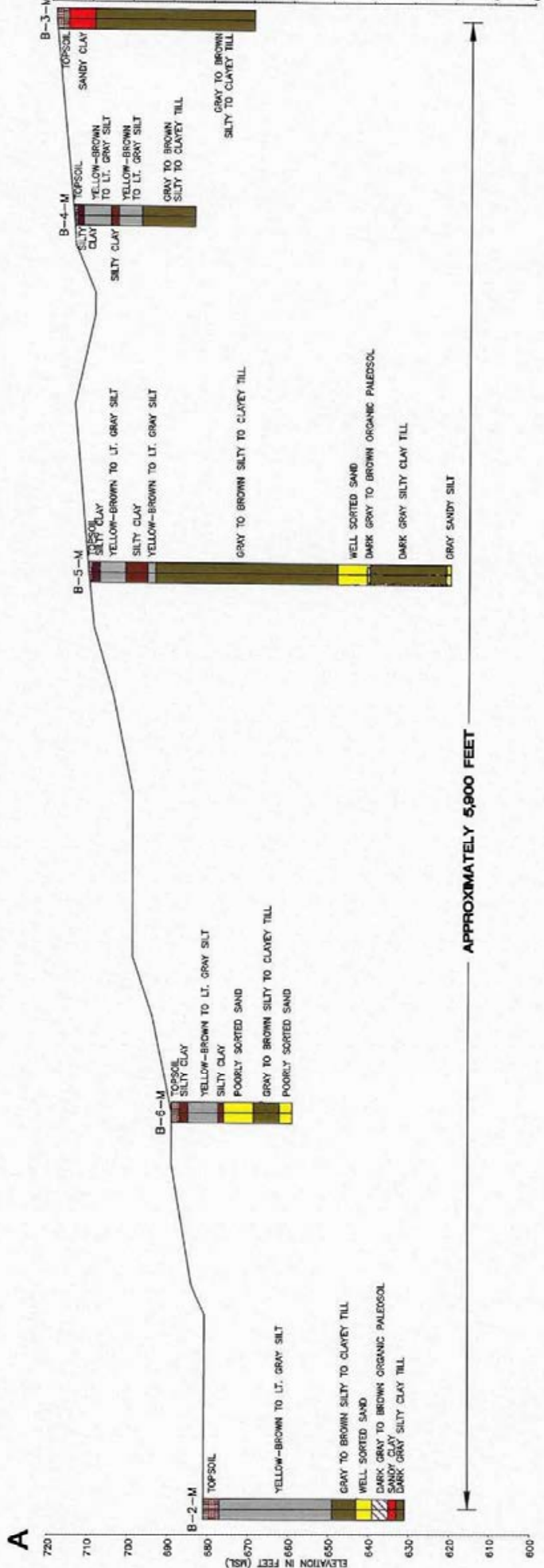

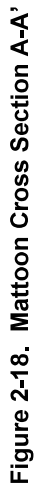
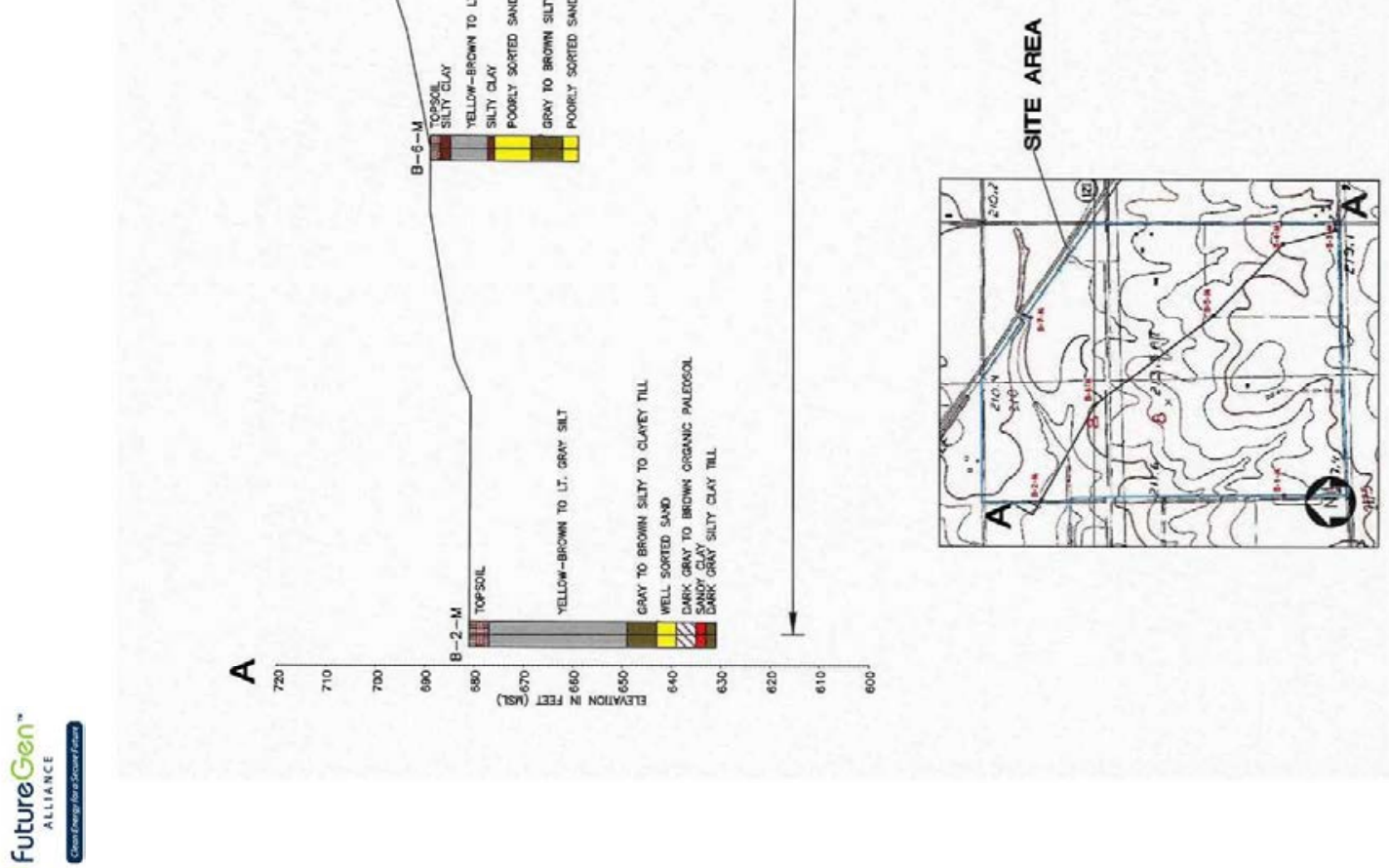

a 


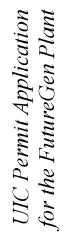

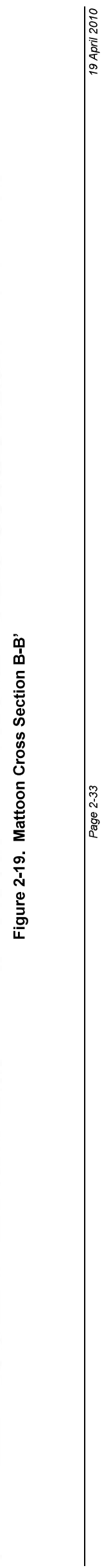




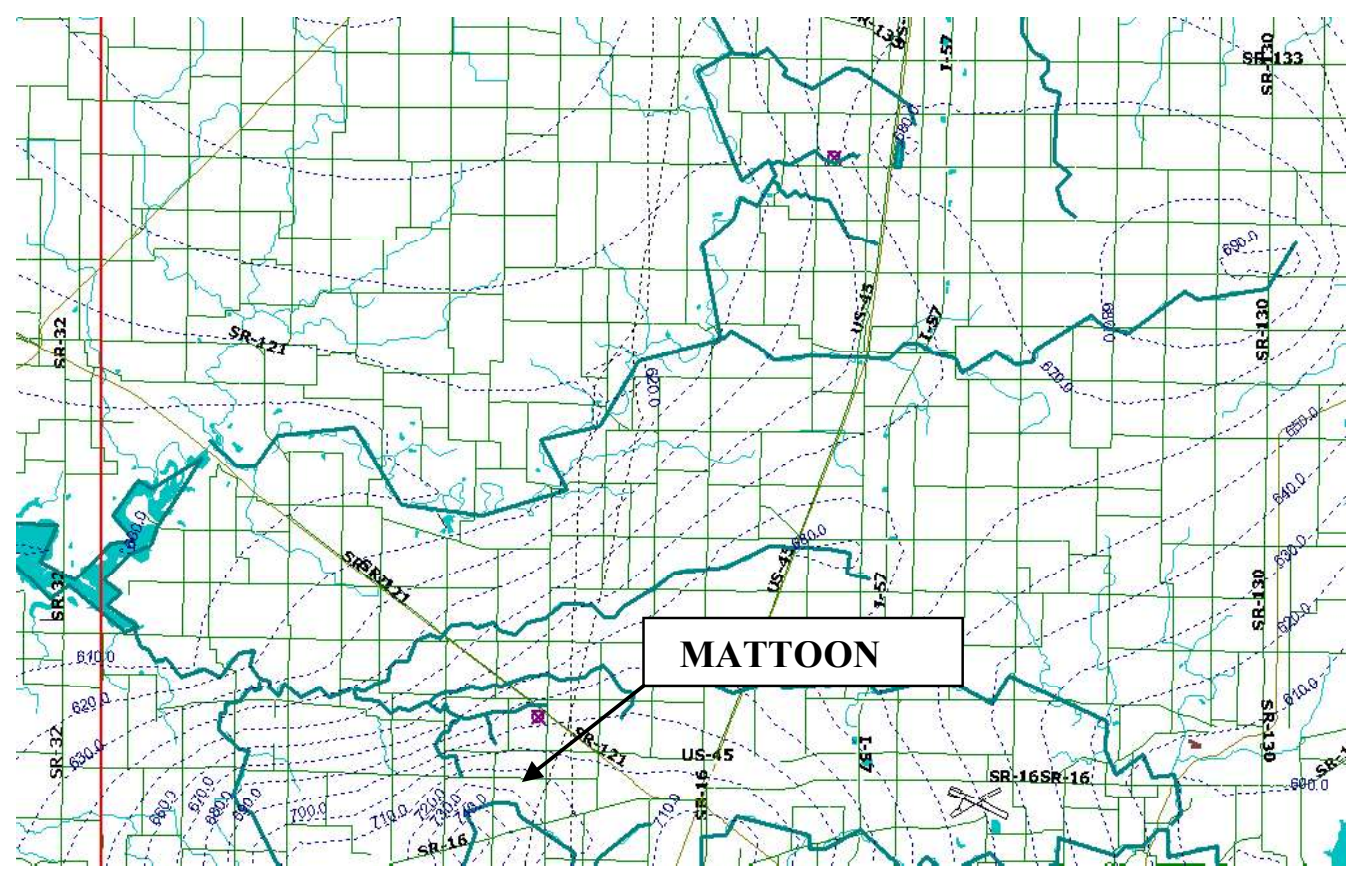

Figure 2-20. GFLOW Contour Map of the Estimated Water Table Beneath the Mattoon Injection Site (Dashed blue lines represent the water table, 10-foot, [3.05 m] contour interval.)

located downgradient from the site, but closer than well \#1202 9016 1100, include well \#1202 $92393200, \# 120292393300$ and seven other wells. These wells are all engineering test holes or dry holes.

\section{$2.8 \quad$ Minerals and Hydrocarbons}

\subsubsection{Mineral or Natural Resources Beneath or Within 5 miles of the Site}

\subsubsection{Stone, Sand, Clay and Gravel}

Limestone beds, 15 to $25 \mathrm{ft}$ (4.6 to $7.6 \mathrm{~m}$ ) thick, are sporadically present in the rocks of the Pennsylvanian System in central Illinois. In Coles County, the highest potential for shallow limestone aggregates occurs in the southeastern part of the county. The nearest quarry to the proposed plant site is more than 15 miles $(24.1 \mathrm{~km})$ to the east, about 2.5 miles $(4.0 \mathrm{~km})$ northeast of Charleston. Elsewhere, especially in the Mattoon area and around the proposed plant site, limestone is either absent or too thin or deep to be economically minable. Some areas, starting about 5 miles $(8.0 \mathrm{~km})$ to the south of the plant site, have a higher potential for sand and gravel aggregate resources. This mostly includes T11N-R7E and some in townships to the east and west. An active sand and gravel pit (as of 2004) about 8 miles $(12.9 \mathrm{~km})$ south of the proposed plant site has been extracting sand and gravel aggregate in Section 19, $11 \mathrm{~N}$, $7 \mathrm{E}$. Other areas with potential shallow sand and gravel resources lie in some areas in T13N, R7E and T13N and R8E. These resources have not been evaluated and their thickness and distribution are not known. To be economical, sand and gravel deposits need to be at least $10 \mathrm{ft}$ $(3.0 \mathrm{~m})$ thick with a ratio of deposit to overburden thickness of about 2:1. Minable deposits should also be at least 20 acres $\left(0.08 \mathrm{~km}^{2}\right)$ in area. These restrictions limit most areas for exploration. Clay-rich materials that are useful for pond liners, landfill liners and covers, and 

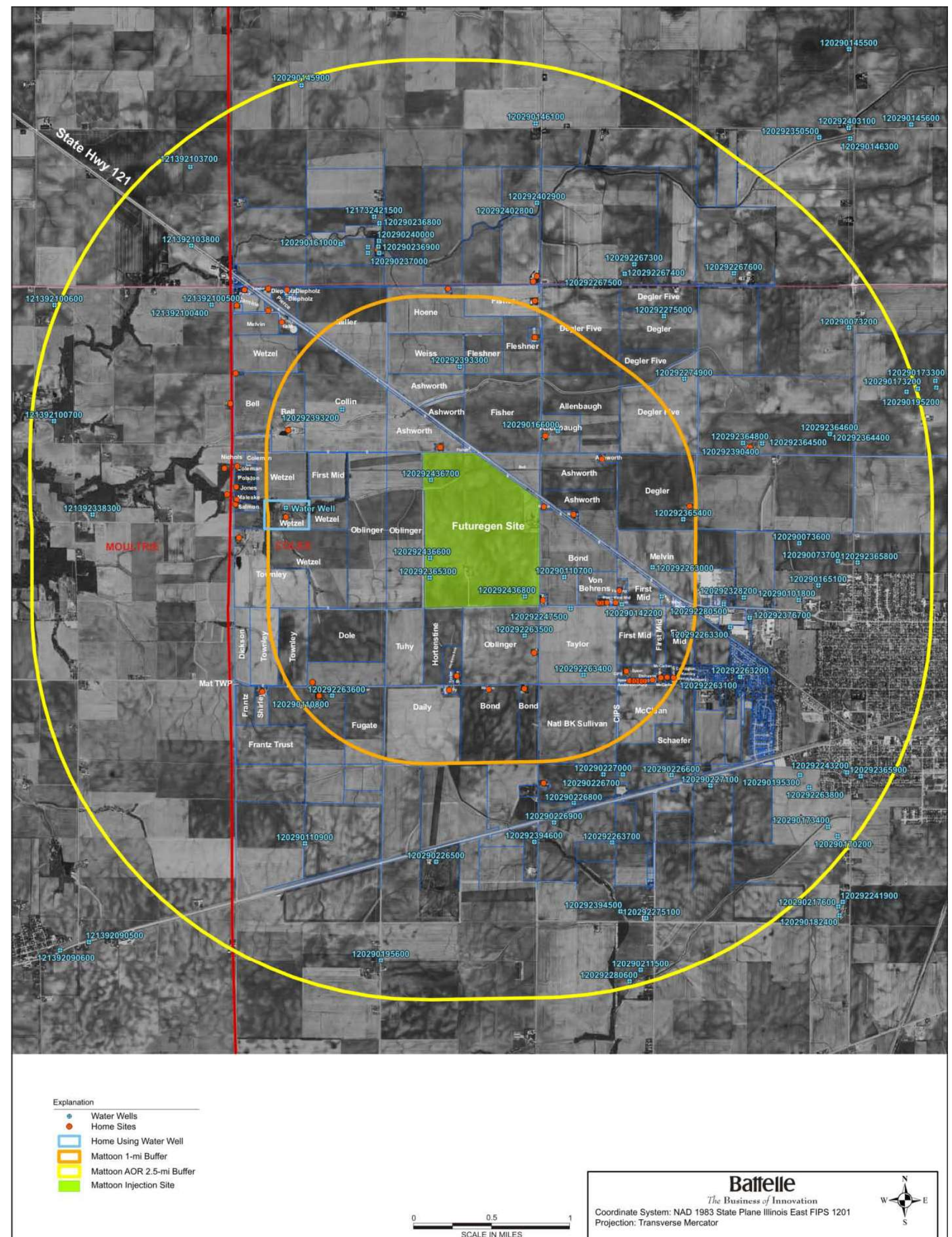

SCALE IN MILE

Figure 2-21. Locations of Water Wells and Residences 
similarly engineered barriers and berms can be obtained from some of the Quaternary units that are near the surface. This same clay and bedrock shale could be used to make ceramic products; however, the Quaternary materials are generally not the materials of choice in Illinois, and new ventures of this type require an additional source of profitability, such as a low-cost source of natural gas.

\subsubsection{Coal}

Although coal is present throughout the area, relatively small areas of Springfield and Herrin Coal are considered available for mining in the local area. "Available" coal means coal that is not known to have geological, technological, or land-use restrictions that would negatively impact the economics or safety of mining. The resources are not necessarily economically minable at the present time, but they are expected to have mining conditions comparable with those currently being mined in the state. The Springfield, Herrin, and Danville Coals, where available for mining, average approximately 3.5 to $5.5 \mathrm{ft}(1.07$ to $1.68 \mathrm{~m})$ thick in this area (Treworgy et al., 1999, 2000; Korose et al., 2002). Overall, the thickness of the coals is quite variable in this area, and the coals are thin (less than $2.5 \mathrm{ft}[0.76 \mathrm{~m}]$ thick) and/or eroded outside the areas classified as available for mining. The Herrin and Springfield Coals average 1,000 to $1,100 \mathrm{ft}$ (305 to $335 \mathrm{~m}$ ) deep near the Mattoon site, and the Danville Coal averages 900 to $1,000 \mathrm{ft}$ (274 to $305 \mathrm{~m})$ deep.

The nearest active coal mining is approximately 50 miles $(80.5 \mathrm{~km})$ to the northeast, in Vermilion County, Illinois, where the Black Beauty Coal Company operates the Riola and Vermilion Grove Mines. These mines are in the Herrin Coal, at an average depth of $250 \mathrm{ft}$ $(76 \mathrm{~m})$ and seam thickness of 5 to $6 \mathrm{ft}$ (1.52 to $1.83 \mathrm{~m})$. Production for each mine was approximately one million short tons in 2004 (Illinois Department of Commerce and Economic Development [IL DCEO], 2004).

The nearest historical coal mining on record at the ISGS was a single shaft in the center of the City of Mattoon, about 3 miles $(4.8 \mathrm{~km})$ to the southeast. This mine was operated by the Mattoon Mining Co., from 1882 to 1888, and was reportedly $904 \mathrm{ft}(276 \mathrm{~m})$ deep. In 1883, it had reportedly mined 1 acre $\left(0.004 \mathrm{~km}^{2}\right)$ of coal, $3.5 \mathrm{ft}(1.067 \mathrm{~m})$ thick, likely in the Danville Coal. Based on the total production of the mine listed as 198,923 short tons, it is estimated that an area of approximately 35 acres $\left(0.14 \mathrm{~km}^{2}\right)$ has been undermined at this location.

There is a cluster of drift and slope mine shafts approximately 10 miles $(16.1 \mathrm{~km})$ southsouthwest of the Mattoon site, in Shelby County. Not much is known about these local mines, other than the majority of them pre-date the 1940s.

\subsubsection{Oil and Gas}

Located east of the proposed Mattoon Plant/Injection site is the Mattoon Field, a mature, 22.7 million barrel oil field with minor gas production. Primary reservoirs are Mississippian sandstones that range in depth from 1,750 to 2,950 $\mathrm{ft}$ (533 to $899 \mathrm{~m}$ ) along the compound anticlinal structure. Scattered minor gas production from Devonian sandstones at a depth of less than 3,200 ft $(975 \mathrm{~m})$ has been established. The western-most producing wells were located approximately 1.5 miles $(2.4 \mathrm{~km})$ to the east of the plant site although most of the wells throughout the field have been plugged and abandoned. Scattered active wells and associated production facilities remain within the 12 square mile, north-south trending field. 
The next petroleum production in proximity to the Mattoon plant/injection site is Gays Field. The field is 4.5 miles $(7.2 \mathrm{~km})$ to the west-southwest and is 200 acres $\left(0.81 \mathrm{~km}^{2}\right)$ in size. Production has been established from Mississippian and Devonian sandstones at depths ranging from 1,970 to $3,200 \mathrm{ft}(975 \mathrm{~m})$. Records show that five wells are still active and about 154,000 barrels of oil have been produced from the field.

\section{$2.9 \quad$ Attachments}

Map of mineral resources: Mattoon_Geology.pdf

\subsection{References}

Appendix, Mattoon Subsurface Data package submitted by Illinois State Geological Survey, Sections 1_1_6_struc_resvr, 1_3_2_struc_seal, and 1_3_3_isopach_seal.

Appendix, Mattoon Subsurface Data package submitted by Illinois State Geological Survey, 1_2_7_perm_resvr_mattoon.doc.

Appendix, Mattoon Subsurface Data package submitted by Illinois State Geological Survey, 1_1_3_ReservoirGeology_Mattoon.doc.

Appendix, Mattoon Subsurface Data package submitted by Illinois State Geological Survey, 1_2_3_pressure_resvr_mattoon.doc

Appendix, Mattoon Subsurface Data package submitted by Illinois State Geological Survey, 1_3_4 Seal_Geolog_Mattoon.doc.

Appendix, Mattoon Subsurface Data package submitted by Illinois State Geological Survey, 1_3_6 Seal Porosity and Diagenesis_Mattoon.doc.

Bickford, M.E., W.R. Van Schmus, and I. Zietz. 1986. "Proterozoic History of the Midcontinent Region of North America." Geology 14:492-496.

Bond, D.C. 1972. Hydrodynamics of Deep Aquifers of the Illinois Basin, Circ. 470, 72 pp., III. State Geol. Surv., Champaign.

Bredehoeft, J.D., C.R. Blyth, W.A. White, and G.B. Maxey. 1963. "Possible Mechanism for Concentration of Brines in Subsurface Formations." AAPG Bulletin 47(2):257-269.

Davis, J.C. 2002. Statistics and Data Analysis in Geology. New York, John Wiley \& Sons, Inc.

Domenico, P.A. and F.W. Schwartz. 1990. Physical and Chemical Hydrogeology. New York, John Wiley \& Sons, Inc.

Driese, S.G., C.W. Byers, and R.H. Dott, Jr. 1981. "Tidal Deposition in the Basal Upper Cambrian Mt. Simon Formation in Wisconsin." Journal of Sedimentary Petrology 51(2):367381.

Freeze, R.A., and J.A. Cherry. 1979. Groundwater. Englewood Cliffs, N.J., Prentice Hall, Inc.

FutureGen Alliance. 2006. Mattoon Site Environmental Information Volume. Washington, DC. Accessed online at http://www.futuregenalliance.org/news/evi.stm.

Gupta, N., and E.S. Bair. 1997. "Variable-density Flow in the Midcontinent Basins and Arches Region of the United States." Water Resources Research 33(8):1785-1802. 
Huang, T., and J.W. Rudnicki. 2006. "A Mathematical Model for Seepage of Deeply Buried Groundwater Under Higher Pressure and Temperature." Journal of Hydrology 327:42-54.

Illinois Department of Commerce and Economic Development (IL DCEO)—Office of Coal Development. 2004. "DNR 2004 Mine Statistics”, http://dnr.state.il.us/mines/public/asr2004.pdf.

Illinois State Geological Survey (ISGS). 1985. "Geology, Hydrology, and Water Quality of the Cambrian and Ordovician Systems in Northern Illinois."

Kestin, J., H.E. Khalifa, and R.J. Correia. 1981. "Tables of the Dynamic and Kinematic Viscosity of Aqueous $\mathrm{NaCl}$ Solutions in the Temperature Range of $20-150^{\circ} \mathrm{C}$ and the Pressure Range 0.1-35 MPa." Journal of Physical and Chemical Reference Data 10(1):71-87.

Korose C.P., C.G. Treworgy, R.J. Jacobson, S.D. Elrick. 2002. "Availability of the Danville, Jamestown, Dekoven, Davis, and Seelyville Coals for Mining in Selected Areas of Illinois." Illinois State Geological Survey, Illinois Minerals 124, 44 p.

Leetaru, H.E., D.G. Morse, R. Bauer, S. Frailey, D. Keefer, D. Kolata, C. Korose, D.M.E. Mehnert, S. Rittenhouse, J. Drahovzal, S. Fisher, J. McBride. 2005. "Saline Reservoirs as a Sequestration Target." In An Assessment of Geological Carbon Sequestration Options in the Illinois Basin, Final Report for U.S. DOE Contract DE-FC26-03NT41994, Principal Investigator Robert Finley, p. 253-324. Accessed April 22, 2009 at http://sequestration.org/report.htm.

Mehnert, E., W. Dey, H. Hue-Hwa D. Keefer, T. Holm, T. Johnson, W. Beaumont, M. Wander, J. Sanford, J. McDonald, and S. Shiffer. 2006. "Mass Balance of Nitrogen and Phosphorus in an Agricultural Watershed; The Shallow Groundwater Component." Illinois State Geological Survey Open-File Series Report 2005-3, July.

Morse, D.G., and H.E. Leetaru. 2005. "Reservoir Characterization and Three-Dimensional Models of Mt. Simon Gas Storage Fields in the Illinois Basin." Illinois State Geological Survey 567, Champaign, Illinois.

Patrick Engineering, Inc., 2006. Preliminary Geotechnical Investigation and General Foundation Recommendations - Mattoon Site. From Matt Breitenbach, P.E.to Illinois Clean Coal Institute; Patrick Project No. 20603.015; December 5, 2006

Sargent, M.L., and Z. Lasemi. 1993. "Tidally Dominated Depositional Environment for the Mt. Simon Sandstone in central Illinois." Great Lakes Section, Geological Society of America, Abstracts and Programs 25(3):78.

Student, J.D., et al. 1981. "Aquifers of Illinois: Underground Sources of Drinking Water and Non-Drinking Water.” September, pp123 - Plate 11.

Treworgy C.G., C.P. Korose, and C.L. Wiscombe. 2000. "Availability of the Herrin Coal for Mining in Illinois." Illinois State Geological Survey, Illinois Minerals 120, 54 p.

Treworgy C.G., C.P. Korose, C.A. Chenoweth and D.L. North. 1999. "Availability of the Springfield Coal for Mining in Illinois." Illinois State Geological Survey, Illinois Minerals 118, 43 p.

Willman, H.B., et. al. 1975, Handbook of Illinois Stratigraphy, Illinois State Geological Survey, Bulletin 95. Illinois State Geological Survey. 


\title{
DRAFT UIC PERMIT FORMS
}

\section{ILLINOIS ENVIRONMENTAL PROTECTION AGENCY \\ UNDERGROUND INJECTION CONTROL PERMIT APPLICATION}

\author{
FORM $4 \mathrm{~b}$ - INJECTION WELL DESIGN, CONSTRUCTION TESTS and LOGS \\ USEPA ID NUMBER_not applicable \\ IEPA ID NUMBER 0290255208 \\ WELL NUMBER - FutGen-INJ-1 and FutGEN-INJ-2
}

Location in Application

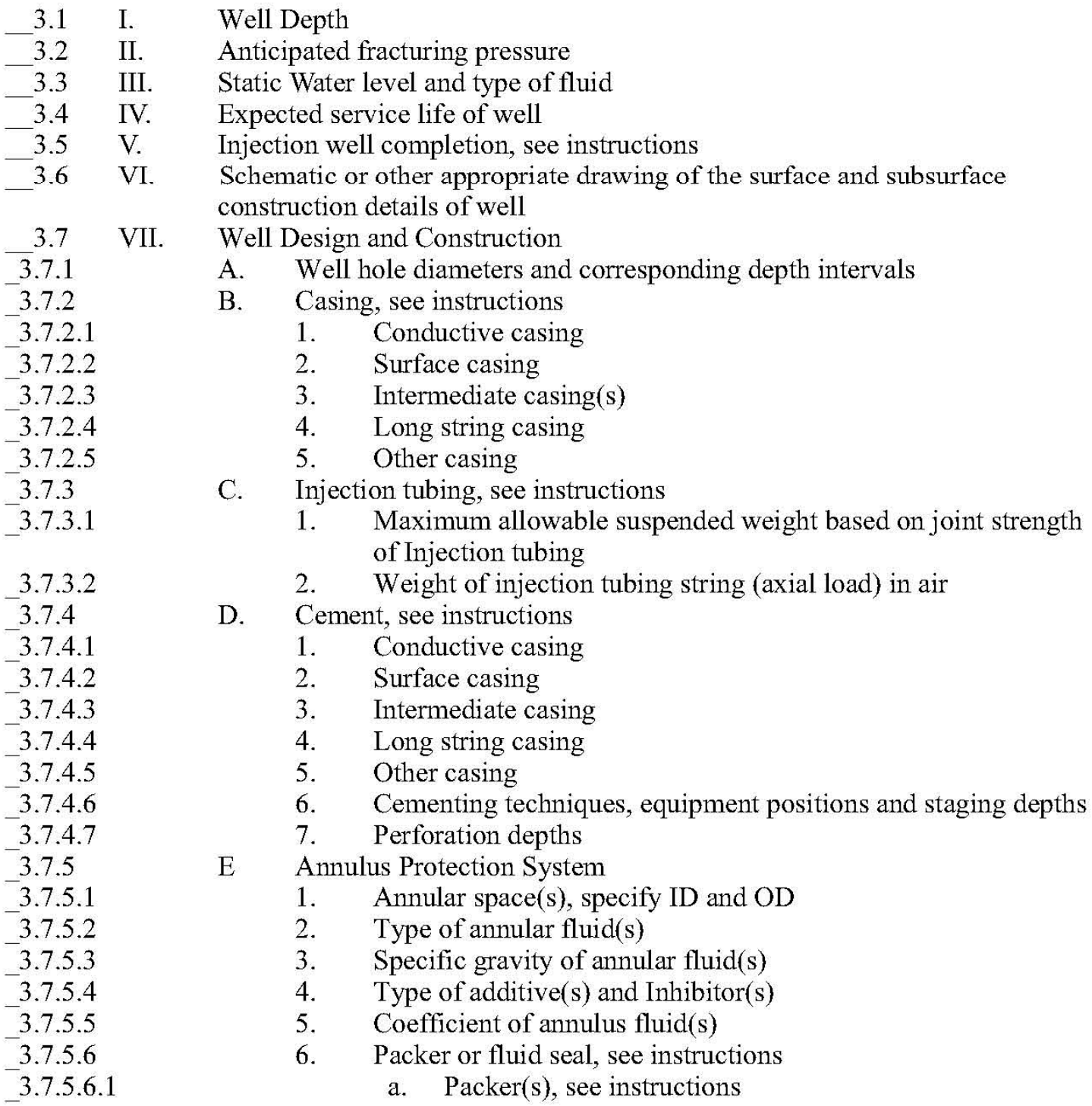


3.7.5.6.2

-3.8 VIII b. Fluid spotting procedure, frequency and quantity Information on well drilling company used during construction, see instructions

3.9 IX. Tests and Logs, see instructions

3.9.1 A. During drilling

3.9 .2

$-3.9 .3$

3.9 .4

B. During and after casing installation

C. Demonstration of mechanical integrity

D. Copies of the logs and tests listed above

\section{Certification}

I certify under penalty of law that this document and all attachments were prepared under my direction or supervision in accordance with a system designed to assure that qualified personnel properly gather and evaluate the information submitted. Based on my inquiry of the person or persons who managed the system, or those persons directly responsible for gathering the information, the information submitted is, to the best of my knowledge and belief, true, accurate and complete. I am aware that there are significant penalties for submitting false information, including the possibility of fine and imprisonment for knowing violations. 


\section{INJECTION WELL DESIGN, CONSTRUCTION TESTS, AND LOGS (Form 4b)}

\subsection{Well Depth}

The injection well(s) have been designed to inject $\mathrm{CO}_{2}$ into the Mt. Simon Formation. As discussed in Section 2, the depth of the Mt. Simon Formation at the Mattoon site is estimated to be between 7,353 and $8,996 \mathrm{ft}$ bgs $\left(1,643 \mathrm{ft}\right.$ thick). $\mathrm{CO}_{2}$ will likely be injected into only a portion of the estimated 1,643-ft thick section of Mt. Simon present at this site. A relatively coarsegrained arkosic interval that is usually present in the lower portion of the Mt. Simon (Leetaru et al., 2005) is a potentially attractive interval from an injectivity standpoint. At the Mattoon site, the arkosic interval is estimated to extend from $8,698 \mathrm{ft}$ bgs to $8,958 \mathrm{ft}$ bgs ( $260 \mathrm{ft}$ thick). The exact injection interval(s) will be determined after the well is drilled and characterized (i.e., geophysical logging, core analysis, hydraulic testing).

For the purpose of designing the $\mathrm{CO}_{2}$ injection well(s), it was assumed that the Mt. Simon Formation is present between depths of 7,353 and 8,996 ft bgs and the injection well(s) extend $100 \mathrm{ft}$ below the base of the Mt. Simon. Therefore, the depth of the well(s) is estimated to be $9,096 \mathrm{ft}$ bgs. The exact depth of the well(s) may differ from this estimate as it will depend on the results of the geologic characterization data obtained during drilling.

\subsection{Anticipated Fracturing Pressure}

As presented in Section 2.4.3.3, the actual fracture pressures in the Mt. Simon Formation that would cause new or existing fractures to open are not known with certainty. Leetaru et al. (2005, p. 312) stated that fracture stimulation companies commonly use a fracture gradient of $1.0 \mathrm{psi} / \mathrm{ft}$ in stimulating wells in the Illinois Basin. Fracture pressure gradients range from 0.8 to $0.95 \mathrm{psi} / \mathrm{ft}$ for reservoirs between 3,000 and 10,000 ft bgs (Howard and Fast, 1970).

Once the initial Mt. Simon well is drilled at the Mattoon Site, additional subsurface characterization activities will be conducted, including hydraulic testing (e.g., step-rate test) to determine the fracture pressure of the injection interval. The fracture opening/closure pressures determined from site-specific testing will be used to establish the safe injection pressure (i.e., maximum injection pressure).

\subsection{Static Water Level and Type of Fluid}

As discussed in Section 2.4.4, fluids in the Mt. Simon Formation have a salinity (TDS) range between 100,000 and 140,000 ppm, although salinity data from the Mt. Simon Sandstone are sparse in the Illinois Basin, with the few measurements available confined to natural gas storage fields in which the Mt. Simon is the storage reservoir (Leetaru et al., 2005). The stated salinity values were estimated from a regional Mt. Simon map published by the ISGS (Leetaru et al., 2005). A TDS value of $130,000 \mathrm{ppm}$ was used to model the injection and transport of $\mathrm{CO}_{2}$ at the site. Using the correlation provided in Bond (1972, Figure 9) and a TDS value of 130,000 $\mathrm{mg} / \mathrm{L}$, the relative density (specific gravity) of the interstitial fluid in the Mt. Simon is estimated to be 1.09; this corresponds to a density of approximately 68.02pound per cubic foot $\left(\mathrm{lb} / \mathrm{ft}^{3}\right)(1,090$ $\mathrm{kg} / \mathrm{m}^{3}$ ). Based on the expected depth interval for the Mt. Simon (Table 2-1), the formation temperature in the Mt. Simon should vary from $134^{\circ} \mathrm{F}\left(57^{\circ} \mathrm{C}\right)$ at the top of the formation to $145^{\circ} \mathrm{F}$ 
$\left(63^{\circ} \mathrm{C}\right)$ at the base. The estimated temperatures are based on the assumption of a geothermal gradient of $1^{\circ} \mathrm{F} / 100 \mathrm{ft}$ from a near-surface datum of $62^{\circ} \mathrm{F}$ at $100 \mathrm{ft}$ (Leetaru et al., 2005, p. 310). These temperatures are well above the threshold temperature $\left(87.9^{\circ} \mathrm{F}, 31.1^{\circ} \mathrm{C}\right)$ required to maintain the injected $\mathrm{CO}_{2}$ in a supercritical state.

No penetrations of the Mt. Simon exist in the Mattoon area, so the elevation of the potentiometric surface is not accurately known. A drillstem test (of the Mt. Simon Formation) from the Weaber-Horn \#1 well had a pressure gradient essentially equivalent to a freshwater gradient of $0.433 \mathrm{psi} / \mathrm{ft}$ (9.79 kilopascal per meter [kPa/m]) (Appendix, Mattoon Subsurface Data package submitted by ISGS, 1_2_3_pressure_resvr_mattoon.doc). At this gradient, the fluid pressure at the top of the Mt. Simon Formation (estimated depth 7,353 ft bgs) would be 3,184 psi. Under these conditions, the static fluid level would occur at/near ground surface $\mathrm{ft}$ bgs (i.e., a pressure of $0.433 \mathrm{psi}$ is sufficient to lift a column of freshwater [density $=62.4 \mathrm{lb} / \mathrm{ft}^{3}$ ] a distance of $1 \mathrm{ft}$ ). For fluids such as those in the Mt. Simon Formation with a density greater than freshwater, the static water level will be lower than the freshwater head assuming the same formation pressure. For example, assuming a reservoir pressure of 3,184 psi at the top of the Mt. Simon Formation (depth 7,353 ft bgs) and a fluid with specific gravity of $1.09\left(68.02 \mathrm{lb} / \mathrm{ft}^{3}\right)$, the static water level would be approximately $615 \mathrm{ft}$ bgs. Hydraulic testing of the initial well at the Mattoon Site will be used to verify the site-specific potentiometric surface of the Mt. Simon.

\subsection{Expected Service Life of Well}

The planned duration of the FutureGen demonstration phase is 4 years after regular $\mathrm{CO}_{2}$ injection begins. The injection well(s) have been designed to have a life expectancy that exceeds this period; however, the exact life expectancy is not known. The use of corrosion resistant alloy materials for selected well components (e.g., casing, packer, wellhead, cement) will likely result in a life expectancy for the injection well(s) that is far in excess of 4 years. Sections 7.5.4.1 through 7.5.4.7 discuss the compatibility of well materials (injection tubing, casing, cement, packer, wellhead) and the $\mathrm{CO}_{2}$ injectate, including estimates of corrosion rates for well tubulars composed of different types of steel. These analyses suggest that carbon steel well tubulars (e.g., casing, tubing) will be sufficient for the expected lifetime of the project. However, corrosion resistant alloys will provide significantly longer service, depending on the alloy. It should be noted that selected well components, such as injection tubing, packers, and wellheads, can be replaced to extend the service life of the well. The use of $\mathrm{CO}_{2}$ resistant cement across the injection reservoir will also help extend the service life of the well by ensuring that cement corrosion is significantly retarded. Cement corrosion can lead to the formation of channels adjacent to the wellbore that could allow leakage of the injected $\mathrm{CO}_{2}$ out of the target injection interval.

Another factor affecting the service life of the well is the pressure buildup in the injection reservoir. After a period of time, it may no longer be possible to continue injection if reservoir pressure increases to the point where the injection pressures are required to exceed the maximum allowable injection pressure. $\mathrm{CO}_{2}$ fate and transport modeling performed for this permit application (see Section 5.4) suggests that $\mathrm{CO}_{2}$ injection can continue for at least 27 years at the design injection rate of $\sim 1.95$ million metric ton (MMT)/yr (this rate is based on an instantaneous injection rate of $0.006312 \mathrm{MMT} /$ day with two 28-day plant shutdowns per year); therefore, pressure buildup is not likely to limit the service life of the well. Nevertheless, 
pressure fall-off tests will be conducted periodically during the active injection phase to monitor pressure buildup in the injection reservoir.

\subsection{Injection Well Completion}

The injection well(s) will be fully cased across the Mt. Simon Formation (i.e., not an open-hole completion) and the casing will be cemented to ground surface with appropriate types of cement, including $\mathrm{CO}_{2}$ resistant cement extending, at minimum, across the Mt. Simon Formation. The casing will be perforated across selected intervals in the Mt. Simon Formation having properties that are conducive for injection.

\subsection{Schematic or Other Appropriate Drawing of the Surface and Subsurface Construction Details of the Well}

The injection well(s) will include the following casing strings: a 30 -inch diameter conductor string set a depth of approximately $100 \mathrm{ft}$ bgs; a 20 -inch diameter surface string set a depth of approximately 250 to $500 \mathrm{ft}$ bgs; a 13-3/8 inch diameter intermediate string set a depth of approximately 5,000 to 7,000 ft bgs; and a 9-5/8 inch diameter deep (injection) string set an approximate depth of $9,100 \mathrm{ft}$ bgs. All casing strings will be cemented to surface. The purpose of the conductor string is to provide a stable borehole across the near-surface, unconsolidated glacial deposits before drilling the remaining deeper casing strings and to help protect the USDW. As discussed in Section 2.7.2, groundwater in the vicinity of the Mattoon site is normally obtained from sand and gravel deposits that are contained within the unconsolidated Quaternary-age material above bedrock. The sand and gravel deposits for the vicinity of the proposed site range in depth from about 25 to $125 \mathrm{ft}$ bgs. Bedrock is indicated by a boring on the southwest border of the site to be approximately $90 \mathrm{ft}$ below the surface. The surface string will extend across the uppermost bedrock layers (Pennsylvanian age) and will help to further isolate and protect the USDWs. The intermediate casing string will extend across and isolate deeper potentially unstable layers or layers where there is potential for lost circulation to ensure that the well can be drilled to total depth. The deepest casing string will extend to approximately $100 \mathrm{ft}$ below the base of the Mt. Simon Formation, into the underlying Precambrian-age granite bedrock.

A diagram of the injection well casing plan is provided in Figure 3-1 and Figure 3-2. Two versions of the well diagram are provided because the depth of the intermediate casing is uncertain at this time. In Figure 3-1, the intermediate casing is set just below the St. Peter Sandstone in the Upper Knox at a depth of approximately 5,000 ft bgs. In Figure 3-2, the intermediate casing is set in the Eau Claire Formation at an approximate depth of 7,000 $\mathrm{ft}$ bgs. The design with the deeper casing would be implemented if there is an indication that hole stability below $5,000 \mathrm{ft}$ is an issue and thus would warrant extending the depth of this casing string to isolate problem ones. The deeper intermediate casing string would be preferable if the borehole across the Mt. Simon is left open to allow extended open-hole testing, as this would minimize the amount of openhole susceptible to caving during testing. Also, the difference in depth necessitates minor changes in the weight and grades of materials used for the intermediate casing string. The depth of the intermediate casing string may not be finalized until drilling is underway. 


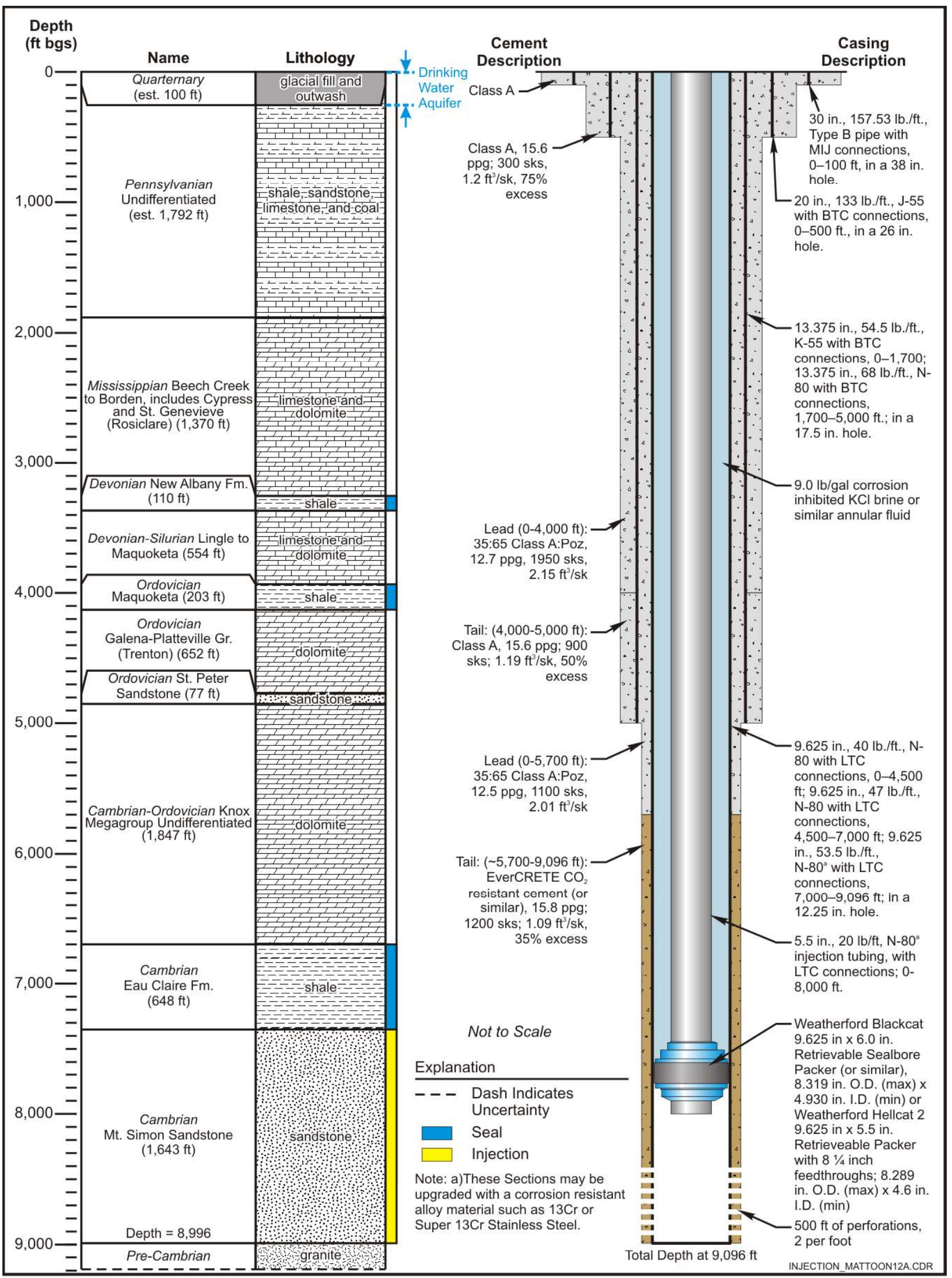

Figure 3-1. Injection Well Schematic (5,000 ft Intermediate Casing String) 


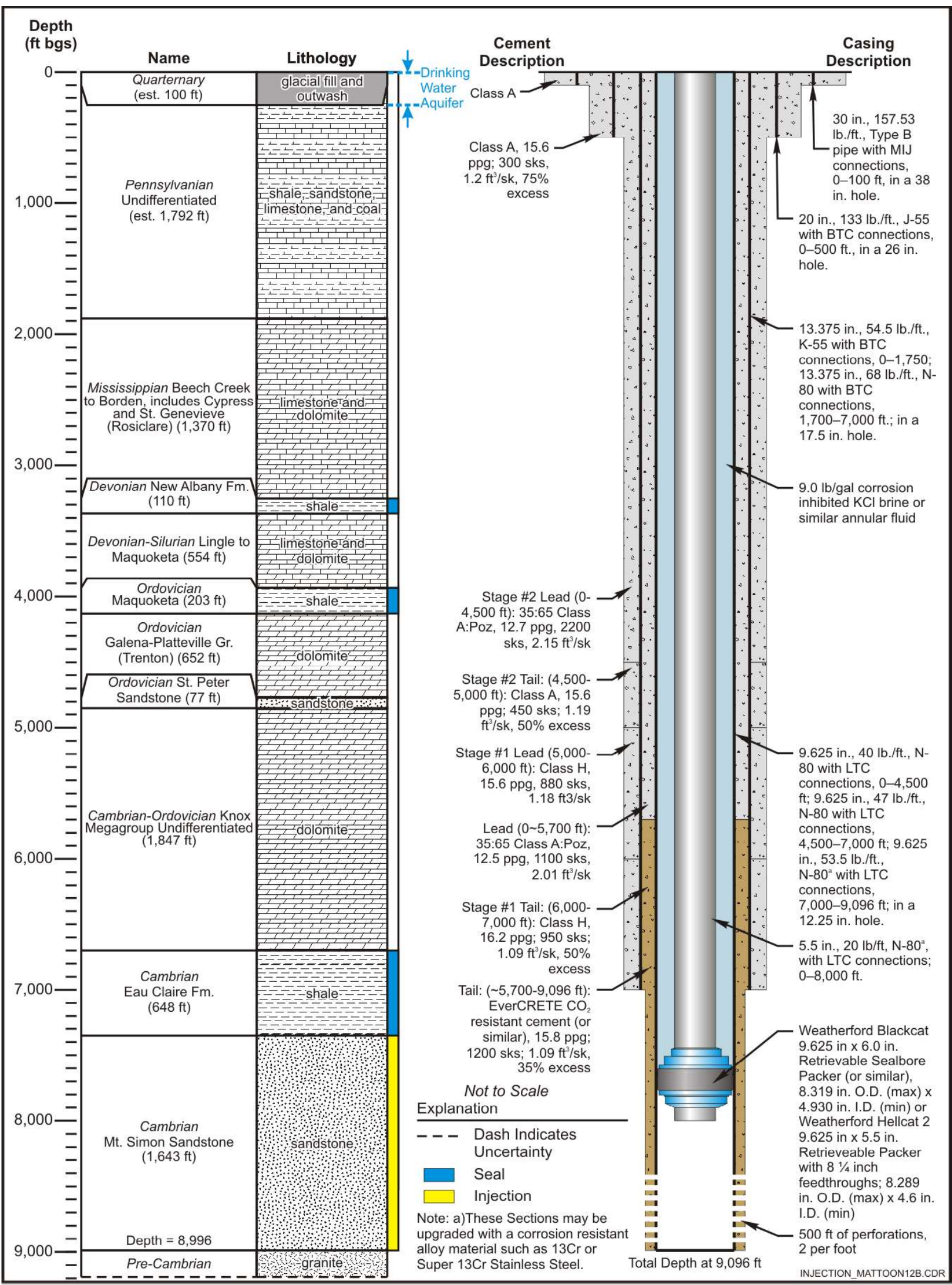

Figure 3-2. Injection Well Schematic (7,000 ft Intermediate Casing String) 


\subsection{Well Design and Construction}

The injection well was designed using the program Tubular Design and Analysis System (TDAS), version 6.16 (Schlumberger, 2006). The primary output produced by TDAS is a well casing plan, which includes the weight, grades and material for each casing string. The number of casing strings and their depth are specified by the user, but the casing specifications are determined based on a series of load scenarios that are programmed into the TDAS program. The user also specifies a pore pressure gradient and a fracture pressure gradient. Load cases are defined by a temperature profile, an internal pressure profile (i.e., inside the casing), and an external pressure profile (i.e., outside the casing). Default load scenarios included in the TDAS program are listed in Table 3-1. For each casing string, five design factors are computed by TDAS, including burst, collapse, tension, compression, and triaxial loading (i.e., Von Mises). The TDAS program includes three different rule sets that can be chosen by the user, each with different minimum acceptable design factors, but these can be altered by the user. The minimum acceptable design factors used to design the $\mathrm{CO}_{2}$ injection well are as follows: burst (1.1), collapse (1.1), tension (1.5), compression (1.3), and triaxial loading (1.25). All casing strings included in the well design equal or exceed these design factors for the load scenarios that were evaluated. By evaluating multiple load scenarios, a more rigorous well design is possible. This approach is advantageous compared to the common technique of defining a single worst case burst scenario and a single worst case collapse scenario.

\subsubsection{Well Hole Diameters and Corresponding Depth Intervals}

The borehole diameters for the various casing strings are as follows: 30 -inch diameter casing string - 38 inches; 20-inch diameter surface casing - 26 inches; 13-3/8 inch diameter intermediate casing string - 17.5 inches; 9-5/8-inch diameter deep (injection) casing string - 12$1 / 4$ inches. These borehole diameters are considered conventional sizes for the sizes of casing that will be used and should allow ample clearance between the outside of the casing and the borehole wall to ensure that a continuous cement sheath can be emplaced along the entire length of the casing string. Table 3-2 summarizes information about the borehole diameter and depth for each casing string.

\subsubsection{Casing}

As discussed in Section 3.6, the injection well will include the following casing strings: a 30-inch diameter conductor string set a depth of approximately $100 \mathrm{ft}$ bgs; a 20 -inch diameter surface string set a depth of approximately 250 to $500 \mathrm{ft}$ bgs; a 13-3/8 inch diameter intermediate string set at a depth of approximately 5,000 to 7,000 ft bgs; and a 9-5/8 inch diameter deep (injection) string set an approximate depth of $9,100 \mathrm{ft}$ bgs. All casing strings will be cemented to surface. Table 3-3 and Table 3-4 summarize the casing program for the injection well. Table 3-3 describes the casing program for a 5,000 ft deep intermediate casing string, whereas Table 3-4 describes the casing program for the scenario in which the intermediate casing string is $7,000 \mathrm{ft}$ deep. Note that except for the intermediate casing string, the two well designs are identical. Table 3-5 summarizes properties of each casing material. 
Table 3-1. Load Scenarios Evaluated

\begin{tabular}{|c|c|c|}
\hline Load Name & Description & $\begin{array}{l}\text { Casing } \\
\text { String }\end{array}$ \\
\hline Installed Load & $\begin{array}{l}\text { Casing is filled with mud with weight it was run in with, cement outside } \\
\text { casing, static temperature profile. }\end{array}$ & All \\
\hline $\begin{array}{l}1 / 3 \\
\text { Evacuation }\end{array}$ & $\begin{array}{l}\text { Casing is evacuated to a depth equal to } 1 / 3 \text { the depth of the next casing } \\
\text { point (below this, mud is present with weight used to drill subsequent } \\
\text { section), mud with weight casing string was run in with is present outside } \\
\text { casing, static temperature profile. Note that this results in complete } \\
\text { evacuation of the casing if the depth of the subsequent casing point is }>3 x \\
\text { the depth of the casing string evaluated. }\end{array}$ & $\mathrm{C}, \mathrm{S}, \mathrm{I}$ \\
\hline $\begin{array}{l}\text { Full } \\
\text { Evacuation }\end{array}$ & $\begin{array}{l}\text { Casing is completely evacuated, mud with weight casing string was run in } \\
\text { with is present outside casing, static temperature profile. }\end{array}$ & $P$ \\
\hline Pressure Test & $\begin{array}{l}\text { Casing is filled with mud with weight casing was run in with and surface } \\
\text { pressure is applied that produces a pressure at the shoe equal to the } \\
\text { fracture pressure plus a margin of safety ( } 0.2 \text { pound per gallon [ppg]), } \\
\text { natural pore pressure gradient outside the casing, static temperature profile. }\end{array}$ & $\mathrm{C}, \mathrm{S}, \mathrm{I}$, \\
\hline 50 bbl kick & $\begin{array}{l}\text { Simulates gas kick of specified volume; internal pressure profile depends on } \\
\text { size of gas bubble, natural pore pressure gradient outside the casing, } \\
\text { temperature profile is based on correlation by Kutasov and Taighi (see } \\
\text { TDAS manual). }\end{array}$ & $\mathrm{S}, \mathrm{I}$ \\
\hline $\begin{array}{l}1 / 3 \text { gas } \\
\text { replacement }\end{array}$ & $\begin{array}{l}\text { Casing is filled with } 0.0 \text { psi/ft gas to a depth equal to } 1 / 3 \text { the depth of the } \\
\text { next casing point (below this, mud is present with weight used to drill } \\
\text { subsequent section), natural pore pressure gradient outside the casing, } \\
\text { static and circulating temperature profiles are both considered. }\end{array}$ & S, I \\
\hline $\begin{array}{l}\text { Surface tubing } \\
\text { leak }\end{array}$ & $\begin{array}{l}\text { Internal pressure profile is defined by wellhead shut in pressure acting on the } \\
\text { packer fluid, natural pore pressure gradient outside the casing, static and } \\
\text { flowing temperature profiles. The shut-in pressure is calculated internally by } \\
\text { TDAS using the gas pressure prediction model. }\end{array}$ & $P$ \\
\hline
\end{tabular}

Note: C (conductor casing), S (Surface casing), I (intermediate casing), P (production or long-string casing)

Table 3-2. Borehole Diameters and Depths for Casing Strings for the $\mathrm{CO}_{2}$ Injection Well

\begin{tabular}{|l|c|c|c|}
\hline \multicolumn{1}{|c|}{ Casing String } & $\begin{array}{c}\text { Casing Depth } \\
\text { (ft bgs) }\end{array}$ & $\begin{array}{c}\text { Borehole Diameter } \\
\text { (inches) }\end{array}$ & $\begin{array}{c}\text { Casing Outside } \\
\text { Diameter (inches) }\end{array}$ \\
\hline Conductor & 100 & 38 & 30 \\
\hline Surface & 500 & 26 & 20 \\
\hline Intermediate & 5,000 to 7,000 & 17.5 & 13.375 \\
\hline Long String & 9,096 & 12.25 & 9.625 \\
\hline Tubing & 8,000 & NA & 5.5 \\
\hline
\end{tabular}

\subsubsection{Conductive Casing}

As shown in Table 3-3 and Table 3-4, the conductor casing will be 30 inch diameter $157.53 \mathrm{lb} / \mathrm{ft}$ (0.5 inch wall thickness) carbon steel or similar. Table 3-6 summarizes the load scenarios that were evaluated in the TDAS well design program to determine the conductor casing specification. Minimum design factors for this casing string are provided on Table 3-7. 
Table 3-3. Casing Program for the $\mathrm{CO}_{2}$ Injection Well (5,000 ft Intermediate Casing String)

\begin{tabular}{|l|c|c|c|l|c|}
\hline \multirow{2}{*}{$\begin{array}{c}\text { Casing } \\
\text { String }\end{array}$} & $\begin{array}{c}\text { Casing Depth } \\
\text { (ft bgs) }\end{array}$ & $\begin{array}{c}\text { Borehole } \\
\text { Diameter } \\
\text { (inches) }\end{array}$ & $\begin{array}{c}\text { Casing } \\
\text { Outside } \\
\text { Diameter } \\
\text { (inches) }\end{array}$ & $\begin{array}{c}\text { Casing Material } \\
\text { (weight/grade/ } \\
\text { connection) }\end{array}$ & $\begin{array}{c}\text { Coupling O.D. } \\
\text { (inches) }\end{array}$ \\
\hline Conductor & 100 & 38 & 30 & $157.53 \mathrm{lb} / \mathrm{ft}, \mathrm{B}, \mathrm{MlJ}$ & 33.525 \\
\hline Surface & 500 & 26 & 20 & $133 \mathrm{lb} / \mathrm{ft}, \mathrm{J}-55, \mathrm{BTC}$ & 21.000 \\
\hline Intermediate & $0-1,750$ & 17.5 & 13.375 & $54.5 \mathrm{lb} / \mathrm{ft}, \mathrm{K}-55, \mathrm{BTC}$ & 14.375 \\
\cline { 2 - 4 } & $1,750-5,000$ & & 13.375 & $68 \mathrm{lb} / \mathrm{ft}, \mathrm{N}-80, \mathrm{BTC}$ & 14.375 \\
\hline \multirow{2}{*}{ Long String } & $0-4,500$ & \multirow{2}{*}{12.25} & 9.625 & $40 \mathrm{lb} / \mathrm{ft}, \mathrm{N}-80, \mathrm{LTC}$ & 10.625 \\
\cline { 2 - 4 } & $4,500-7,000$ & & 9.625 & $47 \mathrm{lb} / \mathrm{ft}, \mathrm{N}-80, \mathrm{LTC}$ & 10.625 \\
\cline { 2 - 4 } & $7,000-9,096$ & & 9.625 & $53.5 \mathrm{lb} / \mathrm{ft}, \mathrm{N}-80, \mathrm{LTC}^{(\mathrm{b})}$ & 10.625 \\
\cline { 5 - 6 } & & & &
\end{tabular}

(a) This section may be upgraded with $68 \mathrm{lb} / \mathrm{ft} \mathrm{K}-55$ or N-80.

(b) These sections may be replaced with corrosion resistant alloy material, such as $13 \%$ chromium (Cr) stainless steel or similar.

Table 3-4. Casing Program for the $\mathrm{CO}_{2}$ Injection Well (7,000 ft Intermediate Casing String)

\begin{tabular}{|c|c|c|c|c|c|}
\hline $\begin{array}{l}\text { Casing } \\
\text { String }\end{array}$ & $\begin{array}{c}\text { Casing Depth } \\
\text { (ft bgs) }\end{array}$ & $\begin{array}{c}\text { Borehole } \\
\text { Diameter } \\
\text { (inches) }\end{array}$ & $\begin{array}{c}\text { Casing } \\
\text { Outside } \\
\text { Diameter } \\
\text { (inches) }\end{array}$ & $\begin{array}{l}\text { Casing Material } \\
\text { (weight/grade/ } \\
\text { connection) }\end{array}$ & $\begin{array}{l}\text { Coupling O.D. } \\
\text { (inches) }\end{array}$ \\
\hline Conductor & 100 & 38 & 30 & $157.53 \mathrm{lb} / \mathrm{ft}, \mathrm{B}, \mathrm{MIJ}$ & 33.525 \\
\hline Surface & 500 & 26 & 20 & $133 \mathrm{lb} / \mathrm{ft}, \mathrm{J}-55, \mathrm{BTC}$ & 21.000 \\
\hline \multirow[t]{2}{*}{ Intermediate } & $0-1,700$ & \multirow[t]{2}{*}{17.5} & 13.375 & $54.5 \mathrm{lb} / \mathrm{ft}, \mathrm{K}-55, \mathrm{BTC}^{(\mathrm{a})}$ & 14.375 \\
\hline & $1,700-7,000$ & & 13.375 & $68 \mathrm{lb} / \mathrm{ft}, \mathrm{N}-80, \mathrm{BTC}$ & 14.375 \\
\hline \multirow[t]{3}{*}{ Long String } & $0-4,500$ & \multirow[b]{3}{*}{12.25} & 9.625 & $40 \mathrm{lb} / \mathrm{ft}, \mathrm{N}-80, \mathrm{LTC}$ & 10.625 \\
\hline & $4,500-7,000$ & & 9.625 & $47 \mathrm{lb} / \mathrm{ft}, \mathrm{N}-80, \mathrm{LTC}$ & 10.625 \\
\hline & $7,000-9,096$ & & 9.625 & $53.5 \mathrm{lb} / \mathrm{ft}, \mathrm{N}-80, \mathrm{LTC}^{(\mathrm{b})}$ & 10.625 \\
\hline
\end{tabular}

(a) This section may be upgraded with $68 \mathrm{lb} / \mathrm{ft} \mathrm{K}-55$ or N-80.

(b) These sections may be replaced with corrosion resistant alloy material, such as $13 \% \mathrm{Cr}$ stainless steel or similar.

ksi - kilopound per square inch

\subsubsection{Surface Casing}

As shown in Table 3-3 and Table 3-4, the surface casing is 20 inch diameter $133 \mathrm{lb} / \mathrm{ft} \mathrm{J}-55$ pipe (0.635 inch wall thickness) with buttress thread casing and coupling (BTC) connections. The metallurgy of this casing string is carbon steel. Table 3-8 summarizes the load scenarios that were evaluated in TDAS to determine the surface casing specification. Minimum design factors for this casing string are provided on Table 3-9. 
Table 3-5. Properties of Well Casing Materials

\begin{tabular}{|c|c|c|c|c|c|c|c|c|}
\hline $\begin{array}{l}\text { Casing } \\
\text { String }\end{array}$ & $\begin{array}{c}\text { Casing } \\
\text { Material } \\
\text { (weight/ } \\
\text { grade/ } \\
\text { connection) }\end{array}$ & $\begin{array}{c}\text { Casing } \\
\text { Outside/lnside/ } \\
\text { Drift } \\
\text { Diameter } \\
\text { (inches) }\end{array}$ & $\begin{array}{l}\text { Yield } \\
\text { (ksi) }\end{array}$ & $\begin{array}{c}\text { Tensile } \\
\text { (ksi) }\end{array}$ & $\begin{array}{c}\text { Burst } \\
\text { (psi) } \\
\text { Plain } \\
\text { End } \\
\end{array}$ & $\begin{array}{c}\text { Collapse } \\
\text { (psi) }\end{array}$ & $\begin{array}{c}\text { Tension } \\
(1,000 \mathrm{lb}) \\
\\
\text { Joint (J) } \\
\text { and } \\
\text { Body (B) }\end{array}$ & $\begin{array}{c}\text { Compression } \\
(1,000 \mathrm{lb})\end{array}$ \\
\hline Conductor & $\begin{array}{l}157.53 \mathrm{lb} / \mathrm{ft}, \\
\mathrm{B}, \mathrm{MlJ}\end{array}$ & $\begin{array}{l}30 / 29 / 28.813 \\
(0.5 \text { in wall) }\end{array}$ & 35 & 60 & 1020 & 220 & 1622 & 1622 \\
\hline Surface & $\begin{array}{l}133 \mathrm{lb} / \mathrm{ft}, \mathrm{J}- \\
55, \mathrm{BTC}\end{array}$ & $\begin{array}{l}20 / 18.73 / 18.543 \\
\text { (0.635 in wall) }\end{array}$ & 55 & 75 & 3060 & 1500 & $\begin{array}{l}2012(\mathrm{~J}) \\
2125(\mathrm{~B})\end{array}$ & 1476 \\
\hline \multirow[t]{2}{*}{ Intermediate } & $\begin{array}{l}54.5 \mathrm{lb} / \mathrm{ft}, \mathrm{K}- \\
55, \mathrm{BTC}\end{array}$ & $\begin{array}{l}13.375 / 12.615 / \\
12.459 \\
(0.380 \text { in wall })\end{array}$ & 55 & 95 & 2730 & 1130 & $\begin{array}{l}1038(\mathrm{~J}) \\
853(\mathrm{~B})\end{array}$ & 601 \\
\hline & $\begin{array}{l}68 \mathrm{lb} / \mathrm{ft}, \mathrm{N}-80, \\
\text { BTC }\end{array}$ & $\begin{array}{l}13.375 / 12.415 / \\
12.259 \\
(0.480 \text { in wall })\end{array}$ & 80 & 100 & 5020 & 2270 & $\begin{array}{l}1585(\mathrm{~J}) \\
1556(\mathrm{~B})\end{array}$ & 1268 \\
\hline \multirow[t]{3}{*}{ Long String } & $\begin{array}{l}40 \mathrm{lb} / \mathrm{ft}, \mathrm{N}-80 \text {, } \\
\text { LTC }\end{array}$ & $\begin{array}{l}9.625 / 8.835 / \\
8.750 \\
(0.395 \text { in wall) }\end{array}$ & 80 & 100 & 5750 & 3090 & $\begin{array}{l}737(\mathrm{~J}) \\
916(\mathrm{~B})\end{array}$ & 708 \\
\hline & $\begin{array}{l}47 \mathrm{lb} / \mathrm{ft}, \mathrm{N}-80, \\
\text { LTC }\end{array}$ & $\begin{array}{l}9.625 / 8.681 / \\
8.525 \\
(0.472 \text { in wall) }\end{array}$ & 80 & 100 & 6870 & 4760 & $\begin{array}{c}905 \\
1086(\mathrm{~B})\end{array}$ & 869 \\
\hline & $\begin{array}{l}53.5 \mathrm{lb} / \mathrm{ft}, \mathrm{N}- \\
80, \mathrm{LTC}\end{array}$ & $\begin{array}{l}9.625 / 8.535 / \\
8.500 \\
(0.545 \text { in wall) }\end{array}$ & 80 & 100 & 7930 & 6620 & $\begin{array}{l}1062(\mathrm{~J}) \\
1244(\mathrm{~B})\end{array}$ & 1019 \\
\hline $\begin{array}{l}\text { Alternate } \\
\text { Long String }\end{array}$ & $\begin{array}{l}53.5 \mathrm{lb} / \mathrm{ft} \\
13 \mathrm{Cr} 95\end{array}$ & $\begin{array}{l}9.625 / 8.535 / \\
8.500 \\
(0.545 \text { in wall) }\end{array}$ & 95 & 120 & 10900 & 7950 & $\begin{array}{l}1062(\mathrm{~J}) \\
1244(\mathrm{~B})\end{array}$ & 1019 \\
\hline Tubing & $\begin{array}{l}20 \mathrm{lb} / \mathrm{ft}, \mathrm{N}-80 \text {, } \\
\text { LTC }\end{array}$ & $\begin{array}{l}5.5 / 4.778 / 4.653 \\
(0.361 \text { in wall) }\end{array}$ & 80 & 100 & 9190 & 8830 & 427.9 & 350.6 \\
\hline
\end{tabular}

Table 3-6. Conductor Casing Load Scenarios

\begin{tabular}{|c|c|c|c|c|c|}
\hline $\begin{array}{l}\text { Casing } \\
\text { String/ } \\
\text { Load } \\
\text { Scenario }\end{array}$ & $\begin{array}{c}\text { Load } \\
\text { Scenario } \\
\text { Name } \\
\text { (a) }\end{array}$ & $\begin{array}{l}\text { Internal } \\
\text { Pressure } \\
\text { Profile }^{(a)}\end{array}$ & $\begin{array}{l}\text { External } \\
\text { Pressure } \\
\text { Profile }^{(a)}\end{array}$ & $\begin{array}{c}\text { Temperature } \\
\text { Profile }^{(a)}\end{array}$ & Other/Comments $^{(b)}$ \\
\hline \multicolumn{6}{|c|}{ Conductor (30 inch, $100 \mathrm{ft}$ ) } \\
\hline A & Installed Load & $8.5 \mathrm{ppg}$ mud & $\begin{array}{l}\text { Mud/cement- } \\
\text { str } 1\end{array}$ & $\begin{array}{l}\text { Static } \\
\text { Temperature }\end{array}$ & $\begin{array}{l}\text { Cement weight } 16.2 \mathrm{ppg} \\
(0-100 \mathrm{ft})\end{array}$ \\
\hline B & $\begin{array}{l}1 / 3 \\
\text { Evacuation- } \\
500^{\prime} \text { str } 1\end{array}$ & $\begin{array}{l}1 / 3 \\
\text { Evacuation- } \\
500^{\prime}\end{array}$ & $8.5 \mathrm{ppg}$ mud & $\begin{array}{l}\text { Static } \\
\text { Temperature }\end{array}$ & Casing fully evacuated \\
\hline C & $\begin{array}{l}\text { Pressure } \\
\text { Test- } \\
100 \text { ' str } 1\end{array}$ & $\begin{array}{l}\text { Press test- } \\
\text { str } 1\end{array}$ & $\begin{array}{l}\text { Natural Pore } \\
\text { Pressure }\end{array}$ & $\begin{array}{l}\text { Static } \\
\text { Temperature }\end{array}$ & $\begin{array}{l}\text { Internal pressure at } \\
\text { surface = } 38 \text { psi; Pore } \\
\text { pressure } 0.43 \text { psi/ft ( } 8.3 \\
\text { ppg) }\end{array}$ \\
\hline
\end{tabular}

(a) Names of load scenarios and temperature and pressure profiles correspond to those used in the TDAS program.

(b) Wall loss (4\%) and temperature derating considered in all scenarios. 
Table 3-7. Minimum Design Factors and Corresponding Scenarios for Conductor Casing String

\begin{tabular}{|c|c|c|c|c|c|}
\hline Casing String & Burst & Collapse & Tension & Compression & Von Mises \\
\hline Conductor $(30$ inch, $100 \mathrm{ft})$ & $25.95(\mathrm{C})$ & $4.53(\mathrm{~B})$ & $>100(\mathrm{C})$ & $50.75(\mathrm{~B})$ & $25.14(\mathrm{~B})$ \\
\hline
\end{tabular}

Note: Letters in parenthesis correspond to load scenario with minimum design factor.

Table 3-8. Surface Casing Load Scenarios

\begin{tabular}{|c|c|c|c|c|c|}
\hline $\begin{array}{c}\text { Casing } \\
\text { String/Load } \\
\text { Scenario }\end{array}$ & $\begin{array}{c}\text { Load } \\
\text { Scenario } \\
\text { Name }^{(a)}\end{array}$ & $\begin{array}{l}\text { Internal } \\
\text { Pressure } \\
\text { Profile }^{(a)}\end{array}$ & $\begin{array}{l}\text { External } \\
\text { Pressure } \\
\text { Profile }^{(a)}\end{array}$ & $\begin{array}{c}\text { Temperature } \\
\text { Profile }^{(a)}\end{array}$ & Other/Comments $^{(\mathbf{b})}$ \\
\hline \multicolumn{6}{|c|}{ Surface (20 inch, 500 ft) } \\
\hline A & $\begin{array}{l}\text { Installed } \\
\text { Load }\end{array}$ & $9.2 \mathrm{ppg}$ mud & $\begin{array}{l}\text { Mud/cement- } \\
\text { str } 2\end{array}$ & $\begin{array}{l}\text { Static } \\
\text { Temperature }\end{array}$ & $\begin{array}{l}\text { Cement weight } 16.2 \mathrm{ppg} \\
(0-500 \mathrm{ft})\end{array}$ \\
\hline B & $\begin{array}{l}1 / 3 \\
\text { Evacuation- } \\
5,000^{\prime} \text { str } 2\end{array}$ & $\begin{array}{l}1 / 3 \\
\text { Evacuation- } \\
5,000^{\prime}\end{array}$ & $9.2 \mathrm{ppg}$ mud & $\begin{array}{l}\text { Static } \\
\text { Temperature }\end{array}$ & Casing fully evacuated \\
\hline C & $\begin{array}{l}\text { Pressure } \\
\text { Test- } \\
500^{\prime} \text { str } 2\end{array}$ & $\begin{array}{l}\text { Press test- } \\
\text { str } 2\end{array}$ & $\begin{array}{l}\text { Natural Pore } \\
\text { Pressure }\end{array}$ & $\begin{array}{l}\text { Static } \\
\text { Temperature }\end{array}$ & $\begin{array}{l}\text { Internal pressure at } \\
\text { surface = } 166 \text { psi; Pore } \\
\text { pressure } 0.43 \text { psi/ft ( } 8.3 \\
\text { ppg) }\end{array}$ \\
\hline $\mathrm{D}$ & $\begin{array}{l}50.0 \text { bbl } \\
\text { Kick-5,000' } \\
\text { str } 2\end{array}$ & $\begin{array}{l}50.0 \text { bbl } \\
\text { Kick-5,000' }\end{array}$ & $\begin{array}{l}\text { Natural Pore } \\
\text { Pressure }\end{array}$ & $\begin{array}{l}50.0 \mathrm{bbl} \\
\text { Kick-5,000' }\end{array}$ & $\begin{array}{l}\text { Internal pressure at } \\
\text { surface = } 592 \mathrm{psi} \text {; Pore } \\
\text { pressure } 0.43 \mathrm{psi} / \mathrm{ft}(8.3 \\
\text { ppg) }\end{array}$ \\
\hline$E$ & $\begin{array}{l}\text { 1/3 Replc- } \\
5,000^{\prime} \text { str } 2 \\
\mathrm{C}, \mathrm{W}\end{array}$ & $\begin{array}{l}\text { 1/3 Replc- } \\
5,000^{\prime}\end{array}$ & $\begin{array}{l}\text { Natural Pore } \\
\text { Pressure }\end{array}$ & $\begin{array}{l}\text { Circulating } \\
5,000^{\prime}\end{array}$ & $\begin{array}{l}\text { Internal pressure at } \\
\text { surface = } 823 \mathrm{psi} \text {; Pore } \\
\text { pressure } 0.43 \mathrm{psi} / \mathrm{ft}(8.3 \\
\text { ppg) }\end{array}$ \\
\hline $\mathrm{F}$ & $\begin{array}{l}\text { 1/3 Replc- } \\
5,000^{\prime} \text { str } 2 \\
\text { S,W }\end{array}$ & $\begin{array}{l}\text { 1/3 Replc- } \\
5,000^{\prime}\end{array}$ & $\begin{array}{l}\text { Natural Pore } \\
\text { Pressure }\end{array}$ & $\begin{array}{l}\text { Static } \\
\text { Temperature }\end{array}$ & $\begin{array}{l}\text { Internal pressure at } \\
\text { surface = } 823 \mathrm{psi} \text {; Pore } \\
\text { pressure } 0.43 \mathrm{psi} / \mathrm{ft}(8.3 \\
\text { ppg) }\end{array}$ \\
\hline
\end{tabular}

(a) Names of load scenarios and temperature and pressure profiles correspond to those used in the TDAS program.

(b) Wall loss (4\%) and temperature derating considered in all scenarios.

bbl - barrel

ppg - pound per gallon

Table 3-9. Minimum Design Factors and Corresponding Scenarios for Surface Casing String

\begin{tabular}{|l|l|l|l|l|l|}
\hline \multicolumn{1}{|c|}{ Casing String } & Burst & Collapse & Tension & Compression & Von Mises \\
\hline $\begin{array}{l}\text { Surface } \\
(20 \text { inch, } 500 \mathrm{ft}) \mathrm{w} / 5,000 \mathrm{ft} \text { intermediate }\end{array}$ & $3.57(\mathrm{E})$ & $5.73(\mathrm{~B})$ & $14.28(\mathrm{~F})$ & $9.86(\mathrm{D})$ & $3.61(\mathrm{E})$ \\
\hline $\begin{array}{l}\text { Surface } \\
(20 \text { inch, } 500 \mathrm{ft}) \mathrm{w} / 7,000 \mathrm{ft} \text { intermediate }\end{array}$ & $2.43(\mathrm{E})$ & $5.73(\mathrm{~B})$ & $70.36(\mathrm{C})$ & $12.08(\mathrm{D})$ & $2.43(\mathrm{E})$ \\
\hline
\end{tabular}

Note: Letters in parenthesis correspond to load scenario with minimum design factor.

\subsubsection{Intermediate Casing(s)}


As shown in Table 3-3 and Table 3-4, two intermediate casing string designs are being considered: one that is approximately $5,000 \mathrm{ft}$ long and the other that is approximately $7,000 \mathrm{ft}$ in length. In both cases, the intermediate string will be composed of two materials: an upper section (approximately $1,700 \mathrm{ft}$ in length) of $54.5 \mathrm{lb} / \mathrm{ft} \mathrm{K}-55$ pipe with BTC connections, and a lower section of $68 \mathrm{lb} / \mathrm{ft} \mathrm{N}-80$ pipe with BTC connections. The metallurgy of both materials is carbon steel. Table 3-10 summarizes the load scenarios that were evaluated in TDAS to determine the intermediate casing specification. Minimum design factors for this casing string are provided in Table 3-11.

Table 3-10. Intermediate Casing Load Scenarios

\begin{tabular}{|c|c|c|c|c|c|}
\hline $\begin{array}{l}\text { Casing } \\
\text { Stringl } \\
\text { Load } \\
\text { Scenario }\end{array}$ & $\begin{array}{c}\text { Load Scenario } \\
\text { Name }{ }^{(a)}\end{array}$ & $\begin{array}{l}\text { Internal } \\
\text { Pressure } \\
\text { Profile }^{(a)} \\
\end{array}$ & $\begin{array}{l}\text { External } \\
\text { Pressure } \\
\text { Profile }^{(a)}\end{array}$ & $\begin{array}{c}\text { Temperature } \\
\text { Profile }^{(a)}\end{array}$ & Other/Comments $^{(b)}$ \\
\hline \multicolumn{6}{|c|}{ Intermediate (13.375 inch, 5,000 ft) } \\
\hline A & Installed Load & 10 ppg mud & $\begin{array}{l}\text { Mud/cement- } \\
\text { str } 3\end{array}$ & $\begin{array}{l}\text { Static } \\
\text { Temperature }\end{array}$ & $\begin{array}{l}\text { Cement weight } 12.7 \mathrm{ppg} \\
(0-4,000 \mathrm{ft}), 15.6 \mathrm{ppg} \\
(4,000-5,000 \mathrm{ft})^{(\mathrm{c}) ;} \\
\text { Cement weight } 12.7 \mathrm{ppg} \\
(0-4,500 \mathrm{ft}), 15.6 \mathrm{ppg} \\
(4,500-6,000 \mathrm{ft}) ; 16.2 \\
\text { ppg }(6,000-7,000 \mathrm{ft})^{(\mathrm{d})}\end{array}$ \\
\hline $\mathrm{B}$ & $\begin{array}{l}1 / 3 \\
\text { Evacuation- } \\
9096^{\prime} \text { str } 3\end{array}$ & $\begin{array}{l}1 / 3 \\
\text { Evacuation- } \\
9096^{\prime}\end{array}$ & $9.5 \mathrm{ppg}$ mud & $\begin{array}{l}\text { Static } \\
\text { Temperature }\end{array}$ & $\begin{array}{l}\text { Casing fully evacuated } \\
\text { to } 3,032 \mathrm{ft} \text { bgs }\end{array}$ \\
\hline C & $\begin{array}{l}\text { Pressure Test- } \\
5,000^{\prime} \text { str } 3^{(\mathrm{c})} \\
\text { Pressure Test- } \\
7,000^{\prime} \text { str } 3^{(\mathrm{d})}\end{array}$ & $\begin{array}{l}\text { Press test- } \\
\text { str } 3\end{array}$ & $\begin{array}{l}\text { Natural Pore } \\
\text { Pressure }\end{array}$ & $\begin{array}{l}\text { Static } \\
\text { Temperature }\end{array}$ & $\begin{array}{l}\text { Internal pressure at } \\
\text { surface = } 1,584 \mathrm{psi} \text {; Pore } \\
\text { pressure } 0.43 \mathrm{psi} / \mathrm{ft} \text { (8.3 } \\
\text { ppg) }\end{array}$ \\
\hline $\mathrm{D}$ & $\begin{array}{l}50.0 \text { bbl Kick- } \\
9,096^{\prime} \text { str } 3\end{array}$ & $\begin{array}{l}50.0 \mathrm{bbl} \\
\text { Kick-9,096' }\end{array}$ & $\begin{array}{l}\text { Natural Pore } \\
\text { Pressure }\end{array}$ & $\begin{array}{l}50.0 \text { bbl Kick- } \\
9,096^{\prime}\end{array}$ & $\begin{array}{l}\text { Internal pressure at } \\
\text { surface = 1,293 psi; Pore } \\
\text { pressure } 0.43 \text { psi/ft ( } 8.3 \\
\text { ppg) }\end{array}$ \\
\hline $\mathrm{E}$ & $\begin{array}{l}\text { 1/3 Replc- } \\
9,096 \text { 'str } 2 \\
\text { C,W }\end{array}$ & $\begin{array}{l}\text { 1/3 Replc- } \\
9,096^{\prime}\end{array}$ & $\begin{array}{l}\text { Natural Pore } \\
\text { Pressure }\end{array}$ & $\begin{array}{l}\text { Circulating } \\
9,096^{\prime}\end{array}$ & $\begin{array}{l}\text { Internal pressure at } \\
\text { surface = } 1,733 \mathrm{psi} \text {; Pore } \\
\text { pressure } 0.43 \mathrm{psi} / \mathrm{ft} \text { (8.3 } \\
\mathrm{ppg} \text { ) }\end{array}$ \\
\hline $\mathrm{F}$ & $\begin{array}{l}\text { 1/3 Replc- } \\
9,096^{\prime} \text { str } 2 \\
\text { S,W }\end{array}$ & $\begin{array}{l}\text { 1/3 Replc- } \\
9,096^{\prime}\end{array}$ & $\begin{array}{l}\text { Natural Pore } \\
\text { Pressure }\end{array}$ & $\begin{array}{l}\text { Static } \\
\text { Temperature }\end{array}$ & $\begin{array}{l}\text { Internal pressure at } \\
\text { surface = } 1,733 \mathrm{psi} \text {; Pore } \\
\text { pressure } 0.43 \mathrm{psi} / \mathrm{ft} \text { (8.3 } \\
\text { ppg) }\end{array}$ \\
\hline
\end{tabular}

(a) Names of load scenarios and temperature and pressure profiles correspond to those used in the TDAS program.

(b) Wall loss (4\%) and temperature derating considered in all scenarios.

(c) for $5,000 \mathrm{ft}$ casing string

(d) for 7,000 ft casing string 
Table 3-11. Minimum Design Factors and Corresponding Scenarios for Intermediate Casing String

\begin{tabular}{|l|l|l|l|l|l|}
\hline \multicolumn{1}{|c|}{ Casing String } & \multicolumn{1}{c|}{ Burst } & Collapse & Tension & Compression & Von Mises \\
\hline Intermediate(13.375 inch, 5000 ft) & $1.51(\mathrm{E})$ & $1.18(\mathrm{~B})$ & $3.8(\mathrm{~F})$ & $6.02(\mathrm{~B})$ & $1.67(\mathrm{E})$ \\
\hline Intermediate $(13.375$ inch, $7000 \mathrm{ft})$ & $1.25(\mathrm{C})$ & $1.16(\mathrm{~B})$ & $3.02(\mathrm{C})$ & $4.67(\mathrm{~A})$ & $1.39(\mathrm{C})$ \\
\hline
\end{tabular}

Note: Letters in parenthesis correspond to load scenario with Minimum Design Factor.

\subsubsection{Long-String Casing}

As shown in Table 3-3 and Table 3-4, the long-string casing is 9-5/8 inch diameter pipe composed of three sections, each with a different material. The uppermost section (approximately $4,500 \mathrm{ft}$ ) will be $\mathrm{N}-8040 \mathrm{lb} / \mathrm{ft}$ pipe (0.395 inch wall thickness) with long thread coupling (LTC) connections; the middle section (4,500 to 7,000 ft) will be $\mathrm{N}-80$ or $47 \mathrm{lb} / \mathrm{ft}$ pipe (0.472 inch wall thickness) with LTC connections; and the lower section (7,000 ft to 9,096 ft) will be $\mathrm{N}-80$ or L-80 $53.5 \mathrm{lb} / \mathrm{ft}$ pipe ( 0.545 inch wall thickness) with LTC connections. The metallurgy of the upper and middle sections is carbon steel. The metallurgy of the lower section may be carbon steel or it may be upgraded to a corrosion resistant alloy, such as $13 \% \mathrm{Cr}$ stainless steel. Table 3-12 summarizes the load scenarios that were evaluated in TDAS to determine the long casing specification. Minimum design factors for this casing string are provided in Table 3-13.

Table 3-12. Long String Casing Load Scenarios

\begin{tabular}{|c|c|c|c|c|c|}
\hline $\begin{array}{l}\text { Casing } \\
\text { String/ } \\
\text { Load } \\
\text { Scenario }\end{array}$ & $\begin{array}{l}\text { Load } \\
\text { Scenario } \\
\text { Name }^{(a)}\end{array}$ & $\begin{array}{l}\text { Internal } \\
\text { Pressure } \\
\text { Profile }^{(a)}\end{array}$ & $\begin{array}{l}\text { External } \\
\text { Pressure } \\
\text { Profile }^{(a)}\end{array}$ & $\begin{array}{c}\text { Temperature } \\
\text { Profile }^{(a)}\end{array}$ & Other/Comments ${ }^{(b)}$ \\
\hline \multicolumn{6}{|c|}{ Deep $(9.625$ inch, 9,096 ft) } \\
\hline $\bar{A}$ & $\begin{array}{l}\text { Installed } \\
\text { Load }\end{array}$ & $11 \mathrm{ppg}$ mud & $\begin{array}{l}\text { Mud/cement- } \\
\text { str } 4\end{array}$ & $\begin{array}{l}\text { Static } \\
\text { Temperature }\end{array}$ & $\begin{array}{l}\text { Cement weight } 12.5 \mathrm{ppg} \\
(0-5,700 \mathrm{ft}), 15.8 \mathrm{ppg} \\
(5,700-9,096 \mathrm{ft})\end{array}$ \\
\hline $\mathrm{B}$ & $\begin{array}{l}\text { Full } \\
\text { evacuation- } \\
\text { str } 4\end{array}$ & $\begin{array}{l}\text { Complete } \\
\text { evacuation }\end{array}$ & $11 \mathrm{ppg}$ mud & $\begin{array}{l}\text { Static } \\
\text { Temperature }\end{array}$ & Casing fully evacuated \\
\hline C & $\begin{array}{l}\text { Srf Tbg } \\
\text { Leak-Static } \\
\text { str } 4\end{array}$ & $\begin{array}{l}\text { Surf tbg } \\
\text { leak-static }\end{array}$ & $\begin{array}{l}\text { Natural Pore } \\
\text { Pressure }\end{array}$ & $\begin{array}{l}\text { Static } \\
\text { Temperature }\end{array}$ & $\begin{array}{l}\text { Internal pressure at } \\
\text { surface }=4160 \mathrm{psi} ; \text { Pore } \\
\text { pressure } 0.43 \mathrm{psi} / \mathrm{ft} \text { ( } 8.3 \\
\mathrm{ppg} \text { ) }\end{array}$ \\
\hline $\mathrm{D}$ & $\begin{array}{l}\text { Srf Tbg } \\
\text { Leak-Hot str } \\
4\end{array}$ & $\begin{array}{l}\text { Surf tbg } \\
\text { leak-hot }\end{array}$ & $\begin{array}{l}\text { Natural Pore } \\
\text { Pressure }\end{array}$ & Flowing & $\begin{array}{l}\text { Internal pressure at } \\
\text { surface = } 4213 \text { psi; Pore } \\
\text { pressure } 0.43 \text { psi/ft ( } 8.3 \\
\text { ppg) }\end{array}$ \\
\hline
\end{tabular}

(a) Names of load scenarios and temperature and pressure profiles correspond to those used in the TDAS program.

(b) Wall loss (4\%) and temperature derating considered in all scenarios.

\subsubsection{Other Casing}

The injection well will not have any casing strings other than those discussed in Sections 3.7.2.1 through 3.7.2.4. 


\section{Table 3-13. Minimum Design Factors and Corresponding Scenarios} for Long String Casing

\begin{tabular}{|c|c|c|l|l|l|}
\hline Casing String & Burst & Collapse & Tension & Compression & \multicolumn{1}{c|}{ Von Mises } \\
\hline Deep (9.625 inch, 9,096 ft) & $1.3(\mathrm{D})$ & $1.08(\mathrm{~B})^{\mathrm{a}}$ & $2.11(\mathrm{C})$ & $3.2(\mathrm{~B})$ & $1.43(\mathrm{C})$ \\
\hline
\end{tabular}

Note: Letters in parenthesis correspond to load scenario with Minimum Design Factor.

(a) Although this value slightly exceeds the minimum design factor of 1.1, it was considered acceptable because it is based on a fully-evacuated scenario, which is not possible for the long-string casing. The value was also calculated using $53.5 \mathrm{lb} / \mathrm{ft} \mathrm{N}-80$ casing. $13 \mathrm{Cr} 95$ casing is anticipated to be used in the bottom portion of the long string, which has greater strength properties.

\subsubsection{Injection Tubing}

The injection tubing will be 5-1/2 inch outer diameter (O.D.) pipe. This size tubing is required to accommodate the planned $\mathrm{CO}_{2}$ injection rates.

A thermohydraulic analysis was conducted to determine the proper tubing size for the proposed injection scenario. The injection well at the Mattoon site is designed to have a maximum instantaneous injection rate of $578,568 \mathrm{lb} / \mathrm{hr}$ (this equates to an annual injection rate of approximately $1.95 \mathrm{MMT} / \mathrm{yr}$ as the plant is designed to be shut down for two 28-day periods per year). To achieve this flow rate, the injection pressure must be greater than the minimum bottomhole pressure required to drive the $\mathrm{CO}_{2}$ into the reservoir formation but less than the maximum safe pressure to avoid fracturing. The minimum bottomhole pressure to provide the required flow rate into the Mt. Simon Formation was determined by subsurface reservoir modeling (see Section 5.4). The maximum safe bottomhole pressure is specified as $85 \%$ of the pressure developed assuming $0.8 \mathrm{psi} / \mathrm{ft}$ of depth to the top of the reservoir. These limiting conditions are summarized in Table 3-14. Two scenarios were evaluated. In the first scenario, $\mathrm{CO}_{2}$ is injected across the entire Mt. Simon Formation (7,353 to 8,996 ft bgs), in the second scenario, $\mathrm{CO}_{2}$ is injected only across a $260 \mathrm{ft}$ thick portion of the Mt. Simon Formation (8,698 to $8,958 \mathrm{ft}$ bgs). Each of these scenarios requires a different bottomhole pressure to inject the $\mathrm{CO}_{2}$ into the formation, and thus a different surface injection pressure.

Table 3-14. Flow Rates and Limiting Pressures for Hydraulic Calculations

\begin{tabular}{|c|c|c|}
\hline Parameter & Scenario \#1 $^{\text {(a) }}$ & Scenario \#2 $^{\text {(a) }}$ \\
\hline Depth to top of injection horizon $(\mathrm{ft})$ & 7,353 & 8,698 \\
\hline Flow rate/well $(\mathrm{Ib} / \mathrm{hr})$ & $\begin{array}{c}578,568 \\
(6,312 \text { metric tons/day) }\end{array}$ & $\begin{array}{c}578,568 \\
(6,312 \text { metric tons/day) }\end{array}$ \\
\hline $\begin{array}{c}\text { Max. bottomhole injection pressure }(\mathrm{psi}) \\
\text { (depth } \times 0.85 \times 0.8+14.7)\end{array}$ & 5,015 & 5,929 \\
\hline $\begin{array}{c}\text { Required injection pressure at top of injection zone } \\
\text { (based on reservoir modeling) }(\mathrm{psi})\end{array}$ & 3,411 & 3,959 \\
\hline
\end{tabular}

(a) The first scenario assumes $\mathrm{CO}_{2}$ is injected across the entire Mt. Simon Formation (7,353 to 8,996 $\mathrm{ft}$ bgs); the second scenario assumes $\mathrm{CO}_{2}$ is injected only across a $260 \mathrm{ft}$ thick portion of the Mt. Simon Formation (8,698 to $8,958 \mathrm{ft}$ bgs).

A steady state, one-dimensional flow model was used to calculate the pressure drop along a series of segments of the pipeline or well. Pressure changes from frictional loss, gravity head, and acceleration of the flow are included in the model. The $\mathrm{CO}_{2}$ density is calculated from the pressure and internal energy from the carbon dioxide state equation of Span and Wagner 
(1996). The carbon dioxide is assumed to be a liquid or supercritical fluid and the calculation stops if two-phase conditions occur. The internal energy at the end of a pipe length segment was calculated from the energy equation accounting for the heat transfer from or into the carbon dioxide stream from the surrounding soil or rock, change in potential energy due to pressure, and kinetic energy of the flow. For the well, the ultimate heat sink is the rock far away from the well so steady-state heat transfer cannot be assumed. Instead, an equivalent heat conductance was defined at a given elapsed time after injection starts based on the heat flux calculated with a one-dimensional transient finite difference conduction model.

In the energy equation, the pressure, kinetic energy and gravity terms are relatively small and roughly balance out for moderate friction pressure drops. Depending upon the ambient rock temperature profile and the $\mathrm{CO}_{2}$ temperature at the wellhead, net heat transfer may be from the fluid to the rock or from the rock to the fluid. Changes in internal energy and temperature of the $\mathrm{CO}_{2}$ with depth cause gradual changes in density, which in turn change the velocity and pressure drop. If the friction pressure drop is large (e.g., high velocity flow through small injection tubing), fluid expansion is significant as it moves down the pressure gradient. The resulting cooling effect can potentially have a greater impact on the $\mathrm{CO}_{2}$ temperature than heat transfer to the surroundings.

The combined effect of major phenomena influencing fluid pressure is illustrated in Figure 3-3. If the injection pressure is too high, a higher wellhead temperature, lower wellhead pressure and higher friction pressure drop (higher flow, smaller tubing) are beneficial to achieving stable operating conditions. If the injection pressure is too low, a lower wellhead temperature, higher wellhead pressure, and lower friction pressure drop (lower flow rate, larger tubing, smoother tubing surface) are beneficial.

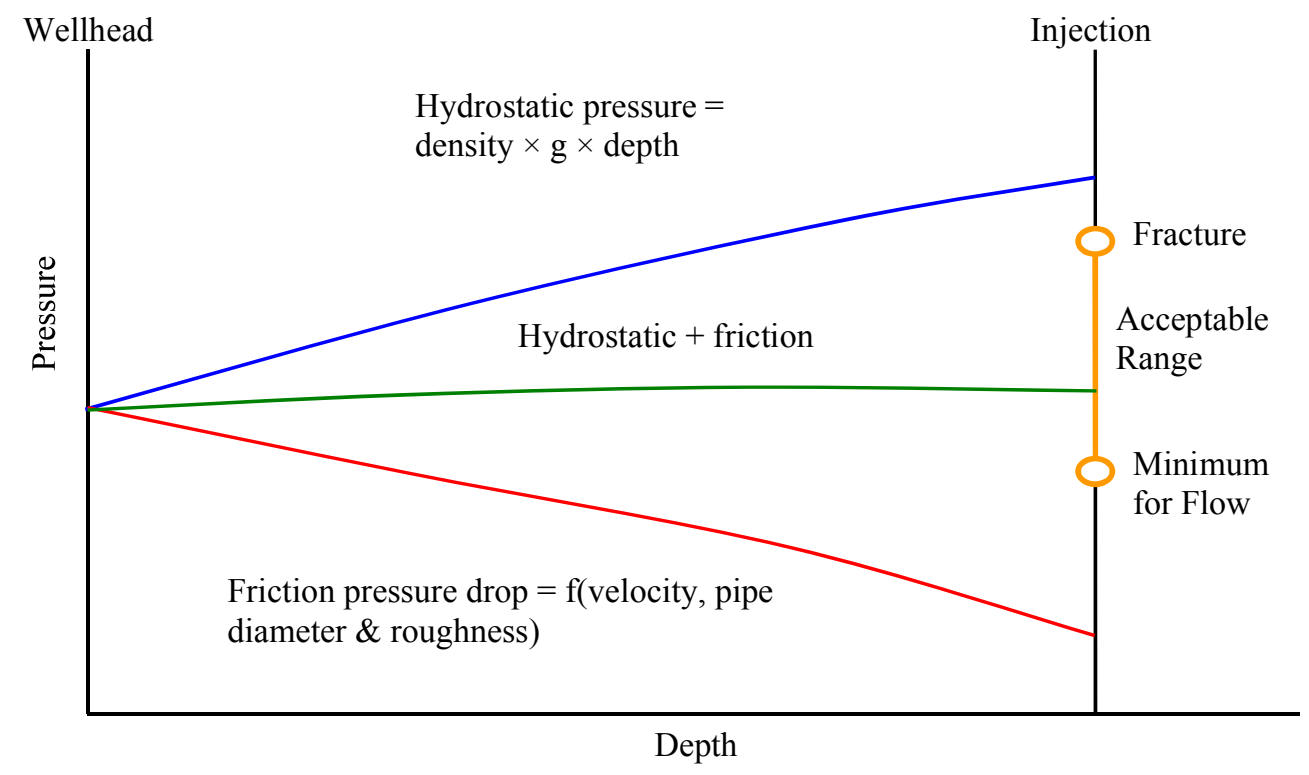

Figure 3-3. Influences on $\mathrm{CO}_{2}$ Pressure versus Depth from Delivery to the Wellhead to Injection at Depth of Target Formation 
Calculations using the thermohydraulic model show that a tubing string with 5-1/2 inch O.D. and 4.778 inch inside diameter (I.D.) will accommodate the peak mass flow rate assuming a $\mathrm{CO}_{2}$ temperature of $95^{\circ} \mathrm{F}$ or lower at the surface and an injection pressure of approximately 2,100 psi. A higher injection pressure would be required if the temperature of the $\mathrm{CO}_{2}$ is $120^{\circ} \mathrm{F}$. The higher temperature results in lower density, leading to less hydrostatic head in the fluid column and higher frictional losses because of higher fluid velocities. This is true for both scenarios that were evaluated - i.e., when $\mathrm{CO}_{2}$ is injected across the entire Mt. Simon Formation (top of injection interval is at a depth of $7,353 \mathrm{ft} \mathrm{bgs}$ ) and when $\mathrm{CO}_{2}$ is injected only across a $260 \mathrm{ft}$ thick portion of the Mt. Simon Formation (top of injection interval at 8,698 ft bgs). A summary of the results is provided in Table 3-15. A tubing string with an inside diameter smaller than 4.778 inches (e.g., $26.8 \mathrm{lb} / \mathrm{ft}$ tubing has an inside diameter of 4.5 inches) would require higher surface pressures to achieve the required bottomhole pressure due to increased frictional losses in the tubing. However, $20 \mathrm{lb} / \mathrm{ft}$ tubing (inside diameter of 4.778 inches) is sufficient for this application based on the mechanical strength properties of the tubing,

Table 3-15. Summary Results of Thermohydraulic Evaluation

\begin{tabular}{|l|c|c|c|c|}
\hline \multicolumn{1}{|c|}{ Parameter } & \multicolumn{2}{c|}{ Scenario \#1 $^{(\mathrm{a})}$} & \multicolumn{2}{c|}{ Scenario \#2 $^{(\mathrm{a})}$} \\
\hline Tubing I.D. (in.) & $4.778^{(\mathrm{b})}$ & $4.778^{(\mathrm{b})}$ & $4.778^{(\mathrm{b})}$ & $4.778^{(\mathrm{b})}$ \\
\hline Wellhead temperature $\left({ }^{\circ} \mathrm{F}\right)$ & 95 & 120 & 95 & 120 \\
\hline Required bottomhole pressure (psi) & 3,411 & 3,411 & 3,959 & 3,959 \\
\hline Predicted bottomhole pressure (psi) & 3,425 & 3,411 & 3,973 & 3,961 \\
\hline Predicted bottomhole temperature $\left({ }^{\circ} \mathrm{F}\right)$ adiabatic & 125 & 150 & 129 & 156 \\
\hline Predicted wellhead pressure $(\mathrm{psi})$ & $1,918^{(\mathrm{c})}$ & $2,242^{(\mathrm{c})}$ & $2,086^{(\mathrm{c})}$ & $2,427^{(\mathrm{c})}$ \\
\hline
\end{tabular}

(a) The first scenario assumes $\mathrm{CO}_{2}$ is injected across the entire Mt. Simon Formation (7,353 to $8,996 \mathrm{ft}$ bgs); the second scenario assumes $\mathrm{CO}_{2}$ is injected only across a $260 \mathrm{ft}$ thick portion of the Mt. Simon Formation (8,698 to $8958 \mathrm{ft}$ bgs).

(b) Tubing string used in calculation is 5.5 inch O.D., $20 \mathrm{lb} / \mathrm{ft} \mathrm{N}-80$. Roughness factor of $4.6 \times 10^{-5} \mathrm{~m}$ for tubing string.

(c) This is the value that is required to produce the predicted bottomhole pressure.

\subsubsection{Maximum Allowable Suspended Weight Based on Joint Strength of Injection Tubing}

The joint strength of the coupling defines the maximum allowable suspended weight. For 20 $\mathrm{lb} / \mathrm{ft} \mathrm{N}-80$ API pipe with LTC couplings, the yield strength is $428,000 \mathrm{lb}$. Table 3-16 describes the properties of the tubing. Based on this, 5-1/2 inch $20 \mathrm{lb} / \mathrm{ft} \mathrm{N}-80$ tubing with LTC couplings can support a string weight of $428,000 \mathrm{lb}$. The pipe body has a yield strength of $466,000 \mathrm{lb}$.

Table 3-16. Properties of Tubing Material

\begin{tabular}{|c|l|l|l|l|l|l|l|}
\hline $\begin{array}{c}\text { Material } \\
\text { (weight/grade/ } \\
\text { connection) }\end{array}$ & $\begin{array}{c}\text { Casing } \\
\text { Outside/Inside/Drift } \\
\text { Diameter (inches) }\end{array}$ & $\begin{array}{c}\text { Yield } \\
\text { (ksi) }\end{array}$ & $\begin{array}{c}\text { Tensile } \\
\text { (ksi) }\end{array}$ & $\begin{array}{c}\text { Burst } \\
\text { (psi) }\end{array}$ & $\begin{array}{c}\text { Consion } \\
\text { Collapse } \\
\text { (psi) }\end{array}$ & $\begin{array}{c}\text { (1000 lb) } \\
\text { Joint (J) } \\
\text { and } \\
\text { Body } \\
\text { (B) }\end{array}$ & $\begin{array}{c}\text { Compression } \\
(\mathbf{1 0 0 0} \mathbf{l b})\end{array}$ \\
\hline $\begin{array}{l}20 \mathrm{lb} / \mathrm{ft}, \mathrm{N}-80, \\
\text { LTC }\end{array}$ & $\begin{array}{l}5.5 / 4.778 / 4.653 \\
(0.361 \text { in wall) }\end{array}$ & 80 & 100 & 9,190 & 8,830 & $\begin{array}{c}427.9(\mathrm{~J}) \\
466(\mathrm{~B})\end{array}$ & 350.6 \\
\hline
\end{tabular}




\subsubsection{Weight of Injection Tubing String (Axial Load) in Air}

The total weight of the tubing string suspended in air is equal to its length in feet multiplied by the weight per foot of the tubing material. The material will be $20 \mathrm{lb} / \mathrm{ft} \mathrm{N}-80$. The exact length of the tubing string will be determined after the well is drilled and characterized (geophysical logging, core analyses, etc.). For the sake of this application, it was assumed that the length of the injection tubing will be $8,000 \mathrm{ft}$, which would position the bottom of the tubing string in the middle to lower half of the Mt. Simon Formation. Based on a length of $8,000 \mathrm{ft}$, the tubing would weigh $160,000 \mathrm{lb}$.

\subsubsection{Cement}

All casing strings will be cemented to surface. A cement program was designed for the injection well by a company specializing in well cementing services (Schlumberger) and is summarized in Table 3-17. The table describes, for each casing string, type of cement, amount of material (in sacks [sks]) including excess if applicable, weight of the mixture in ppg, and yield in $\mathrm{ft}^{3} /$ sack. The table also identifies if a cement column includes more than one stage and/or multiple sections (e.g., lead, tail) and the approximate depth interval of each section. Schlumberger used its CEMCADE program to aid in designing the cement program for the injection well. Details of the CEMCADE analyses are provided in Appendix 3-1. It should be noted that the cement design developed by Schlumberger was based on a preliminary well design; therefore, some of the casing weights used by Schlumberger do not match exactly those described in Section 3.7.2. However, the depths of the casing strings and the borehole diameters used by Schlumberger do match those presented in Section 3.7.2; therefore, the proposed cement design is considered to be very close to a final design. A final cement design that incorporates the final casing details will be prepared prior to drilling the well.

\subsubsection{Conductive Casing}

The cement for the conductive casing will be Type A cement.

\subsubsection{Surface Casing}

The cement for the surface casing will be Type A cement. Approximately 300 sks will be required, including $75 \%$ excess. The mixture will have a weight of approximately $15.6 \mathrm{ppg}$.

\subsubsection{Intermediate Casing}

The cement design for the intermediate casing is different for the two well designs. For the well design with a 5,000 ft intermediate casing string, the intermediate casing will be terminated in the dolomite below the St. Peter sandstone. The cement column will include a lead (upper) section and a tail (lower) section. The lead section, which will extend from ground surface to an approximate depth of 4,000 ft bgs, will be a 35:65 mixture of Type A cement and Pozzolan (Poz) material. A total of approximately $1,950 \mathrm{sks}$ of this mixture will be required. The mixture will have an approximate weight of $12.7 \mathrm{ppg}$. The tail section, which will extend from a depth of approximately 4,000 to $5,000 \mathrm{ft}$ bgs, will be Class A cement and will have a weight of approximately $15.6 \mathrm{ppg}$. Approximately 900 sks will be required, including $50 \%$ excess.

For the well design with a 7,000 ft intermediate casing string, cement will be emplaced in two stages. Both stages will include a lead and tail section, the intermediate casing will be terminated in the Eau Claire Formation above the Mt. Simon Formation. The lower $\left(1^{\text {st }}\right)$ stage, which will extend from approximately 5,000 to $7,000 \mathrm{ft}$ bgs, will include a lead section $(5,000$ to 
Table 3-17. Cement Program for the $\mathrm{CO}_{2}$ Injection Well

\begin{tabular}{|c|c|c|}
\hline Casing String & $\begin{array}{c}\text { Casing Depth } \\
\text { (ft bgs) }\end{array}$ & Cement Description $^{(a)}$ \\
\hline Conductor & 100 & Class A \\
\hline Surface & 500 & Class A, $15.6 \mathrm{ppg} ; 300 \mathrm{sks}, 1.2 \mathrm{ft}^{3} / \mathrm{sk}, 75 \%$ excess \\
\hline Intermediate $(5,000 \mathrm{ft})$ & $0-5,000$ & $\begin{array}{l}\text { Lead }(0-4,000 \mathrm{ft}): 35: 65 \text { Class A:Poz, } 12.7 \mathrm{ppg}, 1950 \mathrm{sks} \text {, } \\
2.15 \mathrm{ft}^{3} / \mathrm{sk} \\
\text { Tail: }(4,000-5,000 \mathrm{ft}): \text { Class A, } 15.6 \mathrm{ppg} ; 900 \text { sks; } 1.19 \\
\mathrm{ft}^{3} / \mathrm{sk}, 50 \% \text { excess }\end{array}$ \\
\hline Intermediate $(7,000 \mathrm{ft})$ & $0-7,000$ & $\begin{array}{l}\text { Stage \#2 Lead (0-4,500 ft): 35:65 Class A:Poz, } 12.7 \mathrm{ppg} \text {, } \\
2200 \mathrm{sks}, 2.15 \mathrm{ft}^{3} / \mathrm{sk} \\
\text { Stage \#2 Tail: }(4,500-5,000 \mathrm{ft}): \text { Class A, } 15.6 \mathrm{ppg} ; 450 \mathrm{sks} \text {; } \\
1.19 \mathrm{ft}^{3} / \mathrm{sk}, 50 \% \text { excess } \\
\text { Stage \#1 Lead }(5,000-6,000 \mathrm{ft}) \text { : Class H, } 15.6 \mathrm{ppg}, 880 \mathrm{sks} \text {, } \\
1.18 \mathrm{ft}^{3} / \mathrm{sk} \\
\text { Stage \#1 Tail: }(6,000-7,000 \mathrm{ft}): \text { Class H, } 16.2 \mathrm{ppg} ; 950 \mathrm{sks} \text {; } \\
1.09 \mathrm{ft}^{3} / \mathrm{sk}, 50 \% \text { excess }\end{array}$ \\
\hline $\begin{array}{l}\text { Deep (with } 5,000 \mathrm{ft} \text { or } \\
7,000 \mathrm{ft} \text { intermediate } \\
\text { casing) }\end{array}$ & $0-9,096$ & $\begin{array}{l}\text { Lead (0 5,700 ft): } 35: 65 \text { Class A:Poz, } 12.5 \mathrm{ppg}, 1100 \mathrm{sks} \text {, } \\
2.01 \mathrm{ft}^{3} / \mathrm{sk} \\
\text { Tail: }(\sim 5,700-9,096 \mathrm{ft}): \text { EverCRETE } \mathrm{CO}_{2} \text { resistant cement } \\
\text { (or similar), } 15.8 \mathrm{ppg} ; 1200 \mathrm{sks} ; 1.09 \mathrm{ft}^{3} / \mathrm{sk}, 35 \% \text { excess }\end{array}$ \\
\hline
\end{tabular}

Actual volumes and depth intervals will depend on true thickness of formations encountered in the well, actual hole size/volume, and other variables that cannot be predicted with complete certainty. Thermal conductivities of cements range from $0.5-0.6 \mathrm{BTU} / \mathrm{ft} \cdot \mathrm{hr} \cdot{ }^{\circ} \mathrm{F}$ for the lead systems to $0.75 \mathrm{BTU} / \mathrm{ft} \cdot \mathrm{hr} \cdot{ }^{\circ} \mathrm{F}$ for the tail systems including the EverCRETE material (or similar).

$6,000 \mathrm{ft}$ bgs) and a tail section (6,000 to 7,000 ft bgs). The lead section will be Class $\mathrm{H}$ cement (approximately $880 \mathrm{sks}$ ) with a weight of $15.6 \mathrm{ppg}$. The tail section will be Class $\mathrm{H}$ cement (approximately $950 \mathrm{sks}$, including $50 \%$ excess) with a weight of $16.2 \mathrm{ppg}$. The upper $\left(2^{\text {nd }}\right)$ stage will extend from ground surface to approximately $5,000 \mathrm{ft}$ bgs and will also have a lead section ( 0 to $4,500 \mathrm{ft} \mathrm{bgs}$ ) and a tail section (4,500 to 5,000 ft bgs). The lead section will be a 35:65 mixture of Type A cement and Pozzolan material. A total of 2,200 sks of this mixture will be required. The mixture will have an approximate weight of $12.7 \mathrm{ppg}$. The tail section will be Class A cement and will have a weight of approximately $15.6 \mathrm{ppg}$. Approximately $450 \mathrm{sks}$ will be required, including $50 \%$ excess.

\subsubsection{Long-String Casing}

The cement for the long-string casing will be installed in a single stage but will include a lead section (ground surface to approximately $5,700 \mathrm{ft}$ bgs) and a tail section (approximately 5,700 to 9,096 ft bgs). The lead section will be a 35:65 mixture of Type A cement and Pozzolan material. A total of approximately 1,100 sks of this mixture will be required. The mixture will have an approximate weight of $12.5 \mathrm{ppg}$. The tail section will be a $\mathrm{CO}_{2}$ resistant cement that is designed to cover at least $1,000 \mathrm{ft}$ above the top of the Eau Claire shale section (for the $5,000 \mathrm{ft}$ intermediate casing scenario) or 1,000 ft inside the intermediate casing (for the 7,000 ft 
intermediate casing scenario). The current cement design includes EverCRETE cement. This mixture will have a weight of approximately $15.8 \mathrm{ppg}$. Approximately 1,200 sks will be required, including $35 \%$ excess.

A description of the EverCRETE $\mathrm{CO}_{2}$ resistant cement, provided by Schlumberger, is provided below. Also, specific properties of the cement are described in Table 3-18.

The EverCRETE $\mathrm{CO}_{2}$ resistant cement has been engineered to be more resistant to degradation by wet $\mathrm{CO}_{2}$ and carbonic acid than traditional portland cement based well cement. The cement mix has been engineered in three different ways to reduce its reactivity:

- the engineering of the mix reduced the amount of portland cement, the reactive component in the mix, by the addition of non-reactive microspheres. The microspheres take up space that would otherwise be taken up by portland cement which lowers the amount of portland cement in the mix.

- it reduced the reactivity of the portland cement in the mix by eliminating calcium hydroxide, the most reactive component of portland cement. Calcium hydroxide is typically up to $20 \%$ of the reaction products formed when portland cement hydrates and it is much more reactive than calcium-silicahydrate, the other major reaction product.

- it reduces the permeability of the entire mix by optimizing the particle size distribution to reduce the permeability of the set cement. By optimizing the sizes of the particles that make up the mix, spaces that would otherwise act as open pores in the set cement are closed which reduces the permeability of the cement.

Table 3-18. Properties of the EverCRETE Cement System

\begin{tabular}{|c|c|c|}
\hline Bottomhole circulating temperature (BHCT) & & $40^{\circ} \mathrm{C} \quad\left[104^{\circ} \mathrm{F}\right]$ \\
\hline Bottomhole static temperature (BHST) & & $50^{\circ} \mathrm{C} \quad\left[125^{\circ} \mathrm{F}\right]$ \\
\hline Specific gravity, Ibm/gal & & $15.8 \mathrm{ppg}$ \\
\hline \multirow{2}{*}{$\begin{array}{l}\text { Rheological properties determined with API R } \\
\text { after mixing }\end{array}$} & Plastic Viscosity (PV), $\mathrm{cp}$ & 208 \\
\hline & Yield Point $\left(T_{y}\right)$, lbf/100ft ${ }^{2}$ & 9 \\
\hline \multirow{7}{*}{$\begin{array}{l}\text { Rheological properties determined with API R1B5 } \\
\text { after conditioning at BHCT }\end{array}$} & $\mathrm{PV}, \mathrm{cp}$ & 207 \\
\hline & $T_{y}, I b f / 100 f^{2}$ & 15 \\
\hline & 10 second gel strength, lbf/100ft ${ }^{2}$ & 7 \\
\hline & 10 minute gel strength, lbf/100ft ${ }^{2}$ & 32 \\
\hline & $\begin{array}{r}\text { Then } 1 \text { minute stirring gel strength, } \\
\qquad \mathrm{lbf} / 100 \mathrm{ft}^{2}\end{array}$ & 14 \\
\hline & Stability & OK \\
\hline & API fluid loss at BHCT & 54 \\
\hline \multirow[t]{2}{*}{ Thickening Time } & $30 \mathrm{Bc}$ & $3 \mathrm{hr}, 54 \mathrm{~min}$ \\
\hline & $70 \mathrm{Bc}$ (unpumpable) & $4 \mathrm{hr}, 31 \mathrm{~min}$ \\
\hline \multirow{3}{*}{$\begin{array}{l}\text { Ultrasonic Cement Analyzer (UCA) cell } \\
\text { compressive strengths }\end{array}$} & $50 \mathrm{psi}$ & $6 \mathrm{hr}, 16 \mathrm{~min}$ \\
\hline & $500 \mathrm{psi}$ & $8 \mathrm{hr}, 04 \mathrm{~min}$ \\
\hline & 24 hour compressive strength psi & 2,982 \\
\hline
\end{tabular}

Note: This table shows typical data, actual test data will be provided. Source: Schlumberger API: American Petroleum Institute; psi (pounds per square inch); Bc (Bearden unit of slurry consistency) lbf - pound-foot

\subsubsection{Other Casing}

Not applicable. 


\subsubsection{Cementing Techniques, Equipment Positions, and Staging Depths}

Cement will be emplaced in a single stage for all casing strings except the intermediate casing string that is $7,000 \mathrm{ft}$ in length (if applicable). For the 7,000 ft intermediate casing string (if applicable), the stage collar would be placed at an approximate depth of 5,000 ft, which is just below the St. Peter Formation. Actual placement of the stage collar will be dependent upon hole conditions encountered while drilling. In addition to the stage collar, additional cementing equipment (hardware) is listed in Table 3-19.

Cementing of all casing strings will require two pump trucks. In addition, a batch mixer will be used for a weighted spacer for the intermediate and injection strings because cement emplacement for the intermediate and injection strings will be preceded with 50 bbls of chemical wash (CW100) and 50 bbls of Mud Push Spacer. An additional (second) batch mixer will be used on the injection string for the EverCRETE.

Table 3-19. Additional Cementing Equipment Required for Each Casing String

\begin{tabular}{|c|c|}
\hline Casing String & Equipment $^{(a)}$ \\
\hline 20-inch Surface Casing (500 ft) & $\begin{array}{l}\text { Float shoe } \\
\text { Guide shoe } \\
\sim 10 \text { centralizers } \\
1 \text { cement basket } \\
2 \text { stop rings }\end{array}$ \\
\hline $\begin{array}{l}133 / 8 \text {-inch intermediate casing } \\
(5,000 \mathrm{ft} \text { or } 7,000 \mathrm{ft})\end{array}$ & $\begin{array}{l}\text { Float shoe } \\
\text { Float collar } \\
\text { 20 centralizers (more for } 7,000 \mathrm{ft} \text { intermediate casing scenario) } \\
2 \text { stop rings } \\
\text { Stage collar (for 7,000 ft intermediate casing scenario) } \\
\text { Cement Basket if stage collar is used }\end{array}$ \\
\hline $\begin{array}{l}95 / 8 \text {-inch long casing string }(9,096 \\
\mathrm{ft})\end{array}$ & $\begin{array}{l}\text { Float shoe (with JFE Bear connection if lower part of casing string is } \\
\text { comprised of 13Cr95 material) } \\
\text { Float collar JFE Bear Connection (with JFE Bear connection if lower } \\
\text { part of casing string is } 13 \text { Cr95 material) } \\
\sim 35 \text { centralizers } \\
\sim 4 \text { stop rings } \\
2 \text { LTC X Bear cross-over connections (if lower part of casing string is } \\
13 \text { Cr95 material) } \\
\text { * Stage collar (not anticipated, but possible) }\end{array}$ \\
\hline
\end{tabular}

All quantities are approximate.

\subsubsection{Perforation Depths}

As previously discussed, $\mathrm{CO}_{2}$ will be injected into the Mt. Simon Formation, which is currently estimated to occur between depths of 7,353 to $8,996 \mathrm{ft}$ bgs (thickness of 1,643 ft). The exact perforation interval will be determined after the well is drilled and characterized with geophysical logging, core analyses, and hydraulic testing. It is possible that multiple intervals with varying length will be perforated rather than a single long perforation interval. Modeling will be used, incorporating the results of the site-specific testing activities, to aid in determining the total length of the perforated intervals as well as to optimize the placement and density of the perforations. Results of the characterization activities along with the proposed perforation interval(s) will be described in the Well Completion Report (i.e., Section 9 [Form 4h] of the UIC 
Permit Application) which will be submitted to the IEPA following completion of the drilling and characterization activities.

\subsubsection{Annulus Protection System}

The purpose of the annulus protection system is to maintain the annular fluid at a prescribed pressure. An automated annulus protection system has been designed for this purpose that is part of the comprehensive well maintenance and monitoring system [WMMS]). The WMMS includes piping, instrumentation valves, controls, and other equipment to accomplish several functions, including:

- Maintaining a prescribed pressure on the annular fluid in the well;

- Automatically delivering annular fluid to the well when the fluid volume in the well decreases due to temperature and/or pressure changes or leaks in the well;

- Automatically removing annular fluid from the wells when the fluid volume in the well increases due to temperature and/or pressure changes;

- Continuously monitoring injection well parameters including annular pressure, wellhead pressure and temperature, and bottomhole pressure and temperature and relay measured parameters to a remote terminal unit (RTU) located in the WMMS building, which are in turn connected to a programmable logic controller (PLC) located near the well;

- Monitoring parameters (e.g., pressure, temperature, fluid levels, nitrogen pressure) associated with the skid-mounted pressure-maintenance system; and,

- Automatically ceasing $\mathrm{CO}_{2}$ injection to the wells when injection pressure or annulus pressure fall outside of prescribed limits.

This section is primarily focused on describing the components of the WMMS that will regulate the annular fluid pressure. The WMMS will maintain the pressure of the annular fluid between the tubing and the long string of casing at pre-determined levels as specified in the permit. The system can maintain the annular pressure at a specified level either above or below the pressure of the $\mathrm{CO}_{2}$ in the injection tubing. For example, the pressure within the annular space, over the interval above the packer to the confining layer, can be maintained at a pressure that is greater than the pressure of the injection zone formation at all times. The annular fluid pressure will be continuously monitored so that $\mathrm{CO}_{2}$ injection can be halted when the annular fluid pressure falls outside the pre-determined range for a period of time that exceeds allowable limits.

The major mechanical components of the WMMS that regulate annular fluid pressure are described below and shown on Figure 3-4. Other components of the WMMS (including instrumentation, controls, and alarms) shown on Figure 3-4 are described in Section 6.4, which describes how the system will detect and respond to out of range conditions that necessitate well shutdown.

- Three vessels (labeled V-1002-A, B, and C) together provide storage for annular fluid and a means for maintaining the pressure on the annular fluid. Because of the high pressure requirements for the annular fluid, a pre-fabricated hydraulic system will be used as the main component of the pressure maintenance system. Vessel V-1002-A 
is the accumulator (storage) tank for the annular fluid system that will supply the well when necessary. This vessel will be partially filled with the same annular fluid that is in the well; the remainder of the vessel will contain pressurized nitrogen. The nitrogen and annular fluid liquid will be separated by a movable piston, the location of which will be monitored to indicate the annular fluid volume in the accumulator tank. Vessels V-1002-B and V1002-C are pressurized nitrogen bottles that provide additional vapor space for the accumulator. This extra volume allows for minimal venting during daily temperature fluctuations.

- A $1 / 2$ inch diameter stainless steel line connects the accumulator $(V-1002-A)$ to the injection well and allows annular fluid to move from the accumulator to the well's annular space or vice versa.

- Nitrogen Cylinders - Six (6) high pressure (approximately 6,000 psig) nitrogen cylinders, divided into two banks of three (3) cylinders each, supply the "blanketing" pressure for the annular fluid in the accumulator. During normal operation, one bank will supply nitrogen to the annular fluid system. A nitrogen manifold with automatic switchover (AS-1000) provides a means for automatically switching from one bank of nitrogen cylinders to another when the pressure in the operating bank drops to a predetermined level. Operators will then replace the "empty" bank with full cylinders.

- Vessel T-1000 is the annular fluid reservoir. This tank will be partially filled with a reserve of annular fluid that can be pumped into the accumulator when the volume in the accumulator isn't adequate to meet the needs of the well. It can also serve as storage capacity for annular fluid bleed off (from the accumulator) during thermal expansion of the annular fluid when $\mathrm{CO}_{2}$ injection is initiated and terminated.

- Annular Fluid Pumps (P-1001, P1002) are high pressure hydraulic pumps that will pump reserve annular fluid from the annular fluid reservoir (T-1000) into the accumulator (V-1002) when the level in the accumulator reaches a low set point. The system is designed so that the pumps alternate operation to ensure that both pumps are operational when needed.

- Control valves PV-3A and PV-3B will provide a controlled gas charge on the accumulator containing the annular fluid. The low pressure control valve, PV-3A, will add nitrogen to increase the charge pressure when necessary; the high pressure control valve, PV-3B, will vent nitrogen to the atmosphere to reduce the charge pressure when necessary.

- Control valve LV-7 will open or close as needed to allow annular fluid to move from the well directly into the annular fluid reservoir (T-1000), rather than into the accumulator, if the fluid level in the accumulator is above a pre-set level.

The nitrogen system will be designed to minimize venting, but small amounts of nitrogen may be vented in response to daily and seasonal temperature changes (warming) or changes in the temperature of the injection fluid. The largest variance in annular fluid volume is expected to occur during the initial injection and subsequent shut-downs and start-ups. The annular fluid will be pumped into the system in small increments to maintain system liquid volume and minimize nitrogen usage. Using a liquid pump and a reserve tank reduces the size of the high-pressure 

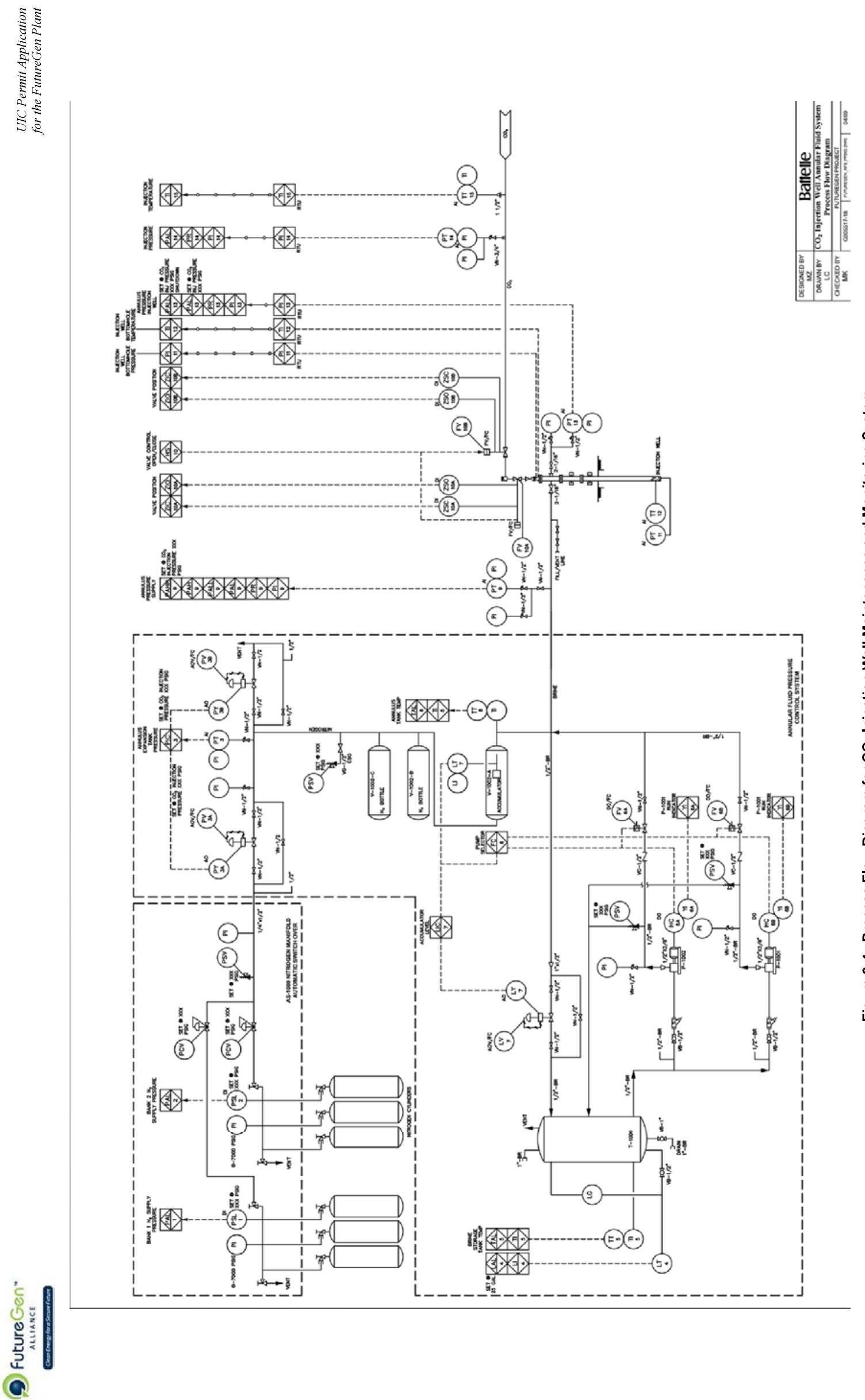
accumulator, and also allows for some operational time if the system has a small annular fluid leak.

The annular fluid system will be monitored through a PLC, with important parameter data logged for documentation and review, and alarms to warn of impending noncompliance or out of operating parameter excursions. Section 6.4 describes alarms and controls included in the WMMS to detect and respond to out of range conditions that necessitate well shutdown.

\subsubsection{Annular Space(s)}

The annular space is the area inside the 9-5/8 inch long-string casing and the outside of the 5$1 / 2$ inch injection tubing, above the packer. Assuming that the packer is placed at a depth of $8,000 \mathrm{ft}$, the volume of the annular space is approximately 15,108 gallons (360 bbls). This is based on the casing design presented in Section 3.7.2. The capacity of the well below the packer is approximately 3,267 gallons ( 78 bbls) and the capacity of the tubing is approximately 7,477 gallons (177 bbls).

\subsubsection{Type of Annular Fluid(s)}

The annular fluid will be a dilute salt solution such as potassium chloride $(\mathrm{KCl})$, sodium chloride $(\mathrm{NaCl})$, calcium chloride $\left(\mathrm{CaCl}_{2}\right)$, or similar. The fluid will be mixed on site from dry salt and good quality (clean) fresh water or it will be acquired pre-mixed. The fluid will also be filtered to ensure that solids do not interfere with the packer or other components of the annular protection system. Final choice of the type of fluid will depend on availability.

\subsubsection{Specific Gravity of Annular Fluid(s)}

The specific gravity of the annular fluid will be approximately 8.5 to $9.0 \mathrm{ppg}$ or similar. These weights will be sufficient to maintain tubular and casing integrity and minimize differential pressure across the packer. A fluid with a higher specific gravity would be needed to prevent freezing near ground surface, if heat tracing isn't applied to the wellhead. A $8.5 \mathrm{ppg} \mathrm{KCl}(3.2 \%)$ fluid contains approximately $11.6 \mathrm{lb}$ of dry $\mathrm{KCl}$ per bbl of fluid; a $9 \mathrm{ppg} \mathrm{KCl}(12.7 \%)$ fluid contains approximately $47.9 \mathrm{lb}$ of dry $\mathrm{KCl}$ per bbl of fluid.

\subsubsection{Type of Additive(s) and Inhibitor(s)}

The annulus fluid will contain additives and inhibitors including: a corrosion inhibitor, biocide (prevent growth of harmful bacteria), and an oxygen scavenger. Example additives and inhibitors are listed below along with approximate mix rates:

- TETRAHib Plus (corrosion inhibitor for carbon steel tubulars) - 10 gal per 100 bbls packer fluid

- CORSAF ${ }^{\mathrm{TM}}$ SF (corrosion inhibitor for use with $13 \mathrm{Cr}$ stainless steel tubulars or a combination of stainless steel and carbon steel tubulars) - 20 gal per 100 bbls packer fluid

- $\quad$ Spec-cide 50 (biocide) - 1 gal per 100 bbls packer fluid

- Oxban-HB (non sulfite oxygen scavenger) - 10 gal per 100 bbls packer fluid

These products were recommended by and are provided by Tetra Technologies, Inc., of Houston, Texas. Material Safety Data Sheets (MSDSs) for each of these products is provided in Appendix 3-2. Actual products may vary from those described above. 


\subsubsection{Expansion Coefficient of Annular Fluid(s)}

The expansion coefficient for the annular fluid is similar to that of water. Injection stream temperatures are expected to be within the range of 105 to $120^{\circ} \mathrm{F}$ and bottomhole temperature in the Mt. Simon formation is anticipated to be 135 to $145^{\circ} \mathrm{F}$, which would be the maximum temperatures the fluid would be exposed to. For a range of temperature from 105 to $145^{\circ} \mathrm{F}$, the expansion coefficient of water ranges from 0.000214 to $0.000290^{\circ} \mathrm{F}^{-1}$ (Engineering Toolbox, 2010) In comparison, the expansion coefficient of a $\mathrm{NaCl}$ solution with a concentration range of 8.5 to $9.0 \mathrm{ppg}$, ranges from 0.000228 to $0.000289^{\circ} \mathrm{F}^{-1}(\mathrm{CRC}, 2009)$.

\subsubsection{Packer or Fluid Seal}

See Sections 3.7.5.2 through 3.7.5.4 for a description of the annular (packer) fluid that will be used in the injection well.

\subsection{Packer(s)}

The choice of packer will depend on whether transmitters/gauges are placed above the packer or below the packer to monitor bottomhole injection pressure and temperature. An example of a packer for both types of monitoring is described below. Manufacturer's information for each of these packers is provided in Appendix 3-3.

Below packer monitoring - The Weatherford HellCat-2 9.625 inch $\times 5-1 / 2$ inch packer (or similar) is suitable for this purpose. It has 5-1/2 inch tubing connections and a minimum inside diameter of 4.60 inches. This packer can accommodate up to eight $1 / 4$ inch lines (i.e., pass through) to allow pressure and temperature gauges/transmitters to be mounted below the packer. The packer is hydraulically set and retrievable. It is retrieved by running a shifting tool inside of the tubing on wireline or slick line (shift to release). After the packer is released, the shifting tool is pulled from the well and the tubing is retrieved. The tubing cannot be disconnected from this packer and therefore cannot be used as a casing bridge plug.

Above packer monitoring - The Weatherford BlackCat 9.625 inch $\times 6$ inch Retrievable Seal Bore Packer has a smooth polished bore and seals connected to tubing that are stung into the bore. The bore of the packer is 6 inches and the inside diameter of the seals is 4.875 inches. The packer is set on an electric line; the seals are simply set down in the packer and rotation is not required to install or remove the packer. Extra polished bore extensions can be added below the packer to allow for long seal lengths to accommodate a large amount of tubing movement. Tailpipe can be run below the packer with a landing nipple. A plug can be set in the nipple and the seals can be retrieved, thus converting the packer to a bridge plug. This allows the tubing to be retrieved for inspection and/or repairs without removing the packer. This packer is retrievable via a separate trip on tubing with a special retrieving tool. It cannot be accidentally retrieved with the seal.

\subsection{Fluid Spotting Procedure, Frequency, and Quantity}

Fluid will not be spotted below the packer and left in the wellbore during the final completion activities. Filtered annular (packer) fluid is pumped into the annular space, above the packer, and is the only fluid that will be spotted in the well. 


\subsection{Information on Well Drilling Company Used During Construction}

A drilling company has not yet been put under contract to drill the injection wells. The wells will be drilled by a traditional mud rotary rig. Drilling will begin as soon as possible after the final UIC permit is issued. Either the injection well or the Mt. Simon monitoring well will be drilled first. Approximately three months will be required to drill and characterize each well. The wells may be drilled sequentially or there may be a time lag between drilling events. A survey of drilling companies in the Illinois Basin and surrounding regions was conducted and a drilling company with the equipment required for this project was identified. The drilling company is Unit Drilling Company (UNIT) of Oklahoma City, Oklahoma. UNIT would use its Rig \#305 (or similar) to drill the injection wells. Rig \#305 has a working depth of 16,000 ft and a static hook capacity of $750,000 \mathrm{lb}$, which will comfortably handle the FutureGen injection well having a depth of approximately $9,100 \mathrm{ft}$ and a maximum string weight of approximately $450,000 \mathrm{lb}$ $(7,000 \mathrm{ft}, 13-3 / 8$ inch intermediate casing). No drilling companies in the Illinois Basin with the capabilities required for this size well were identified. A list of standard equipment included with Rig \#305 is provided in Table 3-20.

\begin{tabular}{|l|}
\hline Unit Drilling Company \\
7101 S. W. 29th St. \\
Oklahoma City, OK 73179 \\
Contact: \\
James L. W. Greer \\
Vice President Marketing \\
Office $405-745-4948$ \\
Fax 405-745-2136 \\
Cell 405-831-7464 \\
\hline
\end{tabular}

Other drillers may be used to install or assist in installing the smaller diameter (7 inch) monitoring wells. One such drilling company is Les Wilson, Inc., of Carmi, Illinois (205 Industrial Avenue, Carmi, Illinois, 62821; Tel. 618-382-4666; Contact: Bob Wilson). Les Wilson Inc. recently drilled a pilot $\mathrm{CO}_{2}$ injection well at the Archers Daniel Midland (ADM) plant in Decatur, Illinois, that is very similar in design to the proposed FutureGen injection well.

\subsection{Tests and Logs}

Logging, coring and testing activities will be conducted during and after drilling to characterize the geology of the site and to demonstrate the integrity of the well to prevent upward migration of fluids from the injection reservoir. After drilling, additional injection tests may be conducted on selected intervals in the Mt. Simon Formation to aid in evaluating injection capacity prior to injecting $\mathrm{CO}_{2}$. Also, if necessary, the well may be stimulated to enhance injectivity of the formation near the wellbore. Initially, acidization and swabbing of the perforated zone will be performed on the well to remove particulate matter from the perforations and the injection reservoir. However, during characterization and testing activities, it may be determined that the injection reservoir needs to be fractured with a propping material in order to achieve the desired $\mathrm{CO}_{2}$ injection rates. 
Table 3-20. Description of Unit Drilling Company Rig 305

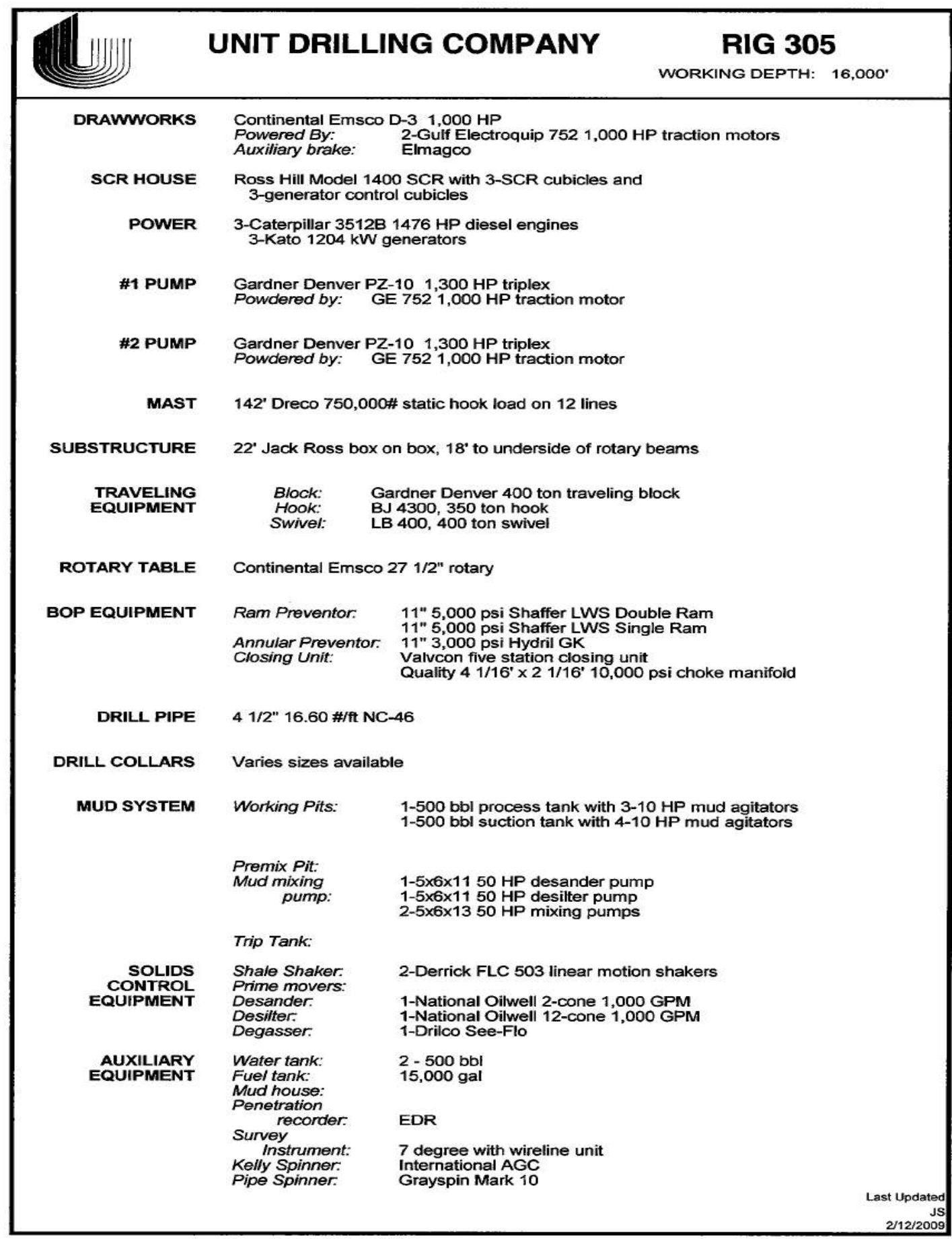

\subsubsection{During Drilling}

Activities during drilling will include geophysical logging, coring, fluid sampling, and formation pressure tests. At minimum, the logging and testing activities meet the logging and testing requirements for the UIC permit application. A preliminary logging and testing program is outlined in Table 3-21. 
Table 3-21. Preliminary Logging and Testing Program

\begin{tabular}{|c|c|c|}
\hline Depth Interval & Log or Test & Purpose/Comments \\
\hline \multirow[t]{3}{*}{$\begin{array}{l}\text { Surface Casing } \\
\text { Interval } \\
\text { (Below conductor } \\
\text { casing to } 500 \mathrm{ft} \text { bgs) }\end{array}$} & $\begin{array}{l}\text { Basic log suite (gamma ray, } \\
\text { formation density, neutron porosity, } \\
\text { resistivity }^{(a)}, \text { spontaneous potential }^{(a)} \\
\left.\text { photoelectric factor, caliper }^{(a)}\right)\end{array}$ & $\begin{array}{l}\text { - Characterize basic geology (lithology, } \\
\text { mineralogy, porosity) } \\
\text { - Evaluate borehole condition prior to } \\
\text { cementing }\end{array}$ \\
\hline & Dipole sonic shear (DSI) $\log ^{(6)}$ & $\begin{array}{l}\text { - Provide sonic data to calibrate surface } \\
\text { seismic and other purposes }\end{array}$ \\
\hline & - Cement bond log ${ }^{(c)}$ & - Evaluate cement integrity \\
\hline \multirow[t]{5}{*}{$\begin{array}{l}\text { Intermediate Interval } \\
\text { ( } 500 \text { to } 5,000 \mathrm{ft} \text { bgs to } \\
7,000 \text { bgs) }\end{array}$} & $\begin{array}{l}\text { Basic log suite (gamma ray, } \\
\text { formation density, neutron porosity, } \\
\text { resistivity }^{(a)}, \text { spontaneous potential }^{(a)} \text {, } \\
\text { photoelectric factor, caliper }^{(a)} \text { ) }\end{array}$ & $\begin{array}{l}\text { - Characterize basic geology (lithology, } \\
\text { mineralogy, porosity) } \\
\text { - Evaluate borehole condition prior to } \\
\text { cementing }\end{array}$ \\
\hline & $\begin{array}{l}\text { Enhanced log suite (dipole sonic } \\
\text { shear log, resistivity-based } \\
\text { microimage log, nuclear magnetic } \\
\text { resonance log, elemental capture } \\
\text { spectroscopy log) }^{(b)}\end{array}$ & $\begin{array}{l}\text { Enhanced characterization of geologic } \\
\text { properties that control injectivity and seal } \\
\text { integrity. Focused on formations in this } \\
\text { interval that are potential seals. }\end{array}$ \\
\hline & $\begin{array}{l}\text { - Formation fluid samples }{ }^{(\mathfrak{b})} \\
\text { - }\end{array}$ & $\begin{array}{l}\text { - Focused on formations or zones in this } \\
\text { section of the well that have sufficient } \\
\text { porosity and permeability to host } \\
\text { monitoring wells (e.g., St. Peter } \\
\text { Sandstone, Franconia) } \\
\text { - Characterize baseline geochemistry of } \\
\text { formation fluids and determine pre- } \\
\text { injection reservoir pressure }\end{array}$ \\
\hline & - Whole cores and/or sidewall cores ${ }^{(\mathrm{b})}$ & $\begin{array}{l}\text { - Focused on formations in this interval that } \\
\text { are potential seals. }\end{array}$ \\
\hline & Cement bond log & - Evaluate cement integrity \\
\hline \multirow[t]{7}{*}{$\begin{array}{l}\text { Long String Casing } \\
\text { Interval ( } 5,000 \text { to } \\
7,000 \mathrm{ft} \text { bgs to } 9,100 \\
\mathrm{ft} \text { bgs) }\end{array}$} & $\begin{array}{l}\text { Basic log suite (gamma ray, } \\
\text { formation density, neutron porosity, } \\
\text { resistivity }{ }^{(a)}, \text { spontaneous potential }{ }^{(a)} \\
\text { photoelectric factor, caliper }^{(a)} \text { ) }\end{array}$ & \begin{tabular}{|l} 
- \\
Characterize basic geology (lithology, \\
mineralogy, porosity) \\
Evaluate borehole condition prior to \\
cementing
\end{tabular} \\
\hline & $\begin{array}{l}\text { Enhanced log suite (dipole sonic } \\
\text { shear log, resistivity-based } \\
\text { microimage log, nuclear magnetic } \\
\text { resonance log, elemental capture } \\
\text { spectroscopy log) } \\
\end{array}$ & $\begin{array}{l}\text { Enhanced characterization of geologic } \\
\text { properties that control injectivity and } \\
\text { caprock/seal integrity }\end{array}$ \\
\hline & - Inclinometer survey & - Determine hole trajectory \\
\hline & $\begin{array}{ll}\text { - } & \text { Formation fluid samples } \\
\text { - } & \text { Reservoir pressure }\end{array}$ & $\begin{array}{l}\text { - Focused on formations or zones in this } \\
\text { section of the well that have sufficient } \\
\text { porosity and permeability to host } \\
\text { monitoring wells (e.g., Franconia) and } \\
\text { intervals within the Mt. Simon that are } \\
\text { candidates for } \mathrm{CO}_{2} \text { injection. Fluid } \\
\text { sampling from Mt. Simon may be deferred } \\
\text { until after well completion. } \\
\text { - Characterize baseline geochemistry of } \\
\text { formation fluids and determine pre- } \\
\text { injection reservoir pressure }\end{array}$ \\
\hline & Whole cores and/or sidewall cores & $\begin{array}{l}\text { - Evaluate properties of caprock (Eau } \\
\text { Claire) and injectivity of storage reservoir } \\
\text { (Mt. Simon) }\end{array}$ \\
\hline & - Cement bond log ${ }^{(c)}$ & - Evaluate cement integrity \\
\hline & $\begin{array}{ll}- & \text { Baseline temperature } \log ^{(\mathrm{c})} \\
\text { - } & \text { Baseline oxygen activation } \log ^{(\mathrm{c})}\end{array}$ & $\begin{array}{l}\text { Determine natural geothermal gradient } \\
\text { outside well for comparison to future } \\
\text { temperature logs for external mechanical }\end{array}$ \\
\hline
\end{tabular}


Table 3-21. Preliminary Logging and Testing Program (Continued)

\begin{tabular}{|c|c|c|}
\hline Depth Interval & Log or Test & Purpose/Comments \\
\hline & & $\begin{array}{l}\text { integrity evaluations. Baseline log is run } \\
\text { as long as possible after drilling and } \\
\text { casing/cementing the well as temperature } \\
\text { anomalies due to circulation of drilling fluid } \\
\text { will persist for several weeks to months. } \\
\text { - Baseline oxygen activation log will provide } \\
\text { confirmation of temperature log and } \\
\text { provide baseline measurement for future } \\
\text { pulsed neutron capture logging runs aimed } \\
\text { at detecting vertical distribution of } \mathrm{CO}_{2} \\
\text { outside the well. }\end{array}$ \\
\hline & $\begin{array}{l}\text { Injection tests (during and after } \\
\text { drilling) }\end{array}$ & $\begin{array}{l}\text { - During drilling, conduct open-hole tests to } \\
\text { determine fracture pressure of caprock } \\
\text { (Eau Claire) and storage reservoir (Mt. } \\
\text { Simon). Testing of Mt. Simon may be } \\
\text { deferred until after well completion. } \\
\text { - After well is completed, test potential } \\
\text { injection zone(s) in Mt. Simon prior to } \\
\text { injecting } \mathrm{CO}_{2} \text {. }\end{array}$ \\
\hline
\end{tabular}

(a) Required by IEPA UIC Permit Requirements.

(b) One or more of these logs may be run across selected intervals of this section of the well.

(c) Cased-hole log

\subsubsection{Open-Hole Logging}

All sections of the hole below the conductor casing will be logged with a basic suite of logging tools, including gamma radiation, formation lithodensity (bulk density), photoelectric factor (PEF), borehole caliper, neutron porosity, resistivity, and spontaneous potential. Logging tools are available that can combine most or all of these logs in a single tool string run at one time.

The gamma-ray tool measures the gamma radiation of uranium $(U)$, potassium $(K)$, and thorium (Th), which occur naturally in many rocks. Because of the relative abundance of $\mathrm{U}$, Th, and $\mathrm{K}$ within many clay minerals, a high gamma-ray reading is usually indicative of a relatively high clay content in the rock, whereas a low gamma-ray reading often indicates quartz sands and carbonates.

The lithodensity tool consists of a ${ }^{137} \mathrm{Cs}$ source and two gamma-ray detectors mounted on a shielded sidewall skid that is pressed against the formation by a hydraulically activated arm. This arm also provides a caliper measurement of borehole diameter. The gamma rays emitted by the source interact with the electrons in the formation and lose energy as a result of Compton scattering. When gamma-ray energy is low ( $<150$ kiloelectron volts), photoelectric absorption takes place. The number of gamma rays that reach the detectors is directly related to the number of electrons in the formation, which is in turn related to the formation bulk density. The bulk density can be used to calculate a porosity, using the following equation:

$$
\Phi=\left(\rho_{\text {gr }}-\rho_{\mathrm{b}}\right) /\left(\rho_{\mathrm{gr}}-\rho_{\mathrm{w}}\right) \text {, }
$$

where $\rho_{\text {gr }}=$ mean grain density $\left(\mathrm{g} / \mathrm{cm}^{3}\right), \rho_{\mathrm{w}}=$ pore-water density $\left(\mathrm{g} / \mathrm{cm}^{3}\right)$, and $\rho_{\mathrm{b}}=$ bulk density given by the tool $\left(\mathrm{g} / \mathrm{cm}^{3}\right)$. 
The PEF can be assessed by comparing the counts from the far detector of the tool, which is in the high-energy region where only Compton scattering occurs, with those of the near detector, which is in the low-energy region where the PEF is dominant. Photoelectric absorption is strongly dependent on the atomic number of the constituents of the formation. Therefore, the PEF values can give an indication of the chemical composition of the rock.

The neutron porosity tool emits fast neutrons, which lose energy as they collide with hydrogen nuclei in the formation. Once the neutrons have slowed down to reach thermal energies $(0.025$ $\mathrm{eV}$ ), they are captured by the nuclei of chlorine and various heavy elements. This results in a gamma-ray emission. The tool measures the number of neutrons arriving at five different detectors at varying distances from the source. This measurement is inversely proportional to the concentration of hydrogen in the formation. Because the majority of hydrogen is contained in the pore water, the resulting measurement can be used to derive a porosity. However, hydrogen bound in minerals, such as clays, also contributes to the measurement, so that the raw porosity value is often an overestimate. Furthermore, the presence of certain rare earth and trace elements with particularly large capture cross sections (e.g., boron and cadmium) can have a significant effect on the reading.

A typical resistivity logging tool provides three different measurements of electrical resistivity based on multiple depths of investigation: deep induction, medium induction, and shallow, spherically focused resistivity (SFL). Two induction devices produce an alternating magnetic field, which induces Foucault currents around the borehole. These currents produce a new inductive signal, proportional to the conductivity of the rocks which are essentially infinitely resistive relative to the pore fluids. The measured conductivities are then converted to resistivity (in ohm-meters). The SFL measures the current necessary to maintain a constant voltage drop across a fixed interval and is a direct measurement of resistivity because the solid constituents are controlled mainly by the nature of the pore fluids, porosity, and the permeability. Depending on the type of resistivity tool that is used, an optional inclinometer tool that provides tool face orientation and the hole deviation and azimuth may be run to provide information on bedding dip.

In addition to the standard suite of logs, other types of geophysical logging tools will be run over selected intervals of the well. These logs include: sonic, nuclear magnetic resonance, electrical micro imager, and elemental capture spectroscopy (ECS).

The dipole shear sonic imager (DSI) is a type of sonic log. It employs a combination of monopole and dipole transducers to make accurate measurements of sonic wave propagation in a wide variety of lithologies. In addition to robust and high-quality determination of compressional wave velocity, the DSI excites a flexural mode in the borehole that can be used to determine shear-wave velocity. Sonic data provide a means for converting surface seismic data from time-dependent data to depth-dependent data. The sonic log can also be used to create synthetic seismograms; with these synthetics, the expected changes in seismic properties from injected $\mathrm{CO}_{2}$ can be anticipated and modeled. The results of this would allow seismic operators to change any parameters to maximize plume monitoring after injection begins. Anisotropy can also be determined with certain versions of the sonic log.

The nuclear magnetic resonance tool measures the total magnetic field using a proton precession magnetometer. It provides permeability estimates based on porosity and pore size 
distribution. Consequently, it can distinguish permeability differences among rocks having the same porosity.

The microimage log creates a high resolution microresistivity image of the borehole capable of detecting features as small as $50 \mu \mathrm{m}$. The tool consists of multiple imaging pads, each containing multiple microelectrodes, which are in direct contact with the borehole wall and emit a focused current into the formation. The current intensity fluctuations are measured, then converted to color images that reflect microresistivity variations (the lighter the color, the greater the resistivity). This log is helpful for characterizing rock structures, such as bedding, fracturing, slump folding, and other structural and depositional features. And, because the images are oriented, bed orientations can be measured. Combined with information from the nuclear magnetic resonance log, the local stress field can be determined. This information is needed if hydraulic fracturing is deemed necessary and to support numerical modeling.

The ECS logging tool uses gamma ray spectroscopy to determine lithology and the elemental composition of the rocks adjacent to the well bore. It provides information about the relative amounts of selected elements ( $\mathrm{Si}, \mathrm{Fe}, \mathrm{Ca}, \mathrm{S}, \mathrm{Ti}, \mathrm{Gd}, \mathrm{Cl}, \mathrm{Ba}$ and $\mathrm{H}$ ) and uses this information to infer mineralogy and matrix density.

\subsubsection{Rock Coring and Analysis}

In addition to geophysical logging, rock coring and analysis will support the geological characterization of the site. Whole core or sidewall coring may be conducted in selected intervals in the well. Whole coring will provide continuous sections of core, typically 3.5 inches in diameter by 30 feet in length, that are collected during drilling. Consequently, selection of whole core intervals depends on existing data from nearby off-set wells. For this reason, the amount of whole core collected from the initial well drilled at the site will be minimal, and additional whole core will be collected from subsequent wells (monitoring wells). Sidewall cores (small plugs approximately 1 inch in diameter) will be selected from specific points of interest identified on geophysical logs.

Core collection will most likely be limited to specific zone(s) in the injection reservoir and the caprock; these cores (possibly 2 inch diameter in length cut perpendicular to the borehole) will be collected from discrete depths after the interval of interest has been drilled and logged. Therefore, sidewall core points can be other formations that may serve as seals to prevent upward fluid migration. At least one section of whole core will be collected from the caprock (Eau Claire). Because of the thickness of the Mt. Simon Formation, at least three sections of core will be collected from this formation. These may be distributed throughout the upper, middle, and lower sections of the formation, or they may all be collected from a single continuous zone. Sidewall cores will be collected from several locations within the injection reservoir that appear to have permeability and porosity appropriate for $\mathrm{CO}_{2}$ injection based on the geophysical logs.

Possible testing of core samples is outlined in Table 3-22. For example, a whole core would be plug sampled for permeability testing, and would be cut open (slabbed) to allow the entire section of core to be photographed, gamma logged (to determine lithology), and to determine a continuous permeability profile along the entire sample. In addition, porosity, grain density, permeability, and bulk density would be determined on one sample per foot of whole core (or similar frequency) along with all sidewall samples. In addition to these basic core tests, a suite 
Table 3-22. Preliminary Core Analysis Program

\begin{tabular}{|l|l|}
\hline \multicolumn{1}{|c|}{ Core } & \multicolumn{1}{|c|}{ Test/Frequency } \\
\hline Whole core & $\begin{array}{l}\text { Plug sampling, full core slabbing, gamma log, profile permeability, over- } \\
\text { view slab photo (continuous) }\end{array}$ \\
\cline { 2 - 3 } & $\begin{array}{l}\text { Porosity, grain density, horizontal permeability, bulk density (1 per ft of } \\
\text { core or similar frequency) }\end{array}$ \\
\cline { 2 - 3 } & $\begin{array}{l}\text { Thin section, core description, }{ }^{(a)} \text { detailed petrographic description } \\
\text { (s) }\end{array}$ \\
\cline { 2 - 2 } & $\begin{array}{l}\text { Gelected samples) } \\
\text { Modulus, Poisson's Ratio, and compressive strength; sonic velocity } \\
\text { testing for dynamic Young's Modulus and Poisson's Ratio; calibration of } \\
\text { sonic and dipole log; fracture azimuth and maximum stress azimuth } \\
\text { [sonic velocity anisotropy]) (selected samples) }\end{array}$ \\
\cline { 2 - 3 } & $\begin{array}{l}\text { Flow properties: capillary pressure, relative permeability (selected } \\
\text { samples) }\end{array}$ \\
\hline Sidewall Core & $\begin{array}{l}\text { Porosity, grain density, horizontal permeability, bulk density (all } \\
\text { samples) }\end{array}$ \\
\cline { 2 - 3 } & Detailed petrographic description ${ }^{(\mathrm{b})}$ (selected samples) \\
\hline
\end{tabular}

(a) Parameters such as lithology, texture, inorganic and biogenetic structures, fossils, grain size trends, depositional environment may also be included.

(b) May include thin section analysis, x-ray diffraction (XRD), scanning electron microscopy/energy dispersive spectrometer (SEM/EDS) for quantitative determination of composition, visual estimation of interconnected macroporosity, description of sorting and porosity, measurement of framework grain size and a qualitative assessment of reservoir quality.

of more detailed core analyses would be performed on a subset of samples. These analyses would include a petrographic description, a conventional core description, and geomechanical and flow tests. All of these tests would yield important information about the formation properties as well as help calibrate the wireline logs.

\subsubsection{Fluid Sampling}

If possible, formation fluid (brine) samples will be collected from selected formations during borehole drilling operations. More than likely, fluid samples would be collected by conducting a drill-stem test since this method also provides a means for determining reservoir pressure. Alternatively, wireline tools may also be used to collect open-hole fluid samples and to determine formation pressure. In a drill stem test, fluid from the formation is recovered through the drill stem, while several measurements of pressure are being made. The basic drill stem test tool consists of a packer or packers, valves or ports that may be opened and closed from the surface, and two or more pressure-recording devices. The tool is lowered on the drill pipe to the zone to be tested. The packer or packers are set to isolate the zone from the drilling fluid column, and testing measurement begins. Formation fluid is recovered in the drill pipe through temporary relief of backpressure imposed on the formation. Typical drillstem tests consist of several flow and shut in (pressure buildup) periods, during which reservoir pressure data are recorded. Depending on the predefined requirements and goals for the test, it may be of short (an hour or less) or long (e.g., several days) duration. Since these tests would be conducted while drilling, they would be kept short to reduce rig standby time.

Formations of primary interest for fluid sampling include the Mt. Simon Sandstone and permeable units overlying the primary seal, such as the St. Peter Sandstone and possibly the Franconia Formation, since these zones could potentially be used to monitor for upward 
leakage of $\mathrm{CO}_{2}$ (Table 3-23). The Ironton Galesville Sandstone, if present at this location, is another possible candidate for fluid sampling. Fluid sample collection from the Mt. Simon Formation may be deferred until after the well is completed (perforated).

Table 3-23. Possible Intervals for Fluid Sampling During Drilling

\begin{tabular}{|l|l|}
\hline \multicolumn{1}{|c|}{ Formation } & Formation and Approximate Depth to Top/Bottom \\
\hline St. Peter Sandstone & 4,781 to $4,858(77 \mathrm{ft})$ \\
\hline $\begin{array}{l}\text { Franconia Formation } \\
\text { (Lower Knox) }\end{array}$ & 6,405 to $6,705(300 \mathrm{ft})$ \\
& $\begin{array}{l}\text { If present at this location, the Ironton Galesville } \\
\text { Formation is an alternate candidate zone. }\end{array}$ \\
\hline Mt. Simon Sandstone & $\begin{array}{l}7,353 \text { to } 8,996(1,643 \mathrm{ft}) \\
\text { Specific sampling interval(s) to be determined. } \\
\text { Fluid sampling from Mt. Simon may be deferred } \\
\text { until after well is completed }\end{array}$ \\
\hline
\end{tabular}

Estimated depth interval of Undifferentiated Knox Group is 4,858 to 6,705 ft bgs; see Section 2.

Fluid samples will be analyzed to determine the chemical and isotopic characteristics of the formation fluids. These analyses will provide a means for characterizing the baseline (pre injection) geochemistry of these formation fluids. This information will allow detection of $\mathrm{CO}_{2}$ invasion and a better understanding of the chemical interactions between injected $\mathrm{CO}_{2}$, brine, and host minerals. Results of the analyses may also provide information on the relative age of the fluids, whether there has been mixing of brine with meteoric water, and if hydraulic isolation exits between permeable layers that are separated by seals.

\subsubsection{Open-Hole Injection Testing to Determine Formation Fracture Pressure}

During drilling, open hole mini frac testing (microhydraulic fracturing) will be conducted in the caprock (Eau Claire Formation) to determine the fracture pressure of this formation. This parameter is important for designing the $\mathrm{CO}_{2}$ injection strategy because it will constrain the upper bound of the injection pressure. $\mathrm{CO}_{2}$ injection pressures will be maintained at a value below the fracture pressure of the caprock to avoid creating fractures that could provide conduits for upward fluid migration out of the storage reservoir.

Mini-frac testing will most likely be conducted using a wireline tool that is designed specifically for this purpose (Schlumberger's Modular Reservoir Dynamics Tester [MDT]) or with a straddlepacker assembly. With this tool, it is possible to isolate a small interval (approximately $5 \mathrm{ft}$ in length) for fracture testing. An upper and lower packer on the tool bounds the test interval, and fluid is pumped into the formation from the surface to build pressure. Pressure gauges on the tool monitor pressure throughout the test and convey this information to surface. Pressure buildup is allowed to continue until the formation fractures. Once the formation fractures, pumping is discontinued and declining pressures are recorded to determine the fracture closure pressure. This cycle can be repeated multiple times within each test interval before moving to another interval in the formation. This tool is best suited for low-permeability formations.

Mini-frac testing with the MDT tool may not be possible in the storage reservoir (Mt. Simon) due to the higher volumetric pump rates required to achieve fracture pressure. Therefore, injection tests in the Mt. Simon Formation may be conducted after the well is cased and perforated using 
conventional step-rate testing techniques if the MDT tool or other open-hole techniques are not feasible. Possible test intervals for open-hole mini-frac testing during drilling are identified in Table 3-24.

Table 3-24. Test Intervals for Microhydraulic Fracture Testing During Drilling Using MDT Tool

\begin{tabular}{|l|l|}
\hline \multicolumn{1}{|c|}{ Formation } & Formation and Approximate Depth to Top/Bottom \\
\hline $\begin{array}{l}\text { Eau Claire Formation } \\
\text { (Caprock) }\end{array}$ & $\begin{array}{l}6,705 \text { to } 7,353(648 \mathrm{ft}) \\
\text { Specific test interval(s) to be determined after } \\
\text { geophysical logging. } \\
\text { At least 3 locations would be tested. }\end{array}$ \\
\hline Mt. Simon Formation & $\begin{array}{l}7,353 \text { to } 8,996(1,643 \mathrm{ft}), \\
\text { Specific sampling interval(s) to be determined. } \\
\text { May not be possible to achieve fracture pressure } \\
\text { with MDT tool; therefore, may be deferred until after } \\
\text { well completion. }\end{array}$ \\
\hline
\end{tabular}

\subsubsection{Other Types of Open-Hole Reservoir Tests}

In addition to the mini-frac testing described above, other types of reservoir tests might be conducted during drilling when the borehole is still in an open-hole condition across the storage reservoir (i.e., after drilling to total depth but before installing casing), depending on how long the hole is left open before installing casing. For example, a dynamic fluid logging survey (flow meter and fluid temperature) conducted during an open borehole, air-lift pumping test would provide a means of identifying zones of higher permeability within an open borehole section that are contributing flow to the borehole. These zones would be candidates for injecting $\mathrm{CO}_{2}$. Results of these tests would be useful for identifying zones that are candidates for $\mathrm{CO}_{2}$ injection and also for additional reservoir testing before or after well completion.

\subsubsection{Cased-Hole Logging}

After each casing string is cemented and the cement has set up, a cement bond logging tool will be run across the entire length of the casing string (all casing strings will be cemented to surface). The purpose of running the cement bond logging tool is to evaluate the integrity of the cement sheath outside the casing, primarily to ensure that channels do not exist that could prove conduits for fluid migration out of the storage reservoir.

\subsubsection{During and After Casing Installation Drilling}

After the well is drilled, including installation and cementing of the long-casing string, the well will be completed with the formation (i.e., perforated). Once this is done, additional injection testing may be conducted prior to beginning regular $\mathrm{CO}_{2}$ injection.

\subsubsection{Well Completion}

Well completion will primarily entail perforating the well across intervals within the Mt. Simon Formation where $\mathrm{CO}_{2}$ will be injected. Perforation intervals will be determined based on results of geophysical logging, core analyses, and other characterization and testing data gathered during drilling. Acid treatment of the well will be conducted in conjunction with perforating to reduce or remove wellbore "skin" associated with perforating, drilling, and cementing and to 
enhance the connectivity between the well and the formation. At this time, the need for more extensive well stimulation (e.g., hydrofracturing) is not anticipated, although this will be verified during injection testing after well completion.

Prior to perforating the well, acid will be introduced into the bottom of the well so that it covers the perforating interval(s) and is in contact with the perforations when the well is perforated. After the well is perforated, pressure will be applied to the well by pumping in brine to encourage the acid to enter the perforations. After the acid has been in contact with the perforations for a period of time, the well will be swabbed to remove the acid and to collect formation fluid samples. During swabbing, fluid samples will be recovered at land surface and analyzed to monitor water quality parameters (e.g., specific conductance, $\mathrm{pH}$ ). Once sufficient water has been removed via swabbing so that representative formation fluids unaffected by acid are being recovered, water samples for laboratory analysis will be collected. Because the well will likely be perforated across a considerable length, the process of perforating, acidizing, and swabbing will likely be conducted in a series of steps in which an isolated section of the well is completed.

\subsubsection{Injection Testing}

Once the well is completed, one or more injection tests will be conducted to test the injectivity of the Mt. Simon Formation. If open-hole testing was not conducted to determine the fracture pressure of the formation, the injection tests will be conducted in a manner to determine fracture pressure.

One type of injection test will involve conducting step-rate injection tests using water (brine) as the injection fluid. The test is conducted by injecting into the formation at a series of increasing rates, allowing each to stabilize, and noting the stabilized injection pressure for each rate. A plot of injection pressure versus injection rate is then made to identify the fracture pressure. Data from a step-rate test can also be analyzed to determine reservoir properties, such as permeability. The principle is the same as the microhydraulic fracturing test (mini frac test) described previously. The basic equipment required to conduct a step-rate test includes: a supply (this could be several hundreds of thousands of barrels) of clean, filtered water (brine) with weight similar to that in the test formation; a pressure source (e.g., a cement truck) capable of pumping the water into the well under increasing pressures; monitoring equipment capable of measuring injection rate at the surface and injection and bottomhole pressure. Injection is accomplished through tubing with a packer to isolate the test interval on the top. When testing a section of the well that is perforated above and below, it would be necessary to also use a bridge plug or similar device to isolate the test interval on the bottom in addition to the packer on top.

The following outlines the process of conducting a step-rate fracture test.

- Prior to the test, the well should be shut in long enough so that the bottomhole pressure is near the shut-in formation pressure (e.g., 48 hours).

- Each rate should be allowed to stabilize before proceeding to the next higher rate. A step duration of 60 minutes is usually required for formations with permeability less than $10 \mathrm{mD}$, and 10 to 30 minutes for formations with permeability greater than 10 $\mathrm{mD}$. However, shorter test durations may be required if the required volume of fluid to be injected is excessive such that the test becomes infeasible. Each step should be similar in duration to the preceding step. 
- Ideally, injection rates for the test should ramp up to and include the proposed maximum daily injection rate (e.g., $5 \%, 10 \%, 20 \%, 40 \%, 80 \%$, and $100 \%$ ); however, given the high proposed $\mathrm{CO}_{2}$ injection rate $(578,568 \mathrm{lb} / \mathrm{hr}$ is approximately equal to 2,051 gallons [49 bbls] per minute), depending on the temperature and pressure of the $\mathrm{CO}_{2}$ (which affects density), it will not be possible to test at these rates. The first rate should be near the rate at which the formation begins to accept fluid. In addition, it is preferable to test at least two rates below the expected fracture pressure.

- Once the fracture pressure is reached, continuing the test by stepping downward will refine the fracture pressure and provide quality control for the test. However, if the test is not continued after fracturing occurs, pressure monitoring should be continued for a sufficient period of time after injection is stopped to capture the pressure fall-off response. These data can then be analyzed to provide valuable information about the hydraulic properties (e.g., transmissivity) of the formation.

- Specific intervals within the Mt. Simon Formation will be identified for injection testing. Zones that have log characteristics that could be correlated to other intervals will be given priority.

- Other types of injection tests that may be conducted after the well is completed include extended constant rate pumping or injection tests. These longer-term tests are aimed at characterizing hydraulic properties of the injection reservoir away from the well. Examples of types of data that can be obtained from these types of tests include far-field permeability and information about hydraulic boundaries useful for reservoir modeling. Also, pilot-scale $\mathrm{CO}_{2}$ injection testing may be conducted using a truck-supplied source of $\mathrm{CO}_{2}$. These additional tests, if conducted, would be carried out before regular $\mathrm{CO}_{2}$ injection commences.

\subsubsection{Demonstration of Mechanical Integrity}

After the well is completed, including the installation of tubing, packer, and annular (packer) fluid, but prior to initiating regular $\mathrm{CO}_{2}$ injection, a test of the well's internal mechanical integrity will be performed. Internal integrity refers to the absence of leaks in the tubing, packer, and casing above the packer. This will be accomplished by conducting an annular pressure test (APT). The APT is a short-term test wherein the fluid in the annular space between the tubing and casing is pressurized, the well is shut in and the pressure of the annular fluid is monitored. If the pressure can be maintained for a specified period of time within a specified percentage of loss or gain, the well is deemed to have internal mechanical integrity. The criteria for the initial APT will be as follows:

- the test shall consist of the annulus being pressured to the maximum injection pressure and held for one hour.

- if the pressure has less than a $\pm 10 \%$ loss in pressure, the well will be deemed to have adequate mechanical integrity.

If the well fails the APT, the tubing and packer may need to be removed from the well to determine the cause of the leak. Regulators will be notified at least 30 days prior to conducting the APT so that they can witness the test, if desired. A repeat APT will be performed any time 
the injection tubing/packer is removed from the well (e.g., well workovers) prior to resuming injection.

Additional testing will be conducted after regular $\mathrm{CO}_{2}$ injection begins to demonstrate that the well has sufficient external mechanical integrity. External mechanical integrity refers to the absence of fluid movement/leaks through channels adjacent to the injection wellbore that could result in fluid migration into an USDW. External integrity is usually evaluated annually after the start of injection. Typical methods for evaluating external mechanical integrity include:

- a tracer survey such as oxygen-activation logging or radioactive tracer logging;

- a temperature or noise log; or,

- a casing inspection log.

One or more of these methods will be used to routinely evaluate the well's external mechanical integrity.

A baseline temperature log and oxygen activation log will be run on the well after well construction but prior to commencing $\mathrm{CO}_{2}$ injection. These logs will serve as a reference for comparing future temperature logs and oxygen activation logs. An oxygen activation log is done using pulsed neutron capture technology, which is also useful for detecting $\mathrm{CO}_{2}$ outside the well. Therefore, oxygen activation logging can be used to determine the vertical distribution of $\mathrm{CO}_{2}$ outside the wellbore and to determine if fluid movement is occurring.

\subsubsection{Copies of the Logs and Tests Listed Above}

Copies of all logs and testing results obtained during drilling will be provided to the agency in the well completion report that will be submitted after the well is drilled. The well completion report comprises part of this UIC permit application (Form 4h).

Results of logging and testing that will be conducted after drilling may not be available in the timeframe required for the well completion report (e.g., the well completion report is usually required within 3 to 4 months from the time the well is drilled). For example, the well may not be perforated immediately after drilling is completed. In this case, any cased-hole injection tests that are planned would not be available until later. Similarly, the baseline temperature log and oxygen activation log may be conducted several months after the well is drilled to ensure that any potential anomalies due to drilling have dissipated. Results of these logs/tests would be submitted at a later date as an addendum to the well completion report.

\subsection{References}

Bond, D.C. 1972. Hydrodynamics of Deep Aquifers of the Illinois Basin, Circ. 470, 72 pp., III. State Geol. Surv., Champaign.

CRC Handbook of Chemistry and Physics (CRC). $89^{\text {th }}$ ed. CRC Press Boca Raton, FL, 20082009; p 6-9.

Engineering ToolBox, 2010. Thermal Properties of Water. http://www.engineeringtoolbox.com/water-thermal-properties-d 162.html . March 24.

Howard and Fast. 1970. copy from ADM UIC permit application ADM - UIC permit application. Leetaru, H.E., D.G. Morse, R. Bauer, S. Frailey, D. Keefer, D. Kolata, C. Korose, D.M.E. Mehnert, S. Rittenhouse, J. Drahovzal, S. Fisher, J. McBride. 2005. "Saline Reservoirs as a 
Sequestration Target." In An Assessment of Geological Carbon Sequestration Options in the Illinois Basin, Final Report for U.S. DOE Contract DE-FC26-03NT41994, Principal Investigator Robert Finley, p. 253-324. Accessed April 22, 2009 at http://sequestration.org/report.htm.

Schlumberger, 2006. Tubular Design and Analysis System (TDAS), Version 6.1.6. Houston, Texas.

Span, R. and W. Wagner. 1996. A new equation of state for carbon dioxide covering the fluid region from the triple-point temperature to $1100 \mathrm{~K}$ at pressures up to $800 \mathrm{MPa}$. Journal of Physical and Chemical Reference Data. Vol. 25, 16. 1509-1596. 


\section{DRAFT UIC PERMIT FORMS}

\section{ILLINOIS ENVIRONMENTAL PROTECTION AGENCY UNDERGROUND INJECTION CONTROL PERMIT APPLICATION}

FORM 4c - OPERATION PROGRAM AND SURFACE FACILITIES

USEPA ID NUMBER_not applicable

IEPA ID NUMBER _0290255208

WELL NUMBER _FutGen-INJ-1 and FutGEN-INJ-2

Location in Application

$4.1 \quad$ I. $\quad$ Operation Program

4.1.1

-4.1.1.1

-4.1.1.2

4.1.1.3

-4.1.1.4

-4.1.1.5

4.1.2.1

-4.1.2.2

-4.1.2.3

4.1.2.4

-4.1.2.5

4.1.2.6

4.1.2.7

4.1.2.8

4.1 .2 .9

- 4.1.2.10

4.2 II.

4.2.1

4.2.1.1

-4.2.1.2

4.2.1.3

4.2 .2

$-4.2 .3$
A. Area Injection Project (if applicable)

1. Maximum fluid to be injected per day

2. Years remaining in area injection project

3. Anticipated total number of injection wells required

4. Injection wells operate with/without common manifold

5. Number of injection zone monitoring wells, include list and schematics

6. Number of, name and location of injection wells currently in project, see instructions

B. Single Injection Well (if area permit is applied for, provide for typical well)

1. Number or name of well

2. Location, see instructions

3. Expected service life

4. Operation during 24 hour period

5. Operation days per month

6. Injection pressure, average and maximum

7. Injection rate, average and maximum

8. Casing-tubing annulus pressure, average and maximum

a. During operation, average and maximum

9. Other annulus pressure

10. Number of injection zone monitoring wells, include schematics

Surface Facilities

A. Injection fluid storage

1. Storage capacity in days and gallons

2. Type of storage facility(s)

3. Storage capacity in case of well failure, describe

B. Holding tanks and flow lines, describe

C. Process and Instrumentation Diagram attachment 


\section{(2) Future Gen" \\ ALLIANCE \\ Gean Energyfora Secure future}

UIC Permit Application

for the FutureGen Plant

\begin{tabular}{|c|c|c|}
\hline 4.2 .4 & D. & Filter(s) \\
\hline 4.2.4.1 & & Location \\
\hline 4.2.4.2 & & Type \\
\hline -4.2.4.3 & & Name \\
\hline 4.2.4.4 & & Model Number \\
\hline 4.2.4.5 & & Capacity, gallons per minute \\
\hline-4.2 .4 .6 & & Pore size, microns \\
\hline 4.2 .5 & E. & Injection Pump(s) \\
\hline -4.2.5.1 & & Location \\
\hline-4.2 .5 .2 & & Tyре \\
\hline-4.2 .5 .3 & & Name \\
\hline 4.2 .5 .4 & & Model Number \\
\hline 4.2.5.5 & & Capacity, gallons per minute \\
\hline
\end{tabular}

Certification

I certify under penalty of law that this document and all attachments were prepared under my direction or supervision in accordance with a system designed to assure that qualified personnel properly gather and evaluate the information submitted. Based on my inquiry of the person or persons who managed the system, or those persons directly responsible for gathering the information, the information submitted is, to the best of my knowledge and belief, true, accurate and complete. I am aware that there are significant penalties for submitting false information, including the possibility of fine and imprisonment for knowing violations.

Name \& Official Title

Phone Number

Signature

Date Signed

Note: per direction from the Illinois EPA, a signature is not required on this form. 


\section{OPERATION PROGRAM AND SURFACE FACILITIES (Form 4c)}

\subsection{Operation Program}

As an area UIC permit is being requested, information is being provided in Sections 4.1 .1 and 4.1.2, per the Illinois EPA UIC Permit instructions. Section 4.1.1 describes the total amount of $\mathrm{CO}_{2}$ to be injected, number and location of injection wells, and number, location, and description of injection zone monitoring wells (i.e., monitoring wells completed in the injection reservoir). A map is included (Figure 4-1) that shows preliminary locations for the primary and alternate injection wells and deep monitoring wells (final locations cannot be determined until the final plot plan for the FutureGen plant is available). Section 4.1.2 provides additional information about the operational aspects of the injection program, including life expectancy of the injection well, the injection schedule (e.g., hours per day, days per month), injection pressure, etc. Where two sections are present with the same title, information is provided only once and referenced in the other section. For example, Sections 4.1.1.5 and 4.1.2.10 both are titled "Number of Injection Zone Monitoring Wells, Include List and Schematics".

\subsubsection{Area Injection Project}

Two $\mathrm{CO}_{2}$ injection wells may be constructed. The primary injection well will be constructed at the onset of the project. The second well will be drilled if results from the drilling, characterizing and testing of the first well indicate that the additional well is needed; or, if early $\mathrm{CO}_{2}$ injection results indicate the need for the additional well. Therefore, an area UIC permit is requested.

\subsubsection{Maximum Fluid to be Injected Per Day}

The FutureGen facility is designed to process a range of coals, though it plans to operate using Illinois 6 coal, which also results in the highest $\mathrm{CO}_{2}$ production. The maximum flow of $\mathrm{CO}_{2}$ for the Illinois 6 coal will be 6,312 metric tons per day $(578,568 \mathrm{lb} / \mathrm{hr})$. The flow rate will be reduced during periods when the plant is operated below full capacity. The $\mathrm{CO}_{2}$ injection wells have been designed to inject the maximum production rate.

\subsubsection{Years Remaining in Area Injection Project}

The planned duration of $\mathrm{CO}_{2}$ injection is 4 years.

\subsubsection{Anticipated Total Number of Injection Wells Required}

Up to two $\mathrm{CO}_{2}$ injection wells may be constructed. The primary injection well will be constructed at the onset of the project. The second well will be drilled if results from the drilling, characterizing and testing of the first well indicate that the additional well is needed; or, if early $\mathrm{CO}_{2}$ injection results indicate the need for the additional well. Regular well maintenance, such as mechanical integrity tests, will be scheduled during plant shutdowns (planned maintenance outages).

\subsubsection{Injection Wells Operate With/Without Common Manifold}

A single pipeline will convey $\mathrm{CO}_{2}$ from the plant to the injection well. In the event that the alternate well will also be drilled and used for injection, the pipeline will include a " $T$ " connection 
that connects the main branch of the pipeline to two secondary branches, each going to one of the injection wells.

\subsubsection{Number of Injection Zone Monitoring Wells, Include List and Schematics}

Up to three injection zone monitoring wells are planned at this time. Their preliminary locations are shown on Figure 4-1. The location of these wells may change once the $\mathrm{CO}_{2}$ monitoring program is finalized. These monitoring wells would likely be used for multiple monitoring purposes, for example pressure monitoring, fluid sampling, and cross-well seismic monitoring.

A diagram illustrating the construction specifications for the monitoring wells is provided in Figures 4-2 and 4-3. Note that two designs are proposed for the monitoring wells: one design has an intermediate casing string that is approximately 5,000 ft deep; the other has an intermediate casing string that is approximately $7,000 \mathrm{ft}$ deep. The design with the deeper intermediate string would be implemented if there is an indication that hole stability below 5,000 $\mathrm{ft}$ is an issue and thus would warrant extending the depth of this casing string to isolate problem zones. As with the injection wells, the final design may not be determined until drilling is underway. The monitoring wells would extend to the base of the Mt. Simon and would be constructed very similar to the injection wells except they would be smaller in diameter. The diameter of the long-string casing in the monitoring wells will be 7 inches rather than 9-5/8 inches. The intermediate casing string would be 9-5/8 inches rather than 13-3/8 inches, and the surface casing would be 13-3/8 inches in diameter rather than 20 inches. As with the injection wells, all casing strings would be cemented to surface, and acid resistant cement would be used across the injection reservoir. Completion details for the monitoring wells (e.g., perforated zone, internal components such as type of packer and instrumentation) may differ. The wells would be perforated across a portion of the Mt. Simon and would include tubing and a packer as illustrated in the well diagrams in Figures 4-2 and 4-3; however, the exact perforation interval(s) and specifications for the internal well components cannot be determined until after the $\mathrm{CO}_{2}$ monitoring program is finalized.

\subsubsection{Number of, Name, and Location of Injection Wells Currently In Project}

The location of the primary injection well and the alternate well is provided on Table 4-1, including: county name, township, range, section and coordinate within the section. Also included are the coordinates in Illinois State Plane and in latitude and longitude.

\subsubsection{Single Injection Well}

Not applicable.

\subsubsection{Number or Name of Well}

Not applicable.

\subsubsection{Location}

See Section 4.1.1.6. 


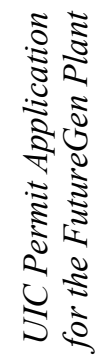

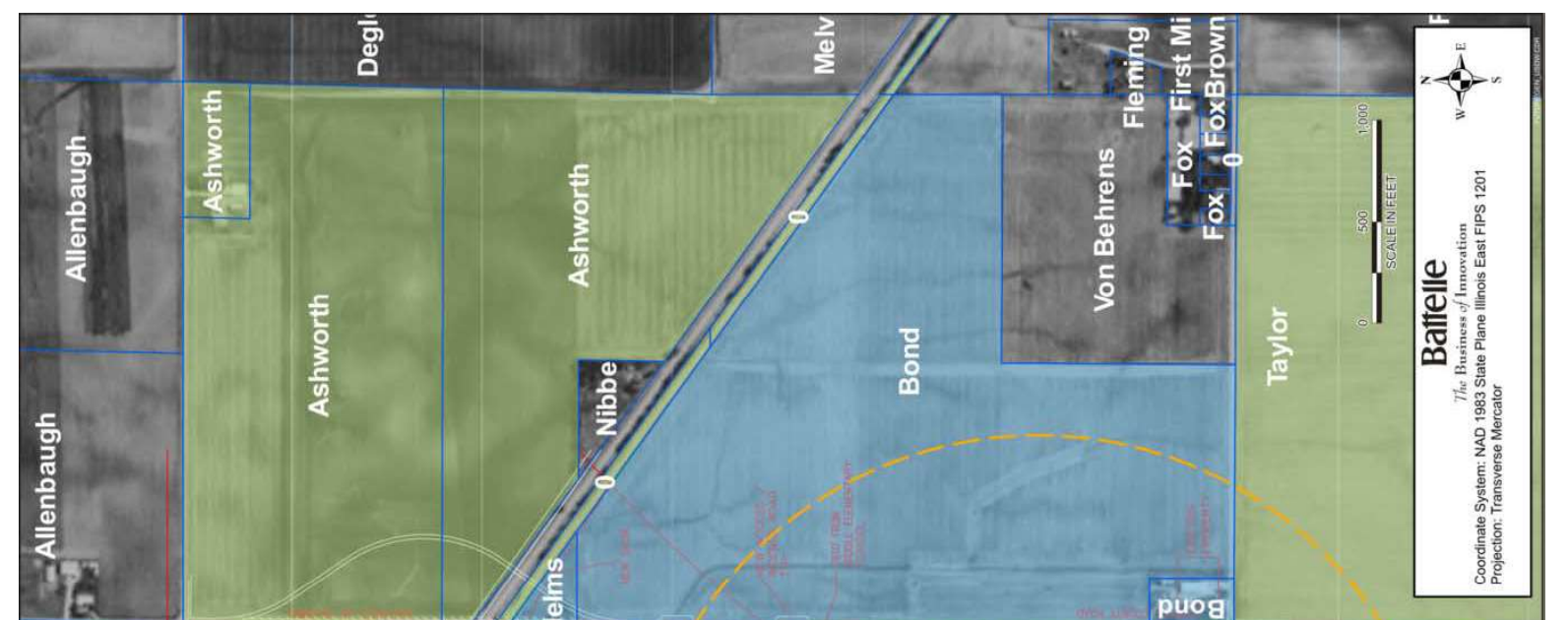

गำ

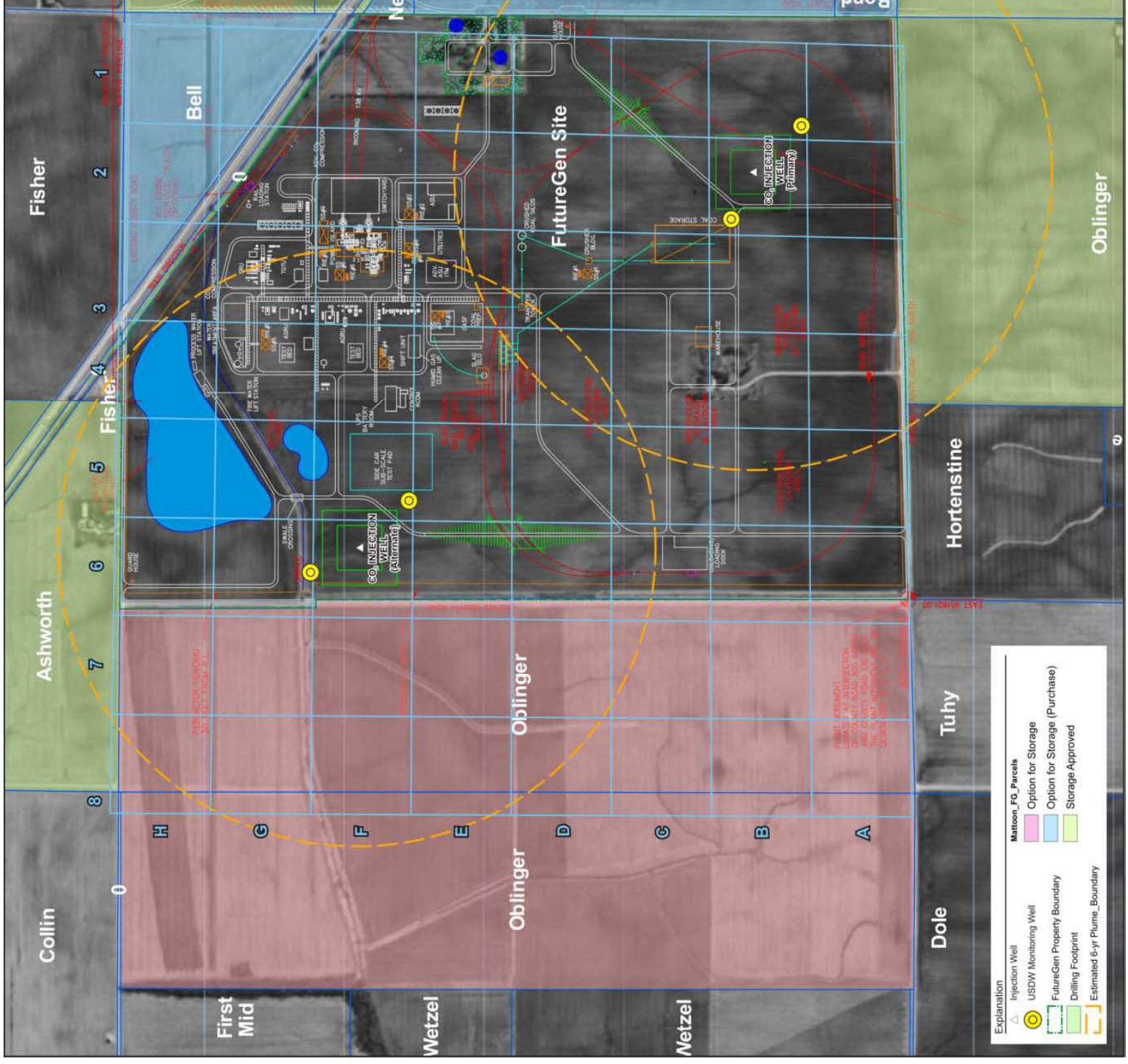

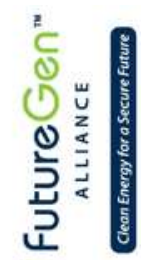

a 

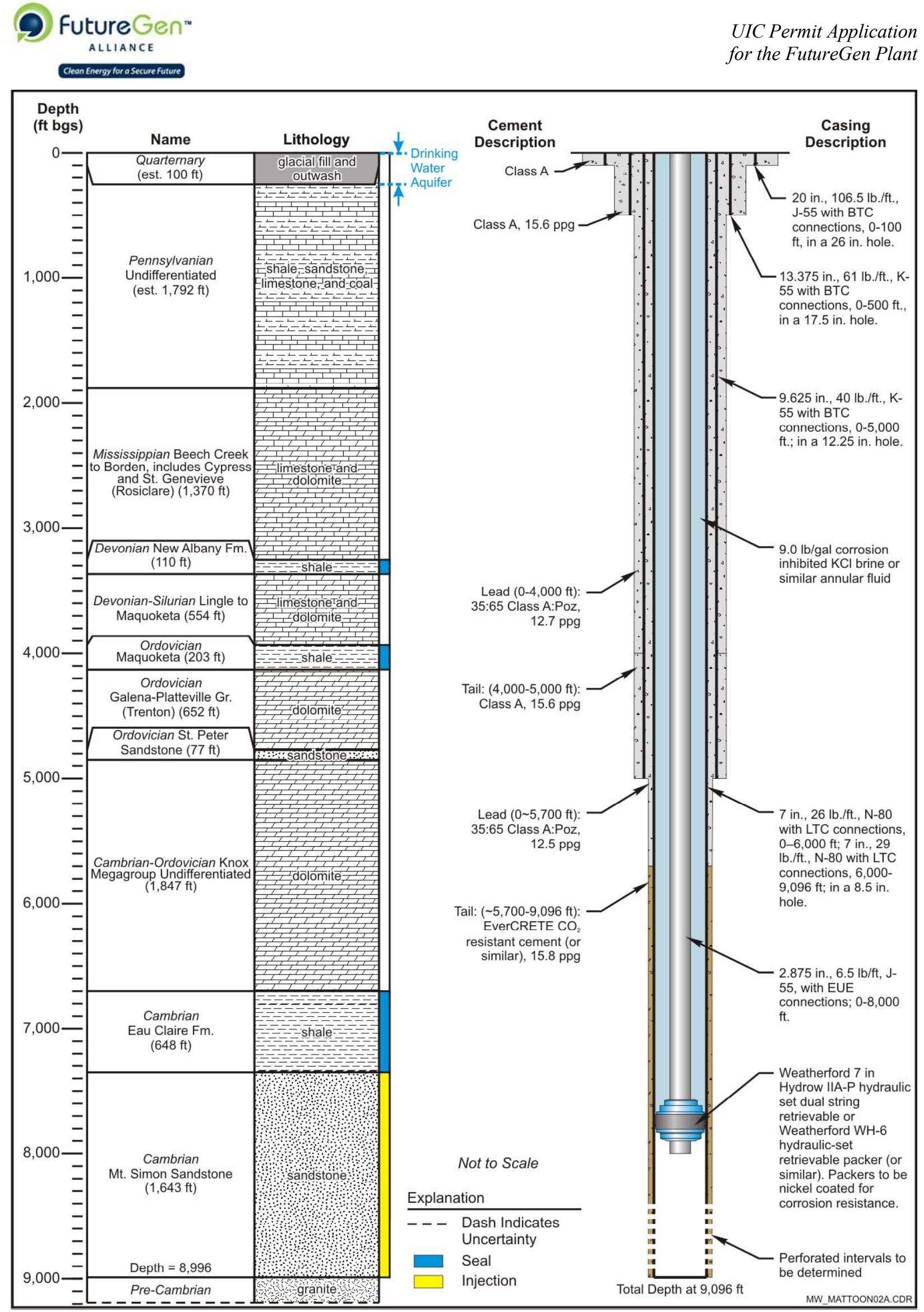

Figure 4-2. Monitoring Well Construction Diagram (5,000 ft Intermediate Casing) 

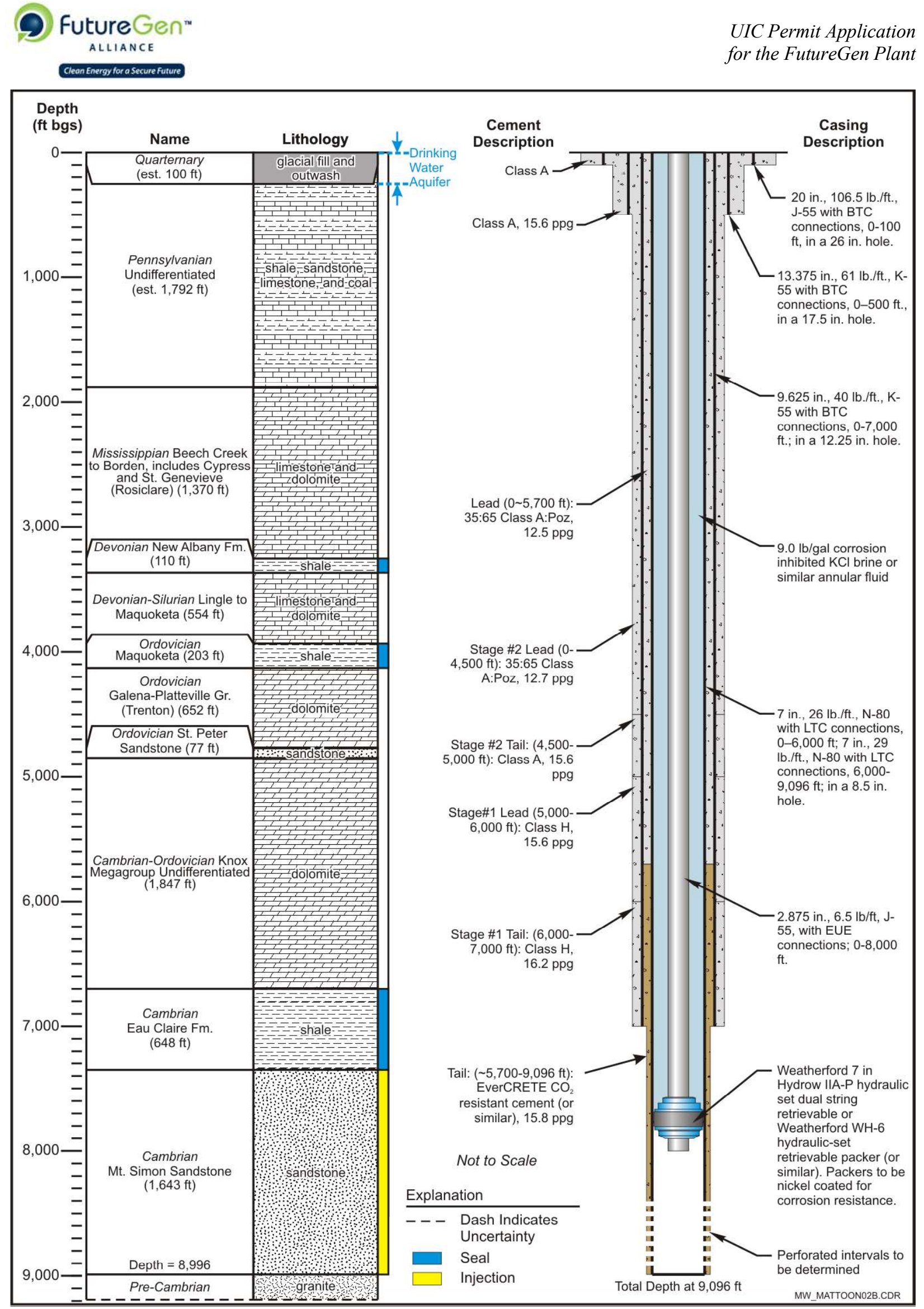

Figure 4-3. Monitoring Well Construction Diagram (7,000 ft Intermediate Casing) 
Table 4-1. Location of Primary Injection and Backup Wells

\begin{tabular}{|c|c|c|}
\hline Descriptor & Primary Injection Well & Alternate Injection Well \\
\hline County name & COLES COUNTY & COLES COUNTY \\
\hline Township & $12 \mathrm{~N}$ & $12 \mathrm{~N}$ \\
\hline Range & $7 E$ & $7 \mathrm{E}$ \\
\hline Section & 8 & 8 \\
\hline $\begin{array}{l}\text { Coordinates within the } \\
\text { section }^{(a)}\end{array}$ & $\begin{array}{l}\text { Quarter Quarter Section } \\
\text { C1 }\end{array}$ & Quarter Quarter Section F6 \\
\hline $\begin{array}{l}\text { Coordinates (State Plane, } \\
\text { NAD 83) }\end{array}$ & $\begin{array}{l}\text { NAD83 State Plane Illinois } \\
\text { East FIPS } 1201 \\
\text { Northing } 1029866.71, \\
\text { Easting } 954973.88\end{array}$ & $\begin{array}{l}\text { NAD83 State Plane Illinois } \\
\text { East FIPS } 1201 \\
\text { Northing } 1031943.5 \\
\text { Easting } 952125.16 \\
\end{array}$ \\
\hline $\begin{array}{l}\text { Coordinates (latitude and } \\
\text { longitude) }\end{array}$ & $\begin{array}{l}\text { Lat-Long NAD83 } \\
39.494704478^{\circ} \mathrm{N}, \\
88.437072080^{\circ} \mathrm{W}\end{array}$ & $\begin{array}{l}\text { Lat-Long NAD83 } \\
39.500396646^{\circ} \mathrm{N} \\
88.447175686^{\circ} \mathrm{W}\end{array}$ \\
\hline
\end{tabular}

(a) This refers to the $1 / 8$ mile $\times 1 / 8$ mile square that the wells are located within. Each section is divided into $641 / 8$ mile $\times 1 / 8$ mile squares $(8 \times 8)$. The rows are numbered from east to west and lettered from south to north.

\subsubsection{Expected Service Life}

The expected service life of the wells was discussed in Section 3.4. The wells have been designed to exceed the planned injection period of 4 years. With proper maintenance and periodic inspection and replacement of certain critical components (e.g., tubing, packer), the wells should be able to operate for much more than 4 years.

\subsubsection{Operation During 24-Hour Period}

The FutureGen facility is designed to operate 24 hours per day and 7 days per week with planned maintenance outages twice per year. The planned outages will initially be four weeks in duration. The number and duration of the planned outages are expected to be reduced after the first few years of operation. During initial operation, there will be unplanned outages such that the overall on-line availability will be less than $100 \%$. The maximum flow of $\mathrm{CO}_{2}$ for the Illinois 6 coal will be 6,312 metric tons per day $(578,568 \mathrm{lb} / \mathrm{hr})$. The flow rate will be reduced during periods when the plant is operated below full capacity (i.e., this amount of $\mathrm{CO}_{2}$ will not be produced on a continuous basis).

\subsubsection{Operation Days Per Month}

The FutureGen facility is designed to operate 24 hours per day and 7 days per week, except during scheduled shutdown events.

\subsubsection{Injection Pressure, Average, and Maximum}

The injection pressure was discussed in Section 3.7.3. Refer to that section for information on injection pressure at the wellhead and at the top of the injection zone as well as the method and assumptions used to calculate these pressures.

\subsubsection{Injection Rate, Average, and Maximum}

The maximum flow of $\mathrm{CO}_{2}$ for the Illinois 6 coal will be 6,312 metric tons per day $(578,568 \mathrm{lb} / \mathrm{hr})$. The flow rate will be reduced for other coal types as well as during periods when the plant is operated below full capacity. 


\subsubsection{Casing Tubing Annulus Pressure, Average, and Maximum}

The injection well will be equipped with a system that regulates the pressure of the annular fluid between the tubing and the long-string casing. This system was described in Section 3.7.5. The pressure of the annular fluid (measured at the surface) will be maintained so that the pressure above the packer is greater than the pressure of the injection zone formation below the packer. This arrangement will maintain a downward pressure gradient across the packer at all times.

\subsubsection{Other Annulus Pressure}

Not applicable.

\subsubsection{Number of Injection Zone Monitoring Wells, Include Schematics}

See Section 4.1.1.5.

\subsection{Surface Facilities}

FutureGen is a government-industry, cost-shared project to design, build, and operate a first-ofa-kind coal-fueled, near-zero emission power plant. The FutureGen power plant will produce electricity and hydrogen from coal while capturing and permanently storing $\mathrm{CO}_{2}$ in a deep geologic formation. The nominally rated 275 -megawatt (MW) prototype power plant will operate as a production plant, generating commercially significant levels of electric power. It may also provide a large-scale engineering laboratory for testing new and clean power generation, $\mathrm{CO}_{2}$ capture, and coal-to-hydrogen technologies, as well as including syngas slip-stream access for testing and developing new technologies. It is expected that the FutureGen program will build and operate the cleanest coal-fueled power plant in the world.

The FutureGen facility design has been broken up into process areas or islands for ease of design. Each island is composed of unique geographical process elements called "Areas". The following reflects those Areas:

- Coal Handling Island - Area 100

- Air Separation Unit Island - Area 200

- Gasification Island - Area 300

- Shift Reaction - Area 400

- Mercury Removal - Area 500

- Acid Gas Removal - Area 510

- Sulfur Removal - Area 520

- Tail Gas Treatment Unit - Areas 510, 520 and 530

- Syngas Process Island - Areas 500 through 530

- Power Island - Area 600A

- Grid Interface - Area 600B

- Integration - Area 700

- Balance of Plant - Area 800A

- Process Water Treatment Island - Area 800B

- $\mathrm{CO}_{2}$ Compression Island - Area 900A

- Sequestration (i.e., pipeline and injection wells) - Area 900B

The areas are shown in a flowsheet relationship in Figure 4-4. 

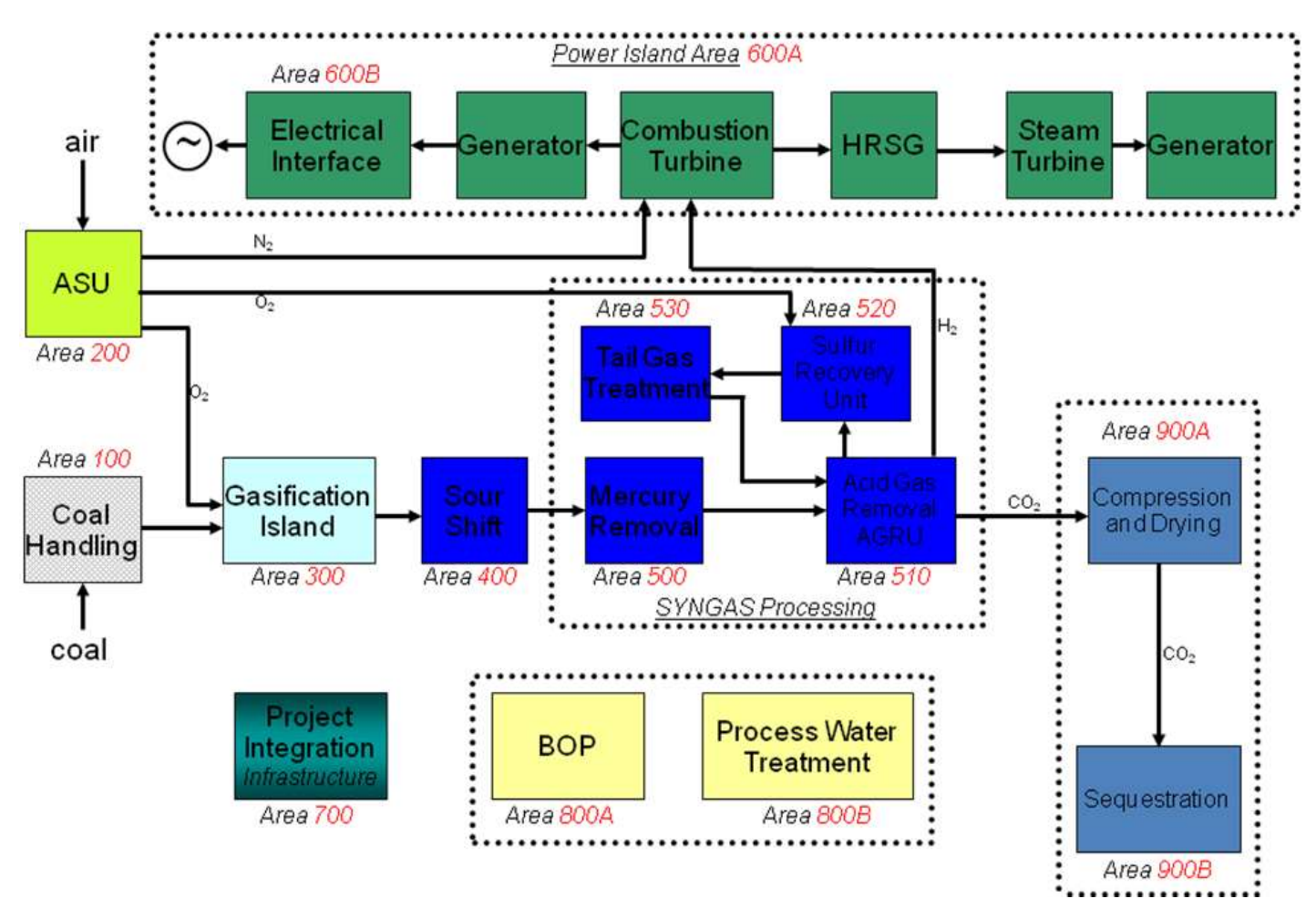

Figure 4-4. Process Areas and their Flowsheet Relationships

\subsubsection{Injection Fluid Storage}

The FutureGen facility will not have storage capacity for the injection fluid, $\mathrm{CO}_{2}$. There will be some storage of $\mathrm{CO}_{2}$ inherent to the system design because of the pipeline size and the knockout pots in the $\mathrm{CO}_{2}$ compression system. The $\mathrm{CO}_{2}$ pipeline from the outlet of the $\mathrm{CO}_{2}$ compressor to the injection well is constructed of 12 inch diameter carbon steel pipe. The final length of the pipeline has not been determined at this time but the initial estimate is 5,800 feet.

\subsubsection{Storage Capacity in Days and Gallons}

Not applicable.

\subsubsection{Type of Storage Facility(s)}

Not applicable.

\subsubsection{Storage Capacity in Case of Well Failure}

Not applicable.

\subsubsection{Holding Tanks and Flow Lines}

The FutureGen facility will not have storage capacity for the injection fluid, $\mathrm{CO}_{2}$.

The $\mathrm{CO}_{2}$ pipeline will be constructed of 12 inch API $5 \mathrm{~L}$ X65 steel pipe. The pipeline will be buried until it reaches the wellhead(s). The pipeline will have a backpressure control valve at the compressor outlet that can also be used as an isolation valve if necessary. If a second well is drilled, the pipeline will have a branch tee near the backup injection well. The pipeline sections downstream from the tee will be the same size and material as the main pipeline. 
wellhead. Each branch line (or mainline if there is only one injection well) will have a flow control valve and an on/off isolation valve near the wellhead. The isolation valves are remotecontrolled valves that can automatically isolate the wellheads if necessary. The flow control valves can be used to control flow if both wells are in use. This would not be normal operation and will likely only be used when switching flow between injection wells. That is, when one well is taken off-line for inspection and the other well is put into service so that plant operation will not be impacted.

Several instruments will be used to monitor the pipeline and well operations. Temperature and pressure are measured at the outlet of the final compressor stage and flowrate near the wellhead. If two wells are drilled, pressure will be measured before the branch tee and flow measured in each leg after the branch tee. The flow meter(s) will also measure fluid density. A corrosion monitor will also be installed on the pipeline.

\subsubsection{Process and Instrumentation Diagram Attachment}

The detailed Process and Instrumentation Diagrams (P\&IDs) are not completed at this stage of design for the FutureGen project. The draft Process Flow Diagrams (PFDs) including major instrumentation are shown in Figure 4-5 $\left(\mathrm{CO}_{2}\right.$ compression with the primary injection well and possible second injection well) and 4-6 ( $\mathrm{CO}_{2}$ dehydration) for the processes of dehydration, compression, and transport to the injection wells. Note that the details of the compression area are not shown on Figure 4-5 as the design is not finalized. These PFDs and the detailed P\&IDs will be completed during definitive design.

\subsubsection{Filter(s)}

The FutureGen facility will not have filters on the $\mathrm{CO}_{2}$ line(s). The particulate is removed from the syngas stream prior to the separation of the $\mathrm{CO}_{2}$ and downstream processing.

\subsubsection{Location}

Not applicable.

\subsubsection{Type}

Not applicable.

\subsubsection{Name}

Not applicable.

\subsubsection{Model Number}

Not applicable.

\subsubsection{Capacity, Gallons Per Minute}

Not applicable.

\subsubsection{Pore Size, microns}

Not applicable. 


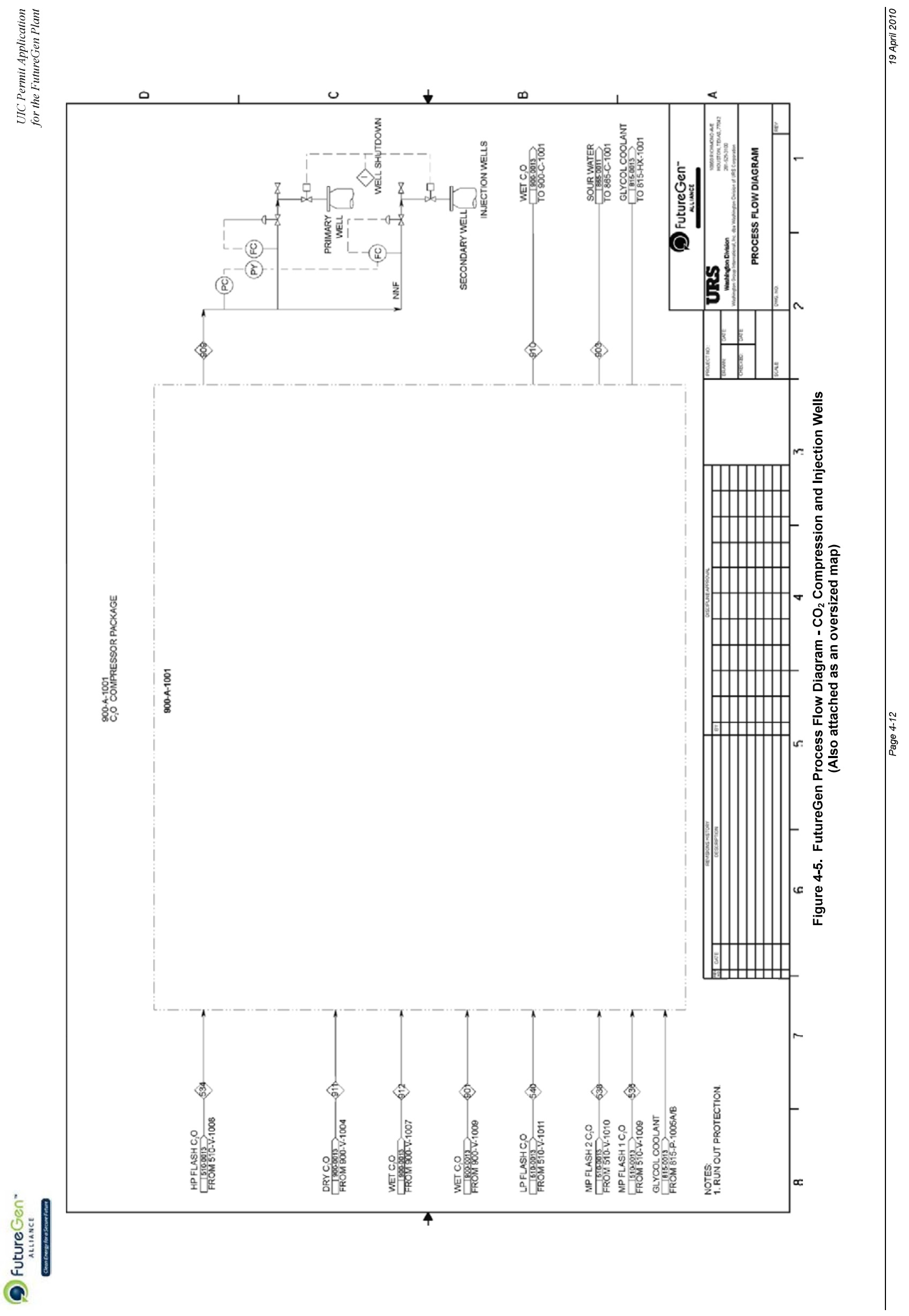


$\sqrt{11}$

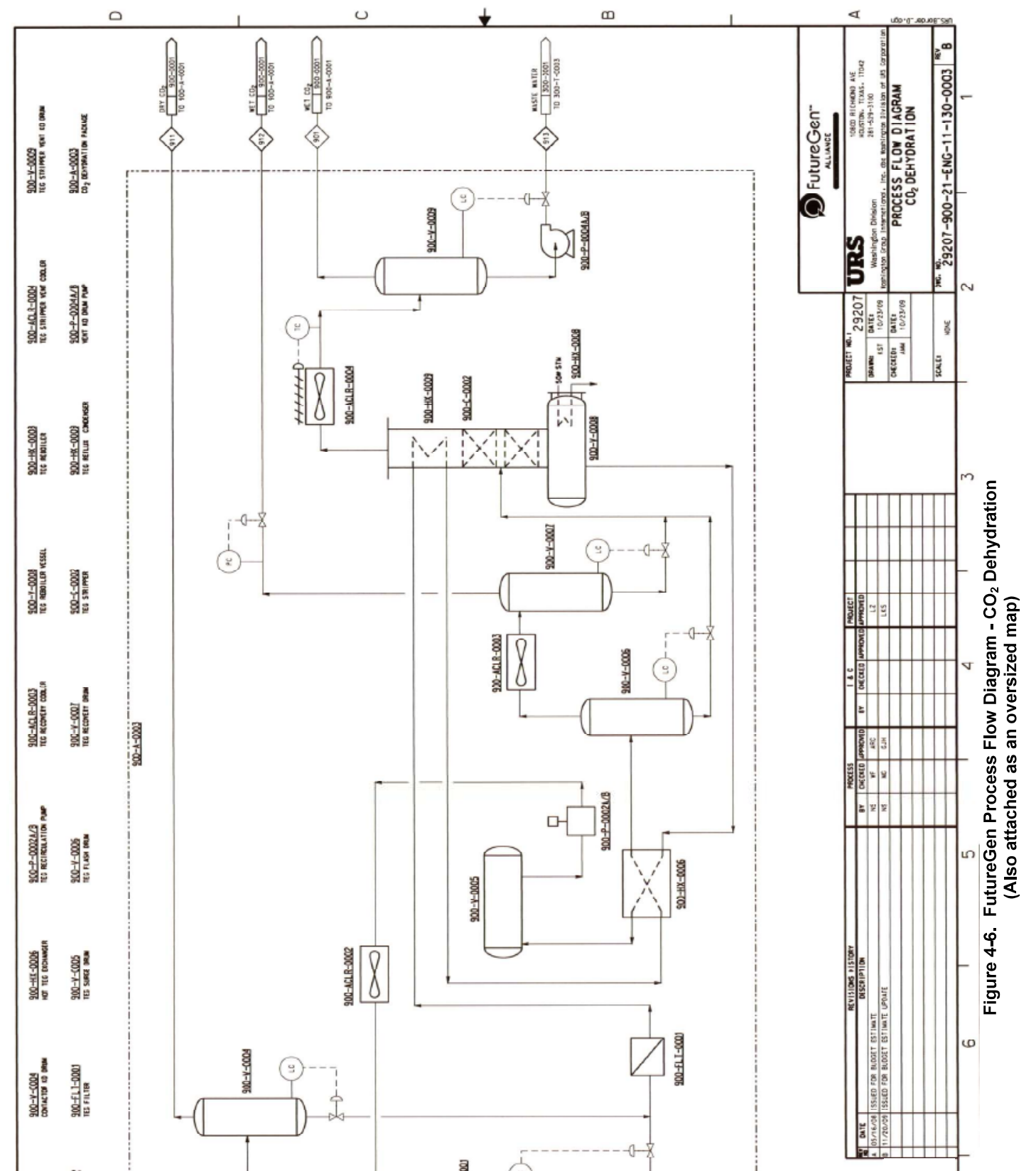

ด

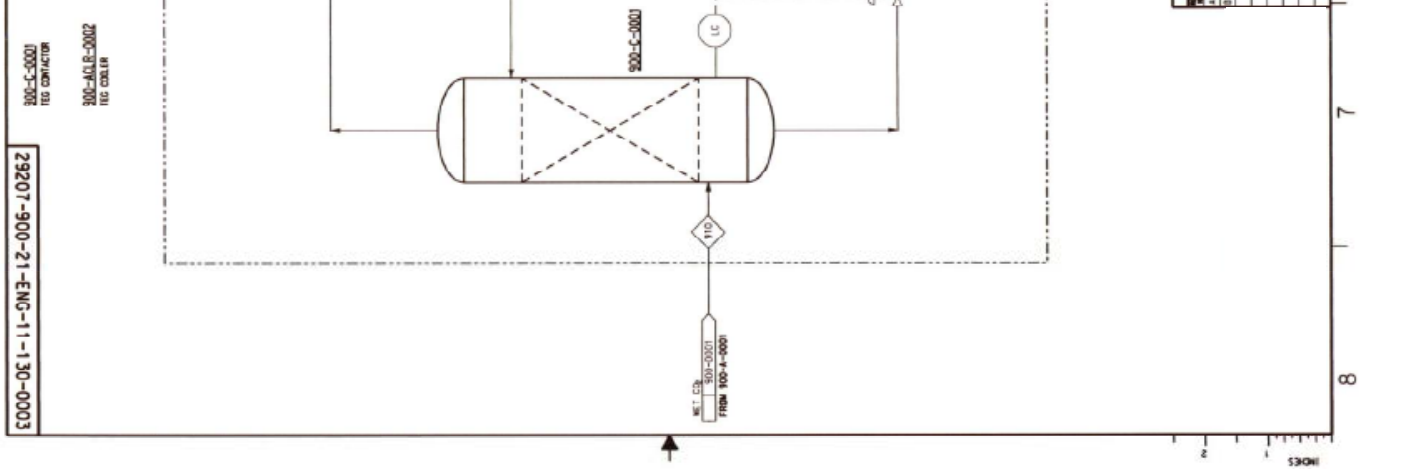




\subsubsection{Injection Pump(s)}

The $\mathrm{CO}_{2}$ compressor system is a centrifugal unit with two compression sections (cases) with each section having two stages of compression.

No interstage cooling is required for the section in low pressure (LP) service. The section in high pressure (HP) service has interstage cooling with the final stage discharging in the supercritical region (2,225 psia) to the air cooled $\mathrm{HP} \mathrm{CO}_{2}$ Compressor Aftercooler. The first suction drum removes water from the inlet streams before the first compression stage. The second knockout drum removes water from the $\mathrm{CO}_{2}$ stream between the LP and HP compression sections. Intercooling is provided by the $\mathrm{CO}_{2} \mathrm{LP} 1$ st Stage Cooler and $\mathrm{CO}_{2} \mathrm{HP}$ 1st Stage Cooler. In addition, the HP $\mathrm{CO}_{2}$ Compressor Recycle Cooler has been included around the final stage of compression. This cooler will provide the ability to operate the compressor in recycle mode (i.e., full-load recycle if the downstream system is being brought on line or taken off line) without overheating the compressor. This will be normally necessary only for initial operation of injection wells and startup of the compression system.

The $\mathrm{CO}_{2}$ Compressor Suction Drum Pump is a small centrifugal type pump that returns any produced water for use in slurry preparation in the gasification area. Although the $\mathrm{CO}_{2}$ is not normally expected to be saturated with water, in some modes of operation a small amount of water may be produced.

The triethylene glycol (TEG) Dehydration Package treats the $\mathrm{CO}_{2}$ at the third stage discharge pressure to reduce the water content to $<100 \mathrm{ppmv}(4.8 \mathrm{Lb} / \mathrm{MMscf})$ to meet the pipeline moisture specification. The TEG package is a high-pressure absorption/low-pressure regeneration circulating solvent system utilizing $99 \%$ TEG as the absorbing solution. Heat for regeneration is supplied using 450 psig plant steam. Cooling for the unit is supplied by air coolers and all vent streams from regeneration are recycled back to the main process. The gas compression system will be housed in a metal building approximately $80 \mathrm{ft} \mathrm{L} \times 40 \mathrm{ft} \mathrm{W} \times 35 \mathrm{ft} \mathrm{H}$ (at eves). The specifics of the compression system have not been finalized and may change from the description provided in this section.

\subsubsection{Location}

The $\mathrm{CO}_{2}$ compression system is located near the center of the surface facility located in the north-central area of the FutureGen site. A preliminary plot plan for the FutureGen site is shown in Figure 4-7 (also attached as an oversized map). The compressor area (900A) is located on the northeast side of the process island. The pipeline routing shown in the figure is for representation only because the exact routing has not been established at this time.

\subsubsection{Type}

The compression system consists of two centrifugal compressors in series. Each compressor has two stages in series for a total of four stages. There is cooling and water removal between the compressors. The downstream HP compressor has heat exchange, water removal and dehydration (using a separate TEG unit) between stages.

\subsubsection{Name}

The final make and model has not been determined at this stage of design. Preliminary design is based on a Dresser-Rand DATUM compressor system (Figure 4-8). This is composed of two centrifugal compressors driven by one 30,000 horsepower (hp) motor. The low-pressure 
compressor design is based on a D6R6S DATUM compressor with a gear increaser. The highpressure compressor design is based on a D12R9B DATUM compressor with a gear increaser.

\subsubsection{Model Number}

See previous section.

\subsubsection{Capacity, Gallons Per Minute}

As shown on the PFDs provided in Figure 4-5 and Figure 4-6, there are several streams at different temperatures and pressures entering the compressors. There are four inlet pressures for the various streams: 15 psia, $45 \mathrm{psia}, 70 \mathrm{psia}$, and $145 \mathrm{psia}$. The total $\mathrm{CO}_{2}$ stream flow rate exiting the last compressor is $578,568 \mathrm{lb} / \mathrm{hr}$ at 2,225 psia. The exact volumetric flow rate is only an estimate at this time because of the gas density issues near the supercritical region at a temperature of $120^{\circ} \mathrm{F}$ and a pressure of $2,225 \mathrm{psia}$, the density of the fluid will be approximately $35 \mathrm{lb} / \mathrm{ft}^{3}$ such that the estimated volumetric flow is 16,456 actual $\mathrm{ft}^{3} / \mathrm{hr}$ or $2,051 \mathrm{gpm}$. This is the maximum volume of the $\mathrm{CO}_{2}$ injection stream that will be delivered to the injection well(s). See Section 7.3 of this document for an expanded discussion of the volume of injection fluid for the range of operating conditions that are anticipated. 


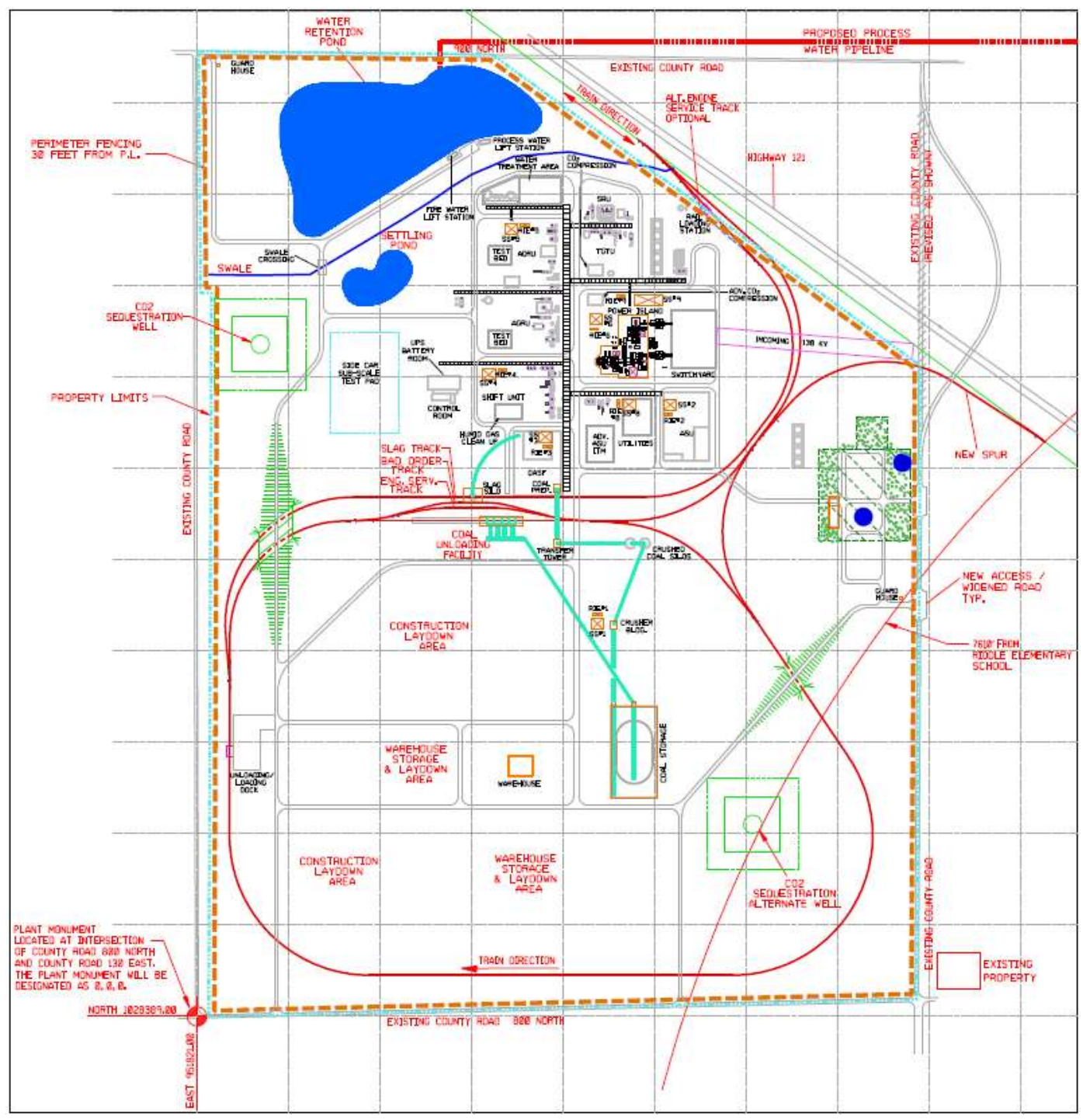

Figure 4-7. FutureGen Preliminary Plot Plan (Location of Well is Preliminary) (Also attached as an oversized map)

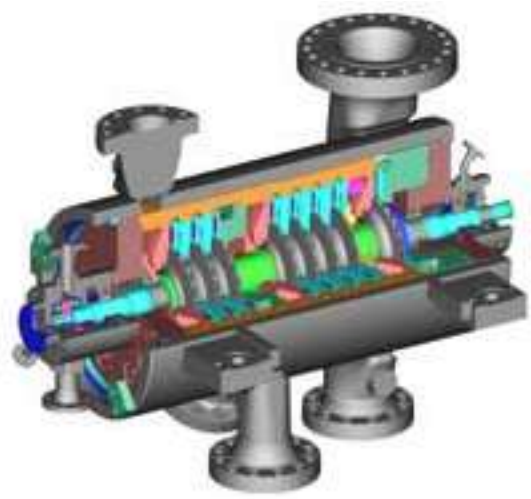

Figure 4-8. Dresser-Rand DATUM Compressor

(Found at http://www.dresser-rand.com/products/turbo/datum/) 
DRAFT UIC PERMIT FORMS

\title{
ILLINOIS ENVIRONMENTAL PROTECTION AGENCY \\ UNDERGROUND INJECTION CONTROL PERMIT APPLICATION
}

\author{
FORM 4d - AREA OF REVIEW
}

\author{
USEPA ID NUMBER not applicable \\ IEPA ID NUMBER 0290255208 \\ WELL NUMBER _FutGen-INJ-1 and FutGEN-INJ-2
}

Location in Application

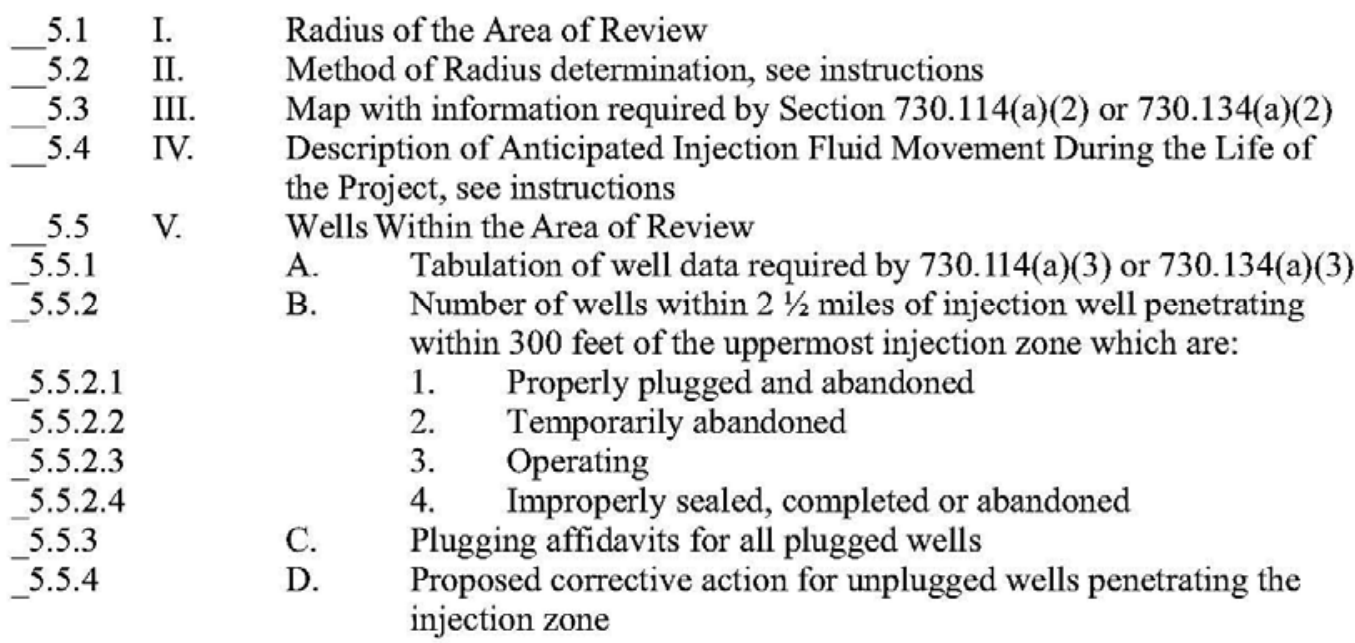

\section{CERTIFICATION}

I certify under penalty of law that this document and all attachments were prepared under my direction or supervision in accordance with a system designed to assure that qualified personnel properly gather and evaluate the information submitted. Based on my inquiry of the person or persons who manage the system, or those persons directly responsible for gathering the information, the information submitted is, to the best of my knowledge and belief, true, accurate and complete. I am aware that there are significant penalties for submitting false information, including the possibility of fine and imprisonment for knowing violations.

Name \& Official Title

Signature

\section{Phone Number}

Date Signed

Note: per direction from the Illinois EPA, a signature is not required on this form. 


\section{AREA OF REVIEW (Form 4d)}

\subsection{Radius of the Area of Review}

A fixed radius of 2.5 miles beyond the edge of the Mattoon Site property was selected for the AOR.

\subsection{Method of Radius Determination}

Modeling performed to determine the anticipated movement of the injected fluid suggests that the radius of the plume will be considerably less than the fixed radius (see Section 5.4).

\subsection{Map with Information Required by Section 730.114(a)(2) or 730.134(a)(2)}

Figure 5-1 (also attached as an oversized map) shows the locations of all of the wells described in the tables found in Appendix 5-1. Each "dot" is representative of a single latitude and longitude coordinate that can contain up to three individual wells. Multiple wells may have the same latitude and longitude listed in the various databases due to the use of the 10-acre plot system, whereby wells are plotted by dividing a section into 64,10 -acre plots. If a well log does not contain a specific latitude and longitude and uses only the 10-acre plot system, the latitude and longitude listed will be the coordinates of the center of that plot. Therefore, several wells may have the same latitude and longitude listed in the database, but are not necessarily in the same location, only in the same 10-acre area.

Wells with the same latitude and longitude designations are grouped together on tables located in Appendix 5-1 with bold outlines.

\subsection{Description of Anticipated Injection Fluid Movement During the Life of the Project}

Predictions of the quantity and distribution of $\mathrm{CO}_{2}$ injected into the Mt. Simon saline reservoir at the Mattoon Site were made using numerical simulation. The governing equations used in the modeling describe the flow and transport of supercritical $\mathrm{CO}_{2}$ through a saline geologic formation and are based on conservation equations for thermal energy, water mass, $\mathrm{CO}_{2}$ mass and salt (White and Oostrom, 2000). The $\mathrm{CO}_{2}$ is prescribed to move through connected pores either through the mobile gas or aqueous phases, where the gas phase comprises mainly supercritical $\mathrm{CO}_{2}$ and water vapor, and the aqueous phase comprises mainly liquid water and dissolved $\mathrm{CO}_{2}$ and salt. The flow of mobile phases is described using the multiple-fluid form of Darcy's law. Mass components (i.e., water, $\mathrm{CO}_{2}$, and salt) migrate through the pore space via advection, hydraulic dispersion and diffusion. Thermal energy is transported through the geologic media via diffusion through the host rock and fluids filling the pores and advectively through the mobile fluids. The governing flow and transport equations contain numerous parameters (e.g., viscosity, solubility, relative permeability, density) that must be computed from the principal unknowns of the governing flow and transport equations. The intermediate equations that relate parameters to the principal unknowns are referred to collectively as the 


Mattoon, IL - Area of Review

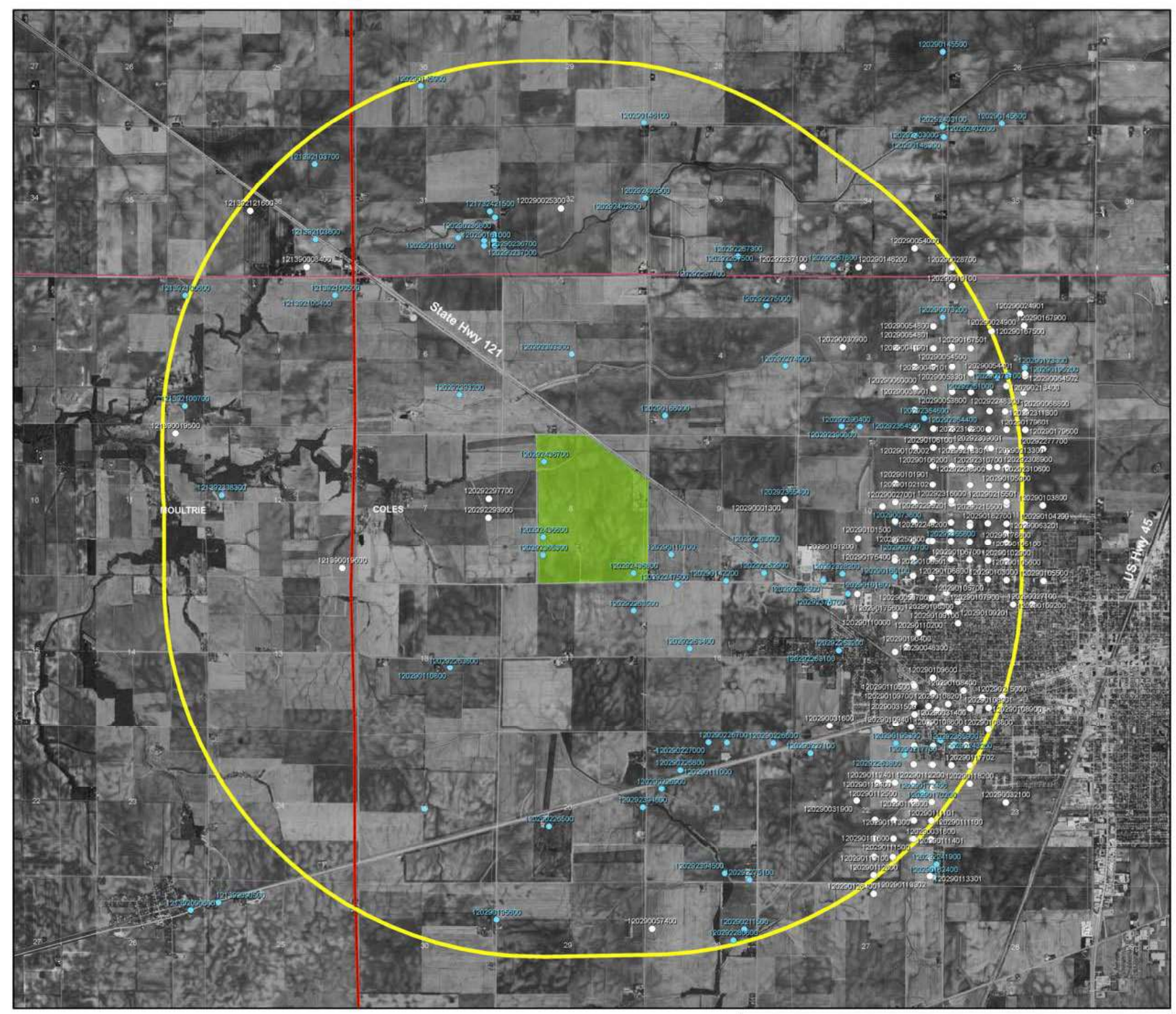

Explanation

Oil \& Gas Wells

- Water Wells
Mattoon AOR 2.5-mi Buffer Mattoon Injection Site
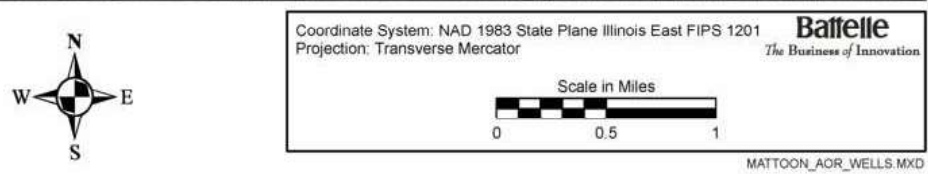

Figure 5-1. Well Locations (Also attached as an oversized map) 
constitutive equations. Constitutive equations can be divided into two categories - those that are independent and dependent on the host rock. Independent constitutive equations are generally associated with fluid properties (e.g., viscosity, density, diffusion coefficient, enthalpy). Dependent constitutive equations are generally associated with transport parameters associated with the host rock (e.g., intrinsic permeability, saturation-capillary pressure relation, relative permeability-saturation relation, thermal conductivity). Numerical simulations of $\mathrm{CO}_{2}$ injection, migration, and redistribution used dependent constitutive equations and parameters determined from site specific data.

\subsubsection{Simulation Software Description and General Assumptions}

Numerical simulations were executed using the sequential version of the Subsurface Transport Over Multiple Phases (STOMP) simulator developed by the Pacific Northwest National Laboratory. STOMP is a collection of multifluid flow and reactive transport simulators with numerous operational modes. STOMP- $\mathrm{CO}_{2} \mathrm{e}$ is the operational mode used for the numerical simulations described in this document. STOMP-CO $\mathrm{CO}_{2} \mathrm{e}$ solves four nonlinear hyperbolic partial differential conservation equations: (1) water mass, (2) $\mathrm{CO}_{2}$ mass, (3) salt mass, and (4) thermal energy. The governing equations are transformed to algebraic form using integral volume spatial discretization on structured orthogonal grids (e.g., Cartesian, cylindrical, or curvilinear boundary fitted) and a backward-Euler temporal discretization (i.e., fully implicit). Nonlinearities in the resulting algebraic equations are linearized via multivariate Newton-Raphson iteration, where the Jacobian matrix is computed using numerical derivatives. Phase transitions are handled using primary variable switching. Details concerning the solved governing equations and numerical solution approaches are reported in the STOMP Theory Guide (White and Oostrom, 2000). Details concerning the use of STOMP- $\mathrm{CO}_{2} \mathrm{e}$, including input formatting details, are reported in the STOMP User's Guide (White and OostroM, 2006).

The STOMP- $\mathrm{CO}_{2}$ e simulator was chosen for its balance of numerical efficiency and simulation capabilities. Inherent in this balance, however, are assumptions concerning the flow and transport processes. STOMP- $\mathrm{CO}_{2}$ e does not simulate geochemical reactions. Injecting $\mathrm{CO}_{2}$ is anticipated to lower the formation aqueous $\mathrm{pH}$ to values approaching 3.5 , which can affect the dissolution of host minerals and subsequent precipitation of carbonates. For these investigations, however, it was assumed that the time-scales for the mineralization reactions to significantly affect the amount of $\mathrm{CO}_{2}$ in the supercritical phase were well beyond the time periods of interest. Therefore, these simulations were conducted without considering reactive transport. However, salt precipitation was modeled as affecting $\mathrm{CO}_{2}$ injectivity by reducing the available pore space.

In addition to geochemical alterations, the reservoir formations are additionally subjected to mechanical stresses via elevated injection pressures and temperature gradients imposed from injecting cold $\mathrm{CO}_{2}$ received via pipeline. However, geomechanical effects were not specifically analyzed for this study. In order to minimize geomechanical effects, injection pressures have been constrained to minimize potential for fracturing both the host formation and especially the primary caprock seal. Also, the short pipeline distances at the Mattoon site mean that wellhead temperatures can easily be controlled to ensure that temperature of the $\mathrm{CO}_{2}$ injected into the reservoir is within a few degrees of in situ conditions, thus minimizing geomechanical stresses induced by temperature change. 


\subsubsection{Site Specific Assumptions and Methodology}

The primary sequestration reservoir for the Mattoon Site is the Mt. Simon Sandstone, in the interval between depths of 7,353 and $8,996 \mathrm{ft}$ bgs. The Mt. Simon is overlain by the Eau Claire shale and underlain by Precambrian basement rock, both of which act as seals.

Data from the Weaber-Horn \#1 well, the closest well that fully penetrates the Mt. Simon with geophysical porosity logs, were used to provide data on the expected rock properties in the Mt. Simon at the Mattoon Site. The Weaber-Horn \#1 well is located approximately 36 miles southwest of the Mattoon Site, in Louden Oil Field, Fayette County, Illinois. Grid spacing in the vertical direction for the reservoir corresponded to the normalized layering from the interpreted Weaber-Horn \#1 well, where the 1,500-ft interval of Mt. Simon in the Weaber-Horn well was normalized to the expected 1,643-ft thickness of the Mt. Simon at the Mattoon Site.

Log data from the Weaber-Horn \#1 Well, reported in 0.5-ft intervals, were grouped into 53 model layers based on analysis of the sonic porosity log. The modeling domain was discretized using a two-dimensional (2D) radially symmetric grid with 60 radial nodes and 63 vertical nodes. The Mt. Simon reservoir is represented in the model by 53 vertical nodes and the overlying and underlying seals were each represented by five vertical nodes. The overlying and underlying seals were included in the simulation domain to allow for energy transfer out of the reservoir as $\mathrm{CO}_{2}$ is injected at a lower temperature than that of the formation. The computational domain was designed to simulate the radial and vertical migration of the injected $\mathrm{CO}_{2}$ from a central well. The radial domain extended from the well casing $4.81 \mathrm{in}$. $(0.12 \mathrm{~m})$ to $16,404.2 \mathrm{ft}(5000 \mathrm{~m})$, using a geometrically radially increasing grid spacing with a 3.28-ft (1-m) grid spacing adjacent to the well casing.

Only the vertical distributions of estimated porosity and intrinsic permeability were available for the Weaber-Horn \#1 well; therefore, a layered lithology with no horizontal heterogeneity was assumed for distribution of rock properties within the reservoir. The STOMP-CO assigns hydrologic properties to grid cells either by specifying a distribution of rock/soil types across the domain and then assigning properties to the specified rock/soil types, or direct specification for every grid cell. For the Mattoon Site, 53 rock types were specified for the model layers in the Mt. Simon. Porosity data for the 53 model layers were computed from the Weaber-Horn \#1 well logs. Permeability values for each layer were estimated from the average porosity data using the following correlation, established by the Illinois State Geologic Survey (Appendix, Mattoon Subsurface Data package submitted by ISGS, 1_1_3_ReservoirGeology_Mattoon.doc, 1_2_3_pressure_resvr_mattoon.doc, 1_2_4_temp_resvr_mattoon.doc, 1_2_7_perm_resvr_mattoon.doc, 1_2_8_Pc_Manlove_Hazen_5.pdf):

$$
\log k=0.268 \varphi-2.08
$$

where:

$$
\begin{aligned}
& \mathrm{k}=\text { permeability } \\
& \varphi=\text { porosity (expressed as percent) }
\end{aligned}
$$

Relative permeability-saturation-capillary pressure function parameters (k-s-P parameters) were derived from mercury injection data for four core samples from the Hazen \#5 Well in the Manlove field. Parameters for the k-s-P functions were assigned to the 53 rock types using 
porosity binning over the four core data. A summary of the hydrologic properties specified for the Mattoon Site rock types is provided in Table 5-1.

Initial conditions for the Mattoon Site simulations were determined from the injection reservoir depth, hydrostatic pressure gradients, geothermal temperature gradients, temperature datums, and salinity data provided by the ISGS (Appendix, Mattoon Subsurface Data package submitted by ISGS, 1_1_3_ReservoirGeology_Mattoon.doc, 1_2_3_pressure_resvr_mattoon.doc, 1_2_4_temp_resvr_mattoon.doc, 1_2_7_perm_resvr_mattoon.doc, 1_2_8_Pc_Manlove_Hazen_5.pdf). The hydrostatic pressure gradient and reservoir depth suggested by the ISGS were used to establish a reference pressure in the sequestration reservoir, but the initial pressure gradient within the reservoir was determined from the density of the reservoir fluids for the initial pressure, temperature, and salinity conditions by the STOMP- $\mathrm{CO}_{2} \mathrm{e}$ simulator. The upper and lower boundaries of the computational domain for the Mattoon Site were assumed to be impermeable. The outer radial boundary was assumed to be under hydrostatic conditions in equilibrium with the initial conditions. A summary of the initial conditions for the Mattoon Site is provided in Table 5-2.

Table 5-1. Summary of Hydrologic Properties for the Mt. Simon

\begin{tabular}{|l|l|l|l|l|}
\hline \multicolumn{1}{|c|}{ Parameter, Units } & \multicolumn{1}{|c|}{ Average } & Minimum & Maximum & $\begin{array}{l}\text { Standard } \\
\text { Deviation }\end{array}$ \\
\hline Diffusive Porosity & 0.131 & 0.063 & 0.234 & 0.042 \\
\hline Total Porosity & 0.131 & 0.063 & 0.234 & 0.042 \\
\hline Rock Compressibility, $1 / \mathrm{Pa}$ & $9.72 \times 10^{-10}$ & & & \\
\hline Intrinsic Permeability, $\mathrm{mD}$ & 161.36 & 0.405 & 2600 & 398.5 \\
\hline Brooks and Corey $\psi, \mathrm{cm}$ & 213.025 & 71.00 & 289.8 & 98.76 \\
\hline Brooks and Corey $\lambda$ & 0.833 & 0.621 & 1.353 & 0.250 \\
\hline Brooks and Corey $\mathrm{s}_{\mathrm{r}}$ & 0.066 & 0.044 & 0.081 & 0.011 \\
\hline Burdine Aqueous $\lambda$ & 0.833 & 0.621 & 1.353 & 0.250 \\
\hline Burdine Gas $\lambda$ & 0.833 & 0.621 & 1.353 & 0.250 \\
\hline Longitudinal Dispersivity, $\mathrm{m}$ & 0.0 & & & \\
\hline Transverse Dispersivity, $\mathrm{m}$ & 0.0 & & & \\
\hline
\end{tabular}

Table 5-2. Summary of Initial Conditions

\begin{tabular}{|l|l|l|}
\hline \multicolumn{1}{|c|}{ Parameter } & \multicolumn{1}{c|}{ English } & \multicolumn{1}{c|}{ SI } \\
\hline Reservoir Bottom Temperature & $152.91^{\circ} \mathrm{F}$ & $67.17^{\circ} \mathrm{C}$ \\
\hline Reservoir Temperature Gradient & $-0.01^{\circ} \mathrm{F} / \mathrm{ft}$ & $-0.018^{\circ} \mathrm{C} / \mathrm{m}$ \\
\hline Aqueous Saturation & 1.0 & 1.0 \\
\hline Reservoir Bottom Pressure & $4041.6 \mathrm{psi}$ & $27.9 \mathrm{MPa}$ \\
\hline Reservoir Pressure Gradient & $-0.47 \mathrm{psi} / \mathrm{ft}$ & $0.011 \mathrm{MPa} / \mathrm{m}$ \\
\hline Salinity & $130,000 \mathrm{ppm}$ & $130,000 \mathrm{ppm}$ \\
\hline
\end{tabular}

\subsubsection{Simulation Results}

Numerical simulations of $\mathrm{CO}_{2}$ injection and redistribution were conducted under the following scenario. The scenario, referred to as the Plant-Lifetime Injection Scenario, involved the injection of $50 \mathrm{MMT}$ of $\mathrm{CO}_{2}$ at a continuous rate of $0.006312 \mathrm{MMT} /$ day $(6,312$ metric ton (MT) 
per day) ( 1.95 MMT/yr). Under this scenario, $\mathrm{CO}_{2}$ was injected for approximately 25.6 years and then allowed to redistribute in the reservoir, until the simulation concluded at 50 years.

The $\mathrm{CO}_{2}$ injection was not over the entire Mt. Simon, but confined to a high permeability interval deep in the Mt. Simon, based on analogy with the Weaber-Horn \#1 well. Limiting the injection to this deeper zone would tend to increase the amount of time before appreciable amounts of $\mathrm{CO}_{2}$ migrate to the top of the Mt. Simon, directly below the Eau Claire seal, and would tend to reduce the pressure exerted by the $\mathrm{CO}_{2}$ on the seal. The injection zone included three of the 53 layers in the Mt. Simon and was $260 \mathrm{ft}$ thick, with an estimated top of 8,698 $\mathrm{ft}$ and a base of $8,958 \mathrm{ft}$, just $38 \mathrm{ft}$ above the base of the Mt. Simon. The estimated porosity and permeability in this lower zone were more than sufficient for injection of the stream of $\mathrm{CO}_{2}$ anticipated over the life of the power plant.

Plume radii were calculated by integrating the mass of $\mathrm{CO}_{2}$ over the total numerical grid domain and setting the radius at the radial distance from the injection well where $95 \%$ of the $\mathrm{CO}_{2}$ mass was contained. The $95 \%$ cutoff was used to ensure that the reported plume radii represent the bulk of the injected $\mathrm{CO}_{2}$. Thin high-permeability zones (stringer layers) interpreted from well log data result in thin layers of $\mathrm{CO}_{2}$ that advance ahead of the main plume. These stringers account for a very small fraction of the injected $\mathrm{CO}_{2}$ and neither their extent nor their actual presence is known. Hence, use of the $95 \%$ cutoff prevented these structures from dominating the plume radius calculations and giving an unrealistically high spatial resolution interpretation of the plume radii that is not justified by the quality of the available reservoir data. Plume radii are presented for selected years in Table 5-3. The modeling results show that the plume, as defined by $95 \%$ of the $\mathrm{CO}_{2}$ mass, will remain well within the AOR.

Table 5-3. Plume Radii (miles) for Modeled Injection Scenario at Selected Times

\begin{tabular}{|c|c|c|}
\hline $\begin{array}{c}\text { Time } \\
\text { (years) }\end{array}$ & $\begin{array}{c}\text { Radius } \\
\text { (feet) }\end{array}$ & $\begin{array}{c}\text { Radius } \\
\text { (miles) }\end{array}$ \\
\hline 5 & 2,237 & 0.42 \\
\hline 10 & 2,831 & 0.54 \\
\hline 20 & 3,303 & 0.63 \\
\hline 50 & 4,251 & 0.81 \\
\hline
\end{tabular}

To visually understand the development of the pure-phase plume of injected $\mathrm{CO}_{2}$, including the potential role of high permeability stringers, a sequence of color-scale profiles of the gas saturation is shown in Figure 5-2. In the injection scenario used in the modeling, $\mathrm{CO}_{2}$ injection halted after 25.6 years and the images in Figure 5-2 show dominantly radial plume growth during the injection period. Between 20 and 50 years, buoyancy effects dominate and the purephase plume movement is primarily vertical. The total plume volume decreases during this period with increasing dissolution of $\mathrm{CO}_{2}$ into the aqueous phase. The modeling results in Figure 5-2 show that, even after 50 years, the $\mathrm{CO}_{2}$ mass present in the high permeability stringers remains well within the fixed 2.5 mile $(13,200 \mathrm{ft})$ radius for the AOR. This is the same conclusion reached for the radius estimated from the $95 \%$ mass calculation. 

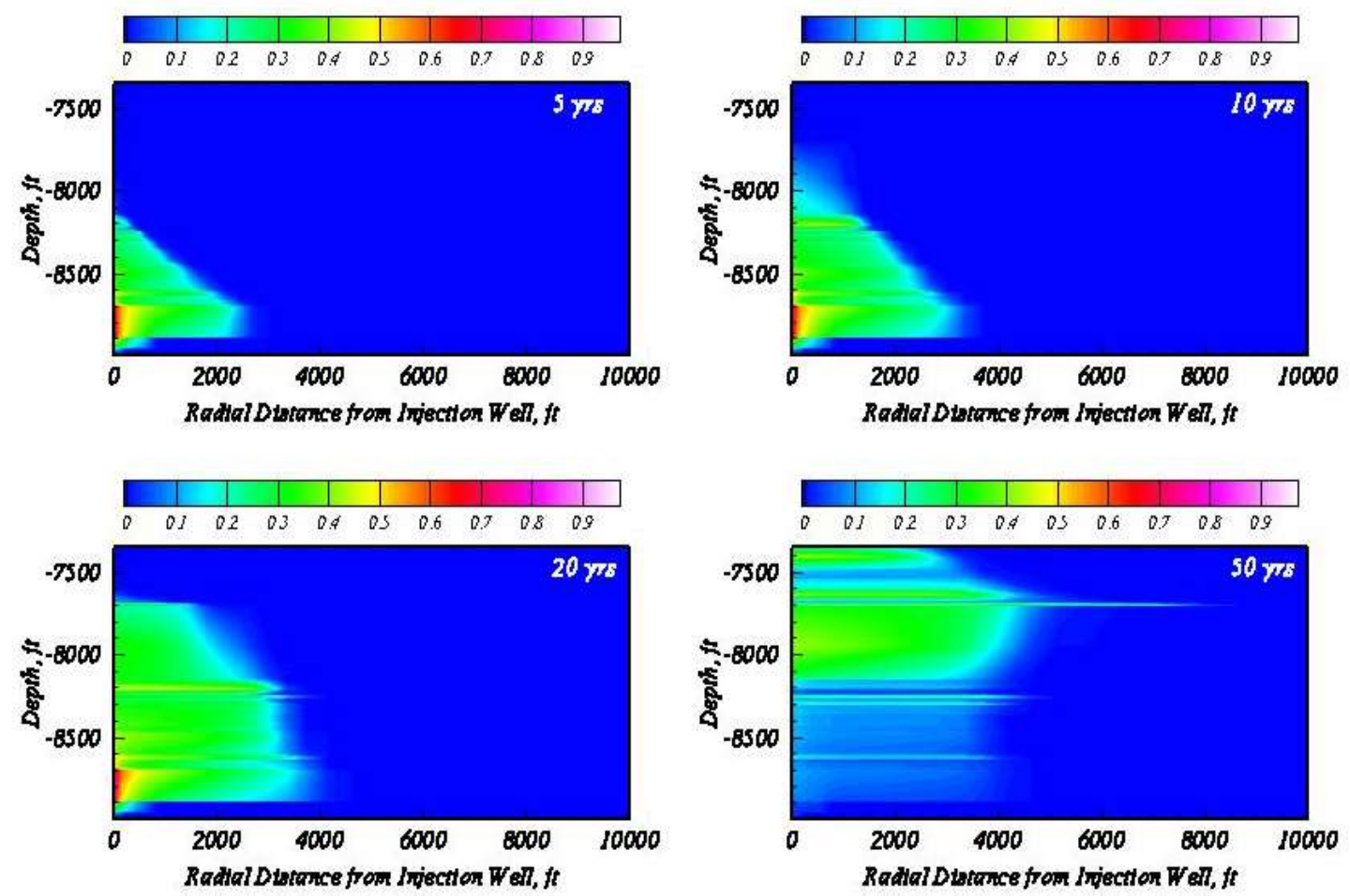

Figure 5-2. Gas-Phase Saturation Profiles at 5, 10, 20, and 50 Years for the Modeled Injection Scenario (Injection of 50 MMT over 25.6 years.)

The bottom right figure illustrates how the $\mathrm{CO}_{2}$ plume relaxes (vertically and horizontally) under the influence of buoyancy after injection stops. Considerable immobile residual gas is trapped in the deepest part of the Mt. Simon formation as the plume relaxes.

\subsection{Wells Within the Area of Review}

\subsubsection{Tabulation of Well Data Required by $730.114(a)(3)$ or $730.134(a)(3)$}

Section 730.114(a)(3) requires "A tabulation of data on all wells within the area of review that penetrate into the proposed injection zone. Such data shall include a description of each well's type, construction, date drilled, location, depth, record of plugging or completion, and any additional information the Agency may require."

Section $730.134(a)(3)$ requires, "A tabulation of data reasonably available from public records or otherwise known to the applicant on wells within the area of review included on the map required under paragraph (a)(2) which penetrate the proposed injection zone. Such data shall include a description of each well's type, construction, date drilled, location, depth, record of plugging and completion, and any additional information the Agency may require. In cases where the information would be repetitive and the wells are of similar age, type and construction the Agency may elect to only require data on a representative number of wells."

Per the above requirements a tabulation of data was compiled from the ISGS WATER database, the ISGS OIL database and the ISWS on all of the known wells located within the $2 \frac{1}{2}$ mile AOR. A total of 348 wells are located within the $2 \frac{1}{2}$ mile AOR. The most common types of wells are oil wells (164 of 348) and water supply wells (51 of 348 wells) (refer to Appendix 5-1). All of the water supply wells have a depth of less than $425 \mathrm{ft}$. Other wells include dry and/or 
abandoned wells, gas wells, test holes, engineering test holes, stratigraphic test holes, monitoring wells, brine wells and unknown well types.

\subsubsection{Number of Wells Within 2 $1 / 2$ Miles of Injection Well Penetrating Within 300 Feet of the Uppermost Injection Zone}

Upon reviewing the well logs available through ISGS, it was found that there are no unplugged wells within the $2 \frac{1}{2}$ mile AOR that penetrate deeper than 3,300 ft. The deepest unplugged well located in the AOR, is a gas well (API \# 120290063201) that is at a depth of 3,254 ft, and approximately 2.8 miles from the injection site. The term unplugged indicates that there are no affidavits showing the well was properly plugged and abandoned. The deepest plugged well is a dry and abandoned well that is $3,585 \mathrm{ft}$ deep, and approximately 0.7 miles from the injection site. The depth of the injection well is expected to be more than $3,000 \mathrm{ft}$ below the maximum depth of known wells.

\subsubsection{Properly Plugged and Abandoned}

There are no plugged or abandoned wells within $2 \frac{1}{2}$ miles of the injection well that penetrate within $300 \mathrm{ft}$ of the uppermost injection zone.

\subsubsection{Temporarily Abandoned}

There are no temporarily abandoned wells within $2 \frac{1}{2}$ miles of the injection well that penetrate within $300 \mathrm{ft}$ of the uppermost injection zone.

\subsubsection{Operating}

There are no operating wells within $2 \frac{1}{2}$ miles of the injection well that penetrate within $300 \mathrm{ft}$ of the uppermost injection zone.

\subsubsection{Improperly Sealed, Completed, or Abandoned}

There are no improperly sealed, completed or abandoned wells within $2 \frac{1}{2}$ miles of the injection well that penetrate within $300 \mathrm{ft}$ of the uppermost injection zone.

Therefore, there are no wells in the $2 \frac{1}{2}$ mile area of review expected to penetrate within $300 \mathrm{ft}$ of the uppermost injection zone.

\subsubsection{Plugging Affidavits for All Plugged Wells}

Plugging affidavits were obtained from the ISGS office and are included as Appendix 5-2. The well plugging information was included in the well data tabulation per 730.134(a)(3).

\subsubsection{Proposed Corrective Action for Unplugged Wells Penetrating the Injection Zone}

No wells have been found to penetrate within $300 \mathrm{ft}$ of the uppermost injection zone necessitating corrective action, per 730.114(14).

\subsection{References}

Appendix, Mattoon Subsurface Data package submitted by Illinois State Geological Survey,

1_1_3_ReservoirGeology_Mattoon.doc, 1_2_3_pressure_resvr_mattoon.doc,

1_2_4_temp_resvr_mattoon.doc, 1_2_7_perm_resvr_mattoon.doc,

1_2_8_Pc_Manlove_Hazen_5.pdf 
White, M.D. and M. Oostrom. 2000. STOMP - Subsurface Transport over Multiple Phases Version 2.0, Theory Guide. PNNL-12030, Pacific Northwest National Laboratory, Richland, Washington.

White, M.D. and M. Oostrom. 2006. STOMP Subsurface Transport over Multiple Phases, Version 4.0, User's Guide. PNNL-15782, Pacific Northwest National Laboratory, Richland, Washington. 


\title{
DRAFT UIC PERMIT FORMS
}

\author{
ILLINOIS ENVIRONMENTAL PROTECTION AGENCY \\ UNDERGROUND INJECTION CONTROL PERMIT APPLICATION
}

FORM 4e - MONITORING INTEGRITY TESTING and CONTINGENCY PLAN

\author{
USEPA ID NUMBER_not applicable \\ IEPA ID NUMBER 0290255208 \\ WELL NUMBER FutGen-INJ-1 and FutGEN-INJ-2
}

Location in Application

$6.1 \quad$ I. Waste Sampling and Analysis

6.1.1 A. Sampling frequency

6.1.2 B. Analysis parameters

6.1.3 C. Sampling location

6.1.4 D. Detailed waste analysis plan

6.2 II. Monitoring Program

6.2.1 A. Recording devices, see instructions

6.2.1.1 1 . Injection pressure gauges

6.2.1.2 2. Casing-tubing annulus pressure gauges

6.2.1.3 3. Flow meters

6.2 .1 .4

6.2 .1 .5

6.2 .2

-6.2.2.1

6.2 .2 .2

6.2 .2 .3

6.2.2.4

6.2 .2 .5

6.2 .2 .6

6.2 .3

6.3 III. Mechanical Integrity Tests During Service Life of Well, see instructions

-6.4 IV. Contingency Plan for Well Failure or Shut In, see instructions

6.4 A. Detailed contingency plan

6.5 B. Corrosion Monitoring Plan (this section is not part of Form 4e, - but was added at the request of I. EPA).

\section{CERTIFICATION}

I certify under penalty of law that this document and all attachments were prepared under my direction or supervision in accordance with a system designed to assure that qualified personnel properly gather and evaluate the information submitted. Based on my inquiry of the person or persons who manage the system, or those persons directly responsible for gathering the information, the information submitted is, to the best of my knowledge and belief, true, accurate and complete. I am aware that there are significant penalties for submitting false information, including the possibility of fine and imprisonment for knowing violations.

Name \& Official Title

Signature
Phone Number

Date Signed

Note: per direction from the Illinois EPA, a signature is not required on this form. 


\section{MONITORING, INTEGRITY TESTING, AND CONTINGENCY PLAN (Form 4e)}

\subsection{Waste Sampling and Analysis}

\subsubsection{Sampling Frequency}

Samples of the $\mathrm{CO}_{2}$ stream will be collected quarterly for chemical analyses.

\subsubsection{Analysis Parameters}

Table 6-1 presents parameters to be analyzed in the $\mathrm{CO}_{2}$ stream. The list of parameters was developed based on the anticipated composition of the $\mathrm{CO}_{2}$ stream at the sampling location. Gas concentration analyses will be done by Atlantic Analytical Laboratory, Inc. (Whitehouse, New Jersey) or a laboratory with similar capabilities. Atlantic Analytical specializes in gas analyses and routinely performs specialized analyses on $\mathrm{CO}_{2}$ for industrial clients.

Table 6-1. Analytes to be Measured in the $\mathrm{CO}_{2}$ Stream

\begin{tabular}{|c|c|c|c|c|}
\hline Constituent & Rational & Analytical Method & Laboratory & Frequency $^{\text {(a) }}$ \\
\hline $\mathrm{N}_{2}$ & $\begin{array}{l}\text { Minor constituent of } \mathrm{CO}_{2} \\
\text { stream }\end{array}$ & Mass Spectrometry & $\begin{array}{c}\text { Atlantic } \\
\text { Analytical }\end{array}$ & Quarterly \\
\hline $\mathrm{O}_{2}$ & $\begin{array}{l}\text { Indicator of atmospheric } \\
\text { contamination }\end{array}$ & Mass Spectrometry & $\begin{array}{c}\text { Atlantic } \\
\text { Analytical }\end{array}$ & Quarterly \\
\hline $\mathrm{Ar}$ & $\begin{array}{l}\text { Minor constituent of } \mathrm{CO}_{2} \\
\text { stream }\end{array}$ & Mass Spectrometry & $\begin{array}{c}\text { Atlantic } \\
\text { Analytical }\end{array}$ & Quarterly \\
\hline $\mathrm{He}$ & $\begin{array}{l}\text { Indicator of insufficient } \\
\text { cylinder purging }\end{array}$ & Mass Spectrometry & $\begin{array}{c}\text { Atlantic } \\
\text { Analytical }\end{array}$ & Quarterly \\
\hline $\mathrm{H}_{2}$ & $\begin{array}{l}\text { Minor constituent of } \mathrm{CO}_{2} \\
\text { stream }\end{array}$ & Mass Spectrometry & $\begin{array}{c}\text { Atlantic } \\
\text { Analytical }\end{array}$ & Quarterly \\
\hline $\mathrm{CO}$ & $\begin{array}{l}\text { Minor constituent of } \mathrm{CO}_{2} \\
\text { stream }\end{array}$ & Gas chromatography & $\begin{array}{c}\text { Atlantic } \\
\text { Analytical }\end{array}$ & Quarterly \\
\hline $\mathrm{CH}_{4}$ & $\begin{array}{l}\text { Minor constituent of } \mathrm{CO}_{2} \\
\text { stream }\end{array}$ & Gas chromatography & $\begin{array}{c}\text { Atlantic } \\
\text { Analytical }\end{array}$ & Quarterly \\
\hline $\mathrm{CO}_{2}$ & $\begin{array}{l}\text { Major constituent of } \mathrm{CO}_{2} \\
\text { stream }\end{array}$ & $\begin{array}{l}\text { Orsat Analysis / } \\
\text { Calculation by Difference }\end{array}$ & $\begin{array}{c}\text { Atlantic } \\
\text { Analytical }\end{array}$ & Quarterly \\
\hline $\begin{array}{l}\text { Volatile Sulfur } \\
\text { Compounds }\end{array}$ & $\begin{array}{l}\text { Detection of minor sulfur } \\
\text { constituents }\left(\mathrm{H}_{2} \mathrm{~S}, \mathrm{COS}\right)\end{array}$ & $\begin{array}{l}\text { Gas chromatography, } \\
\text { Sulfur Chemo- } \\
\text { luminescence Detector }\end{array}$ & $\begin{array}{c}\text { Atlantic } \\
\text { Analytical }\end{array}$ & Quarterly \\
\hline Water Vapor & $\begin{array}{l}\text { Minor constituent of } \mathrm{CO}_{2} \\
\text { stream }\end{array}$ & Electrolytic Hygrometry & $\begin{array}{c}\text { Atlantic } \\
\text { Analytical }\end{array}$ & Quarterly \\
\hline
\end{tabular}

(a) Additional analyses will be performed if coal type changes.

\subsubsection{Sampling Location}

Samples of the $\mathrm{CO}_{2}$ stream will be collected at a location in the system where the material is representative of the material injected. The sampling location is on the contactor knockout drum within the TEG dehydration package, located within the $900 \mathrm{~A}$ (compression) area. This point is located just upstream of the $\mathrm{CO}_{2}$ compressor suction to minimize the potential of any liquid condensation in the pipeline. Thus, this stream is representative of the $\mathrm{CO}_{2}$ composition delivered to the injection wells, although at a lower pressure. Pressure at this point in the 
system is approximately 700 psia; therefore, the $\mathrm{CO}_{2}$ sample will be in a gas phase when it is collected. Physical characteristics of the vapor stream leaving the knockout drum are provided on Table 6-2; a material (chemical) balance for the vapor stream is provided in Table 6-3 and Table 6-4. The information on Table 6-2, Table 6-3, and Table 6-4 is an estimate based on a heat and material balance conducted for the power plant; therefore, actual properties and composition may vary slightly.

Table 6-2. Physical Characteristics of $\mathrm{CO}_{2}$ Stream 911 (Vapor Stream Leaving Knockout Drum)

\begin{tabular}{|l|c|r|r|}
\hline Parameter & \multicolumn{1}{|c|}{ Units } & \multicolumn{1}{|c|}{ ILL 6 $^{(\mathrm{a})}$} & \multicolumn{1}{|c|}{ ILL 6 $^{(\mathrm{b})}$} \\
\hline Temperature & ${ }^{\circ} \mathrm{F}$ & 101.8 & 102 \\
\hline Pressure & $\mathrm{psia}$ & 701.0 & 701 \\
\hline Mass Flow & $\mathrm{Ib} / \mathrm{hr}$ & 578,568 & 531,161 \\
\hline Mole Flow & $\mathrm{Ibmole} / \mathrm{hr}^{\prime}$ & 13,479 & 12,467 \\
\hline Volume Flow & $\mathrm{ft}^{3} / \mathrm{hr}$ & 89,923 & 83,872 \\
\hline Vapor Frac & & 1.000 & 1.000 \\
\hline Enthalpy & $\mathrm{mmbtu} / \mathrm{hr}$ & $-2,227$ & $-2,039$ \\
\hline Mass Enthalpy & $\mathrm{Btu} / \mathrm{lb}$ & $-3,849$ & $-3,840$ \\
\hline Density & $\mathrm{lb} / \mathrm{ft}^{3}$ & 6.434 & 6.333 \\
\hline Molecular Weight & & 42.92 & 42.61 \\
\hline Comp. Factor $(\mathrm{Z})$ & & 0.7762 & 0.7825 \\
\hline Viscosity & $\mathrm{cp}$ & 0.0179 & 0.0179 \\
\hline Thermal Cond. & $\mathrm{Btu} / \mathrm{hr}-\mathrm{ft}-\mathrm{R}$ & 0.0144 & 0.0148 \\
\hline CP/CV & & 1.2846 & 1.2856 \\
\hline Heat Capacity & $\mathrm{Btu} / \mathrm{lb}-\mathrm{R}$ & 0.3173 & 0.3147 \\
\hline
\end{tabular}

(a) Based on Gasifier Technology \#1

(b) Based on Gasifier Technology \#2

mmbtu - one million BTU

R - Rankine

\subsubsection{Detailed Waste Analysis Plan}

A sampling station consisting of a valve and a $1 / 4$ inch National Pipe Threads (NPT) fitting will be installed on the TEG knockout drum for the purpose of collecting gas samples. For gas concentration analyses, double-ended sample cylinders will be provided from Atlantic Analytical, Inc. (Figure 6-1). Specially-treated sulfur-inert cylinders are also available for quantification of low-level sulfur speciation ( $<1 \mathrm{ppm})$. Cylinders will be connected directly to the sampling station on the knockout drum and purged with sample gas at least five times prior to sample collection to remove laboratory-added helium gas and ensure a representative sample. During purging, the outlet of the sample cylinder will be connected to a ventilation line and all waste gas will be vented out of the building. A proper sampling technique is critical for any gas analysis program. Therefore, great care will be taken to ensure that the cylinder is not contaminated by atmospheric gas and the sample is representative of the gas in the knockout drum. To accomplish this, sampling procedures developed by Atlantic Analytical, Inc. will be closely followed (Figure 6-2). Although there is no maximum hold time for the analytes of interest listed in Table 6-1, samples will be shipped to the lab immediately after collection. Because the filled sample cylinders will be under pressure at approximately $700 \mathrm{psi}$, they will be shipped as hazardous material through a qualified ground courier (e.g., FedEx, UPS) with appropriate hazard labels. 
Table 6-3. Estimated Composition of CO2 Stream 911 (Vapor Stream Leaving Knockout Drum) - Gasifier Technology \#1

\begin{tabular}{|l|r|r|}
\hline \multicolumn{3}{|c|}{ ILL 6 } \\
\hline Constituent & \multicolumn{1}{|c|}{ Mass \% } & \multicolumn{1}{|c|}{ Mole \% } \\
\hline Nitrogen & 0.0587 & 0.0900 \\
\hline Argon & 0.0381 & 0.0409 \\
\hline Hydrogen & 0.1091 & 2.3234 \\
\hline Methane & 0.1139 & 0.3047 \\
\hline $\mathrm{CO}$ & 0.0307 & 0.0470 \\
\hline $\mathrm{CO}_{2}$ & 99.6385 & 97.1786 \\
\hline $\mathrm{H}_{2} \mathrm{~S}$ & 0.0016 & 0.0021 \\
\hline $\mathrm{COS}$ & 0.0048 & 0.0035 \\
\hline
\end{tabular}

Table 6-4. Estimated Composition of $\mathrm{CO}_{2}$ Stream 911 (Vapor Stream Leaving Knockout Drum) - Gasifier Technology \#2

\begin{tabular}{|l|r|r|}
\hline \multicolumn{3}{|c|}{ ILL 6 } \\
\hline Constituent & Mass \% & \multicolumn{1}{|c|}{ Mole \% } \\
\hline Nitrogen & 0.2635 & 0.4008 \\
\hline Argon & 0.0392 & 0.0418 \\
\hline Hydrogen & 0.1485 & 3.1380 \\
\hline Methane & 0.0003 & 0.0007 \\
\hline $\mathrm{CO}$ & 0.0719 & 0.1094 \\
\hline $\mathrm{CO}_{2}$ & 99.4640 & 96.2923 \\
\hline $\mathrm{H}_{2} \mathrm{~S}$ & 0.0027 & 0.0034 \\
\hline $\mathrm{COS}$ & 0.0053 & 0.0038 \\
\hline Water & 0.0041 & 0.0096 \\
\hline
\end{tabular}

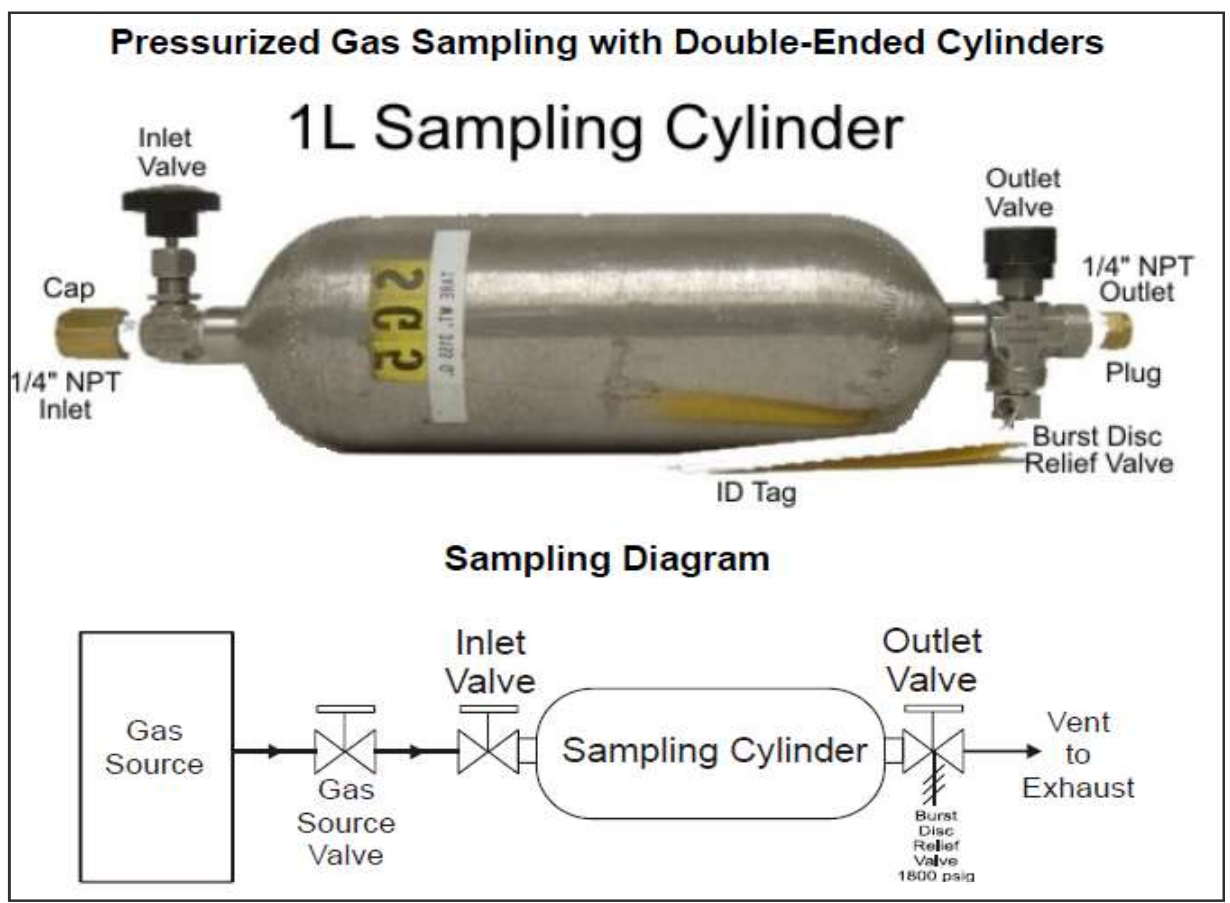

Figure 6-1. Double-Ended Sample Cylinder Provided by Atlantic Analytical Laboratory 
Introduction

Atlantic Analytical Laboratory (AAL) provides pre-cleaned and conditioned stainless steel and sulfur-inerted sampling cylinders as a convenience to our customers. Rental cylinders are available in a variety of sizes, including $75 \mathrm{cc}, 300 \mathrm{cc}, 500 \mathrm{cc}$, and 1 liter. All cylinders are DOT rated for $1,800 \mathrm{psig}$ service, and are equipped with a burst-disc type relief valve set to approximately this pressure. All cylinders are dual ended, with $1 / 4^{\prime \prime}$ NPT valve port fittings. Cylinders are normally shipped with approximately $10 \mathrm{psig}$ UHP grade helium backfill gas to prevent atmospheric contamination during shipment. Cylinders can be shipped under vacuum upon request.

$\underline{\text { Safety }}$

Before sampling, review all MSDS information related to the gases present. Always wear safety glasses, protective gloves, and other necessary safety equipment. Sampling cylinders are only to be used by personnel trained in handling pressurized gases. For safety, always assume any cylinder or gas line contains the maximum amount of pressure possible in the system. Whenever possible, ensure that the sampling cylinder outlet port is attached to an appropriate vent line to avoid a potentially hazardous buildup of the gas being sampled, especially for oxygen and flammable gases. Refer to the back of this page for a diagram of a typical sampling setup.

$>$ DO NOT sample toxic, corrosive, pyrophoric, or extremely reactive gases with these cylinders.

> DO NOT sample cryogenic or liquefied gases using these instructions; instead, refer to separate instructions available from AAL for proper sampling techniques for these gases.

> DO NOT EXCEED the MAXIMUM 1,800 PSIG fill pressure. If the relief valve burst disc ruptures, the cylinder cannot be used for sampling - retum to AAL immediately for repairs, cleaning, and recertification.

Equipment

Sampling cylinder, $1 / 4^{\prime \prime}$ NPT brass end cap, $1 / 4^{\prime \prime}$ NPT brass plug, ID tag.

\section{Sampling Procedure}

1) Remove the brass cylinder end cap and plug and store them in a clean, secure location.

2) Loosely connect the inlet valve of the sampling cylinder to the gas source valve.

3) Carefully open the gas source valve and purge the connecting fittings of air - then tighten these fittings. Keep the gas source valve open until step 11 .

4) Carefully open the cylinder inlet valve to allow the sample gas to fill the cylinder.

5) Close the cylinder inlet valve. Do not over tighten, as this may damage the valve seat and cause leakage.

6) Open the cylinder outlet valve, and allow a majority the cylinder gas to vent. DO NOT blow down completely to atmospheric pressure, as this may cause outside contaminants to diffuse into the cylinder.

7) Close the cylinder outlet valve.

8) Repeat steps $4-7$ a minimum of 5 times to ensure the cylinder has been purged of all fill gas and conditioned with the sample gas.

9) Open the cylinder inlet valve and partially open the cylinder outlet valve to allow the sample gas to flow through the cylinder for at least 2 minutes.

10) Close the cylinder outlet valve and wait at least 30 seconds for the cylinder to fully pressurize.

11) Close both the cylinder inlet and gas source valves - then carefully disconnect the cylinder. Beware of excess gas pressure trapped between the two valves which may release suddenly when disconnecting the cylinder.

12) Apply new tefion tape to the NPT threads on the inlet valve of the cylinder and the brass outlet plug and securely cap both ends of the cylinder. DO NOT over tighten fittings or thread damage may result.

13) Record all sample data on the cylinder ID tag - please do not affix labels to the cylinder body.

14) Package the cylinder in a DOT/ATA approved shipping box or container and insert a completed AAL "Analytical Testing Request" form. Follow all applicable shipping regulations including affixing the proper sample UN designation, shipping name, hazard labels, and identification of the sample contents on all courier paperwork.

15) Ship the sample to AAL via an express air (if eligible) or qualified ground courier as soon as possible.

Figure 6-2. Atlantic Analytical Gas Sampling Instruction Sheet

\subsection{Monitoring Program}

This section describes the pressure, temperature and flow monitoring that will be conducted on the injection well(s). Other types of monitoring, for example monitoring the $\mathrm{CO}_{2}$ injection stream and USWD monitoring, are described elsewhere in this document. 


\subsubsection{Recording Devices}

Recording devices will be used to monitor injection parameters including $\mathrm{CO}_{2}$ injection rate, temperature, and pressure. In addition, bottomhole pressure and temperature and annular pressure will be monitored using instruments affixed to the injection well.

\subsubsection{Injection Pressure Gauges}

The injection well will continuously monitor and record the pressure and temperature of the $\mathrm{CO}_{2}$ as it enters the well. A pressure transmitter (Foxboro I/A Series ${ }^{\circledR}$ Electronic Pressure Transmitter [or similar] with 4 to $20 \mathrm{~mA}$ analog output and maximum pressure rating of 4,500 psi) and a temperature transmitter (Foxboro I/A Series ${ }^{\circledR}$ Intelligent Temperature Transmitter Model RTT20 [or equivalent] with 4 to $20 \mathrm{~mA}$ analog output sensor/transmitters and a maximum temperature rating of $85^{\circ} \mathrm{F}$ ) will be located on the $\mathrm{CO}_{2}$ pipeline at the wellhead. The gauge specifications are included in Appendix 6-1; if a similar gauge is used, it will be sized to ensure that the maximum ratings are $20 \%$ greater than the maximum anticipated operating parameters.

Each sensor/transmitter will be connected to an RTU (Weatherford CS7X- Well Site Management System [or similar]) that will be housed in the WMMS building, located approximately $100 \mathrm{ft}$ from the injection wells. The RTU will allow temperature and pressure, along with other monitored parameters, at each well to be viewed in real time. The temperature and pressure transmitters will also be connected to the Plant Control Center via a PLC in the WMMS building so that these parameters can be monitored by the plant operators in real time. Data can be retrieved from the RTU via cable download or from the data historian located in the Plant Control Center.

Pressure will also be continuously monitored in/near the bottom of the well using a pressure transmitter placed in the tubing either just above the packer or below the packer. The pressure transmitters will include a temperature sensor/transmitter; therefore, bottomhole pressure and temperature data will be collected concurrently. Bottomhole pressure and temperature will be monitored using real-time surface readout instrumentation. These instruments do not have to be removed from the well to retrieve the data because they are connected to a surface controller with display capabilities via a downhole cable. These arrangements are illustrated in Figure 6-3.

The type of sensor/transmitter that will be used in the injection wells is the Weatherford $\mathrm{mPOD}^{\mathrm{TM}} 2+$ multi-point digital pressure/temperature sensor/transmitter (or similar), which is a pizeoresistive, silicon on insulator (SOI) type instrument (specifications included in Appendix 61). The sensor/transmitters will be constructed of stainless steel and have a pressure rating of $7,500 \mathrm{psi}$, an accuracy of $0.075 \%$ of full scale (typically $0.05 \%$ ) and a resolution of $0.002 \%$. The temperature sensor/transmitter is rated to $59^{\circ}$ to $257^{\circ} \mathrm{F}$, with an accuracy of $\pm 1.8^{\circ} \mathrm{F}$ and a resolution of $0.1^{\circ} \mathrm{F}$. The bottomhole pressure/temperature transmitter will be connected to the Weatherford CS7X - Well Site Management System (or similar) RTU that will be located in the WMMS building so that data can be viewed in real time. Data will also be logged at this RTU and can be retrieved at this location at any time. As with the surface pressure/temperature transmitter, the bottomhole pressure/temperature transmitter will also be connected to the Plant Control Center via a PLC in the WMMS building so that these parameters can be monitored by the plant operators in real time. 

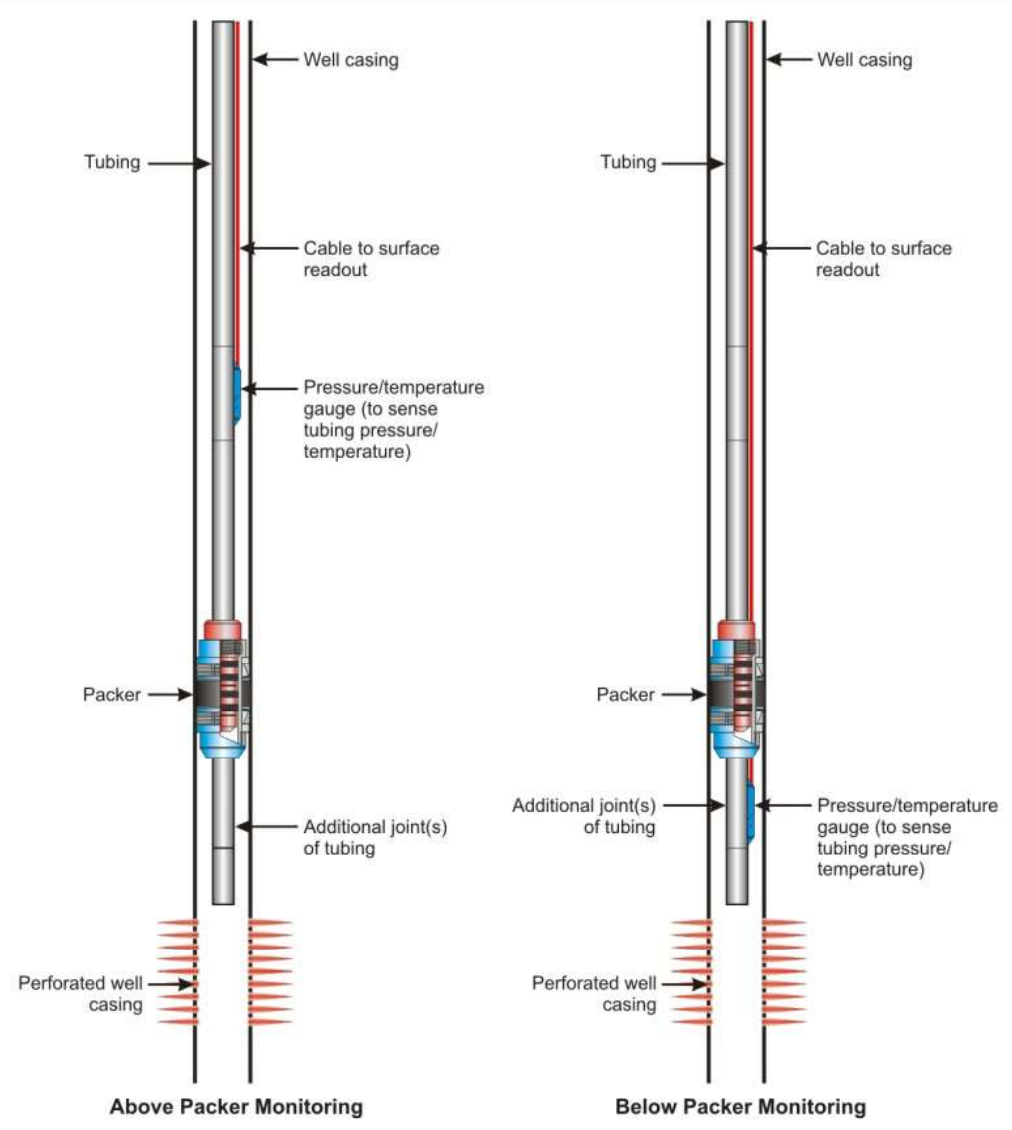

Figure 6-3. Illustration of Bottomhole Monitoring Installations

Injection pressure is one of the key parameters that will be used to initiate automatic shutdown of $\mathrm{CO}_{2}$ injection if the pressure exceeds the maximum allowable injection pressure specified in the UIC permit. Control logic will be developed so that $\mathrm{CO}_{2}$ injection can be halted if surface (injection) pressure or bottomhole pressure exceeds allowable limits.

\subsubsection{Casing-Tubing Annular Pressure Gauges}

Annular pressure (i.e., pressure of the annular fluid between the injection tubing and the longstring casing) will be continuously measured using a pressure transmitter (Foxboro I/A Series ${ }^{\circledR}$ [or similar] Electronic Pressure Transmitter with 4 to 20 milliampere $(\mathrm{mA})$ analog output and maximum pressure rating of $4,500 \mathrm{psi}$ ) installed on the wellhead. As with the other monitoring instrumentation on/in the well, the annulus pressure transmitter will be connected to the Weatherford CS7X - Well Site Management System [or similar] RTU that will be located in the WMMS building. It will also be connected to the Plant Control Center via a PLC in the WMMS building so that these parameters can be monitored by the plant operators in real time. Annular pressure data will be electronically stored by the Real Time Data Base (RTDB) system for retrieval and analysis.

Control logic will be put in place that will trigger alarms and/or halt $\mathrm{CO}_{2}$ injection if annulur pressure suggests failure of internal mechanical integrity (e.g., tubing leak). Flow can be halted automatically by closing the flow valve to the well and the master valves on the well. Each 
injection well will be equipped with two actuated master valves that can be operated remotely from the Control Center.

\subsubsection{Flow Meters}

The pipeline will have a backpressure control valve at the compressor outlet that can also be used as an isolation valve if necessary. The pipeline will be buried until it reaches the injection wells.

If a second injection well is drilled, the pipeline will have a branch tee near the backup injection well. The pipeline sections downstream from the tee will be the same size and material as the main pipeline (12 inch API X65 steel). Each branch line will have a flow control valve and an on/off isolation valve on the wellhead. The isolation valves are remote-controlled valves that can automatically isolate the wellheads if necessary. The flow control valves can be used to control flow if both wells are in use. This would not be normal operation and will likely only be used when switching flow between injection wells (i.e., when one well is taken off-line for inspection and the other well is put into service so that plant operation will not be impacted). Refer to the process flow diagrams in Section 4 (Figure 4-5 and Figure 4-6) for valve and instrument placements.

Several instruments will be used to monitor the pipeline and well operations. Temperature and pressure are measured at the outlet of the final compressor stage, the flowmeter will be located on the pipeline, between the outlet of the compression unit and before the wellhead. The flowrate and density will be continuously measured by a Preso Venturi Flowmeter (or similar), rated to measure $776,648 \mathrm{lb} / \mathrm{hr}$ and data stored on the RTDB system (specifications included in Appendix 6-1). A corrosion monitor will also be installed on the pipeline.

\subsubsection{4 pH Recording Devices}

Because the injection fluid is non-aqueous, it has no $\mathrm{pH}$. Thus, $\mathrm{pH}$ cannot be determined.

\subsubsection{Temperature}

As described in Section 6.2.1.1, the injection well will be instrumented to continuously monitor and record the pressure and temperature of the $\mathrm{CO}_{2}$ as it enters the well. This will be accomplished with a temperature transmitter (Foxboro I/A Series ${ }^{\circledR}$ Intelligent Temperature Transmitter Model RTT20 [or equivalent] with 4 to $20 \mathrm{~mA}$ analog output) located on the $\mathrm{CO}_{2}$ pipeline where it connects to the wellhead.

In addition to monitoring injection temperature, bottomhole temperature will also be monitored in the injection well.

\subsubsection{USDW Monitoring in Area of Review}

\subsubsection{Number of Wells}

Four groundwater monitoring wells will be installed to monitor the USDW aquifer in the vicinity of the $\mathrm{CO}_{2}$ injection well. If a second injection well is added, additional monitoring wells will be installed (at least 3). The wells will be constructed to monitor the interface of the bedrock and overlying unconsolidated glacial sediments (Figure 6-4a). A previous investigation by Patrick Engineering, Inc. (Environmental Information Volume, September 15, 2006) found fractured bedrock (Mattoon Formation) overlain by glacial sediments at approximately $85 \mathrm{ft}$ (boring B-1-M) in the southwest corner of the Mattoon site, though the depth to bedrock varies across the site. 
Patrick Engineering, Inc. did not find groundwater present at the bedrock contact in boring B-1$M$. If groundwater is not found at the bedrock interface, the wells will be screened in an alternate (deeper) zone (Figure 6-4b). As described in Section 2.7.2, there is no major shallow aquifer present, and the local USDW consists of Quaternary-aged glacially-deposited sand and gravel lenses and discontinuous layers of sand approximately 25 to $125 \mathrm{ft}$ bgs. The exact depths and placement of the monitoring wells will be determined based upon the results of exploratory borings conducted while drilling the boreholes for the monitoring wells.

\subsubsection{Type of Wells}

In November 2006, Patrick Engineering completed seven test soil borings at the site ranging from 30 to $90 \mathrm{ft}$ bgs (see Section 2.7.2.3). These borings, which terminated in the unconsolidated sediments overlying bedrock, were successfully completed using hollow-stem auger drilling. Therefore, monitoring wells will be installed using this technology unless they have to be drilled deeper (i.e., into bedrock). If the wells have to be completed in bedrock, they will be drilled with an appropriate technique (e.g., air or mud rotary).

Monitoring wells will be constructed with typical materials used for groundwater monitoring wells. Well screens will be constructed with 2-inch or 4-inch diameter slotted polyvinyl chloride (PVC) casing from the bottom of the boring to a height based on the monitoring interval identified by examining the core samples produced during drilling. A solid PVC riser casing will be used to complete the installation. Sand will be placed in the annular space around the screened interval up to approximately 2 feet above the top of the well screen interval. A bentonite seal at least $2 \mathrm{ft}$ in thickness will be emplaced directly above the sand filter pack. The remaining annular space around the solid portion of the PVC pipe will be backfilled with a cement $(95 \%)$ bentonite $(5 \%)$ slurry to approximately $4 \mathrm{ft}$ bgs. If the monitoring wells are completed in bedrock, a conductor casing set a short distance into bedrock will also be necessary to provide borehole stability and to prevent water in shallow unconsolidated sediments from flowing down the outside of the well casing and contaminating deeper groundwater. If necessary, a steel protective well cover with a locking flange will be placed over the PVC well casing and the remaining annulus will be filled with cement. Figure 6-4 shows typical well construction details for the USDW monitoring wells. All groundwater monitoring wells will be installed and eventually abandoned according to Illinois Department of Public Health regulations (Section 920.170 of the Illinois Water Well Construction Code: http://www.ilga.gov/commission/jcar/admincode/ 077/07700920sections.html).

\subsubsection{Frequency of Monitoring}

At least eight samples will be collected from each USDW monitoring well before $\mathrm{CO}_{2}$ injection begins in order to establish background concentrations for parameters of interest. During the four-year active injection period, the monitoring frequency will be quarterly for the full suite of parameters (see Section 6.2.3.2 for a detailed explanation of analytes). The sampling will continue semi-annually for at least 2 years after injection ceases. If, after two years, there is no evidence that there has been $\mathrm{CO}_{2}$ migration into the USDW and no operational disturbances that could cause leakage or migration, monitoring will be discontinued.

At this time, the total monitoring timeline is 7 to 8 years, including one to two years of preinjection monitoring, 4 years of monitoring during active injection, and 2 years of post-injection monitoring. 
A.

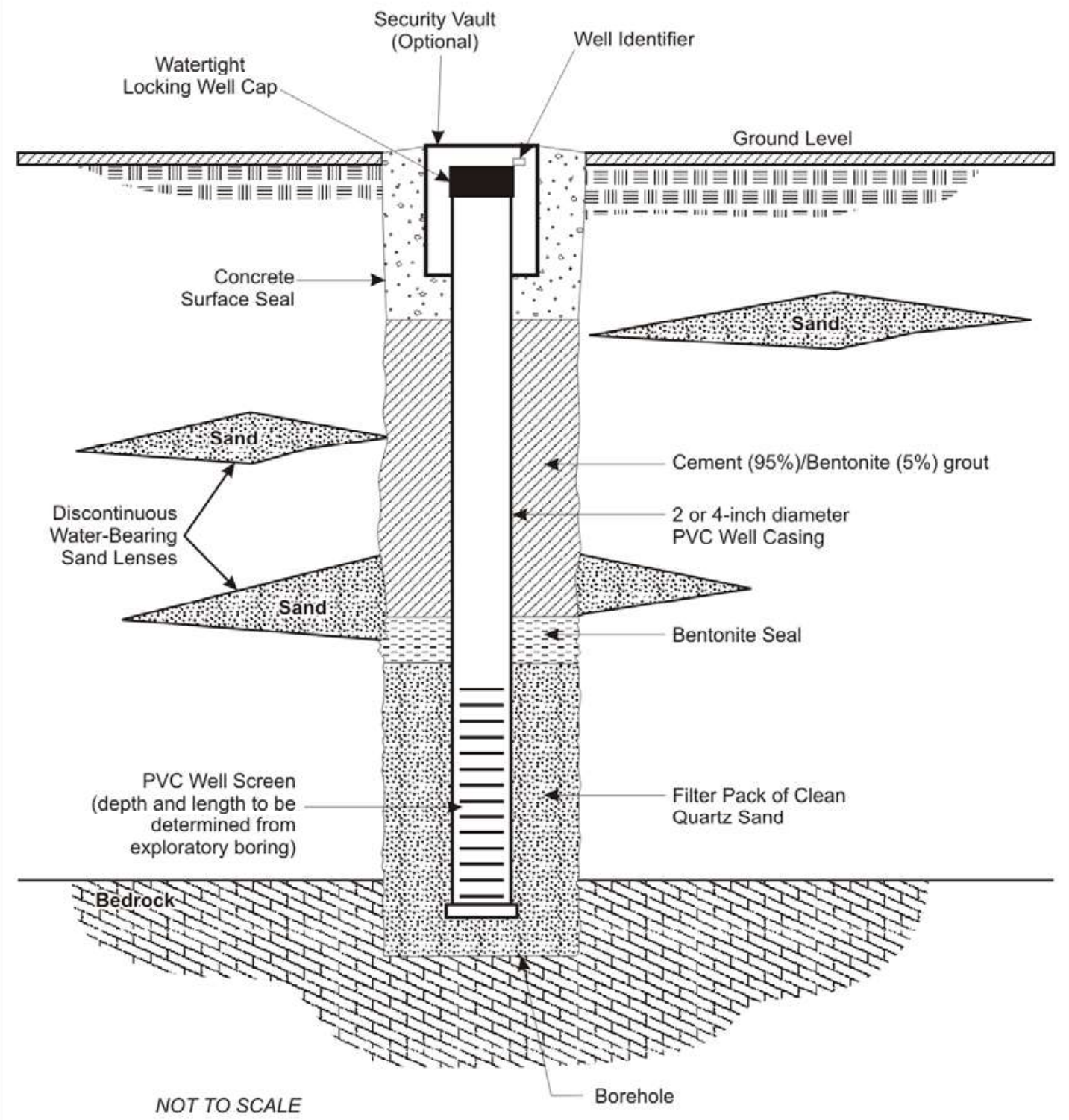

Figure 6-4a. Example Monitoring Well Construction Details for Wells Constructed at the Bedrock Interface. If water is not found at bedrock interface, an alternative water-bearing unit will be located. Well may stick up above ground surface or be flush with ground surface depending on site location. 
B.

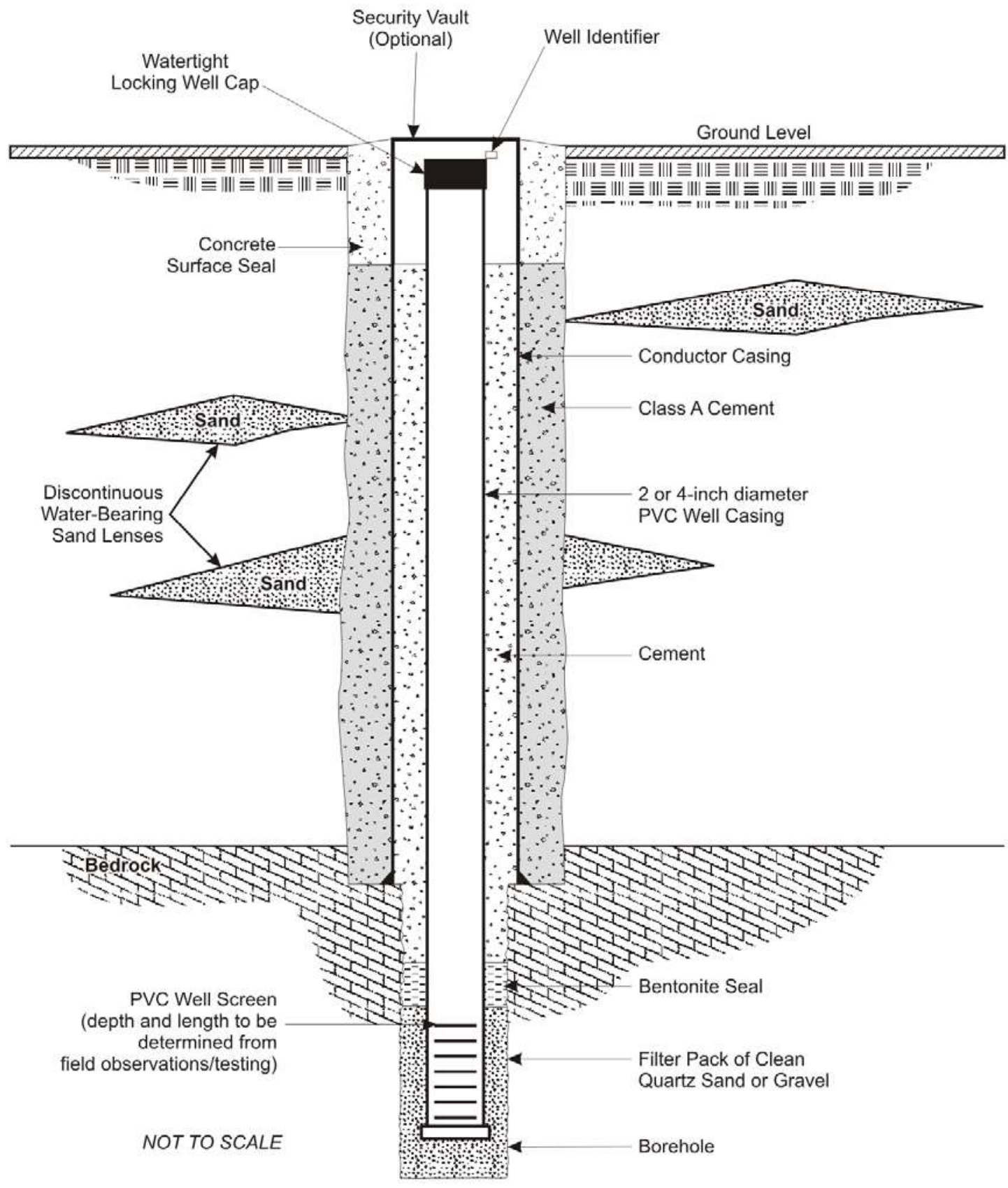

GMW CONDO3.CDR

Figure 6-4b. Example Monitoring Well Construction Details for Wells Constructed in the Shallow Bedrock. If water is not found at bedrock interface, an alternative water-bearing unit will be located. Well may stick up above ground surface or be flush with ground surface depending on site location. 


\subsubsection{Types of Samples}

Grab samples will be obtained from the USDW monitoring wells and analyzed for a suite of chemical parameters that are indicators of $\mathrm{CO}_{2}$ or brine invasion into the shallow aquifer. For details regarding sample collection procedures, analyses and quality assurance see Section 6.2.3.

\subsubsection{Parameters}

The following sample/data types will be collected as part of the USDW monitoring program:

- Discrete water samples will be collected from the shallow USDW wells following the sampling timeline outlined in Section 6.2.2.3. The water quality in the USDW formations will be used to determine if deep formation brine and $\mathrm{CO}_{2}$ are leaking upward. Great care will be taken to ensure the water samples taken from the USDW are representative of water within the formation. Details regarding the collection methods, parameters measured, and analytical methods for water samples collected from USDW are located in Section 6.2.3.

- Water quality parameters will be measured during well purging prior to sample collection. Groundwater $\mathrm{pH}$, temperature, conductivity, dissolved oxygen, and oxidation/reduction potential (ORP) will be monitored in the field using portable meters and flow-through cells.

- In addition to water quality parameters, the water level in each well will be either continuously monitored using a dedicated pressure transducer and/or periodically (e.g., quarterly) determined using an electronic water level indicator prior to sample collection.

- During the drilling of the wells located in the USDW, soil cores or cuttings will be photographed and described.

- A pneumatic slug test (or similar) will be performed to determine shallow aquifer properties (hydraulic conductivity) after well installation.

\subsubsection{Map of Well Location and Logs}

The locations of the monitoring wells are designed to monitor the area corresponding to the size of the $\mathrm{CO}_{2}$ plume after 4 years of injection at the rate of approximately $1.95 \mathrm{MMT} / \mathrm{year}$ and 2 years of post-injection relaxation. A radius of 0.39 miles was originally modeled for the plume extent after the initial limited injection operation, and can be used for estimation purposes.

Figure 6-5 shows the approximate locations of the proposed USDW monitoring wells (locations are tentative, pending the final location of the injection well(s). Two of the four primary USDW monitoring wells will be placed near the injection well, as close as possible without interfering with plant facilities or injection operations. An additional well as requested by the IEPA will also be placed near the anticipated 4-year plume boundary in the direction that is up-dip from the injection well (i.e., buoyant forces may result in preferentially spreading $\mathrm{CO}_{2}$ in the up-dip direction), as requested by the IEPA. However, this well cannot be located until after the seismic survey is completed to determine bedrock dip direction. A fourth monitoring well will be located outside the modeled $\mathrm{CO}_{2}$ plume in the southwest corner of the site to serve as a control well during injection. If the secondary injection site is used, three more USDW wells will be installed 

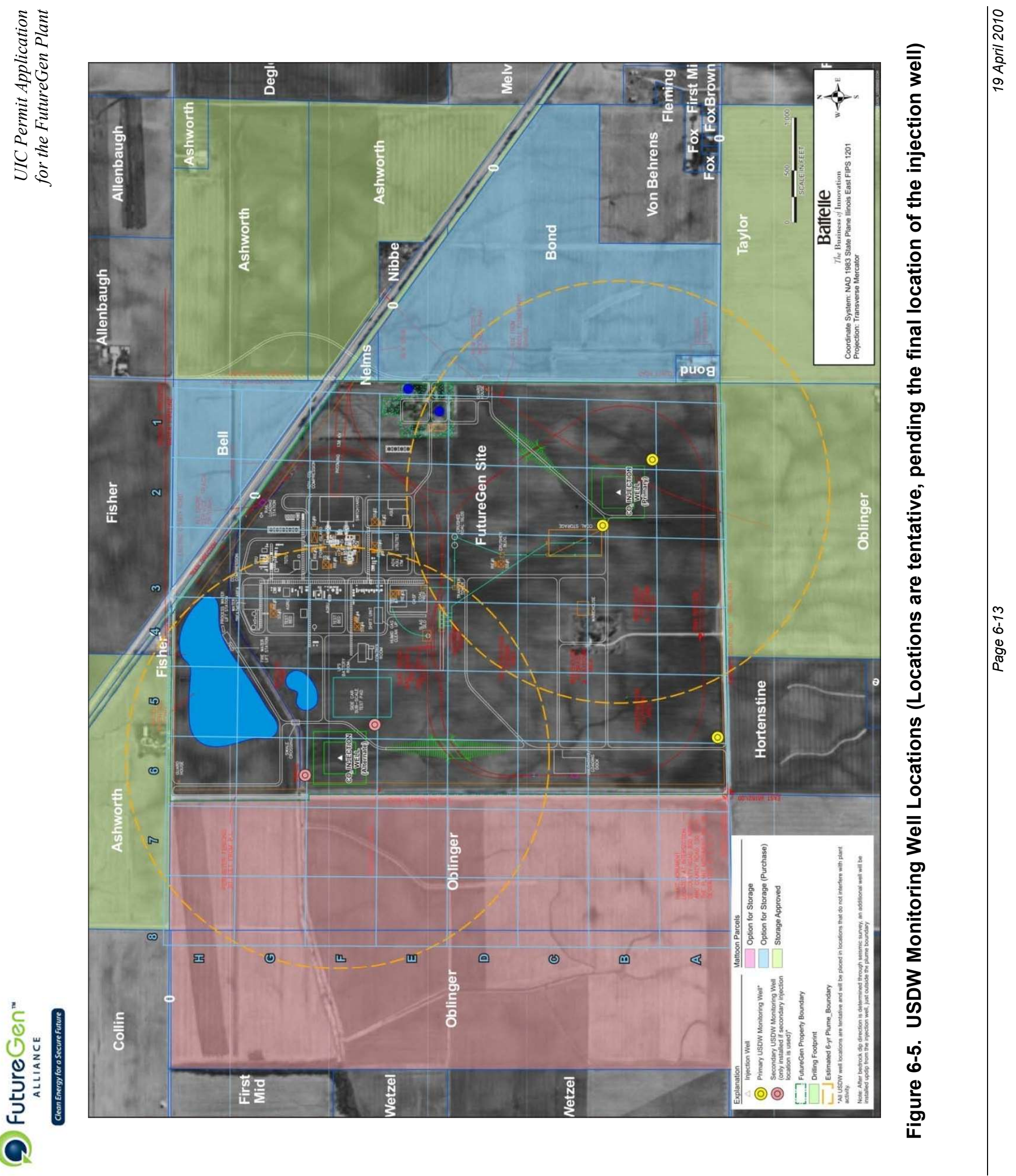
following the same rationale explained above. That is, two of the wells would be located near the injection location and a third well would be placed near the anticipated plume boundary in the up-dip direction relative to the injection well.

\subsubsection{Detailed Groundwater Monitoring Plan}

\subsubsection{Project Definition and Objectives}

A comprehensive groundwater monitoring plan is proposed to detect any $\mathrm{CO}_{2}$ leakage or upward displacement of deep brine fluids into groundwater formations used as a water supply near the injection wells. Monitoring wells will provide access to the aquifer to obtain both hydraulic and geochemical data. Water levels in the monitoring wells will be either continuously or periodically monitored to monitor changes in the direction of groundwater movement. Water quality monitoring will focus on parameters most influenced by the addition of $\mathrm{CO}_{2}$.

Geochemical modeling suggests that $\mathrm{CO}_{2}$ effects on water quality will likely influence the carbonate system and will be expressed as changes in $\mathrm{pH}$, dissolved $\mathrm{CO}_{2}$, and alkalinity. Stable carbon and oxygen isotopic analyses will also be performed to monitor isotopic changes in shallow groundwater caused by mixing of injected $\mathrm{CO}_{2}$ which has a significantly different isotopic signature. This section details the groundwater sampling methodology, chemical parameters to be measured and quality assurance plans for the shallow groundwater monitoring plan.

\subsubsection{Geochemical Parameters}

Groundwater samples will be analyzed for a suite of chemical parameters that are indicators of $\mathrm{CO}_{2}$ or brine invasion into the shallow aquifer. As outlined in Section 6.2.2.3, the monitoring wells will be sampled quarterly for one year prior to injection for the entire suite of parameters to obtain representative background conditions and continue through the injection and postinjection phases.

Table 6-5 outlines the geochemical parameters to be measured in the grab samples obtained from the monitoring wells, and Table 6-6 suggested analytical laboratories to be used. As mentioned previously, $\mathrm{CO}_{2}$ invasion would likely first influence carbonate phases in affected groundwaters, and consequently dissolved $\mathrm{CO}_{2}$ will be measured directly. Increased dissolved $\mathrm{CO}_{2}$ concentrations would also lead to increased carbonic acid concentrations and lower $\mathrm{pH}$, which may result in increased dissolution rates of subsurface carbonates, and therefore increased alkalinity concentrations. TDS, cations, anions and metals will be measured to monitor possible mixing of upwelling deep brine fluid with groundwater. Stable oxygen and hydrogen isotopes of formation water will help characterize the fluids in different formations. In the midcontinent basins, the isotopic composition of the bedrock fluids shows characteristic deviations from the global meteoric water line (Graf et al., 1965, Clayton et al., 1966). If fluids from deeper formations began to mix with shallower units, oxygen and hydrogen isotope $\left(\delta^{18} \mathrm{O}\right.$ and $\delta \mathrm{D})$ analyses could identify such mixing. Stable carbon isotopes $\left({ }^{13} \mathrm{C}\right)$ will be measured in the dissolved $\mathrm{CO}_{2}$ and bicarbonate $\left(\mathrm{HCO}_{3}{ }^{-}\right)$. Carbon isotopes in $\mathrm{CO}_{2}$ resulting from coal combustion are typically more strongly depleted (-20 to $-25 \%$ ) than dissolved inorganic carbon $\left(\mathrm{CO}_{2}\right.$ and $\left.\mathrm{HCO}_{3}{ }^{-}\right)$in groundwater. Measurements of carbon isotopes in both the $\mathrm{CO}_{2}$ stream and the shallow groundwater will allow the calculation of a two component mixing model to determine if $\mathrm{CO}_{2}$ is migrating upward into the aquifer. 
Table 6-5. Sample Container, Holding Time, and Preservation Methods for Laboratory Analytes

\begin{tabular}{|c|c|c|c|c|c|}
\hline Parameters & Method & Preservation & Container & $\begin{array}{c}\text { Holding } \\
\text { Time }\end{array}$ & Laboratory \\
\hline $\begin{array}{c}\text { Cations and metals } \\
\mathrm{Na}, \mathrm{K}, \mathrm{Ca}, \mathrm{Mg}, \mathrm{Fe} \\
\mathrm{Mn}, \mathrm{Al}, \mathrm{Ba}\end{array}$ & $\begin{array}{c}\text { SW6010 or } \\
6020\end{array}$ & $\begin{array}{c}\mathrm{HNO}_{3} \text { to } \mathrm{pH}<2 \text {, Filter } \\
0.45 \mu \mathrm{m}\end{array}$ & $\begin{array}{l}250 \mathrm{~mL} \\
\text { HDPE }\end{array}$ & 6 months & \multirow{6}{*}{$\mathrm{DHL}$} \\
\hline $\begin{array}{c}\text { Anions } \\
\mathrm{Cl}^{-}, \mathrm{SO}_{4}{ }^{=}, \mathrm{Br}^{-}, \mathrm{F}^{-}\end{array}$ & E300 & \multirow{5}{*}{ Cool, $4 \pm 2^{\circ} \mathrm{C}$} & \multirow{5}{*}{$1 \mathrm{~L} \mathrm{HDPE}$} & 28 days & \\
\hline $\mathrm{pH}$ & $\mathrm{M} 4500-\mathrm{H}+\mathrm{B}$ & & & None & \\
\hline Alkalinity & M2320 B & & & 28 days & \\
\hline Total Dissolved Solids & M2540C & & & 7 days & \\
\hline Dissolved Silica & M4500 Si-D & & & 28 day & \\
\hline $\begin{array}{c}\text { Dissolved } \\
\text { Carbon Dioxide }\end{array}$ & AM20GAX & $\begin{array}{c}\text { Benzalkonium-Cl, } \\
4 \pm 2^{\circ} \mathrm{C}\end{array}$ & $\begin{array}{c}2 \times 40 \mathrm{~mL} \\
\text { VOA }\end{array}$ & 14 days & Microseeps \\
\hline $\begin{array}{c}\text { Stable Isotopes } \\
\delta^{13} \mathrm{C} \text { (in } \mathrm{HCO}_{3} \text { and } \\
\left.\mathrm{CO}_{2}\right), \delta^{18} \mathrm{O}, \delta \mathrm{D} \text { (in } \\
\mathrm{H}_{2} \mathrm{O} \text { ) }\end{array}$ & $\begin{array}{l}{\mathrm{DIR} / M S^{(a)}}^{(\mathrm{b})} \\
\mathrm{CRDS}^{\left({ }^{\prime}\right)}\end{array}$ & None & $\begin{array}{l}100 \mathrm{~mL} \\
\text { HDPE, zero } \\
\text { headspace }\end{array}$ & None & Isotech \\
\hline
\end{tabular}

(a) Dual inlet ratio mass spectrometry for $\delta^{13} \mathrm{C}$.

(b) Cavity ring-down spectroscopy for $\delta \mathrm{D}$ and $\delta^{18} \mathrm{O}$.

HDPE - high density polyethylene

Table 6-6. Analytical Laboratories

\begin{tabular}{|c|}
\hline Laboratory \\
\hline DHL Analytical \\
2300 Double Creek Drive \\
Round Rock, TX 78664 \\
Microseeps \\
220 William Pitt Way \\
Pittsburgh, PA 15238 \\
Isotech Laboratory \\
1308 Parkland Court \\
Champaign, IL 61821-1826 \\
\hline
\end{tabular}

Field parameters will also be measured using a portable water quality meter and flow through cell prior to collecting water samples. These parameters include $\mathrm{pH}$, temperature, conductivity, dissolved oxygen, turbidity, and ORP. These measurements are used primarily for monitoring water chemistry changes during purging to ensure that a representative sample is collected (see Section 6.2.3.3), but can also be useful for detecting possible chemical changes due to $\mathrm{CO}_{2}$ leakage ( $\mathrm{pH}, \mathrm{ORP})$ and brine invasion (conductivity).

\subsubsection{Groundwater Sample Collection}

\subsection{Water Level Measurements}

Water-level measurements will be taken from each monitoring well prior to initiating the purging or sampling processes for the purposes of determining the current borehole volume of the well and evaluate drawdown during the purging process. The following procedure will be used to determine the level of water in the wells: 
- The water-level probe will be cleaned with de-ionized water.

- The probe will be lowered slowly until the instrument alarm and light response indicate that the water surface has been encountered. The measurement will be taken from the surveyed point on the well's protective enclosure or well casing.

- The measurement will be checked by slowly raising and lowering the tape and watching the instrument response. The measurement will be recorded in the field logbook.

- As the probe is withdrawn from the well, a clean paper towel will be used to wipe any foreign material or liquids off of the probe lead wire.

\subsection{Well Purging Procedures}

All wells to be sampled will be purged prior to collecting water samples using a submersible pump or a low-flow bladder pump if the well does not produce enough water to sustain the minimum flow rate produced by a submersible pump. Purging ensures that the water samples that are collected for analyses are representative of the formation water and entails pumping groundwater from the well until water quality parameters $(\mathrm{pH}$, conductivity, temperature, turbidity) stabilize, or pumping a pre-specified volume of groundwater from the well. The waterlevel measurements made before sampling and purging will be used to determine the volume of water in the well (i.e. borehole volume).

During purging, the discharge water from the pump will be routed to a flow-through cell to measure field parameters, and will be released into a drum or bucket so the effluent can be contained and the volume of water measured. During the purging process, the water levels in the wells will be measured frequently to avoid excessive drawdown (i.e., within 5 feet of the top of the screened interval) of the water level in the well.

Wells that yield sufficiently will be purged using a submersible pump according to the following:

(1) Remove 1.5 borehole volumes of water. During purging, the pumping rate should be adjusted to prevent drawdown of the water level in the well from being less than 5 feet from the top of the well screen.

(2) During purging of the first 1.5 borehole volumes, measurements of field water quality parameters will be made after each 0.25 borehole volume is purged. Purging will be considered adequate after 1.5 borehole volumes have been purged from the well if field parameters have stabilized during the final three measurements, as indicated by the following criteria:

- Temperature $\pm 1^{\circ} \mathrm{C}$

- Specific conductance $<10 \%$ variation

- Turbidity $<10 \%$ variation

- $\mathrm{pH} \pm 0.2 \mathrm{pH}$ units

These parameters will be measured with a portable field instrument connected to the flow-through cell. The instruments will be cleaned and calibrated in accordance with the manufacturer's instructions.

(3) If the purging is considered complete per the requirements in Step 2, proceed to Step 5 . 
(4) If criteria for sufficient purging, presented in Step 2 are not met, continue purging until three consecutive field-parameter readings meet the criteria presented in Step 2. If the water-quality parameters have not stabilized after three borehole volumes have been removed from the well, the purging process will still be considered adequate. Proceed to Step 5.

(5) Allow well to recover to approximately $80 \%$ of its static condition prior to collecting the sample.

For wells that do not yield a sufficient flow rate to sustain an electrical submersible pump without causing excessive drawdown, purging and sampling will be conducted with a low-flow bladder pump. Because purging would be conducted at a very low flow rate, purging would be discontinued once water quality parameters have stabilized as described above, regardless of the volume of water removed from the well.

\subsubsection{Sample Collection Procedures}

Sample collection procedures will follow methods recommended by the analytical laboratories for the specific analyte being collected. Sample preservation methods and containers to be used are outlined in. Samples for metals analysis will be filtered through $0.45 \mu \mathrm{m}$ flow-through high capacity filters (ASTM Method D6564-00). Prior to collection, a minimum of $100 \mathrm{~mL}$ of sample will be flushed through each filter. All samples will be placed into ice chests in the field, maintained at approximately $4^{\circ} \mathrm{C}$, and immediately shipped to analytical laboratories to be analyzed within the holding times presented in.

\subsubsection{Sample Chain of Custody}

All sample bottles will be labeled with waterproof labels and indelible markings. A unique identification number and sampling date/time will be recorded on the sample bottle as well as in the field logbook and purge logs. The logbook will indicate the sampling personnel, date/time, sample location/well, identification number, collection procedures, measured field parameters, well purge logs and additional comments.

A chain-of-custody record will be completed and will accompany every sample or group of samples shipped to analytical laboratories during an individual sampling event to establish documentation of sample possession. This record will contain the following: sampling personnel (with affiliation, address, phone number), project number, project location, sample identification numbers, sample date/time, signature of sampling personnel, and remarks regarding the samples. The sample containers will then be placed into plastic bags and put into an ice chest containing either ice in sealed containers or blue ice packs. Samples will not be considered hazardous and thus will not require any special handling during shipping. The ice chest will be sealed with custody seals prior to shipment to the laboratory to verify the samples have not been tampered with during shipment. Samples will either be shipped to the laboratory overnight or hand delivered the same day of collection. Copies of all chain of custody documentation will be saved electronically.

\subsubsection{Field Quality Control}

Wells will be purged prior to sample collection following the procedures outlined in Section 6.2.3.3 to ensure a representative sample. Water quality meters and flow-through cells used during purging will be calibrated according to the manufacturer's instructions and 
decontaminated with de-ionized water between wells. The pump used for sample collection will be thoroughly cleaned with de-ionized water prior to each use. New polyethylene tubing will be used at each well. If bladder pumps are used, a separate pump may be dedicated to each well.

New unused sample containers provided by the laboratories will be used for sample collection. When collecting samples for volatile analysis such as dissolved $\mathrm{CO}_{2}$, collection methods will minimize contact time with the atmosphere. Filter capsules used for field-filtering samples for dissolved metals analysis will be rinsed with the sample prior to sample collection.

At one of the wells during each sampling event, a field duplicate will be collected for each analysis. The purpose of the field duplicate sample is to evaluate the precision of the overall sample collection and analysis processes. The field duplicate will be collected at the same time using the same methods as one of the original samples. The duplicate samples will be labeled in a manner uniquely identifying the sample as a duplicate sample. An equipment rinsate blank will also be prepared and analyzed for each sampling event. This sample will be prepared by collecting deionized water that is used to rinse the sampling equipment after decontamination.

After the samples are collected and properly preserved, each sample will be placed into an ice chest along with a chain of custody form, kept at $4^{\circ} \mathrm{C}$, and immediately shipped to the analytical laboratories.

\subsubsection{Laboratory Quality Control}

Laboratory quality control (QC) is addressed through the analysis of the laboratory's own QC samples according to established methods and internal laboratory QC practices. Detailed laboratory QC reports will be received with sample results, including results of analytical replicates, matrix spikes, matrix spike duplicates, and spike recovery tests.

\subsubsection{Data Review and Validation}

Project data will undergo a three step data verification and review process. The goal of the process is to perform a systematic review of the analytical data and to determine the accuracy and quality of the data. The verified data will then be assessed to determine the suitability of the data for meeting the overall project objectives.

The first step will be to verify that the analytical data were produced by instruments that were in analytical control (i.e., calibrated correctly and operating properly) as defined by the specific methods being used. This step will be performed by the analytical laboratory.

The second step will be to verify and report study data in relation to the method detection and reporting limits of the analytical method. Data qualifiers or flags will be added to the data if necessary to indicate any exceptions to the limits (e.g., the result falls between the method detection and reporting limits is considered to be an estimated value). This step will be performed by the analytical laboratory.

The third step will be to verify and report study data in relation to the $Q C$ criteria (e.g. the holding time was exceeded for a sample and the result is considered to be an estimated value). This step will also be performed by the analytical laboratory.

The analytical laboratory that generates the data has the primary responsibility for the accuracy and completeness of the data. Before releasing any analytical data, the laboratory will review and verify that the data have met all of the method criteria and are scientifically accurate. 
Battelle will review the data reports produced by the analytical laboratories to ensure that the reports are complete and the data quality is acceptable for meeting the project objectives.

\subsubsection{Data Analysis}

Background values and subsequent post-injection monitoring data from USDW wells will be analyzed using statistical methods to determine the natural variance of background values, and statistically significant changes after injection has begun. Specific statistical methods for the determination of background values and monitoring post-injection chemical data are discussed below.

\subsection{Determination of Background Values}

Background values will be determined for all analytes outlined in Table 6-5 that are above the detection limit. At least eight background samples will be collected from each well before injection (see Section 6.2.2.3). Major ion data will be plotted on Piper trilinear diagrams to evaluate the similarities and differences between samples from the water-bearing formations. Because each well will be sampled at least eight times prior to injection, sufficient data should be available for intrawell comparisons. The background values for all analytes will be assessed to determine how the data are distributed and if multiple populations are present. Probability plots will also be used to estimate background concentration ranges by identifying outliers and differentiating between separate populations. If multiple populations are present, it will be necessary to determine which population represents ambient conditions. Geochemical analyses will be used to ensure that the identified background populations are consistent with the chemical characteristics of the groundwater environment. Additionally, the combined Shewart-cumulative sum (CUSUM) control cart procedure will be used to provide an estimate of the mean and standard deviation of background concentrations for each analyte. These analyses will provide the background data set for each analyte that can be used for subsequent comparisons against groundwater monitoring results collected after $\mathrm{CO}_{2}$ injection begins.

\subsection{Comparisons to Background Values}

Groundwater data collected after the start of injection will be compared to the background data to monitor for potential impacts to the USDW aquifer caused by $\mathrm{CO}_{2}$ injection. Data from each well will be compared to background data from that well (intrawell comparisons) each time a sampling event is conducted. A number of statistical methods may be used to determine whether post-injection concentrations are elevated compared to the background values. Specific methods will depend on the characteristics of the data (e.g., distribution, variability). Shewart-CUSUM control charts are a statistical and visual tool for detecting sudden or gradual changes in concentrations and are useful for conducting intrawell comparisons. Once the background data have been collected and plotted on the Shewart-CUSUM control chart, subsequent sampling results can be statistically compared to the estimated control limit, in terms of both their absolute magnitude and cumulative sum. Another test method that will be considered is the parametric and non-parametric prediction limit test. More information on these methods can be found in a number of references, including: Davis and McNichols, 1999; Gibbons, 1994; Gilbert, 1987; O'Brien and Gilbert, 1997; United States Environmental Protection Agency [U.S. EPA], 1992; and U.S. EPA, 1998a and 1998b. 


\subsection{Criteria for Determining when Background Values are Exceeded and Response Actions}

Specific criteria used to determine when a significant increase has been observed will be determined after background values have been analyzed and natural variation and other characteristics of the analytical parameters have been determined. In general, the criteria will be designed to minimize the chance of failing to detect a significant increase in the concentration of a parameter above background. For tests such as the prediction limit test, the attainable site-wide significance level will also depend on factors such as the number of available background measurements and the number of comparisons to be performed (number of analytes multiplied by number of wells).

In the event that a statistically significant change in groundwater quality is indicated, the IEPA will be notified and an assessment of the data will be undertaken to evaluate potential causes such as sampling error, analytical error, or evaluation error. In addition, the suspect well(s) may be re-sampled (verification re-sampling). If the excursion is attributable to one of these factors, a report will be submitted to IEPA demonstrating that the change in groundwater quality was caused by sampling or analysis error, or some other cause other than injection-related activities. In the event that a statistically significant change cannot be ruled out as being caused by a noninjection related cause (sampling error, analysis error, evaluation error, etc.), the Illinois EPA will be notified.

\subsection{Mechanical Integrity Tests During Service Life of Well}

Regular mechanical integrity testing will be conducted after $\mathrm{CO}_{2}$ injection commences to ensure that the well has adequate internal and external mechanical integrity as injection continues. As described in Section 3.9.3, an initial APT will be conducted on the well upon completion of the well and installation of the tubing, packer and annular fluid. Also, a baseline temperature log and pulsed neutron capture log will be conducted before $\mathrm{CO}_{2}$ injection commences to demonstrate the well's external mechanical integrity. This section describes the mechanical integrity tests that will be conducted during the period of active $\mathrm{CO}_{2}$ injection.

\subsubsection{Continuous Monitoring of Annular Pressure}

Internal mechanical integrity will be continuously monitored by monitoring the annular pressure in the well. Per 35 III. Adm. Code, 730.108, continuous monitoring of annular pressure while maintaining an annular pressure that is greater than atmospheric pressure measured at the surface, is one method for demonstrating internal mechanical integrity. A description of the annular protection system (WMMS) that will maintain pressure on the annular fluid was provided in Section 3.7.5.

Annular pressure will be continuously measured and logged using a pressure sensor/transmitter (Foxboro I/A Series ${ }^{\circledR}$ [or similar] Electronic Pressure Transmitter with 4 to $20 \mathrm{~mA}$ analog output) installed on the wellhead. The sensor/transmitter will be connected to the RTU that will be located in the WMMS building. The RTU will allow annular pressure along with other injection pressures and temperatures at each well to be viewed in real time. The annular pressure sensor/transmitter will also be connected to the real time data base system via the PLC in the WMMS building (near the well) so that this parameter can be monitored in real time and logged on the data historian. 
If annular pressure suggests failure of internal mechanical integrity (e.g., tubing or packer leak), an alarm will be triggered and flow to the well may be halted. Flow can be halted automatically by closing the flow valve to the well and the master valves on the well. The injection well will be equipped with two actuated master valves that can be operated remotely from the Control Center. The alarm and shut down procedure is discussed in Section 6.4 of this document.

In addition to continuous monitoring of the annular pressure, an annular pressure test will be performed whenever the tubing or packer is removed from the well (e.g., during well workovers). The annular pressure test would be conducted in the same manner as the initial annular pressure test, as described in Section 3.9. Procedures for performing the annular pressure testing are provided in Appendix 6-2. Note the procedure provided in Appendix 6-2 may be updated during or after drilling, characterization, and/or testing of the well to account for actual well completion details or site conditions.

\subsubsection{External Mechanical Integrity Testing}

External mechanical integrity refers to the absence of fluid movement/leaks through channels adjacent to the injection wellbore that could result in fluid migration into USDW. Generally accepted methods for evaluating external integrity include the following:

- a tracer survey such as oxygen-activation logging or radioactive tracer logging;

- a temperature or noise log; or,

- a casing inspection log.

As described in Section 3.9.3, an initial (baseline) temperature log and pulsed neutron capture (PNC) log will be run on the well after well construction but prior to commencing $\mathrm{CO}_{2}$ injection. These logs will serve as a reference for comparing future temperature and PNC logs for evaluating external mechanical integrity. The following subsections describe temperature logging and PNC logging during the service life of the well. A third type of mechanical integrity test, a radioactive tracer survey, is also described. This method may be used instead of or in addition to temperature logging or PNC logging if needed to help explain results.

\subsubsection{Temperature Logging}

Temperature logs are a very versatile and sensitive means of identifying fluids that have moved along channels adjacent to the well bore. In addition to identifying injection-related flows behind casing, temperature logs can often locate small casing leaks. They can also be used to monitor fluid movement through the confining zone adjacent to the well bore (inter-formational flows).

Injection of $\mathrm{CO}_{2}$ will have a cooling or heating effect on the natural temperature in the storage reservoirs, depending on the temperature of the injected $\mathrm{CO}_{2}$ and other factors. Once injection starts, the flowing temperature will stabilize quickly (assuming conditions remain steady). When an injection well is shut in for logging, the wellbore fluid begins to revert toward ambient conditions; it is this change that helps identify potential problems in the injection well. Zones that have taken injectate, either by design or not, will exhibit a "storage" signature on shut in temperature surveys (storage signatures are normally cold anomalies in deeper wells, but may be cool or hot depending on the temperature contrast between the injectate and the reservoir). Losses behind pipe from the injection zone can be detected on both flowing and shut in temperature surveys and exhibit a "loss" signature. 
In order for temperature logging to be effective, there should be a contrast in the temperature of the injected $\mathrm{CO}_{2}$ and the reservoir temperature. Natural bottomhole temperatures in the Mt. Simon Formation is expected to be approximately $135^{\circ} \mathrm{F}$ to $145^{\circ} \mathrm{F}$; the temperature of the injected $\mathrm{CO}_{2}$ is anticipated to be on the order of $105^{\circ} \mathrm{F}$ to $120^{\circ} \mathrm{F}$ at the surface but will undergo some additional heating as it travels down the well. The greater the contrast in the $\mathrm{CO}_{2}$ when it reaches the injection zone and the ambient reservoir temperature, the easier it will be to detect temperature anomalies due to leakage behind casing. After the baseline temperature log has been run to determine ambient reservoir temperature, it will be possible to determine whether there will be sufficient temperature contrast to make the temperature log an effective method for evaluating external mechanical integrity.

A temperature logging procedure (Kansas Department of Health \& Environment) for the purpose of evaluating a well's external mechanical integrity is provided in Figure 6-6. Temperature logging would be conducted through the tubing and therefore would not require removal of the tubing and packer from the well. A method for controlling pressure, such as a wellhead lubricator, would be required. Procedures for performing the temperature logging are provided in Appendix 6-2. Note the procedure provided in Appendix 6-2 may be updated during or after drilling, characterization, and/or testing of the well to account for actual well completion details or site conditions.

\subsubsection{Pulsed Neutron Capture Logging}

PNC is a geophysical logging technique that is sensitive to the change in formation fluids due to the introduction of $\mathrm{CO}_{2}$. Thus, it is a potentially useful method for detecting the absence of vertical distribution of $\mathrm{CO}_{2}$ adjacent to the well that is logged. A baseline logging run is collected prior to injection and data from subsequent logging runs is compared to this.

The PNC tool takes advantage of the nuclear reactions for different rocks and fluids. The tool works by pulsing out neutrons into the formation and measuring the rate in which gamma rays are produced when the neutrons interact with the environment. Specifically, when the neutrons are initially emitted, they are of high energy. As they react with the rock, they slow down and become low energy thermal neutrons. These thermal neutrons subsequently interact with the different elements present in the formation, formation fluid or borehole and are captured. This capture reaction emits gamma rays and the rate at which the gamma rays are created is measured in capture units (c.u.). The capture value, referred to as sigma $(\Sigma)$, is recorded by the logging tool (Smonlen, 1996).

The sigma value for the bulk formation that is recorded by the tool includes contributions from the rock matrix and the formation fluid. To resolve the amount of sigma that is due to the formation fluid, additional information about the formation must be known - specifically porosity and lithology. This allows for an assessment of the relative contribution of both the rock matrix and the formation fluid.

The depth of investigation of the tool is typically less than $1 \mathrm{ft}$. Therefore, PNC logging provides information about the formation immediately adjacent to the wellbore. The vertical resolution is approximately $1.5 \mathrm{ft}$. PNC logging should be considered primarily a "near well" monitoring tool. It will detect the movement of $\mathrm{CO}_{2}$ in the formation, near the borehole; however, behavior further into the formation cannot be inferred. The accuracy of PNC tools is $\pm 0.5 \mathrm{c}$.u. (Butch, 2009). 
Processing of the PNC data will be completed as part of the acquisition process. Borehole conditions need to be accounted for so that any sigma values presented are representative of true formation values. Factors that need to be addressed include the casing, the borehole fluid and tubing (if present). Processed output will be an updated (i.e., corrected) PNC log. When results of subsequent surveys are "differenced" from (i.e., compared to) the baseline results, the processed log will also provide an assessment of $\mathrm{CO}_{2}$ presence and saturation outside the wellbore. Data are provided as an image file and in an Excel-type data file. The data include sigma values and $\mathrm{CO}_{2}$ saturation values versus logged depth in $1 \mathrm{ft}$ increments. Procedures for performing the PNC logging are provided in Appendix 6-2. Note this procedure may be updated during or after drilling, characterization, and/or testing of the well to account for actual well completion details or site conditions.

A potential limitation of this method is that it becomes difficult to assess formation fluid characteristics if the porosity is less than $6 \%$. This is largely because at low porosity values the changes in sigma caused by the changes in formation fluid are a small portion of the total sigma value. Thus, at low porosity values, it may not be possible to detect $\mathrm{CO}_{2}$, especially when the rock is only partially saturated with $\mathrm{CO}_{2}$.

PNC logging would be conducted through the tubing and therefore not require removal of the tubing or packer from the well. As with temperature logging, a method for controlling pressure, such as a wellhead lubricator, will be required. Furthermore, logging can be conducted while injecting $\mathrm{CO}_{2}$ or with the well shut in.

\subsubsection{Radioactive Tracer Logging}

A radioactive tracer (RAT) survey is a method for tracking the downward movement of the injected fluid through the well and determining the location(s) (e.g., perforations, leaks through casing) where it exits the well. RAT surveys can also detect fluid movement in vertical channels adjacent to the well. RAT surveys are conducted during injection (i.e., through tubing); however, the injection rate must be limited to a low flow rate so that flow is laminar and detection of the radioactive tracer is possible with the wireline tool.

A RAT survey may be conducted in one of two ways. The first way is referred to as slug tracking (or vertical chase survey). In this method, a small slug (typically about $100 \mathrm{~mL}$ ) of radioactively tagged brine (lodide 131, a gamma-ray emitter, is the most commonly used radioisotope for this purpose) is ejected from the RAT tool (Figure 6-7) and released into the well at a pre-determined depth, usually some distance above the well perforations, while the well is injecting at a low rate (Baker Hughes recommends releasing the iodide tracer $500 \mathrm{ft}$ above the bottom of the tubing). Upon release, the slug begins to move downward into the well toward the perforations. As the slug moves downward in the well, the tool, which is equipped with two gamma detectors (only one is used for this type of test), is repeatedly lowered and raised through the slug to detect and track the position of the radioactive slug over time (i.e., by measuring gamma ray intensity). As the slug moves out of the wellbore through the perforations and horizontally away from the well, the vertical position of the slug will remain relatively constant until eventually the slug moves far enough away from the well that it can no longer be detected. However, if vertical flow channels exist outside the wellbore, the slug would appear to move up over time instead. Thus, the purpose of this test is to verify that no fluid is traveling back vertically behind (outside) the long-string casing. 
Reply to: (785) 296-1843 FAX (785) 296-5509 Bureau of Water - Geology Section 1000 S. W. Jackson, Ste. 420 Topeka, KS 66612-1367

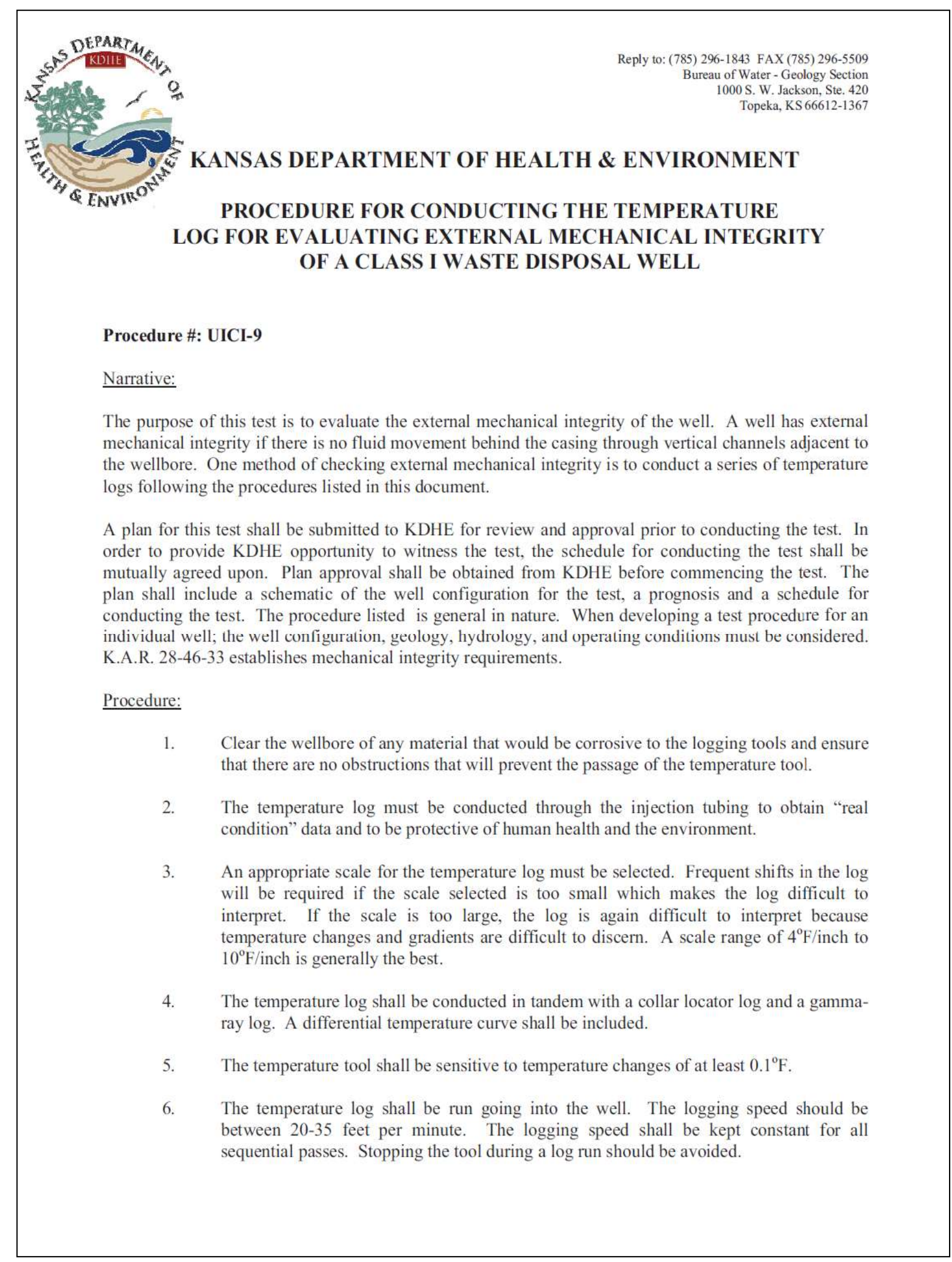

Figure 6-6. Temperature Logging Procedure 
7. The well shall be shut-in for a minimum of 24 hours to allow the well to reach "static" conditions prior to running the base $\log$.

8. Record the beginning and ending clock time on each log pass.

9. Run the base log from surface to total depth after the 24-hour shut-in period.

10. Record the temperature of the liquid to be injected just prior to injection and then periodically during injection, record the temperature of the liquid injected. Provide this information with the final report.

11. Inject the greater of either three well volumes or one barrel of fluid per each foot of disposal interval. The well volume is to be calculated using the volume of the longstring casing plus the open hole interval, if applicable. The best results are obtained when the difference between the injected fluid temperature and the wellbore temperature at the zone of interest is at least $35^{\circ} \mathrm{F}$, especially if the temperature $\log$ is conducted through the tubing. In no case shall the temperature difference be less than $10^{\circ} \mathrm{F}$. Even minor variations in the temperature of the injection water can adversely influence the results; thus, a source of water with a uniform temperature should be used. The injection rate used should be at a normal operational injection rate and, if feasible, the maximum permitted injection rate.

12. Cease injection and place the logging tool at a depth 300 feet above the disposal zone. Make three passes from 300 feet above the disposal zone to total depth at the one-hour, two-hour and the four-hour interval after stopping injection.

13. Pull the temperature log to surface. Run the final base temperature log from surface to total depth.

14. Submit the temperature logs to KDHE with the following information on each log:
a. time log was run
b. well conditions, shut-in, injecting
c. scales
d. logging speed
e. depth and size of various casings, depth and size of tubing, packer seat depth

A report shall accompany the logs describing the procedure, volume of fluid injected, well construction data, rate at which fluid was injected, and the injection pressure. The report shall also include an interpretation of the logs and a description of the temperature log results by a person with the technical expertise to evaluate the logs.

15. If the well is determined to be lacking external mechanical integrity, injection shall cease immediately and the permittee shall submit the following to KDHE for review and approval: 1) an evaluation of the impact to the environment which may require additional testing approved by KDHE, 2) an environmental remediation plan and implementation schedule, and 3) a repair plan and implementation schedule for the well. No work is to commence until plan and schedule approval has been obtained from KDHE.

Procedure.UICI-9

$01 / 00$

Figure 6-6. Temperature Logging Procedure (Continued) 
The second method for conducting a RAT survey is the shot (or stationary) method. In the velocity shot method, a small quantity (shot) of radioactive tracer is ejected from the tool while it is held stationary and the time required for the tracer to travel between the two detectors on the tool is measured. These time measurements are converted to fluid velocities, then to an injection profile. For an injection well, the preferable method is to have the tool arranged such that the two gamma ray detectors are below the ejector section; the time of tracer travel between detectors is then easily measured on a time drive chart. This test is to check for upward fluid migration outside of the tailpipe, either inside the well or outside the long-string casing.

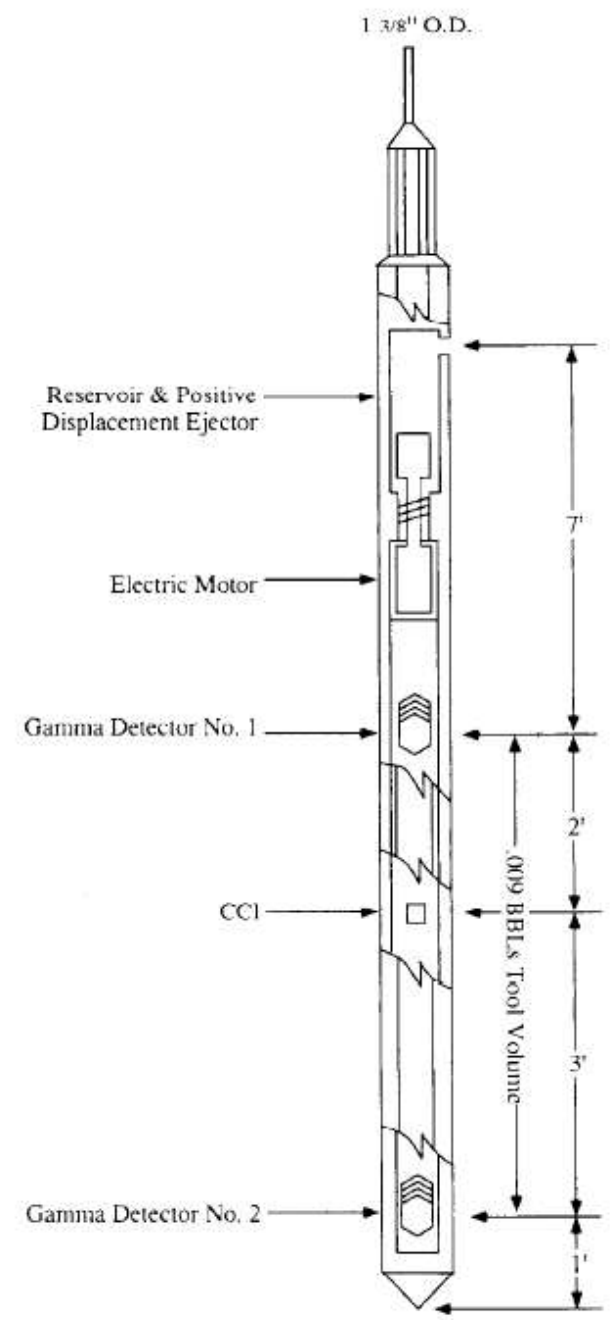

Figure 6-7. Radioactive Tracer Tool for Injection Logging (From U.S. EPA, 1994)

The following recommendations are suggested for use when conducting a RAT survey (source http://www.tceq.state.tx.us/assets/public/permitting/waste/uic/mitguidelines.doc):

- The recommended technique for the RAT is to use a logging tool with a gamma detector above the ejector port and one or two below it. The tool should be able to 
continuously record during tracer fluid ejection. The upper detector should be recorded in track 1 at a scale of 0 to 100 or 150 API units. The lower detector(s) should be recorded in tracks 2 and 3 at a higher scale, typically 0 to 1000 API units.

- Prior to testing, an initial gamma ray base log should be recorded from at least $100 \mathrm{ft}$ above the injection tubing packer to total depth or plugged-back depth (TD/PBTD) of the well.

- A concurrent casing collar locator log for depth correlation is recommended. Two 5 minute time drive statistical checks should also be run prior to the ejection of tracer fluid. These logs and statistical checks are run to determine background radiation prior to tracer fluid ejection.

- During the survey, injection flow rates should be set at the rate at which the fluid will be under laminar flow, while remaining within the maximum permitted operating parameters. The volume of the tracer fluid slug should be sufficient to cause a gamma curve deflection of at least $25 x$ background reading as the ejected slug passes the lower detector(s). This would typically be a full-scale deflection.

- A constant injection (moving) survey (i.e., slug method) should be run from, at least, above the packer to the perforations or screen to check for leaks between those two points. This survey should consist of ejecting a slug above the packer, verifying the ejection, and then dropping down through the slug, and logging up through the slug to above where the slug was first ejected. The tool should then be dropped down through the slug again and logging should continue upward to above where the slug was encountered on the previous pass. This process should be repeated a minimum of two times, until the slug passes out into the formation. If necessary, the injection rate may be decreased to accomplish this test.

- A stationary survey (i.e., shot method) should be run approximately 20 feet or less above the top of the perforated interval or screen to check for upward fluid migration outside the cemented casing. Flow during the stationary surveys should be at sufficient rates to approximate normal operating conditions in the well. The procedure consists of logging on time drive, ejecting a slug, verifying the ejection, and waiting an appropriate amount of time to allow the slug to exit the wellbore and return through channels outside the pipe. The time spent at the station will vary but should be at least twice the time estimated to detect the tracer fluid if channeling existed, or for a minimum of 15 minutes, whichever is greater. If tracer fluid is detected channeling outside of the pipe at any time during the stationary survey, then the survey may be stopped and the tracer fluid's movement should be documented by logging up on depth drive until the tracer exits the channel.

\subsection{Contingency Plan for Well Failure or Shut In}

This section describes the process that will be implemented to safely halt $\mathrm{CO}_{2}$ injection in the event of an injection well or equipment failure. The injection process will be monitored by the WMMS, an integrated system of equipment (tanks, lines, pumps, valves) and instrumentation (pressure and temperature transmitters, PLC, RTU) that will be capable of detecting when injection conditions are out of acceptable limits and responding by either adjusting conditions or 
halting injection. The system is designed to operate automatically with minimal operator intervention. This section is organized into the following sections:

- A description of the alarm system, including the values for tubing pressure, flow rate and annular pressure which will trigger the alarm.

- A description of the automatic shut down of the injection pumps, including the annular pressure, injection pressure and flow rate which will trigger pumps shut down.

- A list of the persons designated to oversee well operations in the event of an emergency. Phone numbers and qualifications should be included.

\subsubsection{Description of Control and Alarm System for the Well Monitoring and Maintenance System}

The WMMS control system architecture and functionality, including process alarms, plant interlocks, shutdown alarms and automatic shutdown sequence, are described in this section. A process flow diagram for the $\mathrm{CO}_{2}$ injection WMMS and instrumentation is also discussed.

\subsubsection{Control System Overview}

The proposed control system for the WMMS consists of a local PLC interfaced with the plant Distributed Control System (DCS) via a communications network. The WMMS PLC will provide control and monitoring of the injection pressure, annular pressure, and related parameters associated with the WMMS. A standard communications protocol (e.g., Modbus) will be used for the PLC to DCS link. Alarms, run enable, and other critical signals will be passed between the WMMS PLC and the plant DCS. A description of the WMMS was provided in Section 3.7 (Annular Protection System) of this permit application. A basic block diagram of the WMMS control system architecture is shown in Figure 6-8.

The WMMS PLC will be located in a WMMS building near the $\mathrm{CO}_{2}$ injection well. The WMMS building will house the WMMS PLC and a local Human Machine Interface (HMI), the wellhead RTU, which serves as an interface for the wellhead instruments, the annular fluid pressure control system, and the nitrogen system. The local HMI will be used to perform startup and testing independently of the plant control system. After startup, the local HMI will be available only for maintenance use. User privileges and other security measures will be implemented to limit access and control of the WMMS equipment through the local HMI during plant operation. Operator interface and control of the WMMS during normal plant operation will be performed through the control room HMI inside the plant. Alarm reporting, alarm logs, command logs, real time trending, and historical trending will be performed by the plant DCS through the control room HMI.

\subsubsection{Annular Fluid Pressure Control}

A description of the Annular Protection System, which is part of the WMMS, was provided in Section 3.7 of this permit application; a brief overview is provided here. An annular fluid pressure control system will maintain the annular fluid in the well at prescribed levels. Two or more banks of nitrogen tanks will supply gas pressure to the annular fluid pressure control system. Control valves will provide a controlled gas charge (pressure) on an accumulator (pressurized tank) that contains excess annular fluid that can be supplied to the well when necessary. A low pressure control valve will add nitrogen to increase the pressure on the 
accumulator; a high pressure control valve will vent nitrogen to the atmosphere to reduce the pressure. The fluid level in the accumulator will be monitored and controlled by the PLC.

Pumps included in the annular fluid pressure control system will replenish the accumulator with annular fluid from a storage tank when the annular fluid level in the well drops by an amount that is greater than the volume of the accumulator. This may occur during seasonal cooling cycles or if the temperature of the injected $\mathrm{CO}_{2}$ decreases. Pressure control valves are included to allow annular fluid to flow to the storage tank from the well when the annular fluid volume in the well expands by an amount that is greater than the capacity of the accumulator. This may occur during seasonal heating or if the temperature of the injected $\mathrm{CO}_{2}$ increases.

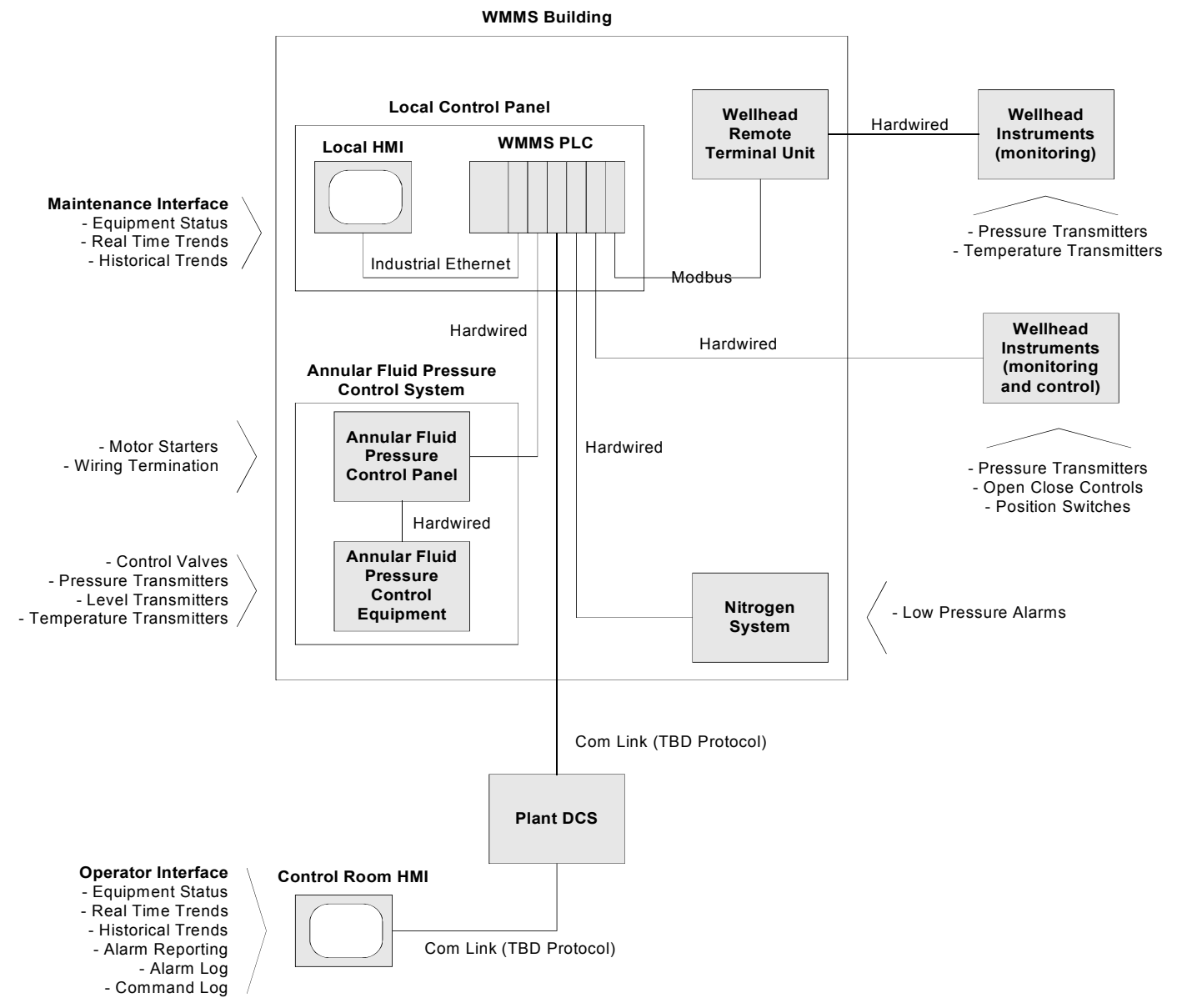

Figure 6-8. WMMS Control System Block Diagram

\subsubsection{Injection Process Control}

Injection pressure will be controlled by the pressure of the $\mathrm{CO}_{2}$ exiting the plant. The current design calls for a maximum $\mathrm{CO}_{2}$ pressure from the plant of 2,200 psi, but this may be increased to 3,000 psi. Some pressure drop is expected between the plant and the injection well; therefore, the maximum pressure at the wellhead will be slightly less than pressure exiting the plant. A control valve will be installed on the $\mathrm{CO}_{2}$ pipeline at a location upstream of where the 
pipeline connects to the wellhead. Adjustments to the injection pressure can be made with the control valve if necessary to stay under the injection pressure limit.

As described in Section 3.7.5, the annulus protection system will be capable of automatically maintaining the pressure of the annular fluid in the $\mathrm{CO}_{2}$ injection well at pre-determined levels. For example, if necessary, the pressure on the annular fluid can be maintained within a predetermined range either above or below the pressure of the $\mathrm{CO}_{2}$ in the injection tube. Annular pressure will be recorded with a pressure transmitter on the wellhead (Instrument Number PT13).

\subsubsection{Automatic Shutdown Procedure}

Alarms will be implemented throughout the plant DCS and monitored by the control room operator. Alarms are of three types: process (non-shutdown) alarms; shutdown alarms; and interlock alarms. Process alarms will be used to alert the control room operator whenever process variables are out of the accepted operating range and operator or maintenance action may be required. Shutdown alarms will indicate critical conditions. An active shutdown alarm or plant interlock will trigger an automatic shutdown sequence in which the $\mathrm{CO}_{2}$ injection process is automatically shut down by the plant DCS and the WMMS PLC. The automatic shutdown sequence for the $\mathrm{CO}_{2}$ injection well is outlined in Section 6.4.2.4.

\subsubsection{Process Alarms (Non-shutdown)}

Process alarm designations will indicate the relative value of the process variable versus the normal value. For instance, a low pressure alarm will indicate that the process pressure is lower than the normally expected pressure. Process alarms will include low, low-low, high, high-high, and deviation (deviation alarm is for a process variable that deviates from the setpoint or expected value). Discrete inputs from binary devices such as pressure switches or alarm contacts are shown as alarms in Figure 6-9 and will be used to indicate conditions that may require action.

Process (non-shutdown) alarms will be used for the following parameters.

- PT-9 Annular Supply Pressure

- PT-13 Annular Pressure Injection Well (High, Low)

- PT-14 $\mathrm{CO}_{2}$ Injection Pressure (High)

- PIC-3 Annular Fluid Pressure Controller

- PT-3 Annular Fluid Expansion Tank Pressure

- TT-5 Annular Fluid Storage Tank Temperature

- TT-8 Annular Fluid Tank Temperature

- LT-7 Accumulator Fluid Level Transmitter

- LT-4 Annular Fluid Storage Tank Level Transmitter

- PAL-1 Nitrogen Bank 1 Low Pressure Switch

- PAL-2 Nitrogen Bank 2 Low Pressure Switch.

Further detail of the process control instrumentation including instrument numbers and a listing of process alarms is provided in Table 6-7.

\subsubsection{Shutdown Alarms}

The $\mathrm{CO}_{2}$ injection process will be automatically shut down under two conditions. One shutdown condition will occur when the annular fluid pressure (instrument number PT-13, see Table 6-7 and Figure 6-9) falls outside the pre-determined range for a period of time that exceeds 


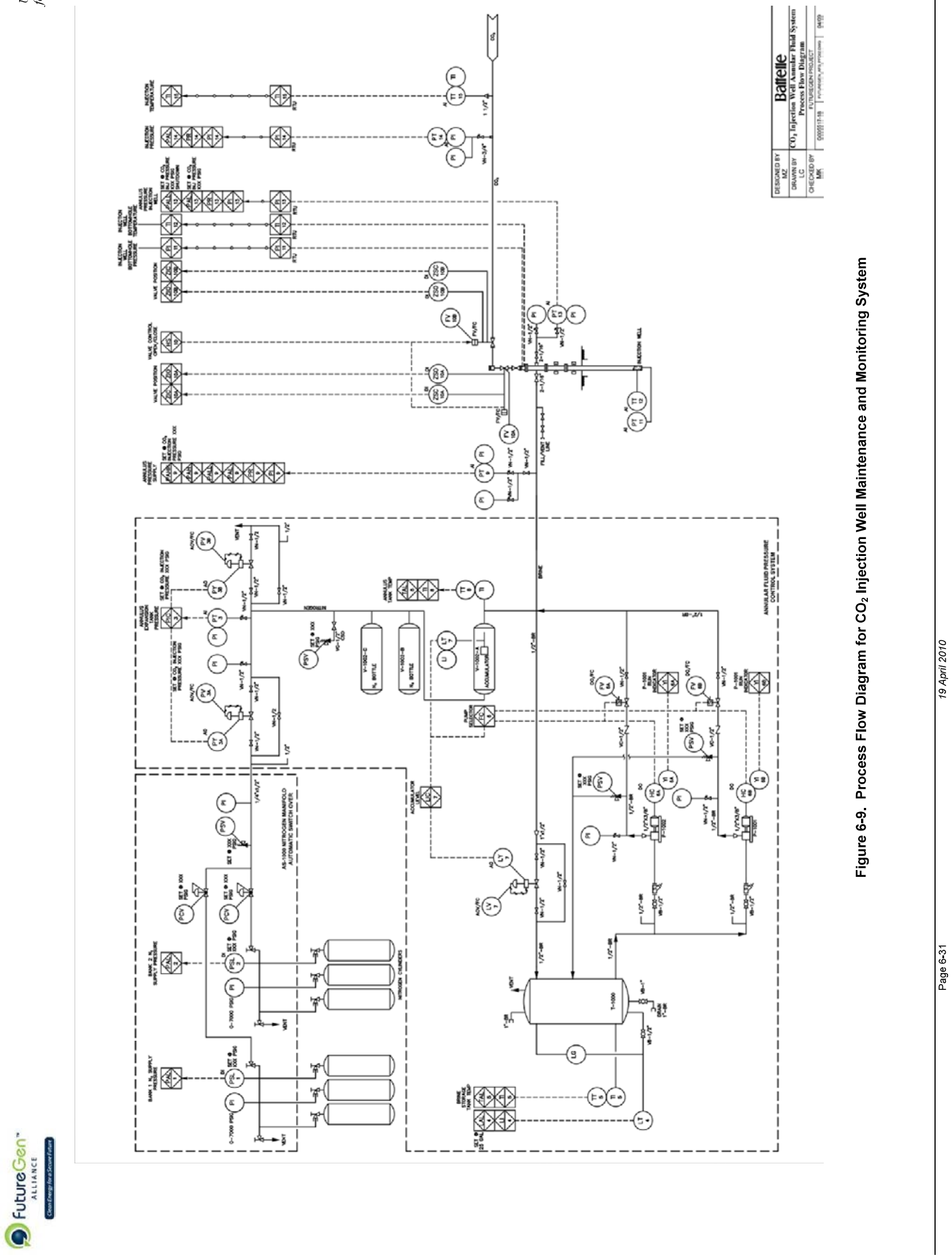


allowable limits. The other primary shutdown condition will occur when the $\mathrm{CO}_{2}$ injection pressure (instrument number PT-14, see Table 6-7 and Figure 6-9) exceeds the maximum injection pressure specified in the permit. Additional automatic shutdowns will be implemented due to plant interlocks as discussed below. Operator intervention will be necessary to restart the injection process after an automatic shutdown sequence

Shutdown alarms will be used for the following parameters.

- PT-13 Annular Fluid Pressure, Injection Well (High-High Alarm, Low-Low Alarm)

- PT-14 $\mathrm{CO}_{2}$ Injection Pressure (High-High Alarm).

Further detail of the process control instrumentation including instrument numbers and a listing of shutdown alarms is shown in Table 6-7.

\subsubsection{Plant Interlocks}

Plant interlock status signal(s) will be sent from the plant DCS to the WMMS PLC. The plant interlock will indicate whether conditions in the main plant are acceptable for the injection process to occur. During run operation, the plant interlock will be used to initiate an automatic shutdown sequence in the event of equipment malfunctions, critical alarms, or other conditions in the main plant that warrant a shutdown of the injection process. During startup operations, the plant interlock will act as a run permission command for the injection process to start up.

\subsubsection{Automatic Shutdown Sequence}

The automatic shutdown sequence will be triggered by a shutdown alarm or plant interlock as described previously.

The following automatic shutdown sequence will be implemented by the plant DCS and the WMMS PLC.

(1) Plant DSC to close main $\mathrm{CO}_{2}$ flow valve controlling flow to well.

(2) Plant DSC/WMMS PLC receives indication $\mathrm{CO}_{2}$ flow valve is closed.

(3) WMMS PLC to close wing valve on injection well (FV-10B).

(4) WMMS PLC/plant DSC receives indication wing valve (FV-10B) is closed.

(5) WMMS PLC to close main valve on injection well (FV-10A).

(6) WMMS PLC/plant DSC receives indication main valve (FV-10A) is closed.

(7) WMMS PLC will automatically adjust annular fluid pressure to setpoint.

(8) Annular fluid pressure system will remain on standby unless shutdown by operator.

(9) Plant DSC/WMMS PLC will continue to collect all data (e.g., annular pressure in well, $\mathrm{CO}_{2}$ pressure in the injection tube).

\subsubsection{Persons Designated to Oversee Well Operations}

A staffing plan has been developed for the FutureGen plant that includes staff responsible for overseeing certain aspects of the injection well operations. The plant staff that will be engaged in well operations includes staff from various departments, including operations, maintenance, and Environmental Safety Health and Quality (ESH\&Q). Operations positions are staffed continuously (4 shifts per day), whereas maintenance and ESH\&Q staff are one shift per day. Examples of well-oversight responsibilities and the responsible staff are identified on Table 6-7. 
Table 6-7. Description of WMMS Instrumentation, Well \#1 and Common Equipment ${ }^{(a)}$

\begin{tabular}{|c|c|c|c|}
\hline $\begin{array}{l}\text { Instrument } \\
\text { Category }\end{array}$ & $\begin{array}{l}\text { Instrument } \\
\text { Number }\end{array}$ & Description & Comments/Details ${ }^{(c)}$ \\
\hline \multirow[t]{4}{*}{$\begin{array}{l}\text { Wellhead } \\
\text { Instruments - } \\
\text { Pressure } \\
\text { Transmitters }\end{array}$} & PT-9 & $\begin{array}{l}\text { Annular Fluid Supply Line } \\
\text { Pressure }\end{array}$ & $\begin{array}{l}\text { - HMI Object } \\
\text { - Low Alarm } \\
\text { - Deviation Alarm (deviates from another } \\
\text { transmitter reading what should be the } \\
\text { same pressure) }\end{array}$ \\
\hline & PT-11 & $\begin{array}{l}\text { Injection Well Bottom-hole } \\
\text { Pressure }\end{array}$ & $\begin{array}{ll}\text { - } & \text { HMI Object } \\
\text { - } & \text { Modbus to PLC from RTU }\end{array}$ \\
\hline & PT-13 & $\begin{array}{l}\text { Injection Well Annular Fluid } \\
\text { Pressure }\end{array}$ & $\begin{array}{l}\text { - HMI Object } \\
\text { - Low Alarm } \\
\text { - High Alarm } \\
\text { - } \text { Low-Low Alarm } \\
\text { - High-High Alarm } \\
\text { - } \text { Deviation Alarm (deviates from another } \\
\text { transmitter reading what should be the } \\
\text { same pressure) } \\
\text { - Shut Down on Low-Low Alarm } \\
\text { - Shut Down on High-High Alarm } \\
\text { - } \text { Modbus to PLC from RTU }\end{array}$ \\
\hline & PT-14 & $\mathrm{CO}_{2}$ Injection Pressure & $\begin{array}{l}\text { - HMI Object } \\
\text { - Low Alarm } \\
\text { - High Alarm } \\
\text { - High-High Alarm } \\
\text { - Shut Down on High-High Alarm } \\
\text { - Modbus to PLC from RTU }\end{array}$ \\
\hline \multirow{2}{*}{$\begin{array}{l}\text { Wellhead } \\
\text { Instruments - } \\
\text { Temperature } \\
\text { Transmitters }\end{array}$} & TT-12 & $\begin{array}{l}\text { Injection Well Bottom-hole } \\
\text { Temperature }\end{array}$ & $\begin{array}{ll}\text { - } & \text { HMI Object } \\
\text { - } & \text { Modbus to PLC from RTU }\end{array}$ \\
\hline & TT-15 & $\mathrm{CO}_{2}$ Injection Temperature & $\begin{array}{ll}\text { - } & \text { HMI Object } \\
\text { - } & \text { Modbus to PLC from RTU }\end{array}$ \\
\hline \multirow[t]{3}{*}{$\begin{array}{l}\text { Wellhead } \\
\text { Instruments - } \\
\text { Open/Close } \\
\text { Controls }\end{array}$} & HS-10 & Valve Open Close Control & $\begin{array}{l}\text { - HMI Object } \\
\text { - Controls solenoid valves to open and } \\
\text { close Main and Wing Valves on well } \\
\text { (i.e., FV-10A and FV-10B) }\end{array}$ \\
\hline & FV-10A & Main Valve & $\begin{array}{l}\text { - Controls pneumatic supply to } \\
\text { wellhead valve }\end{array}$ \\
\hline & FV-10B & Wing Valve & $\begin{array}{l}\text { - Controls pneumatic supply to } \\
\text { wellhead valve }\end{array}$ \\
\hline \multirow{4}{*}{$\begin{array}{l}\text { Wellhead } \\
\text { Instruments - } \\
\text { Position Switches }\end{array}$} & ZSO-10A & Master Valve Open & - HMI Object \\
\hline & ZSC-10A & Master Valve Closed & - HMI Object \\
\hline & ZSO-10B & Wing Valve Open & - HMI Object \\
\hline & ZSC-10B & Wing Valve Closed & - HMI Object \\
\hline \multirow[t]{3}{*}{$\begin{array}{l}\text { Annular Fluid } \\
\text { Pressure Control } \\
\text { Equipment - } \\
\text { Pressure Controls }\end{array}$} & PIC-3 & $\begin{array}{l}\text { PLC Function - Annular Fluid } \\
\text { Pressure Controller }\end{array}$ & $\begin{array}{l}\text { - HMI Object } \\
\text { - Calculated based upon Injection } \\
\text { Pressure } \\
\text { - Process variable input from PT-3 } \\
\text { - } \text { Control output to PY-3A, PY-3B } \\
\text { (pressure control valves) } \\
\text { - Deviation Alarm (actual pressure from } \\
\text { PT-3 deviates from Injection Pressure } \\
\text { calculation) }\end{array}$ \\
\hline & PY-3A & Analog Setpoint from PIC-3 & - HMI Object \\
\hline & PV-3A & $\begin{array}{l}\text { Annular Fluid Pressure Control } \\
\text { Valve }\end{array}$ & - HMI Object \\
\hline
\end{tabular}



Table 6-7. Description of WMMS Instrumentation, Well \#1 and
Common Equipment $^{(a)}$ (Continued)

\begin{tabular}{|c|c|c|c|}
\hline \multirow[t]{3}{*}{$\begin{array}{c}\text { Instrument } \\
\text { Category }\end{array}$} & $\begin{array}{l}\text { Instrument } \\
\text { Number }^{(b)}\end{array}$ & Description & \multirow{2}{*}{ Comments/Details ${ }^{(c)}$} \\
\hline & PY-3B & Analog Setpoint from PIC-3 & \\
\hline & PV-3B & $\begin{array}{l}\text { Annular Fluid Pressure Control } \\
\text { Valve }\end{array}$ & - HMI Object \\
\hline $\begin{array}{l}\text { Annular Fluid } \\
\text { Pressure Control } \\
\text { Equipment - } \\
\text { Pressure } \\
\text { Transmitter }\end{array}$ & PT-3 & $\begin{array}{l}\text { Annular Fluid Expansion Tank } \\
\text { Pressure }\end{array}$ & $\begin{array}{l}\text { - HMI Object } \\
\text { - Deviation Alarm (deviates from another } \\
\text { transmitter reading what should be the } \\
\text { same pressure) }\end{array}$ \\
\hline \multirow{2}{*}{$\begin{array}{l}\text { Annular Fluid } \\
\text { Pressure Control } \\
\text { Equipment - } \\
\text { Temperature } \\
\text { Transmitters }\end{array}$} & TT-5 & $\begin{array}{l}\text { Annular Fluid Storage Tank (T- } \\
\text { 1000) Temperature }\end{array}$ & $\begin{array}{l}\text { - HMI Object } \\
\text { - Low Alarm (freeze protection) }\end{array}$ \\
\hline & TT-8 & $\begin{array}{l}\text { Accumulator Tank (V-1002-A) } \\
\text { Fluid Temperature }\end{array}$ & $\begin{array}{l}\text { - HMI Object } \\
\text { - Low Alarm (freeze protection) }\end{array}$ \\
\hline \multirow{10}{*}{$\begin{array}{l}\text { Annular Fluid } \\
\text { Pressure Control } \\
\text { Equipment - } \\
\text { Accumulator Level } \\
\text { Controls }\end{array}$} & LIC-7 & $\begin{array}{l}\text { PLC Function - Accumulator } \\
\text { Tank (V-1002-A) Fluid Level } \\
\text { Controller }\end{array}$ & $\begin{array}{l}\text { - HMI Object } \\
\text { - Process variable input from LT-7 } \\
\text { - Control output to LY-7 } \\
\end{array}$ \\
\hline & LY-7 & Analog Setpoint from LIC-7 & - HMI Object \\
\hline & LV-7 & $\begin{array}{l}\text { Accumulator Tank (V-1002-A) } \\
\text { Fluid Level Control Valve }\end{array}$ & - HMI Object \\
\hline & FC-6 & Pump Selector & $\begin{array}{l}\text { - HMI Object } \\
\text { - Selects pump control and discharge } \\
\text { valve for either Pump P-1001 or P1002 }\end{array}$ \\
\hline & FV-6A & $\begin{array}{l}\text { P1002 Discharge Valve } \\
\text { Solenoid Valve }\end{array}$ & $\begin{array}{l}\text { - Controls pneumatic supply to P1002 } \\
\text { Discharge Valve }\end{array}$ \\
\hline & HC-6A & P1002 Starter Control & - Starts Pump P1002 \\
\hline & YI-6A & P1002 Starter Aux Contact & $\begin{array}{l}\text { - } \text { HMI Object } \\
\text { - P1002 Motor Run Indicator }\end{array}$ \\
\hline & FV-6B & $\begin{array}{l}\text { P1001 Discharge Valve } \\
\text { Solenoid Valve }\end{array}$ & $\begin{array}{l}\text { - Controls pneumatic supply to P1001 } \\
\text { Discharge Valve }\end{array}$ \\
\hline & HC-6B & P1001 Starter Control & - Starts Pump P1001 \\
\hline & YI-6B & P1001 Starter Aux Contact & $\begin{array}{ll}\text { - } & \text { HMI Object } \\
\text { - } & \text { P1001 Motor Run Indicator }\end{array}$ \\
\hline $\begin{array}{l}\text { Annular Fluid } \\
\text { Pressure Control } \\
\text { Equipment - } \\
\text { Accumulator Level } \\
\text { Transmitter }\end{array}$ & LT-7 & $\begin{array}{l}\text { Accumulator Tank (V-1002-A) } \\
\text { Fluid Level Transmitter }\end{array}$ & $\begin{array}{l}\text { - HMI Object } \\
\text { - Low Alarm } \\
\text { - High Alarm }\end{array}$ \\
\hline $\begin{array}{l}\text { Annular Fluid } \\
\text { Pressure Control } \\
\text { Equipment - } \\
\text { Storage Tank Level } \\
\text { Transmitter }\end{array}$ & LT-4 & $\begin{array}{l}\text { Storage Tank Level } \\
\text { Transmitter }\end{array}$ & $\begin{array}{l}\text { - HMI Object } \\
\text { - Low Alarm }\end{array}$ \\
\hline \multirow[t]{2}{*}{ Nitrogen System } & PAL-1 & $\begin{array}{l}\text { Nitrogen-cylinder Bank \#1 Low } \\
\text { Pressure Switch }\end{array}$ & $\begin{array}{l}\text { - HMI Object } \\
\text { - Discrete Alarm }\end{array}$ \\
\hline & PAL-2 & $\begin{array}{l}\text { Nitrogen-cylinder Bank \#2 Low } \\
\text { Pressure Switch }\end{array}$ & $\begin{array}{l}\text { - HMI Object } \\
\text { - Discrete Alarm }\end{array}$ \\
\hline
\end{tabular}

NOTES:

(a) Instrumentation is shown for a single injection well and equipment common to both wells. Instrumentation for the second injection well is not shown but will have an identical configuration.

(b) Temporary instrument numbers are given for illustration only. Permanent instrument numbers will comply with the plant tag numbering format.

(c) HMI Object refers to the status or process variable that is shown on the HMI display. HMI Objects may also have real time or historical trends and have the data logged as appropriate. 
Table 6-8. Major Responsibilities for Individuals Overseeing Well Operations

\begin{tabular}{|c|c|c|}
\hline Activity & $\begin{array}{l}\text { Staff Position } \\
\text { (Department) }\end{array}$ & Staff, Shifts per Day \\
\hline $\begin{array}{l}\text { Monitor well operations remotely from the plant } \\
\text { control room, }\end{array}$ & $\begin{array}{l}\text { Control Room Operator } \\
\text { (Operations) }\end{array}$ & 2(4) \\
\hline Respond to/investigate alarm situations & $\begin{array}{l}\text { Control Room Operator } \\
\text { (Operations) }\end{array}$ & $2(4)$ \\
\hline $\begin{array}{l}\text { Conduct periodic inspections of the well site, } \\
\text { including the Well Maintenance and Monitoring } \\
\text { System (WMMS) }\end{array}$ & $\begin{array}{l}\text { Area (Outside) Operators } \\
\text { (Operations); } \\
\text { Security (Operations) }\end{array}$ & $\begin{array}{l}\text { 6(4) (Operators) } \\
\text { 1(4) (Security) }\end{array}$ \\
\hline $\begin{array}{l}\text { Perform maintenance on WMMS as needed } \\
\text { including for example. } \\
\text { - } \quad \text { Change out nitrogen cylinders when depleted } \\
\text { Inspect fluid level in annular fluid tank and } \\
\text { mix/add annular fluid to the tank or pump off } \\
\text { annular fluid to provide capacity for expansion } \\
\text { Remove and test pressure relief valves } \\
\text { (several) } \\
\text { Replace air filters associated with limit } \\
\text { switches on actuated valves on well (8 per well } \\
\text { - } 4 \text { per valve) } \\
\text { Periodically inspect fluid pumps to assure the } \\
\text { oil level is satisfactory. Change oil periodically. } \\
\text { Conduct visual inspection for leaks along } \\
\text { above ground section of annular fluid line }\end{array}$ & Millwrights (Maintenance) & $2(1)$ \\
\hline $\begin{array}{l}\text { Test operation of limit switches on actuated } \\
\text { valves on well ( } 2 \text { valves per well), adjust as } \\
\text { needed. } \\
\text { Calibrate wellhead instrumentation (pressure, } \\
\text { temperature sensors/transmitters) }\end{array}$ & $\begin{array}{l}\text { I\&C Technician } \\
\text { (Maintenance) } \\
\text { Electrician (Maintenance) }\end{array}$ & $\begin{array}{l}2(1) \\
2(1)\end{array}$ \\
\hline $\begin{array}{l}\text { - Check circuit breaker to heat trace controller } \\
\text { for heat trace on annular fluid line }\end{array}$ & Electrician (Maintenance) & $2(1)$ \\
\hline Regulatory compliance and reporting & ESH\&Q Manager (ESH\&Q) & $1(1)$ \\
\hline $\begin{array}{l}\text { Conduct well workovers, mechanical integrity tests, } \\
\text { and ambient pressure (fall-off) tests }\end{array}$ & Contractor & \\
\hline
\end{tabular}

\subsection{Corrosion Monitoring Plan}

This subsection discusses the measures that will be taken to monitor corrosion of well materials, including tubulars (i.e., casing, tubing) and cement; it also describes the planned corrosion monitoring frequency. Although this section is not explicitly called out in the UIC permit application instructions, the IEPA requested that a corrosion monitoring plan be included in the application.

\subsubsection{Casing and Tubing}

Potential sites for corrosion of casing and tubing will be evaluated periodically throughout the life of the injection well using wireline tools. Wireline tools are lowered into the well to directly measure properties of the well tubulars (tubing and casing) that indicate corrosion. Four types of wireline tools are available for assessing corrosion of well materials - mechanical, 
electromagnetic, ultrasonic, and videographic. Mechanical and/or ultrasonic tools will be used to monitor well corrosion. If necessary, a wireline video camera may also be used if results of the other methods are ambiguous or inconclusive. Table 6-9 summarizes examples of mechanical and ultrasonic casing evaluation tools. These tools or similar tools from alternate vendors will be used to monitor the condition of well tubing and casing.

Mechanical casing evaluation tools, referred to as calipers, have multiple "fingers" that measure the inner diameter (I.D.) of the tubular as the tool is raised or lowered through the well. Modernday calipers have several fingers and are capable of recording information measured by each finger so that the data can be used to produce highly detailed three-dimensional images of the well. Figure 6-10 is an illustration of the type of output that can be obtained with a mechanical casing evaluation tool. Examples of caliper tools include Schlumberger's Multifinger Imaging Tool and Halliburton's multiple arm caliper (MAC) tool. Both tools are available in multiple sizes to accommodate various sizes of well tubing and casing.

Ultrasonic tools are capable of measuring wall thickness in addition to the inner diameter (radius) of the well tubular. Consequently, these tools can also provide information about the outer surface of the casing or tubing. Examples of ultrasonic tools include Schlumberger's Ultrasonic Casing Imager (UCI) and Ultrasonic Imager (USI), and Halliburton's CAST-V (Figure 6-11) and FastCast Acoustic Scanning Tools. Specifications for these tools are provided on Table 6-9.

Monitoring corrosion of well materials will also be conducted using the corrosion coupon method. Corrosion monitoring of well materials will be conducted using coupons placed in the $\mathrm{CO}_{2}$ pipeline (Figure 6-12). The coupons will be of the same material as the long string of casing and the injection tubing. The coupons will be removed periodically (e.g., quarterly) and assessed for corrosion using ASTM G1-03, Standard Practice for Preparing, Cleaning, and Evaluating Corrosion Test Specimens. This method measures the corrosivity toward steel of both aqueous and non-aqueous liquid wastes. Upon removal, coupons will be inspected visually for evidence of corrosion (e.g., pitting). The weight and size (thickness, width, length) of the coupons will also be measured and recorded each time they are removed. Corrosion rate will be calculated as the weight loss during the exposure period divided by the duration (i.e., weight loss method). The reader is referred to Section 10 of the method, which discusses factors that affect accuracy and precision of the method and measures that can be taken to minimize error in these parameters.

\subsubsection{Well Cement}

The cement associated with the section of long-string casing that spans the injection reservoir (i.e., Mt. Simon Formation) is susceptible to corrosion because of its exposure to injected $\mathrm{CO}_{2}$. Several measures will be taken during the construction and operation of the injection well to monitor the condition of the cement. As described in Section 3 (see Section 3.7), a corrosion resistant cement will be used in this section to mitigate corrosion that could lead to the formation of channels that could transmit fluid. Furthermore, the condition of the cement will be determined initially when the casing string is cemented using cement bond logging (see Section 3.9), and external mechanical integrity tests will be conducted periodically (see Section 6.3) using temperature surveys or other means to look for evidence of fluid movement behind casing that could be caused by cement corrosion. In addition to these measures, 
cement evaluation logging will be conducted whenever the tubing is removed from the injection well (i.e., during well workovers).

Some ultrasonic casing evaluation tools listed in Table 6-9 are capable of assessing the condition of the cement behind casing at the same time that the casing is evaluated (e.g., Schlumberger's USI tool and Halliburton's FastCast Tool). Therefore, information about the near wellbore cement condition will be obtained whenever tubing is removed from the well and a casing evaluation run is performed using one of these casing inspection logging tools (i.e., during well workovers). Information provided by these ultrasonic tools is limited to the cementto-casing bond; therefore, a standard cement bond logging tool will also be run to inspect the condition of the cement beyond the casing-cement contact. CBL tools are capable of providing both cement-to-casing and cement-to-formation information.

\subsubsection{Deployment Plan}

Wireline logging for the purpose of evaluating corrosion of the well tubing and casing will be conducted periodically as permitted by injection operations. Wireline logging to inspect the condition of the tubing can be conducted without removing the tubing but requires halting $\mathrm{CO}_{2}$ injection and temporary shut in of the well. Therefore, tubing inspections will be coordinated with plant shutdowns, unless a well shutdown is triggered that requires an investigation of a potential tubing leak. At minimum, the tubing will be inspected annually to using a casing evaluation wireline tool. Casing evaluation tools are not capable of sensing the condition of the long-string casing through tubing; therefore, tubing must be removed from the well to inspect the condition of the long-string casing and its cement. Therefore, evaluation of the long-string casing and cement will only be conducted when the tubing is removed from the well (i.e., during well workovers).

Because the wells will be under pressure as a result of injecting $\mathrm{CO}_{2}$, pressure control equipment (e.g., grease injectors) will be required when performing cased-hole logging operations. Because of this, mechanical casing evaluation tools (e.g., multifinger imaging tool and MAC tool) are advantageous because they can be run in either memory mode or with a single conductor cable. The ultrasonic tools require a multi-conductor cable, which requires specialized pressure-control equipment that may not be readily available. Furthermore, mechanical caliper tools can also be run in memory (datalogging) mode rather than surface readout, which eliminates a conductor cable to surface and the need for pressure control equipment. Cased-hole evaluations in $\mathrm{CO}_{2}$ injection wells will also require the use of $\mathrm{CO}_{2^{-}}$ resistant cables. 


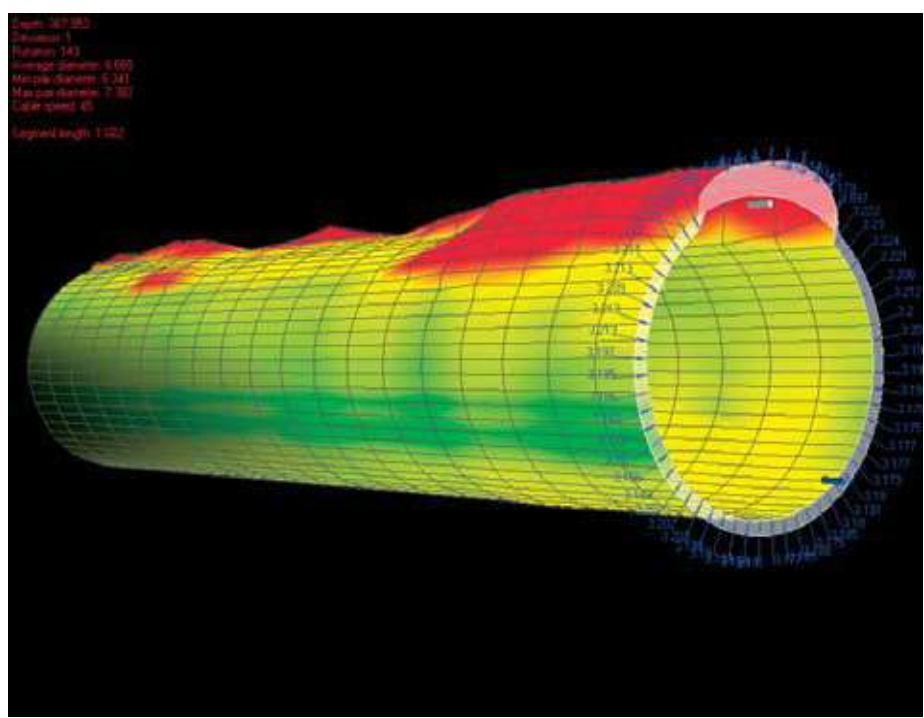

Figure 6-10. A 3D View from a Multi-Arm Caliper (MAC) Tool Shows an Enlarged O.D. Caused by Perforating the Well (Source Halliburton)

Table 6-9. Examples of Wireline Tools for Monitoring Corrosion of Casing and Tubing

\begin{tabular}{|c|c|c|c|c|}
\hline & \multicolumn{2}{|c|}{ Ultrasonic Tools } & \multicolumn{2}{|c|}{ Mechanical Tools } \\
\hline Tool Name & $\begin{array}{l}\text { Ultrasonic Casing } \\
\text { Imager }^{(a)}\end{array}$ & $\begin{array}{l}\text { FastCast Acoustic } \\
\text { Scanning Tool }^{(b)}\end{array}$ & $\begin{array}{l}\text { Multifinger Imaging } \\
\text { Tool }^{(a)}\end{array}$ & $\begin{array}{l}\text { Multi Arm } \\
\text { Caliper Tool }^{(b)}\end{array}$ \\
\hline Type & Ultrasonic & Ultrasonic & Mechanical & Mechanical \\
\hline $\begin{array}{l}\text { What It Measures } \\
\text { (i.e., output) }\end{array}$ & $\begin{array}{l}\text { ID, wall thickness. } \\
\text { Up to } 180 \\
\text { measurements per } \\
\text { revolution }\end{array}$ & $\begin{array}{l}\text { ID, wall thickness } \\
\text { Full } 360 \text { degree } \\
\text { borehole image }\end{array}$ & $\begin{array}{l}\text { Internal radius; } \\
\text { does not measure } \\
\text { wall thickness }\end{array}$ & $\begin{array}{l}\text { Internal radius; } \\
\text { does not measure } \\
\text { wall thickness }\end{array}$ \\
\hline $\begin{array}{l}\text { Tool O.D. } \\
\text { (inches) }\end{array}$ & 3.41 to 8.66 & 3.625 & $\begin{array}{l}1.6875 \text { (PMIT-A) } \\
2.75 \text { (PMIT-B) } \\
4 \text { (PMIT-C) }\end{array}$ & $1.69,2.75,4.0,8.0$ \\
\hline $\begin{array}{l}\text { Tubular Size That } \\
\text { Can Be Measured } \\
\text { Minimum/ } \\
\text { Maximum (inches) }\end{array}$ & $4.5 / 13.375$ & $4.25 / 22.0$ & $\begin{array}{l}\text { 2/4.5 (PMIT-A) } \\
\text { 3/7 (PMIT-B) } \\
\text { 5/10 (PMIT-C) }\end{array}$ & $\begin{array}{l}\text { 1.75-4.524 arm } \\
2.75-7.0 " 40 \mathrm{arm} \\
2.4-9.6360 \mathrm{arm}\end{array}$ \\
\hline $\begin{array}{l}\text { Resolution (mm) } \\
\text { Vertical/Radial }\end{array}$ & $\begin{array}{l}51 \text { to } 381 / 0.005 \\
2 \text { degrees radial }\end{array}$ & 0.1 to 3 in./NA & $\begin{array}{l}2.1 / 0.1 \text { (PMIT-A) } \\
2.8 / 0.13 \text { (PMIT-B) } \\
4.24 / 0.18 \text { (PMIT-C) }\end{array}$ & $\begin{array}{l}0.127 \\
0.508 \\
0.127\end{array}$ \\
\hline Accuracy $(\mathrm{mm})$ & $\begin{array}{l}A= \pm 1 \text { (internal } \\
\text { radius) } \\
A= \pm 4 \% \text { (thickness) } \\
3.8 \mathrm{~mm}(0.15 \text { inch) } \\
\text { pit } \\
7.6 \mathrm{~mm}(0.3 \text { inch) } \\
\text { defect }\end{array}$ & $\mathrm{NA}$ & $\mathrm{A}= \pm 0.76$ to \pm 1.3 & 0.635 \\
\hline
\end{tabular}




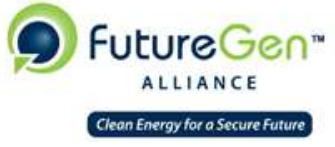

\section{Table 6-9. Examples of Wireline Tools for Monitoring Corrosion of Casing and Tubing (Continued)}

\begin{tabular}{|c|c|c|c|c|}
\hline & \multicolumn{2}{|c|}{ Ultrasonic Tools } & \multicolumn{2}{|c|}{ Mechanical Tools } \\
\hline $\begin{array}{l}\text { Borehole Fluid } \\
\text { Limitations/ } \\
\text { Requirements }\end{array}$ & $\begin{array}{l}\text { Requires static fluid } \\
\text { filled borehole; } \\
\text { therefore, logging all } \\
\text { the way to surface is } \\
\text { usually not possible. } \\
\text { Gas does not } \\
\text { transmit acoustic } \\
\text { signal. Heavy oil } \\
\text { base mud systems } \\
\text { cause attenuation } \\
\text { issues. Scale on } \\
\text { interior of casing can } \\
\text { distort tool } \\
\text { response. } \\
\text { Brine, oil, or very } \\
\text { light muds should be } \\
\text { used. }\end{array}$ & $\begin{array}{l}\text { Requires static fluid } \\
\text { filled borehole; } \\
\text { therefore, logging } \\
\text { all the way to } \\
\text { surface is usually } \\
\text { not possible. } \\
\text { Gas does not } \\
\text { transmit acoustic } \\
\text { signal. Heavy oil } \\
\text { base mud systems } \\
\text { cause attenuation } \\
\text { issues. Scale on } \\
\text { interior of casing } \\
\text { can distort tool } \\
\text { response. }\end{array}$ & $\begin{array}{l}\text { Any type is } \\
\text { acceptable. }\end{array}$ & $\begin{array}{l}\text { Only restricted by } \\
\text { inside diameter of } \\
\text { tubular string. } \\
350^{\circ} \mathrm{F} @ 15 \mathrm{k} \mathrm{psi} \\
\text { rated }\end{array}$ \\
\hline $\begin{array}{l}\text { Comments, } \\
\text { limitations, special } \\
\text { requirements, etc. }\end{array}$ & $\begin{array}{l}\text { An alternate version } \\
\text { of this tool - the USI } \\
\text { can assess cement } \\
\text { simultaneously; } \\
\text { however, may lose } \\
\text { some accuracy/ } \\
\text { resolution. } \\
\text { Therefore, the USI is } \\
\text { recommended over } \\
\text { UCI because it } \\
\text { provides cement } \\
\text { data as well as } \\
\text { casing data. }\end{array}$ & $\begin{array}{l}\text { Pipe inspection and } \\
\text { cement } \\
\text { inspection can be } \\
\text { conducted } \\
\text { simultaneously. } \\
\text { High logging speed } \\
(60 \mathrm{ft} / \mathrm{min}) \text { is } \\
\text { possible. }\end{array}$ & $\begin{array}{l}\text { Typically run on } \\
\text { memory using } \\
\text { slickline. Can also } \\
\text { be run in surface } \\
\text { real time mode. }\end{array}$ & $\begin{array}{l}\text { Typically run on } \\
\text { memory using } \\
\text { slickline. Can also be } \\
\text { run in surface real } \\
\text { time mode. }\end{array}$ \\
\hline
\end{tabular}

(a) Schlumberger

(b) Halliburton

$\mathrm{NA}=$ not available

The multifinger imaging tool (Schlumberger) and MAC Tool (Halliburton) are essentially the same tool (verbal communication, Jim Hill, Halliburton). 


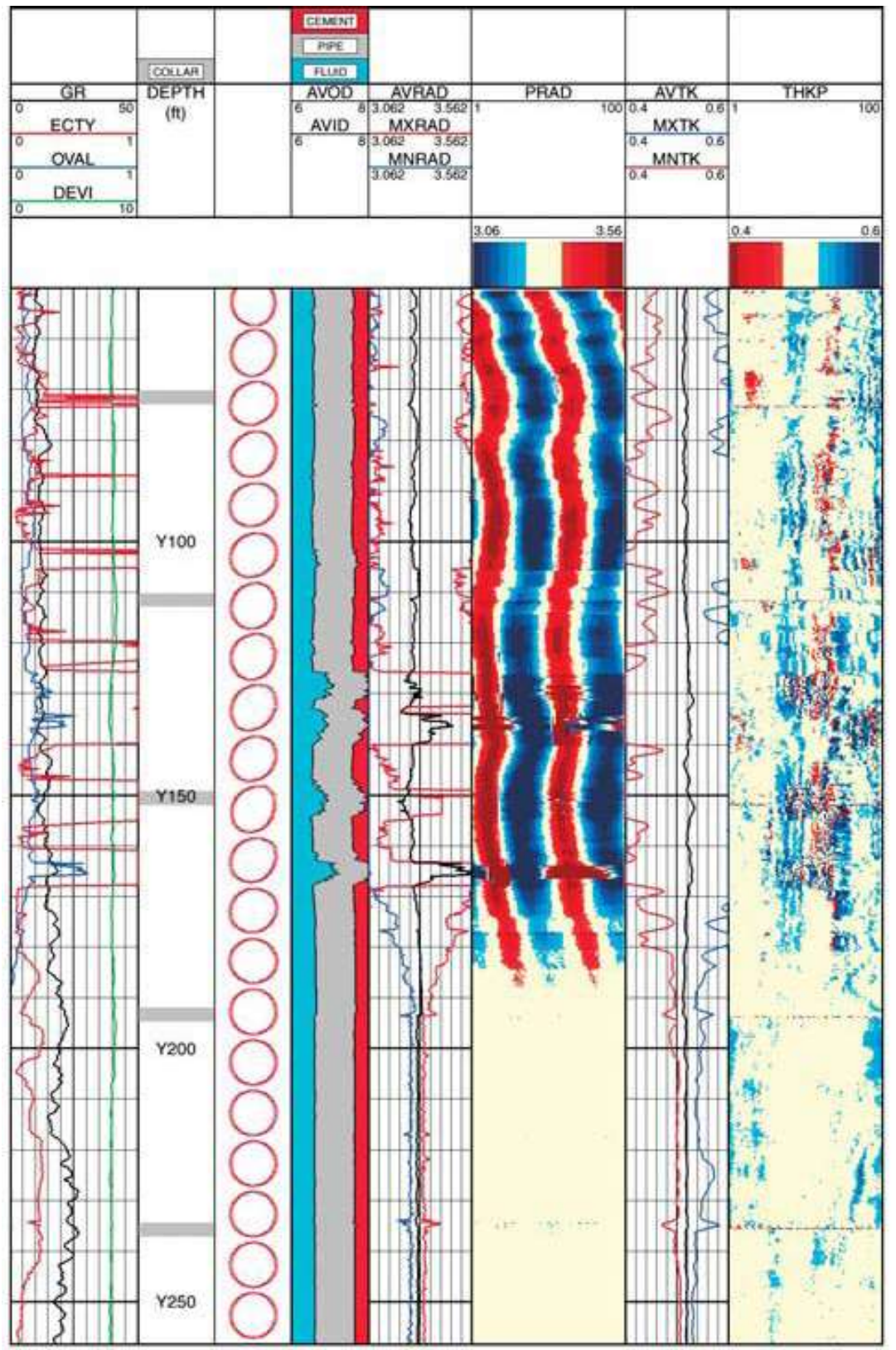

Figure 6-11. Output from Halliburton's CAST-V Acoustic Monitoring Tool (CAST-V has since been replaced by the FastCast Tool). Track 1 shows casing ovality, eccentricity, hole deviation, and gamma ray. Track 2 shows a cross-sectional presentation of the pipe shape. A cross-sectional of the pipe wall is presented in Track 3. Track 4 provides the average, minimum, and maximum value of the pipe radius that is shown in Track 5 . Track 6 provides the average, minimum, and maximum value of the pipe thickness that is the image plotted in last Track 7. On the image logs red shows pipe thinning while blue indicates pipe thickening. (Source: Halliburton). 

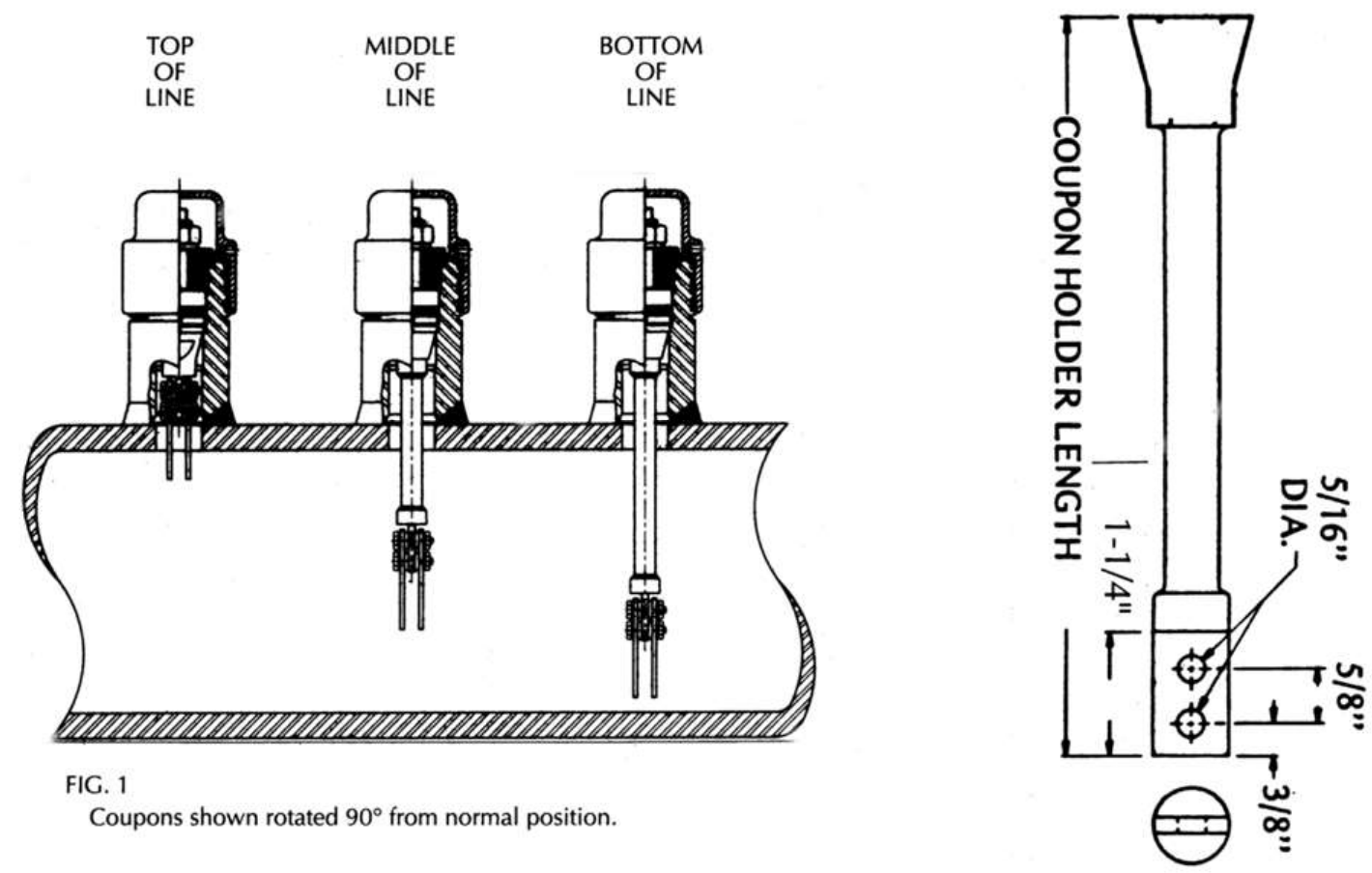

Figure 6-12. Corrosion Coupon Illustration in Pipeline (Source: Rohrback Cosasco Systems, Inc.)

\subsection{References}

ASTM International. 2010. ASTM G1-03, "Standard Practice for Preparing, Cleaning, and Evaluating Corrosion Test Specimens," West Conshohocken, PA, www.astm.org.

ASTM International. 2005. ASTM D6564-00, "Standard Guide for Field Filtration of GroundWater Samples," West Conshohocken, PA, www.astm.org.

ASTM. 2001 Standard Practice for Preparing, Cleaning, and Evaluating Corrosion Test Specimens

Butch, Bob. 2009. Personal communication between Bob Butch of Schlumberger and Jackie Gerst of Battelle, March.

Clayton, J.W. Jr, H. Sherman, S.D. Morrison, J.R. Barnes and D.B. Hood. (1966). Toxicity studies on 1, 1, 2, 2 tetrachloro 1, 2-difluoroethane and 1, 1, 1, 2 tetrachloro 2, 2 difluoroethane." Am. Ind Hyg.

Assoc J., Vol. 27, No. 4, pp. 332-340.

Davis, C.B., and R.J. McNichols. 1999. Simultaneous Non Parametric Prediction Limits. Technometrics. Vol. 41, No.2, 90-112. May.

Graf, D. L., I. Friedman., and W.F. Meents. 1965. "The origin of saline formation waters - II. Isotopic fractionation by shale micropore systems." Illinois State Geo. Survey, Circular 393, p. 132.

Gibbons, R.D. 1994. Statistical Methods for Groundwater Monitoring. New York: Wiley. 
Gilbert, R.O. 1987. Statistical Methods for Environmental Pollution Monitoring. New York: Van Nostrand Reinhold.

O'Brien, R.F., and R.O. Gilbert. 1997. Comparing Sites to Background, Part 1. Environmental Testing \& Analysis (September/October): 12-14.

United States Environmental Protection Agency (U.S. EPA). 1992. Statistical Analysis of Ground-Water Monitoring Data at RCRA Facilities: Addendum to Interim Final Guidance. Washington, DC: Office of Solid Waste. http://www.epa.gov/swertio1/chartext edu.htm\#stats.

United States Environmental Protection Agency (U.S. EPA). 1998a. Statistical Analysis of Ground-Water Monitoring Data at RCRA Facilities: Unified Guidance. Draft. Washington, DC: Office of Solid Waste. http://www.epa.gov/swertio1/chartext edu.htm\#stats.

United States Environmental Protection Agency (U.S. EPA). 1998b. Statistical Tests for Background Comparison at Hazardous Waste Sites. Supplemental Guidance to RAGS: Region 4 Bulletins-Addition \#1. Atlanta, GA. November. http://www.epa.gov/swertio1/chartext_edu.htm\#stats. 


\title{
DRAFT UIC PERMIT FORMS
}

\author{
ILLINOIS ENVIRONMENTAL PROTECTION AGENCY \\ UNDERGROUND INJECTION CONTROL PERMIT APPLICATION
}

\author{
FORM 4f - CHARACTERISTICS, COMPATIBILITY and PRE-INJECTION TREATMENT \\ USEPA ID NUMBER not applicable \\ of INJECTION FLUID \\ IEPA ID NUMBER 0290255208 \\ WELL NUMBER FutGen-INJ-1 and FutGEN-INJ-2
}

Location in Application

\begin{tabular}{|c|c|c|c|c|}
\hline 7.1 & I. & \multicolumn{3}{|c|}{ Component Streams Forming Injection Fluid } \\
\hline 7.2 & II. & \multicolumn{3}{|c|}{ Source and Generation Rate of Component Streams } \\
\hline 7.3 & III. & \multicolumn{3}{|c|}{ Volume of Injection Fluid Generated Daily and Annually } \\
\hline 7.4 & IV. & \multicolumn{3}{|c|}{ Physical and Chemical Characteristics of Injection Fluid, see instructions } \\
\hline 7.4.1 & & A. & \multicolumn{2}{|r|}{ Generic waste/Fluid name } \\
\hline 7.4 .2 & & B. & \multicolumn{2}{|c|}{ Fluid phase } \\
\hline 7.4 .3 & & C. & \multicolumn{2}{|c|}{ Complete waste analysis } \\
\hline 7.4 .4 & & D. & \multicolumn{2}{|c|}{ Flash point } \\
\hline 7.4 .5 & & E. & \multicolumn{2}{|c|}{ Organics } \\
\hline 7.4 .6 & & F. & \multicolumn{2}{|c|}{ TDS } \\
\hline 7.4.7 & & G. & \multicolumn{2}{|c|}{$\mathrm{pH}$} \\
\hline 7.4.8 & & H. & \multicolumn{2}{|c|}{ Temperature } \\
\hline 7.4 .9 & & I. & \multicolumn{2}{|c|}{ Density } \\
\hline 7.4 .10 & & $\mathrm{~J}$. & \multicolumn{2}{|c|}{ Specific gravity } \\
\hline 7.4.11 & & $\mathrm{K}$. & \multicolumn{2}{|c|}{ Compressibility } \\
\hline 7.4.12 & & L. & \multicolumn{2}{|c|}{ Micro organisms } \\
\hline 7.4.13 & & M. & \multicolumn{2}{|c|}{ Chemical persistence } \\
\hline 7.4.14 & & N. & \multicolumn{2}{|c|}{ Key component name(s) } \\
\hline 7.5 & \multirow[t]{14}{*}{ V. } & \multicolumn{3}{|c|}{ Injection Fluid Compatibility } \\
\hline 7.5 .1 & & A. & \multicolumn{2}{|c|}{ Compatibility with injection zone } \\
\hline 7.5 .2 & & B. & \multicolumn{2}{|c|}{ Compatibility with minerals in the injection zone } \\
\hline 7.5 .3 & & C. & \multicolumn{2}{|c|}{ Compatibility with minerals in the confining zone } \\
\hline 7.5 .4 & & D. & \multicolumn{2}{|c|}{ Compatibility with injection well components } \\
\hline 7.5.4.1 & & & & Injection tubing \\
\hline 7.5.4.2 & & & & Long string casing \\
\hline 7.5.4.3 & & & & Cement \\
\hline 7.5.4.4 & & & & Annular fluid \\
\hline 7.5 .4 .5 & & & & Packer(s) \\
\hline 7.5 .4 .6 & & & & Well head equipment \\
\hline 7.5.4.7 & & & & Holding tanks(s) and flow lines \\
\hline 7.5 .5 & & E. & Cor & atibility with filter and filter components \\
\hline 7.5 .6 & & F. & Ful & lescription of compatibility concerns \\
\hline 7.5 .7 & VI. & & ctior & luid Treatment, see instructions \\
\hline
\end{tabular}




\section{Certification}

I certify under penalty of law that this document and all attachments were prepared under my direction or supervision in accordance with a system designed to assure that qualified personnel properly gather and evaluate the information submitted. Based on my inquiry of the person or persons who managed the system, or those persons directly responsible for gathering the information, the information submitted is, to the best of my knowledge and belief, true, accurate and complete. I am aware that there are significant penalties for submitting false information, including the possibility of fine and imprisonment for knowing violations.

Note: per direction from the Illinois EPA, a signature is not required on this form. 


\section{CHARACTERISTICS, COMPATIBILITY AND PRE- INJECTION TREATMENT OF INJECTED FLUID (Form 4f)}

\subsection{Component Streams Forming Injection Fluid}

Section 4.2 of this document provided a description of the FutureGen facility, including the process areas comprising the facility and the component streams forming the injection fluid. As described in Section 4.2 and shown on the process flow diagrams provided in Figure 4-5, and Figure 4-6, there are several streams at different temperatures and pressures entering the compressors and four inlet pressures for the various streams: 15, 45, 70, and 145 psia.

\subsection{Source and Generation Rate of Component Streams}

The total $\mathrm{CO}_{2}$ stream flow rate exiting the last compressor is $578,568 \mathrm{lb} / \mathrm{hr}$ at $2,225 \mathrm{psia}$. The actual flow rate will depend on the type of gasifier used. This rate is the highest estimated mass flow rate for Illinois 6 (ILL 6) coal and two different gasifier technologies that are currently being considered.

\subsection{Volume of Injection Fluid Generated Daily and Annually}

The volumetric flow rate of the $\mathrm{CO}_{2}$ stream can be estimated from the predicted mass flow rate and product density. The mass flow rate is dependent on the type of coal and the gasifier technology. The density is also a function of the temperature. The design temperature is $120^{\circ} \mathrm{F}$ at the plant exit; however, the fluid may be cooled to $105^{\circ} \mathrm{F}$ to facilitate injection. As mentioned in the previous section, two gasifier technologies are currently being evaluated. Table 7-1 presents estimates of volumetric flow rate for three coal types, two gasifier technologies, and temperatures of $105^{\circ} \mathrm{F}$ and $120^{\circ} \mathrm{F}$. The highest volumetric flow rate $\left(16,456 \mathrm{ft}^{3} / \mathrm{hr}\right)$ corresponds to the Illinois $6 \mathrm{coal}$, gasifier technology \#1, and a temperature of $120^{\circ} \mathrm{F}$. The lowest volumetric flow rate $\left(11,149 \mathrm{ft}^{3} / \mathrm{hr}\right)$ corresponds to the Pitt 8 coal, gasifier technology \#2, and a temperature of $105^{\circ} \mathrm{F}$. This corresponds to a range of daily volumetric flow rates of 267,565 to 394,949

$\mathrm{ft}^{3} /$ day and a range of annual flow rates of approximately 98 to 144 million $\mathrm{ft}^{3} / \mathrm{yr}$.

Table 7-1. Volumetric Flow Rate Estimates

\begin{tabular}{|l|c|c|c|}
\hline \multirow{2}{*}{ Parameter } & & Gasifier Technology \#1 & Gasifier Technology \#2 \\
\cline { 3 - 4 } & Units & ILL 6 Coal & ILL 6 Coal \\
\hline Mass Flow ${ }^{(a)}$ & $\mathrm{lb} / \mathrm{hr}$ & 578,568 & 531,161 \\
\hline $\begin{array}{l}\text { Volume Flow @ 2,225 psi } \\
120^{\circ} \mathrm{F}^{(\mathrm{b})}\end{array}$ & $\mathrm{ft}^{3} / \mathrm{hr}$ & 16,456 & 15,606 \\
\hline $\begin{array}{l}\text { Volume Flow @ 2,225 psi } \\
105^{\circ} \mathrm{F}^{(\mathrm{b})}\end{array}$ & $\mathrm{ft}^{3} / \mathrm{hr}$ & 12,366 & 11,353 \\
\hline
\end{tabular}

(a) Mass flow rate estimates based on ASPEN model output for Location 909 (compressor outlet).

(b) Volumetric flow rates at $120^{\circ} \mathrm{F}$ based on density estimates provided in Table 7-2; volumetric flow rates at $105^{\circ} \mathrm{F}$ based on a density estimate of $46.8 \mathrm{lb} / \mathrm{ft}^{3}$. 


\subsection{Physical and Chemical Characteristics of Injection Fluid}

Table 7-2 provides a description of the physical and chemical characteristics of the injection fluid. The information in Table 7-2 describes the injection fluid downstream of the final compression stage and therefore is representative of the fluid that will be delivered to the injection wells. The $\mathrm{CO}_{2}$ will be in a supercritical liquid phase at this point. This information is an estimate based on a heat and material balance conducted for the power plant; therefore, actual properties may vary slightly. Also, actual temperature may be reduced via air cooling to as low as $105^{\circ} \mathrm{F}$ and pressure may be increased as high as 3,000 psia if necessary to facilitate injection.

Table 7-2. Physical and Chemical Characteristics of Injection Fluid

\begin{tabular}{|c|c|c|c|}
\hline & & Gasifier Technology \#1 & Gasifier Technology \#2 \\
\hline Parameter & Units & ILL 6 Coal & ILL 6 Coal \\
\hline Temperature & ${ }^{\circ} \mathrm{F}$ & 120 & 2,225 \\
\hline Pressure & psia & 2,225 & 2,225 \\
\hline Mass Flow & $\mathrm{Ib} / \mathrm{hr}$ & 578,568 & 531,161 \\
\hline Mole Flow & lbmole/hr & 13,479 & 12,467 \\
\hline Volume Flow & $\mathrm{ft}^{3} / \mathrm{hr}$ & 16,456 & 15,606 \\
\hline Enthalpy & $\mathrm{mmbtu} / \mathrm{hr}$ & $-2,262$ & -2071.4 \\
\hline Mass Enthalpy & $\mathrm{btu} / \mathrm{lb}$ & $-3,910$ & $-3,900$ \\
\hline Density & $\mathrm{lb} / \mathrm{ft}^{3}$ & 35.158 & 34.036 \\
\hline Molecular Weight & & 42.92 & 42.61 \\
\hline \multicolumn{4}{|c|}{ Dense Phase } \\
\hline Comp. Factor (Z) & & 0.4367 & 0.4473 \\
\hline Viscosity & $\mathrm{cp}$ & 0.0431 & 0.0416 \\
\hline Thermal Cond. & $\begin{array}{c}\text { Btu/hr-ft- } \\
\text { R }\end{array}$ & 0.0372 & 0.0365 \\
\hline $\mathrm{C}_{\mathrm{p}} / \mathrm{C}_{\mathrm{v}}$ & & 1.2804 & 1.2814 \\
\hline Heat Capacity & Btu/lb-R & 0.7874 & 0.7940 \\
\hline
\end{tabular}

$\mathrm{cp}-$ centipoises

$\mathrm{C}_{\mathrm{p}} / \mathrm{C}_{\mathrm{v}}$ - specific heat capacity ratio

\subsubsection{Generic Waste/Fluid Name}

Carbon dioxide.

\subsubsection{Fluid Phase}

The injection fluid will be in a supercritical liquid phase when it is injected into the well.

\subsubsection{Complete Waste Analysis}

An estimate of the injection fluid composition based on a heat and material balance analysis for the power plant was provided in Table 7-2 of this document. Actual properties and composition may vary slightly.

Characteristics of the injection fluid (e.g. toxicity, reactivity, corrosiveness, radioactivity and ignitability) were evaluated according to the provisions of $35 \mathrm{III}$. Adm. Code, Part 721, Subparts $\mathrm{C}$ and D: Characteristics of Hazardous Waste. The injection fluid is not considered to be 
ignitable or toxic. The liquid is non-aqueous and cannot be considered corrosive. It is not reactive nor does it contain any radioactive components. The $\mathrm{CO}_{2}$ stream is not considered hazardous.

\subsubsection{Flash Point}

The injection fluid is not flammable; therefore, flashpoint is not applicable.

\subsubsection{Organics}

Methane and carbonyl sulfide are the only organic compounds expected to be present in the injection fluid (both at trace levels). The estimated quantity of methane in the injection fluid is $0.0002 \%$ to $0.17 \%$ by weight, depending on the type of coal and the gasifier technology that is employed. The estimated quantity of carbonyl sulfide is 0.0003 to $0.0053 \%$ by weight. No other organic compounds, including volatile organic compounds and semi-volatile organic compounds, are expected to be present in the injection fluid. See Table 7-2 for a comprehensive estimate of the chemical composition of the injection fluid.

\subsubsection{TDS}

The combined content of all inorganic and organic substances contained in the injection fluid is very small; therefore, the TDS concentration of the injection fluid is expected to be negligible.

\subsection{7 $\quad \mathrm{pH}$}

Because the injection fluid is non-aqueous, it has no $\mathrm{pH}$ and this term is not applicable. Injection of $\mathrm{CO}_{2}$ will result in lowering of the $\mathrm{pH}$ in the $\mathrm{Mt}$. Simon storage reservoir. Modeling conducted by the Illinois Geological Survey (Fisher, 2005, Table 8-5) suggest that the $\mathrm{pH}$ of the Mt. Simon formation water may be reduced from an initial value of 6.3 to approximately 3.4 due to the formation of carbonic acid when the injected $\mathrm{CO}_{2}$ reacts with pore water.

\subsubsection{Temperature}

The current design temperature of the injection fluid exiting the plant is approximately $120^{\circ} \mathrm{F}$; however, additional cooling capacity may be added to reduce the product temperature to as low as $105^{\circ} \mathrm{F}$ in order to increase the density of the product and facilitate injection. The injection fluid will undergo a small amount of temperature change as it travels through the pipeline on the way to the injection wells; however, given the short distance of the pipeline, the temperature change will be small.

\subsubsection{Density}

The estimated density of the injection fluid is $35 \mathrm{lb} / \mathrm{ft}^{3}$ at temperature of $120^{\circ} \mathrm{F}$ and a pressure of 2,225 psi (Table 7-2). This estimate was derived from the ASPEN process-engineering software that was used to model the heat and material balance for the power plant. This model uses a Peng-Robinson equation of state to determine product density. At a temperature of $105^{\circ} \mathrm{F}$, the density will be greater. A density of $46.8 \mathrm{lb} / \mathrm{ft}^{3}$ was estimated based on the PengRobinson equation of state and a pressure of 2,225 psi. The plant is being designed to compress the $\mathrm{CO}_{2}$ stream up to 3,000 psi. At a pressure of 3000 psi, the density of the compressed $\mathrm{CO}_{2}$ stream is estimated to be $49.91 \mathrm{lb} / \mathrm{ft}^{3}$ at $120^{\circ} \mathrm{F}$ and $52.69 \mathrm{lb} / \mathrm{ft}^{3}$ at $105^{\circ} \mathrm{F}$. 


\subsubsection{Specific Gravity}

At a temperature of $120^{\circ} \mathrm{F}$ and a pressure of $2,225 \mathrm{psi}$ (density of $35 \mathrm{Ib} / \mathrm{ft}^{3}$ ), the injection fluid will have a specific gravity of approximately 0.55 . At a temperature of $105^{\circ} \mathrm{F}$ and a pressure of $2,225 \mathrm{psi}$ (density of $47 \mathrm{lb} / \mathrm{ft}^{3}$ ), the injection fluid will have a specific gravity of approximately 0.75 . Similarly, the specific gravity would be higher at a temperature of $105^{\circ} \mathrm{F}$ and a pressure of $3,000 \mathrm{psi}$. These estimates are based on a reference density of water equal to $62.4 \mathrm{lb} / \mathrm{ft}^{3}$.

\subsubsection{Compressibility}

Because the injection fluid will be in a liquid phase, its compressibility is negligible. The estimated compressibility factor $(Z)$ for the injection fluid is estimated to be approximately 0.44 (Table 7-2).

\subsubsection{Microorganisms}

Microorganisms are not a component of the injection fluid.

\subsubsection{Chemical Persistence}

The predominant component of the injection fluid is $\mathrm{CO}_{2}$, representing approximately $99.5 \%$ of the injection fluid by mass. The major fate processes that will affect the injected $\mathrm{CO}_{2}$ are partitioning and chemical reaction. Injected $\mathrm{CO}_{2}$ would partition in the reservoir between the non-aqueous pure phase, entrapped phase, and dissolved phase. The short-term partitioning of $\mathrm{CO}_{2}$ between the pure and aqueous phases is dependent on the aqueous phase salinity; the amount of $\mathrm{CO}_{2}$ dissolved in the aqueous phase is inversely proportional to the salinity.

Dissolution is expected to be a very slow process such that most of the injected $\mathrm{CO}_{2}$ will remain in the pure phase. Depending on the reservoir geochemical environment and rock compositions, injected $\mathrm{CO}_{2}$ may also mineralize as carbonates over time (salt formation). Chemical reactivity between the injected $\mathrm{CO}_{2}$ and the rocks and minerals comprising the storage reservoir is expected to be very limited, as discussed in Sections 7.5.1 through 7.5.3.

\subsubsection{Key Component Name(s)}

A description of the injection fluid composition was provided in Tables 6-3 and 6-4 of this document.

\subsection{Injection Fluid Compatibility}

\subsubsection{Compatibility with Injection Zone}

A recent assessment of carbon sequestration potential in the Illinois Basin found no incompatibility for injection of $\mathrm{CO}_{2}$ into the Mt. Simon Sandstone (Fisher, 2005). That study used geochemical modeling to evaluate the effects of $\mathrm{CO}_{2}$ injection into a saline reservoir in the Illinois Basin. The geochemical modeling software package Geochemist's Workbench (Bethke, 2004) was used for the modeling. The conceptual model for the reservoir was based on geologic and water chemistry data from the Mt. Simon Formation at Manlove Gas Storage Field, in Illinois. Geologic data from Manlove Field were used as an analog in developing estimates of properties expected for the Mt. Simon at the Mattoon Site (e.g., Section 2.4.3.4 of this application). Several geochemical reactions were modeled in that study, including formation of $\mathrm{CO}_{2}$ plume water from reaction of supercritical $\mathrm{CO}_{2}$ with Mt. Simon formation water; reaction of the $\mathrm{CO}_{2}$ plume water with minerals of the Mt. Simon Formation (discussed in Section 7.5.2); and 
reaction of that water with shale interbeds in the Mt. Simon and with the Eau Claire sealing formation (discussed in Section 7.5.3).

The reaction of formation water with supercritical $\mathrm{CO}_{2}$ did not suggest any incompatibility of the injection fluid and the Mt. Simon formation water. The reaction led to a decrease in $\mathrm{pH}$ from an initial value of 6.3 to 3.4 , and an increase in dissolved carbon from 81.8 to $4.4 \times 10^{4} \mathrm{mg} / \mathrm{kg} \mathrm{H} \mathrm{H}_{2} \mathrm{O}$ (Fisher, 2005, Table 8-5).

\subsubsection{Compatibility with Minerals in the Injection Zone}

Fisher (2005) modeled the reaction of the fluid formed by reaction of supercritical $\mathrm{CO}_{2}$ with Mt. Simon formation water with the minerals of the Mt. Simon Formation. The composition of the Mt. Simon at Manlove Field is dominantly quartz sand with a small amount of potassium feldspar (Fisher, 2005). Because quartz sand does not react strongly to low-pH water, Fisher (2005) modeled the reaction of the $\mathrm{CO}_{2}$ plume fluid with microcline (a potassium feldspar). Modeling of this reaction led to an increase in $\mathrm{pH}$ of the plume fluid from 3.4 to 4.95. A small amount of sodium aluminum carbonate hydroxide (dawsonite) was predicted to precipitate, reducing the porosity from $10 \%$ to approximately $9.9 \%$. The small amount of porosity reduction expected in the Mt. Simon Sandstone would not be expected to have any impact on injection of $\mathrm{CO}_{2}$ into the formation.

Fisher (2005) also modeled the interaction of the plume fluid with shale interbeds that are present within the Mt. Simon Sandstone at Manlove Field. Samples from the shale interbeds have about $50 \%$ shale, most of which is illite. As the result of the reaction with the shale interbeds, the fluid $\mathrm{pH}$ would increase to 6.7, a small amount of illite would dissolve, and several minerals would precipitate in small concentrations (Fisher, 2005, Figure 8-6). However, total change in porosity would be minor, a decrease from $10 \%$ to about $9.3 \%$. Again, this would not be expected to impact injection of the $\mathrm{CO}_{2}$, and indicates a potential for a small amount of $\mathrm{CO}_{2}$ to be sequestrated in the Mt. Simon Formation by mineral precipitation.

\subsubsection{Compatibility with Minerals in the Confining Zone}

Due to buoyancy of the $\mathrm{CO}_{2}$ plume, it will eventually rise until it contacts the Eau Claire Shale, the primary confining unit (e.g., see Section 5.4). Fisher (2005) modeled the reaction of the $\mathrm{CO}_{2}$ plume water with the minerals of the Eau Claire Formation. The composition of the Eau Claire was estimated from a silty shale sample provided by the ISGS. The composition of that sample was about $40 \%$ clay, with most of that being illite. This is very similar to the composition of the Mt. Simon shale interbeds, so the same results would be obtained by reaction of the illite in the Eau Claire with the plume fluid, i.e., dissolution of a small amount of illite, with precipitation of small amounts of magnesite, quartz, kaolinite and other minerals (Fisher, 2005, Figure 8-6). The minor amounts of dissolution and precipitation described by Fisher (2005) based on geochemical modeling, with an overall small net decrease in porosity of the Eau Claire, do not suggest anything that would decrease the integrity or effectiveness of the caprock.

\subsubsection{Compatibility with Injection Well Components}

Corrosion of the injection tubing and long-string casing will be mitigated in several ways: using corrosion resistant alloys for selected portions of the well; injecting dry $\mathrm{CO}_{2}$, which reduces the formation of corrosive carbonic acid; fully cementing the long-string casing to surface to 
minimize contact with brine and $\mathrm{CO}_{2}$ that could cause corrosion; and using an annular fluid with corrosion inhibitors.

\subsubsection{Injection Tubing}

Because of the similarity between the injection tubing and the long-string casing, this section discusses compatibility between the $\mathrm{CO}_{2}$ injection stream and both the injection tubing and longstring casing. Injection tubing and long-string casing used in the injection well(s) will be comprised of API grade carbon steel (e.g., N-80) and a corrosion resistant stainless steel such as $13 \%$ chromium material $(\mathrm{Cr} 13 \%)$. At minimum, the section of the long-string casing spanning the injection zone (the Mt. Simon Sandstone) will be comprised of a corrosion resistant alloy material. The injection tubing may be comprised of carbon steel (e.g., N-80) or stainless steel because the tubing will be periodically inspected for corrosion and replaced if necessary.

A corrosion modeling assessment was conducted to evaluate the compatibility of carbon steel (API Grade L-80) ( $\mathrm{L}-80$ is comparable to N-80 in terms of physical properties such as yield strength. L-80 is more suitable for sour gas service, which is not a concern at this site) and three varieties of stainless steel with the $\mathrm{CO}_{2}$ injection fluid to aid in selecting appropriate well materials. Two types of corrosion were evaluated - general corrosion and pitting corrosion. The three grades of stainless steel that were evaluated in the assessment include: conventional $\mathrm{Cr} 13 \%$, modified $\mathrm{Cr} 13 \%$, and Super $\mathrm{Cr} 13 \%$ (Super $\mathrm{Cr} 13 \%$ is a trade name of the Sumitomo Company). Other steel companies refer to this material by other names. For example, JFE manufactures a similar material that is called HP2 Cr13\%. The composition of the three alloys used in the modeling is provided in Table 7-3. The significant difference between these materials is the decreased amount of carbon and the increased amount of other materials, namely molybdenum (Mo) and nickel (Ni) going from conventional $\mathrm{Cr} 13 \%$ to Super $\mathrm{Cr} 13 \%$.

Table 7-3. Composition of Three Stainless Steel Alloys

\begin{tabular}{|l|c|c|c|c|c|c|c|c|}
\hline \multicolumn{1}{|c|}{ Grade } & C & Mn & Si & Cr & Mo & P & S & Ni \\
\hline Conventional Cr13\% $^{2}$ & 0.21 & 0.35 & 0.46 & 12.8 & 0.02 & 0.015 & 0.001 & 0.12 \\
\hline Modified Cr13\% $^{\mathrm{a}}$ & 0.007 & 0.67 & 0.26 & 12.77 & 0.6 & 0.004 & 0.001 & 4.59 \\
\hline Super Cr13\% $^{\mathrm{a}}$ & 0.007 & 1.25 & 0.23 & 12.2 & 2 & 0.02 & 0.001 & 6.05 \\
\hline
\end{tabular}

(a) Amaya, Hisashi, Tomoki Mori, Kunio Kondo, Hiroyuki Hirata, and Masakatsu Ueda. 1998. "Effect on Chromium and Molybdenum on Corrosion Resistance of Super Cr 13 Martensitic Stainless Steel in $\mathrm{CO}_{2}$ Environment," NACE International, CORROSION 98, March 22-27.

The modeling assessment estimated the time required for general corrosion to penetrate each material, assuming an initial wall thickness of 0.5 inches. Parameters used for the corrosion modeling analyses are summarized in Table 7-4. Parameters used to model general corrosion include temperature, $\mathrm{CO}_{2}$ pressure, and pipe properties (wall thickness, composition). Parameters used for the pitting corrosion scenario include temperature, $\mathrm{CO}_{2}$ pressure, pipe properties (wall thickness, composition), and flow rate. In addition, the general and pitting analyses assume sufficient water $\left(>18 \mathrm{ppm} \mathrm{H}_{2} \mathrm{O}\right)$ is present to activate corrosion immediately. The section of the long-string casing that is below the packer and tubing is the most likely section to be affected by $\mathrm{CO}_{2}$-induced corrosion because $\mathrm{CO}_{2}$ might mix with water in this zone . 


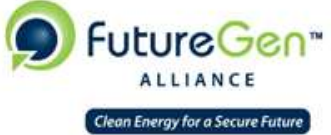

Table 7-4. Operating Conditions for Corrosion Modeling Analyses

\begin{tabular}{|l|l|l|}
\hline \multicolumn{1}{|c|}{ Parameter } & \multicolumn{1}{|c|}{ Value } & \multicolumn{1}{c|}{ Scenario } \\
\hline Tubing & $\begin{array}{l}\text { O.D. }=5-1 / 2 \text { inches } \\
\text { I.D. }=4.50 \text { inches (wall thickness }=0.50 \\
\text { inches) }\end{array}$ & $\begin{array}{l}\text { General Corrosion, Pitting } \\
\text { Corrosion }\end{array}$ \\
\hline Casing & $\begin{array}{l}\text { O.D. }=9-5 / 8 \text { inches } \\
\text { I.D. }=8.50 \text { inches (wall thickness }=0.5 \\
\text { inches) }\end{array}$ & $\begin{array}{l}\text { General Corrosion, Pitting } \\
\text { Corrosion }\end{array}$ \\
\hline Wellhead pressure & 2,200 psi & $\begin{array}{l}\text { General Corrosion, Pitting } \\
\text { Corrosion }\end{array}$ \\
\hline Bottomhole temperature & $147^{\circ} \mathrm{F}$ to $165^{\circ} \mathrm{F}$ & $\begin{array}{l}\text { General Corrosion, Pitting } \\
\text { Corrosion }\end{array}$ \\
\hline Reynolds Number & $\begin{array}{l}561,266 \text { (corresponding to mass flow rate of } \\
\text { approximately } 263 \text { tonnes } / \mathrm{hr} \text { ) } \\
256,000 \text { (corresponding to mass flow rate of } \\
\text { approximately } 114 \text { tonnes } / \mathrm{hr} \text { ) }\end{array}$ & Pitting Corrosion \\
\hline
\end{tabular}

Figure 7-1 shows the general corrosion modeling results for the four different steel materials over a range of temperatures. The temperature interval from $147^{\circ} \mathrm{F}$ to $165^{\circ} \mathrm{F}$ is highlighted because this is the approximate temperature range of the reservoir at the bottom of the well. As shown on Figure 7-1, there is a decrease in penetration time with increasing temperature. For the temperature range of interest, estimated penetration times for the four materials range from approximately 3.5 years (carbon steel, highest temperature) to 127 years (SuperCr13, lowest temperature) (Table 7-5).

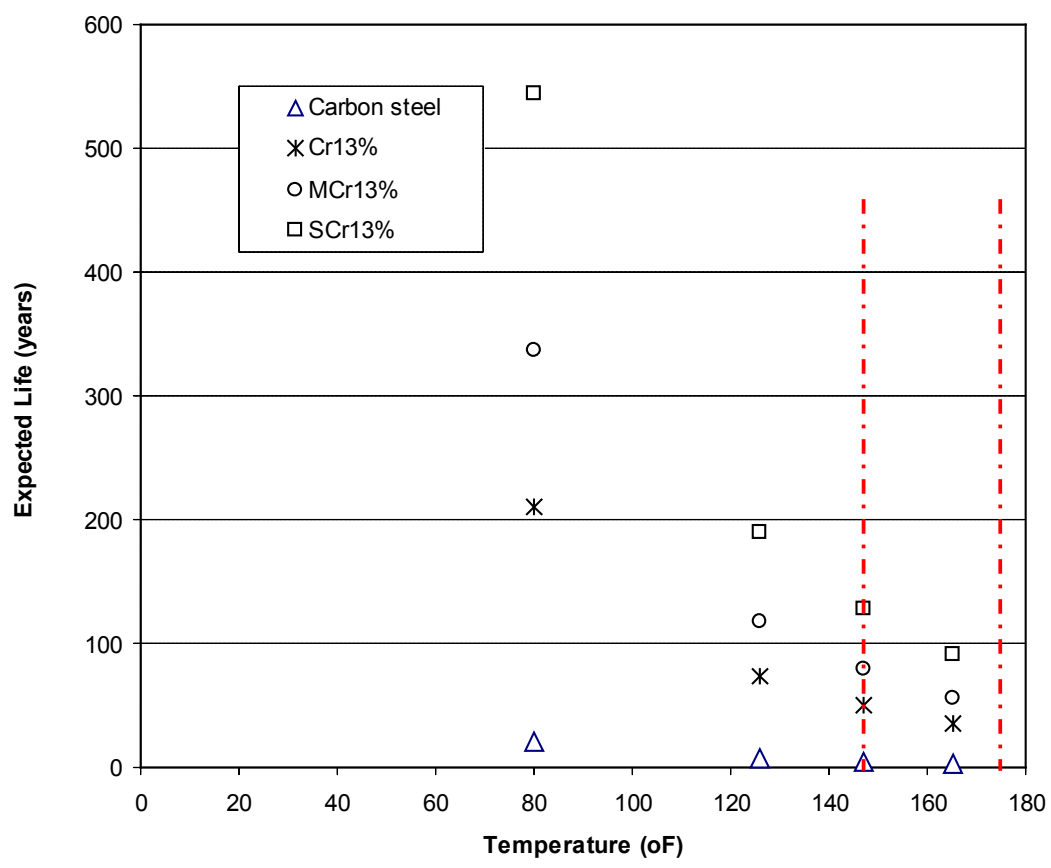

Figure 7-1. Expected Penetration Times (0.5 inch) for Four Materials Assuming General Corrosion Process (Red Lines Bracket Anticipated Bottomhole Temperature) 
Table 7-5. Expected Life ( $100 \%$ penetration of 0.5 inch) for Four Materials Assuming General Corrosion

\begin{tabular}{|c|c|c|c|c|}
\hline $\begin{array}{c}\text { Temperature } \\
\left({ }^{\circ} \mathrm{F}\right)\end{array}$ & $\begin{array}{c}\text { Expected life } \\
\text { (years) } \\
\text { Carbon Steel }\end{array}$ & $\begin{array}{c}\text { Expected life } \\
\text { (years) } \\
\text { Cr13\% }\end{array}$ & $\begin{array}{c}\text { Expected life } \\
\text { (years) } \\
\text { MCr13\% }\end{array}$ & $\begin{array}{c}\text { Expected life } \\
\text { (years) } \\
\text { SCr13\% }\end{array}$ \\
\hline 147 & 4.9 & 49 & 79 & 127 \\
\hline 165 & 3.5 & 35 & 56 & 91 \\
\hline
\end{tabular}

MCr13\% - Modified Cr13\%

SCr13\% - SuperCr13\%

The pitting analysis evaluated penetration time of the 5-1/2 inch (4.5 inch I.D.) injection tubing due to pitting corrosion. The pitting analysis takes into account the flow conditions (represented by Reynolds Number). Pitting can occur only after a defect develops; however, in this analysis, it was conservatively assumed that the defect is present initially to activate corrosion. Results are provided in Table 7-6 and Figure 7-2. Results are provided in Table 7-6 for a range of Reynolds numbers and materials. There is an inverse relationship between Reynolds number and the modeled penetration time for any particular material. Penetration occurs most rapidly in carbon steel and takes considerably longer in corrosion resistant alloys. In Figure 7-2, a Reynolds number of 561,266 is highlighted because this is the approximate value anticipated for the Reynolds number when $\mathrm{CO}_{2}$ mass flow rate is steady at the maximum possible plant output of 263 tonnes/hr $(578,568 \mathrm{lb} / \mathrm{hr})$. This flow rate corresponds to the rate that would be expected if the plant is continuously producing the maximum possible amount of $\mathrm{CO}_{2}$. If the flow rate is less, this would result in a lower Reynolds number. For example, for a flow rate of 1 million tonnes per year (114 tonnes/hr), the Reynolds number is 256,000 (also highlighted on the figure). As shown on Figure 7-2, a lower Reynolds number results in longer penetration time. These results suggest that there is a potential for penetration of the injection tubing within the four-year injection phase under the worst case scenario of continuous injection at the maximum flow rate. Periodic (e.g., annual) corrosion monitoring can be performed to detect and monitor pitting and take correction action as needed (e.g., replacement) before complete penetration of the injection tubing occurs. Using stainless steel material for the injection tubing would decrease the potential for corrosion and the frequency of well workovers requiring tubing replacement or repair.

Table 7-6. Expected Penetration Time for Injection Tubing Assuming Pitting Corrosion

\begin{tabular}{|l|c|c|c|c|c|}
\hline \multirow{2}{*}{ Material } & \multicolumn{4}{|c|}{ Modeled Penetration Time (years) for Various Values of Reynolds Number } \\
\cline { 2 - 6 } & $\mathbf{R e}=\mathbf{1 , 1 0 0 , 0 0 0}$ & $\mathbf{R e}=\mathbf{1 , 0 0 0 , 0 0 0}$ & $\mathbf{R e}=\mathbf{5 0 0 , 0 0 0}$ & $\mathbf{R e}=\mathbf{3 0 0 , 0 0 0}$ & $\mathbf{R e = 1 0 0 , 0 0 0}$ \\
\hline Carbon Steel & 1.50 & 1.62 & 2.82 & 4.24 & 10.22 \\
\hline Conventional Cr13\% & 1.55 & 1.67 & 2.91 & 4.37 & 10.53 \\
\hline Modified Cr13\% & 2.03 & 2.19 & 3.81 & 5.74 & 13.81 \\
\hline Super Cr13\% & 2.26 & 2.44 & 4.25 & 6.40 & 15.42 \\
\hline
\end{tabular}

Note: The Reynolds number is based on the non-dimensional expression: $\mathrm{Re}=\frac{\rho V D}{\mu}=\frac{V D}{v}$ where, $\mathrm{V}$ is the mean fluid velocity, $(\mathrm{m} / \mathrm{s}), \mu$ is the dynamic viscosity of the fluid $\left(\mathrm{Pa} \cdot \mathrm{s}\right.$ or $\left.\mathrm{N} \cdot \mathrm{s} / \mathrm{m}^{2}\right), v$ is the kinematic viscosity, $(v=\mu / \rho), \rho$ is the density of the fluid $\left(\mathrm{Kg} / \mathrm{m}^{3}\right)$, and $D$ is the diameter of the pipe $(\mathrm{m})$. 


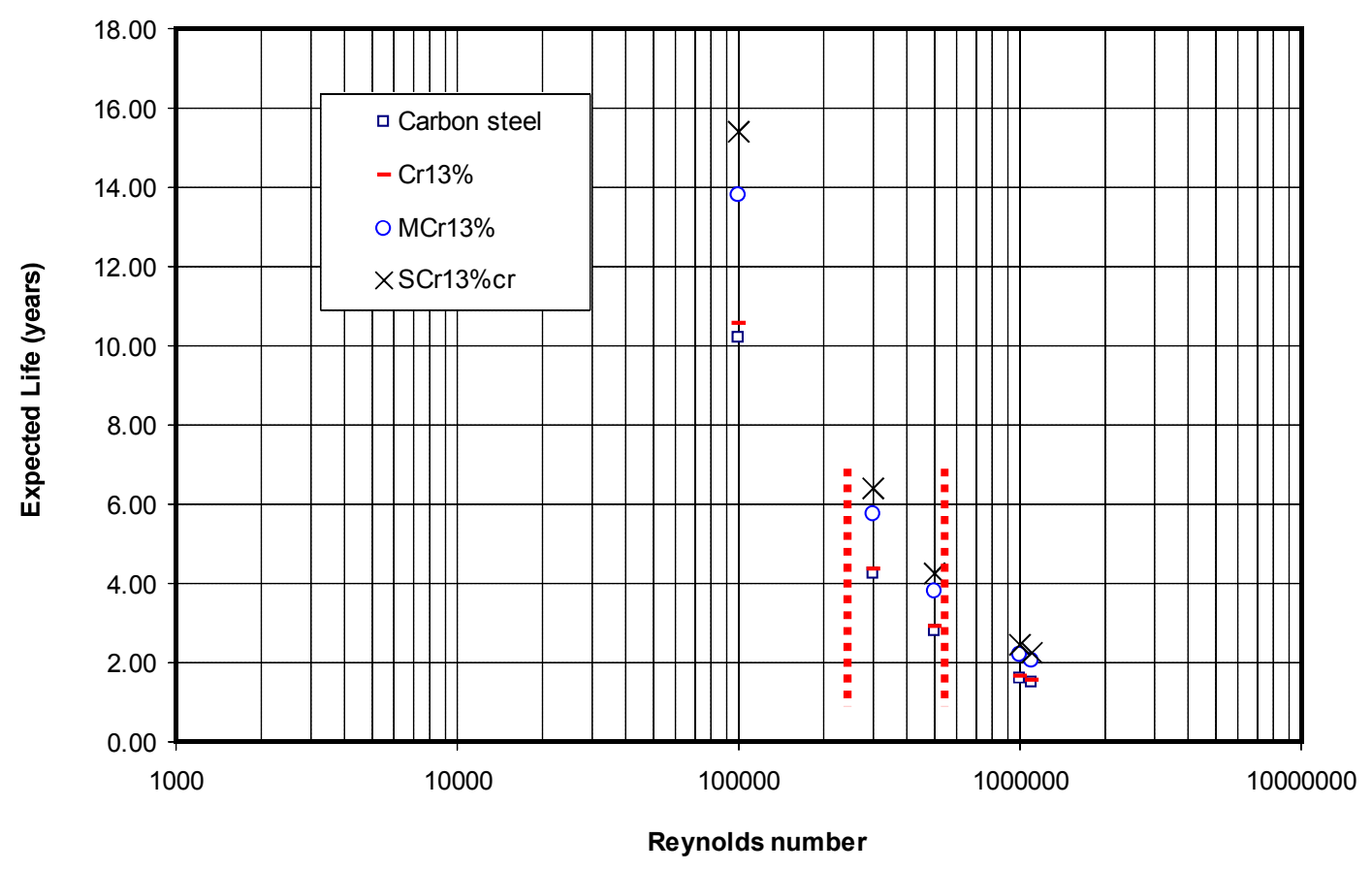

Figure 7-2. Expected Penetration Time for Injection Tubing Four Materials Assuming Pitting Corrosion

\subsubsection{Long String Casing}

Compatibility between the $\mathrm{CO}_{2}$ injection stream and long-string casing was discussed in the previous section.

\subsubsection{Cement}

A CO 2 -resistant cement will be used for the injection interval to provide increased resistance to degradation by $\mathrm{CO}_{2}$ (carbonic acid) compared to traditional portland cement-based materials. At this time, the cement that has been selected for the long-string casing opposite the storage reservoir is EverCRETE ${ }^{\text {TM }}$ Cement (Schlumberger). A description of this material, including its corrosion resistant properties, was provided in Section 3.7.4.4 of this document.

\subsubsection{Annular Fluid}

An annular fluid will be emplaced in the well in the space above the packer between the injection tubing and the long-string casing. The specific fluid will be a light brine such as $\mathrm{KCl}$ or $\mathrm{CaCl}_{2}$ with a weight of approximately $8.5 \mathrm{ppg}$. The final weight will be determined following drilling and downhole testing to determine the weight and pressure of the formation fluid in the Mt. Simon injection interval. The annular fluid will be filtered to avoid introducing suspended matter into the annular that could interfere with the downhole equipment and the aboveground annular pressure maintenance system (see Section 3.7.5). The annular fluid will contain a corrosion inhibitor that is compatible with the well materials and an oxygen scavenger to reduce the potential for corrosion of the tubing, casing and packer. A sample annular corrosion inhibitor that is compatible with both carbon steel and stainless steel (e.g., Cr13\%) is CORSAF SF, manufactured by Tetra Technologies, Inc. (The Woodlands, Texas). This inhibitor would be applied at a rate of approximately 20 gallons per 100 bbls of annular fluid. 


\subsubsection{Packer(s)}

Examples of the type of packer that will be used in the injection wells were presented in Section 3 (see Section 3.7.5.6.1) of this document. Materials of construction for the packers will be compatible with the injection fluid and the potential for $\mathrm{CO}_{2}$-induced corrosion. The steel components of these packers can be manufactured from a choice of materials, including carbon steel, nickel-coated steel, or corrosion resistant alloys such as $13 \mathrm{Cr}$, Super13Cr and higher grades. Most likely, the steel components will be of $13 \mathrm{Cr}$, which is also being considered for the lower portion of the 9-5/8 inch long-string casing and the 5-1/2 inch tubing. The packer element will be hydrogenated nitrile butadiene rubber (HNBR). The packer will be a retrievable type packer so that it can be removed without milling for re-dressing or replacement if necessary.

\subsubsection{Well Head Equipment}

The wellhead and Christmas tree will be comprised of materials that are compatible with the injection fluid to minimize corrosion. In general, all components that come into contact with the $\mathrm{CO}_{2}$ injection fluid will be a corrosion-resistant alloy such as stainless steel. Because the $\mathrm{CO}_{2}$ injection fluid will be very dry, use of stainless steel components for the flow-wetted components is a conservative measure to minimize corrosion and increase the life expectancy of this equipment. Materials that will not have contact with the injection fluid will be manufactured of carbon steel. A preliminary materials specification for the wellhead and Christmas tree assembly is described in Table 7-7 using material classes as defined in API Specification 6A (Specification for Wellhead and Christmas Tree Equipment). A summary of material class definitions is provided in Table 7-8. The final wellhead and Christmas tree materials specification may vary slightly from the information given below because the wellhead/Christmas tree has not yet been selected. An illustration of the wellhead and Christmas tree is provided in Figure 7-3.

Table 7-7. Materials Specification of Wellhead and Christmas Tree

\begin{tabular}{|l|l|l|}
\hline \multicolumn{2}{|c|}{ Component } & \multicolumn{1}{c|}{ Material Class $^{(\mathrm{a})}$} \\
\hline $\begin{array}{l}\text { Casing Head Housing (for 20 } \\
\text { inch surface casing) }\end{array}$ & DD, EE \\
\hline \multirow{2}{*}{$\begin{array}{l}\text { Casing Head Spool (for 13-3/8 } \\
\text { inch intermediate casing }\end{array}$} & $\begin{array}{l}\text { Casing spool (20-3/4" 3K X } \\
13-5 / 85 \mathrm{~K})\end{array}$ & AA, BB, DD, EE \\
\cline { 2 - 3 } & Casing hanger (20" X 13-3/8") & AA, DD \\
\hline Tubing Spool Assembly (for 9- & Spool & AA \\
\cline { 2 - 3 } $5 / 8$ inch long-string casing) & Casing hanger & AA, DD \\
\hline Christmas Tree & Tubing head adapter & DD, EE \\
\cline { 2 - 3 } & Manual Gate Valve & BB \\
\cline { 2 - 3 } & $\begin{array}{l}\text { Pneumatic actuated Gate } \\
\text { Valves (2) }\end{array}$ & BB \\
\cline { 2 - 3 } & $\begin{array}{l}\text { Tubing hangar (for 5-1/2-inch } \\
\text { tubing) }\end{array}$ & CC \\
\hline
\end{tabular}

(a) When multiple classes given, highest class applies. Cameron uses this convention because not all components are available in all class types. 


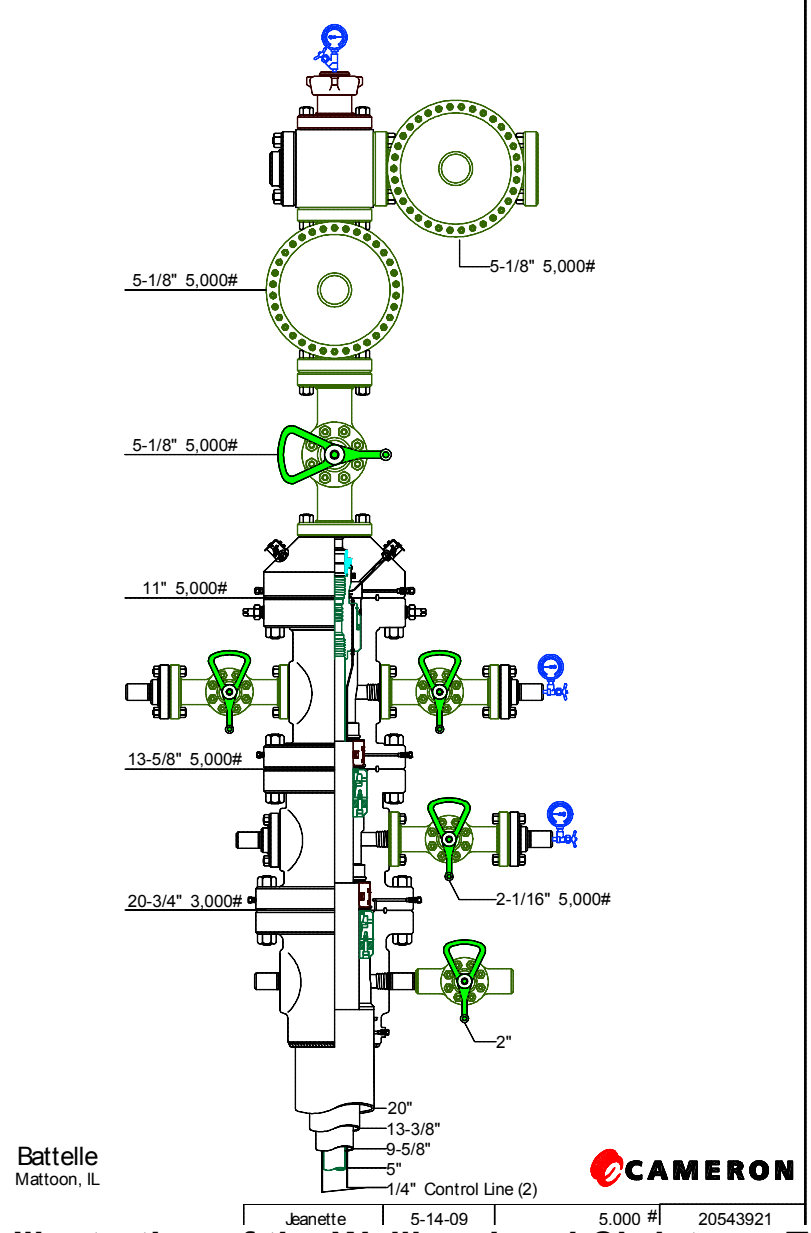

Figure 7-3. Illustration of the Wellhead and Christmas Tree

Table 7-8. Material Classes from API 6A

(Specification for Wellhead and Christmas Tree Equipment)

\begin{tabular}{|c|c|c|}
\hline API Material Class & $\begin{array}{c}\text { Body, Bonnet, End \& Outlet } \\
\text { Connections }\end{array}$ & $\begin{array}{l}\text { Pressure Controlling Parts, } \\
\text { Stems, \& Mandrel Hangers }\end{array}$ \\
\hline AA - General Service & Carbon or alloy steel & Carbon or low alloy steel \\
\hline BB - General Service & Carbon or low alloy steel & Stainless steel \\
\hline CC - General Service & Stainless Steel & Stainless steel \\
\hline DD - Sour Service ${ }^{(a)}$ & Carbon or low alloy steel $^{(\mathrm{b})}$ & Carbon or low alloy steel $^{(\mathrm{b})}$ \\
\hline EE - Sour Service ${ }^{(a)}$ & Carbon or low alloy steel $^{(\mathrm{b})}$ & Stainless steel ${ }^{(\mathrm{b})}$ \\
\hline FF - Sour Service ${ }^{(a)}$ & Stainless steel $^{(\mathrm{b})}$ & Stainless steel $^{(\mathrm{b})}$ \\
\hline $\mathrm{HH}-$ Sour Service ${ }^{(a)}$ & Corrosion Resistant Alloy ${ }^{(\mathrm{b})}$ & Corrosion Resistant Alloy ${ }^{(\mathrm{b})}$ \\
\hline
\end{tabular}

Source: Cameron Surface Systems, Houston, Texas

(a) As defined by National Association of Corrosion Engineers (NACE) Standard MR075.

(b) In compliance with NACE Standard MR0175.

\subsubsection{Holding Tanks(s) and Flow Lines}

There are no $\mathrm{CO}_{2}$ holding tanks associated with the $\mathrm{CO}_{2}$ sequestration system. $\mathrm{CO}_{2}$ will be piped from the plant to the injection wells via a pipeline. 


\subsubsection{Compatibility with Filter and Filter Components}

Not applicable.

\subsubsection{Full Description of Compatibility Concerns}

As discussed previously in this section, no significant compatibility issues have been reported between the $\mathrm{CO}_{2}$ injection fluid and the geologic containment system (i.e., injection reservoir and confining unit). As discussed, geochemical modeling of $\mathrm{CO}_{2}$ injection into the Mt. Simon Formation predicted a small amount of mineral precipitation and a minor reduction in porosity; however, the small amount of porosity reduction would not be expected to have any impact on the injection of $\mathrm{CO}_{2}$ into the formation. A similar effect (i.e., minor dissolution followed by precipitation, with an overall small net decrease in porosity) was predicted for the Eau Claire Formation, the primary confining unit overlying the Mt. Simon Formation; however, the extent of these processes would be small and would not be expected to decrease the integrity or effectiveness of the caprock.

Critical well materials that are exposed to the $\mathrm{CO}_{2}$ injection fluid (i.e., tubing, long-string casing, packer, cement, wellhead and Christmas tree) have been designed to minimize the potential for corrosion and increase the service life of the well. Therefore, the well has been designed to eliminate compatibility issues.

\subsubsection{Pre-Injection Fluid Treatment}

After the $\mathrm{CO}_{2}$ stream undergoes compression, it will not undergo further treatment that will alter its physical characteristics or composition, other than those caused by pressure and temperature changes as the fluid travels down the well.

\subsection{References}

Bethke, C.M. 2004. The Geochemist's Workbench. Rockware, Golden, CO.

Fisher, S. 2005. "Geochemistry of the Mt. Simon Sandstone with Carbon Dioxide Sequestration." In, An Assessment of Geological Carbon Sequestration Options in the Illinois Basin, Final Report for U.S. DOE Contract DE-FC26-03NT41994, Principal Investigator Robert Finley, p. 360-374. Available April 22, 2009 at http://sequestration.org/report.htm. 


\section{DRAFT UIC PERMIT FORMS}

\section{ILLINOIS ENVIRONMENTAL PROTECTION AGENCY UNDERGROUND INJECTION CONTROL PERMIT APPLICATION}

\section{FORM 4g - PLUGGING AND ABANDONMENT PROCEDURE}

USEPA ID NUMBER_not applicable

IEPA ID NUMBER 0290255208

WELL NUMBER _FutGen-INJ-1 and FutGEN-INJ-2

Location in Application

8.1 I. Description of Plugging Procedures, see instructions

\begin{tabular}{|c|c|c|}
\hline 8.1 .1 & A & Abandonment during construction \\
\hline 8.1 & B. & Abandonment after injection \\
\hline 8.1 & C & Type and quantity of plugging materials, depth interval \\
\hline & & $\begin{array}{l}\text { iled plugging and abandonment procedures } \\
\text { estimate for plugging and abandonment }\end{array}$ \\
\hline
\end{tabular}

Certification

I certify under penalty of law that this document and all attachments were prepared under my direction or supervision in accordance with a system designed to assure that qualified personnel properly gather and evaluate the information submitted. Based on my inquiry of the person or persons who managed the system, or those persons directly responsible for gathering the information, the information submitted is, to the best of my knowledge and belief, true, accurate and complete. I am aware that there are significant penalties for submitting false information, including the possibility of fine and imprisonment for knowing violations. 


\section{PLUGGING AND ABANDONMENT PROCEDURES (Form 4g)}

As discussed previously, no significant compatibility issues have been reported between the $\mathrm{CO}_{2}$ injection fluid and the geologic containment system (i.e., injection reservoir and confining zone).

\subsection{Description of Plugging Procedures for Injection Well}

This section describes procedures for plugging and abandoning the injection well at various stages of the well's life, including during construction (i.e., drilling) and after the useful life of the well has been reached.

\subsubsection{Injection Well Abandonment During Construction}

Plugging and abandonment of the well during construction (during drilling) is highly unlikely as this implies that the well would be abandoned prior to completing its construction, perhaps even before reaching total depth of the well. However, per the requirements of the UIC permit application, it is necessary to define how the well would be plugged in such a case. The plugging and abandonment procedure that would be implemented during well construction depends on the stage of drilling when abandonment occurs. Three discrete scenarios are possible: after the conductor casing has been set but before the surface casing has been set; after the surface casing has been set but before the intermediate casing has been set; and after the intermediate casing has been set but before the long-string casing has been set. Since there are two possible depth scenarios for the intermediate casing string (i.e., 5,000 and 7,000 $\mathrm{ft}$ ), this results in a total of five possible scenarios. A description of each of the five "abandonment during construction" scenarios follows:

- Scenario 1: Drilling terminates at $500 \mathrm{ft}$ before setting the 20 inch surface casing. Therefore, open borehole ( 26 inch diameter) exists from the bottom of the 30 inch conductor casing@100 ft to TD@500 ft.

- Scenario 2: Drilling terminates at 5,000 ft before setting the 13-3/8 inch intermediate casing. Therefore, open borehole (17-1/2 inch diameter) exists from the bottom of the 20 inch surface casing @500 ft to TD@5,000 ft.

- Scenario 3: Drilling terminates at 7,000 ft before setting the 13-3/8 inch intermediate casing. Therefore, open borehole (17-1/2 inch diameter) exists from the bottom of the 20 inch surface casing @500 ft to TD@ 7,000 ft.

- Scenario 4: Drilling terminates at 9,100 $\mathrm{ft}$ before setting the 9-5/8 inch long casing. Therefore, open borehole (12-1/4 inch diameter) exists from the bottom of the 13-3/8 inch intermediate casing @5,000 ft to TD@ 9,100 ft.

- Scenario 5: Drilling terminates at 9,100 $\mathrm{ft}$ before setting the 9-5/8 inch long casing. Therefore, open borehole (12-1/4 inch diameter) exists from the bottom of the 13-3/8 inch intermediate casing @7,000 ft to TD@ 9,100 ft.

If the well has to be abandoned during construction, it would be filled with a series of cement plugs placed at strategic locations in the well. Strategic locations for setting cement plugs include: across the drinking water aquifer ( $200 \mathrm{ft}$ below the lowest USDW to surface); across 
coal seams ( $50 \mathrm{ft}$ above and $50 \mathrm{ft}$ below); casing size transition or line junction ( $50 \mathrm{ft}$ above and $50 \mathrm{ft}$ below); injection zone ( $250 \mathrm{ft}$ above the injection zone). A plugging plan for all five abandonment scenarios is provided in Table 8-1, including the depth interval where the plug(s) would be placed, the quantity and type of cement that would be used, and any additives that would be used. The placement of the cement plugs is also shown graphically in Figure 8-1.

Prior to initiating well abandonment procedures, every attempt will be made to recover all inhole equipment. In-hole equipment may consist of drill collars, drill pipe, drill bits, and testing tools (core barrel, well log tool, etc.). Following equipment recovery, standard plugging and abandonment procedures will be initiated per the UIC permit.

\section{Table 8-1. Cement Plugs and Quantities Assuming Drilling Terminates Before Well is Completed}

\begin{tabular}{|c|c|c|c|}
\hline $\begin{array}{l}\text { Cement Plug Depth } \\
\text { Interval }\end{array}$ & Plug Description & $\begin{array}{l}\text { Cement (Qty/ } \\
\text { Type/Additives) }\end{array}$ & $\begin{array}{l}\text { Casing/Hole } \\
\text { Description }\end{array}$ \\
\hline \multicolumn{4}{|c|}{$\begin{array}{l}\text { Scenario 1: Drilling terminates at } 500 \mathrm{ft} \text { before setting the } 20 \text { inch surface casing. Therefore, open } \\
\text { borehole ( } 26 \text { inch diameter) exists from the bottom of the } 30 \text { inch conductor casing @ } 100 \mathrm{ft} \text { to TD@ } 500 \mathrm{ft}\end{array}$} \\
\hline $0-500 '$ & $\begin{array}{l}\text { Continuous plug from } \\
\text { ground surface to } 500 \mathrm{ft} .\end{array}$ & $\begin{array}{l}360 \text { sks Class A (inside } 30- \\
\text { inch conductor string) } \\
1,240 \text { sks Class A }\end{array}$ & $\begin{array}{l}\text { 0'-100' } 30 \text { ' conducto } \\
100 \text { ' - 500' open } \\
\text { borehole ( } 26 \text { inch) }\end{array}$ \\
\hline
\end{tabular}

Scenario 2: Drilling terminates at 5,000 ft before setting the 13-3/8 inch intermediate casing. Therefore, open borehole (17-1/2 inch diameter) exists from the bottom of the 20 inch surface casing @500 ft to TD@ $5,000 \mathrm{ft}$.

\begin{tabular}{|c|c|c|c|}
\hline $0^{\prime}-150$ & $\begin{array}{l}\text { Continuous plug from } \\
\text { ground surface to } 50 \mathrm{ft} \\
\text { below conductor casing } \\
\text { shoe. }\end{array}$ & 241 sks Class $A$ & \multirow[t]{5}{*}{$\begin{array}{l}\text { 0'-500' } 20 \text { " } 133 \mathrm{lb} / \mathrm{ft} \\
\text { surface casing; } \\
500 \text {-5,000' open } \\
\text { borehole (17-1/2 inch) }\end{array}$} \\
\hline 150'-450' & Mud & Mud & \\
\hline 450'-1,200' & $\begin{array}{l}\text { From } 50 \mathrm{ft} \text { above surface } \\
\text { casing shoe to } 50 \text { ' below } \\
\text { coal seams }\end{array}$ & 1,063 sks Class $A$ & \\
\hline $1,200-4,500$ & Mud & Mud & \\
\hline $4,500-5,000$ & Across St. Peter & 702 sks Class $A$ & \\
\hline \multicolumn{4}{|c|}{$\begin{array}{l}\text { Scenario 3: Drilling terminates at 7,000 ft before setting the } 13-3 / 8 \text { inch intermediate casing. Therefore, } \\
\text { open borehole (17-1/2 inch diameter) exists from the bottom of the } 20 \text { inch surface casing @500 ft to TD@ } \\
7,000 \mathrm{ft} \text {. }\end{array}$} \\
\hline $0-150^{\prime}$ & Class $A$ & 241 sks Class A & \multirow{6}{*}{$\begin{array}{l}\text { 0'-500' } 20 " 133 \mathrm{lb} / \mathrm{ft} \\
\text { surface casing; } 500 \text { '- } \\
7,000 \text { ' open borehole } \\
(17-1 / 2 \text { inch) }\end{array}$} \\
\hline $150^{\prime}-450 \prime$ & Mud & Mud & \\
\hline $450-1,200^{\prime}$ & $\begin{array}{l}\text { From } 50 \mathrm{ft} \text { above surface } \\
\text { casing shoe to } 50 \text { ' below } \\
\text { coal seams }\end{array}$ & 1,063 sks Class $A$ & \\
\hline $1,200^{\prime}-4,500^{\prime}$ & Mud & Mud & \\
\hline $4,500^{\prime}-5,000^{\prime}$ & Across St. Peter & 702 Class A & \\
\hline $5,000^{\prime}-7,000^{\prime}$ & Mud & Mud & \\
\hline \multicolumn{4}{|c|}{$\begin{array}{l}\text { Scenario 4: Drilling terminates at } 9,100 \mathrm{ft} \text { before setting the } 9-5 / 8 \text { inch long casing. Therefore, open } \\
\text { borehole (12-1/4 inch diameter) exists from the bottom of the } 13-3 / 8 \text { inch intermediate casing @ } 5,000 \mathrm{ft} \text { to } \\
\text { TD@ } 9,100 \mathrm{ft} \text {. }\end{array}$} \\
\hline $0-150^{\prime}$ & Class A & 109 sks Class $A$ & \multirow{3}{*}{$\begin{array}{l}0-5,000 \text { ' } 13-3 / 8 " 54.5 \\
\text { to } 68 \mathrm{lb} / \mathrm{ft} \text { intermediate } \\
\text { casing; } 5,000^{\prime}-9,100 \\
\text { ft open borehole (12- } \\
1 / 4 \text { inch) }\end{array}$} \\
\hline 150'-450' & Mud & Mud & \\
\hline $450 '-550^{\prime}$ & $\begin{array}{l}\text { From } 50 \text { ' above to } 50 \\
\text { below surface casing } \\
\text { shoe }\end{array}$ & 73 sks Class $A$ & \\
\hline
\end{tabular}


Table 8-1. Cement Plugs and Quantities Assuming Drilling Terminates Before Well is Completed (Continued)

\begin{tabular}{|c|c|c|c|}
\hline $\begin{array}{c}\text { Cement Plug Depth } \\
\text { Interval }\end{array}$ & Plug Description & $\begin{array}{c}\text { Cement (Qtyl } \\
\text { Type/Additives) }\end{array}$ & $\begin{array}{l}\text { Casing/Hole } \\
\text { Description }\end{array}$ \\
\hline $550^{\prime}-4,950 \prime$ & Mud & Mud & \\
\hline $4,950^{\prime}-5,050^{\prime}$ & $\begin{array}{l}\text { From } 50 \text { ' above to } 50 \\
\text { below intermediate casing } \\
\text { shoe }\end{array}$ & 71 sks Class $A$ & \\
\hline $5,050^{\prime}-7,000^{\prime}$ & Mud & Mud & \\
\hline $7,000^{\prime}-9,100^{\prime}$ & Across Mt. Simon & $\begin{array}{l}1444 \text { sks Class A with } 1 \% \\
\text { D65 (TIC), } 0.1 \% \text { D201 } \\
\text { Retarder }\end{array}$ & \\
\hline \multicolumn{4}{|c|}{$\begin{array}{l}\text { Scenario 5: Drilling terminates at } 9,100 \mathrm{ft} \text { before setting the } 9-5 / 8 \text { inch long casing. Therefore, open } \\
\text { borehole (12-1/4 inch diameter) exists from the bottom of the } 13-3 / 8 \text { inch intermediate casing @ } 9,000 \mathrm{ft} \text { to } \\
\text { TD@ 9,100 ft. }\end{array}$} \\
\hline $0-150$ & Class A & 109 sks & \multirow{5}{*}{$\begin{array}{l}0-7,000 \text { ' } 13-3 / 8 " 54.5 \\
\text { to } 68 \mathrm{lb} / \mathrm{ft} \text { Intermediate } \\
\text { casing; } 7,000 \text { ' }-9,100 \text { ' } \\
\text { open borehole }(12-1 / 4 \\
\text { inch) }\end{array}$} \\
\hline $150^{\prime}-450^{\prime}$ & Mud & Mud & \\
\hline $450^{\prime}-550 \prime$ & $\begin{array}{l}\text { From } 50 \text { ' above to } 50 \\
\text { below surface casing } \\
\text { shoe }\end{array}$ & 73 sks Class $A$ & \\
\hline $550^{\prime}-6,950 \prime$ & Mud & Mud & \\
\hline $6,950^{\prime}-9,100^{\prime}$ & $\begin{array}{l}\text { From 50' above } \\
\text { intermediate casing shoe } \\
\text { extending across Mt. } \\
\text { Simon to TD }\end{array}$ & $\begin{array}{l}1480 \text { sks Class A with 1\% } \\
\text { D65 (TIC), } 0.1 \% \text { D201 } \\
\text { Retarder }\end{array}$ & \\
\hline
\end{tabular}

TIC - turbulence inducer

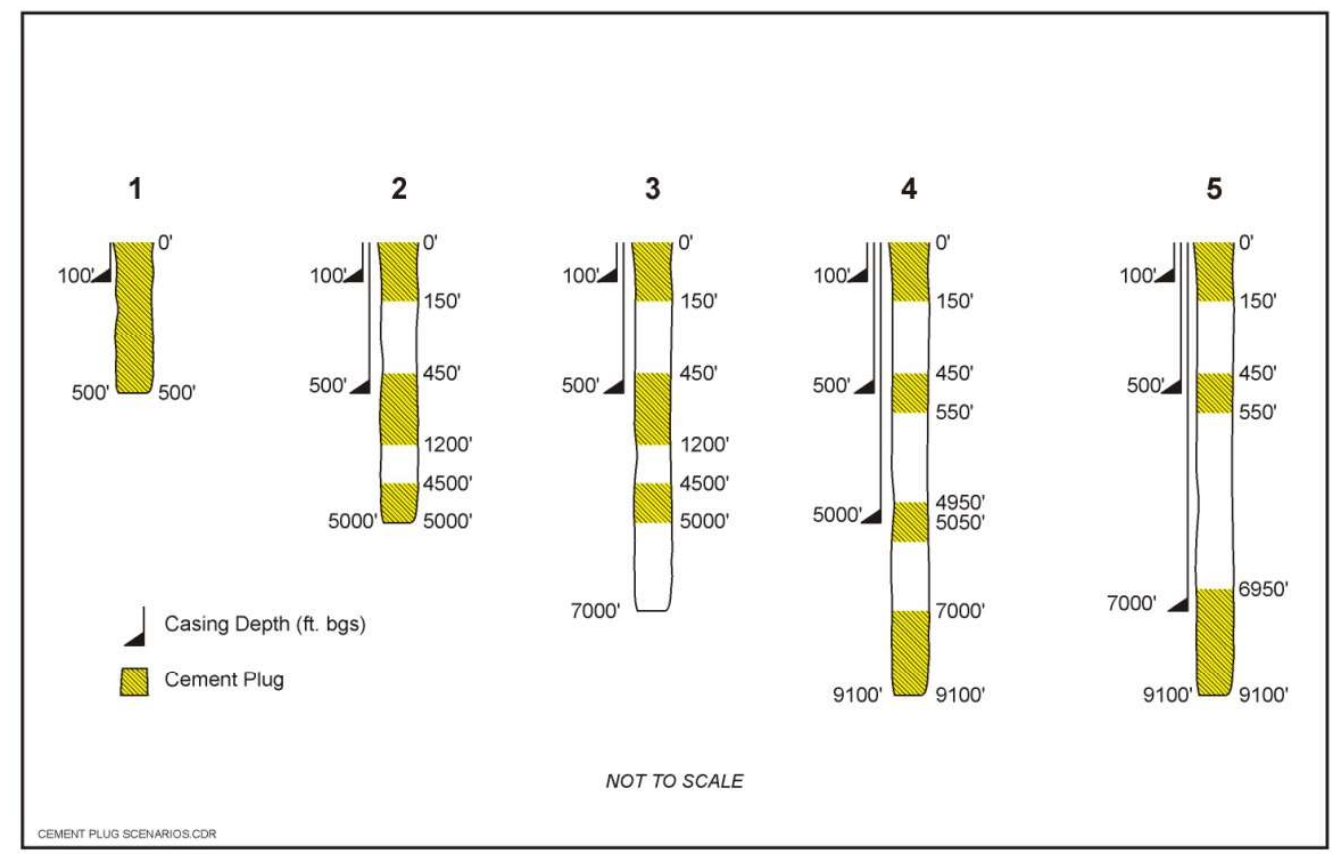

Figure 8-1. Plugging Scenarios for Injection Abandonment During Construction 


\subsubsection{Injection Well Abandonment After Injection}

At the end of the serviceable life of the injection well, the well will be plugged and abandoned.

The well will be filled with cement from its total depth to ground surface as required by the IEPA. This could be accomplished in one of two ways: either by filling the entire well with cement in one continuous effort until it is full, or by emplacing the cement in sections, allowing time between each section. The first approach would require significantly less time; however, it would cost more than the second approach. Therefore, the first approach is described in this section because it provides a more conservative (i.e., higher) cost basis for financial assurance and would allow either option to be implemented. Regardless of the abandonment approach implemented, every attempt will be made to recover the injection equipment (injection tubing, packer, etc.) from the cased hole prior to initiating abandonment procedures. The type and quantity of plugging materials are described in Section 8.1.3. A detailed description of the procedure for abandoning the well is described in Section 8.1.4.

\subsubsection{Type and Quantity of Plugging Materials, Depth Intervals}

Two types of cement will be used to plug the well after injection. Cement plugs set below a depth of 3,000 ft would be Type A cement with 1\% D-65 TIC (retarder). Cement plugs above a depth of $3,000 \mathrm{ft}$ would be Type A cement. The quantity of cement required to fill approximately 9,100 ft of 9-5/8 inch casing following this procedure would be approximately 3,160 sks emplaced in 24 plugs. The types of cement and quantity of materials required are summarized in Table 8-2.

Table 8-2. Cement Types and Quantities for Abandonment After Injection

\begin{tabular}{|l|l|l|}
\hline \multicolumn{1}{|c|}{ Depth Interval } & \multicolumn{1}{|c|}{$\begin{array}{c}\text { Number Plugs and Quantity of } \\
\text { Material }\end{array}$} & \multicolumn{1}{c|}{ Type of Plugging Material } \\
\hline $0-7,600 \mathrm{ft}$ & $\begin{array}{l}19 \text { plugs, 140 sks each (approx 2,660 } \\
\text { sks total) }\end{array}$ & Type A cement \\
\hline $7,600-9,100 \mathrm{ft}$ & $\begin{array}{l}5 \text { plugs, 100 sks each (approx 500 sks } \\
\text { total) }\end{array}$ & $\begin{array}{l}\text { Type A cement with 1\% D-65 TIC } \\
\text { (retarder). }\end{array}$ \\
\hline
\end{tabular}

\subsubsection{Detailed Plugging and Abandonment Procedures}

This section describes plugging and abandonment procedures after injection. The plugging procedure will consist of removing all components of the completion system and then spotting cement plugs along the entire length of the well. At the surface, the wellhead will be removed, casing will be cut off $3 \mathrm{ft}$ below grade, and a steel blanking plate (inscribed with the required permit information) will be welded across the top of the well casing. This inscribed blanking plate will serve as a marker monument to the location of the well. A detailed plugging and abandonment procedure is described below:

1. Prior to commencing plugging and abandonment activities, ensure that all local, state, and Federal agencies are properly notified and that all required permits are in place and followed, as described.

2. Move in a workover rig with pump and appropriate tanks.

3. Nipple down wellhead and nipple up blow-out preventer. 
4. Fill hole with workover brine of sufficient density to maintain well control.

5. Remove tubing and packer from well.

6. Pick up 3-1/2 inch tubing work string (or comparable) and trip in hole to PBTD.

7. Circulate hole with two revolutions to ensure that uniform density fluid is in the well.

8. Start setting cement plugs by spotting 100 sks of Class A cement with $1 \%$ D-65 TIC and $0.15 \%$ D 201. This amount is equal to $300 \mathrm{ft}$ in the 9-5/8 inch casing. Pull 10 joints of tubing and reverse circulate hole for two tubing volumes. Lay down tubing as it is pulled from the well.

9. Repeat plug setting procedure until uppermost set of perforations is covered, then reverse circulate hole one revolution.

10. Pull 20 joints of tubing and shut down overnight.

11. On the next morning, trip in the hole with 20 joints of tubing and tag cement plug. Resume plugging procedure as before but increase plug 140 sks each, covering an interval approximately $400 \mathrm{ft}$ in length with each. Use 1\% D-65 TIC in plugs below $3,000 \mathrm{ft}$.

12. Repeat above procedure until just before the last plug at surface; the appropriate volume of cement to reach is within $3 \mathrm{ft}$ of surface.

13. Nipple down blow-out preventers.

14. Cut off all wellhead components and cut off all casings at $3 \mathrm{ft}$ below ground level.

15. Finish filling well with cement.

16. Install permanent marker back to surface on which all pertinent well information is inscribed.

17. Fill cellar (dug out area surrounding well) with topsoil.

18. Rig down workover unit and move out all equipment. Haul off all workover fluids to proper disposal site.

19. Reclaim surface to normal grade and reseed location with desired vegetation, depending on land use requirements.

\subsubsection{Cost Estimate for Plugging and Abandonment}

A cost estimate for plugging and abandoning a single injection well after injection operations are completed is summarized in Table 8-3. Costs for abandoning two injection wells would be double the cost given on Table 8-3, assuming the wells are abandoned at different times. The cost estimate conservatively assumes the injection well will be continuously cemented from its total depth to land surface. In addition to the cost for plugging (cementing) the well, the total cost estimate also includes other items required by the IEPA's UIC permit application instructions, including: evaluation of the condition of the cement and casing and repairing problems prior to plugging the well; disposal of miscellaneous equipment and drilling fluids; oversight labor; taxes; and, a contingency. In this case, it was assumed that a 500 -ft section of cement would need to be rehabilitated before the well can be plugged. This would be 
Table 8-3. Itemized Plugging and Abandonment Costs (Single Injection Well)

\begin{tabular}{|c|c|c|}
\hline Event & Event Description & $\begin{array}{c}\text { Cost } \\
\text { Estimate }\end{array}$ \\
\hline \multirow{5}{*}{$\begin{array}{l}\text { Casing and Cement } \\
\text { Evaluation }\end{array}$} & $\begin{array}{l}\text { Mobilization of wireline equipment and crews to Mattoon, IL, } \\
\text { equipment setup, and report preparation/submittal. }\end{array}$ & $\$ 9,014$ \\
\hline & $\begin{array}{l}\text { UltraSonic Imager Tool - Gamma Ray. Cement and casing } \\
\text { inspection log (includes gamma ray and tool insurance). }\end{array}$ & $\$ 14,447$ \\
\hline & Cement Bond Log - Variable Density Log. & $\$ 5,062$ \\
\hline & $\begin{array}{l}\text { Temperature Log via Platform Basic Measurement Sonde } \\
\text { (includes pressure, temperature, and gamma ray). Assumes } \\
\text { three passes of the survey tool. }\end{array}$ & $\$ 13,104$ \\
\hline & $\begin{array}{l}\text { Perform pressure test of casing supported by pump truck, plus } \\
\text { engineering/coordination/labor. }\end{array}$ & $\$ 11,745$ \\
\hline $\begin{array}{l}\text { Evaluation of problems } \\
\text { discovered by the } \\
\text { casing evaluation }\end{array}$ & $\begin{array}{l}\text { Includes interpretation of survey logs listed above by log } \\
\text { analyst and assessment of corrective action alternatives. }\end{array}$ & $\$ 2,372$ \\
\hline $\begin{array}{l}\text { Repair of any problems } \\
\text { identified and cleanup } \\
\text { of any groundwater or } \\
\text { soil contamination }\end{array}$ & $\begin{array}{l}\text { Assumes a hypothetical cement squeeze job required at } 6,000 \\
\mathrm{ft} \text { to } 6,500 \mathrm{ft} \text {, which also necessitates perforation of casing and } \\
\text { a bridge plug. Contamination of groundwater and or soil is not } \\
\text { anticipated therefore, soil and groundwater remediation costs } \\
\text { are not included. }\end{array}$ & $\$ 25,290$ \\
\hline $\begin{array}{l}\text { Well Plugging (i.e., } \\
\text { cementing) }^{(a)}\end{array}$ & $\begin{array}{l}\text { Well plugging assumes plugging from total depth of well to } \\
\text { surface. Assumes } 5 \text { days to perform well plugging services. }\end{array}$ & $\$ 200,000$ \\
\hline $\begin{array}{l}\text { Labor, engineering, rig } \\
\text { time, equipment, and } \\
\text { consulting }\end{array}$ & $\begin{array}{l}\text { Costs include labor and engineering services. Rig and } \\
\text { associated equipment are included in the costs above for "Well } \\
\text { Plugging". Contracted consulting services/fees are also } \\
\text { considered for this event. }\end{array}$ & $\$ 17,750$ \\
\hline $\begin{array}{l}\text { Decontamination of } \\
\text { equipment }\end{array}$ & $\begin{array}{l}\text { A cost for decontamination of equipment is not included as this } \\
\text { is not relevant; however, cost associated with the disposal of } \\
\text { well fluids is considered. }\end{array}$ & $\$ 9,240$ \\
\hline $\begin{array}{l}\text { Disposal of any } \\
\text { equipment }\end{array}$ & $\begin{array}{l}\text { Disposal of equipment/scrap metal from the project site will not } \\
\text { incur cost. Cost is for a waste dumpster and hauling for } \\
\text { miscellaneous debris which will be required. }\end{array}$ & $\$ 300$ \\
\hline Estimated sales tax & $\begin{array}{l}\text { Sales tax for the City of Mattoon Illinois is } 6.75 \% \text {. Assumes } \\
\text { sales tax for the tasks outlined above. }\end{array}$ & $\$ 20,812$ \\
\hline $\begin{array}{l}\text { Miscellaneous and } \\
\text { minor contingencies }\end{array}$ & $\begin{array}{l}\text { Miscellaneous and minor contingencies are calculated by } \\
\text { assuming } 20 \% \text { of the costs outlined in the tasks above. }\end{array}$ & $\$ 65,827$ \\
\hline Total & & $\$ 384,963^{(b)}$ \\
\hline
\end{tabular}

(a) Costs for alternate well plugging (i.e., cementing) scenarios are as follows: Scenario B1 - \$54000; Scenarios B2 and B3 $-\$ 68,000$; Scenario B4 $-\$ 73,000$; Scenario B5 $-\$ 75,000$.

(b) Total plugging and abandonment cost $(\$ 384,963)$ is for a single injection well, cost will be doubled for determining financial responsibility requirements.

accomplished by perforating the casing opposite the damaged section of cement and emplacing new cement behind casing via "squeezing".

\subsection{Description of Plugging Procedures for Injection Reservoir Monitoring Well}

This section describes procedures for plugging and abandoning the injection reservoir monitoring well at various stages of the well's life, including during construction (i.e., drilling) and after the useful life of the well has been reached. 


\subsubsection{Injection Reservoir Monitoring Well Abandonment During Construction}

As previously mentioned in Section 8.1.1, plugging and abandonment of the well during construction is highly unlikely; however, per the requirements of the UIC permit application, this section details how the injection reservoir monitoring well will be plugged in such a case. Since the injection reservoir monitoring well will be very similar in construction to the injection well (the difference being casing diameter), plugging and abandonment scenarios and procedures outlined in Section 8.1.1 will be consistent.

Table 8-4 provides the plugging plan for all five abandonment scenarios, including the depth interval where the plug(s) would be placed, the quantity and type of cement that would be used, and any additives that would be used. The subject table (Table 8-4) is identical to Table 8-1, with the exception of the casing diameters and cement quantities because the injection reservoir monitoring well casing is smaller. A graphical illustration of these scenarios is provided above in Figure 8-1.

\section{Table 8-4. Cement Plugs and Quantities Assuming Drilling Terminates} Before Well is Completed

\begin{tabular}{|c|c|c|c|}
\hline $\begin{array}{c}\text { Cement Plug Depth } \\
\text { Interval }\end{array}$ & Plug Description & $\begin{array}{c}\text { Cement (Qtyl } \\
\text { Type/Additives) }\end{array}$ & $\begin{array}{c}\text { Casing/Hole } \\
\text { Description }\end{array}$ \\
\hline
\end{tabular}

Scenario 1: Drilling terminates at $500 \mathrm{ft}$ before setting the 13-3/8 inch surface casing. Therefore, open borehole (17-1/2 inch diameter) exists from the bottom of the 20 inch conductor casing @100 ft to TD@ $500 \mathrm{ft}$.

\begin{tabular}{|l|l|l|l|}
\hline $0-500^{\prime}$ & $\begin{array}{l}\text { Continuous plug from } \\
\text { ground surface to } 500 \mathrm{ft} .\end{array}$ & $\begin{array}{l}160 \text { sks Class A (inside 20- } \\
\text { inch conductor string) } \\
561 \text { sks Class A }\end{array}$ & $\begin{array}{l}0^{\prime}-100 \text { ' 20" conductor; } \\
100 \text { ' }-500 \text { ' open } \\
\text { borehole (17-1/2 inch) }\end{array}$ \\
\hline
\end{tabular}

Scenario 2: Drilling terminates at 5,000 ft before setting the 9-5/8 inch intermediate casing. Therefore, open borehole (12-1/4 inch diameter) exists from the bottom of the 13-3/8 inch surface casing @500 ft to TD@ 5,000 ft.

\begin{tabular}{|c|c|c|c|}
\hline $00^{\prime}-150 \prime$ & $\begin{array}{l}\text { Continuous plug from } \\
\text { ground surface to } 50 \mathrm{ft} \\
\text { below conductor casing } \\
\text { shoe. }\end{array}$ & 117 sks Class $A$ & \multirow[t]{5}{*}{$\begin{array}{l}\text { 0'-500' 13-3/8" } 133 \\
\text { lb/ft surface casing; } \\
500 \text { '-5,000' open } \\
\text { borehole (12-1/4 inch) }\end{array}$} \\
\hline $150 \prime-450$ ' & Mud & Mud & \\
\hline 450 '-1,200' & $\begin{array}{l}\text { From } 50 \mathrm{ft} \text { above surface } \\
\text { casing shoe to } 50 \text { ' below } \\
\text { coal seams }\end{array}$ & 518 sks Class $A$ & \\
\hline $1,200^{\prime}-4,500^{\prime}$ & Mud & Mud & \\
\hline $4,500-5,000$ ' & Across St. Peter & 345 sks Class $A$ & \\
\hline \multicolumn{4}{|c|}{$\begin{array}{l}\text { Scenario 3: Drilling terminates at 7,000 } \mathrm{ft} \text { before setting the } 9-5 / 8 \text { inch intermediate casing. Therefore, } \\
\text { open borehole (12-1/4 inch diameter) exists from the bottom of the } 13-3 / 8 \text { inch surface casing @ } 500 \mathrm{ft} \text { to } \\
\text { TD@ } 7,000 \mathrm{ft} \text {. }\end{array}$} \\
\hline $0-150$ ' & Class A & 117 sks Class $A$ & \multirow{6}{*}{$\begin{array}{l}\text { 0'-500' 13-3/8" } 133 \\
\text { lb/ft surface casing; } \\
500 \text { '-7,000' open } \\
\text { borehole (12-1/4 inch) }\end{array}$} \\
\hline 150 '-450' & Mud & Mud & \\
\hline $450-1,200^{\prime}$ & $\begin{array}{l}\text { From } 50 \mathrm{ft} \text { above surface } \\
\text { casing shoe to } 50 \text { ' below } \\
\text { coal seams }\end{array}$ & 518 sks Class $A$ & \\
\hline $1,200^{\prime}-4,500^{\prime}$ & Mud & Mud & \\
\hline $4,500^{\prime}-5,000^{\prime}$ & Across St. Peter & 345 Class A & \\
\hline $5,000^{\prime}-7,000^{\prime}$ & Mud & Mud & \\
\hline
\end{tabular}


Table 8-4. Cement Plugs and Quantities Assuming Drilling Terminates Before Well is Completed (Continued)

\begin{tabular}{|c|c|c|c|}
\hline $\begin{array}{c}\text { Cement Plug Depth } \\
\text { Interval }\end{array}$ & Plug Description & $\begin{array}{c}\text { Cement (Qty/ } \\
\text { Type/Additives) }\end{array}$ & $\begin{array}{l}\text { Casing/Hole } \\
\text { Description }\end{array}$ \\
\hline \multicolumn{4}{|c|}{$\begin{array}{l}\text { Scenario 4: Drilling terminates at 9,100 ft before setting the } 7 \text { inch long casing. Therefore, open borehole } \\
\text { (8-1/2 inch diameter) exists from the bottom of the 9-5/8 inch intermediate casing @ } 5,000 \mathrm{ft} \text { to TD@ 9,100 } \\
\mathrm{ft} .\end{array}$} \\
\hline $0-150$ & Class A & 57 sks Class $A$ & \multirow{7}{*}{$\begin{array}{l}0-5,000 \text { ' } 9-5 / 8^{\prime \prime} 54.5 \text { to } \\
68 \mathrm{lb} / \mathrm{ft} \text { intermediate } \\
\text { casing; } 5,000 \text { ' }-9,100 \\
\text { ft open borehole }(8-1 / 2 \\
\text { inch) }\end{array}$} \\
\hline 150'-450' & Mud & Mud & \\
\hline $450^{\prime}-550 \prime$ & $\begin{array}{l}\text { From } 50 \text { ' above to } 50^{\prime} \\
\text { below surface casing } \\
\text { shoe }\end{array}$ & 38 sks Class $A$ & \\
\hline $550^{\prime}-4,950$ ' & Mud & Mud & \\
\hline $4,950^{\prime}-5,050$ ' & $\begin{array}{l}\text { From } 50 \text { ' above to } 50 \\
\text { below intermediate casing } \\
\text { shoe }\end{array}$ & 37 sks Class $A$ & \\
\hline $5,050^{\prime}-7,000^{\prime}$ & Mud & Mud & \\
\hline $7,000^{\prime}-9,100^{\prime}$ & Across Mt. Simon & $\begin{array}{l}736 \text { sks Class A with } 1 \% \\
\text { D65 (TIC), } 0.1 \% \text { D201 } \\
\text { Retarder }\end{array}$ & \\
\hline \multicolumn{4}{|c|}{$\begin{array}{l}\text { Scenario 5: Drilling terminates at 9,100 ft before setting the } 7 \text { inch long casing. Therefore, open borehole } \\
\text { (8-1/2 inch diameter) exists from the bottom of the 9-5/8 inch intermediate casing @7,000 ft to TD@ } 9,100 \\
\mathrm{ft} \text {. }\end{array}$} \\
\hline $0-150$ & Class A & 57 sks & \multirow{5}{*}{$\begin{array}{l}0-7,000 \text { ' 9-5/8" } 54.5 \text { to } \\
68 \text { lb/ft Intermediate } \\
\text { casing; } 7,000 \text { ' }-9,100 \\
\text { open borehole }(8-1 / 2 \\
\text { inch) }\end{array}$} \\
\hline $150^{\prime}-450^{\prime}$ & Mud & Mud & \\
\hline $450^{\prime}-550 \prime$ & $\begin{array}{l}\text { From } 50 \text { 'above to } 50 \\
\text { below surface casing } \\
\text { shoe }\end{array}$ & 38 sks Class $A$ & \\
\hline $550^{\prime}-6,950 \prime$ & Mud & Mud & \\
\hline 6,950 '-9,100' & $\begin{array}{l}\text { From } 50 \text { ' above } \\
\text { intermediate casing shoe } \\
\text { extending across Mt. } \\
\text { Simon to TD }\end{array}$ & $\begin{array}{l}770 \text { sks Class A with } 1 \% \\
\text { D65 (TIC), 0.1\% D201 } \\
\text { Retarder }\end{array}$ & \\
\hline
\end{tabular}

\subsubsection{Injection Reservoir Monitoring Well Abandonment After Construction}

At the end of the serviceable life of the injection reservoir monitoring well, the well will be plugged and abandoned, consistent with the procedures detailed in Section 8.1.2 and 8.1.4. The type and quantity of plugging materials are described in Section 8.2.3.

\subsubsection{Type and Quantity of Plugging Materials, Depth Intervals}

Two types of cement will be used to plug the well after injection. Cement plugs set below a depth of 3,000 ft would be Type A cement with 1\% D-65 TIC (retarder). Cement plugs above a depth of $3,000 \mathrm{ft}$ would be Type A cement. The quantity of cement required to fill approximately $9,100 \mathrm{ft}$ of $9-5 / 8$ inch casing following this procure would be approximately 1,673 sks emplaced in 24 plugs. The types of cement and quantity of materials required are summarized in Table 85 .

\subsubsection{Detailed Plugging and Abandonment Procedures}

Section 8.1.4 provides detailed procedures for plugging and abandoning the injection well. Those same procedures will be implemented for plugging and abandoning the injection 
Table 8-5. Cement Types and Quantities for Abandonment After Injection

\begin{tabular}{|l|l|l|}
\hline \multicolumn{1}{|c|}{ Depth Interval } & \multicolumn{1}{|c|}{$\begin{array}{c}\text { Number Plugs and Quantity of } \\
\text { Material }\end{array}$} & \multicolumn{1}{|c|}{ Type of Plugging Material } \\
\hline $0-7,600 \mathrm{ft}$ & $\begin{array}{l}19 \text { plugs, 74 sks each (approx 1,408 sks } \\
\text { total) }\end{array}$ & Type A cement \\
\hline $7,600-9,100 \mathrm{ft}$ & $\begin{array}{l}5 \text { plugs, 53 sks each (approx 265 sks } \\
\text { total) }\end{array}$ & $\begin{array}{l}\text { Type A cement with 1\% D-65 TIC } \\
\text { (retarder). }\end{array}$ \\
\hline
\end{tabular}

reservoir monitoring well, with the exception of procedural Step 8 and Step 11 because of the smaller casing diameter of the injection reservoir monitoring well. For the purposes of plugging and abandonment of the injection reservoir monitoring well, replace procedural Step 8 and Step 11 in Section 8.1.4 with the procedural steps detailed below.

8. (Replacement Step) Start setting cement plugs by spotting 53 sks of Class A cement with $1 \%$ D-65 TIC and $0.15 \%$ D 201. This amount is equal to $300 \mathrm{ft}$ in the 7 inch casing. Pull 10 joints of tubing and reverse circulate hole for two tubing volumes. Lay down tubing as it is pulled from the well.

11. (Replacement Step) On the next morning, trip in the hole with 20 joints of tubing and tag cement plug. Resume plugging procedure as before but increase plug 74 sks each, covering an interval approximately $400 \mathrm{ft}$ in length with each. Use 1\% D-65 $\mathrm{TIC}$ in plugs below 3,000 ft.

\subsubsection{Cost Estimate for Plugging and Abandonment}

The cost estimate presented in Table 8-3 (cost estimate for plugging and abandonment of a single injection well) will also be used for the cost basis for plugging and abandoning a single injection reservoir monitoring well after injection operations are completed. As previously stated, the difference in the two types of wells is that the casing diameter is smaller for the injection reservoir monitoring well. Hence, the events detailed in Table 8-3 will be the same for plugging and abandonment of the injection reservoir monitoring well and the cost represents a conservative (i.e., higher) estimate for financial assurance. The cost estimate $(\$ 384,963)$ conservatively assumes continuous cement from total depth to land surface. In addition, the cost includes all items required by the IEPA's UIC permit application instructions.

\subsection{Description of Plugging Procedures for USDW Well}

This section describes procedures for plugging and abandoning the USDW well at various stages of the well's life, including during construction (i.e., drilling) and after the useful life of the well has been reached.

\subsubsection{USDW Well Abandonment During Construction}

Plugging and abandonment of the well during construction (during drilling) is highly unlikely; however, per the requirements of the UIC permit application, it is necessary to define how the well would be plugged in such a case. The plugging and abandonment procedure that would be implemented during well construction is consistent, one scenario possible, regardless of the stage of drilling when abandonment occurs. The USDW well construction is a single casing, 4inch PVC with 4-inch stainless steel screen; therefore plugging during construction would occur before casing is set. 
Plugging and abandonment of the well during construction could occur from surface to $100 \mathrm{ft}$ bgs (maximum depth of USDW well). If the well has to be abandoned during construction, it would be filled with a continuous plug of neat cement tremied from the bottom of the borehole to surface. Regardless of depth, prior to initiating well abandonment procedures, every attempt will be made to recover all in-hole equipment. In-hole equipment may consist of drill pipe, drill bit, etc. Following equipment recovery, standard plugging and abandonment procedures will be initiated per the UIC permit.

\subsubsection{USDW Well Abandonment After Construction}

At the end of the serviceable life of the USWD well, the well will be plugged and abandoned. The well will be filled with cement from its total depth to $2 \mathrm{ft}$ bgs. This will be accomplished by filling the entire well with cement in one continuous effort until it is full. Prior to initiating the abandonment procedure, every attempt will be made to recover the in-well equipment (if any) from the cased hole. The type and quantity of plugging materials are described in Section 8.3.3. A detailed description of the procedure for abandoning the well is described in Section 8.3.4.

\subsubsection{Type and Quantity of Plugging Materials, Depth Intervals}

Neat cement (portland cement) will be used to plug the well at the end of the serviceable life of the well. The cement plug will be continuous, tremied from the bottom of the borehole to $2 \mathrm{ft}$ bgs. The quantity of cement required to fill $100 \mathrm{ft}$ (maximum depth of USDW well) of 4 inch casing would be approximately 18 sks emplaced in one continuous plug.

\subsubsection{Detailed Plugging and Abandonment Procedures}

This section describes plugging and abandonment procedures at the end of the serviceable life of the well. The plugging procedure will simply consist of removing all components (if any) from the well and then spotting a continuous cement plug along the entire length of the well. At the surface, the wellhead will be removed, casing will be cut off $2 \mathrm{ft}$ below grade, and topsoil will be used as backfill material to restore surface to native elevation. A detailed plugging and abandonment procedure is described below:

1. Prior to commencing plugging and abandonment activities, ensure that all local, state, and Federal agencies are properly notified and that all required permits are in place and followed, as described.

2. Move in a service truck with pump and appropriate tanks.

3. Remove all components from within the well.

4. Set cement plug by spotting 18 sacks of neat cement. This amount is equal to $100 \mathrm{ft}$ in the 4 inch casing.

5. Cut off all wellhead components and cut off all casings at $2 \mathrm{ft}$ below ground level.

6. Finish filling well with cement.

7. Dispose of all waste equipment and materials.

8. Reclaim surface to normal grade and reseed location with desired vegetation, depending on land use requirements. 


\subsubsection{Cost Estimate for Plugging and Abandonment}

In accordance with the plugging and abandonment procedures, the cost estimate for plugging and abandonment of a single USDW well will be $\$ 760$. The cost estimate conservatively assumes continuous cement from total depth to land surface. In addition, the cost includes all items required by the IEPA's UIC permit application instructions. 
APPENDIX 3-1

Well Cementing Plan 


\section{CemCADE ${ }^{*}$ Well Cementing Recommendation for 20" Surface Casing $(500 \mathrm{ft})$}




\section{CemCADE ${ }^{*}$ well cementing recommendation for $20^{\prime \prime}$ Surface}

\begin{tabular}{|c|c|c|c|}
\hline $\begin{array}{l}\text { Operator } \\
\text { Country } \\
\text { State }\end{array}$ & $\begin{array}{l}\text { : Mattoon/Future Gen } \\
: \text { USA } \\
: \text { IL }\end{array}$ & $\begin{array}{l}\text { Well } \\
\text { Field }\end{array}$ & $\begin{array}{l}: \text { ISGS/ADM Well \#1 } \\
: \text { CO2 Disposal }\end{array}$ \\
\hline $\begin{array}{l}\text { Prepared for } \\
\text { Proposal No. } \\
\text { Date Prepared }\end{array}$ & $\begin{array}{l}: \text { SLB } \\
: \\
: 05-26-2009\end{array}$ & $\begin{array}{l}\text { Location } \\
\text { Service Point } \\
\text { Business Phone } \\
\text { FAX No. }\end{array}$ & $\begin{array}{l}: \text { Decatur, IL } \\
: \text { Prestonsburg } \\
: \text { (606) } 2982200 \\
: \text { (606) } 2982248\end{array}$ \\
\hline $\begin{array}{l}\text { Prepared by } \\
\text { Phone } \\
\text { E-Mail }\end{array}$ & $\begin{array}{l}\text { : Donald Leach } \\
\vdots(606) 791-4194 \\
: \\
\text { dleach@prestonsburg.oilfield.slb.com }\end{array}$ & & \\
\hline
\end{tabular}

Configurati Casing
on
Csg/Liner MD : $550.0 \mathrm{ft}$
Landing Collar MD
Casing/liner Shoe MD
Mud Line
Total MD
BHST
Bit Size
Mean OH Diameter
Mean Annular Excess
Mean OH Equivalent Diameter
Total OH Volume

\section{well description}

Stage : Single
OD : $20 \mathrm{in}$
$510.0 \mathrm{ft}$
$550.0 \mathrm{ft}$
$0.0 \mathrm{ft}$
$550.0 \mathrm{ft}$
$68 \mathrm{degF}$
$24 \mathrm{in}$
$24.000 \mathrm{in}$
$75.0 \%$
$26.608 \mathrm{in}$ (including excess)
$378.3 \mathrm{bbl}$.

Rig Type : Land

Weight : $106.5 \mathrm{lb} / \mathrm{ft}$

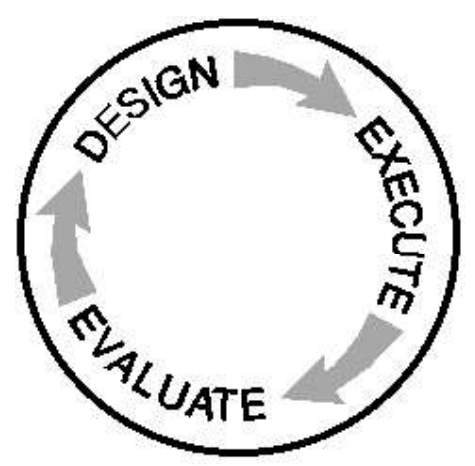

Disclaimer Notice:

This information is presented in good faith, but no warranty is given by and Schlumberger assumes no liability for advice or recommendations made concerning results to be obtained from the use of any product or service. The results given are estimates based on calculations produced by a computer model including various assumptions on the well, reservoir and treatment. The results depend on input data provided by the Operator and on estimates as to unknown data and can be no more accurate than the model, the assumptions and such input data. The information presented is Schlumberger's best estimate of the actual results that may be achieved and should be used for comparison purposes rather than absolute values. The quality of input data, and hence results, may be improved through the use of certain tests and procedures which Schlumberger can assist in selecting.

The Operator has superior knowledge of the well, the reservoir, the field and conditions affecting them. If the Operator is aware of any conditions whereby a neighboring well or wells might be affected by the treatment proposed herein it is the Operator's responsibility to notify the owner or owners of the well or wells accordingly.

Prices quoted are estimates only and are good for 30 days from the date of issue. Actual charges may vary depending upon time, equipment, and material ultimately required to perform these services.

Freedom from infringement of patents of Schlumberger or others is not to be inferred. 


\section{Section 1: fluid sequence}

Job Objectives:

20" SURFACE CEMENT TREATMENT AS PER CUSTOMER REQUEST

\begin{tabular}{|lll|}
\hline Original fluid & Fresh Water & $8.32 \mathrm{lb} / \mathrm{gal}$ \\
& $\mathrm{P}_{\mathrm{v}}: 0.900 \mathrm{cP}$ & Ty: $0.50 \mathrm{lbf} / 100 \mathrm{ft} 2$ \\
Displacement Volume & $178.8 \mathrm{bbl}$ & \\
Total Volume & $386.9 \mathrm{bbl}$ & \\
TOC & $0.0 \mathrm{ft}$ & \\
\hline
\end{tabular}

\begin{tabular}{|c|c|c|c|c|c|c|c|}
\hline Name & $\begin{array}{c}\text { Volume } \\
\text { (bbl) }\end{array}$ & $\begin{array}{c}\text { Ann. Len } \\
(\mathrm{ft})\end{array}$ & $\begin{array}{c}\text { Top } \\
\text { (ft) }\end{array}$ & $\begin{array}{l}\text { uid Sequ } \\
\text { Density } \\
\text { (lb/gal) }\end{array}$ & nce & ology & \\
\hline Fresh Water & 20.0 & 0.0 & & 8.32 & $P v: 0.900 \mathrm{cP}$ & & Ty:0.50 lbf/100ft2 \\
\hline Lead Slurry & 124.0 & 382.6 & & 15.60 & $\mathrm{k}: 2.99 \mathrm{E}-1 \mathrm{lbf} . \mathrm{s}^{\wedge} \mathrm{n} / \mathrm{ft} 2$ & $\mathrm{n}: 0.269$ & Ty:1.84 lbf/100ft2 \\
\hline Tail Slurry & 64.1 & 167.4 & 382.6 & 15.60 & $P v: 63.653 \mathrm{cP}$ & & Ty:86.23 lbf/100ft2 \\
\hline Fresh Water & 178.8 & & 0.0 & 8.32 & $P v: 0.900 \mathrm{cP}$ & & Ty:0.50 lbf/100ft2 \\
\hline
\end{tabular}

\section{WARNING : CASING PUMP OUT}

\begin{tabular}{|lll|}
\hline \multicolumn{2}{|l|}{ Static Security Checks : } & \\
\hline Frac & $0 \mathrm{psi}$ & at $0.0 \mathrm{ft}$ \\
Pore & $0 \mathrm{psi}$ & at $0.0 \mathrm{ft}$ \\
Collapse & $566 \mathrm{psi}$ & at $510.0 \mathrm{ft}$ \\
Burst & $2410 \mathrm{psi}$ & at $0.0 \mathrm{ft}$ \\
Csg.Pump out & $-5 \mathrm{fon}$ & \\
\hline
\end{tabular}

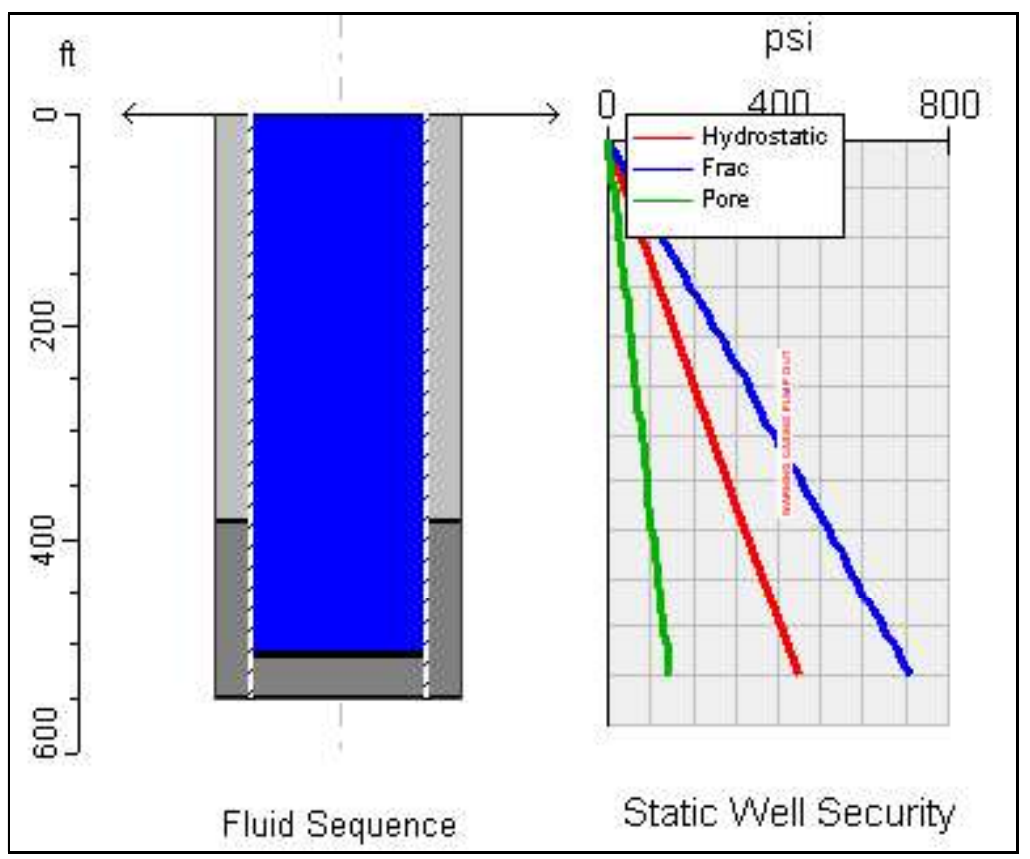




\section{Section 2: pumping schedule}

\begin{tabular}{|c|c|c|c|c|c|c|}
\hline \multicolumn{7}{|c|}{ Pumping Schedule } \\
\hline Name & $\begin{array}{l}\text { Flow Rate } \\
\text { (bbl/min) }\end{array}$ & $\begin{array}{l}\text { Volume } \\
\text { (bbl) }\end{array}$ & $\begin{array}{l}\text { Stage Time } \\
\text { (min) }\end{array}$ & $\begin{array}{l}\text { Cum.Vol } \\
\text { (bbl). }\end{array}$ & $\begin{array}{l}\text { Inj. } \\
\text { Temp. } \\
\text { (degF) }\end{array}$ & Comments \\
\hline Fresh Water & 6.0 & 20.0 & 3.3 & 20.0 & 80 & $\begin{array}{l}\text { Water spacer ahead of } \\
\text { cement }\end{array}$ \\
\hline Lead Slurry & 5.0 & 124.0 & 24.8 & 124.0 & 80 & $A+D 130$ \\
\hline Tail Slurry & 5.0 & 64.1 & 12.8 & 64.1 & 80 & $A+S 001+D 130$ \\
\hline Pause & 0.0 & 0.0 & 3.0 & 0.0 & 80 & Shut Down, Drop Plug \\
\hline Fresh Water & 6.0 & 178.8 & 29.8 & 178.8 & 80 & Start Displacement \\
\hline
\end{tabular}

End Job:

Cement not at surface in simulation due to $75 \%$ excess hole size in design

\begin{tabular}{|lll|}
\hline \multicolumn{2}{|l|}{ Dynamic Security Checks : } \\
\hline Frac & $0 \mathrm{psi}$ & at $0.0 \mathrm{ft}$ \\
Pore & $0 \mathrm{psi}$ & at $0.0 \mathrm{ft}$ \\
Collapse & $566 \mathrm{psi}$ & at $510.0 \mathrm{ft}$ \\
Burst & $2196 \mathrm{psi}$ & at $0.0 \mathrm{ft}$ \\
\hline
\end{tabular}

\begin{tabular}{|c|c|c|c|}
\hline \multicolumn{4}{|c|}{ Temperature Results } \\
\hline BHCT & 80 degF & Simulated Max HCT & 80 degF \\
\hline Simulated BHCT & 80 degF & Max HCT Depth & $550.0 \mathrm{ft}$ \\
\hline CT at TOC & 75 degF & Max HCT Time & 01:09:20 hr:mn:sc \\
\hline \multicolumn{4}{|c|}{ Static temperatures: } \\
\hline At Time & (hr:mn) & (hr:mn) & Geo. Temp. \\
\hline Top of Cement & $(\operatorname{deg} \mathrm{F})$ & $(\operatorname{deg} F)^{\prime}$ & $62 \operatorname{deg} F$ \\
\hline Bottom Hole & $(\operatorname{deg} F)$ & (degF) & 68 degF \\
\hline
\end{tabular}




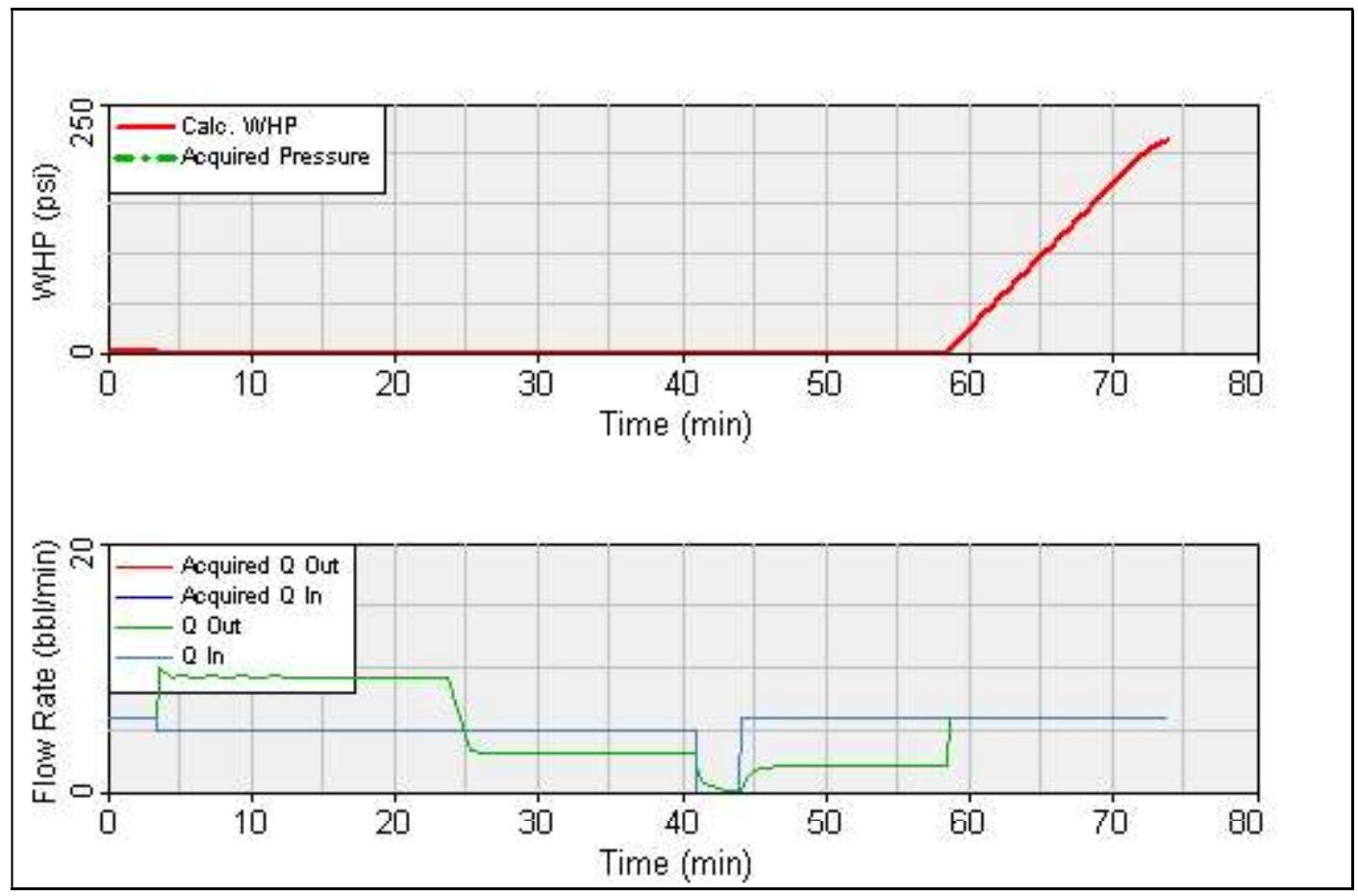

\section{Section 3: fluid description}

\section{Lead Slurry DESIGN}

Fluid No: 1

Rheo. Model

At temp.

: HERSCHEL_B. : 80 degF

\section{DESIGN}

BLEND

Name

$:$ A

Dry Density : $197.27 \mathrm{lb} / \mathrm{ft} 3$

Sack Weight : $94 \mathrm{lb}$

BASE FLUID

Type : Fresh water

$\begin{array}{ll}\text { Density } & : 15.60 \mathrm{lb} / \mathrm{gal} \\ \mathrm{k} & : 2.99 \mathrm{E}-1 \mathrm{lbf} . \mathrm{s}^{\wedge} \mathrm{n} / \mathrm{ft} 2 \\ \mathrm{n} & : 0.269 \\ \text { Ty } & : 1.84 \mathrm{lbf} / 100 \mathrm{ft} 2 \\ \text { Gel Strength } & : 62.97 \mathrm{lbf} / 100 \mathrm{ft} 2\end{array}$

SLURRY

Mix Fluid : $5.248 \mathrm{gal} / \mathrm{sk} \quad$ Job volume : $124.0 \mathrm{bbl}$

Yield : $1.18 \mathrm{ft} 3 / \mathrm{sk}$

Solid Fraction : : $40.6 \%$

Quantity : $589.10 \mathrm{sk}$

Density $\quad: 8.32 \mathrm{lb} / \mathrm{gal}$

Base Fluid : $5.248 \mathrm{gal} / \mathrm{sk}$

\begin{tabular}{|lll|}
\hline Code & Conc. & Additives \\
\hline D130 & $0.250 \mathrm{lb} / \mathrm{sk}$ blend & Function \\
\hline
\end{tabular}

Thickening Time

Compressive Strength
Schedule ()

Schedule ( )
$100 \mathrm{Bc}$

(psi) $\begin{array}{ll}\text { at } & 02: 19 \mathrm{hr}: \mathrm{mn} \\ \text { at } & (\mathrm{hr}: \mathrm{mn})\end{array}$ 


\section{Fresh Water DESIGN}

Fluid No: 2

Rheo. Model

At temp.

: BINGHAM
$: 60$ degF

Density $\quad: 8.32 \mathrm{lb} / \mathrm{gal}$

$\mathrm{P}_{\mathrm{v}} \quad: 0.900 \mathrm{cP}$

Ty $: 0.50 \mathrm{lbf} / 100 \mathrm{ft} 2$

Gel Strength : $0.00 \mathrm{lbf} / 100 \mathrm{ft} 2$

Job volume : $198.8 \mathrm{bbl}$

\section{Tail Slurry DESIGN}

Fluid No: 3

Rheo. Model : BINGHAM

At temp. $\quad: 80 \mathrm{deg} F$

DESIGN

BLEND

Name : A

Dry Density : $197.27 \mathrm{lb} / \mathrm{ft} 3$

Sack Weight : $94 \mathrm{lb}$

BASE FLUID

Type : Fresh water

$\begin{array}{ll}\text { Density } & : 15.60 \mathrm{lb} / \mathrm{gal} \\ \mathrm{Pv}_{\mathrm{v}} & : 63.653 \mathrm{cP} \\ \text { Ty } & : 86.23 \mathrm{lbf} / 100 \mathrm{ft} 2 \\ \text { Gel Strength } & : 66.17 \mathrm{lbf} / 100 \mathrm{ft} 2\end{array}$

SLURRY

Mix Fluid : $5.239 \mathrm{gal} / \mathrm{sk}$

Yield $\quad: 1.19 \mathrm{ft} 3 / \mathrm{sk}$

Solid Fraction : : $41.1 \%$

Density $\quad: 8.32 \mathrm{lb} / \mathrm{gal}$

Base Fluid : $5.239 \mathrm{gal} / \mathrm{sk}$

\begin{tabular}{|lll|}
\hline Code & Conc. & Additives \\
\hline D130 & $0.250 \mathrm{lb} / \mathrm{sk}$ blend & Function \\
S001 & $1.000 \%$ BWOC & Lost circ \\
\hline
\end{tabular}

\begin{tabular}{|c|c|c|c|c|}
\hline Thickening Time & Schedule () & $70 \mathrm{Bc}$ & at & 01:55 hr:mn \\
\hline Compressive Strength & Schedule () & (psi) & at & (hr:mn) \\
\hline
\end{tabular}




\section{CemCADE ${ }^{*}$ well Cementing Recommendation for 13-3/8" Intermediate Casing $(5,000 \mathrm{ft})$}




\section{CemCADE ${ }^{*}$ well cementing recommendation for 13 3/8" Intermediate}

\begin{tabular}{|c|c|c|c|}
\hline $\begin{array}{l}\text { Operator } \\
\text { Country } \\
\text { State }\end{array}$ & $\begin{array}{l}\text { : Mattoon/Future Gen } \\
: \text { USA } \\
: \text { IL }\end{array}$ & $\begin{array}{l}\text { Well } \\
\text { Field }\end{array}$ & $\begin{array}{l}\text { : Batelle Mattoon/FutureGen } \\
: \text { CO2 Disposal }\end{array}$ \\
\hline $\begin{array}{l}\text { Prepared for } \\
\text { Proposal No. } \\
\text { Date Prepared }\end{array}$ & $\begin{array}{l}: \text { SLB } \\
: \\
: 05-26-2009\end{array}$ & $\begin{array}{l}\text { Location } \\
\text { Service Point } \\
\text { Business Phone } \\
\text { FAX No. }\end{array}$ & $\begin{array}{l}: \text { Decatur, IL } \\
: \text { Prestonsburg } \\
: \text { (606) } 2982200 \\
: \text { (606) } 2982248\end{array}$ \\
\hline $\begin{array}{l}\text { Prepared by } \\
\text { Phone } \\
\text { E-Mail }\end{array}$ & $\begin{array}{l}\text { : Donald Leach } \\
\vdots:(606) 791-4194 \\
\text { dleach@prestonsburg.oilfield.slb.com }\end{array}$ & & \\
\hline
\end{tabular}

\section{well description}

Configurati Casing
on
Prev.String MD : $350.0 \mathrm{ft}$
Csg/Liner MD : $5000.0 \mathrm{ft}$
Landing Collar MD
Casing/liner Shoe MD
Mud Line
Total MD
BHST
Bit Size
Mean OH Diameter
Mean Annular Excess
Mean OH Equivalent Diameter
Total OH Volume

Stage : Single
OD : $20 \mathrm{in}$
OD $: 133 / 8 \mathrm{in}$
$4960.0 \mathrm{ft}$
$5000.0 \mathrm{ft}$
$0.0 \mathrm{ft}$
$5000.0 \mathrm{ft}$
$117 \mathrm{degF}$
$171 / 2 \mathrm{in}$
$17.500 \mathrm{in}$
$50.0 \%$
$19.234 \mathrm{in}$
$1671.0 \mathrm{bbl}$ (including excess)

Rig Type : Land

Weight : $94.0 \mathrm{lb} / \mathrm{ft}$ Weight : $72.0 \mathrm{lb} / \mathrm{ft}$

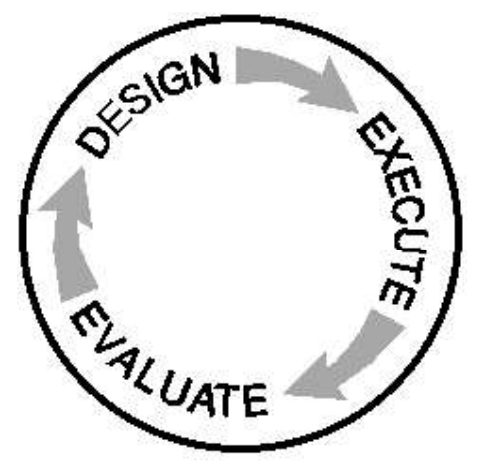

Disclaimer Notice:

This information is presented in good faith, but no warranty is given by and Schlumberger assumes no liability for advice or recommendations made concerning results to be obtained from the use of any product or service. The results given are estimates based on calculations produced by a computer model including various assumptions on the well, reservoir and treatment. The results depend on input data provided by the Operator and on estimates as to unknown data and can be no more accurate than the model, the assumptions and such input data. The information presented is Schlumberger's best estimate of the actual results that may be achieved and should be used for comparison purposes rather than absolute values. The quality of input data, and hence results, may be improved through the use of certain tests and procedures which Schlumberger can assist in selecting.

The Operator has superior knowledge of the well, the reservoir, the field and conditions affecting them. If the Operator is aware of any conditions whereby a neighboring well or wells might be affected by the treatment proposed herein it is the Operator's responsibility to notify the owner or owners of the well or wells accordingly.

Prices quoted are estimates only and are good for 30 days from the date of issue. Actual charges may vary depending upon time, equipment, and material ultimately required to perform these services.

Freedom from infringement of patents of Schlumberger or others is not to be inferred. Mlark or Schiumiverget 


\section{Section 4: fluid sequence}

Job Objectives:

13.375 " casing cement treatment

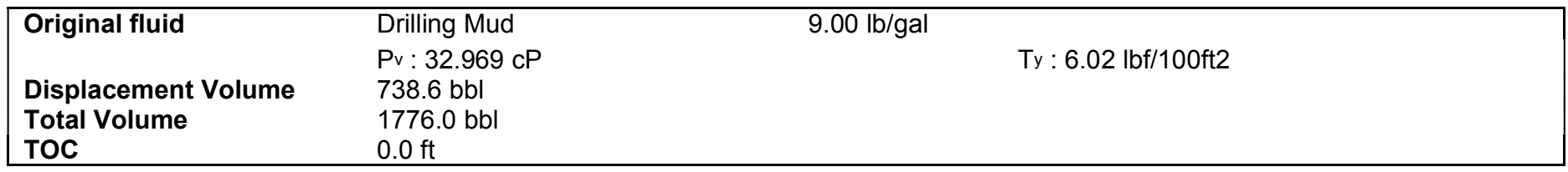

\begin{tabular}{|c|c|c|c|c|c|c|c|}
\hline Name & \multicolumn{6}{|c|}{ Fluid Sequence } & \\
\hline MUDPUSH II & 50.0 & 0.0 & & 12.00 & $P v: 19.736 \mathrm{cP}$ & & Ty:16.38 lbf/100ft2 \\
\hline CW100 & 50.0 & 0.0 & & 8.33 & $\mathrm{Pv}: 0.900 \mathrm{cP}$ & & Ty:0.50 lbf/100ft2 \\
\hline 35:65 @ 12.7 ppg & 746.7 & 4004.1 & & 12.70 & $\mathrm{Pv}_{\mathrm{v}} 8.190 \mathrm{cP}$ & & Ty:9.14 lbf/100ft2 \\
\hline D901 Tail @ 15.6 ppg & 190.8 & 995.9 & 4004.1 & 15.60 & k:7.49E-2 lbf.s^n/ft2 & $\mathrm{n}: 0.450$ & Ty:1.05 lbf/100ft2 \\
\hline Drilling Mud & 738.6 & & 0.0 & 9.00 & $P v: 32.969 \mathrm{cP}$ & & Ty:6.02 lbf/100ft2 \\
\hline
\end{tabular}

\begin{tabular}{|lll|}
\hline \multicolumn{2}{l|}{ Static Security } & Checks : \\
\hline Frac & $49 \mathrm{psi}$ & at $350.0 \mathrm{ft}$ \\
Pore & $79 \mathrm{psi}$ & at $350.0 \mathrm{ft}$ \\
Collapse & $1394 \mathrm{psi}$ & at $4960.0 \mathrm{ft}$ \\
Burst & $5020 \mathrm{psi}$ & at $0.0 \mathrm{ft}$ \\
Csg.Pump out & 74 ton & \\
\hline
\end{tabular}

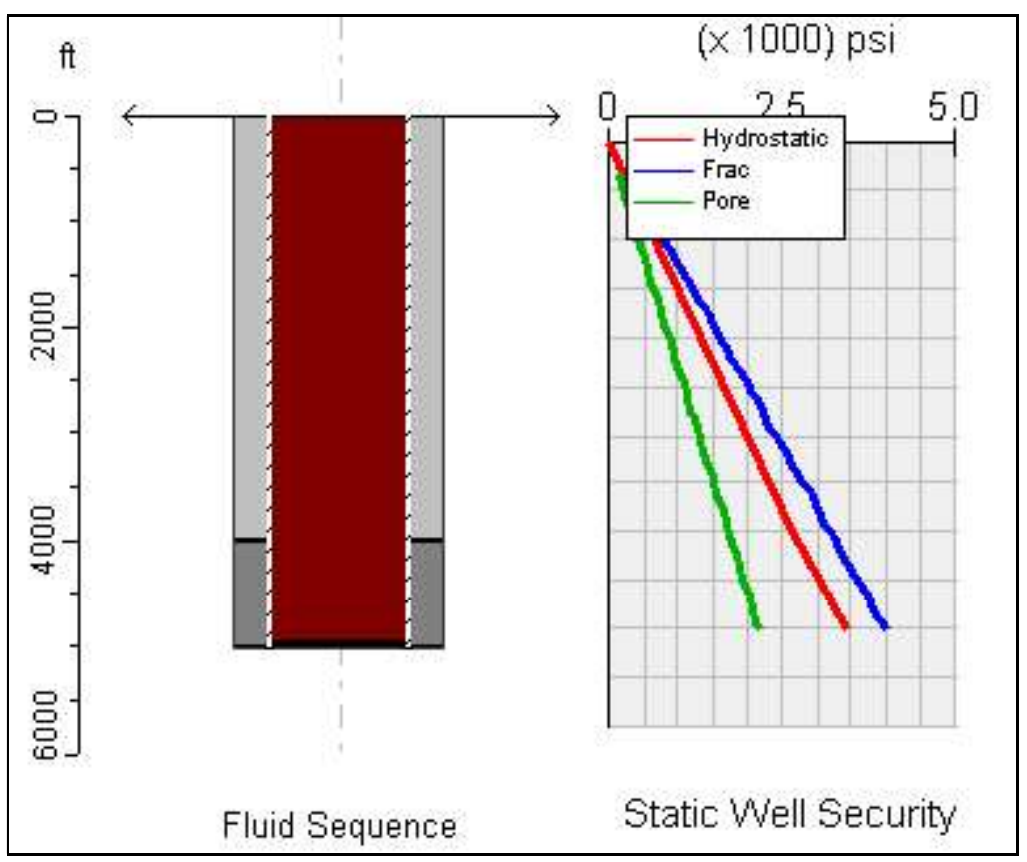




\section{Section 5: pumping schedule}

\section{Start Job:}

Hole circulated with mud @ 75F for 4 hours before pumping job

\begin{tabular}{|c|c|c|c|c|c|c|}
\hline \multicolumn{7}{|c|}{ Pumping Schedule } \\
\hline Name & $\begin{array}{l}\text { Flow Rate } \\
\text { (bbl/min) }\end{array}$ & $\begin{array}{c}\text { Volume } \\
\text { (bbl) }\end{array}$ & $\underset{(\min )}{\text { Stage Time }}$ & $\begin{array}{c}\text { Cum.Vol } \\
\text { (bbl). }\end{array}$ & $\begin{array}{c}\text { Inj. } \\
\text { Temp. } \\
\text { (degF) }\end{array}$ & Comments \\
\hline MUDPUSH II & 7.0 & 50.0 & 7.1 & 50.0 & 80 & \\
\hline CW100 & 7.0 & 50.0 & 7.1 & 50.0 & 80 & \\
\hline $35: 65 @ 12.7$ & 7.0 & 746.7 & 106.7 & 746.7 & 80 & \\
\hline $\mathrm{ppg}$ & & & & & & \\
\hline D901 Tail @ & 7.0 & 190.8 & 27.3 & 190.8 & 80 & \\
\hline $15.6 \mathrm{ppg}$ & & & & & & \\
\hline Pause & 0.0 & 0.0 & 5.0 & 0.0 & 80 & \\
\hline Drilling Mud & 7.0 & 730.0 & 104.3 & 730.0 & 80 & \\
\hline Drilling Mud & 2.0 & 8.6 & 4.3 & 738.6 & 80 & \\
\hline & & Total & $\begin{array}{l}04: 21 \\
\text { hr:mn }\end{array}$ & 1776. & & \\
\hline
\end{tabular}

\section{End Job:}

Designed displacement is with drilling mud

\begin{tabular}{|lll|}
\hline \multicolumn{2}{|l|}{ Dynamic Security Checks : } \\
\hline Frac & $47 \mathrm{psi}$ & at $350.0 \mathrm{ft}$ \\
Pore & $12 \mathrm{psi}$ & at $350.0 \mathrm{ft}$ \\
Collapse & $1394 \mathrm{psi}$ & at $4960.0 \mathrm{ft}$ \\
Burst & $3881 \mathrm{psi}$ & at $0.0 \mathrm{ft}$ \\
\hline
\end{tabular}

\begin{tabular}{|c|c|c|c|}
\hline \multicolumn{4}{|c|}{ Temperature Results } \\
\hline BHCT & $101 \mathrm{deg} F$ & Simulated Max HCT & 117 degF \\
\hline Simulated BHCT & 86 degF & Max HCT Depth & $5000.0 \mathrm{ft}$ \\
\hline CT at TOC & 84 degF & Max HCT Time & 00:00:00 hr:mn:sc \\
\hline \multicolumn{4}{|c|}{ Static temperatures: } \\
\hline At Time & (hr:mn) & (hr:mn) & Geo. Temp. \\
\hline Top of Cement & $(\operatorname{deg} F)$ & $(\operatorname{deg} F)$ & $62 \operatorname{deg} F$ \\
\hline Bottom Hole & (degF) & (degF) & $117 \mathrm{deg} F$ \\
\hline
\end{tabular}


String : 20" Surface

District : Prestonsburg

Country : USA

Loadcase : 20

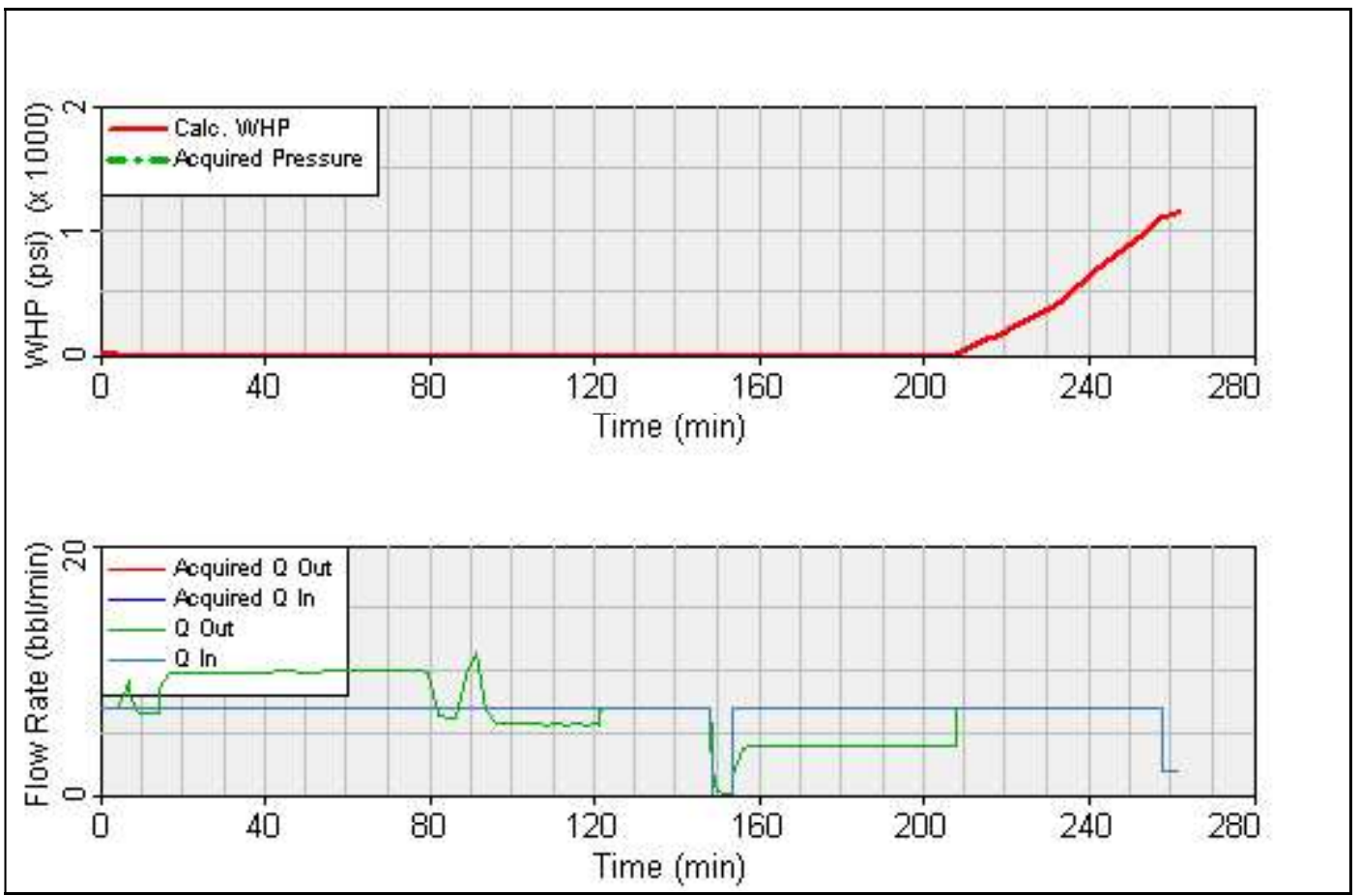

\section{Section 6: fluid description}

\section{5:65 @ 12.7 ppg DESIGN}

Fluid No: 1

Rheo. Model

At temp.

: BINGHAM

: $81 \mathrm{deg} F$

DESIGN

BLEND

Name

: 35:65

Dry Density : $181.77 \mathrm{lb} / \mathrm{ft} 3$

Sack Weight : $90 \mathrm{lb}$

BASE FLUID

Type : Fresh water

$\begin{array}{ll}\text { Density } & : 12.70 \mathrm{lb} / \mathrm{gal} \\ \mathrm{Pv}_{\mathrm{v}} & : 8.190 \mathrm{cP} \\ \text { Ty } & : 9.14 \mathrm{lbf} / 100 \mathrm{ft} 2 \\ \text { Gel Strength } & : 19.21 \mathrm{lbf} / 100 \mathrm{ft} 2\end{array}$

SLURRY

Mix Fluid : $11.397 \mathrm{gal} / \mathrm{sk} \quad$ Job volume $: 746.7 \mathrm{bbl}$

Yield : $2.10 \mathrm{ft} 3 / \mathrm{sk} \quad$ Quantity : $1992.60 \mathrm{sk}$

Solid Fraction : $27.6 \%$

Density $\quad: 8.32 \mathrm{lb} / \mathrm{gal}$

Base Fluid : $11.047 \mathrm{gal} / \mathrm{sk}$

\begin{tabular}{|lll|}
\hline Code & Conc. & Additives \\
\hline D020 & $4.000 \% B W O B$ & Function \\
D044 & $10.000 \%$ BWOW & Salt \\
D046 & $0.200 \%$ BWOB & Antifoam \\
D042 & $5.000 \mathrm{lb} / \mathrm{sk}$ blend & LCM/extender \\
\hline
\end{tabular}

\begin{tabular}{|c|c|c|c|c|}
\hline Thickening Time & Schedule () & $70 \mathrm{Bc}$ & at & 04:36 hr:mn \\
\hline Compressive Strength & Schedule () & (psi) & at & (hr:mn) \\
\hline
\end{tabular}




\section{CW100 DESIGN}

Fluid No: 2

Rheo. Model

At temp.

: BINGHAM
$: 60$ degF

Density $\quad: 8.33 \mathrm{lb} / \mathrm{gal}$

$\mathrm{Pv} \quad: 0.900 \mathrm{cP}$

Ty $: 0.50 \mathrm{lbf} / 100 \mathrm{ft} 2$

Gel Strength : $0.00 \mathrm{lbf} / 100 \mathrm{ft} 2$

Job volume $\quad: 50.0 \mathrm{bbl}$

\section{Drilling Mud DESIGN}

Fluid No: 4

Rheo. Model

At temp.

: BINGHAM

: 80 degF

MUD

Mud Type : WBM

Water Type : Fresh

VOLUME FRACTION

Solids $\quad: 4.5 \%$

Oil $\quad: 0.0 \%$

Water $\quad: 95.5 \%$
Density $\quad: 9.00 \mathrm{lb} / \mathrm{gal}$

Pv $\quad: 32.969 \mathrm{cP}$

Ty $: 6.02 \mathrm{lbf} / 100 \mathrm{ft} 2$

Gel Strength : $17.08 \mathrm{lbf} / 100 \mathrm{ft} 2$

Job volume : $738.6 \mathrm{bbl}$

\section{MUDPUSH II DESIGN}

Fluid No: 5

Rheo. Model

At temp.
: BINGHAM

: $81 \mathrm{deg} F$

$\begin{array}{ll}\text { Density } & : 12.00 \mathrm{lb} / \mathrm{gal} \\ \mathrm{P}_{\mathrm{v}} & : 19.736 \mathrm{cP} \\ \mathrm{Ty} & : 16.38 \mathrm{lbf} / 100 \mathrm{ft} 2 \\ \text { Gel Strength } & : 12.81 \mathrm{lbf} / 100 \mathrm{ft} 2 \\ \text { Job volume } & : 50.0 \mathrm{bbl}\end{array}$

Density $\quad: 12.00 \mathrm{lb} / \mathrm{gal}$

Pv $\quad: 19.736 \mathrm{cP}$

Ty $: 16.38 \mathrm{lbf} / 100 \mathrm{ft} 2$

Job volume $: 50.0 \mathrm{bb}$

\section{D901 Tail @ 15.6 ppg DESIGN}

Fluid No: 6

Rheo. Model : HERSCHEL_B.

At temp. $\quad: 81 \mathrm{deg} F$

\section{DESIGN}

BLEND

Name : A

Dry Density : $197.27 \mathrm{lb} / \mathrm{ft} 3$

Sack Weight : $94 \mathrm{lb}$

BASE FLUID

Type : Fresh water

$\begin{array}{ll}\text { Density } & : 15.60 \mathrm{lb} / \mathrm{gal} \\ \mathrm{k} & : 7.49 \mathrm{E}-2 \mathrm{lbf} . \mathrm{s}^{\wedge} \mathrm{n} / \mathrm{ft} 2 \\ \mathrm{n} & : 0.450 \\ \text { Ty } & : 1.05 \mathrm{lbf} / 100 \mathrm{ft} 2 \\ \text { Gel Strength } & :(\mathrm{lbf} / 100 \mathrm{ft} 2)\end{array}$

SLURRY

Mix Fluid : $5.217 \mathrm{gal} / \mathrm{sk} \quad$ Job volume : $190.8 \mathrm{bbl}$

Yield : $1.19 \mathrm{ft} 3 / \mathrm{sk} \quad$ Quantity : $900.92 \mathrm{sk}$

Solid Fraction : : $41.3 \%$

Density $\quad: 8.32 \mathrm{lb} / \mathrm{gal}$

Base Fluid : $5.217 \mathrm{gal} / \mathrm{sk}$ 
Client : Mattoon/Future Gen

Well : ISGS/ADM Well \#1

String : 20" Surface

District : Prestonsburg

Country : USA

Loadcase : 20

\begin{tabular}{|lll|}
\hline Code & Conc. & Additives \\
\hline D065 & $1.000 \%$ BWOC & Function \\
D167 & $0.200 \%$ BWOC & Fispersant \\
D046 & $0.200 \%$ BWOC & Antifoam loss \\
\hline
\end{tabular}

Thickening Time

Compressive Strength
Schedule ( )

Schedule ()
(Bc)

(psi) at (hr:mn)

at (hr:mn) 


\section{CemCADE ${ }^{*}$ well Cementing Recommendation for 13-3/8" Intermediate Casing $(7,000 \mathrm{ft})$ \\ $1^{\text {st }}$ (Lower) Stage of 2-Stage Cement Installation}




\section{CemCADE* well cementing recommendation for $133 / 8 "$ Intermediate}

\begin{tabular}{|c|c|c|c|}
\hline $\begin{array}{l}\text { Operator } \\
\text { Country } \\
\text { State }\end{array}$ & $\begin{array}{l}\text { : Mattoon/Future Gen } \\
: \text { USA } \\
: \text { IL }\end{array}$ & $\begin{array}{l}\text { Well } \\
\text { Field }\end{array}$ & $\begin{array}{l}\text { : Batelle Mattoon/FutureGen } \\
: \text { CO2 Disposal }\end{array}$ \\
\hline $\begin{array}{l}\text { Prepared for } \\
\text { Proposal No. } \\
\text { Date Prepared }\end{array}$ & $\begin{array}{l}: \text { SLB } \\
: \\
: 05-26-2009\end{array}$ & $\begin{array}{l}\text { Location } \\
\text { Service Point } \\
\text { Business Phone } \\
\text { FAX No. }\end{array}$ & $\begin{array}{l}: \text { Decatur, IL } \\
: \text { Prestonsburg } \\
: \text { (606) } 2982200 \\
: \text { (606) } 2982248\end{array}$ \\
\hline $\begin{array}{l}\text { Prepared by } \\
\text { Phone } \\
\text { E-Mail }\end{array}$ & $\begin{array}{l}\text { : Donald Leach } \\
\vdots:(606) 791-4194 \\
\text { dleach@prestonsburg.oilfield.slb.com }\end{array}$ & & \\
\hline
\end{tabular}

\begin{tabular}{|c|c|}
\hline $\begin{array}{l}\text { Configurati } \\
\text { on } \\
\text { Prev.String } \\
\text { Csg/Liner } \\
\text { 1st Stage Coll } \\
\text { Landing Collar } \\
\text { Casing/liner St } \\
\text { Mud Line } \\
\text { Total MD } \\
\text { BHST } \\
\text { Bit Size } \\
\text { Mean OH Diam } \\
\text { Mean Annular } \\
\text { Mean OH Equi } \\
\text { Total OH Volur }\end{array}$ & $\begin{array}{l}\text { Casing } \\
\text { MD : } 500.0 \mathrm{ft} \\
\text { MD : } 7000.0 \mathrm{ft} \\
\text { ar } \\
\text { r MD } \\
\text { hoe MD }\end{array}$ \\
\hline
\end{tabular}

\section{well description}

Stage : 1st of 2
OD : $20 \mathrm{in}$
OD : $133 / 8 \mathrm{in}$
$5000.0 \mathrm{ft}$
$6920.0 \mathrm{ft}$
$7000.0 \mathrm{ft}$
$0.0 \mathrm{ft}$
$7000.0 \mathrm{ft}$
$139 \mathrm{degF}$
$171 / 2 \mathrm{in}$
$17.500 \mathrm{in}$
$50.0 \%$
$19.234 \mathrm{in}$
$2335.8 \mathrm{bbl}$ (including excess)

Rig Type : Land

Weight : $106.5 \mathrm{lb} / \mathrm{ft}$ Weight : $72.0 \mathrm{lb} / \mathrm{ft}$

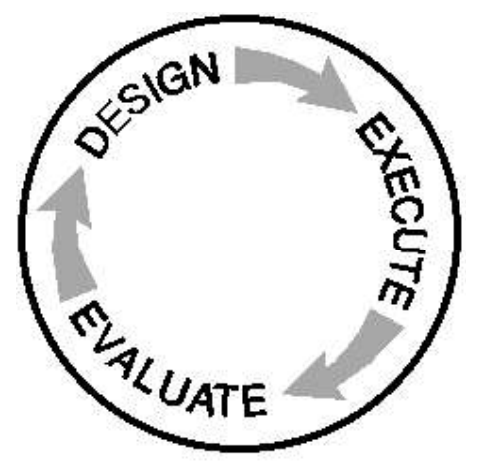

Disclaimer Notice:

This information is presented in good faith, but no warranty is given by and Schlumberger assumes no liability for advice or recommendations made concerning results to be obtained from the use of any product or service. The results given are estimates based on calculations produced by a computer model including various assumptions on the well, reservoir and treatment. The results depend on input data provided by the Operator and on estimates as to unknown data and can be no more accurate than the model, the assumptions and such input data. The information presented is Schlumberger's best estimate of the actual results that may be achieved and should be used for comparison purposes rather than absolute values. The quality of input data, and hence results, may be improved through the use of certain tests and procedures which Schlumberger can assist in selecting.

The Operator has superior knowledge of the well, the reservoir, the field and conditions affecting them. If the Operator is aware of any conditions whereby a neighboring well or wells might be affected by the treatment proposed herein it is the Operator's responsibility to notify the owner or owners of the well or wells accordingly.

Prices quoted are estimates only and are good for 30 days from the date of issue. Actual charges may vary depending upon time, equipment, and material ultimately required to perform these services.

Freedom from infringement of patents of Schlumberger or others is not to be inferred. Mlark or Schiumiverget 


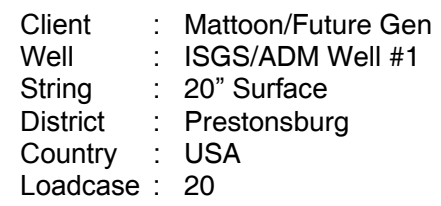

\section{Section 7: fluid sequence}

Job Objectives:

13.375" TWO-STAGE CASING CEMENT TREATMENT

\begin{tabular}{|lll|}
\hline Original fluid & Drilling Mud & $9.00 \mathrm{lb} / \mathrm{gal}$ \\
& $\mathrm{P}_{\mathrm{v}}: 32.969 \mathrm{cP}$ & $\mathrm{Ty}: 6.02 \mathrm{lbf} / 100 \mathrm{ft} 2$ \\
Displacement Volume & $1030.5 \mathrm{bbl}$ & \\
Total Volume & $1500.5 \mathrm{bbl}$ & \\
TOC & $5070.1 \mathrm{ft}$ \\
1st stage collar & $5000.0 \mathrm{ft}$ & \\
\hline
\end{tabular}

\begin{tabular}{|c|c|c|c|c|c|c|}
\hline Name & \multicolumn{5}{|c|}{ Fluid Sequence } & Rheology \\
\hline MUDPUSH II & 50.0 & 269.4 & 4531.2 & 12.00 & $\mathrm{Pv}_{\mathrm{v}} 19.736 \mathrm{cP}$ & Ty:16.38 lbf/100ft2 \\
\hline CW100 & 50.0 & 269.4 & 4800.7 & 8.33 & $\mathrm{Pv}: 0.900 \mathrm{cP}$ & Ty:0.50 lbf/100ft2 \\
\hline $\begin{array}{r}\text { 1st Stage - } 15.6 \mathrm{ppg} \\
\text { Class H }\end{array}$ & 185.3 & 998.5 & 5070.1 & 15.60 & $\mathrm{P}_{\mathrm{v}}: 60.176 \mathrm{cP}$ & Ty:49.90 lbf/100ft2 \\
\hline $\begin{array}{r}\text { 1st Stage - } 16.2 \mathrm{ppg} \\
\text { Class H }\end{array}$ & 184.7 & 931.4 & 6068.6 & 16.20 & $P_{v}: 67.068 \mathrm{cP}$ & Ty:59.77 lbf/100ft2 \\
\hline Drilling Mud & 1030.5 & & 0.0 & 9.00 & $P v: 32.969 \mathrm{cP}$ & Ty:6.02 lbf/100ft2 \\
\hline
\end{tabular}

\begin{tabular}{|lll|}
\hline \multicolumn{2}{|l|}{ Static Security Checks : } \\
\hline Frac & $166 \mathrm{psi}$ & \\
Pore & $17 \mathrm{psi}$ & at $500.0 \mathrm{ft}$ \\
Collapse & $1728 \mathrm{psi}$ & at $500.0 \mathrm{ft}$ \\
Burst & $5020 \mathrm{psi}$ & at $6920.0 \mathrm{ft}$ \\
Csg.Pump out & $163 \mathrm{ton}$ & at $0.0 \mathrm{ft}$ \\
\hline
\end{tabular}

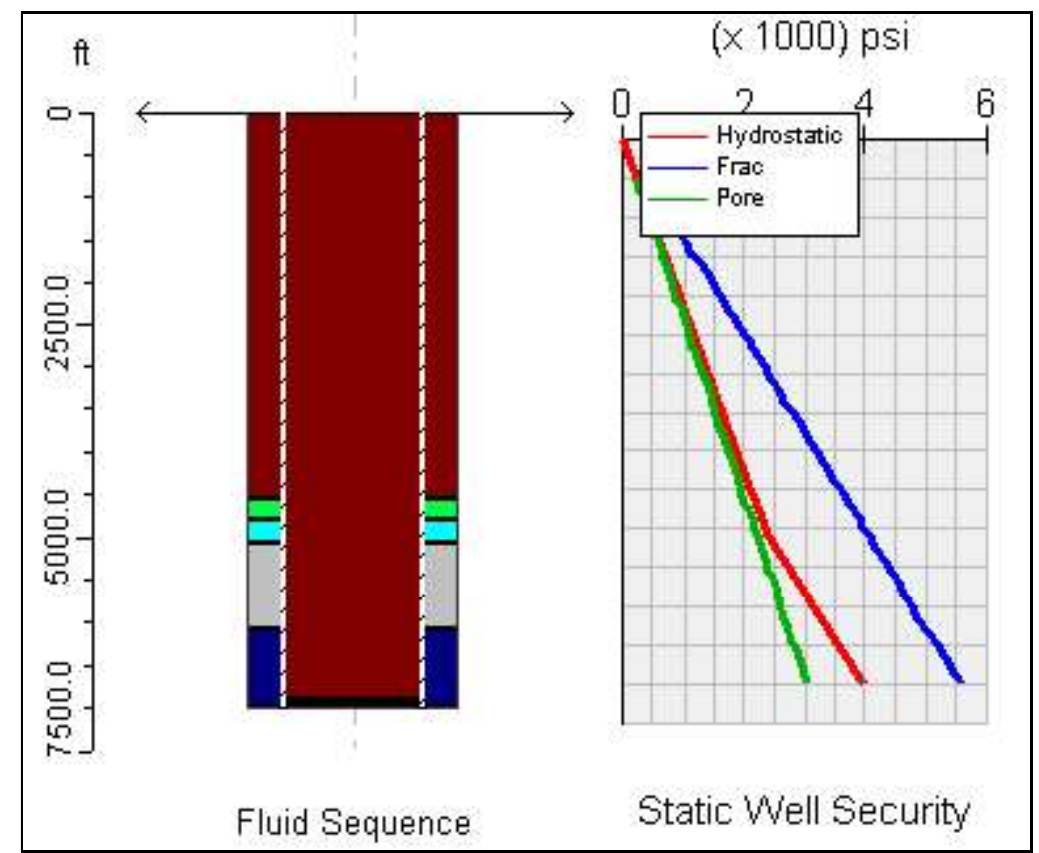


String : 20" Surface

District : Prestonsburg

Country : USA

Loadcase : 20

\section{Section 8: pumping schedule}

\section{Start Job:}

Hole circulated with mud @ 75F for 4 hours before pumping job

\begin{tabular}{|c|c|c|c|c|c|c|}
\hline \multicolumn{7}{|c|}{ Pumping Schedule } \\
\hline Name & $\begin{array}{l}\text { Flow Rate } \\
\text { (bbl/min) }\end{array}$ & $\begin{array}{c}\text { Volume } \\
\text { (bbl) }\end{array}$ & $\begin{array}{l}\text { Stage Time } \\
\text { (min) }\end{array}$ & $\begin{array}{c}\text { Cum.Vol } \\
\text { (bbl). }\end{array}$ & $\begin{array}{l}\text { Inj. } \\
\text { Temp. } \\
\text { (degF) }\end{array}$ & Comments \\
\hline MUDPUSH II & 7.0 & 50.0 & 7.1 & 50.0 & 80 & \\
\hline CW100 & 7.0 & 50.0 & 7.1 & 50.0 & 80 & \\
\hline 1st Stage - 15.6 & 7.0 & 185.3 & 26.5 & 185.3 & 80 & \\
\hline ppg Class H & & & & & & \\
\hline 1st Stage - 16.2 & 7.0 & 184.7 & 26.4 & 184.7 & 80 & \\
\hline ppg Class $\mathrm{H}$ & & & & & & \\
\hline Pause & 0.0 & 0.0 & 5.0 & 0.0 & 80 & \\
\hline Drilling Mud & 7.0 & 1020.0 & 145.7 & 1020.0 & 80 & \\
\hline Drilling Mud & 2.0 & 10.5 & 5.2 & 1030.5 & 80 & \\
\hline & & Total & $\begin{array}{l}03: 43 \\
\text { hr:mn }\end{array}$ & $1500.5 \mathrm{bbl}$ & & \\
\hline
\end{tabular}

End Job:

Designed displacement is with drilling mud

\begin{tabular}{|lll|}
\hline \multicolumn{2}{|l|}{ Dynamic Security Checks : } \\
\hline Frac & $163 \mathrm{psi}$ & at $500.0 \mathrm{ft}$ \\
Pore & $17 \mathrm{psi}$ & at $500.0 \mathrm{ft}$ \\
Collapse & $1284 \mathrm{psi}$ & at $3480.0 \mathrm{ft}$ \\
Burst & $4226 \mathrm{psi}$ & at $0.0 \mathrm{ft}$ \\
\hline
\end{tabular}

\begin{tabular}{|c|c|c|c|}
\hline \multicolumn{4}{|c|}{ Temperature Results } \\
\hline BHCT & $117 \mathrm{deg} F$ & Simulated Max HCT & $111 \mathrm{deg} F$ \\
\hline Simulated BHCT & $93 \operatorname{deg} F$ & Max HCT Depth & $4714.3 \mathrm{ft}$ \\
\hline CT at TOC & 99 degF & Max HCT Time & 00:00:00 hr:mn:sc \\
\hline \multicolumn{4}{|c|}{ Static temperatures: } \\
\hline At Time & (hr:mn) & (hr:mn) & Geo. Temp. \\
\hline Top of Cement & $(\operatorname{deg} F)$ & $(\operatorname{deg} F)$ & $118 \operatorname{deg} \mathrm{F}$ \\
\hline Bottom Hole & (degF) & (degF) & 139 degF \\
\hline
\end{tabular}


Client : Mattoon/Future Gen

Well : ISGS/ADM Well \#1

String : 20" Surface

District : Prestonsburg

Country : USA

Loadcase : 20

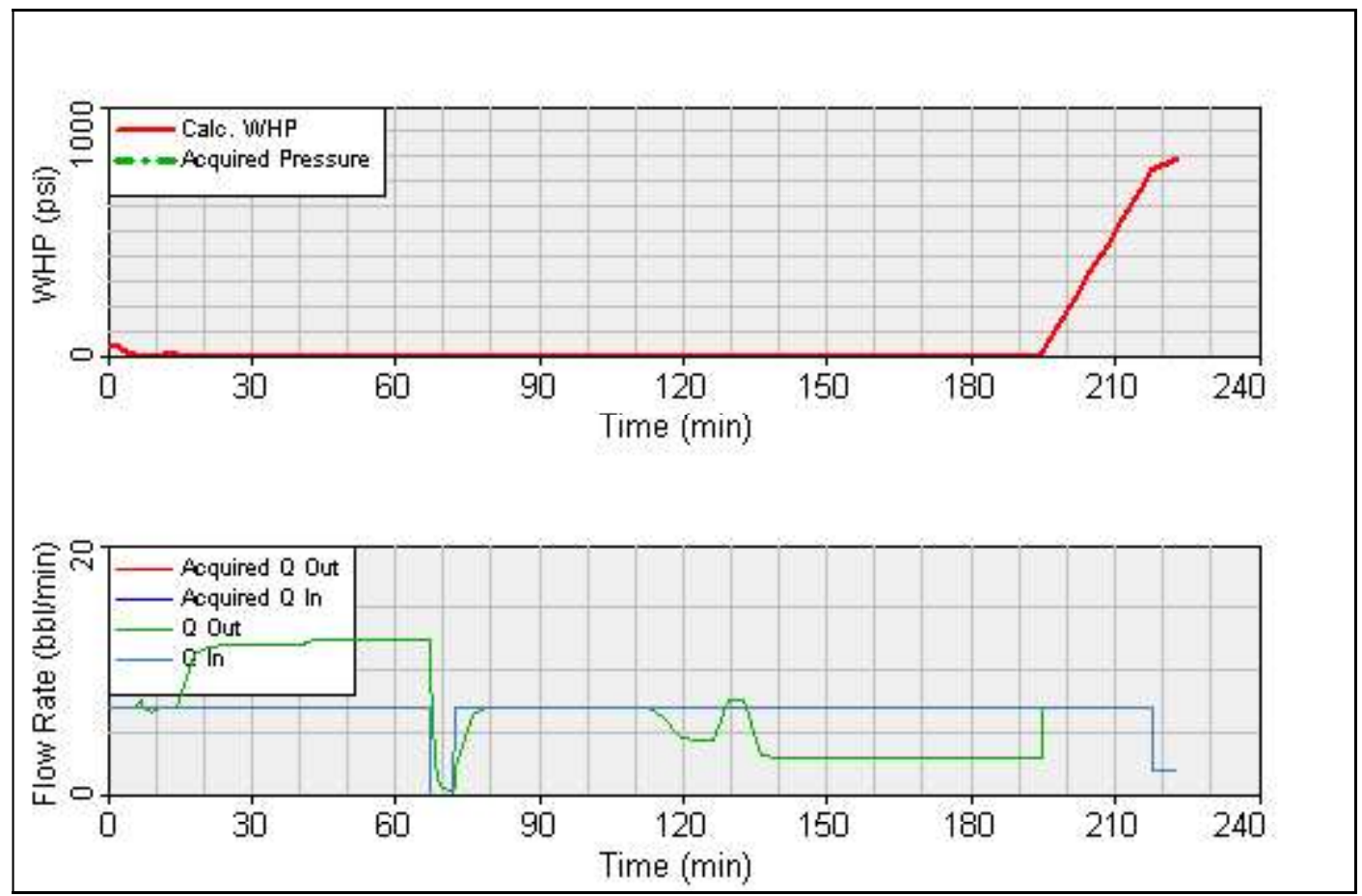




\section{Section 9: fluid description}

\section{CW100 DESIGN}

Fluid No: 2

Rheo. Model

: BINGHAM

Density $\quad: 8.33 \mathrm{lb} / \mathrm{gal}$

At temp. $\quad: 60 \mathrm{degF}$

Pv $\quad: 0.900 \mathrm{cP}$

Ty $\quad: 0.50 \mathrm{lbf} / 100 \mathrm{ft} 2$

Gel Strength : $0.00 \mathrm{lbf} / 100 \mathrm{ft} 2$

Job volume $\quad: 50.0 \mathrm{bbl}$

\section{Drilling Mud DESIGN}

Fluid No: 4

Rheo. Model : BINGHAM

At temp.

: 80 degF

\section{MUD}

Mud Type : WBM

Water Type : Fresh

VOLUME FRACTION

Solids $\quad: 4.5 \%$

Oil $\quad: 0.0 \%$

Water $\quad: 95.5 \%$
Density $\quad: 9.00 \mathrm{lb} / \mathrm{gal}$

$\mathrm{Pv}_{\mathrm{v}} \quad: 32.969 \mathrm{cP}$

Ty $\quad: 6.02 \mathrm{lbf} / 100 \mathrm{ft} 2$

Gel Strength : $17.08 \mathrm{lbf} / 100 \mathrm{ft} 2$

Job volume $\quad: 1030.5 \mathrm{bbl}$

\section{MUDPUSH II DESIGN}

Fluid No: 5

Rheo. Model

At temp.

: BINGHAM

: $81 \mathrm{deg} F$

$\begin{array}{ll}\text { Density } & : 12.00 \mathrm{lb} / \mathrm{gal} \\ \mathrm{Pv} & : 19.736 \mathrm{cP} \\ \text { Ty } & : 16.38 \mathrm{lbf} / 100 \mathrm{ft} 2 \\ \text { Gel Strength } & : 12.81 \mathrm{lbf} / 100 \mathrm{ft} 2 \\ \text { Job volume } & : 50.0 \mathrm{bbl}\end{array}$

Density $\quad: 12.00 \mathrm{lb} / \mathrm{gal}$

$\mathrm{Pv}_{\mathrm{v}} \quad: 19.736 \mathrm{cP}$

Ty $\quad: 16.38 \mathrm{lbf} / 100 \mathrm{ft} 2$

Job volume $\quad: 50.0 \mathrm{bbl}$

\section{1st Stage - 16.2 ppg Class H DESIGN}

\section{Fluid No: 6}

Rheo. Model

At temp.

: BINGHAM

: 80 degF

\section{DESIGN}

BLEND

Name : $\mathrm{H}$

Dry Density : $197.27 \mathrm{lb} / \mathrm{ft} 3$

Sack Weight : $94 \mathrm{lb}$

BASE FLUID

Type : Fresh water

$$
\begin{array}{ll}
\text { Density } & : 16.20 \mathrm{lb} / \mathrm{gal} \\
\mathrm{Pv}_{\mathrm{v}} & : 67.068 \mathrm{cP} \\
\mathrm{Ty}_{\mathrm{y}} & : 59.77 \mathrm{lbf} / 100 \mathrm{ft} 2 \\
\text { Gel Strength } & :(\mathrm{lbf} / 100 \mathrm{ft} 2)
\end{array}
$$

SLURRY

Mix Fluid : $4.605 \mathrm{gal} / \mathrm{sk} \quad$ Job volume $: 184.7 \mathrm{bbl}$

Yield : $1.09 \mathrm{ft} 3 / \mathrm{sk} \quad$ Quantity $: 948.45 \mathrm{sk}$

Solid Fraction : : $43.7 \%$

Density : $8.32 \mathrm{lb} / \mathrm{gal} \quad$ Base Fluid $: 4.605 \mathrm{gal} / \mathrm{sk}$ 
Client : Mattoon/Future Gen

Well : ISGS/ADM Well \#1

String : 20" Surface

District : Prestonsburg

Country : USA

Loadcase : 20

\begin{tabular}{|lll|}
\hline Code & Conc. & Additives \\
\hline D201 & $0.200 \%$ BWOC & Function \\
\hline
\end{tabular}

$\begin{array}{llllll}\text { Thickening Time } & \text { Schedule } & () & (\mathrm{Bc}) & \text { at } & (\mathrm{hr}: \mathrm{mn}) \\ \text { Compressive Strength } & \text { Schedule } & () & \text { (psi) } & \text { at } & (\mathrm{hr}: \mathrm{mn})\end{array}$

\section{1st Stage -15.6 ppg Class H DESIGN}

Fluid No: 7

Rheo. Model : BINGHAM

At temp. $: 80 \mathrm{deg} F$

\section{DESIGN}

BLEND

Name : $\mathrm{H}$

Dry Density : $197.27 \mathrm{lb} / \mathrm{ft} 3$

Sack Weight : $94 \mathrm{lb}$

BASE FLUID

Type : Fresh water

$$
\begin{array}{ll}
\text { Density } & : 15.60 \mathrm{lb} / \mathrm{gal} \\
\mathrm{P}_{\mathrm{v}} & : 60.176 \mathrm{cP} \\
\mathrm{T}_{\mathrm{y}} & : 49.90 \mathrm{lbf} / 100 \mathrm{ft} 2 \\
\text { Gel Strength } & :(\mathrm{lbf} / 100 \mathrm{ft} 2)
\end{array}
$$

SLURRY

Mix Fluid : $5.279 \mathrm{gal} / \mathrm{sk} \quad$ Job volume : $185.3 \mathrm{bbl}$

Yield : :1.18 ft3/sk Quantity : 879.07 sk

Solid Fraction : $40.4 \%$

Density $\quad: 8.32 \mathrm{lb} / \mathrm{gal}$

Base Fluid : $5.259 \mathrm{gal} / \mathrm{sk}$

\begin{tabular}{|lll|}
\hline & \multicolumn{1}{c|}{ Additives } \\
Code & Conc. & Function \\
\hline D201 & $0.200 \%$ BWOC & Retarder \\
D047 & $0.020 \mathrm{gal} / \mathrm{sk}$ blend & Antifoam \\
\hline
\end{tabular}

Thickening Time

Compressive Strength
Schedule ( )

Schedule ()
$(\mathrm{Bc})$

(psi) at (hr:mn)

at (hr:mn) 


\section{CemCADE ${ }^{*}$ well Cementing Recommendation for 13-3/8" Intermediate Casing $(7,000 \mathrm{ft})$ \\ $2^{\text {nd }}$ (Upper) Stage of 2-Stage Cement Installation}




\section{CemCADE* well cementing recommendation for $133 / 8 "$ Intermediate}

\begin{tabular}{|c|c|c|c|}
\hline $\begin{array}{l}\text { Operator } \\
\text { Country } \\
\text { State }\end{array}$ & $\begin{array}{l}\text { : Mattoon/Future Gen } \\
: \text { USA } \\
: \text { IL }\end{array}$ & $\begin{array}{l}\text { Well } \\
\text { Field }\end{array}$ & $\begin{array}{l}\text { : Batelle Mattoon/FutureGen } \\
: \text { CO2 Disposal }\end{array}$ \\
\hline $\begin{array}{l}\text { Prepared for } \\
\text { Proposal No. } \\
\text { Date Prepared }\end{array}$ & $\begin{array}{l}: \text { SLB } \\
: \\
: 05-26-2009\end{array}$ & $\begin{array}{l}\text { Location } \\
\text { Service Point } \\
\text { Business Phone } \\
\text { FAX No. }\end{array}$ & $\begin{array}{l}: \text { Decatur, IL } \\
: \text { Prestonsburg } \\
: \text { (606) } 2982200 \\
: \text { (606) } 2982248\end{array}$ \\
\hline $\begin{array}{l}\text { Prepared by } \\
\text { Phone } \\
\text { E-Mail }\end{array}$ & $\begin{array}{l}\text { : Donald Leach } \\
\vdots:(606) 791-4194 \\
\text { dleach@prestonsburg.oilfield.slb.com }\end{array}$ & & \\
\hline
\end{tabular}

\begin{tabular}{|c|c|}
\hline $\begin{array}{l}\text { Configurati } \\
\text { on } \\
\text { Prev.String } \\
\text { Csg/Liner } \\
\text { 1st Stage Coll } \\
\text { Landing Collar } \\
\text { Casing/liner St } \\
\text { Mud Line } \\
\text { Total MD } \\
\text { BHST } \\
\text { Bit Size } \\
\text { Mean OH Diam } \\
\text { Mean Annular } \\
\text { Mean OH Equi } \\
\text { Total OH Volur }\end{array}$ & $\begin{array}{l}\text { Casing } \\
\text { MD : } 500.0 \mathrm{ft} \\
\text { MD : } 7000.0 \mathrm{ft} \\
\text { ar } \\
\text { r MD } \\
\text { hoe MD }\end{array}$ \\
\hline
\end{tabular}

\section{well description}

Stage : 2 nd of 2
OD : $20 \mathrm{in}$
OD : $13 \mathrm{3} / 8 \mathrm{in}$
$5000.0 \mathrm{ft}$
$6920.0 \mathrm{ft}$
$7000.0 \mathrm{ft}$
$0.0 \mathrm{ft}$
$7000.0 \mathrm{ft}$
$117 \mathrm{degF}$
$171 / 2 \mathrm{in}$
$17.500 \mathrm{in}$
$50.0 \%$
$19.234 \mathrm{in}$
$2335.8 \mathrm{bbl}$ (including excess)

Rig Type : Land

Weight : $106.5 \mathrm{lb} / \mathrm{ft}$ Weight : $72.0 \mathrm{lb} / \mathrm{ft}$

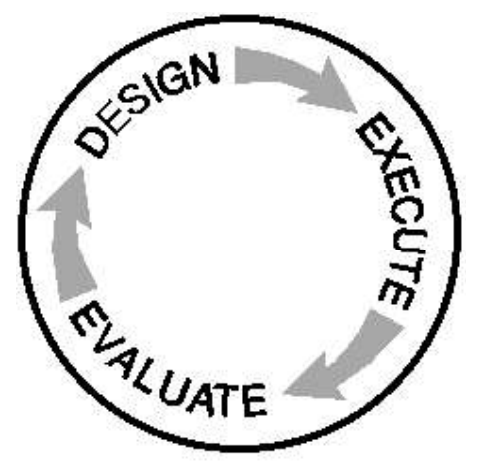

Disclaimer Notice:

This information is presented in good faith, but no warranty is given by and Schlumberger assumes no liability for advice or recommendations made concerning results to be obtained from the use of any product or service. The results given are estimates based on calculations produced by a computer model including various assumptions on the well, reservoir and treatment. The results depend on input data provided by the Operator and on estimates as to unknown data and can be no more accurate than the model, the assumptions and such input data. The information presented is Schlumberger's best estimate of the actual results that may be achieved and should be used for comparison purposes rather than absolute values. The quality of input data, and hence results, may be improved through the use of certain tests and procedures which Schlumberger can assist in selecting.

The Operator has superior knowledge of the well, the reservoir, the field and conditions affecting them. If the Operator is aware of any conditions whereby a neighboring well or wells might be affected by the treatment proposed herein it is the Operator's responsibility to notify the owner or owners of the well or wells accordingly.

Prices quoted are estimates only and are good for 30 days from the date of issue. Actual charges may vary depending upon time, equipment, and material ultimately required to perform these services.

Freedom from infringement of patents of Schlumberger or others is not to be inferred. Mlark or Schiumiverget 


\section{Section 10: fluid sequence}

Job Objectives:

13.375" TWO-STAGE CASING CEMENT TREATMENT

\begin{tabular}{|c|c|c|c|}
\hline Original fluid & Drilling Mud & $9.00 \mathrm{lb} / \mathrm{gal}$ & \\
\hline & $\mathrm{Pv}_{\mathrm{v}}: 32.969 \mathrm{cP}$ & & Ty : $6.02 \mathrm{lbf} / 100 \mathrm{ft} 2$ \\
\hline Dead end fluid & CW100 & & $8.33 \mathrm{lb} / \mathrm{gal}$ \\
\hline Displacement Volume & $746.2 \mathrm{bbl}$ & & \\
\hline Total Volume & $1784.1 \mathrm{bbl}$ & & \\
\hline TOC & $0.0 \mathrm{ft}$ & & \\
\hline Previous TOC & $5070.1 \mathrm{ft}$ & & \\
\hline
\end{tabular}

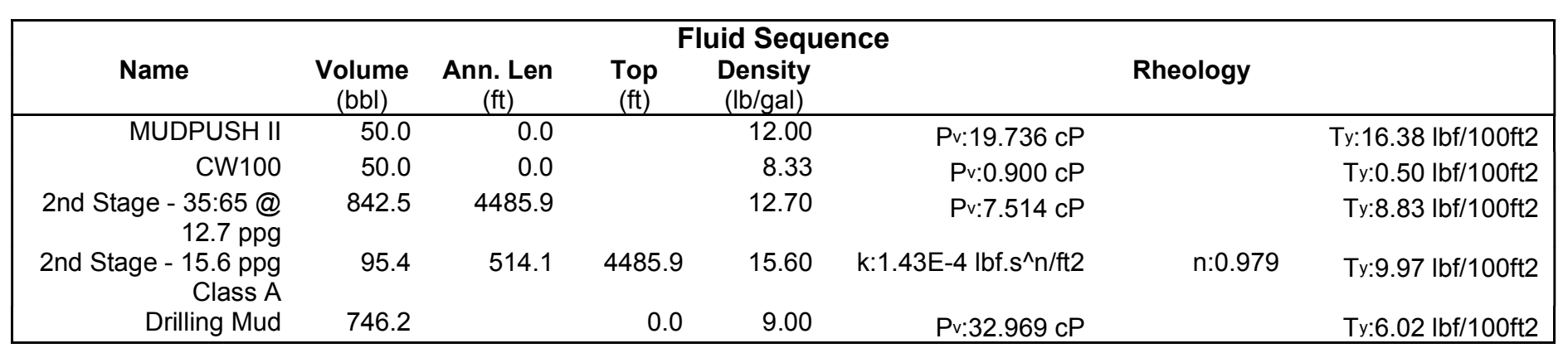

\begin{tabular}{|lll|}
\hline \multicolumn{2}{|l|}{ Static Security } & Checks : \\
\hline Frac & $70 \mathrm{psi}$ & at $500.0 \mathrm{ft}$ \\
Pore & $113 \mathrm{psi}$ & at $500.0 \mathrm{ft}$ \\
Collapse & $1452 \mathrm{psi}$ & at $5000.0 \mathrm{ft}$ \\
Burst & $5020 \mathrm{psi}$ & at $0.0 \mathrm{ft}$
\end{tabular}

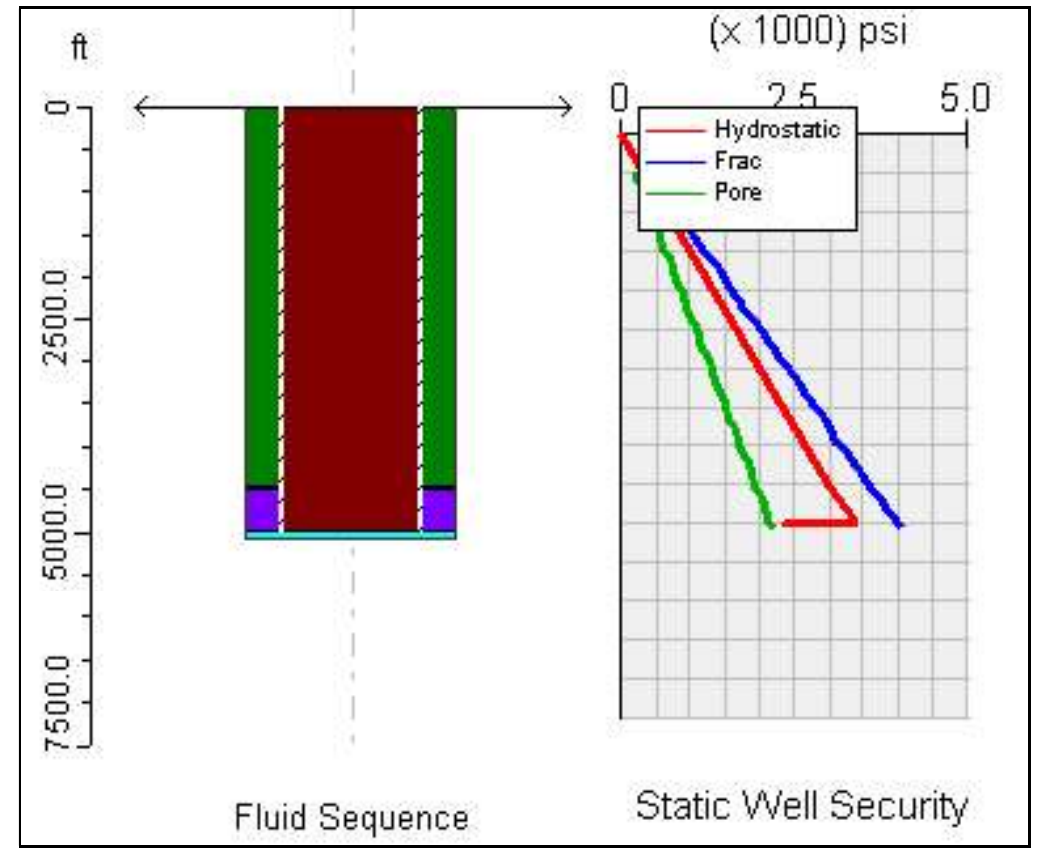




\section{Section 11: pumping schedule}

\section{Start Job:}

Hole circulated with mud @ 75F for 4 hours before pumping job

\begin{tabular}{|c|c|c|c|c|c|c|}
\hline \multicolumn{7}{|c|}{ Pumping Schedule } \\
\hline Name & $\begin{array}{l}\text { Flow Rate } \\
\text { (bbl/min) }\end{array}$ & $\begin{array}{c}\text { Volume } \\
\text { (bbl) }\end{array}$ & $\underset{(\min )}{\text { Stage Time }}$ & $\begin{array}{l}\text { Cum.Vol } \\
\text { (bbl). }\end{array}$ & $\begin{array}{c}\text { Inj. } \\
\text { Temp. } \\
\text { (degF) }\end{array}$ & Comments \\
\hline MUDPUSH II & 7.0 & 50.0 & 7.1 & 50.0 & 80 & \\
\hline CW100 & 7.0 & 50.0 & 7.1 & 50.0 & 80 & \\
\hline 2nd Stage - & 7.0 & 842.5 & 120.4 & 842.5 & 80 & \\
\hline 35:65@12.7 & & & & & & \\
\hline ppg & & & & & & \\
\hline 2nd Stage - & 7.0 & 95.4 & 13.6 & 95.4 & 80 & \\
\hline 15.6 ppg Class & & & & & & \\
\hline A & & & & & & \\
\hline Pause & 0.0 & 0.0 & 5.0 & 0.0 & 80 & \\
\hline Drilling Mud & 7.0 & 737.0 & 105.3 & 737.0 & 80 & \\
\hline Drilling Mud & 2.0 & 9.2 & 4.6 & 746.2 & 80 & \\
\hline & & Total & $\begin{array}{l}04: 23 \\
\text { hr:mn }\end{array}$ & bbl & & \\
\hline
\end{tabular}

\section{End Job:}

Designed displacement is with drilling mud

\begin{tabular}{|lll|}
\hline \multicolumn{2}{|l|}{ Dynamic Security Checks : } \\
\hline Frac & $67 \mathrm{psi}$ & at $500.0 \mathrm{ft}$ \\
Pore & $17 \mathrm{psi}$ & at $500.0 \mathrm{ft}$ \\
Collapse & $1452 \mathrm{psi}$ & at $5000.0 \mathrm{ft}$ \\
Burst & $3945 \mathrm{psi}$ & at $0.0 \mathrm{ft}$ \\
\hline
\end{tabular}

\begin{tabular}{|c|c|c|c|}
\hline \multicolumn{4}{|c|}{ Temperature Results } \\
\hline BHCT & $101 \mathrm{deg} F$ & Simulated Max HCT & 91 degF \\
\hline Simulated BHCT & 84 degF & Max HCT Depth & $1938.8 \mathrm{ft}$ \\
\hline CT at TOC & 82 degF & Max HCT Time & 00:00:00 hr:mn:sc \\
\hline \multicolumn{4}{|c|}{ Static temperatures: } \\
\hline At Time & (hr:mn) & (hr:mn) & Geo. Temp. \\
\hline Top of Cement & $(\operatorname{deg} F)^{\prime}$ & $(\operatorname{deg} F)^{\prime}$ & $62 \operatorname{deg} F$ \\
\hline Bottom Hole & (degF) & (degF) & $117 \mathrm{degF}$ \\
\hline
\end{tabular}


Client : Mattoon/Future Gen

Well : ISGS/ADM Well \#1

String : 20" Surface

District : Prestonsburg

Country : USA

Loadcase : 20

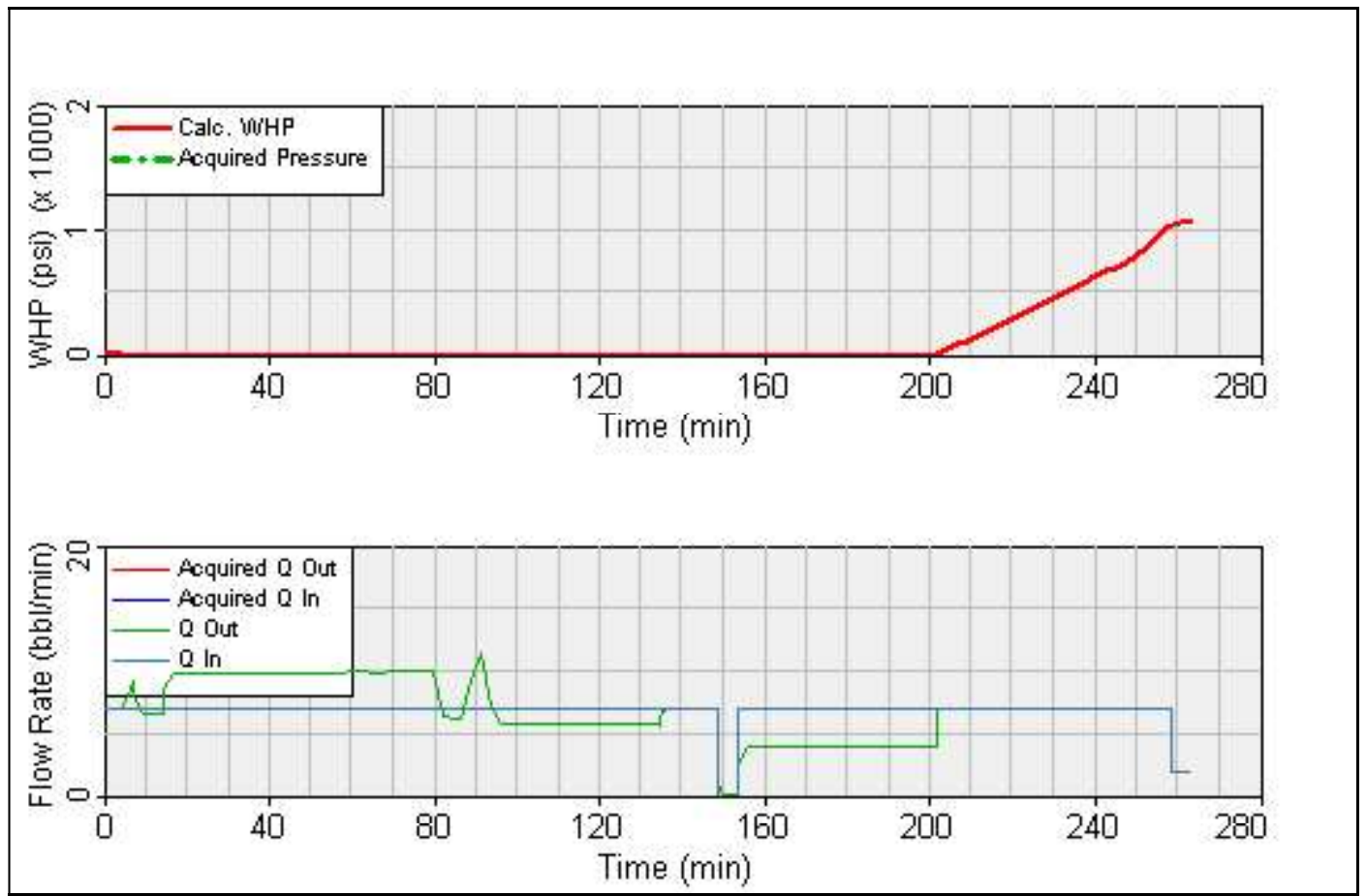




\section{Section 12: fluid description}

\section{CW100 DESIGN}

Fluid No: 1

Rheo. Model

At temp.

\author{
: BINGHAM \\ : 60 degF
}

$\begin{array}{ll}\text { Density } & : 8.33 \mathrm{lb} / \mathrm{gal} \\ \mathrm{Pv}_{\mathrm{v}} & : 0.900 \mathrm{cP} \\ \text { Ty } & : 0.50 \mathrm{lbf} / 100 \mathrm{ft} 2 \\ \text { Gel Strength } & : 0.00 \mathrm{lbf} / 100 \mathrm{ft} 2 \\ \text { Job volume } & : 50.0 \mathrm{bbl}\end{array}$

\section{Drilling Mud DESIGN}

Fluid No: 3

Rheo. Model : BINGHAM

At temp.

: 80 degF

\section{MUD}

Mud Type : WBM

Water Type : Fresh

VOLUME FRACTION

Solids $\quad: 4.5 \%$

Oil $\quad: 0.0 \%$

Water $\quad: 95.5 \%$

$\begin{array}{ll}\text { Density } & : 9.00 \mathrm{lb} / \mathrm{gal} \\ \mathrm{Pv}_{\mathrm{v}} & : 32.969 \mathrm{cP} \\ \text { Ty } & : 6.02 \mathrm{lbf} / 100 \mathrm{ft} 2 \\ \text { Gel Strength } & : 17.08 \mathrm{lbf} / 100 \mathrm{ft} 2 \\ & \\ \text { Job volume } & : 746.2 \mathrm{bbl}\end{array}$

Density $\quad: 9.00 \mathrm{lb} / \mathrm{gal}$

\section{MUDPUSH II DESIGN}

Fluid No: 4

Rheo. Model

At temp.
: BINGHAM

: $81 \mathrm{degF}$

$\begin{array}{ll}\text { Density } & : 12.00 \mathrm{lb} / \mathrm{gal} \\ \mathrm{Pv} & : 19.736 \mathrm{cP} \\ \text { Ty } & : 16.38 \mathrm{lbf} / 100 \mathrm{ft} 2 \\ \text { Gel Strength } & : 12.81 \mathrm{lbf} / 100 \mathrm{ft} 2 \\ \text { Job volume } & : 50.0 \mathrm{bbl}\end{array}$

Density $\quad: 12.00 \mathrm{lb} / \mathrm{gal}$

$\mathrm{Pv}_{\mathrm{v}} \quad: 19.736 \mathrm{cP}$

Ty $\quad: 16.38 \mathrm{lbf} / 100 \mathrm{ft} 2$

Job volume $\quad: 50.0 \mathrm{bbl}$

\section{2nd Stage - 35:65 @ 12.7 ppg DESIGN}

Fluid No: 7

Rheo. Model

At temp.

: BINGHAM

: $81 \mathrm{deg} F$

\section{DESIGN}

BLEND

Name

: 35:65

Dry Density : $181.77 \mathrm{lb} / \mathrm{ft} 3$

Sack Weight : $90 \mathrm{lb}$

BASE FLUID

Type : Fresh water

$\begin{array}{ll}\text { Density } & : 12.70 \mathrm{lb} / \mathrm{gal} \\ \mathrm{P}_{\mathrm{v}} & : 7.514 \mathrm{cP} \\ \mathrm{T}_{\mathrm{y}} & : 8.83 \mathrm{lbf} / 100 \mathrm{ft} 2 \\ \text { Gel Strength } & : 18.14 \mathrm{lbf} / 100 \mathrm{ft} 2\end{array}$

SLURRY

Mix Fluid : $11.397 \mathrm{gal} / \mathrm{sk} \quad$ Job volume $: 842.5 \mathrm{bbl}$

Yield : $2.10 \mathrm{ft} 3 / \mathrm{sk} \quad$ Quantity : $2248.25 \mathrm{sk}$

Solid Fraction : $: 27.6 \%$

Density $\quad: 8.32 \mathrm{lb} / \mathrm{gal} \quad$ Base Fluid : $11.047 \mathrm{gal} / \mathrm{sk}$ 
Client : Mattoon/Future Gen

Well : ISGS/ADM Well \#1

String : 20" Surface

District : Prestonsburg

Country : USA

Loadcase : 20

\begin{tabular}{|lll|}
\hline Code & Conc. & Additives \\
\hline D020 & $4.000 \%$ BWOB & Function \\
D044 & $10.000 \%$ BWOW & Salt \\
D046 & $0.200 \%$ BWOB & Antifoam \\
D042 & $5.000 \mathrm{lb} /$ sk blend & LCM/extender \\
\hline
\end{tabular}

Thickening Time

Compressive Strength
Schedule ( )
Schedule ()

(Bc)

(psi)

\section{2nd Stage - 15.6 ppg Class A DESIGN}

Fluid No: 8

Rheo. Model

At temp.

$$
\text { : HERSCHEL_B. }
$$$$
\text { : } 80 \mathrm{deg} F
$$

\section{DESIGN}

BLEND

Name

$: A$

Dry Density : $197.27 \mathrm{lb} / \mathrm{ft} 3$

Sack Weight : $94 \mathrm{lb}$

BASE FLUID

Type : Fresh water

$\begin{array}{ll}\text { Density } & : 15.60 \mathrm{lb} / \mathrm{gal} \\ \mathrm{k} & : 1.43 \mathrm{E}-4 \mathrm{lbf} . \mathrm{s}^{\wedge} \mathrm{n} / \mathrm{ft} 2 \\ \mathrm{n} & : 0.979 \\ \mathrm{Ty}_{\mathrm{y}} & : 9.97 \mathrm{lbf} / 100 \mathrm{ft} 2 \\ \text { Gel Strength } & :(\mathrm{lbf} / 100 \mathrm{ft} 2)\end{array}$

SLURRY

Mix Fluid : $5.217 \mathrm{gal} / \mathrm{sk} \quad$ Job volume : $95.4 \mathrm{bbl}$

Yield $\quad: 1.19 \mathrm{ft} 3 / \mathrm{sk}$

Solid Fraction : : $41.3 \%$

Quantity : 450.58 sk

Density $\quad: 8.32 \mathrm{lb} / \mathrm{gal}$

Base Fluid : $5.217 \mathrm{gal} / \mathrm{sk}$

\begin{tabular}{|lll|}
\hline Code & Conc. & Additives \\
\hline D065 & $1.000 \%$ BWOC & Function \\
D167 & $0.200 \%$ BWOC & Fispersant \\
D046 & $0.200 \%$ BWOC & Antifoam loss \\
\hline
\end{tabular}

Thickening Time

Compressive Strength
Schedule ( )

Schedule ()
(Bc)

(psi)
at $\quad(\mathrm{hr}: \mathrm{mn})$
at (hr:mn) 


\section{CemCADE ${ }^{*}$ Well Cementing Recommendation for 9-5/8" Long Casing $(9,100 \mathrm{ft})$ \\ Single Stage}

* Mark of Schlumberger 


\section{CemCADE* well cementing recommendation for 9 5/8"}

\section{Production Longstring}

\begin{tabular}{|c|c|c|c|}
\hline Operator & : Mattoon/Future Gen & Well & $\begin{array}{l}\text { : Batelle Mattoon/Future } \\
\text { Gen }\end{array}$ \\
\hline $\begin{array}{l}\text { Country } \\
\text { State }\end{array}$ & $\begin{array}{l}: \text { USA } \\
: \text { IL }\end{array}$ & Field & : CO2 Disposal \\
\hline $\begin{array}{l}\text { Prepared for } \\
\text { Proposal No. } \\
\text { Date Prepared }\end{array}$ & $\begin{array}{l}: \text { SLB } \\
: \\
: 04-25-2009\end{array}$ & $\begin{array}{l}\text { Location } \\
\text { Service Point } \\
\text { Business Phone } \\
\text { FAX No. }\end{array}$ & $\begin{array}{l}: \text { Decatur, IL } \\
: \text { Prestonsburg } \\
: \text { (606) } 2982200 \\
: \quad(606) 2982248\end{array}$ \\
\hline $\begin{array}{l}\text { Prepared by } \\
\text { Phone } \\
\text { E-Mail }\end{array}$ & $\begin{array}{l}\text { : Donald Leach } \\
: \text { (606) } 2982200 \\
: \\
\text { dleach@prestonsburg.oilfielc }\end{array}$ & & \\
\hline
\end{tabular}

Configurati Casing
on
Prev.String MD : $5000.0 \mathrm{ft}$
Csg/Liner MD : $9100.0 \mathrm{ft}$
Landing Collar MD
Casing/liner Shoe MD
Mud Line
Total MD
BHST
Mean OH Diameter
Mean Annular Excess
Mean OH Equivalent Diameter
Total OH Volume

well description

Stage : Single
OD : $133 / 8 \mathrm{in}$
OD : $95 / 8 \mathrm{in}$
$9020.0 \mathrm{ft}$
$9100.0 \mathrm{ft}$
$0.0 \mathrm{ft}$
$9100.0 \mathrm{ft}$
$162 \mathrm{degF}$
$12.250 \mathrm{in}$
$35.0 \%$
$13.045 \mathrm{in}$
$677.7 \mathrm{bbl}$ (including excess)

\section{Rig Type : Land}

Weight : $72.0 \mathrm{lb} / \mathrm{ft}$
Weight $: 58.4 \mathrm{lb} / \mathrm{ft}$

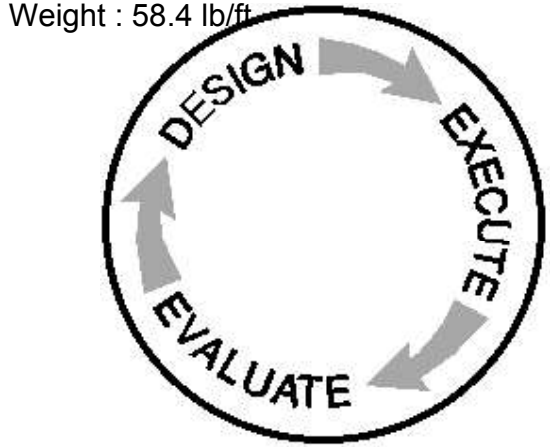

Disclaimer Notice:

This information is presented in good faith, but no warranty is given by and Schlumberger assumes no liability for advice or recommendations made concerning results to be obtained from the use of any product or service. The results given are estimates based on calculations produced by a computer model including various assumptions on the well, reservoir and treatment. The results depend on input data provided by the Operator and on estimates as to unknown data and can be no more accurate than the model, the assumptions and such input data. The information presented is Schlumberger's best estimate of the actual results that may be achieved and should be used for comparison purposes rather than absolute values. The quality of input data, and hence results, may be improved through the use

of certain tests and procedures which Schlumberger can assist in selecting.

The Operator has superior knowledge of the well, the reservoir, the field and conditions affecting them. If the Operator is aware of any conditions whereby a neighboring well or wells might be affected by the treatment proposed herein it is the Operator's responsibility to notify the owner or owners of the well or wells accordingly.

Prices quoted are estimates only and are good for 30 days from the date of issue. Actual charges may vary depending upon time, equipment, and material ultimately required to perform these services.

Freedom from infringement of patents of Schlumberger or others is not to be inferred. Mlark or Schiumiverget 


\section{Section 13: fluid sequence}

Job Objectives:

9 5/8" SINGLE STAGE PRODUCTION CEMENT TREATMENT

\begin{tabular}{|llll|}
\hline Original fluid & $\mathrm{KCl}$ Drilling Mud & $9.70 \mathrm{lb} / \mathrm{gal}$ & \\
& $\mathrm{k}: 2.54 \mathrm{E}-2 \mathrm{lbf} . \mathrm{s}^{\wedge} \mathrm{n} / \mathrm{ft} 2$ & $\mathrm{n}: 0.399$ & $\mathrm{Ty}: 0.02 \mathrm{lbf} / 100 \mathrm{ft} 2$ \\
Displacement Volume & $645.9 \mathrm{bbl}$ & \\
Total Volume & $1318.4 \mathrm{bbl}$ & \\
TOC & $0.0 \mathrm{ft}$ & \\
\hline
\end{tabular}

\begin{tabular}{|c|c|c|c|c|c|c|c|}
\hline Name & \multicolumn{6}{|c|}{ Fluid Sequence } & \\
\hline MUDPUSH II & 60.0 & 0.0 & & 11.00 & $\mathrm{k}: 2.79 \mathrm{E}-2 \mathrm{lbf} . \mathrm{s}^{\wedge} \mathrm{n} / \mathrm{ft} 2$ & $\mathrm{n}: 0.387$ & Ty:4.59 lbf/100ft2 \\
\hline 35:65 Lead @ 12.5 & 379.5 & 6079.3 & & 12.50 & k:2.17E-3 lbf.s^n/ft2 & $\mathrm{n}: 0.747$ & Ty:2.29 lbf/100ft2 \\
\hline EverCRETE-6 & 233.0 & 3020.7 & 6079.3 & 15.83 & $\mathrm{k}: 1.92 \mathrm{E}-2 \mathrm{lbf} . \mathrm{s}^{\wedge} \mathrm{n} / \mathrm{ft} 2$ & $\mathrm{n}: 0.719$ & Ty:1.22 lbf/100ft2 \\
\hline Fresh Water & 645.9 & & 0.0 & 8.32 & $P_{v}: 0.900 \mathrm{cP}$ & & Ty:0.50 lbf/100ft2 \\
\hline
\end{tabular}

\begin{tabular}{|lll|}
\hline \multicolumn{2}{|l|}{ Static Security Checks : } \\
\hline Frac & $748 \mathrm{psi}$ & at $5000.0 \mathrm{ft}$ \\
Pore & $1075 \mathrm{psi}$ & at $5000.0 \mathrm{ft}$ \\
Collapse & $3333 \mathrm{psi}$ & at $5500.0 \mathrm{ft}$ \\
Burst & $6870 \mathrm{psi}$ & at $0.0 \mathrm{ft}$ \\
Csg.Pump out & $115 \mathrm{ton}$ & \\
\hline
\end{tabular}

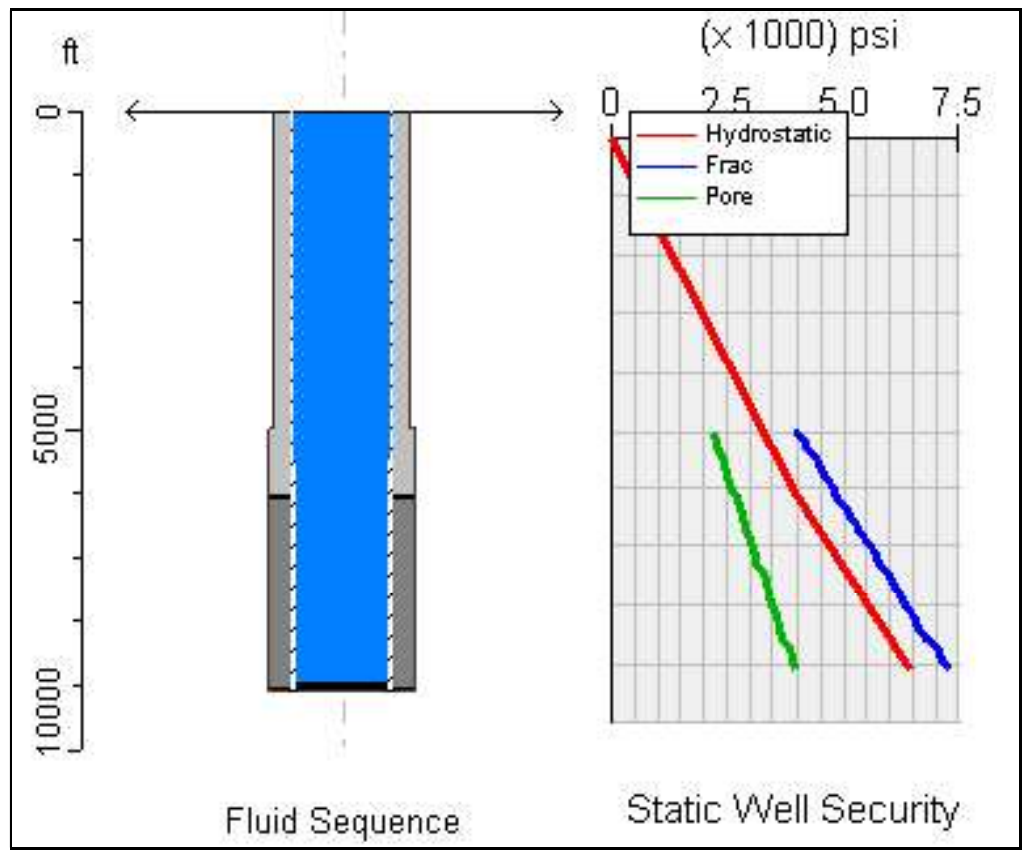


String : 20" Surface

District : Prestonsburg

Country : USA

Loadcase : 20

\section{Section 14: pumping schedule}

\section{Start Job:}

Hole circulated with mud @ 75F for 3 hours before pumping job

\begin{tabular}{|c|c|c|c|c|c|c|}
\hline \multicolumn{7}{|c|}{ Pumping Schedule } \\
\hline Name & $\begin{array}{l}\text { Flow Rate } \\
\text { (bbl/min) }\end{array}$ & $\begin{array}{c}\text { Volume } \\
\text { (bbl) }\end{array}$ & $\begin{array}{l}\text { Stage Time } \\
\text { (min) }\end{array}$ & $\begin{array}{l}\text { Cum.Vol } \\
\text { (bbl). }\end{array}$ & $\begin{array}{c}\text { Inj. } \\
\text { Temp. } \\
\text { (degF) }\end{array}$ & Comments \\
\hline MUDPUSH II & 7.0 & 60.0 & 8.6 & 60.0 & 80 & \\
\hline $\begin{array}{r}35: 65 \text { Lead @ } \\
12.5 \text { ppg }\end{array}$ & 7.0 & 379.5 & 54.2 & 379.5 & 80 & \\
\hline EverCRETE-6 & 7.0 & 233.0 & 33.3 & 233.0 & 80 & \\
\hline Pause & 0.0 & 0.0 & 5.0 & 0.0 & 80 & \\
\hline Fresh Water & 7.0 & 636.0 & 90.9 & 636.0 & 80 & \\
\hline Fresh Water & 2.0 & 9.9 & 5.0 & 645.9 & 80 & \\
\hline & & Total & $\begin{array}{l}\text { 03:16 } \\
\text { hr:mn }\end{array}$ & $1318.4 \mathrm{bbl}$ & & \\
\hline
\end{tabular}

\section{End Job:}

Designed displacement is with Fresh Water

\begin{tabular}{|lll|}
\hline \multicolumn{2}{|l|}{ Dynamic Security Checks : } \\
\hline Frac & $670 \mathrm{psi}$ & at $9100.0 \mathrm{ft}$ \\
Pore & $348 \mathrm{psi}$ & at $5000.0 \mathrm{ft}$ \\
Collapse & $3333 \mathrm{psi}$ & at $5500.0 \mathrm{ft}$ \\
Burst & $4284 \mathrm{psi}$ & at $0.0 \mathrm{ft}$ \\
\hline
\end{tabular}

\begin{tabular}{|c|c|c|c|}
\hline \multicolumn{4}{|c|}{ Temperature Results } \\
\hline $\mathrm{BHCT}$ & $134 \mathrm{deg} F$ & Simulated Max HCT & $134 \mathrm{deg} F$ \\
\hline Simulated BHCT & 132 degF & Max HCT Depth & $8542.9 \mathrm{ft}$ \\
\hline CT at TOC & $81 \mathrm{deg} F$ & Max HCT Time & 03:16:53 hr:mn:sc \\
\hline \multicolumn{4}{|c|}{ Static temperatures: } \\
\hline $\begin{array}{l}\text { At Time } \\
\text { Top of Cement } \\
\text { Bottom Hole }\end{array}$ & $\begin{array}{l}\text { (hr:mn) } \\
\text { (degF) } \\
\text { (degF) }\end{array}$ & $\begin{array}{l}\text { (hr:mn) } \\
\text { (degF) } \\
\text { (degF) }\end{array}$ & $\begin{array}{l}\text { Geo. Temp. } \\
62 \text { degF } \\
162 \text { degF }\end{array}$ \\
\hline
\end{tabular}


Client : Mattoon/Future Gen

Well : ISGS/ADM Well \#1

String : 20" Surface

District : Prestonsburg

Country : USA

Loadcase : 20

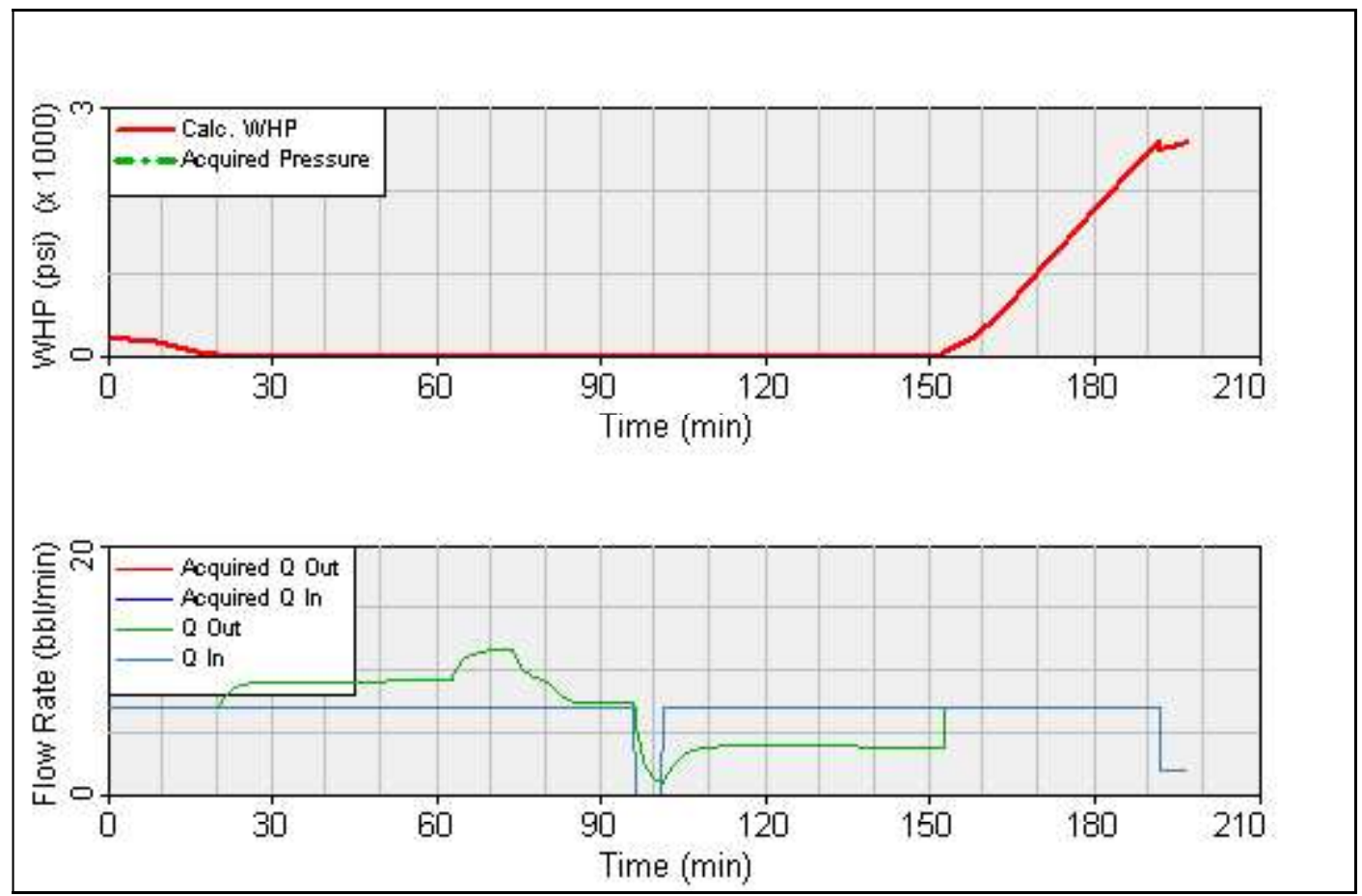




\section{Section 15: fluid description}

\section{Fresh Water DESIGN}

Fluid No: 2

Rheo. Model

At temp.

: BINGHAM

$:(\operatorname{deg} F)$

$\begin{array}{ll}\text { Density } & : 8.32 \mathrm{lb} / \mathrm{gal} \\ \mathrm{Pv} & : 0.900 \mathrm{cP} \\ \text { Ty } & : 0.50 \mathrm{lbf} / 100 \mathrm{ft} 2 \\ \text { Gel Strength } & :(\mathrm{lbf} / 100 \mathrm{ft} 2) \\ \text { Job volume } & : 645.9 \mathrm{bbl}\end{array}$

MUDPUSH II DESIGN

Fluid No: 4

Rheo. Model : HERSCHEL B.

At temp.

: $81 \mathrm{degF}$

$\begin{array}{ll}\text { Density } & : 11.00 \mathrm{lb} / \mathrm{gal} \\ \mathrm{k} & : 2.79 \mathrm{E}-2 \mathrm{lbf} . \mathrm{s}^{\wedge} \mathrm{n} / \mathrm{ft} 2 \\ \mathrm{n} & : 0.387 \\ \mathrm{Ty} & : 4.59 \mathrm{lbf} / 100 \mathrm{ft} 2 \\ \text { Gel Strength } & : 12.81 \mathrm{lbf} / 100 \mathrm{ft} 2 \\ & \\ \text { Job volume } & : 60.0 \mathrm{bbl}\end{array}$

\section{5:65 Lead @ 12.5 ppg DESIGN}

Fluid No: 5

Rheo. Model : HERSCHEL_B.

At temp.

: 115 degF

$\begin{array}{ll}\text { Density } & : 12.50 \mathrm{lb} / \mathrm{gal} \\ \mathrm{k} & : 2.17 \mathrm{E}-3 \mathrm{lbf} . \mathrm{s}^{\wedge} \mathrm{n} / \mathrm{ft} 2 \\ \mathrm{n} & : 0.747 \\ \mathrm{Ty}_{\mathrm{y}} & : 2.29 \mathrm{lbf} / 100 \mathrm{ft} 2 \\ \text { Gel Strength } & : 12.81 \mathrm{lbf} / 100 \mathrm{ft} 2\end{array}$

SLURRY

Mix Fluid : $11.005 \mathrm{gal} / \mathrm{sk}$

Yield $\quad: 2.01 \mathrm{ft} 3 / \mathrm{sk}$

Solid Fraction : $26.6 \%$

Job volume : $379.5 \mathrm{bbl}$

Quantity : 1062.59 sk

Sack Weight : $90 \mathrm{lb}$
Density $\quad: 8.32 \mathrm{lb} / \mathrm{gal}$
Base Fluid : $11.005 \mathrm{gal} / \mathrm{sk}$
Type
: Fresh water

Function

Extender

Antifoam

Fluid loss

Thickening Time

Schedule ( )

$100 \mathrm{Bc}$

at

08:33 hr:mn

Compressive Strength

Schedule ()

283 psi

at $24: 00 \mathrm{hr}: \mathrm{mn}$ 
EverCRETE-6 DESIGN

Fluid No: 6

Rheo. Model : HERSCHEL_B.

At temp. $: 110 \mathrm{deg} F$

\section{DESIGN}

BLEND

Name : EverCRETE_15

Dry Density : $158.71 \mathrm{lb} / \mathrm{ft} 3$

Sack Weight : $100 \mathrm{lb}$

BASE FLUID

Type : Fresh water

$\begin{array}{ll}\text { Density } & : 15.83 \mathrm{lb} / \mathrm{gal} \\ \mathrm{k} & : 1.92 \mathrm{E}-2 \mathrm{lbf} . \mathrm{s}^{\wedge} \mathrm{n} / \mathrm{ft} 2 \\ \mathrm{n} & : 0.719 \\ \mathrm{Ty} & : 1.22 \mathrm{lbf} / 100 \mathrm{ft} 2 \\ \text { Gel Strength } & : 28.82 \mathrm{lbf} / 100 \mathrm{ft} 2\end{array}$

SLURRY

Mix Fluid : $3.413 \mathrm{gal} / \mathrm{sk} \quad$ Job volume : $233.0 \mathrm{bbl}$

Yield $\quad: 1.09 \mathrm{ft} 3 / \mathrm{sk}$

Solid Fraction : $58.0 \%$

Quantity : 1204.22 sk

Density $\quad: 8.32 \mathrm{lb} / g a l$

Base Fluid : $3.153 \mathrm{gal} / \mathrm{sk}$

\begin{tabular}{|lll|}
\hline Code & Conc. & Additives \\
\hline D081 & $0.040 \mathrm{gal} / \mathrm{sk}$ blend & Function \\
D168 & $0.200 \mathrm{gal} / \mathrm{sk}$ blend & Retarder \\
D047 & $0.020 \mathrm{gal} / \mathrm{sk}$ blend & Antifoam \\
\hline
\end{tabular}

Thickening Time

Compressive Strength

Schedule ( ) $100 \mathrm{Bc}$

Schedule ( )

$\begin{array}{ll}\text { at } & 08: 30 \mathrm{hr}: \mathrm{mn} \\ \text { at } & 24: 00 \mathrm{hr}: \mathrm{mn}\end{array}$




\section{CemCADE * Well Cementing Recommendation for 9-5/8" Long Casing $(9,100 \mathrm{ft})$}

\section{Two Stage Option}




\section{CemCADE* well cementing recommendation for 9 5/8"}

\section{Production Longstring}

\begin{tabular}{|c|c|c|c|}
\hline Operator & : Mattoon/Future Gen & Well & $\begin{array}{l}\text { : Batelle Mattoon/Future } \\
\text { Gen }\end{array}$ \\
\hline $\begin{array}{l}\text { Country } \\
\text { State }\end{array}$ & $\begin{array}{l}: \text { USA } \\
: \text { IL }\end{array}$ & Field & : CO2 Disposal \\
\hline $\begin{array}{l}\text { Prepared for } \\
\text { Proposal No. } \\
\text { Date Prepared }\end{array}$ & $\begin{array}{l}: \text { SLB } \\
: \\
: 04-25-2009\end{array}$ & $\begin{array}{l}\text { Location } \\
\text { Service Point } \\
\text { Business Phone } \\
\text { FAX No. }\end{array}$ & $\begin{array}{l}: \text { Decatur, IL } \\
: \text { Prestonsburg } \\
: \text { (606) } 2982200 \\
: \quad(606) 2982248\end{array}$ \\
\hline $\begin{array}{l}\text { Prepared by } \\
\text { Phone } \\
\text { E-Mail }\end{array}$ & $\begin{array}{l}\text { : Donald Leach } \\
: \text { (606) } 2982200 \\
: \\
\text { dleach@prestonsburg.oilfielc }\end{array}$ & & \\
\hline
\end{tabular}

\section{well description}

$\begin{array}{ll}\begin{array}{ll}\text { Configurati } \\ \text { on }\end{array} & \text { Casing } \\ \begin{array}{ll}\text { Prev.String }: \text { Single } \\ \text { Csg/Liner }: 7000.0 \mathrm{ft}\end{array} & \text { OD : } 133 / 8 \mathrm{in} \\ \text { Landing Collar MD }: 9100.0 \mathrm{ft} & \text { OD : } 95 / 8 \mathrm{in} \\ \text { Casing/liner Shoe MD } & 9020.0 \mathrm{ft} \\ \text { Mud Line } & 9100.0 \mathrm{ft} \\ \text { Total MD } & 0.0 \mathrm{ft} \\ \text { BHST } & 9100.0 \mathrm{ft} \\ \text { Bit Size } & 162 \mathrm{degF} \\ \text { Mean OH Diameter } & 121 / 4 \mathrm{in} \\ \text { Mean Annular Excess } & 12.250 \mathrm{in} \\ \text { Mean OH Equivalent Diameter } & 35.0 \% \\ \text { Total OH Volume } & 13.045 \mathrm{in} \\ \end{array}$

\section{Rig Type : Land}

Weight : $72.0 \mathrm{lb} / \mathrm{ft}$
Weight : $58.4 \mathrm{lb} / \mathrm{ft}$

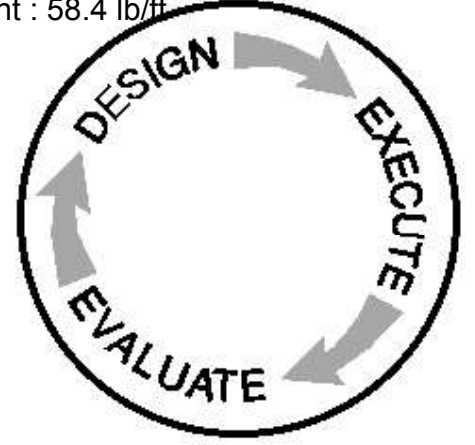

Disclaimer Notice:

This information is presented in good faith, but no warranty is given by and Schlumberger assumes no liability for advice or recommendations made concerning results to be obtained from the use of any product or service. The results given are estimates based on calculations produced by a computer model including various assumptions on the well, reservoir and treatment. The results depend on input data provided by the Operator and on estimates as to unknown data and can be no more accurate than the model, the assumptions and such input data. The information presented is Schlumberger's best estimate of the actual results that may be achieved and should be used for comparison purposes rather than absolute values. The quality of input data, and hence results, may be improved through the use

of certain tests and procedures which Schlumberger can assist in selecting.

The Operator has superior knowledge of the well, the reservoir, the field and conditions affecting them. If the Operator is aware of any conditions whereby a neighboring well or wells might be affected by the treatment proposed herein it is the Operator's responsibility to notify the owner or owners of the well or wells accordingly.

Prices quoted are estimates only and are good for 30 days from the date of issue. Actual charges may vary depending upon time, equipment, and material ultimately required to perform these services.

Freedom from infringement of patents of Schlumberger or others is not to be inferred. Mlark or Schiumiverget 


\section{Section 16: fluid sequence}

Job Objectives:

9 5/8" SINGLE STAGE PRODUCTION CASING CEMENT TREATMENT

\begin{tabular}{|llll|}
\hline Original fluid & $\mathrm{KCl}$ Drilling Mud & $9.70 \mathrm{lb} / \mathrm{gal}$ & \\
& $\mathrm{k}: 2.54 \mathrm{E}-2 \mathrm{lbf} . \mathrm{s}^{\wedge} \mathrm{n} / \mathrm{ft} 2$ & $\mathrm{n}: 0.399$ & $\mathrm{Ty}: 0.02 \mathrm{lbf} / 100 \mathrm{ft} 2$ \\
Displacement Volume & $645.9 \mathrm{bbl}$ & \\
Total Volume & $1316.7 \mathrm{bbl}$ & \\
TOC & $0.0 \mathrm{ft}$ & \\
\hline
\end{tabular}

\begin{tabular}{|c|c|c|c|c|c|c|c|}
\hline \multirow[b]{2}{*}{ Name } & \multicolumn{6}{|c|}{ Fluid Sequence } & \\
\hline & $\begin{array}{c}\text { Volume } \\
\text { (bbl) }\end{array}$ & $\begin{array}{c}\text { Ann. Len } \\
(\mathrm{ft})\end{array}$ & $\begin{array}{c}\text { Top } \\
\text { (ft) }\end{array}$ & $\begin{array}{c}\text { Density } \\
\text { (lb/gal) }\end{array}$ & & ology & \\
\hline MUDPUSH II & 60.0 & 0.0 & & 11.00 & $\mathrm{k}: 2.79 \mathrm{E}-2 \mathrm{lbf} . \mathrm{s}^{\wedge} \mathrm{n} / \mathrm{ft} 2$ & $\mathrm{n}: 0.387$ & Ty:4.59 lbf/100ft2 \\
\hline 35:65 Lead @ 12.5 & 393.8 & 6082.1 & & 12.50 & $\mathrm{k}: 2.17 \mathrm{E}-3 \mathrm{lbf} . \mathrm{s}^{\wedge} \mathrm{n} / \mathrm{ft} 2$ & $\mathrm{n}: 0.747$ & Ty:2.29 lbf/100ft2 \\
\hline $\begin{array}{r}\text { ppg } \\
\text { EverCRETE-6 }\end{array}$ & 217.0 & 3017.9 & 6082.1 & 15.83 & k:1.92E-2 lbf.s^n/ft2 & $\mathrm{n}: 0.719$ & Ty-1 $22 \mathrm{lbf} / 100 \mathrm{ft} 2$ \\
\hline Fresh Water & 645.9 & & 0.0 & 8.32 & Pv: $0.900 \mathrm{cP}$ & & Ty:0.50 lbf/100ft2 \\
\hline
\end{tabular}

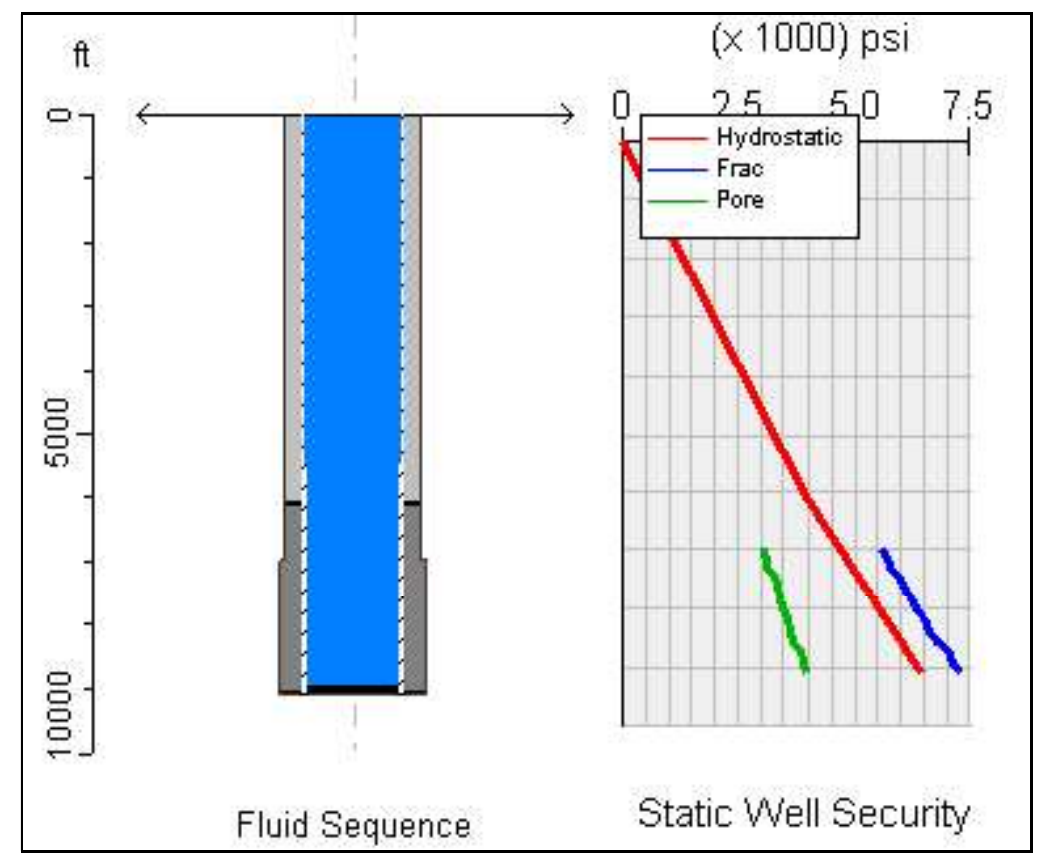


String : 20" Surface

District : Prestonsburg

Country : USA

Loadcase : 20

\section{Section 17: pumping schedule}

\section{Start Job:}

Hole circulated with mud @ 75F for 3 hours before pumping job

\begin{tabular}{|c|c|c|c|c|c|c|}
\hline \multicolumn{7}{|c|}{ Pumping Schedule } \\
\hline Name & $\begin{array}{l}\text { Flow Rate } \\
\text { (bbl/min) }\end{array}$ & $\begin{array}{l}\text { Volume } \\
\text { (bbl) }\end{array}$ & $\begin{array}{l}\text { Stage Time } \\
\text { (min) }\end{array}$ & $\begin{array}{l}\text { Cum.Vol } \\
\text { (bbl). }\end{array}$ & $\begin{array}{c}\text { Inj. } \\
\text { Temp. } \\
\text { (degF) }\end{array}$ & Comments \\
\hline Pause & 0.0 & 0.0 & 5.0 & 0.0 & 80 & 4-Drop Bottom Plug \\
\hline MUDPUSH II & 7.0 & 60.0 & 8.6 & 60.0 & 80 & 7-Start Pumping Spacer \\
\hline 35:65 Lead @ & 7.0 & 393.8 & 56.3 & 393.8 & 80 & 13-Start Mixing Lead Slurry \\
\hline $12.5 \mathrm{ppg}$ & & & & & & \\
\hline EverCRETE-6 & 6.0 & 217.0 & 36.2 & 217.0 & 80 & 16-Start Mixing Tail Slurry \\
\hline Pause & 0.0 & 0.0 & 7.0 & 0.0 & 80 & 18-Drop Top Plug and \\
\hline Fresh Water & 8.0 & 645.9 & 80.7 & 645.9 & 80 & 19-Start Displacement \\
\hline
\end{tabular}

\section{End Job:}

Designed displacement is with Fresh Water

\begin{tabular}{|lll|}
\hline \multicolumn{2}{|l|}{ Dynamic Security Checks : } \\
\hline Frac & $581 \mathrm{psi}$ & at $9100.0 \mathrm{ft}$ \\
Pore & $487 \mathrm{psi}$ & at $7000.0 \mathrm{ft}$ \\
Collapse & $3333 \mathrm{psi}$ & at $5500.0 \mathrm{ft}$ \\
Burst & $4139 \mathrm{psi}$ & at $0.0 \mathrm{ft}$ \\
\hline
\end{tabular}

\begin{tabular}{|c|c|c|c|}
\hline \multicolumn{4}{|c|}{ Temperature Results } \\
\hline BHCT & $134 \mathrm{deg} F$ & Simulated Max HCT & 133 degF \\
\hline Simulated BHCT & 131 deg $F$ & Max HCT Depth & $8171.4 \mathrm{ft}$ \\
\hline CT at TOC & $81 \mathrm{deg} F$ & Max HCT Time & 00:05:00 hr:mn:sc \\
\hline \multicolumn{4}{|c|}{ Static temperatures: } \\
\hline At Time & (hr:mn) & (hr:mn) & Geo. Temp. \\
\hline Top of Cement & $(\operatorname{deg} F)$ & $(\operatorname{deg} F)$ & $62 \operatorname{deg} F$ \\
\hline Bottom Hole & (degF) & (degF) & $162 \mathrm{deg} F$ \\
\hline
\end{tabular}


Client : Mattoon/Future Gen

Well : ISGS/ADM Well \#1

String : 20" Surface

District : Prestonsburg

Country : USA

Loadcase : 20

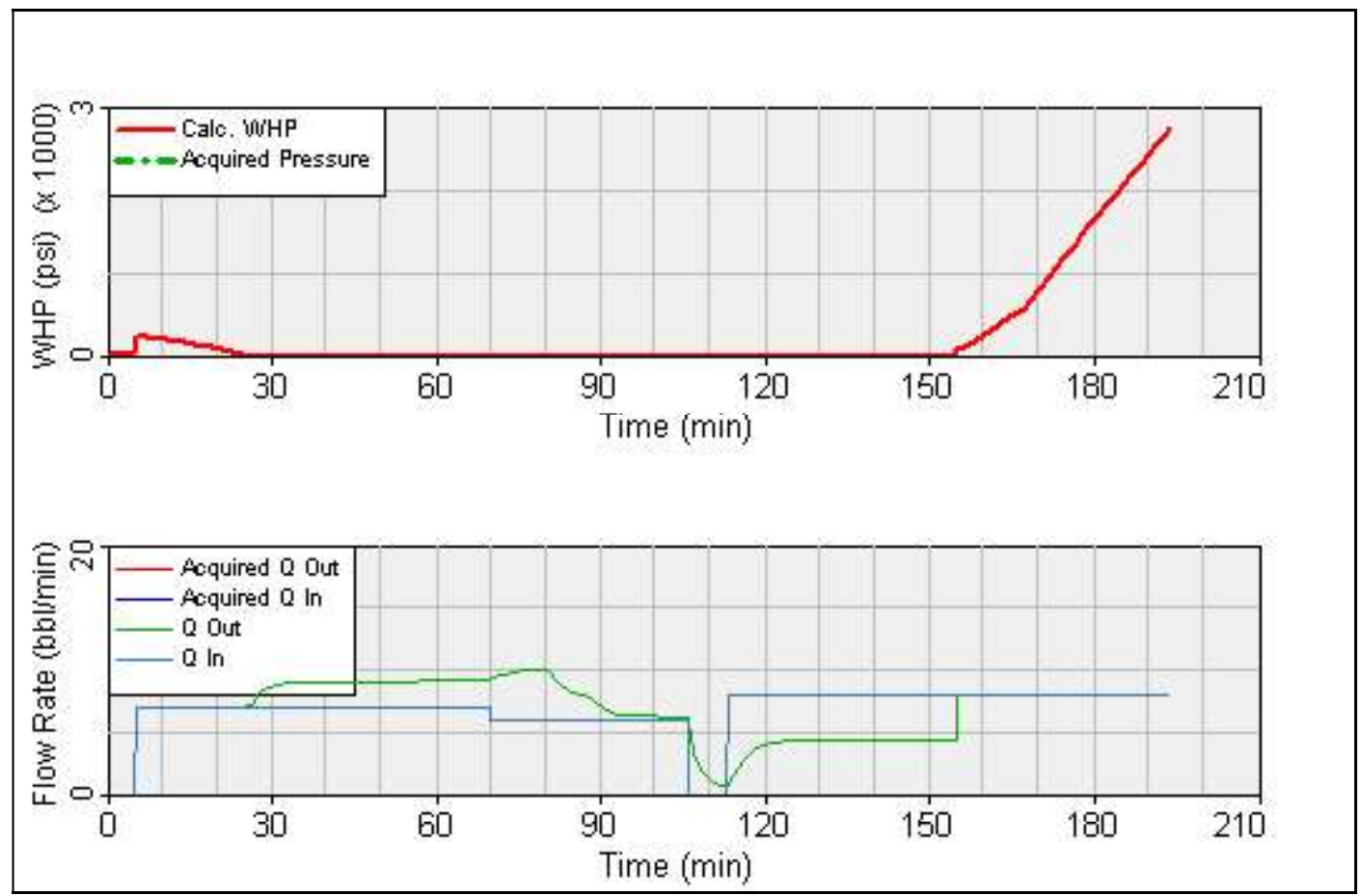




\section{Section 18: fluid description}

\section{Fresh Water DESIGN}

Fluid No: 2

Rheo. Model

At temp.

: BINGHAM

$:(\operatorname{deg} F)$

$\begin{array}{ll}\text { Density } & : 8.32 \mathrm{lb} / \mathrm{gal} \\ \mathrm{Pv} & : 0.900 \mathrm{cP} \\ \text { Ty } & : 0.50 \mathrm{lbf} / 100 \mathrm{ft} 2 \\ \text { Gel Strength } & :(\mathrm{lbf} / 100 \mathrm{ft} 2) \\ \text { Job volume } & : 645.9 \mathrm{bbl}\end{array}$

MUDPUSH II DESIGN

Fluid No: 4

Rheo. Model : HERSCHEL B.

At temp.

: $81 \mathrm{degF}$

$\begin{array}{ll}\text { Density } & : 11.00 \mathrm{lb} / \mathrm{gal} \\ \mathrm{k} & : 2.79 \mathrm{E}-2 \mathrm{lbf} . \mathrm{s}^{\wedge} \mathrm{n} / \mathrm{ft} 2 \\ \mathrm{n} & : 0.387 \\ \mathrm{Ty} & : 4.59 \mathrm{lbf} / 100 \mathrm{ft} 2 \\ \text { Gel Strength } & : 12.81 \mathrm{lbf} / 100 \mathrm{ft} 2 \\ & \\ \text { Job volume } & : 60.0 \mathrm{bbl}\end{array}$

\section{5:65 Lead @ 12.5 ppg DESIGN}

Fluid No: 5

Rheo. Model : HERSCHEL_B.

At temp.

: 115 degF

$\begin{array}{ll}\text { Density } & : 12.50 \mathrm{lb} / \mathrm{gal} \\ \mathrm{k} & : 2.17 \mathrm{E}-3 \mathrm{lbf} . \mathrm{s}^{\wedge} \mathrm{n} / \mathrm{ft} 2 \\ \mathrm{n} & : 0.747 \\ \mathrm{Ty}_{\mathrm{y}} & : 2.29 \mathrm{lbf} / 100 \mathrm{ft} 2 \\ \text { Gel Strength } & : 12.81 \mathrm{lbf} / 100 \mathrm{ft} 2\end{array}$

SLURRY

Mix Fluid : $11.005 \mathrm{gal} / \mathrm{sk}$

Yield $\quad: 2.01 \mathrm{ft} 3 / \mathrm{sk}$

Solid Fraction : $26.6 \%$

Job volume : $393.8 \mathrm{bbl}$

Quantity : 1102.63 sk

Sack Weight : $90 \mathrm{lb}$
Density $\quad: 8.32 \mathrm{lb} / \mathrm{gal}$
Base Fluid : $11.005 \mathrm{gal} / \mathrm{sk}$
Type
: Fresh water

Function

Extender

Antifoam

Fluid loss

Thickening Time

Schedule ( )

$100 \mathrm{Bc}$

at

08:33 hr:mn

Compressive Strength

Schedule ()

283 psi

at $24: 00 \mathrm{hr}: \mathrm{mn}$ 
EverCRETE-6 DESIGN

Fluid No: 6

Rheo. Model : HERSCHEL_B.

At temp. $: 110 \mathrm{deg} F$

\section{DESIGN}

BLEND

Name

Dry Density : $158.71 \mathrm{lb} / \mathrm{ft} 3$

Sack Weight : $100 \mathrm{lb}$

BASE FLUID

Type

: Fresh water

$\begin{array}{ll}\text { Density } & : 15.83 \mathrm{lb} / \mathrm{gal} \\ \mathrm{k} & : 1.92 \mathrm{E}-2 \mathrm{lbf} . \mathrm{s}^{\wedge} \mathrm{n} / \mathrm{ft} 2 \\ \mathrm{n} & : 0.719 \\ \mathrm{Ty}_{\mathrm{y}} & : 1.22 \mathrm{lbf} / 100 \mathrm{ft} 2 \\ \text { Gel Strength } & : 28.82 \mathrm{lbf} / 100 \mathrm{ft} 2\end{array}$

SLURRY

Mix Fluid : $3.413 \mathrm{gal} / \mathrm{sk} \quad$ Job volume $: 217.0 \mathrm{bbl}$

Yield : $1.09 \mathrm{ft} 3 / \mathrm{sk}$

Solid Fraction : $58.0 \%$

Quantity : 1121.53 sk

Density $\quad: 8.32 \mathrm{lb} / g a l$

Base Fluid : $3.153 \mathrm{gal} / \mathrm{sk}$

\begin{tabular}{|lll|}
\hline Code & Conc. & Additives \\
\hline D081 & $0.040 \mathrm{gal} / \mathrm{sk}$ blend & Function \\
D168 & $0.200 \mathrm{gal} / \mathrm{sk}$ blend & Retarder \\
D047 & $0.020 \mathrm{gal} / \mathrm{sk}$ blend & Antifoam \\
\hline
\end{tabular}

Thickening Time

Compressive Strength

Schedule ( ) $100 \mathrm{Bc}$

Schedule ( ) 3230 psi

$\begin{array}{ll}\text { at } & 08: 30 \mathrm{hr}: \mathrm{mn} \\ \text { at } & 24: 00 \mathrm{hr}: \mathrm{mn}\end{array}$




\section{APPENDIX 3-2}

\section{Material Safety Data Sheets for Annular Fluid Additives and Inhibitors}

Specific MSDS sheets for TETRA chemical products can be obtained at http://www.tetrachemicals.com/ 
APPENDIX 3-3

Example Packers for Above Packer Monitoring and Below Packer Monitoring

Weatherford Sealbore and Production Packer specifications can be found at http://www.weatherford.com/Products/Completion/PackerSystems/ 
APPENDIX 5-1

Tables Listing Oil and Gas Wells and Water Wells in the Area of Review 


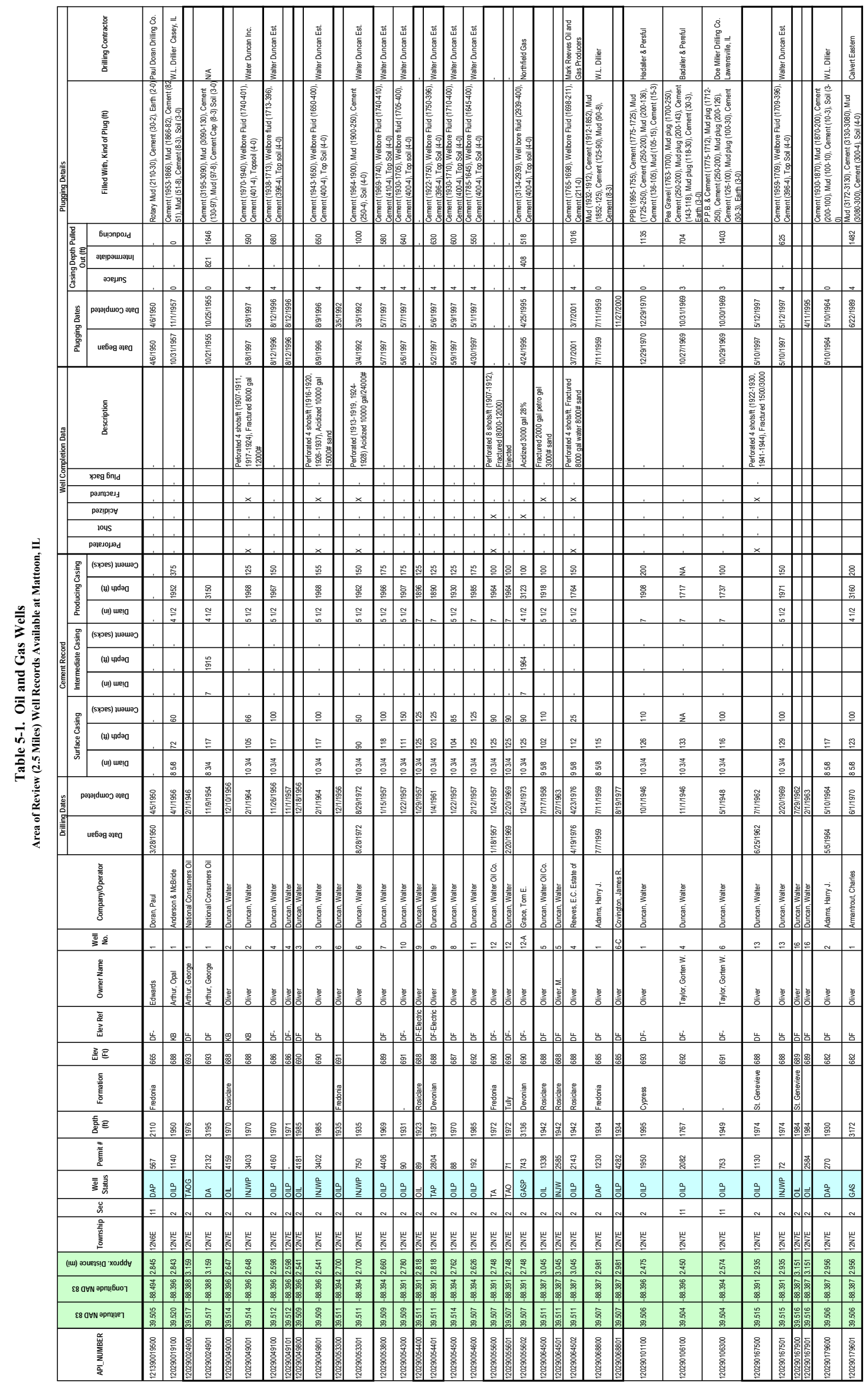




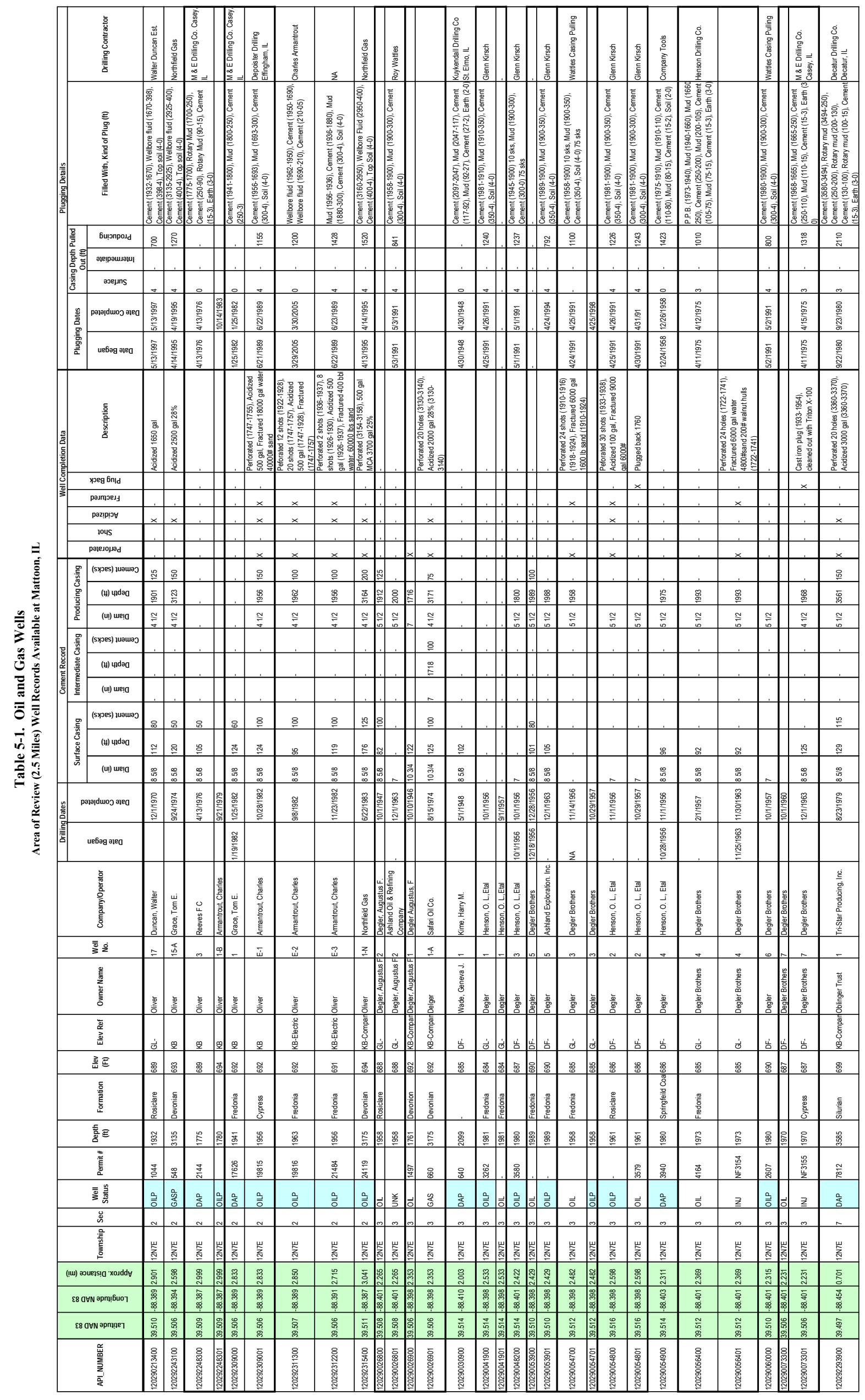




\begin{tabular}{|c|c|c|c|c|c|c|c|c|c|c|c|c|c|c|c|c|c|c|c|}
\hline 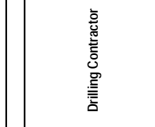 & 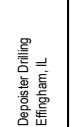 & & 喜 & 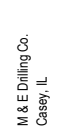 & 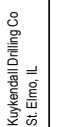 & 言 & 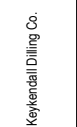 & & 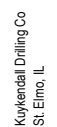 & 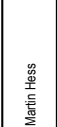 & 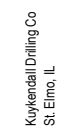 & & & $\begin{array}{l}\text { 言 } \\
\frac{15}{5}\end{array}$ & & & $\begin{array}{l}\frac{5}{2} \\
\frac{5}{5}\end{array}$ & $\begin{array}{l}\text { 言 } \\
\frac{5}{5}\end{array}$ & 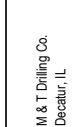 \\
\hline 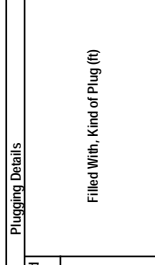 & 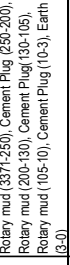 & & 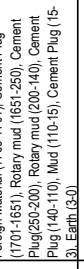 & 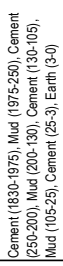 & 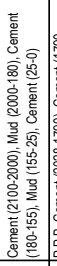 & 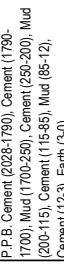 & 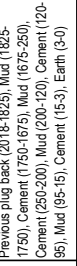 & & 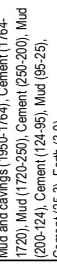 & 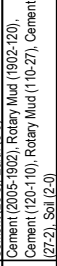 & 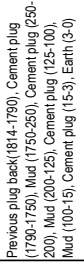 & & & 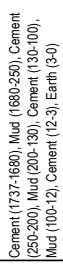 & & & 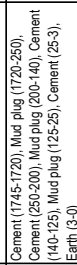 & 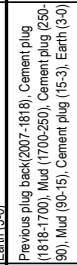 & 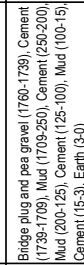 \\
\hline 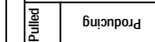 & $\mathscr{\Xi}$ & & g & 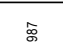 & . & $\frac{\circ}{\circ}$ & 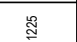 & & 8 & $\begin{array}{ll} \\
\end{array}$ & $\%$ & & & 产 & & & 8 & 甍 & $\approx$ \\
\hline 獄 & & & & & & & & & & & & & & & & & & & \\
\hline 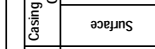 & $\infty$ & & $a$ & $\infty$ & . & + & $\infty$ & & $\infty$ & a & + & & & $\infty$ & & & $\infty$ & + & 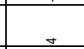 \\
\hline 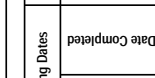 & 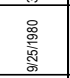 & & 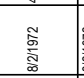 & 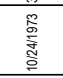 & 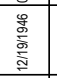 & 喠 & 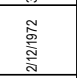 & & 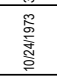 & 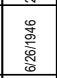 & 产 & 产 & & 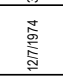 & 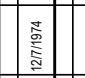 & & 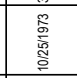 & 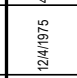 & 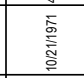 \\
\hline 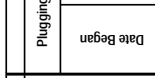 & \begin{tabular}{|l|} 
兽 \\
票 \\
\end{tabular} & & 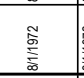 & 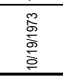 & 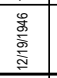 & 产 & 旁 & & 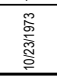 & 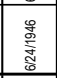 & 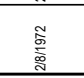 & & & 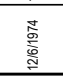 & & & 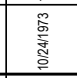 & 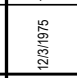 & 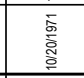 \\
\hline $\begin{array}{l}\text { 흥 } \\
\text { 䇏 }\end{array}$ & 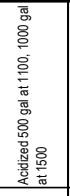 & & & & & & 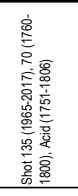 & & & & & & 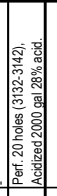 & & & & & & 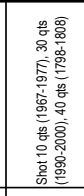 \\
\hline xpeg bind & & & & & 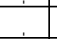 & & & & & 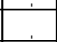 & & & te & & & & & & \\
\hline pampoes & - & & & & & & & & & & & & . & & & & & & \\
\hline pezppoy & $x$ & & & & & & $x$ & & 3 &. & & 4 & $\times$ & - & & & . &. & \\
\hline \begin{tabular}{|l} 
pous \\
paieroy,
\end{tabular} & 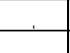 & & & & . & & & & &. & & + & .1 &. & & & & & $x$ \\
\hline 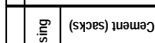 & 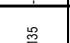 & & 8 & & 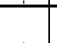 & 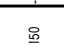 & & & 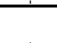 & 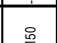 & & & 8 & 6 & & & 8 & 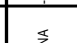 & \\
\hline (1)(1) पdra & \% & & 重 & $\frac{\tilde{q}}{\tilde{g}}$ & \&ू. & $\frac{5}{2}$ & 墨 & & 镸 & $\frac{1}{2}$ & ह & है & 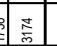 & 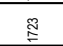 & & & 电 & $\frac{1}{2}$ & 占 \\
\hline 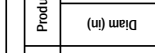 & $\cong$ & & & $\begin{array}{ll}\frac{4}{2} \\
\frac{1}{4}\end{array}$ & 产 & & & & $\frac{10}{\overline{0}}$ & $\cong$ & & - & $\frac{7}{\square}$ & & & & & $\frac{\square}{0}$ & \\
\hline 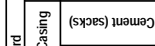 & & & & & & & & & & & & & 5 & & & & & & \\
\hline (4)1) undaa & & & & & & & & & & & & & 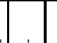 & & & & & & \\
\hline 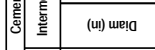 & & & & & & & & & & & & & . & & & & & & \\
\hline 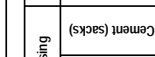 & ه్ & & 오 & & & $\cong$ & & & & 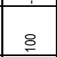 & & 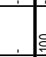 & $\frac{\dot{b}}{5}$ & 올 & & & ع & $\frac{1}{2}$ & \\
\hline (1) & $\approx$ & & $\dddot{\varpi}$ & ¿ & 올 & $\underline{m}$ & $\cong$ & & $\Xi$ & $\cong$ & $\cong$ & 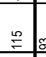 & O & $\approx$ & & & 单 & $\stackrel{\infty}{\underline{e}}$ & $\cong$ \\
\hline $\begin{array}{ll}\text { (1) we welo } \\
\end{array}$ & $\begin{array}{l}\infty \\
\infty \\
\infty\end{array}$ & & 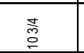 & 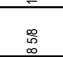 & 要 & 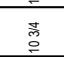 & 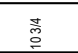 & & 怘 & 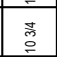 & 嘉 & 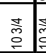 & 范 & 嘉 & & & 嘉 & 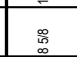 & 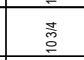 \\
\hline рәэлдио әюе & 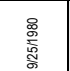 & 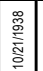 & 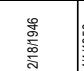 & $\begin{array}{l}\text { 䩧 } \\
\text { 言 }\end{array}$ & 箁 & 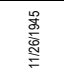 & 熟 & 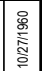 & 善 & \begin{tabular}{|l|l|} 
\\
\end{tabular} & 誉 & 里 & 譬 & $\begin{array}{l}\text { 虽 } \\
\text { 誉 }\end{array}$ & & 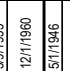 & 总 & 善 & 爰 \\
\hline иебәв әрес & & & 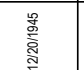 & & & & & & & & & & 产 & & & & & & \\
\hline 今心 & 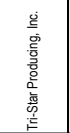 & 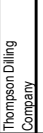 & 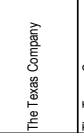 & 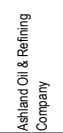 & $\begin{array}{l}3 \\
\text { 盖 } \\
\end{array}$ & 峷 & 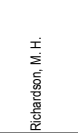 & 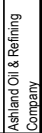 & 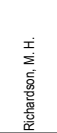 & 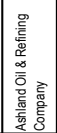 & 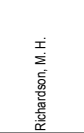 & 裹 & 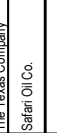 & 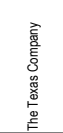 & & & 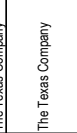 & 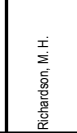 & 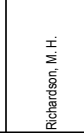 \\
\hline 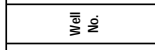 & 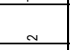 & & & 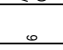 & & & & & . & & & $=t$ & 每 & $\infty$ & & +6 & $\infty$ & $\ldots$ & a \\
\hline 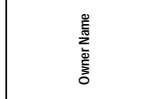 & 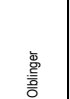 & 高 & 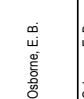 & 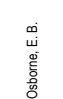 & 言 & 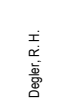 & 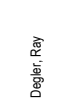 & 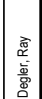 & $\begin{array}{l}\text { 商 } \\
\text { 点 } \\
\text { 要 }\end{array}$ & 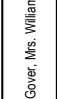 & 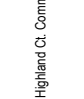 & 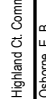 & 产 & & & 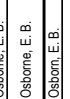 & 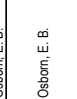 & 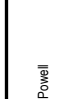 & 裹 \\
\hline 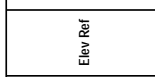 & $\dot{\underline{x}}$ & | & $\dot{0}$ & 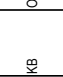 & $\dot{0}$ & : & $\dot{0}$ & : & $\dot{\sigma}$ & $\dot{0}$ & $\dot{\sigma}$ & 它递 & 语 & $\dot{0}$ & & : & $\dot{0}$ & 殅 & $\vec{o}$ \\
\hline 咅至 & : & : & $\frac{8}{2}$ & $\bar{s}$ & $\approx$ & $\therefore$ & $\frac{m}{2}$ & $\begin{array}{lll}0 \\
2\end{array}$ & $\stackrel{8}{\Sigma}$ & $\approx$ & 용 & 焉 & 8 & $\approx$ & 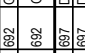 & 8 & $\overline{8}$ & : & $\approx$ \\
\hline $\begin{array}{l}\text { 言 } \\
\text { 言 } \\
\end{array}$ & 憘 & $\mid \frac{\frac{m}{3}}{\frac{3}{\omega}}$ & $\frac{\frac{n}{3}}{\frac{3}{5}}$ & 鮚 & 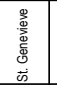 & 善 & 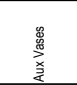 & 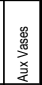 & 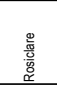 & & 善 & & 童 & $\frac{\frac{2}{3}}{\frac{2}{3}}$ & & 䰹 & & $\frac{\sqrt[0]{5}}{\frac{5}{2}}$ & \\
\hline 啻理 & 㕆 & 视 & 畧 & 离 & $\frac{1}{8}$ & ฉू & $\frac{\infty}{2}$ & \begin{tabular}{|l|l|}
$\frac{2}{2}$ \\
\end{tabular} & \% & $\approx$ & $\underline{\underline{\underline{p}}}$ & $\underline{w}$ & $\frac{\mathrm{m}}{\mathrm{m}}$ & $\stackrel{z}{z}$ & 羊 & 盖 & 嘿 & 高 & 㺃 \\
\hline 焉 & 带 & & $\frac{\mathscr{q}}{\bar{N}}$ & 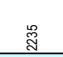 & 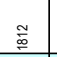 & $\bar{s}$ & 喜 & & $\mathscr{8}$ & 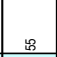 & 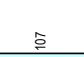 & & $:$ & & . & & $\frac{\circ}{10}$ & $\underline{\underline{E}}$ & 垔 \\
\hline 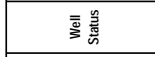 & 㙜 & 畓 & 㐔 & $\underline{\underline{z}}$ & 옿 & $\frac{a}{\partial}$ & 言 & $\underline{\underline{z}}$ & $\frac{2}{\partial}$ & 옿 & 言 & $\underline{\underline{\underline{z}}} \overline{\underline{\underline{a}}}$ & $\frac{9}{8}$ & 항 & $\underline{\underline{z}}$ & $\underline{\underline{z}}$ & 言 & 言 & 言 \\
\hline $\mathscr{~}$ & s & - & 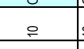 & ? & 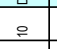 & 8 & $\div$ & : & $\div$ & 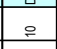 & 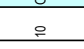 & $=$ & $=$ & 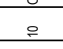 & 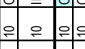 & $=0$ & $\therefore$ & 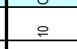 & 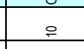 \\
\hline 剖言 & 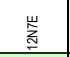 & 岃 & 嵩 & 唇 & 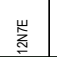 & $\underset{\Sigma}{\underline{\Sigma}}$ & $\underset{\sim}{\underline{w}}$ & 茲 & $\overbrace{\underline{i}}^{u}$ & 崩 & 茲 & 岃 & 崩 & w్ & 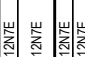 & 崇药 & 岕 & $\underset{\underline{w}}{\underline{w}}$ & 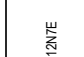 \\
\hline 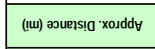 & $\frac{1}{8}$ & 蛋 & 尊 & 善 & 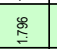 & $\overline{\mathrm{g}}$ & 兽 & \begin{tabular}{|l|l|}
\multirow{2}{*}{} \\
\multirow{2}{*}{}
\end{tabular} & 兽 & 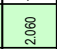 & 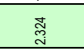 & 苞: & 氛 & $\overline{\tilde{\tilde{N}}}$ & 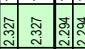 & 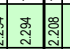 & ב్ & 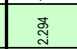 & $\frac{8}{i}$ \\
\hline 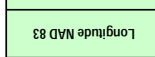 & 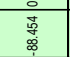 & 勇 & $\frac{9}{\overline{8}}$ & 亳 & 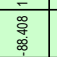 & 管 & 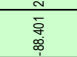 & 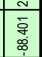 & 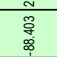 & 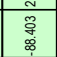 & 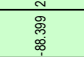 & 管事 & $\begin{array}{l}0 \\
0 \\
0 \\
0\end{array}$ & 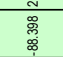 & 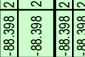 & 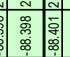 & 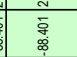 & 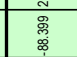 & 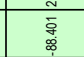 \\
\hline 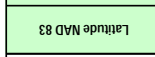 & 兽 & 糞 & 虽 & 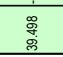 & 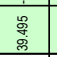 & 蹇 & 棗 & 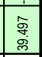 & 害 & \begin{tabular}{|l|} 
變 \\
\end{tabular} & 票 & 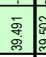 & 言 & 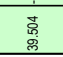 & 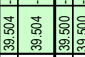 & 悹䇏 & 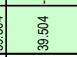 & 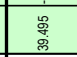 & 耪 \\
\hline 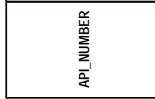 & 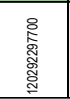 & & 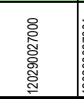 & 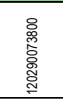 & 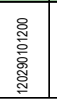 & 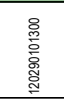 & 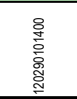 & \begin{tabular}{|l|}
$\underline{\underline{y}}$ \\
\end{tabular} & & 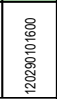 & 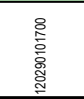 & & & 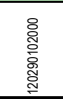 & & & 享 & 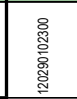 & 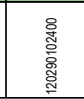 \\
\hline
\end{tabular}




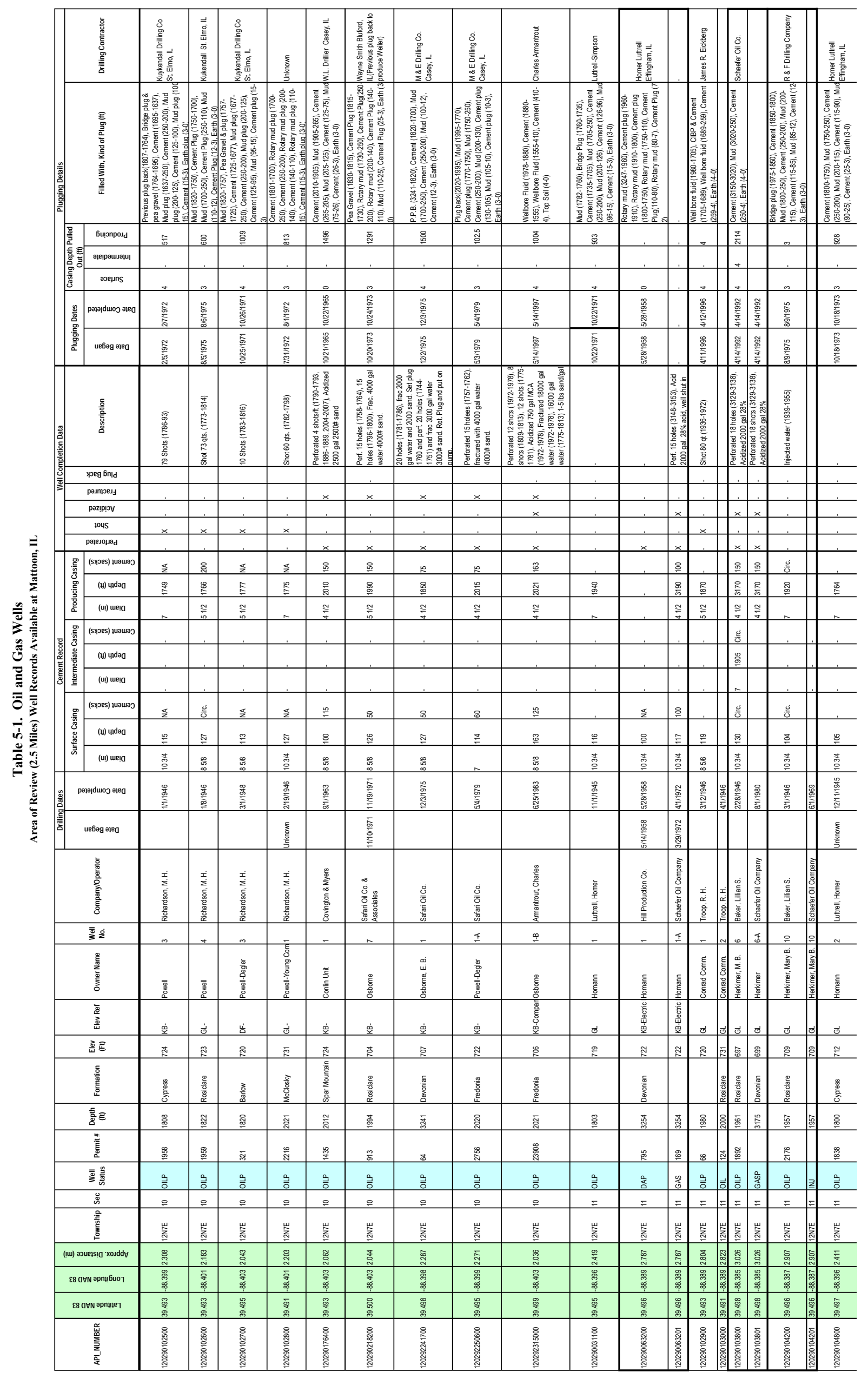




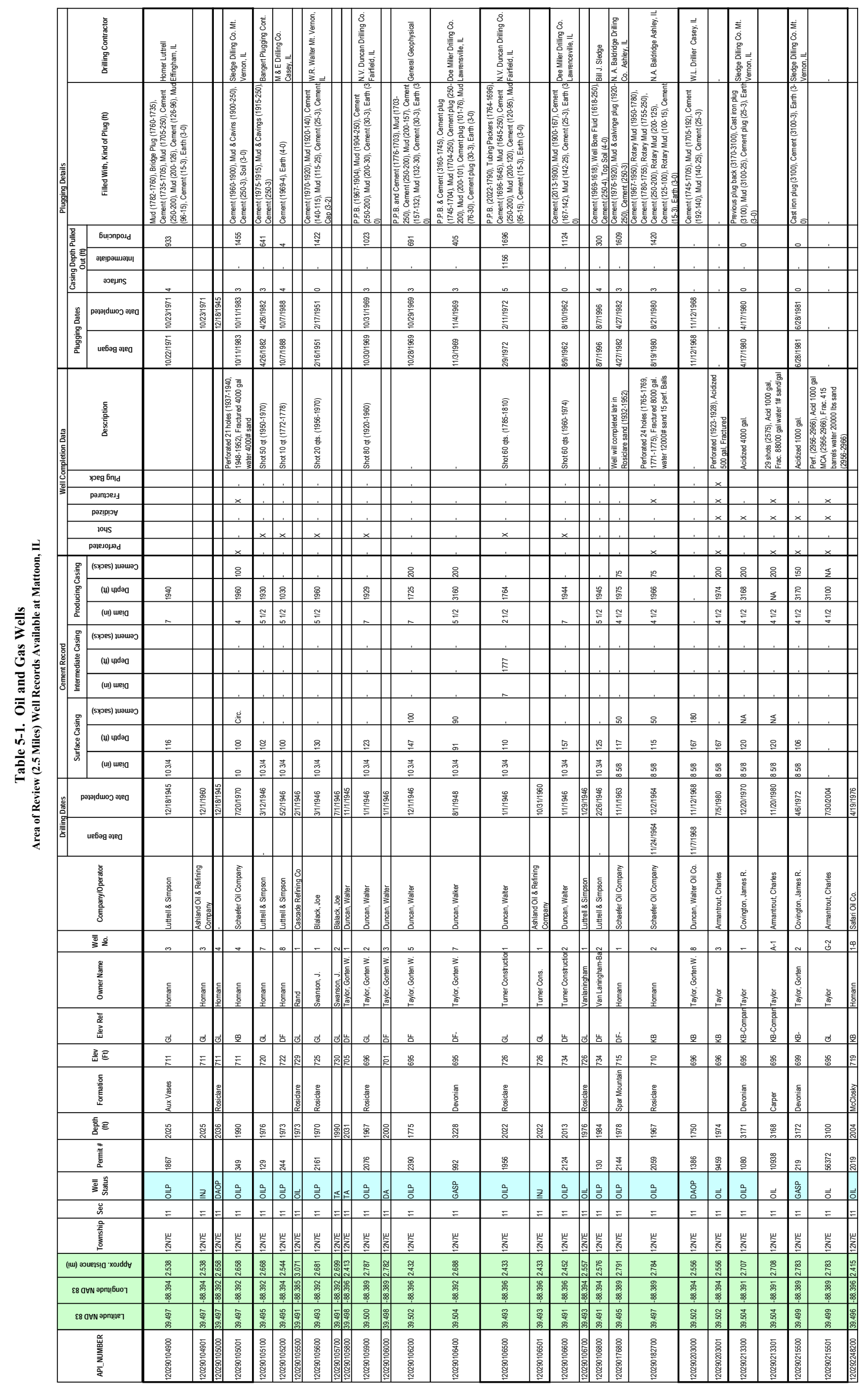




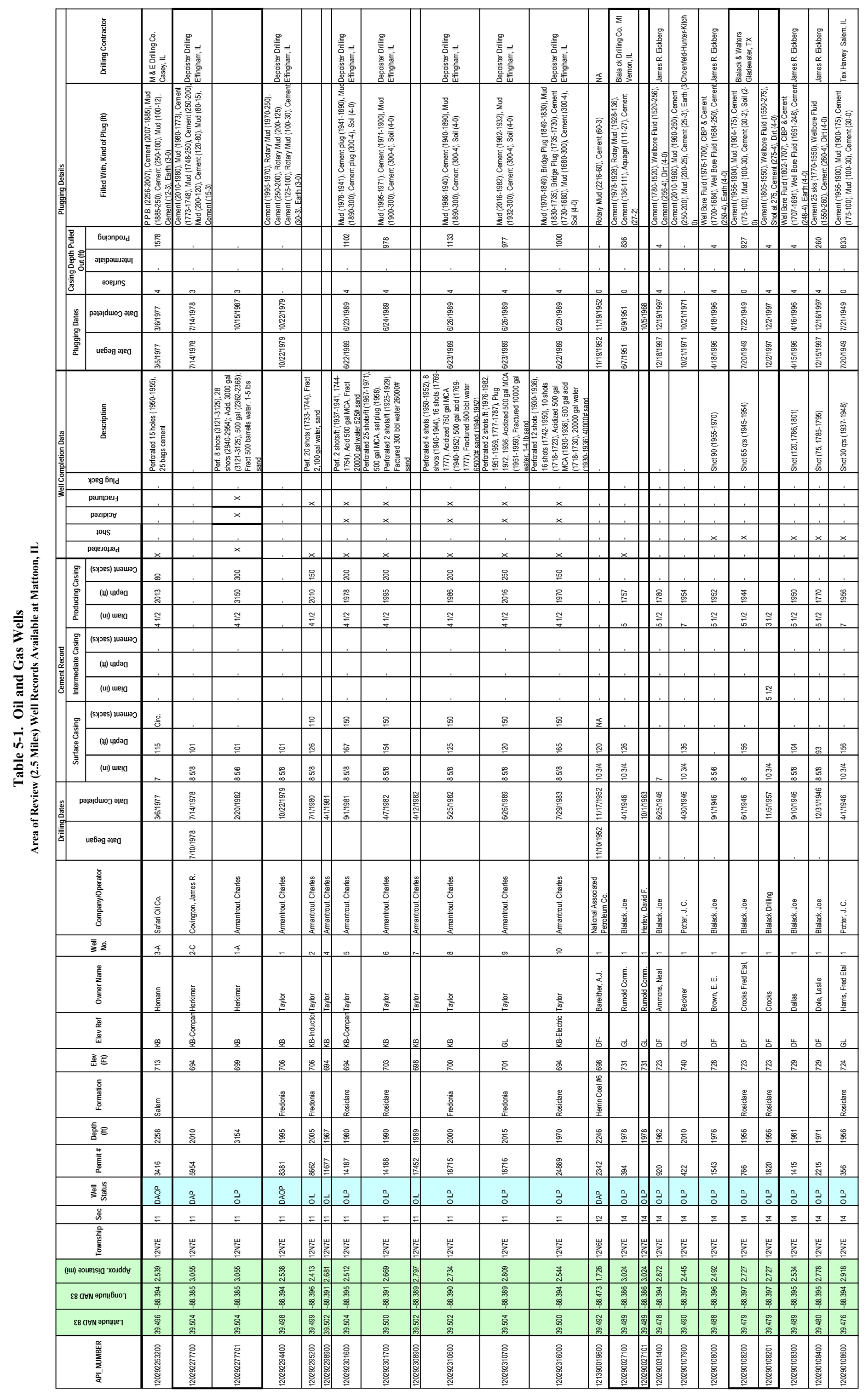




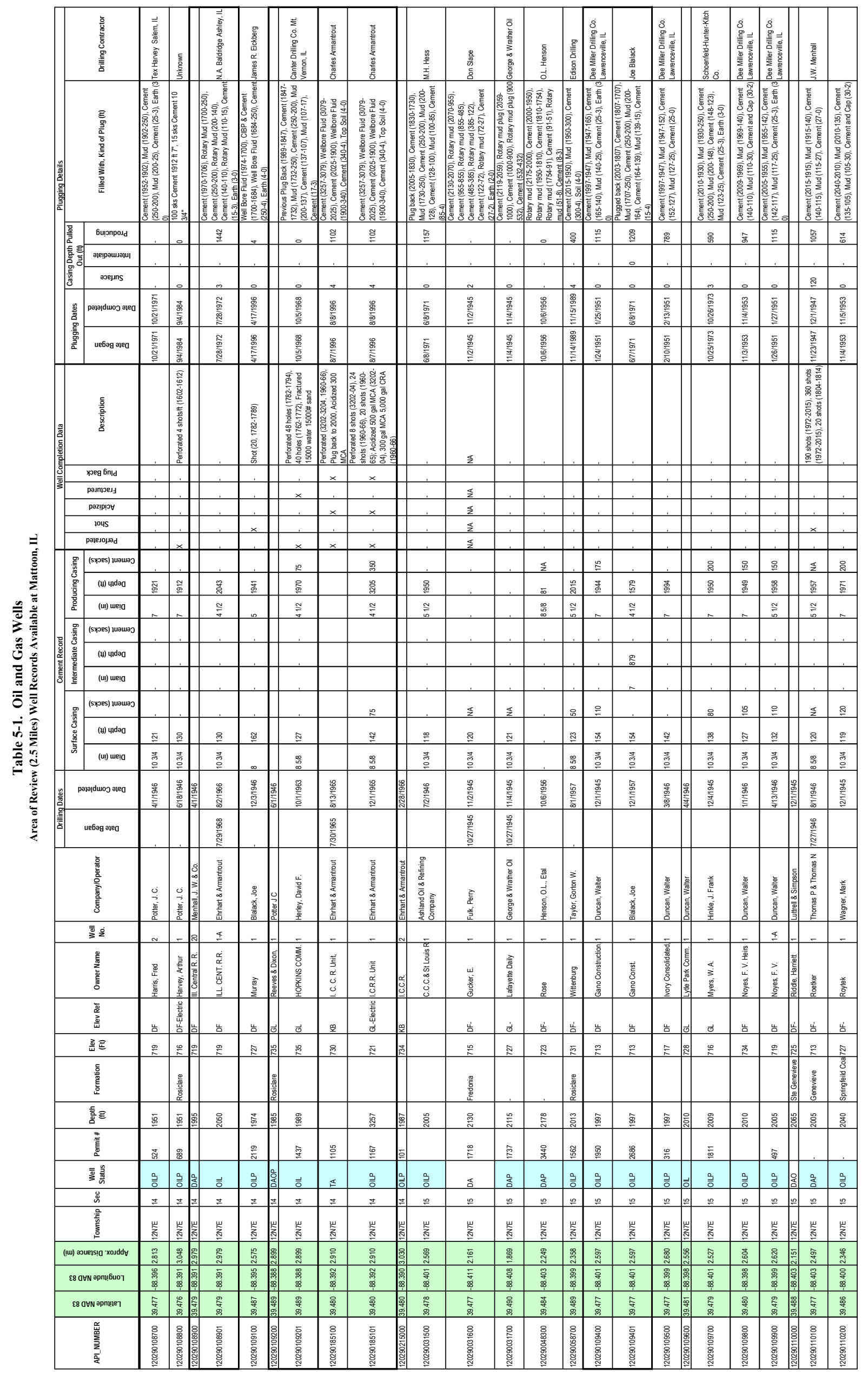




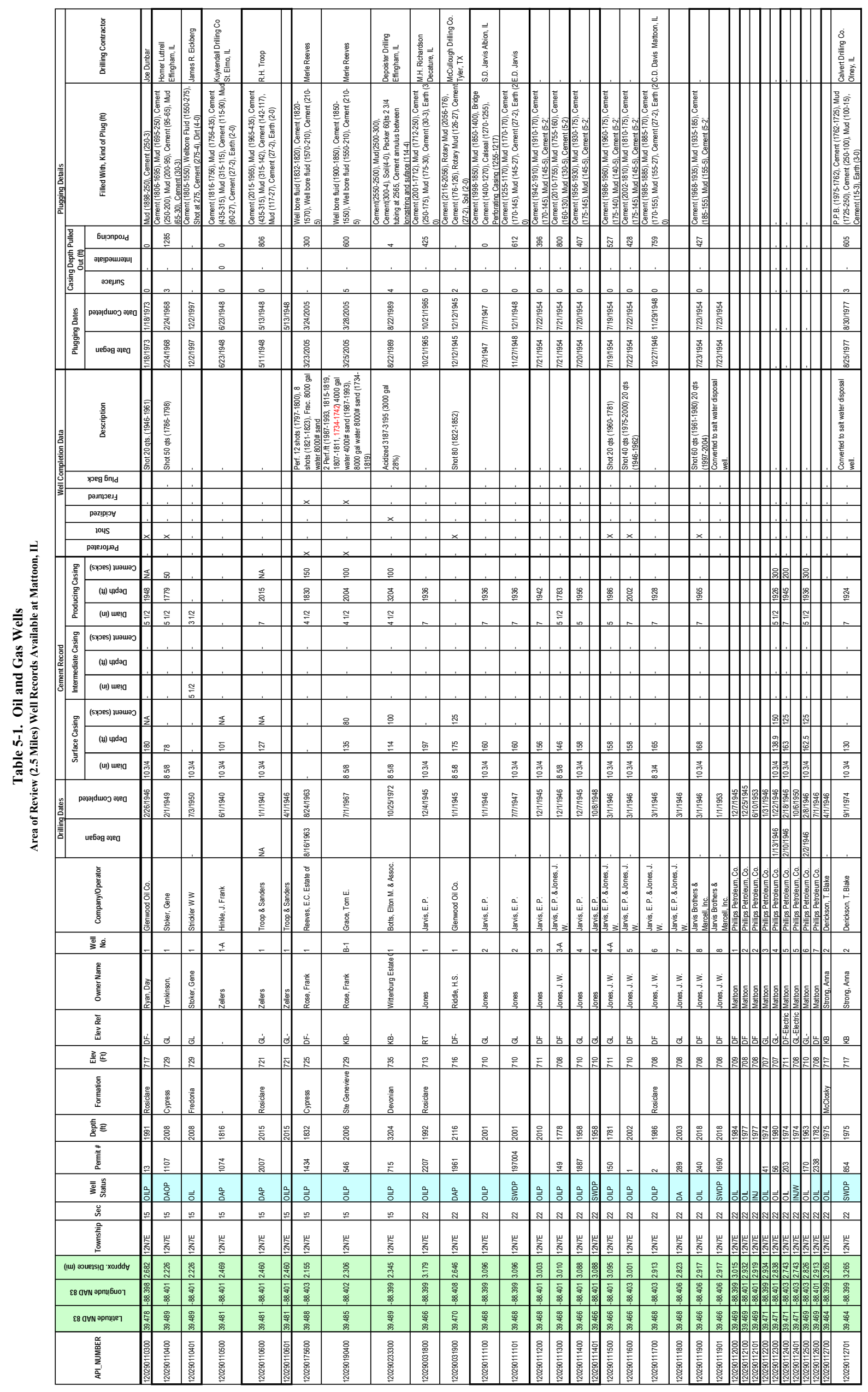




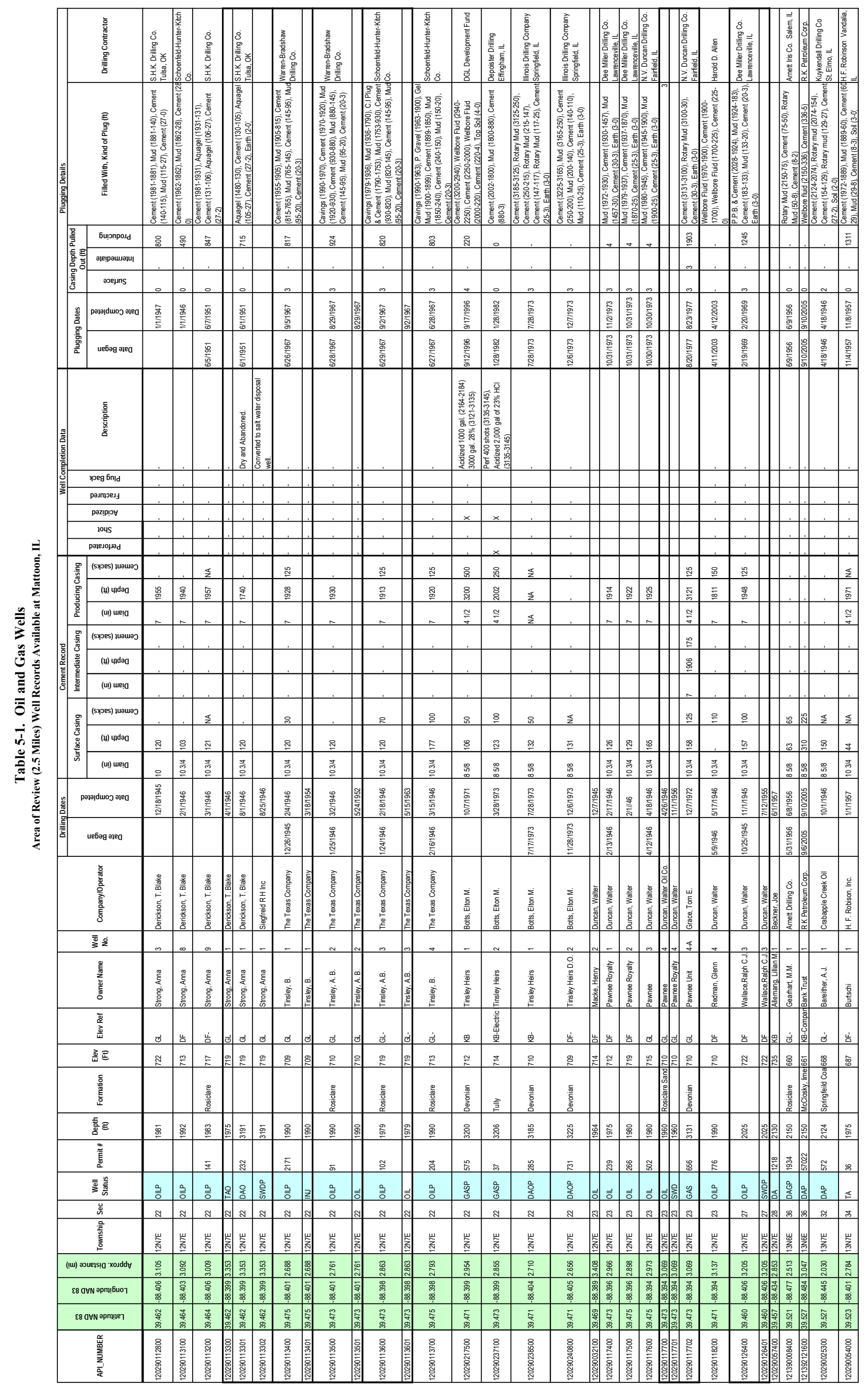




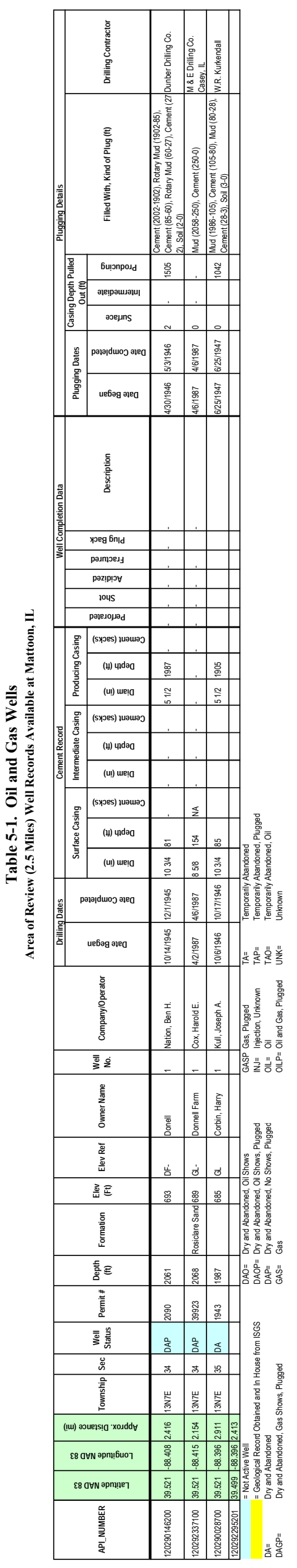




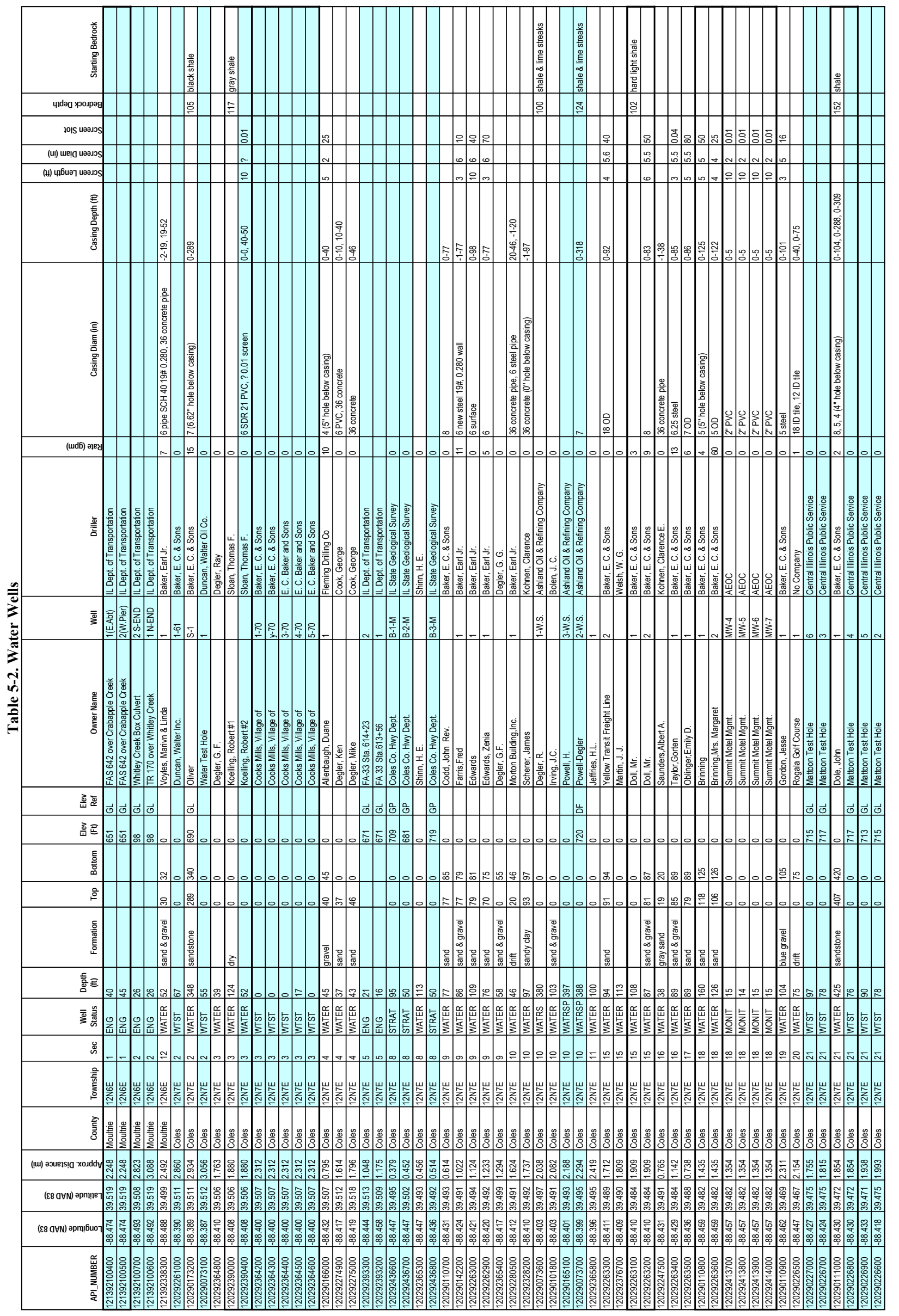




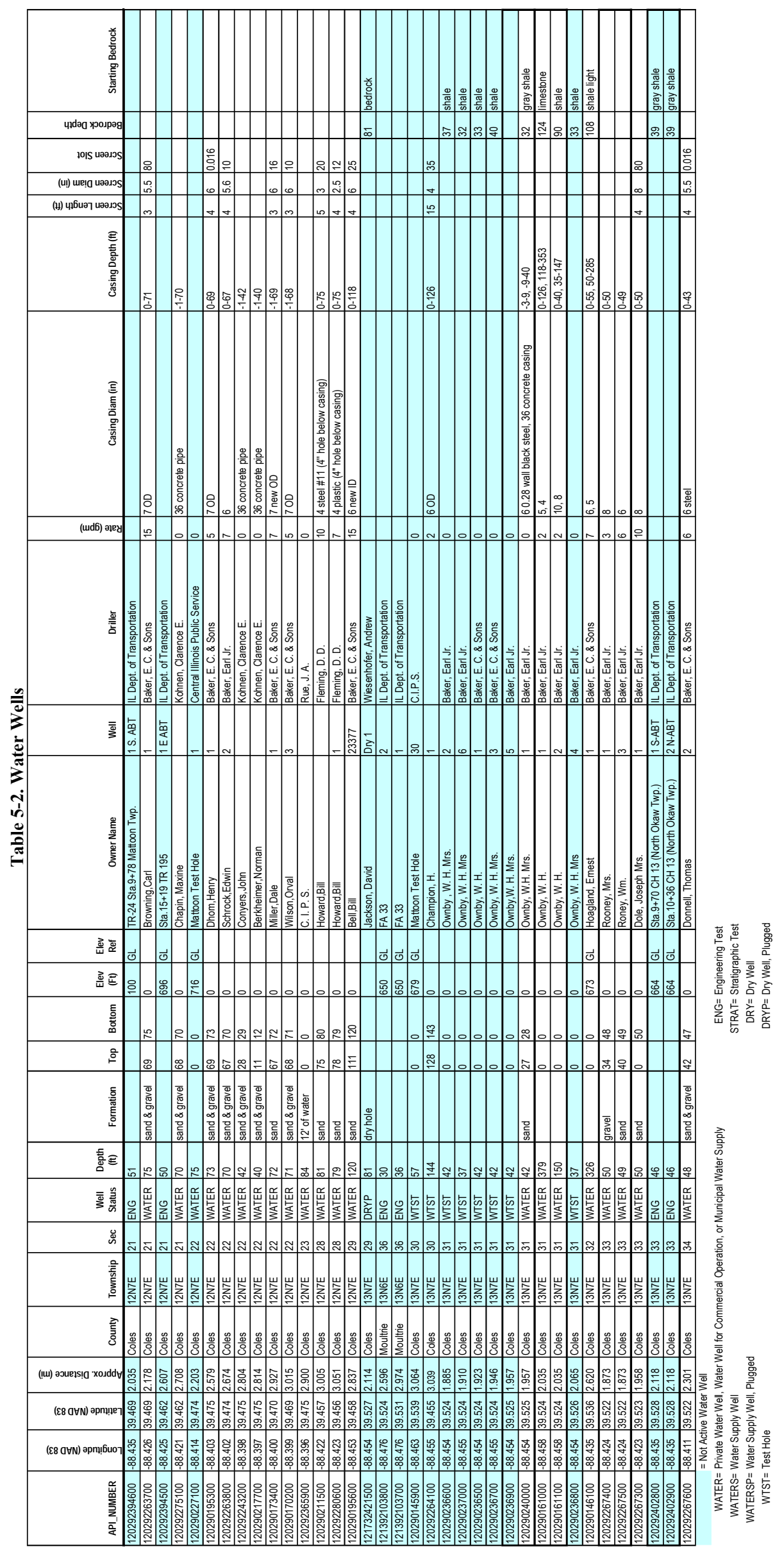




\section{APPENDIX 5-2}

Plugging Affidavits for Wells in the Area of Review 
2-12N-7E 

\}s. WELL PLUGGING AFFIDAVIT \} ss. WELL PLUGGING AFFIDAVIT $\{$ ss. WELLPLUCGING AFFIDAVIT

Lestes Burton being first duly sworn, do depose and say the following is a true and correct statement of the details of the plugging of a certain well drilled for oll and / ox tas

known as the ol mas (Indicate whether for oll, gas, water or other purposes)

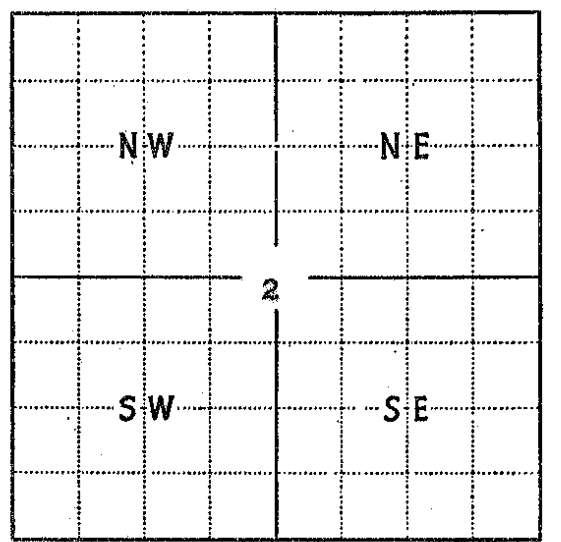

Locate well accurately on plat of section (Seale one inch-2,000 ft.)
Lessor Ouver Estate

Lessee Haryy I. Aday

Drilling Contractor I. L. DLILex and located as follows: 33

ft. north; f._.ft. south; _ 330 ft. east; _.___ ft. west of the of the__ Quarter of the Quarter of Section__ _ _., Township___2 (North or Sauth) Range $7 \quad$, (East or Wrat), of the 2 nd Princiual Meridian,__col County, Illinois. Elevation above sea level is $\left\{\begin{array}{l}\text { Derrick Floor } \\ \text { Ground } 680\end{array}\right.$ Total depth 1920 Formation Lower-Rosedar Date permit to drill isstied/64__Permit No.27o

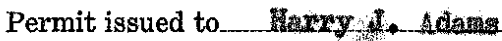
Date drilling began $-5 / 5 / 64$ Date drilling completed $5 / 10 / 64$ Kind of drilling tools used Rotery Date plugging began $5 / 20 / 6 / 4$

Date plugging completed $\quad 5 / 20 / 64$

Address_rabtoon, Tulnow

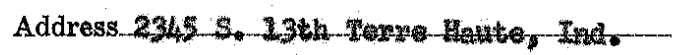
Address Cos, numaia

DETAILS OF PLUGGING:

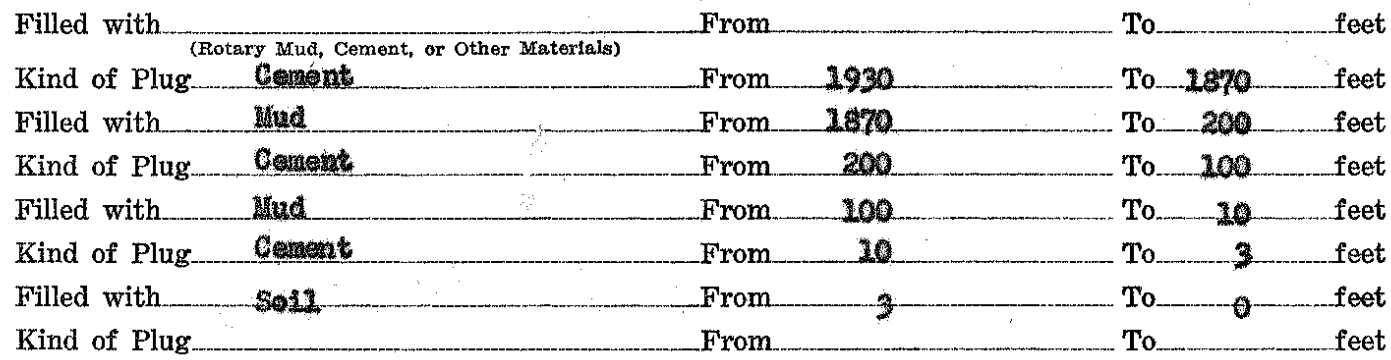

IF WORKABLE COAL BEDS WERE ENCOUNTERED IN THIS HOLE, DESCRIBE THE METHOD EMPLOYED TO PROTECT SAME. (A workable coal bed is thirty inches or more in thickness above 1,000 feet in depth) _._._. Ho wowlable eon

(1) Have pits and other excavations been filled?.

(2) Have the following been removed?

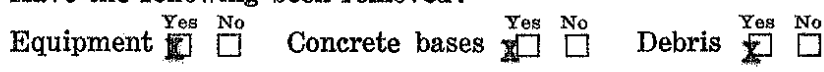

(3) Has surface casing been cut off three feet below ground surface?

(4) Has well-site been levelled?

If this was a producing well, give date and amount of last production Dry

$\left[\begin{array}{ll}\mathrm{Xas} & \text { No } \\ \square & \text { D }\end{array}\right.$

$\begin{array}{ll}\text { Yes } & \text { No } \\ \square & \square^{\text {Yes }} \\ \square & \square\end{array}$

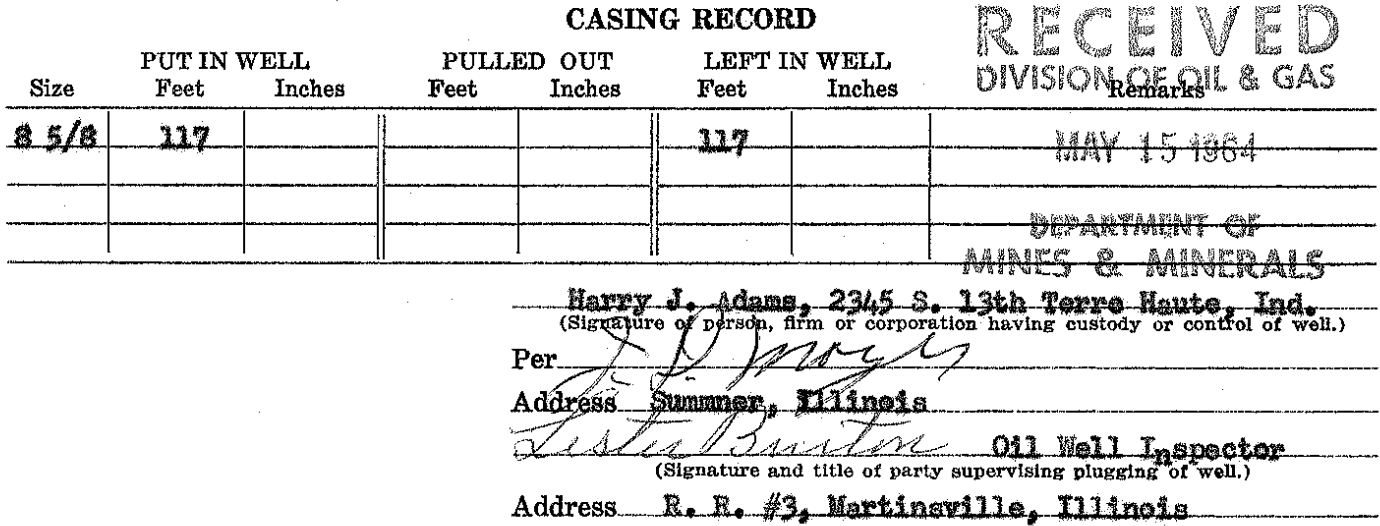

Subscribed and sworn to before me this__13___day of M. A. 19_64 My commission expires. Jum 1965 Lewe 


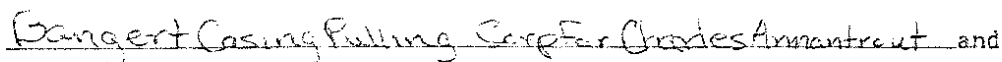
Revin spencer being first duiy sworn. do depose and say the following is a true and correct siatement of the details of the plugging of a certain well ormed for Cas

known as the Giver E. El

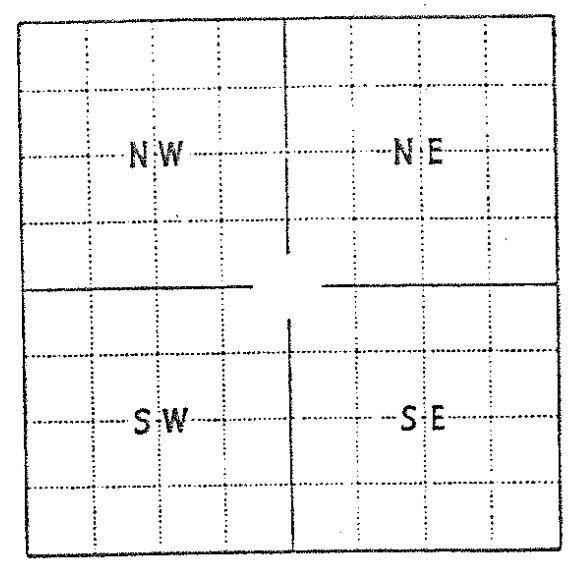

Locate well sccurstely on plat of section
(Scale one incti-2,000 $\mathrm{ft}$.) (indicate whether for oll, gas. water or othet purposes) and located as follows: $330 \mathrm{ft}$ north: ft. soutr: 330 ft. east; ft. west of the SW corner of the SE Quarter of the Quarter of the Quarter of

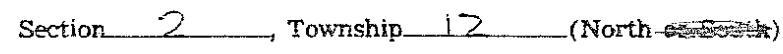
Range 7 (East Principal Mieridian, Coles County, minois. Elevation above sea level is $\begin{cases}\text { Derrick Floor } 694 & \mathrm{ft} \\ \text { Ground }-695 & \mathrm{ft} .\end{cases}$ Total depth $3172 \quad$ Formation Devionien Date permit to arill issued $5 / 25 / 70$ Permit No. 415 permit issued to Charles Armentroist Date drilling began $5 / 26 / 1970$ Date drilling completed $6 / 5 / 20$ Kind of drilling tools used Rotary Date plugging began $6 / 22 / 89$

Date plugging completed

\section{Lessor Oliver Lesser Charles Armantrout Drilling Contractor Calvert Eastern} Address $n$ nattoon

\section{DETAILS OF PLUGGing:}

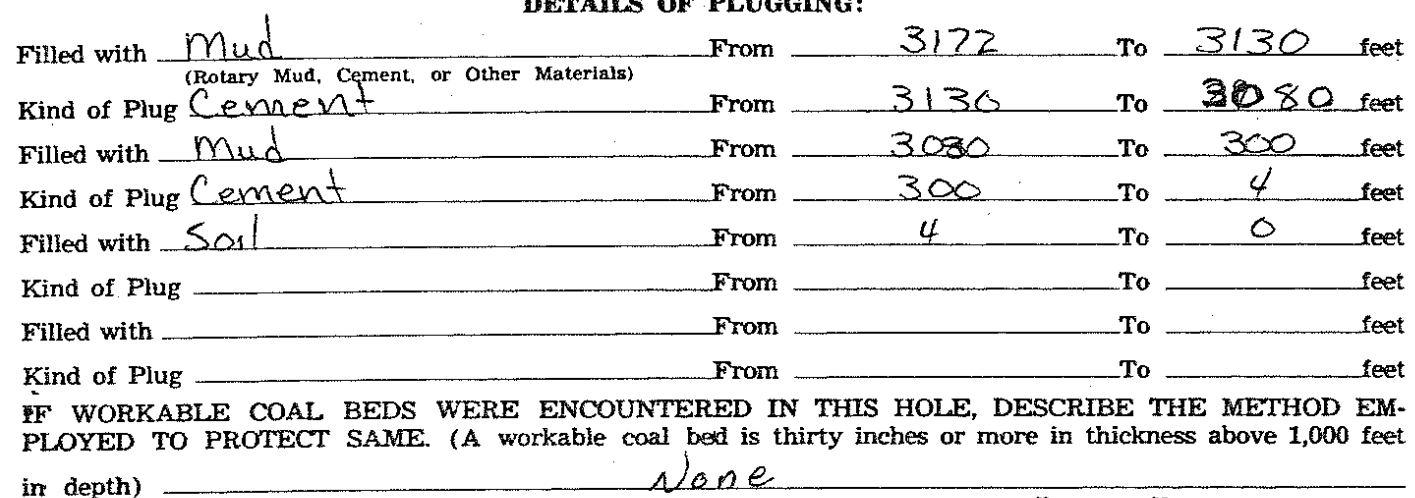

(1) Hiave pits and other excavations been fllled? Lone

(2) Have the following been removed?

Equipment $\square^{\text {No }}$ Concrete bases $\mathrm{X}^{\text {No }}$ Debris $\square$

(3) Has surface casing been cut off three feet below ground surface? 0 Nokf $y$

(4) Has well-site been leveled? . . . . . . . . . . . . . . . . . . .

If this was a producing well, give date and amount of last production

CASENG EECORD

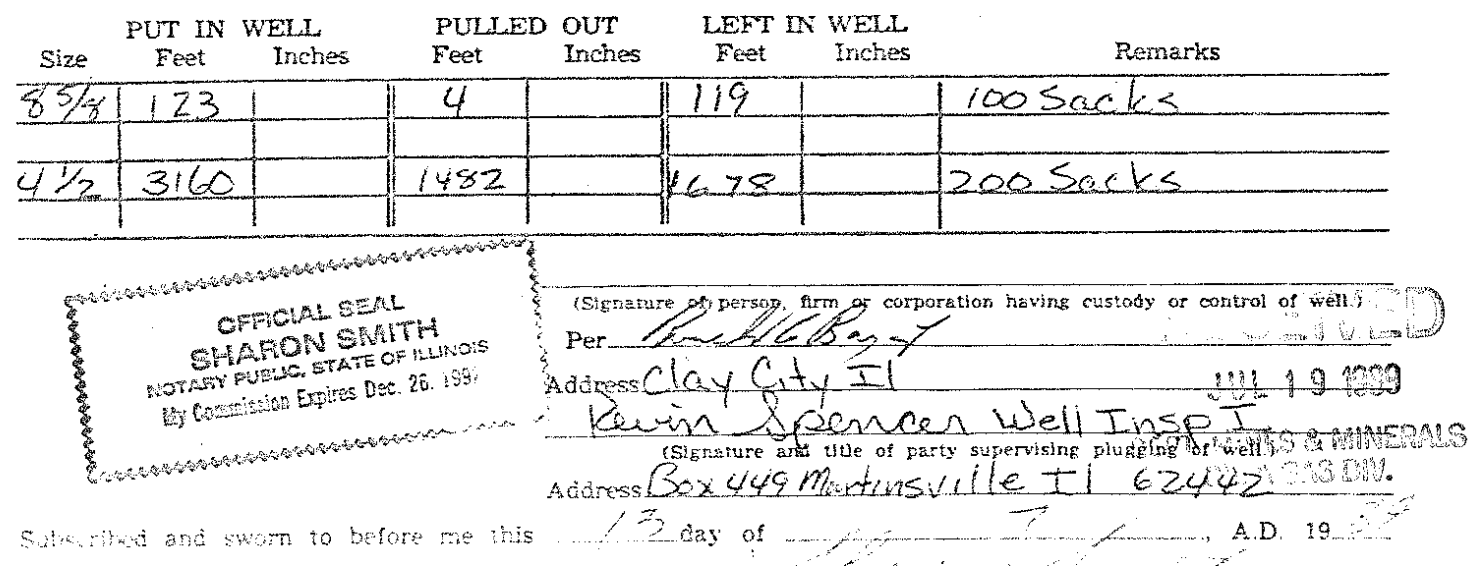




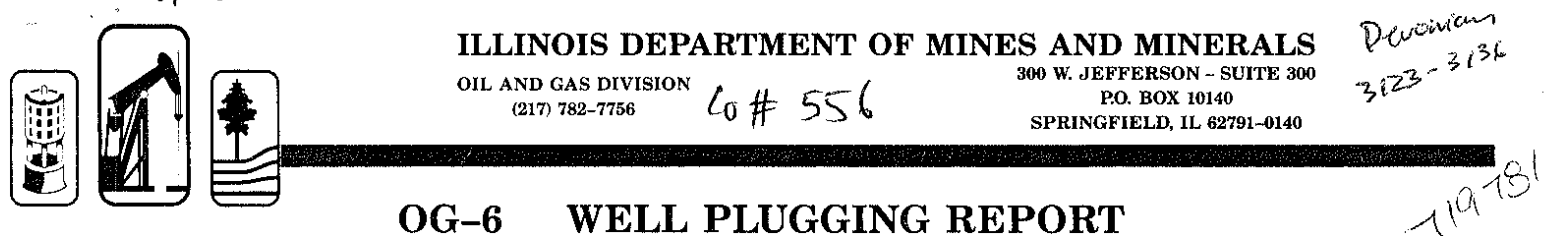

TYPE OF WELL: $\$ PRODUCTION $\square$ CLASS II $\square$ OBSERVATION $\square$ GAS STORAGE $\square$ REPLUG $\square$ OTHER PERMITEE: Northrield Gas well name: Oliver \#12-A PERMIT NO. $\frac{0 \times 9743}{\text { (ISSUE DATE IF NO }}$ PERMiTTEE NO. 1190 \begin{tabular}{|l|l|l|l|l|l|l|l|}
\hline & & & & & & & \\
\hline & $\mathrm{NW}$ & & & \multicolumn{1}{|c|}{} & \\
\hline & & & & & $\mathrm{NE}$ & \\
\hline & & & & & & & \\
\hline & & & & & & \\
\hline & $\mathrm{SW}$ & & & $\mathrm{SE}$ & \\
\hline & & & & & & \\
\hline
\end{tabular} REFERENCE NO. 140810

COUNTY $\frac{C \text { Coles }}{12 N}$ SECTION $\frac{2}{7 E}$

LOCATION: — FT. NORTH; OR 1650 FT. SOUTH; AND 330 FT. EAST; OR___ FT. WEST OF THE N N _ ? CORNER OF THE NE QUARTER OF THE SW QUARTER OF THE___ QUARTER OF THE QUARTER. Matom WELL DATA:

\begin{tabular}{|c|c|c|}
\hline SURFACE ELEVATION & 686 & PRODUCING / INJECTION INTERVALS \\
\hline TOTAL DEPTH OF WELL & 3134 & FROM 3123 To 31.34 \\
\hline PLUGGED BACK TOTAL DEPTH & N/A FT. & FROM — To \\
\hline BASE OF FRESHWATER ZONE & 3.36 & FROM \\
\hline WORKABLE COALS PRESENT AT & _ FT. & \\
\hline
\end{tabular}

DESCRIBE PREVIOUS PLUGBACK PROCEDURE:

DETAILS OF PLUGGING:

\begin{tabular}{|c|c|c|}
\hline FILLED WITH $C \sum \sin _{\text {(ROTARY MUD, WELLBORE FLUID, CEMENT, OR OTHER MATERIALS) }}$ & FROM 3134 & - To 2939 FT. \\
\hline FILLED WITH we $\|$ baes flueid & FROM 2439 & 400 \\
\hline FILLED WITH $C E$ ins $N$ t & FROM 400 & TO \\
\hline FILLED WITH tep $\approx \mathrm{coc}$ l & FROM & - то scet $x<$ Fт. \\
\hline FILLED WITH & FROM & — то \\
\hline FILLED WITH & 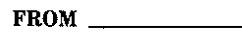 & - TO _ FT. \\
\hline FILLED WITH & FROM & _ TO \\
\hline COMMENTS: & & \\
\hline
\end{tabular}

WELL DATA:

\begin{tabular}{|l|c|c|c|c|c|c|}
\hline \multicolumn{1}{|c|}{ CASING } & SIZE & $\begin{array}{c}\text { SETTING } \\
\text { DEPTH }\end{array}$ & $\begin{array}{c}\text { SACKS } \\
\text { CEMENT }\end{array}$ & $\begin{array}{c}\text { HOLE } \\
\text { SIZE }\end{array}$ & $\begin{array}{c}\text { EST TOP OF } \\
\text { CEMENT }\end{array}$ & $\begin{array}{c}\text { AMOUNT OF } \\
\text { CASING REMOVED }\end{array}$ \\
\hline SURFACE & $10^{3 / 4}$ & $N R$ & $N R$ & $N R$ & $N R$ & $4^{\prime}$ \\
\hline $\begin{array}{l}\text { INTERMEDIATE /MINE } \\
\text { STRING /OR LINER }\end{array}$ & $7^{\prime \prime}$ & 1964 & $N R$ & $N R$ & $N R$ & 408 \\
\hline PRODUCTION & $4 / 1 / 2$ & $3 / 23$ & $N R$ & $6 \%$ & $N R$ & $5 / 8$ \\
\hline
\end{tabular}

UNDER PENALTIES OF PERJURÝ, I DEChARE THAT I HAVE EXAMINED THIS FORM INCLUDING ACCOMPANYING STATEMENTS AND DOCUMENTS, AND TO THE BEST OF NY KNøWLERGE, IT IS TRUE, CORRECT, AND COMPLETE. PERMTTEE QR DESIGNEE ADDRESS
SIGNATURE OF: 1$):$ : DATE PLUGGING BEGAN 24 Aprid 1995

\section{CITY, STATE}

ZIP

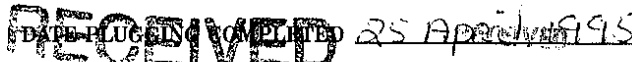$$
\text { MAY ? } 1000
$$$$
\text { Atof } 201995
$$

IL 472-0198 (Rev 8/93)
(OVER) 

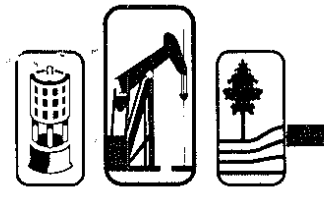

\section{ILLINOIS DEPART \\ OIL AND GAS DrvisION \\ (217) 782-7756

S AND MINERALS

300 W. JEFFERSON - SUTTE 300

P.O. BOX 10140

1X. 62791 0140

\section{OG-6 WELL PLUGGING REPORT}

TYPE OF WELL: $\bigotimes$ PRODUCTION $\square$ CLASS II $\square$ OBSERVATION $\square$ GAS STORAGE $\square$ REPLUG $\square$ OTHER PERMITTEE: North field GAS Well Name: Oliver $15-A$ PERMTT NO. $\frac{000548}{\text { (ISSUE DATE IF NO NUMBER) }}$

$$
\text { PERMITTEE NO. } 1190
$$

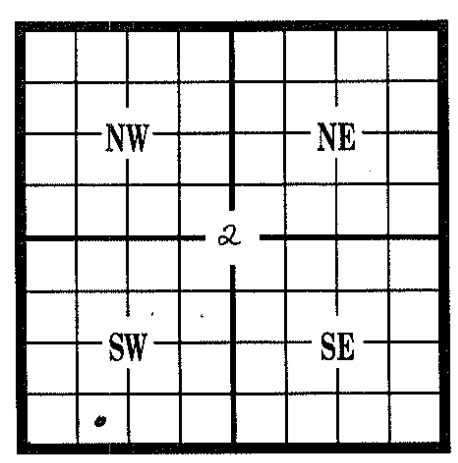

\begin{tabular}{|c|c|}
\hline county Coles & SECTION 2 \\
\hline TOWNSHIP $\quad 12 N$ & RANGE \\
\hline
\end{tabular}

990 FT. EAST; OR

CORNER OF THE

QUARTER OF THE

QUARTER.
REFERENCE No. $14 / 08 / 2$

\section{WELL DATA:}

\begin{tabular}{|c|c|c|}
\hline SURFACE ELEVATION & $688 \quad$ FT. & PRODUCING / INJECTION INTERVALS \\
\hline TOTAL DEPTH OF WELL & $3135 \quad$ FT & FROM $3 / 23$ то $3 / 33$ \\
\hline PLUGGED BACK TOTAL DEPTH & NONE FT. & FROM \\
\hline BASE OF FRESHWATER ZONE & $338 \quad$ FT. & FROM $\longrightarrow$ TO \\
\hline WORKABLE COALS PRESENT AT & NONE & FROM — TO \\
\hline
\end{tabular}

DETAILS OF PLUGGING:

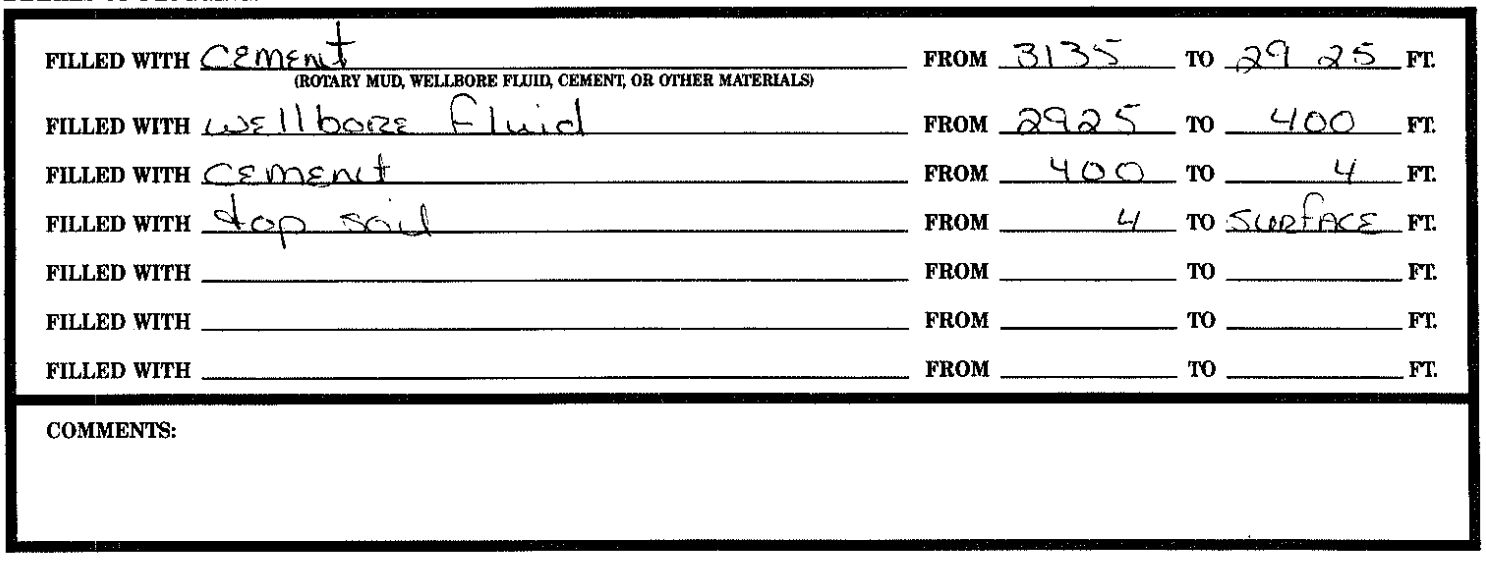

WELL DATA:

\begin{tabular}{|c|c|c|c|c|c|c|}
\hline CASING & SIZE & $\begin{array}{l}\text { SETTING } \\
\text { DEPTH }\end{array}$ & $\begin{array}{c}\text { SACKS } \\
\text { CEMENT }\end{array}$ & $\begin{array}{l}\text { HOLE } \\
\text { SIZE }\end{array}$ & $\begin{array}{l}\text { EST. TOP OF } \\
\text { CEMENT }\end{array}$ & $\begin{array}{c}\text { AMOUNT OF } \\
\text { CASING REMOVED }\end{array}$ \\
\hline SURFACE & 278 & 120 & 50 & & & 4 \\
\hline \multicolumn{7}{|l|}{$\begin{array}{l}\text { INTERMEDIATE /MINE } \\
\text { STRING / OR LINER }\end{array}$} \\
\hline PRODUCTION & $4 \% 2$ & $3 / 23$ & 1.50 & $6 \% 2$ & & 1270 \\
\hline
\end{tabular}

UNDER PENALTIES OF PERJURY, I DECLARE THAT I HAVE EXAMINED THIS FORM INCLUDING ACCOMPANYING STATEMENTS AND DOCUMENTS, AND TO THE BEST OR MY KNOWLEDGE, IT IS TRUE, CORRECT, AND COMPLETE.

SIGNATURE OF:

IL 472-0198 (Rev 8/93)
DATE PLUGGING BEGAN 14 ApRi/ $25^{-}$
DATE PLUGGING COMPLETED 19 ApRi/95

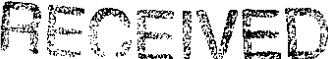
$1+\cdots \quad 1995$

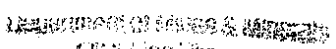

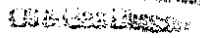

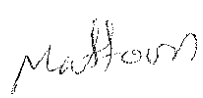




\section{ILLINOIS DEPARTMENT OF NATURAL RESOURCES Office of Mines and Minerals Division of Oil and Ga
(217) $782-7756$ COUNTY No. 544 \\ 524 South Second Street

\section{OG-6 WELL PLUGGING REPORT}

TYPE OF WELL: \ PRODUCTION $\square$ Class II $\square$ observation $\square$ GAS STORAGe $\square$ REPLUG $\square$ other Permitee: Lalter Duncaiv INeC WeLL Name: Cliver atg PERMIT NO. $\frac{002864}{\text { (ISSUE DATE IF NO NUMBER) }}$ PERMITTEE NO. 860 REFERENCE NO. 129365

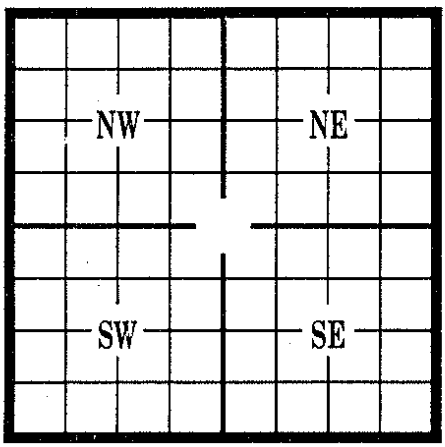

COUNTY COLS SECTION $\frac{2}{212 N}$ RANGE
LOCATION: 2310 FT. NORTH; OR FT. SOUTH; AND $16 S O$ FT. EAST; OR FT. WEST OF THE SCL CORNER OF THE _______ Q__ QUARTER OF THE ___ _ _ _ QUARTER OF THE —_ _ Q QUARTER.

\section{Mattoon}

WELL DATA:

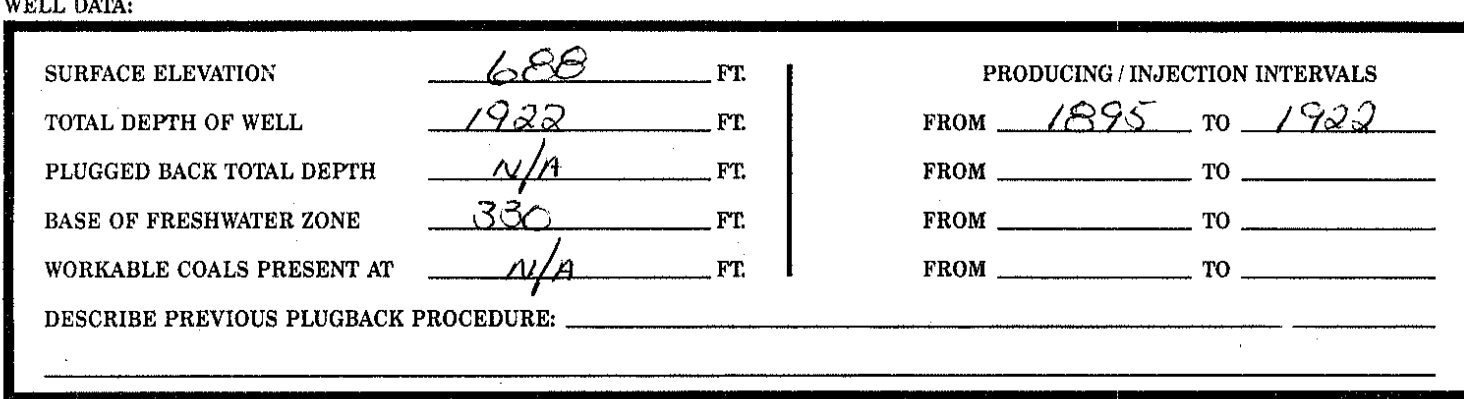

DETAILS OF PLUGGING:

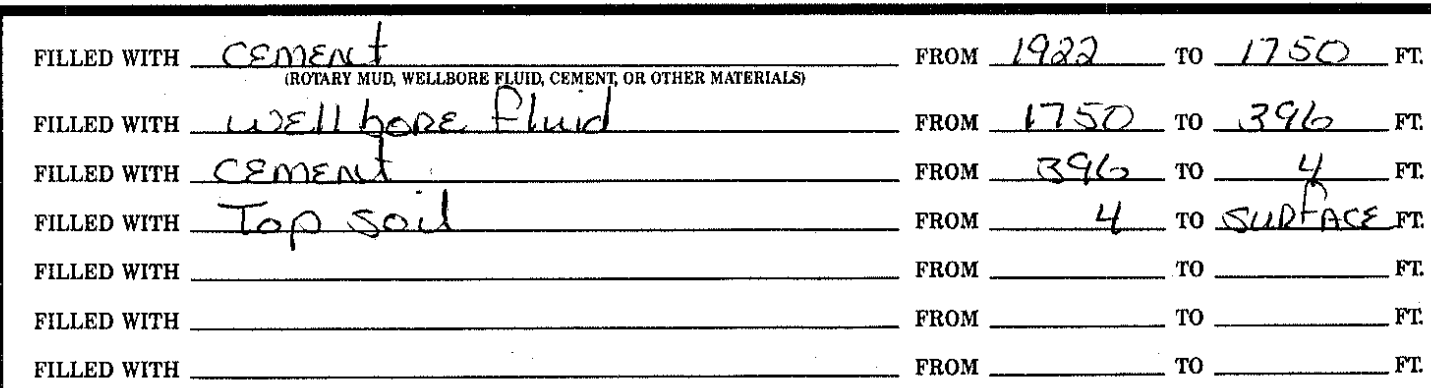

COMMENTS:

WELL DATA:

\begin{tabular}{|l|c|c|c|c|c|c|}
\hline \multicolumn{1}{|c|}{ CASING } & SIZE & $\begin{array}{c}\text { SETYING } \\
\text { DEPTH }\end{array}$ & $\begin{array}{c}\text { SACKS } \\
\text { CEMENT }\end{array}$ & $\begin{array}{c}\text { HOLE } \\
\text { SIZE }\end{array}$ & $\begin{array}{c}\text { EST. TOP OF } \\
\text { CEMENT }\end{array}$ & $\begin{array}{c}\text { AMOUNT OF } \\
\text { CASING REMOVED }\end{array}$ \\
\hline SURFACE & $10^{\prime} \% / 4$ & 120 & 125 & $12^{\prime \prime}$ & $6 /$ & $4^{\prime}$ \\
\hline $\begin{array}{l}\text { INTERMEDIATE/MINE } \\
\text { STRING/OR LINER }\end{array}$ & & & & & & \\
\hline PRODUCTION & $7^{\prime \prime}$ & 1890 & 125 & $8 / 2$ & 850 & 630 \\
\hline
\end{tabular}

UNDER PENALTIES OF PERJURY, I DECLARE THAT I HAVE EXAMINED THIS FORM INCLUDING ACCOMPANYING STATEMENTS AND DOCUMENTS, AND TO THE BEST OF MY KNOWLEDGE, IT IS TRUE, CORRECT, AND COMPLETE.

SIGNATURE OF: Pि Deres

$$
\frac{P 0 .}{20 x} 932
$$$$
\frac{\text { AD a }}{\text { CITY STATE }}
$$

DATE PLUGGING BEGAN 210 HYY 9

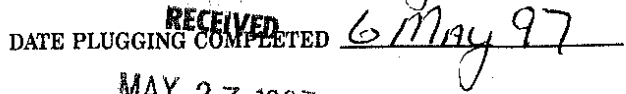
MAY 271997

GEOLOCEC DECOMn 


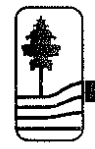

\section{OG-6}

\section{WELL PLUGGING REPORT}

TYPE OF WELL: $\square$ PRODUCTION $\square$ CLASS II $\square$ OBSERVATION $\triangle$ GAS STORAGE $\square$ REPLUG $\square$ OTHER PERMITteE: Alorth field Gas PERMITTEE NO. 1196 WELL NAME: CluER $\not / N$ PERMIT NO. $\frac{024 / 19}{\text { (ISSUE DATE IF NONUMBER? }}$ REFERENCE NO. $\left\langle 4 \bigcirc \varepsilon_{i} \backslash\right.$

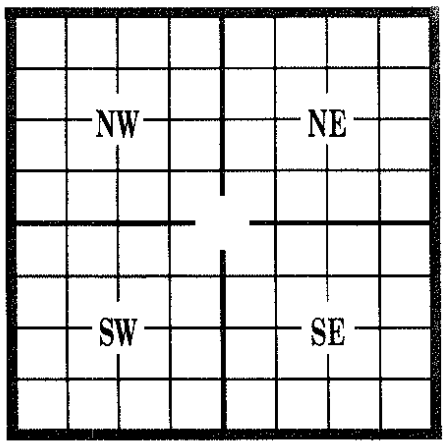

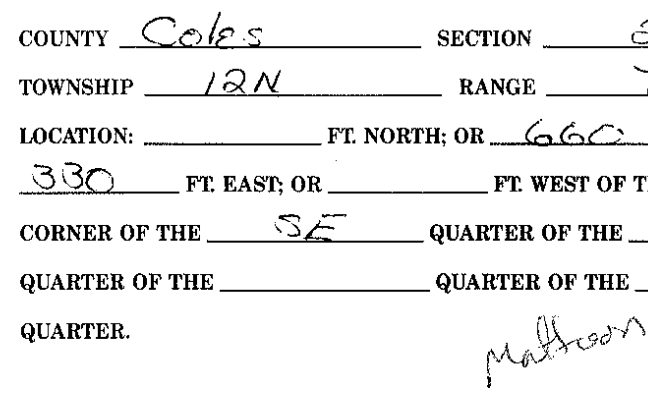

WELL DATA:

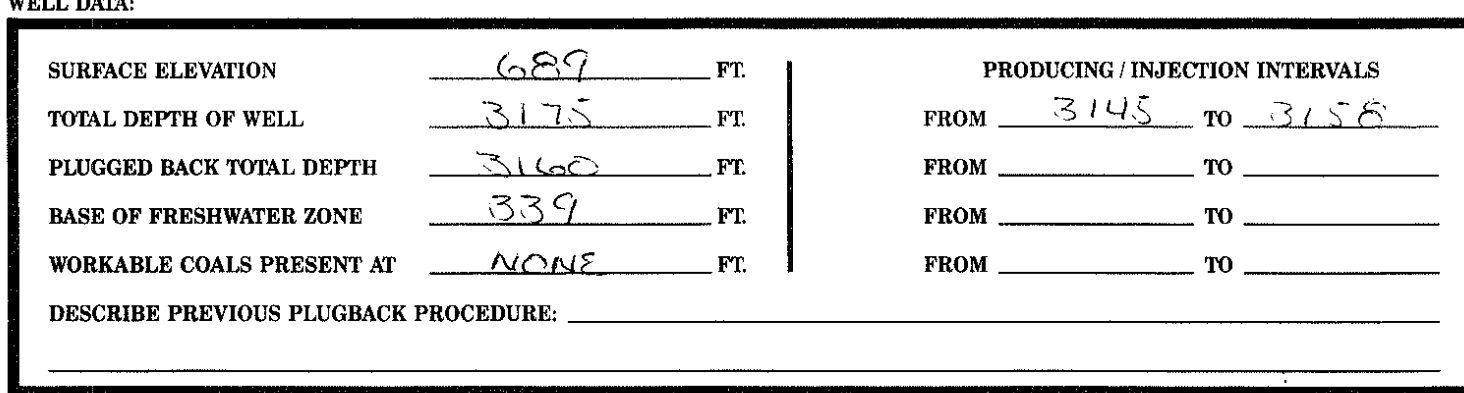

DETAILS OF PLUGGING:

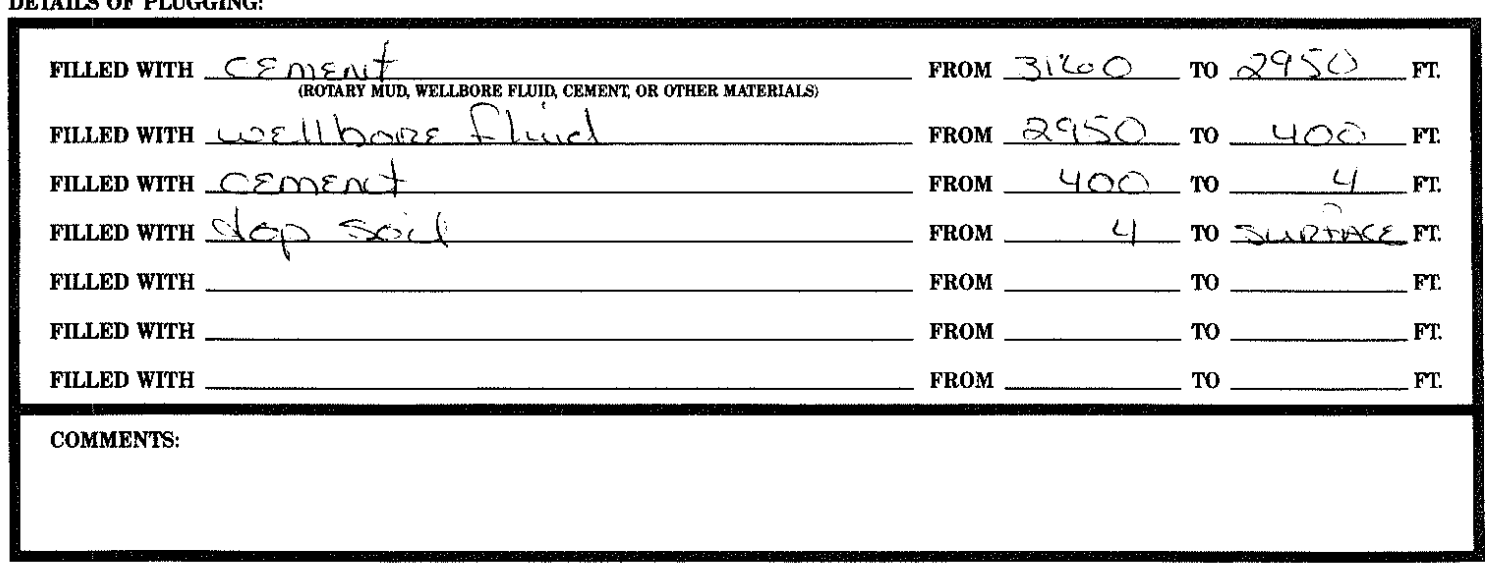

WELL DATA:

\begin{tabular}{|l|c|c|c|c|c|c|}
\hline \multicolumn{1}{|c|}{ CASING } & SIZE & $\begin{array}{c}\text { SETTING } \\
\text { DEPTH }\end{array}$ & $\begin{array}{c}\text { SACKS } \\
\text { CEMENT }\end{array}$ & $\begin{array}{c}\text { HOLE } \\
\text { SIZE }\end{array}$ & $\begin{array}{c}\text { EST. TOP OF } \\
\text { CEMENT }\end{array}$ & $\begin{array}{c}\text { AMOUNT OF } \\
\text { CASING REMOVED }\end{array}$ \\
\hline SURFACE & $\varepsilon^{2} / \varepsilon$ & 176 & 125 & $12 \%$ & $6 / 2$ & 4 \\
\hline $\begin{array}{l}\text { INTERMEDIATE /MINE } \\
\text { STRING / OR LINER }\end{array}$ & & & & & & \\
\hline PRODUCTION & $4 / 2$ & 3164 & 200 & $77 / 8$ & & 1526 \\
\hline
\end{tabular}

UNDER PENALTIES OF PERJURY, I DECLARE THAT I HAVE EXAMINED THIS FORM INCLUDING ACCOMPANYING STATEMENTS AND DOCU. MENTS, AND TO THE BEST OF MY KNOWLEDGE, IT IS TRUE, CORRECT, AND COMPLETE.

SIGNATURE OF:

IL 472-0198 (Kev 8/93)
(OVER)

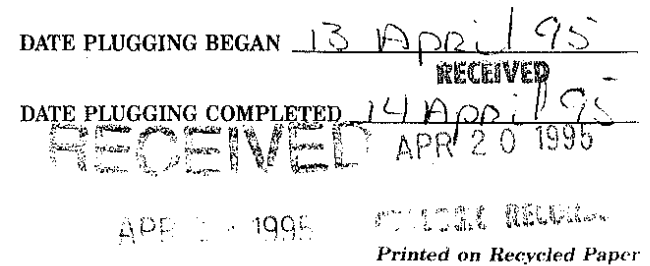

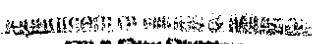

manomian 
H. Noblit State Well Inspector

being first duly sworn do depose and say the following is a true and correct statement of the details of the plugging of a certain well drilled for $0 j 1$

(Indicate whether for oil, gas, water or other purposes) 330

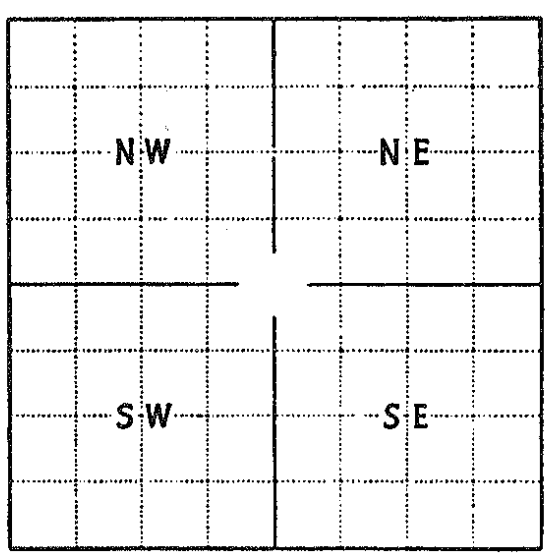

Locate well accurately on plat of section (Scale one inch-2,000 ft.)
ft. east; $330 \quad$ ft. west
ft. south

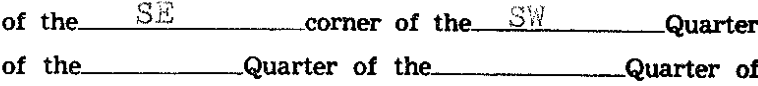

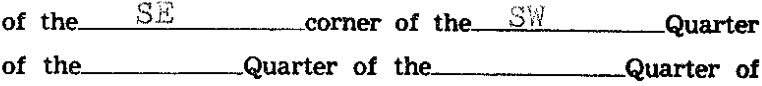
Section 2 , Township__ 12 ___ (North or/Sopphy) Range 7 , (East or West 6 , of the

Principal Meridian,__oles____County, mlinois. Elevation above sea level is $\begin{cases}\text { Derrick Floor } & \mathrm{ft} . \\ \text { Ground }-689.3 \mathrm{ft} .\end{cases}$

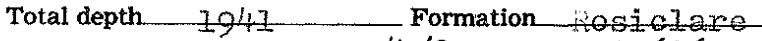
Date permit to drill issued 1/4/82 Permit No. 17626

Permit issued to Fom Grace

Date drilling began_ $1 / 19 / 82$

Date drilling completed_ $1 / 25 / 82$

Kind of drilling tools used Rotary

Date plugging began $\quad 1 / 25 / 828$

Date plugging completed $\quad 1 / 25 / 82$

\begin{tabular}{|c|c|}
\hline Lessor Mary E.\& Edgar P. Oliver & iNattoon.IIIinois \\
\hline Lessee Mon Gr & Address Box \#457 Wattoon, IJ.61938 \\
\hline rilling Contractor & Address_Gasey, III, 62420 \\
\hline DETALLS OF & PLUGGING: \\
\hline Cement & 1800 \\
\hline $\begin{array}{l}\text { (Rotary Mud, Cement, or Other Materials) } \\
\text { Kind of Plug }\end{array}$ & \\
\hline $\begin{array}{l}\text { Kind of Plug }- \text { Cement } \\
\text { Filled with }\end{array}$ & $\begin{array}{l}1800 \\
\text { From }-\quad 250\end{array}$ \\
\hline Kind of Plug & _From \\
\hline Filled with & + \\
\hline Kind of Plug & From \\
\hline Filled & From … \\
\hline ind of Plug & From \\
\hline
\end{tabular}

IF WORKABLE COAL BEDS WERE ENCOUNTERED IN THIS HOLE, DESCRIBE THE METHOD EMPLOYED TO PROTECT SAME. (A workable coal bed is thirty inches or more in thickness above 1,000 feet in depth) None

(1) Have pits and other excavations been filled? ................ ${ }^{\text {Yes }}$

(2) Have the following been removed?

$$
\text { Equipment } \stackrel{\text { Yes }}{\square} \stackrel{\text { No }}{\square} \text { Concrete bases } \stackrel{\text { Yes }}{\square} \stackrel{\text { No }}{\square} \text { Debris } \stackrel{\text { Yes }}{\square} \text { 晜 }
$$

(3) Has surface casing been cut off three feet below ground surface?

(4) Has well-site been leveled?

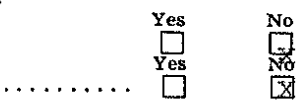

If this was a producing well, give date and amount of last production Dry Hole

CASING RECORD

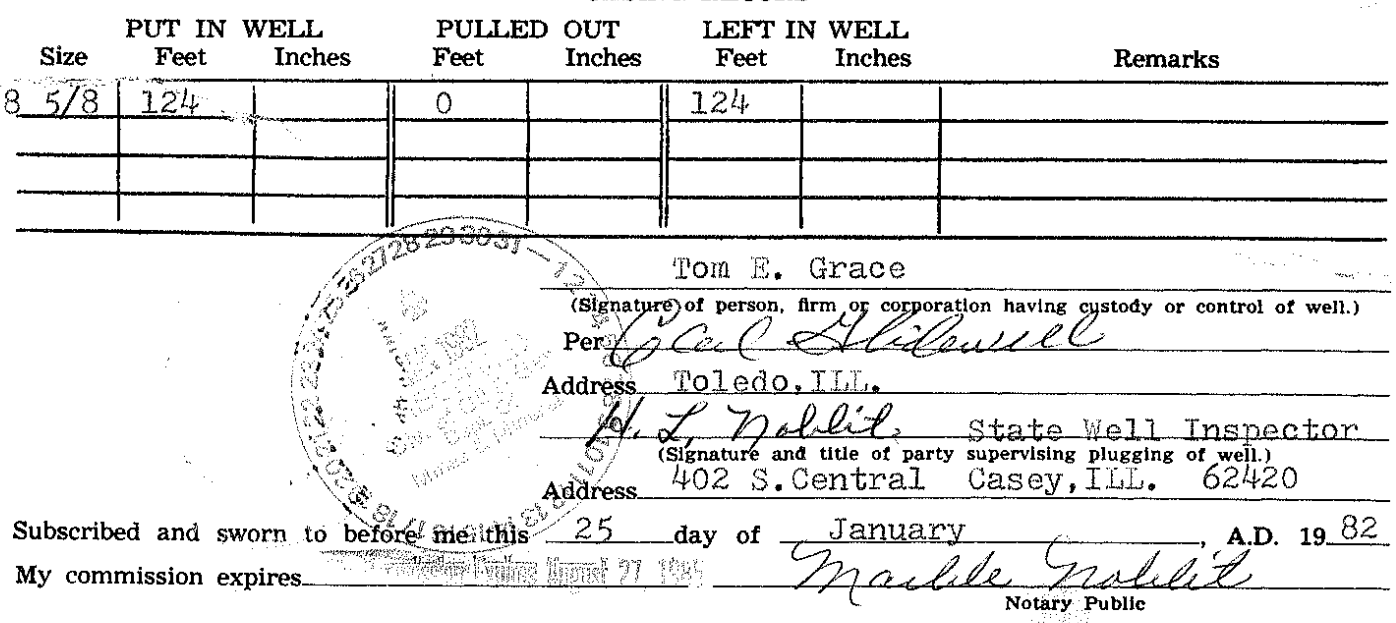



do depose and say the following is a true and correct statement of the details of the plugging of a certain well drilled for _._. $Q 1$

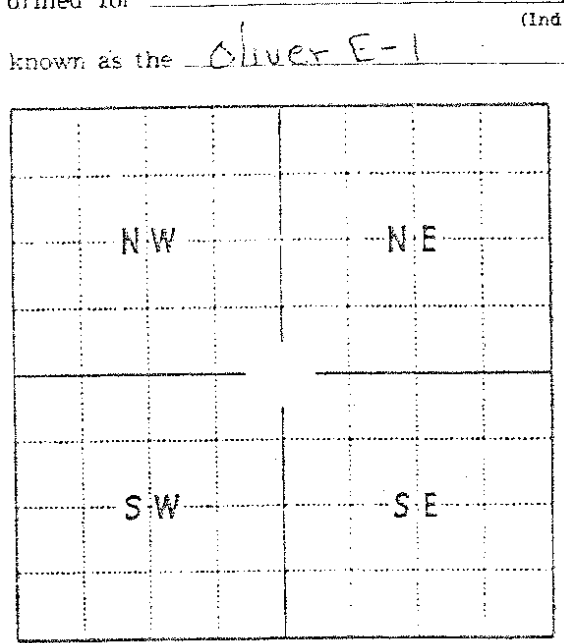

Laste reli accurateiy on plat of section (Scaie ane suct, $-2,000 \mathrm{it.}$ ndicate whether for oh, gat, water or other purposes and located as follows: __ 3.30 ft. north; ft. south: ft. east; 330 Fi. west of the SE comer of the SW Quarter of the______uarter of the___ Quarter of Section 2 , Township_12 (Norh Range 7 , (East of the Principal Meridian, Coles county, Illinois. Elevation above sea level is $\left\{\begin{array}{l}\text { Derrick Floor } 69 ? \text { ft. } \\ \text { Ground } 689 \text { it. }\end{array}\right.$ Total deptin 1954 . FormationRosiclare Date permit to drill issued $7 / 20 / s ?$ Permit No 19815 Permit issued tofharles Armantrout Date drilling began $7 / 20 / 82$ Date drilling completed $7 / 27 / 82$ Kind of drilling tools used Rotary Date plugging began $6 / 21 / 89$ Date plugging completed $6 / 22 / 89$

Lessor Oliver Lessee Charles Armantrout Drilling contractor Depoister Drla
Address

Adoress Mattoon II Adress Effinaham I
Filled with $\underbrace{\text { e ement }}_{\text {(Rotary Mud. Cement, or other Materials) }}$

Kind of Plug - mud

Filled with Cement

Kind of Plug S Sol

Filied with

Kind of Plug

Filled with

Kind of Plug

\section{PLUgGing:}

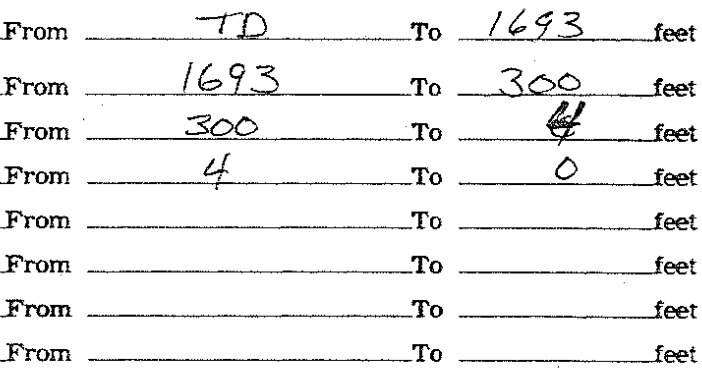

IF WORKABLE COAL BEDS WERE ENCOUNTERED IN THIS HOLE, DESCRIBE THE METHOD EMVPLOYED TO PROTECT SAME. (A workable coal bed is thirty inches or more in thickness above 1,000 feet in depth) None

(1) Have pits and other excavations been filled?

(2) Have the following been removed?

$$
\text { Equipment } \stackrel{\text { Ye }}{\square} \text { Concrete bases } \stackrel{\text { Yes }}{\square} \text { Debris } \square
$$

(3) Has surface casing been cut of three feet below ground surface?

(4) Has well-site been leveled?

If this was a producing well, give date and amount of last production

\section{CASEG FECORD}

\begin{tabular}{|c|c|c|c|c|c|c|c|}
\hline Size & $\begin{array}{c}\text { PUT IN } \\
\text { Eeet }\end{array}$ & $\frac{\text { WELL }}{\text { Inches }}$ & $\begin{array}{l}\text { PULEE } \\
\text { Feet }\end{array}$ & $\begin{array}{l}\text { out } \\
\text { Incties }\end{array}$ & $\begin{array}{l}\text { LEFT } \\
\text { Feet }\end{array}$ & $\begin{array}{l}\text { MELL } \\
\text { netes }\end{array}$ & Remariss \\
\hline 554 & 124 & & 4 & & $1=0$ & & $100 \operatorname{seck} s$ \\
\hline & & & 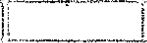 & & 1 & & \\
\hline $2 \sqrt{2}$ & 1456 & & 1155 & & 501 & & 150 Sacks \\
\hline 20 & & I & & & 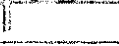 & & 40 \\
\hline
\end{tabular}

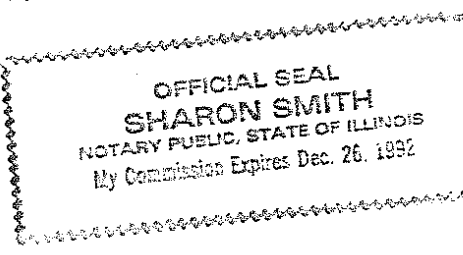

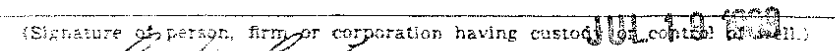

$$
\text { per }
$$




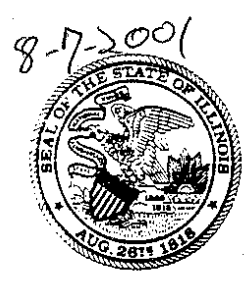

\section{ILLINOIS DEPARTMENT OF NATURAL RESOURCES Office of Mines and Minerals \\ Division of $\mathrm{Oll}$ and G $\mathrm{G} 24$ South Second Street (217) $782-7756$ \\ 2156 pringfield, Illinois $62701-1787$

\section{OG-6 WELL PLUGGING REPORT}

TYPE OF WELL: $\square$ PRODUCTION $\searrow$ CLASS II $\square$ OBSERVATION $\square$ GAS STORAGE $\square$ REPLUG $\square$ OTHER PERMITtEe: Charles Armantrout well Name: Oliver " $C$ " 2

\section{PERMIT NO. 003792}

PERMITTEE NO. 110

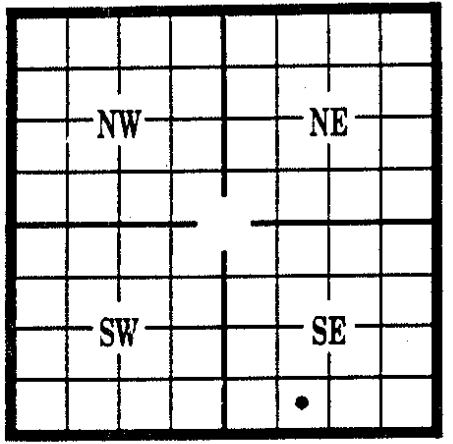

countr Coles

SECTION 02

TOWNSHIP $12 N$

RANGE $07 E$

LOCATION: 0330 FT NORTH; OR FT. SOUTH; AND FT EAST; OR 1650 FT. WEST OF THE SE

CORNER OF THE QUARTER OF THE QUARTER OF THE QUARTER OF THE QUARTER.

WELL DATA:

SURFACE ELEVATION

TOTAL DEPTH OF WELL

PLUGGED BACK TOTAL DEPTH

BASE OF FRESHWATER ZONE

WORKABLE COALS PRESENT AT WORKABLE COALS PRESENT AT

\section{9

1934 FT. \\ 1800 FT. FT.}

E.

$\frac{2}{8}$

DETAILS OF PLUGGING:

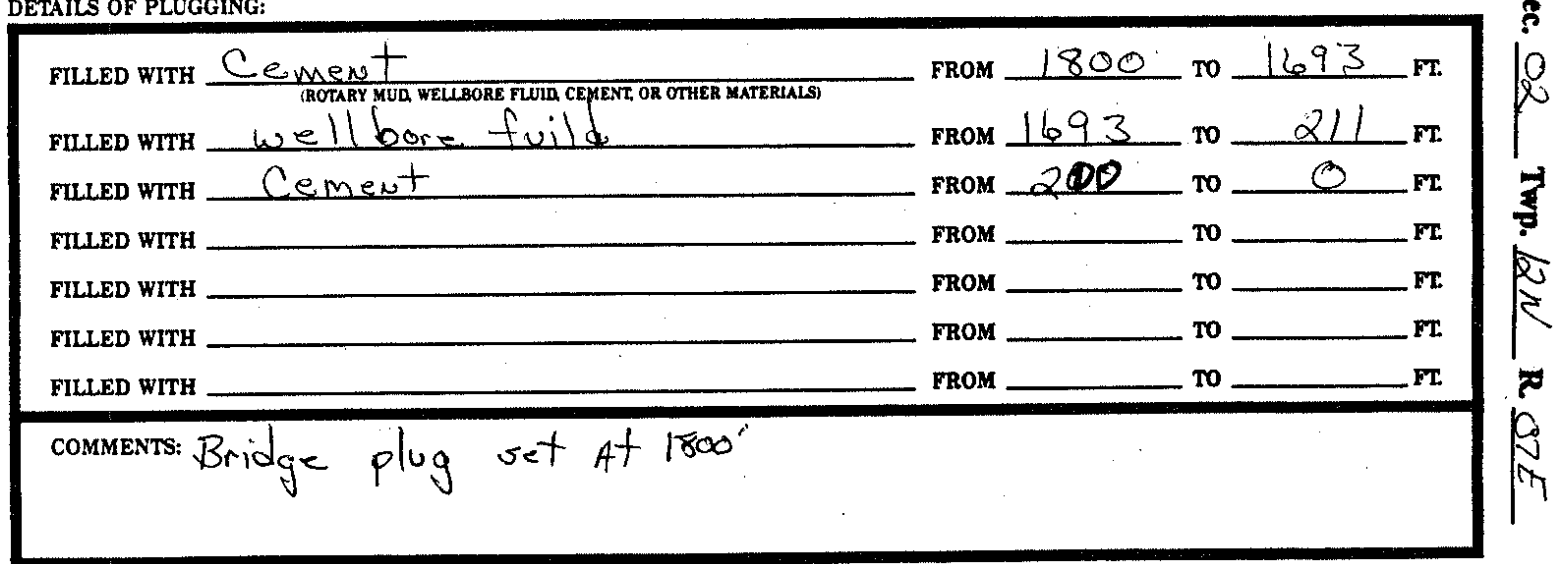

WELL DATA:

\begin{tabular}{|l|c|c|c|c|c|c|}
\hline \multicolumn{1}{|c|}{ CASING } & SIZE & $\begin{array}{c}\text { SETTING } \\
\text { DEPTH }\end{array}$ & $\begin{array}{c}\text { SACKS } \\
\text { CEMENT }\end{array}$ & $\begin{array}{c}\text { HOLE } \\
\text { SILE }\end{array}$ & $\begin{array}{c}\text { EST TOP OF } \\
\text { CEMENT }\end{array}$ & $\begin{array}{c}\text { AMOUNT OF } \\
\text { CASING REMOVED }\end{array}$ \\
\hline SURFACE & $8 \% / 8$ & 97 & & & & 4 \\
\hline $\begin{array}{l}\text { INTERMEDLATE MMINE } \\
\text { STRING / OR LINER }\end{array}$ & & & & & & \\
\hline PRODUCTION & $41 / 2$ & 1934 & 150 & $72 / 8$ & & 4 \\
\hline
\end{tabular}

UNDER PENALTIES OF PERJURY, I DECLARE THAT I HAVE EXAMINED THIS FORM INCLUDING ACCOM̃PANYING STATEMENTS AND DOCU. MENTS, AND TO THE BESTOF MY KNGWLEDGE, IT IS, TRUE, CORRECT, AND COMPLETE. MENTS, AND TO THE BESPOF MY KNGWLEDGE, IT ISTAUE, COR DATE PLUGGINGBEGAN $\frac{8-6-2001}{\text { DATE PLUGGING GOMPLETED } 8-7-2001}$

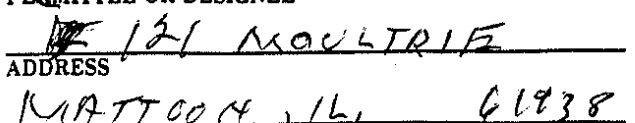




\section{BANGERT CASING PULLING CORP FOR CHARLES ARMANTROUT Ind}

KEVIN SPENCER

being first duly sworn do depose and say the following is a true and correct statement of the details of the plugging of a certain well drilled for OIL

known as the OLIVER E-3

(Indicate whether for oil, gas, water or other purposes)

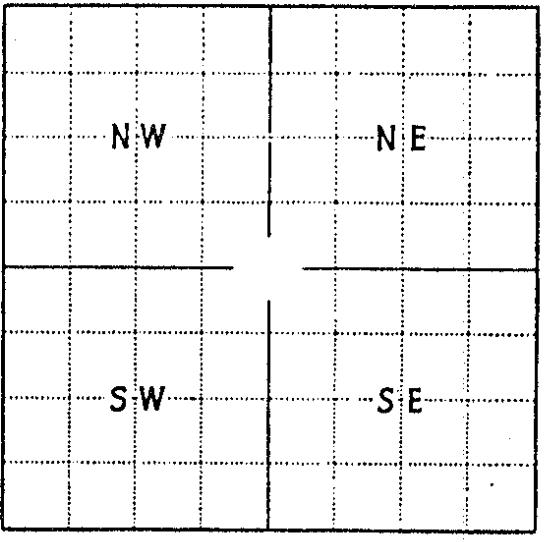

Locate well accurately on plat of section (Scale one inch-2,000 $\mathrm{ft}$ ) and located as follows:

of the $S W$ corner of the SE_Quarter of the $S N$ SEQuarter of the Quarter of Section 2 2 , Township_ 12 (North or Xouth) Range 7 , (East of the Principal Meridian,___ COLES County, Illinois Elevation above sea level is $\left\{\begin{array}{l}\text { Derrick Floor } \frac{690}{6 t} \text { ft. } \\ \text { Ground } \frac{688 \mathrm{ft} .}{}\end{array}\right.$ Total depth1956 Formation ROS ICLARE Date permit to drill issued10/27/8Rermit No21484 Permit issued to CHARLES ARMANTROUT Date drilling began $10 / 27 / 82$ Date drilling completed $10 / 29 / 82$ Kind of drilling tools used ROTARY Date plugging began $6 / 22 / 89$ Date plugging completed $6 / 23 / 89$

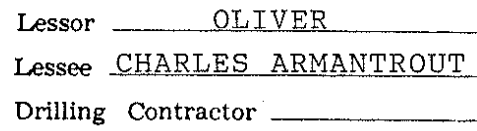

Details of PLUgGing:

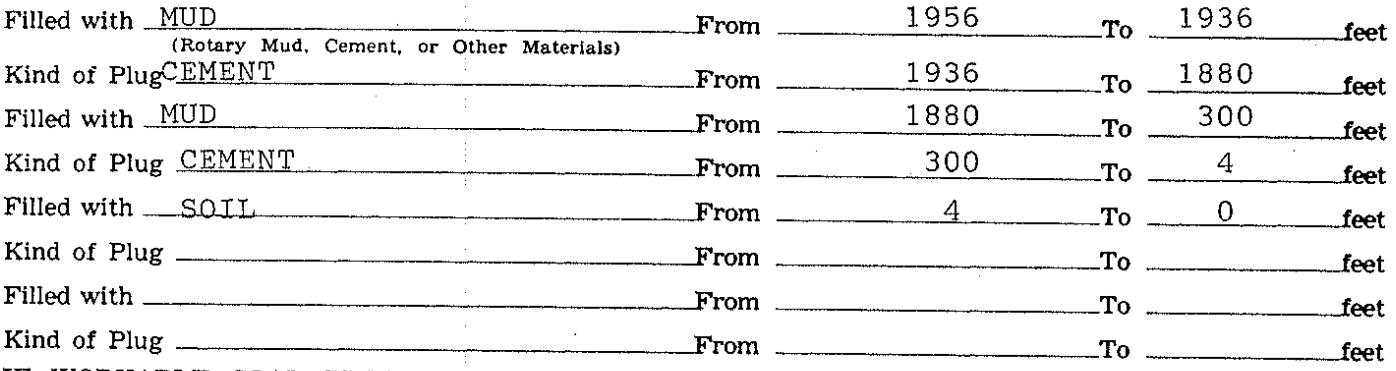
IF WORKABLE COAL BEDS WERE ENCOUNTERED IN THIS HOLE, DESCRIBE THE METHOD EMPLOYED TO PROTECT SAME. (A workable coal bed is thirty inches or more in thickness above 1,000 feet in depth) NONE

(1) Have pits and other excavations been flled? $\ldots \ldots \ldots \ldots \ldots \ldots \ldots \ldots$, ,

(2) Have the following been removed?

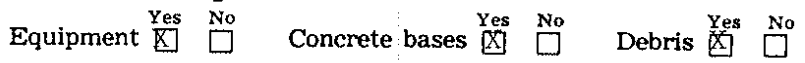

(3) Has surface casing been cut off three feet below ground surface?

(4) Has well-site been leveled?

(4) Has well-site been leveled? $\ldots \ldots \ldots \ldots \ldots \ldots \ldots \ldots \ldots \ldots \ldots \ldots$
If this was a producing well, give date and amount of last production

CASING RECORD >

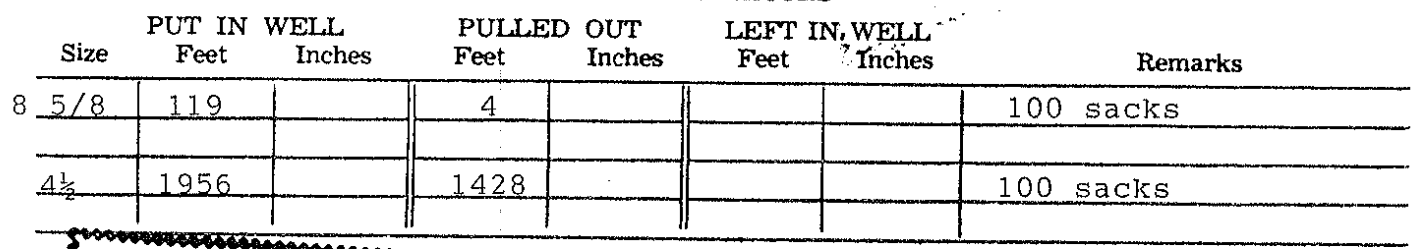

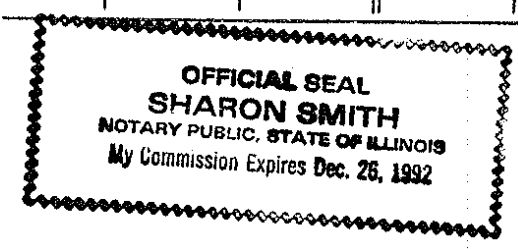

(SIgnature ff person, ftrm or corporation having custody or control of well.)

Per Lemello Dange

Address CTAY GFTY IL

Celmi Laenden WELI INSP. I

(Signature afd title of party supdrvlsing plugging of well.)

Address_BOX 449, MAERTINSVILLE IL. 62442

Subscribed and sworn to before me this

3 day of 


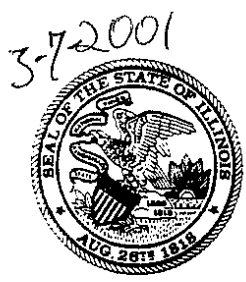

\section{ILLINOIS DEPARTMENT OF NATURAL RESOURCES Office of Mines and Minerals \\ Division of Oil and Ghath 524 South Second Street (217) $782-7756$ COUNTY NO. 0.45

\section{OG-6 WELL PLUGGING REPORT}

TYPE OF WELL: $\rrbracket$ PRODUCTION $\square$ CLASS II $\square$ OBSERVATION $\square$ GAS STORAGE $\square$ REPLUG $\square$ OTHER permitree: Merte Recues $O_{i}$ i Gas Producers PERMITTEE No. 555 well Name: Oliver 4 PERMIT No. 002143 REFERENCE NQ 503572

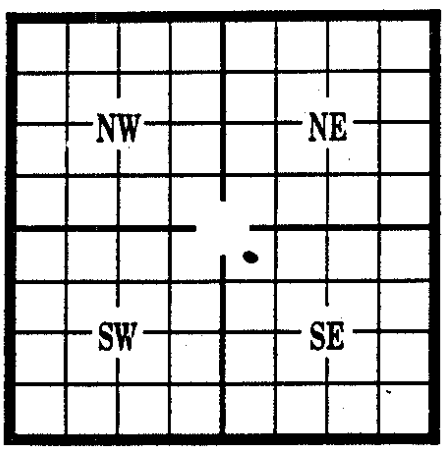

county Coles TOWNSHIP $12 \mathrm{~N}$ LOCATION: 2310 FT. EAST; OR 2,310 FT. NORTH; OR SECTION 02 RANGe $07 E$

$$
\text { contest }
$$
CORNER OF THE ___ QUARTER OF THE __ QUARTER.

WELL DATA:

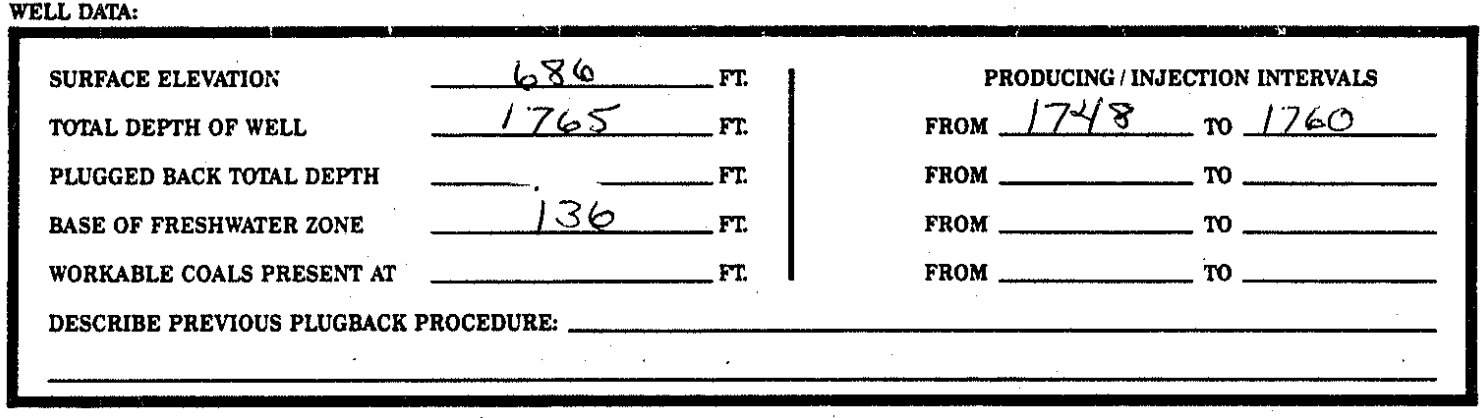

DETAILS OF PLUGGING:

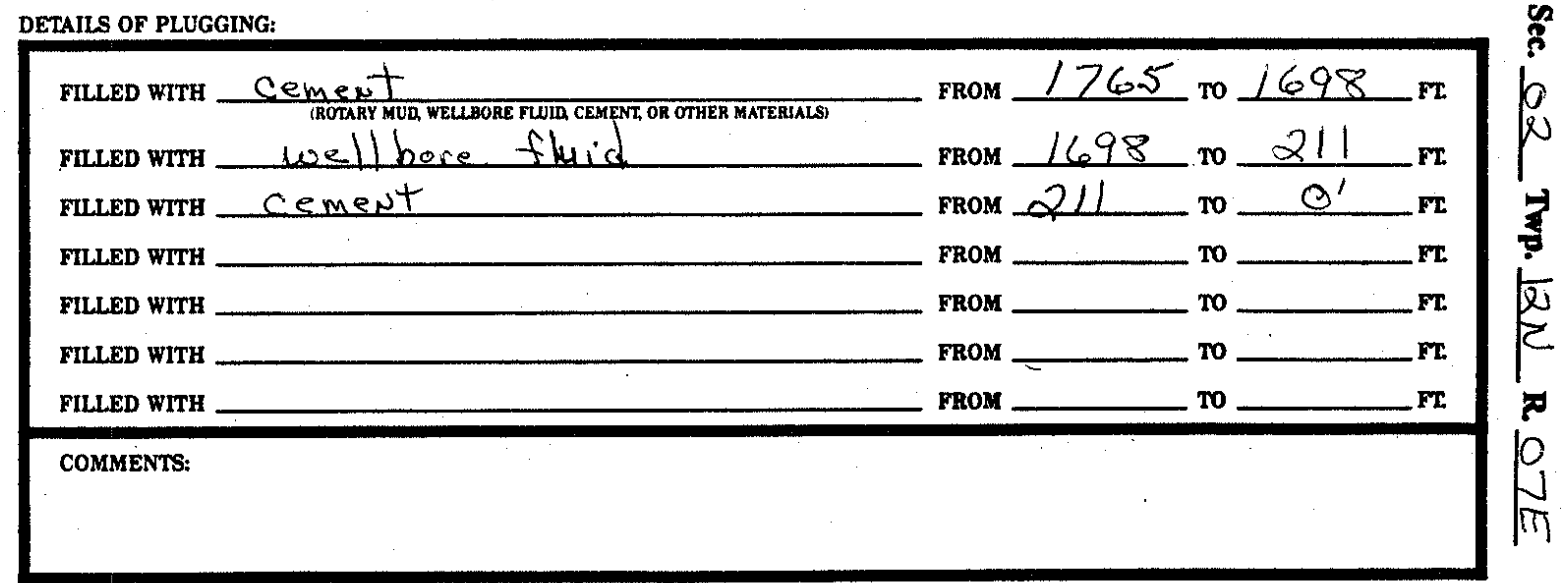

WELL DATA:

\begin{tabular}{|l|c|c|c|c|c|c|}
\hline \multicolumn{1}{|c|}{ CASING } & SIZE & $\begin{array}{c}\text { SETTING } \\
\text { DEPTH }\end{array}$ & $\begin{array}{c}\text { SACKS } \\
\text { CEMENT }\end{array}$ & $\begin{array}{c}\text { HOLE } \\
\text { SIZE }\end{array}$ & $\begin{array}{c}\text { EST. TOP OF } \\
\text { CEMENT }\end{array}$ & $\begin{array}{c}\text { AMOOUNT OF } \\
\text { CASING REMOVED }\end{array}$ \\
\hline SURFACE & $95 / 8$ & $1 / 2$ & 25 & 12 & & $4 /$ \\
\hline $\begin{array}{l}\text { INTERMEDIATE IMINE } \\
\text { STRING /OR LINER }\end{array}$ & & & & & & \\
\hline PRODUCTION & $5 / 2$ & 1764 & 150 & $77 / 8$ & & $/ 0^{\prime} / 6^{\prime}$ \\
\hline
\end{tabular}

UNDER PENALTIES OF PERJURY, I DECLARE THAT I HAVE EXAMINED THIS FORM INCLUDING ACCOMPANYING STATEMENTS AND DOCU. MENTS, AND TO THE BEST OF MY KNOWLEDGE, IT IS TRUE, CORRECT, AND COMPLETE.

SIGNATURE OF: $\frac{1}{\text { PERMITTEE OR DESIGNEE }}$ ADDRESS

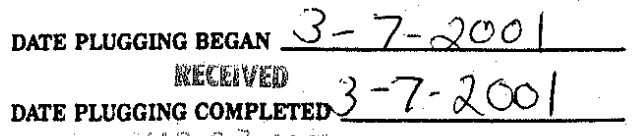




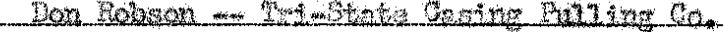

being first duly sworn, do depose and say the following is a true and correct statement of the details of the plugging of a certain well drilled for

(Indicate whether for oll, gas, water or other purposes)

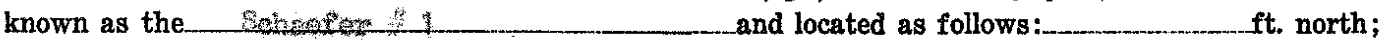

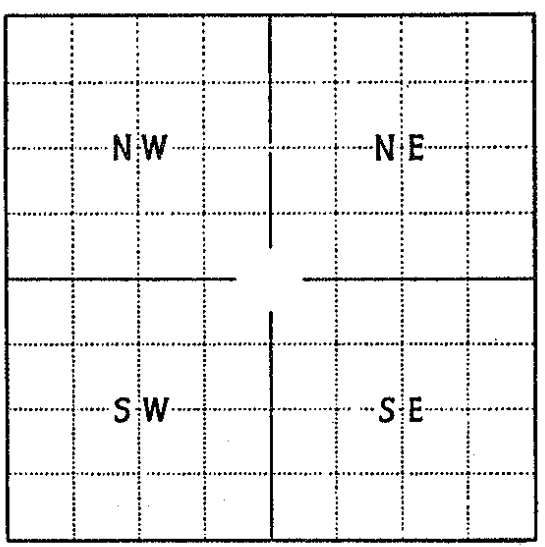

Locate well accurately on plat of section (Scale one inch-2,000 ft.)

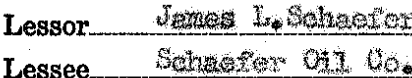
Drilling Contractor 1 the ft. south; ft. east; 170 ft. west of the WH corner of the__uarter of the ___ Quarter of the___ Quarter of Section 2 , Township_ If___(North or Sout

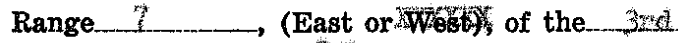
Principal Meridian, County, Illinois. Elevation above sea level is $\left\{\begin{array}{l}\text { Derrick Floor } \\ \text { Ground } 63\end{array}\right.$ Total depth 1995 Formation MieCLosing Date permit to drill issued $2 / 12 / 66$ ermit No. 1930

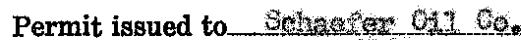
Date drilling began $2 / 6 / 67$

Date drilling completed $\quad 2 / 9467$

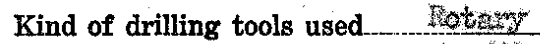
Date plugging began $\quad 2 / 22 / 60$ Date plugging completed: $2 / 2 \sqrt{ } / 6$

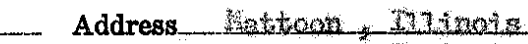
Address Wattoon, Thunds

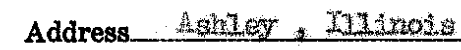

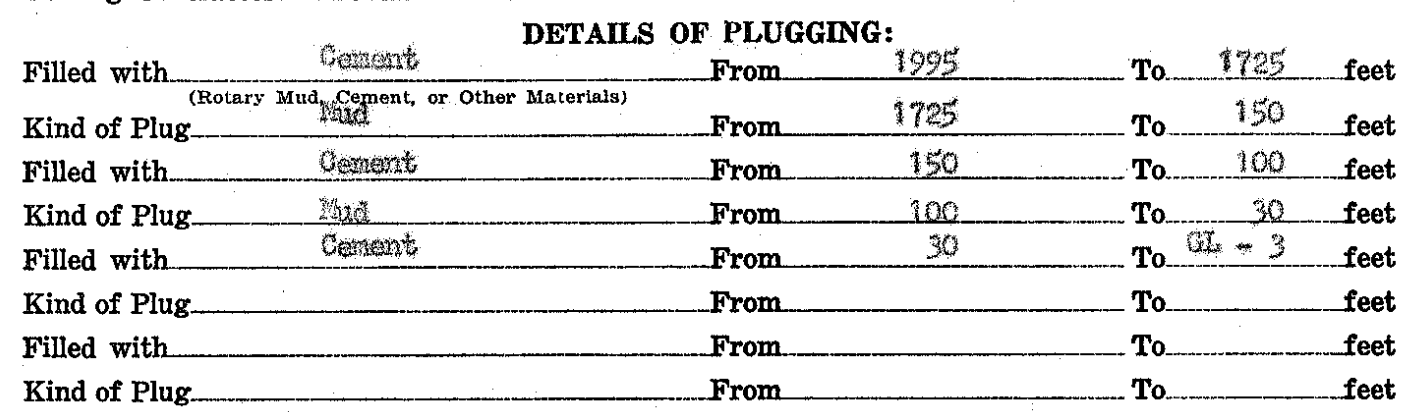

IF WORKABLE COAL BEDS WERE ENCOUNTERED IN THIS HOLE, DESCRIBE THE METHOD EMPLOYED TO PROTECT SAME. (A workable coal bed is thirty inches or more in thickness above

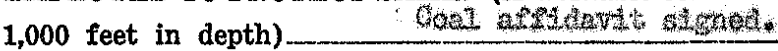

(1) Have pits and other excavations been filled? $\ldots \ldots \ldots \ldots \ldots \ldots \ldots$ Yos

(2) Have the following been removed?

Equipment $\square^{\text {No }}$ Concrete bases $\square^{\text {No }}$ Debris 覴 $\square^{\text {No }}$

(3) Has surface casing been cut off three feet below ground surface?

(4) Has well-site been levelled? . . . . . . . . . . . . . . . .

If this was a producing well, give date and amount of last production $2 / 1 / 63$ a

CASING RECORD

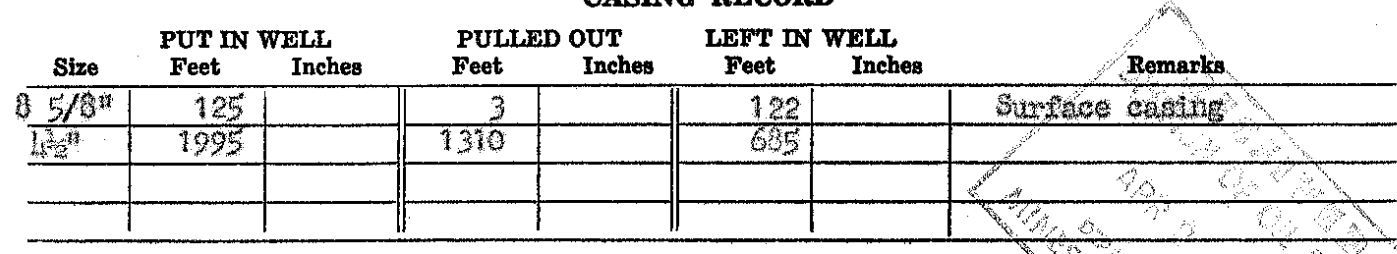

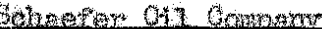

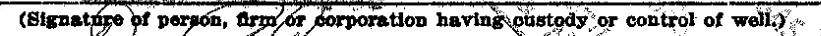
Per $f_{2}$

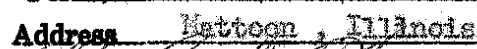

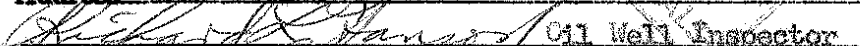

(Elgnafure and titio of parts expeyvising plustine of won.)

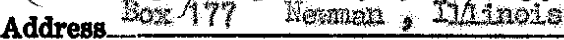

Subscribed and sworn to before me this $23 x \mathrm{c}$ day of Wangh My commission expires. $5 / 10 / 71$ 


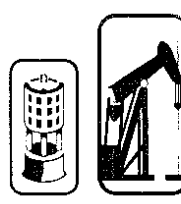

ILLINOIS DEPARTMENT OF MINES AND MINERALS
$\begin{aligned} & \text { OIL AND GAS DIVISION } \\ & \text { (217) 782-7756 }\end{aligned} \quad$ W. JEFERSON-SUITE 300
P.O. BOX 10140

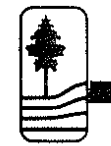

POO. BOX 10140
SPRINGFIELD, IL 62791-0140

\section{OG-6 WELL PLUGGING REPORT}

TYPE OF WELL: $\square$ PRODUCTION $\backslash$ CLASS II $\square$ OBSERVATION $\square$ GAS STORAGE $\square$ REPLUG $\square$ OTHER PERMitTEE: LLA A well name: Opal Aethur $\# 3-1$ PERMITTEE No. 96

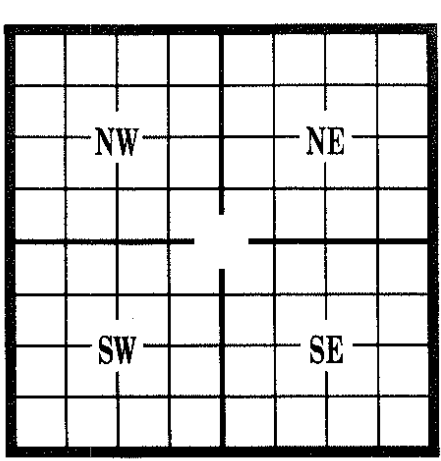
PERMIT NO. $\frac{00,2586}{\text { (ISSUE DATE IF NO NUMBER }}$ REFERENCE No. 1326

WELL DATA:

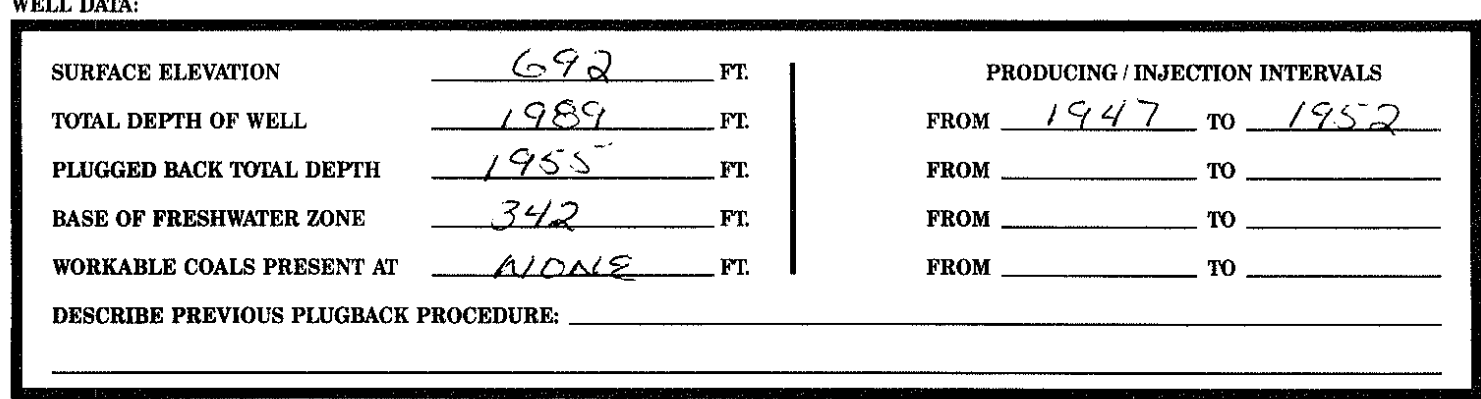

DETAILS OF PLUGGING:

\begin{tabular}{|c|c|}
\hline 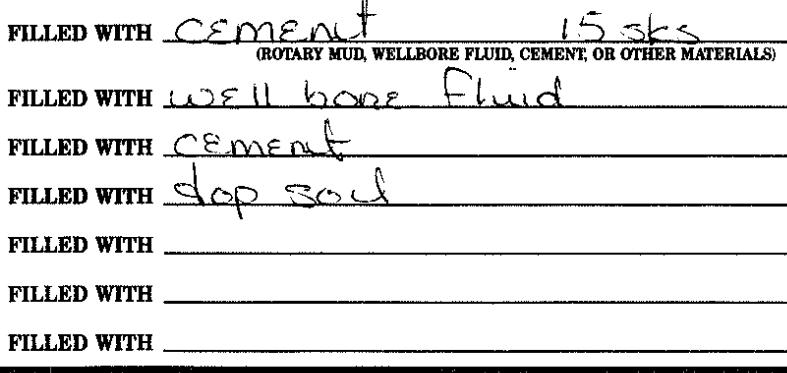 & 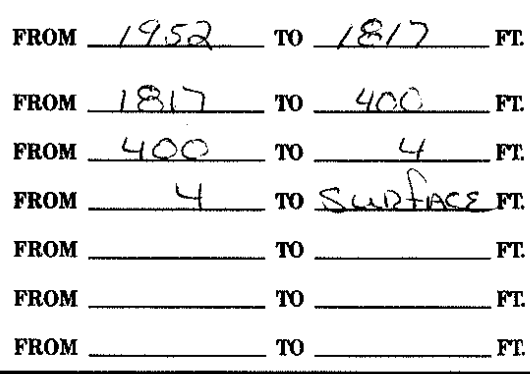 \\
\hline COMMENTS: & \\
\hline
\end{tabular}

WELL DATA:

\begin{tabular}{|l|c|c|c|c|c|c|}
\hline \multicolumn{1}{|c|}{ CASING } & SIZE & $\begin{array}{c}\text { SETTING } \\
\text { DEPTH }\end{array}$ & $\begin{array}{c}\text { SACKS } \\
\text { CEMENT }\end{array}$ & $\begin{array}{c}\text { HOLE } \\
\text { SIZE }\end{array}$ & $\begin{array}{c}\text { EST TOP OF } \\
\text { CEMENT }\end{array}$ & $\begin{array}{c}\text { AMOUNT OF } \\
\text { CASING REMOVED }\end{array}$ \\
\hline SURFACE & $8^{5 / 8}$ & $1 / 4$ & 100 & $12 / 2$ & $6 h$ & $4^{\prime}$ \\
\hline $\begin{array}{l}\text { INTERMEDIATE MINE } \\
\text { STRING/OR LINER }\end{array}$ & & & & & & \\
\hline PRODUCTION & $5 / 2$ & 1987 & 100 & $73 / 8$ & 1227 & $700^{\prime}$ \\
\hline
\end{tabular}

UNDER PENALTIES OF PERJURY, I DECLARE THAT I HAVE EXAMINED THIS FORM INCLUDING ACCOMPANYING STATEMENIS AND DOCUMENTS, AND TO THE BEST OF MY KNOWLEDGE, IT IS TRUE, CORRECT, AND COMPLETE.

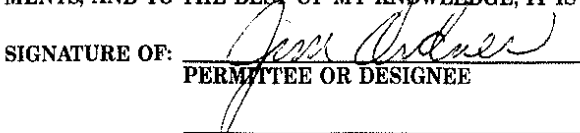 ADDRESS

counry Coles SECTION

LOCATION: FT. NORTH; OR 1346,5 FT. SOUTH; AND

2310 FT. EAST; OR QUARTER OF THE QUARTER OF THE M. Hom QUARTER.

QUARTER OF THE


do depose and say the following is a true and correct statement of the details of the plugging of a certain well drilled for Qit and $\mathrm{ara}^{\mathrm{Q}} \mathrm{Gas}$ Lit

known as the Ojigre (Indicate whether for oll, gas, water or other purponow)

\section{:}

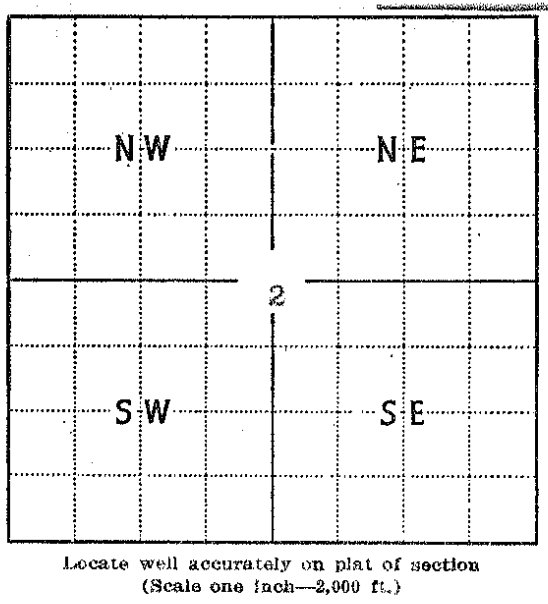

and located as follows:

990 ft. north;

ft. south; -30 ft. east; ft. west of the sil corner of the Quarter of the_Q_Quarter of the___ Quarter of Section 2 , Township_ 12, (North or/South) Range 7 , (East or West), of the Principal Meridian, Wlevation above sea level is $\left\{\begin{array}{lr}\text { Derrick Floor } & \text { ft. } \\ \text { Ground } & \text { tt. }\end{array}\right.$ Total depth $193 \%$ Formation Date permit to drill issued $7-7-59$ Permit No. 1230 응 Permit issued to ____ Haxry of. Mdarss: Date drilling began In_y $7,1,59$ Date drilling completed Juy 11,125 Kind of drilling tools used Sotisysy Date plugging began_. July 11,1959 Date plugging completed July 12,1959

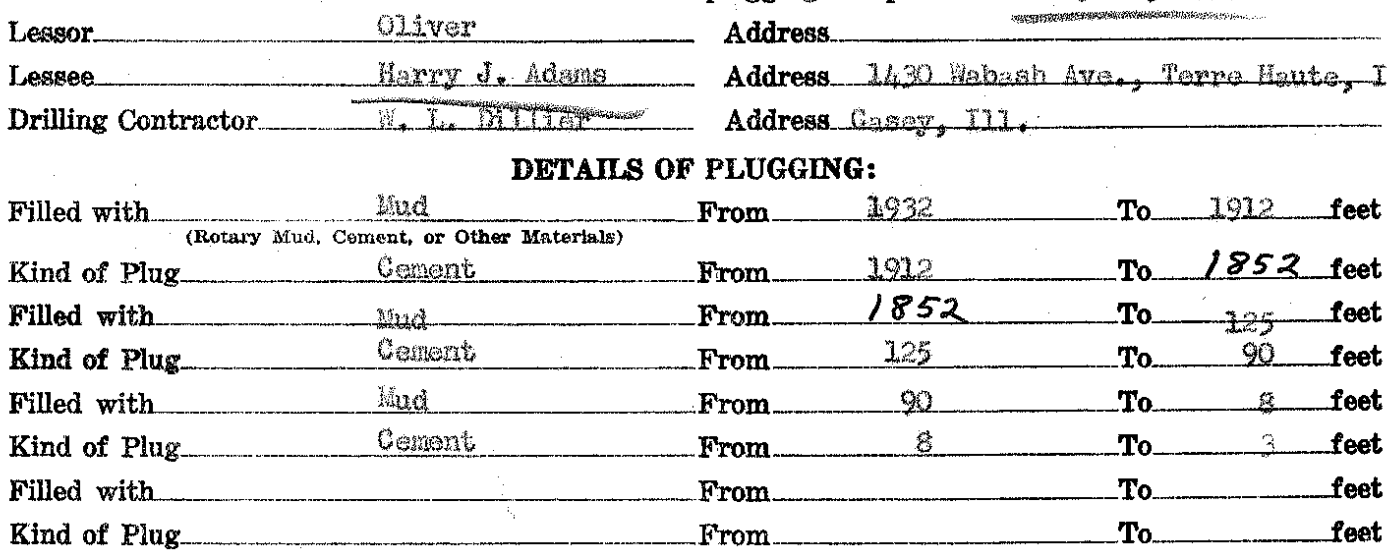

IF WORKABLE COAL BEDS WERE ENCOUNTERED IN THIS HOLE, DESCRIBE THE METHOD EMPLOYED TO PRO'TECT SAME. (A workable coal bed is thirty inches or more in thickness above 1,000 feet in depth) Jonats

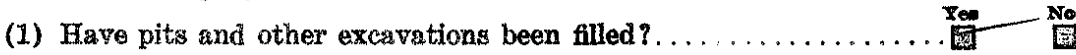

(2) Have the following been removed?

Equipment $\left[\begin{array}{lll}\text { Yes } \\ \square]\end{array}\right.$

(3) Has surface casing been cut off three feet below ground surface?

(4) Has well-site been levelled?

If this was a producing well, give date and amount of last production

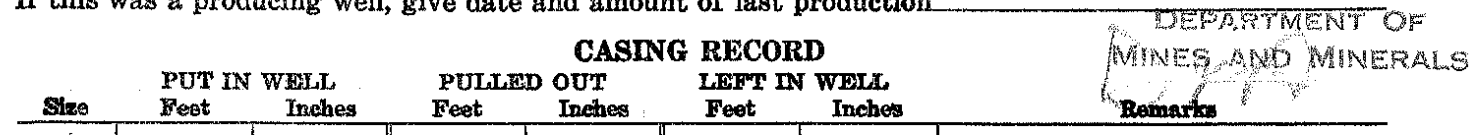

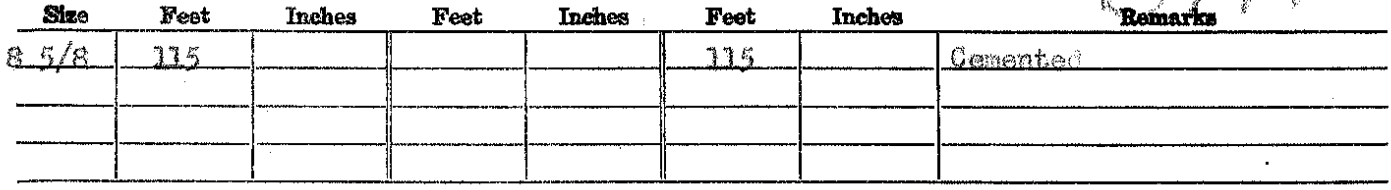

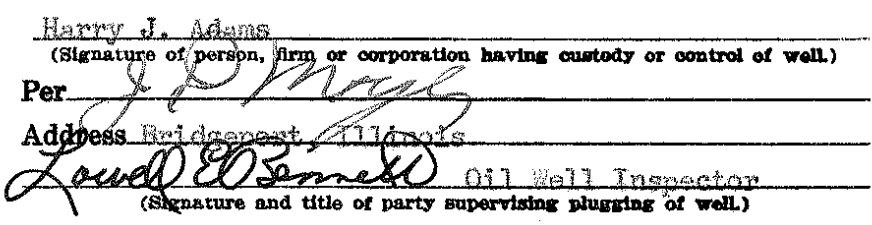

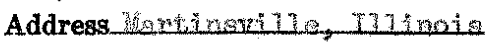

Subscribed and sworn to before me this

My commission expires $1 / 9 / 62$

7ib day of 6 , dinge.

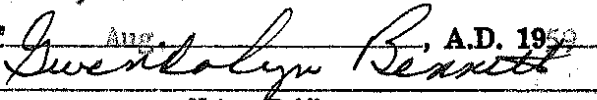




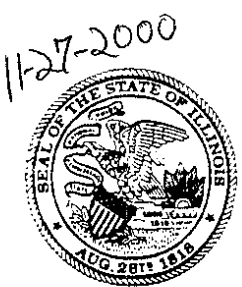

\section{ILLINOIS DEPARTMENT OF NATURAL RESOURCES \\ Office of Mines and Minerals \\ Division of Oil and (217) $782-7756$

\section{OG-6 WELL PLUGGING REPORT}

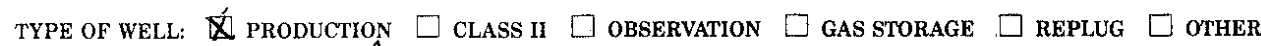
permittee: Charles Arwentrout well Name: $O$ liver $\#$ b-C PERMiT No. CO4282 PERMitTeE No. $1 / 0$

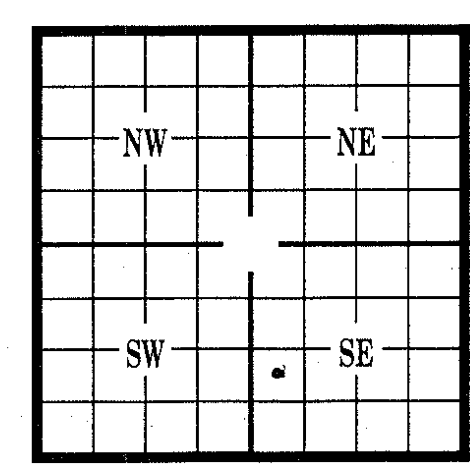
(ISSUE DATE IF NO NUMBER) REFERENCE No. 128462

county Coles TOWNSHIP $12 N$ LOCATION: 0990 0330 FT. CORNER OF THE QUARTER OF THE QUARTER.

SECTION $\bigcirc 2$ RANGE $07 E$ FT. NORTH; OR FT. SOUTH; AND FT. WEST OF THE $S W$ QUARTER OF THE QUARTER OF THE $5 E$ WELL DATA:

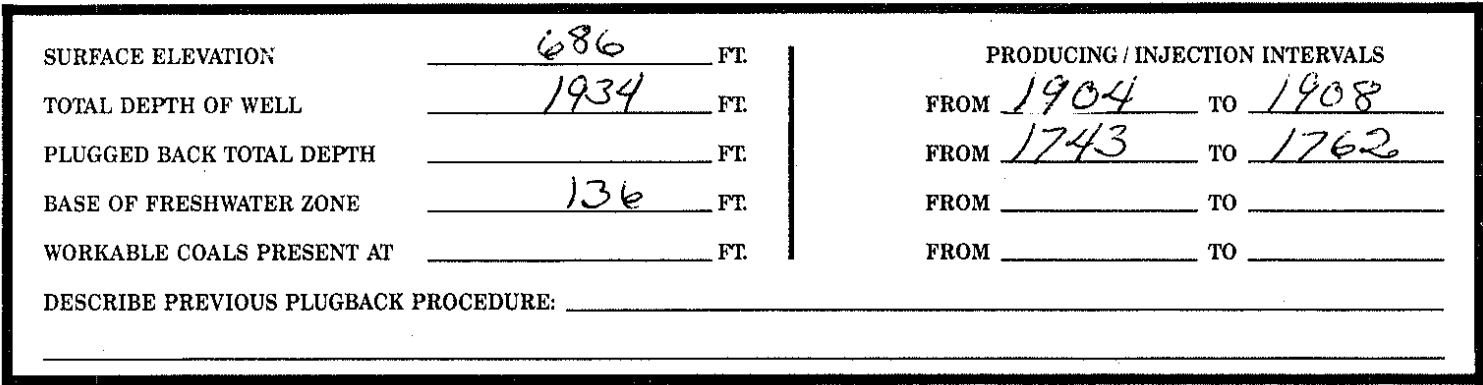

DETAILS OF PLUGGING:

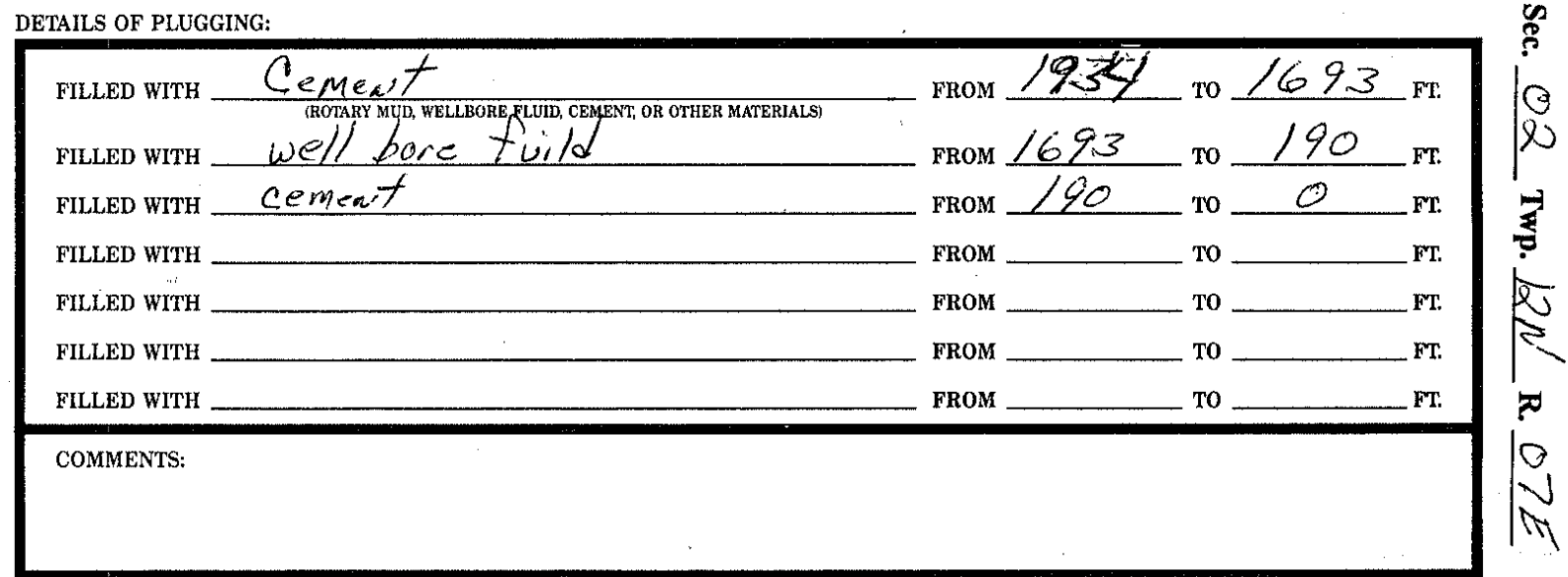

WELL DATA:

\begin{tabular}{|c|c|c|c|c|c|c|}
\hline CASING & SIZE & $\begin{array}{l}\text { SETTING } \\
\text { DEPTH }\end{array}$ & $\begin{array}{l}\text { SACKS } \\
\text { CEMENT }\end{array}$ & $\begin{array}{l}\text { HOLE } \\
\text { SIZE }\end{array}$ & $\begin{array}{l}\text { EST: TOP OF } \\
\text { CEMENT }\end{array}$ & $\begin{array}{c}\text { AMOUNT OF } \\
\text { CASING REMOVED }\end{array}$ \\
\hline SURFACE & $8 \% 5$ & $n_{0}^{\prime}+K_{N}$ & & & & \\
\hline \multicolumn{7}{|l|}{$\begin{array}{l}\text { INTERMEDIATE /MINE } \\
\text { STRING / OR LINER }\end{array}$} \\
\hline PRODUCTION & $41 / 2$ & & 200 & 778 & $\begin{array}{l}5^{\prime \prime} \text { bollow } \\
40 \text { ind }\end{array}$ & $10,30^{\circ}$ \\
\hline
\end{tabular}

UNDER PENALTIES OF PERJURY, I DECLARE THAT I HAVE EXAMINED THIS FORM INCLUDING ACCOMPANYING STATEMENTS AND DOCUMENTS, AND TO THE BEST OF MY KNOWLEDGE, IT IS TRUE, CORRECT, AND COMPLETE.

SIGNATURE OF: $\frac{M}{\text { PERMITTE OR DESIGNEE }}$ ADDRESS CITX, STATE
DATE PLUGG

DATE PLUGGING BEGAN $/ 1-22-2000$

DATE PLUGGING COMPLETED $11-27-x<$

DEC 082000

\section{2}




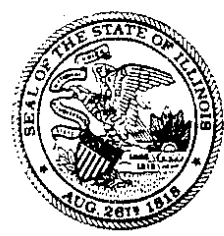

\section{ILLINOIS DEPARTMENT OF NATURAL RESOURCES Office of Mines and Minerals \\ Division of Oil and Gas 524 South Second Street (217) 782-7756 COMNTy $54 / 3$ ppringfield, Illinois 62701-1787}

\section{OG-6 WELL PLUGGING REPORT}

TYPE OF WELL: X PRODUCTION $\square$ CLASS II $\square$ obSERVATION $\square$ GAS STORAGE $\square$ REPLUG $\square$ OTHER $\square \mathbf{7 6 5 0 6}$ permittee: Walter Duncan Ine weLl NAME: Cliver \#10 PERMIT NO PERMITTEE NO. 86.8

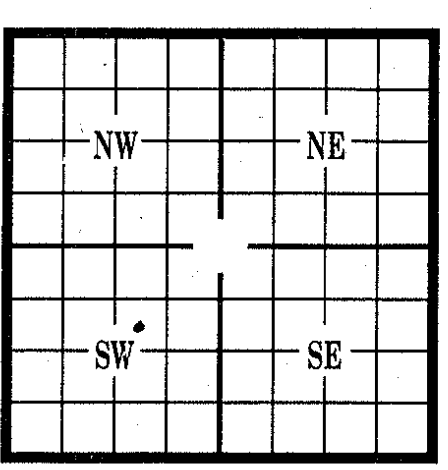
90 REFERENCE NO. 129366

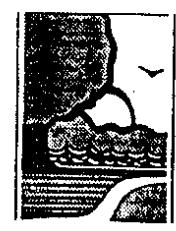

WELL DATA:

\begin{tabular}{llr} 
SURFACE ELEVATION & 691 \\
TOTAL DEPTH OF WELL & 1931 \\
PLUGGED BACK TOTAL DEPTH & FT. \\
\cline { 2 - 2 } BASE OF FRESHWATER ZONE & 341 \\
WORKABLE COALS PRESENT AT & FT. \\
FAT.
\end{tabular}

Countr Coles

SECTION

TOWNSHIP

$12 N$

RANGE

2

LOCATION: 1650 FT. NORTH; OR

FT SOUTH: AND

1650 FT. EAST; OR

FT. WEST OF THE SL

CORNER OF THE _ _ QUARTER OF THE _

QUARTER OF THE QUARTER OF THE

QUARTER.

$$
\text { Mattoon }
$$

DESCRIBE PREVIOUS PLUGBACK PROCEDURE:

DETAILS OF PLUGGING:

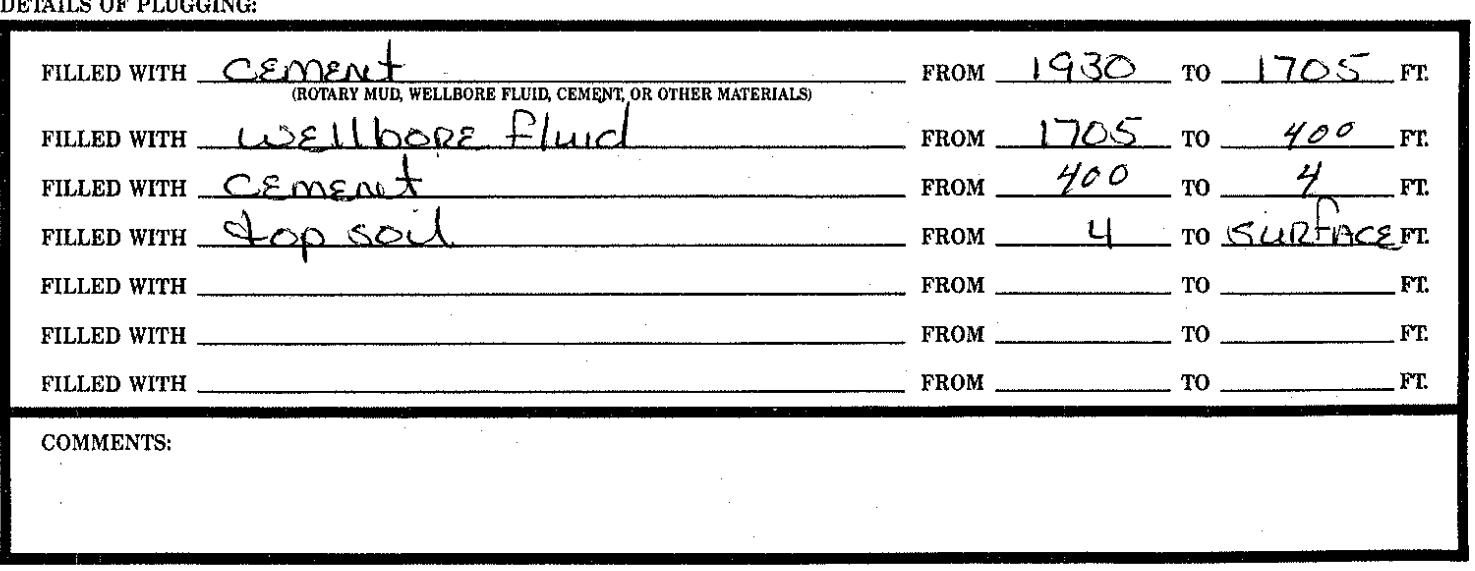

WELṫ DATA:

\begin{tabular}{|c|c|c|c|c|c|c|}
\hline CASING & SIZE & $\begin{array}{l}\text { SETPTING } \\
\text { DEPTH }\end{array}$ & $\begin{array}{c}\text { SACKS } \\
\text { CEMENT }\end{array}$ & $\begin{array}{l}\text { HOLE } \\
\text { SIZE } \\
\end{array}$ & $\begin{array}{l}\text { EST. TOP OF } \\
\text { CEMENT }\end{array}$ & $\begin{array}{c}\text { AMOUNT OF } \\
\text { CASING REMOVED } \\
\end{array}$ \\
\hline SURFACE & $103 / 4$ & 111 & 150 & $k \chi$ & $G h$ & $4^{\prime}$ \\
\hline \multicolumn{7}{|l|}{$\begin{array}{l}\text { INTERMEDIATE/MINE } \\
\text { STRING / OR LINER } \\
\end{array}$} \\
\hline PRODUCTION & $5 \%$ & 1900 & 175 & $77 / 8$ & 8,40 & 640 \\
\hline
\end{tabular}

UNDER PENALTIES OF PERJURY, I DECLARE THAT I HAVE EXAMINED THIS FORM INCLUDING ACCOMPANYING STATEMENTS AND DOCU. MENTS, AND TO THE BEST OF MY KNOWLEDGE, IT IS TRUE, CORRECT, AND COMPLETE.

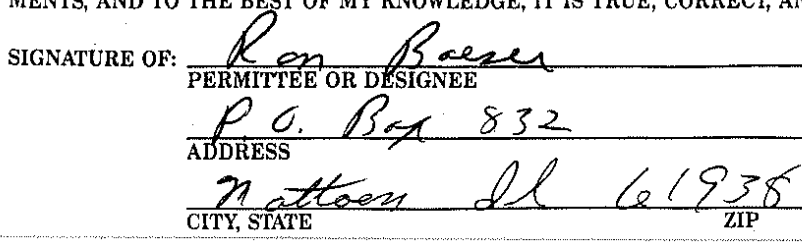

DATE PLUGGING BeGaN $611+4,97$

DATE PLUGGING COMPLETED 
$5-1$
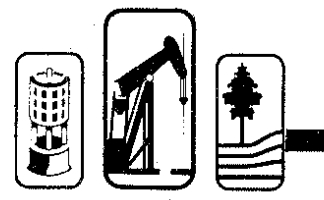

ILLINOIS DEPARTMENT OF MINES AND MINERALS

OIL AND GAS DIVISION

(217) 782-7756 COUNTY NO. 546

300 W. JEFFERSON - SUITE 300

P.O. BOX 10140

SPRINGFIELD, IL 62791-0140

\section{OG-6 WELL PLUGGING REPORT}

TYPE OF WELL: \ PRODUCTION $\square$ CLASS II $\square$ OBSERVATION $\square$ GAS STORAGE $\square$ REPLUG $\square$ OTHER 776909

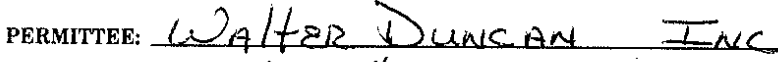
WELL NAME: $O /$ iver \#) PERMIT NO. $\frac{\mathrm{CrO}}{19} 192$

Permittee No. 868

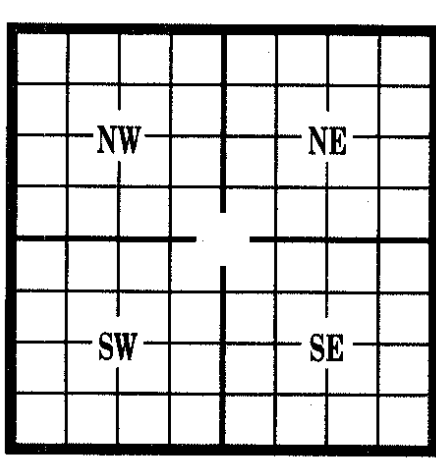
(ISSUE DATE IF NO NUMBEE REFERENCE No. 129367

COUNTY Coles $\quad$ SECTION $\frac{2}{72}$

LOCATION: 990 FT. NORTH; OR FT. SOUTH; AND 990 FT EAST; OR__ _ FT. WEST OF THE S $\mathrm{SCl}_{2}$ CORNER OF THE S S C 2 QUARTER OF THE - QUARTER OF THE ___ QUARTER OF THE QUARTER.

$$
\text { mattoon }
$$

WELL DATA:

SURFACE ELEVATION

TOTAL DEPTH OF WELL.

PLUGGED BACK TOTAL DEPTH

BASE OF FRESHWATER ZONE

WORKABLE COALS PRESENT AT

DESCRIBE PREVIOUS PLUGBACK PROCEDURE:

\begin{tabular}{c}
692 \\
1885 \\
$1785^{-}$ \\
\hline 242 \\
$-1 / A$
\end{tabular}
FT. FT FT.
PRODUCING / INJECTION INTERVALS FROM 1740 To 1746 FROM FROM To FROM TO

DETAILS OF PLUGGING:

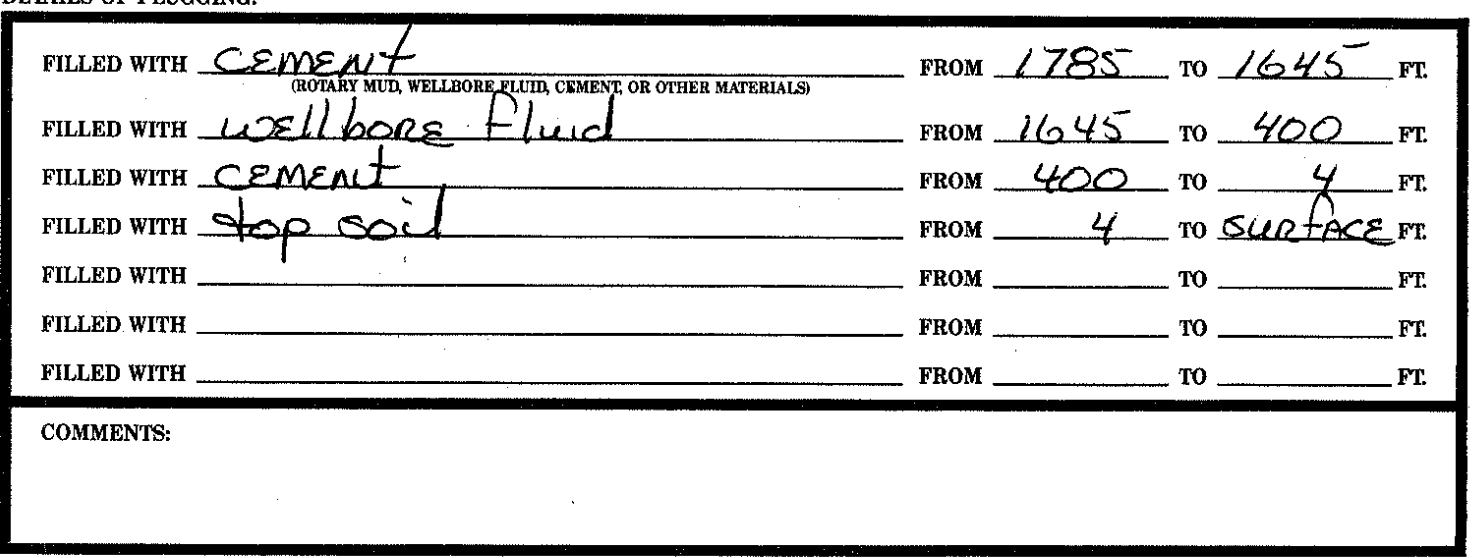

WELL DATA:

\begin{tabular}{|c|c|c|c|c|c|c|}
\hline CASING & SIZE & $\begin{array}{l}\text { SETTING } \\
\text { DEPTH }\end{array}$ & $\begin{array}{l}\text { SACKS } \\
\text { CEMENT }\end{array}$ & $\begin{array}{l}\text { YOLE } \\
\text { SIZE }\end{array}$ & $\begin{array}{l}\text { EST TOP OP } \\
\text { CEMENT }\end{array}$ & $\begin{array}{c}\text { AMOUNT OF } \\
\text { CASING REMOVED }\end{array}$ \\
\hline SURFACE & $10^{3 / 4}$ & 125 & 125 & $12^{\prime \prime}$ & GL & $4^{\circ}$ \\
\hline $\begin{array}{l}\text { INTERMEDIATE /MINE } \\
\text { STRING / OR LINER }\end{array}$ & & & & & & \\
\hline PRODUCTION & $7^{\prime \prime}$ & 1985 & 175 & $8^{1 / 2}$ & 800 & 550 \\
\hline
\end{tabular}

UNDER PENALTIES OF PERJURY, I DECLARE THAT I HAVE EXAMINED THIS FORM INCLUDING ACCOMPANYING STATEMENTS AND DOCUMENTS, AND TO THE BEST OF MY KNOWLEDGE, IT IS TRUE, CORRECT, AND COMPLETE.

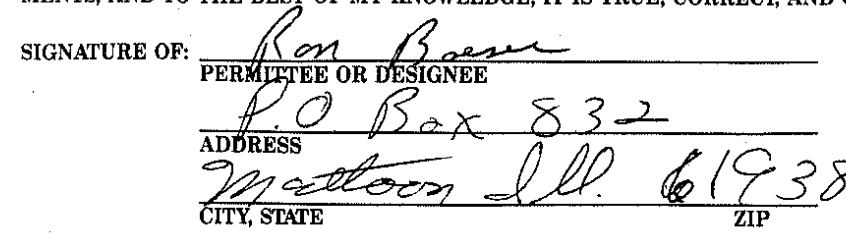

IL $472-0198(\operatorname{Rev} 8 / 93)$

\begin{abstract}
date PlugGing Began 30 Aprilq7 DATE PLUGGRECEPMPLETED $\perp$ MAY 97 MAY 271997
\end{abstract}

GEOLOGC RECORDS 


\section{ILLINOIS DEPARTMENT OF NATURAL RESOURCES Office of Mines and Minerals \\ Division of Oil and Gas COUNry $1675 \quad 524$ South Second Street (217) $782-7756$ COUNTY No. ............... Springfield, Illinois 62701-1787}

\section{OG-6 WELL PLUGGING REPORT}

type of weLL: Х production \Class in $\square$ observation $\square$ gas Storage $\square$ replug $\square$ orter PERMITTE: Whalter D.encen ZNC

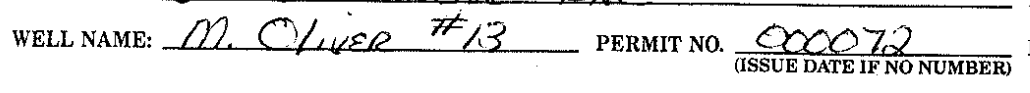

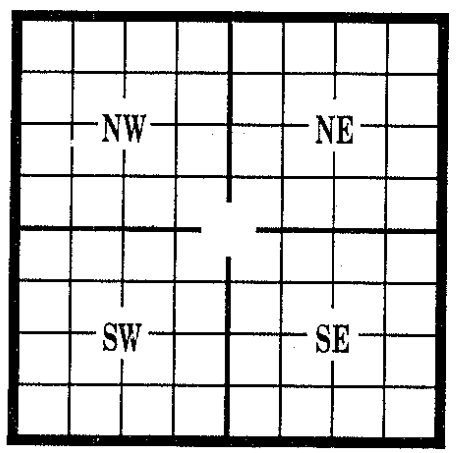
\begin{tabular}{l} 
COUNTY Coles \\
TOWNSHIP $\frac{12 N}{925}$ SECTION 2 \\
LOCATION: \\
\hline RANGE NORTH; OR \\
\hline
\end{tabular} FT, SOUTH; AND 1725 FT. EAST; OR_ _ FT. WEST OF THE $\delta \omega$ CORNER OF THE NCW QUARTER OF THE - QUARTER OF THE — _ Q QUARTER OF THE _ _ _ QUARTER. Mattion

WELL DATA:

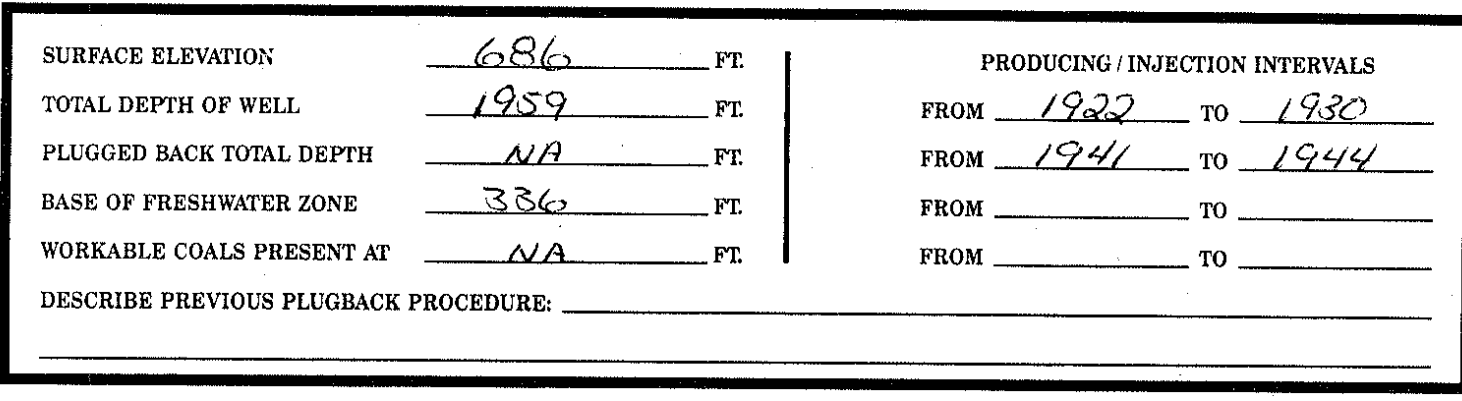

WELL DATA:

\begin{tabular}{|c|c|c|c|c|c|c|}
\hline CASING & SIZE & $\begin{array}{l}\text { SETTING } \\
\text { DEPTH }\end{array}$ & $\begin{array}{l}\text { SACKS } \\
\text { CEMENT }\end{array}$ & $\begin{array}{l}\text { HOLE } \\
\text { SIZE }\end{array}$ & $\begin{array}{l}\text { EST. TOP OF } \\
\text { CEMENT }\end{array}$ & $\begin{array}{c}\text { AMOUNT OF } \\
\text { CASING REMOVED }\end{array}$ \\
\hline SURFACE & $10^{3} / 4$ & 129 & 100 & $12^{\prime \prime}$ & $G h$ & $4^{\prime}$ \\
\hline \multicolumn{7}{|c|}{$\begin{array}{l}\text { INTERMEDIATE /MINE } \\
\text { STRING / OR LINER } \\
\end{array}$} \\
\hline PRODUCTION & $51 / 2$ & 1971 & 150 & $\varepsilon^{\prime \prime}$ & 845 & $62.5^{\prime}$ \\
\hline
\end{tabular}

UNDER PENALTIES OF PERJURY, I DECLARE THAT I HAVE EXAMINED THIS FORM INCLUDING ACCOMPANYING STATEMENTS AND DOCU. MENTS, AND TO THE BESS OF MY KNOWLEDGE, IT IS TRUE, CORRECT, AND COMPLETE. SIGNATURE OF: PERAITTEE OR DESIGNEE

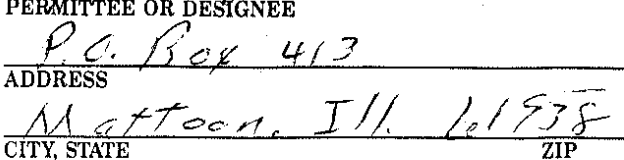

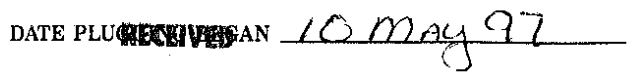
DATE HUAGGLGCQMgLETED $12 \mathrm{MAL} 97$

GEOLOGR RECOHES 


\section{OG-6 WELL PLUGGING REPORT}

TYPE OF WELL: PRODUCTIÓN $\square$ CLASS II $\square$ OBSĘRVATION $\square$ GAS STORAGE $\square$ REPLUG $\square$ g grHer Permitre: Lla well Name: Oliver \#/5 PERMIT No. $\mathrm{OOM} / 129$ PERMITTEE No. $\& 6 \Omega$

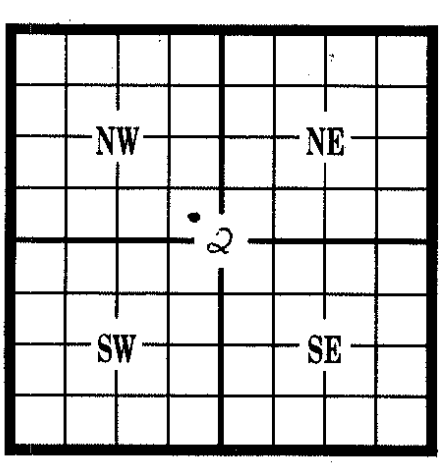
(ISSUE DATE IF NO NUMBER) REFERENCE No. 128368

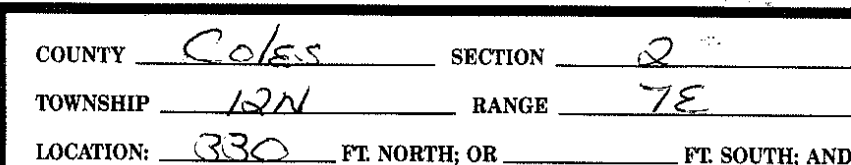
2310 FT. EAST; OR FT. WEST OF THE SU CORNER OF THE : NCs, ? QUARTER OF THE - QUARTER OF THE ___ _ Q Q QUARTER.

$$
\text { Mattoon }
$$

WELL DATA:

\begin{tabular}{|c|c|c|}
\hline SURFACE ELEVATION & 687 & PRODUCING / INJECTION INTERVALS \\
\hline TOTAL, DEPTH OF WELL & 1967 & FROM 1907 то 1916 \\
\hline PLUGGED BACK TOTAL DEPTH & NA & FROM 1924 то 1927 \\
\hline BASE OF FRESHWATER ZONE & 337 & FROM _ TO \\
\hline WORKABLE COALS PRESENT AT & FT. & FROM $\longrightarrow$ To \\
\hline
\end{tabular}

DETALLS OF PLUGGING:

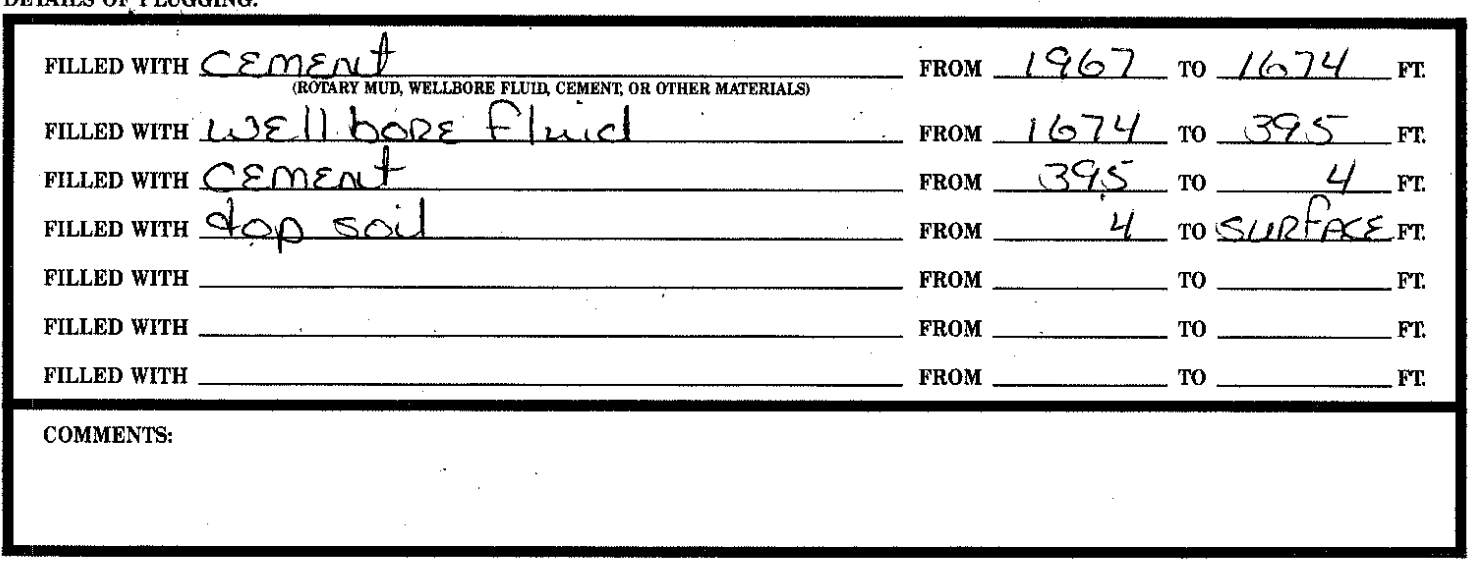

WELL DATA:

\begin{tabular}{|l|c|c|c|c|c|c|}
\hline \multicolumn{1}{|c|}{ CASING } & SIZE & $\begin{array}{c}\text { SETTING } \\
\text { DEPTH }\end{array}$ & $\begin{array}{c}\text { SACKS } \\
\text { CEMENT }\end{array}$ & $\begin{array}{c}\text { HOLE } \\
\text { SIZE }\end{array}$ & $\begin{array}{c}\text { EST TOP OF } \\
\text { CEMENT }\end{array}$ & $\begin{array}{c}\text { AMOUNT OF } \\
\text { CASING REMOVED }\end{array}$ \\
\hline SURFACE & $10^{3 / 4}$ & $1 / 2$ & 100 & $N R$ & $S L$ & $4^{\prime}$ \\
\hline $\begin{array}{l}\text { INTERMEDIATE } / M I N E \\
\text { STRING/OR LINER }\end{array}$ & & & & & & \\
\hline \begin{tabular}{l} 
PRODUCTION \\
\hline
\end{tabular} & $5 / 2$ & 1967 & 125 & $N / 2$ & 700 & 650 \\
\hline
\end{tabular}

UNDER PENALTIES OF PERJURY, I DECLARE THAT I HAVE EXAMINED THIS FORM INCLUDING ACCOMPANYING STATEMENTS AND DOCU. MENTS, AND TO THE BEST OF MY KNOWLEDGE, IT IS TRUE, CORRECT, AND COMPLETE.

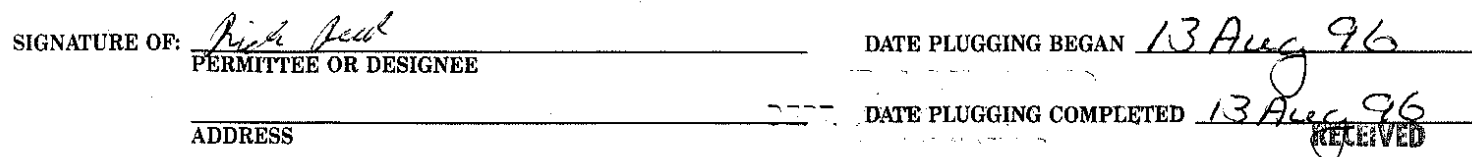

CITY, STATE




\section{OG-6 WELL PLUGGING REPORT}

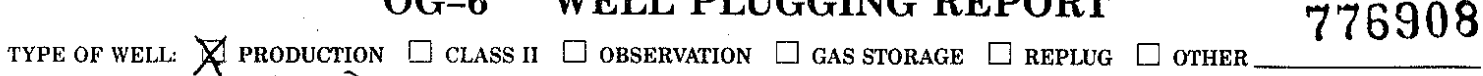
permitte: LJa/ter Duncani Inc

well name: Oliver $\#, 7$

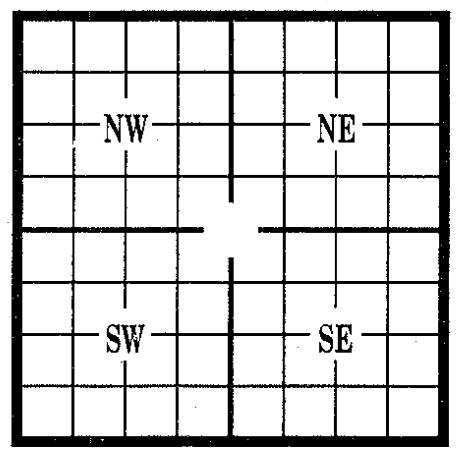

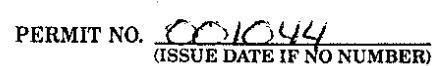

PERMITTEE No. 868

REFERENCE No. 129369

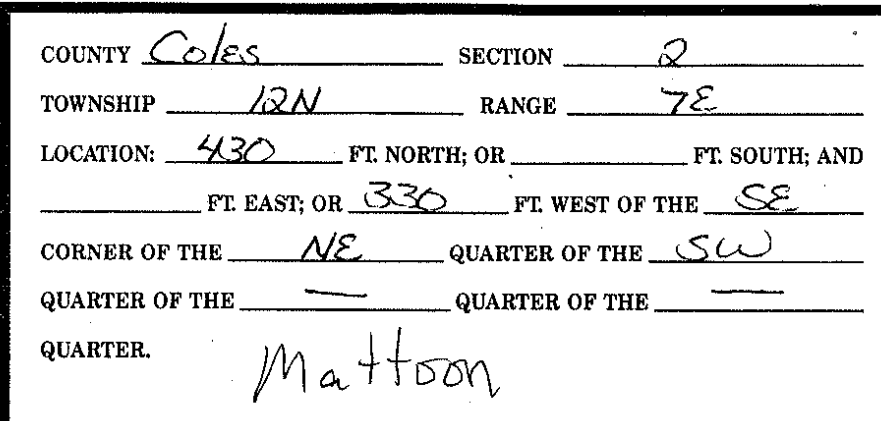

WELL DATA:

\section{SURFACE ELEVATION}

TOTAL DEPTH OF WELL

PLUGGED BACK TOTAL DEPTH

BASE OF FRESHWATER ZONE

WORKABLE COALS PRESENT AT

DESCRIBE PREVIOUS PLUGBACK PROCEDURE:

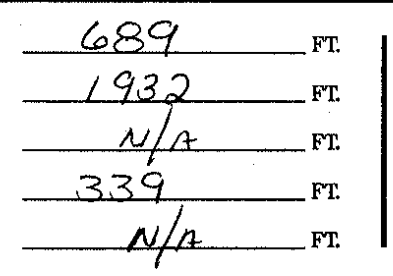

PRODUCING / INJECTION INTERVALS

FROM $1904 \quad 1920$
FROM To
FROM
FROM
To
To

DETAILS OF PLUGGING:

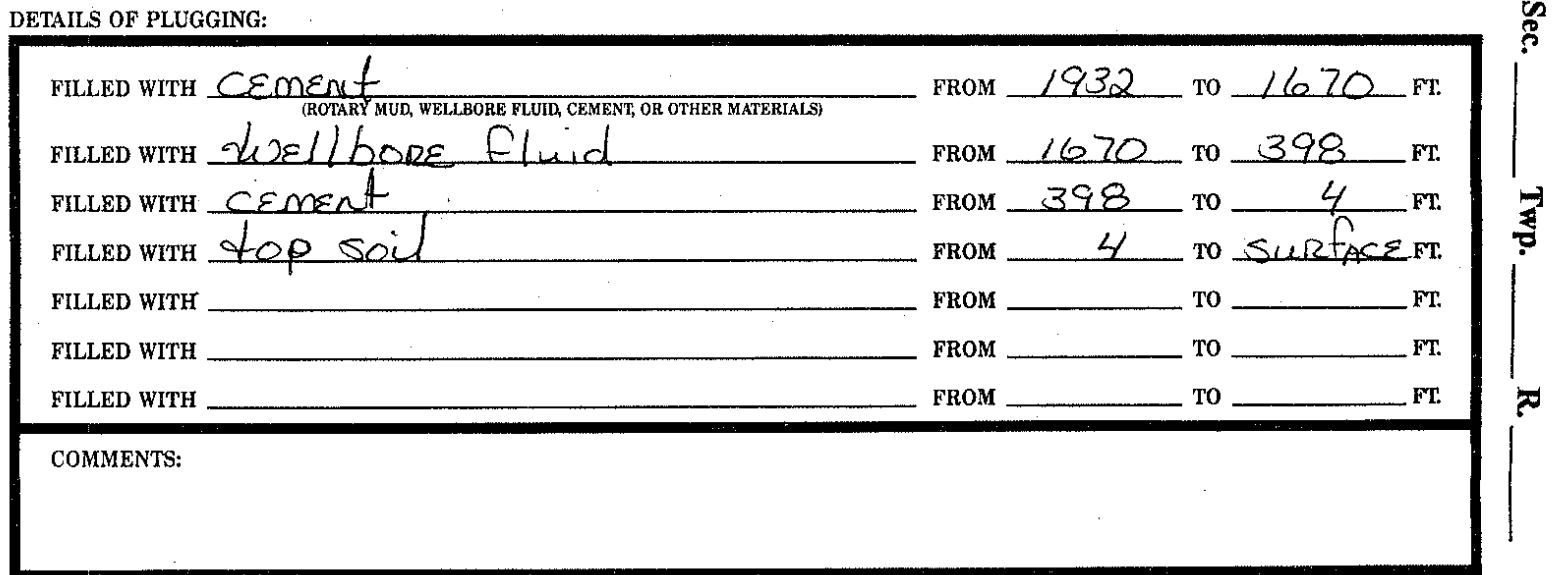

WELL DATA:

\begin{tabular}{|l|c|c|c|c|c|c|}
\hline \multicolumn{1}{|c|}{ CASING } & SIZE & $\begin{array}{c}\text { SETTING } \\
\text { DEPTH }\end{array}$ & $\begin{array}{c}\text { SACKS } \\
\text { CEMENT }\end{array}$ & $\begin{array}{c}\text { HOLE } \\
\text { SIZE }\end{array}$ & $\begin{array}{c}\text { EST. TOP OF } \\
\text { CEMENT }\end{array}$ & $\begin{array}{c}\text { AMOUNT OF } \\
\text { CASING REMOVED }\end{array}$ \\
\hline SURFACE & $85 / 8$ & $1 / 2$ & 80 & $12 / 4$ & $6 h$ & $4^{\prime}$ \\
\hline $\begin{array}{l}\text { INTERMEDIATE/MINE } \\
\text { STRING / OR LINER }\end{array}$ & & & & & & \\
\hline PRODUCTION & $4 / 2$ & $190 /$ & 125 & $77 / 8$ & 1100 & $700^{\prime}$ \\
\hline
\end{tabular}

UNDER PENALTIES OF PERJURY, I DECLARE THAT I HAVE EXAMINED THIS FORM INCLUDING ACCOMPANYING STATEMENTS AND DOCU. MENTS, AND TO THE BEST OF MY KNOWLEDGE, IT IS TRUE, CORRECT, AND COMPLETE.
SIGNATURE OF
tom 0

$$
\text { PERMTTEE OR PESTGNEE }
$$$$
\text { Po } 1 \text { ox } 832
$$ ADDRESS
2) ateren,
DATE PLUGGING BEGAN $\frac{13 / 77 \text { Ay } 97}{0}$ DATE PLUGGEGYSERPLTED 13 Maq 97 MAY 271997


$5-8$

\section{ILLINOIS DEPARTMENT OF NATURAL RESOURCES Office of Mines and.Minerals \\ Division of Oil and Gas COUMry 40.40 South Second Street (217) $782-7756$ COUn, illinois $62704-1787$}

\section{OG-6 WELL PLUGGING REPORT}

TYPE OF WELL: PRODUCTION $\square$ CLASS II $\square$ OBSERVATION $\square$ GAS STORAGE $\square$ REPLUG $\square$ OTHER PERMITTEE: _ Walter Duncan, Inc. WELL NAME: O1iver \# 2 PERMIT NO. $\frac{3403}{\text { (ISSUE DATE IF NO NUMBER) }}$ PERMITTEE NO. $\quad 868$
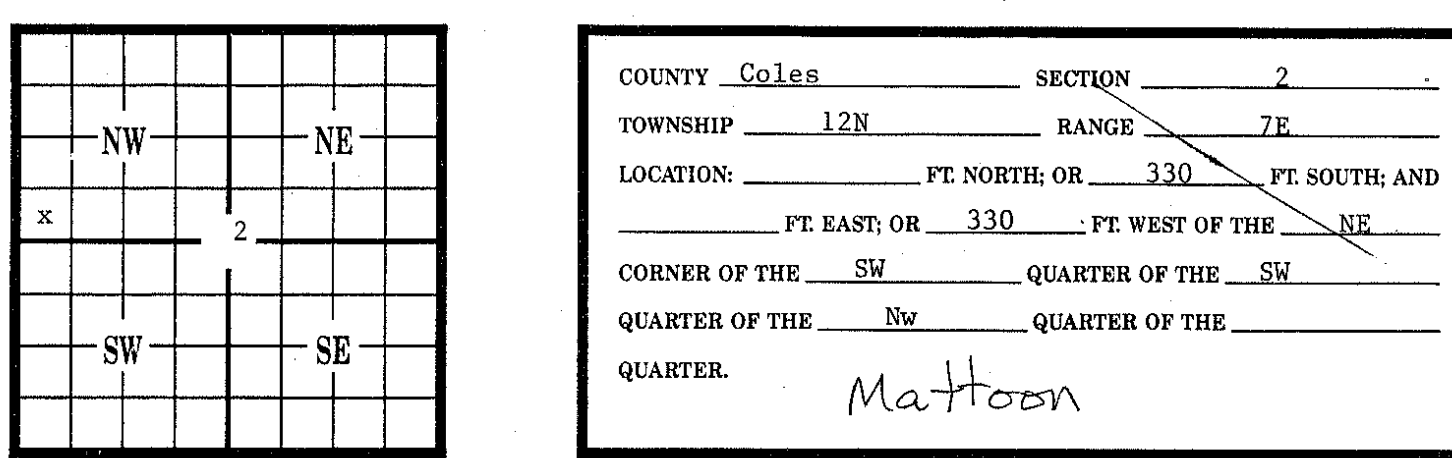

WELL DATA:

\begin{tabular}{|c|c|c|}
\hline SURFACE ELEVATION & $685 \quad$ FT. & PRODUCING / INJECTION INTERVALS \\
\hline TOTAL DEPTH OF WELL & 1970 & FROM 1907 TO 1911 \\
\hline PLUGGED BACK TOTAL DEPTH & $1937 \quad F T$. & FROM 1917 To 1924 \\
\hline BASE OF FRESHWATER ZONE & $\ldots \mathrm{Fr}$. & FROM __ TO \\
\hline WORKABLE COALS PRESENT AT & N/A & FROM \\
\hline
\end{tabular}

DETAILS OF PLUGGING:

\begin{tabular}{|c|c|c|c|c|}
\hline FILLED WITH & $\begin{array}{l}\text { cement } \\
\text { (ROTARY MUD, WELLBORE FLUID, CEMENT, OR OTHER MATERIALS) }\end{array}$ & \multirow{2}{*}{$\begin{array}{l}\text { FROM } \\
\text { FROM }\end{array}$} & 1970 & -1940 \\
\hline FILLED WITH & wellbore fluid & & 1740 & - To $\quad 401$ \\
\hline FLLLED WITH & cement & FROM & 401 & FT. \\
\hline FLLLED WITH & topsoil & FROM & 4 & $-\mathrm{TO}=0 \quad \mathrm{FT}$ \\
\hline FILLED WITH & & FROM & & - TO _ \\
\hline FILLED WITH & & FROM & - & $-\mathrm{TO} \_$FT \\
\hline FILLED WITH & & FROM & -1 & - To __ FT. \\
\hline COMMENTS: & & & & \\
\hline
\end{tabular}

WELL DATA:

\begin{tabular}{|l|c|c|c|c|c|c|}
\hline \multicolumn{1}{|c|}{ CASING } & SIZE & $\begin{array}{c}\text { SETTING } \\
\text { DEPTH }\end{array}$ & $\begin{array}{c}\text { SACKS } \\
\text { CEMENT }\end{array}$ & $\begin{array}{c}\text { HOLE } \\
\text { SIZE }\end{array}$ & $\begin{array}{c}\text { EST. TOP OF } \\
\text { CEMENT }\end{array}$ & $\begin{array}{c}\text { AMOUNT OF } \\
\text { CASING REMOVED }\end{array}$ \\
\hline SURFACE & $103 / 4$ & 105 & 66 & 13.75 & 0 & $4^{\prime}$ \\
\hline $\begin{array}{l}\text { INTERMEDIATE /MINE } \\
\text { STRING / OR LINER }\end{array}$ & $5 \frac{1}{2}$ & 1968 & 125 & $77 / 8$ & & $590^{\prime}$ \\
\hline \begin{tabular}{l} 
PRODUCTYN \\
\hline
\end{tabular} & & & & & & \\
\hline
\end{tabular}

UNDER PENALTIES OF PERJURY, I DECLARE THAT I HAVE EXAMINED THIS FORM INCLUDING ACCOMPANYING STATEMENTS AND DOCUMENTS, AND TO THE BEST OF GY KNOWLEDGE, IT IS TRUE, CORRECT, AND COMPLETE.

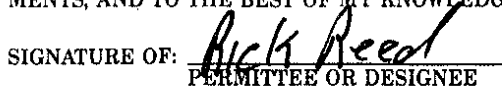

ADDRESS
DATE PLUGGING BEGAN

$5-8-97$ 


\section{OG-6 WELL PLUGGING REPORT 755512}

TYPE OF WELL: $\square$ PRODUCTION \ CLASS II $\square$ OBSERvation $\square$ GAS STORAGE $\square$ REPLUG $\square$ OTHER PermitreE: Lla/ter Duncan Est well Name: $0 / /$ Ue $\mathbb{R}_{3}$ PERMIT NO. $\frac{0 \mathrm{3} 402}{\text { (ISSUE DATE IF NO NUMBER) }}$ PERMITTEE NO. 868 REFERENCE NO. 1322

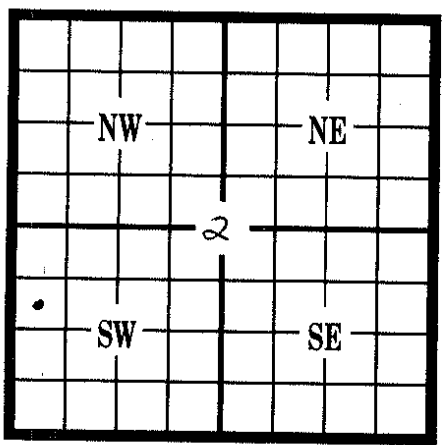
COUNTY $\frac{\text { CO/ES }}{12 N}$ SECTION $\frac{2}{1650}$ RANGE $\frac{7 \varepsilon}{\text { FOCNONHIP NORT; OR }}$ 330 FT. EAST; OR CORNER OF THE ___ FT. WEST OF THE SL, QUARTER OF THE _—_ _ QUARTER OF THE _ _ QUARTER.

\section{mattoon}

WELL DATA:

\begin{tabular}{|c|c|c|}
\hline SURFACE ELEVATION & 690 & PRODUCING / INJECTION INTERVALS \\
\hline TOTAL DEPTH OF WELL & 1985 & FROM 1916 To 1920 \\
\hline PLUGGED BACK TOTAL DEPTH & 1943 & FROM 1926 то 1932 \\
\hline BASE OF FRESHWATER ZONE & 340 & FROM $\longrightarrow$ ro. \\
\hline WORKABLE COALS PRESENT AT & NOAlE FT. & FROM — To. \\
\hline
\end{tabular}

DETAILS OF PLUGGING:

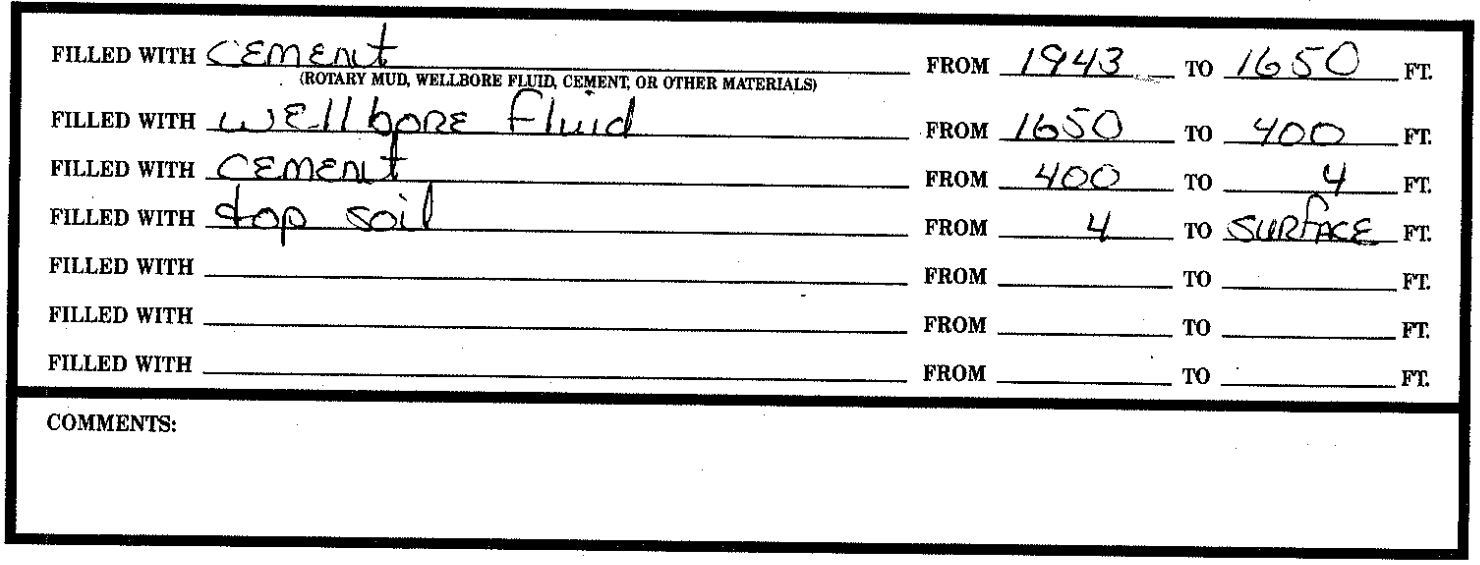

WELL DATA:

\begin{tabular}{|l|c|c|c|c|c|c|}
\hline \multicolumn{1}{|c|}{ CASING } & SIZE & $\begin{array}{c}\text { SETTING } \\
\text { DEPTH }\end{array}$ & $\begin{array}{c}\text { SACKS } \\
\text { CEMENT }\end{array}$ & $\begin{array}{c}\text { HOLE } \\
\text { SIZE }\end{array}$ & $\begin{array}{c}\text { EST TOP OF } \\
\text { CEMENT }\end{array}$ & $\begin{array}{c}\text { AMOUNT OF } \\
\text { CASING REMOVED }\end{array}$ \\
\hline SURFACE & $10^{3 / 4}$ & $117^{\prime}$ & 100 & $N R$ & 62 & 4 \\
\hline $\begin{array}{l}\text { INTERMEDIATE } / M I N E \\
\text { STRING } / \text { OR LINER }\end{array}$ & & & & & & \\
\hline PRODUCTION & $5 / 2$ & 1968 & 155 & $77 / 8$ & 805 & 650 \\
\hline
\end{tabular}

UNDER PENALTIES OF PERJURY, I DECLARE THAT I HAVE EXAMINED THIS FORM INCLUDING ACCOMPANYING STATEMENTS AND DOCUMENTS, AND TO THE BEST OF YI KNOWLEDGE, IT IS TRUE, CORRECT, AND COMPLETE.

SigNaTuRe OF:

ADDRESS

CITY STATE

IL 472-0198 (Rev $8 / 93)$ ZIP AUG $1: 1996$

(OVER) DATE PLUGGING BEGAN 9 Auy 96

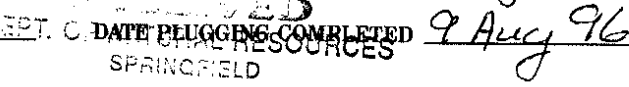


TYPE OF WELL: $\Varangle$ PRODUCTION $\square$ CLASS II $\square$ OBSERVATION $\square$ GAS STORAGE $\square$ REPLUG $\square$ OTHER PermitteE: Lialter Duncan Est well Name: Oliver \#4 PERMIT No. $0,4 / 60$ PERMITTEE No. 869 REFERENCE No. 129362

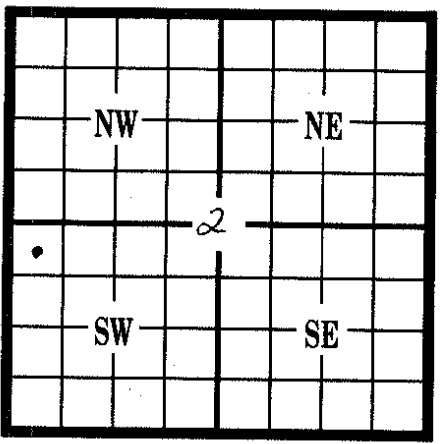

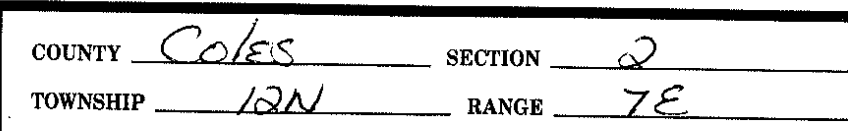

LOCATION: — FT. NORTH; OR BQC FT. SOUTH; AND 330 FT. EAST; OR CORNER OF THE__SW FT. WEST OF THE $N / 2$ QUARTER.

$$
\text { Mattoon }
$$

WELL DATA:

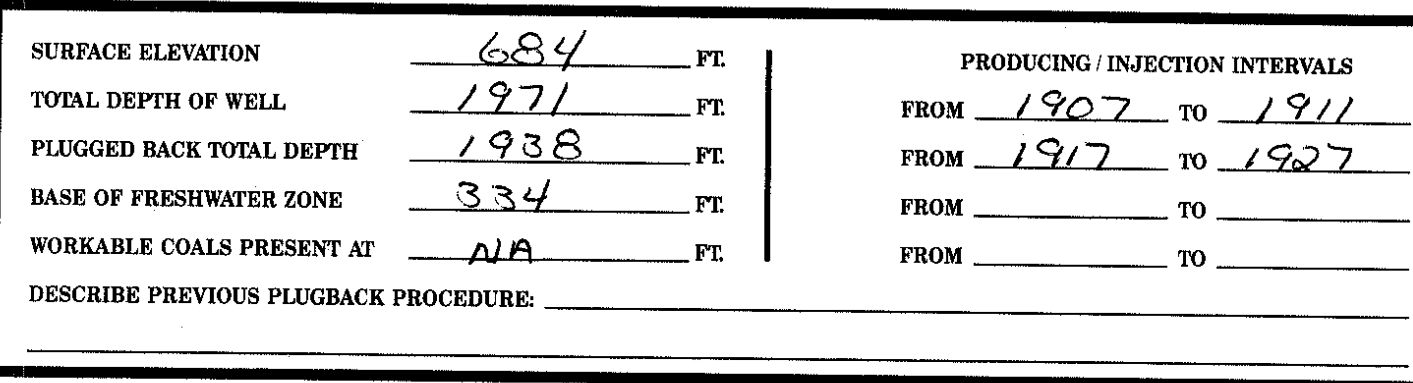

DETAILS OF PLUGGING:

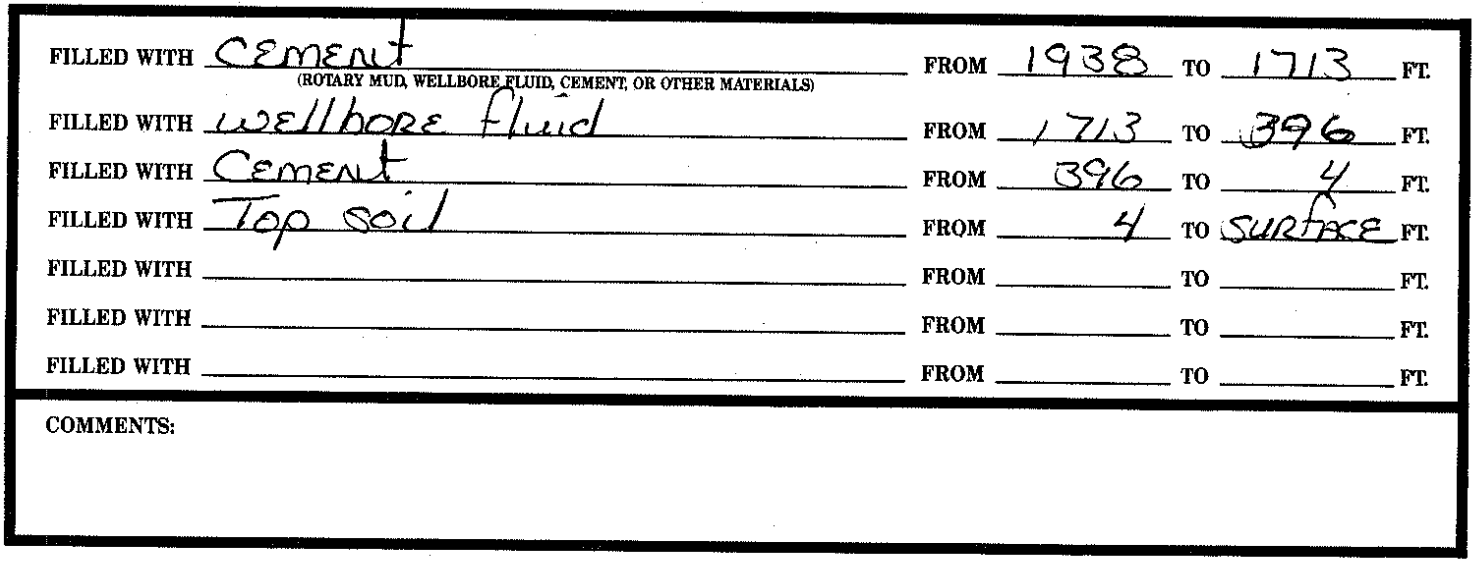

WELL DATA:

\begin{tabular}{|l|c|c|c|c|c|c|}
\hline \multicolumn{1}{|c|}{ CASING } & SIZE & $\begin{array}{c}\text { SETTING } \\
\text { DEPTH }\end{array}$ & $\begin{array}{c}\text { SACKS } \\
\text { CEMENT }\end{array}$ & $\begin{array}{c}\text { HOLE } \\
\text { SIZE }\end{array}$ & $\begin{array}{c}\text { EST TOP OF } \\
\text { CEMENT }\end{array}$ & $\begin{array}{c}\text { AMOUNT OF } \\
\text { CASING REMOVED }\end{array}$ \\
\hline SURFACE & $103 / 4$ & 117 & 100 & $N R$ & $6 L$ & $4^{\prime}$ \\
\hline $\begin{array}{l}\text { INTERMEDIATE/MINE } \\
\text { STRING/OR LINER }\end{array}$ & & & & & & \\
\hline PRODUCTION & $5 / 1 / 2$ & 1967 & 150 & $N R$ & 750 & $68 \Omega^{\prime}$ \\
\hline
\end{tabular}

UNDER PENALTIES OF PERJURY, I DECLARE THAT I HAVE EXAMINED THIS FORM INCLUDING ACCOMPANYING STATEMENTS AND DOCUMENTS, AND TO THE BEST OF MY KNOWLEDGE, IT IS TRUE, CORRECT, AND COMPLETE.

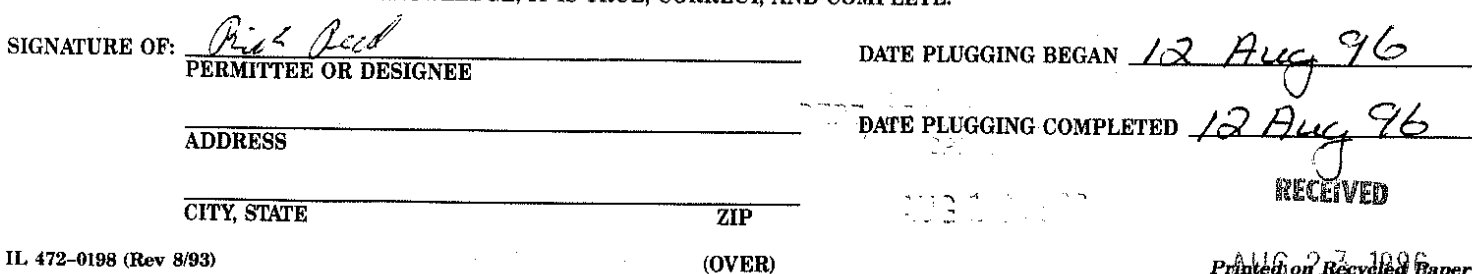




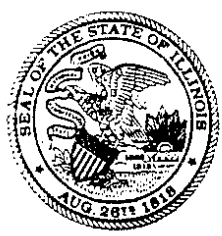

\section{ILLINOIS DEPARTMENT OF NATURAL RESOURCES Office of Mines and Minerals \\ Division of Oil and Gas couNyy 538 . 524 South Second Street (217) 782-7756 COUNTY No, 538 ............. Springfield, llinois 62701-1787}

OG-6 WELL PLUGGING REPORT

TYPE OF WELL: $\mathbb{X}$ PRODUCTION $\square$ CLASS II $\square$ OBSERVATION $\square$ GAS STORAGE $\square$ REPLUG $\square$ OTHER

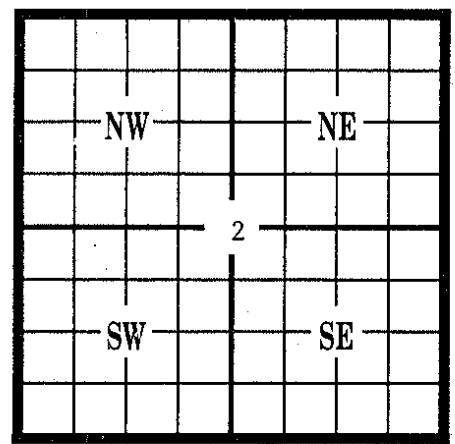

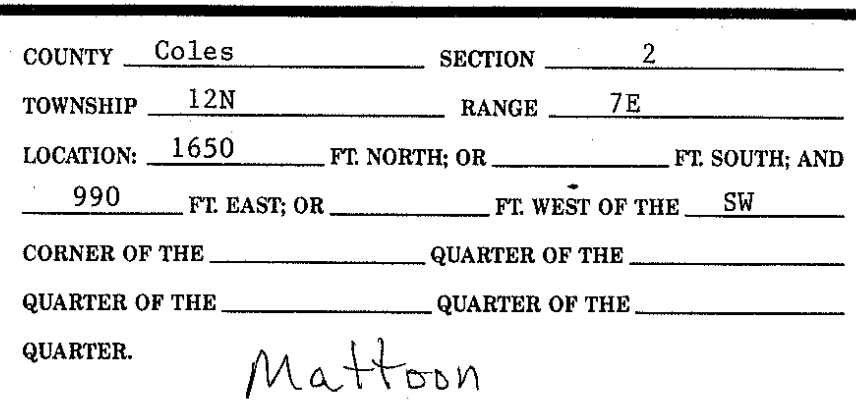

WELL DATA:

\begin{tabular}{|c|c|c|}
\hline SURFACE ELEVATION & $689 \quad$ FT. & PRODUCING / INJECTION INTERVALS \\
\hline TOTAL DEPTH OF WELL & 1969 & FROM 1906 \\
\hline PLUGGED BACK TOTAL DEPTH & $\perp^{\mathrm{FT}}$. & FROM _ To. \\
\hline BASE OF FRESHWATER ZONE & 339 & FROM — TO \\
\hline WORKABLE COALS PRESENT AT & N/A & $\longrightarrow$ To \\
\hline
\end{tabular}

DETAILS OF PLUGGING:

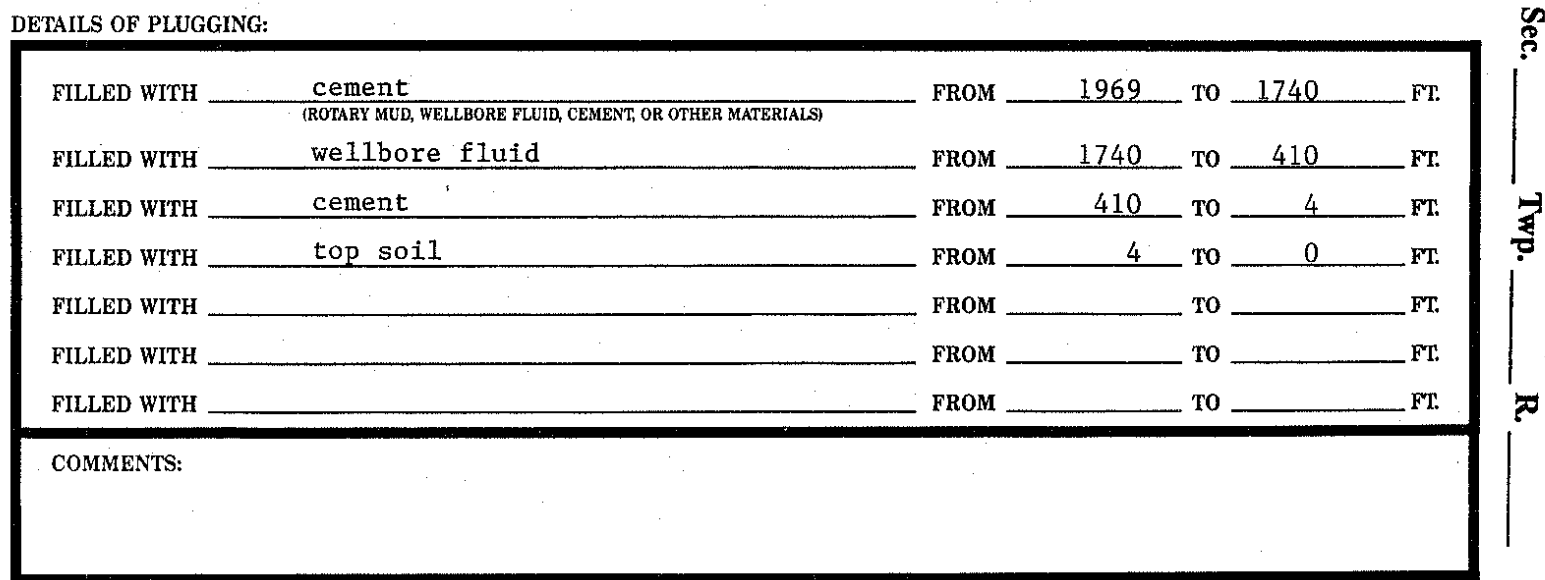

WELL DATA:

\begin{tabular}{|l|c|c|c|c|c|c|}
\hline \multicolumn{1}{|c|}{ CASING } & SIZE & $\begin{array}{c}\text { SETrING } \\
\text { DEPTH }\end{array}$ & $\begin{array}{c}\text { SACKS } \\
\text { CEMENT }\end{array}$ & $\begin{array}{c}\text { HOLE } \\
\text { SIZE }\end{array}$ & $\begin{array}{c}\text { EST. TOP OF } \\
\text { CEMENT }\end{array}$ & $\begin{array}{c}\text { AMOUNT OF } \\
\text { CASING REMOVED }\end{array}$ \\
\hline SUREACE & $103 / 4$ & 118 & 100 & 13.75 & 0 & $4^{\prime}$ \\
\hline $\begin{array}{l}\text { INTERMEDIATE /MINE } \\
\text { STRING/OR LINER }\end{array}$ & $5 \frac{1}{2}$ & 1966 & 175 & 7.38 & 712 & $580^{\prime}$ \\
\hline $\begin{array}{l}\text { PRODUCTION } \\
\text { PRON }\end{array}$ & & & & & & \\
\hline
\end{tabular}

UNDER PENALTIES OF PERJURY, I DECLARE THAT I HAVE EXAMINED THIS FORM INCLUDING ACCOMPANYING STATEMENTS ANDDOCU. MENTS, AND TO THE BEST OF MY KNOWLEDGE, IT IS TRUE, CORRECT, AND COMPLETE.

SIGNATURE OF: Pon PaCR

DATE PLUGGING BEGAN

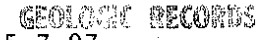

P.o. Pot 832

DATE PLUGGING COMPLETED

Mn alteon ale lols38




\section{OG-6 WELL PLUGGING REPORT}

TYPE OF WELL: $]$ PRODUCTION $\square$ CLASS II $\square$ OBSERVATION $\square$ GAS STORAGE $\square$ REPLUG $\square$ OTHER 776714

PERMITTEE: Walter Duncan, Inc.

WELL NAME: Oliver \#8

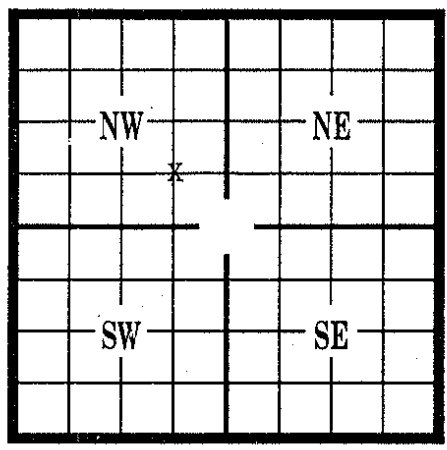

PERMITTEE NO. 868 PERMIT NO. $\frac{88}{\text { (ISSUE DATE IF NO NUMBER) }}$

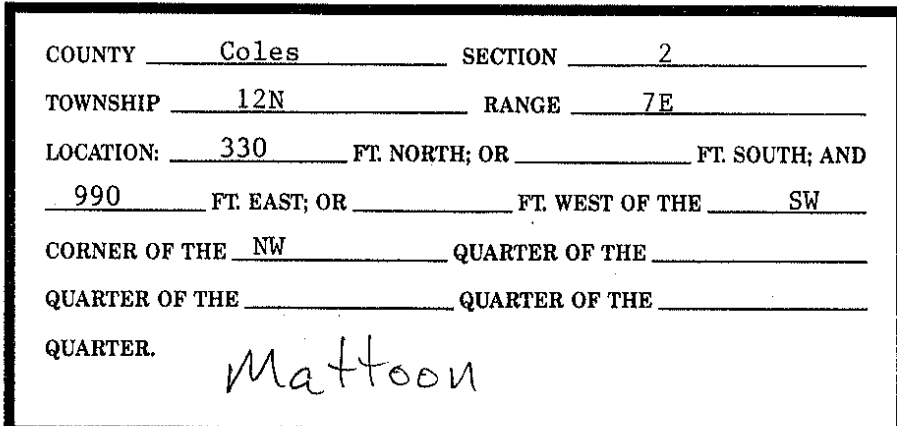

WELL DATA:

\begin{tabular}{lcr} 
SURFACE ELEVATION & 688 \\
\cline { 2 - 2 } TOTAL DEPTH OF WELL & 1930 \\
\cline { 2 - 2 } PLUGGED BACK TOTAL DEPTH & FT. \\
BASE OF FRESHWATER ZONE & 338 \\
WORKABLE COALS PRESENT AT & NT. \\
\cline { 2 - 2 } & FT.
\end{tabular}

\section{T.} FT. DESCRIBE PREVIOUS PLUGBACK PROCEDURE:

\section{DETAILS OF PLUGGING:}

\begin{tabular}{|c|c|c|c|c|c|c|}
\hline \multirow{2}{*}{$\begin{array}{l}\text { FILLED WITH } \\
\text { FILLED WITH }\end{array}$} & \multicolumn{3}{|c|}{ (ROTARY MUD, WELLBORE FLUID, CEMENT, OR OTHER MATERIALS) } & \multirow{2}{*}{$\begin{array}{l}\text { FROM } \\
\text { FROM }\end{array}$} & 1930 & \multirow{2}{*}{$\begin{array}{l}710 \\
400 \\
\end{array}$} \\
\hline & \multicolumn{3}{|c|}{ wellbore fluid } & & 1710 & \\
\hline FILLED WITH & \multicolumn{3}{|l|}{ cement } & \multirow{5}{*}{$\begin{array}{l}\text { FROM } \\
\text { - FROM } \\
\text { - FROM } \\
\text { - FROM } \\
\text { - FROM }\end{array}$} & 400 & _FT. \\
\hline FILLED WITH & \multicolumn{3}{|c|}{ top soil } & & 4 & _ FT. \\
\hline \multicolumn{4}{|l|}{ FILLED WITH } & & 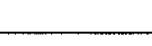 & $\mathrm{O}$ \\
\hline \multicolumn{4}{|l|}{ FILLED WITH } & & - & — FT. \\
\hline \multicolumn{4}{|l|}{ FILLED WITH } & & & FT. \\
\hline \multicolumn{7}{|l|}{ COMMENTS: } \\
\hline \multicolumn{7}{|l|}{ VELL DATA: } \\
\hline CASING & SIZE & $\begin{array}{l}\text { SETTING } \\
\text { DEPTH }\end{array}$ & $\begin{array}{l}\text { SACKS } \\
\text { CEMENT }\end{array}$ & $\begin{array}{l}\text { HOLE } \\
\text { SIZE }\end{array}$ & $\begin{array}{l}\text { EST. TOP OF } \\
\text { CEMENT }\end{array}$ & $\begin{array}{l}\text { AMOUNT OF } \\
\text { CASING REMOVED }\end{array}$ \\
\hline SURFACE & $103 / 4$ & 104. & 85 & 13.75 & 0 & $4^{\prime}$ \\
\hline \multicolumn{7}{|c|}{$\begin{array}{l}\text { INTERMEDIATE /MINE } \\
\text { STRING / OR LINER } \\
\end{array}$} \\
\hline PRODUCTION & 7 & 1930 & 125 & 8.75 & 1145 & $600^{\prime}$ \\
\hline
\end{tabular}

UNDER PENALTIES OF PERJURY, I DECLARE THAT I HAVE EXAMINED THIS FORM INCLUDING ACCOMPANYING STATEMENTS AND DOCUMENTS, AND TO THE BEST OF MY KNOWLEDGE, IT IS TRUE, CORRECT, AND COMPLETE.

SIGNATURE OF:

\section{PERMITTEE OR DESIGNEE}

ADDRESS
DATE PLUGGING BEGAN

DATE PLUGGING COMPLETED
$5-9-97$

$5-9-97$

\section{CITY, STATE}




\section{ILLINOIS DEPARTMENT OF NATURAL RESOURCES \\ Office of Mines and Minerals \\ Division of Oil and Gf) 524 South Second Street (217) 782-7756 COUNTY NO.2. 480 Springfield, Illinois 62701-1787}

\section{OG-6 WELL PLUGGING REPORT}

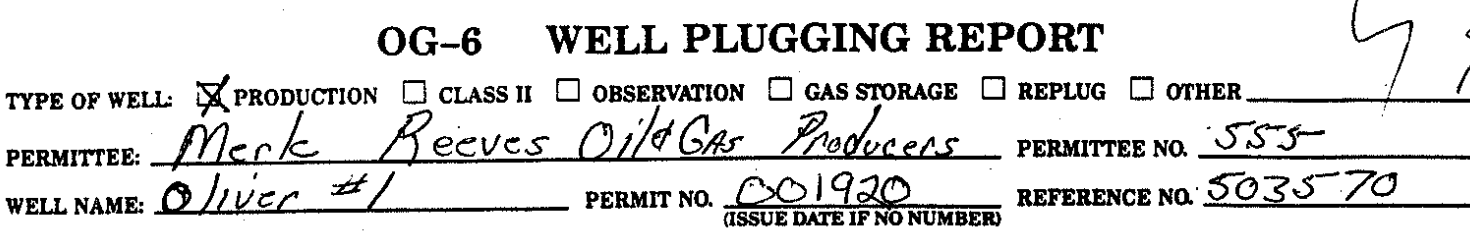

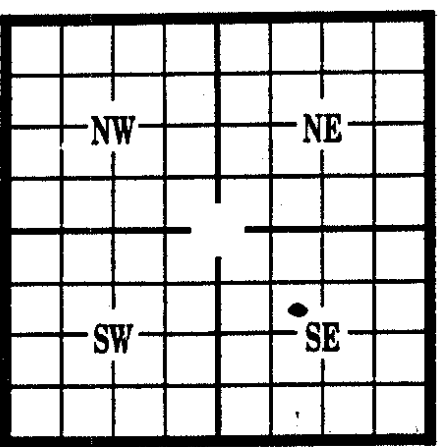
countr Coles TOWNSHIP $12 N$ SECTION 02 LOCATION: 1650 RANGe $O 7 \%$ FT. NORTH; OR $\longrightarrow$ FT. SOUTH; AND — FT EAST; OR 1650 FT. WEST OF THE $S E$ CORNER OF THE _ _ _ QUARTER OF THE $\longrightarrow$ QUARTER OF THE QUARTER OF THE QUARTER.

WELL DATA:

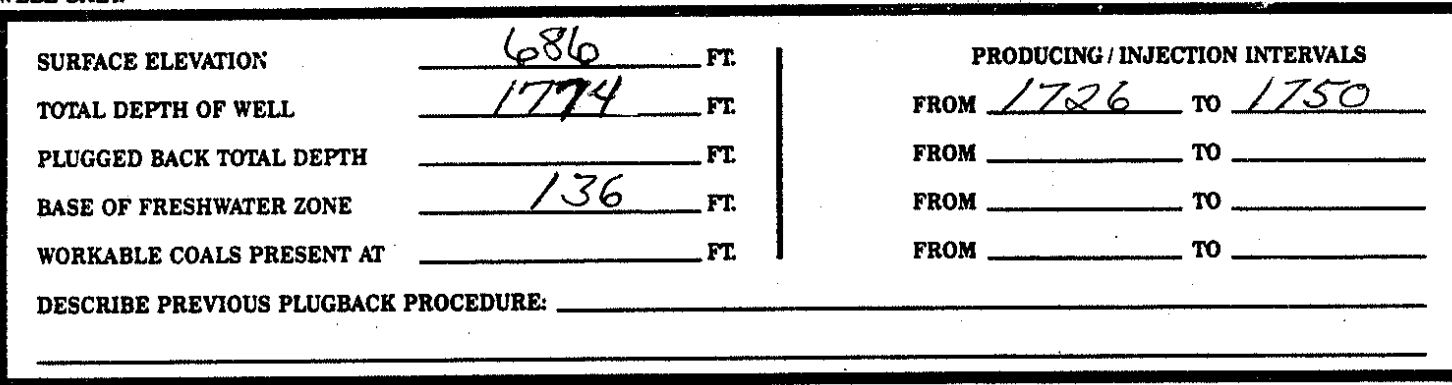

DETAILS OF PLUGGING:

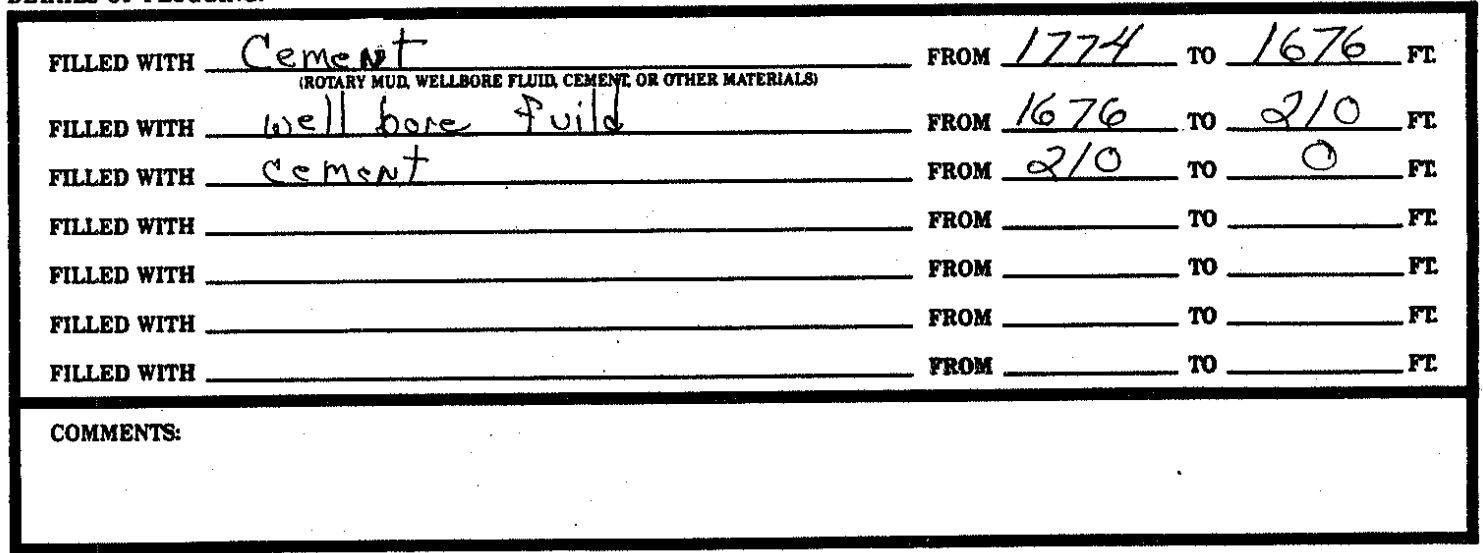

WELL DATA:

\begin{tabular}{|l|c|c|c|c|c|c|}
\hline \multicolumn{1}{|c|}{ CASING } & SIZE & $\begin{array}{c}\text { SETTING } \\
\text { DEPTH }\end{array}$ & $\begin{array}{c}\text { SACKS } \\
\text { CEMENT }\end{array}$ & $\begin{array}{c}\text { HOLE } \\
\text { SIZE }\end{array}$ & $\begin{array}{c}\text { EST TOP OF } \\
\text { CEMENT }\end{array}$ & $\begin{array}{c}\text { AMOUNT OF } \\
\text { CASING REMOVED }\end{array}$ \\
\hline \begin{tabular}{l} 
SURFACE \\
\hline $\begin{array}{l}\text { INTERMEDLATE MINE } \\
\text { STRING /OR LINER }\end{array}$
\end{tabular} & $8 / 8$ & $1 / 4$ & 25 & $12 \%$ & & \\
\hline PRODUCTION & $4 / 2$ & $1768^{\circ}$ & 150 & $7 \% / 8$ & & 815 \\
\hline
\end{tabular}

UNDER PENALTIES OF PERJURY, I DECLARE THAT I HAVE EXAMINED THIS FORM INCLUDING ACCOMPANYING STATEMENTS AND DOCU.

MENTS, AND TO THE BEST OF MY KNOWLEDGE, IT IS TRUE, CORRECT, AND COMPLETE.

ADDRESS
DATE PLUGGING BEGAN $>3-|2-200|$
DATE PLUGGINGCOMRETED $3-13-2001$

औit 200 
County of

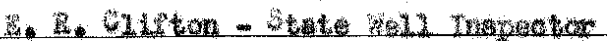

being first duly sworn, do depose and say the following is a true and correct statement of the details of the plugging of a certain well di the

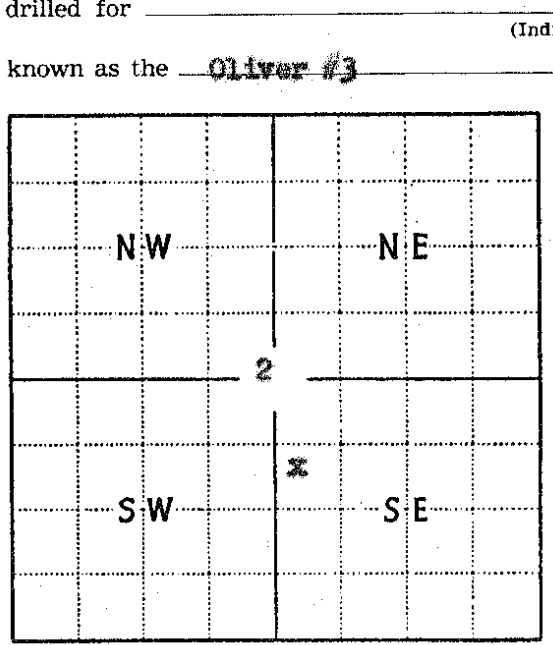

Locate well accurately on plat of section (Scale one inch-2,000 ft.)

(Indicate whether for oll, gas, water or other purposes)

and located as follows: $1650 \quad$ ft. north; ft. south; $\mathrm{ft}$ east; 2310 ft. west of the corner of the Quarter of the Quarter of the Quarter of

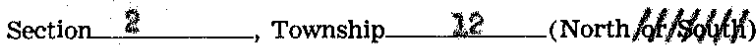
Range 7 , (East $6($ West) of the 3 a Principal Meridian,___ otede County, Illinois. Elevation above sea level is $\begin{cases}\text { Derrick Floor } & \mathrm{ft} . \\ \text { Ground } & \mathrm{ft} .\end{cases}$ Total depth $\quad 2775$ Formation _ Date permit to drill issued $4 / 2 / 76$ Permit No. 2Wh Permit issued to Date drilling bẻgan $\quad 4-\$-76$ Date drilling completed $\$ / 22 / 76$ Kind of drilling tools used Date plugging completed $\quad 4 / 2176$

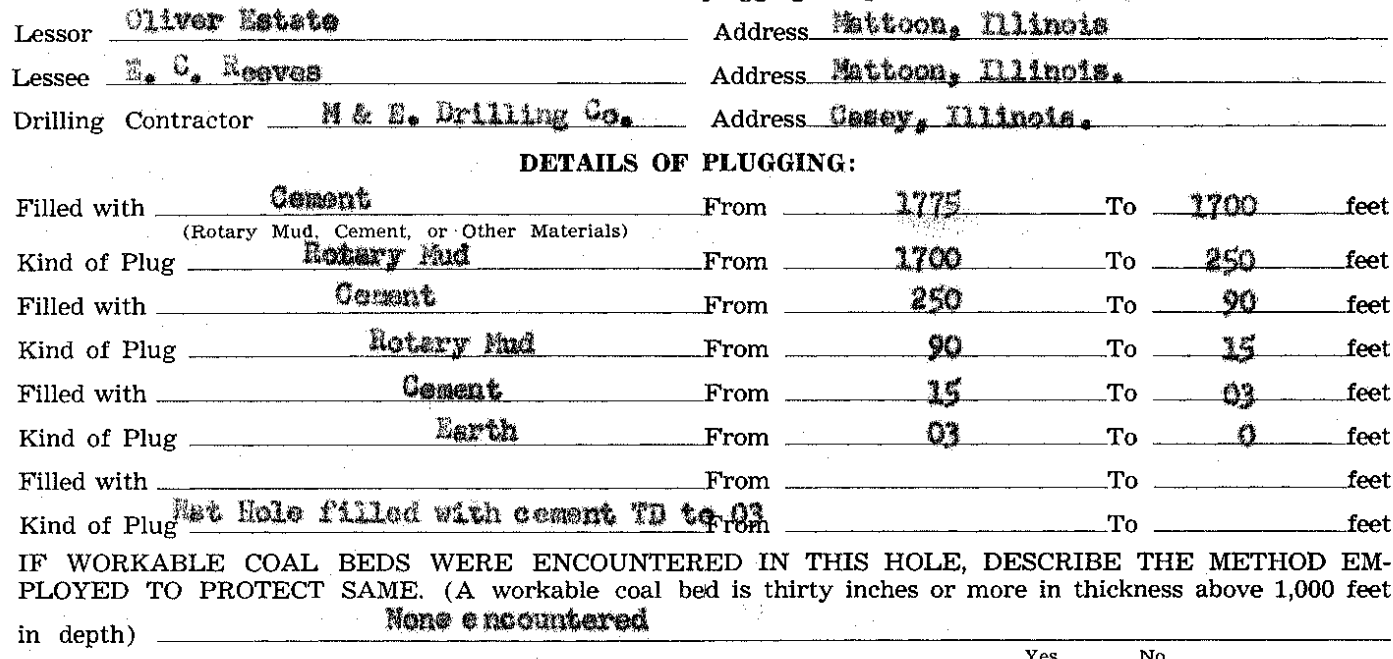

(1) Have pits and other excavations been filled?................ $\square^{\text {Yes }}$

(2) Have the following been remoxed? Equipment $\stackrel{\text { Yes }}{\square}$ Concrete bases $\stackrel{\text { Yes }}{\square} \stackrel{\text { No }}{\square}$ Debris $\square^{\square}$

(3) Has surface casing been cut off three feet below ground surface?

(4) Has well-site been leveled?

If this was a producing well, give date and amount of last production

\section{CASING RECORD}

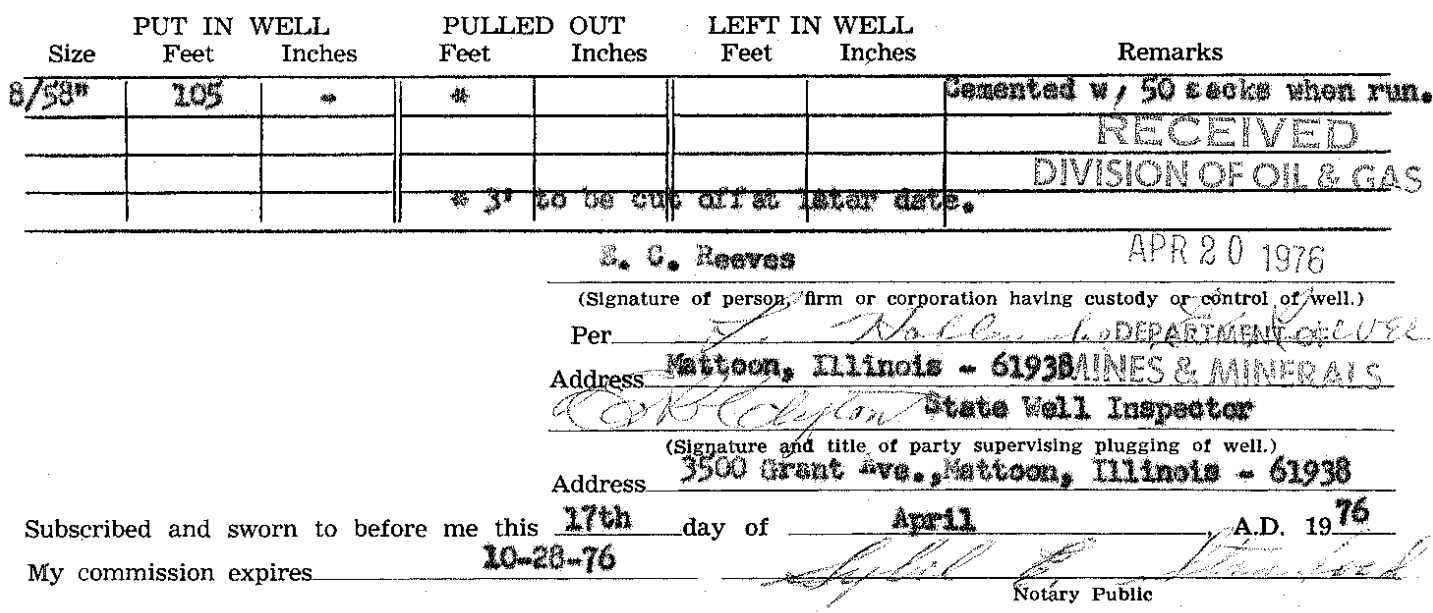




\section{$\left.\begin{array}{l}\text { STATE of illinois } \\ \text { County of coles }\end{array}\right\}$ ss. WELL PLUGGINC AFFIDAVIT}

1. L. Noblit State vell Inspeotoc

being first duly sworn do depose and say the following is a true and correct statement of the details of the plugging of a certain well drilled for Oil

known as the $\quad$. 1 ver $1-\mathrm{B}$

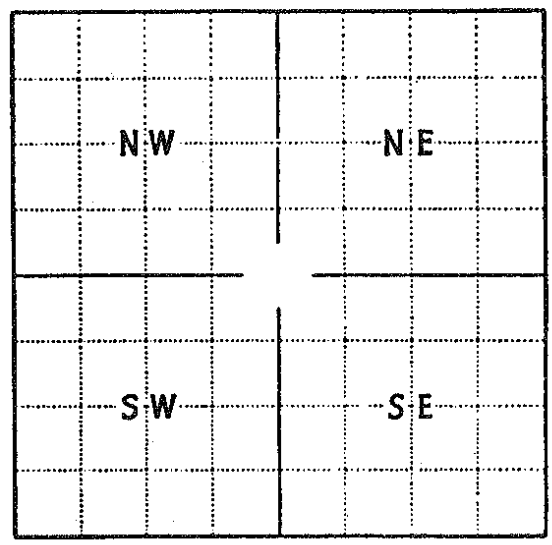

Locate well eccurately on plat of section (Scale one inch-2,000 $\mathrm{ft}$.) (Indicate whether for oil, gas, water or other purposes) and located as follows: _ $1650 \quad$ ft. north;

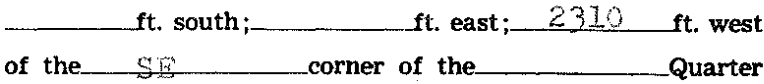

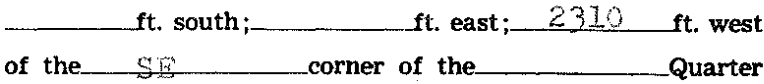
of the Quarter of the___ Quarter of Section 2 , Township_ 12 (North or South) $x$ Range 7 , (East or Whest), of the Principal Meridian, Coles County, Illinois.

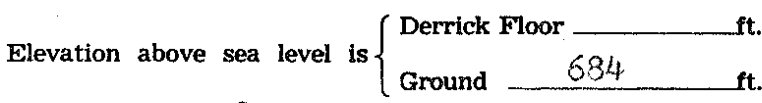
Total depth 1730 Formation Cypress Date permit to drill issued $3 / 16 / 79$ Permit No. 7914 Permit issued to Charles Amantrout Date drilling began_... $8 / 16 / 79$ Date drilling completed. $8 / 12 / 79$

Kind of drilling tools used___ sotany Date plugging began $108 / 24 / 83$ Date plugging completed $\quad 10 / 14 / 83$

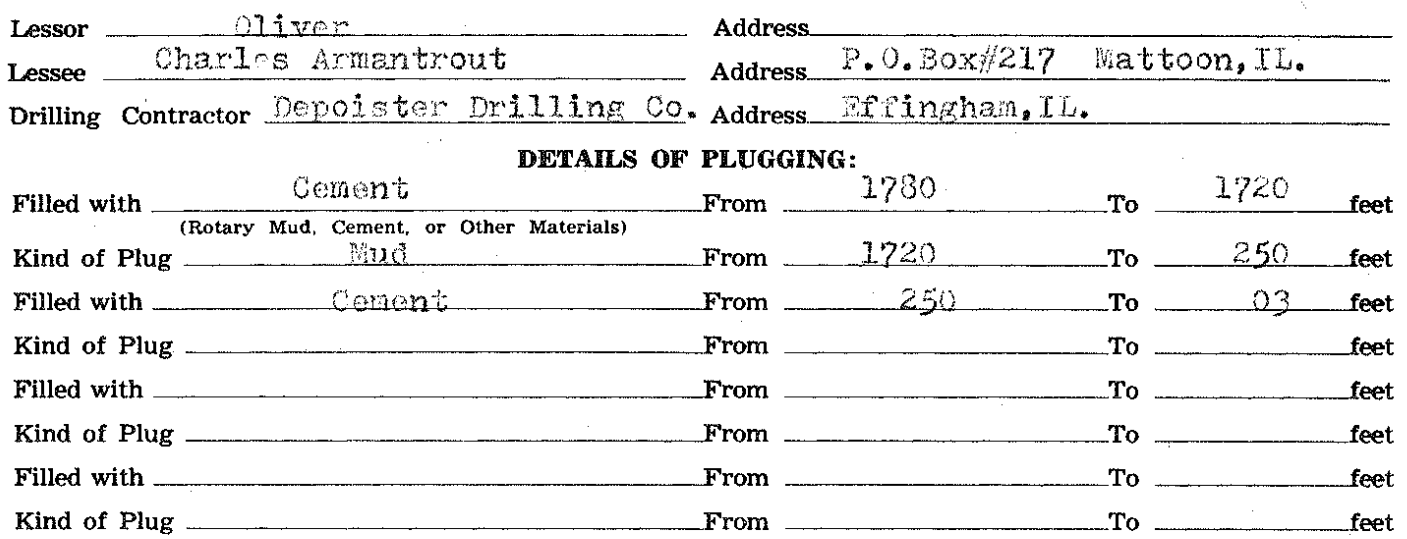
IF WORKABLE COAL BEDS WERE ENCOUNTERED IN THIS HOLE, DESCRIBE THE METHOD EMPLOYED TO PROTECT SAME, (A workable coal bed is thirty inches or more in thickness above 1,000 feet in depth) irone

(1) Have pits and other excavations been flled? ............... Yes

(2) Have the following been removed?

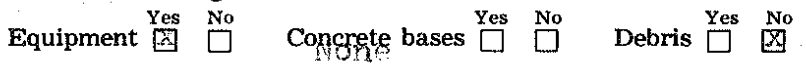

(3) Has surface casing been cut off three feet below ground surface?

(4) Has well-site been leveled?

If this was a producing well, give date and amount of last production

\section{OASING RECORD
OANG}

\begin{tabular}{|c|c|c|c|c|c|c|c|}
\hline \\
\hline & PUT IN V & WELL & PULLED & OUT & LEFT & WELL & \multirow[b]{2}{*}{ Remarks } \\
\hline Size & & & & & & Inches & \\
\hline$x+1$ & \multicolumn{2}{|l|}{ 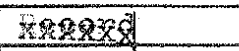 } & & & & & \\
\hline 4 & 1290 & & 1260 & & 520 & & \\
\hline 3.540 & 795 & & 3 & & & & \\
\hline & & & & & & & \\
\hline
\end{tabular}

$$
\text { Charles Arantrout }
$$

(Signature of gerson, frm or corporation having custody or control or well.)

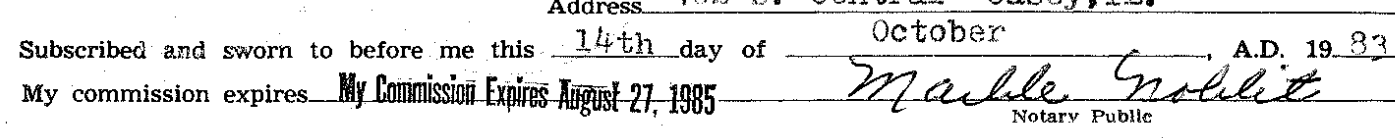




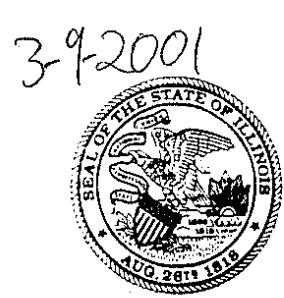

\section{ILLINOIS DEPARTMENT OF NATURAL RESOURCES Office of Mines and Minerals \\ Division of Oil and G: 524 South Second Street (217) $782-7756$ counTY NO.2.181 pringfield, Illinois $62701-1787$}

\section{OG-6 WELL PLUGGING REPORT}

TYPE OF WELL: $\triangle$ PRODUCTION $\square$ CLASS II $\square$ OBSERVATION $\square$ GAS STORAGE $\square$ REPLUG $\square$ OTHER permittee Merle Reeves Oil \& Gijs Produers WELL NAME: 0 liveV $Q$ PERMIT No. 001929 PERMITTEE NO. 5.55

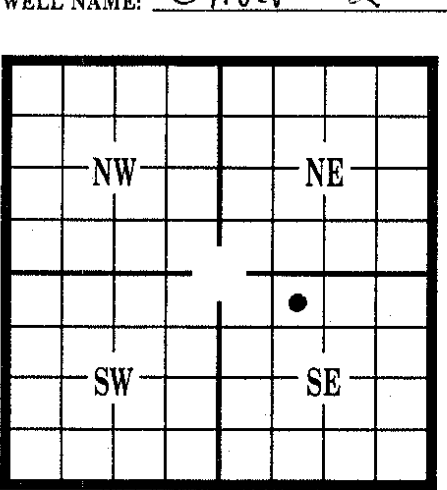
ISSUE DATE IF NO NUMBER REFERENCE NO. 50,3571

WELL DATA:

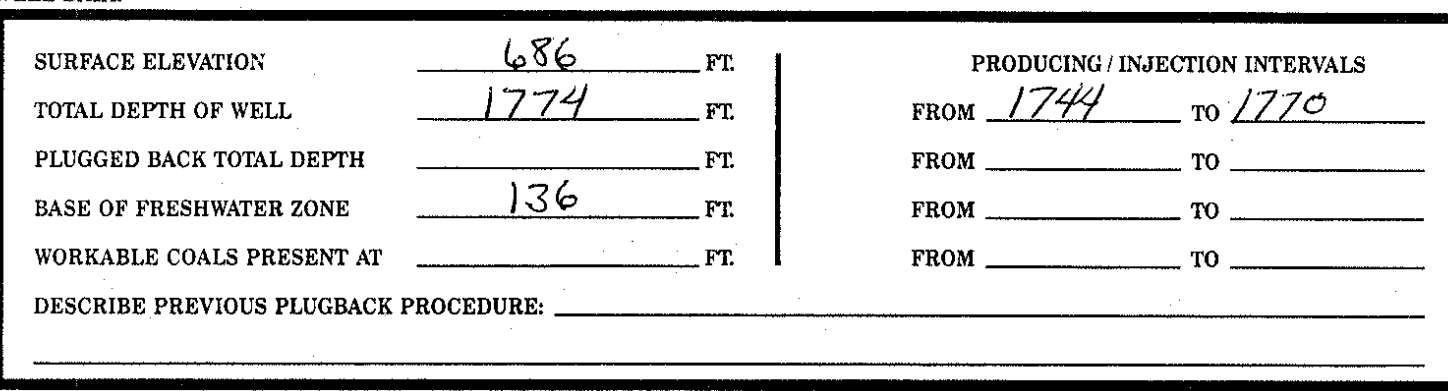

\begin{tabular}{|c|c|}
\hline county Coles & SECTION $Q 2$ \\
\hline TOWNSHIP lep & RANGE $O 7 E$ \\
\hline LOCATION: $\frac{2310}{\text { FT. EAST; }}$ & $\begin{array}{l}\text { FT. NORTH; OR } \\
1650 \text { FT. SOUTH; AND }\end{array}$ \\
\hline
\end{tabular}

CORNER OF THE QUARTER OF THE

QUARTER OF THE QUARTER OF THE QUARTER.

DETAILS OF PLUGGING:

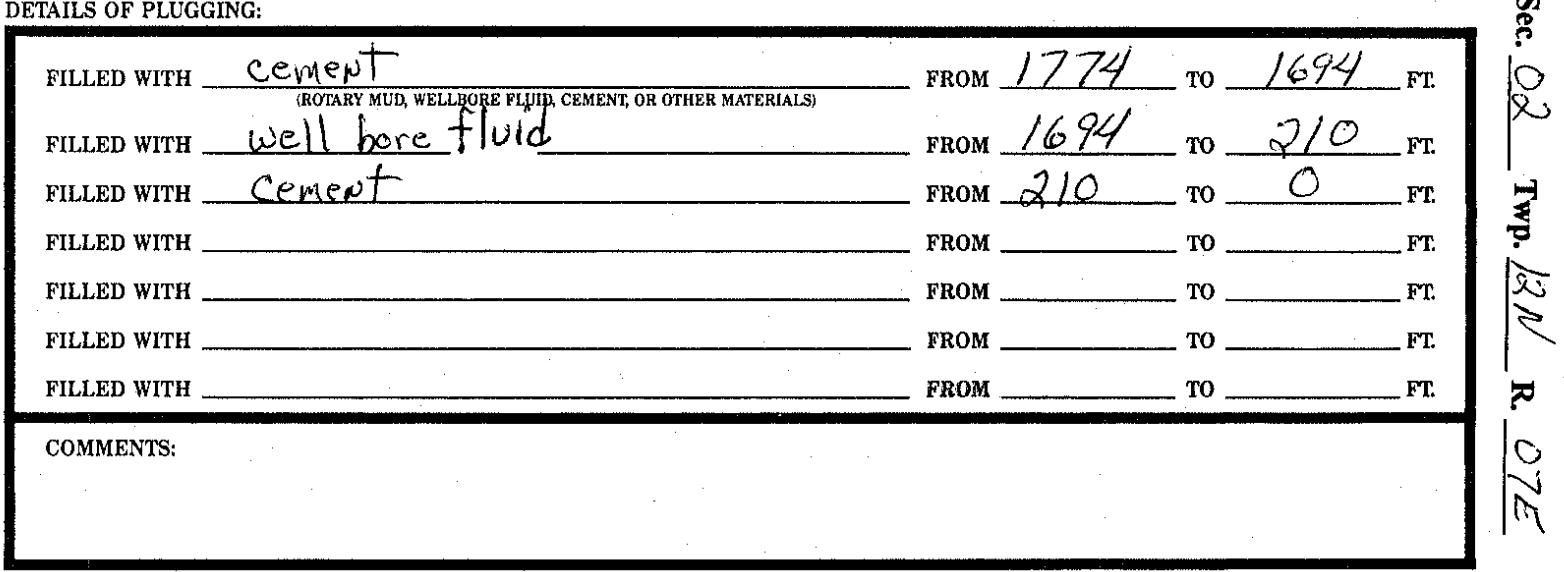

WELL DATA:

\begin{tabular}{|l|c|c|c|c|c|c|}
\hline \multicolumn{1}{|c|}{ CASING } & SIZE & $\begin{array}{c}\text { SETTING } \\
\text { DEPTH }\end{array}$ & $\begin{array}{c}\text { SACKS } \\
\text { CEMENT }\end{array}$ & $\begin{array}{c}\text { HOLE } \\
\text { SIZE }\end{array}$ & $\begin{array}{c}\text { EST TOP OF } \\
\text { CEMENT }\end{array}$ & $\begin{array}{c}\text { AMOUNT OF } \\
\text { CASING REMOVED }\end{array}$ \\
\hline SURFACE & $8 \% 8$ & $1 / 4$ & 25 & $12 / 4$ & & 4 \\
\hline $\begin{array}{l}\text { INTERMEDIATE /MINE } \\
\text { STRING / OR LINER }\end{array}$ & & & & & & \\
\hline PRODUCTION & $4 / 2$ & 1770 & 150 & $7 / 6$ & 700 & 750 \\
\hline
\end{tabular}

UNDER PENALTIES OF PERJURY, I DECLARE THAT I HAVE EXAMINED THIS FORM INCLUDING ACCOMPANYING STATEMENTS AND DOCU. MENTS, AND TO THE BESY OF MY KNOWLEDGE, IT ES TRYE, CORRECT, AND COMPLETE.

SIGNATURE OF: $\frac{1}{\text { PERMITTEE OR DESIGNEE }}$

ADDRESS
DATE PLUGGING BEGAN $3-8-2001$

DATE PLUGGING COMPLETED $3-9-200$

he 200 
do depose and say the following is a true and correct statement of the details of the plugging of a certain well drilled for -

known as the Mand

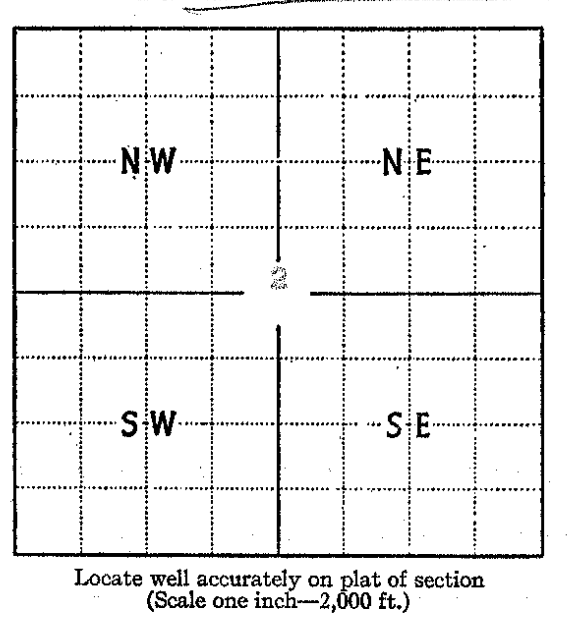

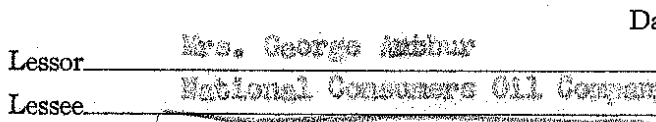

and located as follows:

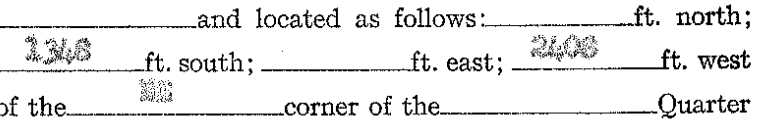
of the___ Quarter of the__uarter of Section C Township_

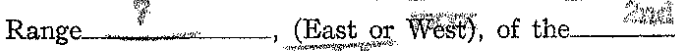
Principal Meridian,___. County, Illinois. Elevation above sea level is $\left\{\begin{array}{l}\text { Derrick Floor_ ft_ ft. } \\ \text { Ground }\end{array}\right.$

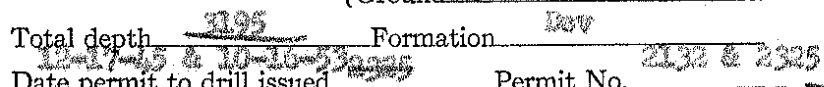

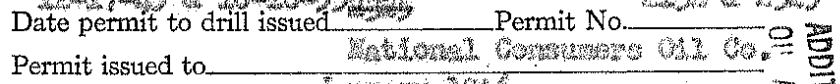

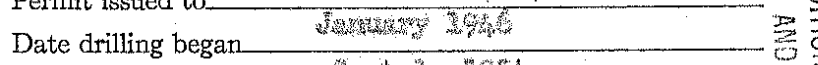
Date drilling completed

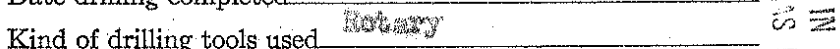
Date plugging began - का

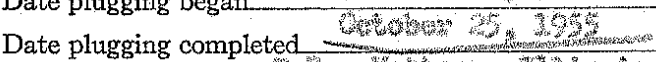
电 Lessee_Drilling Contractor DETAILS OF PLUGGING:

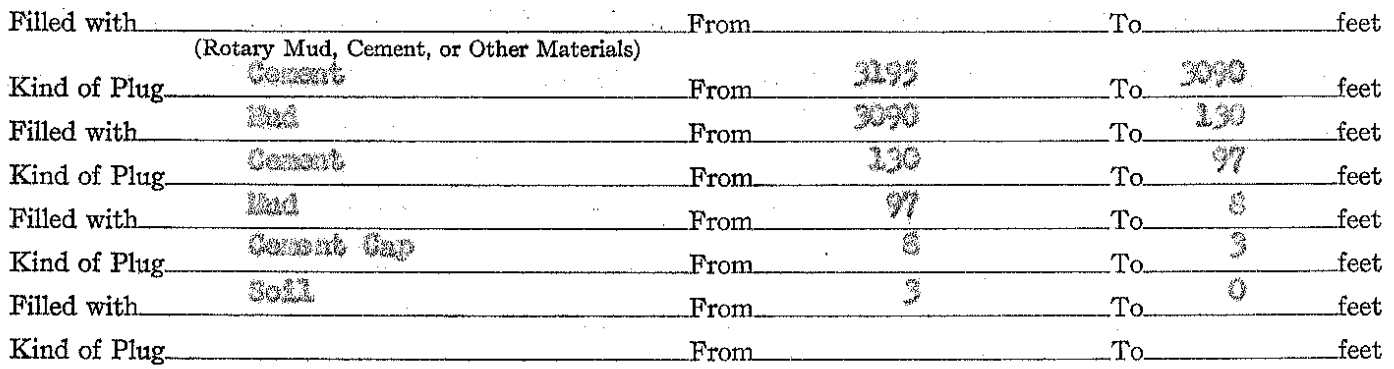

IF WORKABLE COAL BEDS WERE ENCOUNTERED IN THIS HOLE, DESCRIBE THE METHOD EMPLOYED TO PROTECT SAME. (A workable coal bed is thirty inches or more in thickness above 1,000 feet in depth)

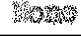

(1) Have pits and other excavations been filled?............ $\square^{\text {Yes }}$

(2) Have the following been removed?

Equipment $\square$ 踏 Concrete bases $\square$ Des

(3) Has surface casing been cut off three feet below ground surface?

(4) Has well-site been levelled?.

If this was a producing well, give date and amount of last production

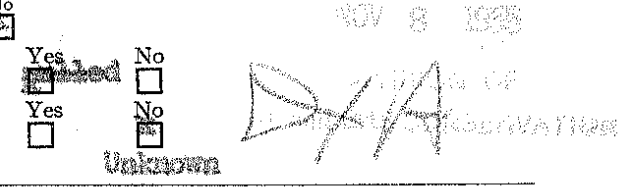

GASING RECORD

\begin{tabular}{|c|c|c|c|c|c|c|c|}
\hline & \multicolumn{2}{|c|}{ PUT IN WELL } & \multicolumn{2}{|c|}{ PULLED OUT } & \multicolumn{2}{|c|}{ LEFT IN WELL } & \multirow{2}{*}{ Remarks } \\
\hline Size & $\frac{\text { Feet }}{37}$ & Inches & Feet & Inches & Feet & Inches & \\
\hline 7 & Why & & 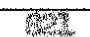 & & Prata & & 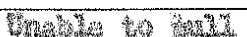 \\
\hline b. & Mys & & X) & & 3ypt & & Whes \\
\hline & & & & & & & \\
\hline
\end{tabular}

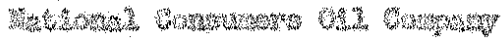

(Sigrature of person, firnd or corporation having custody or control of well.)

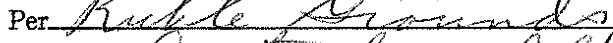

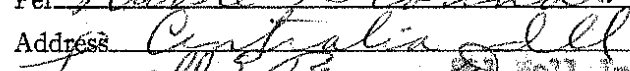

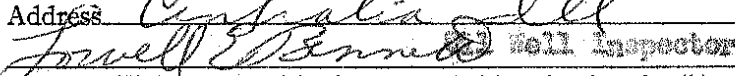

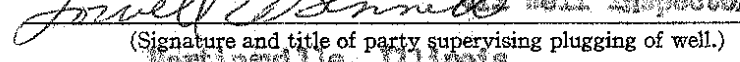
(Signature and title of party supervising

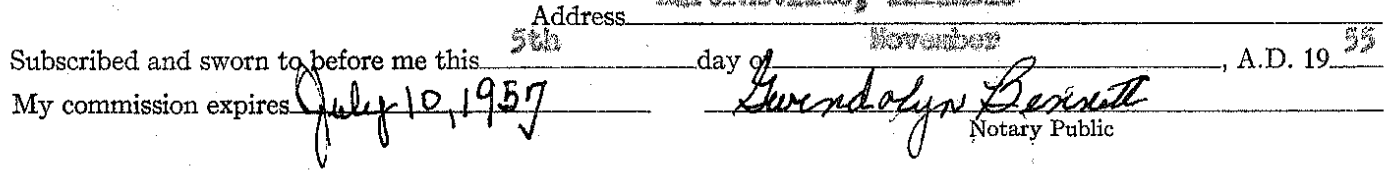




\section{$60+1010$}

STATE OF ILLINOIS,

County of Calee $\}$ ss.

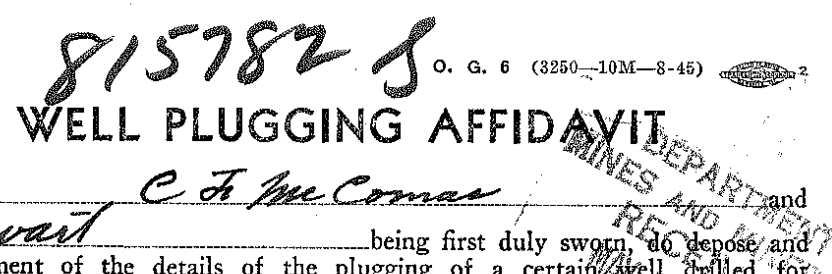
say the following is a true and correct statement of the details of the plugging of a certainstyelly drilled tor

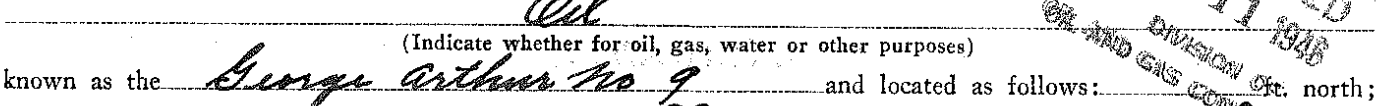

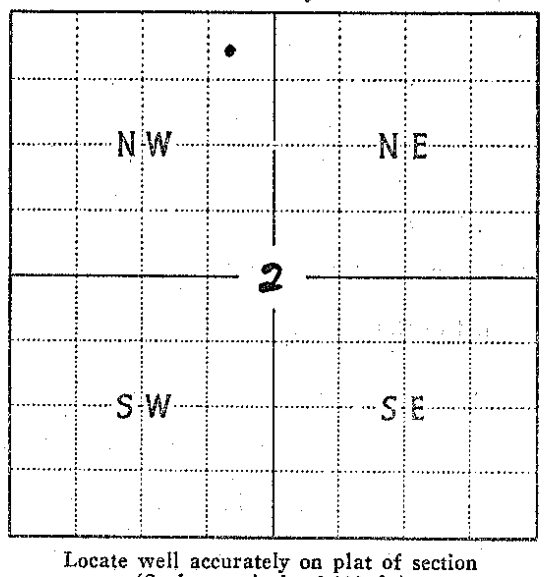
(Scale one inch-2,000 ft.)
Lessor Benzec asthers

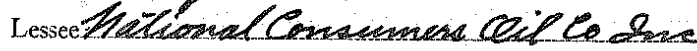
Drilling Contractor ToretLace 106
$330 \mathrm{ft}$. south; ft. east; 3068 wift. west of the $N E \quad$ corner of the $N E \quad$ Quatower of the Quarter of the Section 2 ..., Township 12 (North Range 7 , (East of the 3

Principal Meridian,

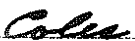
County, Illinois.

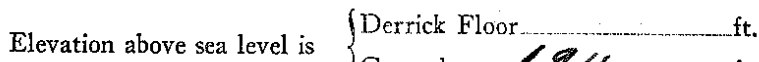
Total depth of well is Ground $6 \% 4 \mathrm{ft}$ Date permit to drill issued feanceny $23-1946$

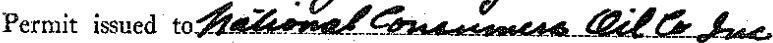
Date drilling began $0<2-1946$ Date drilling completed Thet $15 \cdot 12 \leqslant 6$ Kind of drilling tools used Atense Date plugging began $7-1946$ Date plugging completed $80,19<6$

Filled with DETAILS OF PLUGGING:
Kind of Plug From
Filled with
Kind of Plug
Address Traper $p$

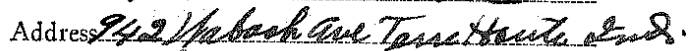
Address

IF WORKABLE COAL BEDS WERE ENCOUNTERED IN THIS HOLE, DESCRIBE THE METHOD EMPLOYED 'TO PROTECT SAME. (A workable coal bed is thirty inches or more in thickness above 1,000 feet in depth.

Other details

If this was a producing well, give date and amount of last production

CASING RECORD

\begin{tabular}{|c|c|c|c|c|c|c|c|}
\hline \multirow[b]{2}{*}{ Size } & \multicolumn{2}{|c|}{ PUT IN WELL } & \multicolumn{2}{|c|}{ PULLED OUT } & \multicolumn{2}{|c|}{ LEFT IN WELL } & \multirow[b]{2}{*}{ Remarks } \\
\hline & Feet & Inches & & Inches & & Inches & \\
\hline $5 \%$ & 2010 & & 2010 & & & & \\
\hline$\angle O$ & 66 & & 2 & & 64 & & $\therefore$ \\
\hline & & & & & & & \\
\hline & & & & & & & \\
\hline
\end{tabular}

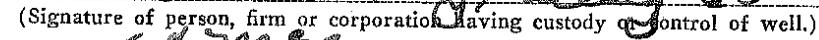

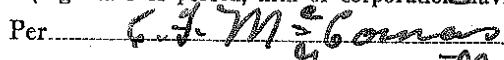

Address 10 vay 2010

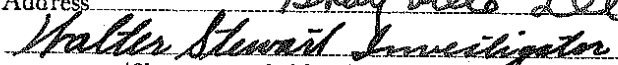
(Signature and title of party superviling plugging of well.)

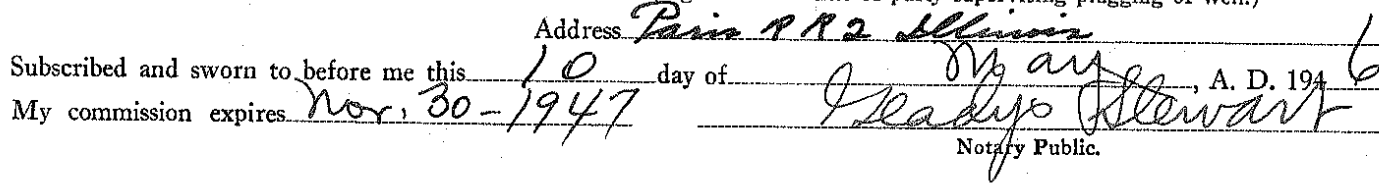




\section{ST. WELL PLUGCING AFFIDAVIT}

1. Anderson and

Lomel1 2. being first duly sworn, do depose and say the following is a true and correct statement of the details of the plugging of gertajn well drilled for Q11 and Gas

(Indicate whether for oil, gas, water or other purposes)

known as the Opan Anthus 1 and located as follows :

ft. north;

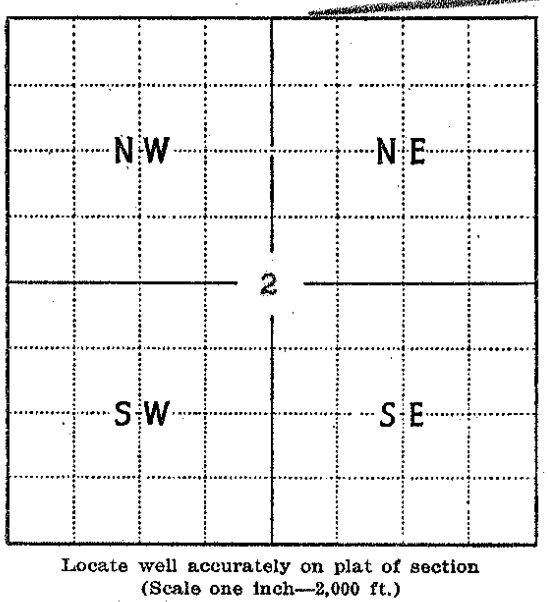

$330 \mathrm{ft}$. south; $330 \mathrm{ft}$. east;

ft. west of the Wr corner of the Quarter of the Quarter of the Quarter of

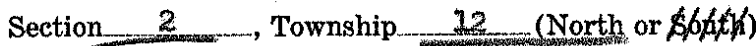
Range 7 (East or $W(6 / 6 t)$, of the

Principal Meridian, Colos County, Illinois. Elevation above sea level is $\left\{\begin{array}{l}\text { Derrick Floor } \\ \text { Ground }\end{array}\right.$ Total depth 1953 Formation.

Date permit to drill issued $4-6-56$ Permit No. 1140

Permit issued to R. I. Anderson \& Jomes

Date drilling began__Aaci 1 5, 1956

Date drilling completed Apzi1 11, 1956

Kind of drilling tools usedhotiary

Date plugging began Ootobew 34,1957

Date plugging completed Wovengen 1,1957

Lessor___urs. O021 Arthur Address R. . D. $19 t$ toon 111 inols

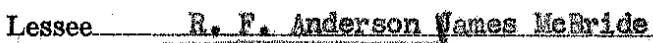

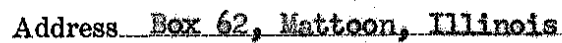

Drilling Contractor 1 . Di210 Address Casey, nllinois

DETAILS OF PLUGGING:

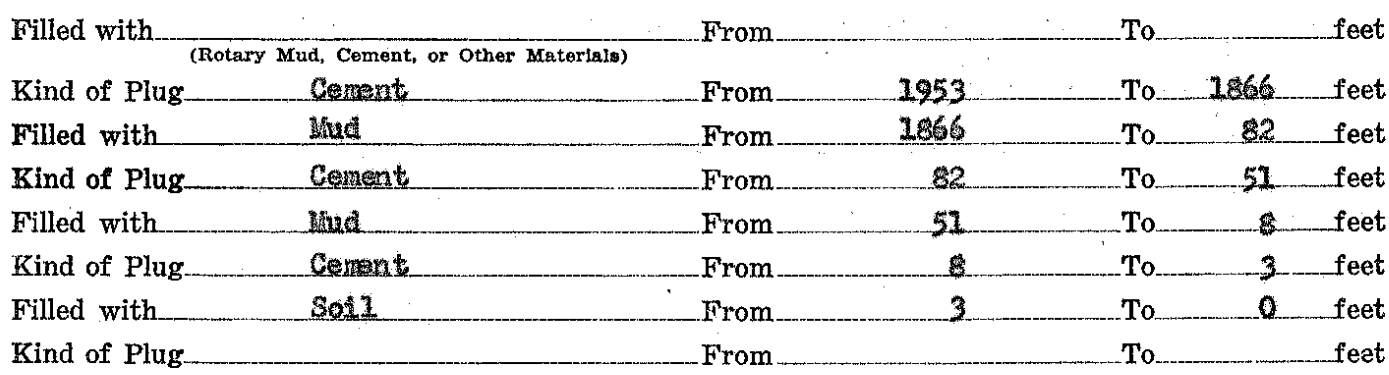

IF WORKABLE COAL BEDS WERE ENCOUNTERED IN THIS HOLE, DESCRIBE THE METHOD EMPLOYED TO PROTECT SAME. (A workable coal bed is thirty inches or more in thickness above 1,000 feet in depth) 10.

(1) Have pits and other excavations been filled? $\ldots \ldots \ldots \ldots \ldots \ldots \ldots$ Yes

(2) Have the following been removed?

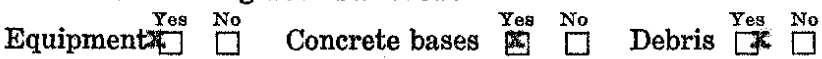

(3) Has surface casing been cut off three feet below ground surface?

(4) Has well-site been levelled?

If this was a producing well, give date and amount of last production

\begin{tabular}{|c|c|c|c|c|c|c|c|}
\hline \multirow[b]{2}{*}{ Size } & \multirow{2}{*}{\multicolumn{2}{|c|}{ PUT IN WELL }} & \multicolumn{4}{|c|}{ CASING RECORD } & \multirow{2}{*}{ 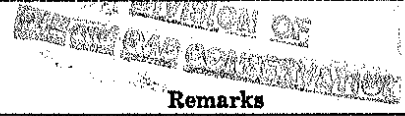 } \\
\hline & & & PULLED OUT & $\begin{array}{l}\text { OUT } \\
\text { Inches }\end{array}$ & \multicolumn{2}{|c|}{ LEFT IN WELL } & \\
\hline $5 / 8$ & 72 & & none & & 72 & & Cemented in \\
\hline $41 / 2$ & 1952 & & none & & 1952 & & Cenented in (cira.) \\
\hline & & & & & & & \\
\hline
\end{tabular}

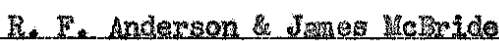

(Slgnature of piexson, firm or corporgtion having custody or control of weil.)

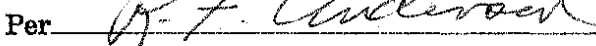

Address Dox 62, gattoon, Itinols 

do depose and say the following is a true and correct statement of the details of the plugging of a certain well drilled for oxt

known as the outrex 1

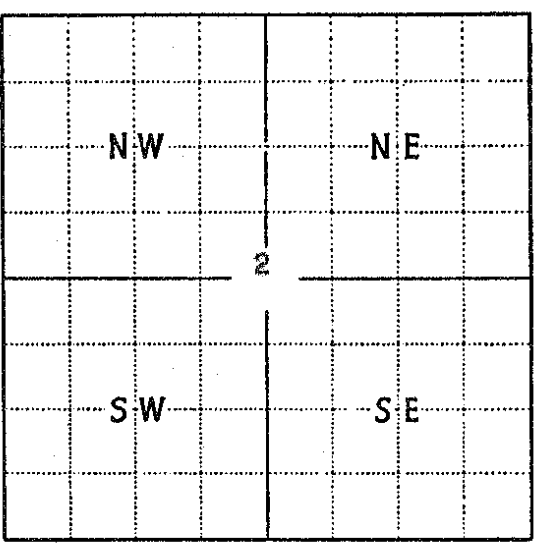

Locate well accurately on plat of section (Scale one inch-2,000 $\mathrm{ft}$.)

Lessor

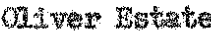

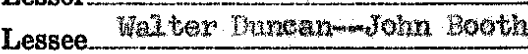

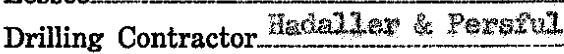

(Indlcate whether for ofl, sas, water or other purposes) and located as follows: 330 ft. south; 330

ft. east ft. north; of the 10 in of the SU Quarter of the Quarter of Section $\frac{2}{7}$, Township 12 - (North or \$arth) Range I (East or Principal Meridian,_oles__County, nlinois. Elevation above sea level is $\{$ Derrick Floor $693 \mathrm{ft}$.

Total depth $2995 \quad$ Formation Oypress Date permit to drill issued $30 / 10 / 46$ ermit No. 2950 Permit issued to We Iter Muxcanwown John Eoth Date drilling began $10 / 10746$

Date drilling completed $10 / 2 \% / 6$

Kind of drilling tools used Dotary

Date plugging began $32 / 29 / 70$

Date plugging completed $12 / 29 / 70$

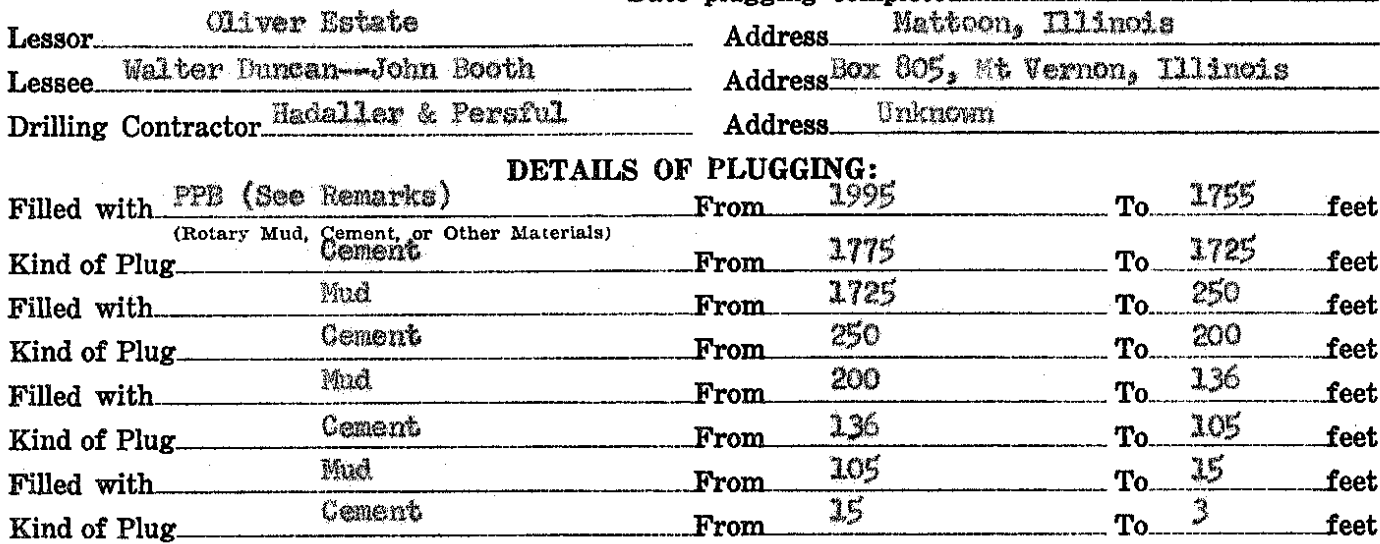

IF WORKABLE COAL BEDS WERE ENCOUNTERED IN THIS HOLE, DESCRIBE THE METHOD EMPLOYED TO PROTECT SAME. (A workable coal bed is thirty inches or more in thickness above 1,000 feet in depth) ___ (tones

(1) Have pits and other excavations been filled? . . . . . . . . .

(2) Have the following been removed?

Equipment $\square$ No Concrete bases $\square^{\text {No }}$ Debris $\square$ No

(3) Has surface casing been cut off three feet below ground surface? Yes

(4) Has well-site been levelled?.....................

If this was a producing well, give date and amount of last production 2 bbi ger wasek

\section{CASING RECORD}

\begin{tabular}{|c|c|c|c|c|c|c|c|}
\hline \multirow[b]{2}{*}{ Size } & \multicolumn{2}{|c|}{ PUT IN WELL } & \multicolumn{2}{|c|}{ PULLED OUT } & \multicolumn{2}{|c|}{ LEFT DN WELC } & \multirow[b]{2}{*}{ Remarks } \\
\hline & Feet & Inches & Feet & Inches & Feet & Inches & \\
\hline 79 & 1906 & & 1135 & & 773 & & One strung of tools and on \\
\hline $103 / 4$ & 126 & & & & 223 & & 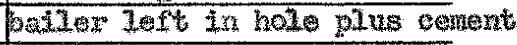 \\
\hline & & & & & & & 1011925 1975 \\
\hline
\end{tabular}

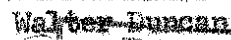

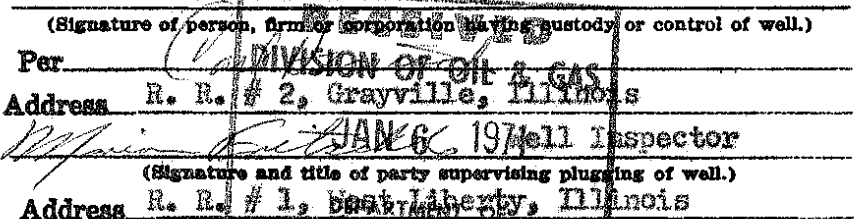

Subscribed and sworn to betore me this $3,-C$, day MWE My commission expires $10,30<4,2$ 


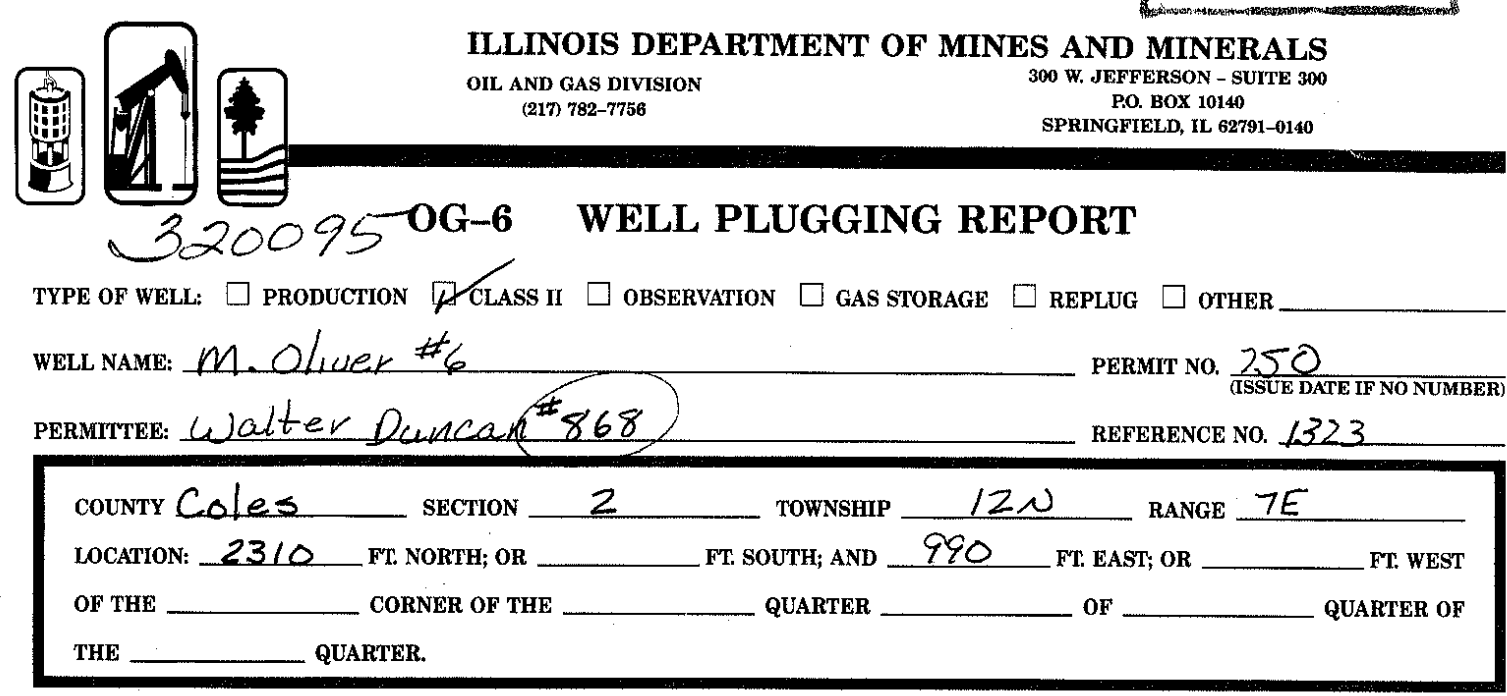

DATE PLUGGING BEGAN $3-4-92$ DAte PlugGing Began $3-4-92$
Plugging contractor Bangert Casing Pulling
address Clay Caty $\mathrm{I} /$

WELL DATA:

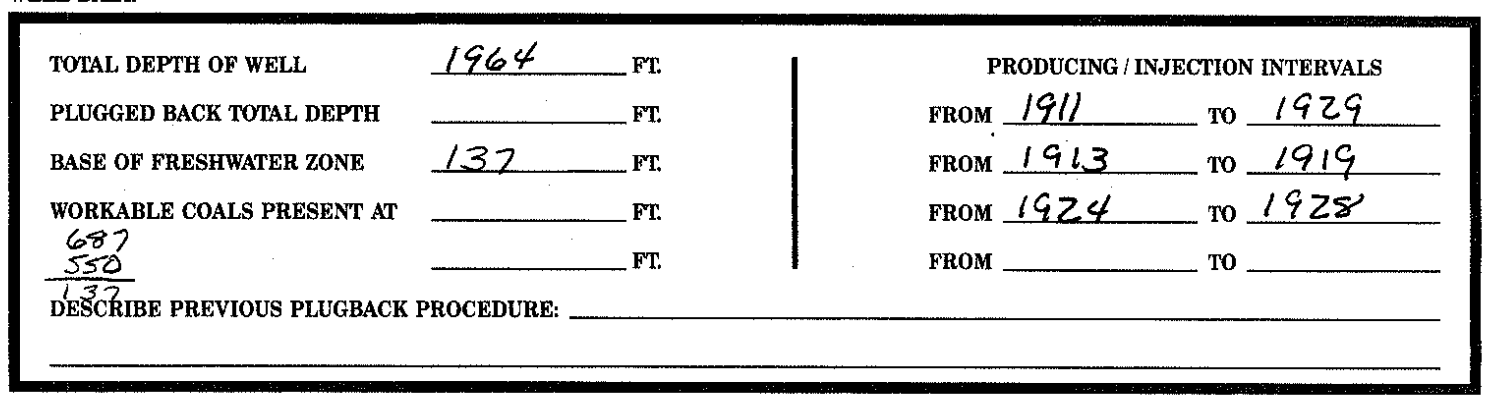

DETAILS OF PLUGGING:

\begin{tabular}{|c|c|c|}
\hline FILLED WTH Cement & FROM TD & $1900 \mathrm{FT}$ \\
\hline FILLED WITH hud & FROM 1900 & $250 \quad \mathrm{FT}$ \\
\hline FILlED WITH Cement & FROM 250 & 4 \\
\hline FILLED WITH 3011 & FROM 4 & 0 \\
\hline FILLED WITH & FROM & FT. \\
\hline COMMENTS: & & \\
\hline
\end{tabular}

WELL DATA:

\begin{tabular}{|l|c|c|c|c|c|c|}
\hline \multicolumn{1}{|c|}{ CASING } & SIZE & $\begin{array}{c}\text { SETTING } \\
\text { DEPTH }\end{array}$ & $\begin{array}{c}\text { SACKS } \\
\text { CEMENT }\end{array}$ & $\begin{array}{c}\text { HOLE } \\
\text { SIZE }\end{array}$ & $\begin{array}{c}\text { EST. TOP OF } \\
\text { CEMENT }\end{array}$ & $\begin{array}{c}\text { AMOUNT OF } \\
\text { CASING REMOVED }\end{array}$ \\
\hline SURFACE & $103 / 4$ & 90 & 50 & & & 4 \\
\hline $\begin{array}{l}\text { INTERMEDIATE /MINE } \\
\text { STRING/OR LINER }\end{array}$ & & & 50 & & & \\
\hline PRODUCTION & $51 / 2$ & 1962 & 150 & & $1000^{\circ}$ & $1000^{\prime}$ \\
\hline
\end{tabular}

UNDER PENALTIES OF PERJURY, I DECLARE THAT I HAVE EXAMINED THIS FORM INCLUDING ACCOMPANYING STATEMENTS AND DOCUMENTS, AND TO THE BEST OF MY KNOWLEDGE, IT IS TRUE, CORRECT, AND COMPLETE.

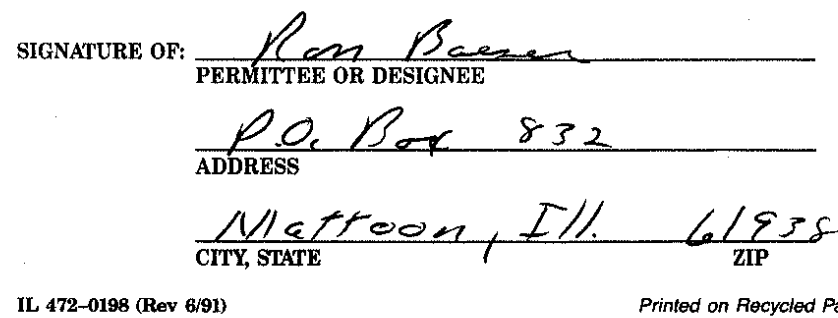

$$
\begin{aligned}
& \text { P.O, Sor } 832 \\
& \text { ADDRESS } \\
& \text { CITY, STATE } \\
& \text { 6/91) }
\end{aligned}
$$

Senin Dpencen

INSPECTOR WITNESSING PLUGGING

$\frac{3-5-92}{\text { DATE }}$$$
\text { DATE }
$$$$
{ }_{1}=y_{1}
$$$$
944+\quad 199
$$ 


\section{2-12N-7E-1}




\section{OG-6 WELL PLUGGING REPORT}

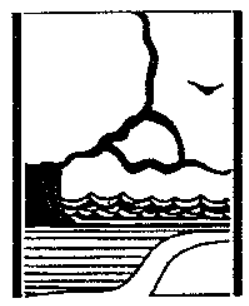

TYPE OF WELL: XPRODUCTION $\square$ CLASS II $\square$ GAS STORAGE $\square$ REPLUG $\square$ OTHER

Permitee: Charles Arman trout PERMITTEE\#:

WELL NAME: Oliver $2-E$

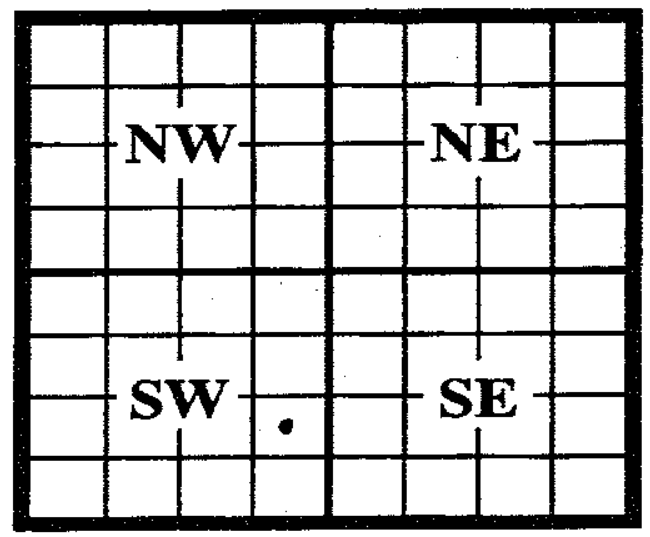

PERMITH:019816 REFERENCE\#: 128460 (ISSUE DATE IF NO NUMBER

COUNTY Coles

SECTION 02 TWP I2N RANGE OTE

LOCATION: 0330 FT. NORTH; OR

FT. SOUTH, AND

FT. EAST; OR 0330

FT. WEST OF THE SE CORNER OF THE NE QUARTER OF THE SE QUARTER OF THE $5 \omega$ QUARTER OF THE QUARTER.

WELL DATA:

SURFACE ELEVATION: TOTAL DEPTH OF WELL PLUGGED BACK TOTAL DEPTH BASE OF FRESHWATER ZONE WORKABLE COALS PRESENT AT DESCRIBE PREVIOUS PLUGBACK PROCEDURE:

\begin{tabular}{cc}
6888 & FT. \\
\hline 1962 & FT. \\
\hline 138 & FT. \\
\hline & FT.
\end{tabular}

FT FT. FT. FT

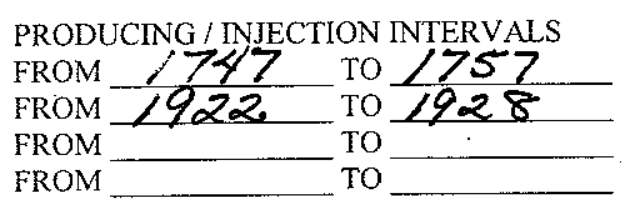

DETAILS OF PLUGGING:

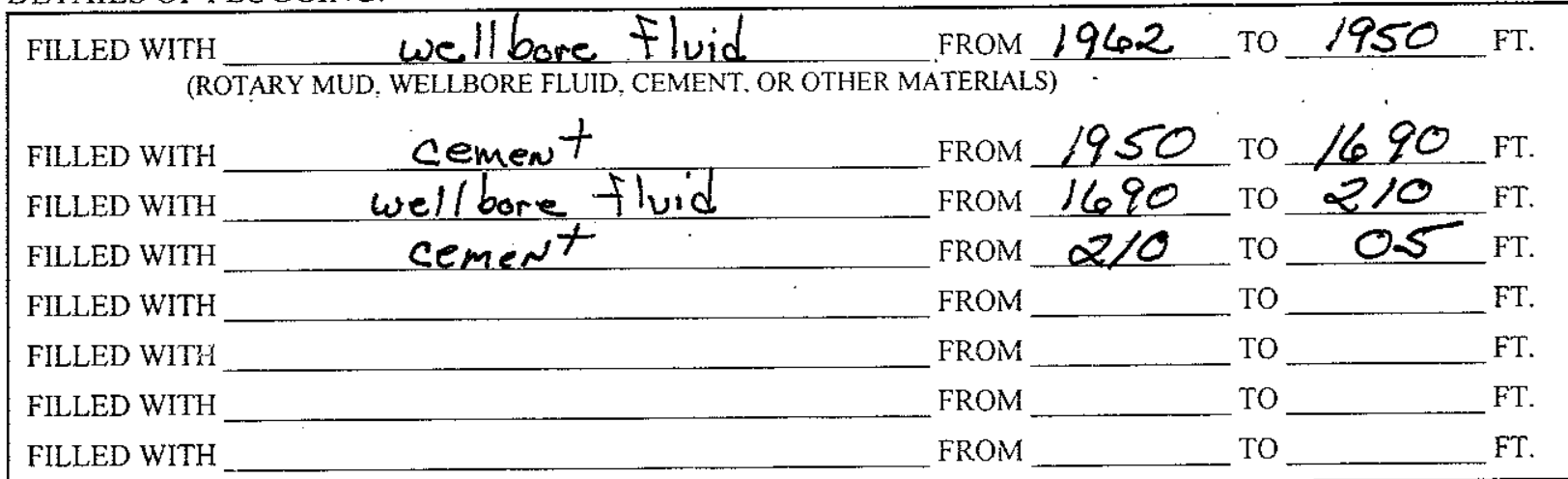

Comments: 
WELL DATA:

\begin{tabular}{|l|c|c|c|c|c|c|}
\hline \multicolumn{1}{|c|}{ CASING } & SIZE & $\begin{array}{c}\text { SETTING } \\
\text { DEPTH }\end{array}$ & $\begin{array}{c}\text { SACKS } \\
\text { CEMENT }\end{array}$ & $\begin{array}{c}\text { HOLE } \\
\text { SIZE }\end{array}$ & $\begin{array}{c}\text { EST. TOP } \\
\text { OF } \\
\text { CEMENT }\end{array}$ & $\begin{array}{c}\text { AMOUNT OF } \\
\text { CASING } \\
\text { REMOVED }\end{array}$ \\
\hline SURFACE & 8.63 & 95 & 100 & 12.25 & 0 & \\
\hline $\begin{array}{l}\text { INTERMEDIATE/ } \\
\text { MINE STRING/OR } \\
\text { LINER }\end{array}$ & & & & & & \\
\hline PRODUCTION & 4,50 & 1962 & 100 & 7.88 & 1420 & 1200 \\
\hline
\end{tabular}

Under penalties of perjury, I declare that I have examined this form including accompanying statements and documents, and to the best of my knowledge, $f t$ is true, correct and complete.

Mourice $\mathrm{Cl}_{\text {Signature of Permittee or Designe }}$

Address
$3-29-05$

Date Plugging began

$3-30-05$

Date Plugging Completed

City, State, Zip

Х Inspector present during plugging operations

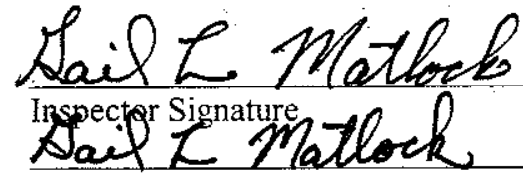

Inspector Signature

Inspector Signature

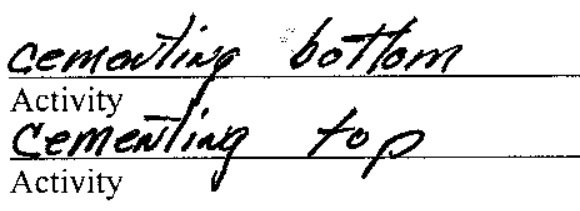

Activity

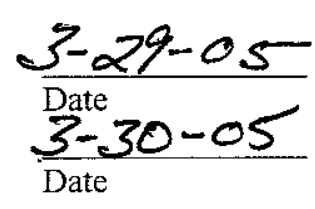

Date

$\square \quad$ Inspector not present during plugging operations

Authorization for Inspector not being present

Plugging information sent to District Office

Inspector site visit to pick up plugging information 


\section{2-12N-7E-2}




\title{
ILLINOIS
County of coles ss. WELL PLUGGING AFFIDAVIT
}

\author{
R. I. Anderson
}

and

Lowell Bernett being first duly sworn, do depose and say the following is a true and correct statement of the details of the plugging of a gertain well drilled for 011 and Gas

known as the (Indicate whether for oil, gas, water or other purposes)

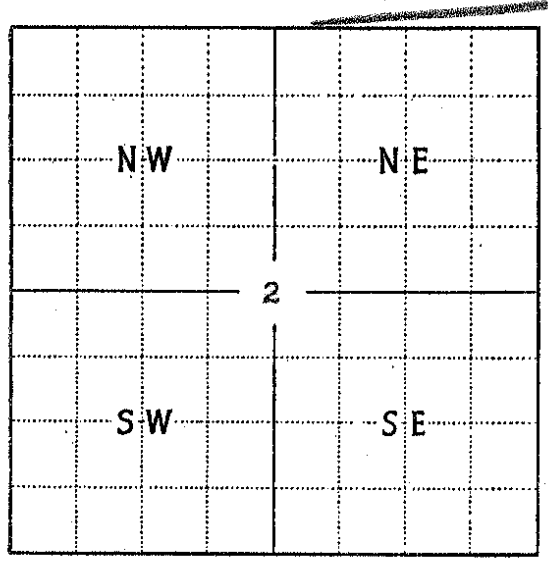

Locate well accurately on plat of section (Scale one 1nch-m-2,000 ft.)

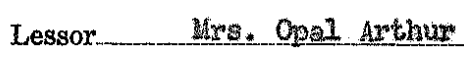

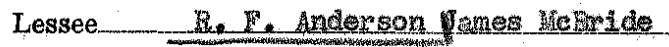

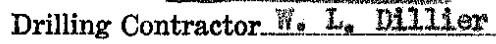
and located as follows:

ft. north;

$330 \mathrm{ft}$ south; $330 \mathrm{ft}$. east;____ ft. west

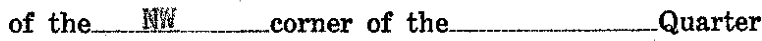
of the ___ Quarter of the_____uarter of

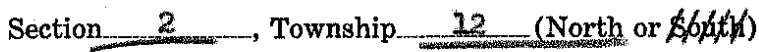
Range $z$, (East or $W\left(66 x^{*}\right.$ ), of the Principal Meridian, Colos County, nlinois. Elevation above sea level is $\left\{\begin{array}{l}\text { Derrick Floor } \\ \text { fround. }\end{array}\right.$ Total depth_ 1953 Formation Date permit to drill issued $4-6-56$ Permit No. 1140

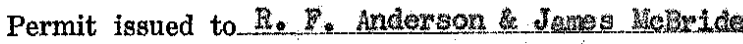
Date drilling began Ar $11,5,1956$ Date drilling completed Arxi1 11, 2956 Kind of drilling tools usedicotory

Date plugging began Oetobex 31,1957

Date plugging completed Wovanbor $1,195 \%$ Address R. F, D. Hatuon, IIInola Address Box 62, Mattoon, N11nots Address Casey, I11 inols

DETAILS OF PLUGGING:

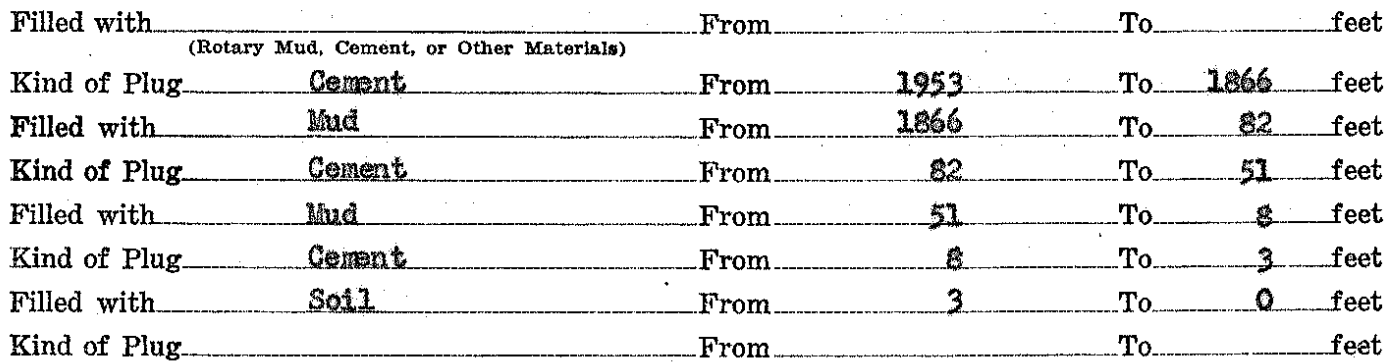

IF WORKABLE COAL BEDS WERE ENCOUNTERED IN THIS HOLE, DESCRIBE THE METHOD EMPLOYED TO PROTECT SAME. (A workable coal bed is thirty inches or more in thickness above 1,000 feet in depth) Hod

(1) Have pits and other excavations been filled? ............

(2) Have the following been removed?

Equipment $\square \stackrel{\text { Yos }}{\square}$ Concrete bases $\underset{\square}{\square} \stackrel{\text { No }}{\square}$ Debris $\stackrel{\text { Yes }}{\square} \square$

(3) Has surface casing been cut off three feet below ground surface?

(4) Has well-site been levelled?

If this was a producing well, give date and amount of last production

\begin{tabular}{|c|c|c|c|c|c|c|c|}
\hline \multirow{3}{*}{ Size } & \multirow{2}{*}{\multicolumn{2}{|c|}{ PUT IN WELL }} & \multicolumn{4}{|c|}{ CASING RECORD } & \multirow{3}{*}{ 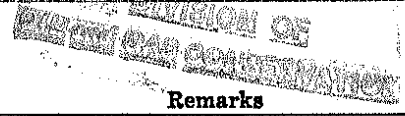 } \\
\hline & & & \multicolumn{2}{|c|}{ PULLED OUT } & \multicolumn{2}{|c|}{ LEFT IN WELL } & \\
\hline & tet & menes & Feet & Inches & Feet & Inches & \\
\hline $5 / 8$ & 72 & & none & & 72 & & Cemented in \\
\hline $41 / 2$ & 1952 & & none & & 1952 & & Cemented in (Cire.) \\
\hline & & & & & & & \\
\hline & & & & & & & \\
\hline
\end{tabular}

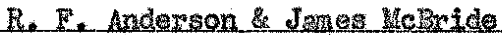
(Signature or perseg, firmony corporation having custody or control of well.) Per $\quad 4) Z$.

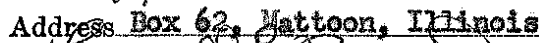

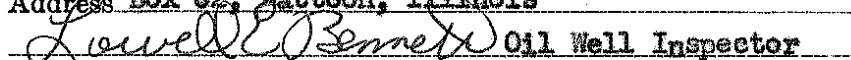
(Signature and title of party supervising plugging of well.)

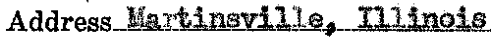

Subscribed and sworn to before me this 8 , day of 2202, A.D. 1952 My commission expires___ $8-7-60$ 
3-12N-7E 


\section{OG-6 WELL PLUGGING REPORT}

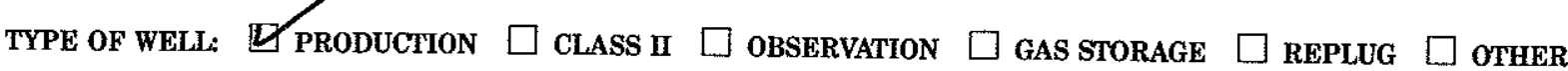

PERMTTEE: Glen A. A. Kirsch WELl NAME: Degler * 1

COUNTY Coles SECTION 3 TOWNSHIP iZN) RANGE ZE LOCATION: $\frac{530}{2}$ FT. NORTH; OR WEST OF THE FT. EAST; OR 330 FT. WEST THE QUARTER. OF QUARTER OF

DATE PLUGGING BEGAN $4 / 25 / 91$ PlugGing CONTRACTOR le lattles Casing Peulling
ADDRESS ADDRESS

WELL DATA:

TOTAL DEPTH OF WELL

PLUGGED BACK TOTAL DEPTH

BASE OF FRESHWATER ZONE

WORKABLE COALS PRESENT AT

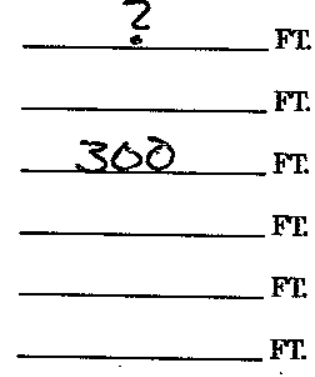

FT.

FT.

DESCRIBE PREVIOUS PLUGBACK PROCEDURE:

DETAILS OF PLUGGING:

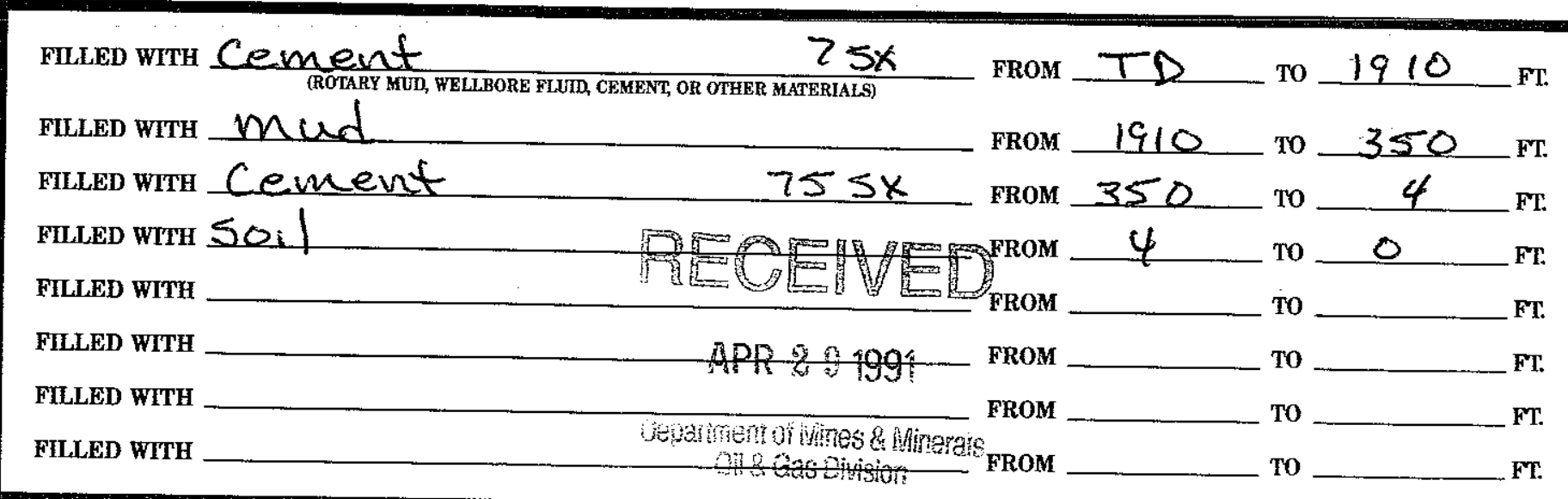


WELL DATA:

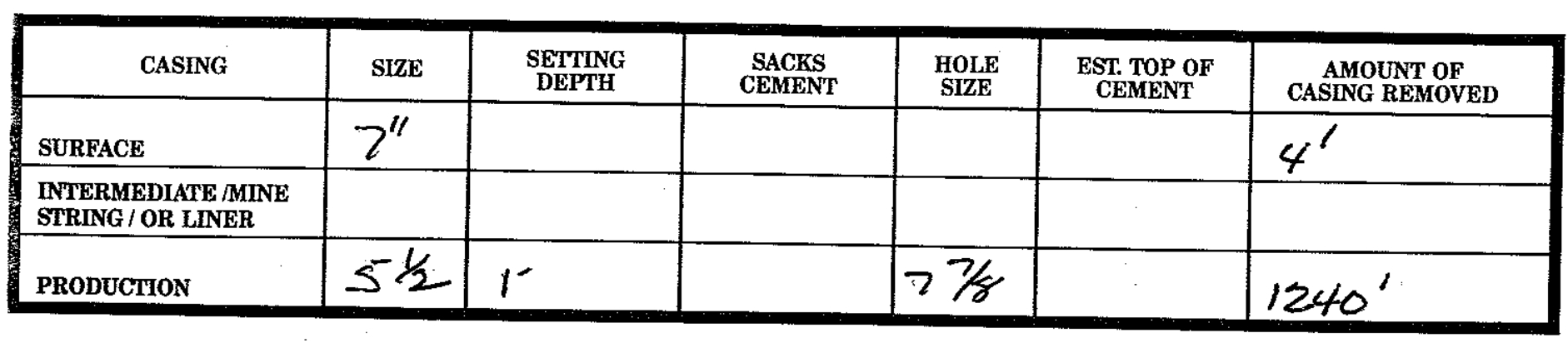

UNDER PENALTIES OF PERJURY, I DECLARE THAT I HAVE EXAMINED THIS FORM INCLUDING ACCOMPANYING STATEMENTS AND DOCUGENTS, AND TO THE BEST OF MY KNOWLEDGE, IT IS TRUE, CORRECT, AND COMPLETE.
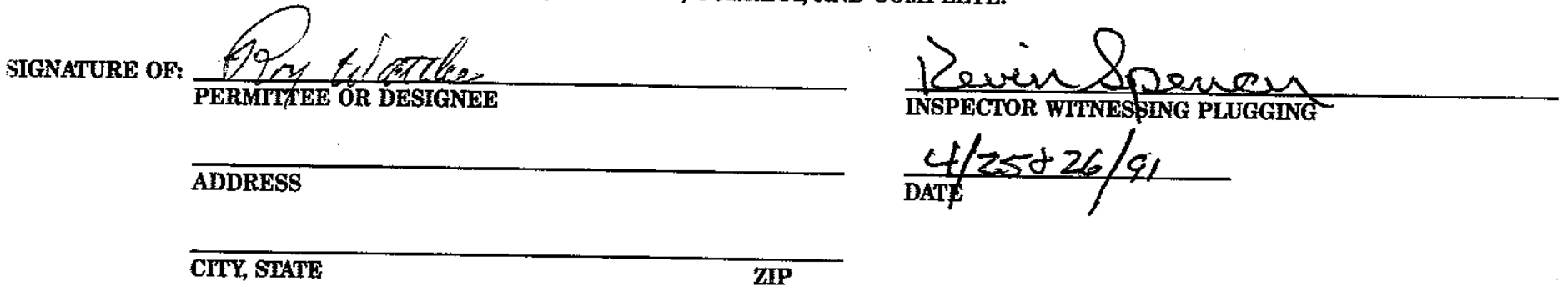


\section{OG-6 WELL PLUGGING REPORT}

TYPE OF WELL: $\square$ PRODUCTION $\square$ ClASS II $\square$ OBSERVATION $\square$ GAS STORAGE $\square$ REPLUG $\square$ OTHER

PERMTTEE: Glenn Kirsch

REFERENCE NO. 123056

weL NAME: Degler 2

PERMT NO. $\frac{.3579}{129}$

COUNTY Coles TECTION 3 TOWNSHIP $12 N$ RANGE $7 E$

LOCATION: $=$ FT. NORTH; OR 330 FT. SOUTH; AND $=$ FI. EAST; OR 330 FT. WEST WEST OF THE NE CORNER OF THE SEE QUARTER NE OF QUARTER OF

THE QUARTER.

DATE PLUGGING BEGAN $4 / 30 / 91$ DATE PLUGGING COMPLETED $4 / 30 / 91$ wathorr plugaing contractor Waftles Casing Pulling

ADDRESS

WELL DATA:

TOTAL DEPTH OF WELL

PLUGGED BACK TOTAL DEPTH

BASE OF FRESHWATER ZONE

WORKABLE COALS PRESENT AT

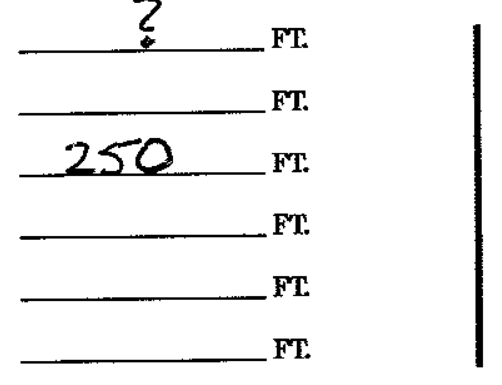

PRODUCING / INJECTION INTERVALS

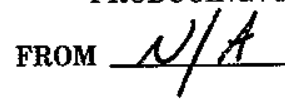

TO

FROM

TO

FROM

TO

FROM

TO

FROM no

DESCRIBE PREVIOUS PLUGBACK PROCEDURE:

\section{DETAILS OF PLUGGING:}

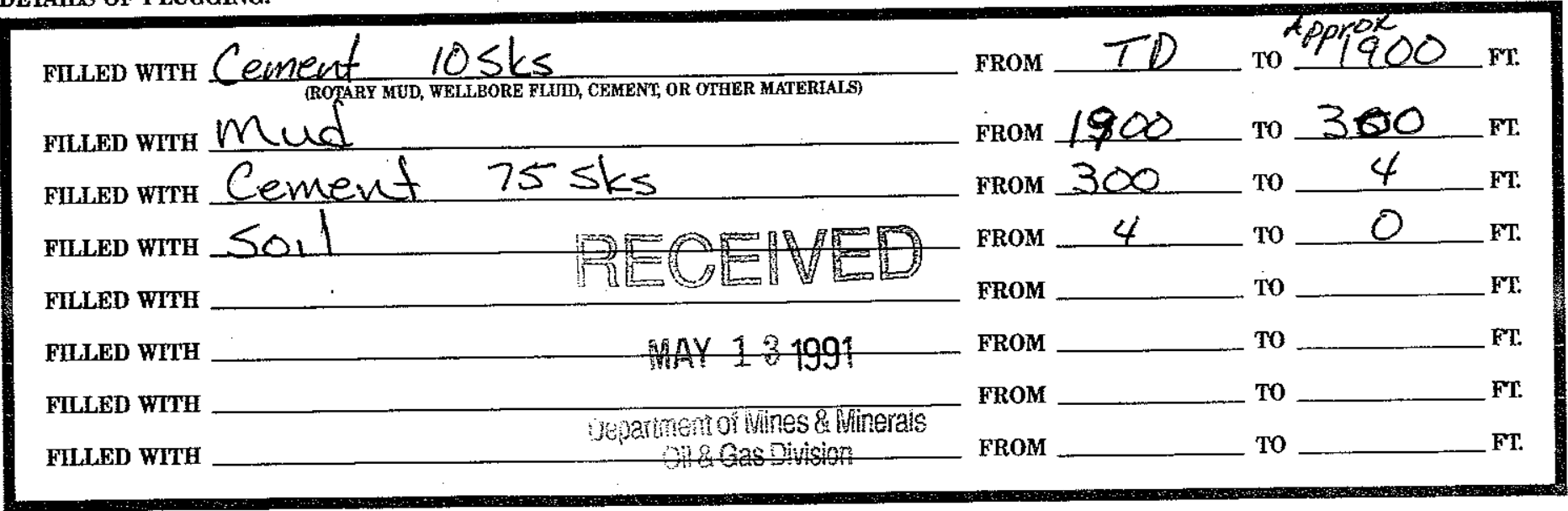


WELL DATA:

\begin{tabular}{|c|c|c|c|c|c|c|}
\hline CASING & SIZE & $\begin{array}{c}\text { SETTING } \\
\text { DEPTH }\end{array}$ & $\begin{array}{c}\text { SACKS } \\
\text { CEMENT } \\
\end{array}$ & $\begin{array}{l}\text { HOLE } \\
\text { SIZE }\end{array}$ & $\begin{array}{c}\text { ESE TOP OF } \\
\text { CEMENT }\end{array}$ & $\begin{array}{c}\text { AMOUNT OF } \\
\text { CASING REMOVED }\end{array}$ \\
\hline SURFACE & & 2 & & & ris & \\
\hline \multicolumn{7}{|c|}{$\begin{array}{l}\text { INTERMEDIATE /MINE } \\
\text { STRING / OR LINER } \\
\end{array}$} \\
\hline PRODUCTION & & 2 & & & & \\
\hline
\end{tabular}

UNDER PENALTIES OF PERJURY, I DECLARE THAT I HAVE EXAMINED THIS FORM INCLUDING ACCOMPANYING STATEMENTS AND DOCUMENTS, AND TO THE BEST OF MY KNOWLEDGE, IT IS TRUE, CORRECT, AND COMPLETE.

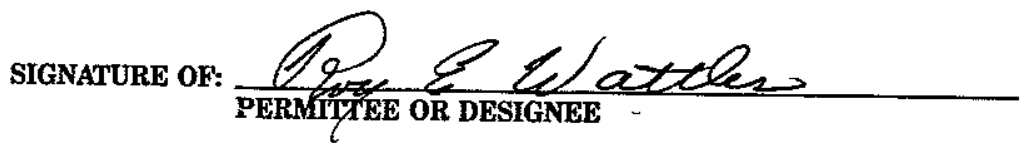<smiles>C1CC2CC[Ge](C1)O2</smiles>

Didinot superuis ADDRESS INSPECTOR WITNESSTING PLUGGING $4 / 30 / 91$

CITY, STATE 


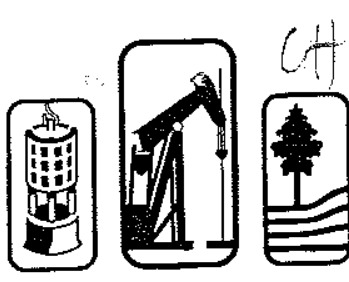

MT TNOTC OFPATMTNT OF

ILINOIS DEPARTMENT OF MINES AND MINERALS

OIL AND GAS DIVISTON

(217) 782-7756

P.O. BOX 10140

SPRINGFIELD, IL 62791-0140

\section{OG-6 WELL PLUGGING REPORT}

TYPE OF WELL: $\square$ PRODUCTION $\square$ ClASS II $\square$ OBSERVATION $\square$ GAS STORAGE $\square$ REPLUG $\square$ oTHER PERMTTEE: Glennakirsch well NAME: Defler

REFERENCE NO. 123056 PERMIT NO.

COUNTY Coles SECTION 3

TOWNSHIP $12 \times 3$

RANGE $Z E$ LOCATION: FT. NORTH; OR 330 FT. SOUTH; AND FT. EAST; OR 330 FT. WEST OF $\$<\Leftarrow$ QUARTER OF THE QUARTER.

DATE PLUGGING BEGAN $4 / 25$ DATE PLUGGING COMPLETED $4 / 26 / 41$ PLugGing contractor lattles casing Pulling ADDRESS

WELL DATA:

TOTAL DEPTH OF WELL

PLUGGED BACK TOTAL DEPTH

BASE OF FRESHWATER ZONE

WORKABLE COALS PRESENT AT

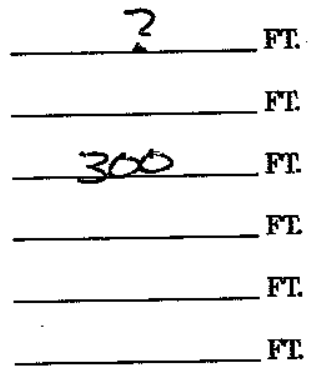

T.

T.

$\mathbf{T}$

FT.

FT.

\section{PRODUCING / INJECTION INTERVALS}

$\begin{array}{lr}\text { FROM } & \text { TO } \\ \text { FROM TO } & \text { TO } \\ \text { FROM } & \text { TO } \\ \text { FROM } & \text { TO }\end{array}$

DESCRIBE PREVIOUS PLUGBACK PROCEDURE:

DEIAILS OF PLUGGING:

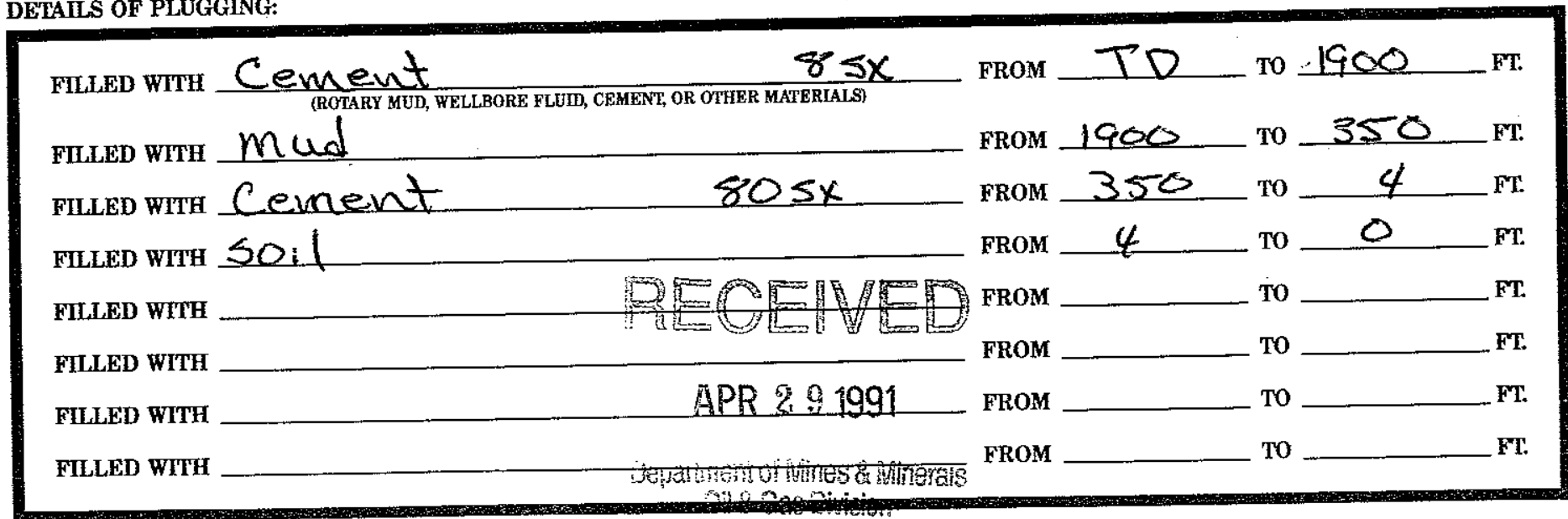


WELL DATA:

\begin{tabular}{|c|c|c|c|c|c|c|}
\hline CASING & SIZE & $\begin{array}{c}\text { SETTING } \\
\text { DEPTH }\end{array}$ & $\begin{array}{l}\text { SACKS } \\
\text { CEMENT }\end{array}$ & $\begin{array}{l}\text { HOLE } \\
\text { SIZE }\end{array}$ & $\begin{array}{l}\text { EST. TOP OF } \\
\text { CEMENT }\end{array}$ & $\begin{array}{c}\text { AMOUNT OF } \\
\text { CASING REMOVED }\end{array}$ \\
\hline SURFACE & & & & & & 4 \\
\hline $\begin{array}{l}\text { INTERMEDIATE MINE } \\
\text { STRING / OR LINER }\end{array}$ & & & & & & \\
\hline PRODUCTION & & & & & & 76 \\
\hline
\end{tabular}

INDER PENALTIES OF PERUUY, I DECLARE THAT I HAVE EXAMINED THIS FORM INCLUDING ACCOMPANYING STATEMENTS AND DOCURENTS, AND TO THE BEST OF MY KNOWLEDGE, IT IS TRUE, CORRECT, AND COMPLETE.

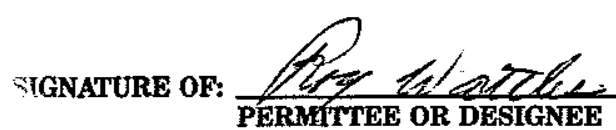

ADDRESS

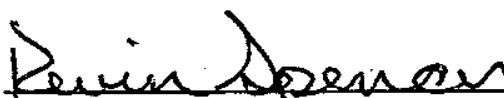
INSPECTOR WITNESTING PLUGGING

$\frac{4 / 25+26}{D A / E}$ 


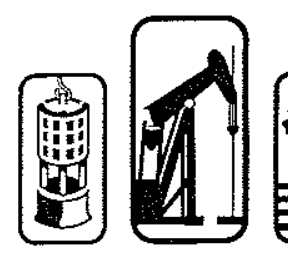

\section{ILLINOIS DEPARTMENT OF MIN OIL AND GAS DIVISION (217) 782-7756}

AND MINERALS

300 W. JEFFERSON - SUITE 300

P.o. BoX 10140

福

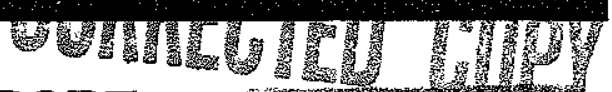

\section{OG-6 WELL PLUGGING REPORT}

TYPE OF WELA: $\square$ PRODUCTION $\square$ CLASS II $\square$ OBSERVATION $\square$ GAS STORAGE $\square$ REPLUG $\square$ OTHER PERMTTEE: Glenh Kirsch weLl NaME: Degler \#3 PERMIT NO.

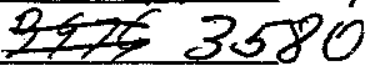

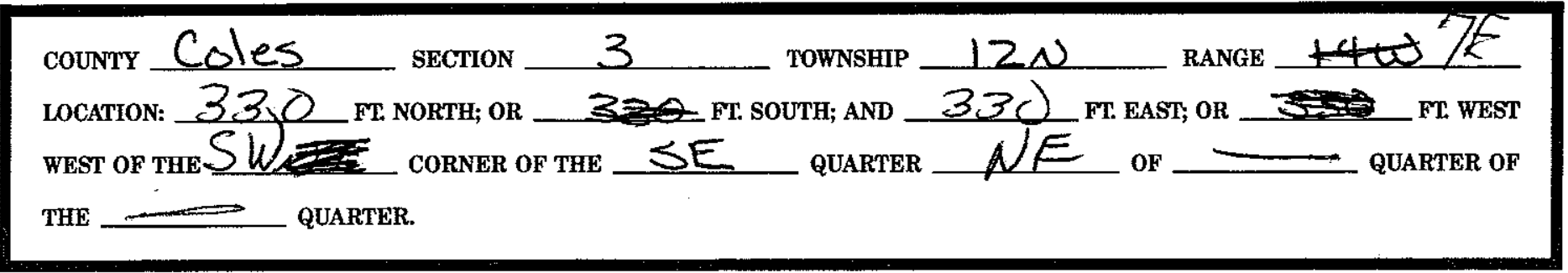

DATE PLUGGING BEGAN S/1/91, DATE PLUGGING COMPLETED $5 / 1 / 91$

PLUGGING CONTRACTOR

ADDRESS

WELL DATA:

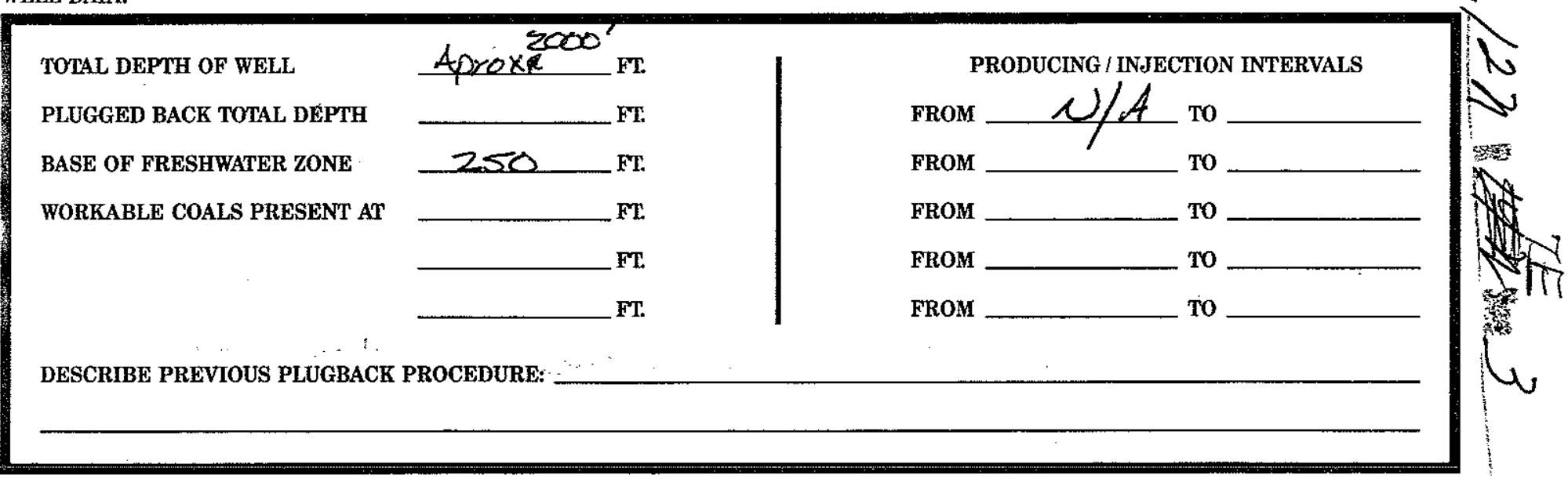

DETAILS OF PLUGGING:

FILLED WTTH Cement 10 sks

FROM TO To 1900 FT

FHLED WITH had

FuLED wITH Cement $755 k_{s}$ FROM 1900 To 300 FT

FLLLED WITH TE(CE) 300 To 0 FT.

FILLED WTTH

FILLED WITH WAY 1.3199 To FT. FROM To FT.

FILLED WITH

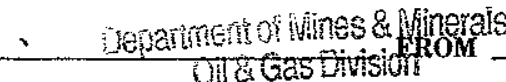
FILLED WITH To FE: FROM TO FT. Fr. 


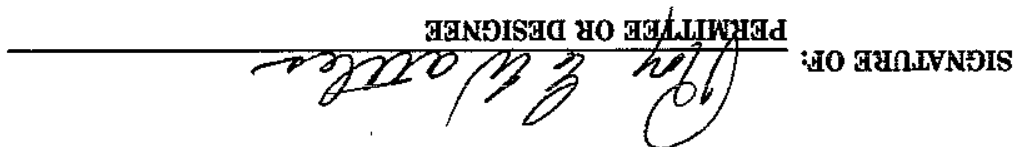

SSTYadV

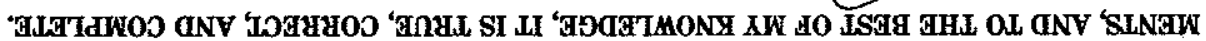

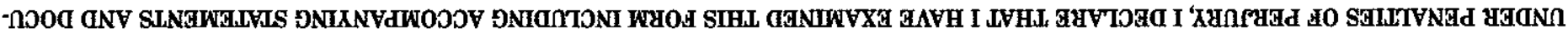

\begin{tabular}{|c|c|c|c|c|c|c|}
\hline,$\left\langle\sum Z_{1}\right.$ &,$\infty 78$ & & $7 / C$ & $p^{\prime} / N$ & & NOLLOAGO\&d \\
\hline & & & & & & 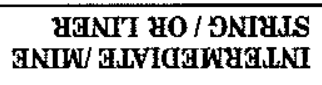 \\
\hline , t & & & $\forall / \curvearrowright$ & $\forall / \Omega$ & ${ }_{11} L$ & ตวขมชns \\
\hline 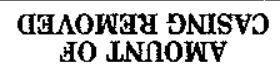 & $\begin{array}{l}\text { INGWFO } \\
\text { 4O dOL ISG }\end{array}$ & $\begin{array}{l}\text { AZIS } \\
\text { GTOH }\end{array}$ & $\begin{array}{l}\text { INAWHP } \\
\text { SYOVS }\end{array}$ & $\begin{array}{l}\text { HIdAG } \\
\text { DNILIAS }\end{array}$ & AZIS & DNISVD \\
\hline
\end{tabular}




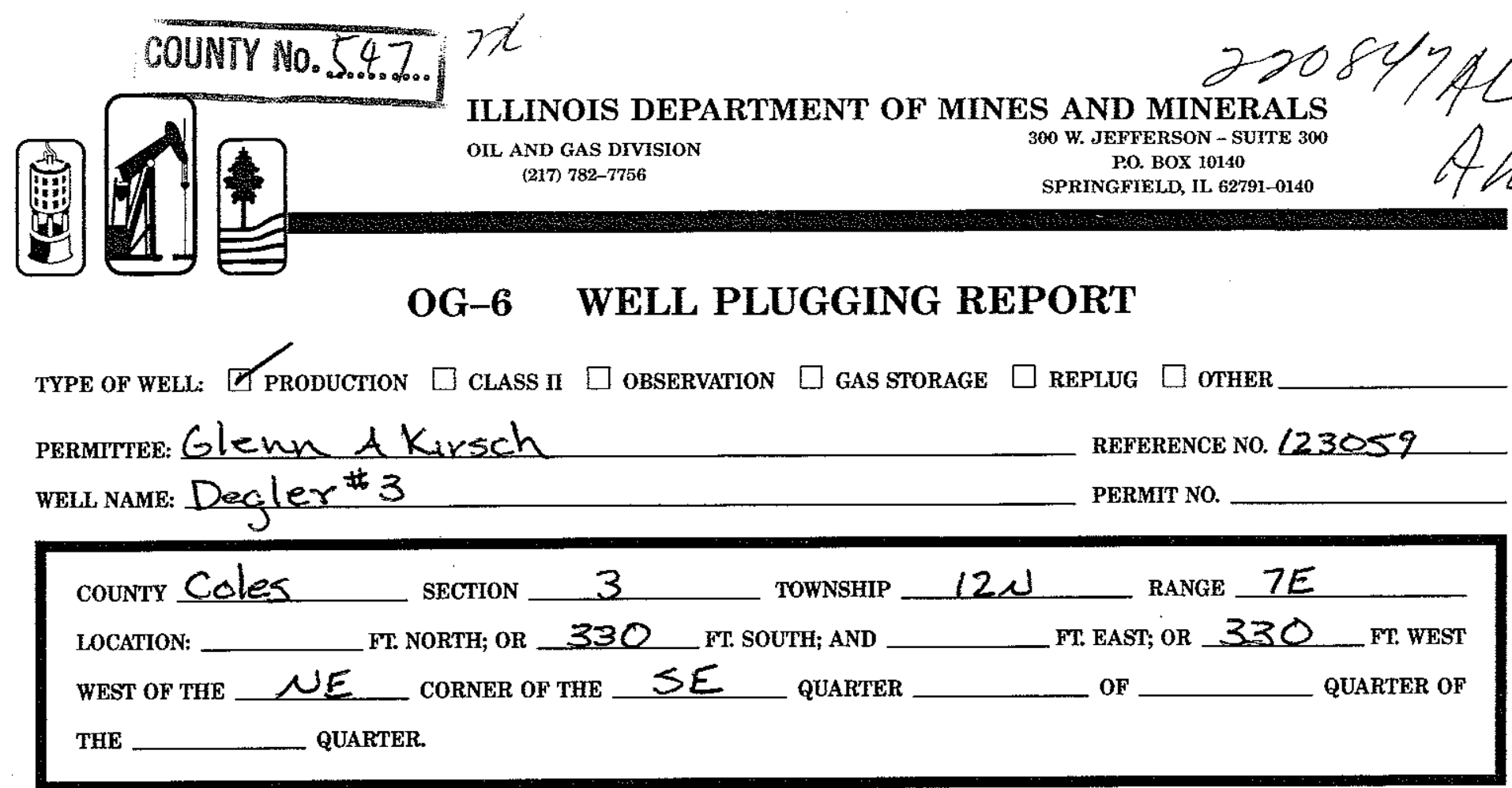

DATE PLUGGING BEGAN $4 / 24 / 91$ DATE PLUGGING COMPLETED $4 / 25 / 91$ pungeing contractor Wattles Casing Pulling ADDRESS

WELL DATA:

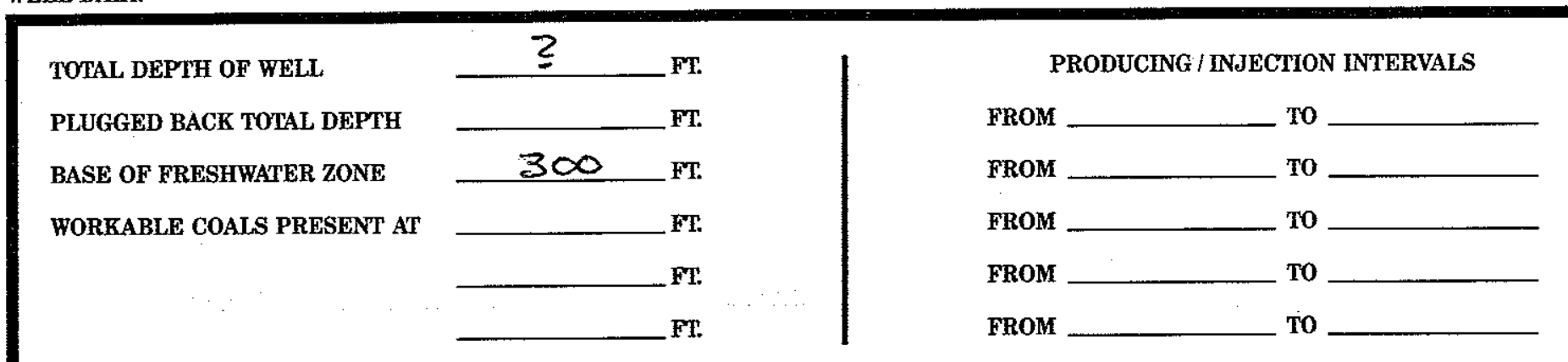

DESCRIBE PREVIOUS PLUGBACK PROCEDURE:

DETAIIS OF PLUGGING:

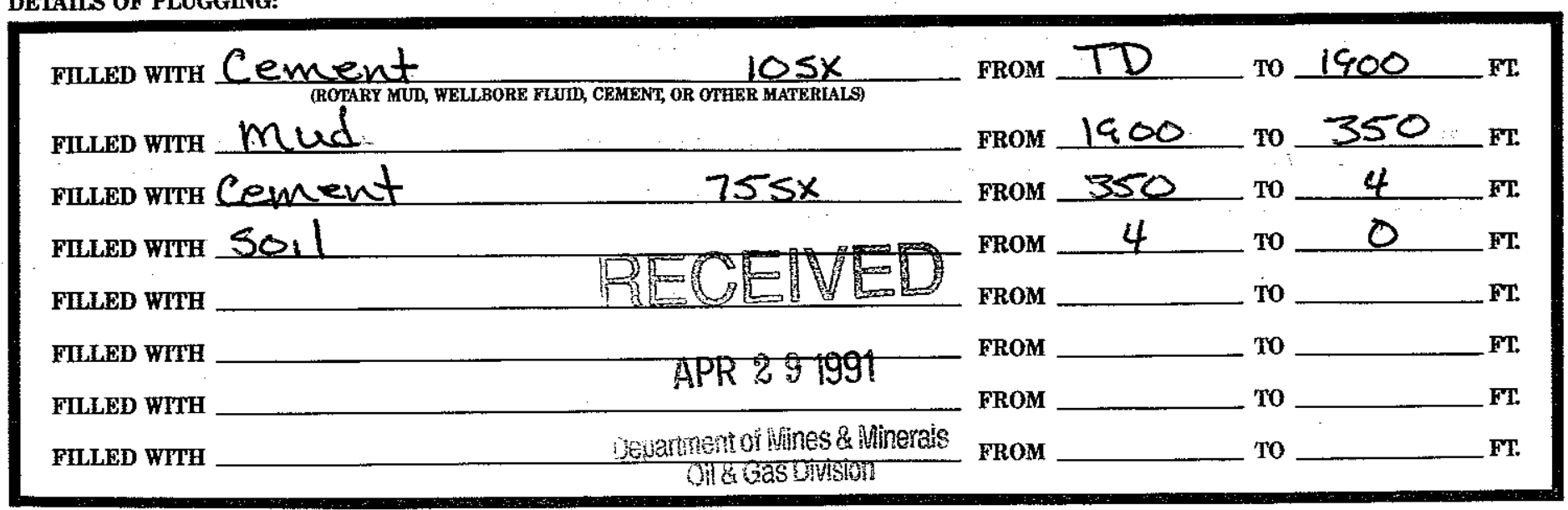


WELL DATA:

\begin{tabular}{|l|c|c|c|c|c|c|}
\hline \multicolumn{1}{|c|}{ CASING } & SIZE & $\begin{array}{c}\text { SETTING } \\
\text { DEPTH }\end{array}$ & $\begin{array}{c}\text { SACKS } \\
\text { CEMENT }\end{array}$ & $\begin{array}{c}\text { HOLE } \\
\text { SIZE }\end{array}$ & $\begin{array}{c}\text { EST. TOP OF } \\
\text { CEMENT }\end{array}$ & $\begin{array}{c}\text { AMOUNT OF } \\
\text { CASING REMOVED }\end{array}$ \\
\hline SURFACE & & & & & \\
\hline $\begin{array}{l}\text { INTERMEDIATE /MINE } \\
\text { STRING / OR LINER }\end{array}$ & & & & & \\
\hline PRODUCTION & $5 / 2$ & 2 & $7 / 2 / 00$ & $1 / 0$ \\
\hline
\end{tabular}

UNDER PENAIMES OF PERJURY, I DECLARE THAT I HAVE EXAMINED THIS FORM INCLUDING ACCOMPANYING STATEMENTS AND DOCUMENTS, AND TO THE BEST OF MY KNOWLEDGE, IT IS TRUE, CORRECT, AND COMPLETE.

signature of: PERMTITTEE OR DESIGNEE

ADDRESS

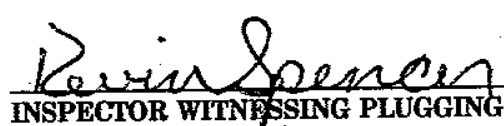

$\frac{4 / 24+25 / 91}{D+1}$

CITY, STATE ZIP 


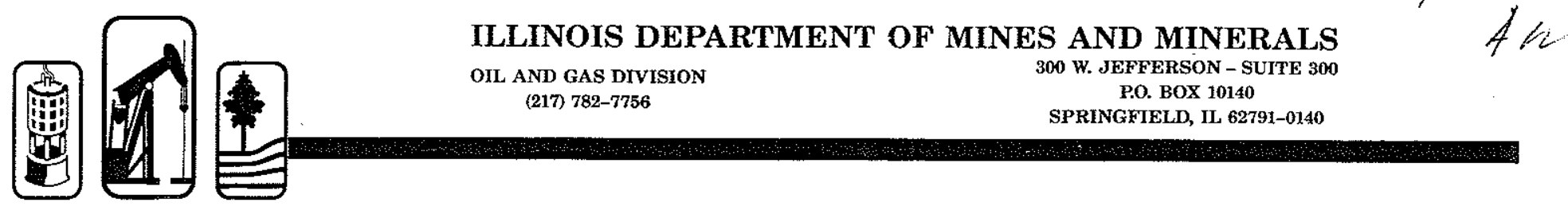

\section{OG-6 WELL PLUGGING REPORT}

TYPE OF WELL: $\square$ PRODUCTION $\square$ ClASS II $\square$ OBSERVATION $\square$ GAS STORAGE $\square$ REPLUG $\square$ OTHER PERMITtE: Glenn Kirsch weLl Name: Degler \#3 PERMIT NO.

COUNTY Coles SECTION_3 TOWNSHIP - 12N RANGE $14 \omega$

LOCATION: FT. NORTH; OR 330 FT. SOUTH; AND FT. EAST; OR 330 FT. WEST WEST OF THE $\perp E$ CORNER OF THE SE QUARTER oF QUARTER OF THE QUARTER.

DATE PlUGGING BEGAN S/1/91 DATE PLUGGING COMPLETED PLUGGING CONTRACTOR ADDRESS

WELL DATA:

TOTAL DEPTH OF WELL

PLUGGED BACK TOTAL DEPTH

BASE OF FRESHWATER ZONE

WORKABLE COALS PRESENT AT
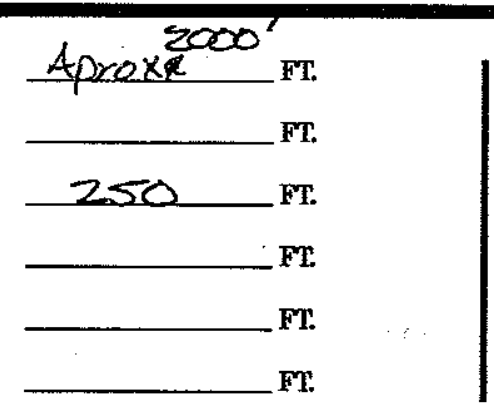

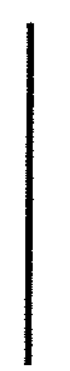

\section{PRODUCING / INJECTION INTERVALS}

FROM TO
FROM TO
FROM TO
FROM TO
FROM To

DESCRIBE PREVIOUS PLUGBACK PROCEDURES

DETAILS OF PLUGGING:

FULED WITH Cemeint 10 S ks

FILLED WITH $\mathrm{mud}$

FILED WITH Cement 75 sks

FILLED WITH REC

FRom TO To 1900 FT.

FILLED WTTH

FILLED WTTH

MAY $13199^{\text {FROM }}$

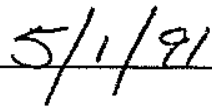


WELL DATA:

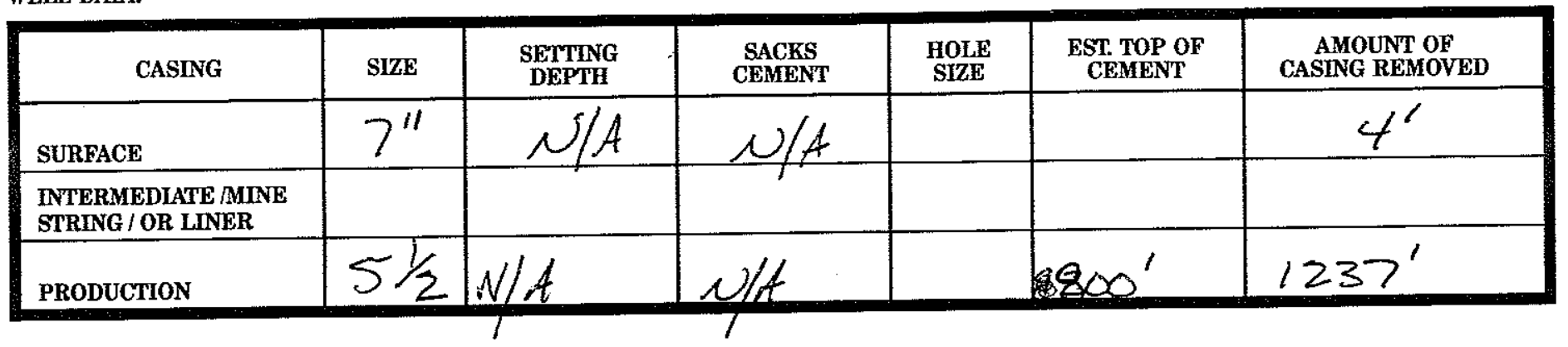

UNDER PENAIMES OF PERJURY, I DECLARE THAT I HAVE EXAMINED THIS FORM INCLUDING ACCOMPANYING STATEMENTS AND DOCU. MENTS, AND TO THE BEST OF MY KNOWLEDGE, IT IS TRUE, CORRECT, AND COMPLETE.

SIGNATURE OF:

ADDRESS
Levin Xopunes INSPECTOR WITNESSNG PLUGGING

$5 / 1 / 91$ 


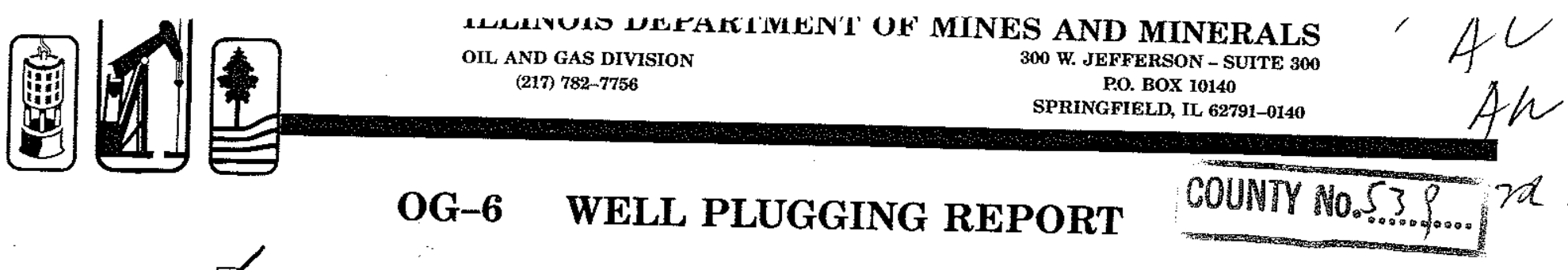

TYPE OF WELL: $\square$ PRODUCTION $\square$ CLASS II $\square$ OBSERVATION $\square$ GAS STORAGE $\square$ REPLUG $\square$ ONHER

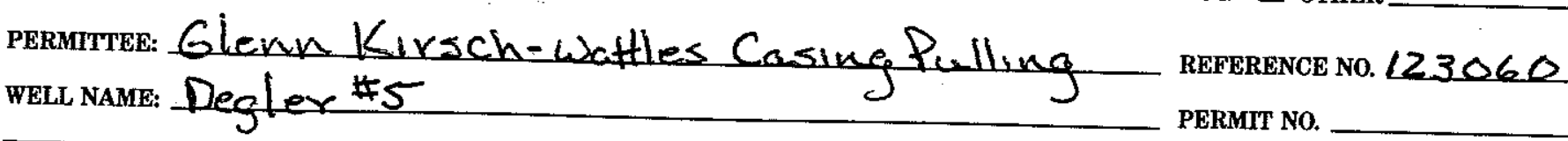

countr Coles SECTION 3 TOWNSHIP $12 \mu$ RANGE $7 E$ LOCATION: 330 FT. NORTH; OR FT. SOUTH; AND WEST OF THE SE_ CORNER OF THE $N E$ THE QUARTER. QUARTER $S E$ FT. EAST; OR 330 FT. WEST OF QUARTER OF

DATE PLUGGING BEGAN $4 / 23 / 91$

PLugGing contractor wattles Casing Pulling ADDRESS RR 3 Box 150 Lamisulle Il 62s58

WELL DATA:

TOTAL DEPTH OF WELL

PLUGGED BACK TOTAL DEPTH

BASE OF FRESHWATER ZONE

WORKABLE COALS PRESENT AT

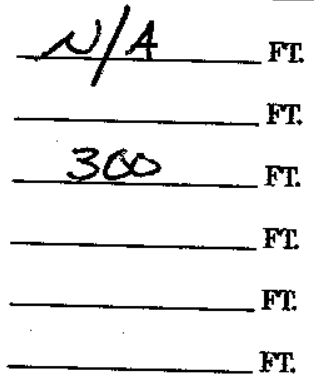

PRODUCING / INJECTION INTERVALS

$\begin{array}{lr}\text { FROM } & \text { To } \\ \text { FROM } & \text { TO } \\ \text { FROM To } & \text { TO } \\ \text { FROM TO } & \text { TO }\end{array}$

DESCRIBE PREVIOUS PLUGBACK PROCEDURE:

DETAILS OF PLUGGING:

FILLED WITH Cement $105 x$ (ROTARY MUD, WELLBORE FLUID, CEMENT, OR OTHER MATERIAIS) FILLED WITH Mud

FILED WITH 5 Cement $755 x$

FILIED WITH Sol

FILLED WITH MI

FTLLED WITH

FILLED WITH APR ? 999

FROM TD FROM 1900 FROM -350 FROM 4 FROM FROM FROM

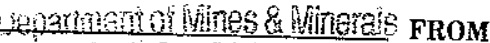
Tís Gas Divicion To 1900 FT то 350 FT. To 4 FT. TO $\mathrm{O} \quad \mathrm{FT}$. To _ _ FT. TO __ FT. TO _ _ FT. TO FT. 
WELL DATA:

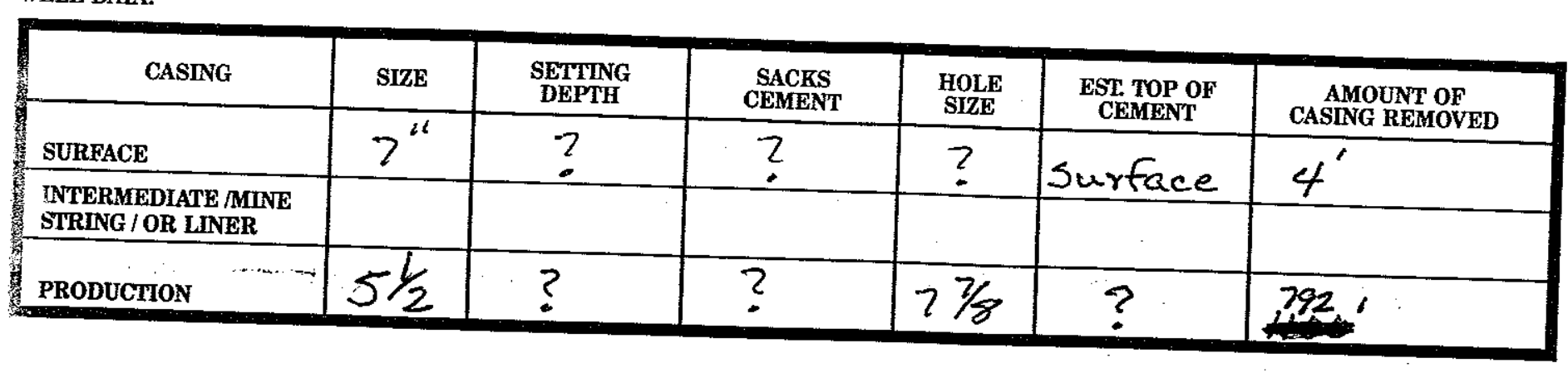

UNDER PENALTIES OF PERJURY, I DECLARE THAT I HAVE EXAMINED THIS FORM INCLUDING ACCOMPANYING STATEMENTS AND DOCU. HINTS, AND TO THE BEST OF MY KNOWLEDGE, IT IS TRUE, CORRECT, AND COMPLETE.

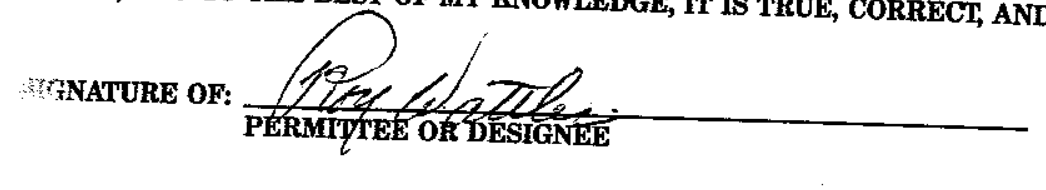

ADDRESS

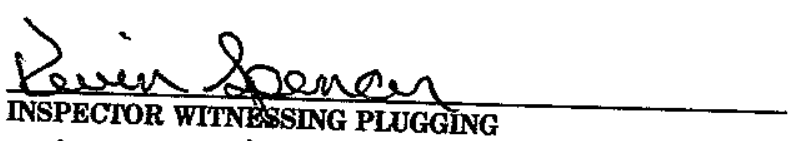

INSPECTOR WITNESSING PLUGGING

$\frac{4 / 23+2491}{D A T E}$

CITY, STATE

ZIP 


\section{OG-6 WELL PLUGGING REPORT}

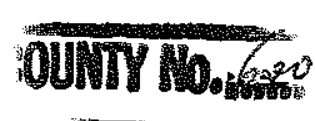

TYPE OF WELL: $\square$ PRODUCTION $\square$ Class II $\square$ observation $\square$ GAS STORAGE $\square$ REPLUG $\square$ OTHER

PERMITTE: Glenn Kirsch

well Name: Degley \#6
REFERENCE No. 123061 PERMIT NO. county Coles section 3 TOWNSHIP isu

LOCATION: 330 FT. NORTH; OR WEST OF THE $5 \omega$ THE QUARTER. QUARTER
FT. SOUTH; AND 330 FT. EAST; OR RANGE L4t $7 E$ FT. WEST OF SE QUARTER OF

DATE PLUGGING BEGAN $5 / 2 / 91$

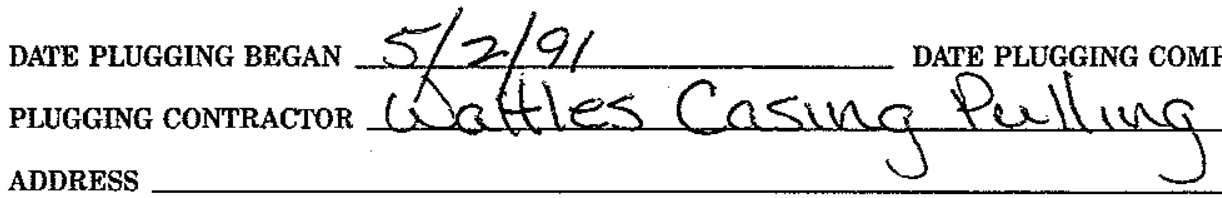

\section{WELL DATA:}

TOYAL DEPTH OF WELL

PLUGGED BACK TOTAL DEPTH

BASE OF FRESHWATER ZONE

WORKABLE COALS PRESENT AT
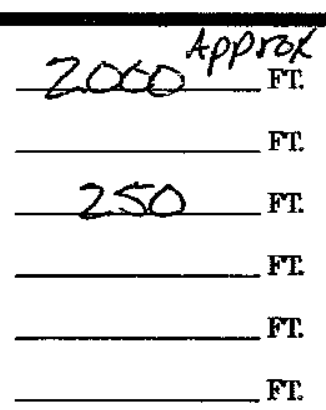
$5 / 2 / 91$

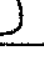

TPLETED $S$ 
WELL DATA:

\begin{tabular}{|c|c|c|c|c|c|c|}
\hline CASING & SIZE & $\begin{array}{c}\text { SETYTNG } \\
\text { DEPTH }\end{array}$ & $\begin{array}{c}\text { SACKS } \\
\text { CEMENT }\end{array}$ & $\begin{array}{l}\text { HOLE } \\
\text { SIZE }\end{array}$ & $\begin{array}{l}\text { EST. TOP OF } \\
\text { CEMENT }\end{array}$ & $\begin{array}{c}\text { AMOUNT OF } \\
\text { CASING REMOVED }\end{array}$ \\
\hline SURFACE & $7^{h}$ & & & & & $4^{\prime}$ \\
\hline $\begin{array}{l}\text { INTERMEDIATE /MINE } \\
\text { STRING / OR LINER }\end{array}$ & & & & & & \\
\hline PRODUCTION & & & - & & & \\
\hline
\end{tabular}

UNDER PENALTIES OF PERJURY, I DECLARE THAT I HAVE EXAMINED THIS FORM INCLUDING ACCOMPANYING STATEMENTS AND DOCU. MEN'T, AND TO THE BEST OF MY KNOWLEDGE, IT IS TRUE, CORRECT, AND COMPLETE.

Signature of: Pry \& tades. PEKMTTTEE OR DESIGNEE

ADDRESS

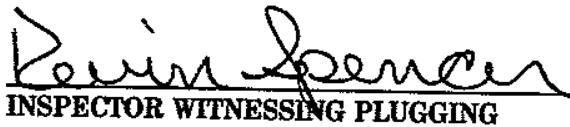

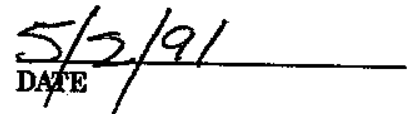

CITY, STATE 


\section{OG-6 WELL PLUGGING REPORT}

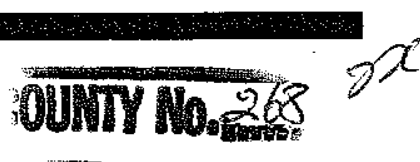

TYPE OF WELL: $\square$ PRODUCTION $\square$ ClASS II $\square$ OBSERVATION $\square$ GAS STORAGE $\square$ REPLUG $\square$ OTHER

PERMTTEE: Glenn Kirsch welu name: Augustus Degler county Coles SECTION 3 CORNER OF THE

WEST OF THE
REFERENCE No. 123058 PERMT No. 1671
LOCATION: 990 FT. NORTH; OR _ FT. SOUTH; AND

THE QUARTER.
40 $2 x$

ATE PLUGGING Began $5 / 3 / 91$ plugging contractor Roy uxaffles DATE PLUGGING COMPLETED $5 / 3 / 61$ ADDRESS

WELL DATA:

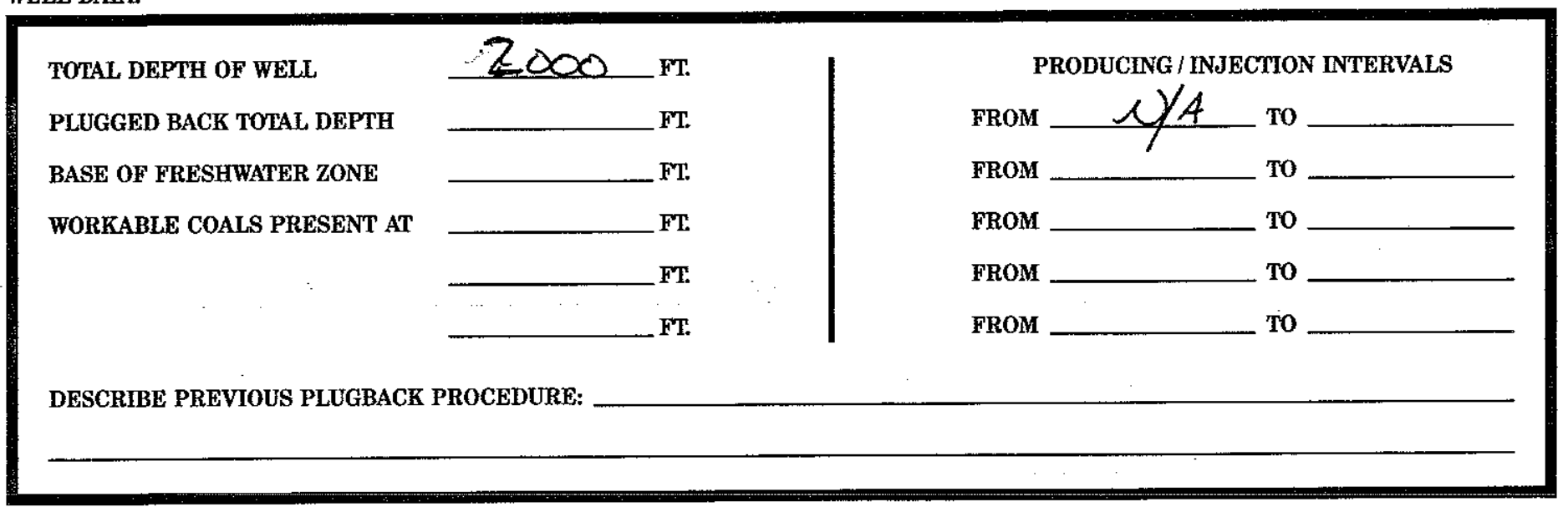

DETAIIS OF PLUGGING:

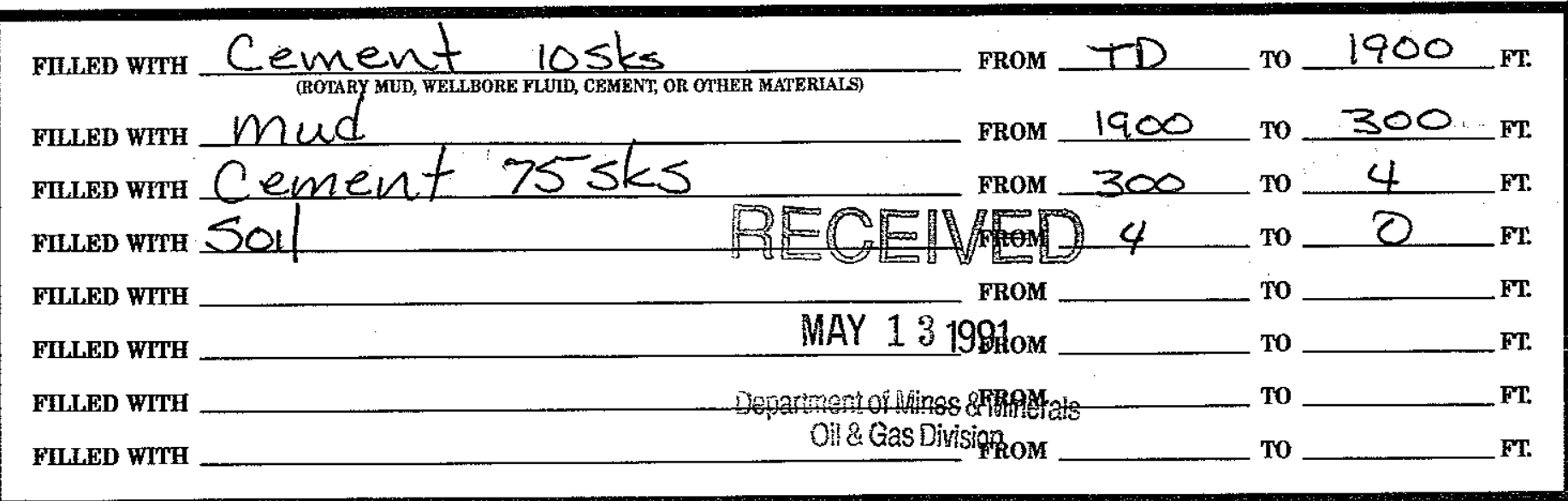

IL 472-0198 (Rev 12/90) 
WELL DATA:

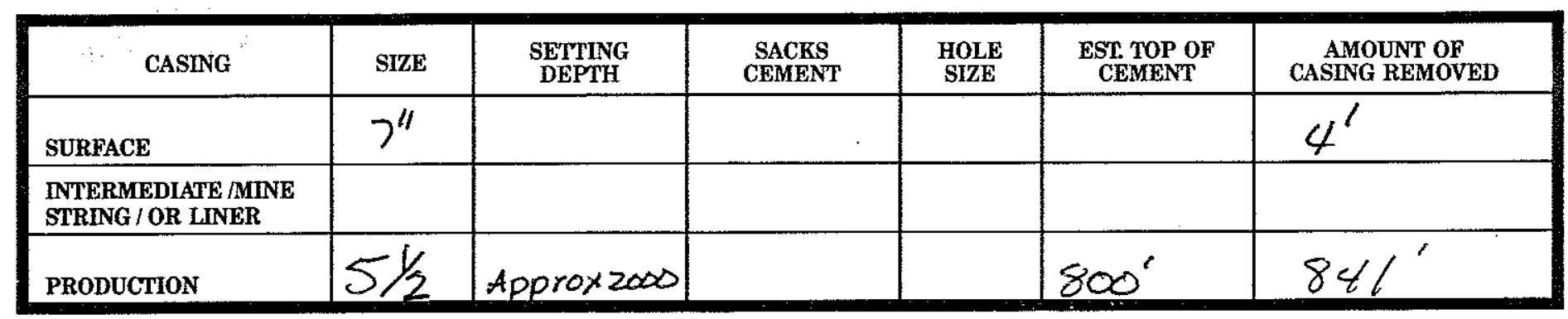

UNDER PENAETIES OF PERJURY, I DECLARE THAT I HAVE EXAMINED THIS FORM INCLUDING ACCOMPANYING STATEMENTS AND DOCUMENTS, AND TO THE BEST OF MY KNOWLEDGE, IT IS TRUE, CORRECT, AND COMPLETE.

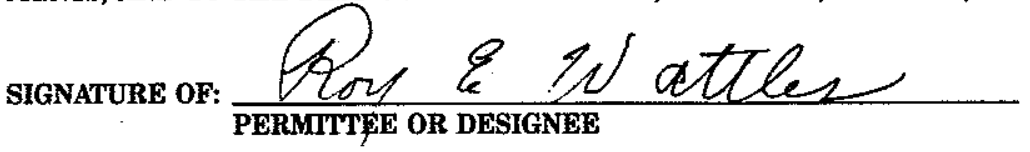

ADDRESS

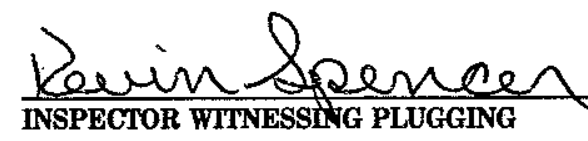

$5 / \Sigma / 91$

CITY, STATE ZIP 


\section{3-12N-7E-1}




\section{County of Clece WEL PLUGGING AFFIDAVIT}

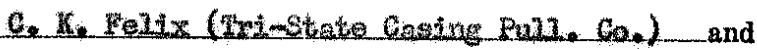

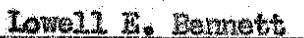
being first duly sworn, do depose and say the following is a true and correct statement of the details of the plugging of a certain well drilled for aid 0 ces

known as the

Principal Meridian, Elevation above sea level is $\begin{cases}\text { Derrick Floor______ft. } & \text { ft. }\end{cases}$ E Total depth $1975 \quad$ Formation Date permit to drill issued $20-25-56$ permit No. $\quad 390$

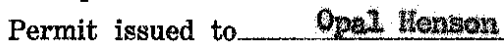
Date drilling began Octobor 28. 1956 Locate well accurately on plat of section Date drilling completed Wovenber 7, 1956 Kind of drilling tools used hotary ( Scale one ench-2,000 ft.)

Date plugging began Dacendore 24,2958

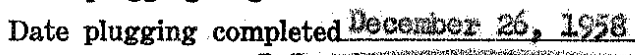

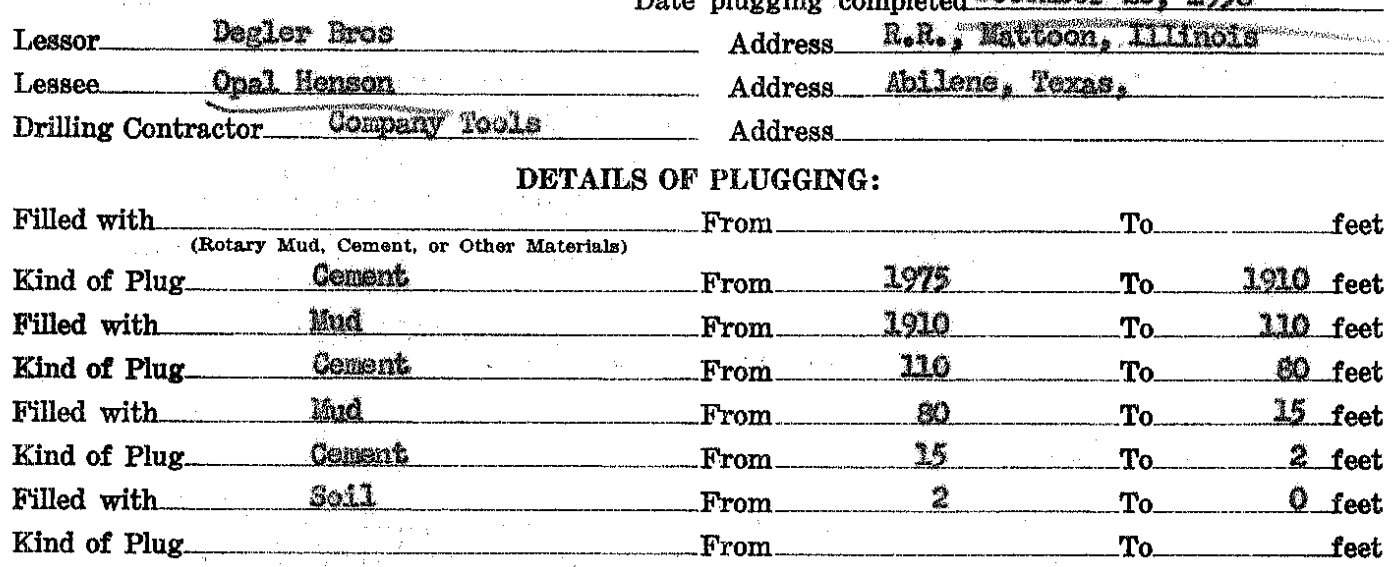

IF WORKABLE COAL BEDS WERE ENCOUNTERED IN THIS HOLE, DESCRIBE THE METHOD EMMPLOYED TO PROTECT SAME. (A workable coal bed is thirty inches or more in thickness above 1,000 feet in depth) ___ None

(1) Have pits and other excavations been filled?

(2) Have the following been removed?

\section{Equipment $\left[\begin{array}{lll}\text { Yes } \\ \square\end{array}\right.$ Concrete bases 国}

(3) Has surface casing been cut off three feet below ground surface?

(4) Has well-site been levelled?.

If this was a producing well, give date and amount of last production

\begin{tabular}{|c|c|c|c|c|c|c|c|}
\hline \multirow[b]{2}{*}{ Size } & \multicolumn{7}{|c|}{ CASING RECORD } \\
\hline & Feet & Inches & Feot & Inches & Feet & Inches & Ramarks \\
\hline$+5 / 8$ & 96 & & nowe & & 96 & & 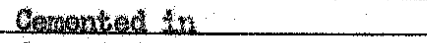 \\
\hline$\$ 1 / 2$ & 197 & & 2423 & & 522 & & 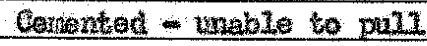 \\
\hline & & & & & & & \\
\hline
\end{tabular}

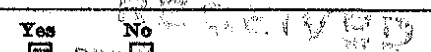
on: 0 , wh

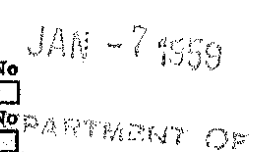
AMs Whong

\section{Orat Henes.}

(Stgngture of peragn, frm or corporation having custody or control of woll.)

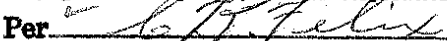

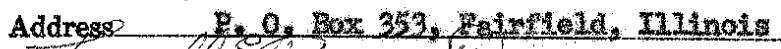

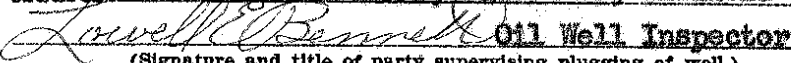
(Signature and title of party supervising plugetng of well) Address

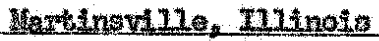

Subscribed and sworn to before me this 2 th day of My commission expires_____ $\quad \mathbf{3}-9-62$ 

ntro

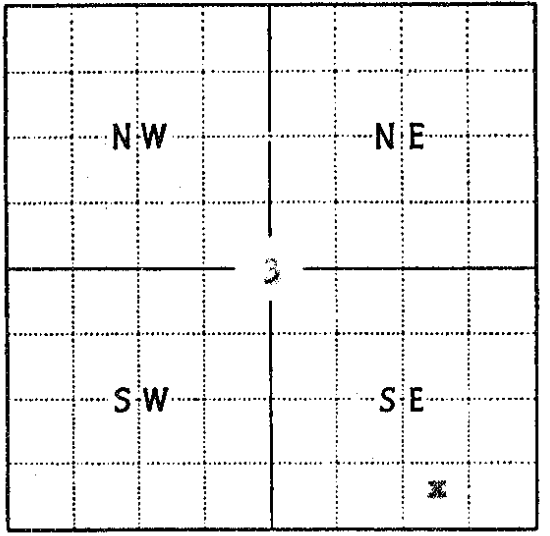

Locate well accurately on plat of section (Scale one inch-2,000 ft.) and located as follows: 330 ft. north;

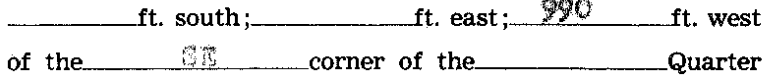

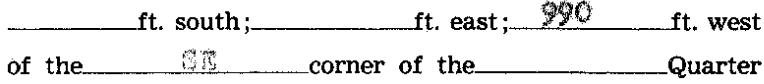

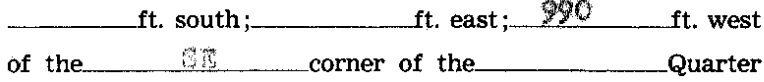
of the___ Quarter of the____ Quarter of Section $\quad 3$, Township_L_ (North of/South) Range o (East of (Wést) of the 37 ,

Principal Meridian, County, Illinois. Elevation above sea level is $\left\{\begin{array}{l}\text { Derrick Floor } \\ \text { Ground } \mathrm{ft} .\end{array}\right.$

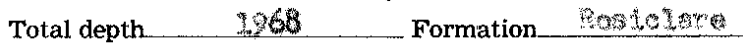
Date permit to drill issued $10-10-60$ ermit No. $208-w / 3.3 \%$

Permit issued to

Date drilling began $\quad 30-70-60$

Date drilling completed $10-13-0$

Kind of drilling tools used... Rotesisy Date plugging began ‥ $\quad x-12-13$

Date plugging completed $\quad 4-13-7$

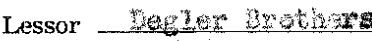
Address H

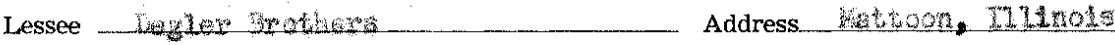

Drilling Contractor 蛙

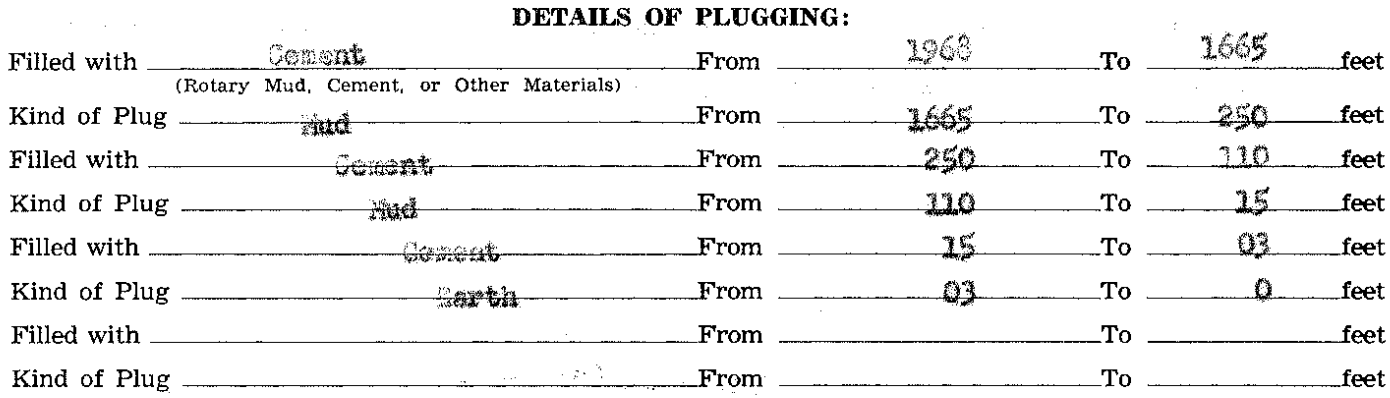
IF WORKABLE COAL BEDS WERE ENCOUNTERED IN THIS HOLE, DESCRIBE THE METHOD EMPLOYED TO PROTECT SAME. (A workable coal bed is thirty inches or more in thickness above 1,000 feet in depth) tot

(1) Have pits and other excavations been filled?

(2) Have the following been removed?

$$
\text { Equipment } \stackrel{\text { Yes }}{\square} \underset{\text { No }}{\square} \text { Concrete bases } \stackrel{\text { Yes }}{\square} \text { o. Debris } \stackrel{\text { Yes }}{\square} \text { № }
$$

(3) Has surface casing been cut off three feet below ground surface?

(4) Has well-site been leveled? . . . . . . . . . . . . . . . . . . . . . . . . . .

If this was a producing well, give date and amount of last production

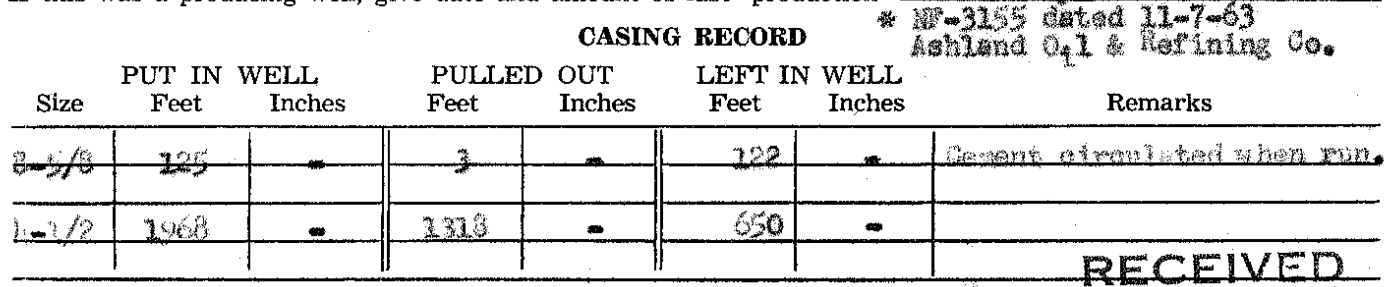

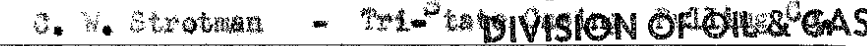

(Slgnature of person farm or corporation having custody or control of well.)

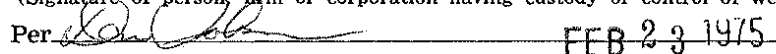

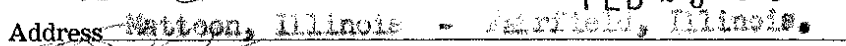

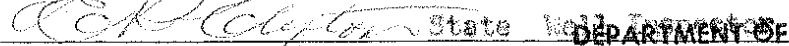

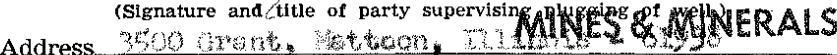

Subscribed and sworn to before me this 7 day of day My commission expires__ $\quad 10-23-76$

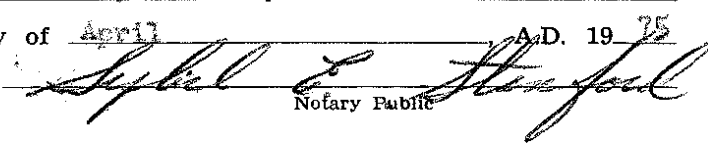




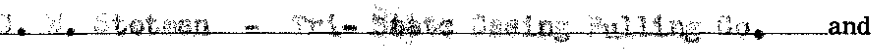

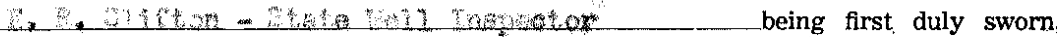
do depose and say the following is a true and correct statement of the details of the plugging of a certain well drilled for in.

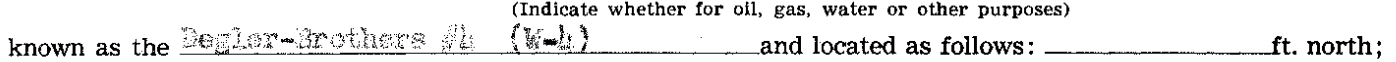

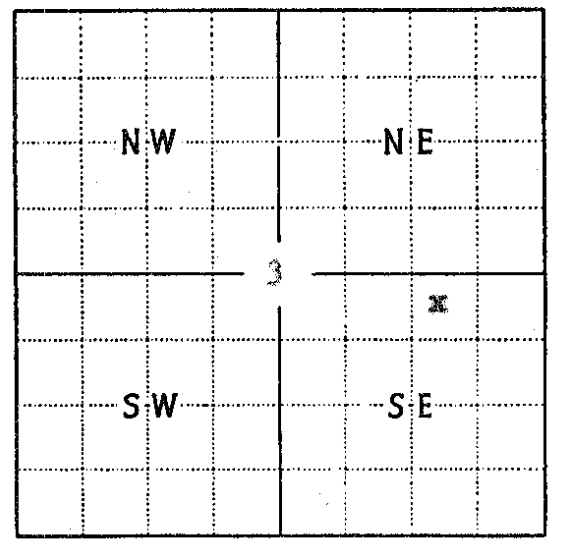

Locate well accurately on plat of section (Scale one inch-2,000 $\mathrm{ft}_{\mathrm{t}}$ ) 30 ft. south; 330 ft. east;___ ft. west of the corner of the cul

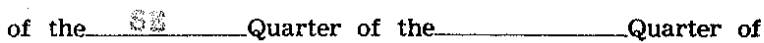
Section 3 , Township___ 22 (North ac/South)

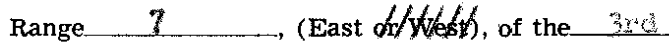

Principal Meridian,_one County, Illinois. Elevation above sea level is $\begin{cases}\text { Derrick Floor } 60 \mathrm{ft} . & \mathrm{ft} . \\ \text { Ground } & \mathrm{ft}\end{cases}$ Total depth 1013 . Formation

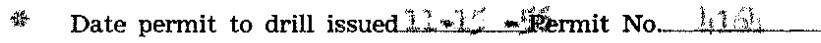

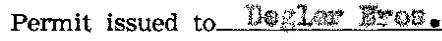

Date drilling began $\quad 1 \mathrm{x}-1,-56$

Date drilling completed $\quad 21+23+56$

Kind of drilling tools used

Date plugging began

Date plugging completed $\quad 4-2+2-3$

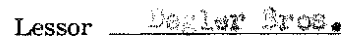

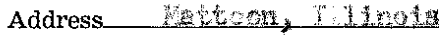

Lessee Oolating

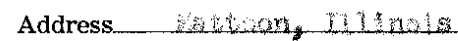

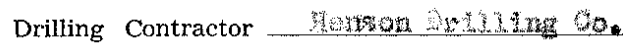

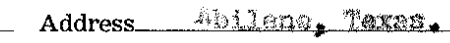

P. W DETAILS OF PLUGGING: 1973 Filled with $\frac{\text { (Rotary Mud, Cement, or Other Materials) }}{\text { (a) }}$ Kund of Plug From $\quad$ Dels

340

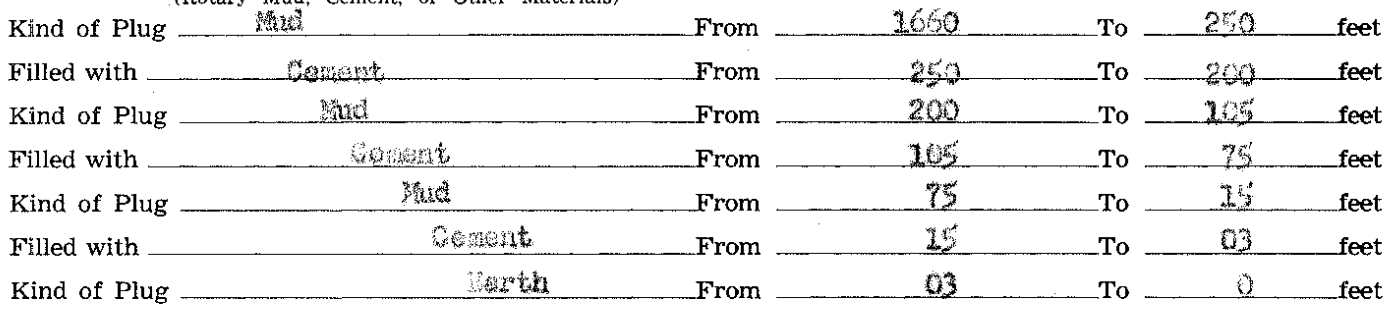
IF WORKABLE COAL BEDS WERE ENCOUNTERED IN THIS HOLE, DESCRIBE THE METHOD EMPLOYED TO PROTECT SAME. (A workable coal bed is thirty inches or more in thickness above 1,000 feet in depth) Hente

(1) Have pits and other excavations been filled?...............

(2) Have the following been removed?

$$
\text { Equipment Yes }
$$

(3) Has surface casing been cut off three feet below ground surface?

(4) Has well-site been leveled?

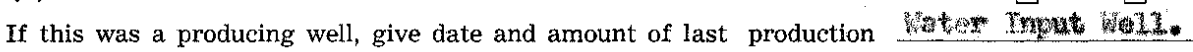

\begin{tabular}{|c|c|c|c|c|c|c|c|}
\hline Size & $\begin{array}{c}\text { PUT IN } \\
\text { Feet }\end{array}$ & $\begin{array}{l}\text { WELL } \\
\text { Inches }\end{array}$ & $\begin{array}{l}\text { PULLED } \\
\text { Feet }\end{array}$ & $\begin{array}{l}\text { CASII } \\
\text { OUT } \\
\text { Inches }\end{array}$ & $\begin{array}{c}\text { RECOR } \\
\text { LEFT } \\
\text { Feet }\end{array}$ & $\begin{array}{l}\text { WELL } \\
\text { Inches }\end{array}$ & 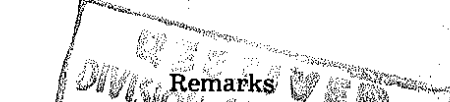 \\
\hline $6.5 / 6$ & 92 & $=$ & 3 & $=$ & 9 & $=$ & 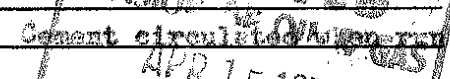 \\
\hline $50 / 2$ & 2823 & - & 2020 & $=$ & 293 & $=$ & 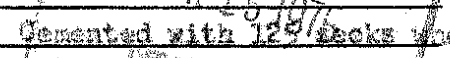 \\
\hline
\end{tabular}

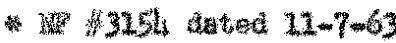

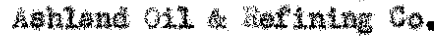

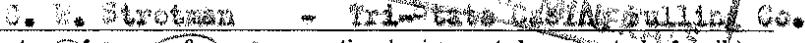
(Slgnature of person, firy or) corporation having custody or control of well.) Per 20

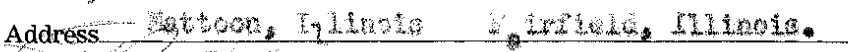

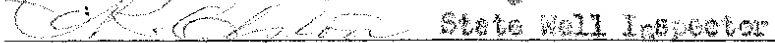

(Signature anid title of party supervising plugging of well.)

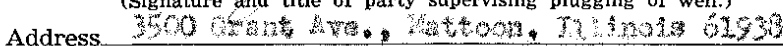

Subscribed and sworn to before me this 12 day of 4

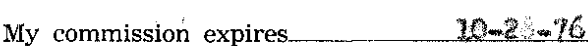


STATE OF ILLINOIS, County of coles $\}$ WELL PLUGGING AFFIDAVIT

Haxy $M$ Kime and a a

Tawrenoe Jandreth being first duly sworn, do depose and say the following is a true and correct statement of the details of the plugging of a certain well drilled for oj1 or gas

(Indicate whether for oil, gas, water or other purposes)

known as the Geneva Jo $\operatorname{Vade} \frac{H}{4}$

and located as follows

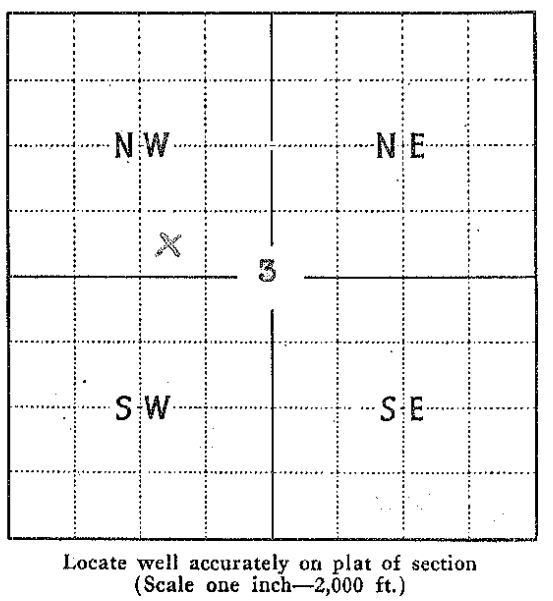

ft. south; 1706 ft. east; f ft. west of the $\quad \mathrm{SW} \quad$ corner of the MNQ Quarter of the Q Quarter of the _____ Quarter of Section 3 , Township 12 (North ox swath) Range 7 , (East $3 \mathrm{~d}$ Principal Meridian, _____Coles _ County, Illinois. Elevation above sea level is $\{$ Derrick Floor__ ft. Total depth of well is $\quad 2092$ Date permit to drill issued. $4-21-18$

Permit issued to Harry Mt Hime

Date drilling began $4-22-48$

Date drilling completed $4-30-48$

Kind of drilling tools used Rotary

Date plugging began $4=30-18$

Date plugging completed $4-30-48$

\begin{tabular}{|c|c|}
\hline Lessee Harry M. Kime & $1503 \mathrm{~N} \cdot 10 \mathrm{th} \mathrm{st}$ \\
\hline Drilling Contractor $W_{\odot} P \cdot$ Kuykenda I & EImo, Ilinots \\
\hline
\end{tabular}

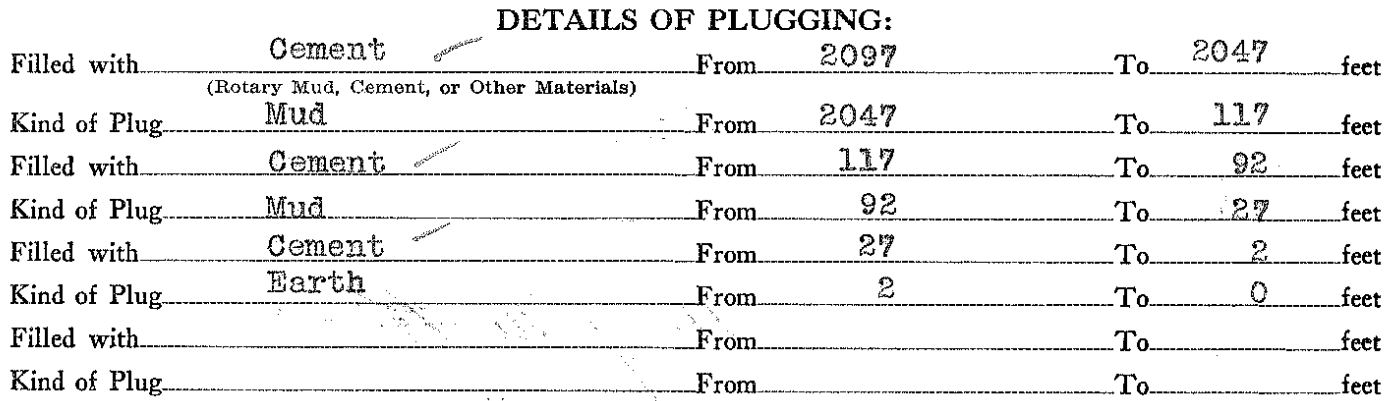

IF WORKABLE COAL BEDS WERE ENCOUNTERED IN THIS HOLE, DESCRIBE THE METHOD EMPLOYED TO PROTECT SAME. (A workable coal bed is thirty inches or more in thickness above 1,000 feet in depth) Affidarit on back

(1) Have pits, cellar and other excavations been filled? Yes No

(2) Have equipment, concrete bases and debri been removed?

(3) Has Yes No

(3) Has surface casing been cut off below plow depth?.... $\square$

(4) Has wcll-site been levelled ?................ $\quad \square \quad \begin{aligned} & \text { Yes } \\ & \square\end{aligned}$

If this was a producing well, give date and amount of last production Droy Hole

CASING RECORD

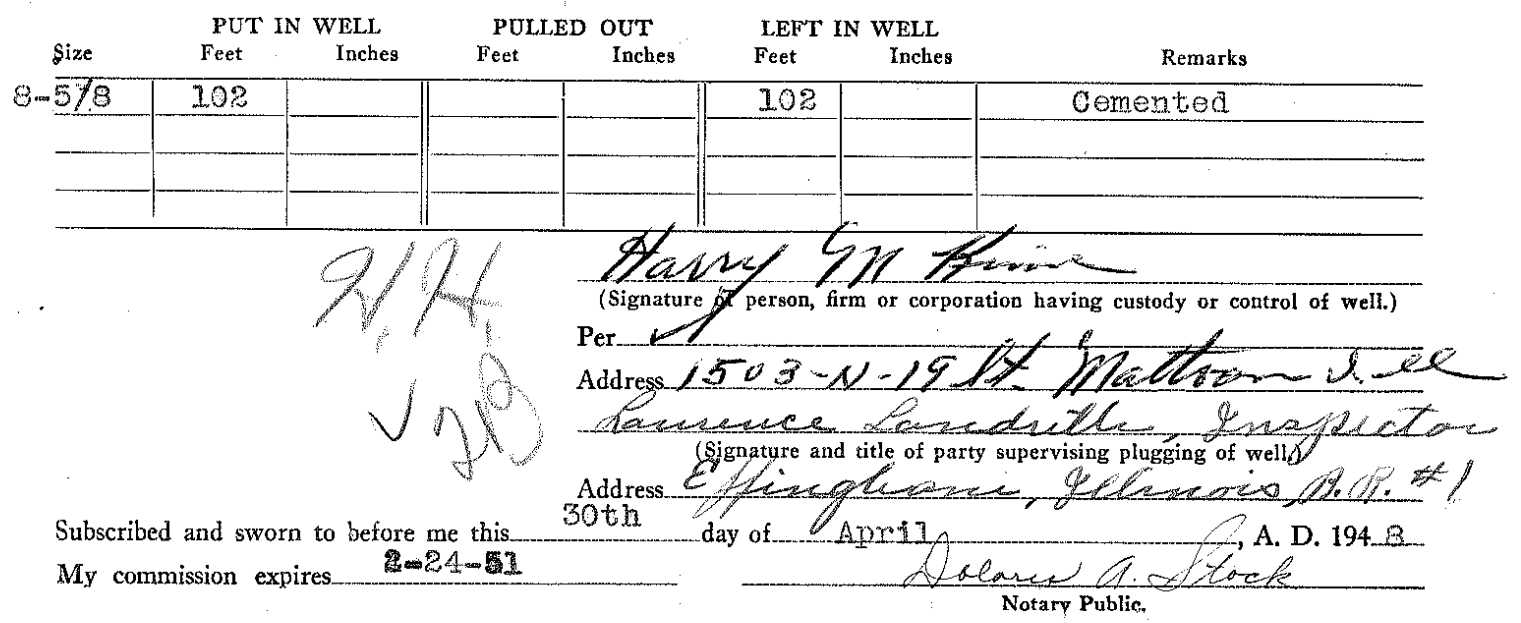


7-12N-7E 


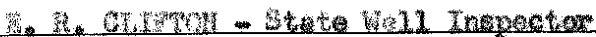

the details of the phome drilled for ort.

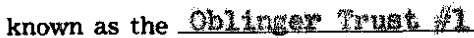
Indicate whether for oll, gas, water or other purposes)

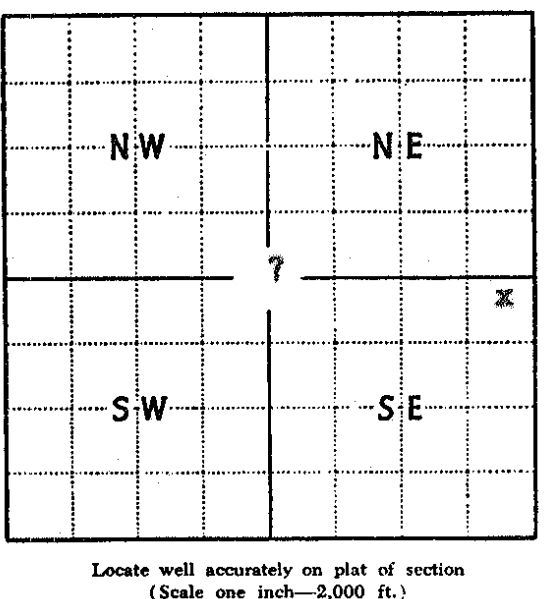
and located as follows:

ft. north; being first duly sworn $330 \mathrm{ft}$ south ft. east $; 30$ ft. west of the corner of the of the___ Quarter of the_Quarter of Section 7 , Township 2 (North 6f Solth) Range_ $\quad 7$, (East $66 / 6664 / \%$ of the 3 rod Principal Meridian,___ County, Illinols. Elevation above sea level is $\left\{\begin{array}{l}\text { Derrick Floor } \frac{\mathrm{ft}}{(0 .(690.9} \mathrm{ft} . \\ \text { Ground }-1)\end{array}\right.$ Total depth 350 . Formation Devoridan Date permit to drill issued $7 / 31 / 79_{\text {Permit No. } 7142}$

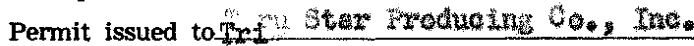
Date drilling began $\quad 0-7 \%$ Date drilling completed $\quad 8+160+79$ Kind of drilling tools used L Low Date plugging began 9-22-00 Date plugging completed $9-33-60$

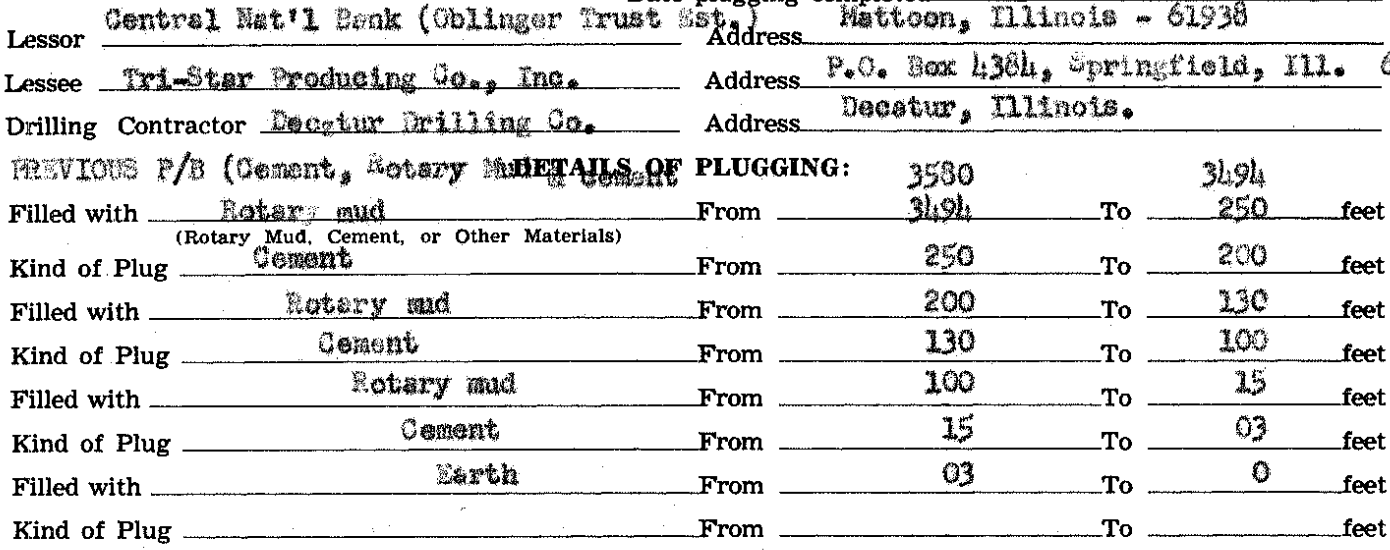
IF WORKABLE COAL BEDS WERE ENCOUNTERED IN THIS HOLE, DESCRIBE THE METHOD EMPLOYED TO PROTECT SAME. (A workable coal bed is thirty inches or more in thickness above 1,000 feet in depth) Wow

(1) Have pits and other excavations been flled? .................

(2) Have the following been removed?

$$
\text { Equipment } \stackrel{\text { Yes }}{\square} \stackrel{\text { No }}{\square} \text { Concrete bases } \square^{\square} \stackrel{\text { No }}{\square} \text { Debris } \square^{\square}
$$

(3) Has surface casing been cut off three feet below ground surface?

(4) Has well-site been leveled?

If this was a producing well, give date and amount of last production

CASING RECORD

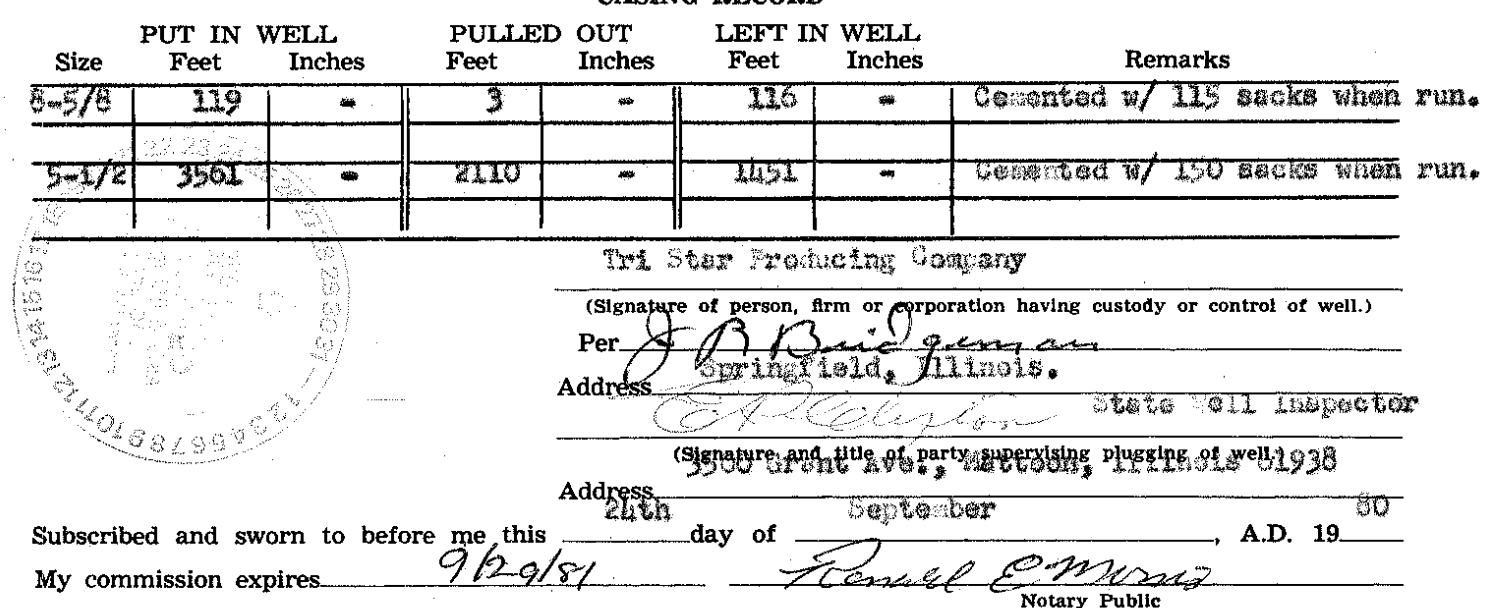




\section{STATE OF ILLINOIS \\ County of \} ss. \\ WELL PLUGGING AFFIDAVIT

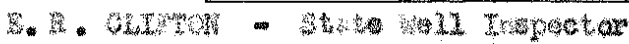

being first duly sworn do depose and say the following is a true and correct statement of the details of the plugging of a certain well drilled for

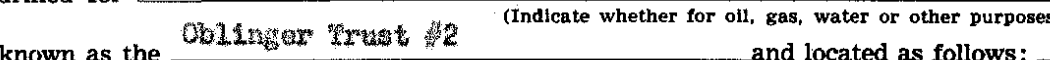

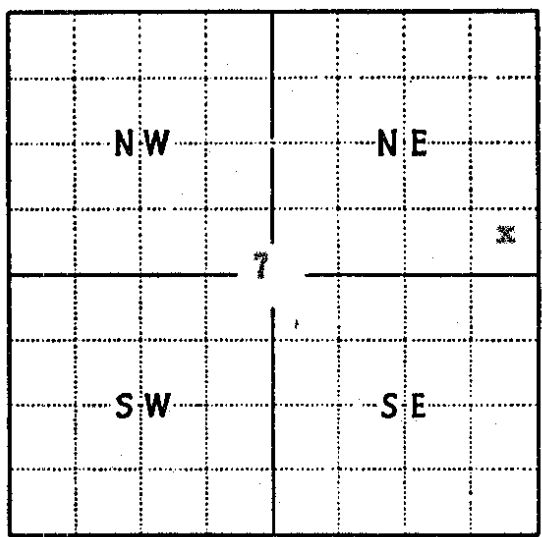

Locate well accurately on plat of section (Scale one inch-2,000 $\mathrm{ft}_{\text {. }}$ )
30 ft. north:

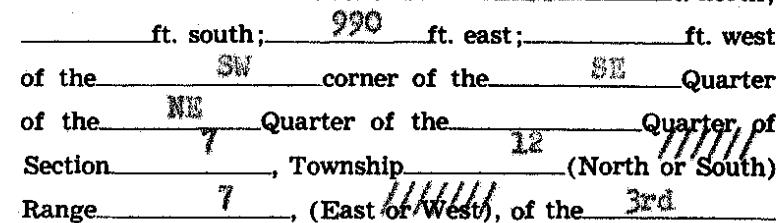

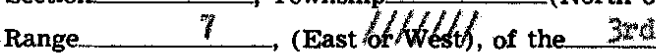

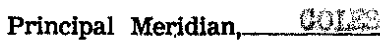

Elevation above sea level is $\{$ Derrick Floor___ft.

Total depth $33 / 2 \quad$ Formation _ _ n

Date permit to arill issued $6 / 20 / 60$ Permit No. 1054

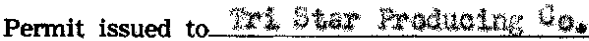

Date drilling began__ $\quad 7-0$

Date drilling completed__ -10

Kind of drilling tools used_L_tatery

Date plugging began _ _ $3-20$

\begin{tabular}{|c|c|c|}
\hline & 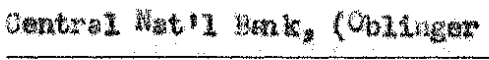 & 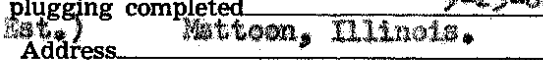 \\
\hline essee & 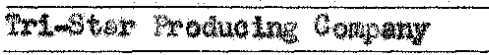 & 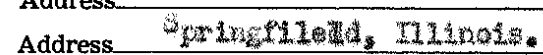 \\
\hline Drilling & 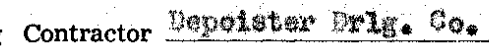 & 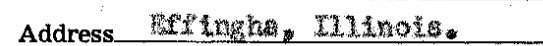 \\
\hline
\end{tabular}

DETAILS OF PLUGGING:

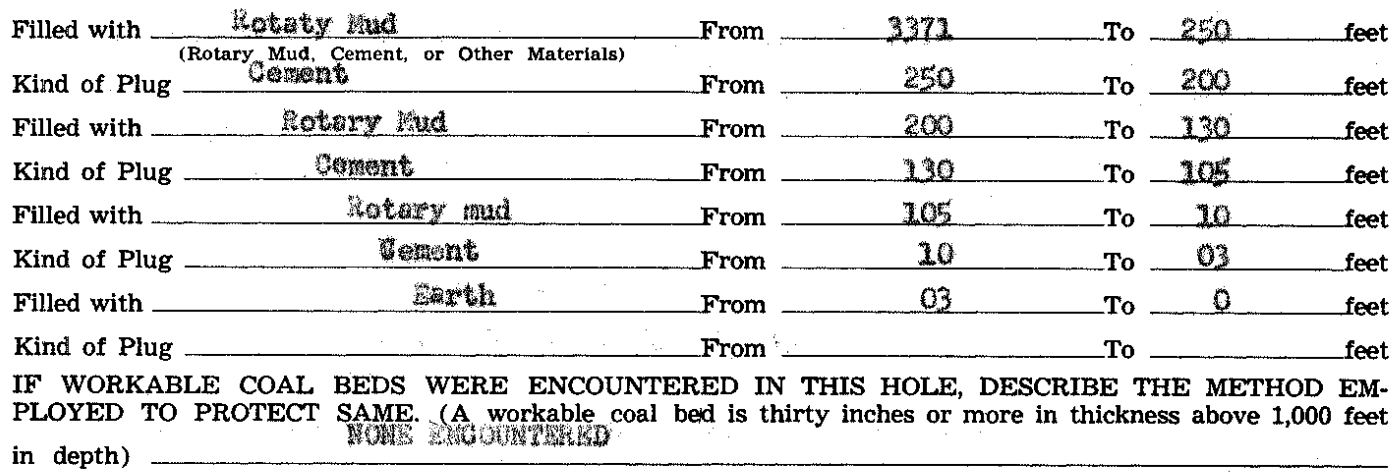

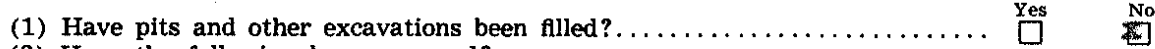

(2) Have the following been removed?
Equipment $\stackrel{\text { Yes }}{\square}$ Concrete bases $\square^{\square} \stackrel{\text { No }}{\square}$ Debris $\stackrel{\text { Yes }}{\square}$

(3) Has surface casing been cut off three feet below ground surface?

(4) Has well-site been leveled? $\ldots \ldots \ldots \ldots \ldots \ldots \ldots \ldots \ldots \ldots \ldots \ldots \ldots \ldots$

If this was a producing well, give date and amount of last production $104+100$

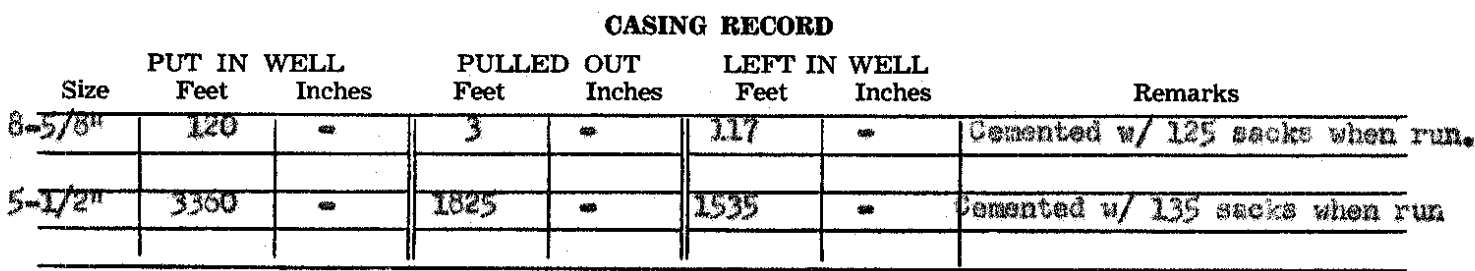

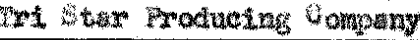

(Signatape of person, firm or pofporation having custody or control of well.)

Per $5=270$

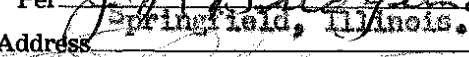

$1 \mathrm{~W}^{2}$ (

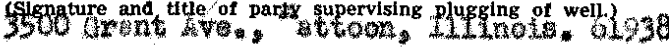

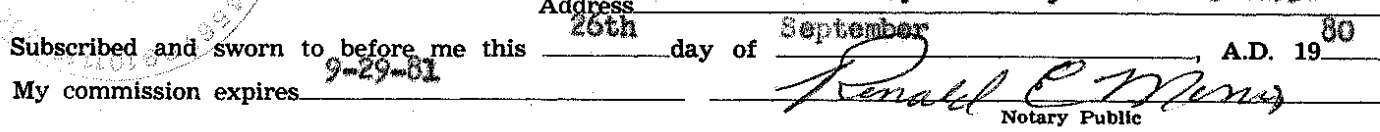


10-12N-7E 

do depose and say the following is a true and correct statement of the details of the plugging of a certain well drilled for $011 /$ asas known as the A. B. Oskonn 11 (Indicate whether for oil, gas, water or other purposes) $330 \quad$ and located as follows: $\quad 3$ north;

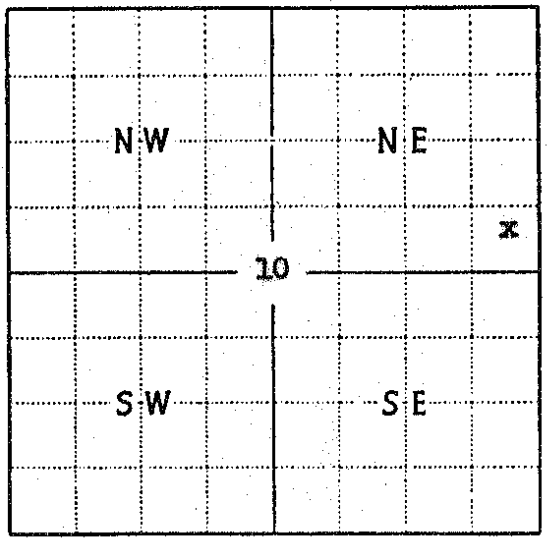

Locate well accurately on plat of section ( Scale one inch $-2,000 \mathrm{ft}$.)

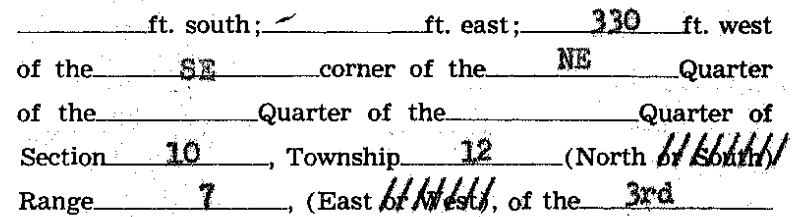

Principal Meridian, COLNS County, Illinois. Elevation above sea level is $\left\{\begin{array}{l}\text { Derrick Floor } \frac{706}{7 t} \\ \text { Ground }\end{array}\right.$ Total depth 3242 Formation Devonien. Date permit to drill issued $1 / 30 / 74$ Permit No $\quad 64$ Permit issued to Safari 011 Company Date drilling began_ $\quad 4-25-75$

Date drilling completed 5-6-75

Kind of drilling tools used Rotary

Date plugging began $12-2-75$

Date plugging completed $\quad 12-3-75$

Lessor H. Osborn Lessee Safart o1 $0_{\text {ompany }}$

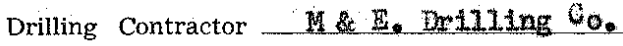
Address Mattoon, $T_{1}$ Linols Address Mattoon, ILLinois Address Casey, Mlinois.

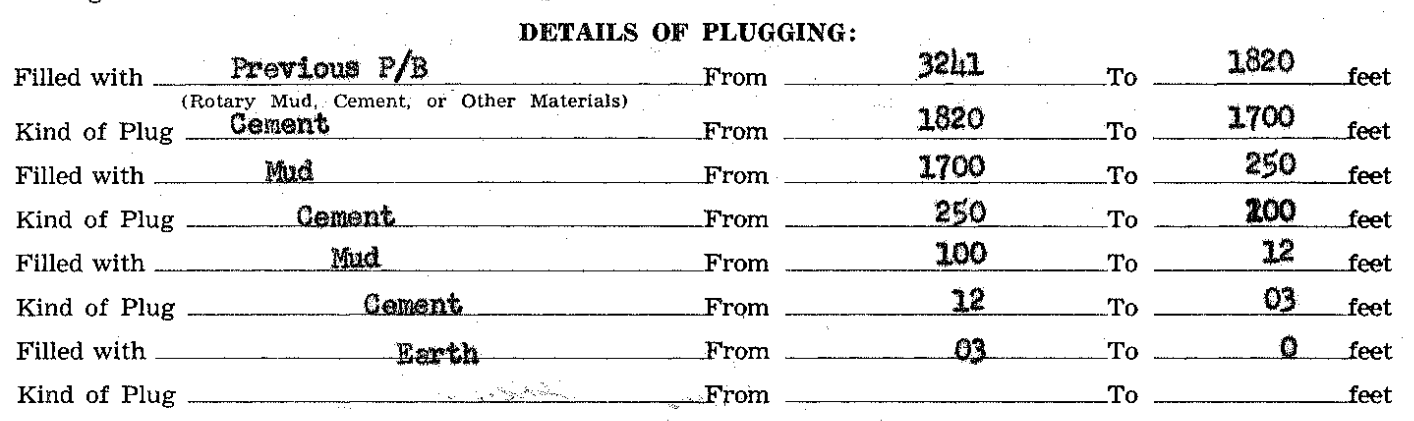
IF WORKABLE COAL BEDS WERE ENCOUNTERED IN THIS HOLE, DESCRIBE THE METHOD EMPLOYED TO PROTECT SAME. (A workable coal bed is thirty inches or more in thickness above 1,000 feet in depth) None encountered

(1) Have pits and other excavations been Equipment $[\square]$ Concrete bases $\square^{\text {Yes }} \stackrel{\text { No }}{\square}$ Debris $\square$ Yes

(3) Has surface casing been cut off three feet below ground surface?

(4) Has well-site been leveled?

If this was a producing well, give date and amount of last production Innknown

$\stackrel{\text { Yes }}{\square} \underset{\square}{\square}$

$\stackrel{\text { No }}{\square}$

\begin{tabular}{|c|c|c|c|c|c|c|c|}
\hline \multicolumn{8}{|c|}{ CASING RECORD } \\
\hline Size & $\begin{array}{c}\text { PUT IN } \\
\text { Feet }\end{array}$ & $\begin{array}{l}\text { WELL } \\
\text { Inches }\end{array}$ & $\begin{array}{l}\text { PULLED } \\
\text { Feet }\end{array}$ & $\begin{array}{l}\text { OUT } \\
\text { Inches }\end{array}$ & $\begin{array}{c}\text { LEFT } \\
\text { Feet }\end{array}$ & $\begin{array}{l}\text { WELL } \\
\text { Inches }\end{array}$ & Remarks \\
\hline $8-5 / 6 n$ & 127 & - & 4 & $=$ & 123 & - & Cemented w/ 50 sacks when run \\
\hline $4-1 / 2$ & 1850 & $=$ & 1500 & - & 350 & - & 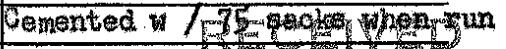 \\
\hline & & & & & & & $=$ \\
\hline
\end{tabular}

\section{CASING RECORD}

Safart on ompany

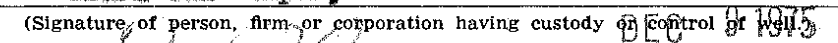

Per_,

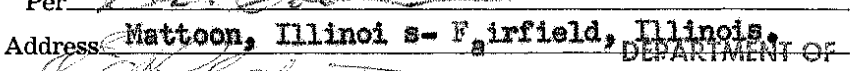

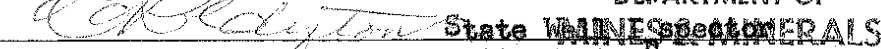

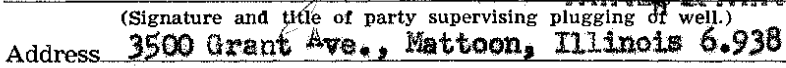

Subscribed and sworn to before me this

6 th Decomber 


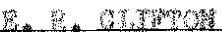

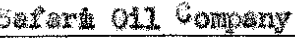

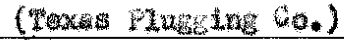

being first duly do depose and say the following is a true and correct statement of the details of the plugging of a certain well drilled for on $1 /$ as

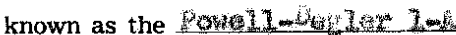
(Indicate whether for oil, gas, water or other purposes) and located as follows:

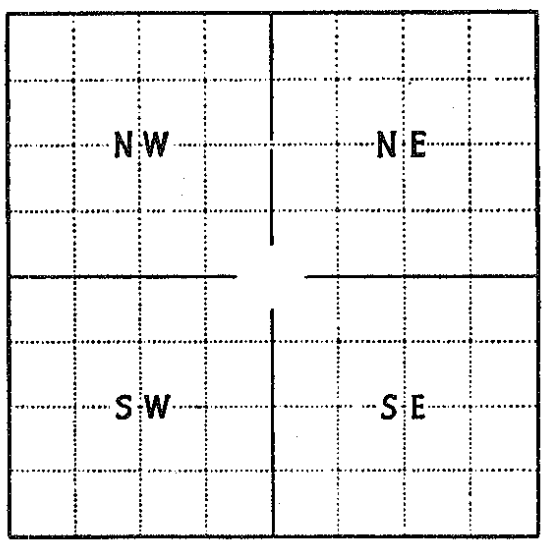

Locate well accurately on plat of section (Scale one inch-2,000 $\mathrm{ft}$.)

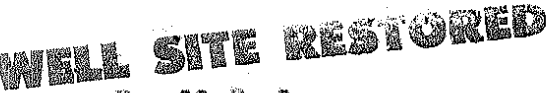

$\$ 0 \mathrm{ft}$. south:

of the of the Wuarter of the ft. east; 480 ft. west

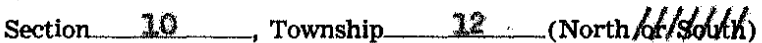
Range $\quad 7$, (East of Whett) of the 3xd Principal Meridian, COLS? Elevation above sea level is $\left\{\begin{array}{l}\text { Derrick Floor } \\ \text { Ground } \quad \mathrm{ft} .\end{array}\right.$ Total depth 2020____ Formation ow Date permit to drill issued $7 / 27 / 76$ Permit No. 2756

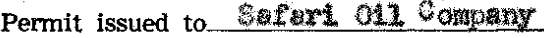
Date drilling began_ Date drilling completed $\quad 3-24-76$ Kind of drilling tools used Rotary Date plugging began $\quad 5-3-79$

Date plugging completed $5-4=79$

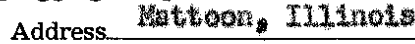
Address_tuthoon Hnots

Lessee S Drilling Contractor Address casey, nIIThois

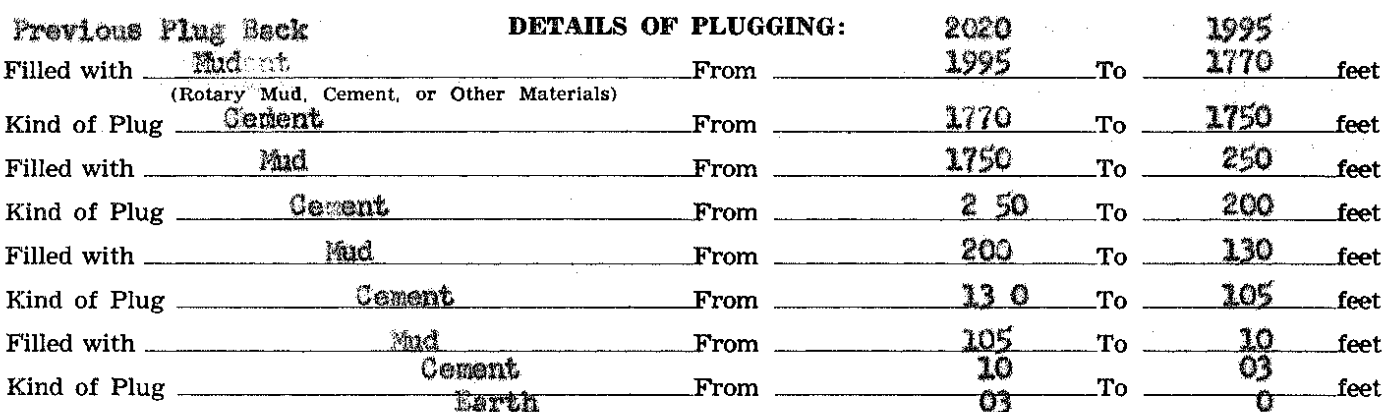
IF WORKABLE COAL BEDS WERE ENCOUNTERED IN THIS HOLE, DESCRIBE THE METHOD EMPLOYED TO PROTECT SAME. (A workable coal bed is thirty inches or more in thickness above 1,000 feet in depth)

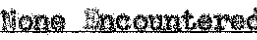

(1) Have pits and other excavations been filled?............... Y

(2) Have the following been removed?

$$
\text { Equipment } \stackrel{\text { Yes. No }}{\square} \text { Concrete bases } \stackrel{\text { Yes }}{\square} \stackrel{\text { No }}{\square} \text { Debris } \begin{array}{lll}
\text { Yes } & \text { No } \\
\square
\end{array}
$$

(3) Has surface casing been cut off three feet below ground surface?

(4) Has well-site been leveled?

If this was a producing well, give date and amount of last production

CASING RECORD

\begin{tabular}{|c|c|c|c|c|c|c|c|}
\hline Size & $\begin{array}{c}\text { PUT IN } \\
\text { Feet }\end{array}$ & $\begin{array}{l}\text { WELL } \\
\text { Inches }\end{array}$ & $\begin{array}{l}\text { PULL } \\
\text { Feet }\end{array}$ & $\begin{array}{l}\text { OUT } \\
\text { Inches }\end{array}$ & $\begin{array}{c}\text { LEFT } \\
\text { Feet }\end{array}$ & $\begin{array}{l}\text { WELL } \\
\text { Inches }\end{array}$ & Remarks \\
\hline $7^{n}$ & 124 & - & 3 & 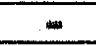 & 111 & - & 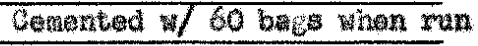 \\
\hline$L^{3}$ & 2015 & - & 2025 & - & 990 & - & 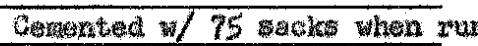 \\
\hline
\end{tabular}

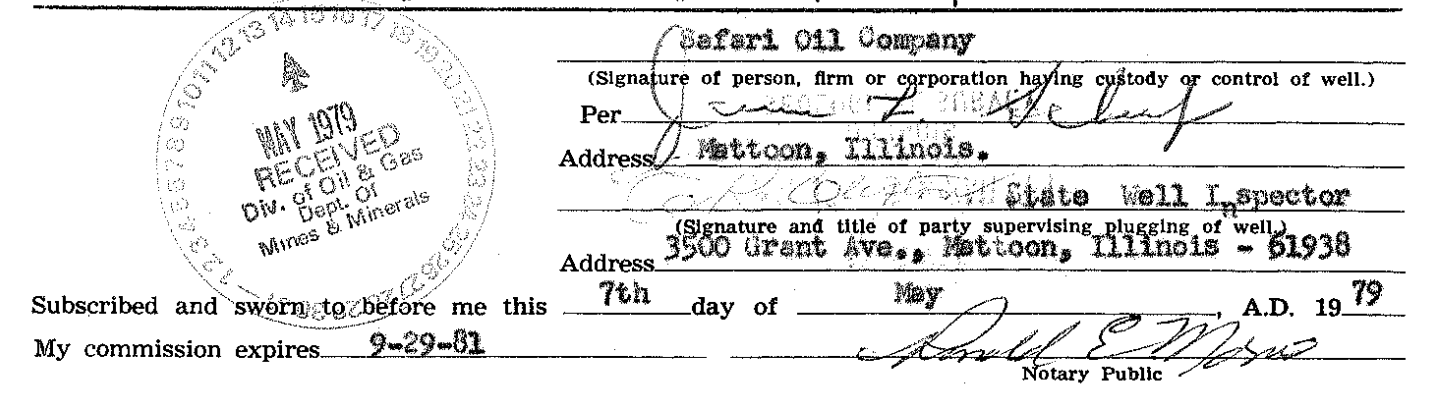


$5-14$

\section{ILLINOIS DEPARTMENT OF NATURAL RESOURCES Office of Mines and Minerals \\ Division of Oil and Gas 524 South Second Street (217) 782-7756 COUNTY No. Z3/50 Springfield, Illinois 62704-1787}

\section{OG-6 WELL PLUGGING REPORT}

TYPE OF WELL: \ Production $\square$ Class II $\square$ observation $\square$ Gas Storage $\square$ REPLUG $\square$ other permitte: Charlss Armantrout WELL NAME: OSbORNE \#/-B PERMIT No. 023908 PERMITTEE NO. 110

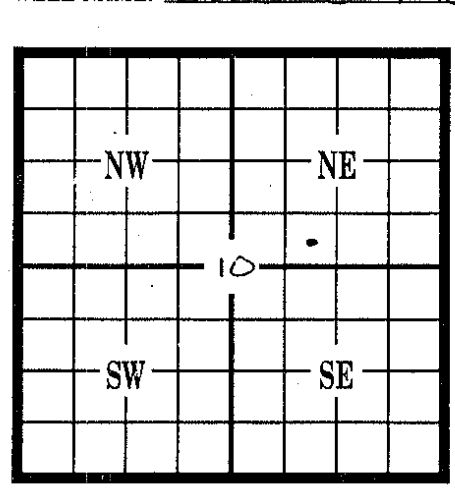
$\frac{023908}{\text { (ISSOE DARE IF NO NUMBERI }}$ REFERENCE NO. 128463

WELL DATA:

\begin{tabular}{|c|c|c|}
\hline SURFACE ELEVATION & 701 & PRODUCING / INJECTION INTERVALS \\
\hline TOTAL DEPTH OF WELL & 2021 & FROM 1774 'о 1978 \\
\hline PLUGGED BACK TOTAL DEPTH & 1880 & FROM \\
\hline BASE OF FRESHWATER ZONE & FT. & FROM _ To \\
\hline WORKABLE COALS PRESENT AT & $N / A \quad$ FT. & FROM \\
\hline
\end{tabular}

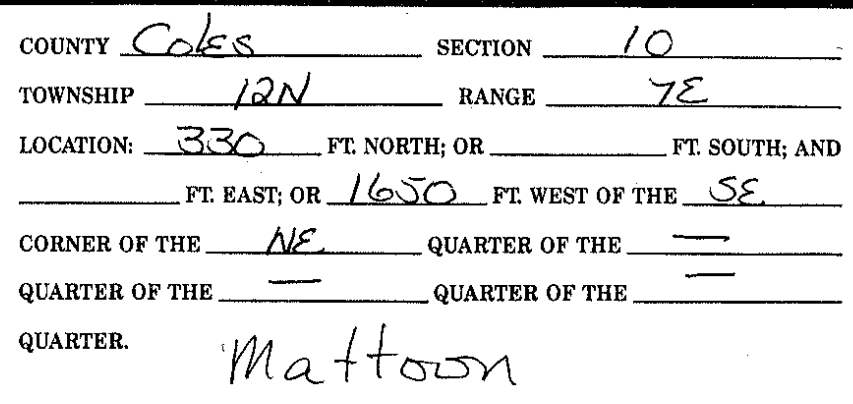

DETAILS OF PLUGGING:

\begin{tabular}{|c|c|}
\hline FILLED wITH well bore fluid & FROM 1978 то 1880 Fт. \\
\hline FILLED WITH cement & FROM 1880 To 1555 FT. \\
\hline FILLED with wo ll boos flind & FROM $\frac{1555}{150}$ To 410 FT. \\
\hline FILLED WITH CQmen廿 & FROM 440 To. \\
\hline FILLED WITH top soil & FROM 4 to surface FT. \\
\hline FILLED WITH & FROM _ TO _ \\
\hline FILLED WITH & FROM $\longrightarrow$ TO \\
\hline COMMENTS: & \\
\hline
\end{tabular}

WELL DATA:

\begin{tabular}{|l|c|c|c|c|c|c|}
\hline \multicolumn{1}{|c|}{ CASING } & SIZE & $\begin{array}{c}\text { SETTING } \\
\text { DEPTH }\end{array}$ & $\begin{array}{c}\text { SACKS } \\
\text { CEMENT }\end{array}$ & $\begin{array}{c}\text { HOLE } \\
\text { SIZE }\end{array}$ & $\begin{array}{c}\text { EST. TOP OF } \\
\text { CEMENT }\end{array}$ & $\begin{array}{c}\text { AMOUNT OF } \\
\text { CASING REMOVED }\end{array}$ \\
\hline SURFACE & $8 \% / 8$ & 163 & 125 & $121 / 4$ & $6 \mathrm{~L}$ & $4^{\prime}$ \\
\hline $\begin{array}{l}\text { INTERMEDIATE/MINE } \\
\text { STRING / OR LINER }\end{array}$ & & & & & & \\
\hline PRODUCTION & $41 / 2$ & 2020 & 163 & $7 \%$ & & 1004 \\
\hline
\end{tabular}

UNDER PENALTIES OF PERJURY, I DECLARE THAT I HAVE EXAMINED THIS FORM INCLUDING ACCOMPANYING STATEMENTS AND DOCU. MENTS, AND TO THE BEST OF MY KNOWLEDGE, IT JS TRUE, CORRECT, AND COMPLETE.

SIGNATURE OF: Ecec SheCeTh

\section{ADDRESS}

\section{CITY, STATE}

$$
\begin{aligned}
& \text { DATE PLUGGING BEGAN } 14 \text { may } 97 \\
& \text { DATE PRECGINEROMPLETED } 14127 \text { a } 97 \\
& \text { MAY } 271997
\end{aligned}
$$

GEOLGC RECORE

Printed on Recycled Pape 


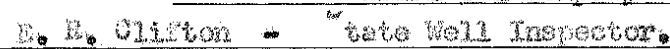

being first duly swor

do depose and say the following is a true and correct statement of the details of the plugging of a certain well drilled for

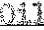

known as the bowne ing

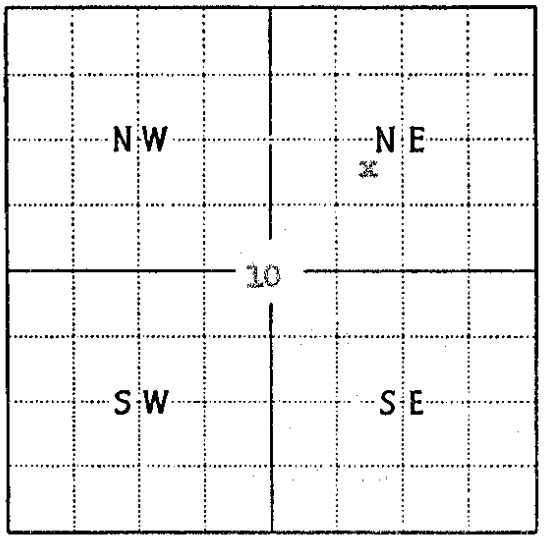

Locate well accurately on plat of section (Scale one inch-2,000 it.) ater or other purposes) and located as follows: ginterth ft. south ft. east; 1 ft. west

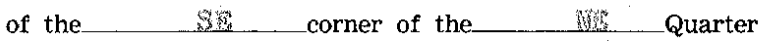
of the___ Quarter of the___ _ Quarter of Section 10 , Township_ 12 (North 6r S6lath)

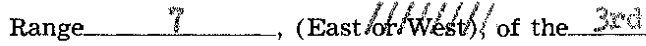
Principal Meridian, Wats County, Illinois. Elevation above sea level is $\begin{cases}\text { Derrick Floor _ } ~ & \mathrm{ft} \\ \text { Ground } & \mathrm{ft}\end{cases}$

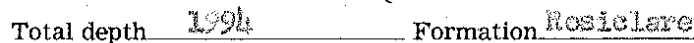
Date permit to drill issued $10-22=6 / 2$ Permit No. 923

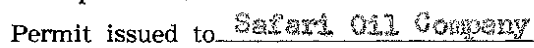

Date drilling began $\quad 24-10-12$

Date drilling completed $\quad 13-19+2,1$

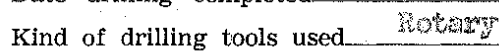

Date plugging began $\quad 10-20-73$

Date plugging completed___ $\quad 20+24+73$

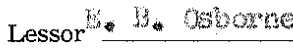
Address Mis

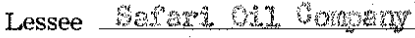

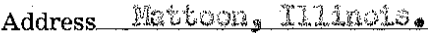

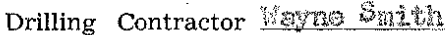

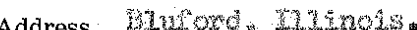

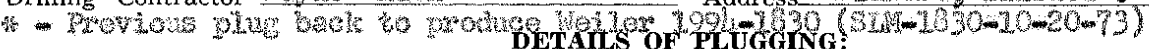

\begin{tabular}{|c|c|c|c|c|c|}
\hline Filled with & 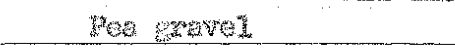 & From & 1350 & T & 215 \\
\hline Kind of Plug & $\begin{array}{l}\text { (Rotary Mud, Cement, or Other Materials) } \\
\text { Uenente }\end{array}$ & From & 280 & To & 3730 \\
\hline Filled with & rhet & From & 39.90 & To & 250 \\
\hline Kind of Plug & ostanes & From & 2,50 & To & 2,3 \\
\hline Filled with & 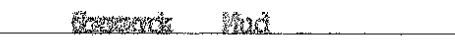 & From & 20 & To & 120 \\
\hline Kind of Plug & oenerste & From & 21,0 & _To & 20 \\
\hline Filled with & shed & From & 210 & To & 25 \\
\hline ind of $P$ & Wenton & From & $e_{3}^{3}$ & To & 0 \\
\hline
\end{tabular}

IF WORKABLE COAL BEDS WERE ENCOUNTERED IN THIS HOLE, DESCRIBE THE METHOD EMPLOYED TO PROTECT SAME. (A workable coal bed is thirty inches or more in thickness above 1,000 feet in depth) more

(1) Have pits and other excavations been filled?

(2) Have the following been removed?
Equipment
Concrete bases $\stackrel{\text { Yes }}{\square}$
Debris $\square$ Yes

(3) Has surface casing been cut off three feet below ground surface?

(4) Has well-site been levelled?

If this was a producing well, give date and amount of last production

No

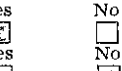

000602073

\section{CASING RECORD}

\begin{tabular}{|c|c|c|c|c|c|c|c|}
\hline Size & $\begin{array}{c}\text { PUT IN } \\
\text { Feet }\end{array}$ & $\begin{array}{l}\text { WELL } \\
\text { Inches }\end{array}$ & $\begin{array}{l}\text { PULLED } \\
\text { Feet }\end{array}$ & $\begin{array}{l}\text { OUT } \\
\text { Inches }\end{array}$ & $\begin{array}{l}\text { LEFT } \\
\text { Feet }\end{array}$ & $\begin{array}{l}\text { WELL } \\
\text { Inches }\end{array}$ & Remarks \\
\hline $\mathrm{B}-\mathrm{E} / \mathrm{B}$ & 126 & - & 3 & 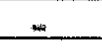 & $1 e^{3}$ & $=$ & Hov 31 get 0 \\
\hline $2=1 / 2$ & 1200 & $=$ & $22 \%$ & $=$ & 69 & - & \\
\hline
\end{tabular}

Whim कि का

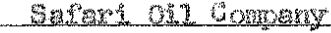

(Signature of person, firm or çroporation having custody or control of well.) Per fomald G. Sarat

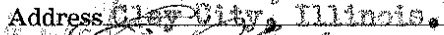

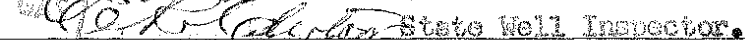

(Signature and tite of party supervising plugging of well.)

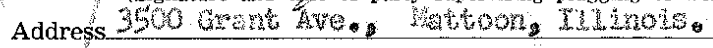

Subscribed and sworn to before me this 2 day of 1973 My commission expires 
do depose and say the following is a true and correct statement of the details of the plugging of a certain well drilled for Whesureng

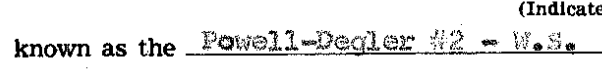

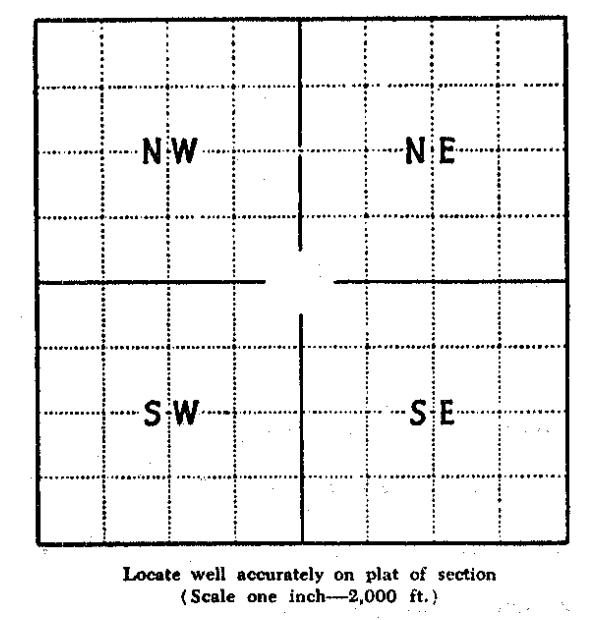
and located as follows:

ft. north:

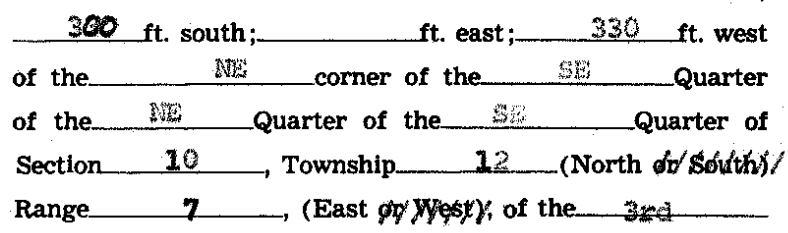

Principal Meridian,_._CLE County, Illinois. Elevation above sea level is $\left\{\begin{array}{l}\text { Derrick Floor } \frac{700}{7 t} \text { ft. } \\ \text { Ground }\end{array}\right.$ Total depth 380 Formation Water sand Date permit to drill issued $9 / 30 / 60$ Permit No. 2227 Permit issued to Ashutand $\mathrm{AL}$ co.

Date drilling began $10=2-60$

Date drilling completed $10-3-60$

Kind of drilling tools used rotany

Date plugging began 12-4-75

Date plugging completed $12 * 4+75$

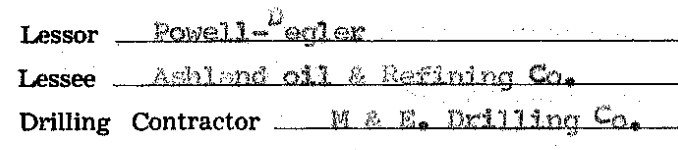
DETAILS OF PLUGGING:
Address Wattoon, In Ininäs

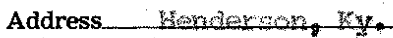

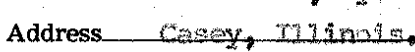

Filled with $\frac{\text { Cenorit }}{\text { (Rotary Mud, Cement, or Other Materlals) }}$

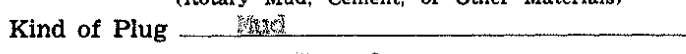

Filled with Cenent

Kind of Plug ___ newerth

Filled with

Kind of Plug

Filled with

Kind of Plug

IF WORKABL

PLOYED TO PROTECT SAME. (A workable coal bed

in depth)

From

From

From

From

From

From

From

From

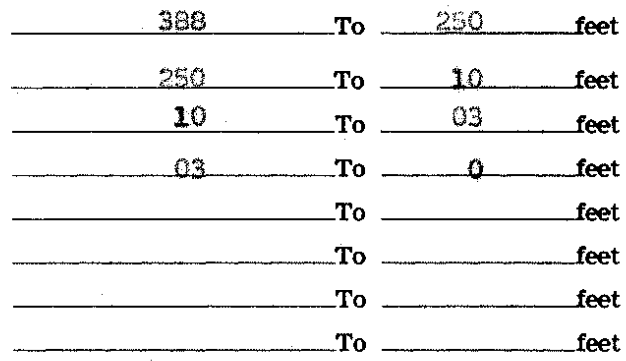

(1) Have pits and other excavations been flled?

(2) Have the following been removed?
Equipment $\stackrel{\text { Yes }}{\square} \stackrel{\text { No }}{\square}$
Concrete bases $\stackrel{\text { Yes }}{\mathrm{N}} \mathrm{\square}$
Debris Yes No

(3) Has surface casing been cut off three feet below ground surface?

(4) Has well-site been leveled? $\ldots \ldots \ldots \ldots \ldots \ldots \ldots \ldots \ldots \ldots \ldots \ldots \ldots \ldots$

If this was a producing well, give date and amount of last production watere cuboly

\begin{tabular}{|c|c|c|c|c|c|c|c|}
\hline \multicolumn{8}{|c|}{ CASING RECORD } \\
\hline Size & $\begin{array}{l}\text { PUT IN } \\
\text { Feet }\end{array}$ & $\begin{array}{l}\text { WELL } \\
\text { Inches }\end{array}$ & $\begin{array}{l}\text { PULLEDD } \\
\text { Feet }\end{array}$ & $\begin{array}{l}\text { OUT } \\
\text { Inches }\end{array}$ & $\begin{array}{c}\text { LEFT } \\
\text { Feet }\end{array}$ & $\begin{array}{l}\text { WELL } \\
\text { Inches }\end{array}$ & Remarks \\
\hline \multirow[t]{7}{*}{$7:$} & 318 & - & $\Delta$ & - & 314 & - & Candert canculated when nun \\
\hline & & & & & & & \\
\hline & 1 & 1 & & & & & 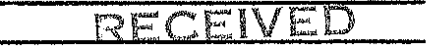 \\
\hline & \multicolumn{6}{|c|}{ 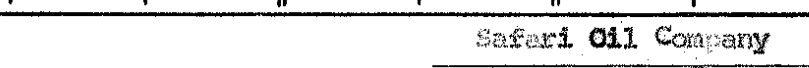 } & DUISIOU OIOLACAS \\
\hline & & & & \multicolumn{4}{|c|}{ (Signature persop, firm or -cerporation having custody or control of well.) } \\
\hline & & & & \multicolumn{4}{|c|}{ 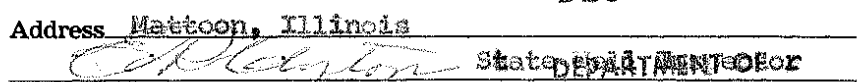 } \\
\hline & & & & & ature a & tutie of $\mathrm{p}$ & 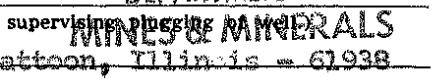 \\
\hline
\end{tabular}

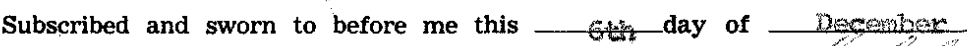
My commission expires $10 \mathrm{~m} 28 \mathrm{~g}=7$ 
$40^{3} 11012$

3. STATE OF ILLINOIS,

Iawrence Iandreth

\section{Joe Dunivan} say the following is a true and correct statement of the details of the plugging of the certain well drilled for 011 known as the Conlin $\# 1$

(Indicate whether for oil, gas, water or other purposes)

and located as follows: $330 \%$ or ft. north;

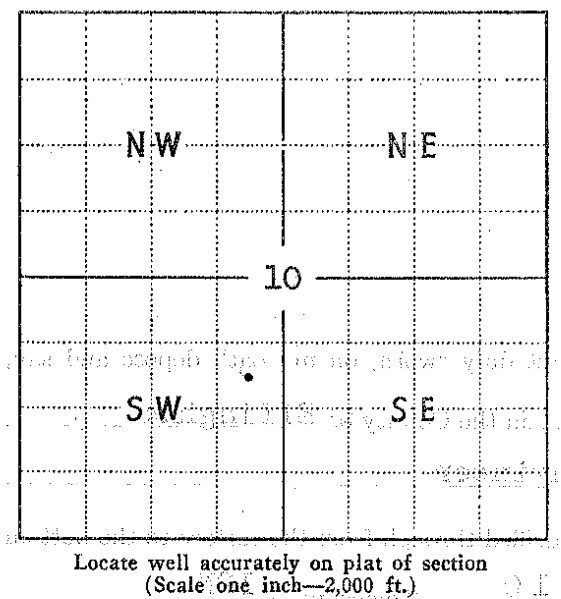
fixposixth;

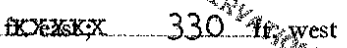

of the SE corner of the NE Quarter of the SW Quarter of the Quarter of Section 10 , Township 12 (North oxsow) Range 7 (East of

Principal Meridian, .... Coles $\mathrm{OQ}$ County, Wlinois. Elevation above sea level is $\left\{\begin{array}{l}\text { Derrick Floor } \\ \text { Ground } 712\end{array}\right.$ Total depth of well is 2100 Date permit to drill issued November 8,1945

Permit issued to L. J. Block Date drilling began November 16,1945 Date drilling completed December 1,1945

Kind of drilling tools used. Rotary

Date plugging began Dec. 19,1946

Date plugging completed Dec. 19,1946
Lessor Conlin

Lessee L. J. Block

Drilling Contractor Kuykenda 1I Drilling Co.
Address Mattoon, Illinois Address 1385 Riverview, Decatur, Address St. Elmo, I11 Inois

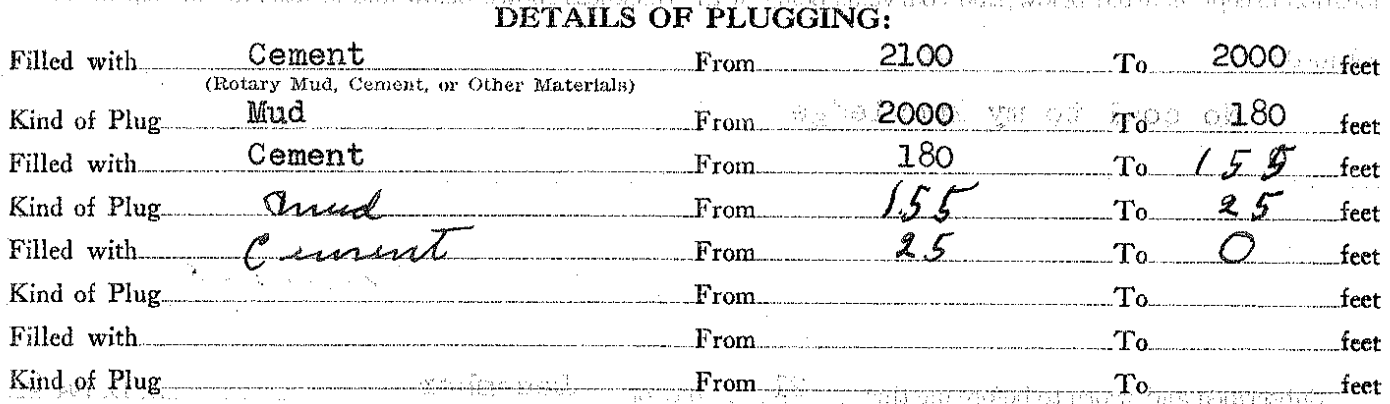

IF WORKABLE COAL BEDS WERE ENCOUNTERED IN THIS HOLE, DESCRIBE THE METHOD EMPLOYED TO PROTECT SAME. (A workable coal bed is thirty inches or more in thickness above 1,000 feet in depth) Affidavit on back

(1) Haye pits, cellar and other excavations been flled? Yes

(2) Have equipment, concrete bases and debris been removed? Yes

(3) Has surface casing been cut off below plow depth? .... Yes

(4) Has well-site been Ievelled?

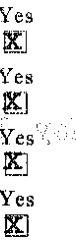

If this was a producing well, give date and amount of last production

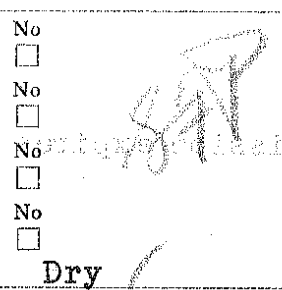

\section{CASING RECORD}

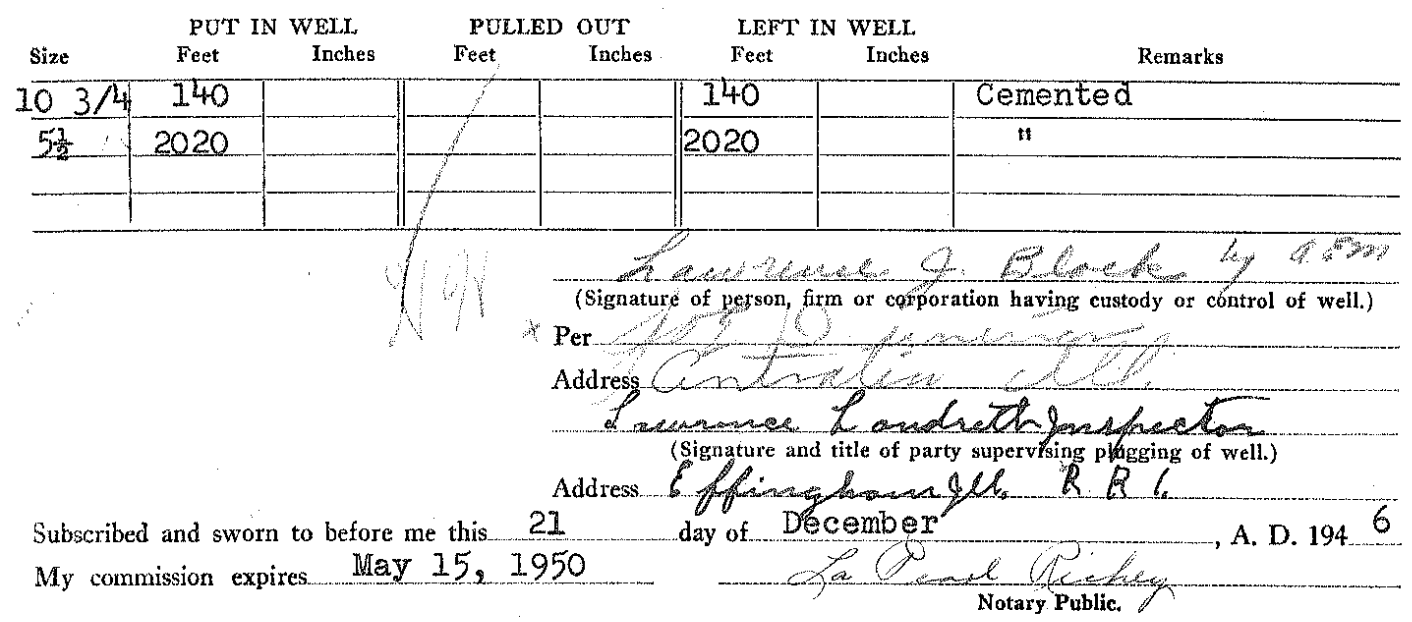



do depose and say the following is a true and correct statement of the details of the plugging of a certain well drilled for 012 w

(Indicate whether for oll, gas, water or other purposes)

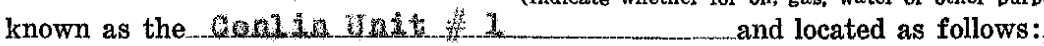

ft. north

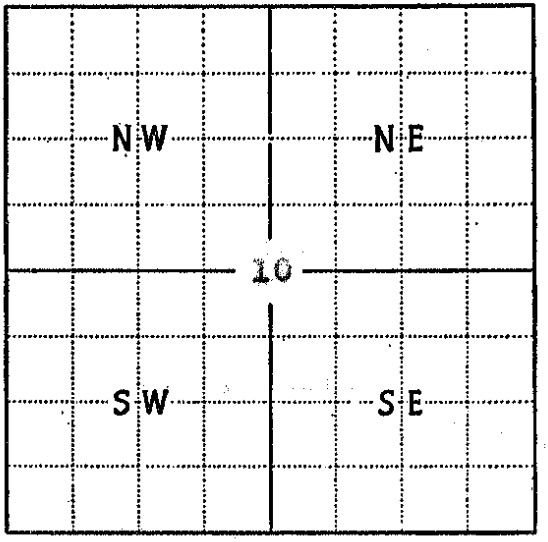

Locate well accurately on plat of section (Scale one inch-2,000 ft.)
40 ft. south; ft. east; -330

of the We corner of the

of the Quarter of the

Section 10 Township 12

Range 7 , (East or West), of the whisid

Princiual Meridian, 0 , Elevation above sea level is $\begin{cases}\text { Derrick Floor } & \mathrm{ft} . \\ \text { Ground } 2.220 & \mathrm{ft} .\end{cases}$

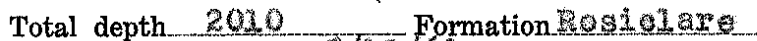
Date permit to drill issued 163 Permit No.1425

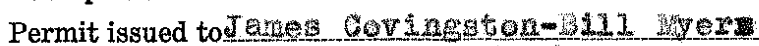
Date drilling began $\quad 0 / 26 / 63$ Date drilling completed $\quad 2 / 2 / 63$ Kind of drilling tools used 20 ten Date plugging began $\quad 10 / 21 / 6$ Date plugging completed $\quad 10 / 22 / 65$

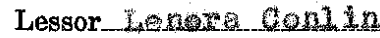
Address

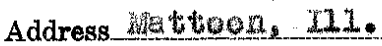
Address Cases.
PLUGGING :

\section{DETAILS OF PLUGGING:}

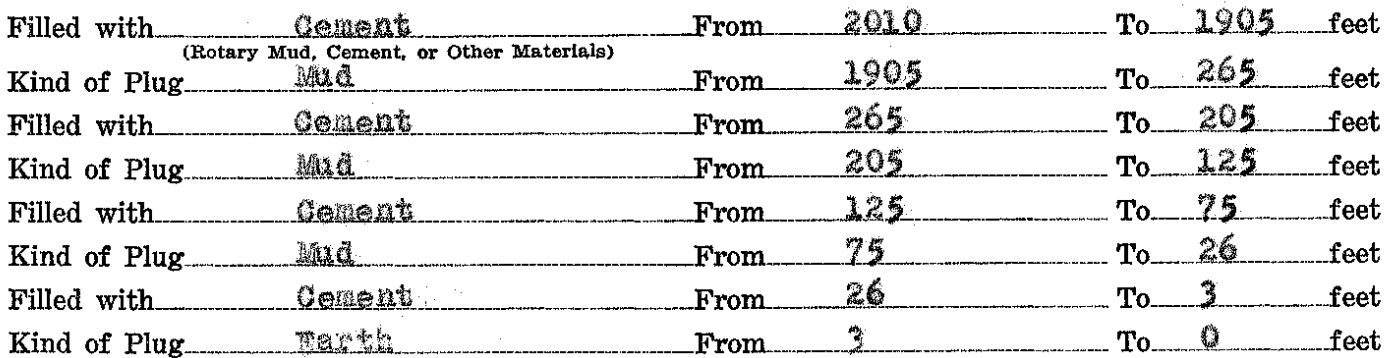

IF WORKABLE COAL BEDS WERE ENCOUNTERED IN THIS HOLE, DESCRIBE THE METHOD EMPLOYED TO PROTECT SAME. (A workable coal bed is thirty inches or more in thickness above 1,000 feet in depth) None

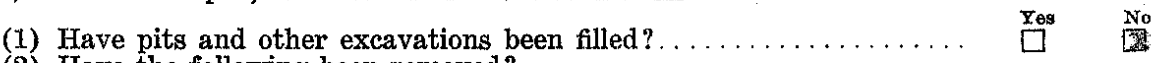

(2) Have the following been removed?

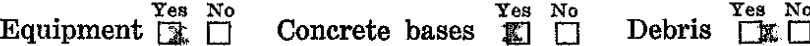

(3) Has surface casing been cut off three feet below ground surface?

(4) Has well-site been levelled?

If this was a producing well, give date and amount of last production.

CASING RECORD

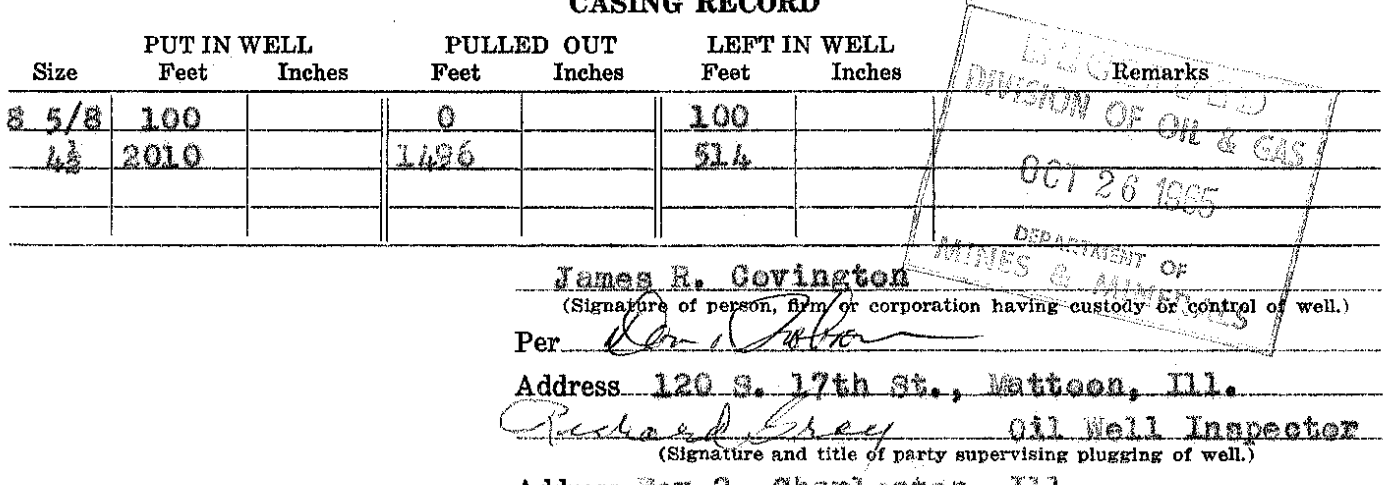


STATE OF ILLINOIS

County of

\section{WELL PLUGGING AFFIDAVIT}

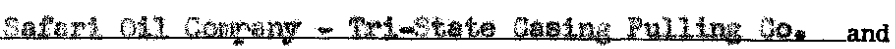

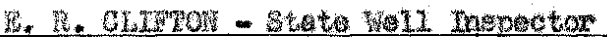
being first duly sworn. do depose and say the following is a true and correct statement of the details of the plugging of a certain well drilled for $\quad$ oxt.

(Indicate whether for oil, gas, water or other purposes)

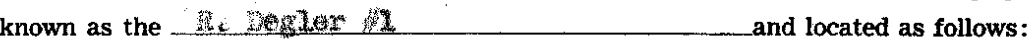

ft. north;

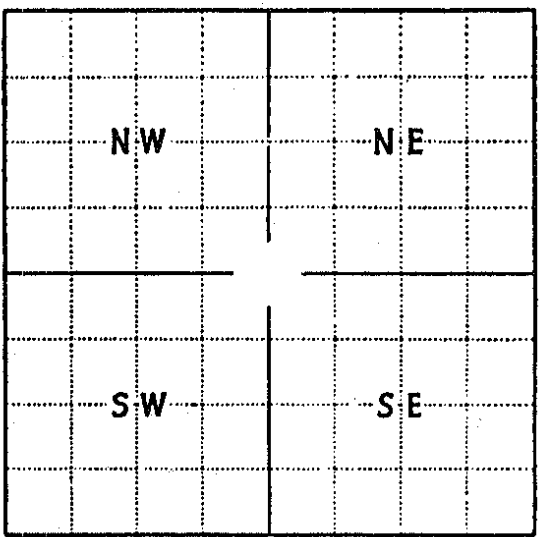

Locate well accurately on plat of section (Scale one inch-2,000 ft.)

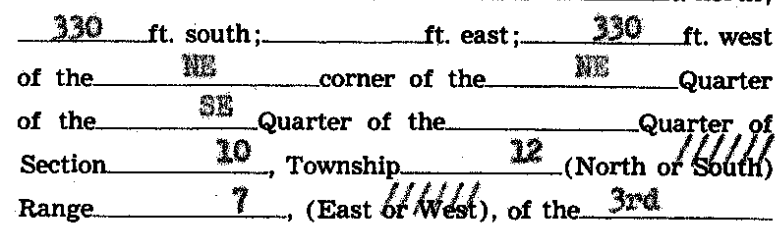

Principal Meridian, DoL

County, Illinois.

Elevation above sea level is $\left\{\begin{array}{l}\text { Derrick Floor } \\ \text { Ground } \mathrm{ft} .\end{array}\right.$

Total depth 2028 Formation wryestis

Date permit to drill issued $12 / 4 / 45$ Permit No. 1351

Permit issued to

Date drilling began 12-13-45

Date drilling completed $\quad 21-2,2-45$

Kind of drilling tools used

Date plugging began

$5-7-77$

Date plugging completed

$5-9-77$

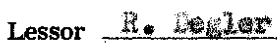

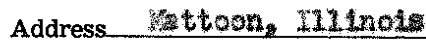

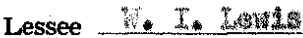

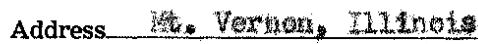

Drilling Contractor Unknown

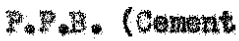

Filled with

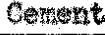

Mud, Cement, or Other Materlals)

Address.

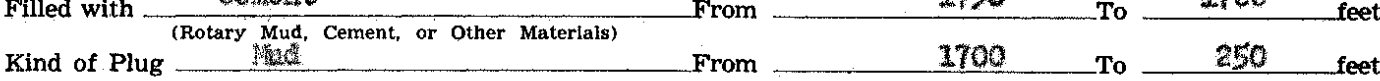

Filled with $\quad$ From $\quad 250$ To $\quad 200$

$200 \quad$ To 255

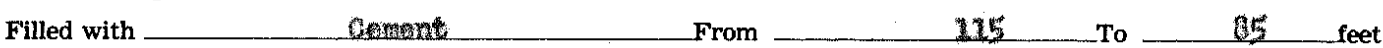

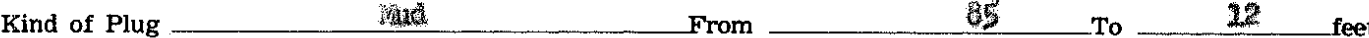

Filled with $\quad$ wentent $\quad$ From $\quad 12 \quad$ To 03 feet

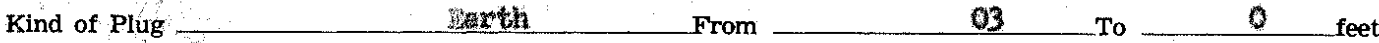

IF WORKABLE COAL BEDS WERE ENCOUNTERED IN THIS HOLE, DESCRIBE THE METHOD EMPLOYED TO PROTECT SAME. (A workable coal bed is thirty inches or more in thickness above 1,000 feet in depth)

(1) Have pits and other excavations been filled?............... Yes

(2) Have the following been removed?

Equipment $\stackrel{\text { Yes }}{\square}$ Concrete bases $\stackrel{\text { Yes }}{\square}$ Do Debris $\stackrel{\text { Yes }}{\square}$ No

(3) Has surface casing been cut off three feet below ground surface?

(4) Has well-site been leveled?

If this was a producing well, give date and amount of last production

Undurow

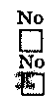

CASING RECORD

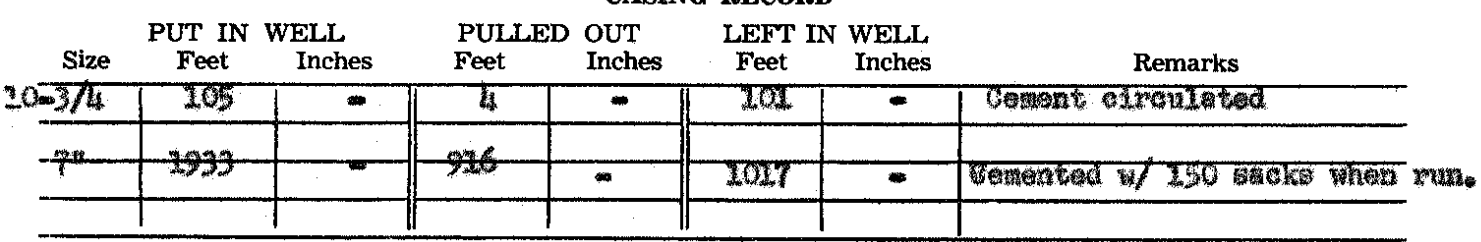

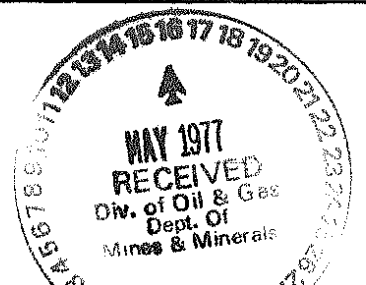

35.

(Signatyre of person, frm gr corporation having custody or control of well.)

Per Kox 20 .

Address

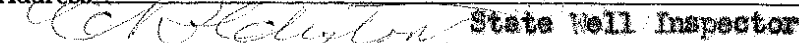

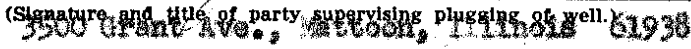

Address

Subscribed and sworn to beforme this 12 tay of My commission expires 
do depose and say the following is a true and correct statement of the details of the plugging of a certain well drilled for tis

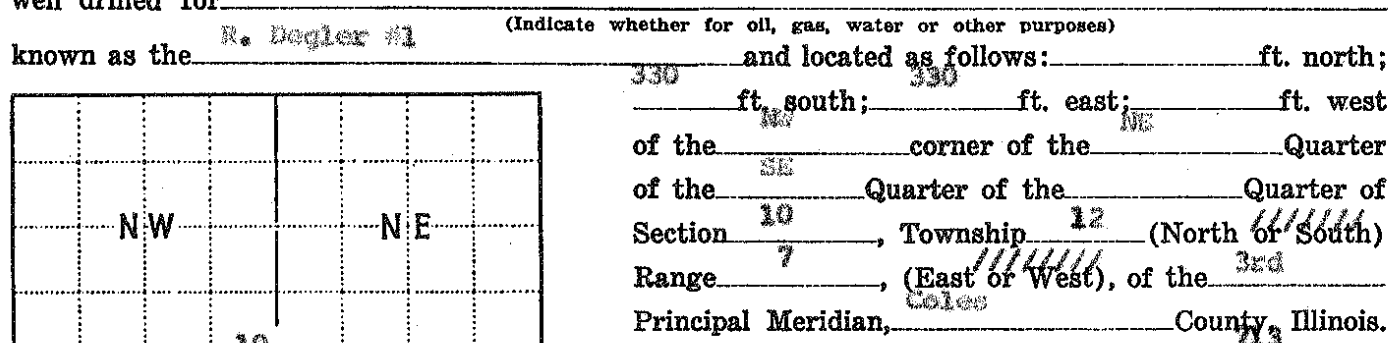
Principal Meridian,

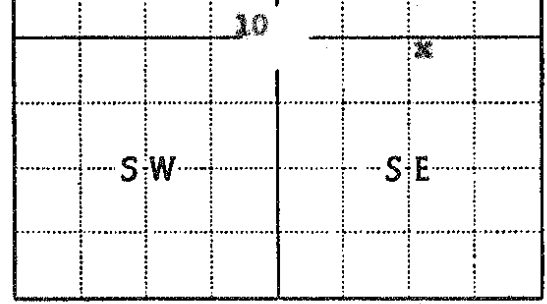

Locate well accurately on plat of section (Seale one inch-2,000 ft.)

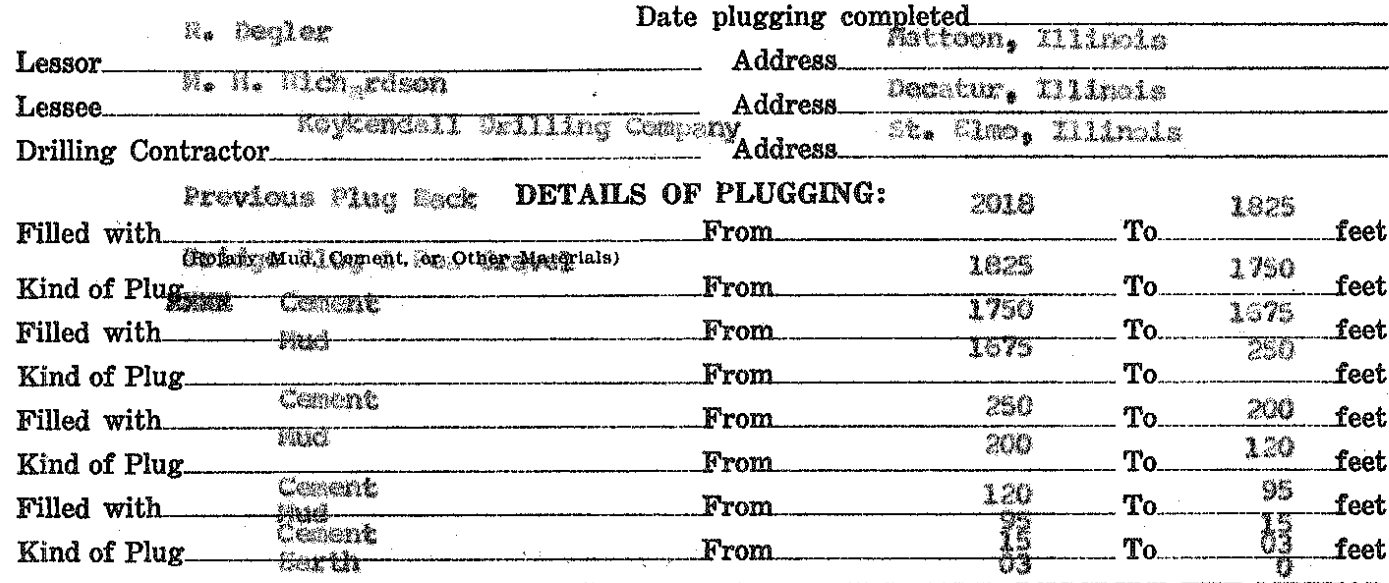
Flevation above sea level is $\left\{\begin{array}{l}\text { Derrick Floor } \\ \text { Ground }\end{array}\right.$ Total depth 2014

Date permit to drill issued Permit No......................

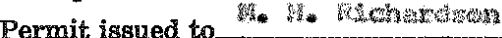

Date drilling began ___ I _

Date drilling completed 1 -

Kind of drilling tools used

Date plugging began

Date plugging completed 

drilled for

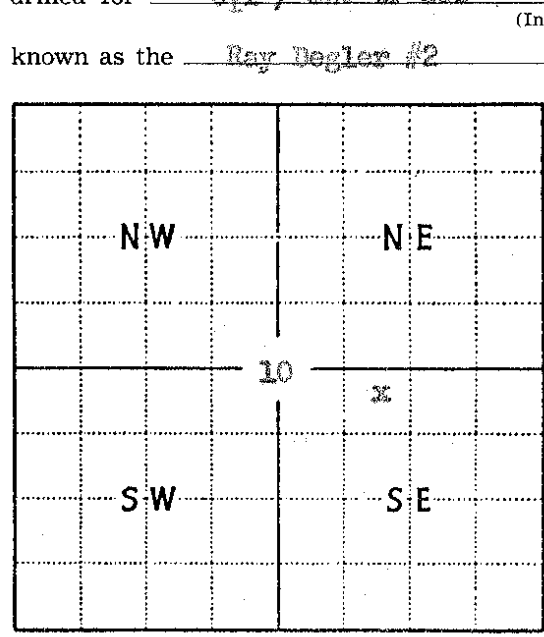

Locate well accurately on piat of section (Scale one inch-2,000 ft.)

(Indicate whether for oil, gas, water or other purposes)

and located as follows :

30 ft. south;___ft. east; 2650 ft. west

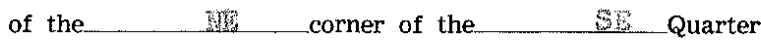

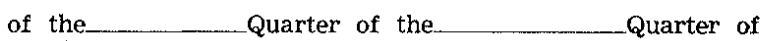

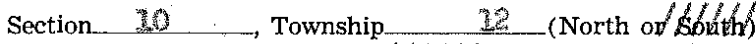
Range of (East of d esty, of the gow

Principal Meridian, Roves County, Illinois. Elevation above sea level is $\begin{cases}\text { Derrick Floor } & \mathrm{ft} . \\ \text { Ground } & \mathrm{ft} .\end{cases}$

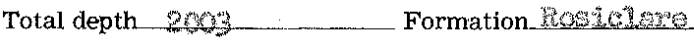
Date permit to drill issued2/ $00 / 4 \mathrm{~g}^{2}$ Permit No. 252

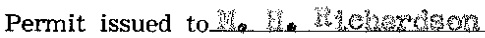

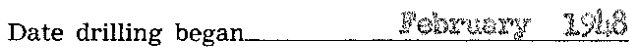
Date drilling completed $\quad 3-26 \mathrm{ml}$ Kind of drilling tools used_aturay Date plugging began $\quad 10423.73$ Date plugging completed ___

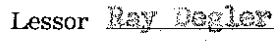

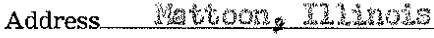

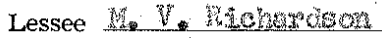
Address W W

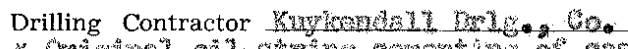

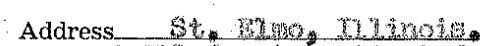

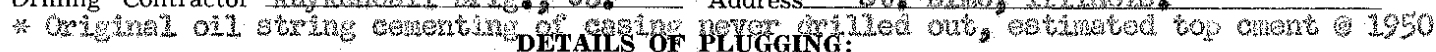

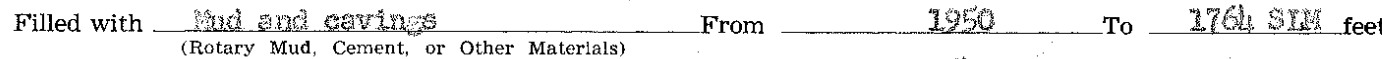
Kind of Plug Gangent From 1764 To 1720 feet

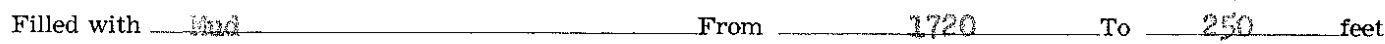
Kind of Plug osmentut Filled with Kind of Plug centerngti Filled with From 250 To 200 feet

Kind of Plug Qerent

From 200 To $\quad$ Th feet

IF WORKABLE COAL BEDS WERE ENCOUNTERED IN THIS HORE DESCRIBE THE METHOD EMPLOYED TO PROTECT SAME. (A workable coal bed is thirty inches or more in thickness above 1,000 feet in depth) Inone

(1) Have pits and other excavations been filled? .............

(2) Have the following been removed?
Equipment
Concrete bases Yes No
Debris $\stackrel{\text { Yes }}{\square} \stackrel{\text { No }}{\square}$

(3) Has surface casing been cut off three feet below ground surface?

(4) Has well-site been levelled?

If this was a producing well, give date and amount of last production

124 To - Toet

95

\begin{tabular}{|c|c|c|c|c|c|c|c|}
\hline \multirow[b]{2}{*}{ Size } & \multicolumn{7}{|c|}{ CASING RECORD } \\
\hline & $\begin{array}{c}\text { PUT IN } \\
\text { Feet }\end{array}$ & $\begin{array}{l}\text { WELL } \\
\text { Inches }\end{array}$ & $\begin{array}{l}\text { PULLED } \\
\text { Feet }\end{array}$ & $\begin{array}{l}\text { OUT } \\
\text { Inches }\end{array}$ & $\begin{array}{c}\text { LEFT } \\
\text { Feet }\end{array}$ & $\begin{array}{l}\text { WELL } \\
\text { Inches }\end{array}$ & Remarks \\
\hline $8=5 / 6$ & $\mathrm{NH}$ & - & 3 & - & 132 & - & 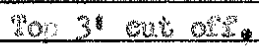 \\
\hline$-9 / 2$ & 2962 & - & 700 & - & 2261 & - & \\
\hline
\end{tabular}

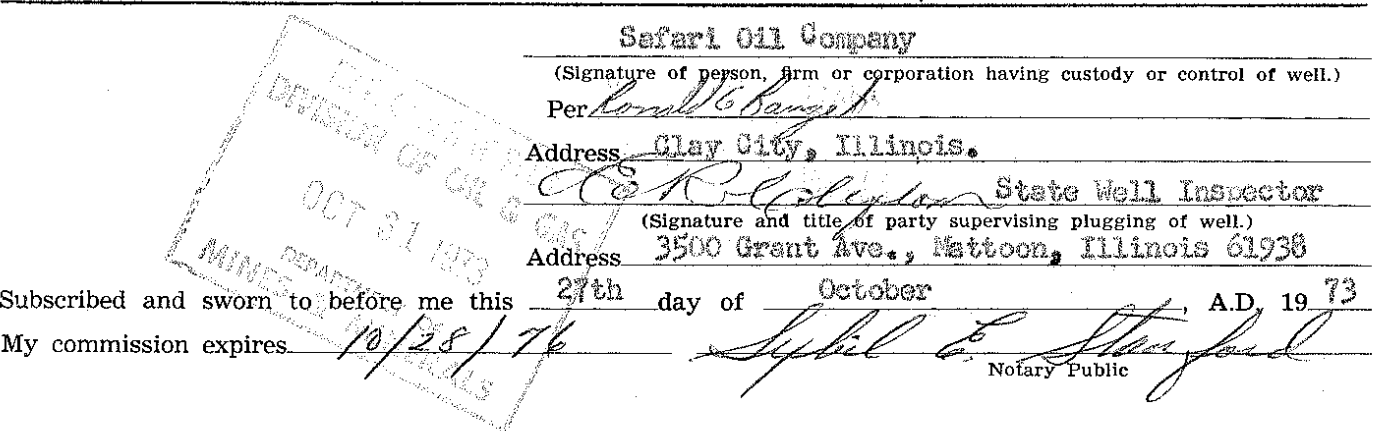


STATE OF ILLINOIS, Co County of Celes $\}$ ss. WELL PLUGGING AFFISAVIT 7 m

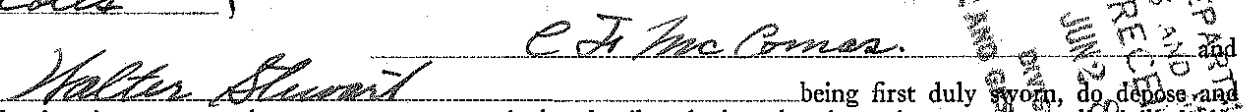

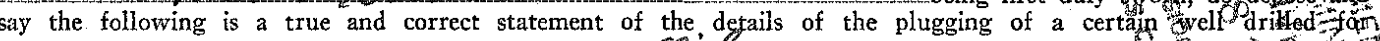
Q12 known as the (Indicate whether for oil, gas, water or other purposes)

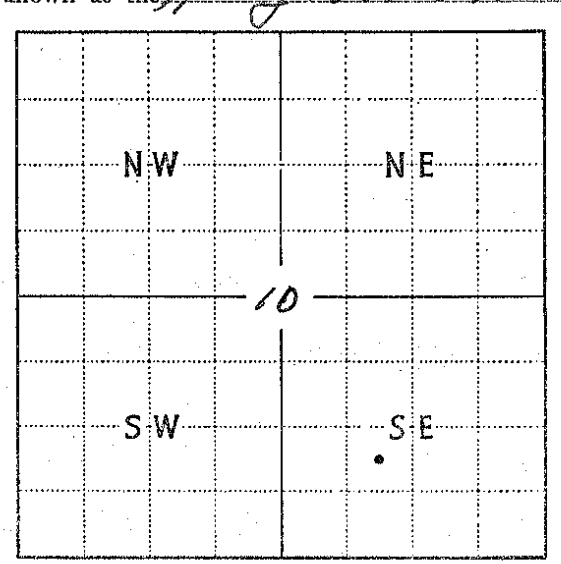

Locate well accurately on plat of section (Scale one inch-2,000 ft.)
330 of the $N E$

and of the $S E$ Section $<0$ Range $z$

Principal Meridian,

Elevation above sea level is

Total depth of well is corner of the $S \mathrm{~W}$ the $S W$ 2. f. f. west Quarter Quarter of Date permit to drill issued Oen $14 \quad 1246$

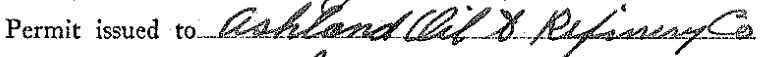
Date driling began $\operatorname{lan}<2<18$ Date drilling completed fan $29 \quad 12 \leqslant 6$ Kind of drilling tools used Powery Date plugging began ferene $245,2<6$ Date plugging completed \&ower $26-19 \& 6$

\section{Lessor Ene \& Lever Dene}

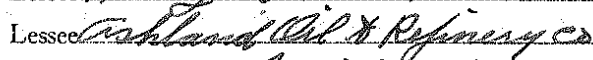
Drilling Contractor Heatse trese

\section{DETAILS OF PLUGGING:}

Filled with (Rotary Mud, cement, on oner Materials) From
Kind of Plug Prom

IF WORKABLE COAL BEDS WERE ENCOUNTERED IN THIS HOLE, DESCRIBE THE METHOD EMPLOYED TO PROTECT SAME. (A workable coal bed is thirty inches or more in thickness above 1,000 feet in depth.

Other details

If this was a producing well, give date and amount of last production

CASING RECORD

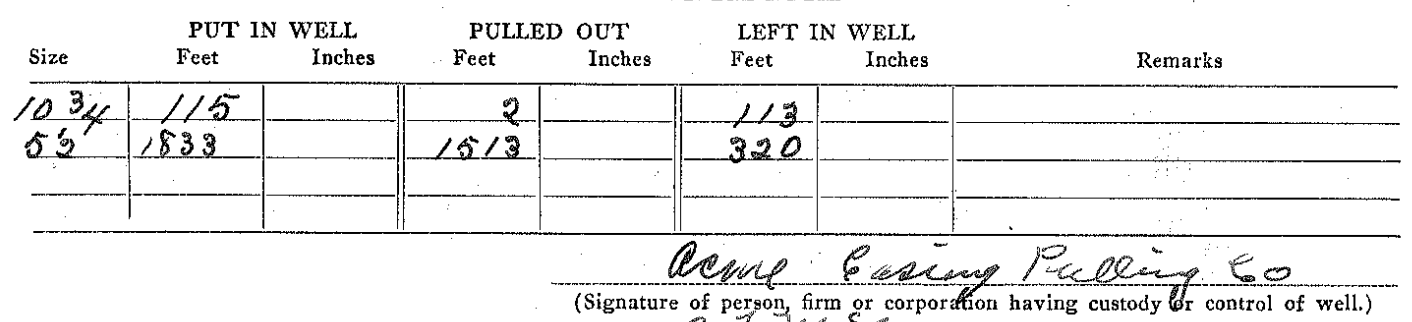

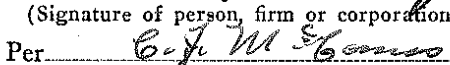

Per $\quad 6-8$ Q

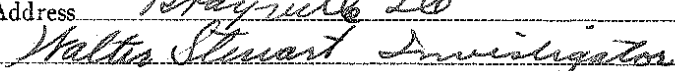

(Signature and title of party supervising plefgging of well.)

Subscribed and sworn to before me this 2

My commission expires. Narr $30-1942$ 
County of

\section{WELLPLUGGING AFEIDAVIT}

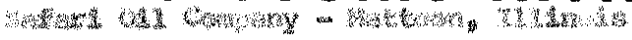
and

1.

being first duly sworn, do depose and say the following is a true and correct statement of the details of the plugging of a certain well drilled for (t)

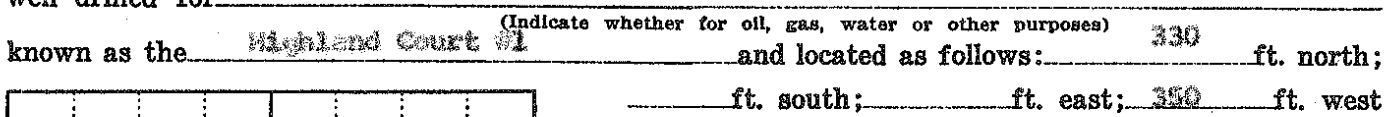

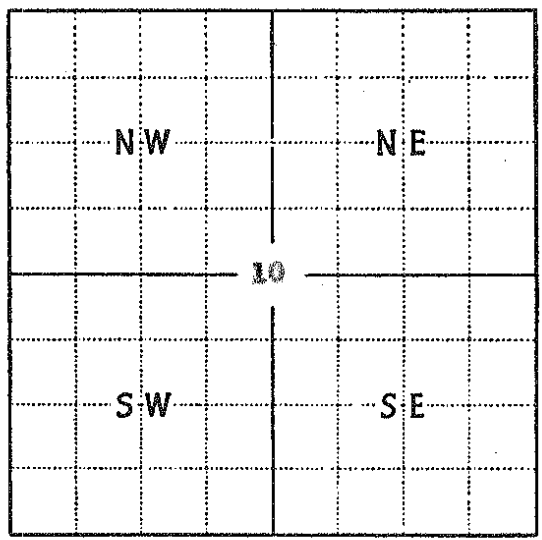

Locate well accurately on plat of section

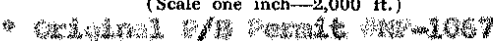
atson 20

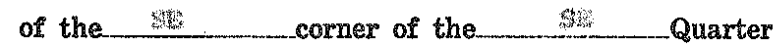

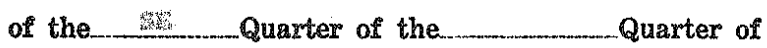

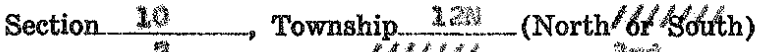
Range $\quad$ (East of West), of the

Principal Meridian, Cun County, nlinois. Wlevation above sea level is $\left\{\begin{array}{l}\text { Derrick Floor fround } \\ \text { Ground. }\end{array}\right.$

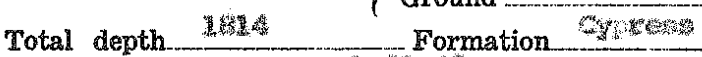

Date permit to drill issued

40 Permit isgued to

Permit issued to ___

Date drilling began

Date drilling completed

Kind of drilling tools used

Date plugging began _.

Date plugging completed

W

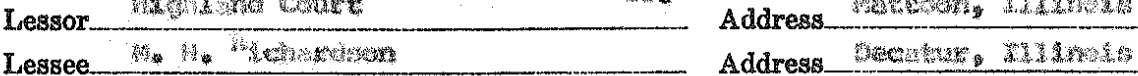

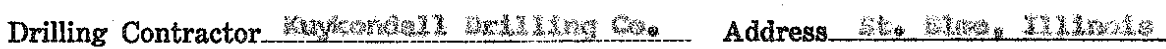

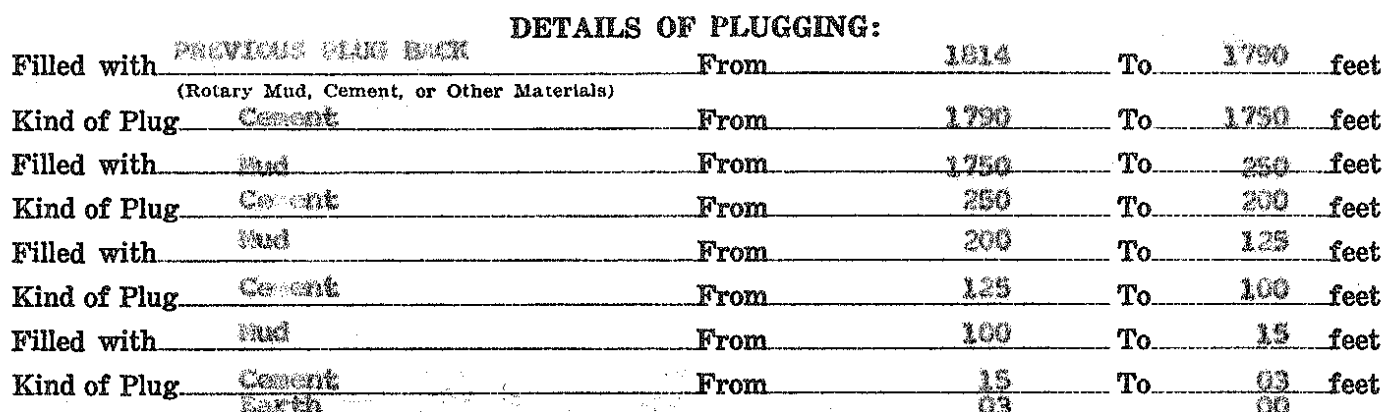

IF WORKABLE COAL BEDS WERE ENCOUNTERED IN THIS HOLE, DESCRIBE THE METHOD EMPLOYED TO PROTECT SAME. (A workable coal bed is thirty inches or more in thickness above 1,000 feet in depth) ___ w

(1) Have pits and other excavations been filled?.

(2) Have the following been removed?

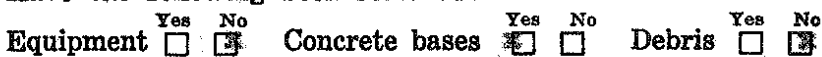

(3) Has surface casing been cut off three feet below ground surface?

(4) Has well-site been levelled? Yeg

If this was a producing well, give date and amount of last production

\section{CASTNG RECORD}

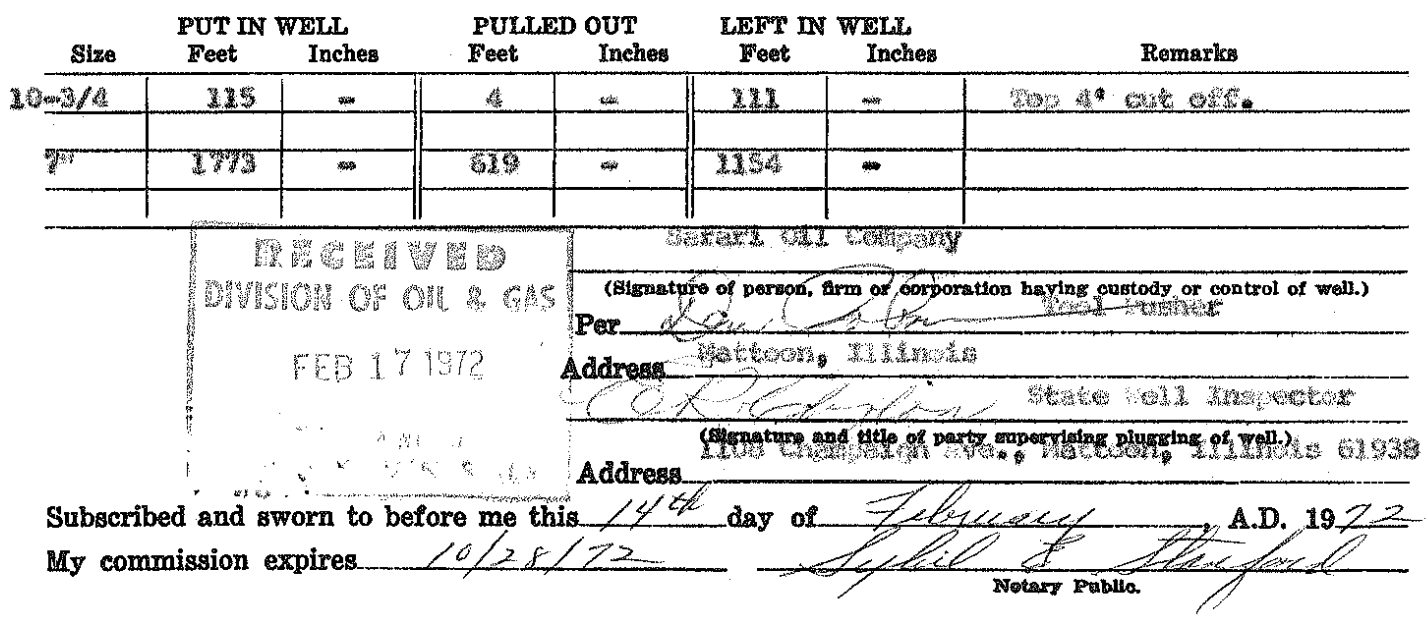



do depose and say the following is a true and correct statement of the details of the plugging of a certain well drilled for int:

known as the (Indicate whether Por ofl, gas, water or other purposeg)

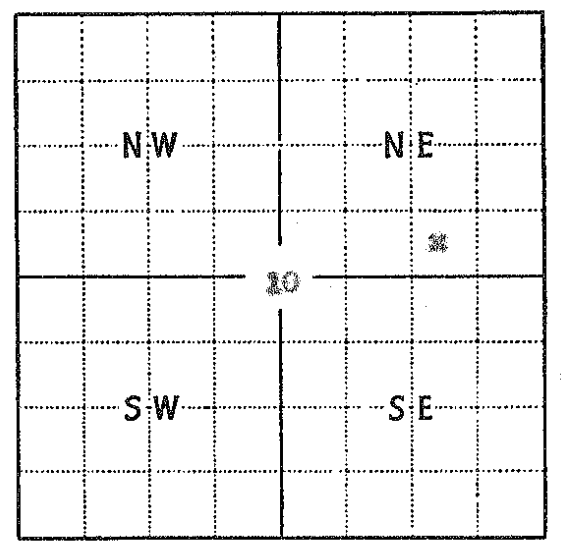

Locate well accurately on plat of section (Scale one inch-2,000 ft.) and located as follows:

Fise ft. north; ft. south; _._.

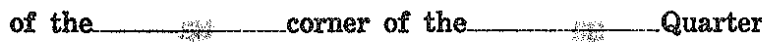
of the Q__ Quarter of the Quarter of

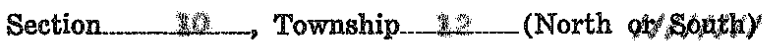
Range $\quad$ (East of W W Principal Meridian, County, nlinois.

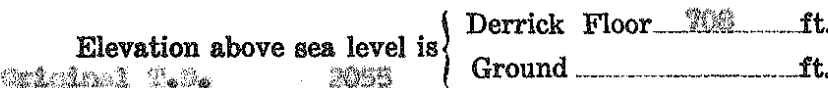

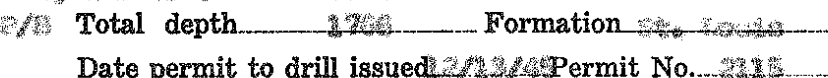

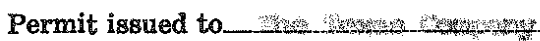

Date drilling began _._____.._.

Date drilling completed _____

Kind of dxilling tools used _._._. W

Date plugging began (1)

Date plugging completed Les

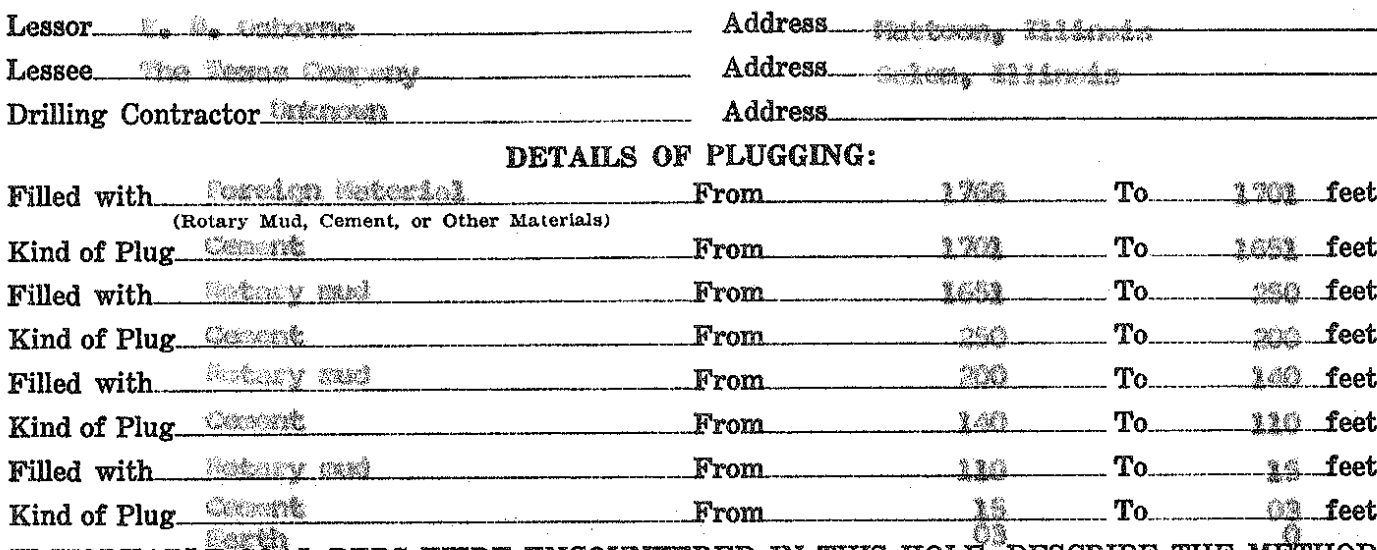
IF WORKABLE COAL BEDS WERE ENCOUNTERED IN THIS HOLE, DESCRIBE THE METHOD EMPLOYED TO PROTECT SAME. (A workable coal bed is thirty inches or more in thickness above 1,000 feet in depth)

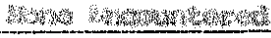

(1) Have pits and other excavations been filled?

(a) Have the following been removed?

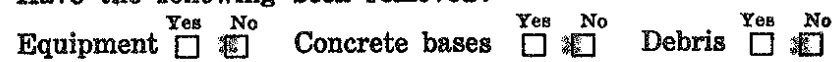

(3) Has surface casing been cut off three feet below ground surface?

(4) Has well-site been levelled?.

If this was a producing well, give date and amount of last production

踏

(1)


do depose and say the following is a true and correct statement of the details of the plugging of a certain well drilled for Wht $\quad($ w

known as the

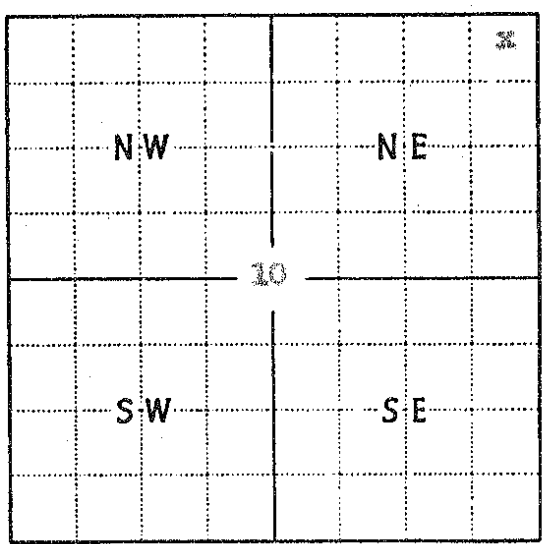

Locate well accurately on plat of section (Scale one inch-2,000 ft.) (Indicate whether for oil, gas, water or other purposes)
and located as follows: (Indicate whether for oil, gas, water or other purposes
and located as follows: fe. north;

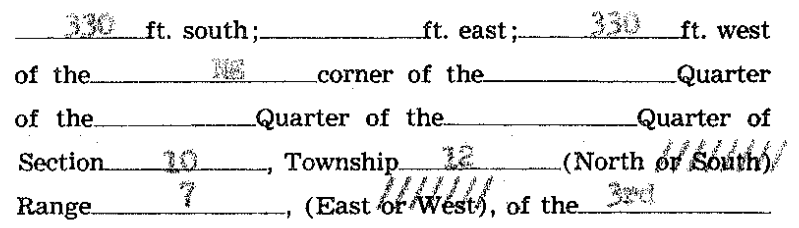

Principal Meridian, County, Illinois. Elevation above sea level is $\left\{\begin{array}{l}\text { Derrick Floor } \\ \text { Ground } \mathrm{ft} .\end{array}\right.$

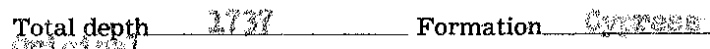

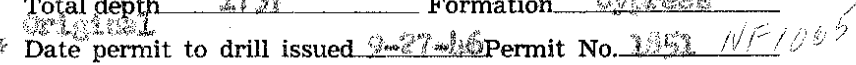

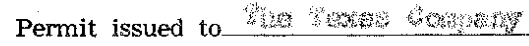
Date drilling began_.

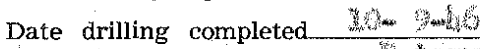
Kind of drilling tools used Date plugging began tus Date plugging completed

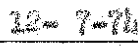

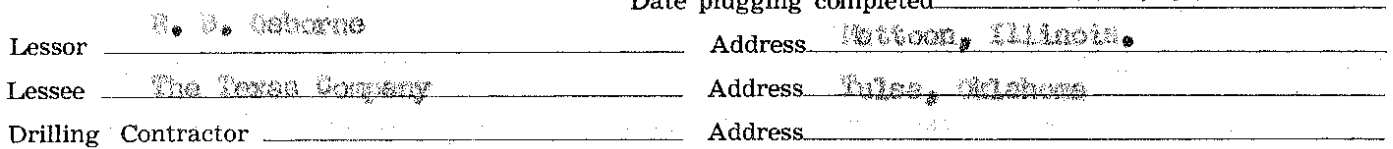

DETAILS OF PLUGGING:

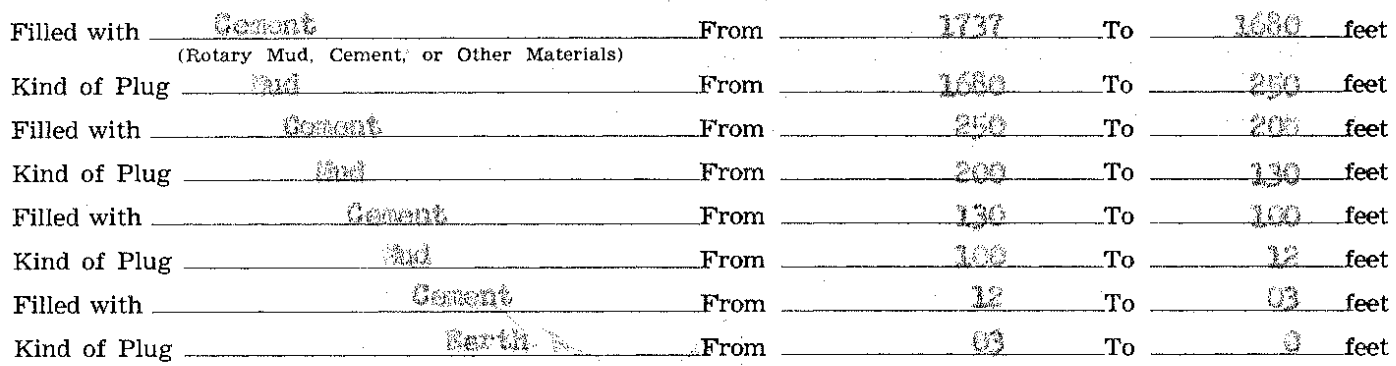

IF WORKABLE COAL BEDS WERE ENCOUNTERED IN THIS HOLE, DESCRIBE THE METHOD EMPLOYED TO PROTECT SAME. (A workable coal bed is thirty inches or more in thickness above 1,000 feet in depth) Whith

(1) Have pits and other excavations been filled $\ldots \ldots \ldots \ldots \ldots \ldots \ldots \ldots \ldots$ Yes

(2) Have the following been removed?
Equipment $\stackrel{\text { Yes }}{\square}$ 筙
Concrete bases $\stackrel{\text { Yes }}{\square}$
Debris $\stackrel{\text { Yes }}{\square}$ 晸

(3) Has surface casing been cut off three feet below ground surface?

(4) Has well-site been leveled?

If this was a producing well, give date and amount of last production

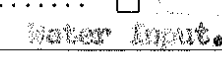

\begin{tabular}{|c|c|c|c|c|c|c|c|}
\hline \multirow[b]{2}{*}{ Size } & \multicolumn{7}{|c|}{ CASING RECORD } \\
\hline & $\begin{array}{l}\text { PUT IN } \\
\text { Feet }\end{array}$ & $\begin{array}{l}\text { WELL } \\
\text { Inches }\end{array}$ & $\begin{array}{l}\text { PULLED } \\
\text { Feet }\end{array}$ & $\begin{array}{l}\text { OUT } \\
\text { Inches }\end{array}$ & $\begin{array}{l}\text { LEFT } \\
\text { Feet }\end{array}$ & WELL & Remarks \\
\hline \multirow[t]{2}{*}{ 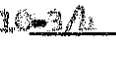 } & $1 \mathrm{~L}^{2}$ & $=$ & 3 & $=$ & 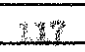 & $=$ & 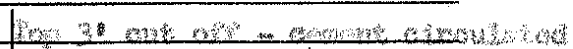 \\
\hline & & & & & & & 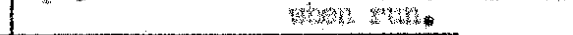 \\
\hline \multirow[t]{2}{*}{ 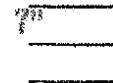 } & 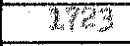 & & Ellat: & - & कe & - & 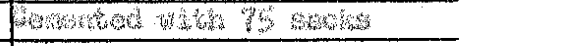 \\
\hline & & & & & & & \\
\hline \multirow{5}{*}{\multicolumn{4}{|c|}{ 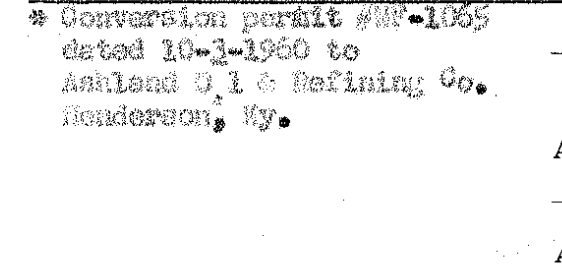 }} & \multicolumn{3}{|c|}{ 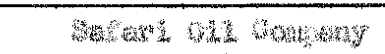 } & 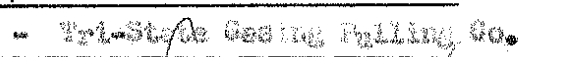 \\
\hline & & & & \multicolumn{4}{|c|}{ (Signature of persop, $\mathrm{Arm}$ yr gonporation having chstody or control of well.) } \\
\hline & & & & \multicolumn{4}{|c|}{ 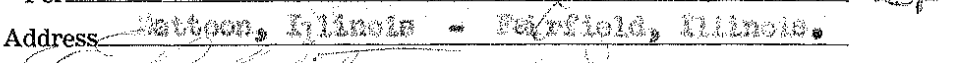 } \\
\hline & & & & \multirow{2}{*}{\multicolumn{4}{|c|}{ 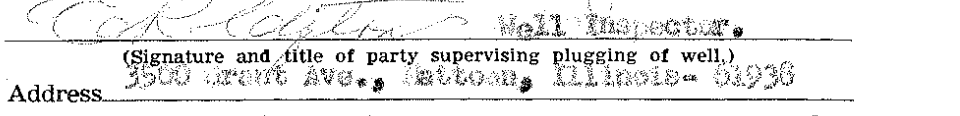 }} \\
\hline & & & & & & & \\
\hline \multicolumn{8}{|c|}{ 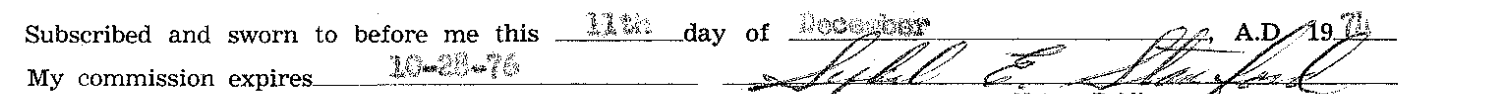 } \\
\hline
\end{tabular}




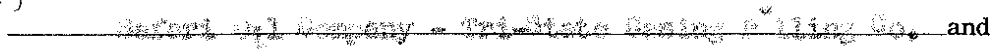

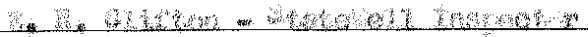

being first duly sworn, do depose and say the following is a true and correct statement of the details of the plugging of a certain well

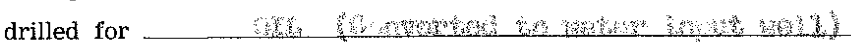
(Indicate whether for oil, gas, water or other purposes)

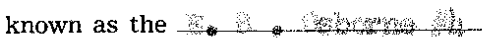

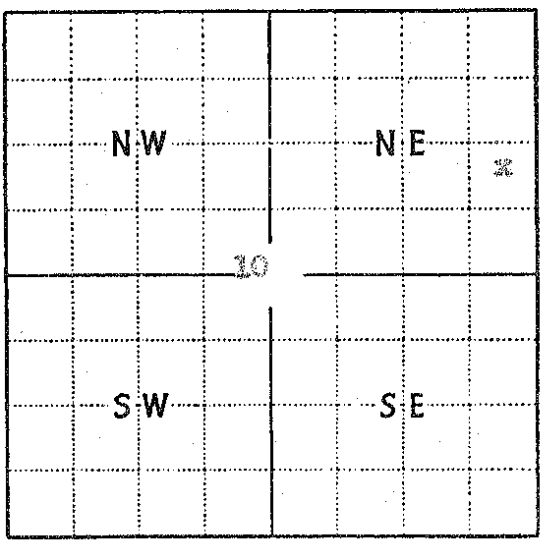

Locate well accurately on plat of section (Scale one inch-2, $2,000 \mathrm{ft}$.) and located as follows:

ft. north;

$310 \mathrm{ft}$. south;

ft. east ; 3 ft. west of the corner of the curster

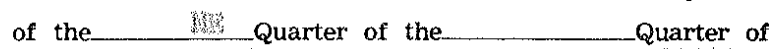
Section $\quad$ Township__.

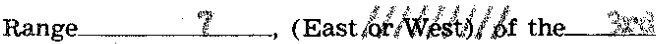
Principal Meridian,______ne__ounty, Illinois. Elevation above sea level is $\left\{\begin{array}{l}\text { Derrick Floor } \ldots \text { ft. } \\ \text { Ground }\end{array}\right.$

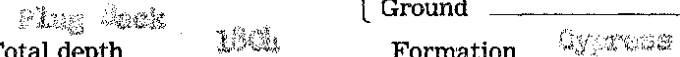

* Date permit to drill issued

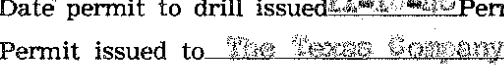
Date drilling began_... Date drilling completed Kind of drilling tools used

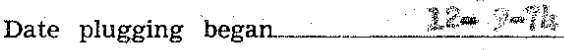

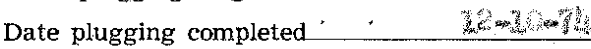

\begin{tabular}{|c|c|c|c|}
\hline 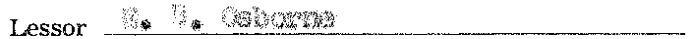 & ss. & 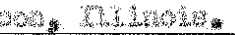 & \\
\hline essee & Address_ & 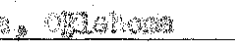 & \\
\hline rilling Contractor & Address & & \\
\hline 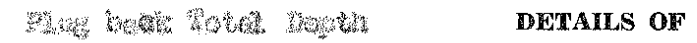 & PLUGGING: & 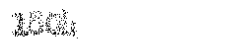 & and \\
\hline Filled with & From & 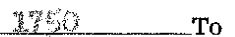 & then \\
\hline Kind of Plug (Rotary Mud, Cement, or Other Materials) & From & 整? To & ons \\
\hline Filled with ___ _ & From & $m_{1}$ & $2 x$ \\
\hline Kind of Plug & From & sive & $y_{1}$ \\
\hline illed with & From & 3is & sts \\
\hline Kind of Plug & From & $f_{n+1}$ & $z^{2}$ \\
\hline Filled with & From & $e_{3}$ & 3 \\
\hline 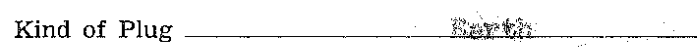 & From & To & \\
\hline
\end{tabular}
IF WORKABLE COAL BEDS WERE ENCOUNTERED IN THIS HOLE, DESCRIBE THE METHOD EMPLOYED TO PROTECT SAME. (A workable coal bed is thirty inches or more in thickness above 1,000 feet

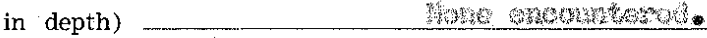

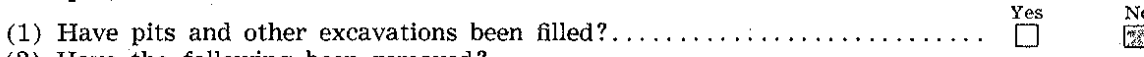

(2) Have the following been removed?

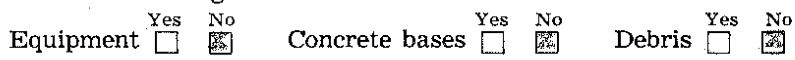

(3) Has surface casing been cut off three feet below ground surface?

(4) Has well-site been leveled?

If this was a producing well, give date and amount of last production

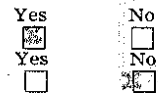

CASING RECORD

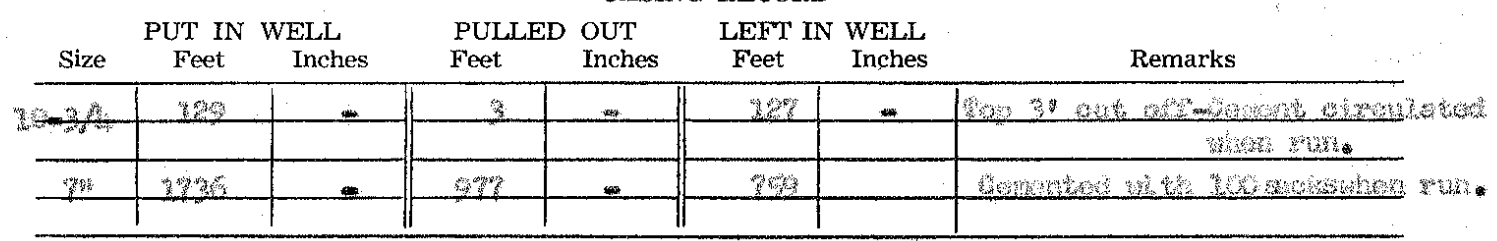

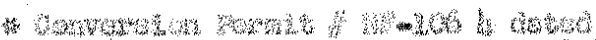

整,

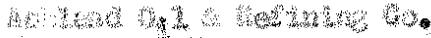

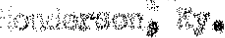

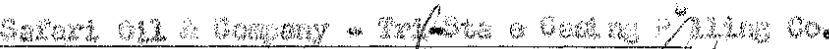
(Signature of person, firm or gorporation having cusfody or control gf welly)

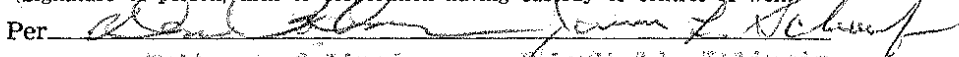

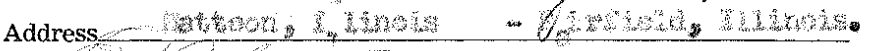

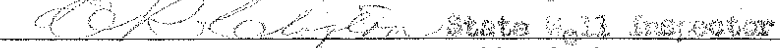
(Signature and title/ of party supervising plugging of well.)

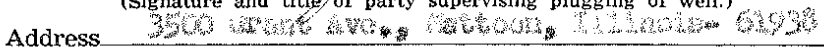

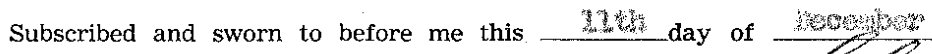
My commission expires____
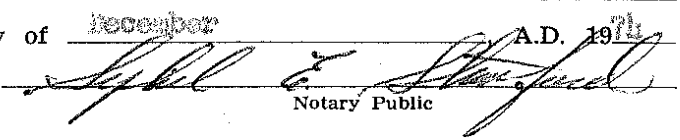


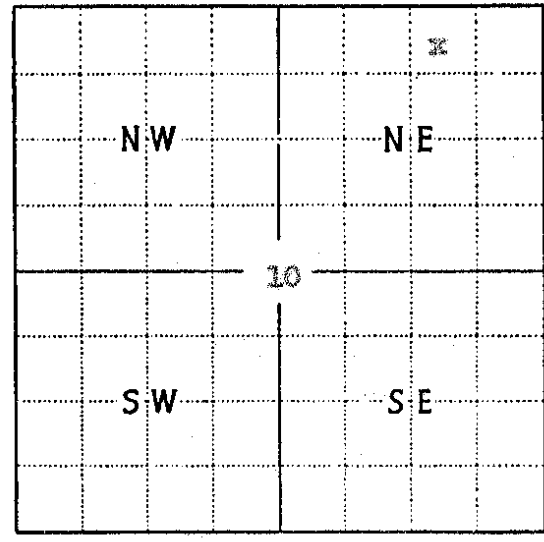

Locate well accurately on plat of section (Scale one inch-2-2,000 ft:

330 ft. south; 330 ft. east;____ f ft. west

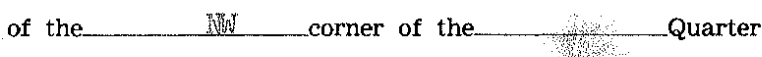
of the Q Quarter of the

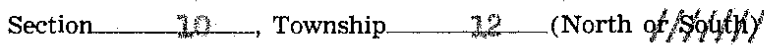

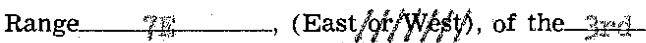

Principal Meridian, Quldes County, Illinois. Elevation above sea level is $\begin{cases}\text { Derrick Floor } & \mathrm{ft} . \\ \text { Ground } \frac{62}{6 t} & \mathrm{ft} .\end{cases}$

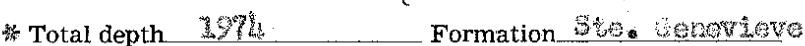
Date permit to drill issued $1-5-28$ Permit No. 56

Permit issued to 의a

Date drilling began Wom chen $701 \%$

Date drilling completed Aym 1948

Kind of drilling tools used Potuny

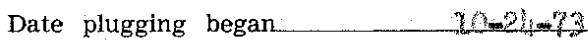

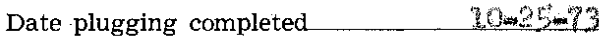

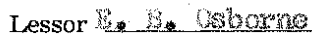

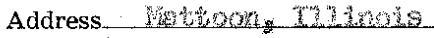

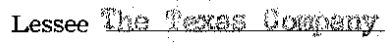

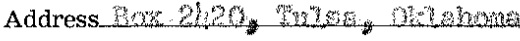

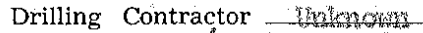
Address

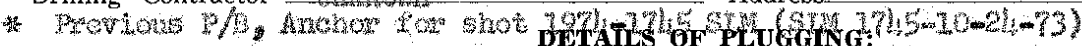

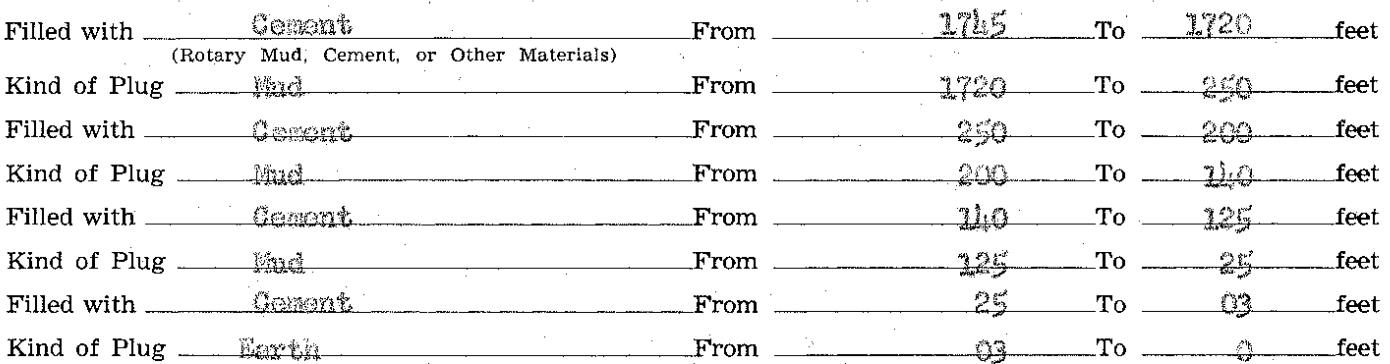

IF WORKABLE COAL BEDS WERE ENCOUNTERED IN THIS HOLE, DESCRIBE THE METHOD EMPLOYED TO PROTECT SAME. (A workable coal bed is thirty inches or more in thickness above 1,000 feet in depth) frone

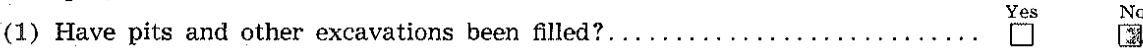

(2) Have the following been removed?
Equipment $\stackrel{\text { Yes }}{\square}$ No
Concrete bases $\stackrel{\text { Yes }}{\square}$ No
Debris $\stackrel{\text { Yes }}{\square}$ No

(3) Has surface casing been cut off three feet below ground surface?

(4) Has well-site been levelled?

If this was a producing well, give date and amount of last production

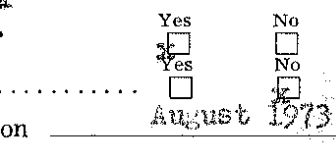

\section{CASING RECORD}

\begin{tabular}{|c|c|c|c|c|c|c|c|}
\hline Size & $\begin{array}{c}\text { PUT IN } \\
\text { Feet }\end{array}$ & $\begin{array}{l}\text { WELL } \\
\text { Inches }\end{array}$ & $\begin{array}{l}\text { PULLED } \\
\text { Feet }\end{array}$ & $\begin{array}{l}\text { OUT. } \\
\text { Inches }\end{array}$ & $\begin{array}{c}\text { LEFT } \\
\text { Feet }\end{array}$ & $\begin{array}{l}\text { WELL } \\
\text { Inches }\end{array}$ & Remarks \\
\hline \multirow[t]{2}{*}{ 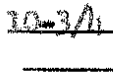 } & 230 & Sy & 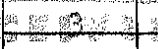 & $y-$ & 212 & $=$ & 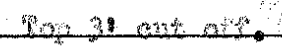 \\
\hline & & Hogng & $4 y^{2}=0$ & 2. & & & \\
\hline \multirow[t]{2}{*}{ 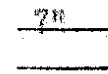 } & 173 & $=$ & 36 & $\longrightarrow$ & 124n & $=$ & \\
\hline & & H & +20197 & & & & \\
\hline
\end{tabular}

syedeftanase of (Signalure of person, firm or corporation having custody or control of well.)

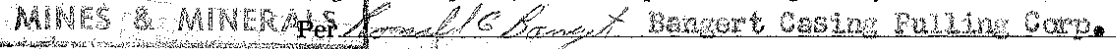
4 th०

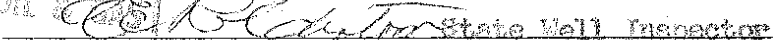
(Signature and title of party supervising plugging of well.) Address 3500 meat

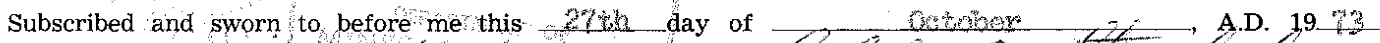
My commission expires $20 / 26 / 26$

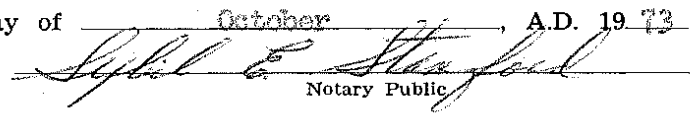



do depose and say the following is a true and correct statement of the details of the plugging of a certain well

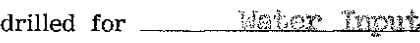

known as the mowowe no (Indicate whether for oil, gas; water or other purposes)

known as the wewomention

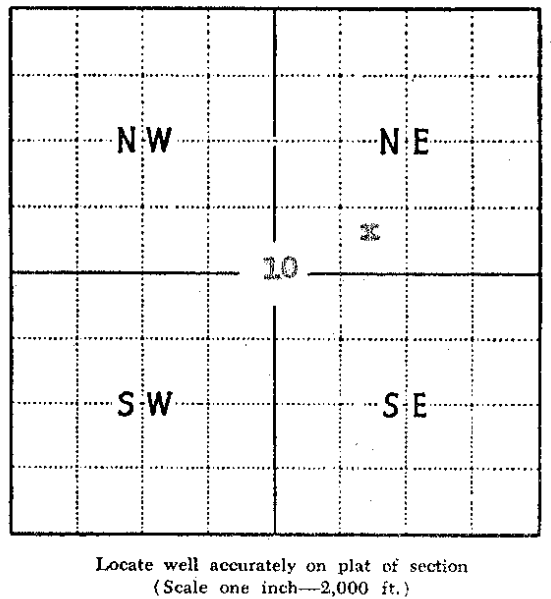
and located as follows: 260 ft. north; ft. south;_ 50 ft. east;___ ft. west

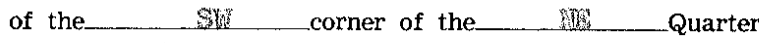
of the - Quarter of the - Quarter of Section 10 , Township_ 22 (North/or/Solth) Range $\quad 7$, (East of $/$ hest), of the 3 wet

Principal Meridian,_oodos County, Illinois.

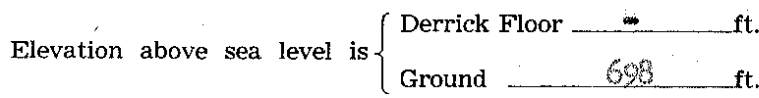
Total depth $\quad 530$ Formation dy pess

Date permit to drill issuedio/3/60 Permit No.22 2

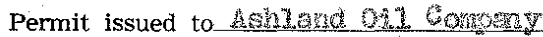

Date drilling began_. $10-10 \mathrm{mb}$

Date drilling completed $10-7 \%-60$

Kind of drilling tools used

Date plugging began $\quad 19-19-73$

Date plugging completed $\quad 20-24-7$

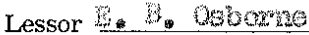

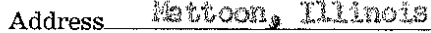

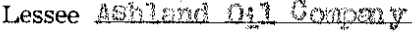

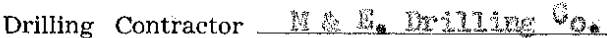

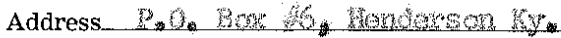

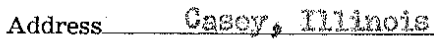

\section{DETAILS OF PLUGGING:}

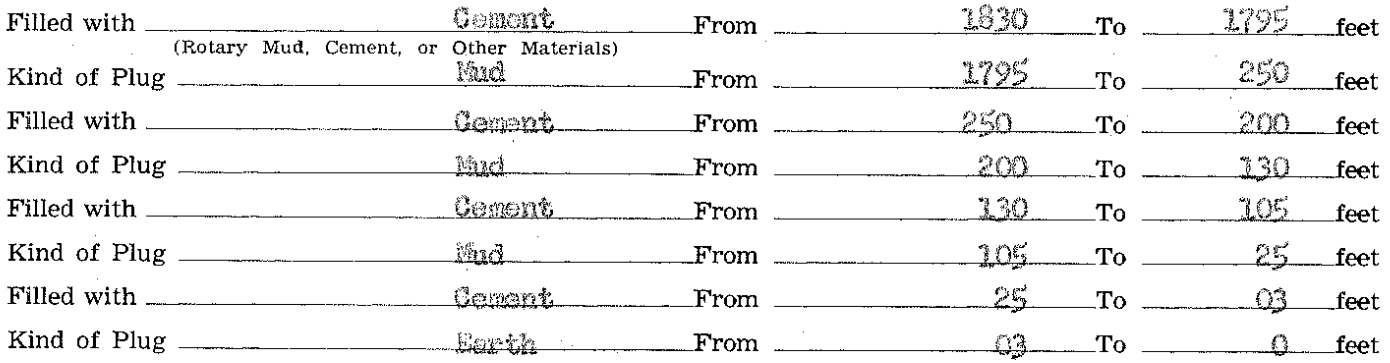

IF WORKABLE COAL BEDS WERE ENCOUNTERED IN THIS HOLE, DESCRIBE THE METHOD EMPLOYED TO PROTECT SAME. (A workable coal bed is thirty inches or more in thickness above 1,000 feet in depth) miche

(1) Have pits and other excavations been filled?

(2) Have the following been removed?

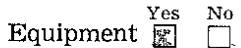
Concrete bases $\stackrel{\text { Yes }}{\square]}$
No Debris $\stackrel{\mathrm{W}}{\mathrm{W}}^{\mathrm{N}}$

(3) Has surface casing been cut off three feet below ground surface?

(4) Has well-site been levelled?

If this was a producing well, give date and amount of last production

\section{CASING RECORD}

\begin{tabular}{|c|c|c|c|c|c|c|c|}
\hline Size & $\underset{\text { Feet }}{\text { PUT IN }}$ & $\begin{array}{l}\text { WELL } \\
\text { Inches }\end{array}$ & $\begin{array}{l}\text { PULLED } \\
\text { Feet }\end{array}$ & $\begin{array}{l}\text { OUT } \\
\text { Inches }\end{array}$ & $\begin{array}{r}\text { LEFT } \\
\text { Feet }\end{array}$ & $\begin{array}{l}\text { WELL } \\
\text { Inches }\end{array}$ & Remarks \\
\hline $3-5$ & 120 & $=$ & 3 & $=$ & 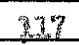 & $=$ & 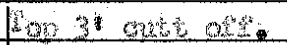 \\
\hline $1-1 / 2$ & 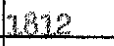 & $=$ & 282 & $=$ & 825 & - & \\
\hline
\end{tabular}

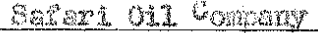

(Signature of persop, firm go corporation having cuștody or control of well.)

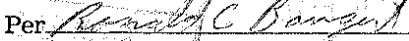

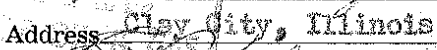

Cof (Signature and tifle of party supervising plugging of well.)

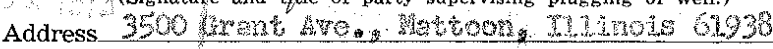

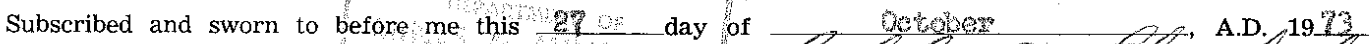
My commission expires 


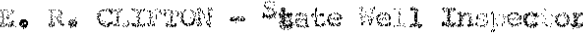

being first duly sworn do depose and say the following is a true and correct statement of the details of the plugging of a certain well drilled for ots.

known as the Wonel 13

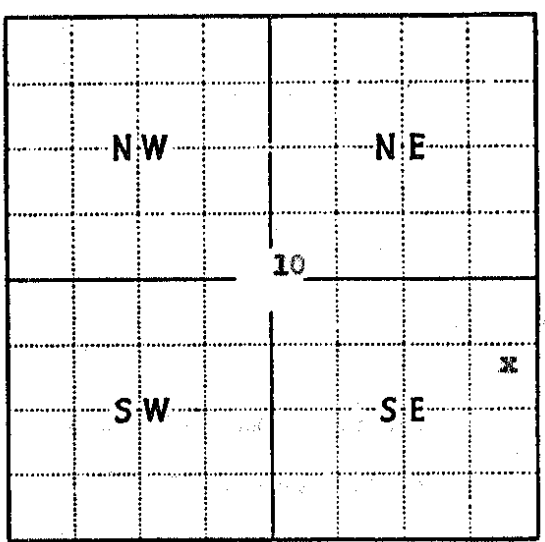

Locate well accurately on plat of section Scale one inch-2,000 it.)

and located as follows:

ft. north; $990 \mathrm{ft}$. south ft. east: $\quad 330$ ft. west of the corner of the ST_ Q of the Quarter of the___ Quarter of

Section $\frac{10}{7}$, Township $\frac{12}{12}$ (North or South)

Range (East $/ \mathrm{r} / \mathrm{w}$ (t) $)$, of the $3 \mathrm{ra}$ Principal Meridian,__County, Illinois. Elevation above sea level is $\left\{\begin{array}{l}\text { Derrick Floor } \frac{720}{71.9} \mathrm{ft} . \\ \text { Ground } \mathrm{ft} .\end{array}\right.$ Total depth 2007 Formation $40.10 \sin y$ Date permit to drill issued $0 / 3 / 45$ Permit No. 1527

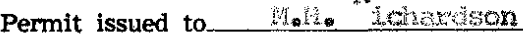
Date drilling began $\quad 1900+25$ Date drilling completed $\quad 20-1,30-1 / 5$ Kind of drilling tools used__ Rotivy Date plugging began $\quad 12-3 \operatorname{3in}$ Date plugging completed $12-4,75$

\begin{tabular}{|c|c|}
\hline Lessor & W \\
\hline Lessee & W. W. Helardson \\
\hline
\end{tabular}

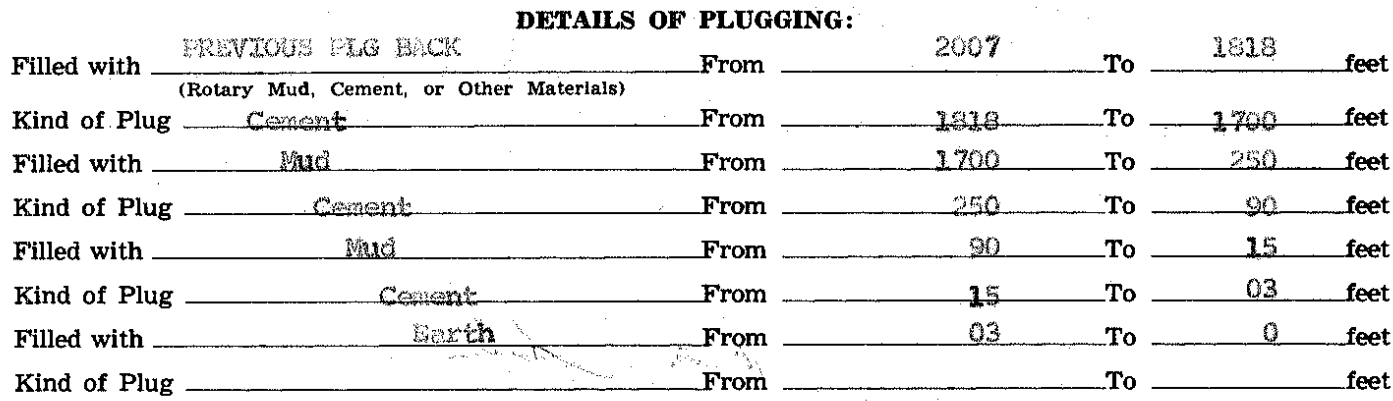

IF WORKABLE COAL BEDS WERE ENCOUNTERED IN THIS HOLE, DESCRIBE THE METHOD EMPLOYED TO PROTECT SAME. (A workable coal bed is thirty inches or more in thickness above 1,000 feet in depth) Mone sncounteren

(1) Have pits and other excavations been flled?................ 通

(2) Have the following been removed?
Equipment $\stackrel{\text { Yes }}{\square}$ o
Concrete bases $\stackrel{\text { Yes }}{\square} \stackrel{\text { No }}{\square}$
Debris $\stackrel{\text { Yes }}{\square} \stackrel{\text { No }}{\square}$

(3) Has surface casing been cut off three feet below ground surface?

(4) Has well-site been leveled? $\ldots \ldots \ldots \ldots \ldots \ldots \ldots \ldots \ldots \ldots \ldots \ldots \ldots$ [

If this was a producing well, give date and amount of last production

Undruturat

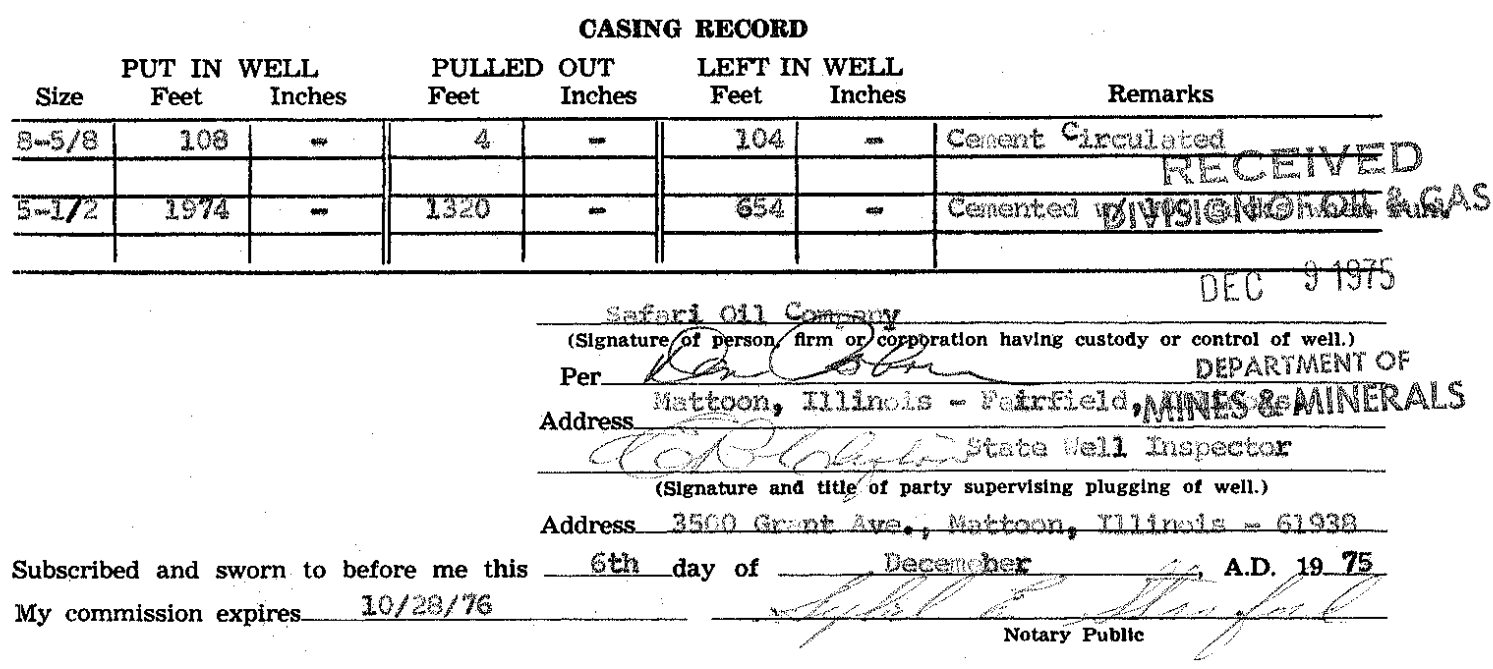


do depose and say the following is a true and correct statement of the details of the plugging of a certain well drilled for

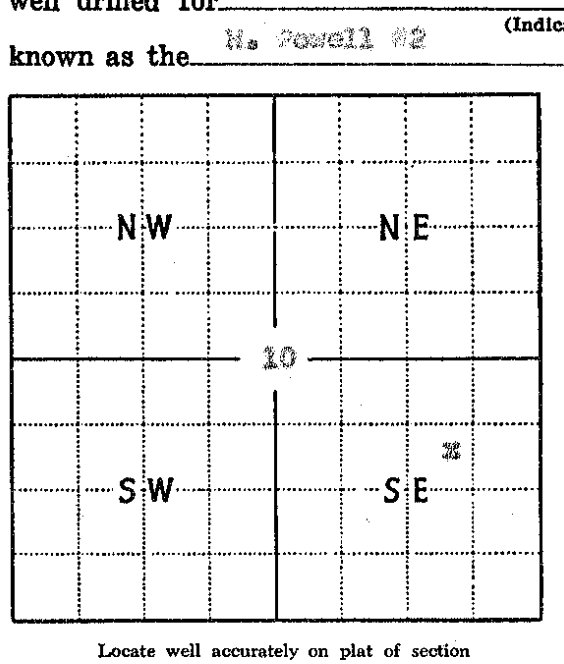

Locate well accurately on plat of section (Scale one inch-2,000 ft.)

whether for ofl, gas, water or other purposeg)

Wether for ofl, gas, water or other purposes) and located as follows:_____north ft. south;____fft. east; _ _ f f west of the corner of the of the___ Quarter of the_Quarter of Section Township.... Range_, (East or West), of the

Principal Meridian, County, nlinois. Elevation above sea level is $\left\{\begin{array}{l}\text { Derrick Floor } \\ \text { Ground }\end{array}\right.$ Total depth Formation Date permit to drill issued $21+4$ Permit issued to Date drilling began Date drilling completed Kind of drilling tools used. Date plugging began Date plugging completed.

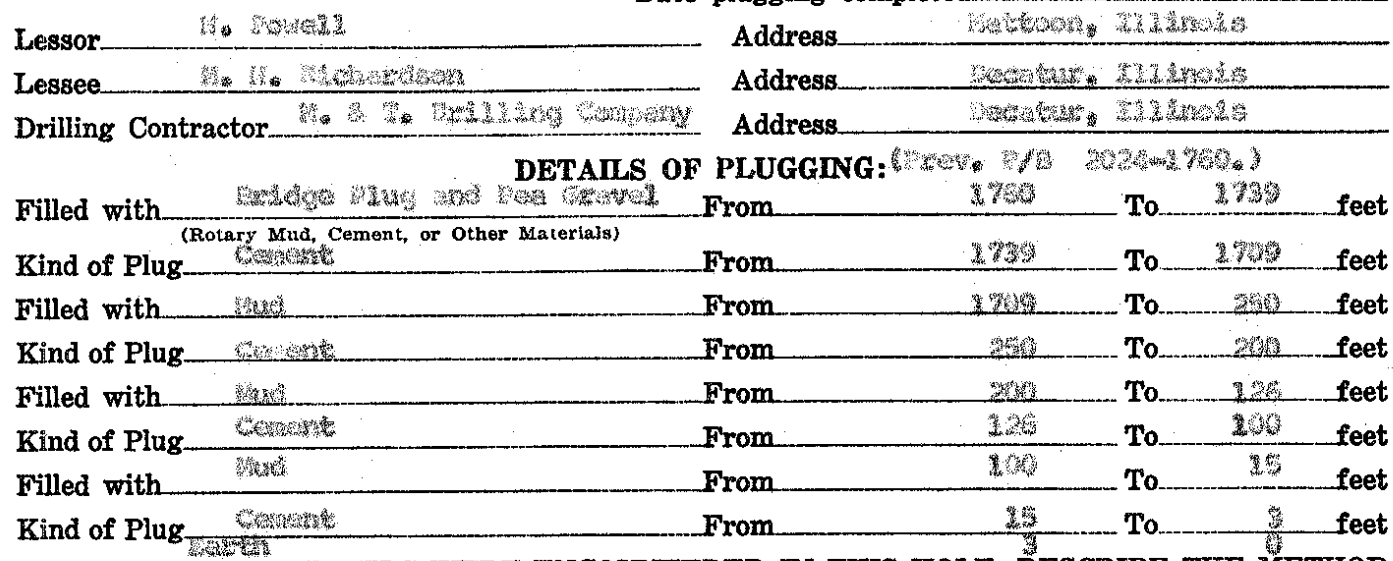
IF WORKABLE COAL BEDS WERE ENCOUNTERED IN THIS HOLE, DESCRIBE THE METHOD EMPLOYED TO PROTECT SAME. (A workable coal bed is thirty inches or more in thickness above 1,000 feet in depth) *

(1) Have pits and other excavations been filled?

(2) Have the following been removed?

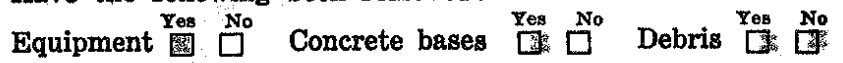

(B) Has surface casing been cut off three feet below ground surface?

(4) Has well-site been levelled?

If this was a producing well, give date and amount of last production

\section{CASING RECORD}

\begin{tabular}{|c|c|c|c|c|c|c|c|}
\hline & \multicolumn{2}{|c|}{ PUT IN WELL } & \multicolumn{2}{|c|}{ PULLED OUT } & \multicolumn{2}{|c|}{ LEFT IN WELL } & \multirow[b]{2}{*}{ Remarkss } \\
\hline Size & Feet & Inches & Feet & Inches & Feet & Inches & \\
\hline$\sqrt{1+\cos p / 4}$ & $\sqrt{2}$ & sosia & 萑 & 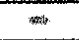 & 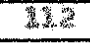 & & 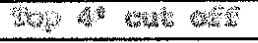 \\
\hline 繁䋨 & 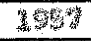 & in & 3 & 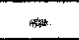 & 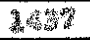 & & \\
\hline
\end{tabular}

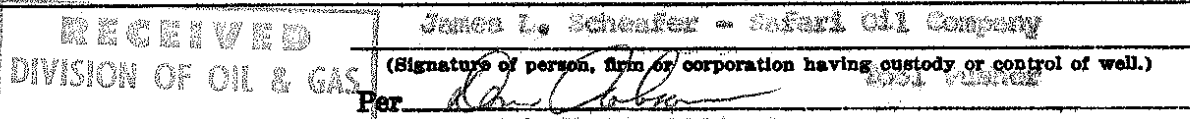

OCT 771971 Addrean

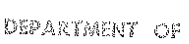

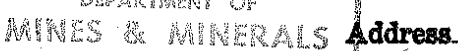

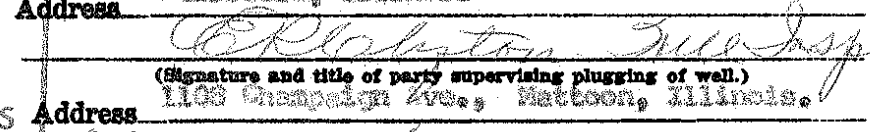




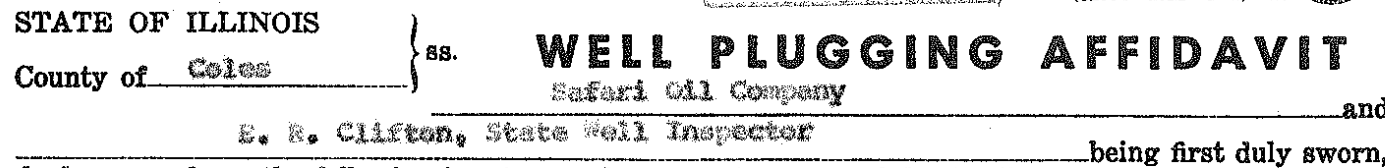
do depose and say the following is a true and correct statement of the details of the plugging of a certain well drilled for. (1)

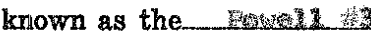

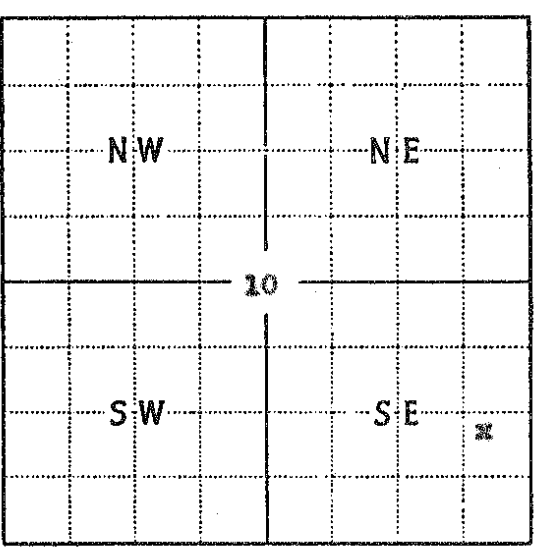

Locate well accurately on plat of section (Scale one inch-2,000 ft.)

Lessor

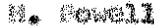
and located as follows

fit. north;

1050 ft. south;___ft. east; $\quad \mathrm{fat} \mathrm{ft}$. west of the corner of the Quarter of the Quarter of the Quarter of

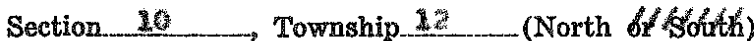

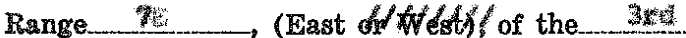

Principal Meridian, faletes County, nlinois. Hlevation above sea level is $\{$ Derrick Floor

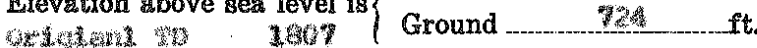

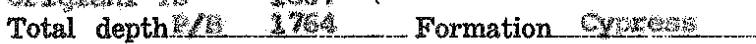
Date permit to drill issued $3=0.4$ Permit No. 195

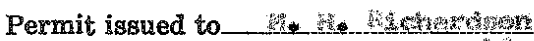

Date drilling began in i

Date arilling completed _____n

Kind of drilling tools used_._..........

Date plugging began

$5-72$

Date plugging completed

$2+7-7+2$

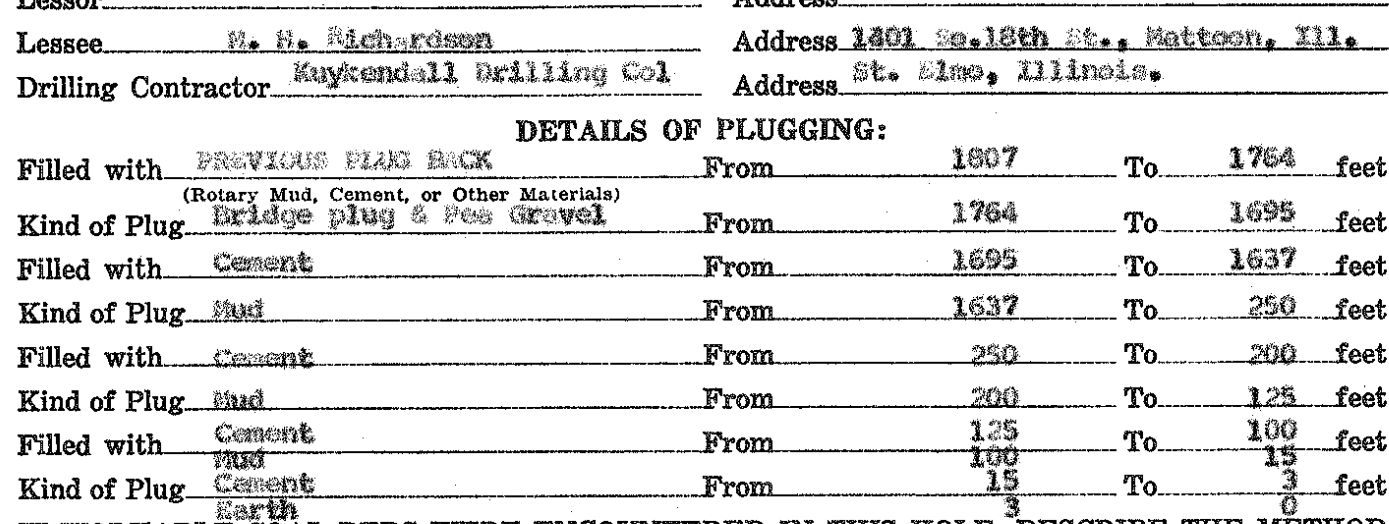

IF WORKABLE COAL BEDS WERE ENCOUNTERED IN THIS HOLE, DESCRIBE THE METHOD EMPLOYED TO PROTECT SAME. (A workable coal bed is thirty inches or more in thickness above 1,000 feet in depth)

(1) Have pits and other excavations been filled $\ldots \ldots \ldots \ldots \ldots \ldots, \square$

(2) Have the following been removed?

Equipment $\square$ No Concrete bases $\stackrel{\text { Yes }}{\square}$ No Debris $\square^{\text {Yes }}\left[\begin{array}{c}\text { No } \\ \square\end{array}\right.$

(8) Has surface casing been cut off three feet below ground surface?

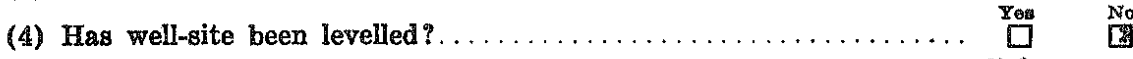

If this was a producing well, give date and amount of last production mande

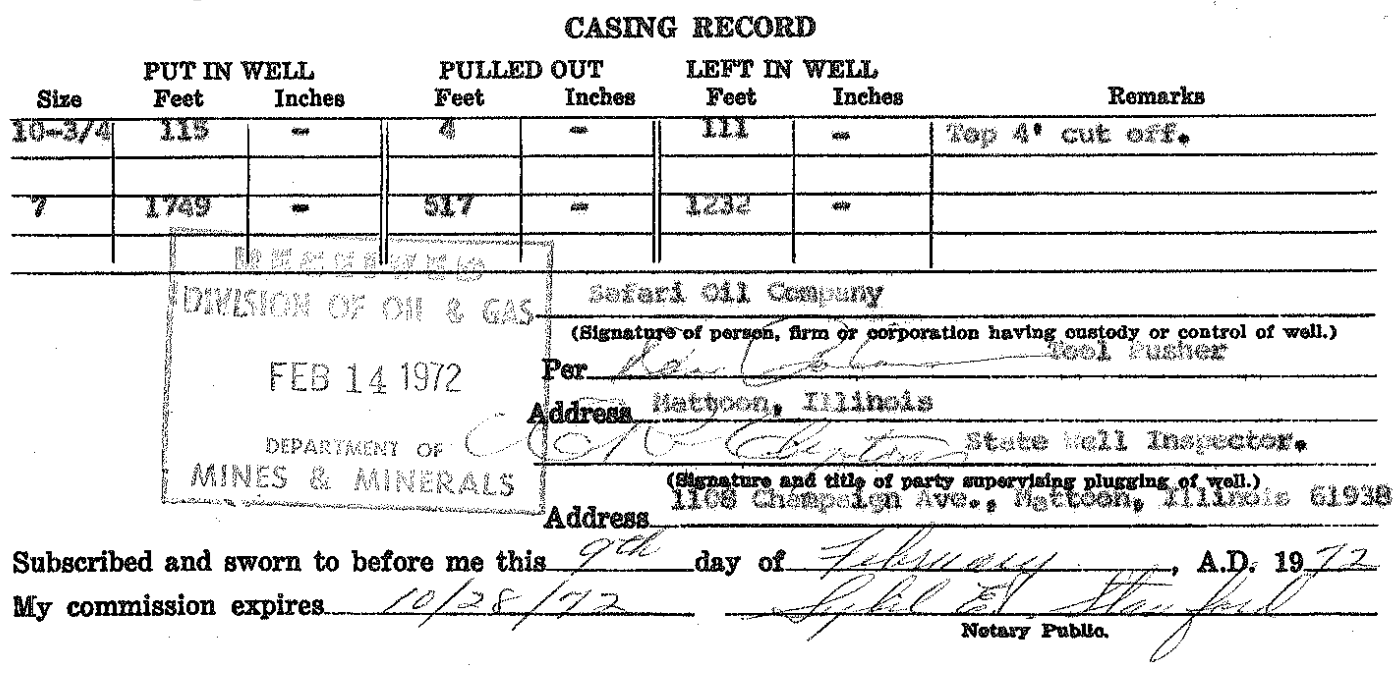



do depose and say the following is a true and correct statement of the details of the plugging of a certain well drilled for Ot1/Cas

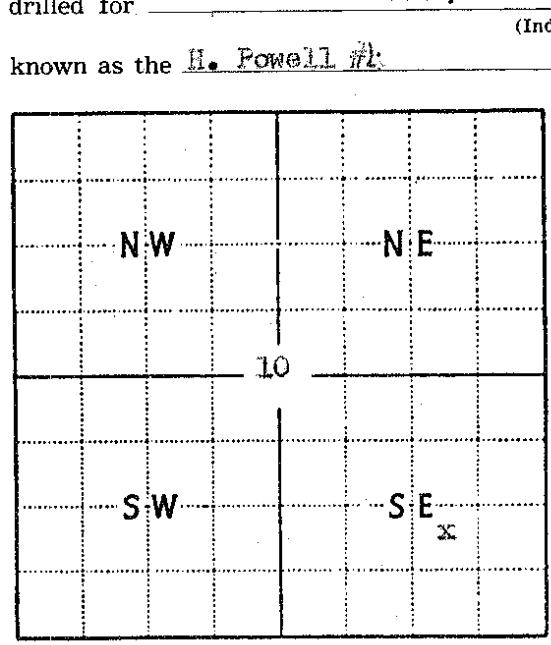

Locate well accurately on plat of section (Scale one inch $-2,000 \mathrm{ft}$ ) Indicate whether for oll, gas, water or other purposes) and located as follows:

ft. north; 2650 ft. south;___ ft. east; 290 ft. west of the NE corner of the $\quad \mathrm{NE}$ Quarter of the Quarter of the 12 Quarter of
Section 10 Range 7 , (East/of/Wtest) $/$ of the $3 \mathrm{ra}$

Principal Meridian,Corss County, Illinois. Elevation above sea level is $\begin{cases}\text { Derrick Floor } 723 \mathrm{ft} . \\ \text { Ground } & \mathrm{ft} .\end{cases}$ Total depth $2020 \quad$ Formation Rosiclare Date permit to drill issued11/27/45 Permit No. 1959 Permit issued to N. W. Wichaxds on Date drilling began $\quad 21-27-45$ Date drilling completed. $12-5-45$ Kind of drilling tools used Rotary Date plugging began $8-5-75$

Date plugging completed_ $\quad 3-6-75$

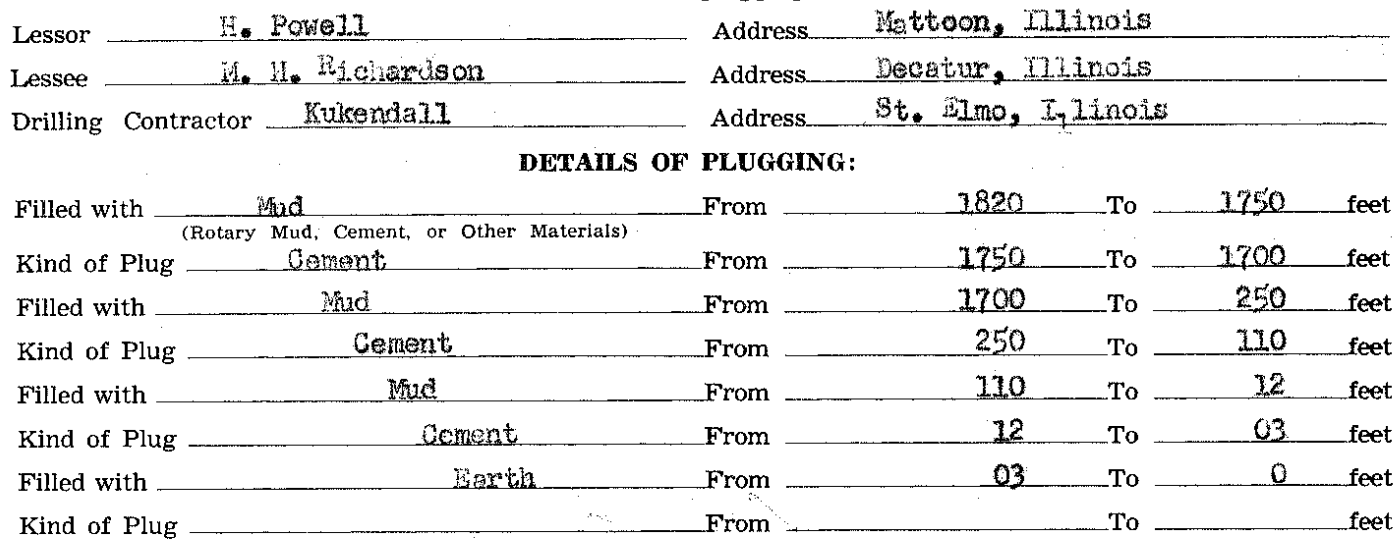
IF WORKABLE COAL BEDS WERE ENCOUNTERED IN THIS HOLE, DESCRIBE THE METHOD EMPLOYED TO PROTECT SAME. (A workable coal beld is thirty inches or more in thickness above 1,000 feet in depth) Von ensountered

(1) Have pits and other excavations been fild

(2) Have the following been removed?
Equipmenty $\stackrel{\text { Yes }}{\square} \stackrel{\text { No }}{\square}$
Concrete bases Yes
Debris 帒

(3) Has surface casing been cut off three feet below ground surface?

(4) Has well-site been leveled?

If this was a producing well, give date and amount of last production Unknown

Yes $\quad$ No

CASING RECORD

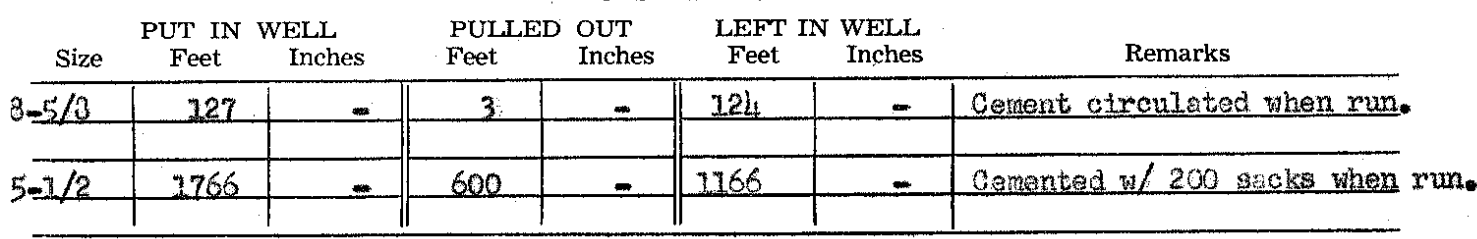

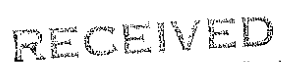

ONISONOHOLEAS

$$
\text { AUG } 131975
$$

DHAMHSH

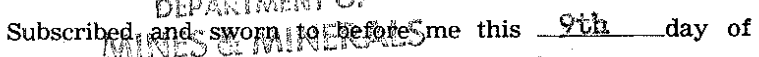
My commission expires $20-28-76$

$$
\text { Safari } 011 \text { Company }
$$

(Slgnature of person, firm lor corporation having custody or control of well.)

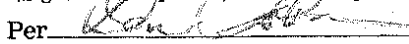

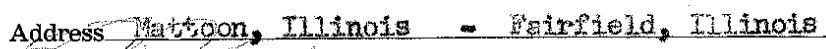
A $30,2,3$ tate rell Inspector (Signature and title of party supervising plugging of well.) Address 3500 Grant Ave, Mattoon, D1Linols 61938 
County of do depose and say the following is a true and correct statement of the details of the plugging of a certain well drilled for Fipter Supp $1 y$

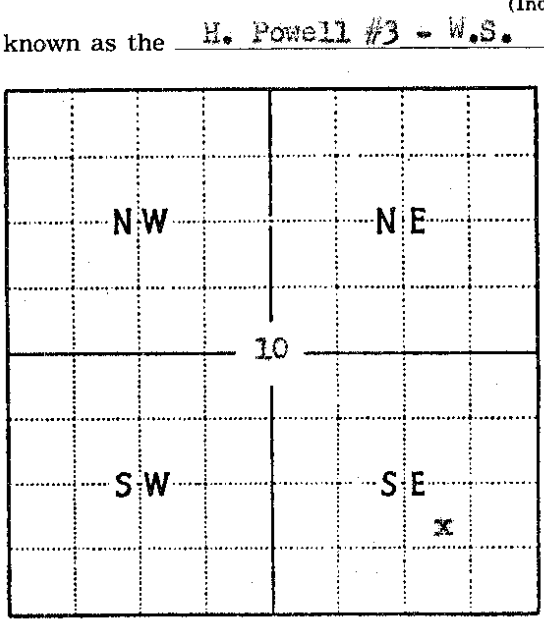

Locate well accurately on plat of section (Scale one inch-2,000 ft.) Indicate whether for oil, gas, water or other purposes)

Lessor H. Powe11

Lessee Ashland oll \& Refining Co.

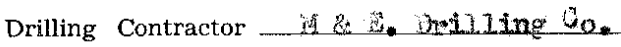

and located as follows:

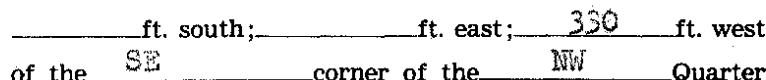
of the 32 Quarter of the $\mathrm{SE} \quad$ Quarter of Section $\quad 10$, Township_ 12 (North of S6lth)

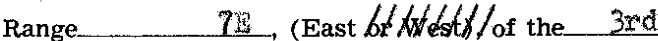
Principal Meridian,_._otes County, Illinois. Elevation above sea level is $\left\{\begin{array}{l}\text { Derrick Floor } \\ \text { Ground }\end{array}\right.$ Total depth 400 Formation Weter Sand Date permit to drill issued $9 / 29 / 61$ Permit No. 2030 Permit issued to ASHland OLI Ref ming $\mathrm{Co}$ Date drilling began $\quad 10-2-61$ Date drilling completed $10-7-61$ Kind of drilling tools used_Rotary Date plugging began $8-7-75$

Date plugging completed_, $\quad 3-8.73$

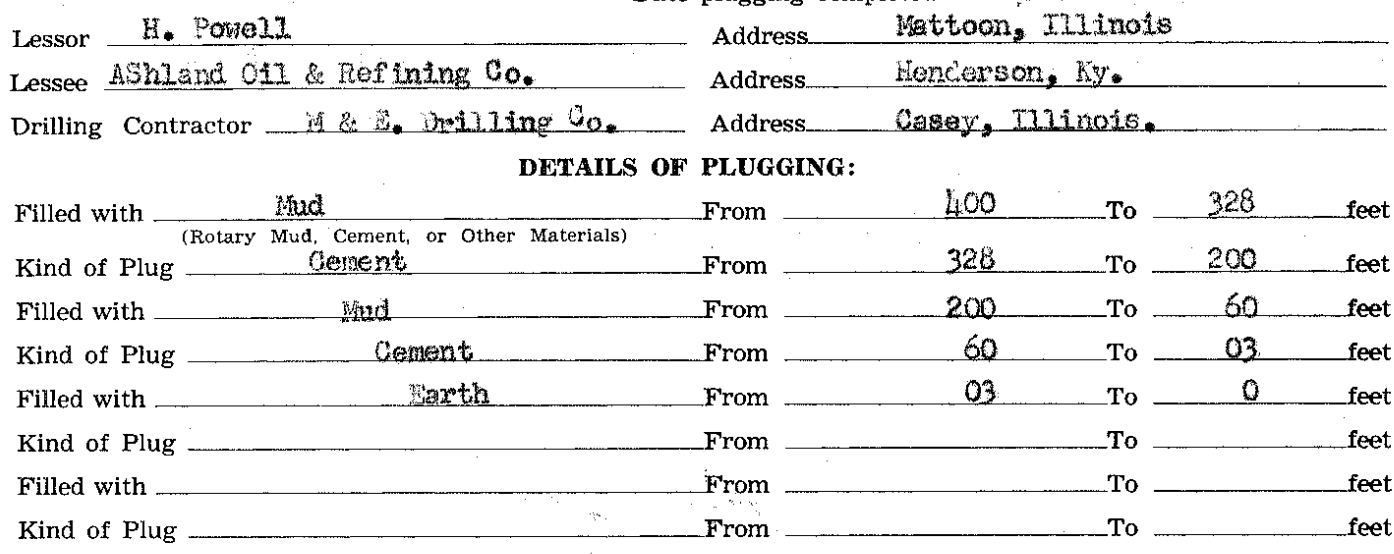
IF WORKABLE COAL BEDS WERE ENCOUNTERED IN THIS HOLE, DESCRIBE THE METHOD EMPLOYED TO PROTECT SAME. (A workable coal bed is thirty inches or more in thickness above 1,000 feet in depth) Wone encountered

(2) Have the following been removed?
Equipment $\mathrm{Yes}$.No
Concrete bases
Debris $\stackrel{\text { Yes }}{\text { No }}$

(3) Has surface casing been cut off three feet below ground surface?

(4) Has well-site been leveled? $\ldots \ldots \ldots \ldots \ldots \ldots \ldots \ldots \ldots \ldots \ldots \ldots$ Yes

If this was a producing well, give date and amount of last production Waten suphy

CASING RECORD

\begin{tabular}{|c|c|c|c|c|c|c|c|}
\hline Size & $\begin{array}{c}\text { PUT IN } \\
\text { Feet }\end{array}$ & $\begin{array}{l}\text { WELL } \\
\text { Inches }\end{array}$ & $\begin{array}{l}\text { PULL } \\
\text { Feet }\end{array}$ & $\begin{array}{l}\text { OUT } \\
\text { Inches }\end{array}$ & $\begin{array}{c}\text { LEFT } \\
\text { Feet }\end{array}$ & $\begin{array}{l}\text { WELL } \\
\text { Inches }\end{array}$ & Remarks \\
\hline $7^{n}$ & 328 & - & 145 & $=$ & 283 & - & Cenented o/ 50 scoks when mun. \\
\hline & & & & & & & \\
\hline & & & & & & & \\
\hline & & & & & & & \\
\hline
\end{tabular}

Safaxi oj1 Company

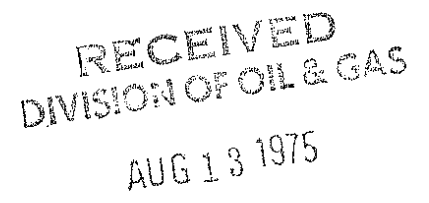

(Slgnature or person, firm gr eorporation having custody or control of well.) Per_L

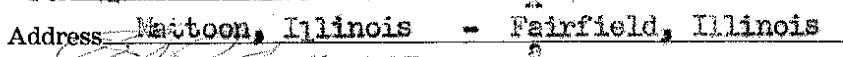

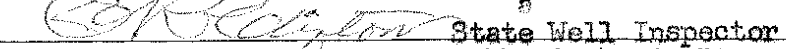
(Signature and title of party supervising plugging of well.) Address_3500 Grent Ave, Hattoon, I11inotis - 61938

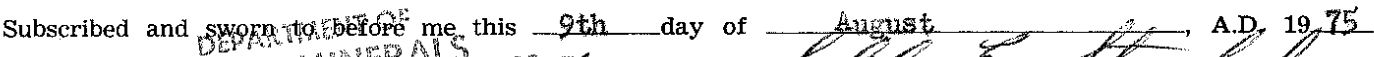

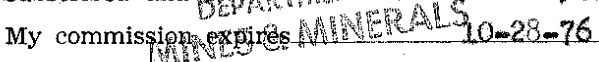

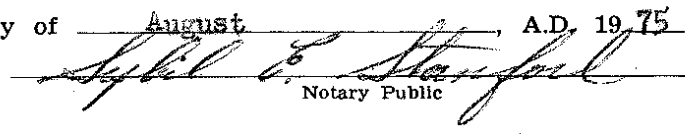




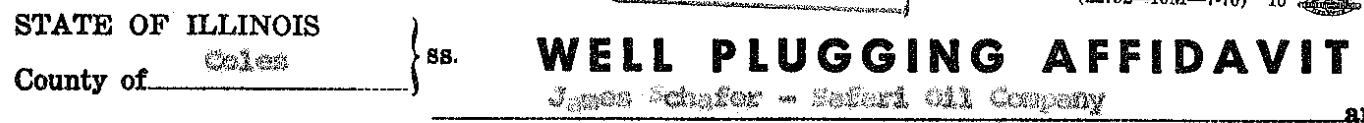

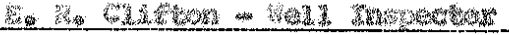

being first duly sworn, do depose and say the following is a true and correct statement of the details of the plugging of a certain well drilled for

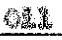

(Indicate whether for oll, gas, water or other purposes)

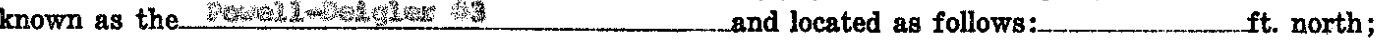

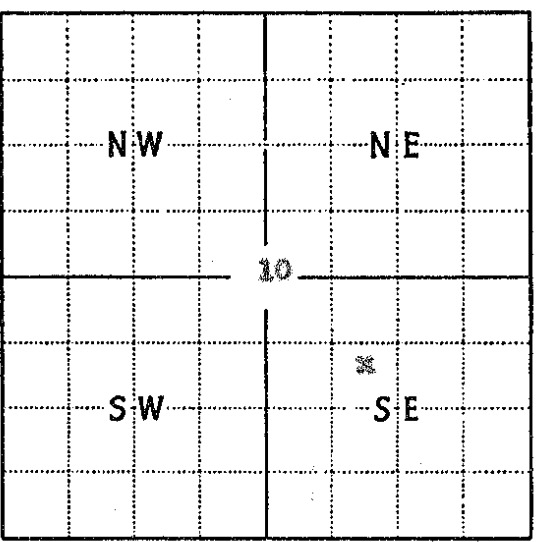

Locate well accurately on plat of section (Scale one inch-2,000 ft.)

6. whom syo ft. south;

of the of the Q__ Quarter of the Quarter of Section L Township__ I

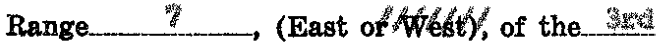

Principal Meridian,_._. obs County, Illinois. Elevation above sea level is $\{$ Derrick Floor Total depth__

Date permit to drill issued

Permit issued to _

Date drilling began _________a

Date drilling completed._.

Kind of drilling tools used.............

Date plugging began $\quad 10-25$

Date plugging completed._._._._.

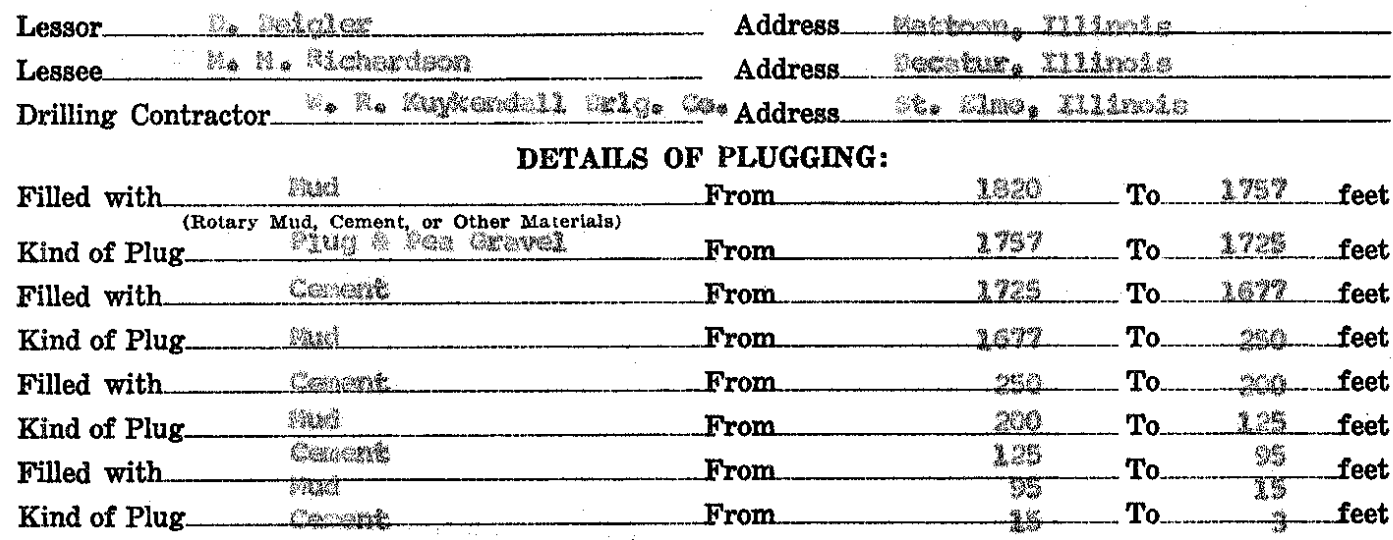

IF' WORKABLE COAL BEDS WERE ENCOUNTERED IN THIS HOLE, DESCRIBE THE METHOD EMPLOYED TO PROTECT SAME. (A workable coal bed is thirty inches or more in thickness above 1,000 feet in depth)

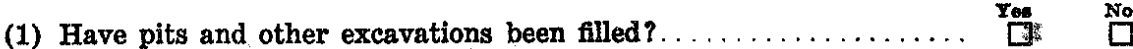

(2) Have the following been removed?
Equipment $\square^{\text {Yes }} \square$ Co Concrete bases $\square^{\text {Nes }}$ No Debris $\square$

(8) Has surface casing been cut off three feet below ground surface?

(4) Has well-site been levelled?

If this was a producing well, give date and amount of last production

\section{CASING RECORD}

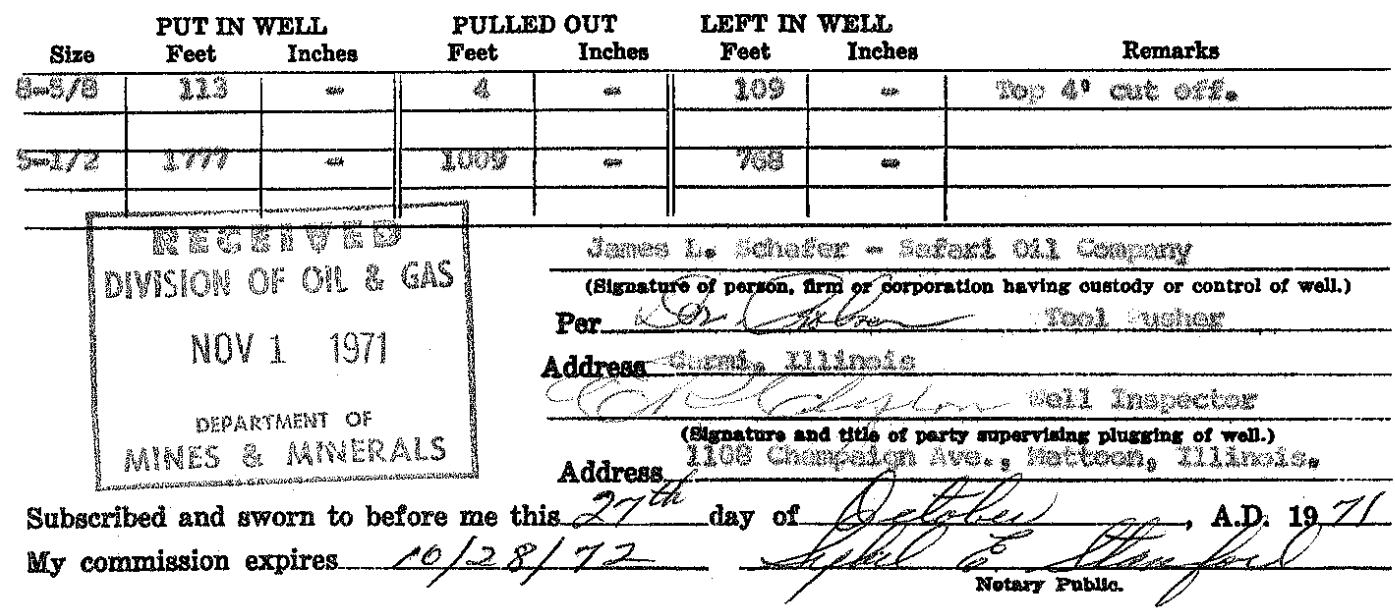


County of coses

$$
\text { - }
$$

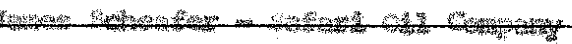

being first duly sworn, do depose and say the following is a true and correct statement of the details of the plugging of a certain well drilled for.

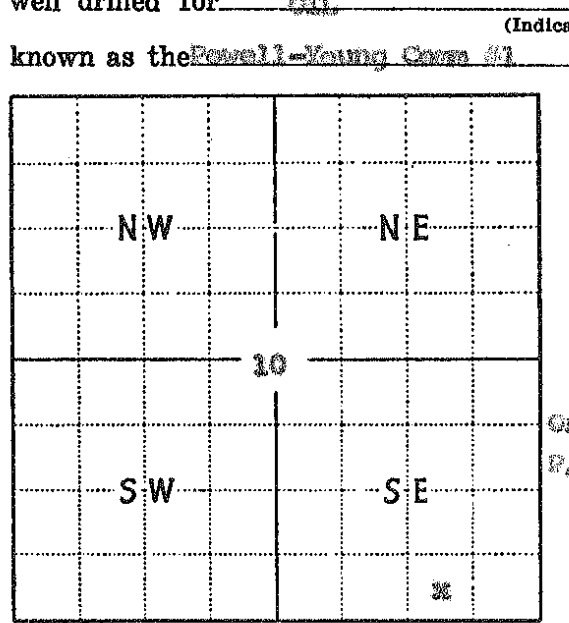

Locate well accurately on plat of section (Scale one inch-2,000 ft.)

dicate whether for oll, gas, water or other purposes)

and located as follows:-_.___n north;

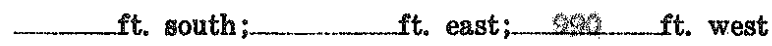
of the se corner of the _ _ _ Cuarter of the_Q_Quarter of the Quarter of

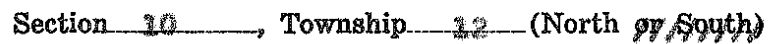
Range _ Principal Meridian,______ County, Mlinois. Elevation above sea level is $\left\{\begin{array}{l}\text { Derrick Floor } \\ \text { Ground }\end{array}\right.$ and

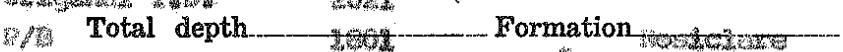
Date permit to drill issued 4 as

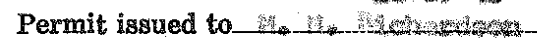
Date drilling began ______._.

Date drilling completed_3 3 wir.

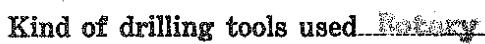

Date plugging began _.

Date plugging completed H

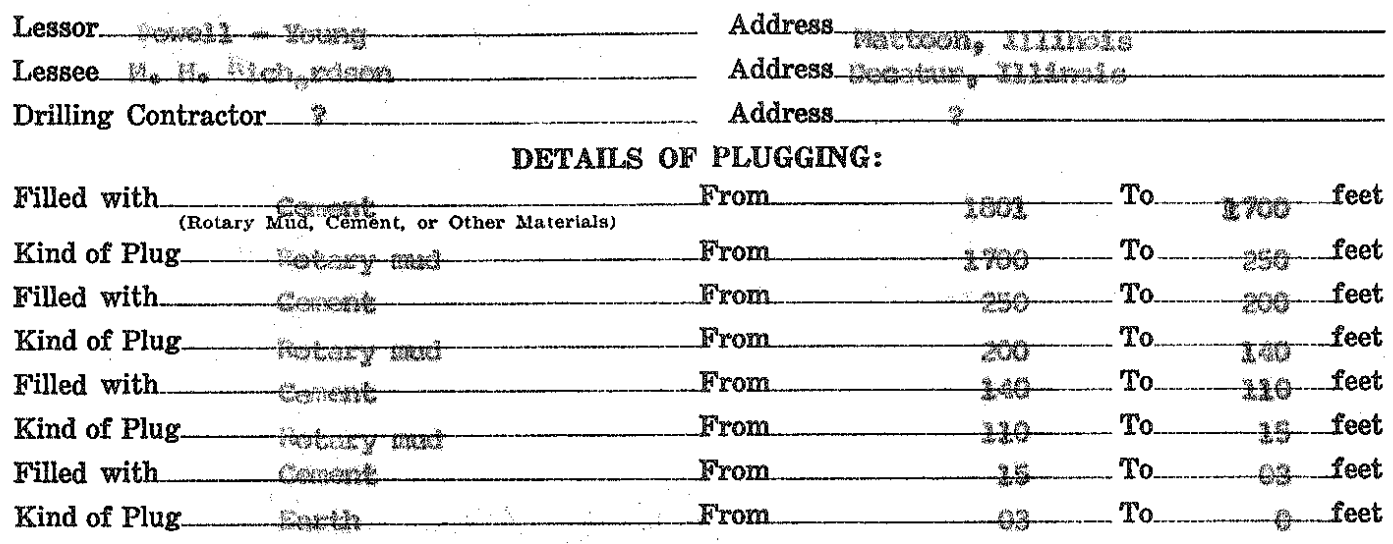

IF WORKABLE COAL BEDS WERE ENCOUNTERED IN THIS HOLE, DESCRIBE THE METHOD EMPLOYED TO PROTECT SAME. (A workable coal bed is thirty inches or more in thickness above 1,000 feet in depth)

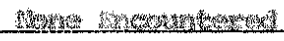

(1) Have pits and other excavations been filled?

(2) Have the following been removed?

Equipment $\square$ Concrete bases $\square^{\text {No }}$ Debris $\square$

(3) Has surface casing been cut off three feet below ground surface?

(4) Has well-site been levelled?

If this was a producing well, give date and amount of last production

Wo

\section{No}

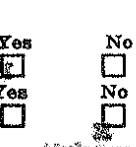

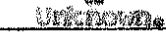

\section{CASING RECORD}

\begin{tabular}{|c|c|c|c|c|c|c|c|}
\hline & \multicolumn{2}{|c|}{ PUT IN WELL } & \multicolumn{2}{|c|}{ PULLED OUT } & \multicolumn{2}{|c|}{ LEET IN WELL } & \multirow[b]{2}{*}{ Remarks } \\
\hline Size & Feet & Inches & Feet & Inches & Feet & Inches & \\
\hline 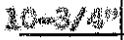 & 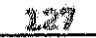 & $\neq$ & $9^{9}$ & 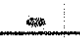 & 1.20 & 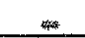 & 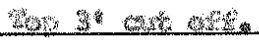 \\
\hline an & 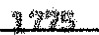 & sey & 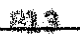 & & $w^{2}$ & & \\
\hline & & & 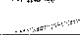 & & & & \\
\hline
\end{tabular}


11-12N-6E 


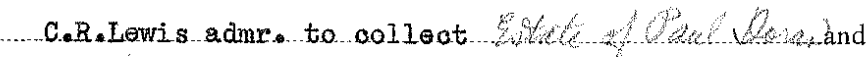
Haldon Moore

being first duly sworn do depose and say the following is a true and correct statement of the details of the plugging of a certain well drilled for oil. (Indicate whether for oil, gas, water or other purposes)

known as the...... Edwards $\frac{4}{7}$

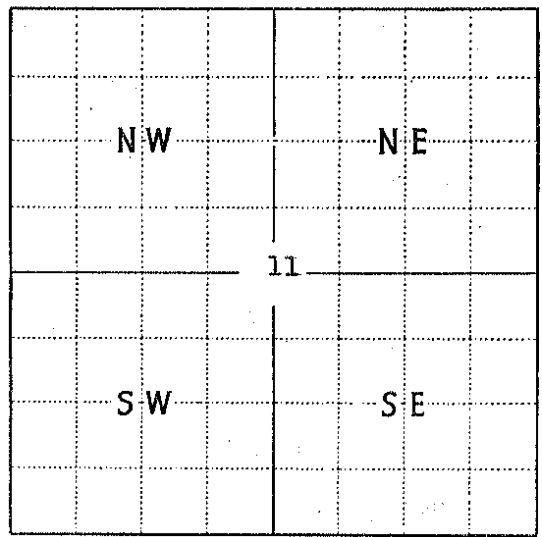

Locate well accurately on plat of section (Scale one inch-2,000 ft.)

and located as follows:

ft. north;

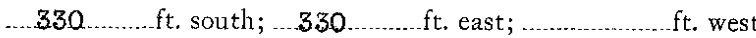

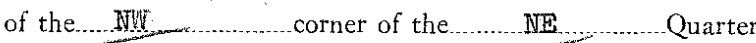
of the IVE Quarter of the Q Quarter of

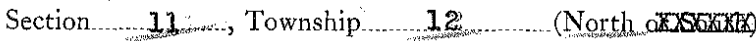

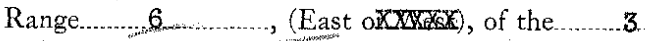
Principal Meridian,...phoultrie _ _ . County, Illinois. Elevation above sea level is $\left\{\begin{array}{l}\text { Derrick Floor } 663 \ldots \ldots . . . . . f t . \\ \text { Ground }\end{array}\right.$ Total depth of well is ....2118 Date permit to drill issued $3-24-50^{\circ}$. Permit No. 567 Permit issued to C.R.Ioms a adme to collect Date drilling began $3=28=50$.

Date drilling completed $4-5-50$

Kind of drilling tools used.

Rotary.

Date plugging began $\ldots . . . .4-6=50$

Date plugging completed $4=6=50$

Lessor John Edwaxds

Lessee C.R.Lewi.s adrar to collect $(1 / H+h)$ Address Vandalia, I11.

Drilling Contractor...Pal...Daran .Drilling...Ca. Address ..... Vandalia, I11.

\section{DETAILS OF PLUGGING:}

Filled with $\begin{gathered}\text { Rotary. Pufud } \\ \text { (Rotary Mud, Cement, or Other Materials) }\end{gathered}$
Kind of Plug... Cement
Filled with

IF WORKABLE COAL BEDS WERE ENCOUNTERED IN THIS HOLE, DESCRIBE THE METHOD EMPLOYED TO PROTEC'T SAME. (A workable coal bed is thirty inches or more in thickness above 1,000 feet in depth) ....... No coal encountered.

(1) Have pits, cellar and other excavations been filled?.

(2) Have equipment, concrete bases and debris been removed?

(3) Has surface casing been cut off below plow depth?.....

(4) Has well-site been levelled?

If this was a producing well, give date and amount of last production

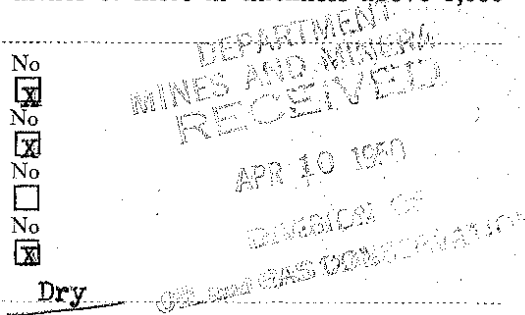

\section{CASING RECORD}

\begin{tabular}{|c|c|c|c|c|c|c|c|}
\hline \multicolumn{3}{|c|}{ PU'T IN WELL } & \multicolumn{2}{|c|}{ PULLED OUT } & \multicolumn{2}{|c|}{ LEFT IN WELL } & \multirow[b]{2}{*}{ Remarks } \\
\hline Size & Feet & Inches & Feet & Inches & Feet & Inches & \\
\hline & None & & & & & & .. \\
\hline & & & & & & & \\
\hline & & & & & & & \\
\hline & & & & & & & \\
\hline
\end{tabular}

C.a. .Iewis admr. to collect

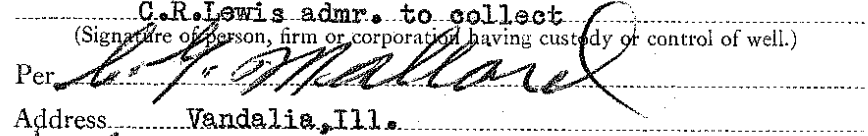

Address Vandalio $T 11$

20telon hough oil Woll Inspactor (Signaturt and title of party supervising plugging of well.)

Address ..... Moweaqua., I11 Subscribed and sworn to before me this 7
My commission expires $Y_{0}+24 \quad 1984$ 
11-12N-7E 


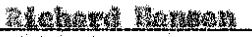

being first duly sworn, do depose and say the following is a true and correct statement of the details of the plugging of a certain well drilled for arendor

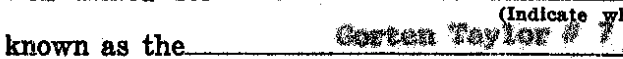

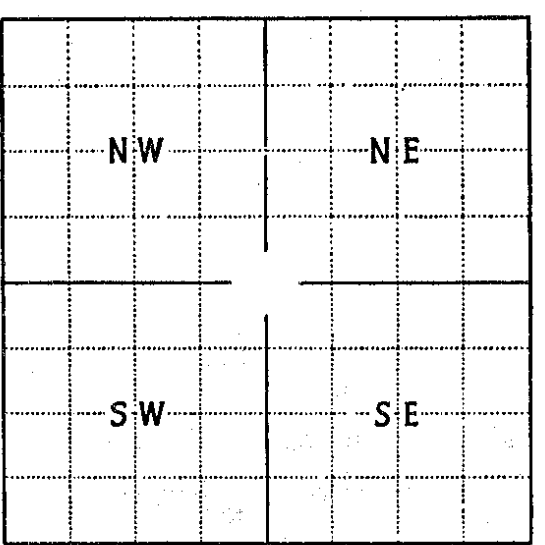

Locate well accurately on plat of section (Scale one inch-2,000 ft.)

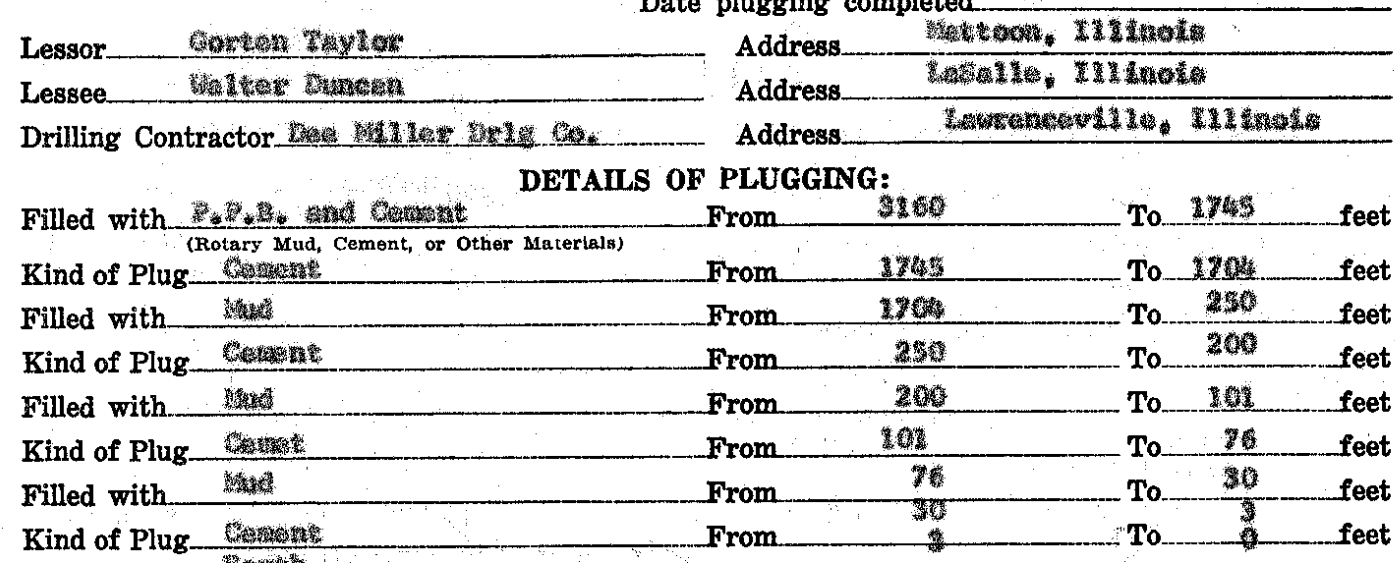
IF WORKABLE COAL BEDS WERE ENCOUNTERED IN THIS HOLE, DESCRIBE THE METHOD EMPLOYED TO PROTECT SAME. (A workable coal bed is thirty inches or more in thickness above 1,000 feet in depth)

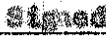

(1) Have pits and other excavations been filled?

(2) Have the following been removed?

Equipment $\square$ (No Concrete bases $\square^{\text {Yes }}$ Debris $\square^{\text {Nes }}$

(3) Has surface casing been cut off three feet below ground surface?

(4) Has well-site been levelled?

If this was a producing well, give date and amount of last production

\section{CASING RECORD}

\begin{tabular}{|c|c|c|c|c|c|c|c|}
\hline \multirow[b]{2}{*}{ Size } & \multicolumn{2}{|c|}{ PUT IN WELL } & \multicolumn{2}{|c|}{ PULLED OUT } & \multicolumn{2}{|c|}{ LEFT IN WEL } & \multirow[b]{2}{*}{ Remarks } \\
\hline & Feet & Inches & Fe & Incher & Feet & Inches & \\
\hline 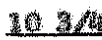 & 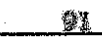 & & 3 & & 籍 & & \\
\hline 瑟 & 3 Un & & 20 & & 2635 & & \\
\hline & & & & & & & \\
\hline
\end{tabular}

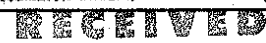

DVISION OF OLL \& GAS

$$
\text { DEC } 21969
$$

DEPARTMENT OF MINS MINERALS

Subscribed and sworn to before me this My commission expires

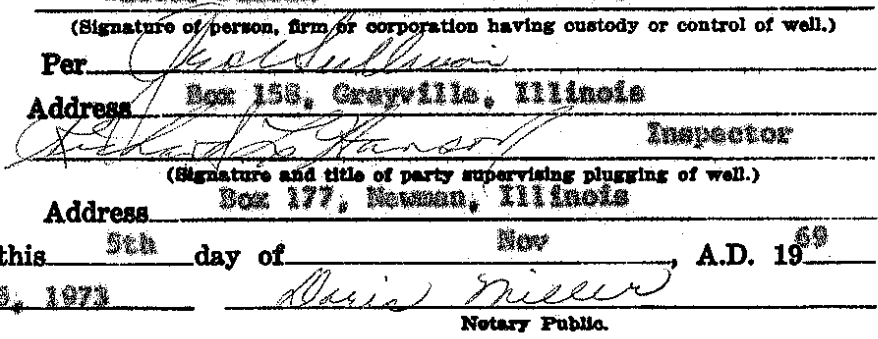


Form OG-6

STATE OF ILLINOIS

County of

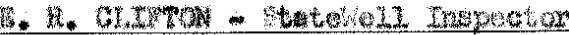
being first duly sworn, do depose and say the following is a true and correct statement of the details of the plugging of a certain well drilled for (Indicate whether for oil, gas, water or other purposes)

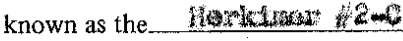

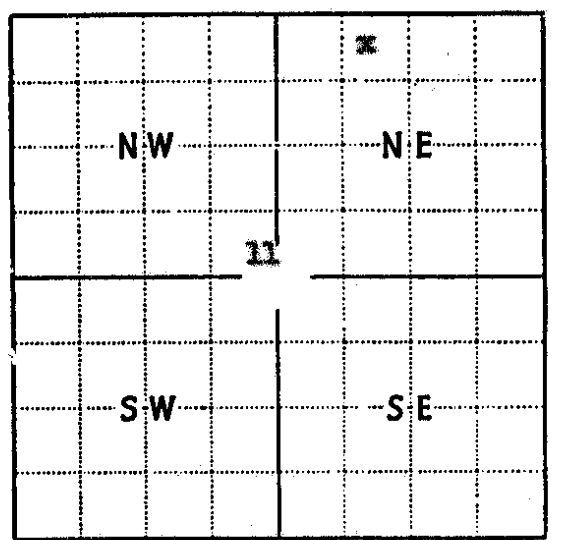

Locate well accurately on plat of section (Scale one inch-2,000 ft.) and located as follows:

ft. north; $330 \mathrm{ft}$. south;__ ft. east; $\quad 330 \mathrm{ft}$. west

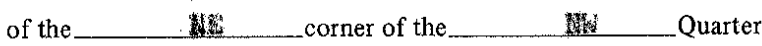
of the___ Quarter of the ___ Quarter of

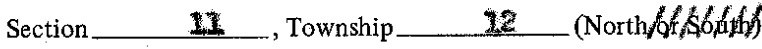

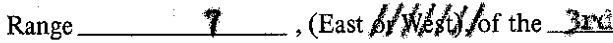

Principal Meridian, $0 \mathrm{OL}$

Elevation above sea level is

Total depth 2010 County, Illinois

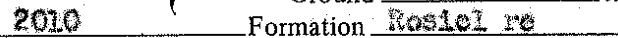
Date permit to drill issued $7 / 6 / 7 \mathrm{z}$ _ Permit No. 20

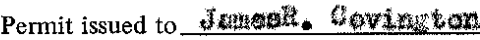

Date drilling began $\quad 7-\mathrm{L} 0-\mathrm{T}$

Date drilling completed $\quad 7-1 / 4-7$

Kind of drilling tools used 解ots

Date plugging began

$7-11=-76$

Date plugging completed

$7-12-80$

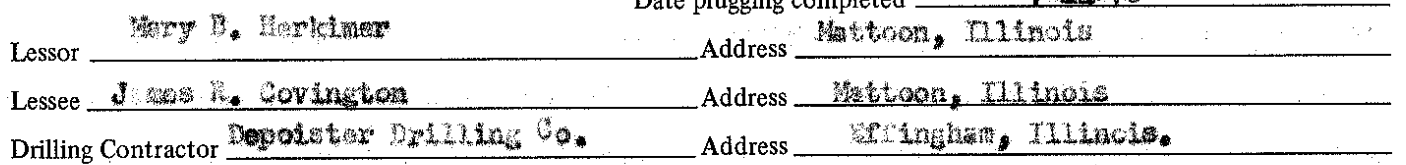

DETAILS OF PLUGGING:

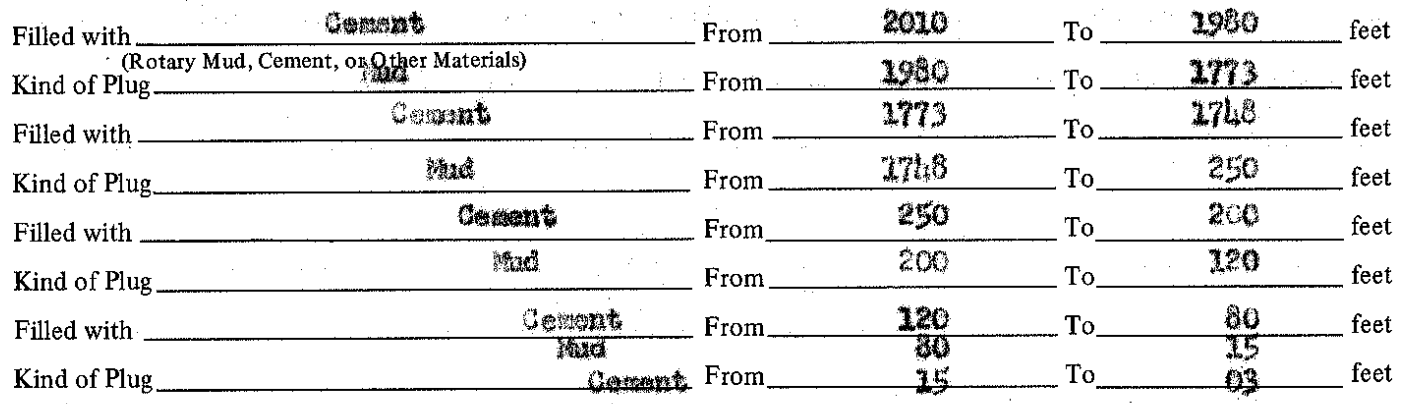

IF WORKABLE COAL BEDS WERE ENCOUNTERED IN THIS HOLE, DESCRIBE THE METHOD EMPLOYED TO PROTECT SAME. (A workable coal bed is thirty inches or more in thickness above 1,000 feet in depth)

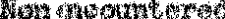

$\frac{\text { (1) Have pits and other excavations been filled? } \ldots \ldots \ldots \ldots \ldots \ldots \ldots \ldots \ldots \ldots \text { Yes }}{\text { (2) Have the following been removed? }}$
Equipment $\square^{\text {Yes }} \mathrm{x}_{\square}^{\text {No }}$ Concrete bases $\square$ Yes

(3) Has surface casing been cut off three feet below ground surface?

Yes No

(4) Has well-site been leveled? . . . . . . . . . . . . . . .

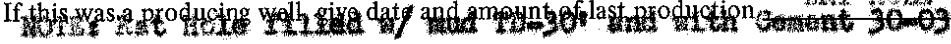

\section{CASING RECORD}

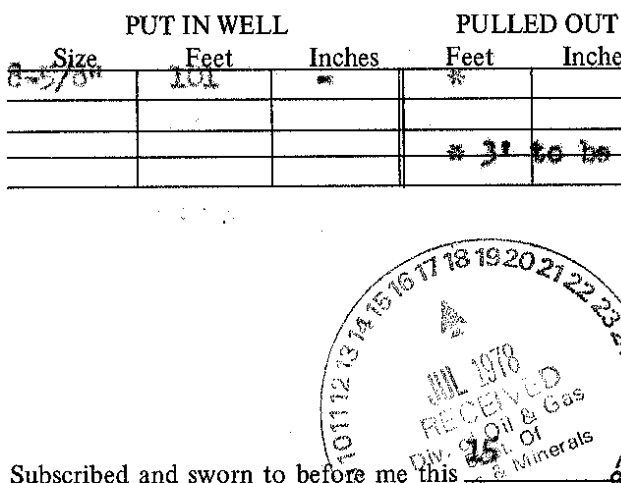

LEFT IN WELL

Feet Inches

Feet Inches Remarks 


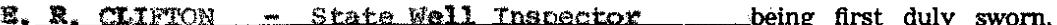
do depose and say the following is a true and correct statement of the details of the plugging of a certain well drilled for ors.

known as the vextimex $1-\mathrm{A}$

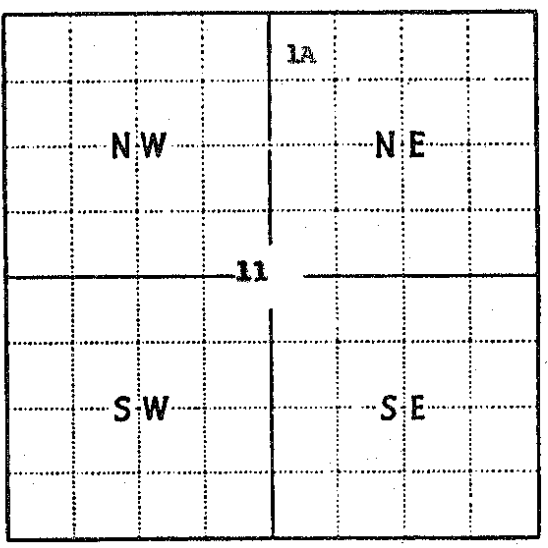

Locate well accurately on plat of section (Scale one inch-2,000 ft.) and located as follows:

ft. north;

330 ft. south; neme fint. east; 330 ft. west
of the corner of the Non Nonarter of the N Q Q Q Q Q Q Q Q Q Q Section_ $\quad 11$, Township__ $\quad 12$ _North 6 $6666 \mathrm{~K}$ )

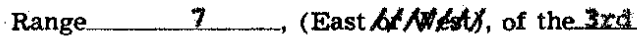
Principal Meridian,__CoLES_County, Illinois.

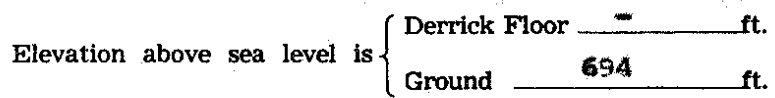

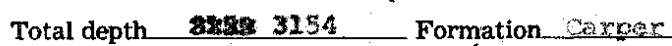
Date permit to drill issued $12.14 \mathrm{~J} /$ Permit No. $/ 2,32 \%$

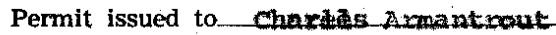

Date drilling began_ 12-14-81.

Date drilling completed 12-18-91.

Kind of drilling tools used Botary

Date plugging began

10-15-87

Date plugging completed $10-15-87$

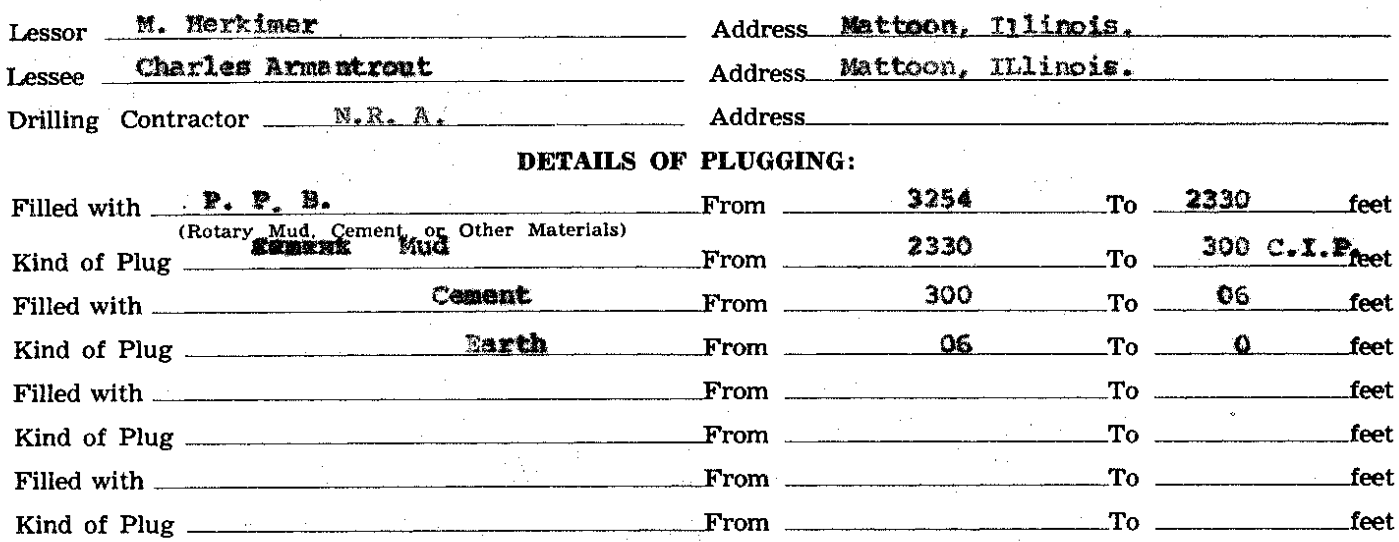

IF WORKABLE COAL BEDS WERE ENCOUNTERED IN THIS HOLE, DESCRIBE THE METHOD EMPLOYED TO PROTECT SAME. (A workable coal bed is thirty inches or more in thickness above 1,000 feet

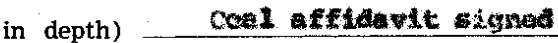

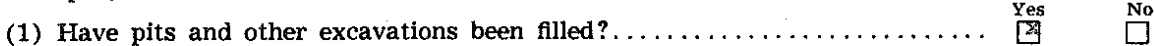

(2) Have the following been removed?

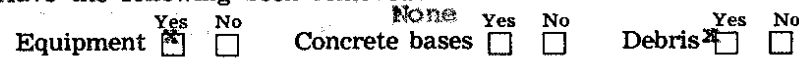

(3) Has surface casing been cut off three feet below ground surface?

(4) Has well-site been leveled?

If this was a producing well, give date and amount of last production

Balled to roduce

CASING RECORD

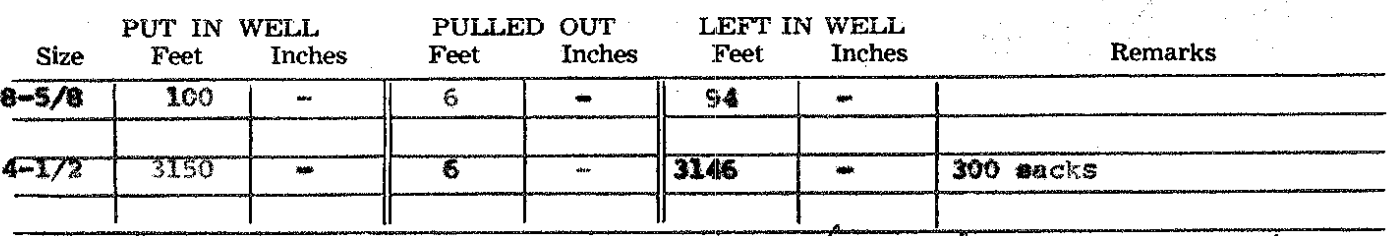

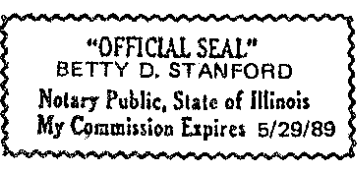

Subscribed and sworn to before me this My commission expires

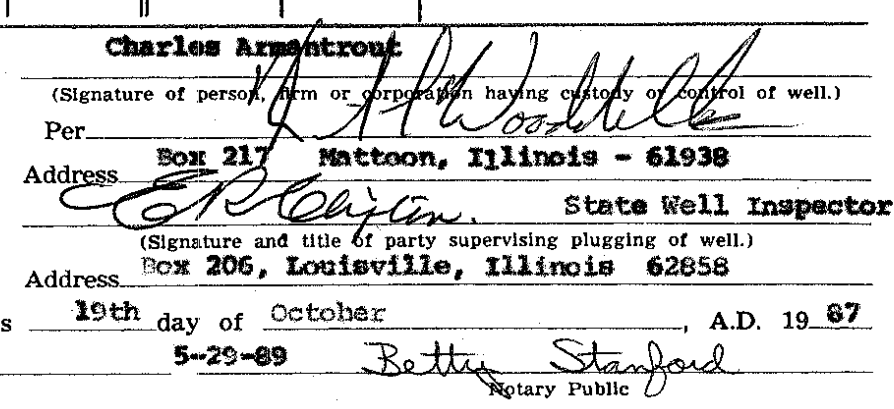


Trancs a covingtion

being first duly sworn, do depose and say the following is a true and correct statement of the details of the plugging of a certain well drilled for $0 j 1$

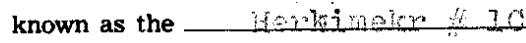
(Indicate whether for oil, gas, water or other purposes)

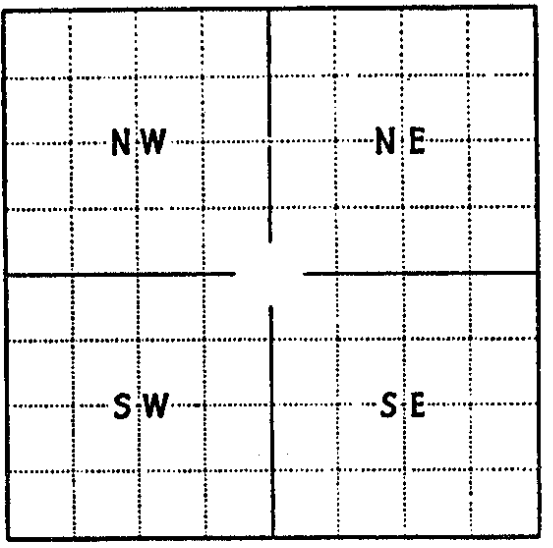

Locate well accurately on plat of section (Scale one inch-2,000 ft.)

and located as follows:

ft. north;

330 ft. south; 330 ft. east;___ft. west
of the Mut corner of the W Quarter of the_Quarter of the____ Quarter of Section 71 , Township_ (North or South') Range_ (East or West), of the Principal Meridian,_County, Illinols. Elevation above sea level is $\left\{\begin{array}{l}\text { Derrick Floor } \\ \text { Ground ft. }\end{array}\right.$ Total depth 2172 Formation Date permit to drill issued $12 / 1 / 2$ Permit No. 132 Permit issued to James Covington Date drilling began $\quad .2 / 2 / 70$

Date drilling completed

Kind of drilling tools used otay Date plugging began $/ 6 / 2 / 9 / 81$

Date plugging completed $2 / 10 / 8$ ?

Lessor Address

Lessee

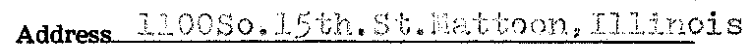
Drilling Contractor

\section{P.P.B.} From $3172-1780$ Filled with $\frac{\text { Cement }}{\text { (Rotary Mud, Cement, or Other Materials) }}$ Kind of Plug Cetary Mud, Cement, or

Filled with _comont

Kind of Plug

$\operatorname{cosin}$

Filled with Cemert:

DeTAILS OF PLUGGING:

Kind of Plug

Comert

Filled with aartin

Kind of Plug

$$
\text { From }
$$

Cast Iron Plug Set To 1700 feet

IF WORKABLE COAL BEDS WERE ENCOUNTERED IN THIS HOLE DESCRIBE THE METHOD PLOYED TO PROTECT SAME. (A workable coal bed is thirty inches or more in thickness above 1,000 feet in depth) ivone

(1) Have pits and other excavations been flled?

(2) Have the following been removed?
Equipment $\stackrel{\text { Yes }}{\square}$ №
Concrete bases
Yes
Debris $\frac{\text { Yes }}{\square}$

(3) Has surface casing been cut off three feet below ground surface?

(4) Has well-site been leveled?

If this was a producing well, give date and amount of last production

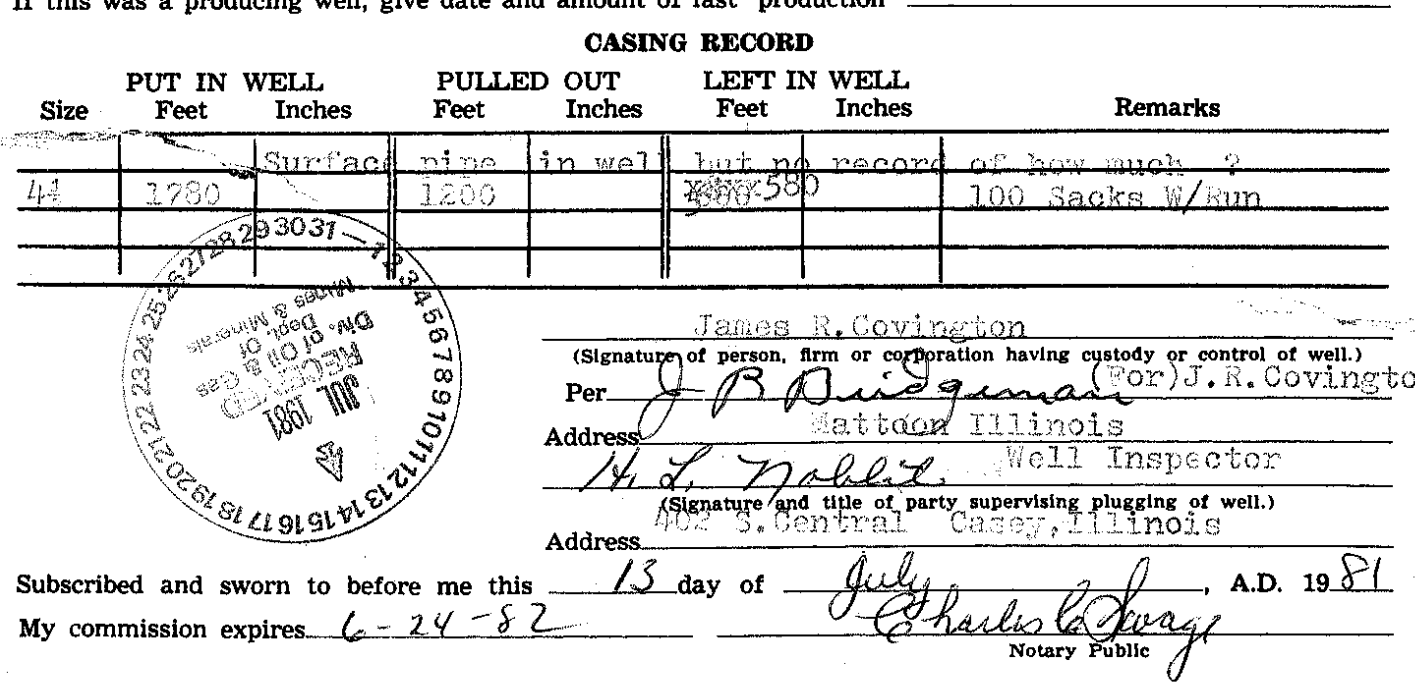


Form OG-6

STATE OF ILLINOIS

County of...ton

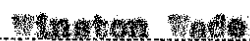

do depose and say the following is a true and correct statement of the details of the plugring of a first duly sworn for

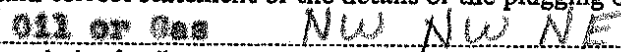

(Indicate whether for oil, gas, water or other purposes)

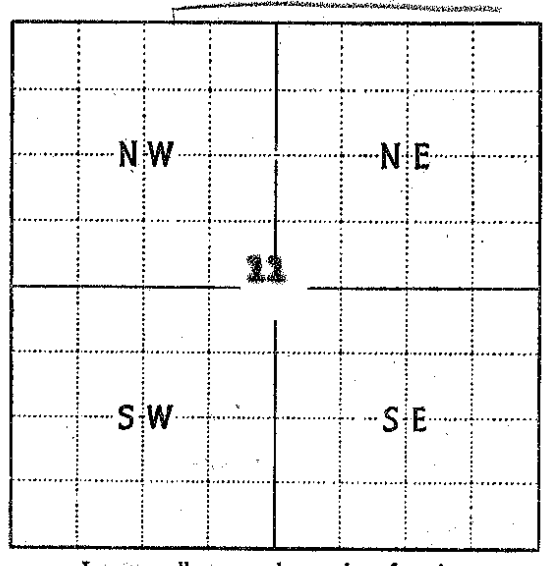

Locate well accurately on plat of section Scale one inch-2,000 ft. known as the ...

and located as follows:

ft. north;

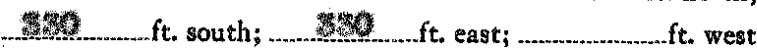

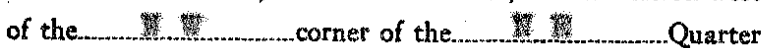
of the _............... Quarter of the

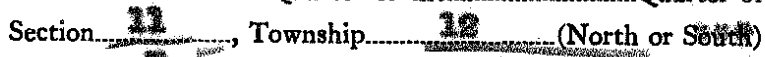
Range $/ 7 /$.

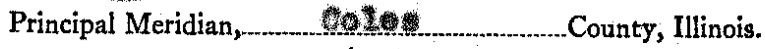
Elevation above sea level is $\left\{\begin{array}{l}\text { Derrick Floor } \\ \text { fround }\end{array}\right.$

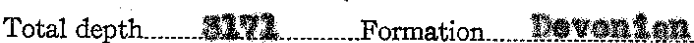
Date permit to drill issued.. Permit issued to.....

Date drilling began .........

Date drilling completed._.

Kind of drilling tools used.......

Date plugging began

Date plugging completed.

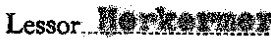
Address... W

Lessee-1) A

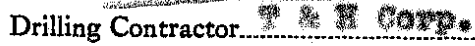

\section{DETAILS OF PLUGGING:}

Filled with..
(Rotary Mud, Cement, or Other Materials)

IF WORKABLE COAL BEDS WERE ENCOUNTERED IN THIS HOLE, DESCRIBE THE METHOD EMPLOYED TO PROTECT SAME. (A workable coal bed is thirty inches or more in thickness above 1,000 feet in depth) _.....

(1) Have pits and other excavations been filled? $\ldots \ldots \ldots \ldots \ldots \ldots \ldots$, Yes
(2) Have the following been removed? Equipment $\square$ 程

(3) Has surface casing been cut off three feet below ground surface?

(4) Has well-site been levelled?

If this was a producing well, give date and amount of last production

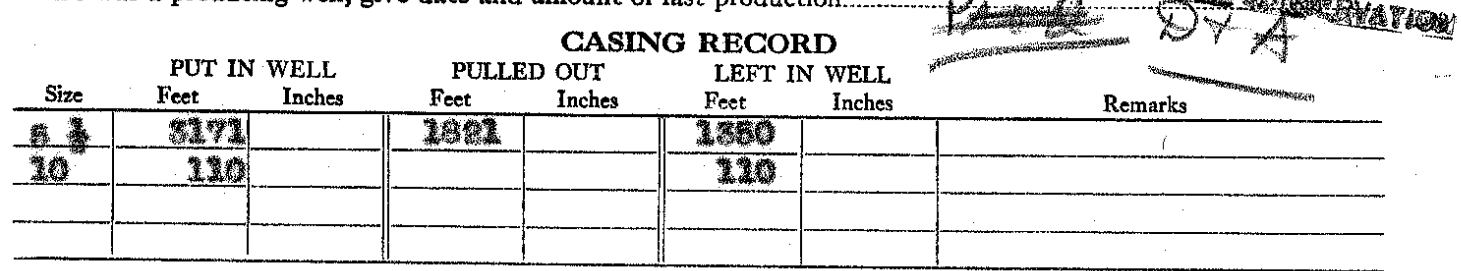

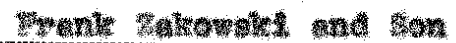

Signature of person, firm or corporation having custody or control of well.)

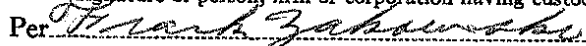

Address. 1 or

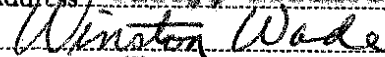

(Signature and title of party supervising plugging of well.)

Address_.

Subscribed and sworn to before me this b....... 64 day of My commission expires 222 ack 197 

drilled for ort

known as the Herkimex 6

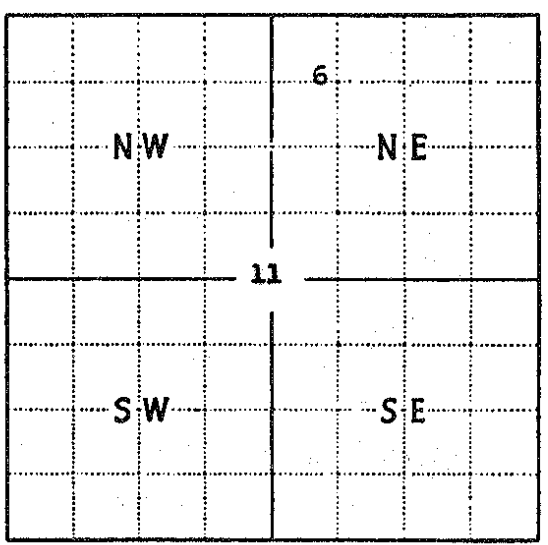

Locate well accurately on plat of section (Scale one inch-2,000 ft.)
Lessor Mary Uemulker

Lessee Raxry Adams

Drilling Contractor Di11ara/knternan

(Indicate whether for oil, gas, water or other purposes)

and located as follows:

-.... fist. north;

660. ft. south; $330 \quad$ ft. east; - _ ft. west

of the corner of the NE_ Q Cuarter

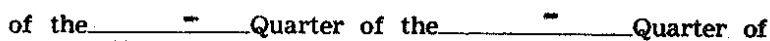

Section 11 , Township_ 12 (North of South)

Range $\quad 7$, (East or (West), of the 3red

Principal Meridian,_cous County, Illinois.

Elevation above sea level is $\begin{cases}\text { Derrick Floor } & \mathrm{ft} \\ \text { Ground } 698 & \mathrm{ft}\end{cases}$

Total depth 3188 Formation Devonion

Date permit to drill issue $12 / 5$ Permit No.

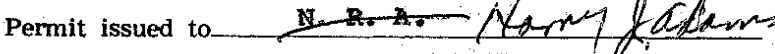

Date drilling began______ $5=12-55$

Date drilling completed $5-22-55$

Kind of drilling tools used Rotary

Date plugging began 10 10 15-87

Date plugging completed $10-15-87$

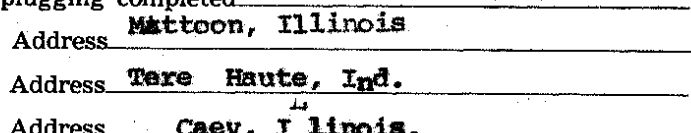

DETAILs of PLUGGING

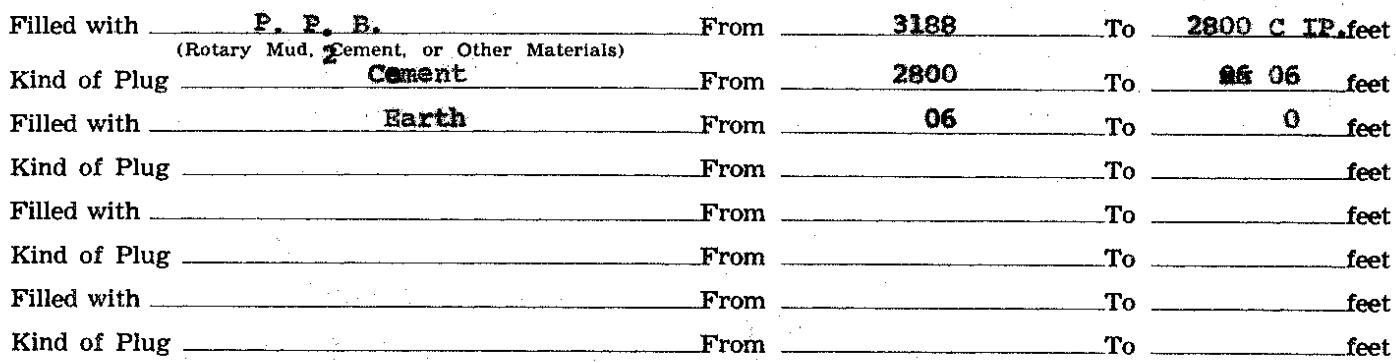

IF WORKABLE COAL BEDS WERE ENCOUNTERED IN THIS HOLE, DESCRIBE THE METHOD EMPLOYED TO PRO'TECT SAME. (A workable coal bed is thirty inches or more in thickness above 1,000 feet in depth) _ Coal affidavit sigued

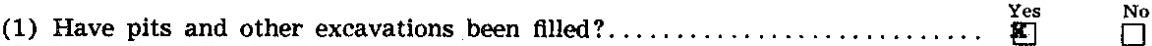

(2) Have the following been removed?

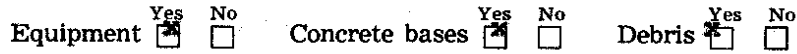

(3) Has surface casing been cut off three feet below ground surface?

(4) Has well-site been leveled? $\ldots \ldots \ldots \ldots \ldots \ldots \ldots \ldots \ldots \ldots \ldots \ldots \ldots \ldots$

If this was a producing well, give date and amount of last production N. R. A.

CASING RECORD

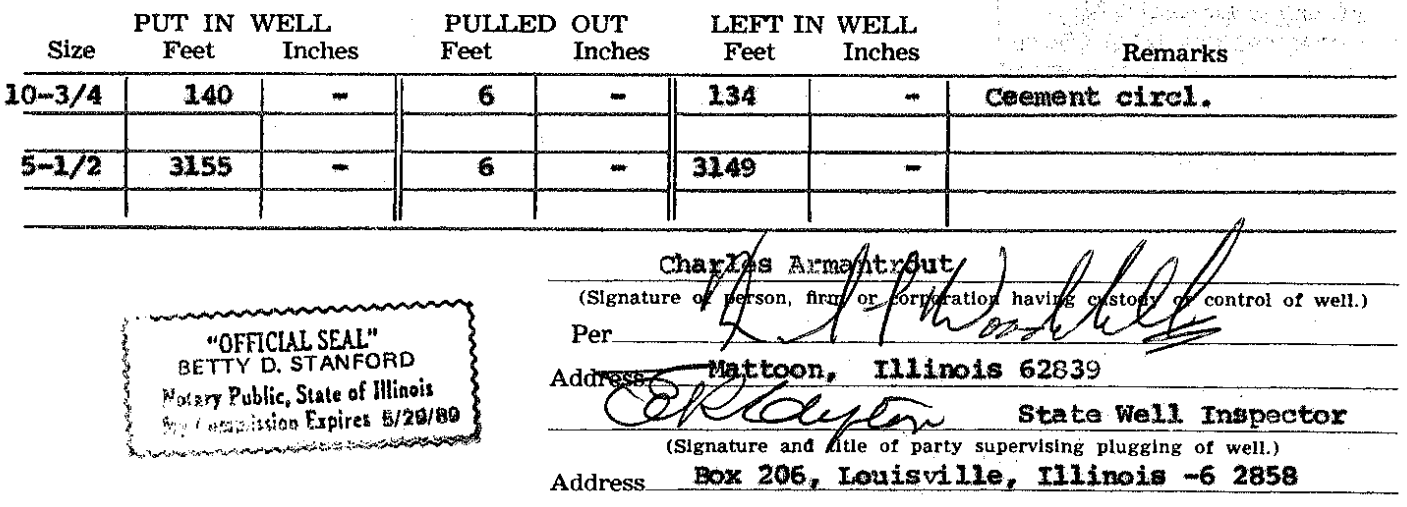

Subscribed and sworn to before me this 19 day of Octobex

My commission expires

$5-29-89$

Brtt

Stanole 


\section{OG-6 WELL PLUGGING REPORT}

TYPE OF WELL: $\quad$ P PRODUCTION $\square$ CLASS II $\square$ OBSERVATION $\square$ GAS STORAGE $\square$ REPLUG $\square$ OTHER WELL NAME: Herkimer \#6-A PERMIT NO. $\frac{9741}{\text { ISSUE }}$ (ISSUE DATE (F NO NUMBER)

F765 PERMITTEE: Schaefer Oi1 Co REFERENCE NO. 112582

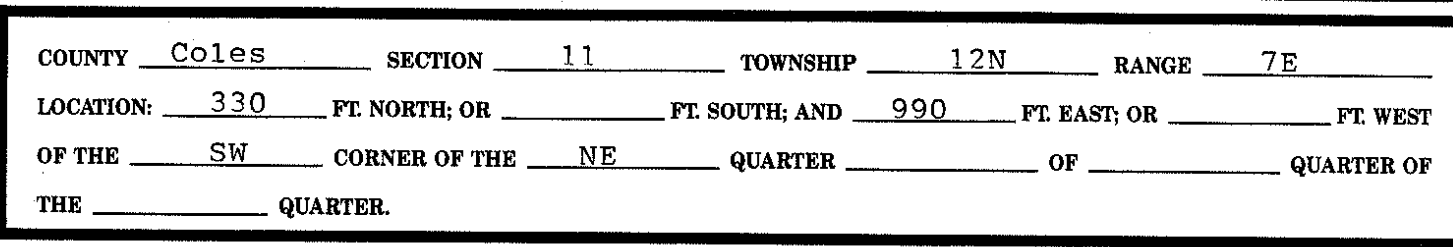

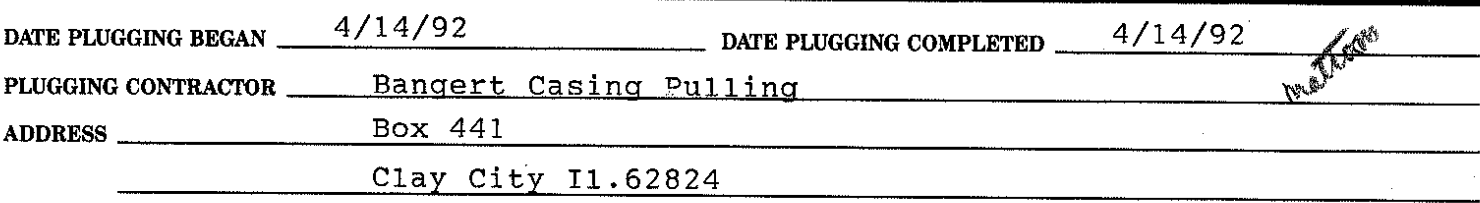

WELL DATA:

\begin{tabular}{|c|c|c|}
\hline TOTAL DEPTH OF WELL & 3175 Fr. & PRODUCING / INJECTION INTERVALS \\
\hline PLUGGED BACK TOTAL DEPTH & FT. & FROM $\quad 3129$ \\
\hline BASE OF FRESHWATER ZONE & 147 FT: & TO \\
\hline WORKABLE COALS PRESENT AT & FT. & To \\
\hline & FT. & _ To \\
\hline \multicolumn{3}{|c|}{ DESCRIBE PREVIOUS PLUGBACK PROCEDURE: } \\
\hline
\end{tabular}

DETAILS OF PLUGGING:

\begin{tabular}{|c|c|c|c|c|}
\hline FILLED WITH & $\begin{array}{l}\text { Cemen } t \\
\text { (ROTARY MUD, WELLBORE FLUTD CEMENT OR OTHER MATERALSS }\end{array}$ & \multirow{2}{*}{$\begin{array}{l}\text { FROM } \\
\text { FROM }\end{array}$} & 3150 & \multirow{2}{*}{$\begin{array}{l}3020 \\
250\end{array}$} \\
\hline FILLED WITH & Mud & & 3020 & \\
\hline FILLED WITH & Cement & FROM & 250 & 04 FT. \\
\hline FILLED WITH & Earth & FROM & 04 & GL. \\
\hline FILLED WITH & & FROM & $\cdot$ & FT. \\
\hline COMMENTS: & & & & \\
\hline
\end{tabular}

WELL DATA:

\begin{tabular}{|c|c|c|c|c|c|c|}
\hline CASING & SIZE & $\begin{array}{l}\text { SETTING } \\
\text { DEPTH }\end{array}$ & $\begin{array}{c}\text { SACKS } \\
\text { CEMENT }\end{array}$ & $\begin{array}{l}\text { HOLE } \\
\text { SIZE }\end{array}$ & $\begin{array}{l}\text { EST. TOP OF } \\
\text { CEMENT }\end{array}$ & $\begin{array}{c}\text { AMOUNT OF } \\
\text { CASING REMOVED }\end{array}$ \\
\hline SURFACE & $103 / 4$ & 130 & $\mathrm{~N} / \mathrm{A}$ & $121 / 4$ & Surface & 4 \\
\hline $\begin{array}{l}\text { INTERMEDIATE /MINE } \\
\text { STRING / OR LINER }\end{array}$ & $7 "$ & 1905 & $\mathrm{~N} / \mathrm{A}$ & $103 / 4$ & Surface & 4 \\
\hline PRODUCTION & & & & & 2400 & \\
\hline
\end{tabular}

UNDER PENALTIES OF PERJURY; I DECLARE THAT I HAVE EXAMINED THIS FORM INCLUDING ACCOMPANYING STATEMENTS AND DOCUMENTS, AND TO THE BEST OF MY KNOWLEDGE, IT IS TRUE, CORRECT, AND COMPLETE.
SIGNATURE OF: $\frac{\text { Samin }}{\text { PERMITTEER bESIGNEE }}$

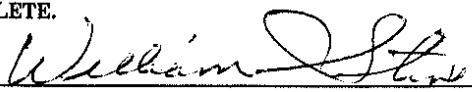$$
\text { Clay City I } 1.62824
$$$$
\text { ADDRESSTUER }
$$$$
\text { CITY, STATE }
$$ INSPECTOR WITNESSING PLUGGING $\frac{4 / 14 / 92}{\text { DATE }}$ RECEN/ED APR 211992 
B. R. CLTwon - state Well Tnswector

being first duly sworn do depose and say the following is a true and correct statement of the details of the plugging of a certain well drilled for oll.

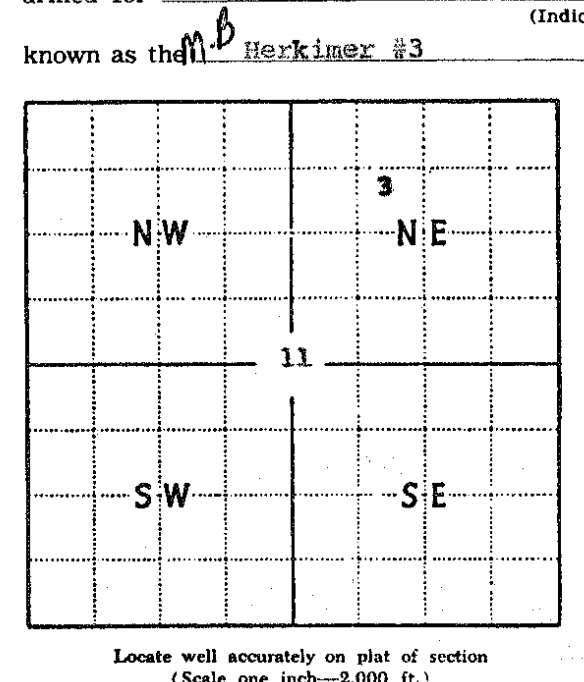

Locate well hocurately on plat of section (Scale one inch- $-2,000 \mathrm{ft}$.) Indicate whether for oil, gas, water or other purposes and located as follows:

ft. north;

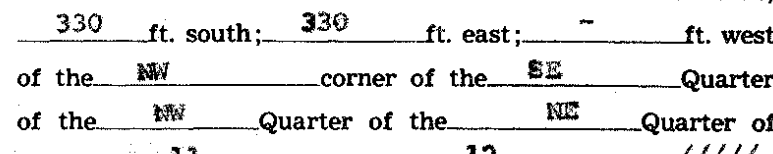

Section 31 , Township_ 12 (North or S6uth)

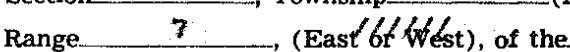
Principal Meridian,___ Colsks _ County, Illinois. Elevation above sea level is $\left\{\begin{array}{l}\text { Derrick Floor } \\ \text { Ground }\end{array}\right.$ Total depth $3172 \quad$ Formation Datrong Date permit to drill issued $1-5-4$ Permit No. Permit issued to Matona 1 consto $0110 \%$ Date drilling began _ 1-0 _ _ Date drilling completed $\quad 2-03-46$

Kind of drilling tools used_r_notary Date plugging began: $10-15-87$

Date plugging completed $10-15-87$

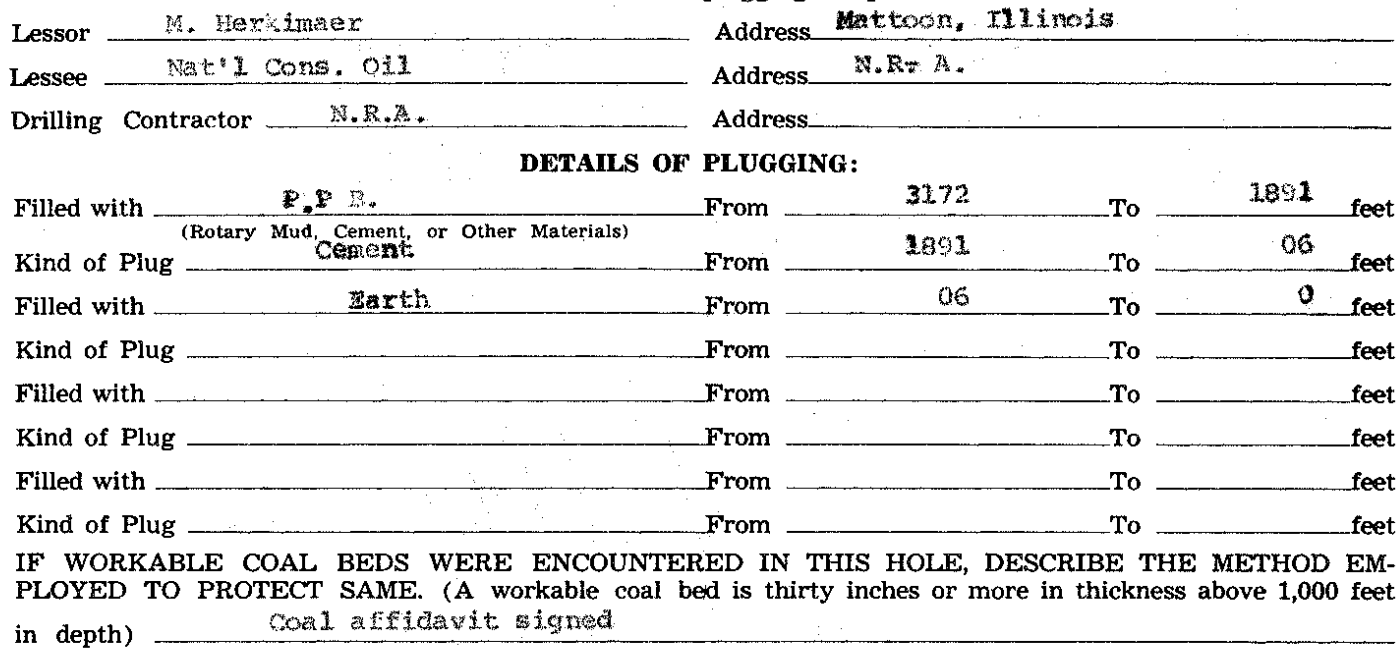

(1) Have pits and other excavations been flled? $\ldots \ldots \ldots \ldots \ldots \ldots \ldots \ldots \ldots$ Yes

(2) Have the following been removed?
Equipment Yes No
Concrete bases ${ }^{\mathrm{Y}} \mathrm{U}$
Debris Yes No

(3) Has surface casing been cut off three feet below ground surface?

(4) Has well-site been leveled? $\ldots \ldots \ldots \ldots \ldots \ldots \ldots \ldots \ldots \ldots \ldots \ldots \ldots \ldots$

If this was a producing well, give date and amount of last production

CASING RECORD

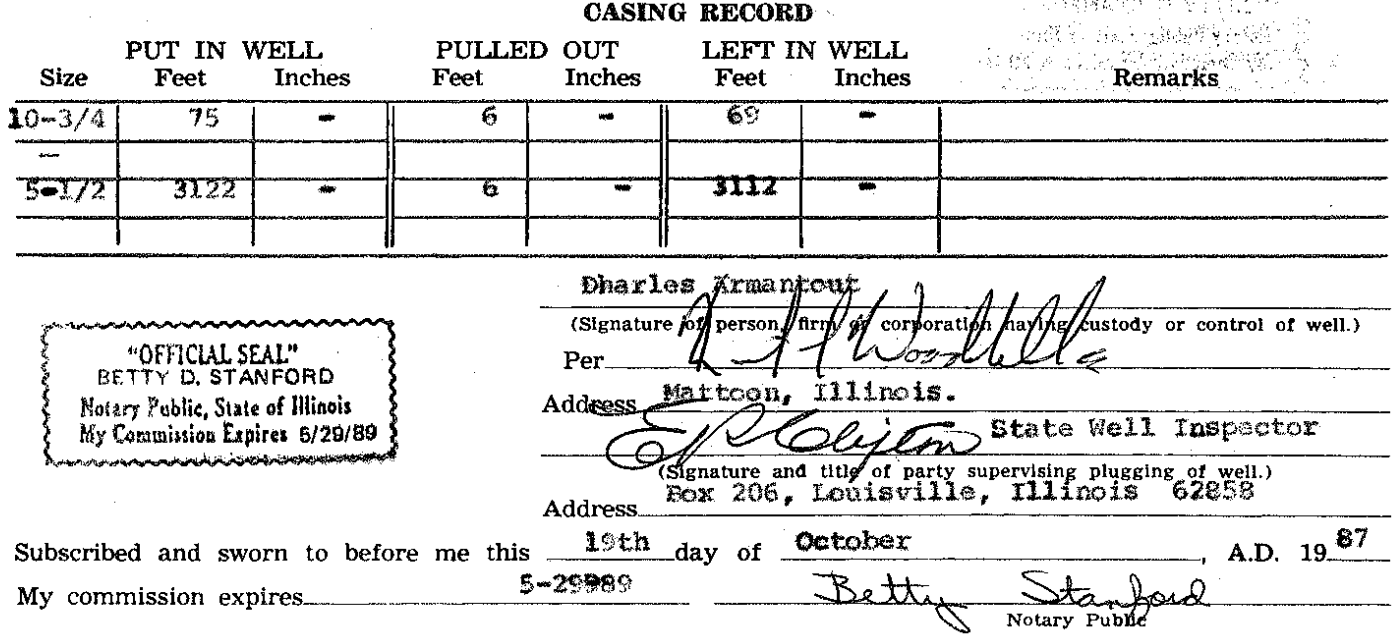




\title{
WELL PLUGGING AFFIDAVIT
}

\author{
D. J. ATUUB
}

do depose and say the following is a true and correct statement of the details of the plugging of a certain well drilled for OTL 2. Es, (Indicate whether for oil, gas, water or other purposew)

known as the How 1

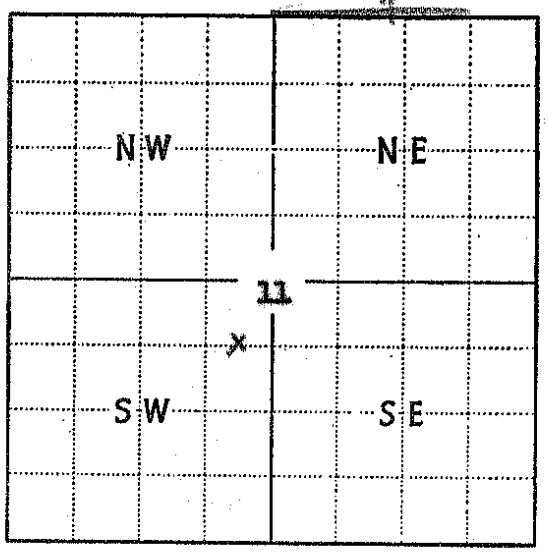

Locate well accurately on plat of section (Scale one inch-2,000 ft.) and located as follows:

ft. north; -660 ft. south; __ft. east; 330 ft. west of the Corner of the________ Quarter of the_Q_Quarter of the Quarter of

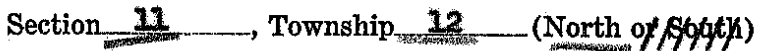

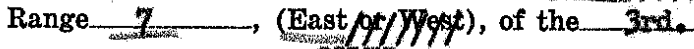
Principal Meridian, COLES County, Mlinois. Elevation above sea level is $\begin{cases}\text { Derrick Floor } & \text { ft. } \\ \text { Ground } n N_{4} & \text { ft. }\end{cases}$ Total depth 3247 Formation DEvoNIAL Date permit to drill issued \$-12-58Permit No. 795 Permit issued to HIJ WOD, CO. Date drilling began $\quad 5-14-5$ Date drilling completed $5-23-56$ Kind of drilling tools used vorAnI

Lessor Howany Date plugging began $\quad 5-28-58$

Date plugging completed $\quad 5-2858$

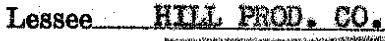

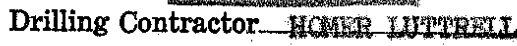
Address Address Maroov, Thithots

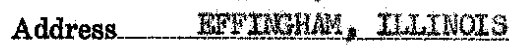

\section{DETAILS OF PLUGGING:}

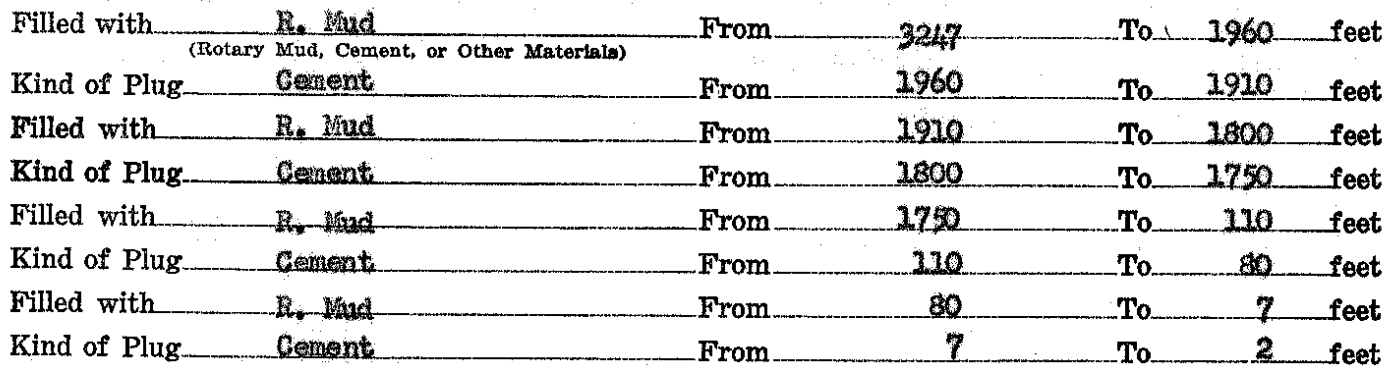

IF WORKABLE COAL BEDS WERE ENCOUNTERED IN THIS HOLE, DESCRIBE THE METHOD EMPLOYED TO PROTECT SAME. (A workable coal bed is thirty inches or more in thickness above 1,000 feet in depth) No con

(1) Have pits and other excavations been filled? $\ldots \ldots \ldots \ldots \ldots \ldots \ldots$ 每

(2) Have the following been removed?

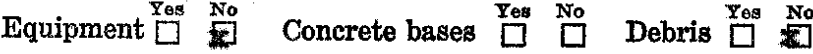

(3) Has surface casing been cut off three feet below ground surface

(4) Has well-site been levelled?.

If this was a producing well, give date and amount of last production

$\begin{array}{ll}Y_{e s} & \text { No } \\ \square & \square \\ \square & \text { No } \\ \square\end{array}$

\begin{tabular}{|c|c|c|c|c|}
\hline & & CAS & RECORD & \\
\hline & PUT IN WELL & PULLED OUT & LEFT IN WELL & \\
\hline ze & Feet Inches & Inches & Inches & Remarks \\
\hline
\end{tabular}

\begin{tabular}{c|c|c|c|c|c|c} 
Size & Feet & Inches & Feet & Inches & Feet & Inches \\
\hline $103 / 4$ & 100 & & & & 100 & \\
\hline & & & & & & \\
\hline & & & & & \\
\hline
\end{tabular}

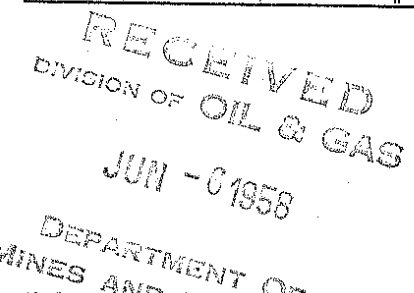

HILE PRODVCTON 00.

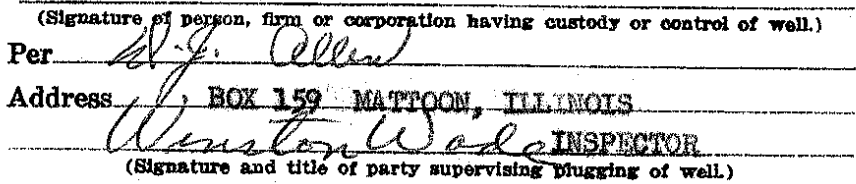

Address FATIS, ITLINOTS

Subscribed andjornt to before me this and My commission expires?

day of 
3. 0 .

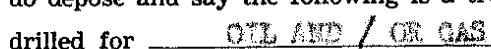
(Indlcate whether for oll, gas, water or other purposes)

known as the

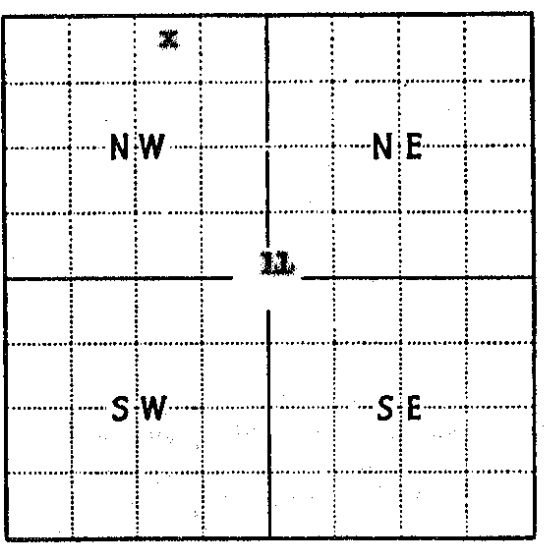

Locate well accurately on plat of section (Scale one inch-2,000 ft.) and located as follows:

ft. north;

300 ft. south;____ ft. east; _ 090 ft. west

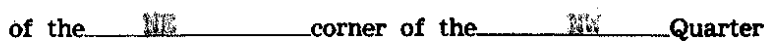
of the Quarter of the____ Quarter of

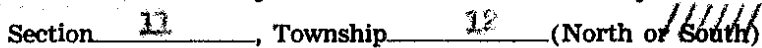
Range 7 , (East of $/ \mathrm{W} / \mathrm{d} / \mathrm{W} / \mathrm{/}$ of the $3 \mathrm{x}$

Principal Meridian,___ COL, County, Illinois. Elevation above sea level is $\left\{\begin{array}{l}\text { Derrick Floor } \\ \text { Ground }-60.5 \% \mathrm{ft} .5\end{array}\right.$ Total depth 3170 Formation Sevonion Date permit to drill issued $11 / \mathcal{L} 6 / 7$ Permit No. 1000

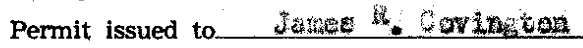
Date drilling began $\quad 21 / 14 / 70$ Date drilling completed $\quad \mathrm{L} / \mathrm{k} \mathrm{k} / \mathrm{h} / \mathrm{s}$ Kind of drilling tools used ackatoy Date plugging began $\quad 4 / 17 / 50$ Date plugging completed $4 / 27 / 20$

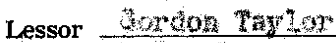

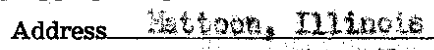

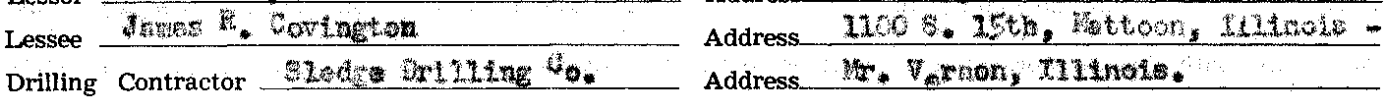

Details of PLUGging:

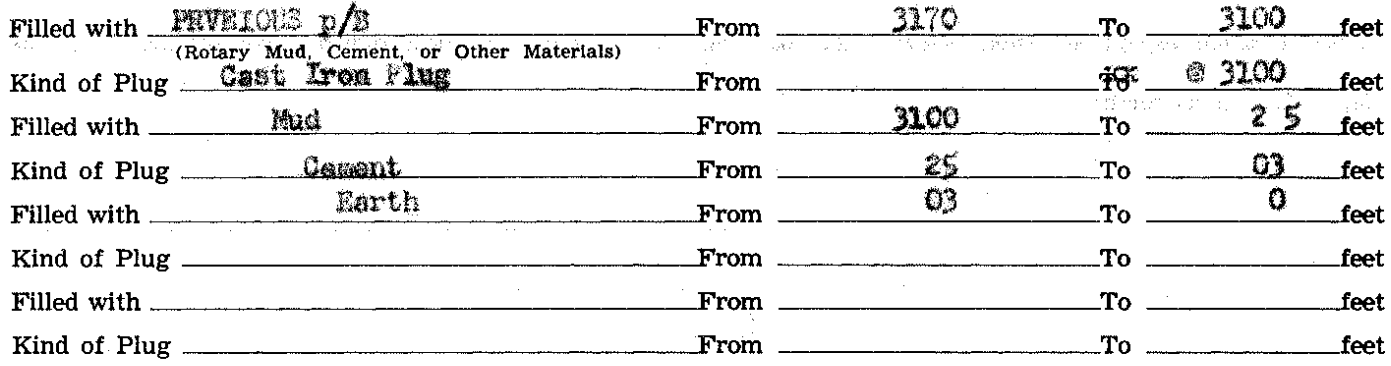
IF WORKABLE COAL BEDS WERE ENCOUNTERED IN THIS HOLE, DESCRIBE THE METHOD EMPLOYED TO PROTECT SAME. (A workable coal bed is thirty inches or more in thickness above 1,000 feet in depth)

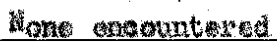

(1) Have pits and other excavations been flled?...............

(2) Have the following been removed?

Equipment $\left[\begin{array}{l}\text { Yes } \\ \square\end{array}\right.$ Concrete bases $\stackrel{\text { Yes }}{\square} \stackrel{\text { No }}{\square}$ Debris $\stackrel{\text { Yes }}{Z} \square^{\text {No }}$

(3) Has surface casing been cut off three feet below ground surface?

(4) Has well-site been leveled?

If this was a producing well, give date and amount of last production $1-\mathbf{z}-17+79$

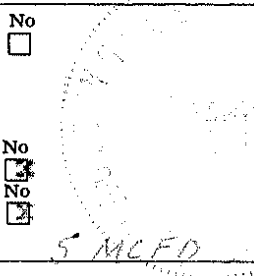

CASING RECORD

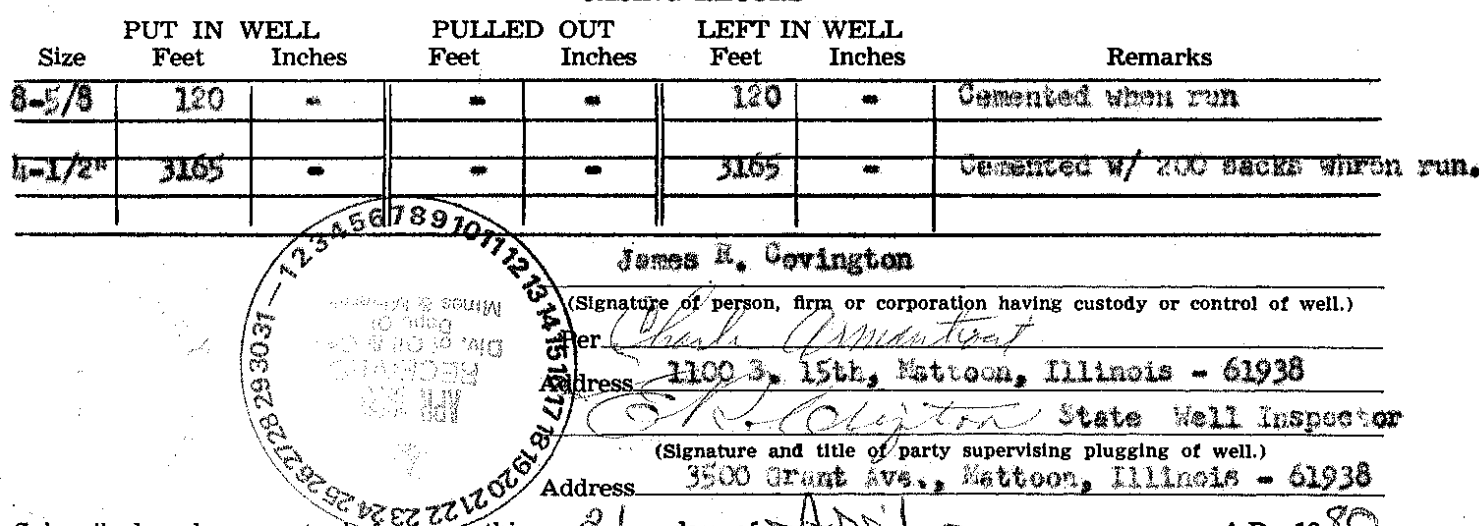

Subscribed and sworn to before me this 21 day of $A$ bril My commission expires $3 / 8 / 83$ 
do depose and say the following is a true and correct being first duly sworn, dhe details of the plugging of a certain well drilled for ONL OHO GS

known as the Gordon Taylor it 2 (Indicate whether for oll, gas, water or other purposes)

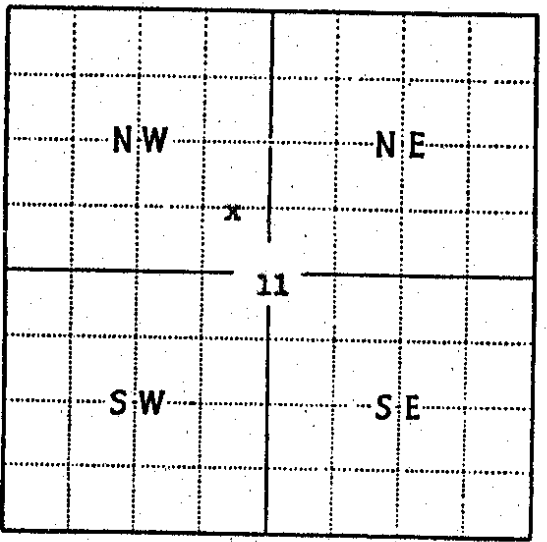

Locate well accurately on plat of section (Scale one inch-2,000 ft.)

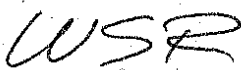

Taylor

$\angle E B$ and located as follows: 430 ft. south;__ft. east; $330 \quad$ ft. west ft. south;__ft. east; $330 \quad$ ft. west ft. north;

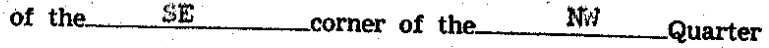
of the Quarter of the Section 11 , Township 12, (North of Bbuttfol

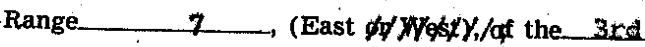
Frincipal Meridian,__CLtis County, nlinois. Elevation above sea level is $\left\{\begin{array}{l}\text { Derrick Floor } \\ \text { Ground }\end{array}\right.$ Total depth 3170 Formation CEDAR VALLEX Date permit to drill issued $4 / 7$ 71 Permit No. 219 Permit issued to $I$ m $k$, Covington Date drilling began $4 / 7,71$ Date drilling completed $4 / 17 / 71$ Kind of drilling tools used Rotany Date plugging began. $6 / 28 / 81$

Date plugging completed. $6 / 28 / 81$

Lessor Gordon (Dectased) Address Mattoon. IIIInols Lessee James $R$, Covington Address 400 50. 15th, Mattoon, IIIlnots -6 Drilling Contractor

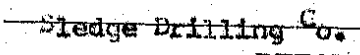
DETAILS OF PLUGGING:

Filled with DRotrous DIUA BACK (Rotary Mud, Cement, or Other Materlals) Kind of Plug Cement Filled with Earth From CAn IRON WHU.

Kind of Plug From

Filled with

Kind of Plug

Filled with

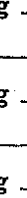
From

From From From From

From

\begin{tabular}{rrr}
3100 & To & $03 \quad$ feet \\
\hline 03 & To & $0 \quad$ feet \\
& To & feet \\
& To & feet \\
& To & feet \\
& To feet \\
& To & feet
\end{tabular}

IF WORKABLE COAL BEDS WERE ENCOUNTER feet PLOYED TO PROTECT SAME. (A workable coal bed is thirty in HOLE, DESCR in depth) NLNE ENGOUNTERED

(1) Have pits and other excavations been flled?

(2) Have the following been removed?

$$
\text { Equipment } \stackrel{\text { Yes }}{\square} \stackrel{\text { No }}{\square} \text { Concrete bases } \stackrel{\text { Yes }}{\square} \stackrel{\text { No }}{\square} \text {. Debris 钅 }
$$

(3) Has surface casing been cut off three feet below ground surface?

(4) Has well-site been leveled? .

If this was a producing well, give date and amount of last production 50 Dec. 1978

\begin{tabular}{|c|c|c|c|c|c|c|c|}
\hline \multirow[b]{2}{*}{ Size } & \multirow[b]{2}{*}{$\begin{array}{c}\text { PUT IN } \\
\text { Feet }\end{array}$} & \multirow[b]{2}{*}{$\begin{array}{l}\text { WELL } \\
\text { Inches }\end{array}$} & \multicolumn{4}{|c|}{ CASHNG RECORD } & \multirow{2}{*}{ Remarks } \\
\hline & & & $\begin{array}{l}\text { PULLED } \\
\text { Feet }\end{array}$ & $\begin{array}{l}\text { OUT } \\
\text { Inches }\end{array}$ & $\begin{array}{c}\text { LEFT I } \\
\text { Feet }\end{array}$ & $\begin{array}{l}\text { WELL } \\
\text { Inches }\end{array}$ & \\
\hline $8 / 5 / 8$ & 106 & $m$ & - & - & 106 & - & \\
\hline $4-1 / 2$ & 3170 & - & - & - & 3170 & & \\
\hline & & & & & & & \\
\hline
\end{tabular}

CASHNG RECORD

$$
\text { James } R_{*} \text { ovington }
$$

(Signature of person, firm or corporation having custody or control of well.) Per

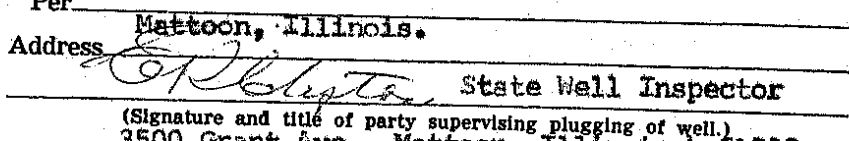

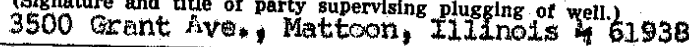
Subscribed and sworn to before me this 28 day of
My commission expires $9 / 29 / 8 /$ 
County of COLES $\}$ SS.

8. R. CuIfHon - State Well Inspector

being first duly sworn do depose and say the following is a true and correct statement of the details of the plugging of a certain well drilled for OII

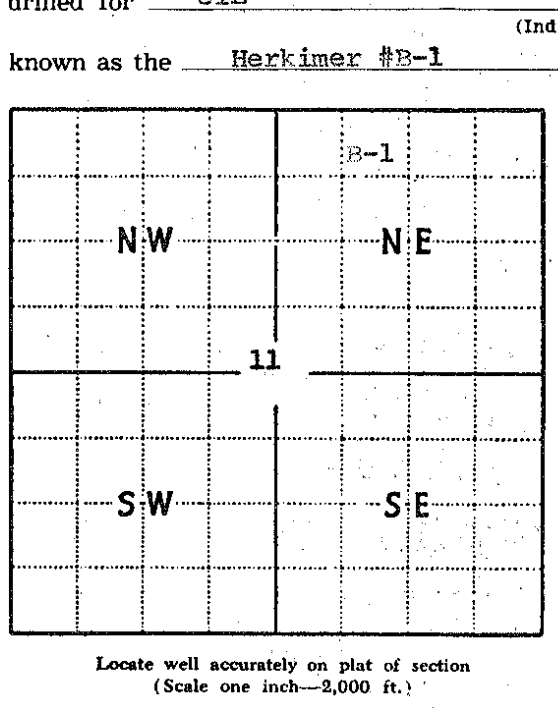

Lessor M. Herkimer Indicate whether for oll, gas, water or other purposes

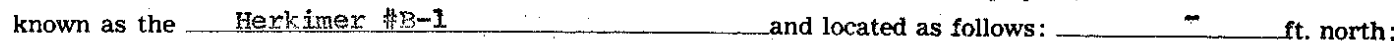

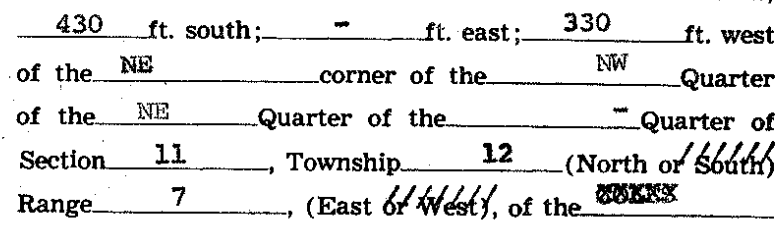

Principal Meridian,_ COLES

County, Illinois.

Elevation above sea level is $\begin{cases}\text { Derrick Floor } & \mathrm{ft} . \\ \text { Ground } 694 & \mathrm{ft} .\end{cases}$

Total depth 2408

Formation Osage

Date permit to drill issued $/ 26-85$ Permit No. 3755

Permit issued to charles Armantrout

Date drilling began $\quad 12-16=85$

Date drilling completed $12 \cdots 20-85$

Kind of drilling tools used Rotary

Date plugging began

$10-15-87$

Date plugging completed

$10-15-87$

Lessee Charels Armantrout

Address Mattoon, Illinois.

Drilling Contractor N. R. A.

Address Mattoon, Illino is.

\section{DeTARs OF PLUGGing:}

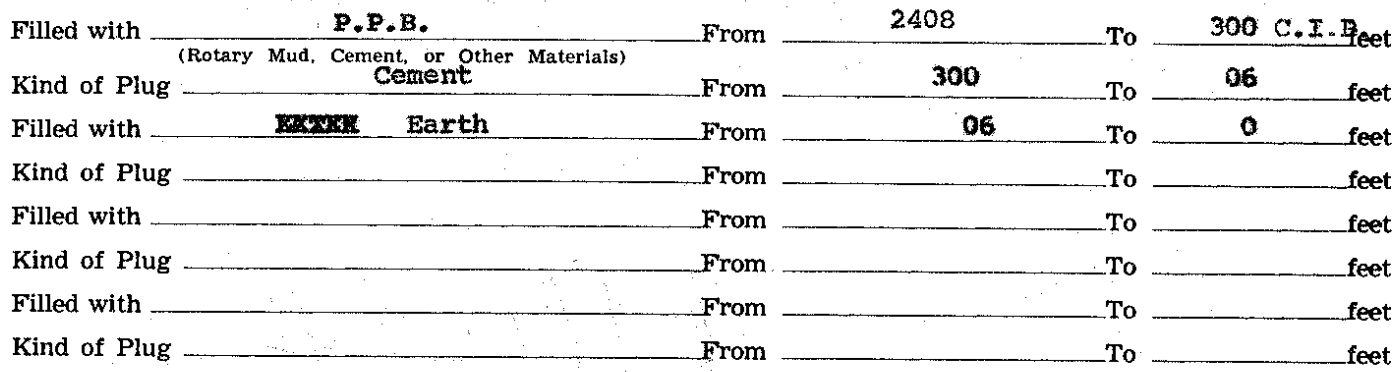

IF WORKABLE COAL BEDS WERE ENCOUNTERED IN THIS HOLE, DESCRIBE THE METHOD EMPLOYED TO PROTECT SAME. (A workable coal bed is thirty inches or more in thickness above 1,000 feet in depth) Coal a filiavit signed

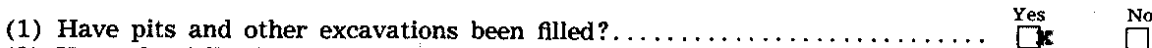

(2) Have the following been removed?

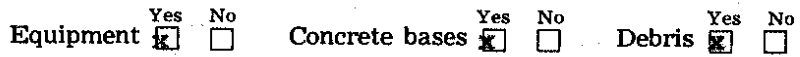

(3) Has surface casing been cut off three feet below ground surface?

(4) Has well-site been leveled?

If this was a producing well, give date and amount of last production _N. R. A.

Xes
Yes

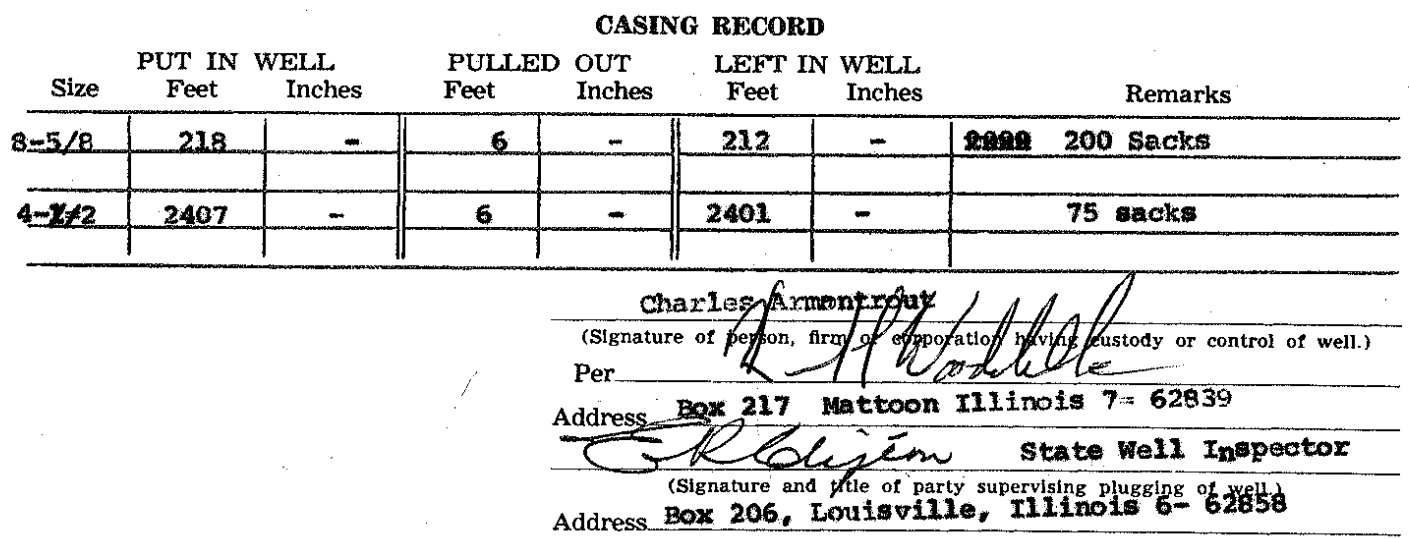

Subscribed and sworn to before me this 19 day of Octobex_A.D. 1987 
County of

\section{WELl PLUGGiNg AFFIDAVIT}

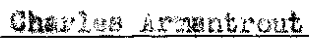

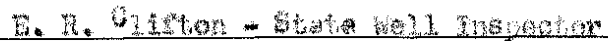

being first duly sworn, do depose and say the following is a true and correct statement of the details of the plugging of a certain well drilled for otz

known as the merom 1

(Indicate whether for oil, gas, water or other purposes)

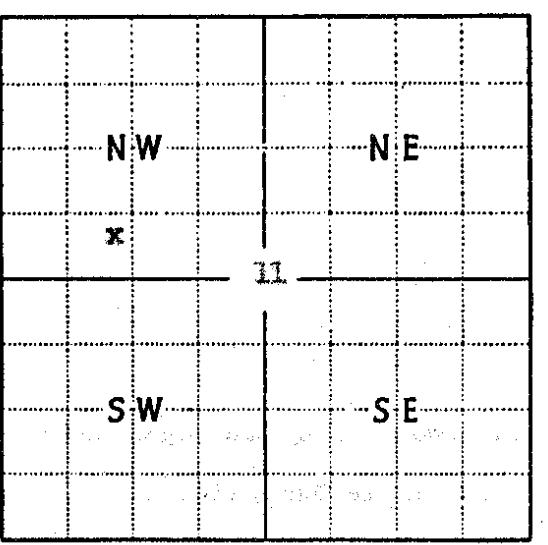
and located as follows:

330 ft. north; ft. south; $\quad 390$ ft. east;

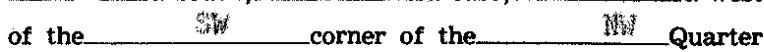
of the_Q_Quarter of the__uarter of Section $\quad 21$, Township_ 32 (North of South) Range $\quad z$, (East or w west), / of the ind

Principal Meridian,___ OtLes

Elevation above sea level is $\left\{\begin{array}{l}\text { Derrick Floor } \\ \text { Ground }\end{array}\right.$

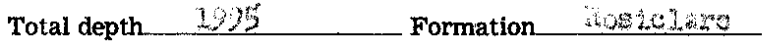

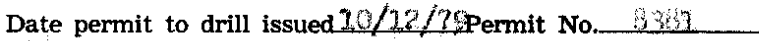
Permit issued to oksalas in

Date drilling began $\quad 10-19-72$

Date drilling completed $\quad 30-2+-79$

Kind of drilling tools used detury well accurately on plat of section
(Scale one inch-2,000 $\mathrm{ft}$.)

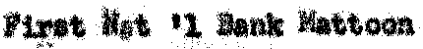

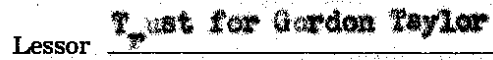
Date plugging began $10-2,29$ Date plugging completed $\quad 12-22-79$

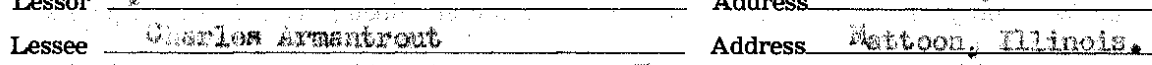

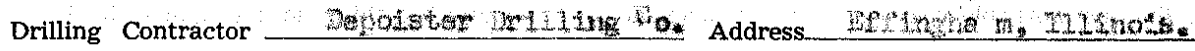

DETAILS OF PLUGGING:

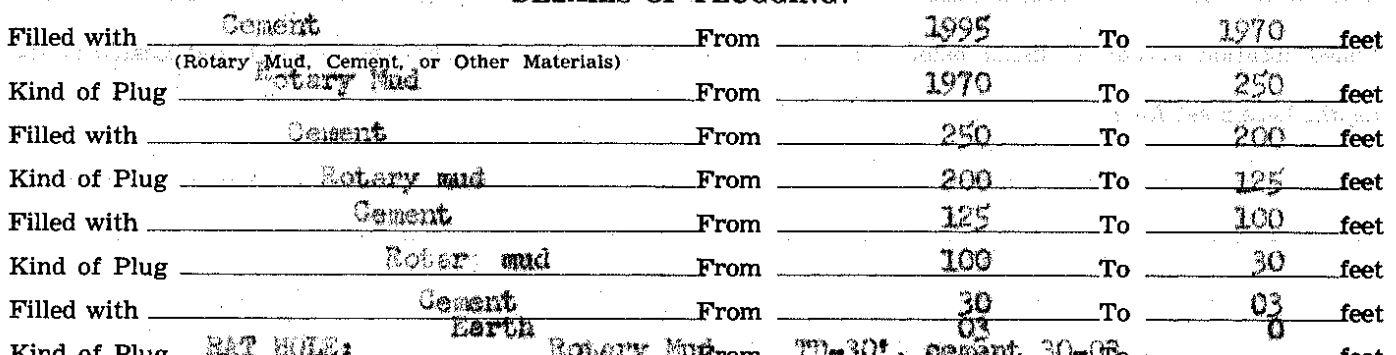

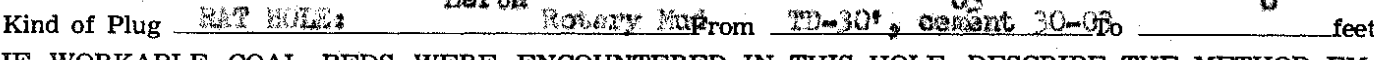
IF WORKABLE COAL BEDS WERE ENCOUNTERED IN THIS HOLE, DESCRIBE THE METHOD EMPLOYED TO PROTECT SAME. A workable coal bed is thirty inches or more in thickness above 1,000 feet in depth)

(1) Have pits and other excavations been flled? . . . . . . . .

(2) Have the following been removed?

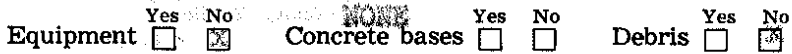

(3) Has surface casing been cut off three feet below ground surface?

(4) Has well-site been leveled?

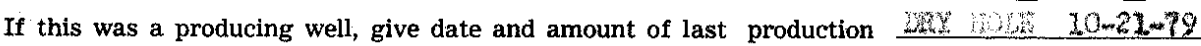

\section{CASING RECORD}

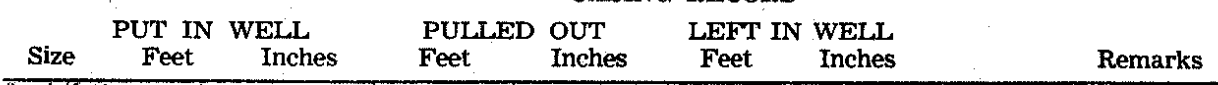

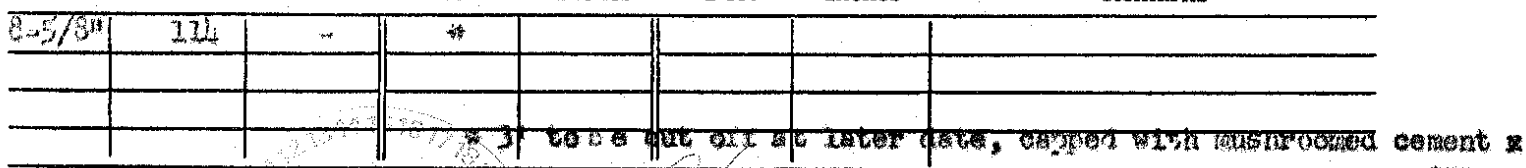

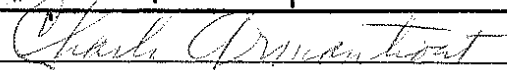


do depase and say the following is a true and correct statement of the detalls of the plugging of a certain well drilled for 011

known as the Taylor $\$ 5^{\text {(Indicate whether for oll. gas, water or other purposes) }}$ ft. north;

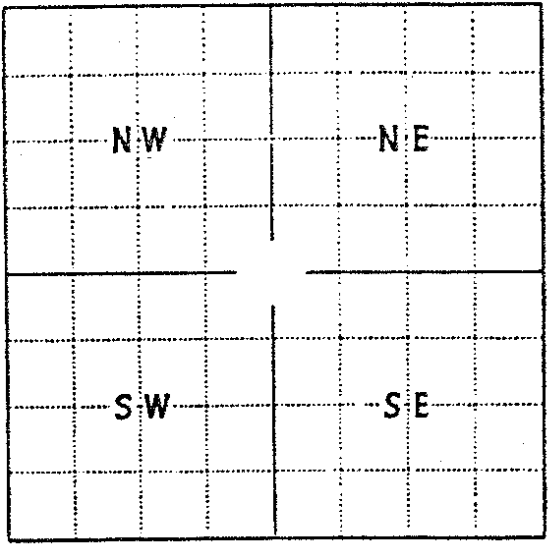

Locate well accurately on plat of section (Scale one inch $-2,000 \mathrm{ft}$ !

Lessor Gorton W. Taylor Lessee Chartes Armantrout Drilling Contractor Depoister Drlg of the N(s) corner of the Quarter of the. Quarter of the Section 11 Township 12 (North Range 78 , (East ox the Principal Meridian, Boles County, Illinois. Elevation above sea level is $\left\{\begin{array}{l}\text { Derrick Floor } 693 \quad \mathrm{ft} . \\ \text { Ground } 690 \mathrm{ft} .\end{array}\right.$ Total depth 1978 Formationkosiclare Date permit to dirill issued $5 / 8 / 81$ Permit No 14187 Permit issued to Charles firmant rout Date drilling began $8 / 30 / 81$

Date drilling completed $9 / 2 / 81$ Kind of drilling tools used Rotary Date plugging began $6 / 22 / 89$ Date plugging completed $6 / 23 / 89$

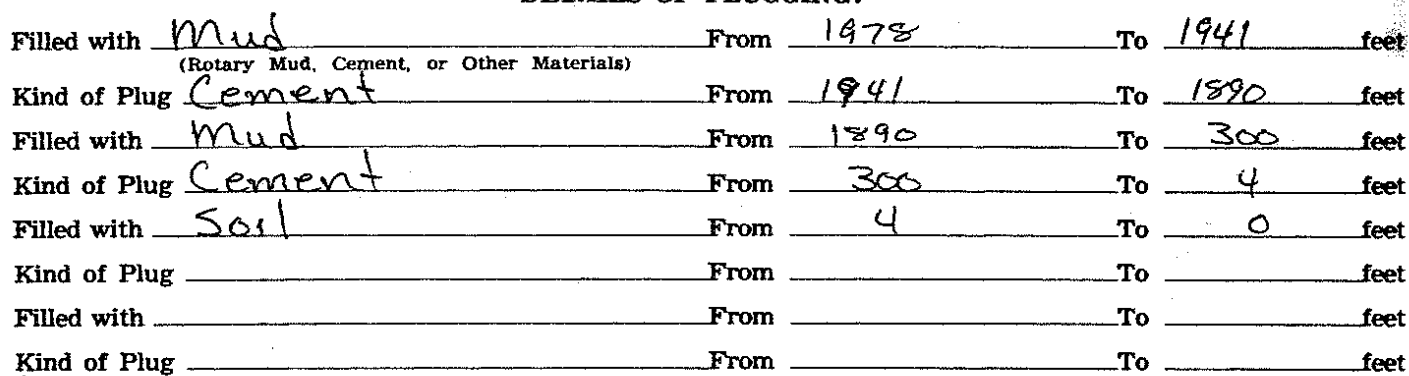

IF WORKABLE COAL BEDS WERE ENCOUNTERED IN THIS HOLE, DESCRIBE THE METHOD EMPLOYED TO PROTECT SAME. (A workable caal bed is thirty inches or more in thickness above 1,000 feet in depth) None

(1) Have pits and other excavations been flled?

(2) Have the following been removed?

$$
\text { Address mattoon Il }
$$
Addressffinghawn I

\section{PLUGGing:}

\section{Equipment 装 $\stackrel{\text { No }}{\square}$ Concrete bases $\stackrel{\text { No }}{\square}$ Debris $\square$}

(3) Has surface casing been cut of three feet below ground surfaces

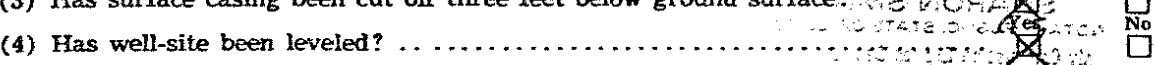

If this was a producing well, give date and amount of last production

\begin{tabular}{|c|c|c|c|c|c|c|c|}
\hline Size & $\begin{array}{c}\text { PUT IN } \\
\text { Feet }\end{array}$ & $\begin{array}{l}\text { WELLL } \\
\text { Inches }\end{array}$ & $\begin{array}{l}\text { PULIED } \\
\text { Feet }\end{array}$ & $\begin{array}{l}\text { OUT } \\
\text { Inches }\end{array}$ & $\begin{array}{c}\text { LEFT } \\
\text { Feet }\end{array}$ & $\begin{array}{l}\text { Went } \\
\text { Inches }\end{array}$ & Remarks \\
\hline \multicolumn{8}{|l|}{ simgs } \\
\hline $85 / 8$ & 167 & & 4 & & 163 & & 150 Sacks \\
\hline $4 / 5$ & 1978 & & 1102 & & 876 & & $200 \mathrm{Sects}$ \\
\hline
\end{tabular}

\section{CASENG RECORE}

$$
\begin{aligned}
& \text { OFFCEL SEAL } \\
& \text { OHMON SMITH }
\end{aligned}
$$



do depose and say the following is a inu do depose and say the following is a trued for

known as the Taylor $\$ 9$

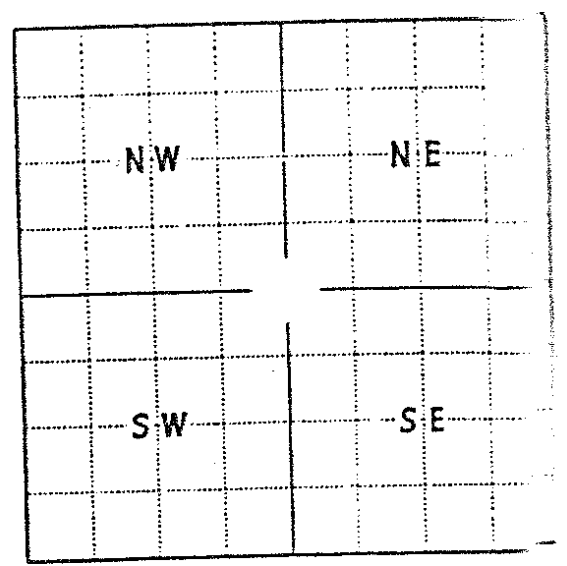

Locate well securately on plat of section (Scale one inch-2,000 ft.? i i. Ea te whether for ofl, gas water or other purposes)

and located as follows: of the. fouth; $S E$ ft. east: comer of the of the Nus Quarter of the Quarter of Section 11 Township 12 (North Range_ 7 (East of the

Principal Meridian, Coles County, Illinois.

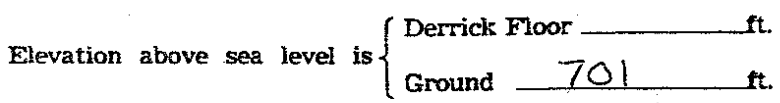
Total depth $20 / 6$ FormationRosiclare Date permit to drill issueds-4-82 Permit No.187/6 Permit issued tofhorles firmentrout Date drilling began $5-4-82$ Date drilling completed $5-8-82$ Kind of drilling tools used Rstary Date plugging began $6 / 23 / 89$ Date plugging completed $6 / 26 / 89$ Address Mattoon II Lessor Gorton W Teylor Lessee Charles Armant it Drilling Contractor Depoister $\mathrm{H}=\mathrm{g}$ Address Mattoon II Address. Effing ham I IDEAILS OF PLUGGING:

Filled with $\frac{\text { Mud }}{\text { (Rotary Mud, cement, or oth }}$
Kind of Plug - Mud
Filled with
Kind of Plug - Cement
Filled with

Kind of Plug Filled with

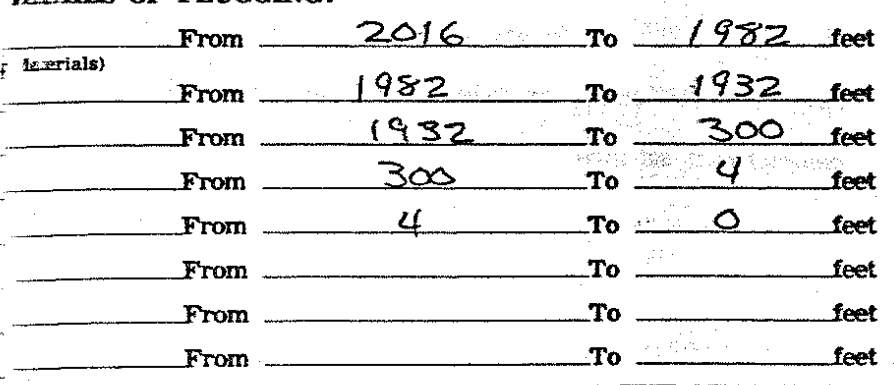

- Kind of Plug _tCOUNTERED IN THIS HOLE, DESCRIBE THE METHOD EMIF WORKABLE COAL BEDS WERE
PLOYED TO PROTECT SAME. (A wite coal bed is thirty inches or more in thickness above 1,000 feet

in depth)

(1) Have pits and other excavations b

(2) Have the following been removed?
Equipment Ye No
Concrete bre $=\stackrel{9}{\square}$
$9 \stackrel{\text { No }}{\square}$ Debris

(3) Has surface casing been cut off the ${ }^{\text {tan }}$ below ground surface?

(4) Has well-site been leveled? .......

mount of last production

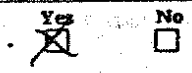

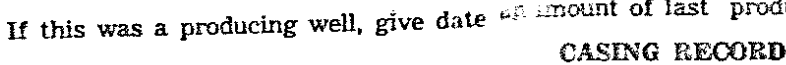

\begin{tabular}{|c|c|c|c|}
\hline Size & $\begin{array}{c}\text { PUT IN } \\
\text { Feet }\end{array}$ & $\begin{array}{l}\text { WELL } \\
\text { Inches }\end{array}$ & $\begin{array}{l}\text { PUls? } \\
\text { Fett }\end{array}$ \\
\hline $85 \%$ & 120 & & 4 \\
\hline $41 / 2$ & 2016 & & Gil \\
\hline & 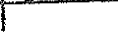 & & \\
\hline
\end{tabular}

\section{YUT LEFT IN WELL}

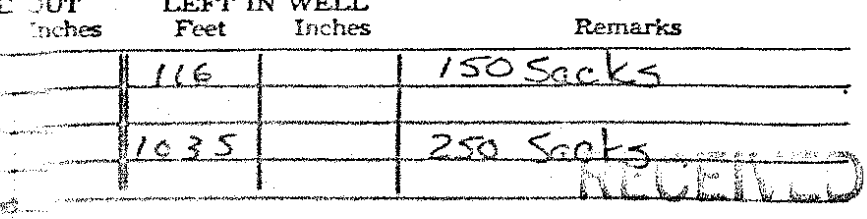

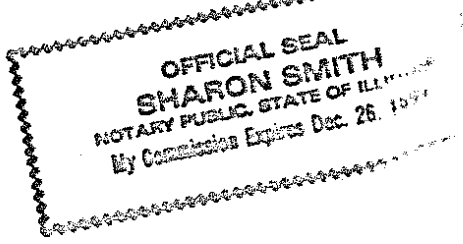

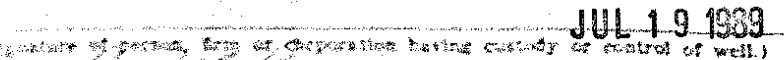

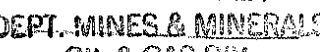

cleycity Il coscoso

Rutin uprom

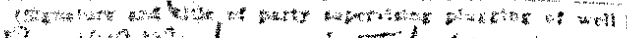

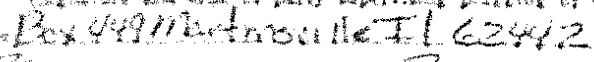

Sulverised and sworn to betore "' 
H. L. Noblit State Well Inspector

being first duly sworn do depose and say the following is a true and correct statement of the details of the plugging of a certain well drilled for oil

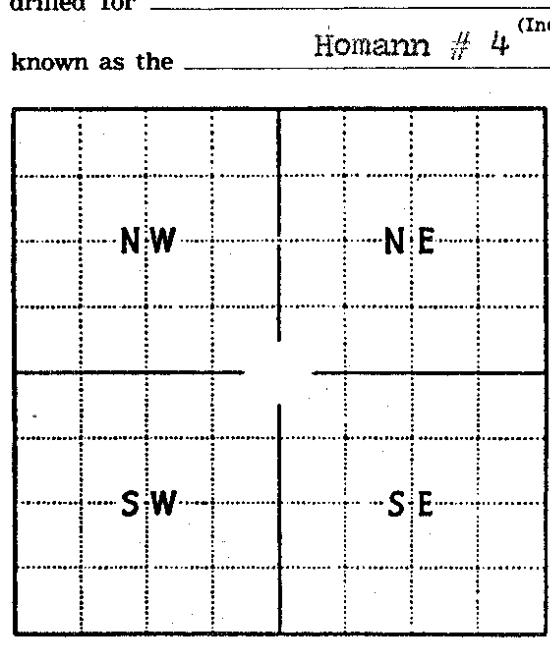

Locate well aceurately on plat of section (Scale one inch-2,000 ft.) (Indicate whether for oil, gas, water or other purposes)

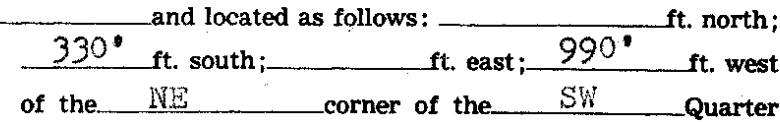
of the Quarter of the Quarter of Section $11 \quad$ Township 12 (North of South) Range 7 , (East or Coles

Principal Meridian County, Illinois.

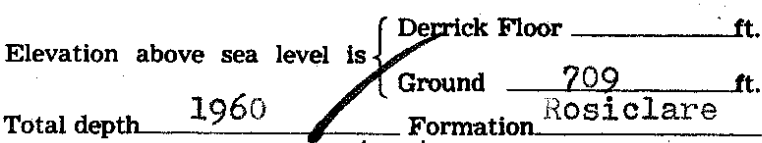
Date permit to drill issued $5 / 11 / 79_{\text {Permit No. } 349}$ Permit issued to Schaefer oil $\mathrm{CO}$. Date drilling began. Date drilling completed N.A. Kind of drilling tools used Rotary Date plugging began 10/11/83 Date plugging completed $\quad 10 / 11 / 83$

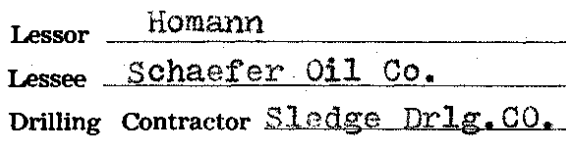

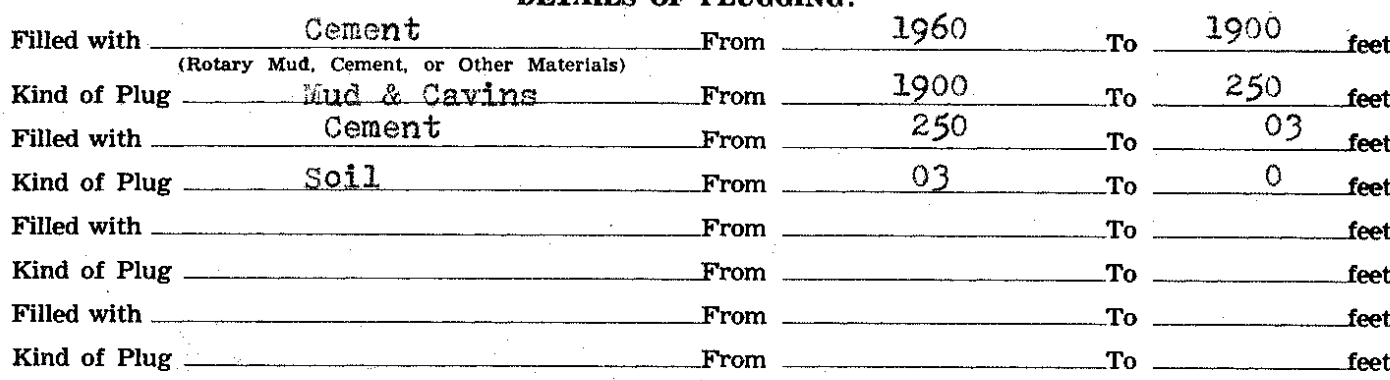
IF WORKABLE COAL BEDS WERE ENCOUNTERED IN THIS HOLE, DESCRIBE THE METHOD EMPLOYED TO PROTECT SAME. (A workable coal bed is thirty inches or more in thickness above 1,000 feet in depth) None

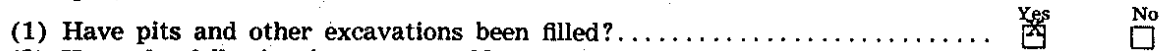

(2) Have the following been removed?
Equipment $\mathrm{Yes}$
Concfetenhases $\stackrel{\text { Yes }}{\square} \stackrel{N}{\square}$
Debris 畾

(3) Has surface casing been cut off three feet below ground surface?

(4) Has well-site been leveled?

If this was a producing well, give date and amount of last production

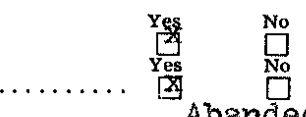
Abanded

CASING RECORD

\begin{tabular}{|c|c|c|c|c|c|c|c|}
\hline Size & \multicolumn{2}{|c|}{ PUT IN WELL } & \multicolumn{2}{|r|}{ OUT } & LEF & WELL & Remarks \\
\hline $10^{\prime \prime}$ & 100 & & 3 & & 97 & & \\
\hline $4 "$ & 1960 & & 1455 & & 505 & & \\
\hline & & & & & & & \\
\hline & & & & & & & \\
\hline
\end{tabular}

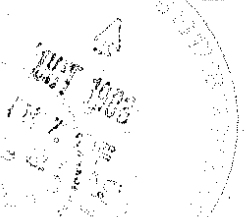

Schaefer ojl Co.

(Signature of person Arm or corporatiog having gistody or control of well.) Per_. $\not 2$ Address Mattoon, IL.

vell Inspector

Address 402 (Signature and title of party supervising plugging of well.)

Subscribed and swom to before me this 12 th day of October $\quad$ A.D. 19

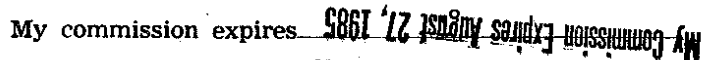
Znathle Eufleit 


\section{Couny of Loles Bangert fasingfuling ferp. For charlesfinnenfondut
Kevin Spencer}

being first duly sworm do depose and say the following is a true and correct statement of the details of the plugging of a certain well drilled for 11

known as the Taylor 10 (Indicate whether for oll gas water or other purposes) $990 \mathrm{ft}$ north;

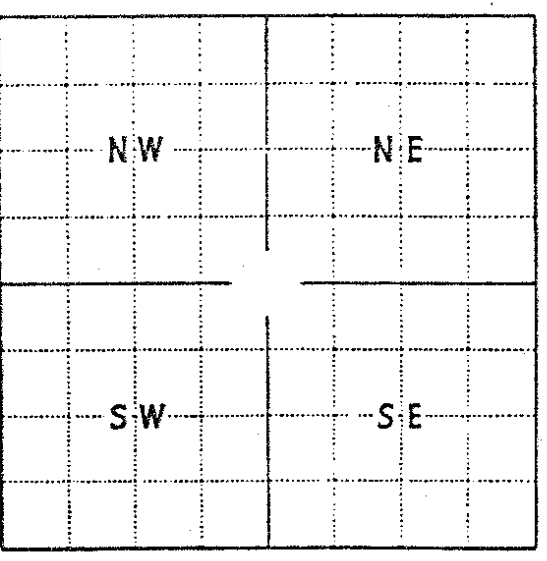

Locate well accurately on plat of section (Scale one inch-2,000 ft:

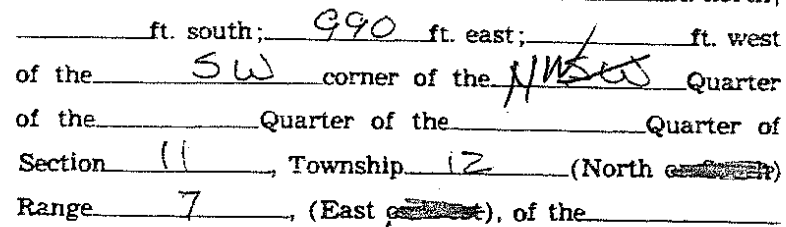

Principal Meridian, Coles County, minois Elevation above sea level is $\left\{\begin{array}{l}\text { Derrick Fioor } 694 \mathrm{ft} \\ \text { Ground } 690 \text { ft. }\end{array}\right.$ Total depth 1970 Formation fuspelese Date permit to drill issued $7 / 5 / 83$ Permit No. 24869 Permit issued to Charles Armantrout Date drilling began $7 / 6 / 83$ Date drilling completed $7 / 9 / 83$ Kind of drilling tools used Rotary Date plugging began $6 / 22 / 89$ Date plugging completed $6 / 23 / 89$

Lessor Gorton w Taylor Address Mattoon II

Lessee Charles Armantrout Address mattoon I Drilling contractor Depoister Drlo Address EFFinghom II Filled with $\frac{\text { Mud }}{\text { (Rotary Mud, Gement. or Other Materials) }}$ Kind of Plug Bridge Plue Filled with Mud Kind of Plug Bridge Plue Filled with Cement Kind of Plug Mud Filled with Cement Kind of Plug SO1 Plugging: IF WORKABLE COAL BEDS WERE ENCOUNTERED IN THIS HOLE, DESCRIBE THE METHOD EM. PLOYED TO PROTECT SAME. (A workable coal bed is thirty inches or more in thickness above 1,000 feet in depth) Lone

(1) Have pits and other excavations been flled? $\ldots \ldots \ldots \ldots \ldots \ldots \ldots \ldots \ldots \ldots$
(2) Have the following been removed?
Equipment $\stackrel{\text { No }}{\square}$
Concrete bases
Debris

(3) Has surface casing been cut off three feet below ground surface?

(4) Has well-site been leveled?

From

1970

1849 To 1830 feet

1830 To 1935 feet

1735 To 1730 feet

1730 To 1680 feet

1680 To 300 feet

If this was a producing well, give date and amount of last production

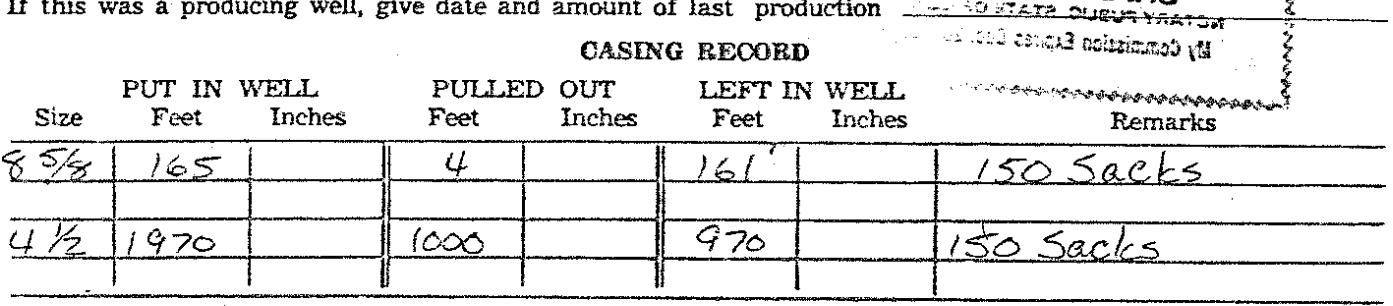

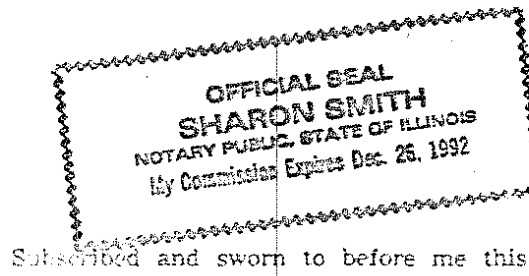

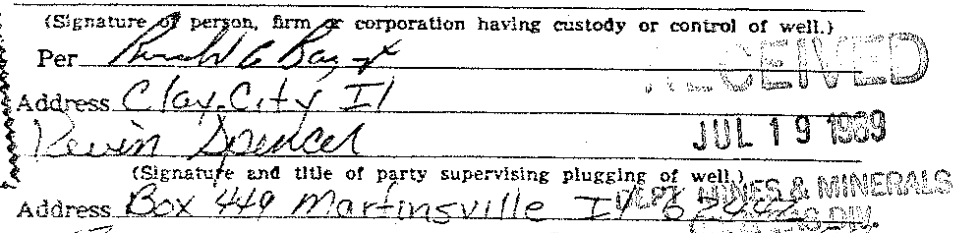


\}ss

\section{WELL PLUGGING AFFIDAVIT}

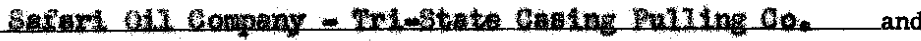

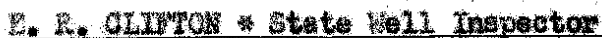

being first duly sworn

do depose and say the following is a true and correct statement of the details of the plugging of a certain well drilled for ollates

(Indicate whether for oll, gas, water or other purposes)

known as the and located as follows

ft. north;

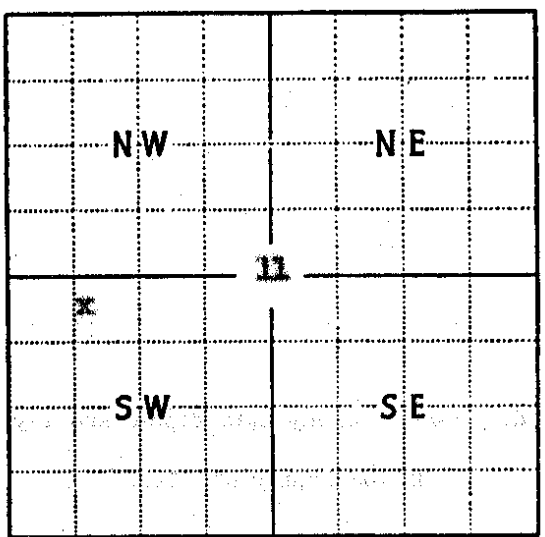

Locate well mecurately on plat of section (Scale one inch-2,000 ft.)

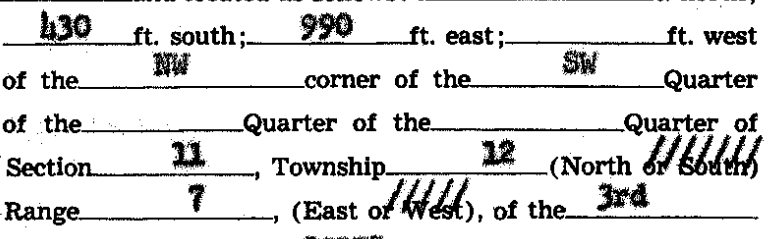

Principal Meridian,_atur

County, mllinois.

Elevation above sea level is $\left\{\begin{array}{l}\text { Derrick Floor } \\ \text { Ground } \mathrm{THO} \text { ft. }\end{array}\right.$

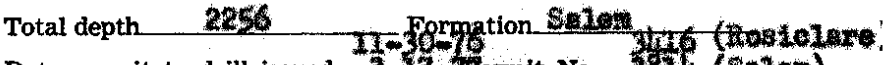

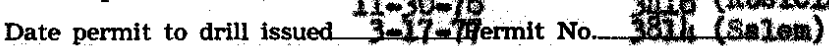

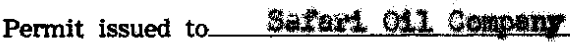

Date drilling began $\quad 3-117$

Date drilling completed $3-10-77$

Kind of drilling tools used

Date plugging began $\quad 3-5-77$

Date plugging completed

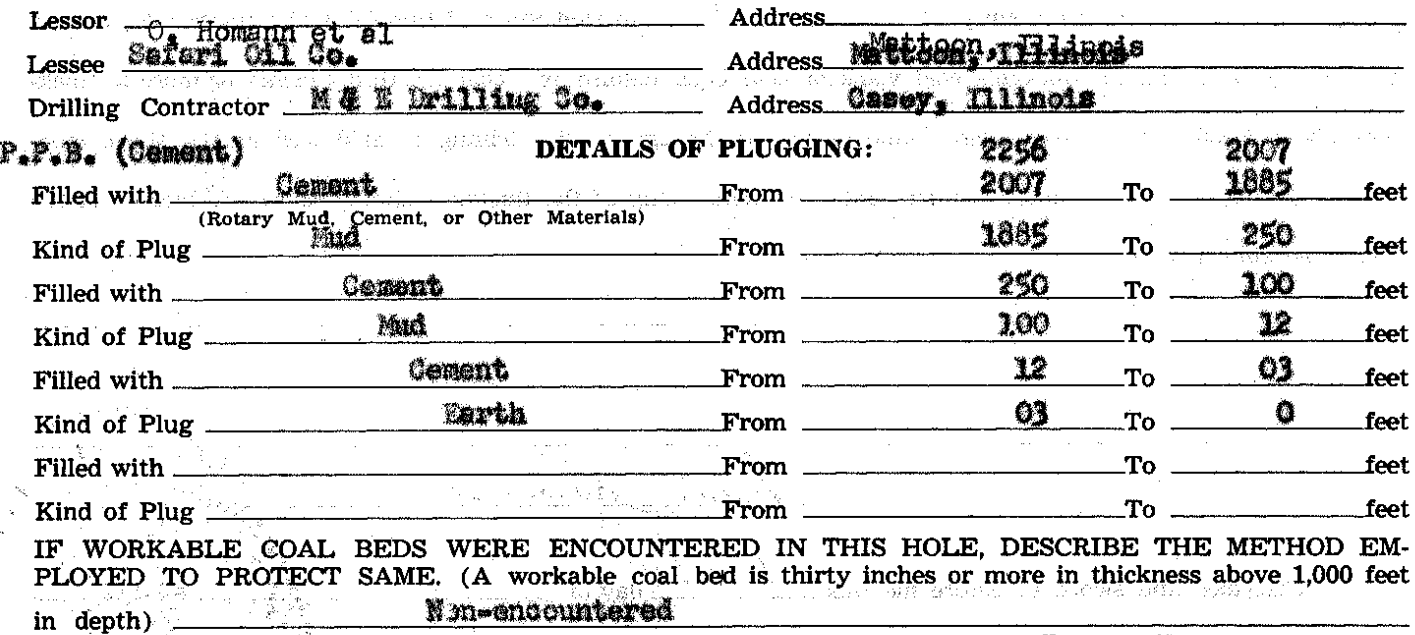

(1) Have pits and other excavations be

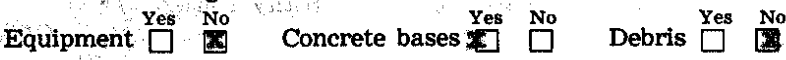

(3) Has surface casing been cut off three feet below ground surface?

(4) Has well-site been leveled?

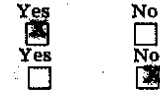

If this was a producing well, give date and amount of last production

CASING RECORD

\begin{tabular}{|c|c|c|c|c|c|c|c|}
\hline Size & $\underset{\text { Feet }}{\text { PUT IN }}$ & $\begin{array}{l}\text { WELL } \\
\text { Inches }\end{array}$ & $\begin{array}{l}\text { PULL } \\
\text { Feet }\end{array}$ & $\begin{array}{l}\text { OUT } \\
\text { Inches }\end{array}$ & $\begin{array}{c}\text { LEFT I } \\
\text { Feet }\end{array}$ & $\begin{array}{l}\text { WELLL } \\
\text { Inches }\end{array}$ & Remarks \\
\hline $9 n$ & 115 & - & 4 & $=$ & 111 & - & 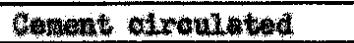 \\
\hline $4-1 / 2 n$ & 2012 & - & 1576 & - & 434 & & Oenduted u/ \\
\hline & & & & & & & \\
\hline
\end{tabular}

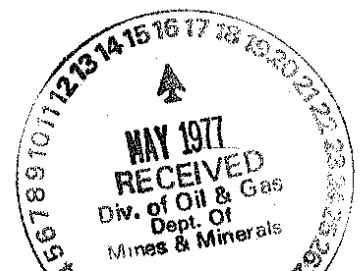

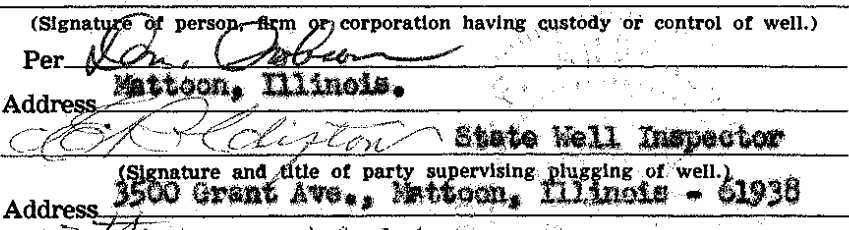

Address 127 day of $\triangle Y \mid C Y$ A.D. $197 Z$

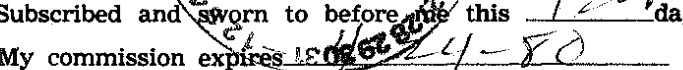
147 Notary Public 20182 

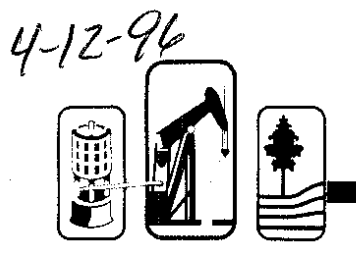

ILLINOIS DEPARTMENT OF MINES AND MINERALS OIL AND GAS DIVISTON
(217) $782-7756$ (217) $782-7756$

\section{OG-6 WELL PLUGGING REPORT}

TYPE OF WELL: XX PRODUCTION $\square$ CLASS II $\square$ OBSERVATION $\square$ GAS STORAGE $\square$ REPLUG $\square$ OTHER $\_4$. PERMTTEE: Lames Eickberg (PRF-96-3-Mattoon) WELL NAME: Conrad Comm.\#1 PERMIT NO. $\frac{66}{\text { (ISSUE DATE IF NO NUMBER) }}$

PERMITTEE NO. 414

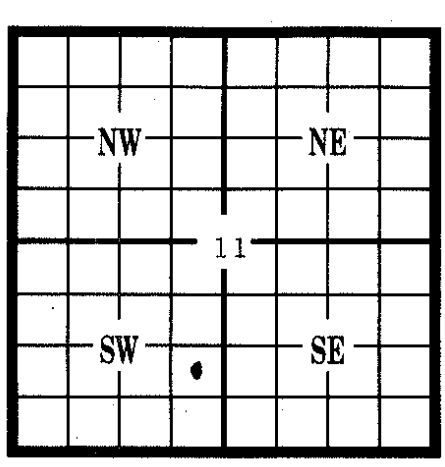
REFERENCE NO. 124034

WELL DATA:

\begin{tabular}{|c|c|c|}
\hline SURFACE ELEVATION & $719 \quad$ FT. & PRODUCING / INJECTION INTERVALS \\
\hline TOTAL DEPTH OF WELL & $N / A \quad F T$ & FROM $\quad \mathrm{N} / \mathrm{A}$ \\
\hline PLUGGED BACK TOTAL DEPTH & FT. & FROM \\
\hline BASE OF FRESHWATER ZONE & 169 & FROM $\_$To \\
\hline WORKABLE COALS PRESENT AT & FT. & FROM \\
\hline \multicolumn{3}{|c|}{ DESCRIBE PREVIOUS PLUGBACK PROCEDURE: } \\
\hline
\end{tabular}

DETAILS OF PLUGGING:

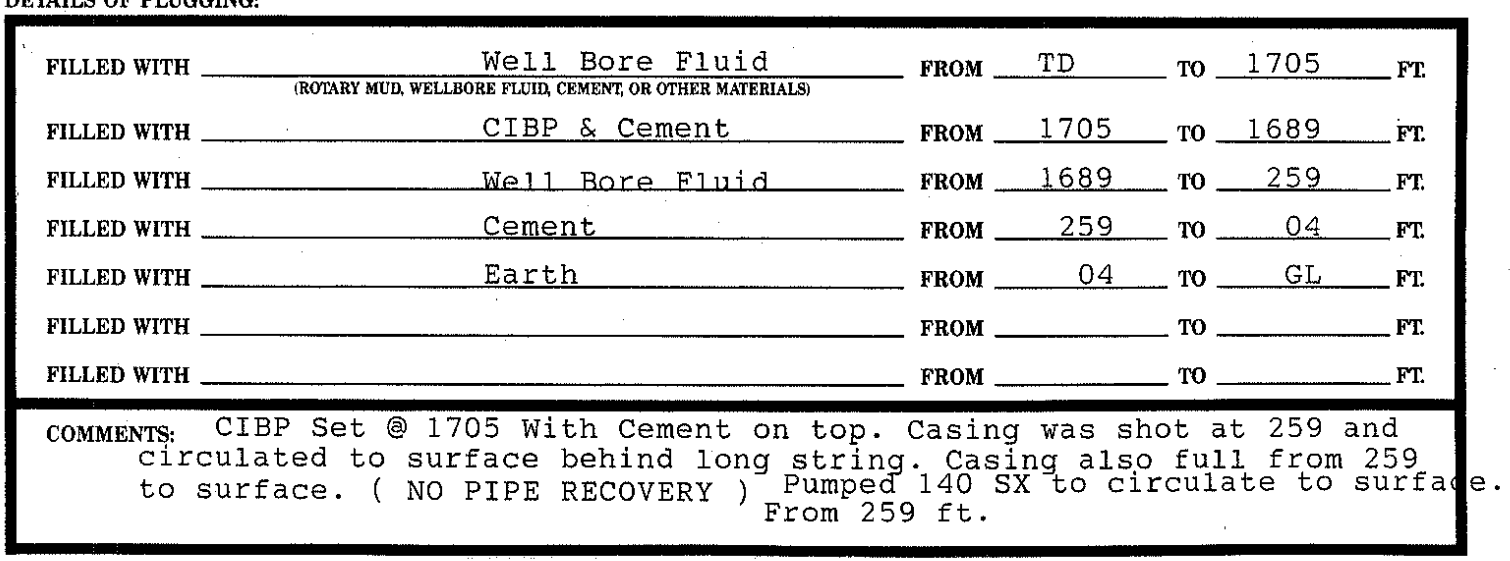

WELL DATA:

\begin{tabular}{|l|c|c|c|c|c|c|}
\hline \multicolumn{1}{|c|}{ CASING } & SIZE & $\begin{array}{c}\text { SETTING } \\
\text { DEPTH }\end{array}$ & $\begin{array}{c}\text { SACKS } \\
\text { CEMENT }\end{array}$ & $\begin{array}{c}\text { HOLE } \\
\text { SIZE }\end{array}$ & $\begin{array}{c}\text { EST TOP OF } \\
\text { CEMENT }\end{array}$ & $\begin{array}{c}\text { AMOUNT OF } \\
\text { CASING REMOVED }\end{array}$ \\
\hline SURFACE & $85 / 8$ & 119 & N/A & N/A & N/A & 4 \\
\hline $\begin{array}{l}\text { INTERMEDIATE /MINE } \\
\text { STRING / OR LINER }\end{array}$ & & & & & & \\
\hline \begin{tabular}{l} 
PRODUCTION \\
\hline
\end{tabular} & $51 / 2$ & 1870 & N/A & N/A & N/A & 4 \\
\hline
\end{tabular}

UNDER PENALTIES OF PERJURY, I DECLARE THAT I HAVE EXAMINED THIS FORM INCLUDING ACCOMPANYING STATEMENTS AND DOCU. MENTS, AND TO THE BESF OF MY KNOWLEDGE, JT IS TRUE, CORRECT, AND COMPLETE.
signature of: Gene Putwer PERMT TTEE OR DESIGNEE /950 sunset RD ADDRESS Sunset RD. PO BOX 402 $\frac{\text { Clay City IL. } 62824}{\text { CITY, STATE }}$
IL 472-0198 (Rev 8/93)

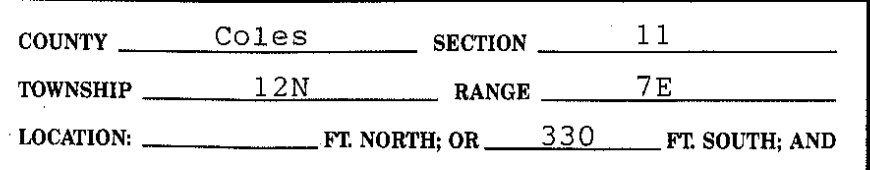
QUARTER OF THE QUARTER OF THE SW QUARTER OF THE

\section{Mattion}



do depose and say the following is a true and correct statement of the details of the plugging of a certain well do depose and say the following is a true and cor

known as the

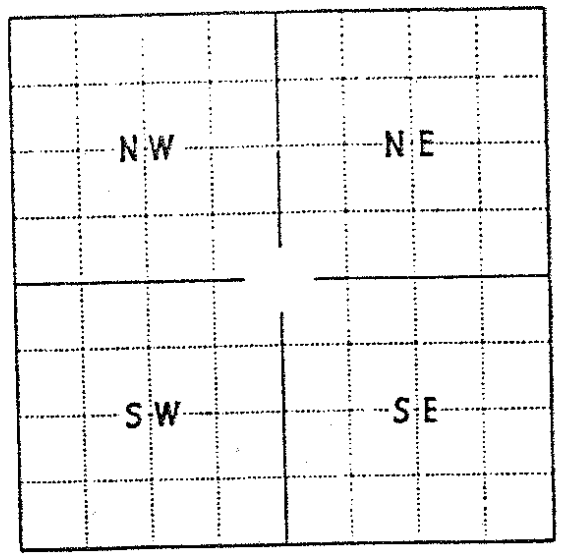

Locate well accurately on plat of section (Scale one inch- $-2,000 \mathrm{ft}$.
$1650 \mathrm{ft}$ south; 1650 ft. east;__ft. west of the NW corner of the Quarter of the Q____uarter of the_Quarter of Section II Township 12 (North Range_ 7 (East of the Principal Meridian, Coles_County, Illinois. Elevation above sea level is $\left\{\begin{array}{l}\text { Derrick Floor } \frac{702}{699} \mathrm{ft} . \\ \text { Ground } \mathrm{ft} .\end{array}\right.$ Total depth 1995 Formationspar mountain Date permit to drill issued $5-8-8 /$ Permit No. $14 / 88$ Permit issued to Charles firmantrout Date drilling began $9(4 / 8)$

Date drilling completed $q / 6 / 8)$

Kind of drilling tools used potary

Date plugging began $6 / 23 / 89$

Date plugging completed $6 / 24 / 89$
Lessor Gorton W Taylor Lessee Charles Armantrout Drilling Contractor Depoister Drlg
Address Mattoon II

Address Mattoon II Address Effing hand I

\section{Demaits of PLugging:}

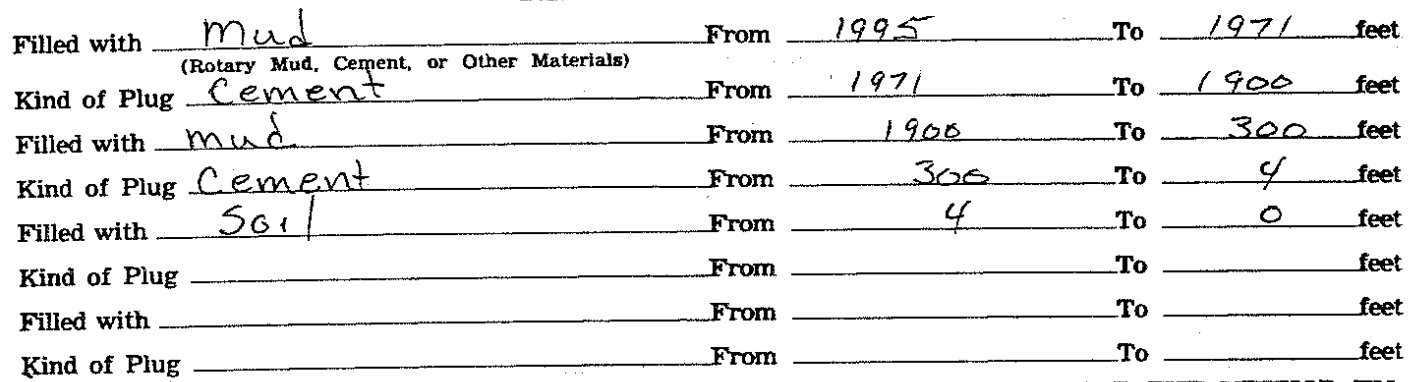

IF WORKABLE COAL BEDS WERE ENCOUNTERED IN THIS HOLE, DESCRIBE THE METHOD EMIF WORE TO PROTECT SAME. (A workable coal bed is thirty inches or more in thickness above 1,000 feet in depth) None

(1) Have pits and other excavations been flled?..........
(2) Have the following been removed?

\section{No Concrete bases

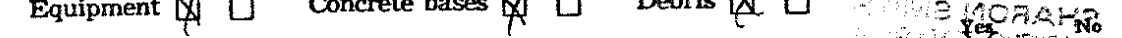

(3) Has surface casing been cut of three feet below ground surface?

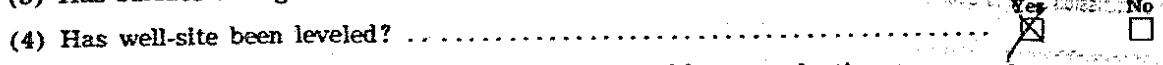

If this was a producing well, give date and amount of last production

\section{CESENG RECORD}

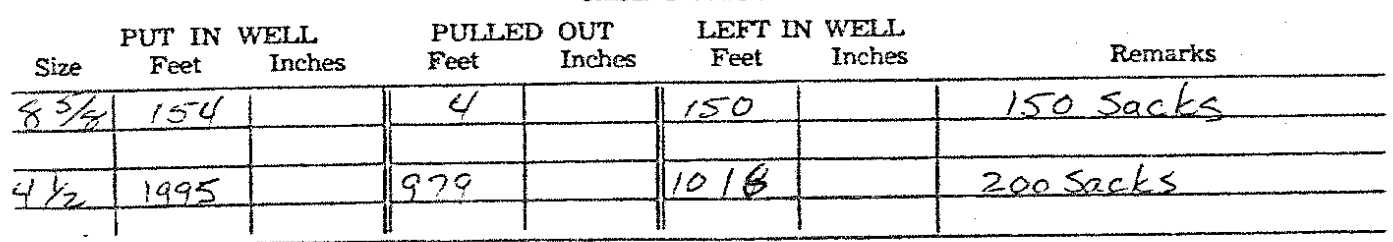

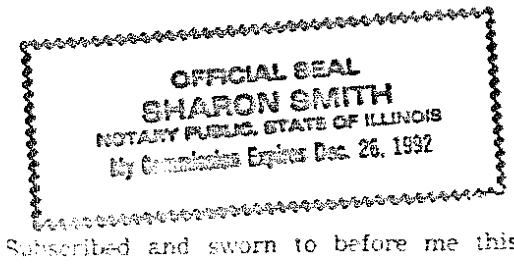

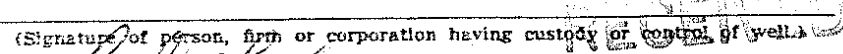
Perfinesteft

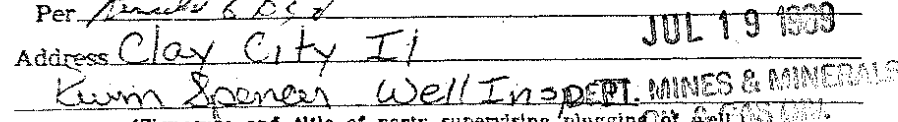

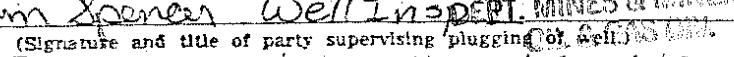
Adores Box 449 noartinsville I) 62442 3 A.D. $19 \leq$ 
$8-1$
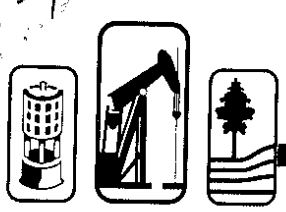

ILLINOIS DEPARTMENT OF MIN
OIL AND GAS DIVISION
(217) 782-7756

\section{OG-6 WELL PLUGGING REPORT}

TYPE OF WELL: \PRODUCTION $\square$ CLASS II $\square$ OBSERVATION $\square$ GAS STORAGE $\square$ REPLUG $\square$ OTHER AND MINERALS

W. JEFFERSON - SUITE 300

P.O. BOX 10140

SPRINGFIELD, IL 62791 -0140 permitree: B./l U. Sledge WELL NAME: VANLANing ham-Batzs

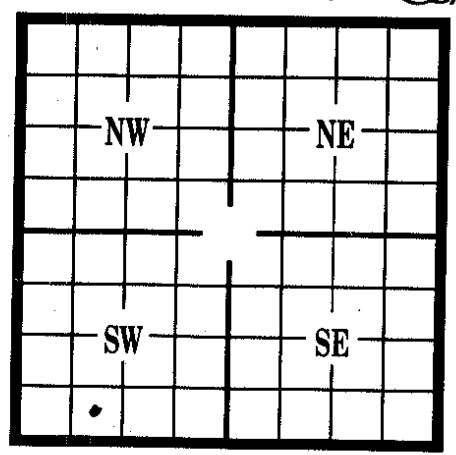
PERMITTEE No. 2209 REFERENCE NO. 112708

\section{5}

WELL DATA:

SURFACE ELEVATION

TOTAL DEPTH OF WELL

PLUGGED BACK TOTAL DEPTH

BASE OF FRESHWATER ZONE

WORKABLE COALS PRESENT AT

\begin{tabular}{c|}
$\frac{734}{1985}$ \\
\hline 1969 \\
\hline 184 \\
\hline 14
\end{tabular}

SECTION $/ 1$

TOWNSHIP $\frac{12 N}{\text { LOCATION: RANGE }}$ 990 FT. EAST; OR FT. WEST OF THE NLS CORNER OF THE SL S Q QUARTER OF THE SLU QUARTER OF THE QUARTER OF THE

QUARTER.

mattoon

DESCRIBE PREVIOUS PLUGBACK PROCEDURE:

DETAILS OF PLUGGING:

\begin{tabular}{|c|c|}
\hline FILLED WITH $\subseteq \varepsilon m \sum_{\text {(ROTARY MUD, WELLBORE FLEID, CEMENT, OR OTHER MATERIALS) }}$ & FROM 1969 To 1618 FT. \\
\hline FILLED WITH Le2E\| bore $t$ huid & FROM 1618 To 250 \\
\hline FILLED WITH $C \varepsilon m \varepsilon n t$ & FROM 250 T0 4 \\
\hline FILLED WITH ofop sol & FROM -4 To suRfACE FT. \\
\hline FILLED WITH & FROM \\
\hline FILLED WITH & FROM $\_$TO \\
\hline FILLED WITH & FROM \\
\hline COMMENTS: & \\
\hline
\end{tabular}

WELL DATA:

\begin{tabular}{|l|c|c|c|c|c|c|}
\hline \multicolumn{1}{|c|}{ CASING } & SIZE & $\begin{array}{c}\text { SETTING } \\
\text { DEPTH }\end{array}$ & $\begin{array}{c}\text { SACKS } \\
\text { CEMENT }\end{array}$ & $\begin{array}{c}\text { HOLE } \\
\text { SIZE }\end{array}$ & $\begin{array}{c}\text { EST. TOP OF } \\
\text { CEMENT }\end{array}$ & $\begin{array}{c}\text { AMOUNT OF } \\
\text { CASING REMOVED }\end{array}$ \\
\hline SURFACE & $103 / 4$ & 125 & NR & NR & & $4 /$ \\
\hline $\begin{array}{l}\text { INTERMEDIATE /MINE } \\
\text { STRING / OR LINER }\end{array}$ & & & & & & \\
\hline \begin{tabular}{l} 
PRODUCTION \\
\hline
\end{tabular} & $5 / 2$ & 1945 & $N R$ & $7 / 8$ & & 300 \\
\hline
\end{tabular}

UNDER PENALTIES OF PERJURY; I DECLARE THAT I HAVE EXAMINED THIS FORM INCLUDING ACCOMPANYING STATEMENTS AND DOCU. MENTS, AND TO THE BEST OF MY KNOWLEDGE, IT IS TRUE, CORRECT, AND COMPLETE.

SIGNATURE OF: $\begin{aligned} & \text { PERMITTEE OR DESIGNEE } \\ & \text { ADDRESS }\end{aligned}$
CITY, STATE 
County of Dounding

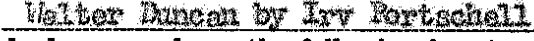

being first duly sworn do depose and say the following is a true and correct statement of the details of the plugging of a certain well drilled for $\$ 2$

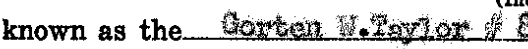

Inalcate whether for oll, gas, water or other purposes)

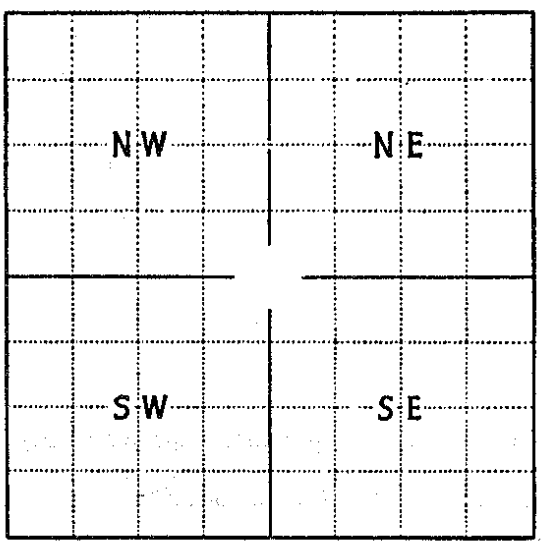

Locate well accurately on plat of section Scale one inch-2,000 ft.) and located as follows:

ft. north; 920 ft. south; 290 ft. east; ft. west of the corner of the Quarter of the_____ Quarter of the______uarter of Section 11 , Township 11 (North or Range I (East or , n

Principal Meridian, County, Illinois. Elevation above sea level is $\begin{cases}\text { Derrick Floor } & \mathrm{ft} . \\ \text { Ground } & 697\end{cases}$ Total depth $17 \mathrm{~L}$ _.... Formation Rejo Date permit to drill issued 10/20/69 ermit No. 1326 Permit issued to Date drilling began $1 / / 7 / 63$

Date drilling completed $11 / 1160$

Kind of drilling tools used

Date plugging began $\quad 11 / 12 / 6$

Date plugging completed $11 / 12 / 6$

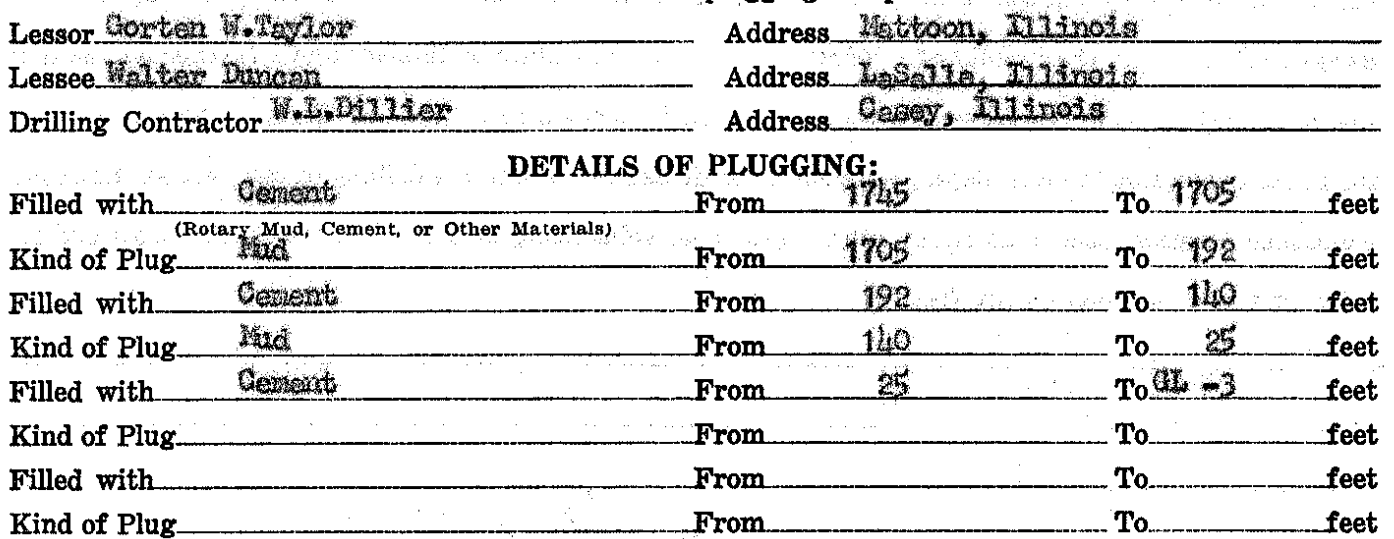

IF WORKABLE COAL BEDS WERE ENCOUNTERED IN THIS HOLE, DESCRIBE THE METHOD EMPLOYED TO PROTECT SAME. (A workable coal bed is thirty inches or more in thickness above 1,000 feet in depth) (ooz atelavet butgad

(1) Have pits and other excavations been filled $\ldots \ldots \ldots \ldots \ldots \ldots \ldots$ ros

(2) Have the following been removed?

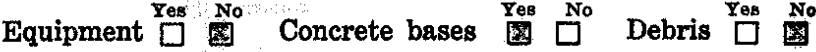

(3) Has surface casing been cut off three feet below ground surface?

(4) Has well-site been levelled?

If this was a producing well, give date and amount of last production

CASING RECORD

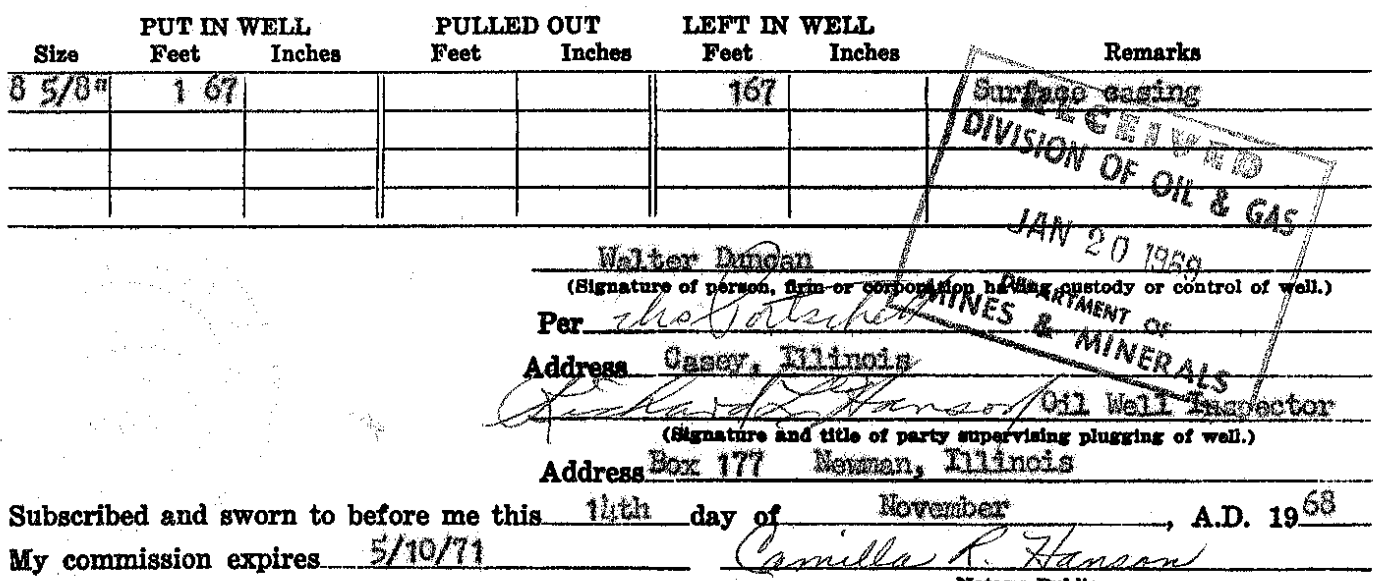


2. R. ClIFron -. state pall Inspecto $x$

being first duly sworn do depose and say the following is a true and correct statement of the details of the plugging of a certain well drilled for orr.

known as the M. B. Hate inar 3 (Indlcate whether for oll, gas, water or other purposes)

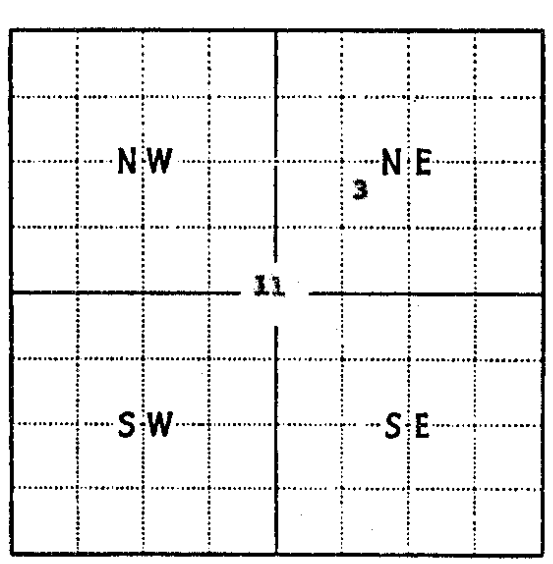

Locate well accurately on plat of section (Scale one inch-2,000 ft.) and located as follows:

-ft. north;

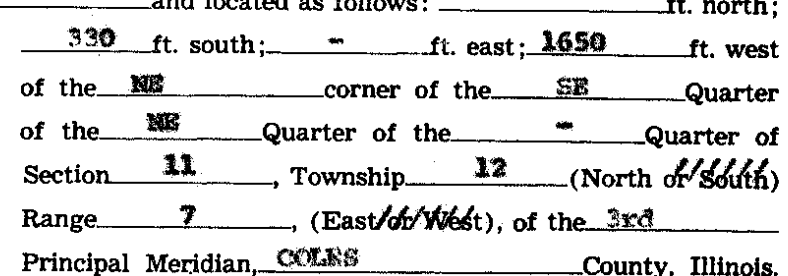

Principal Meridian, otwats County, Illinois.

Elevation above sea level is $\left\{\begin{array}{l}\text { Derrick Floor } \\ \text { Ground }\end{array}\right.$

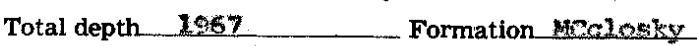

Date permit to drill issued $12 / 19 / 45$ Permit No. 1991 Permit issued to HIIItn $\mathrm{s}_{\text {. }}$.

Date drilling began $\quad \mathbf{I - 0 8 - 8 6}$

Date drilling completed__n

Kind of drilling tools used noway

Date plugging began. 11-01.-86

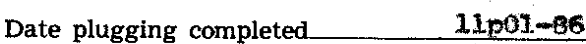

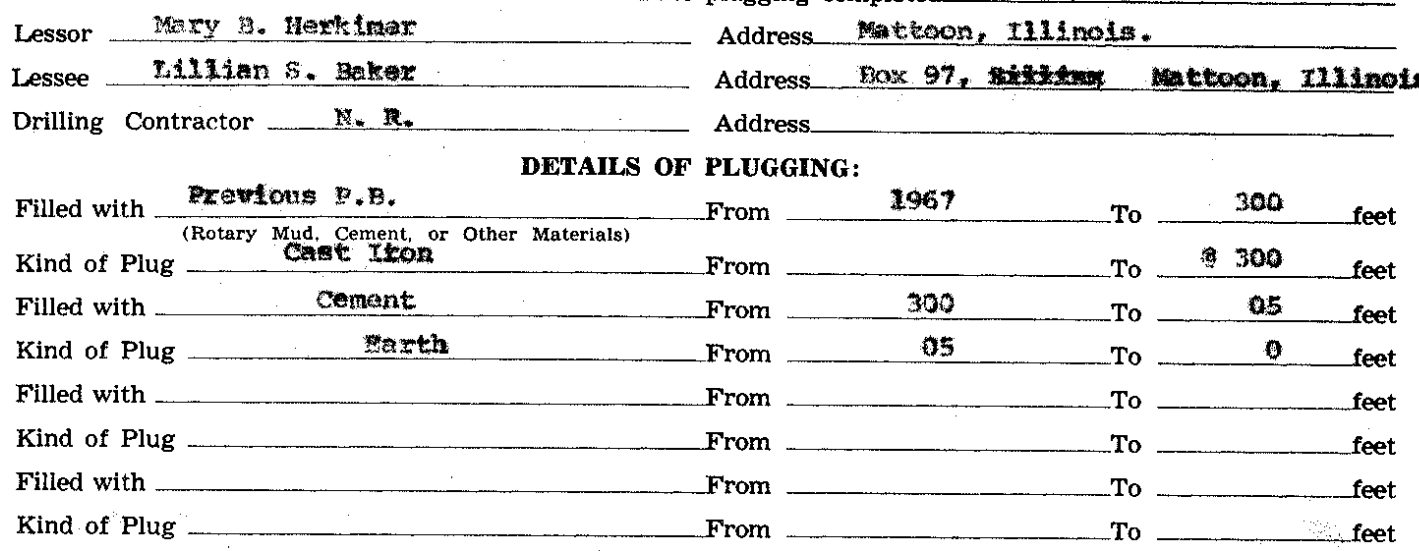

IF WORKABLE COAL BEDS WERE ENCOUNTERED IN THIS HOLE, DESCRIBE THE METHOD EMPLOYED TO PROTEC"T SAME. (A workable coal bed is thirty inches or more in thickness above 1,000 feet in depth)

(1) Have pits and other excavations been filled?............... $\square$

(2) Have the following been removed?
Equipment Yes No
Concrete bases $\mathrm{Yes}$
Debris Yes No

(3) Has surface casing been cut off three feet below ground surface?

(4) Has well-site been leveled?

If this was a producing well, give date and amount of last production

\begin{tabular}{|c|c|c|c|c|c|c|c|}
\hline \multicolumn{8}{|c|}{ CASING RECORD } \\
\hline \multirow[b]{2}{*}{ Size } & \multirow{2}{*}{$\begin{array}{c}\text { PUT IN } \\
\text { Feet }\end{array}$} & \multirow{2}{*}{$\begin{array}{l}\text { WELL } \\
\text { Inches }\end{array}$} & \multirow{2}{*}{$\begin{array}{l}\text { PULLED } \\
\text { Feet }\end{array}$} & \multirow{2}{*}{$\begin{array}{l}\text { OUT } \\
\text { Inches }\end{array}$} & \multicolumn{2}{|c|}{ LEFT IN WELL } & \multirow[b]{2}{*}{ Remarks } \\
\hline & & & & & Feet & Inches & \\
\hline $19-3 / 4$ & 88 & - & 5 & $\Rightarrow$ & 83 & - & \\
\hline $7 \%$ & 1916 & - & 5 & $=$ & 191 & - & \\
\hline & & & & & & & \\
\hline
\end{tabular}

stagesar o, Company

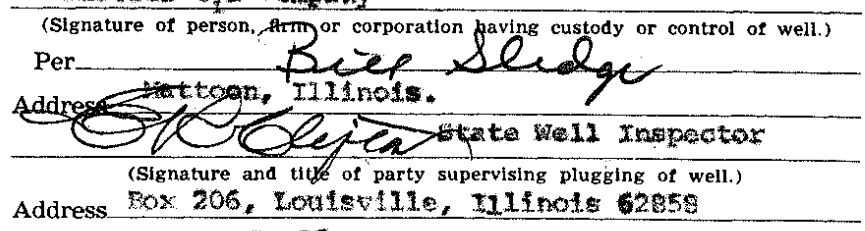

Subscribed and sworn to before me this 3 ra day of $29-3$ -

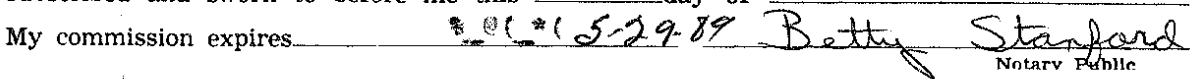


County of cotestos WELL PLUCCING AFFIDAVI

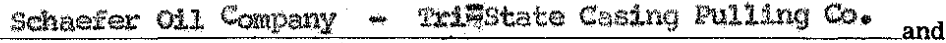

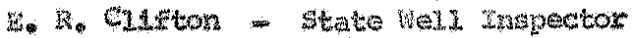
being first duly sworn, do depose and say the following is a true and correct statement gf the details of the plugging of a certain well

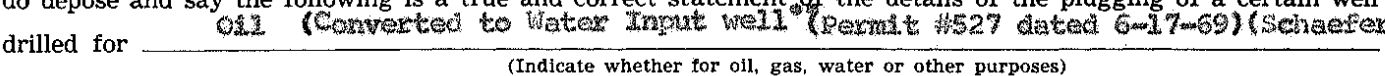
ous

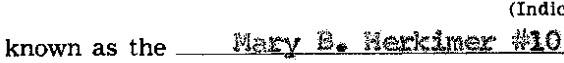
and located as follows:

ft. north;

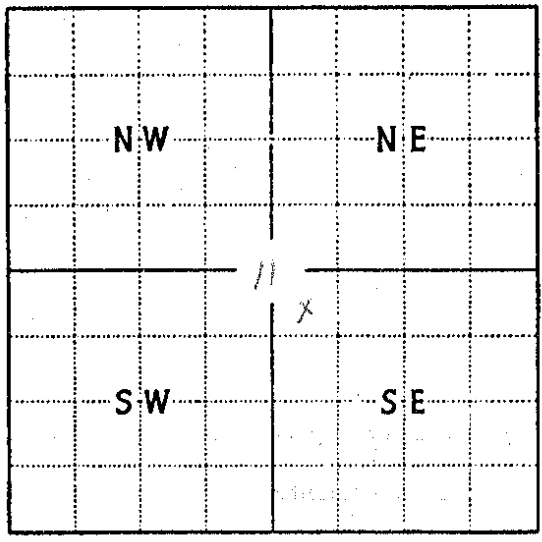

Locate well accurately on plat of section (Scale one inch-2, $2,000 \mathrm{ft}$.) - 390 ft. south;___ft. east; 900 ft. west of the corner of the con of the Se Quarter of the___ Quarter of Section 11 , Township_ 12 (North 64/S646h)

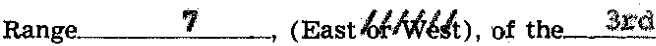

Principal Meridian, Col, County, Illinois. Elevation above sea level is $\begin{cases}\text { Derrick Floor } 6704 \mathrm{ft} . \\ \text { Ground } & \mathrm{ft} .\end{cases}$ Total depth $1975 \quad$ Formation Rostatelare

- Date permit to drill issued ${ }^{32 / 22 / 44}$ Permit No. 2176

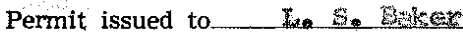
Date drilling began. $12 \mathrm{~m} 23 \mathrm{~m}$.

Date drilling completed 1

Kind of drilling tools used Syotary

Date plugging began $\quad 8-75$

Date plugging completed $9 \mathrm{~m}$

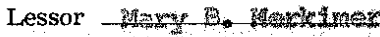

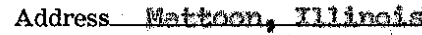

Lessee L. S. Stater Address Matroon, 1121200

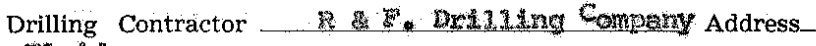
vindo

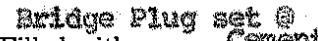
Filled with $\frac{\text { comente }}{\text { (Rotary Mud, C C }}$ (Rotary Mud, Cement, or Other Materials) . Kind of Plug _ _

PLUGGING: From

.
From 1000To 250 feet Filled with contente From 250 To 200 feet

Kind of Plug Mas From $200 \mathrm{To}$ 115 feet

Filled with

centent

From $115 \mathrm{To}$ 85 feet

Kind of Plug Miso

From a $T$

12 feet

Filled with Centent

From

12 To

os feet

Sath $\quad 03$ To 0 From feet IF WORKABLE COAL BEDS WERE ENCOUNTERED IN THIS HOLE, DESCRIBE THE METHOD EMPLOYED TO PROTECT SAME. (A workable coal bed is thirty inches or more in thickness above 1,000 feet in depth) Won encountered

(1) Have pits and other excavations been filled?

(2) Have the following been removed?
Equipment Yes No
Concrete bases $\stackrel{\text { Yes }}{\square}$ No
Debris $\stackrel{\text { Yes }}{\square} \stackrel{\text { No }}{\square}$

(3) Has surface casing been cut off three feet below ground surface?

(4) Has well-site been leveled? . . . . . . . . . . . . . . . . . . . .

If this was a producing well, give date and amount of last production Wetcet. Irroute

\section{CASING RECORD}

\begin{tabular}{|c|c|c|c|c|c|c|c|}
\hline Size & $\begin{array}{l}\text { PUT IN } \\
\text { Feet }\end{array}$ & $\begin{array}{l}\text { WELL } \\
\text { Inches }\end{array}$ & $\begin{array}{l}\text { PULI } \\
\text { Feet }\end{array}$ & $\begin{array}{l}\text { OUT } \\
\text { Inches }\end{array}$ & $\begin{array}{c}\text { LEFT } \\
\text { Feet }\end{array}$ & $\begin{array}{l}\text { WELL } \\
\text { Inches }\end{array}$ & Remarks \\
\hline \multirow[t]{2}{*}{$10 \cdot 9 / 4$} & 104 & - & 3 & - & 101 & ;is & 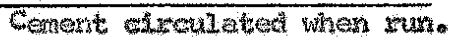 \\
\hline & & & & & & & $\ldots$ \\
\hline \multirow[t]{2}{*}{$\overline{7^{\prime \prime}}$} & 2920 & - & 3 & - & 1917 & 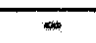 & 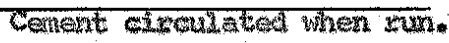 \\
\hline & & & & & & & \\
\hline
\end{tabular}

PECEVED DIVISTCN OR OU. Q GAS

$$
\text { AUG } 131975
$$

DHARMERT OH MWE M MUERES

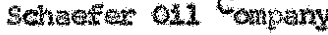

(Signature of person, firing or corporation having custody or control of well.) Per $\quad x_{2}<2$

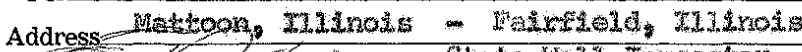

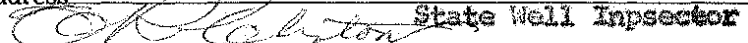
(Signature and title of party supervising plugging of well.)

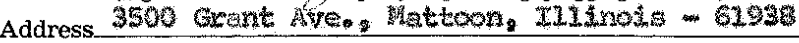

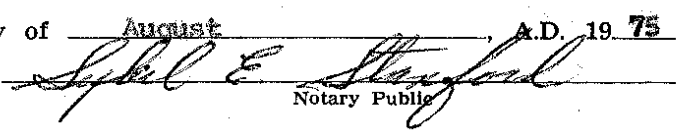


筑. WL being first duly sworn do depose and say the following is a true and correct statement of the details of the plugging of a certain well drilled for ats.

known as the Hariets (Indicate whether for oil, gas, water or other purposes)

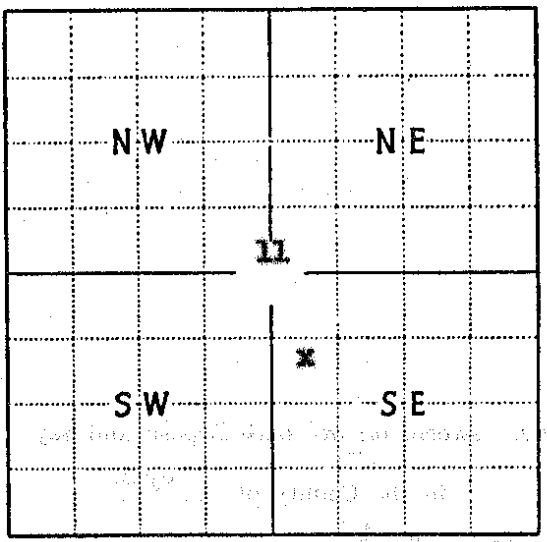

Locate well accurately on plat of section (Scale one inch-2, $2,000 \mathrm{ft}$.)

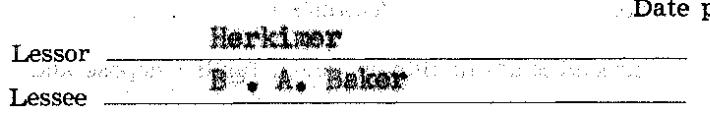
and located as follows: __ $330 \quad \mathrm{ft}$. north; ft. south; $\quad 330$ ft. east; ft. west of the Sor corner of the cuarter of the St 11 Quarter of the 12 Quarter of Range_ 7 , (East of 164 sth, of the $3 r$. Principal Meridian,_Cold County, Illinois. Elevation above sea level is $\begin{cases}\text { Derrick Floor } & \mathbf{7 1 3} \\ \text { Ground } & \mathrm{ft} .\end{cases}$

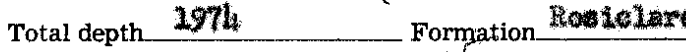
Date permit to drill issued $-26-4$ permit No. 2183 Permit issued to Date drilling began $\frac{1-1-46}{1-164}$ Date drilling completed $\mathbf{1 - 1 6 - 4 6}$ Kind of drilling tools used $\frac{4-1-75}{4-45}$ Date plugging began $\frac{4-1-7}{4-1-75}$

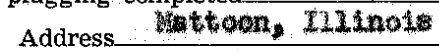

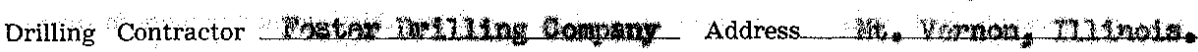

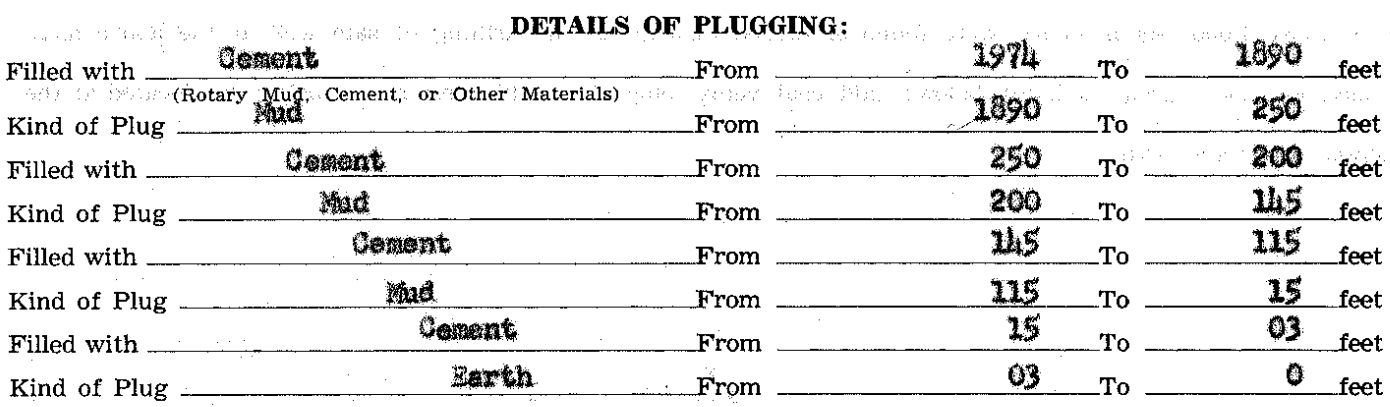
IF WORKABLE COAL BEDS WERE ENCOUNTERED IN THIS HOLE, DESCRIBE THE METHOD EMPLOYED TO PROTECT SAME. (A workable coal bed is thirty inches or more in thickness above 1,000 feet in depth) Wune enconatared

(1) Have pits and other excavations been filled?............... No

(2) Have the following been removed?

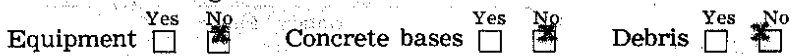

(3) Has surface casing been cut off three feet below ground surface?

(4) Has well-site been leveled?

If this was a producing well, give date and amount of last production imknon

$$
\stackrel{\text { No }}{\square}
$$

\begin{tabular}{|c|c|c|c|c|c|c|c|}
\hline \multirow{3}{*}{$\frac{\text { Size }}{10-3 / 4}$} & \multicolumn{7}{|c|}{ CASING RECORD } \\
\hline & $\begin{array}{c}\text { PUT IN } \\
\text { Feet }\end{array}$ & $\begin{array}{l}\text { WELL } \\
\text { Inches }\end{array}$ & $\begin{array}{l}\text { PULLED } \\
\text { Feet }\end{array}$ & $\begin{array}{l}\text { OUT } \\
\text { Inches }\end{array}$ & $\begin{array}{c}\text { LEFT } \\
\text { Feet }\end{array}$ & $\begin{array}{l}\text { WELL } \\
\text { Inches }\end{array}$ & Remarks \\
\hline & 133 & - & 3 & - & 130 & - & \\
\hline $7^{m}$ & 1924 & & 100 & $=$ & 122 & $=$ & \\
\hline & & & & & & & \\
\hline
\end{tabular}

\section{CASING RECORD}

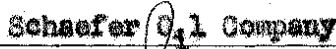

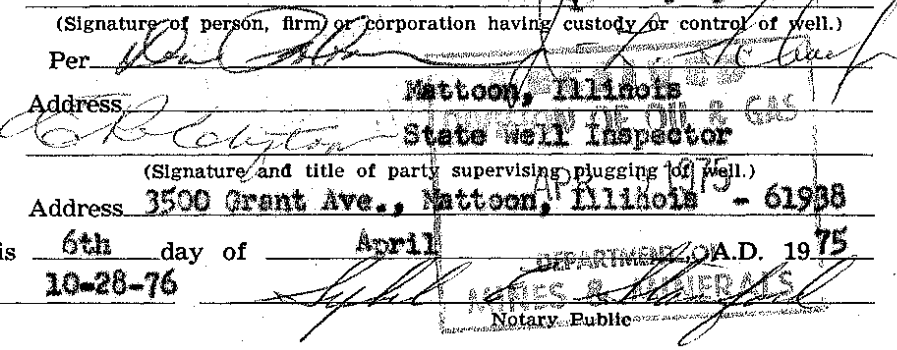

Subscribed and sworn to before me this $\frac{641}{10-28-76}$ day of
My commission expires 
STATE OF TLLNOIS

County of coles

do depose and say the following is a true and correct statement of the details of the plugging of a certain well drilled for ol 1

known as the (Indicate whether Indicate whether for oil, gas, water or other purposes)

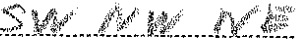

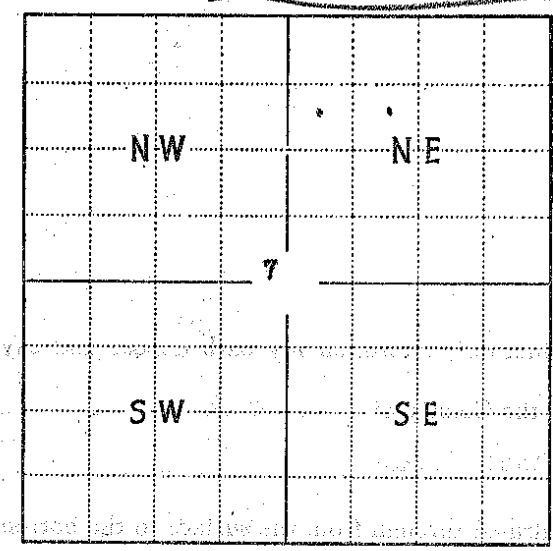

Locate well accurately on plat of section (Scale one inch-2, $000 \mathrm{ft}$.)

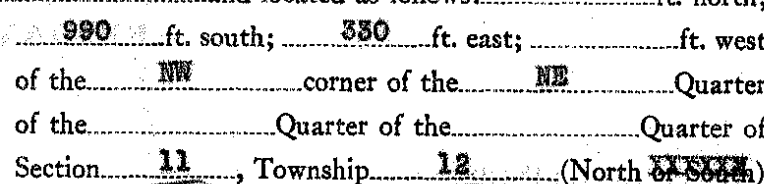

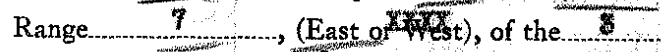

Principal Meridian, Goles

County, Illinois.

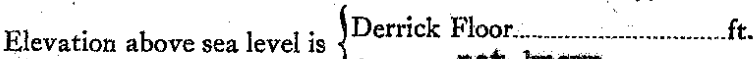

Total depth of well is. 3158 Ground not kanowa

Date permit to drill issued $11-17-45$. Permit No $190 \mathrm{~A}$

Permit issued to Nationel Cona, ol Oo. Ino.

Date drilling began $1-10-46$

Date drilling completed $1-22-46$

Kind of drilling tools used Rotary

Date plugging began $\quad 1+2-52$

Date plugging completed $1-8-8 \mathrm{~g}$

Lessor Hentimer

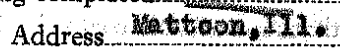

Lessee Hational Conol 1 Co. Ine.

Drilling Contractor Ptotor prulung to.

erra raterest.

(totoon, 111 .

\section{DETAILS OF PLUGGING:}

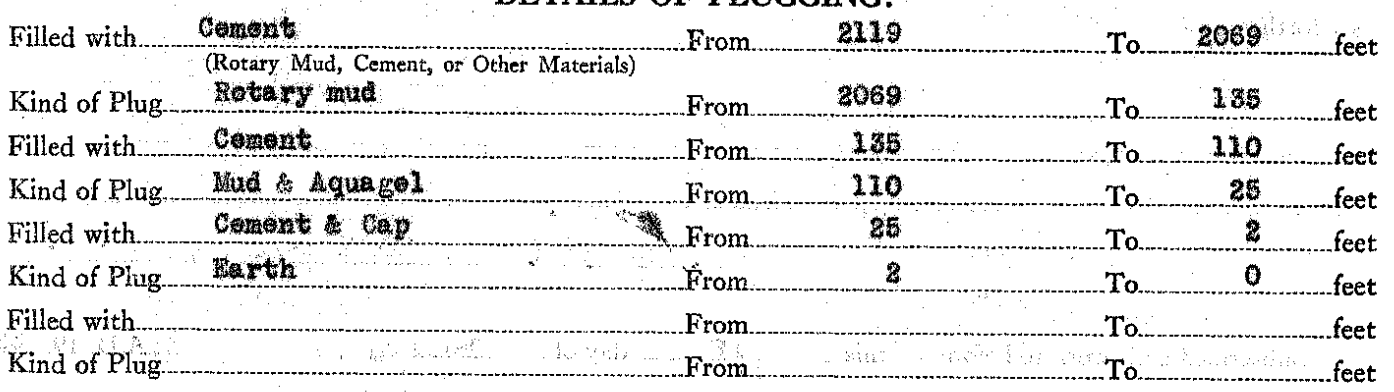

IF WORKABLE COAL BEDS WERE ENCOUNTERED IN THIS HOLE, DESCRIBE THE METHOD EMPLOYED TO PROTECT SAME. (A workable coal bed is thirty inches or more in thickness above 1,000 feet in depth). 10 Coa I oneounterea

(1) Have pits, cellar and other excavations been filled?.....

(2) Have equipment, concrete bases and debris been removed?

(3) Has surface casing been cut off below plow depth?.....

(4) Has well-site been levelled?.

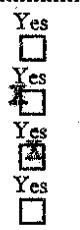

No
$\square_{\text {No }}^{\text {No }}$
$\square$
No

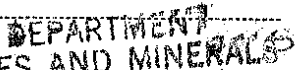

If this was a producing well, give date and amount of last production

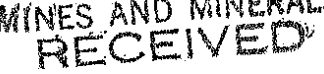

JAW 15 152
DINIS6) ST

CASING RECORD

\begin{tabular}{|c|c|c|c|c|c|c|c|}
\hline \multirow{3}{*}{$\frac{\text { Size }}{103 / 4}$} & \multicolumn{2}{|c|}{ PUT IN WELL } & \multicolumn{2}{|c|}{ PULLED OUT } & \multicolumn{2}{|c|}{ LEFT IN WELL } & \multirow[b]{2}{*}{ Remarks } \\
\hline & Feet & Inches & Feet & Inches & Feet & Inches & \\
\hline & 125 & & & & & & Plug boek frem 3158 to \\
\hline 7 & 1927 & & 886 & & 1041 & & 2119 with lane well plug. \\
\hline 4 & 3150 & & 1641 & & 1509 & & \\
\hline & & & & & & & \\
\hline
\end{tabular}

Velore Blowere Casing Pulling Co.

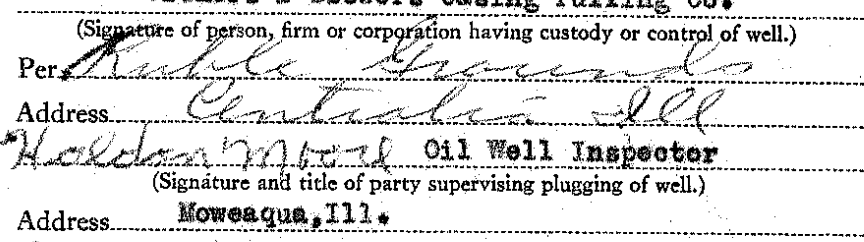

Subscribed and sworn to before me this......... 12 day of Jan Javy 


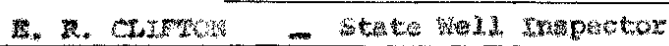

being first duly sworth,
plugging of a certain well drilled for oxt. Indicate whether for oil, gas, water or other purposes) 5. chentex of company

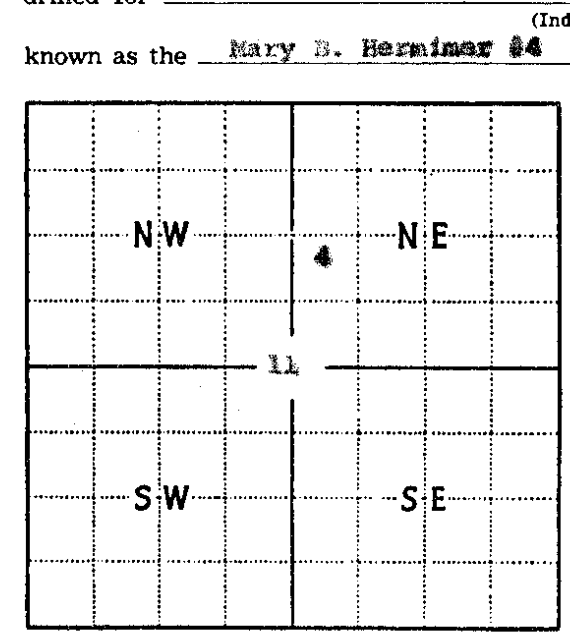

Locate well accurately on plat of section

(Scale one inch-2,000 ft.)

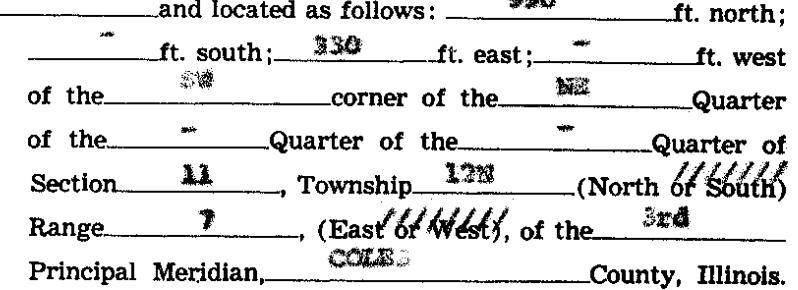

Principal Meridian,__ounty County Ilinois. Elevation above sea level is $\left\{\begin{array}{l}\text { Derrick Floor } \frac{-1}{69} \\ \text { Ground } 69 .\end{array}\right.$ Total depth 1561 Formation Fosictar Date permit to drill issued $11 / 7 / 45$ Permit No. 1802

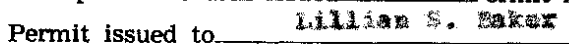

Date drilling began__ n.

Date drilling completed $\quad 11-75-45$

Kind of drilling tools used Retas

Date plugging began 11-01-

Date plugging completed

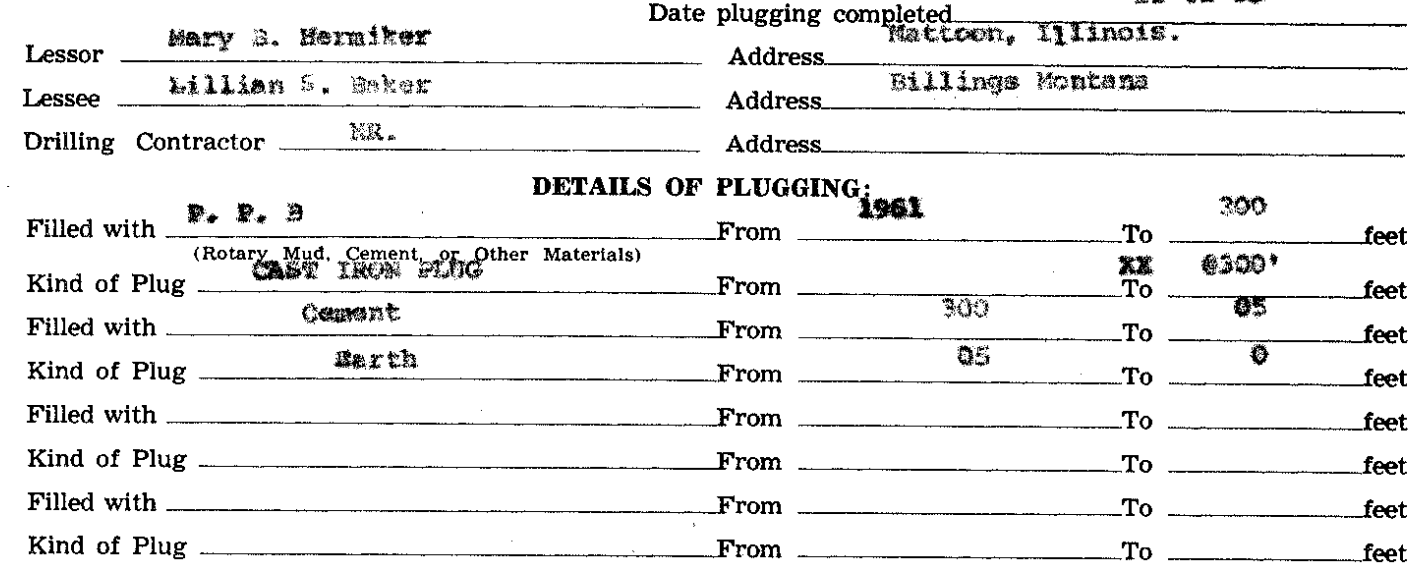

IF WORKABLE COAL BEDS WERE ENCOUNTERED IN THIS HOLE, DESCRIBE THE METHOD EMPLOYED TO PROTECT SAME. (A workable coal bed is thirty inches or more in thickness above 1,000 feet in depth)

(1) Have pits and other excavations been flled?

(2) Have the following been removed?

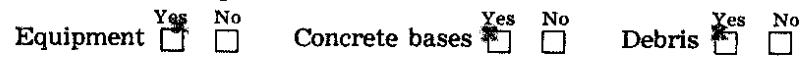

(3) Has surface casing been cut off three feet below ground surface?

(4) Has well-site been leveled?

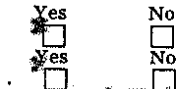

If this was a producing well, give date and amount of last production

10. 1500

CASING RECORD

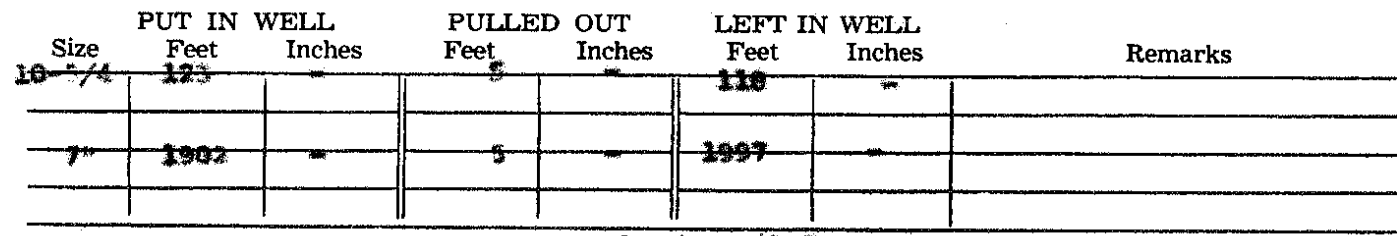

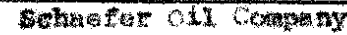

(Signature of,-kersyn, firm or cesporation having custody or control of well.)

Per.

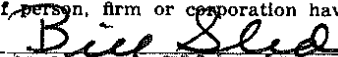

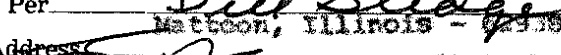

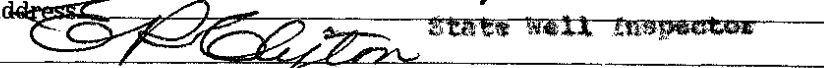

(S1)

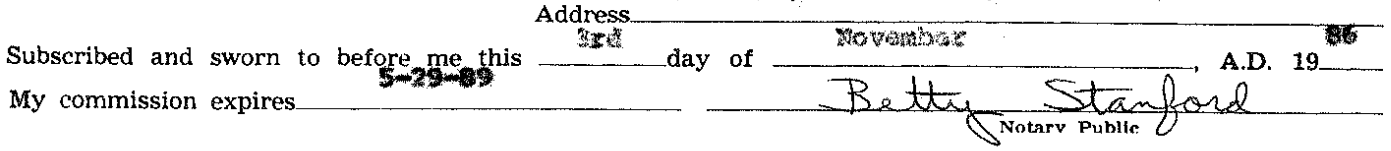


County of Cotesta SS.

2. R. actxprok - stato Well Inspector

being first duly swom do depose and say the following is a true and correct statement of the details of the plugging of a certain well drilled for ors.

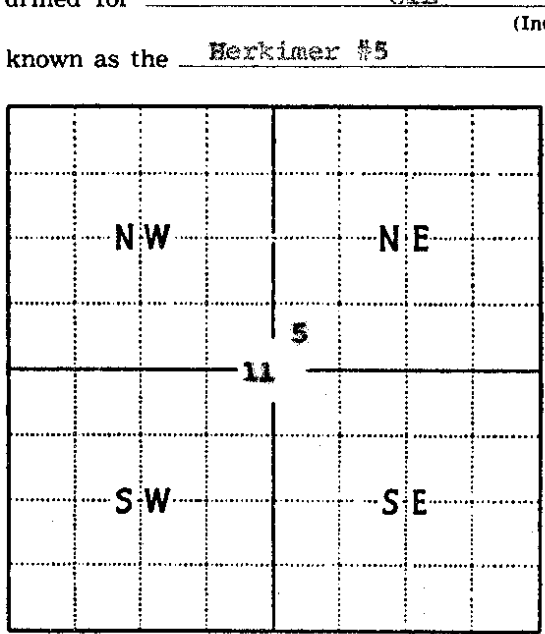

Locate well accurately on plat of section Scale one inch-2,000 ft.)
Indicate whether for oil, gas, water or other purposes) and located as follows:

$$
\text { -ft. south; } 330
$$
t. north;

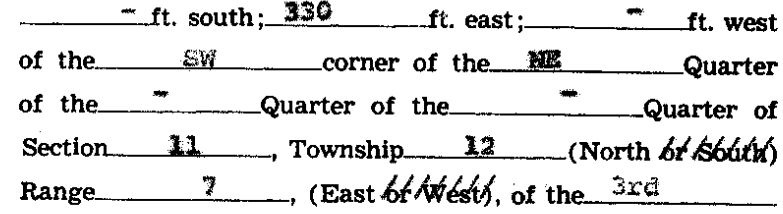

Principal Meridian, cotas County, Illinols.

Elevation above sea level is $\begin{cases}\text { Derrick Floor } & \mathrm{ft} \\ \text { Ground } 700 \quad \mathrm{ft} & \mathrm{ft}\end{cases}$ Total depth 1943 ____ Formation Rosiclaxe

Date permit to drill issued $6-17-60$ Permit No._ 525

Permit issued to Echerer oil comant

Date drilling began $1-27-45-0 \times \operatorname{lot} \cos x+101$ Date drilling completed

Kind of drilling tools used__ Rataxy

Date plugging began $11-01-26$

Date plugging completed_ $11+1=0$

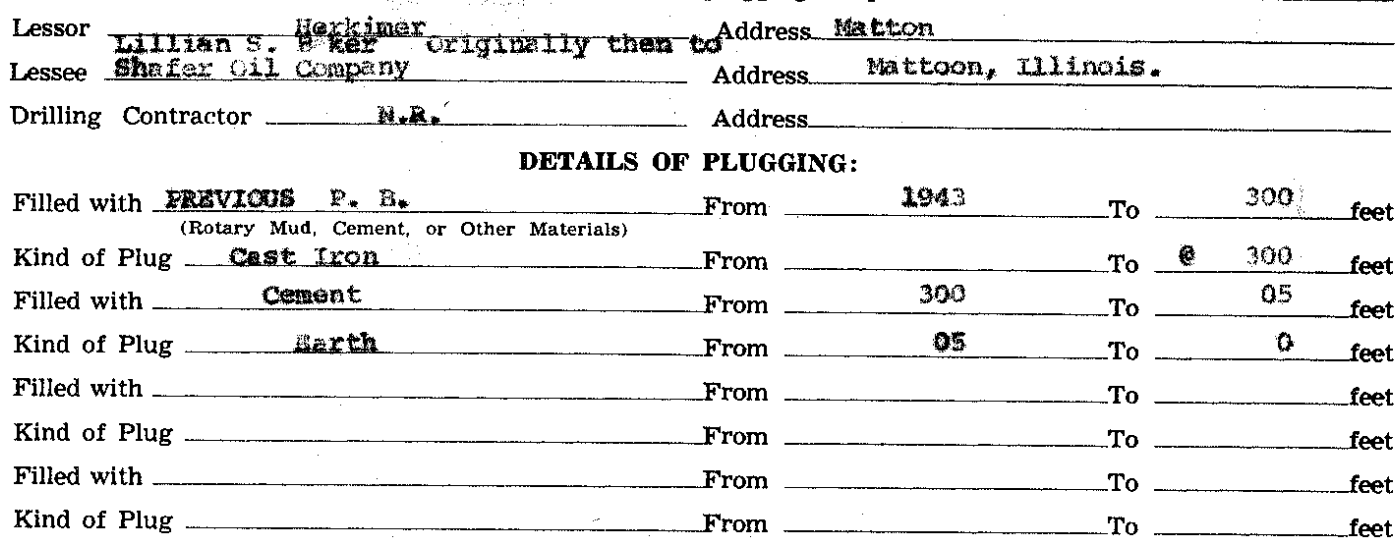

IF WORKABLE COAL BEDS WERE ENCOUNTERED IN THIS HOLE, DESCRIBE THE METHOD EMPLOYED TO PROTECT SAME. (A workable coal bed is thirty inches or more in thickness above 1,000 feet in depth)

(1) Have pits and other excavations been filled? ............... Yes No

(2) Have the following been removed?

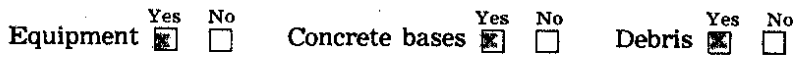

(3) Has surface casing been cut off three feet below ground surface?

(4) Has well-site been leveled?

\begin{tabular}{rr} 
Yes & No \\
Yes & $\square$ \\
\hline
\end{tabular}

If this was a producing well, give date and amount of last production

\begin{tabular}{|c|c|c|c|c|c|c|c|}
\hline \multicolumn{8}{|c|}{ CASING RECORD } \\
\hline Size & $\begin{array}{c}\text { PUT IN } \\
\text { Feet }\end{array}$ & $\begin{array}{l}\text { WELL } \\
\text { Inches }\end{array}$ & $\begin{array}{l}\text { PULLED } \\
\text { Feet }\end{array}$ & $\begin{array}{l}\text { OUT } \\
\text { Inches }\end{array}$ & $\begin{array}{c}\text { LEFT } \\
\text { Feet }\end{array}$ & $\begin{array}{l}\text { WELL } \\
\text { Inches }\end{array}$ & Remarks \\
\hline $10-3 / 4$ & 102 & $=$ & 5 & - & 97 & - & \\
\hline $7^{* t}$ & 1906 & - & 5 & - & xMI & & \\
\hline & & & & & & & \\
\hline
\end{tabular}

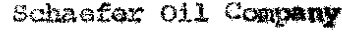

(Signature of nefgon. firm or corpgration having custody or control of well.)

Per B Bes 8 Sese

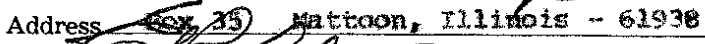

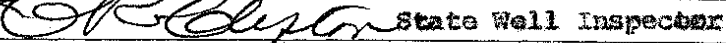

(Signature and title bf party supervising plugging of well.)

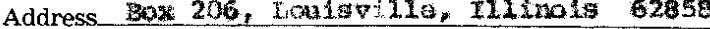

Subscribed and sworn to before me this $\frac{3 \times 0}{3}$ day of _._. Woverabor

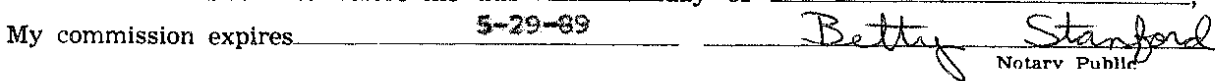


do depose and say the following is a true and correct statement of the detalls of the plugging of a certain well drilled for OII

known as the MARY B. HERKIMER\#9 whether for oll. gas, water or other purposes)

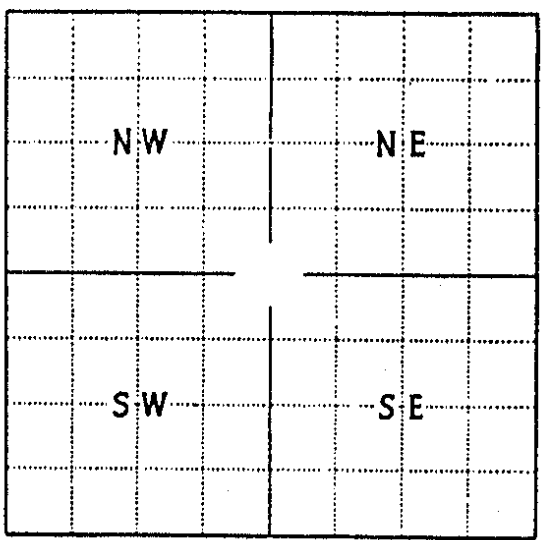
(Scale one inch-2,000 ft.)
Lockte well accurately on plat of section

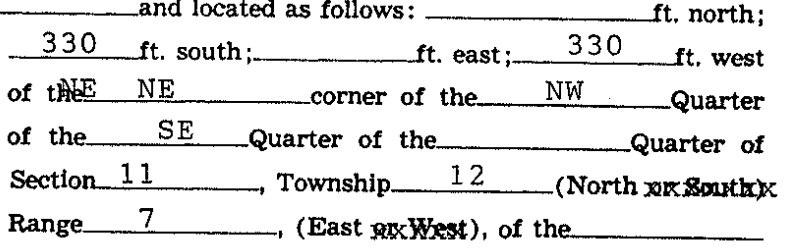

Principal Meridian,__COLES

County, Illinois.

Elevation above sea level is $\left\{\begin{array}{l}\text { Derrick Floor } \\ \text { Ground } f \text { ft. }\end{array}\right.$

Total depth 1957 Formation ROS ICLARE

Date permit to drill issuedl $2 / 26 / 4$ ermit No. 2184

Permit issued to L.S. BAKER

Date drilling began $5 / 13 / 47$

Date drilling completed $5 / 21 / 47$

Kind of drilling tools used $C A B L E$

Date plugging began $11 / 30 / 89$

Date plugging completed SAME

Lessor MARY HERKIMER

Address_MATTOON IL

Lessee L.S. BAKER

Drilling Contractor C.E. CRICK

Address MATTOON IL

Address_MATTOON IL

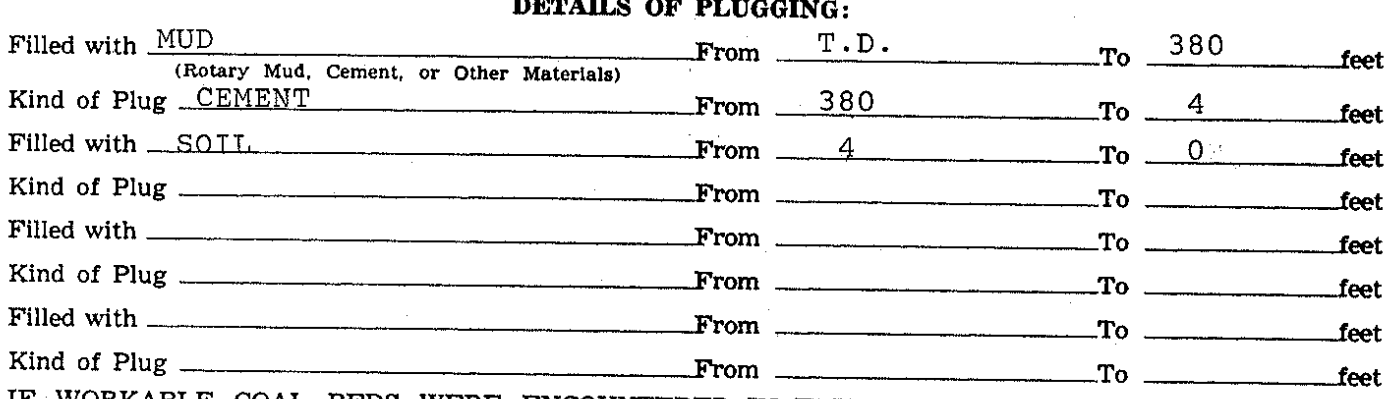

IF WORKABLE COAL BEDS WERE ENCOUNTERED IN THIS HOLE, DESCRIBE THE METHOD EMPLOYED TO PROTECT SAME. (A workable coal bed is thirty inches or more in thickness above 1,000 feet in depth) none encountered

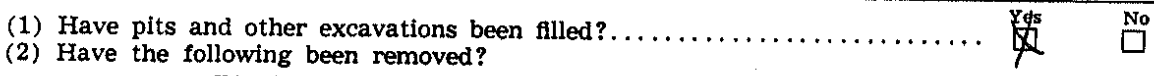

$$
\text { Equipment } \stackrel{\text { No }}{\square} \text { Concrete bases } \square^{\text {No }} \text { Debris }
$$

(3) Has surface casing been cut off three feet below ground surface?

(4) Has well-site been leveled?

If this was a producing well, give date and amount of last production

\section{CASING RECORD}

\begin{tabular}{|c|c|c|c|c|c|c|c|}
\hline Size & $\begin{array}{l}\text { PUT IN } \\
\text { Feet }\end{array}$ & $\begin{array}{l}\text { WELL } \\
\text { Inches }\end{array}$ & $\begin{array}{l}\text { PULLED } \\
\text { Feet }\end{array}$ & $\begin{array}{l}\text { OUT } \\
\text { Inches }\end{array}$ & $\begin{array}{l}\text { LEFT IN } \\
\text { Feet }\end{array}$ & $\begin{array}{l}\text { WELLL } \\
\text { Inches }\end{array}$ & Remarks \\
\hline $10^{3} / 4$ & 106.5 & & 4 & 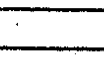 & 102.5 & & Circulated Cemen \\
\hline$z^{i \prime}$ & 1952 & & 4 & & 1953 & & Cla Errecelate \\
\hline
\end{tabular}

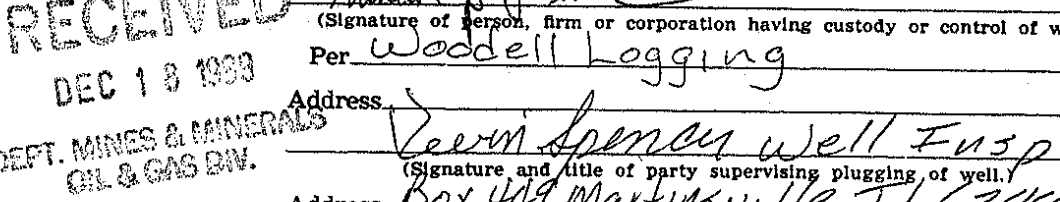

Subscribed and sworn to before me this

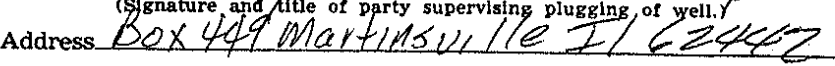



do depose and say the following is a true and correct statement of the details of the plugging of a certain well drilled for____

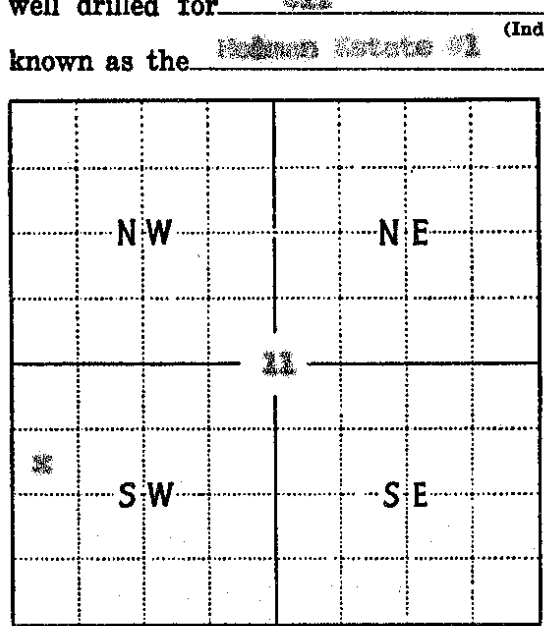

Locate well accurately on plat of section (Scale one inch-2,000 ft.)

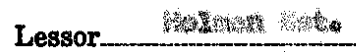

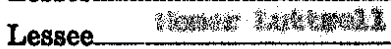

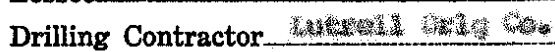

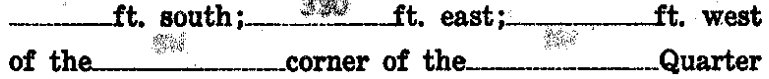
of the ___ Quarter of the Quarter of

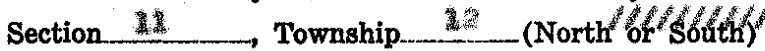

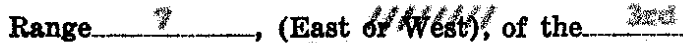

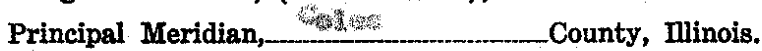

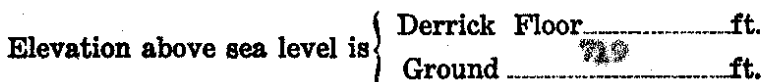

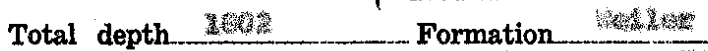
Date permit to drill issued_.

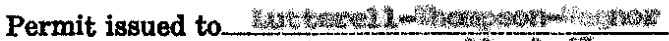
Date drilling began

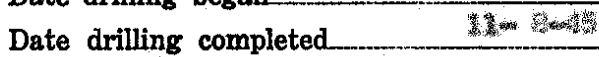

Kind of drilling tools used._.

Date plugging began

Date plugging completed

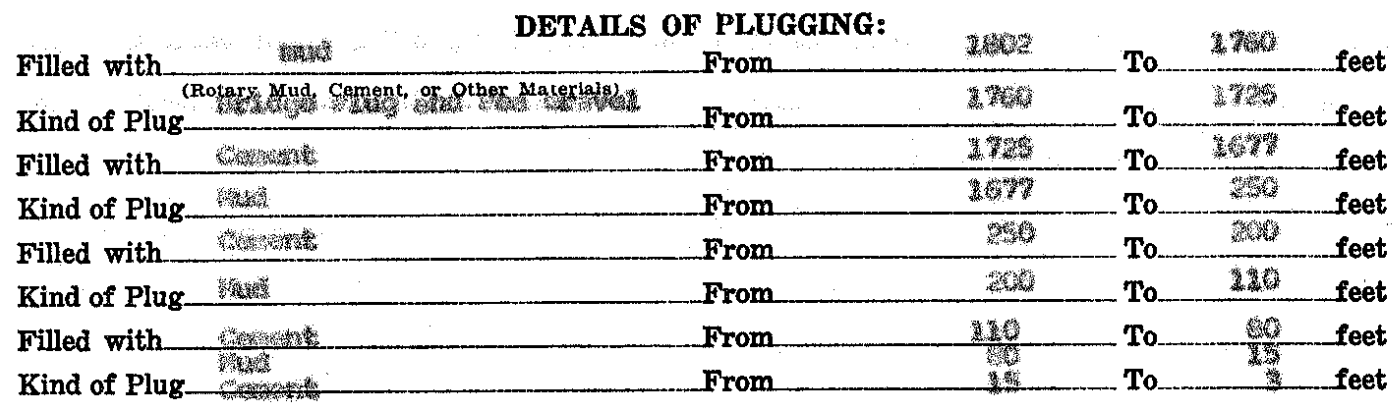

IF WORKABLE COAL BEDS WERE ENCOUNTERED IN THIS HOLE, DESCRIBE THE METHOD EMPLOYED TO PROTECT SAME. (A workable coal bed is thirty inches or more in thickness above (1) 1000 feet in ind

(1) Have pits and other excavations been filled?

Address

Address___.__ W

Address

(1)

(2) Have the following been removed?

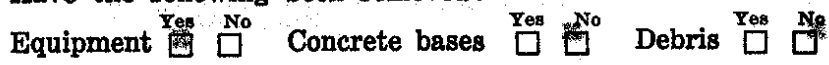

(3) Has surface casing been cut off three feet below ground surface?

(4) Has well-site been levelled?

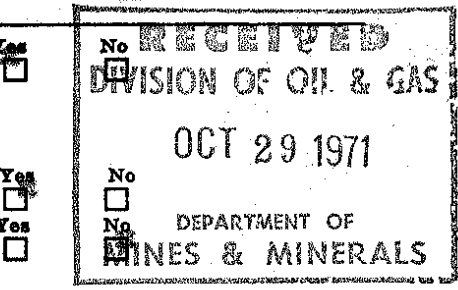

If this was a producing well, give date and amount of last production

CASING RECORD

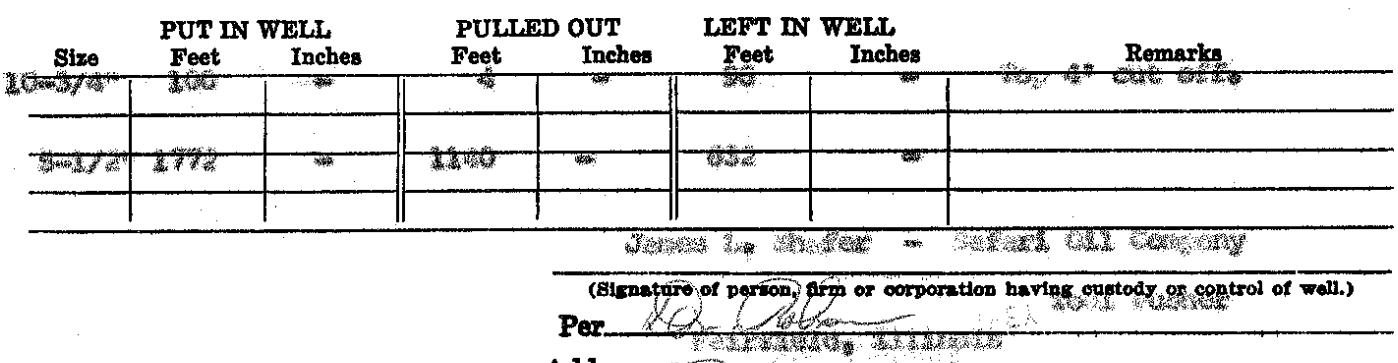

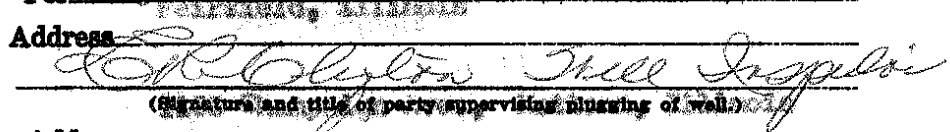

Address. 
Form $0 G-6$

STATE OF ILLINOIS

County of $-\mathrm{Col}$

$$
\text { Jin I. Sehbelep }
$$

and

H. W. Noblit state Vell Inspector

being first duly sworn, do depose and say the following is a true and correct statement of the details of the plugging of a certain well drilled for Q1 I. (Indicate whether for oil. gas, water or other purposes)

known as the Fomam \# I and located as follows: $\quad 330$ ft. north;

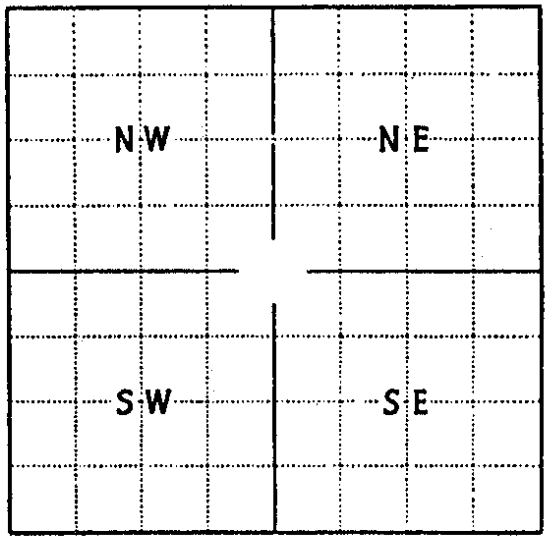

Locate well accurately on plat of section (Scale one inch-2,000 $\mathrm{ft}$.)

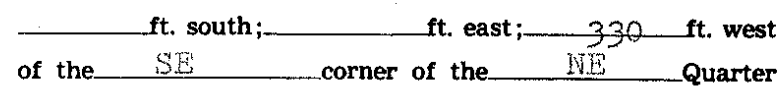

of the SW Quarter of the Q Q Q Q Q Section 11 , Township___ 12 (North or Sojuthy) Range_ 7 , (East or West), of the

Principal Meridian,_._Coles County, Illinois.

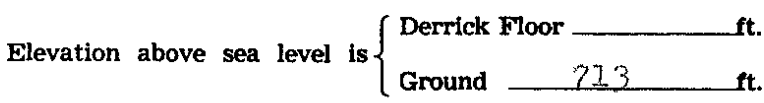
Total depth 1976 Formation Rosiclare Date permit to drill issued $12 / 8 / 6$ Permit No. 2344 Permit issued to Schaeier Oil Company

Date drilling began $\quad 17 / 16 / 63$

Date drilling completed $11 / 25 / 63$

Kind of drilling tools used_r_ Rotary

Date plugging began $\quad 4 / 27 / 82$

Date plugging completed $4 / 27 / 82$

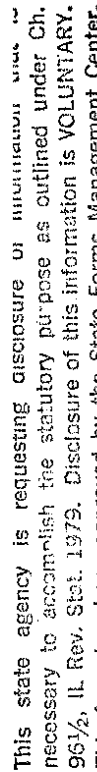

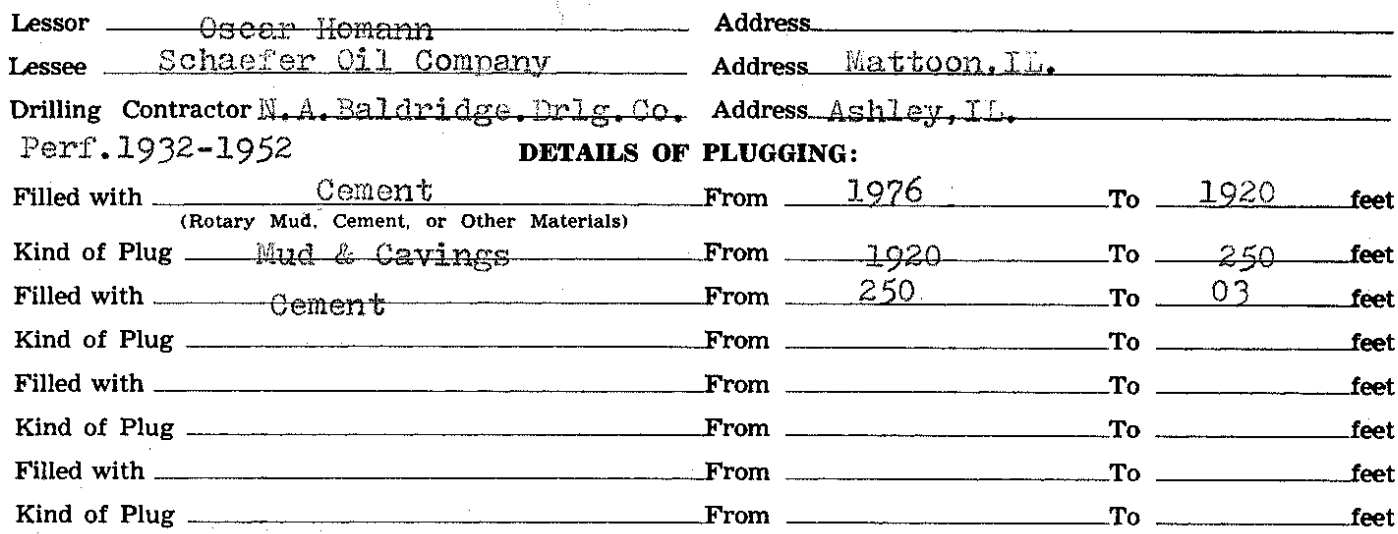

IF WORKABLE COAL BEDS WERE ENCOUNTERED IN THIS HOLE, DESCRIBE THE METHOD EMPLOYED TO PROTECT SAME. (A workable coal bed is thirty inches or more in thickness above 1,000 feet in depth) None

(1) Have pits and other excavations been flled?

(2) Have the following been removed?

Equipment Yes No Concrete bases $\square$ Yes $\square^{\mathrm{No}}$ Debris $\square^{\square} \stackrel{\text { No }}{\square}$

(3) Has surface casing been cut off three feet below ground surface?

(4) Has well-site been leveled?

If this was a producing well, give date and amount of last production

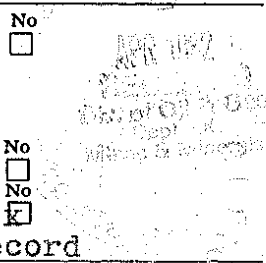

\section{CASING RECORD}

\begin{tabular}{|c|c|c|c|c|c|c|c|}
\hline Size & $\underset{\text { Feet }}{\text { PUT IN }}$ & $\begin{array}{l}\text { WELL } \\
\text { Inches }\end{array}$ & $\begin{array}{l}\text { PULLEI } \\
\text { Feet }\end{array}$ & $\begin{array}{l}\text { OUT } \\
\text { Inches }\end{array}$ & $\begin{array}{c}\text { LEFT } \\
\text { Feet }\end{array}$ & $\begin{array}{l}\text { WELL } \\
\text { Inches }\end{array}$ & Remarks \\
\hline $5 / 8$ & 117 & & 3 & & 114 & & \\
\hline 41 & 1975 & & 1600 & & 366 & & \\
\hline & 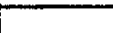 & & & & & & \\
\hline
\end{tabular}

Address $30 \times 35$ ilattoon. II.

MeIl Inspector
(SIgnature and title of party supervising plugging of well.)

Address 402 S. Central Casey, IL.

Subscribed and sworn to before me thisenth day of ApriI My commission expires 


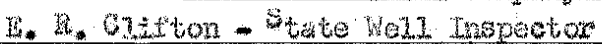
being first duly sworn, do depose and say the following is a true and correct statement of the details of the plugging of a certain well drilled for at drilled for Dins (Indicate whether for oil, gas, water or other purposes)

known as the Homand 3 and located as follows: $330 \quad f t$ north:

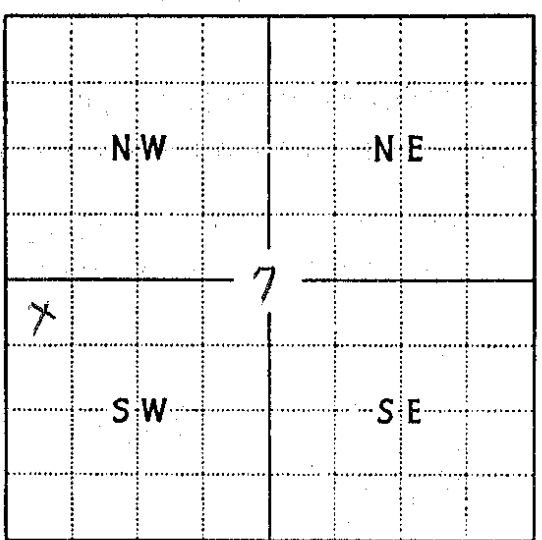

Locate well accurately on plat of section (Scale one inch-2,000 ft.)

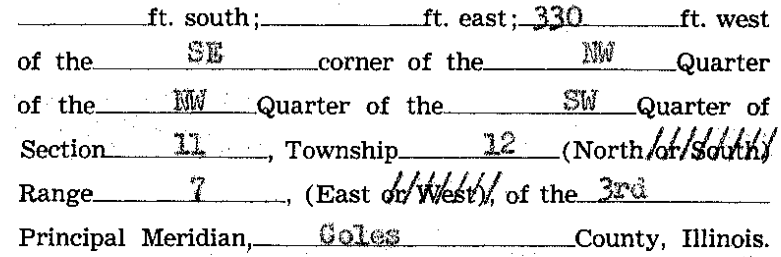

Elevation above sea level is $\left\{\begin{array}{l}\text { Derrick Floor } \frac{7}{72} \mathrm{ft} \\ \text { Ground } \mathrm{ft} .\end{array}\right.$ Total depth $1800 \quad$ Formation WedLers Date permit to drill issued $-13-15$ Permit No. 2838

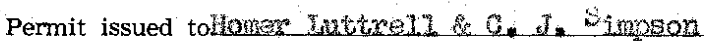
Date drilling began. Unknow

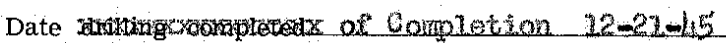
Kind of drilling tools used_. Rotaty Date plugging began $10-13-73$

Date plugging completed $\quad 10-16-73$

Lessor Osont Honara Lessee Honer rutwejy

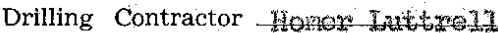

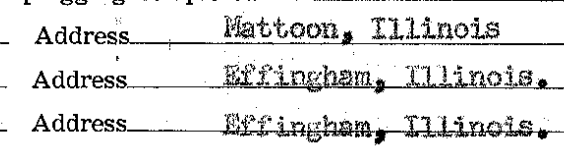

FLUGGING:

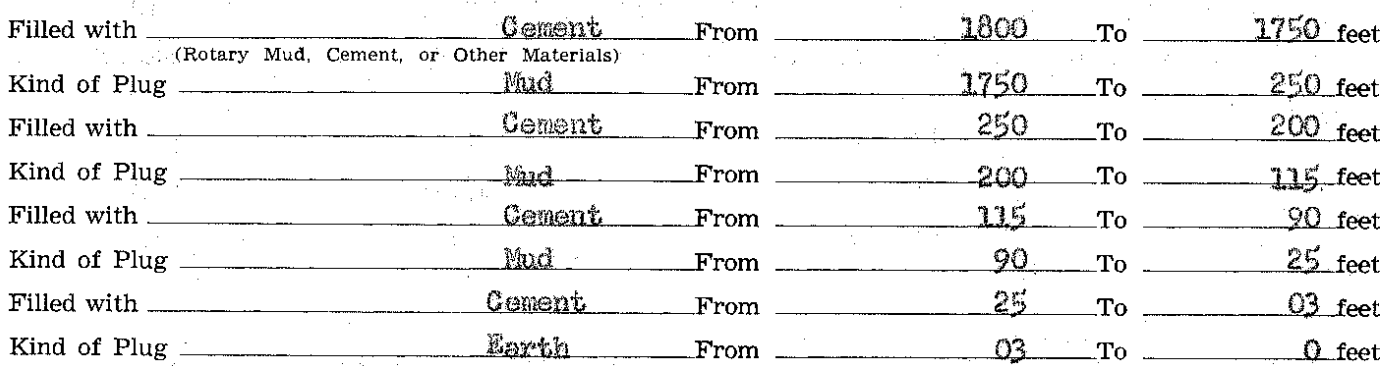
IF WORKABLE COAL BEDS WERE ENCOUNTERED IN THIS HOLE, DESCRIBE THE METHOD EMPLOYED TO PROTECT SAME. (A workable coal bed is thirty inches or more in thickness above 1,000 feet in depth). Hola:

(1) Have pits and other excavations been filled $\ldots \ldots \ldots \ldots \ldots \ldots \ldots \ldots \ldots$ Yes

(2) Have the following been removed?

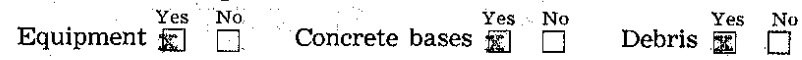

(3) Has surface casing been cut off three feet below ground surface?

(4) Has well-site been levelled?

If this was a producing well, give date and amount of last production

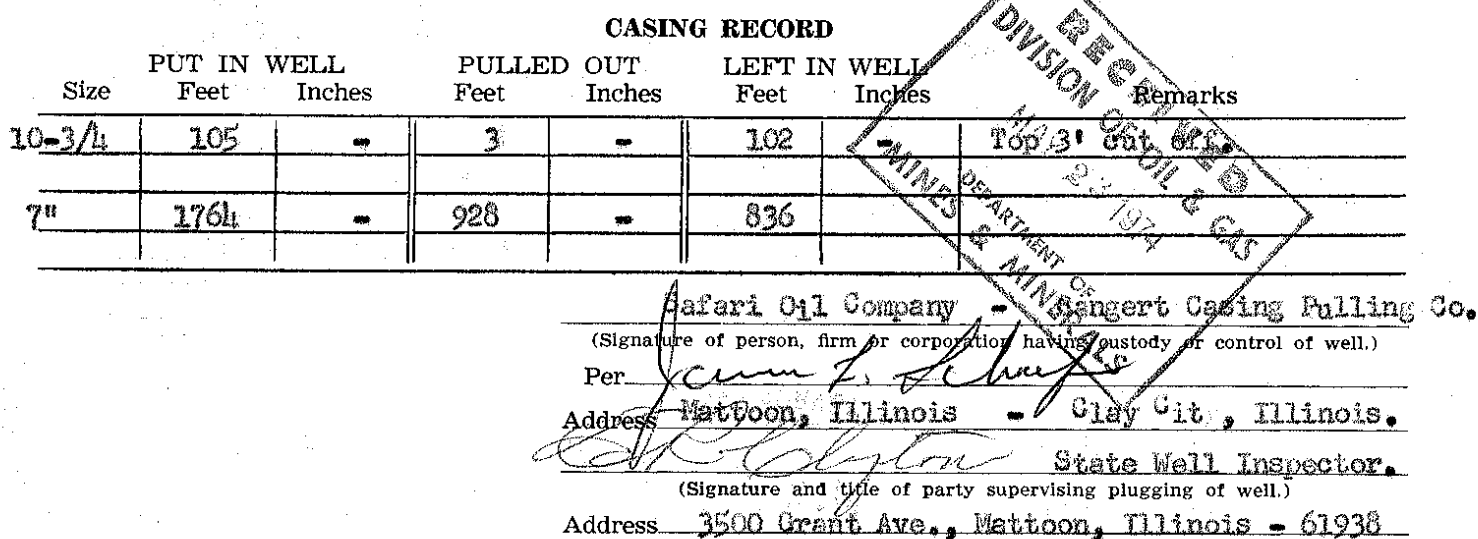

Subscribed and sworn to before me this 27 day of - gotobre _. A.D. 19.73 My commission expires_ $\quad 10 / 28 / 76$

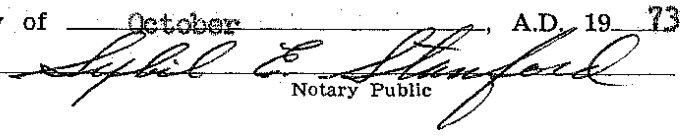




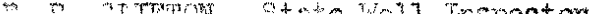

being first duly sworn do depose and say the following is a true and correct statement of the details of the plugging of a certain well drilled for OT,

known as the Homann and located as follows:

ft. north;

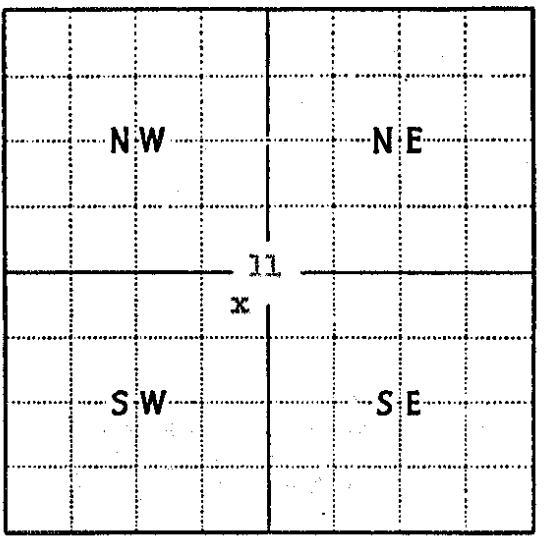

Locate well accurately on plat of section (Scale one inch-2,000 ft.)

Indicate whether for oil, gas, water or other purposes) 330 ft. south;__ ft. east;__ 330 ft. west of the_NS corner of the__. 5 _W_ Quarter

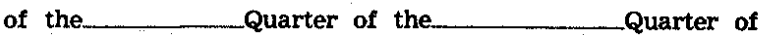

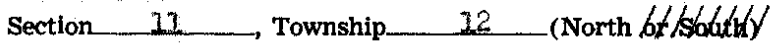
Range_ 7 , (East of $/ 66 s t / 61$ the 390

Principal Meridian, COTJS County, Illinois. Elevation above sea level is $\left\{\begin{array}{l}\text { Derrick Floor } \\ \text { Ground ft. }\end{array}\right.$ Total depth $\quad 1967$ Formation hosicide Date permit to drill issued 13/25/64.Permit No. 2059 Permit issued tôader o1 1 omoany Date drilling began $\quad 73-24-64$ Date drilling completed 12-2-64 Kind of drilling tools used_r_rotary Date plugging began $8-19-80$ Date plugging completed $\quad 8-21-80$

Lessor Oscar Homan Address Nattoor, IIIirois 61938

Lessee solafor of 1 Gomany Address_Battoon, Thinoj -61938

Drilling Contractor $-n,-1,-1 d x+2 \%$

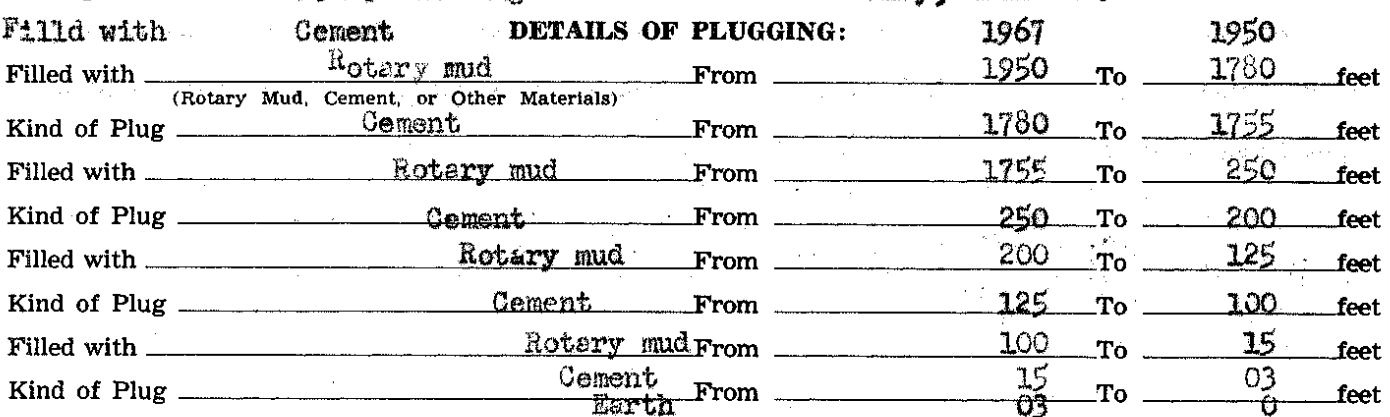
IF WORKABLE COAL BEDS WERE ENCOUNTERED IN THIS HOLE, DESCRIBE THE METHOD EMPLOYED TO PROTECT SAME. (A workable coal bed is thirty inches or more in thickness above 1,000 feet in depth) MON

(1) Have pits and other excavations been flled? $\ldots \ldots \ldots \ldots \ldots \ldots \ldots \ldots \ldots \ldots$ Yes $\square$

(2) Have the following been removed?

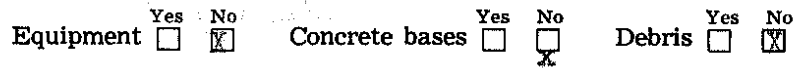

(3) Has surface casing been cut off three feet below ground surface?

(4) Has well-site been leveled?

If this was a producing well, give date and amount of last production Beptembor 1979

\section{CASING RECORD}

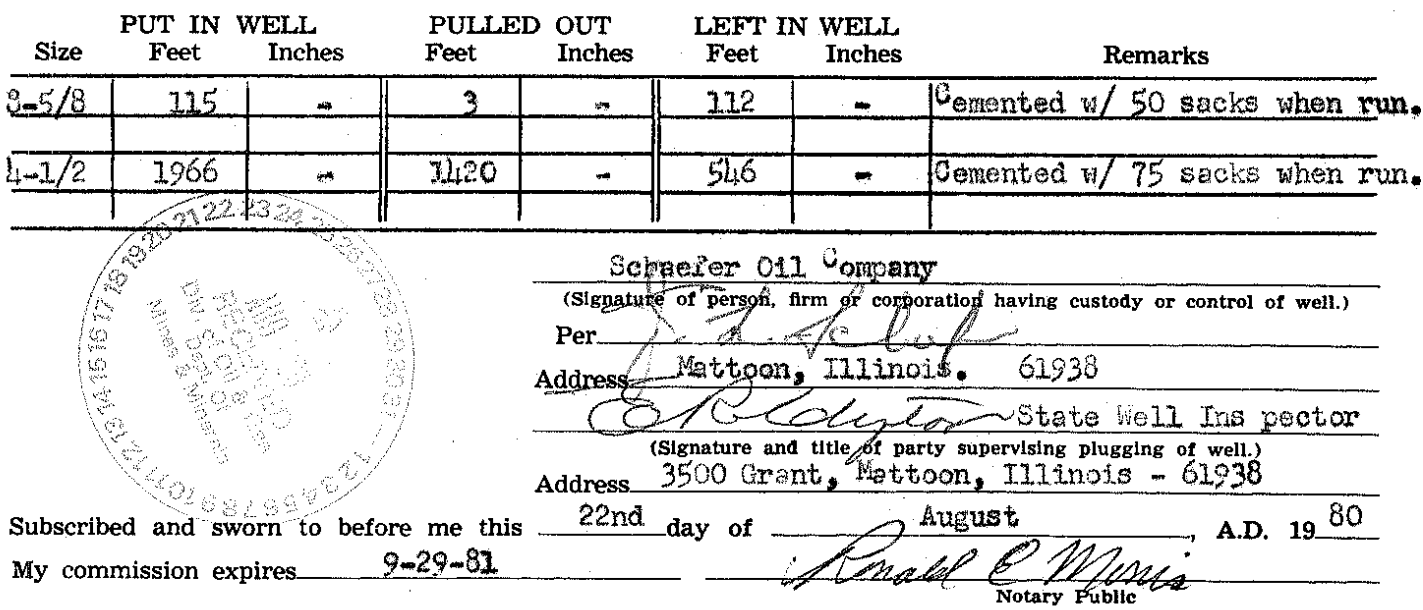


STATE OF ILLINOIS

County of tolos SS. WELL PLUGGING AFFIDAVIT

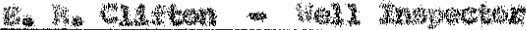

being first duly sworn, do depose and say the following is a true and correct statement of the details of the plugging of a certain well drilled for 4to

known as the

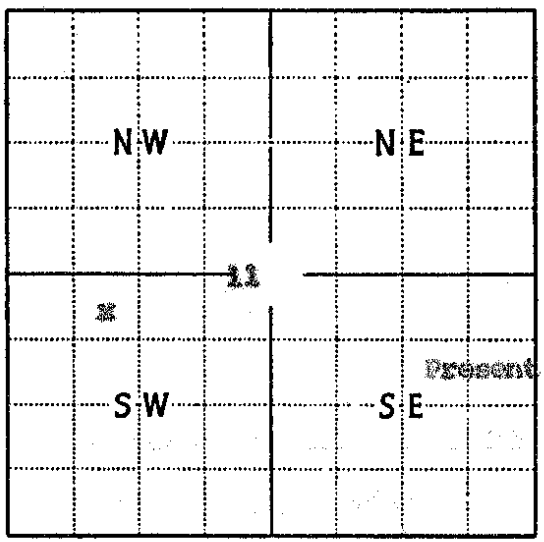

Locate well accurately on plat of section (Scale one inch-2,000 ft.)

斿

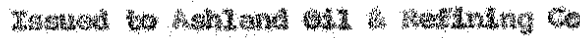

and located as follows:

ft. north;

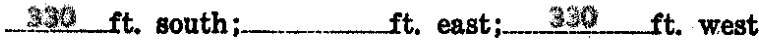

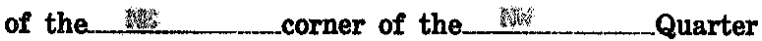

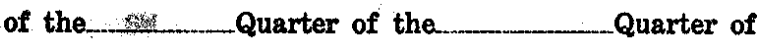

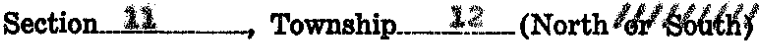

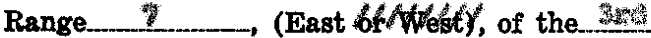

Principal Meridian, -... County, Illinois.

Elevation above sea level is $\{$ Derrick Floor______f $\mathrm{ft}$.

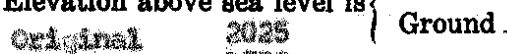
$20 \% \quad \mathrm{ft}$ Wotal depth Tor the Formation

- Date permit to drill issuedU

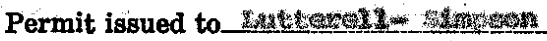

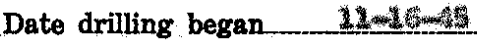
Date drilling completed 11 Kind of drilling tools used Date plugging began _. Date plugging completed

Lessor_. Ho Address__.

Lessee _tint

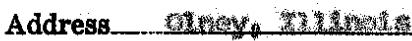

Drilling Contractor_s DETAILS OF PLUGGING:

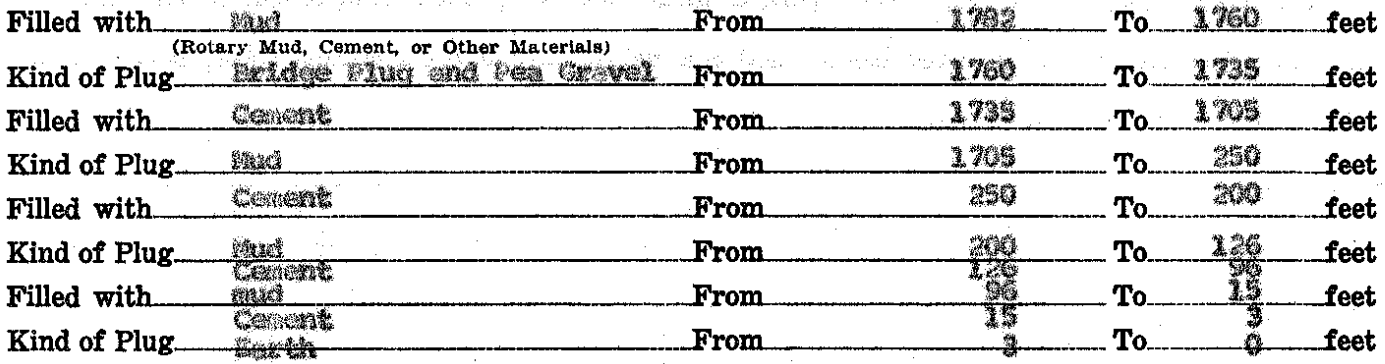

IF WORKABLE COAL BEDS WERE ENCOUNTERED IN THIS HOLE, DESCRIBE THE METHOD EMPLOYED TO PROTECT SAME. (A workable coal bed is thirty inches or more in thickness above 1,000 feet in depth)

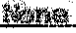

(1) Have pits and other excavations been filled?

(2) Have the following been removed?

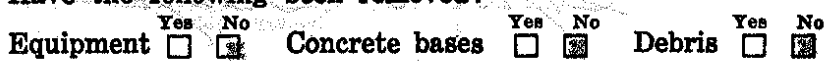

(3) Has surface casing been cut off three feet below ground surface?

(4) Has well-site been levelled?

If this was a producing well, give date and amount of last production

CASING RECORD

\begin{tabular}{|c|c|c|}
\hline & \multicolumn{2}{|c|}{ PUT IN WELL } \\
\hline Size & Feet & Inches \\
\hline $104+7 / 6$ & 2] & \\
\hline 警数 & 40 & $=$ \\
\hline
\end{tabular}

PULLED OUT LEFT IN WELL

\begin{tabular}{|c|c|c|c|c|}
\hline Feet & Inches & Feet & Inches & Remarks \\
\hline 辣 & 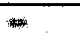 & 16 & 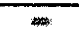 & 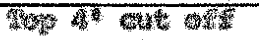 \\
\hline gat & - & 14 & - & \\
\hline
\end{tabular}

W

WWHUN OF OW G

NOV 1971

DEPARIMENT OF MHES MUERLS

\author{
40 \\ (Blenaturio of parmon, arm or gorporation baving oustody or control of wall.)

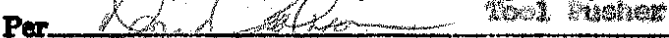

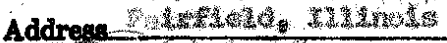

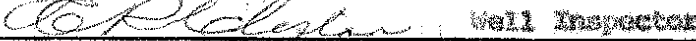

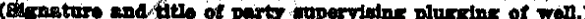

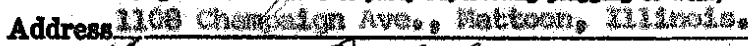



do depose and say the following is a true and correct statement of the details of the plugging of a certain well drilled for $0 i 1$

known as the

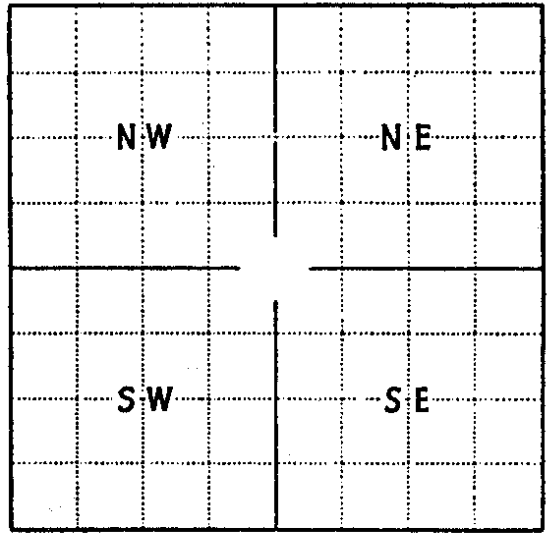

Locate well accurately on plat of section (Scale one inch-2,000 ft.) of the Sw corner of the N $\mathrm{XX}$ NW $Q$ Quarter of the Quarter of the___ Quarter of

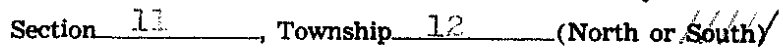
Range $\quad 7$, (East or W(West), of the

Principal Meridian,__County, Illinois. Elevation above sea level is $\begin{cases}\text { Derrick Floor ft. } & \text { ft. } \\ \text { Ground } 719 & \text { ft. }\end{cases}$ Total depth 1975 Formation Rosiolare Date permit to drill issued 1-29-46 Permit No. 129 Permit issued to Simpson \& Luttrell

Date drilling began

Date drilling completed

Kind of drilling tools used. Date plugging began

Date plugging completed sotary

$4 / 26 / 82$

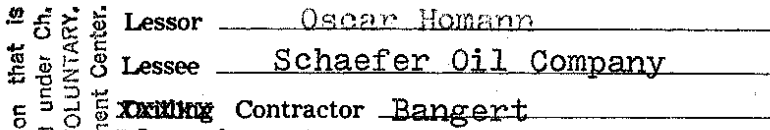
Details of PLUgGing:

Address Mattoon, II. Address CI
PLUGGING:

Kind of Plug

From

To

Filled with

From

From

From

6. From 2 To THE THE METHOD EM-

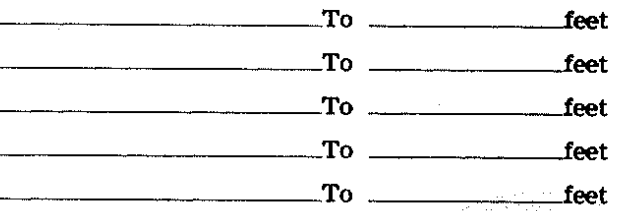
긍 数, in in depth) Hone

ge pits and other excavations been flled?

焉

Debris $\stackrel{\text { Yes }}{\square}$

(3) Has surface casing been cut off three feet below ground surface?

(4) Has well-site been leveled?

If this was a producing well, give date and amount of last production

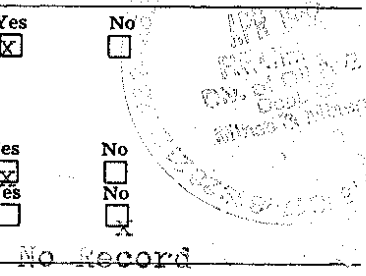

\section{CASING RECORD}

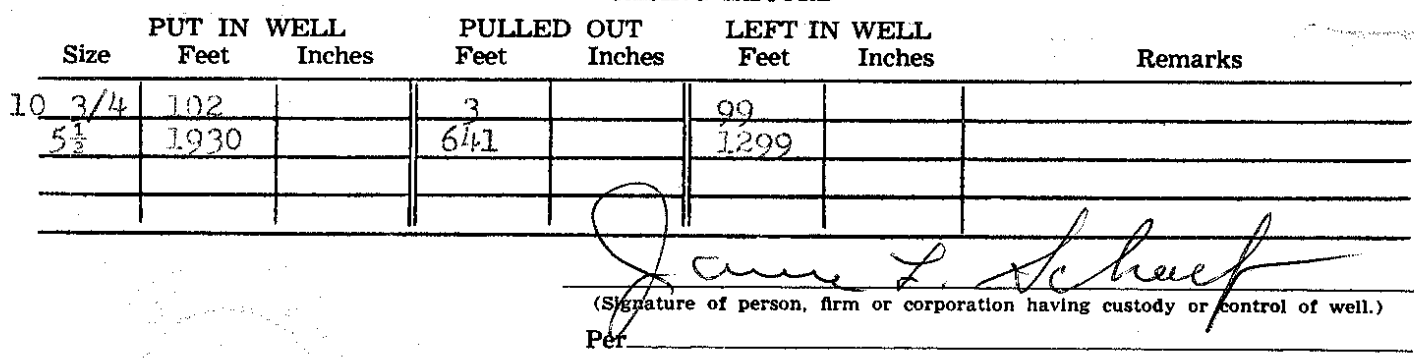

Address Box 35 inattoon, IL.

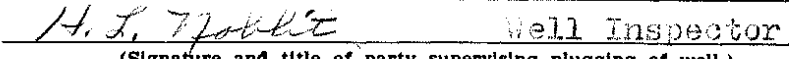

(S1gnature and title of party supervising plugging of well.)

Address $402 \&$, Ceritra $]$ Casey, Ii.

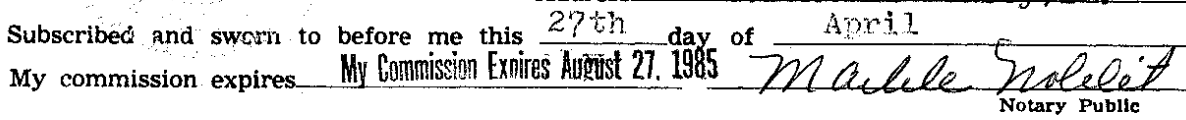

A.D. 19.32 
County of Cores cors $\}$ SS.

WELL PLUGGING AFFIDAVIT

Safari oll company Woodde11, and

F. R. CLIFTOW - state We11 Inspectof do depose and say the following is a true and correct statement of the details of the plugging of a certain well drilled for OIT. orL

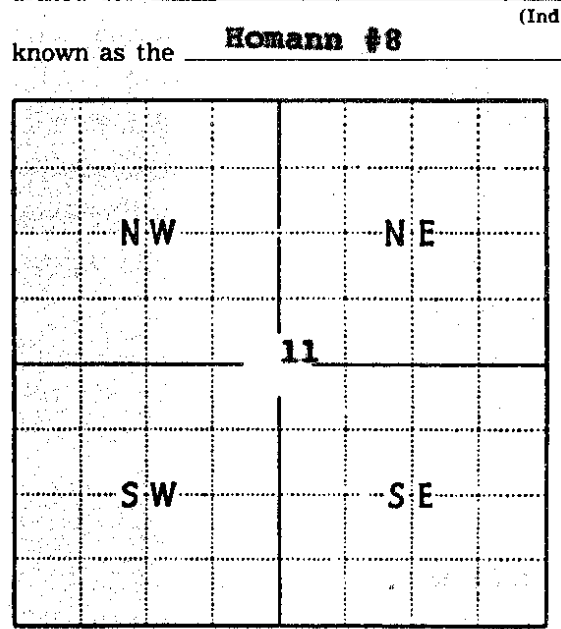
Indicate whether for oll, gas, water or other purposes)

Locate well accurately on plat of section

known as the Homam (Scale one inch-2,000 ft.)

and located as follows:
ft. south; 330 330 ft. north; of the $S \mathscr{L}$ ft. west of the NW Quarter of the SW Quarter of Section 11 , Township 12 (North or South) Range_ 7 , (East or $/ 6$ fest $/$, of the 3rd Principal Meridian,_____________ County, Illinois. Elevation above sea level is $\left\{\begin{array}{r}\text { Derrick Floor } \\ 718\end{array}\right.$ Total depth 1969 Fround Date permit to drill issued $2-20-46$ Permit No. 244

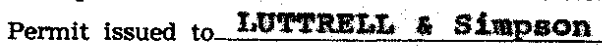

Date drilling began_ 12-11-45

Date drilling completed 2-23-46

Kind of drilling tools used. Rotary

Date plugging began 10-07-88

Date plugging completed. $10-07-98$

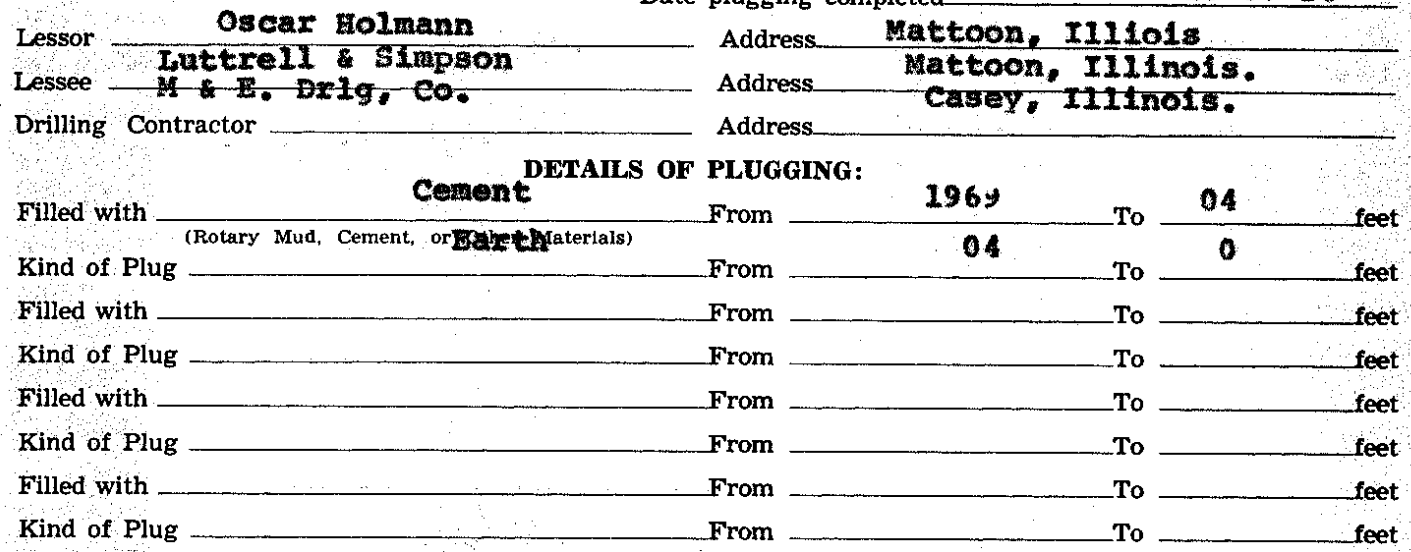
IF WORKABLE COAL BEDS WERE ENCOUNTERED IN THIS HOLE, DESCRIBE THE METHOD EM-

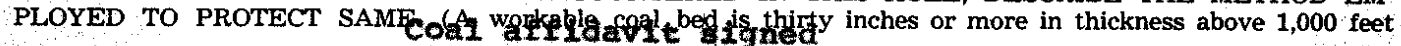
in depth)

(1) Have pits and other excavations been filled? ...............

(2) Have the following been removed?

Equipment $\square$ No $\square$ Concrete bases $\square \square^{\text {No }}$ Debris $\square^{\text {No }}$

(3) Has surface casing been cut off three feet below ground surface?

(4) Has well-site been leveled?

If this was a producing well, give date and amount of last production

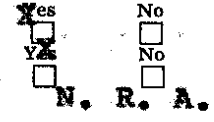

CASING RECORD

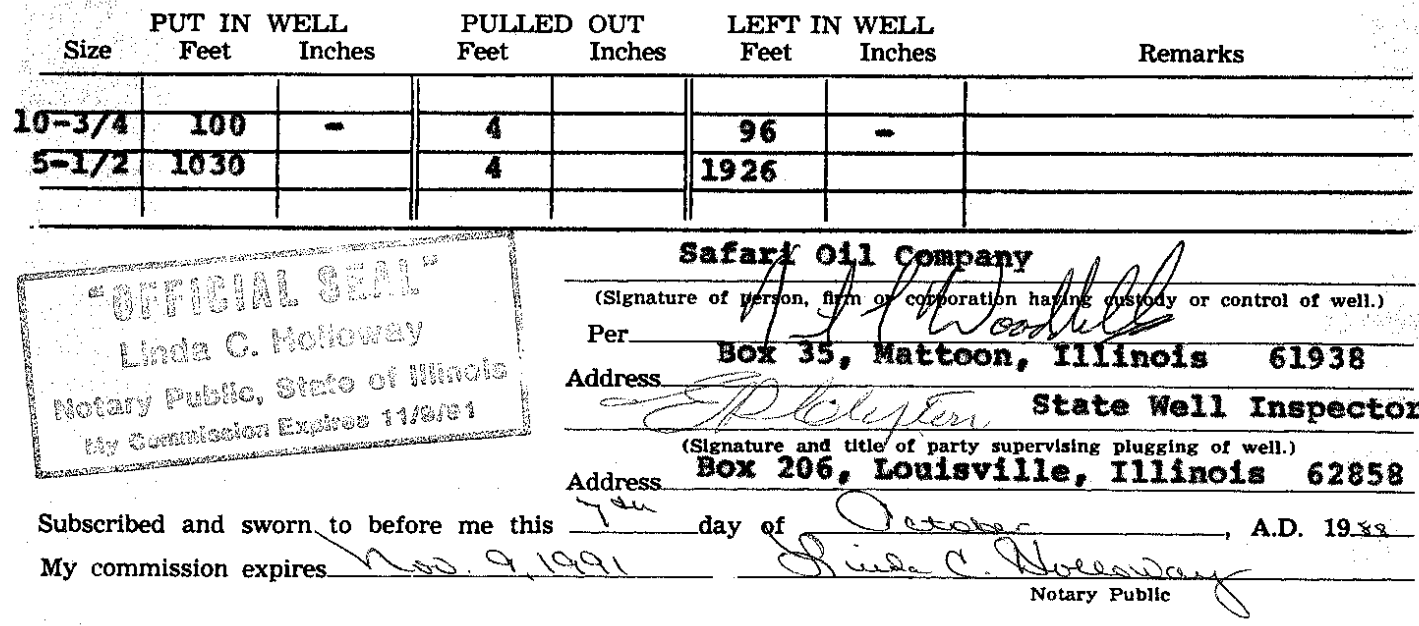


STATE OF ILLINOIS

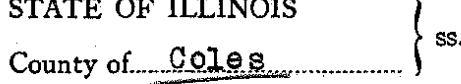

WeIter Welsh

being first duly sworn, for.

011

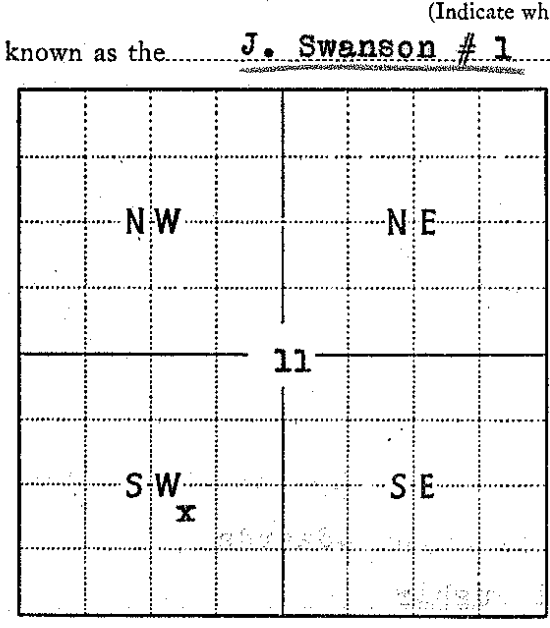

Locate well accurately on plat of section (Scale one inch $-2,000 \mathrm{ft}$.)
Lessor J. Swanson
Lessee Joo BIeleck

Drilling Contractor W.R. Walter Wher for oil, gas, water or other purposes)

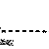

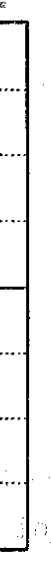

of 330 .....and located as follows:

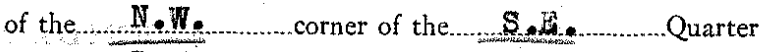
of the S.W. Quarter of the _ _ Q Quarter of

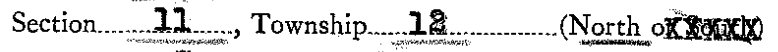

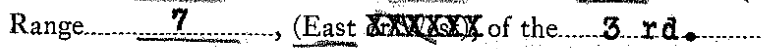
Principal Meridian, Colos County, Illinois.

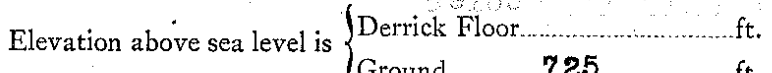
Total depth of well is 7970 ..... Date permit to drill issued $12 / 20 / 45$ Pefmit 20161 Permit issued to Joe BAElock Date drilling began $12 / 20 / 45$ Date drilling completed $1 / 7 / 46$ Kind of drilling tools used . Rotary Date plugging began $2 / 16 / 51$ Date plugging completed $2 / 17 / 51$

J. Swanson
Lessor Date plugging completed $2 / 17 / 51$
Lessee Joe Bleleck
Drilling Contractor W.R. Walter

DETAILS OF PLUGGING:

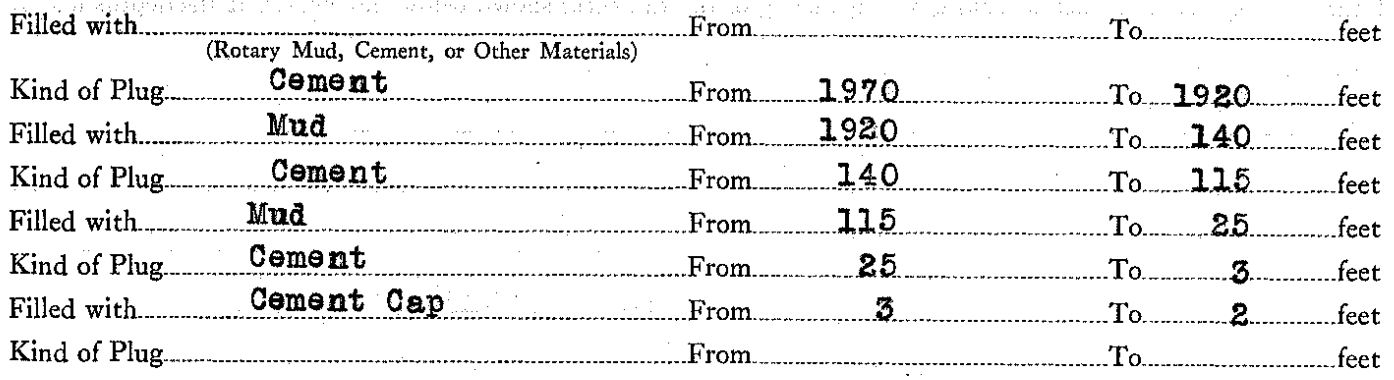

IF WORKABLE COAL BEDS WERE ENCOUNTERED IN THIS HOLE, DESCRIBE THE METHOD EMPLOYED TO PROTECT SAME. (A workable coal bed is thirty inches or more in thickness above 1,000 feet in depth). Seo affidevit on reverse side.

(1) Have pits, cellar and other excavations been filled?..... Yes

(2) Have equipment, concrete bases and debris been removed?

Yes

(3) Has surface casing been cut off below plow depth?.....

\begin{tabular}{|c|c|}
\hline No & 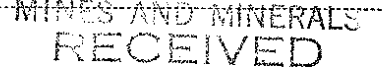 \\
\hline $\begin{array}{l}\mathbb{N}_{\text {No }} \\
\text { Nat }\end{array}$ & FEB 231951 \\
\hline$\square$ & DIVislon or \\
\hline
\end{tabular}

(4) Has well-site been levelled?.

정

OLL and GAS OONSERVATON

If this was a producing well, give date and amount of last production

$12 / 1 / 50-1$ bbl pex day.

\section{CASING RECORD}

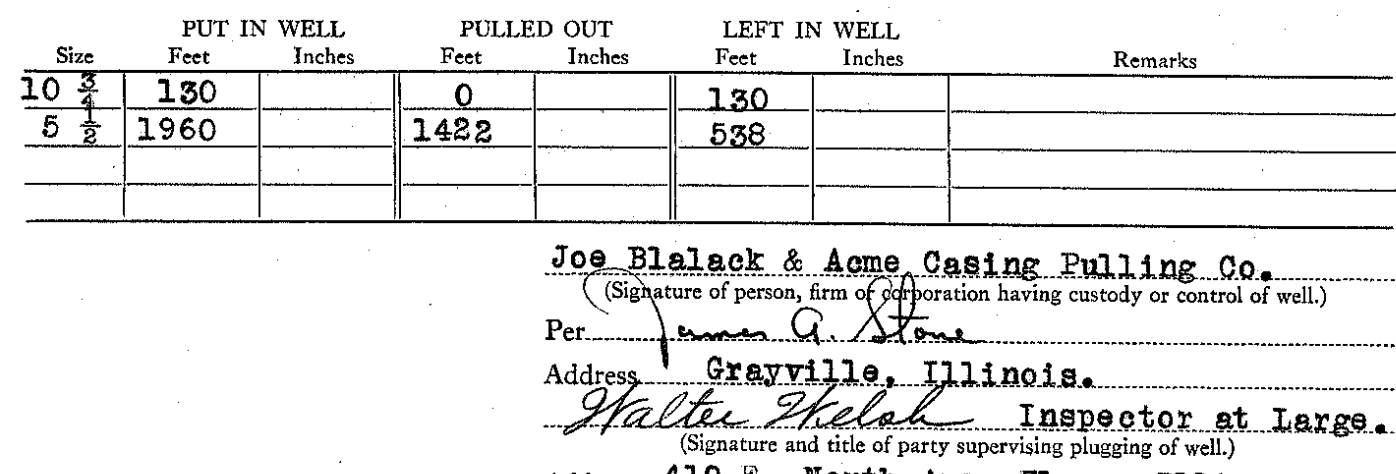

Address 419 E. North Ave. Flora, IIIinois.

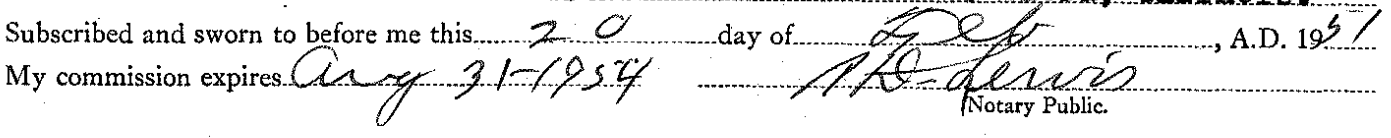


STATE OF LLLNOIS,

County of $\operatorname{coles}$ ss.

Lawrence Landreth

\section{$858 \mathrm{mb}$ \\ WELL PLUGGING AFFIDAVIT}

\section{J. B. Blalack}

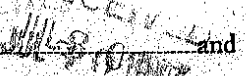
being firstyily swotondo depose and

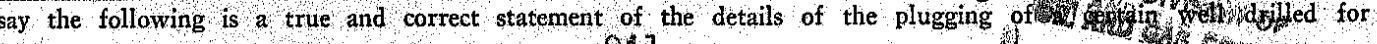
011

(Indicate whether for oll, gas, water or other purposes)

Swanson 12

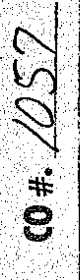

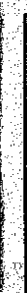

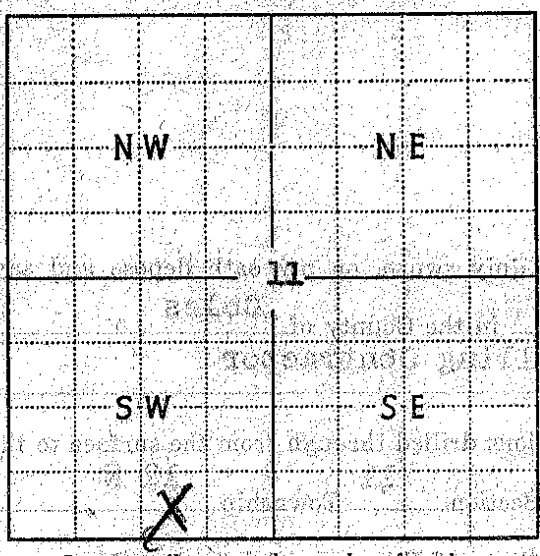

Locate rell gecurately on plat of

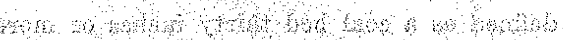

whenson

Lessee MLala ok or Wa Lex

Drilling Contractor D1a1aek and yalter

and located as follows: $-\mathrm{ft}$ north. . ft. south, $\quad$ ft. east, f ft. west of the SW corner of the $\$ \mathrm{~T}, \mathrm{D}, \mathrm{Quarter}$ of the SW Quarter of the Quarter of

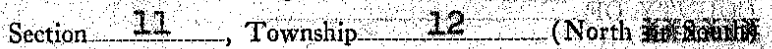
Range 7 , (East ow ow of the $3 \mathrm{~d}$

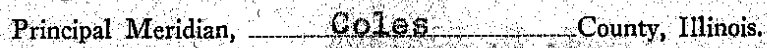
Elevation above sea level is $\int$ Derrick Floor $730 \mathrm{f}$.

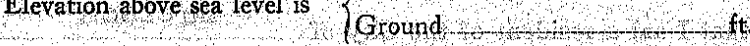

Total depth of well is $\quad 1974$ ft.

Date permit to drill issued J6hodery 5,1946

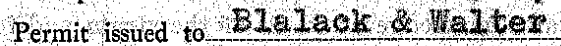

Date drilling began Janua 1 y 8, 1946

Date drilling completed Jamua $x y 29,1946$

Kind of drilling tools used Motery

Date plugging began $, J 11019,194$ ?

Date plugging completed $047 \mathrm{y} 22,1947$

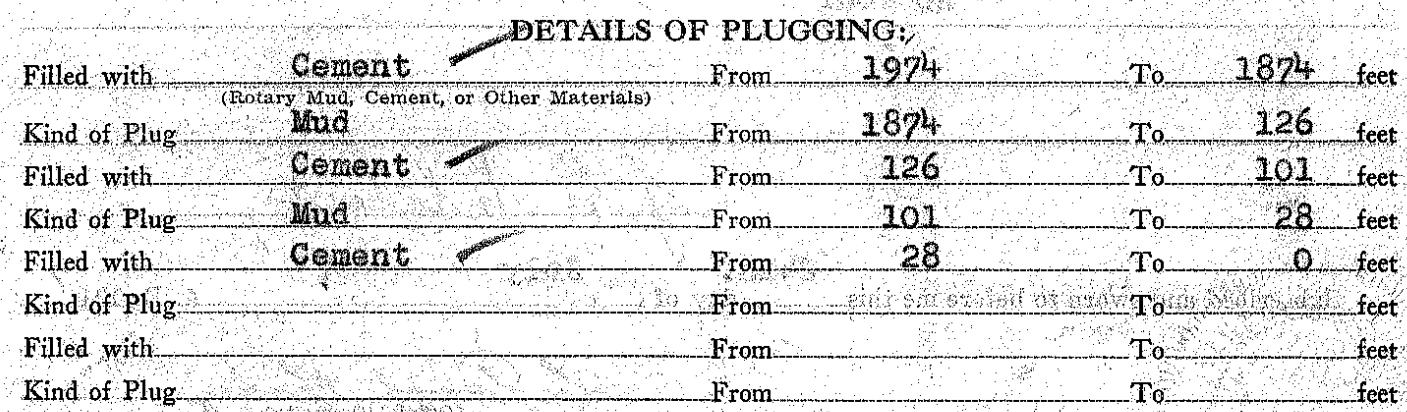

IF WORKABLE COAL BEDS WERE ENCOUNTERED IN THIS HOLE, DESCRIBE THE METHOD EMPLOYED TO PROTECT SAME, (A workable coal bed is thirty inches or more in thickness above 1,000 feet in depth.

(Aftade on bach)

Address 3 t ttoon, 111 lnols

Address 14 . Vomon, 1121 nols

Address ift Vezmon, 111 mols

Other detals

If this was a producing well, give date and amount of last production

Dry

CASING RECORD

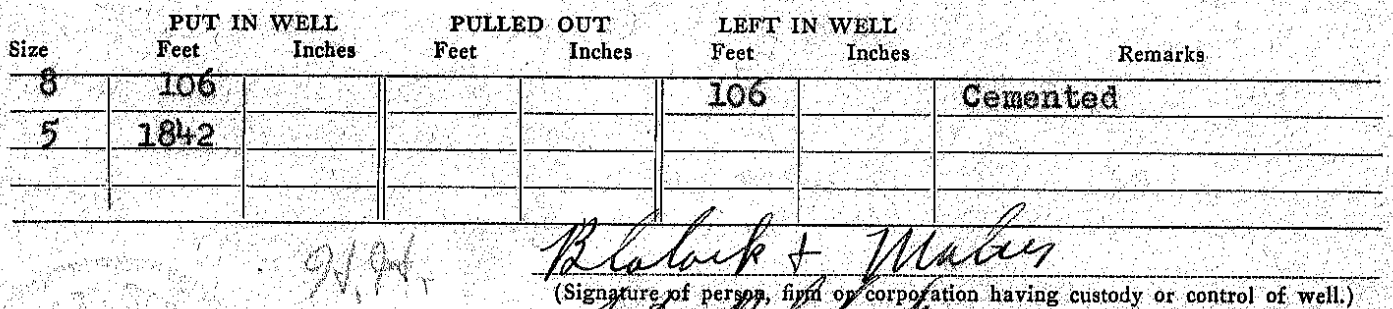

(Signgture of pergog, fipfor corpofation having custody or control of well)

Per 4020102

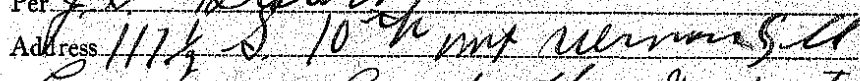

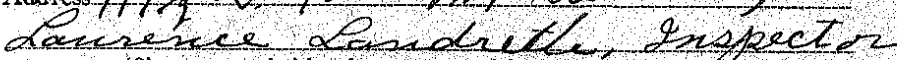
(Signgture and title of party supervising plugging of well)

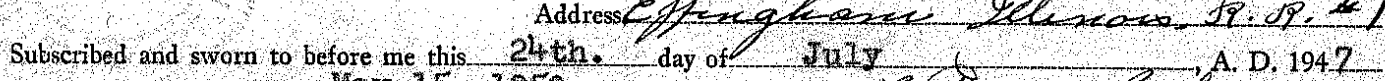


Haxomer Lanareth

say the following is a true and correct statement of the details of the plugging of a certara yell ofilled for 012 or

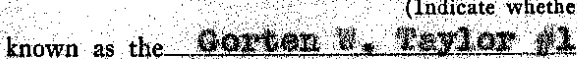

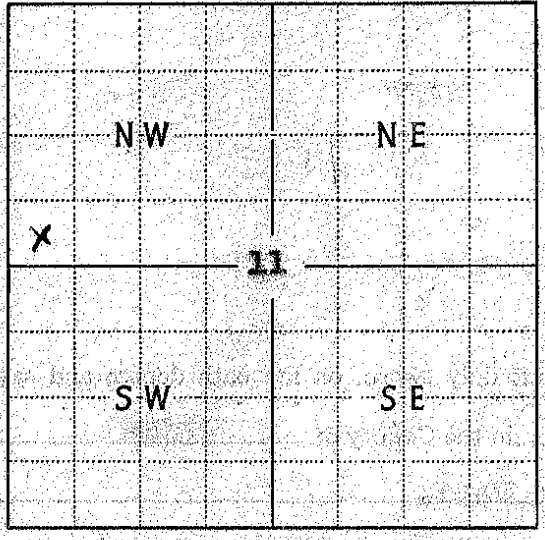

Locate well accuratel on plat of section (Scale one inch-2,000 ft) of the $\quad$ whe

of the conner of the

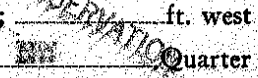
11. Township 12 Modell (North or South)

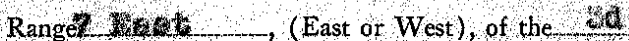

Principal Meridian, - ov 20 County, llinois. Elevation above sea level is $\int$ Derrick floor $20 \mathrm{~S}$ ft Total depth of well is 20 wh

Date permit to drill issued $12,-2,40$

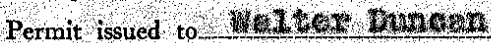

Date driling began, 11-2, 1 45

Date drilling completed $11-26$ - 6

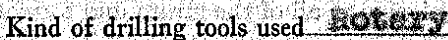

Date plugging began, $1 / 4+6404$

Date plugging completed $11,-20,4$

Lessor Gortern W Ieytar Address MUt 6002,111 .

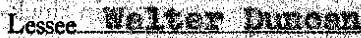

Drilling Contractor $1, X$, Duncou

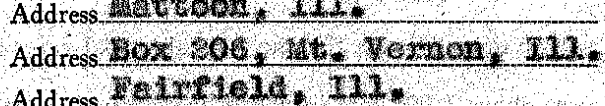

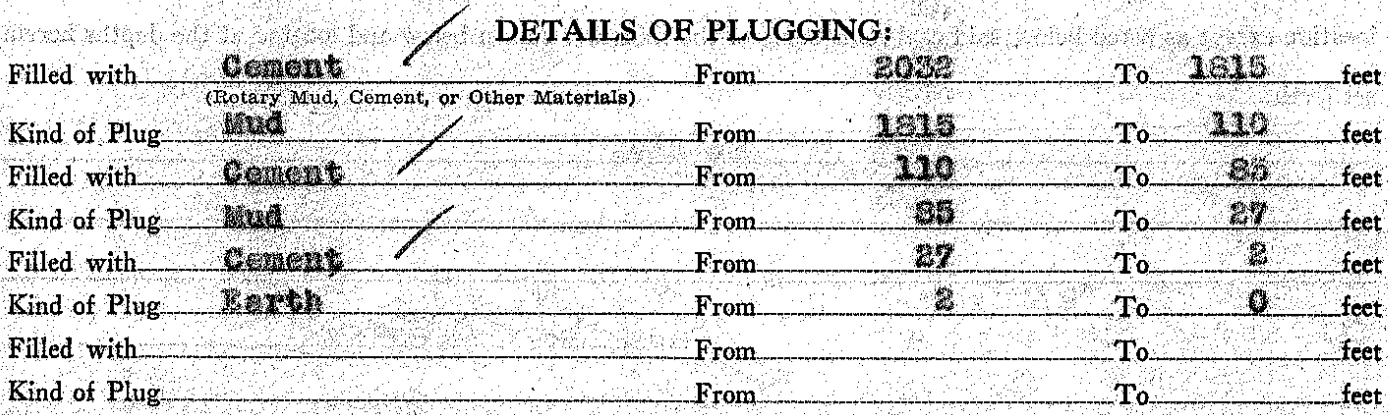

IF WORK ABLE COAL BEDS WERE ENCOUNTERED IN THIS HOLE, DESCRABE THE METHOD EMPLOYED TO PROTECT SAME (A workable coal bed is thirty inches or more in thickness above 1,000 feet in depth)

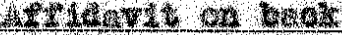

(1) Haye pits, cellar and other excavations been filled?

(2) Have equipment, concrete bases and debris been removed?

(3) Has surface casing been cut of below plow depth?

Yes
Yes
Yes
Yes

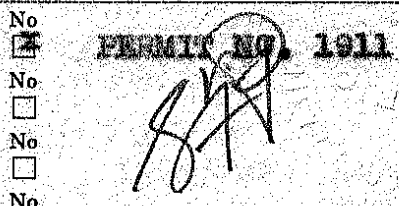

(4) Has well-site been levelled?

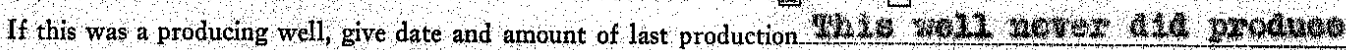

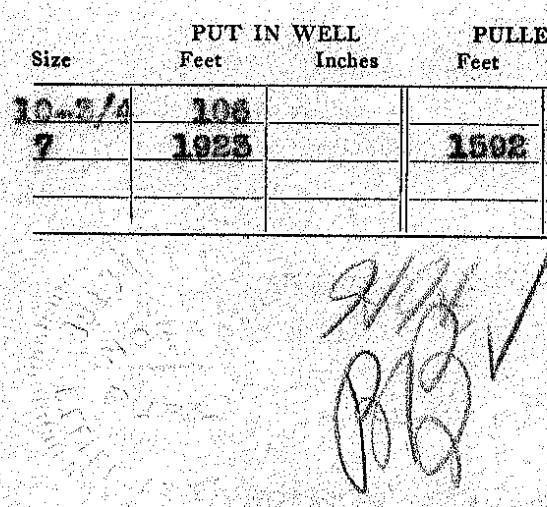

CASING RECORD

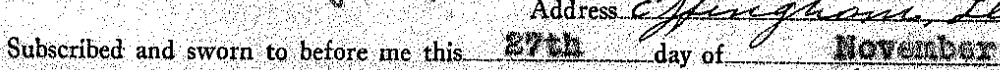

My commission expires ${ }^{-} 2-2,3-6$

(sigagare of pegh, firm or corpor tion having custody or control of well.)

$\mathrm{Per}, 2,0,2,22 \mathrm{C}, \mathrm{d}$

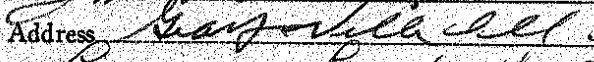

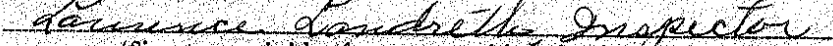

Signature and title of party supervising plugging of well.) Remarks

Inches

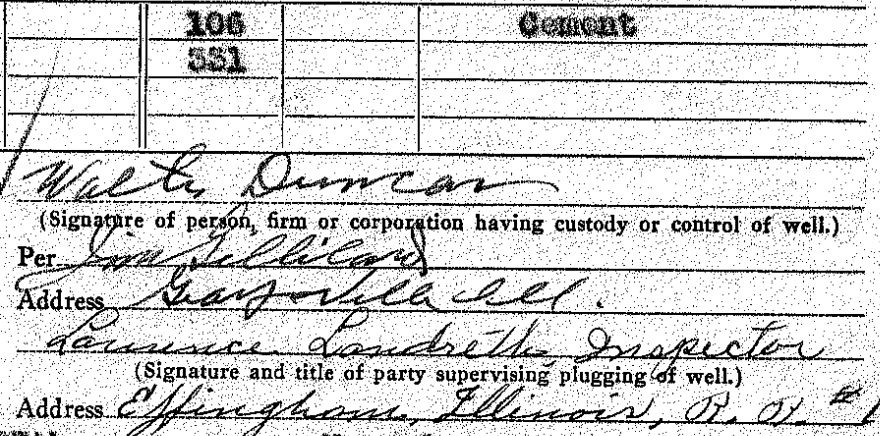


STATE OF ILLINOIS, County of Coles $c_{1} \geqslant 1060 / 5878$

WELL PLUGGING AFFIDAVIT

Lawrence Landreth JL Q1L1Land

being first duly sworn, Afoydepose and

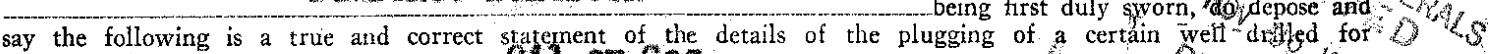
say the following is a true and correct statement of the

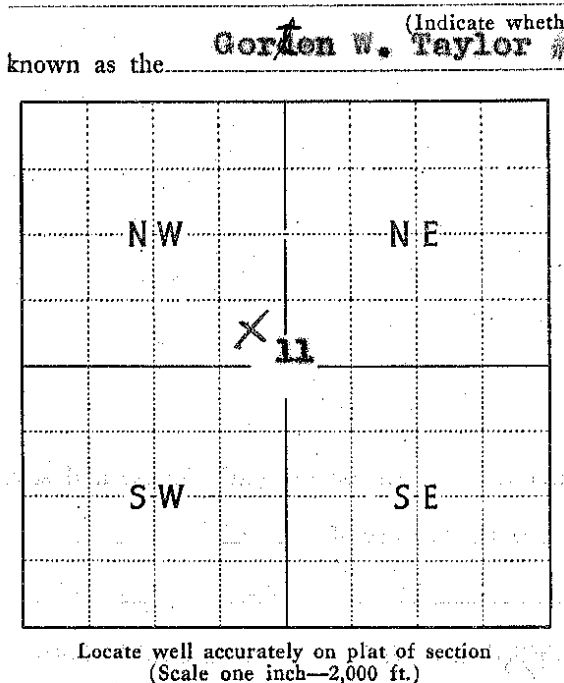

(Scale one inch-2,000 ft.)

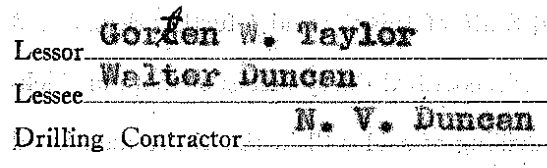

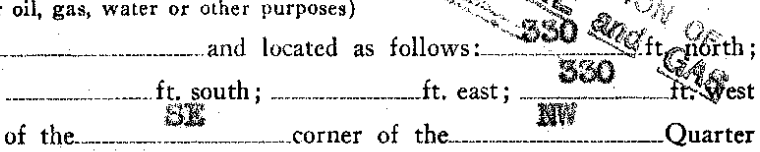

of the-

Quarter of the

Section -11
Range $\quad 7$
,

Principal Meridian, Doles County, Llinois.

Elevation above sea level is $\{$ Derrick Floor 701 \{round

Total depth of well is

$12-26-45$

Date permit to drill issued

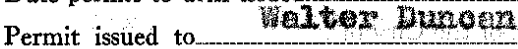

Date drilling began $12 m-46$

Date drilling completed $1-10-40$

Kind of drilling tools used

Date plugging began.

wowaty

Date plugging completed $12-25-46$

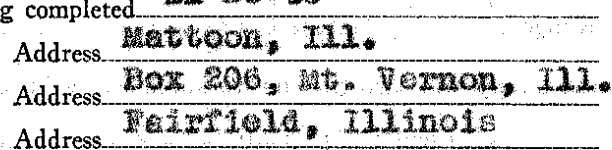

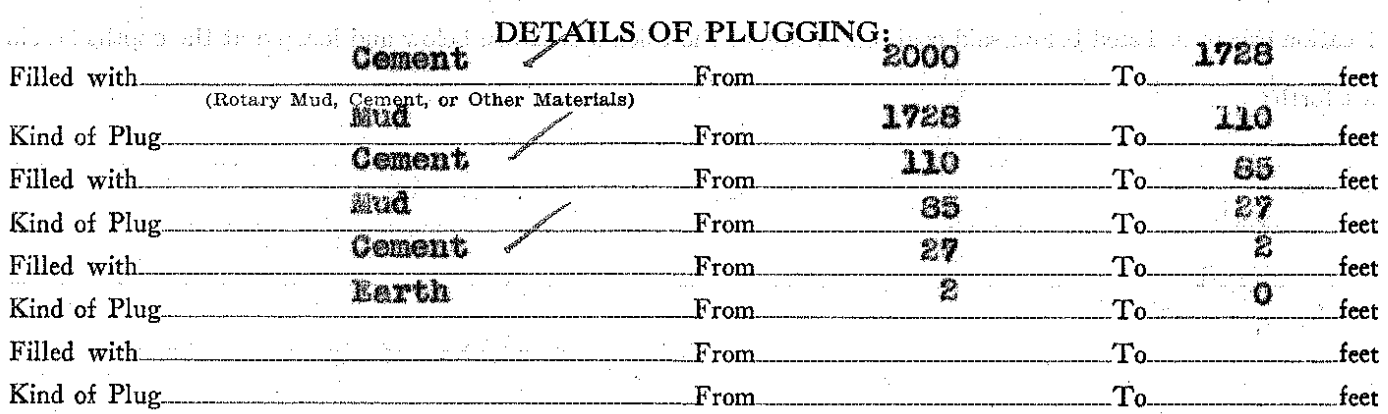

IF WORKABLE COAL BEDS WERE ENCOUNTERED IN THIS HOLE, DESCRIBE THE METHOD EMPLOYED TO PRQTECT SAME. (A workable coal bed is thirty inches or more in thickness above 1,000 feet in depth)

(1) Have pits, cellar and other excavations been filled? .

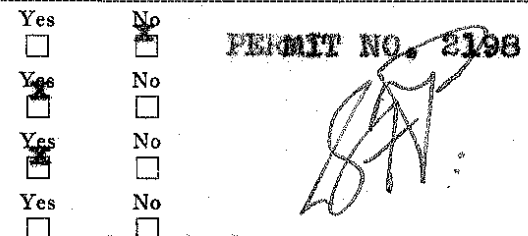

(2) Have equipment, concrete bases and debris been removed?

(3) Has surface casing been cut off below plow depth?

$\square$

(4) Has well-site been levelled?

axy

If this was a producing well, give date and amount of last production

\section{CASING RECORD}

PUT IN WELL
Feet
Size

(Signature of person, firm or corporation having custody or control of well.). eromgetron

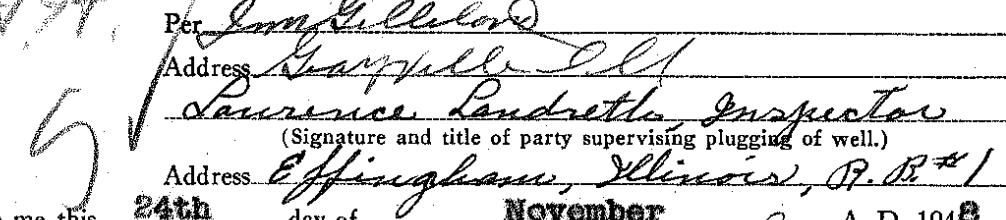


do depose and say the following is a true and correct statement of the details of the plugging of a certain well drilled for. oul 1

known as the_Laylox 5 (ndicate whether for ofl, gas, water or other purposes)

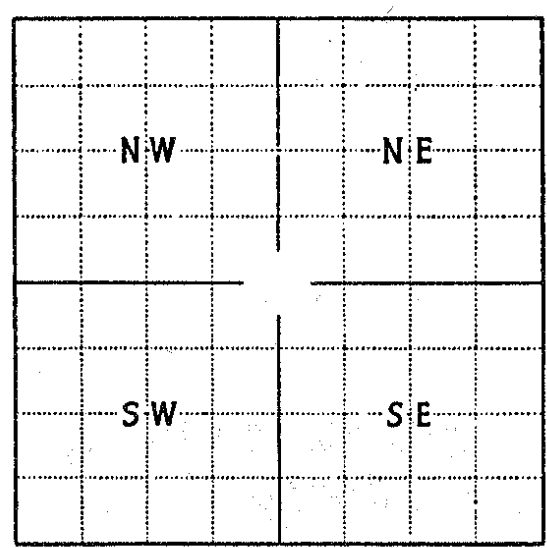

Locate well accurately on plat of section (Scale one inch-me-2,000 ft.)
$965 \mathrm{ft}$. south; $330 \mathrm{ft}$. east;
of the of the Q Quarter of the Section11 Tex Township 12 (North Range_ 7 , (East or What), of the 3 rd Principal Meridian, Coles County, Illinois. Elevation above sea level is $\left\{\begin{array}{l}\text { Derrick Floor } 695 \quad \mathrm{ft} . \\ \text { Ground }\end{array}\right.$ Total depth $1776 \quad$ Formation

Date permit to drill issued $12 / 46$ Permit No._2390

Permit issued to Walter pincan

Date drilling began_12/8/46

Date drilling completed $12 / 13 / 46$

Kind of drilling tools used Rotary

Date plugging began 10/28/69

Date plugging completed 10/2\%/69

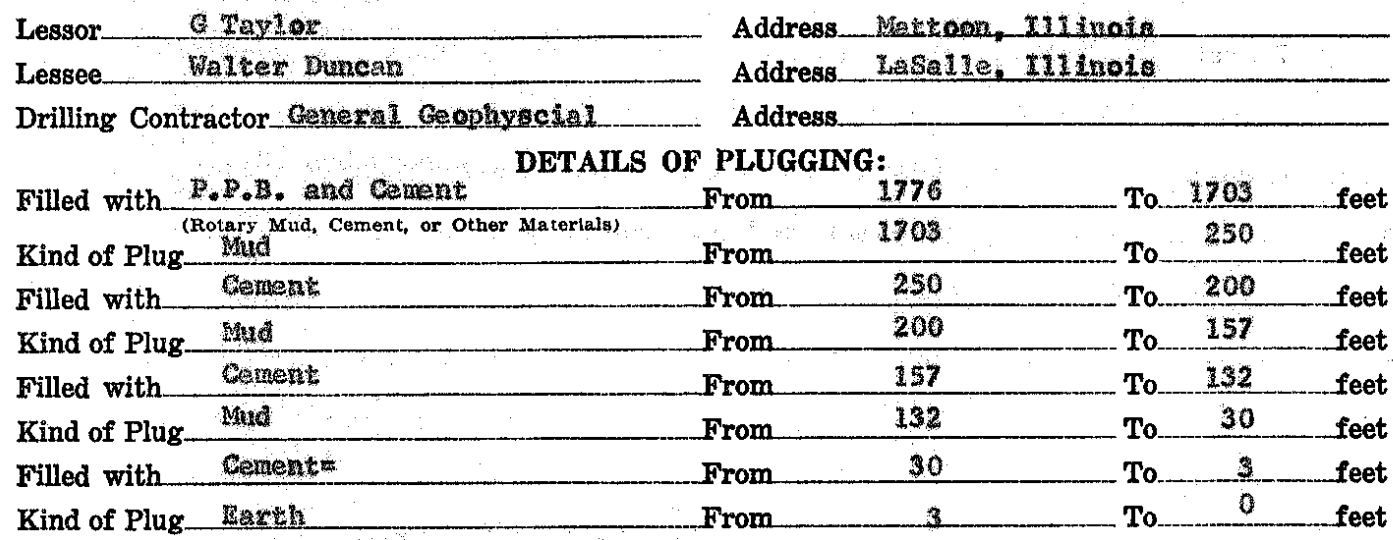

IF WORKABLE COAL BEDS WERE ENCOUNTERED IN THIS HOLE, DESCRIBE THE METHOD EMPLOYED TO PROTECT SAME. (A workable coal bed is thirty inches or more in thickness above 1,000 feet in depth) Sisned

(1) Have pits and other excavations been filled? ..............

(2) Have the following been removed?

Equipment $\stackrel{\text { Yes }}{\square}$ No Concrete bases $\stackrel{\text { Yes }}{\square}$ Debris $\stackrel{\text { Yes }}{\square}$ 苜

(3) Has surface casing been cut off three feet below ground surface?

(4) Has well-site been levelled?

$\underset{\substack{\text { Yes } \\ \text { Yea }}}{\stackrel{\text { No }}{\square}}$

If this was a producing well, give date and amount of last production

\section{CASING RECORD}

\begin{tabular}{|c|c|c|c|c|c|c|c|}
\hline \multirow{3}{*}{$\frac{\text { Sizo }}{103 / 4}$} & \multicolumn{2}{|c|}{ PUT IN WELL } & \multicolumn{2}{|c|}{ PULLED OUT } & \multicolumn{2}{|c|}{ LEFT IN WELL } & Remarks \\
\hline & 147 & & 3 & & 144 & & \\
\hline & 1725 & & 691. & & 1034 & & \\
\hline & & & & & & & \\
\hline
\end{tabular}

\begin{tabular}{|c|c|}
\hline \multirow{3}{*}{ 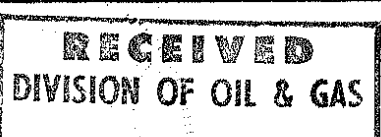 } & 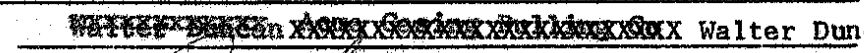 \\
\hline & (Blenaturg of pertion, arm of corporettion having oustody or control of wall.) \\
\hline & Per \\
\hline DEC 21969 & 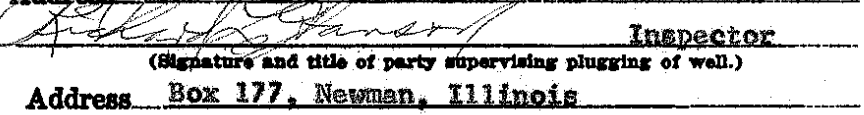 \\
\hline MINES & A.D. 19.69 \\
\hline
\end{tabular}


County of $\}$ ss. WELL PLUGGING AFFIDAVIT

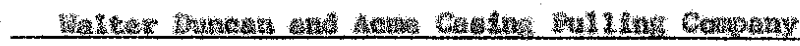

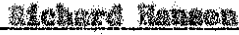

being first duly sworn, do depose and say the following is a true and correct statement of the details of the plugging of a certain well drilled for

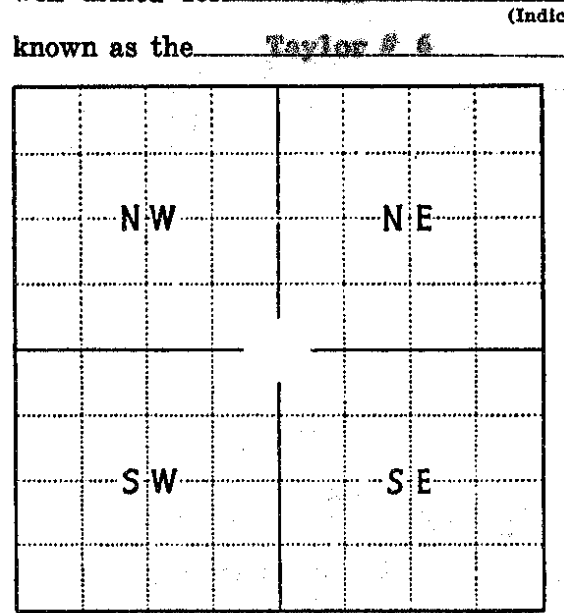

Locate well accurately on plat of section (Scale one inch $-2,000 \mathrm{ft}$.)

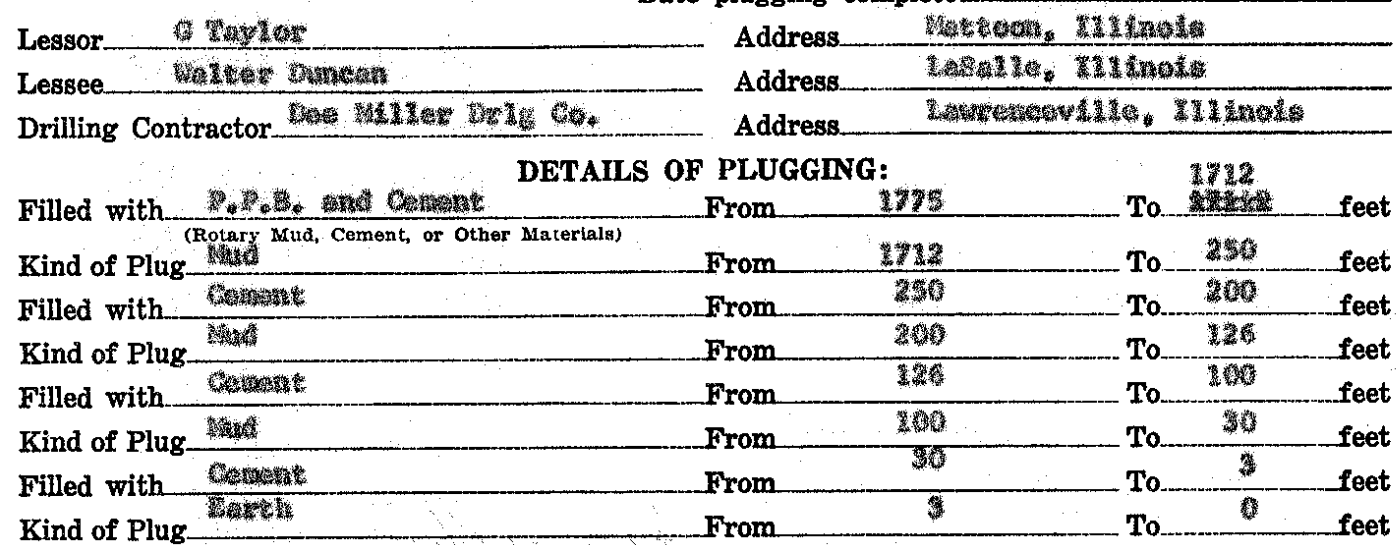

IF WORKABLE COAL BEDS WERE ENCOUNTERED IN THIS HOLE, DESCRIBE THE METHOD EMPLOYED TO PROTECT SAME. (A workable coal bed is thirty inches or more in thickness above 1,000 feet in depth)

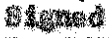

(1) Have pits and other excavations been filled? $\ldots \ldots \ldots \ldots \ldots \ldots$ You

(2) Have the following been removed?

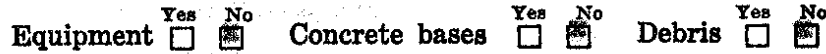

(3) Has surface casing been cut off three feet below ground surface?

(4) Has well-site been levelled?

If this was a producing well, give date and amount of last production

CASING RECORD

\begin{tabular}{|c|c|c|c|c|c|c|c|}
\hline Size & \multicolumn{2}{|c|}{ PUT IN WELL } & \multicolumn{2}{|c|}{ PULLED OUT } & \multicolumn{2}{|c|}{ LEFT IN WELC } & Remarks \\
\hline 10 & 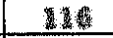 & & 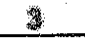 & & 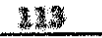 & & \\
\hline $2^{3}$ & $2+2$ & & 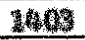 & & 3 & & \\
\hline & & & & & & & \\
\hline & & & & & & & \\
\hline
\end{tabular}

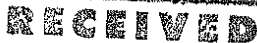
DUWSBON OF OLL \& GAS

DEC 21969

DEPARTMENT OF

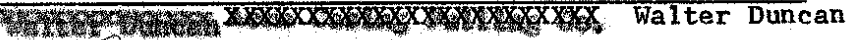

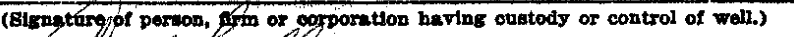

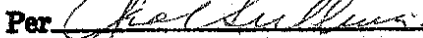

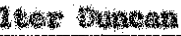


STATE OF ILLINOIS

County of 1
WELL PLUGGING AFFIDAVIT

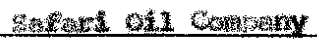
and

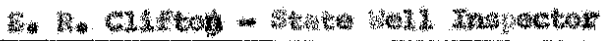

being first duly sworm, do depose and say the following is a true and correct statement of the details of the plugging of a certain well drilled for. and

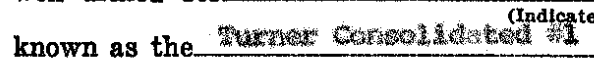

wh

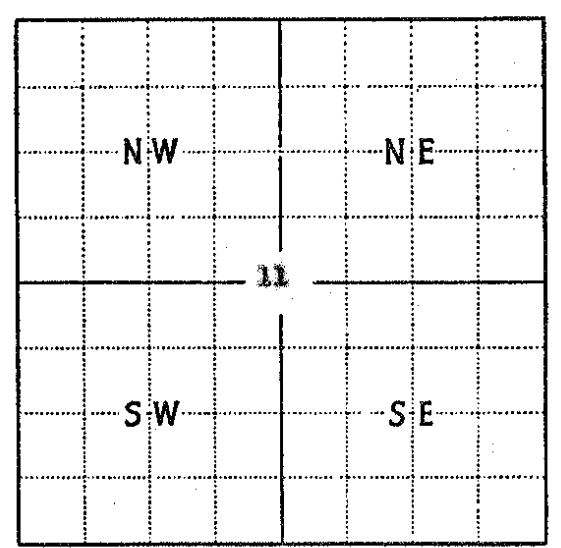

Locate well accurately on plat of section

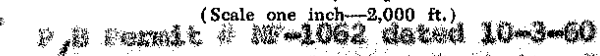

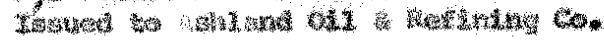

whether for oll, gas, water or other purposes) ____and located as follows:3. ft. Bouth; 320 ft. east;

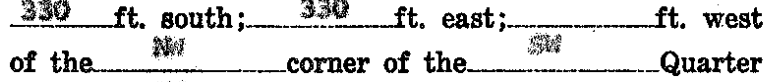
of the Quarter of

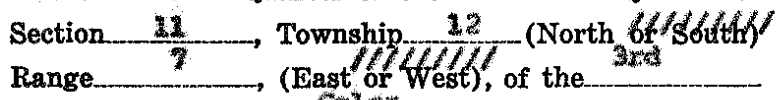
Principal Meridian, Cot Elevation above sea level is $\left\{\begin{array}{l}\text { Derrick Floor } 726 \quad \mathrm{ft} . \\ \text { Ground }\end{array}\right.$

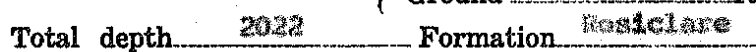

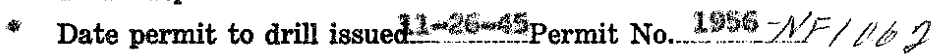

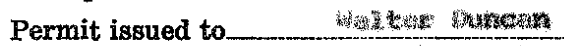

Date drilling began - 1 -

Date drilling completed $12-2-25$

Kind of drilling tools used feots

Date plugging began _._. $2-9-72$

Date plugging completed $2-11-7$ ?

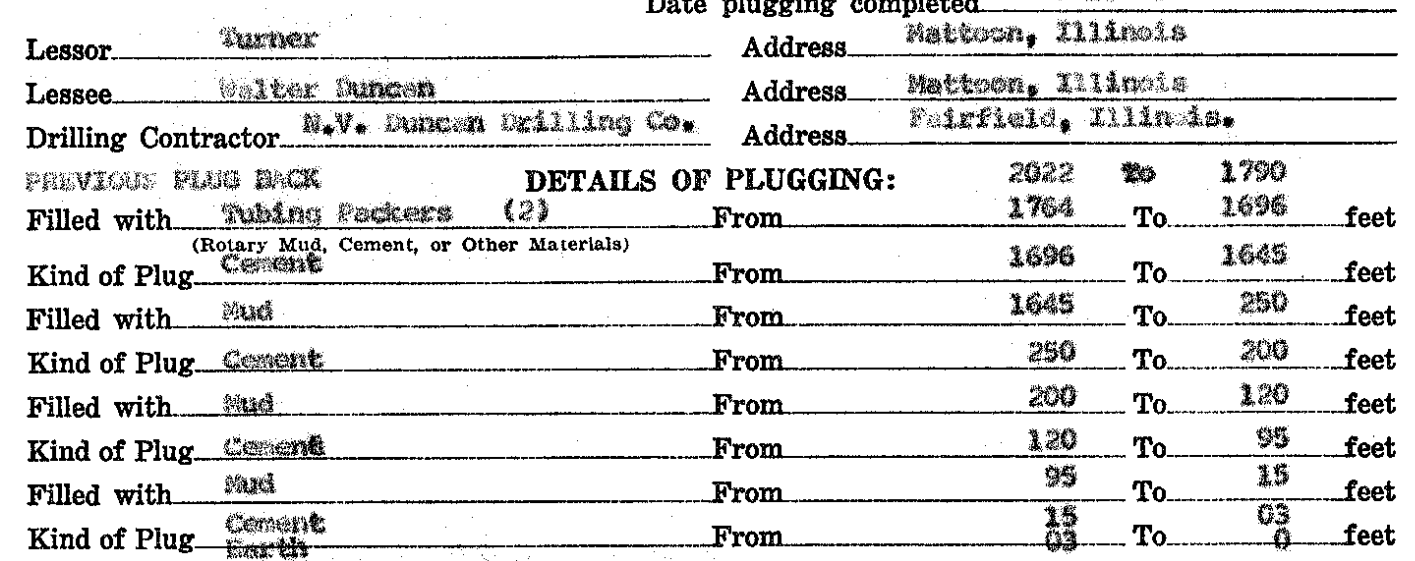

IF WORKABLE COAL BEDS WERE ENCOUNTERED IN THIS HOLE, DESCRIBE THE METHOD EMPLOYED TO PROTECT SAME. (A workable coal bed is thirty inches or more in thickness above

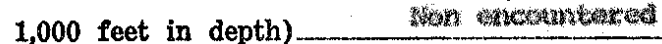

(1) Have pits and other excavations been filled?............. 独

(2) Have the following been removed?

Equipment $\stackrel{\text { Xes }}{\square}$ 을 Concrete bases $\square^{\text {Yes }}$ Debris $\stackrel{\text { Yes }}{\square}$ №

(3) Has surface casing been cut off three feet below ground surface?

(4) Has well-site been levelled?

If this was a producing well, give date and amount of last production.

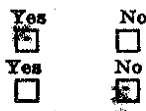

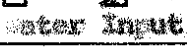

\section{CASING RECORD}

\begin{tabular}{|c|c|c|c|c|c|c|c|}
\hline & $\underset{\text { Feet }}{\text { PUT I }}$ & $\begin{array}{l}\text { ELL } \\
\text { Inches }\end{array}$ & $\begin{array}{l}\text { PUL } \\
\text { Feet }\end{array}$ & $\begin{array}{l}\text { OUT } \\
\text { Inches }\end{array}$ & $\begin{array}{c}\text { LEFT } \\
\text { Feet }\end{array}$ & $\begin{array}{l}\text { ELLL } \\
\text { Inches }\end{array}$ & Remarks \\
\hline $10-3 / 4$ & 2ne & $=$ & 5 & - & 105 & - & 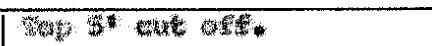 \\
\hline (3) & Th? & $=$ & उदुद & $=$ & 50 & & \\
\hline 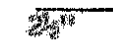 & 176 & 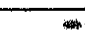 & T1696 & $=$ & द्वा & $=$ & 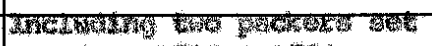 \\
\hline
\end{tabular}

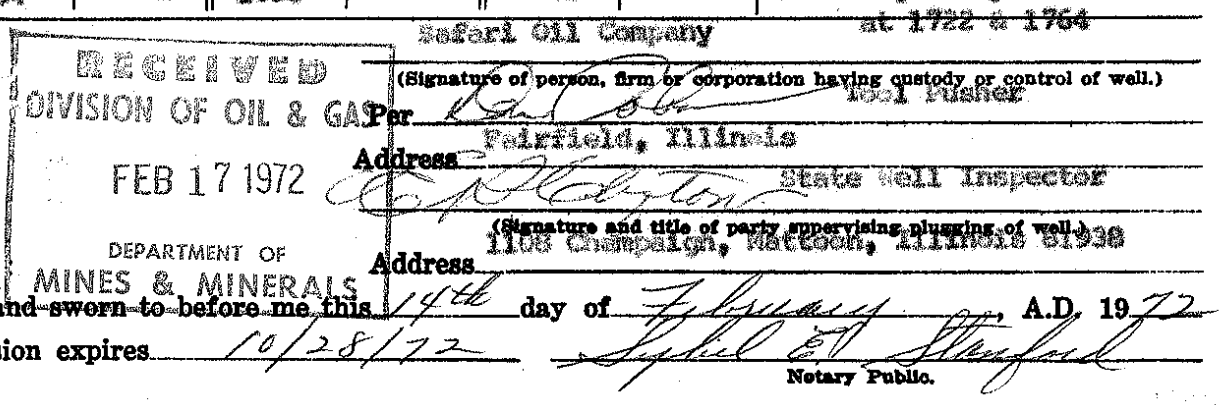




\section{County of coles $\}$ ss. WELL PLUGGING AFFIDAVIT}

\section{Rlohara Gray} do depose and say the following is a true and correct statement of the details of the plugging of a certain well drilled for 011 a

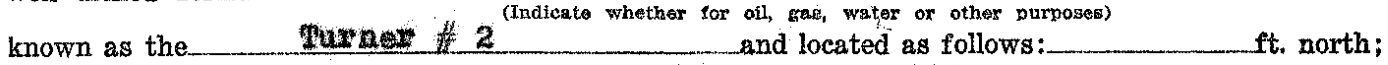

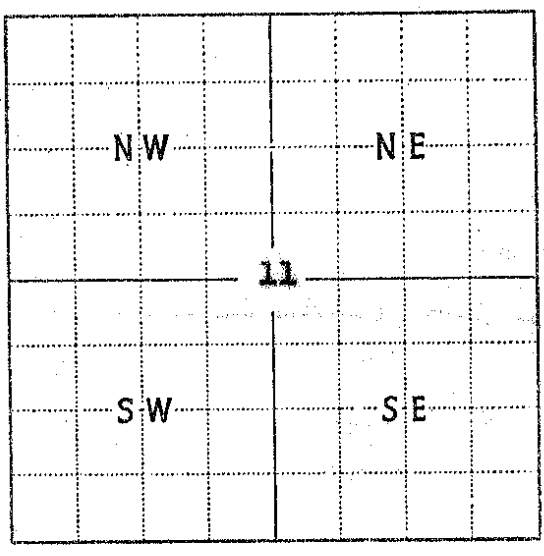

Loceto well accurately on plat of soction (Ghals one Inoh-2,000 tt.)
$990 \mathrm{ft}$. south; $330 \mathrm{ft}$. east; of the Nu comer of the Wu of the SW Quarter of the Quarter of Section 11 , Township 12 (North or 'Stutrit) Range 7 , (East or West), of the $3 \mathrm{ra}$ Principal Meridian, Oelos County, tllinois. Elevation above sea level is $\left\{\begin{array}{l}\text { Derrick Floor } 734 \quad \mathrm{ft} \text {. } \\ \text { Ground }\end{array}\right.$ Total depth 2013 Date permit to drill issued 15/45. Permit No.2124 Permit issued to Waltex Dunoan Date drilling began $12 / 15 / 45$ Date drilling completed $\quad 12 / 28 / 45$ Kind of drilling tools used Rotary Date plugging began $8 / 9 / 62$ Date plugging completed $\quad 8 / 10 / 62$

Lessor Har. Munes Address Hattoon, III.

Lessee Wal ter Duncan Address He Vermon, IIL.

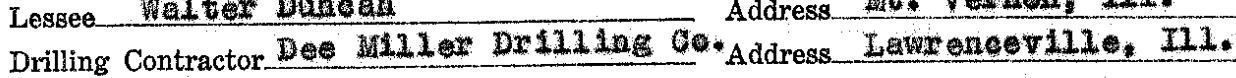

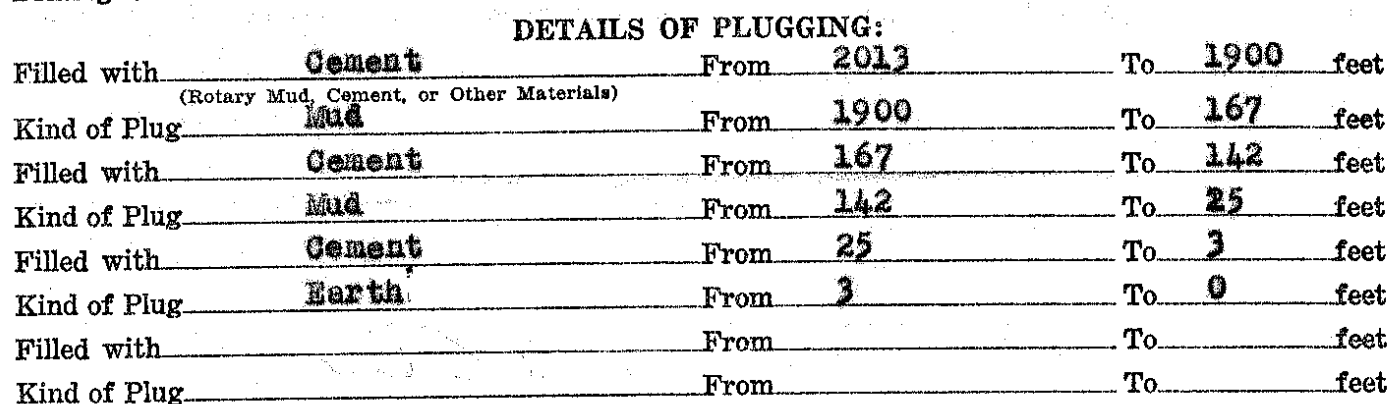

IF WORKABLE COAL BEDS WERE ENCOUNTERED IN THIS HOLE, DESCRIBE THE METHOD EMPLOYED TO PROTECT SAME. (A workable coal bed is thirty inches or more in thickness above 1,000 feet in depth) Nere

(1) Have pits and other excavations been filled?

(2) Have the following been removed?
Equipment $\square \square^{\text {No }}$. Concrete bases $\stackrel{\text { Yes }}{\square}\left[\begin{array}{ll}\text { No } \\ \square\end{array}\right.$

(3) Has surface casing been cut off three feet below ground surface?

(4) Has well-site been levelled?

If this was a producing well, give date and amount of last production $12 / 1 / 61-1,6 \mathrm{~b}$ CASING RECORD

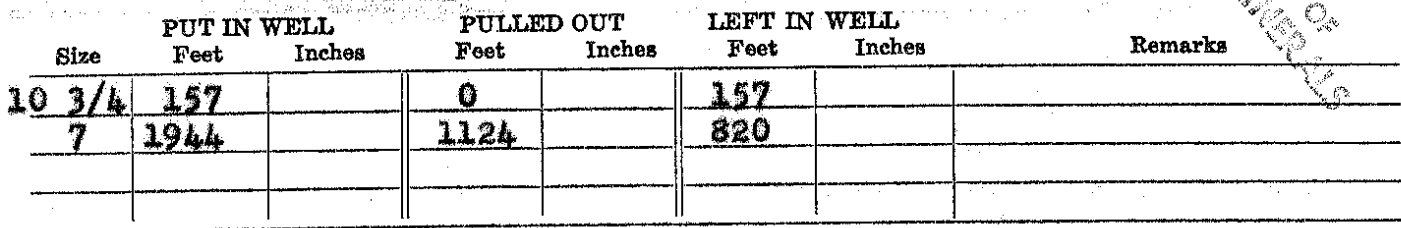

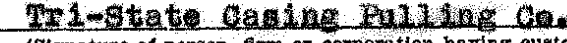

(signature of porgan, firm go corporation having custody or control of woll)

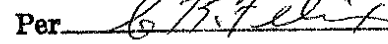

Address Box 353, Tatelelald, N11. 011 tare 1 Inspetor

(Slgnature and title of party supervising plugging of well.)

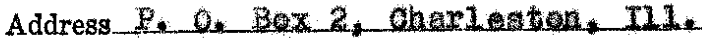

Subscribed and sworn to before me this 14 th day of Augugt My commission expires $5 / 26 / 65$ 
14-12N-7E 

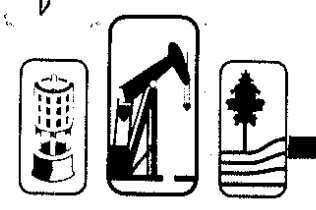

ILLINOIS DEPARTMENT OF MINES AND MINERALS

OIL AND GAS DIVISION
(217) $782-7756$

counTy $185 /$

P.O. BOX 1010 SUTTE 300

\section{OG-6}

WELL PLUGGING REPORT

756511

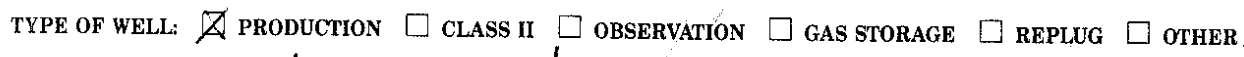
PERMitTeE: Charles Armantrocit well NAME: I.C RR Unit */ PERMit No.

$\frac{0 \times 1 / 67}{\text { (ISSUE DATE IF NO NUMBER) }}$

PERMITTEE NO. 110

REFERENCE NO. $12845 \%$

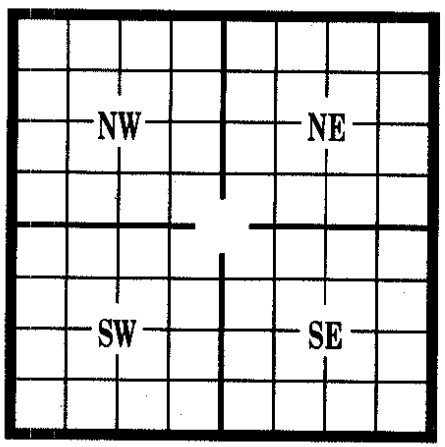

COUNTY CO/ES SECTION $\frac{14}{12 N}$ RANGE 1398 FT. EAST; OR____ FT. WEST OF THE SLe CORNER OF THE _ _ Q QUARTER OF THE _ _ _ QUARTER OF THE ___ _ _ QUARTER OF THE _ _ _ _ QUARTER.

\section{Mattoon}

WELL DATA:

\begin{tabular}{|c|c|c|}
\hline SURFACE ELEVATION & 730 & PRODUCING / INJECTION INTERVALS \\
\hline TOTAL DEPTH OF WELL & 3257 & FROM 3202 ro 3204 \\
\hline PLUGGED BACK TOTAL DEPTH & NONE FT. & FROM 1960 no $1865^{\circ}$ \\
\hline BASE OF FRESHWATER ZONE & 180 & FROM _ TO \\
\hline WORKABLE COALS PRESENT AT & NONE FT. & FROM $\_$TO \\
\hline
\end{tabular}

DETAILS OF PLUGGING:

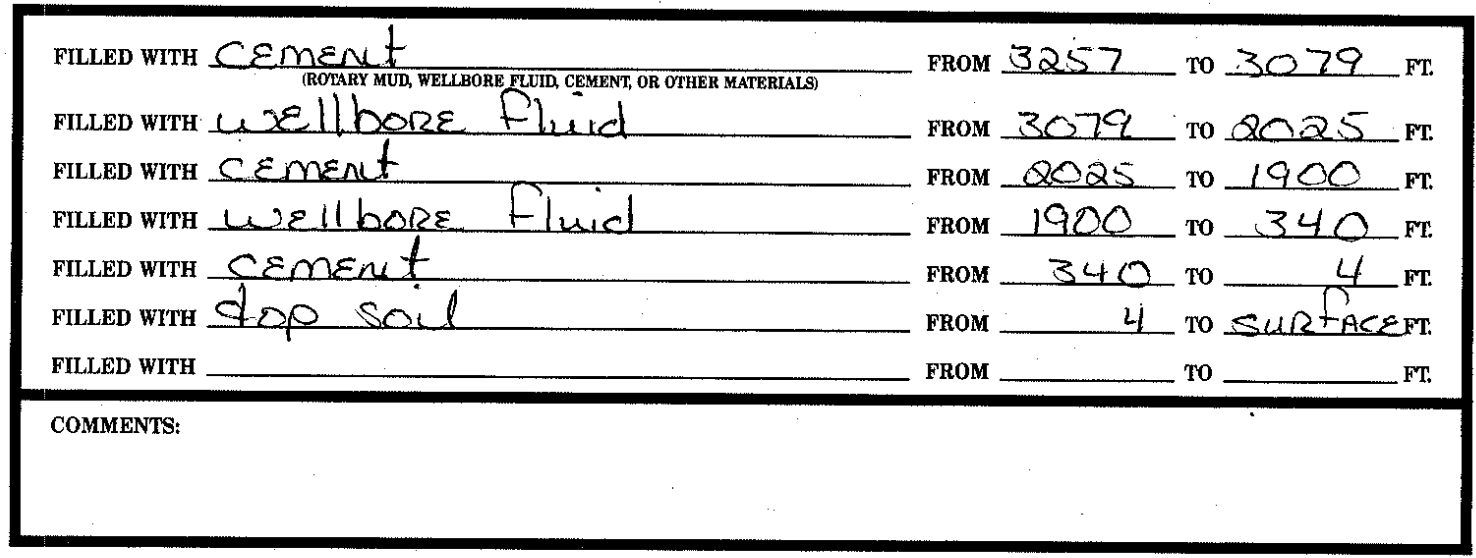

WELL DATA:

\begin{tabular}{|l|c|c|c|c|c|c|}
\hline \multicolumn{1}{|c|}{ CASING } & SIZE & $\begin{array}{c}\text { SETTING } \\
\text { DEPTH }\end{array}$ & $\begin{array}{c}\text { SACKS } \\
\text { CEMENT }\end{array}$ & $\begin{array}{c}\text { HOLE } \\
\text { SIZE }\end{array}$ & $\begin{array}{c}\text { EST TOP OF } \\
\text { CEMENT }\end{array}$ & $\begin{array}{c}\text { AMOUNT OF } \\
\text { CASING REMOVED }\end{array}$ \\
\hline SURFACE & $8^{5 / 8}$ & 142 & 75 & NR & 67 & 4 \\
\hline $\begin{array}{l}\text { INTERMEDIATE/MINE } \\
\text { STRING/OR LINER }\end{array}$ & & & & & & 4 \\
\hline PRODUCTION & $4 / 2$ & 3205 & 350 & $77 / 8$ & 16683 & $1 / 02$ \\
\hline
\end{tabular}

UNDER PENALTIES OF PERJURY, I DECLARE THAT I HAVE EXAMINED THIS FORM INCLUDING ACCOMPANYING STATEMENTS AND DOCUMENTS, AND TO THE BEST OF MY KNOWLEDGE, IT IS TRUE, CORRECT, AND COMPLETE.

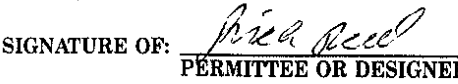

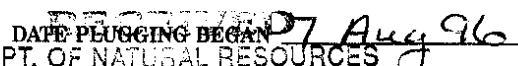
ADDRESS

\section{CITY, STATE}
IL 472-0198 (Rev 8/93)

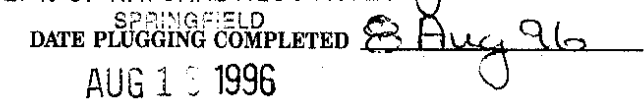



do depose and say the following is a true and correct statement of the details of the plugging of a certain well drilled for

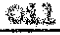

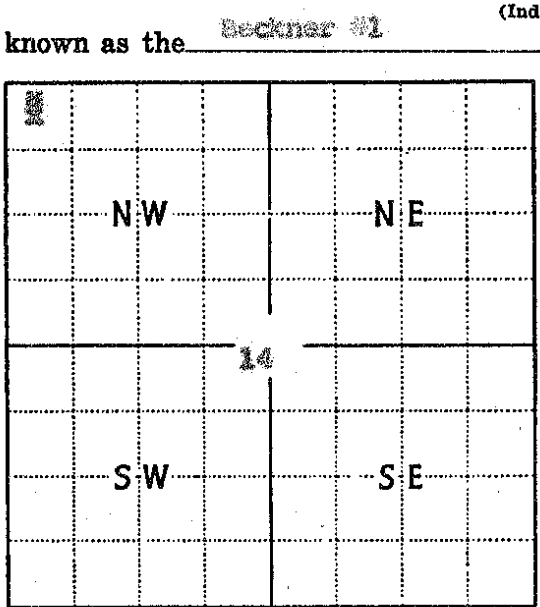

Locate well accurately on plat of section (Scale one inch-2,000 ft.)

oil, gas, water or other purposes) and located as follows:

ft. north;

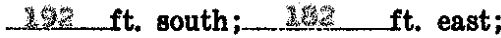
ft. west of the Nurner of the Q____uarter of the Quarter of

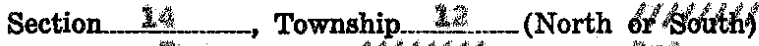
Range (East or West), of the

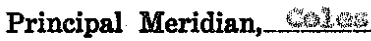
County, Illinois.

Elevation above sea level is $\left\{\begin{array}{l}\text { Derrick Floor___ } \\ \text { Ground }\end{array}\right.$

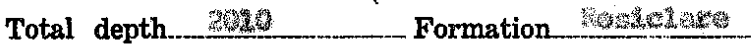

Date permit to drill issued

Permit issued to _._.

Date drilling began

Date drilling completed

Kind of drilling tools used.

Date plugging began_____on

Date plugging completed _

Lessor Address

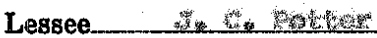
Address_____ n

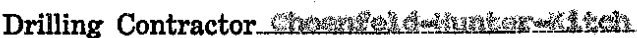
Address

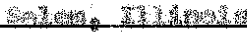

DETAILS OF PLUGGING:

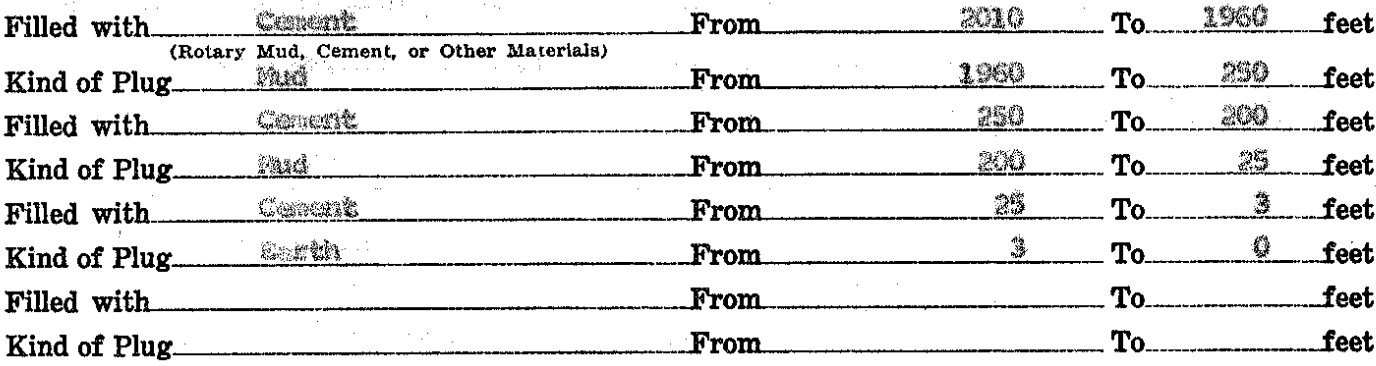

IF WORKABLE COAL BEDS WERE ENCOUNTERED IN THIS HOLE, DESCRIBE THE METHOD EMPLOYED TO PROTECT SAME. (A workable coal bed is thirty inches or more in thickness above 1,000 feet in depth)

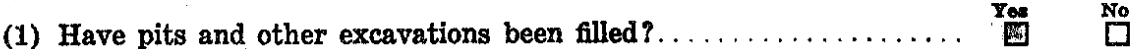

(2) Have the following been removed?

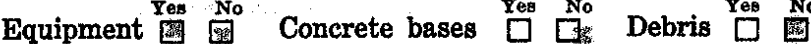

(3) Has surface casing been cut off three feet below ground surface?

(4) Has well-site been levelled?

If this was a producing well, give date and amount of last production

$\begin{array}{cc}\text { Yos } & \text { No } \\ \square & {\left[\begin{array}{l}\text { Yos } \\ \square\end{array}\right.} \\ \square & \text { No }\end{array}$

\begin{tabular}{l} 
Size $\begin{array}{c}\text { CASING RECORD } \\
\text { Feet IN WELL }\end{array}$ Inches \\
\hline
\end{tabular}




\section{OG-6 WELL PLUGGING REPORT}

TYPE OF WELL: $\quad$ X PRODUCTION $\square$ CLASS II $\square$ OBSERVATION $\square$ GAS STORAGE $\square$ REPLUG $\square$ OTHER PERMITTEE: PRF-96-3- Mattoon (Mattoon) 0ld Hole

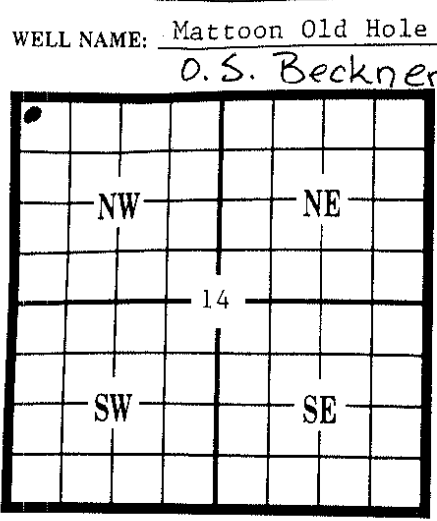

PERMIT No.

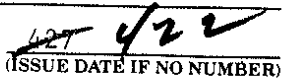

PERMITTEE NO.

REFERENCE NO. 604656

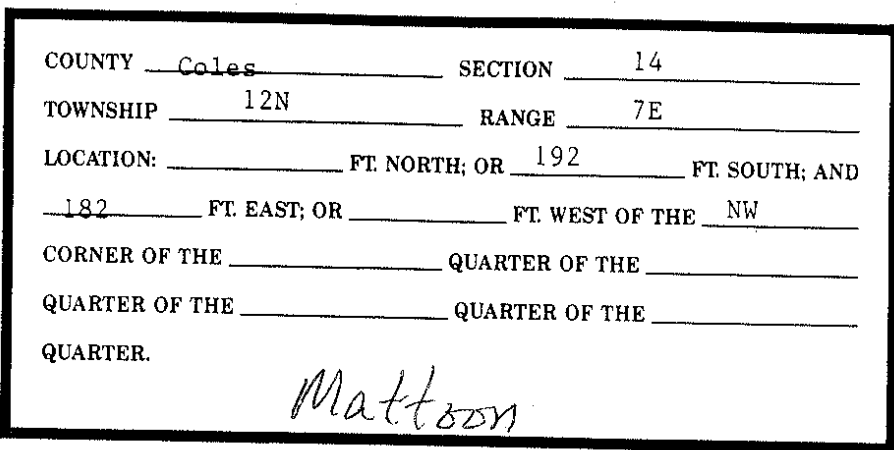

WELL DATA

\begin{tabular}{|c|c|c|}
\hline SURFACE ELEVATION & 730 & PRODUCING / INJECTION INTFRVAIS \\
\hline TOTAL DEPTH OF WELL & 2010 & FROM \\
\hline PLUGGED BACK TOTAL DEPTH & FT. & FROM $\longrightarrow$ To \\
\hline BASE OF FRESHWATER ZONE & {$[$ FT. } & $\ldots$ то \\
\hline WORKABLE COALS PRESENT AT & FT: & FROM $\_$To \\
\hline DESCRIBE PREVIOUS PLUGBACK & DURE: & 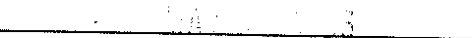 \\
\hline
\end{tabular}

DELAILS OF PLUGGING:

Cit +20

FILLED WITH cement

'ROTARY MUD, WELLBORE FLUID, CEMENT, OR OTHER MATERIALS\}

FROM 2010

T0 1960

FILLED WITH wellbore fluid

FILLED WITH cement

FILLED WITH earth

FROM 1960

T0 256 Fr.

FILLED WITH

FROM 256 TO 04 FT

FLLED wITH

FROM -04

TO GL_ FT

FILLED WITH

FROM

To

FILLED WITH

FROM

To

FT.

COMMENTS

FROM

TO

was drilling on cement, plugged 10-21-71. Drilled out top to replug, drilled to 261 ,

full of cement from 256 to the pipe at 256, circulated around back side, casing

WELL DATA:

\begin{tabular}{|l|c|c|c|c|c|c|}
\hline \multicolumn{1}{|c|}{ CASING } & SIZE & $\begin{array}{c}\text { SETTING } \\
\text { DEPTH }\end{array}$ & $\begin{array}{c}\text { SACKS } \\
\text { CEMENT }\end{array}$ & $\begin{array}{c}\text { HOLE } \\
\text { SIZE }\end{array}$ & $\begin{array}{c}\text { EST. TOP OF } \\
\text { CEMENT }\end{array}$ & $\begin{array}{c}\text { AMOUNT OF } \\
\text { CASING REMOVED }\end{array}$ \\
\hline SURFACE & $103 / 4$ & N/A & N/A & N/A & N/A & 4 \\
\hline $\begin{array}{l}\text { INTERMEDIATE MINE } \\
\text { STRING OR LINER }\end{array}$ & & & & & & \\
\hline PRODUCTION & $7 "$ & N/A & N/A & N/A & N/A & 4 \\
\hline
\end{tabular}

UNDER PENALTIES OF PERJLRY, I DECLARE THAT I HAVE EXAMINED THIS FORM INCLUDING ACCOMPANYING STATEMENTS AND DOCL MENTS, AND TO THE BEST GF MY KNOWLEDGE, IT IS TRUE, CORRECT, AND COMPLETE.

SIGNATURE OF: TERTER OR DESIGNEE

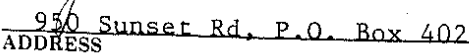

Clay City, IL 62824 CITY, STATE

IL $472-0198$ (Rev 8/93)
DATE PLUGGING BEGAN $\quad 4-24-96$

DATE PLUGGING COMPLETED 4-24-96

\section{REGEVE}

MAY $301996^{\circ}$ Printed on Recycled Paper 


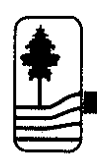

ILLINOIS DEPARTMENT OF MINES AND MINERALS

OIL AND GAS DIVISION (217) $782-7756$ COUUWWIY MO. 1080 P.O. BOX 10140
SPRINGFIELD, IL 62791 0140

\section{OG-6 WELL PLUGGING REPORT}

TYPE OF WELL: XX PRODUCTION $\square$ CLASS II $\square$ OBSERVATION $\square$ GAS STORAGE $\square$ REPLUG $\square$ OTHER $7.7 \%$ PERMITTEE: James Eickberg (PRF-96-3-Mattoon) PERMITTEE No. 414 WELL NAME: E. E. Brown \#1_ PERMIT No. $\frac{1543}{\text { (ISSUE DATE IF NO NUMBER) }}$ REFERENCE No. 124033

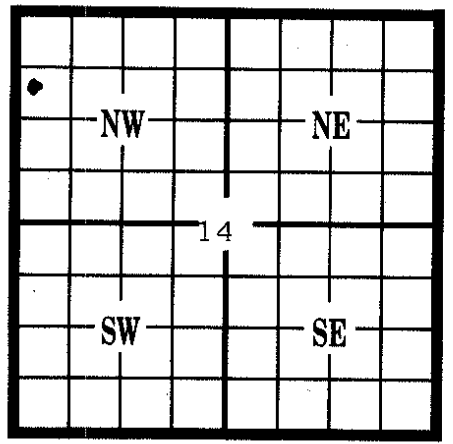

\begin{tabular}{l} 
COUNTY $\frac{\text { Coles }}{\text { SECTION }}$ \\
TOWNSHIP \\
\hline
\end{tabular}

LOCATION: FT. NORTH; OR 870 FT. SOUTH; AND 251 FT. EAST; OR CORNER OF THE QUARTER OF THE QUARTER.
FT. WEST OF THE NW NW QUARTER OF THE QUARTER OF THE

WELL DATA:

SURFACE ELEVATION

TOTAL DEPTH OF WELL.

PLUGGED BACK TOTAL DEPTH

BASE OF FRESHWATER ZONE

WORKABLE COALS PRESENT AT

DESCRIBE PREVIOUS PLUGBACK PROCEDURE:
PRODUCING / INJECTION INTERVALS

$\begin{array}{ll}\text { FROM N N } ~ & \text { To } \mathrm{N} / \mathrm{A} \\ \text { FROM } & \text { To } \\ \text { FROM } & \text { To } \\ \text { FROM } & \text { To }\end{array}$

\section{Mattoon}

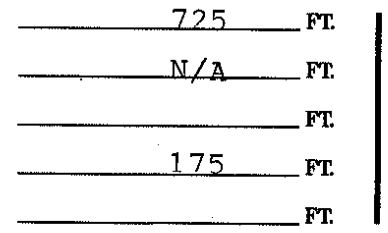

DETAILS OF PLUGGING:

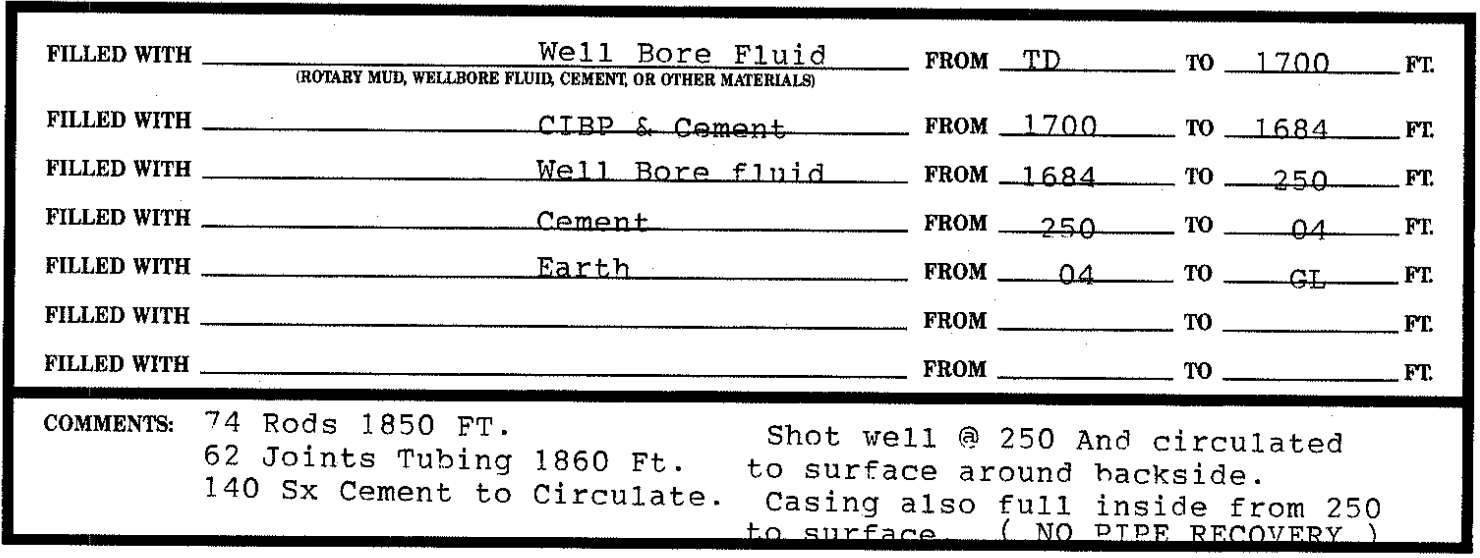

WELL DATA:

\begin{tabular}{|l|c|c|c|c|c|c|}
\hline \multicolumn{1}{|c|}{ CASING } & SIZE & $\begin{array}{c}\text { SETTING } \\
\text { DEPTH }\end{array}$ & $\begin{array}{c}\text { SACKS } \\
\text { CEMENT }\end{array}$ & $\begin{array}{c}\text { HOLE } \\
\text { SIZE }\end{array}$ & $\begin{array}{c}\text { EST. TOP OF } \\
\text { CEMENT }\end{array}$ & $\begin{array}{c}\text { AMOUNT OF } \\
\text { CASING REMOVED }\end{array}$ \\
\hline SURFACE & $85 / 8$ & N/A & N/A & N/A & N/A & 4 \\
\hline $\begin{array}{l}\text { INTERMEDIATE/MINE } \\
\text { STRING / OR LINER }\end{array}$ & & & & & & \\
\hline PRODUCTION & $51 / 2$ & 1952 & $\mathrm{~N} / \mathrm{A}$ & $\mathrm{N} / \mathrm{A}$ & $\mathrm{N} / \mathrm{A}$ & \\
\hline
\end{tabular}

UNDER PENALTIES OF PERJURY, I DECLARE THAT I HAVE EXAMINED THIS FORM INCLUDING ACCOMPANYING STATEMENTS AND DOCUMENTS, AND TO THE BEST OF MY KNOWLEDGE, IT IS TRUE, CORRECT, AND COMPLETE.
SIGNATURE OF:
Gim Undues
PERMIT TEE OR DESIGNEE
950 Sunset RC.PO BOX 402 DEPT. ADDRESS
Clay City I1.62824
CITY, STATE
IL 472-0198 (Rev 8/93)
DATE PLUGGING BEGAN 4/ J.8/96
TESETZDO

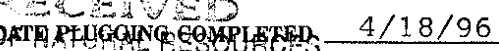 SPRINIFIELD
FR 31996
RECEIVD
PrAfedonzReycledfaper
(OVER) 


\section{OG-6 WELL PLUGGING REPORT}

TYPE OF WELL: XX PRODUCTION $\square$ CLASS II $\square$ OBSERVATION $\square$ GAS STORAGE $\square$ REPLUG $\square$ OTHER

PERMITTEE: James Eickherg (PRF-96-3-Mattoon )

WELL NAME: Da 11 as \#1

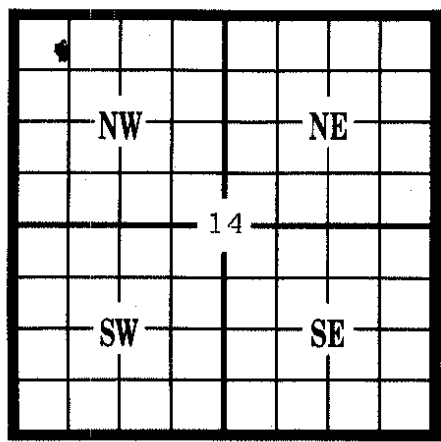

PERMIT NO. $\frac{1415}{\text { ISSUEDATEIE }}$

$\frac{1415}{\text { (ISSUE DATE IF NO NUMBER) }}$
PERMITTEE NO. 414

REFERENCE NO. 124035

WELL DATA

\begin{tabular}{|c|c|c|}
\hline SURFACE ELEVATION & $729 \quad \mathrm{FT}$ & PRODUCING / INJECTION INTERVALS \\
\hline TOTAL DEPTH OF WELL & $\mathrm{N} / \mathrm{A}$ & FROM $N / A \quad$ To $N / A$ \\
\hline PLUGGED BACK TOTAL DEPTH & FT. & FROM \\
\hline BASE OF FRESHWATER ZONE & $179 \quad$ FT. & To \\
\hline WORKABLE COALS PRESENT AT & _FT. & FROM \\
\hline
\end{tabular}

DESCRIBE PREVIOUS PLUGBACK PROCEDURE;

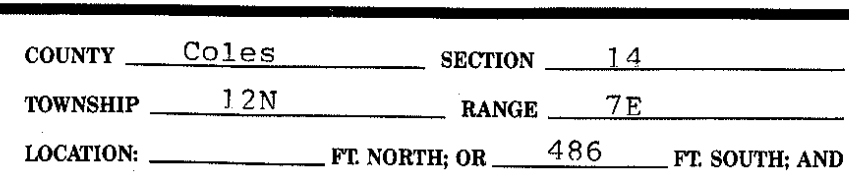
585 FT. EAST; OR

CORNER OF THE

FT. WEST OF THE NTT

QUARTER OF THE QUARTER OF THE

QUARTER.

Mattoon

DETAILS OF PLUGGING:

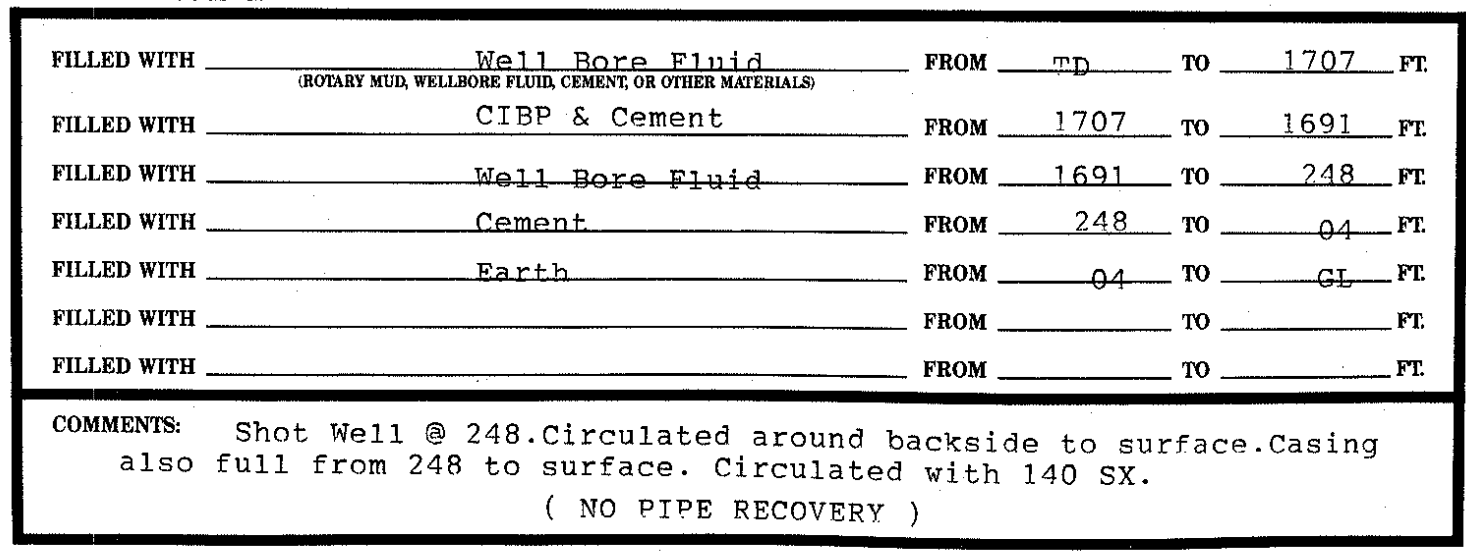

WELL DATA:

\begin{tabular}{|l|c|c|c|c|c|c|}
\hline \multicolumn{1}{|c|}{ CASING } & SIZE & $\begin{array}{c}\text { SETTING } \\
\text { DEPTH }\end{array}$ & $\begin{array}{c}\text { SACKS } \\
\text { CEMENT }\end{array}$ & $\begin{array}{c}\text { HOLE } \\
\text { SIZE }\end{array}$ & $\begin{array}{c}\text { EST TOP OF } \\
\text { CEMENT }\end{array}$ & $\begin{array}{c}\text { AMOUNT OF } \\
\text { CASING REMOVED }\end{array}$ \\
\hline SURFACE & $85 / 8$ & 104 & N/A & N/A & N/A & 4 \\
\hline $\begin{array}{l}\text { INTERMEDIATE MINE } \\
\text { STRING / OR LINER }\end{array}$ & & & & & & \\
\hline \begin{tabular}{l} 
PRODUCTION \\
\hline
\end{tabular} & $5 / 12$ & 1950 & $\mathrm{~N} / \mathrm{A}$ & $77 / 8$ & $\mathrm{~N} / \mathrm{A}$ & 4 \\
\hline
\end{tabular}

UNDER PENALTIES OF PERJURY, I DECLARE THAT I HAVE EXAMINED THIS FORM INCLUDING ACCOMPANYING STATEMENTS AND DOCUMENTS, AND TO THE BEST OF MY KXOWLEDGE, IT IS TRUE, CORRECT, AND COMPLETE.

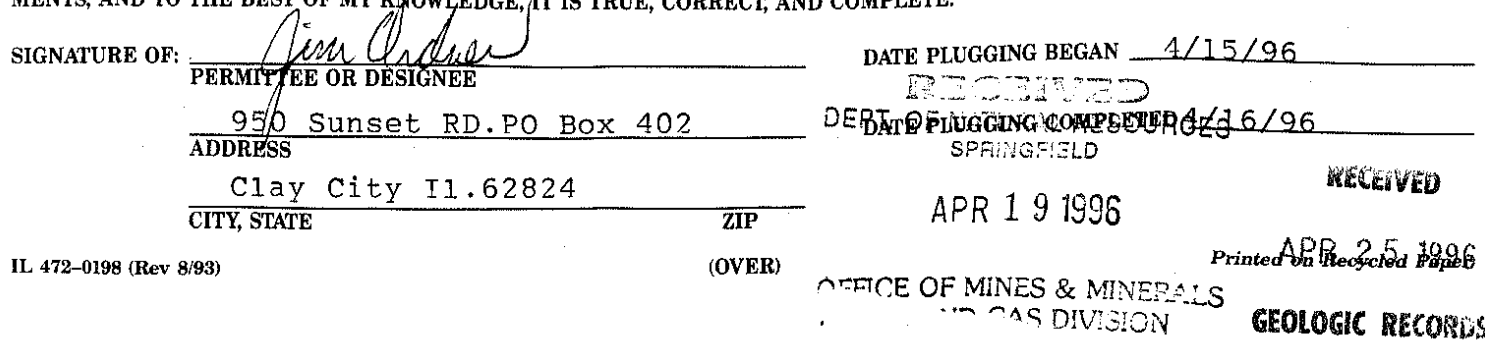



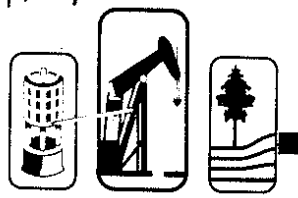

ILLINOIS DEPARTMENT OF MINES AND MINERALS

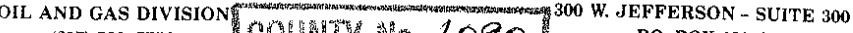

(217) $782-7756$ Po. Box 10140

\section{OG-6 WELL PLUGGING REPORT}

TYPE OF WELL: XX PRODUCTION $\square$ CLASS II $\square$ OBSERVATION $\square$ GAS STORAGE $\square$ REPLUG $\square$ OTHER__, : PERMITTEE: James Eickberg (PRF-96-3-Mattoon) WELL NAME: Johnson Unit \#1-20 PERMIT NO. 197 PERMITTEE NO. 414

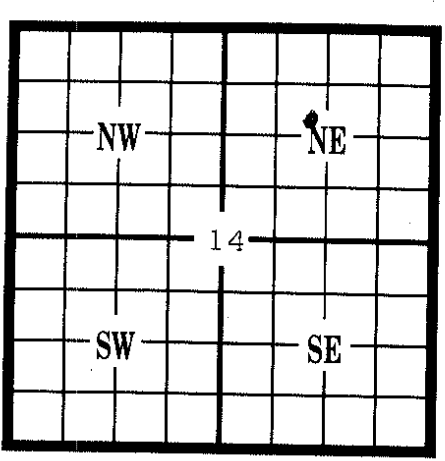
(ISSUE DATE IF NO NUMBER) REFERENCE NO. 124066

\begin{tabular}{|c|}
\hline COUNTY Coles \\
\hline TOWNSHIP $12 \mathrm{~N}$ \\
\hline \multirow{2}{*}{ LOCATION: } \\
\hline \\
\hline CORNER OF THE —_ QUARTER OF THE \\
\hline QUARTER OF THE ___ QUARTER OF THE \\
\hline QUARTER. \\
\hline
\end{tabular}

WELL DATA:

\begin{tabular}{|c|c|c|}
\hline SURFACE ELEVATION & $\begin{array}{l}730 \\
- \text { FT. }\end{array}$ & PRODUCING / INJECTION INTERVALS \\
\hline TOTAL DEPTH OF WELL & $\mathrm{N} / \mathrm{A} \quad$ FT. & FROM N N/A \\
\hline PLUGGED BACK TOTAL DEPTH & FT. & FROM $\longrightarrow$ To \\
\hline BASE OF FRESHWATER ZONE & $180 \quad$ FT. & FROM __ Tо \\
\hline WORKABLE COALS PRESENT AT & $\longrightarrow$ FT. & FROM — TO \\
\hline DESCRIBE PREVIOUS PLUGBACK & PROCEDURE: & \\
\hline
\end{tabular}

DETAILS OF PLUGGING:

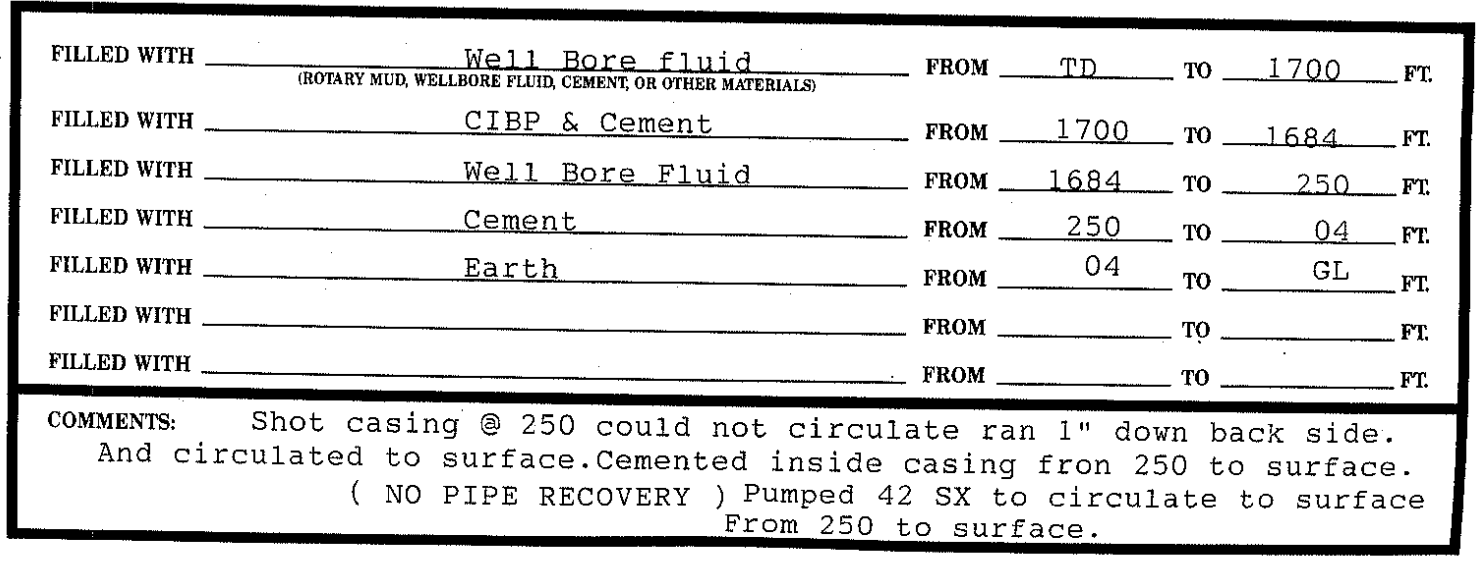

WELL DATA:

\begin{tabular}{|l|c|c|c|c|c|c|}
\hline \multicolumn{1}{|c|}{ CASING } & SIZE & $\begin{array}{c}\text { SETTING } \\
\text { DEPTH }\end{array}$ & $\begin{array}{c}\text { SACKS } \\
\text { CEMENT }\end{array}$ & $\begin{array}{c}\text { HOLE } \\
\text { SIZE }\end{array}$ & $\begin{array}{c}\text { EST. TOP OF } \\
\text { CEMENT }\end{array}$ & $\begin{array}{c}\text { AMOUNT OF } \\
\text { CASING REMOVED }\end{array}$ \\
\hline SURFACE & $85 / 8$ & N/A & N/A & N/A & N/A & 4 \\
\hline $\begin{array}{l}\text { INTERMEDIATE } / \text { MINE } \\
\text { STRING / OR LINER }\end{array}$ & & & & & & \\
\hline \begin{tabular}{l} 
PRODUCTION \\
\hline
\end{tabular} & $51 / 2$ & 1965 & N/A & N/A & N/A & 4 \\
\hline
\end{tabular}

UNDER PENALTIES OF PERJURY, I DECLARE THAT I HAVE EXAMINED THIS FORM INCLUDING ACCOMPANYING STATEMENTS AND DOCU. MENTS, AND TO THE BEST OF MY KNOWLEDGE, IT IS TRUE, CORRECT, AND COMPLETE.

SIGNATURE OF: $\frac{\text { PERMTTEE OR DESIGNEE }}{\text { STE }}$

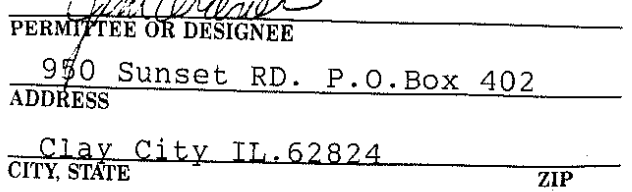

IL $472-0198$ (Rev 8/93)
DATEPLEGGING BEGAN $4 / 10 / 96$ OEPT. OF A FOUFCA $311 / 96$

$$
\text { APR } 191006
$$

Hetivido

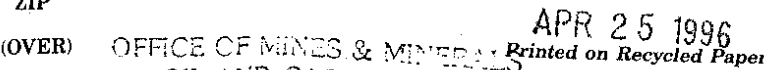

MI. AND GAS DUV $3 \%$ GEOLOGL RECOROS 


\section{OG-6 WELL PLUGGING REPORT}

TYPE OF WELL: XX PRODUCTION $\square$ CLASS II $\square$ OBSERVATION $\square$ GAS STORAGE $\square$ REPLUG $\square$ OTHER

PERMITTE: James Eickberg (PRF-96-3-Mattoon)

WELL NAME: Murray \#1

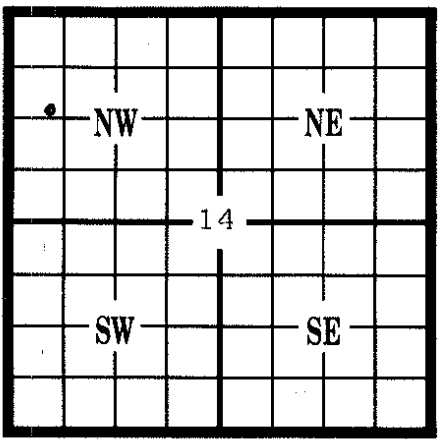
PERMIT NO. $\frac{\theta \theta \theta \theta 0 \theta^{21 / 9}}{\text { (ISSUE DATE IF NO NUMBER) }}$

PERMITTEE NO. 414

WELL DATA:

\begin{tabular}{|c|c|c|}
\hline SURFACE ELEVATION & $729 \quad$ FT. & PRODUCING / INJECTION INTERVALS \\
\hline TOTAL DEPTH OF WELL & $\mathrm{N} / \mathrm{A} \quad \mathrm{FT}$. & FROM N N $\quad$ To $\mathrm{N} / \mathrm{A}$ \\
\hline PLUGGED BACK TOTAL DEPTH & FT. & FROM \\
\hline BASE OF FRESHWATER ZONE & 179 & To \\
\hline WORKABLE COALS PRESENT AT & FT. & To \\
\hline SCRIBE PREVIOUS PLUGBACK & & \\
\hline
\end{tabular}

DETAILS OF PLUGGING:

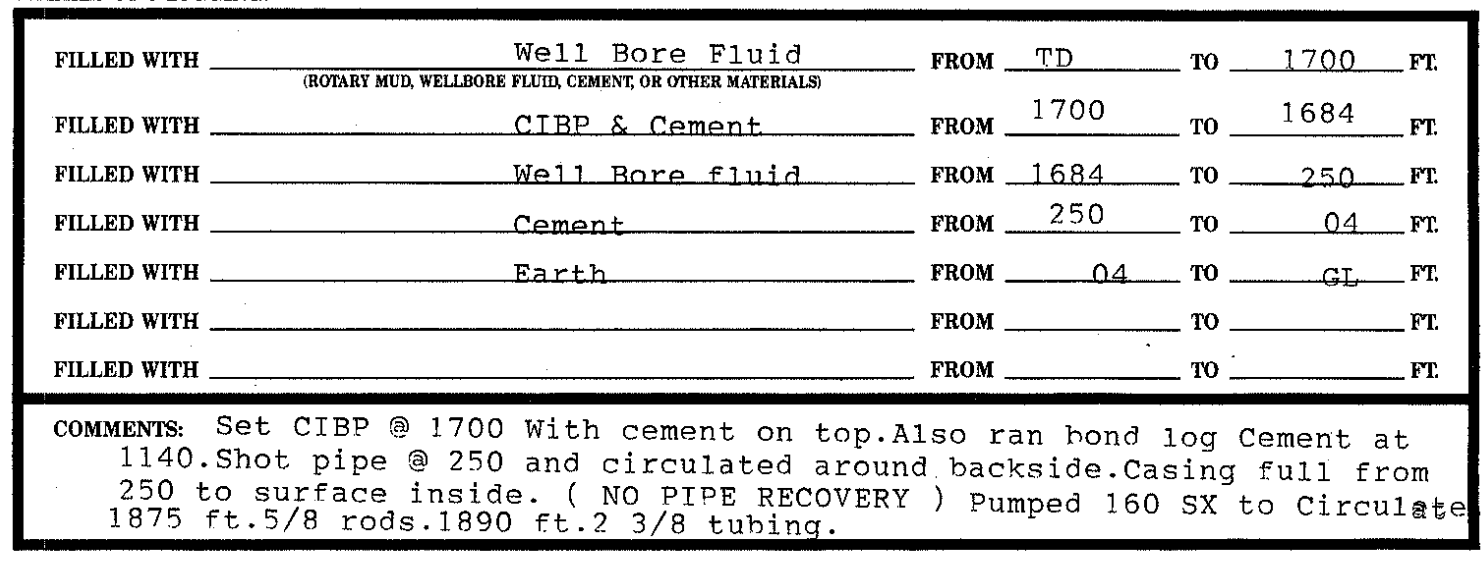

WELL DATA:

\begin{tabular}{|l|l|l|l|l|l|l|}
\hline \multicolumn{1}{|c|}{ CASING } & SIZE & $\begin{array}{c}\text { SETTING } \\
\text { DEPTH }\end{array}$ & $\begin{array}{c}\text { SACKS } \\
\text { CEMENT }\end{array}$ & $\begin{array}{c}\text { HOLE } \\
\text { SIZE }\end{array}$ & $\begin{array}{c}\text { EST TOP OF } \\
\text { CEMENT }\end{array}$ & $\begin{array}{c}\text { AMOUNT OF } \\
\text { CASING REMOVED }\end{array}$ \\
\hline SURFACE & None & N/A & N/A & N/A & N/A & AOne \\
\hline $\begin{array}{l}\text { INTERMEDIATE /MINE } \\
\text { STRING / OR LINER }\end{array}$ & & & & & & \\
\hline PRODUCTION & & $\mathrm{N} / \mathrm{A}$ & $\mathrm{N} / \mathrm{A}$ & $\mathrm{N} / \mathrm{A}$ & $\mathrm{N} / \mathrm{A}$ & \\
\hline
\end{tabular}

UNDER PENALTIES OF PERJURY, I DECLARE THAT I HAVE EXAMINED THIS FORM INCLUDING ACCOMPANYING STATEMENTS AND DOCUMENTS, AND TO THE BEST OF MY KNQWLEDGE, IT IS TRUE, CORRECT, AND COMPLETE.

Signature of: Vine draer PERMTTEE OR BESIGNEE

950/Sunset $R D$ PO $B O X \quad 402$ ADDRESS

Clay City I1.62824 CITY, STATE

IL 472-0198 (Rev 8/93)

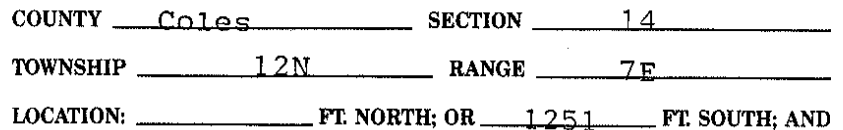

586 FT. EAST; OH QUARTER OF THE

QUARTER OF THE QUARTER OF THE QUARTER.

\section{Mattoon}




\section{a

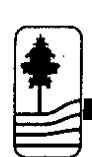 \\ ILLINOIS DEPARTMENT OF MINES AND MINERALS OIL AND GAS DIVISION (217) $782-7756$

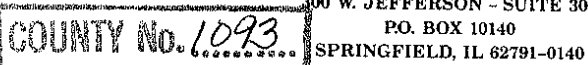 \\ OG-6 WELL PLUGGING REPORT}

TYPE OF WELL: XX PRODUCTION $\square$ CLASS II $\square$ OBSERVATION $\square$ GAS STORAGE $\square$ REPLUG $\square$ OTHER PERMitTeE: Janes Eickberg (PRE-96-3-Mattoon) PERMITTEE NO. 414 WELL NAME: Ralph Stroh? \#1 PERMTT NO. 617 REFERENCE No. 124076

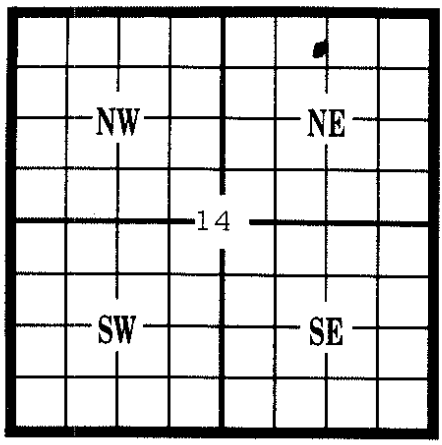

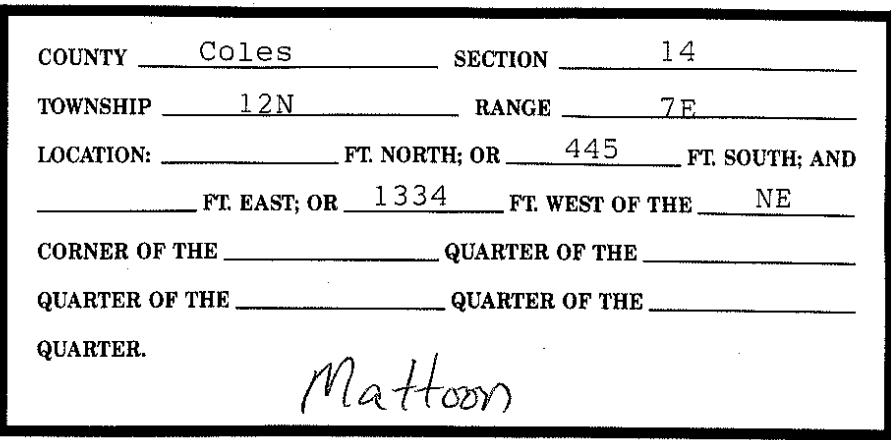

WELL DATA:

\begin{tabular}{|c|c|c|}
\hline SURFACE ELEVATION & $729 \quad$ FT. & PRODUCING / INJECTION INTERVALS \\
\hline TOTAL DEPTH OF WELL & $\mathrm{N} / \mathrm{A} \quad \mathrm{FT}$. & FROM $\quad N / A$ \\
\hline PLUGGED BACK TOTAL DEPTH & FT. & To \\
\hline BASE OF FRESHWATER ZONE & $179 \quad \mathrm{FT}$ & To \\
\hline WORKABLE COALS PRESENT AT & _ FT. & FROM \\
\hline DESCRIBE PREVIOUS PLUGBACK & & \\
\hline
\end{tabular}

DETAILS OF PLUGGING:

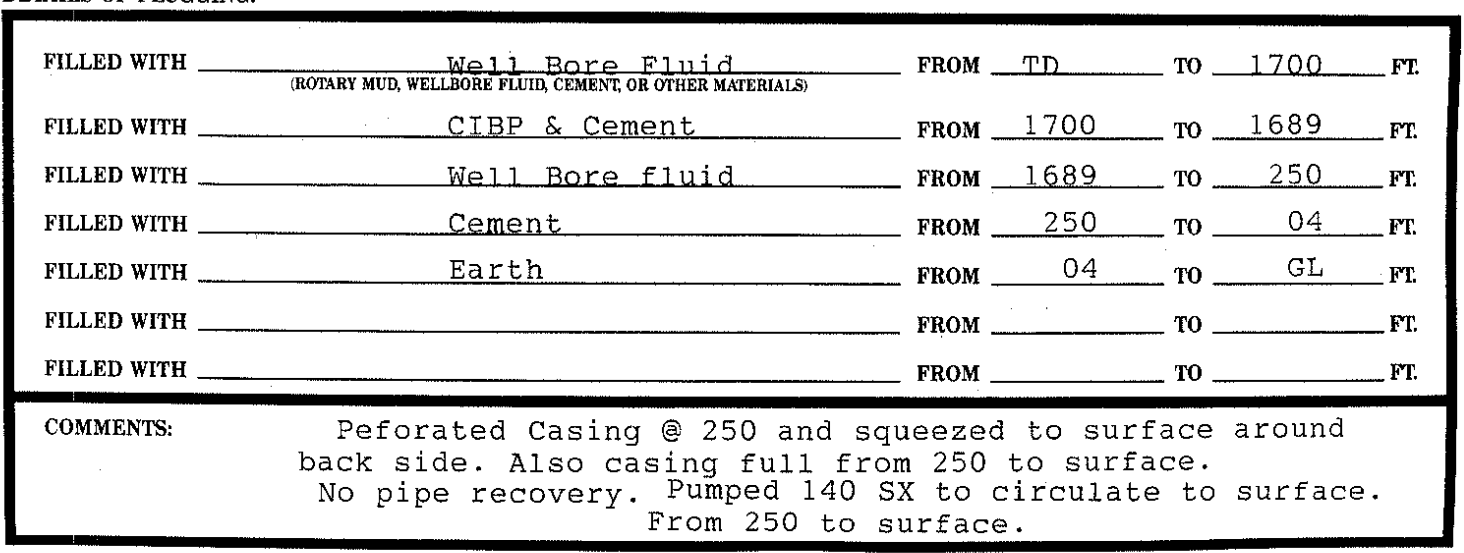

WELL DATA:

\begin{tabular}{|l|c|c|c|c|c|c|}
\hline \multicolumn{1}{|c|}{ CASING } & SIZE & $\begin{array}{c}\text { SETTING } \\
\text { DEPTH }\end{array}$ & $\begin{array}{c}\text { SACKS } \\
\text { CEMENT }\end{array}$ & $\begin{array}{c}\text { HOLE } \\
\text { SIZE }\end{array}$ & $\begin{array}{c}\text { EST, TOP OF } \\
\text { CEMENT }\end{array}$ & $\begin{array}{c}\text { AMOUNT OF } \\
\text { CASING REMOVED }\end{array}$ \\
\hline SURFACE & $103 / 4$ & N/A & N/A & N/A & N/A & 0 \\
\hline $\begin{array}{l}\text { INTERMEDIATE /MINE } \\
\text { STRING / OR LINER }\end{array}$ & & & & & & \\
\hline PRODUCTION & $7 "$ & N/A & N/A & N/A & N/A & 4 \\
\hline
\end{tabular}

UNDER PENALTIES OF PERJURY, I DECLARE THAT I HAVE EXAMINED THIS FORM INCLUDING ACCOMPANYING STATEMENTS AND DOCUMENTS, AND TO THE BEST OF MY GNOWLEDGE, IT IS TRUE, CORRECT, AND COMPLETE.
SignATURE OF: $\frac{\text { PERMITEE OR DESIGNEE }}{\text { PETEN }}$ PERMITEE OR DESIGNEE
9/50 Sunset RD. PO BOX 402
ADDRESS City II. 62824
Clay CItY STATE
DATE PLUGGING BEGAN $\quad 4 / 8 / 96$ 


\section{OG-6 WELL PLUGGING REPORT

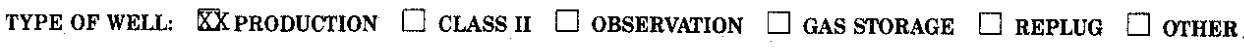

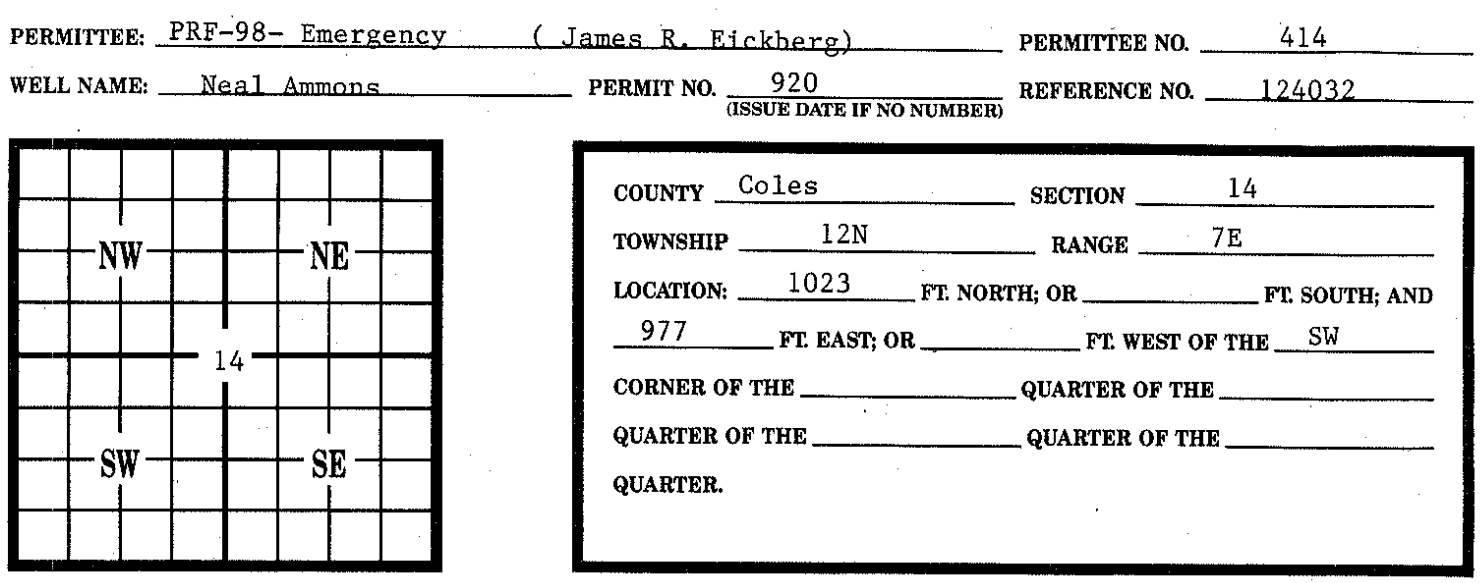

WELL DATA:

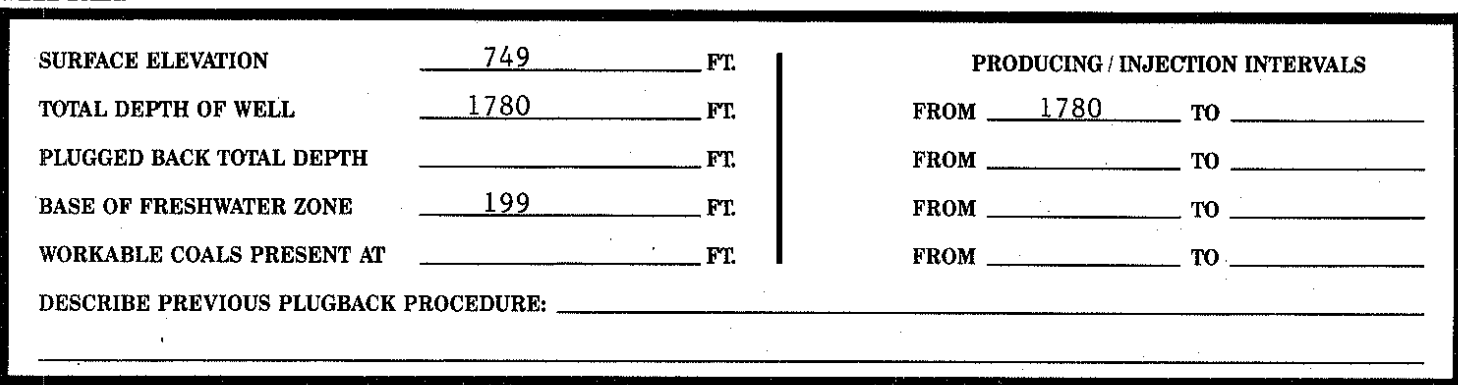

DETAILS OF PLUGGING:

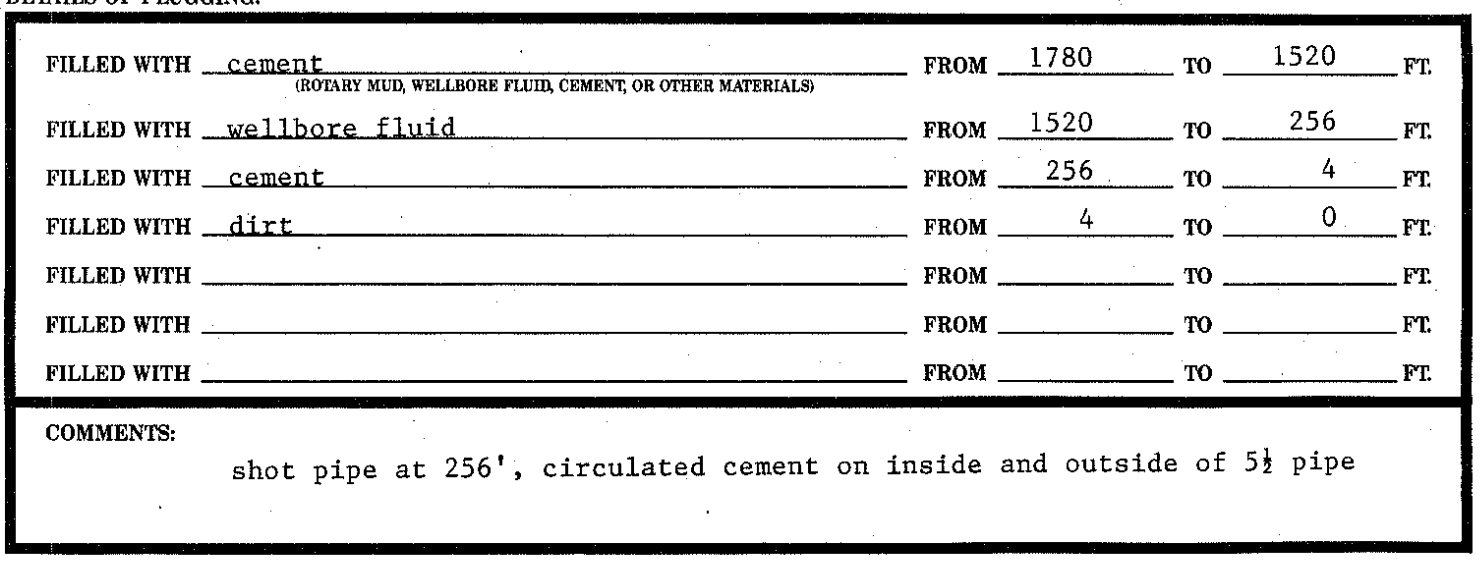

WELL DATA:

\begin{tabular}{|l|c|c|c|c|c|c|}
\hline \multicolumn{1}{|c|}{ CASING } & SIZE & $\begin{array}{c}\text { SETTING } \\
\text { DEPTH }\end{array}$ & $\begin{array}{c}\text { SACKS } \\
\text { CEMENT }\end{array}$ & $\begin{array}{c}\text { HOLE } \\
\text { SIZE }\end{array}$ & $\begin{array}{c}\text { EST TOP OF } \\
\text { CEMENT }\end{array}$ & $\begin{array}{c}\text { AMOUNT OF } \\
\text { CASING REMOVED }\end{array}$ \\
\hline SURFACE & 7 & & & $77 / 8$ & & $4^{\prime}$ cutoff \\
\hline $\begin{array}{l}\text { INTERMEDIATE /MINE } \\
\text { STRING / OR LINER }\end{array}$ & & & & & & \\
\hline PRODUCTION & $5 \frac{1}{2}$ & 1780 & & $77 / 8$ & & 4 'cutoff \\
\hline
\end{tabular}

UNDER PENALTIES OF PERJURY, I HLCLARE THAT I HAVE EXAMINED THIS FORM INCLUDING ACCOMPANYING STATEMENTS AND DOCUMENTS, AND TO THE BEST ORMY KW WWEPGE, IT IS TRUE, CORRECT, AND COMPLETE.

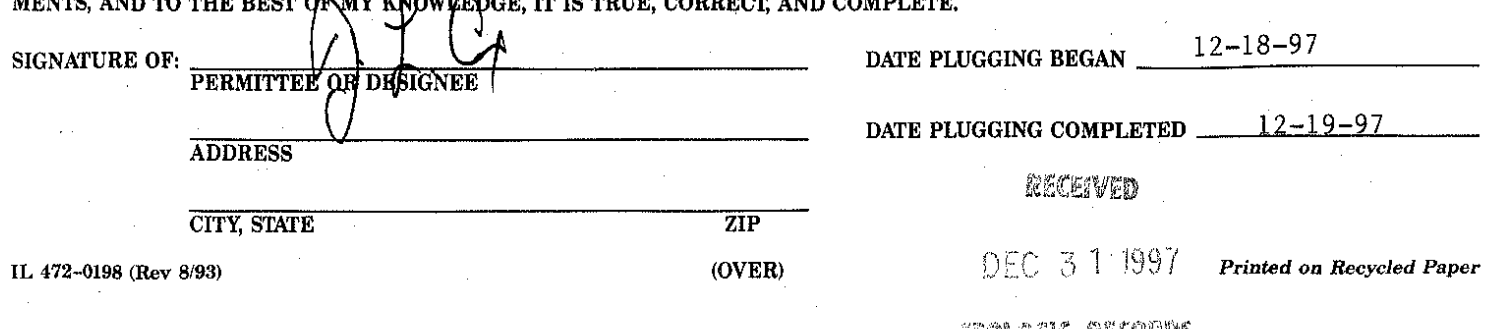



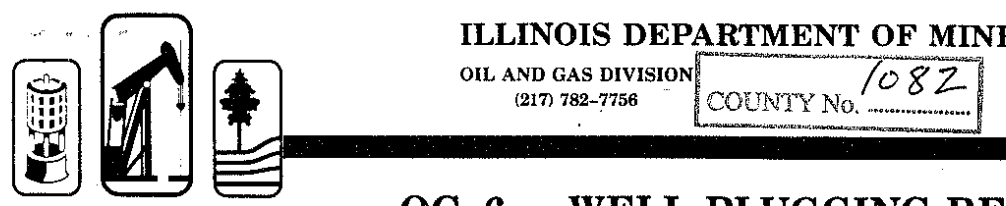

AND MINERALS

OG-6 WELL PLUGGING REPORT

$78 \cap 75.3$

TYPE OF WELL: $\quad$ PRODUCTION $\square$ CLASS II $\square$ OBSERVATION $\square$ GAS STORAGE $\square$ REPLUG $\square$ OTHER PERMITTEE: PRF-98-Emergency (James R. Eickberg) WELL NAME: Stoker \#1 PERMIT NO. $\frac{1820}{\text { (ISSUE }}$ PERMITTEE No. $\quad 414$

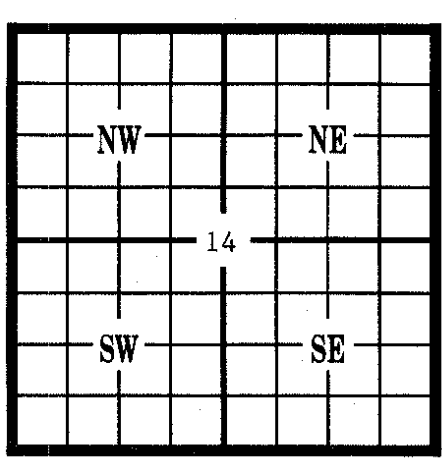

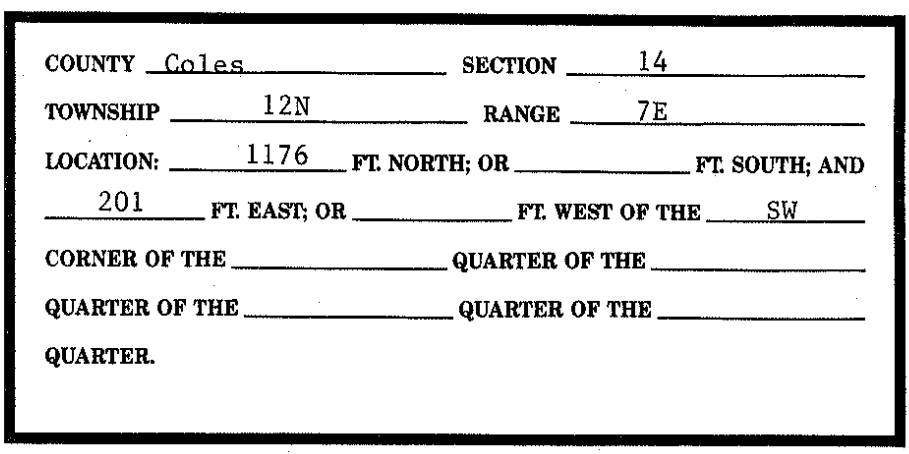

WELL DATA:

\begin{tabular}{|c|c|c|}
\hline SURFACE ELEVATION & 749 & PRODUCING / INJECTION INTERVALS \\
\hline TOTAL DEPTH OF WELL & 1805 & FROM \\
\hline PLUGGED BACK TOTAL DEPTH & 1805 & FROM \\
\hline BASE OF FRESHWATER ZONE & FT. & FROM — TO \\
\hline WORKABLE COALS PRESENT AT & FT. & FROM — To \\
\hline \multicolumn{3}{|c|}{ DESCRIBE PREVIOUS PLUGBACK PROCEDURE: } \\
\hline
\end{tabular}

DETAILS OF PLUGGING:

\begin{tabular}{|c|c|c|c|c|}
\hline FILLED WITH & $\begin{array}{l}\text { cement } \\
\text { (ROTARY MUD, WELLBORE FLUID, CEMENT, OR OTHER MATERIALS) }\end{array}$ & & 1805 To & 1550 FT. \\
\hline FILLED WITH & weIlbore fluid & FROM & 1550 & 275 \\
\hline FILLED WITH & shot at 275 & FROM & 275 To & $4 \quad \mathrm{FT}$. \\
\hline FILLED WITH & dirt & FROM & $4 \quad$ T0 & FT. \\
\hline FILLED WITH & $\square$ & FROM & T0 & _ FT. \\
\hline FILLED WITH & - & FROM & To & FT. \\
\hline FILLED WITH & & FROM & _ & FT. \\
\hline COMMENTS: & & & & \\
\hline
\end{tabular}

WELL DATA:

\begin{tabular}{|l|c|c|c|c|c|c|}
\hline \multicolumn{1}{|c|}{ CASING } & SIZE & $\begin{array}{c}\text { SETTING } \\
\text { DEPTH }\end{array}$ & $\begin{array}{c}\text { SACKS } \\
\text { CEMENT }\end{array}$ & $\begin{array}{c}\text { HOLE } \\
\text { SIZE }\end{array}$ & $\begin{array}{c}\text { EST TOP OF } \\
\text { CEMENT }\end{array}$ & $\begin{array}{c}\text { AMOUNT OF } \\
\text { CASING REMOVED }\end{array}$ \\
\hline $\begin{array}{l}\text { SURFACE } \\
\text { INTERMEDIATE /MINE } \\
\text { STRING / OR LINER }\end{array}$ & $503 / 4$ & & & & & 4'cutoff \\
\hline PRODUCTION & $3 \frac{1}{2}$ & & & & & pulled \\
\hline
\end{tabular}

UNDER PENALTIES OF PERJURY, DECJARE THAT I HAVE EXAMINED THIS FORM INCLUDING ACCOMPANYING STATEMENTS AND DOCUMENTS, AND TO THE BSTT OF MY KNOWLFDGE, IT IS TRUE, CORRECT, AND COMPLETE.

SIGNATURE OF: ADDRESS

\section{CITY, STATE}

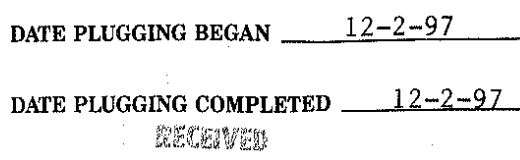

DATE PLUGGING BEGAN $12-2-97$ DATE PLUGGING COMPLETED $12-2-97$

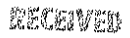

m5? 1907

(OVER) 


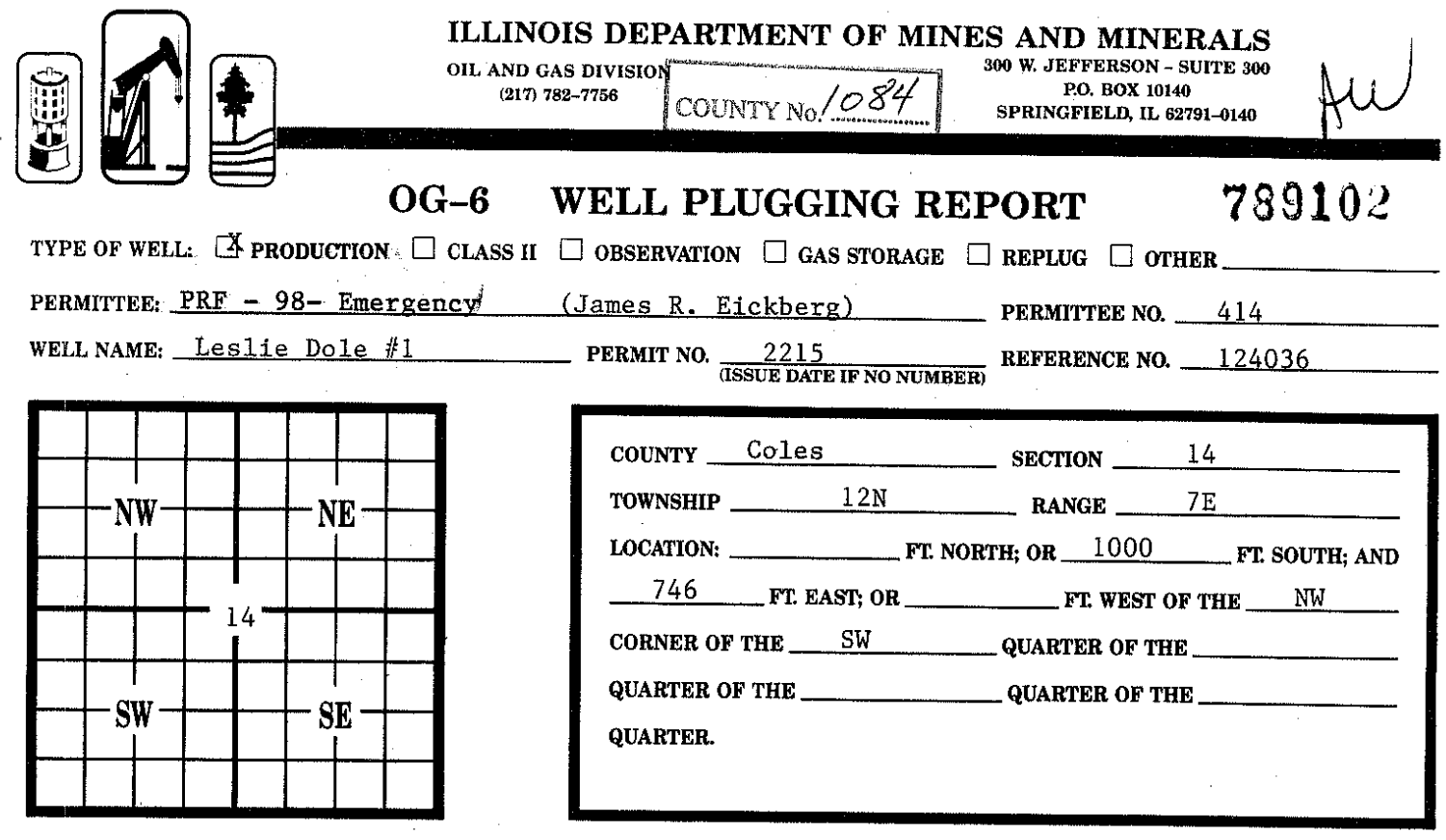

WELL DATA:

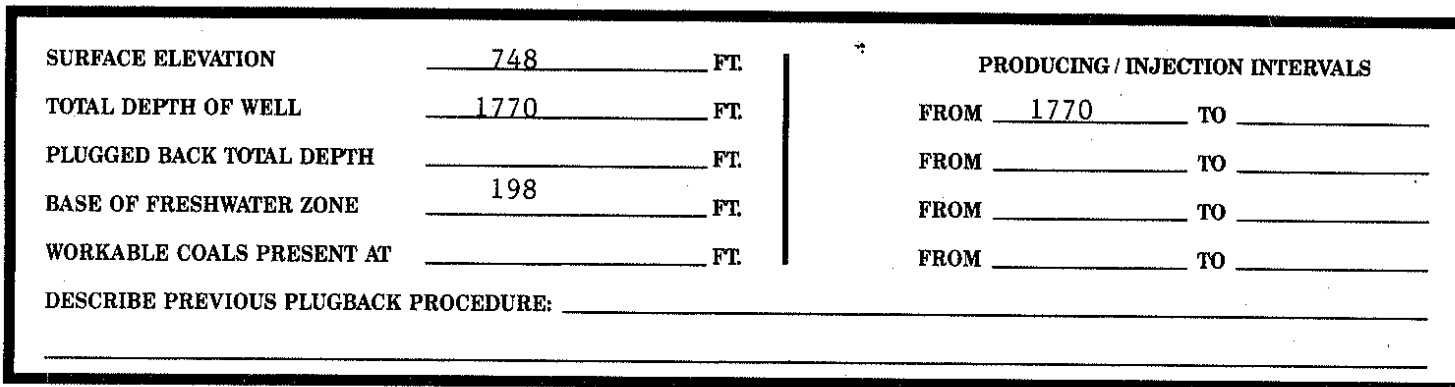

DETAILS OF PLUGGING:

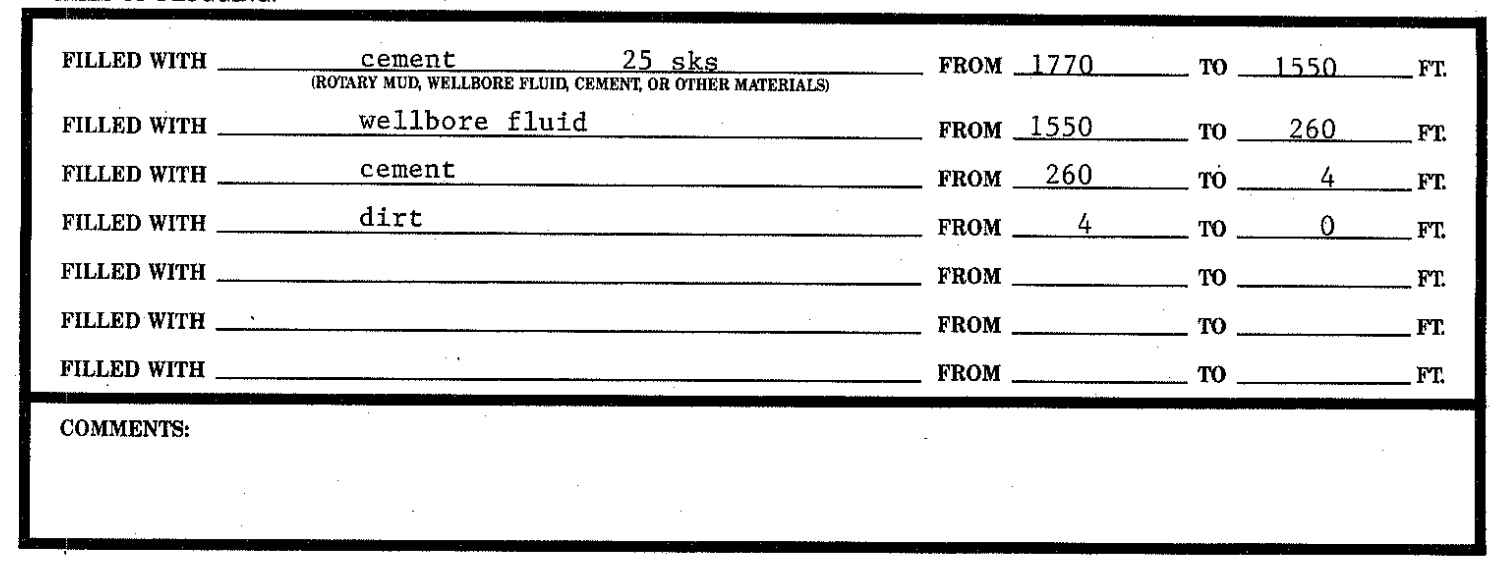

\begin{tabular}{|l|c|c|c|c|c|c|}
\hline \multicolumn{1}{|c|}{ WASING } & SIZE & $\begin{array}{c}\text { SETTING } \\
\text { DEPTH }\end{array}$ & $\begin{array}{c}\text { SACKS } \\
\text { CEMENT }\end{array}$ & $\begin{array}{c}\text { HOLE } \\
\text { SIZE }\end{array}$ & $\begin{array}{c}\text { EST. TOP OF } \\
\text { CEMENT }\end{array}$ & $\begin{array}{c}\text { AMOUNT OF } \\
\text { CASING REMOVED }\end{array}$ \\
\hline SURFACE & $85 / 8$ & 93 & & $12 \frac{1}{4}$ & & \\
\hline $\begin{array}{l}\text { INTERMEDIATE/MINE } \\
\text { STRING/OR LINER }\end{array}$ & & & & & & \\
\hline PRODUCTION & $5 \frac{1}{2}$ & 1770 & & $77 / 8$ & & 260 \\
\hline
\end{tabular}

UNDER PENALTIES OF PERJYRY, I ZECLARE THAT I HAVE EXAMINED THIS FORM INCLUDING ACCOMPANYING STATEMENTS AND DOCU. MENTS, AND TO THE BEST Of MY KNOWLEDGE, IT IS TRUE, CORRECT, AND COMPLETE.

SIGNATURE OF: L C C PERMITU UE OR DESIGNEE ADDRESS

IL 472-Q198 (Rev 8/93)
DATE PLUGGING BEGAN $\quad 12-15-97$

DATE PLUGGING COMPLETED

$12-16-97$

\section{CTTX, STATE}

CITY, STATE

(OVER) 


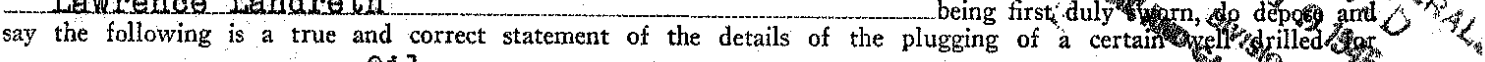
011

(Indicate whether for oil, gas, water or other purposes)

$$
\text { ft. south ; } 2546
$$

known as the cempbe 11 \#1

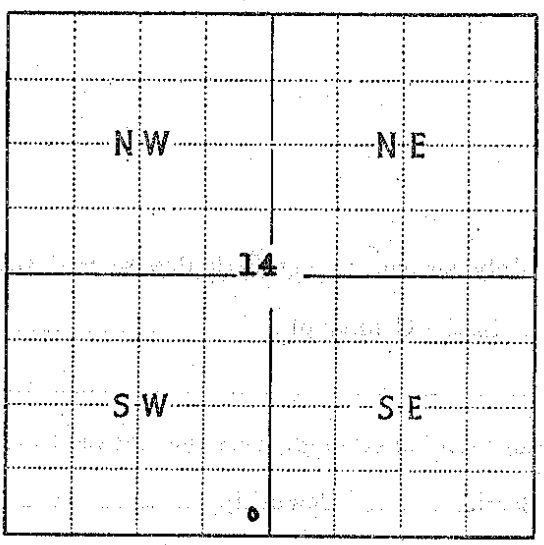

Lacate well accurately on plat of section (Scale one inch-2,000 ft.) of the S.W.

$$
\text { corner }
$$

of the _._. Quarter of the

Section 14_...., Township 12N

Range $7 \mathbf{E}$

, (East or West)

Colos

Counts

Principal Meridian,

Elevation above sea level is $\left\{\begin{array}{l}\text { Derrick Floor } 712 \quad \mathrm{ft} . \\ \mathrm{fround}\end{array}\right.$

Ground $\mathrm{ft}$

Total depth of well is $\quad 2953$

Date permit to drill issued $6-5-46$

Permit issued to J. C. Potter

Date drilling began $\quad 6-5-46$

Date drilling completed $6-11-46$

Kind of drilling tools used Retary

Date plugging began $6-11-46$

Date plugging completed $6-11-46$

Lessor Blalock

Lesse Reeres \& Dixon

Drilling Contractor Schoenfeldt Eunter \& Kitch Addre

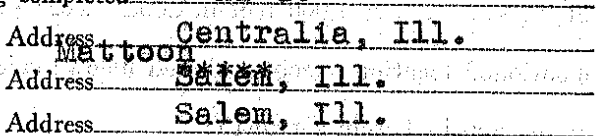

DETAILS OF PLUGGING:

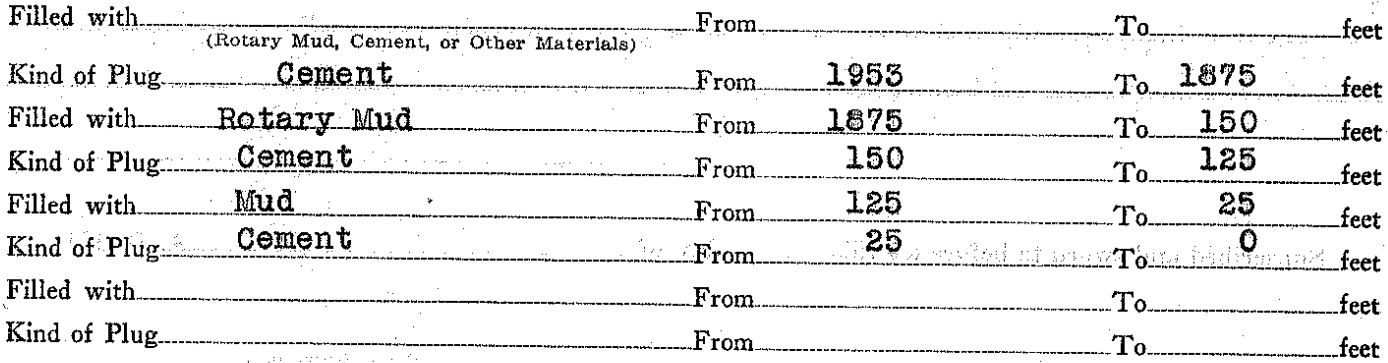

IF WORKABLE COAL BEDS WERE ENCOUNTERED IN THIS HOLE, DESCRIBE THE METHOD EMPLOYED TO PROTECT SAME. (A workable coal bed is thirty inches or more in thickness above 1,000 feet in depth.

Other details

If this was a producing well, give date and amount of last production Dxy

\section{CASING RECORD}

\begin{tabular}{l} 
Size PUT IN WELL \\
\hline Feet
\end{tabular}




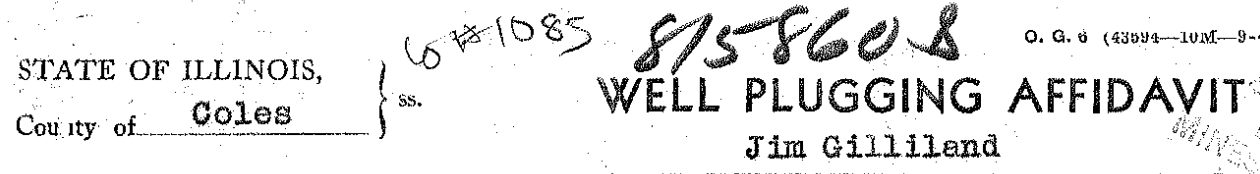

Lavrence Landreth

being first duly sworn, do depose and say the following is a true and correct statement of the details of the plugging of a certain well drilled for

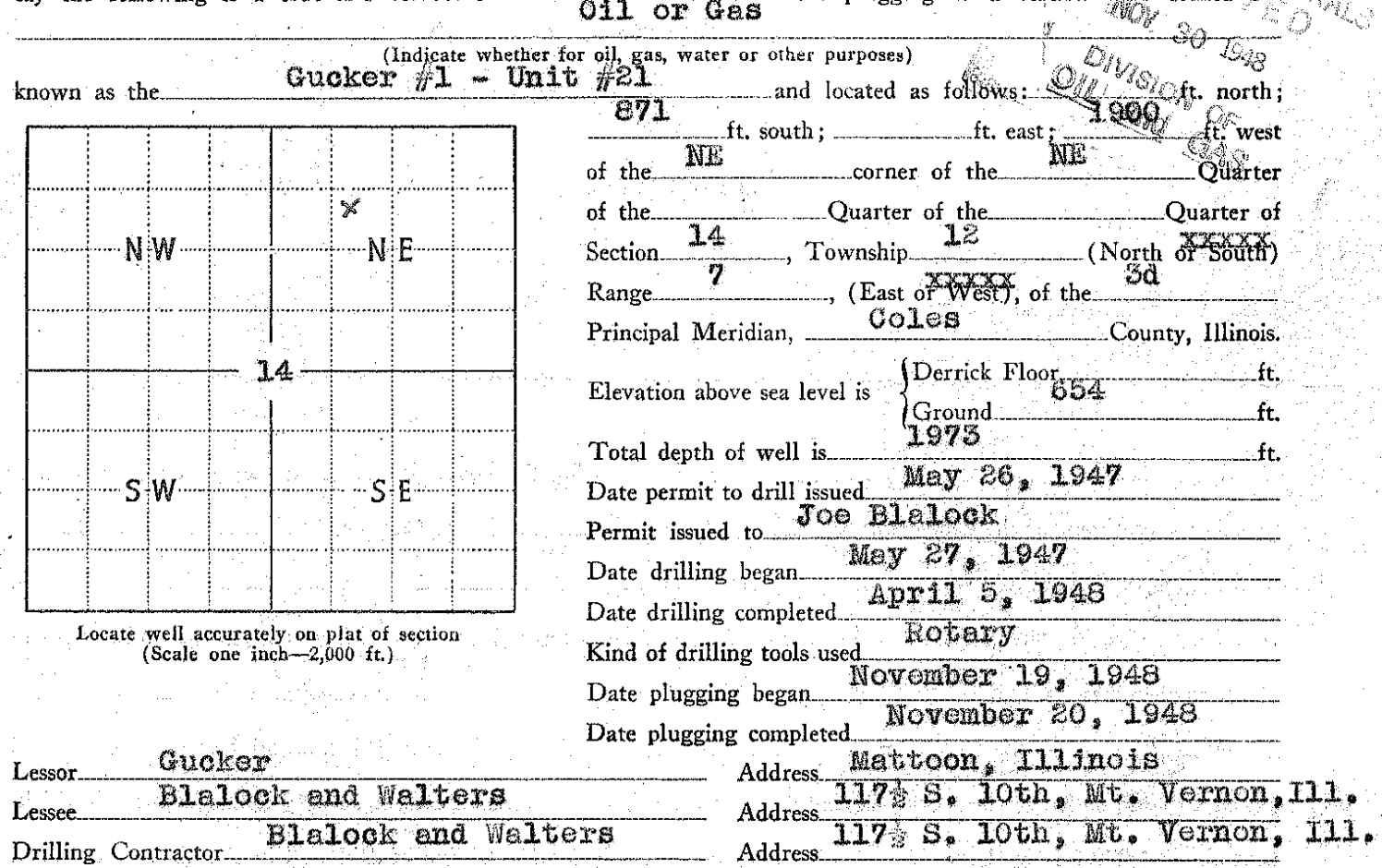

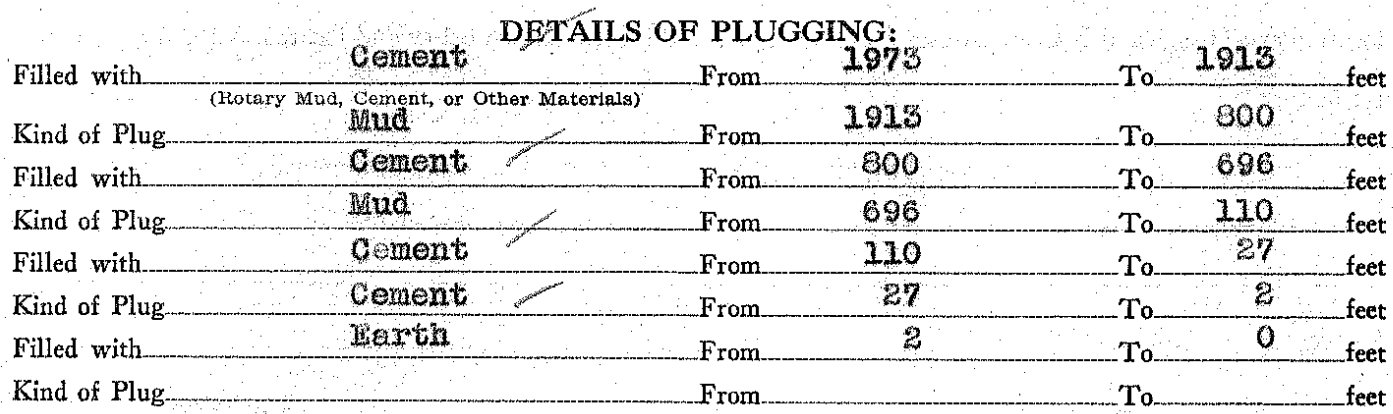

IF WORKABLE COAL BEDS WERE ENCOUNTERED IN THIS HOLE, DESCRIBE THE METHOD

EMPLOYED TO PROTECT SAME. (A workable coal bed is thirty inches or more in thickness above 1,000 feet in depth) Ooul Seam 750 cemented

(1) Have pits, cellar and other excavations been filled?..

(2) Have equipment, concrete bases and debris been removed?

(3) Has surface casing been cut off below plow depth?....

(4) Has well-site been levelled?

If this was a producing well, give date and amount of last production Last production 11/14/48

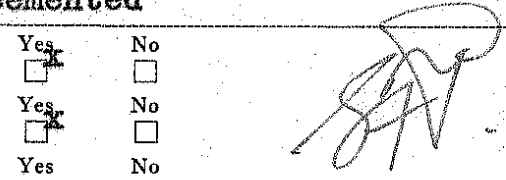

1/4 bbl. bex dey

CASING RECORD Pexalt WOS?

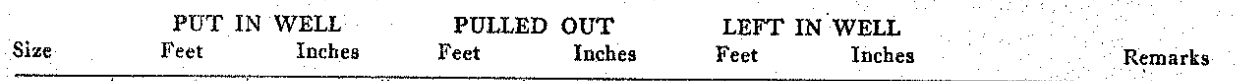

\begin{tabular}{l|l||l|l|l|l|}
\hline 10 & 105 & & & & \\
\hline & & & & & \\
\hline & & & & \\
\hline & & & & \\
\hline
\end{tabular}

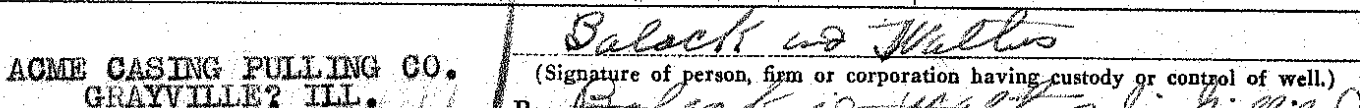

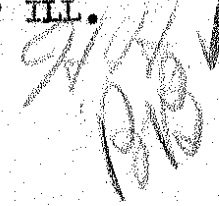

Subscribed and sworn to before me this $22 n d$

My commission expires

$2-24-51$

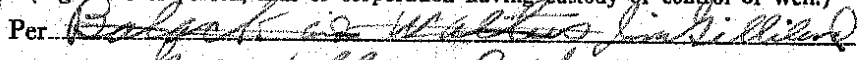

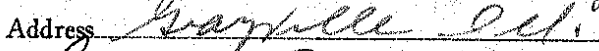

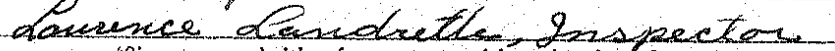
(Signature and title of party supervising plugging of well.) Address Eftacplesw, $20 L^{\circ}$ of op op 22nd day of Novernber

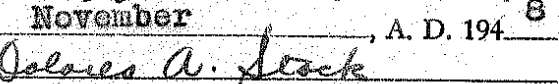


__C and

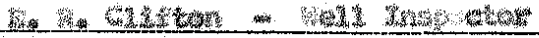

being first duly sworn, do depose and say the following is a true and correct statement of the details of the plugging of a certain well drilled for

(Indicate whether for oll, gas, water or other purpozes)

known as the

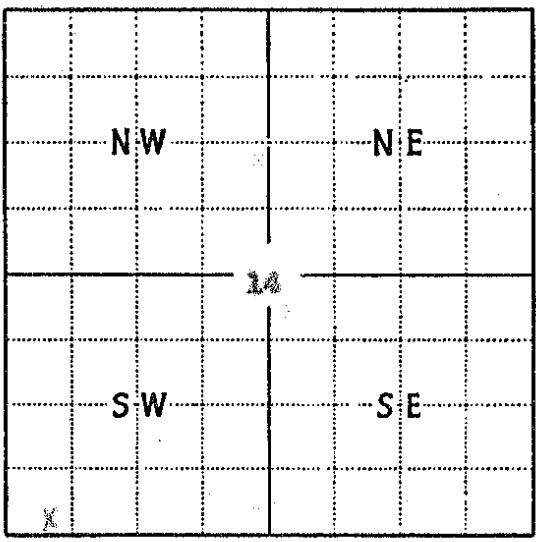

Locate well accurately on plat of section (Scale one inch-2,000 ft.) and located as follows: 3 ft. north; ft. south;___ ft. east; ft. west

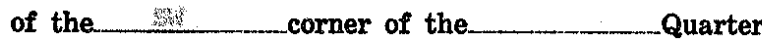
of the Quarter of the Quarter of Section Range (East/ br/West), of the Principal Meridian, _... County, Illinois. Elevation above sea level is $\left\{\begin{array}{l}\text { Derrick Floor } \\ \text { Ground }\end{array}\right.$

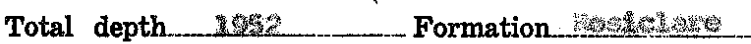
Date permit to drill issued ${ }_{5}$

Permit issued to ___

Date drilling began.

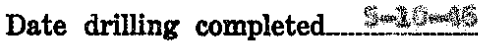

Kind of drilling tools used.

Date plugging began____.

Date plugging completed L $10 \times+2$

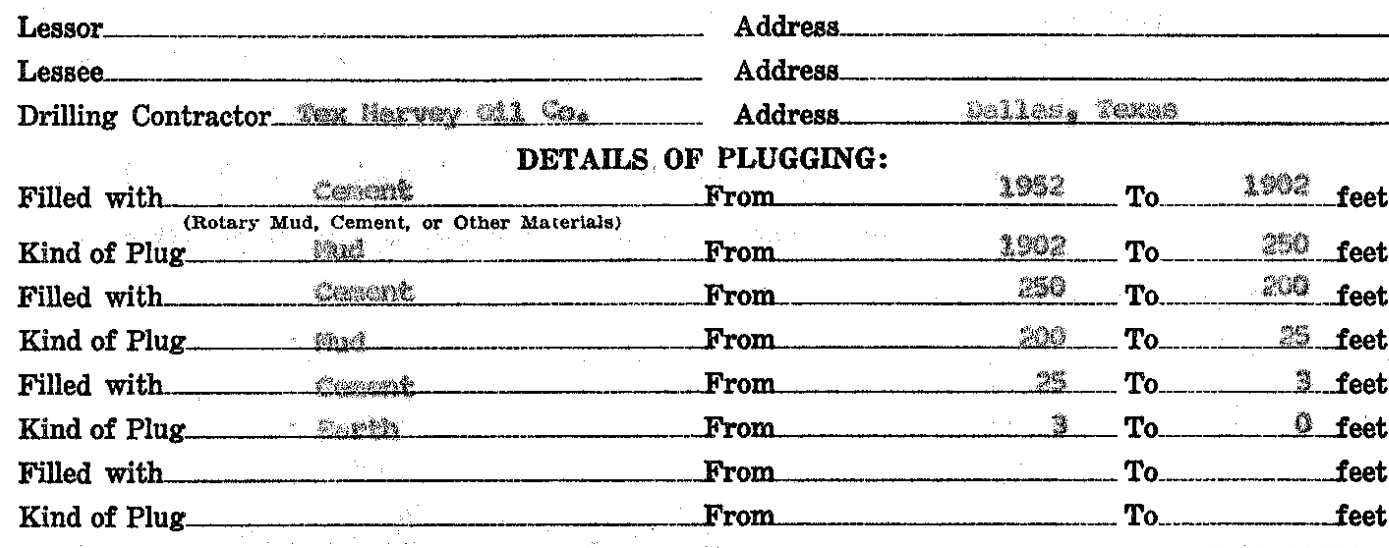

IF WORKABLE COAL BEDS WERE ENCOUNTERED IN THIS HOLE, DESCRIBE THE METHOD EMPLOYED TO PROTECT SAME. (A workable coal bed is thirty inches or more in thickness above 1,000 feet in depth)

(1) Have pits and other excavations been filled?

(2) Have the following been removed?

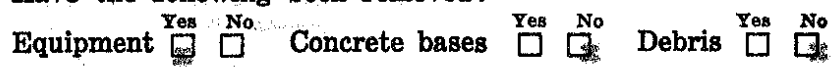

(3) Has surface casing been cut off three feet below ground surface? Yes No

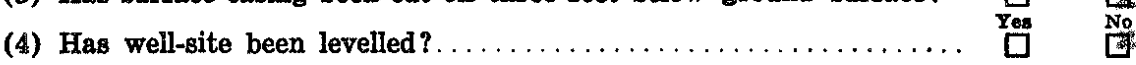

If this was a producing well, give date and amount of last production

CASING RECORD

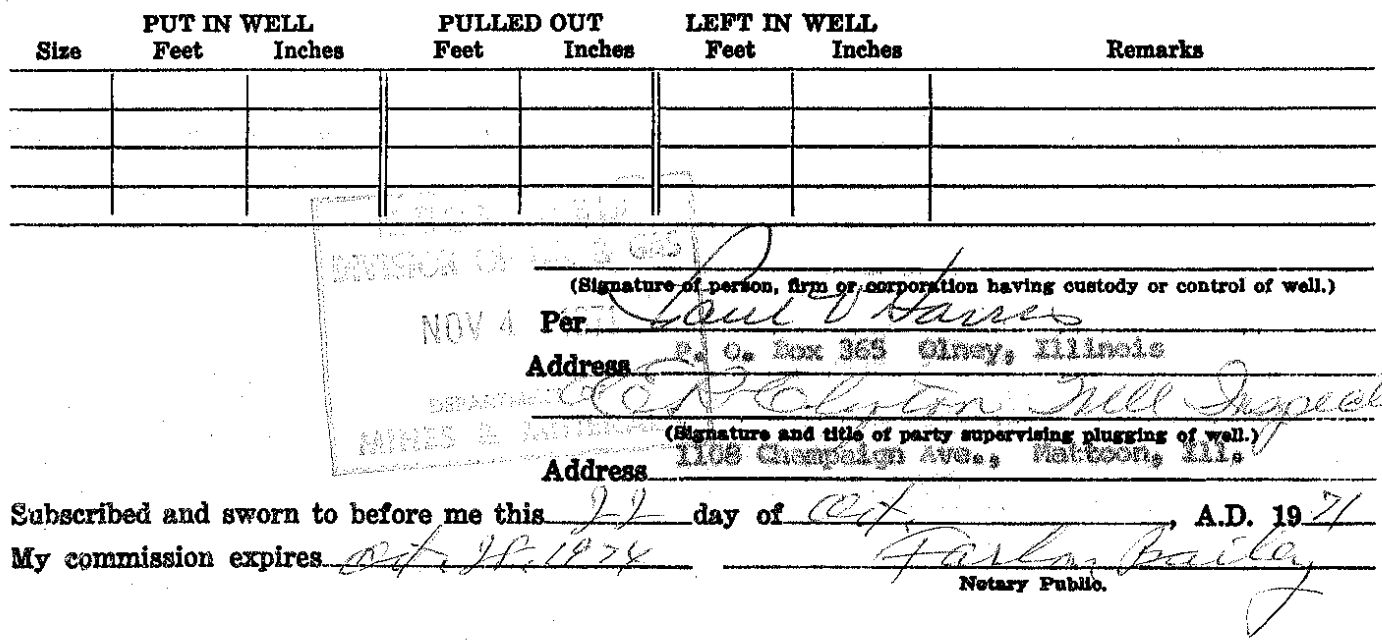


STATE OF ILLINOOIS,

County of Coles
Counv No.1086.

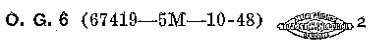

AFIDAVIT

say the following is a true and correct statement of the details of the plugging of a certain well drilled for oil

known as the Fred Herrelo /71

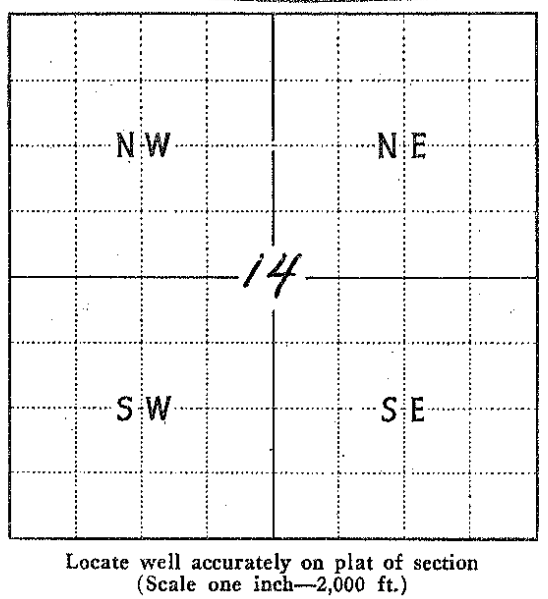
ft. south; 833 ft. east; and located as follows: 280

$b_{\text {sutu. }}$ t. north; ft. west

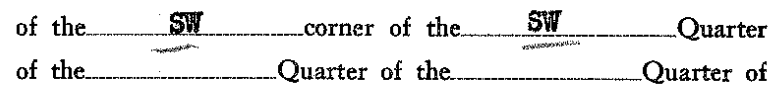

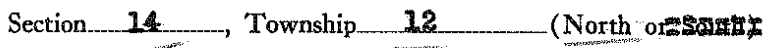
Range 7 (East or West) of the 3rd Principal Meridian, Goles_County, Illinois. Elevation above sea level is Derrick Floor-_._._. Ground 717 ft.

Total depth of well is $\quad 1956 \quad \mathrm{ft}$. Date permit to drill issued $3=11=46 \quad$ Permit No. 356

Permit issued to Joce Bottor, Salom, Hl.

Date drilling began $3-11=46$

Date drilling completed $3-29-46$

Kind of drilling tools used Rotiary

Date plugging began $7-20-49$

Date plugging completed $7-27-49$

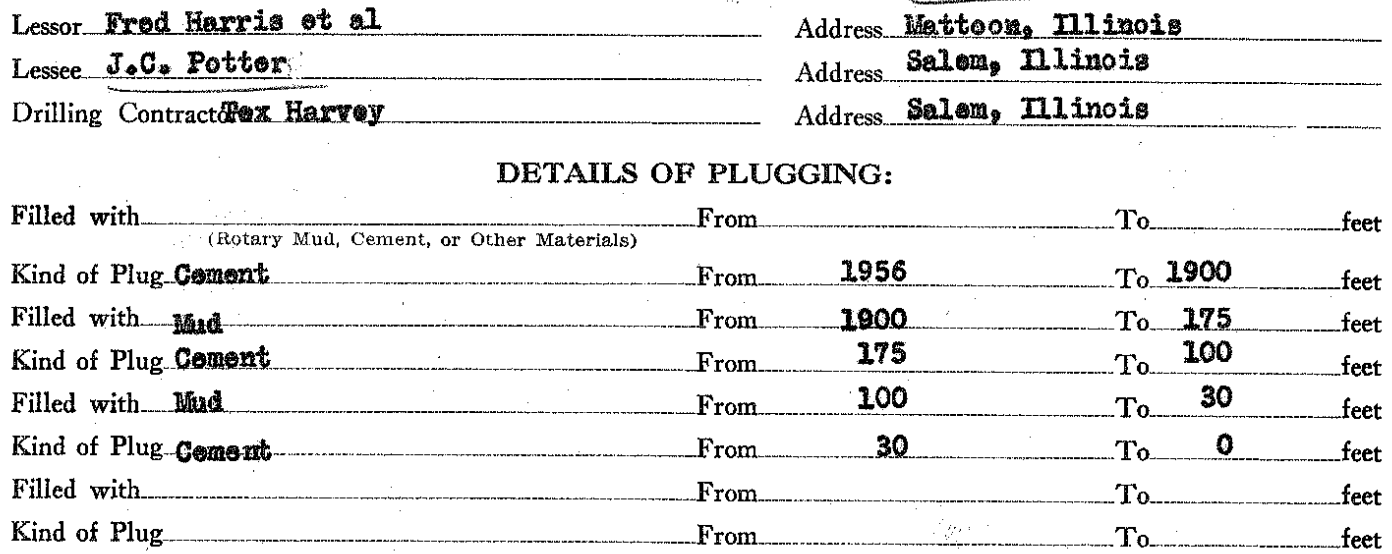

Lessor Fred Harris ot al

Lessee J.C. Potter

Drilling Contractofex Harrey

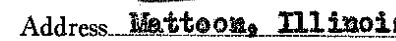

. Address Salom, Ilinois

DETAILS OF PLUGGING:

IF WORKABLE COAL BEDS WERE ENCOUNTERED IN THIS HOLE, DESCRLBE THE METHOD

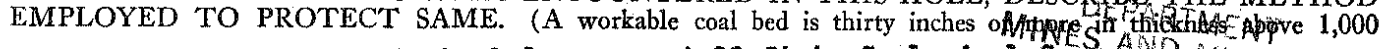

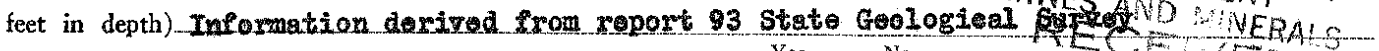

(1) Have pits, cellar and other excavations been filled?...

(2) Have equipment, concrete bases and debris been removed?

(3) Has.surface casing been cut off below plow depth?....

$\begin{array}{cc}\text { Yes } & \text { No } \\ \mathbb{X}] & \square \\ \text { Yes } & \text { No } \\ \text { Yes } & \square \\ \text { Yes } & \text { No } \\ \mathbf{X} & \square \\ \text { Yes } & \text { No } \\ \mathbf{Z} & \square\end{array}$

(†) Has well-site been levelled?

If this was a producing well, give date and amount of last production $4-11-47$

$$
\begin{aligned}
& \text { Jul } 271949 \\
& \text { OMMSTON OF } \\
& \text { OLL and GAS CONGE OW }
\end{aligned}
$$

CASING RECORD

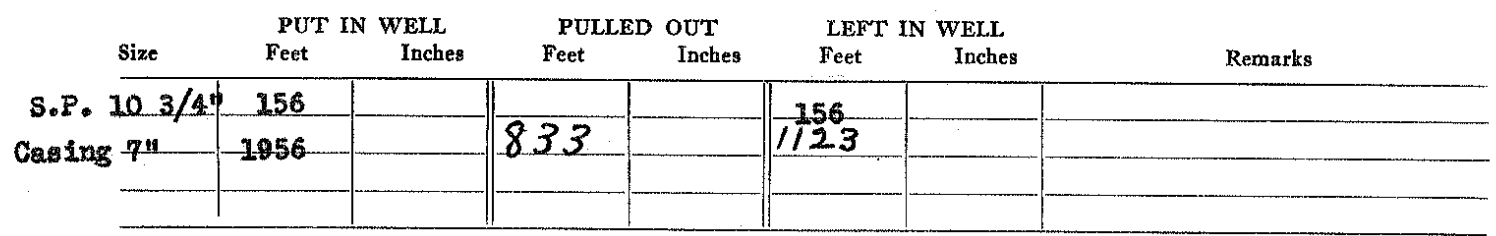

Pr1-State Casing Pulling Company

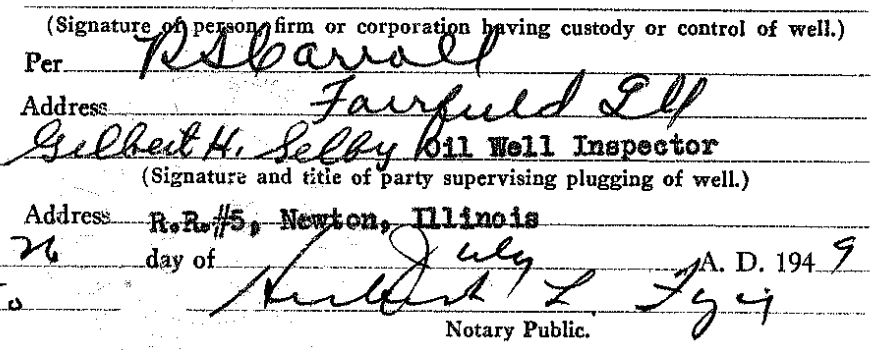

Subscribed and sworn to before me this 2 
H. I. Nobllt State Nell Inspeotor

being first duly sworn do depose and say the following is a true and correct statement of the details of the plugging of a certain well 'drilled for 011 and/or nas

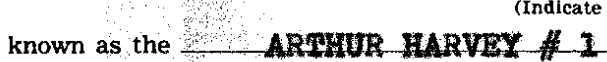

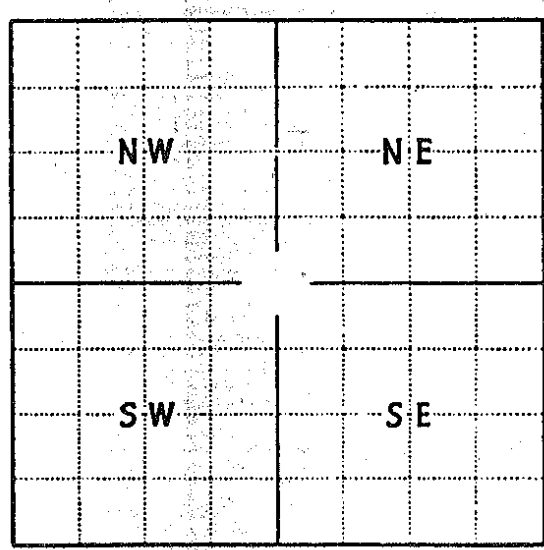

Locate well accurately on plat of section (Scale one inch-2,000 ft.) 275 ft. north. $\begin{array}{lrr} & \text { ft. south; } & 1610 \mathrm{ft} \text { east; } \quad \mathrm{ft} \text { west } \\ \text { of the } \quad \mathrm{SH} & \text { corner of the }\end{array}$ $\begin{array}{ll} & \mathrm{ft} \text {. south; } 1610 \mathrm{ft} \text {. east; } \quad \mathrm{ft} \text { west } \\ \text { of the SWI } & \text { Qurner of the }\end{array}$ of the Quarter of the_Q_Quarter of Section 14 Township_ 12. (North or stomx) Range_ 7 , (East or $\mathrm{XJes}_{\mathrm{t}}$, of the

Principal Meridian Colee County, Illinois Elevation above sea level is $\left\{\begin{array}{l}\text { Derrick Floor } \\ \text { Ground }\end{array}\right.$ Total depth 1951 Formation Ros Lalare Date permit to drill issued $4 / 27 / 48$ ermit No. 689 Permit issued to J.C. Potter

Date drilling began_? ?

Date drilling completed_?

Kind of drilling tools used_r_ Rotary

Date plugging began $\quad 9 / 4 / 84$

Date plugging completed_ $\quad 9 / 4 / 84$

Lessor Address

Lessee non E crace Address Box 457 inatoon. IL,

Drilling Contractor $?$ Address.

Details of PLugGing:

Drilled out of $7^{\circ}$ - $45^{\circ}$

Filled with 100 Sacts coment down $7^{*}$

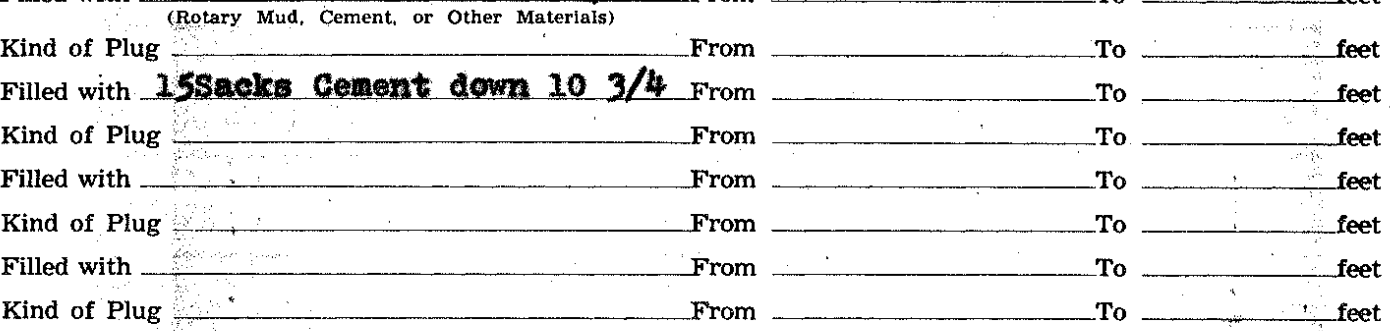
IF WORKABLE COAL BEDS WERE ENCOUNTERED IN THIS HOLE, DESCRIBE THE METHOD EMPLOYED TO PROTECT SAME. (A workable coal bed is thirty inches or more in thickness above 1,000 feet in depth) None

(1) Have pits and other excavations been filled?................. Yes

(2) Have the following been removed?

$$
\text { Equipment } \mathbf{Z}] \stackrel{\text { No }}{\square} \text { Concrete bases } \stackrel{\text { Yes }}{\square} \text { Do Debris } \stackrel{\text { Yes }}{\square} \stackrel{\text { No }}{\square}
$$

(3) Has surface casing been cut off three feet below ground surface?

(4) Has well-site been leveled?

If this was a producing well, give date and amount of last production

Hole $1 \mathrm{n}$

\section{CASING RECORD}

\begin{tabular}{|c|c|c|c|c|c|c|c|}
\hline Size & $\begin{array}{l}\text { PUT IN } \\
\text { Feet }\end{array}$ & $\begin{array}{l}\text { WELL } \\
\text { Inches }\end{array}$ & $\begin{array}{l}\text { PULLED } \\
\text { Feet }\end{array}$ & $\begin{array}{l}\text { OUT } \\
\text { Inches }\end{array}$ & $\begin{array}{c}\text { LEFT } \\
\text { Feet }\end{array}$ & $\begin{array}{l}\text { WELL } \\
\text { Inches }\end{array}$ & Rernarks \\
\hline $\begin{array}{l}103 \\
7^{*}\end{array}$ & $\begin{array}{l}130 \\
1912\end{array}$ & & -0 & & $\begin{array}{l}130 \\
1912\end{array}$ & & 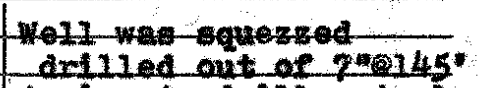 \\
\hline & & & & & & & ins to drel11 out pli \\
\hline
\end{tabular}

$$
\text { (Slgnature of person, frm or corporation having custody or control of well.) }
$$

$$
\text { Per }
$$

Address Box 457 Mattoon. IL -61938

46, 7 , 7 fitie of party supervising plugging of well.)

Address 402 - 8. Contral casey,II.

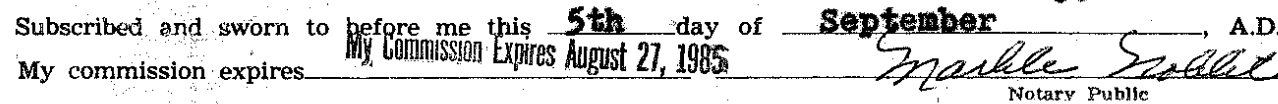




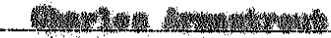
do depose and say the following is a true and correct statement of the details of the plugging of a certain well drilled for

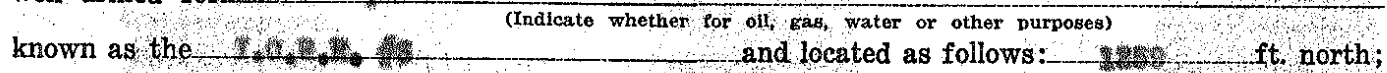

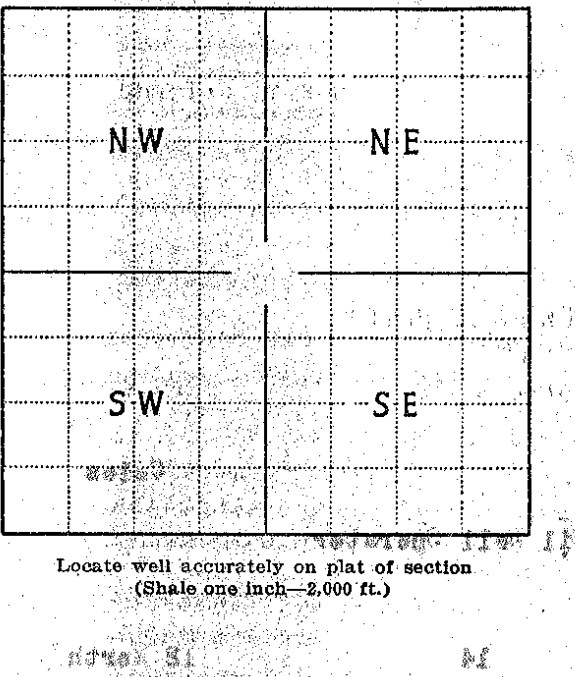

ft. south; ;

ft. east.

of the Quarter of the

of the

Section 1. Township (North or South)

Section 1 , Township (North or South)

Quarter of

Range, 1 , (East or W(st), of the ty

Principal Meridian, County, nlinois.

Elevation above sea level is $\{$ Berrich $\mathrm{mloor}, \mathrm{ft}$.

Total depth - Formation

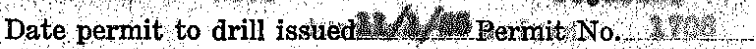

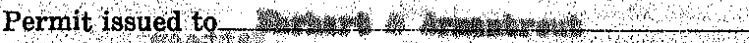

Date drilling began _ / / / /

Date drilling completed w/ $/ 4$ t

Kind of drilling tools used Dof

Date plugging began / / / /

Date plugging completed $4 / 4)$

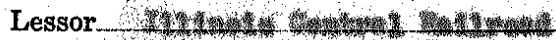

Lessee_3646)

Drilling Contractor.4.6\%

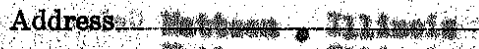

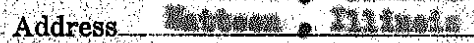
Address__, W

Filled with ${ }_{\text {rotary Nud, cement, or other Ma cerials }}$
Kind of Plug 20.4.

$+$

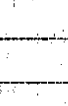

$+$

$-1$

Kind of $\mathrm{Plug}, \mathrm{S}$

Kind of Plut

From

IF WORK A BI C COAT BEDS WERE ENCOUTMER D EMPLOYED TO PROTECT SAME. (A workable coal bed is thirty inches or more in thickness above 1,000 feet in depth)

(1) Have pits and other excavations been filled?

(2) Have the following been removed?
Equipment $\square$,
Concrete bases
$\square$ No Debris $\square \geq$

(3) Has surface casing been cut off three feet below ground surface?

(4) Has well-site been levelled?

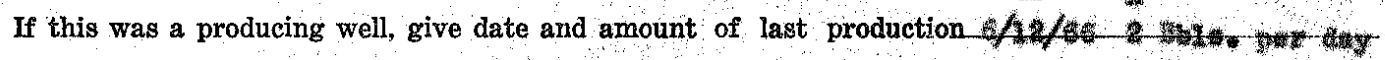

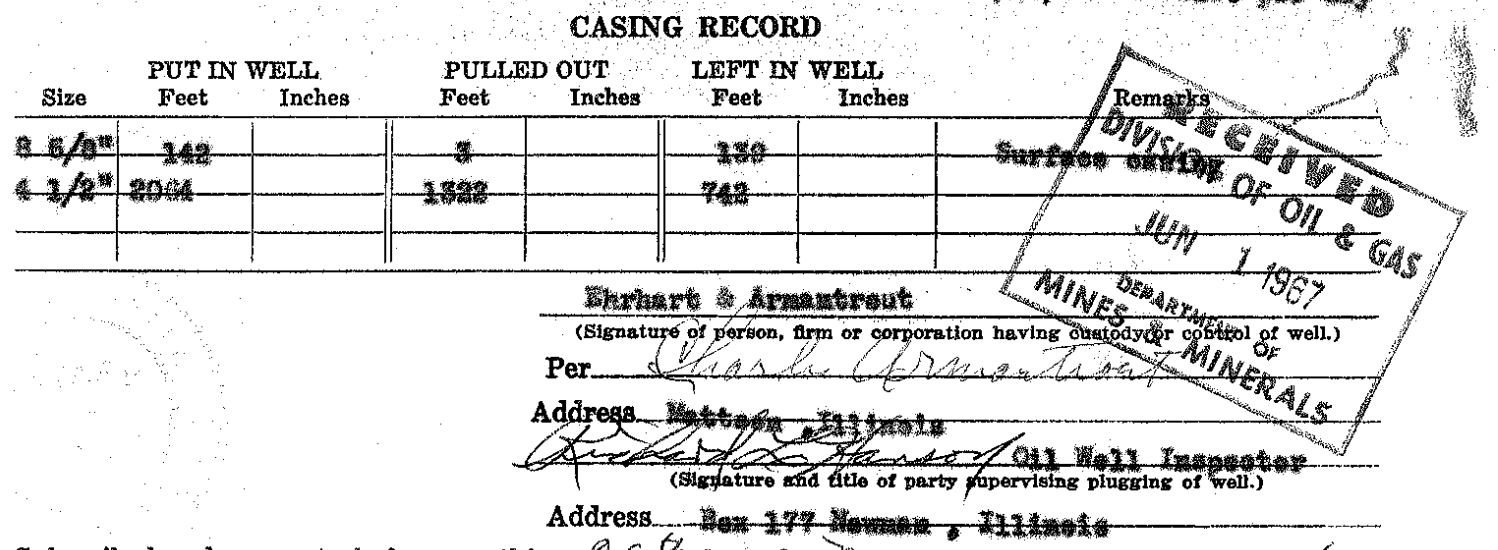

Subscribed and sworn to before me this $29^{6 /}$ day of $72 a$, A.D. 1967 My commission expires $5 \times 10-19 \geq 1$ 


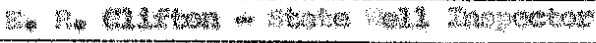

being first duly sworn, do depose and say the following is a true and correct statement of the details of the plugging of a certain well drilled for.

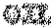

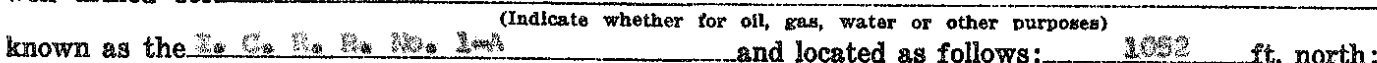

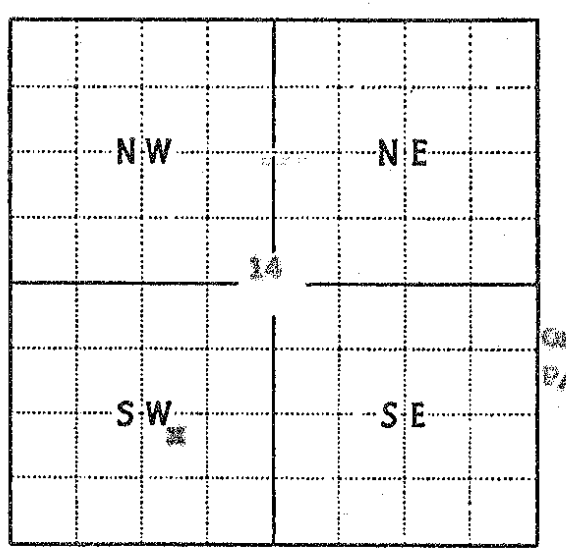

Locate well accurately on plat of section Scale one inch-m-2,000 ft.)

$$
\text { ft. south; }
$$

of the 路絽 corner of the

ft. east

Quarter of the Section Township L

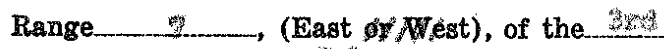

Principal Meridian,

Glevation above sea level is $\left\{\begin{array}{l}\text { Derrick Floor } \quad \text { ft. } \\ \text { Ground }\end{array}\right.$ a

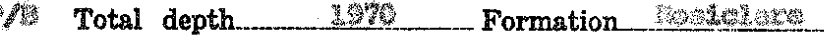
Date permit to drill issued 10 dy

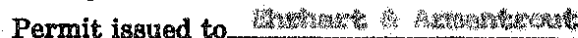

Date drilling began Whats

Date drilling completed thes

Kind of drilling tools used.

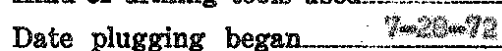

Date plugging completed. of

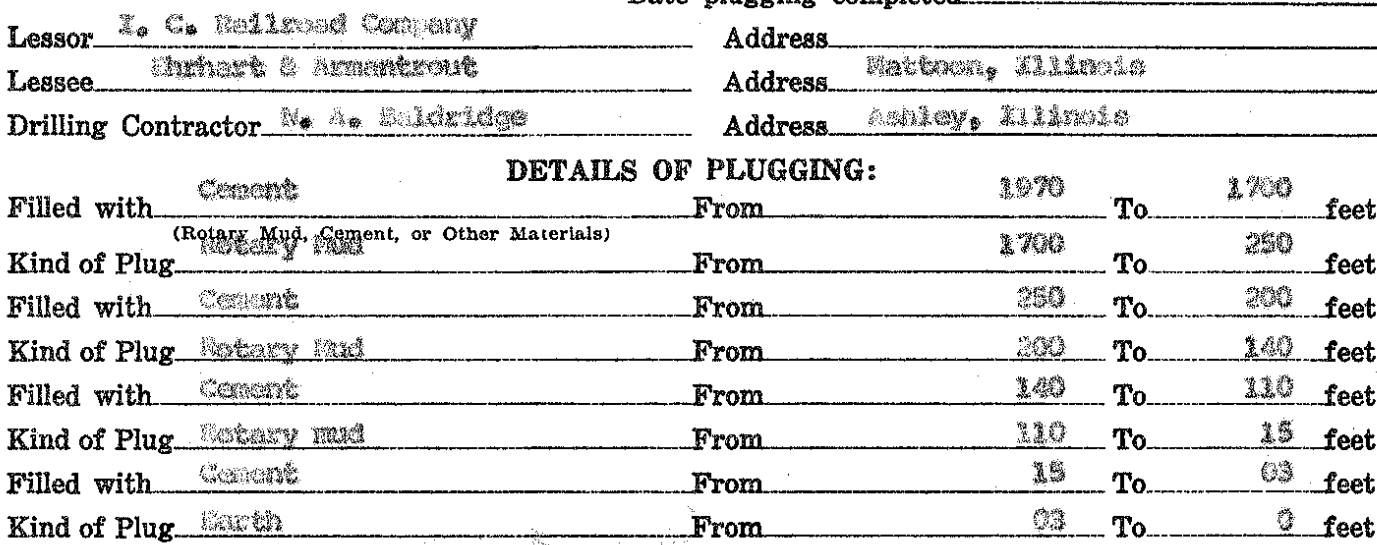

IF WORKABLE COAL BEDS WERE ENCOUNTERED IN THIS HOLE, DESCRIBE THE METHOD EMPLOYED TO PROTECT SAME. (A workable coal bed is thirty inches or more in thickness above 1,000 feet in depth)

(1) Have pits and other excavations been filled?

(2) Have the following been removed?

Equipment $\stackrel{\text { Yes }}{\square}$ Wo Concrete bases $\square \stackrel{\text { Tos }}{\square}$ Debris $\square \square$

(8) Has surface casing been cut off three leet below ground surface?

(4) Hras well-Bite been levelled?

If this was a producing well, give date and amount of last production

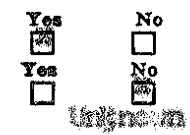

\section{CASING RECORD}

\begin{tabular}{|c|c|c|c|c|c|c|c|}
\hline \multirow[b]{2}{*}{ Size } & \multicolumn{2}{|c|}{ PUT IN WELL } & \multicolumn{2}{|c|}{ PULLED OUT } & \multicolumn{2}{|c|}{ LEIT IN WELC } & \multirow[b]{2}{*}{ Remarks } \\
\hline & Feet & Inches & Fet & Inches & weet & Incisos & \\
\hline W & 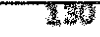 & 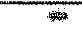 & F & 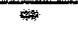 & 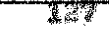 & ? & Hot \\
\hline 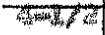 & 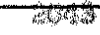 & 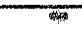 & the & 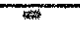 & 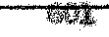 & 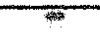 & THA \\
\hline & & & & & & & \\
\hline
\end{tabular}

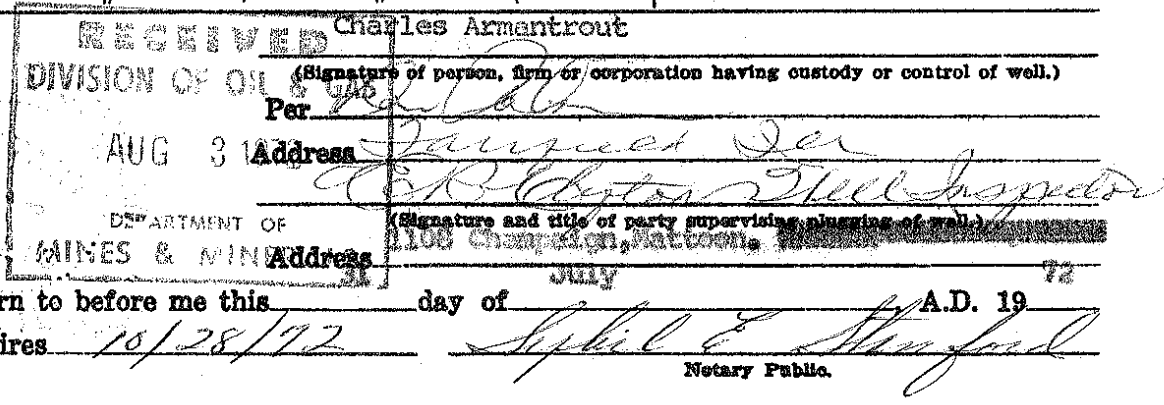

Subscribed and sworn to before me this My commission expires 
Ritchard dingos Ss. WELL PLUGGING AFFIDAVIT well drilled for oil

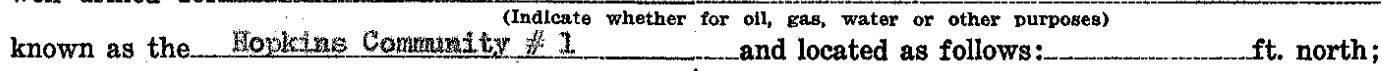

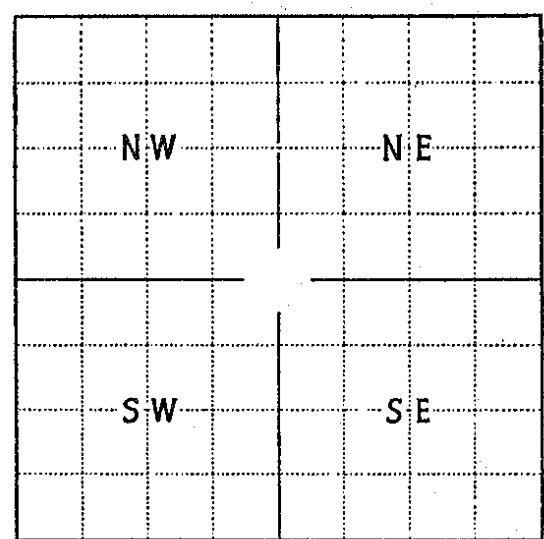

Locate well accurately on plat of section (Scale one inch-2,000 $\mathrm{ft}_{\text {. }}$ )

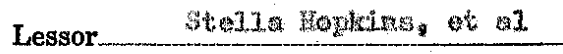

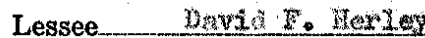

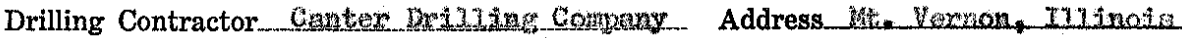

DETAIIS OF PLUGGING:

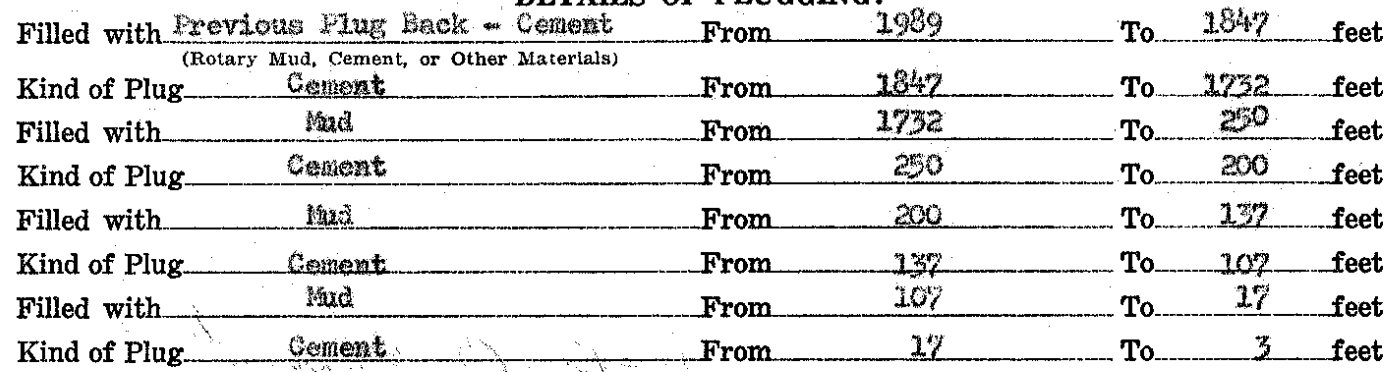

IF WORKABLE COAL BEDS WERE ENCOUNTERED IN THIS HOLE, DESCRIBE THE METHOD EMPLOYED TO PROTECT SAME. (A workable coal bed is thirty inches or more in thickness above 1,000 feet in depth) Hofere

1) Have pits and other excavations been filled?

(2) Have the following been removed?
Equipment
Concrete bases
Debris Yes No

(3) Has surface casing been cut off three feet below ground surface?

(4) Has well-site been levelled $\ldots \ldots \ldots \ldots \ldots \ldots \ldots \ldots \ldots \ldots \ldots$. If this was a producing well, give date and amount of last production $1 / 2 / 68-1 / 2$

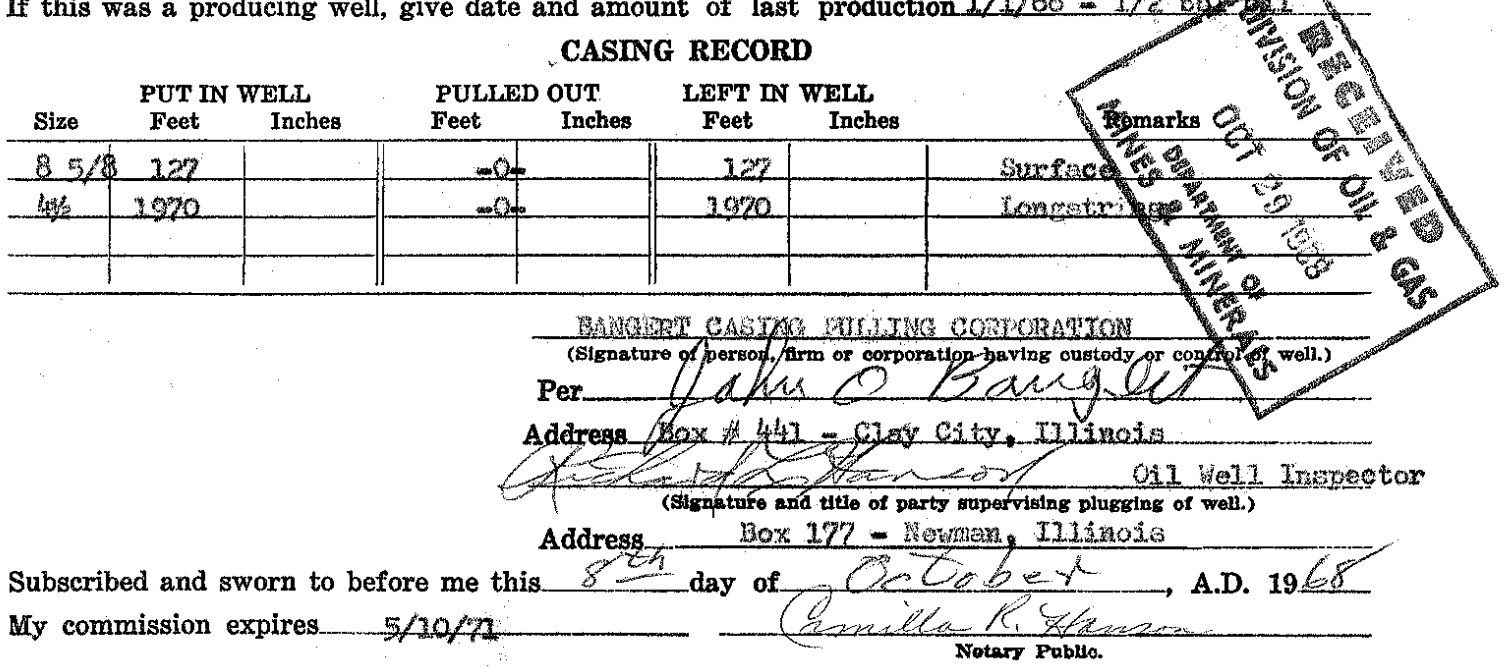


Rjokard Hanson being first duly sworn, do depose and say the following is a true and correct statement of the details of the plugging of a certain well drilled for o는 known as the Rumold Commuatey 1 and located as follows: ft. north;

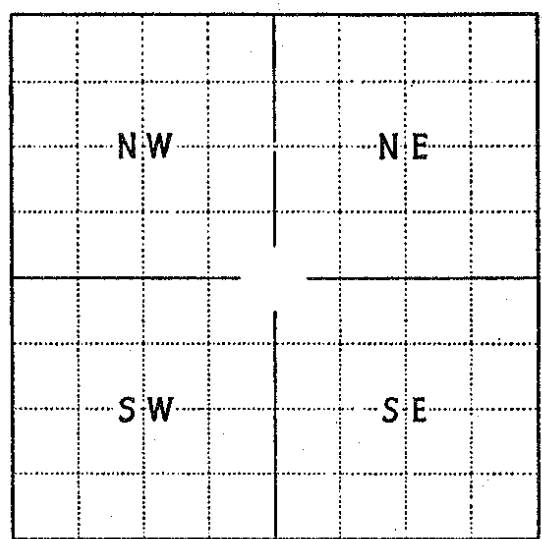

Locate well accirately on plat of section (Scale one inch-2,000 ft.)
$486 \mathrm{ft}$. south ft. east. of the ___ Quarter of the__uarter of Section 14, Township 12 (North 66/86utt6) Range $\quad 2$, (East $\$$ W $W(A t)$, of the $3 \mathrm{sec}$

Principal Meridian, Cales County, Illinois. Elevation above sea level is $\left\{\begin{array}{l}\text { Derrick Floor } 735 \mathrm{ft} . \\ \text { Ground } \\ -732 \mathrm{ft} .\end{array}\right.$ Total depth $1006 \quad$ Formation Losidelate Date permit to drill issued $8-12-63$ Permit No. 2436

Permit issued to thandu

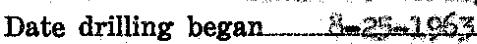
Date drilling completed $9-32-2963$ Kind of drilling tools used... Sotary Date plugging began $\quad 10-5-1968$ Date plugging completed $10-5 \mathrm{~m}-1666^{3}$

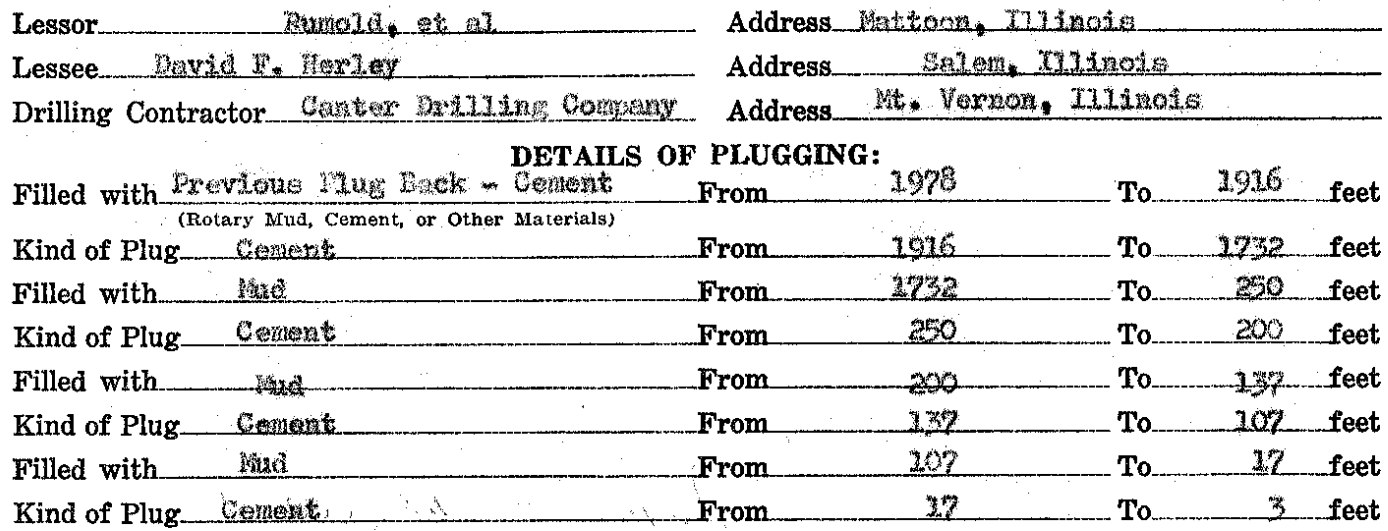
IF WORKABLE COAL BEDS WERE ENCOUNTERED IN THIS HOLE, DESCRIBE THE METHOD EMPLOYED TO PROTECT SAME. (A workable coal bed is thirty inches or more in thickness above 1,000 feet in depth)

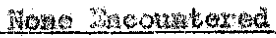

(1) Have pits and other excavations been filled?

(2) Have the following been removed?

Equipment $\left[\square^{\text {No }}\right.$ Concrete bases $\square^{\text {No }}$ Debris ${ }^{\text {Yes }} \square^{\text {No }}$

(3) Has surface casing been cut off three feet below ground surface?

(4) Has well-site been levelled?

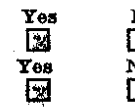

If this was a producing well, give date and amount of last production $1 / 2 / 60$

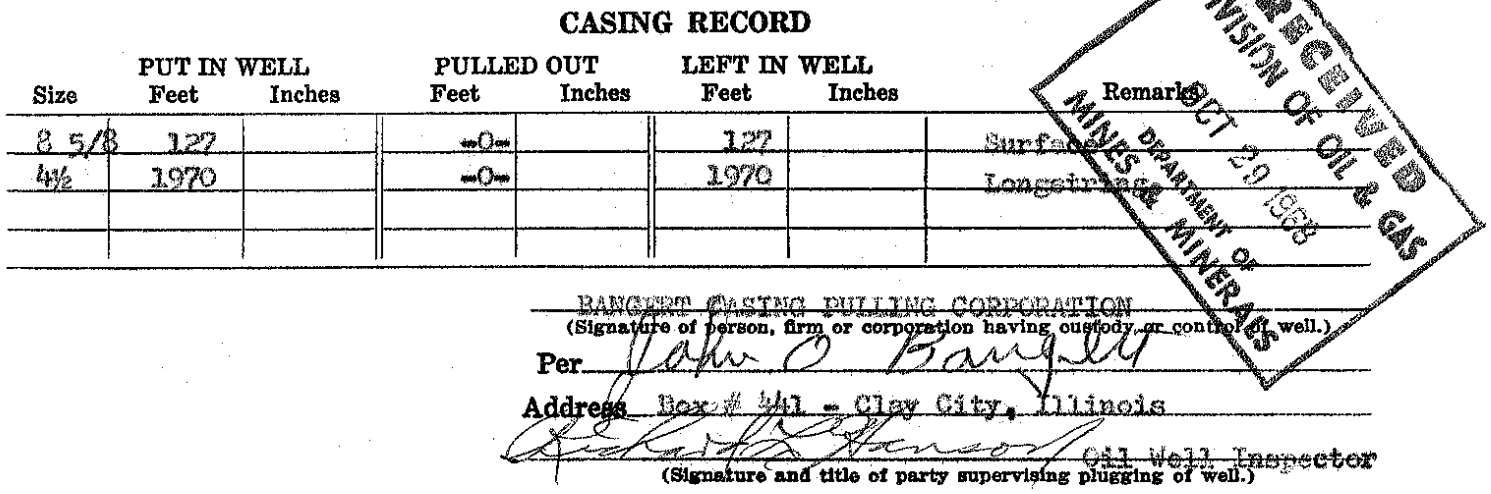

\footnotetext{
Subscribed and sworn to before me this 8 day of $0=0.6 e-196$ My commission expires $\quad 3 / 20 / 7$

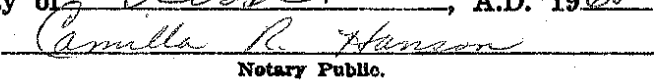


14-12N-7E-1 
STATE OF ILLINOIS

County of Doleter

\section{WELL PLUGGING AFFIDAVIT}

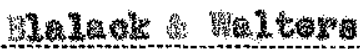
and

Haldoritoon

being first duly sworn, do depose and say the following is a true and correct statement of the details of the plugging of a certain well drilled for

dL

$4 x \mathrm{CH}$

(Indicate whether for oil, gas, water or other purposes)

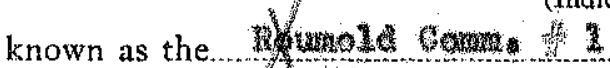

and located as follows:

ft. north;

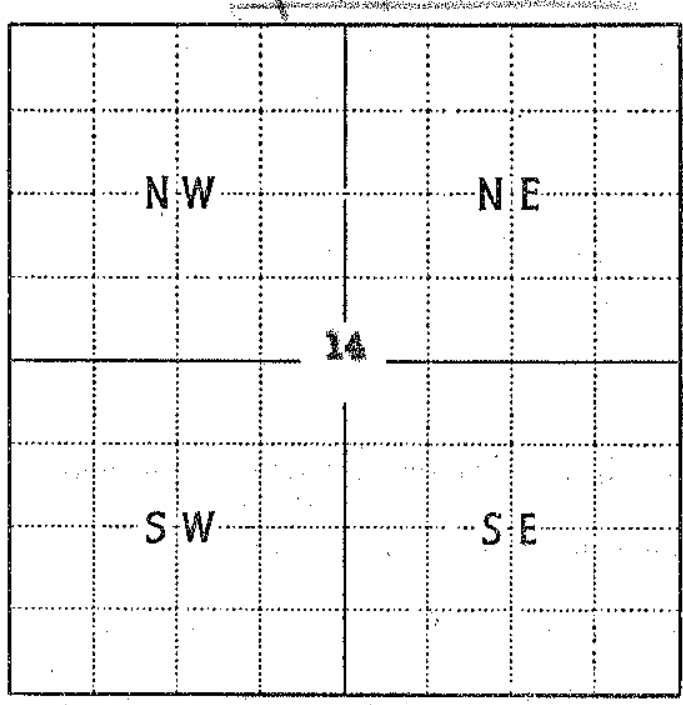

Locate well accurately on plat of section (Scale one inch-2,000 ft.)
46

of the. ft. ft. east:

2043 ft. west

of the _. Quarter of the Quarter Section 14 . Township 12 (North ow Range 7 , (East o of the 8

Principal Meridian, County, Iilinois. Elevation above sea level is $\left\{\begin{array}{l}\text { Derrick Floor. } \\ \text { Ground ty }\end{array}\right.$

Total depth of well is 1989

Date permit to drill issued -

Permit issued to WIALAok

Date drilling began $3-17+46$

Date drilling completed . .

Kind of drilling tools used

Date plugging began. $0+7-5)$

Date plugging completed $\quad 6=9-3$

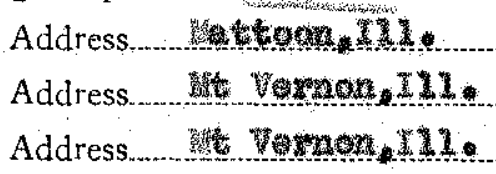

DETAILS OF PLUGGING:

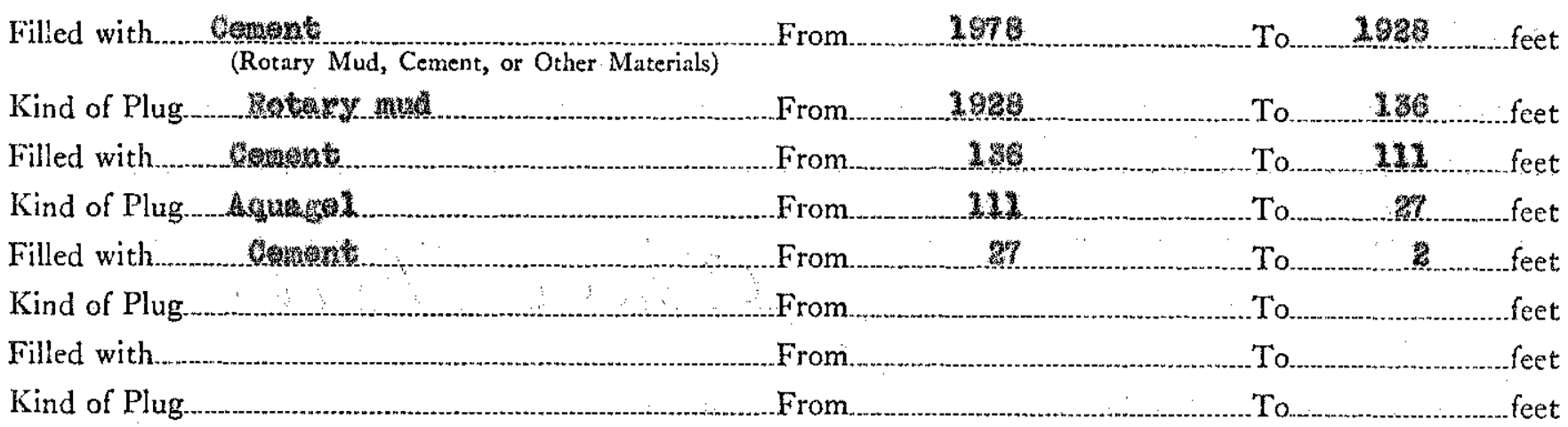

IF WORKABLE COAL BEDS WERE ENCOUNTERED IN THIS HOLE, DESCRIBE THE METHOD EMPLOYED TO PROTECT SAME. (A workable coal bed is thirty inches or more in thickness above 1,000 feet in depth)

(1) Have pits, cellar and other excavations been filled?....

$\begin{array}{cc}\text { Yes } & \text { No } \\ \square & \square \\ \text { Yes } & \text { No } \\ \square & \square \\ \text { Yes } & \text { No } \\ \square & \square \\ \text { Yes } & \text { No } \\ \square & \square\end{array}$

(2) Have equipment, concrete bases and debris been removed?

(3) Has surface casing been cut off below plow depth?.....

(4) Has well-site been levelled?...................

If this was a producing well, give date and amount of last production

No
$\square$
No
$\square$
No
$\square$
No
$\square$

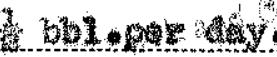

\section{CASING RECORD}

PUT IN WELL PULLED OUT LEFT IN WELL


15-12N-7E 

do depose and say the following is a true and correct statement of the detalls of the plugging of a certain well drilled for Ol!

(Irdicate whether for oil gas. water or other purposes)

known as the Wiftenberc Esteite Comm Ind located as follows:

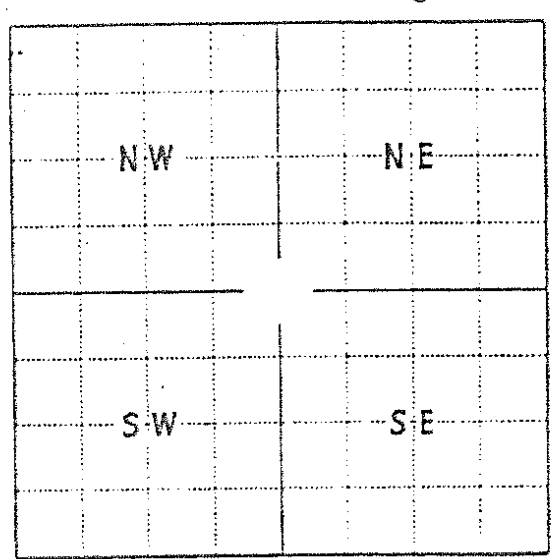

Locate well accurateiy on plat of sectron (Scale ant inct-2,000 ft.
$385 \mathrm{ft}$. soutr:

of the $N E$

corner of the $\triangle \mathrm{NE}$ fit. norih; of the NE Quarter of the NF Quarter of Section 15 Township 12 (North Range 7 , (East of the Principal Meridian, Coles County, Hinois. Elevation above sea level is / Grick Fioor -733 ft. Total depth 3200 Formation Devon $10 \mathrm{n}$ Date permit to drill issueds/ $/ 2 / 2 \geq$ Permit No. $7 / 5$ Permit issued to Elton Botts / Mellow Date drilling began $5 / 2 q / 72$

Date drilling completed $9 / 5 / 72$

Kind of drilling tools used Rotary

Date plugging began $8 / 22 / 89$

Date plugging completed $8 / 22 / 89$

Lessor Communitized

Lessee Elton Botts

Address Matfoon I

Address mattoon $T$ I

Address Effingham $T$

Drilling Contractor Depolster Or/g

DETAILS of PLUgGing:

Filled with Cement From $\quad 2550$

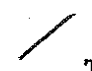

Filled with (Rotary Mud. Cement or Other Materials)

From $2 \operatorname{css} \theta$ To $25 \infty 0$ feet

Kind of Plug mud

Filled with Cement

Kind of Plug Soil

Filled with ug rast $60 \mathrm{Jt}$ Its 2 ker w/60 Its 2
cement Anrulus
string o Surface

Filled with $L$ lug ng

IF WORKABLE COAL BEDS WERE ENCOUNTERED IN THIS HOLE, DESCRIBE THE METHOD ENFLOYED TO PROTECT SAME. (A workable coal bed is thirty inches or more in thickness above 1,000 feet in depth)

(1) Have pits and other excavations been filled? None

\section{(2) Have the following been removed?} Equipment $\square$ No Concrete bases $\square / \mathbb{R} /$ Debris $\square$

(3) Has surface casing been cut off three feet below ground surfae?

(4) Yas well-site been leveled? . . .

If this was a producing well, give date and amount of last production

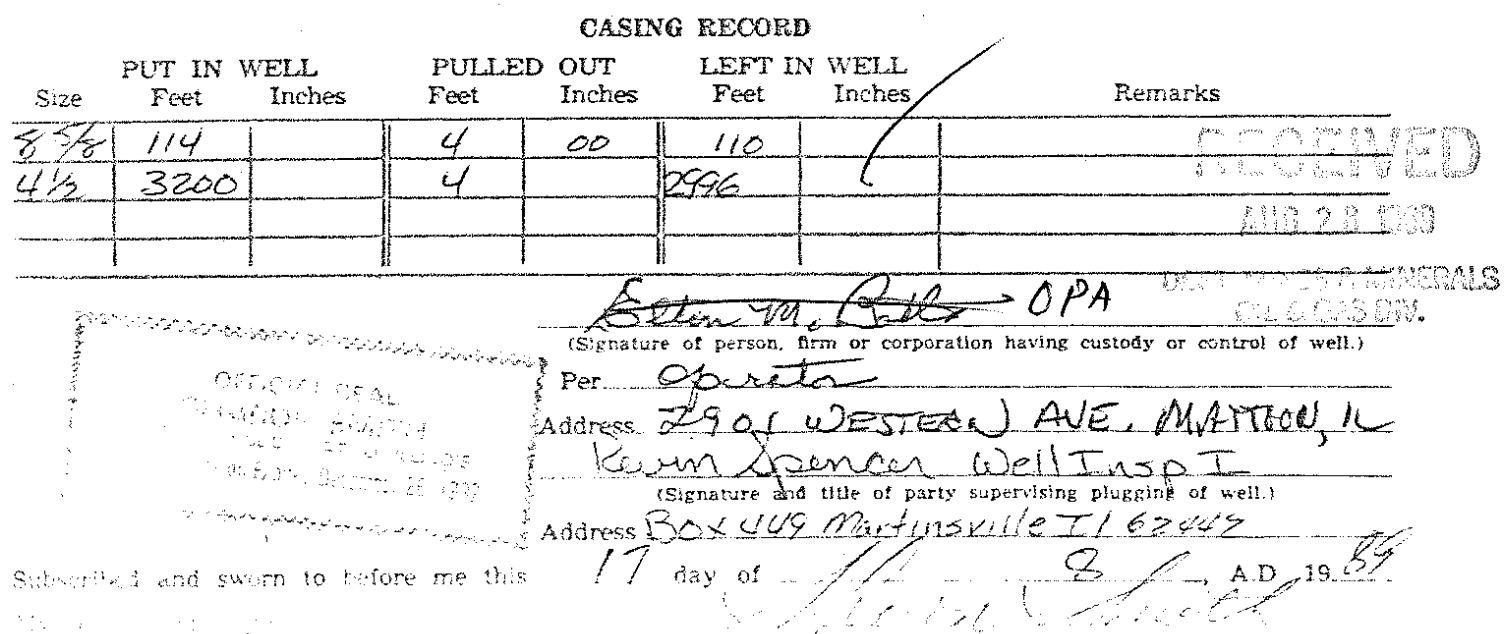




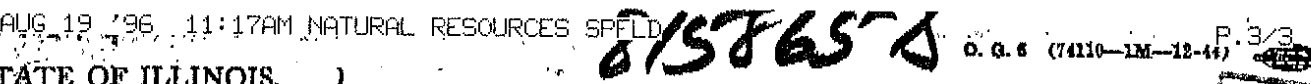

$\left.\begin{array}{l}\text { STATE OF ILLINOIS, } \\ \text { County of Col }\end{array}\right\}$

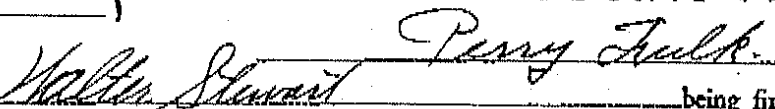

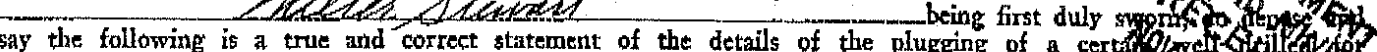

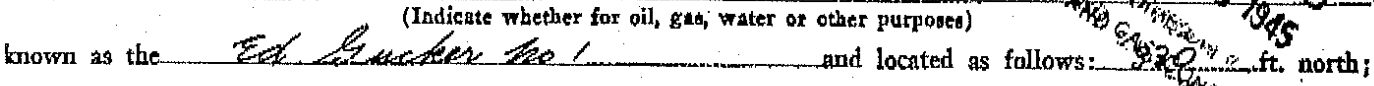

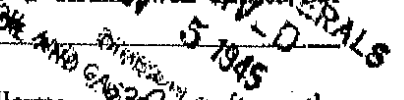

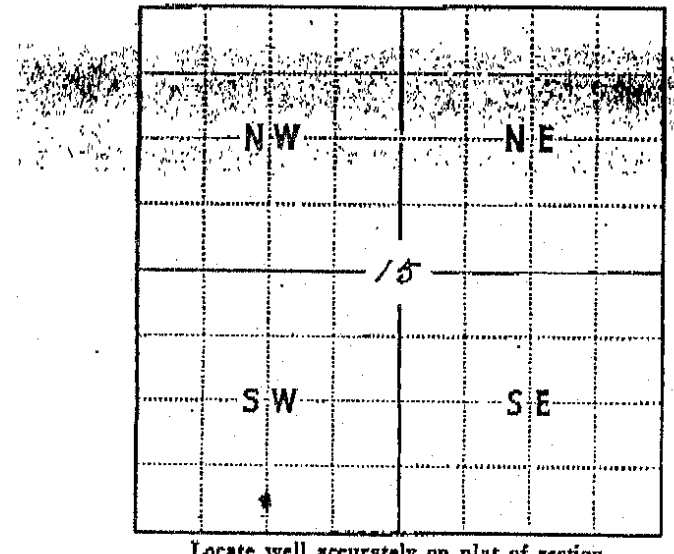

Locate well rocelrstely an plat of bection (Scale one inch-z,000 ft.)

Lessar $z$ Let Letes

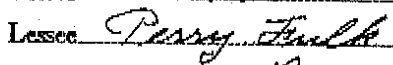

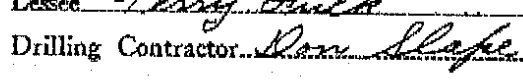
ft. south; $>321$ ft. cast; -

w of the $\mathrm{S}, \mathrm{W}$, and of the

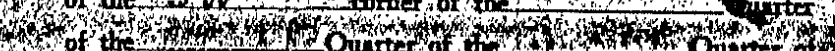

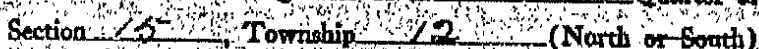

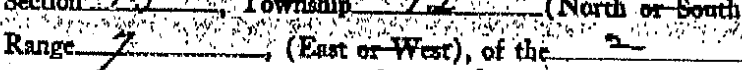

Principal Meridian, _CS-Cet * County, Illinois.

Elevation above sea level is J Derrick Floor__.....................

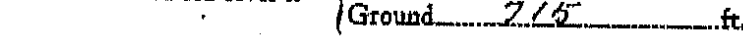

Total depth of well is $\quad 2 / 30$ Date permit to drill issued $Q 22^{2} 27-1243$

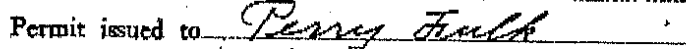
Date drilling began $\mathbb{Q} \times d z=1 z \neq \omega$ Date drilling completed $1202-2-19 \leq 5$

Kind of drilling toolo used. Date plugging began_Zteze 2 \%

Date plugging completed.

\section{DETAILS OF PLUGGING:}

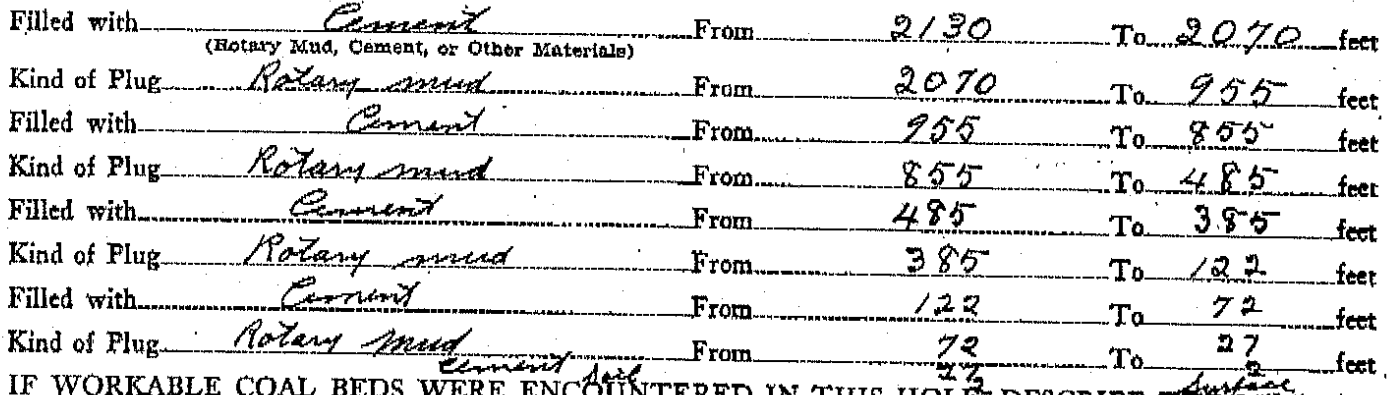

IF WORKABLE COAL BEDS WERE ENCOUOUTTERED IN THIS HOLE, DESCRIBE TAH METHOD EMLOYE TO PROTECT SAME. (A workable coal bed is thirty inches or more in thickness above 1,000 feet in depth and three feet or more in thickness below 1,000 feet in depth.) 0 \&

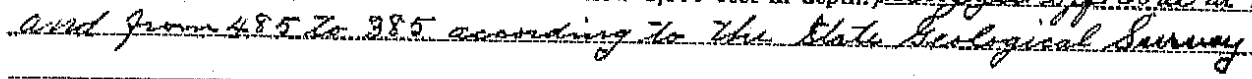

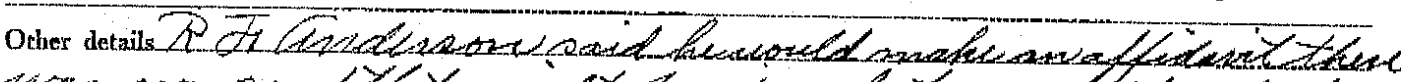

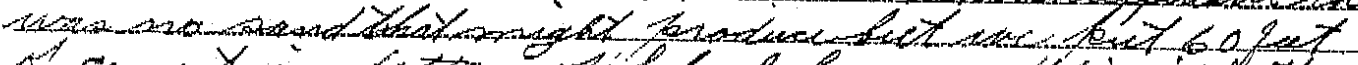
Af this was a producing well, give date and anfont of last production

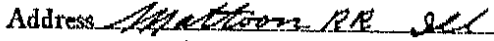
Addrotzan

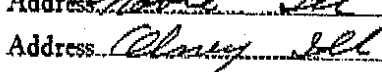

\section{CASING RECORD}

\begin{tabular}{l} 
Gize \\
\hline $10^{3} 4$ \\
\hline
\end{tabular}

(Sigaturg of person, firm of corporation baving cuatody or control of well,

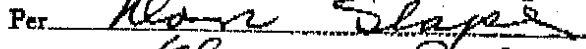
Addres $Q e j a e$ Q

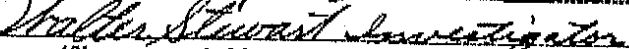

(Signature and title of party uxpervising plugging of well.) Address $S P$ axis $p 2 Q 2<$ 
County of Colas \}ss. WELL PLUGGING AFFIDAVIT

Oon liobson.

being first duly sworm, do depose and say the following is a true and correct statement of the details of the plugging of a certain well drilled for. 011 (Indicate whether for ofl, gas, water or other purposes) known as thes.C. . . . ft. north;

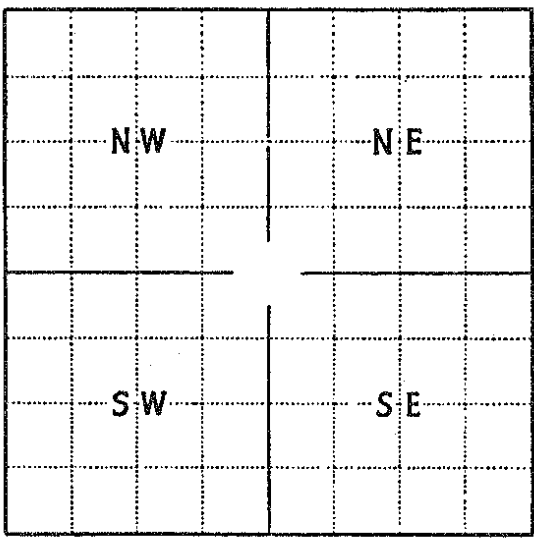

Locate well accurately on plat of section (Scale one inch-2, $2000 \mathrm{ft}$.) ft. south;

ft. east; 989 ft. west of the $S$. of the_____uarter of the__uarter of Section $15 \longrightarrow$ Township $12 \ldots$ (North $2 x_{K}$ Soukh) Range 7 (East quxWest) of the Principal Meridian,_.____oles-____County, Illinois. Elevation above sea level is $\left\{\begin{array}{l}\text { Derrick Floor_t15 } \mathrm{ft} . \\ \text { Ground } \mathrm{ft} .\end{array}\right.$ Total depth 3005 . Formation dosiclare Date permit to drill issued $53-46$ Permit No. 848

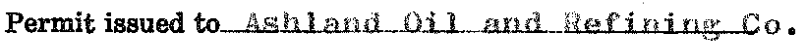
Date drilling began $-5-23-46$

Date drilling completed $5-30-46$

Kind of drilling tools used.....

Date plugging began $\quad 6-8-21$

Date plugging completed $\quad 6-8-21$

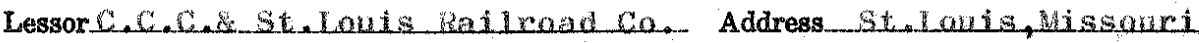
Lessee Ashand oil and hefining co. Address Mvansville, Indiana

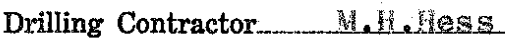
Address Unkrown

DETAILS OF PLUGGING:

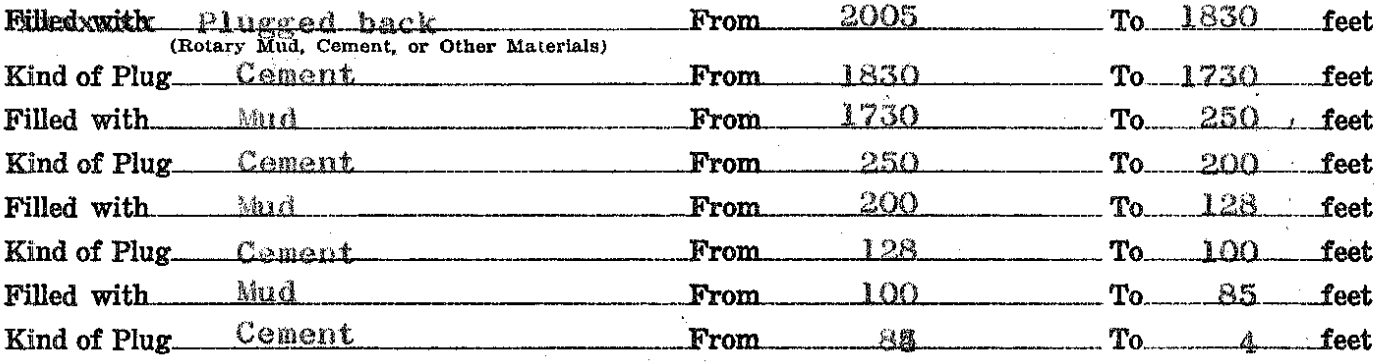

IF WORKABLE COAL BEDS WERE ENCOUNTERED IN THIS HOLE, DESCRIBE THE METHOD EMPLOYED TO PROTECT SAME. (A workable coal bed is thirty inches or more in thickness above 1,000 feet in depth)

(1) Have pits and other excavations been filled?

(2) Have the following been removed?

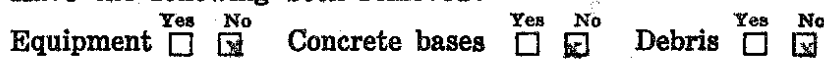

(3) Has surface casing been cut off three feet below ground surface?

(4) Has well-site been levelled? . . . . . . . . . . . . . . . .

If this was a producing well, give date and amount of last production un unowisn

\section{CASING RECORD}

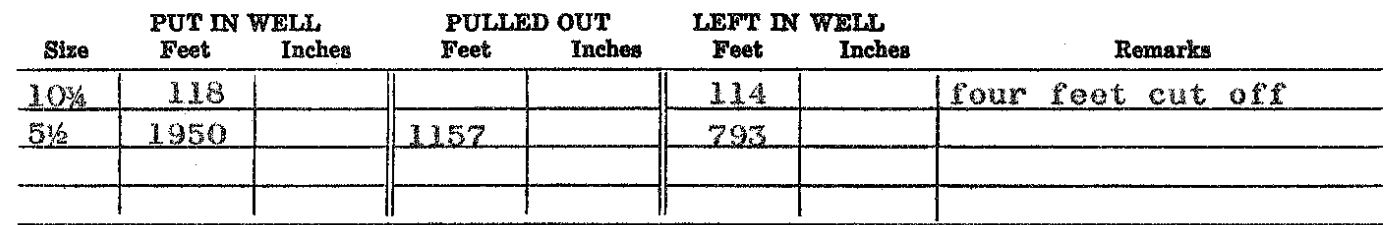

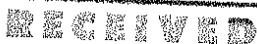

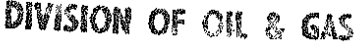

U1 301971

Depaptimest of

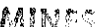
Suberibed and aworn to beford we this loth day of chue Wy commission expires $5 / 18 / 7 \%$ 4
E. C. Reeves

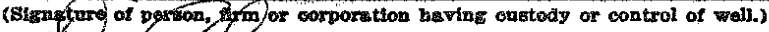
Per. Len athen

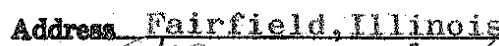

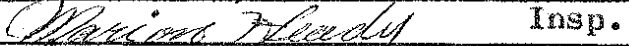

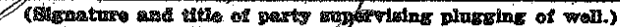

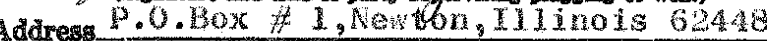


do depose and say the following is a true and correct statement of the details of the plugging of a certain well drilled for 011 $x^{2} 0=1 t^{2}=1 \leq 1 \leq$

known as the Cano Cons. 1

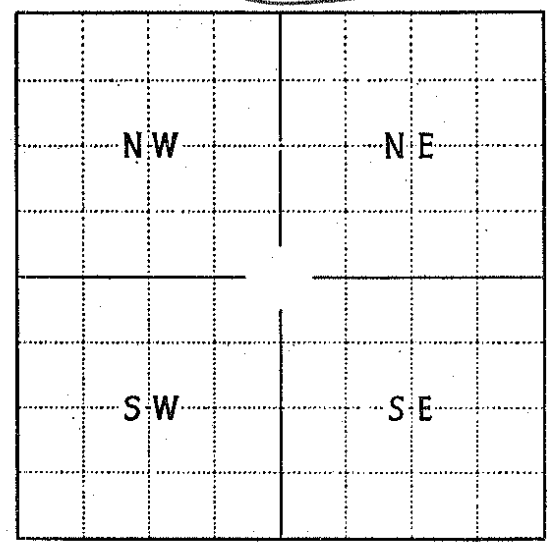

Locate well accurately on plat of section (Scale one inch-2,000 ft.) ndicate whether for oil, gas, water or other purposes) and located as follows: $\quad 340 \quad \mathrm{ft}$. north; ft. south; …....................... east; - 1113 west

of the SD corner of the Quarter

of the - Quarter of the Qu__ Quarter of

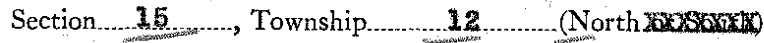
Range.... 7 , (East of the 3 Principal Meridian, Colos County, Illinois.

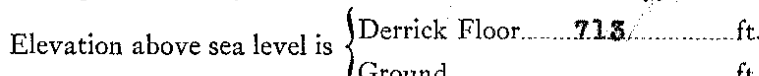

Total depth of well is 1997 fft.

Date permit to drill issued $12-4-45$....Permit No.. 1950

Permit isşued to Nielter Duncen

Date drilling began $18=0-45$

Date drilling completed $\quad 12-21-45$

Kind of drilling tools used Rotaxy

Date plugging began $1-1-24-51$

Date plugging completed $1-26-51$

Lessor Garo Cons

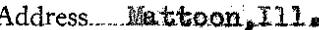

Lessee ......tentaz Daroan

Address LaSa 110. I11.

Drilling Contractor....... Da

Address .....th Carmo1, I11.

\section{DETAILS OF PLUGGING:}

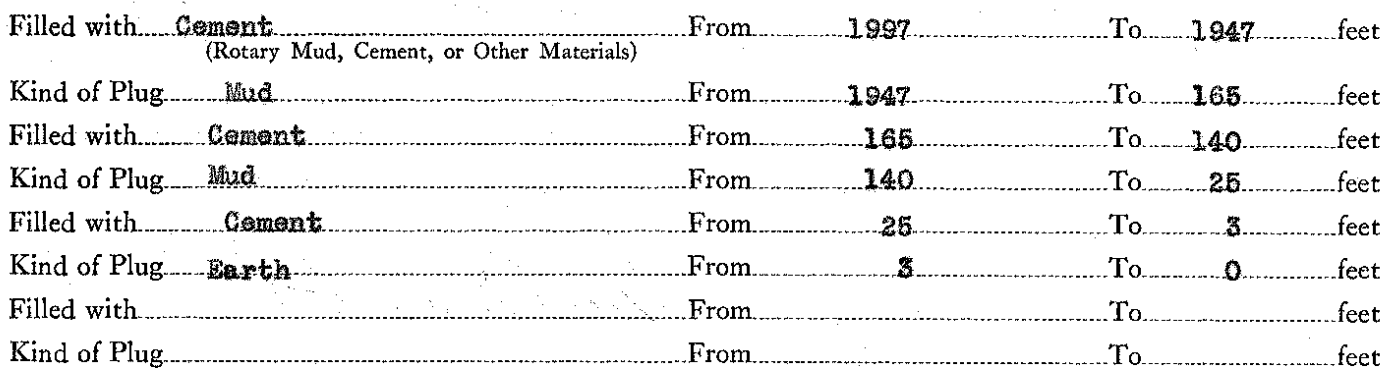

IF WORKABLE COAL BEDS WERE ENCOUNTERED IN THIS HOLE DESCRIBE THE METHOD EMPLOYED TO PROTECT SAME. (A workable coal bed is thirty inches or more in thickness above 1,000 feet in depth)............. Ho coel oncountered

(1) Have pits, cellar and other excavations been filled?......

(2) Have equipment, concrete bases and debris been removed?

$\begin{array}{ll}\text { Yes } & \text { No } \\ \square & \text { No } \\ \text { Yes } & \text { No } \\ \square & \square \\ \text { Yes } & \text { No } \\ \square & \square\end{array}$

(3) Has surface casing been cut off below plow depth?.....

(4) Has well-site been levelled?.

If this was a producing well, give date and amount of last production

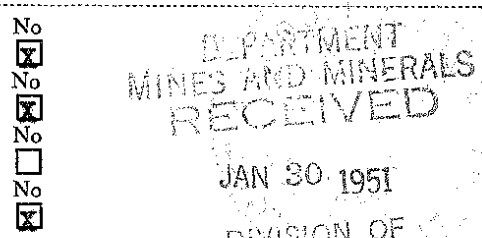
1 bol. $1-4-51$ ond 0 ond

\section{CASING RECORD}

\begin{tabular}{|c|c|c|c|c|c|c|c|}
\hline \multirow[b]{3}{*}{ Size } & \multirow{2}{*}{\multicolumn{2}{|c|}{ PUT IN WELL }} & \multicolumn{4}{|c|}{ KEUUK } & \multirow{3}{*}{$\begin{array}{l}\text { Y } \\
\text { Remarls }\end{array}$} \\
\hline & & & \multicolumn{2}{|c|}{ PULLED OUT } & \multicolumn{2}{|c|}{ LEFT IN WELL } & \\
\hline & Feet & Inches & Feet & Inches & Feet & Inches & \\
\hline $10-3 / 4$ & -154 & & -0 & & 154 & & \\
\hline 2 & 1994 & & 1116 & & 879 & & \\
\hline & & & & & & & \\
\hline
\end{tabular}

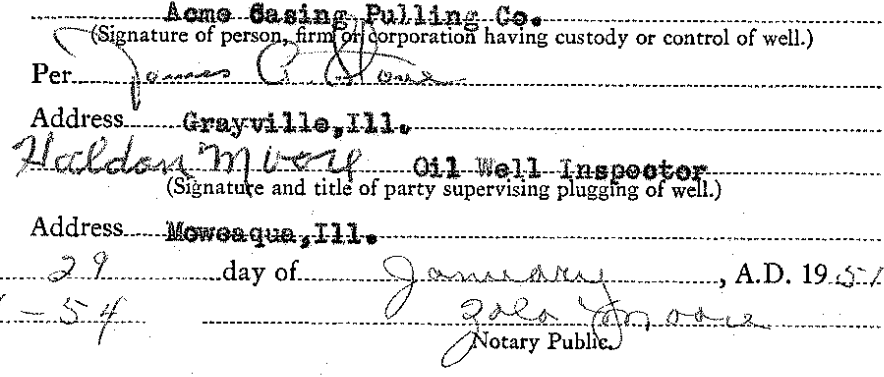



do depose and say the following is a true and correct statement of the details of the plugging of a certain well drilled for oil

known as the Gano cons.

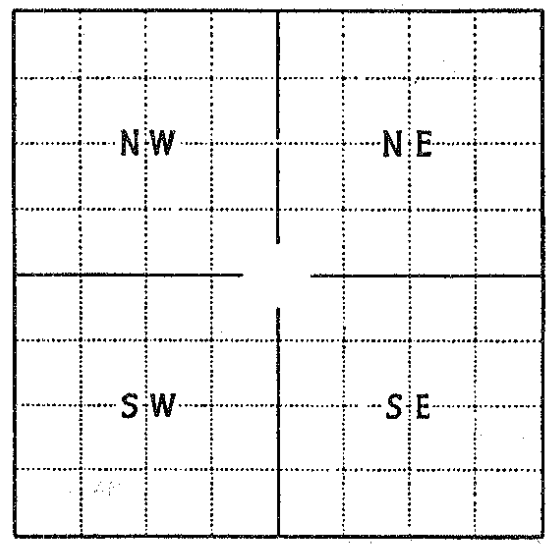

Locate well accurately on plat of section (Scale one inch-2,000 ft.)

(Indicate whether for oll, gas, water or other purposes)

and located as follows : 340

ft. north; and loca

ft. east; 1113

ft. west

of the S. I. Corner of the Quarter of the_____uarter of the Quarter of Section 15 , Township_ 12 (North or Sortin) Range 7 , (East of of the

Principal Meridian,___Coles County, nllinois. Elevation above sea level is $\left\{\begin{array}{l}\text { Derrick Floor } 713 \text { ft. } \\ \text { Ground }\end{array}\right.$ Total depth 2003 Formation Rosiclare Date permit to drill issued $10-57$ Permit No. 2686

Permit issued to Joe Blalack

Date drilling began $12-16-57$

Date drilling completed $12-20-57$

Kind of drilling tools used Rotary

Date plugging began $\quad 6-7-71$

Date plugging completed $6-8-71$

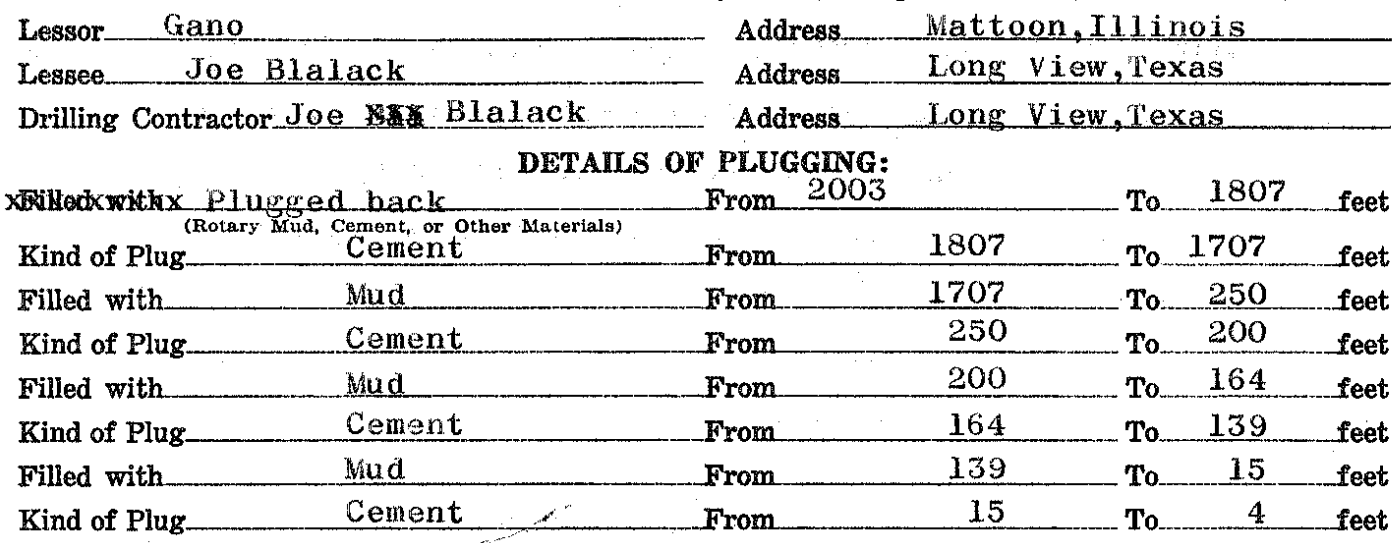

IF WORKABLE COAL BEDS WERE ENCOUNTERED IN THIS HOLE, DESCRIBE THE METHOD EMPLOYED TO PROTECT SAME. (A workable coal bed is thirty inches or more in thickness above 1,000 feet in depth)

(1) Have pits and other excavations been filled?

(2) Have the following been removed?

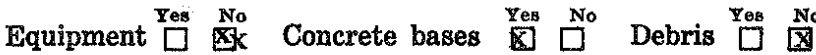

(3) Has surface casing been cut off three feet below ground surface?

(4) Has well-site been levelled?.

If this was a producing well, give date and amount of last production

\section{Yoe No}

\begin{tabular}{|c|c|c|c|c|c|c|c|}
\hline \multicolumn{8}{|c|}{ CASTNG RECORD } \\
\hline & \multicolumn{2}{|c|}{ PUT IN WELL, } & \multicolumn{2}{|c|}{ PULLED OUT } & \multicolumn{2}{|c|}{ LEFT IN WELL } & \multirow[b]{2}{*}{ Remarks } \\
\hline Size & Feet & Inches & Feet & Inches & Feet & Inches & \\
\hline $103 / 4$ & 154 & & & & 150 & & Four feet cut off \\
\hline $7^{\prime \prime}$ & 879 & & & & 879 & & $7 "$ set at 1115 to 1994 \\
\hline $41 / 2$ & 1579 & & 1209 & & 370 & & \\
\hline & & & & & & & \\
\hline
\end{tabular}

E, C.Reeves

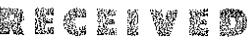
DNISION OF OL \& $6 \mathrm{BS}$

JUN 301971

Subscrined and morantorbefore me this 10 th

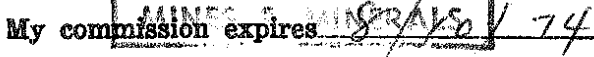

(Gisnatpes of porton arm or fopporation having oustody or control of well.) Per

Addre Fairield, Tllinois

$$
\text { Copene } 300202 \text { Imsp. }
$$

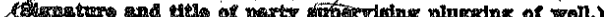

Addres $\mathrm{P} . \mathrm{O} . \mathrm{Box}$ if 1 , Newton, I11inois 62448 Tune

A.D. 19.71 
$\left.\begin{array}{l}\text { STATE OF ILLINOIS } \\ \text { County of Coles }\end{array}\right\}$ ss.

WELL PLUGGING AFFIDAVIT Matroon

Aome Casing Pulling Co. \& Wa ter Duncan

Heldon Mloore.

being first duly sworn do depose and say the following is a true and correct statement of the details of the plugging of a certain well drilled

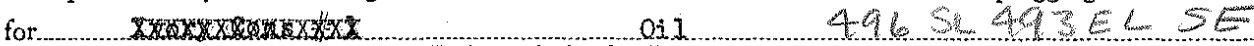
(Indicate whether for oil, gas, water or other purposes)

known as the Ivory Cons If I

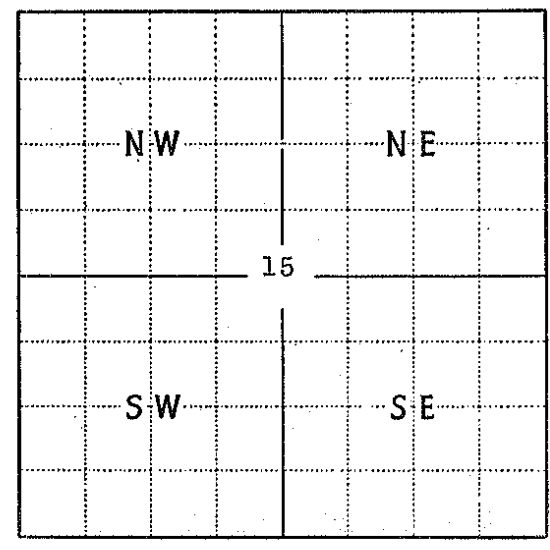

Locate well accurately on plat of section Scale one inch-2,000 ft.) ft. south;

of the $S E$

of the

西

$$
\text { (and }
$$

llows:

$\mathrm{ft}$.

ft. east;

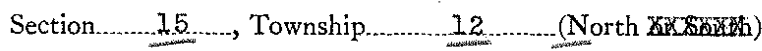

Range $\frac{7}{7}$, (East of the 3

Principal Meridian, Coles... County, Illinois.

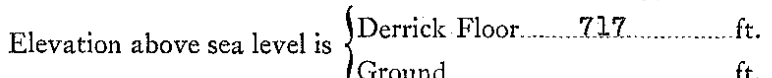

Total depth of well is 1997

Date permit to drill issued $3-1-46 \ldots$.....Permit No. 316

Permit issued to Walter Duncan

Date drilling began . $\quad 3-1-46$

Date drilling completed $3-7-46$

Kind of drilling tools used Rotary

Date plugging began ............ $-10-51$

Date plugging completed $2-13-51$

Lessor........ Irory Cons

Address Whtion, I11.

Lessee . 1 ter Duncon

Address......t Vernon, IIl.

Drilling Contractor Doe Hiller

Address Mt Carmel, Illa

DETAILS OF PLUGGING:

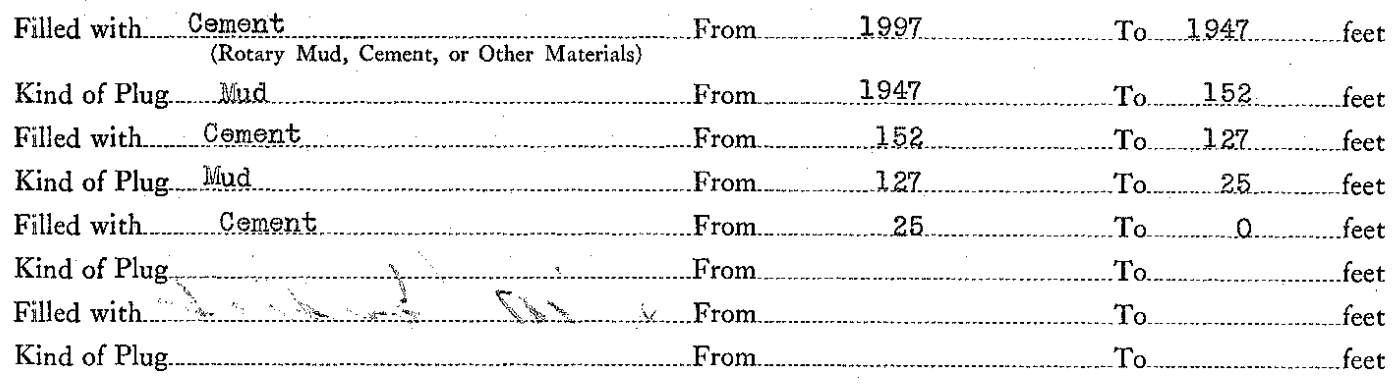

IF WORKABLE COAL BEDS WERE ENCOUNTERED IN THIS HOLE, DESCRIBE THE METHOD EMPLOYED TO PROTECT SAME. (A workable coal bed is thirty inches or more in thickness aboye 1,000 feet in depth) INo Coal oncountered

(1) Have pits, cellar and other excavations been filled?.....

(2) Have equipment, concrete bases and debris been removed?

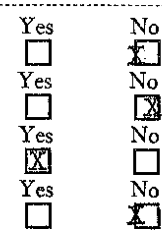

(3) Has surface casing been cut off below plow depth?.... DEPR S NENT

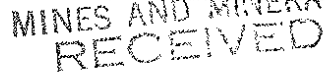

FFB 15195

DVISON OF

(4) Has well-site been levelled? ....................
If this was a producing well, give date and amount of last production

on and Gas consentrin 1 bbl, Nox, 950

CASING RECORD

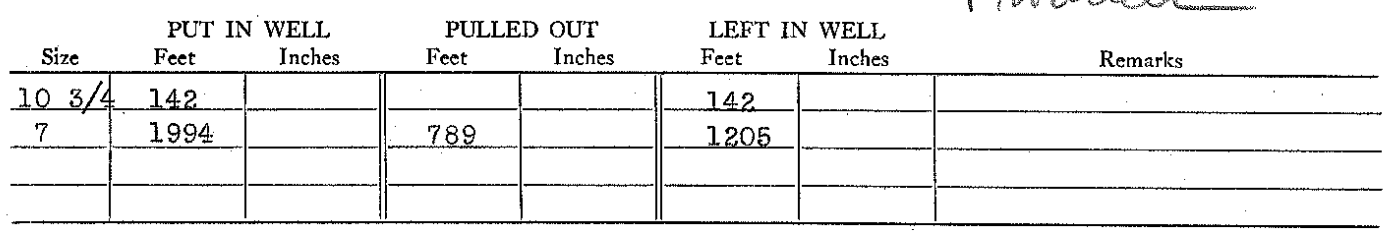

Acme Casing Pulling Co.

(Signatuafe of person, firm or corporation having custody or control of well.)

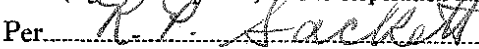

Address Greyville, I11.

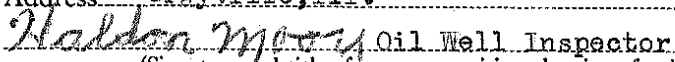

(Signature and title of party supervising plugging of well.)

Address.... Moweaqua, TII.

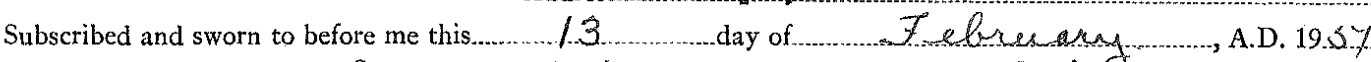
My commission expires....2-24-5-4 
$\left.\begin{array}{l}\text { STATE Of ILLINOIS, } \\ \text { county of } \rho_{2}\end{array}\right\}$ ss. 317 WELL PLUGGING AFFIDAVIT

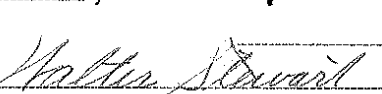
Anger Leat being first duly say the following is a true and correct statement of the details of the plugging of a certath well drilled and

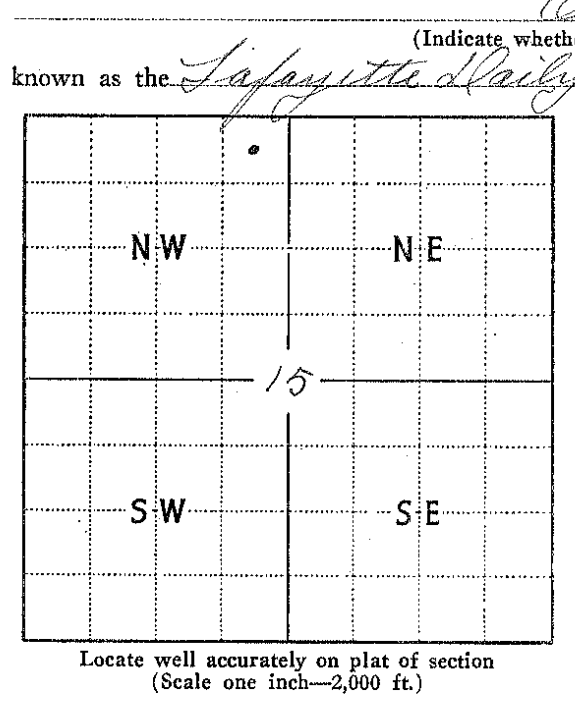

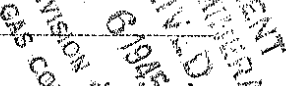
her for oil, gas, water or other purposes)

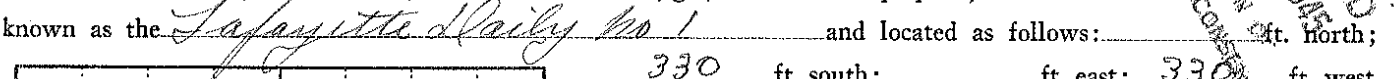

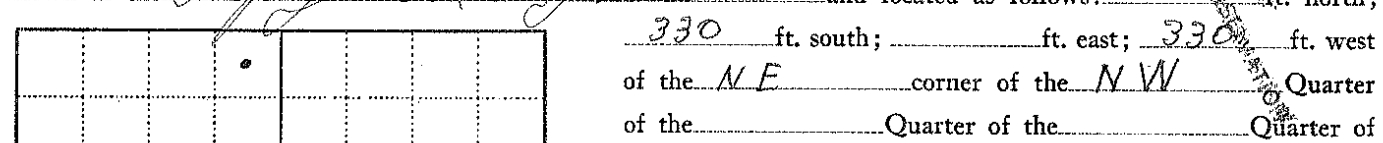
of the Quarter of the Qunarter of Section 15 . Township $/ 2$ (North of South) Range $z$, (East West), of the 3 Principal Meridian, County, lllinois. Elevation above sea level is $\{$ Derrick Floor... $72 y$ ft. Total depth of well is $\quad 2 / 19$ Date permit to drill issued (ex) $31-19 * 6$

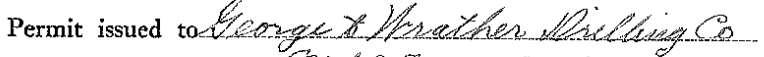
Date drilling began 20122194

Date drilling completed - $1024-1845$ Kind of drilling tools used $\angle P A z$ Date plugging began $2004-1845$

Date plugging completed $2004-1843$

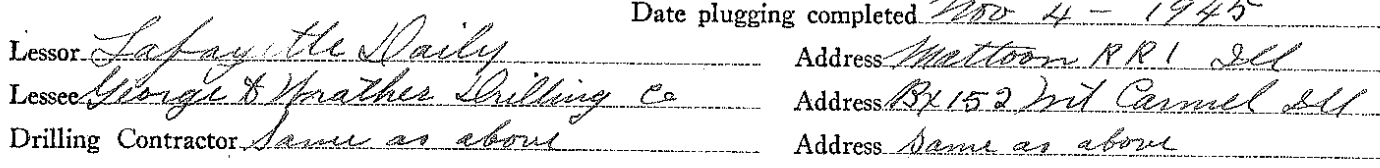

Filled with

DETAILS OF PLUGGING:

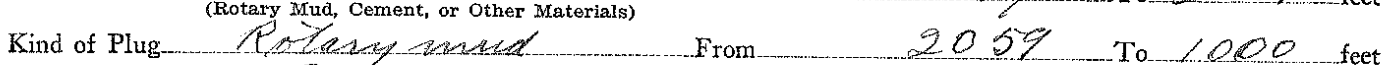

Filled with $\quad 2$ From 1000 To 900 feet

Kind of Plug Potay mend From 900 To 592 feet

Filled with Qement From 532 To 432 feet

Kind of Plug_ From_ feet

Filled with_from_ Foet To fet

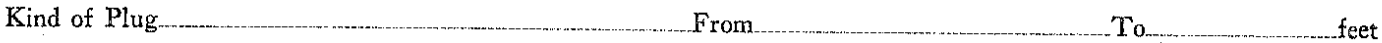

IF WORKABLE COAL BEDS WERE ENCOUNTERED IN THIS HOLE, DESCRIBE THE METHOD EMPLOYED TO PROTECT SAME. (A workable coal bed is thirty inches or more in thickness above 1,000

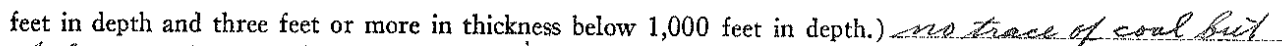

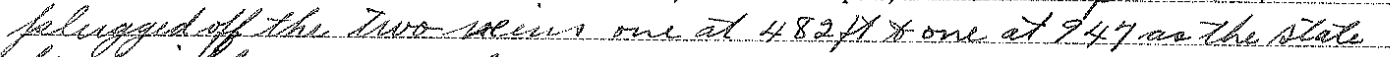

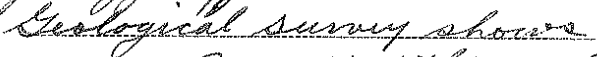

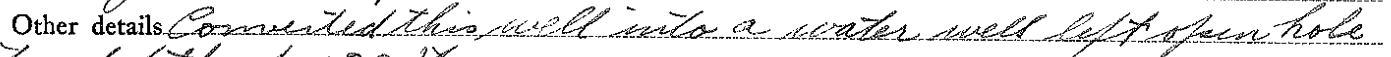
to dertet $42,2 x$

If this was a producing well, give date and amount of last production

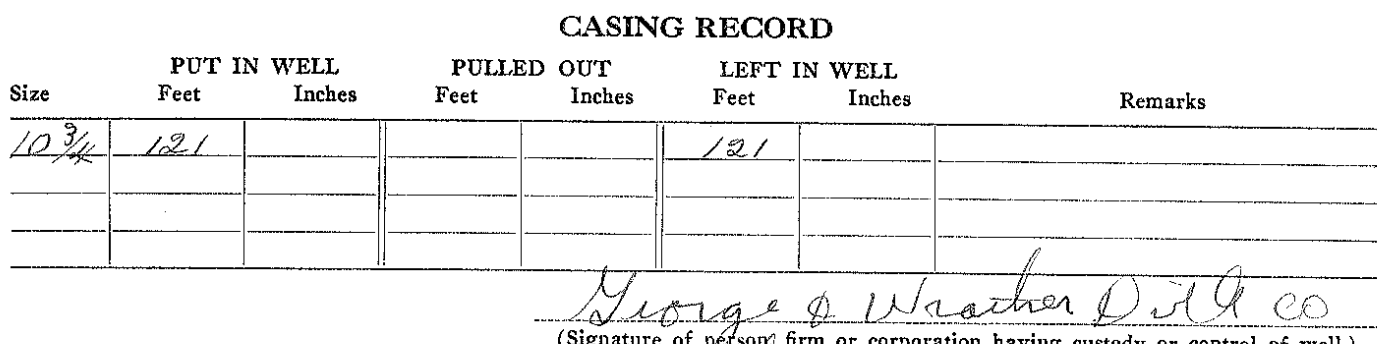

(Signature of persogy firm or corporation having custody or control of well.)

Per Ifect il or corporation

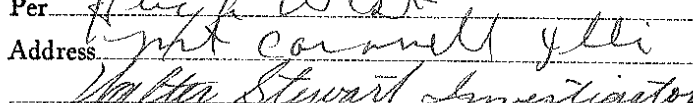

(Signature and title of party supervising plugging of well.)

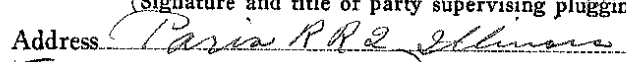
Subscribed and sworn to before me this 5
My commission expires nor. $30-1942$ day of Notary 8 jblic. 
County of wow

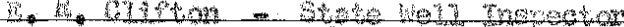

being first duly sworn do depose and say the following is a true and correct statement of the details of the plugging of a certain well drilled for nte

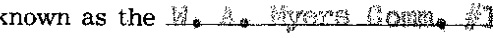
Indicate whether for oil, gas, water or other purposes)

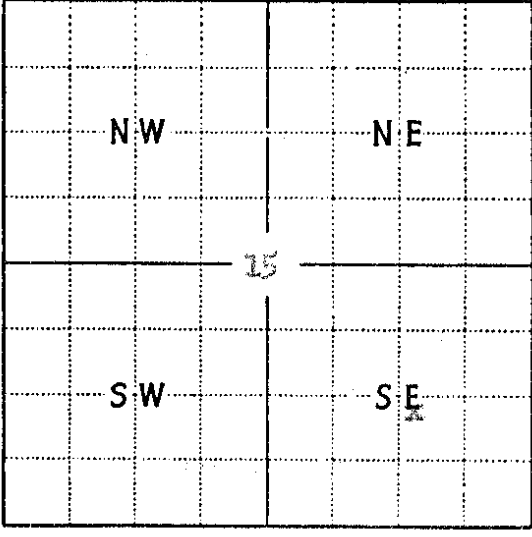

Locate well accurately on plat of section (Scale one inch-2,000 ft.) and located as follows: 19 ft. north; ft. south; ft. east; -

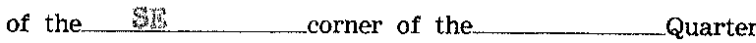

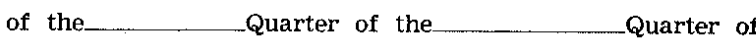

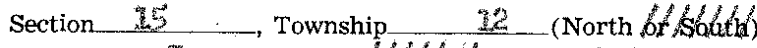

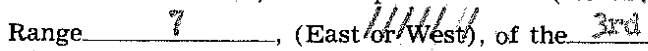

Principal Meridian, 0 ases County, Illinois

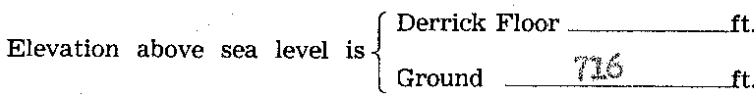
Total depth 2010 Formation

Date permit to drill issueditumPermit issued to d.

Date drilling began $22-6-35-145$ Date drilling completed $12-24-45$

Kind of drilling tools used

Date plugging began $\quad 20-25=73$

Date plugging completed. $\quad 20+26-7 / 3$

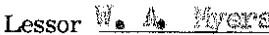

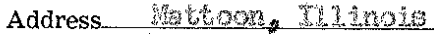

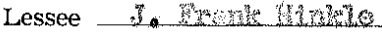

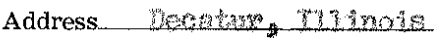

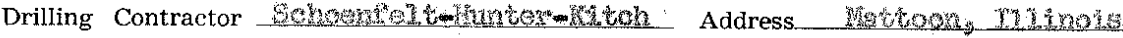

DETAILS OF PLUGGING:

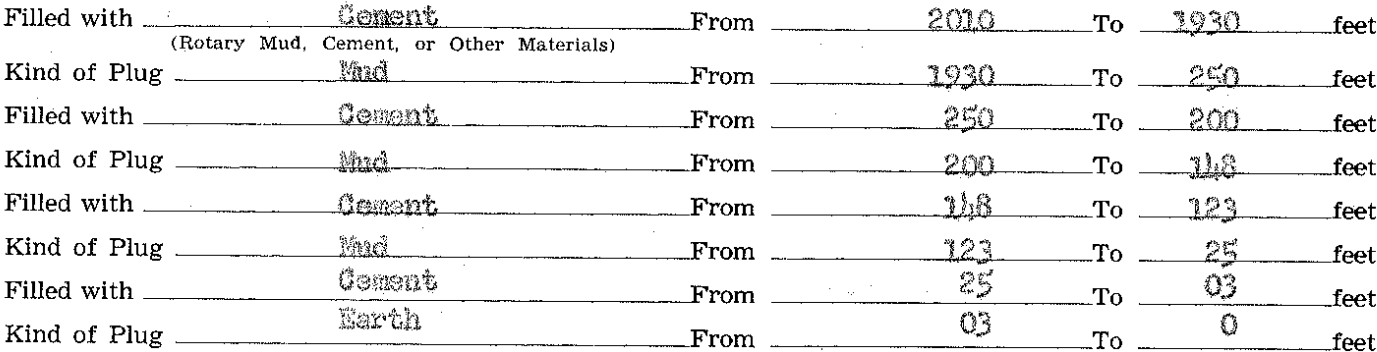

IF WORKABLE COAL BEDS WERE ENCOUNTERED IN THIS HOLE, DESCRIBE THE METHOD EMPLOYED TO PROTECT SAME. (A workable coal bed is thirty inches or more in thickness above 1,000 feet in depth) Sorste

(1) Have pits and other excavations been filled?

(2) Have the following been removed?
Equipment $\stackrel{\text { Yes }}{\square}$ No
Concrete bases $\stackrel{\text { Yes }}{\square}$ №
Debris $\stackrel{\text { Yes }}{\square}$ №

(3) Has surface casing been cut off three feet below ground surface?

(4) Has well-site been levelled?

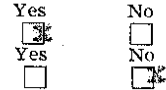

If this was a producing well, give date and amount of last production

\section{CASING RECORD}

\begin{tabular}{|c|c|c|c|c|c|c|c|}
\hline Size & $\begin{array}{c}\text { PUT IN } \\
\text { Feet }\end{array}$ & $\begin{array}{l}\text { WELL } \\
\text { Inches }\end{array}$ & $\begin{array}{l}\text { PULLED } \\
\text { Feet }\end{array}$ & $\begin{array}{l}\text { OUT } \\
\text { Inches }\end{array}$ & $\begin{array}{c}\text { LEFT } \\
\text { Feet }\end{array}$ & $\begin{array}{l}\text { WELL } \\
\text { Inches }\end{array}$ & Remarks \\
\hline$-3 / h^{828}$ & 39 & $\infty$ & 3 & 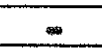 & 2.35 & - & 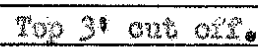 \\
\hline 7 & 2950 & $\infty$ & 590 & - & 1360 & & \\
\hline & & & & & & & \\
\hline
\end{tabular}

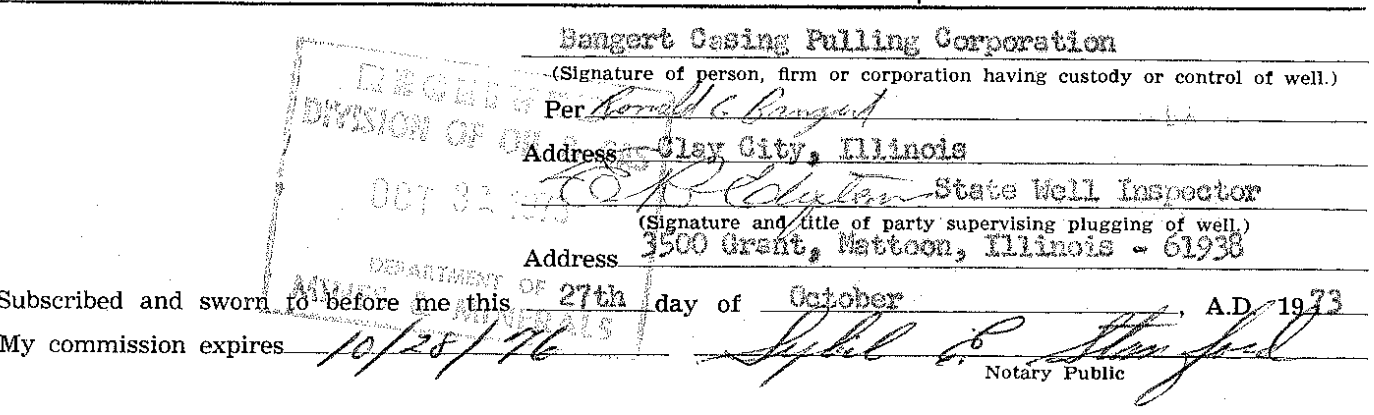



do depose and say the following is a true and correct statement of the details of the plugging of a certain well drilled for. $011 \quad 083$ SL $\quad 495$ (Indicate whether for oil, gas, water or other purposes)

known as the Noyse A I I 1

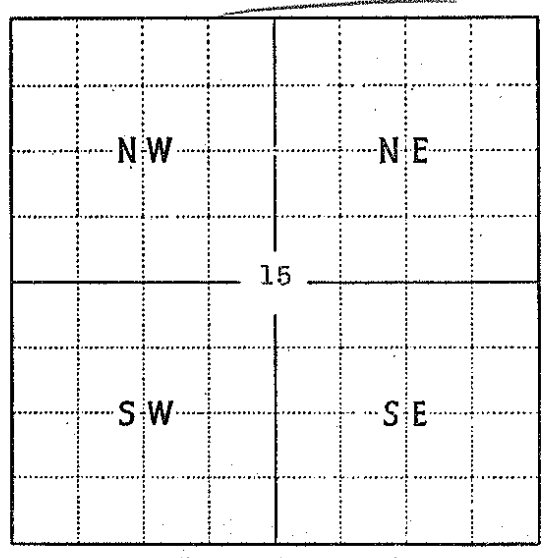

Locate well accurately on plat of section (Scale one inch-2,000 ft.)
$1083 \ldots . . . f t$. south; .......495......ft. east;

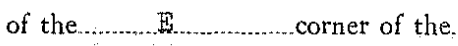

of the _.......................

t. north;

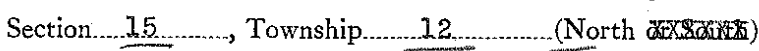

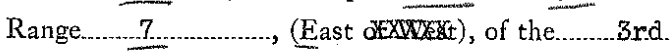

Principal Meridian, Coles County, Illinois. Elevation above sea level is $\left\{\begin{array}{l}\text { Derrick Floor } 719 \ldots \mathrm{ft} . \\ \text { Ground }\end{array}\right.$

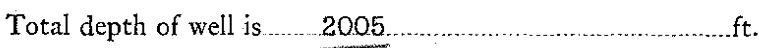

Date permit to drill issued $12-3-46$....Permit No. 497 .

Permit issued to ....... Welter Duncen.

Date drilling began ......... 4-5-46

Date drilling completed $\quad 5-11-46$

Kind of drilling tools used ......ROteary

Date plugging began ........... 1-26-51

Date plugging completed $1-27-51$

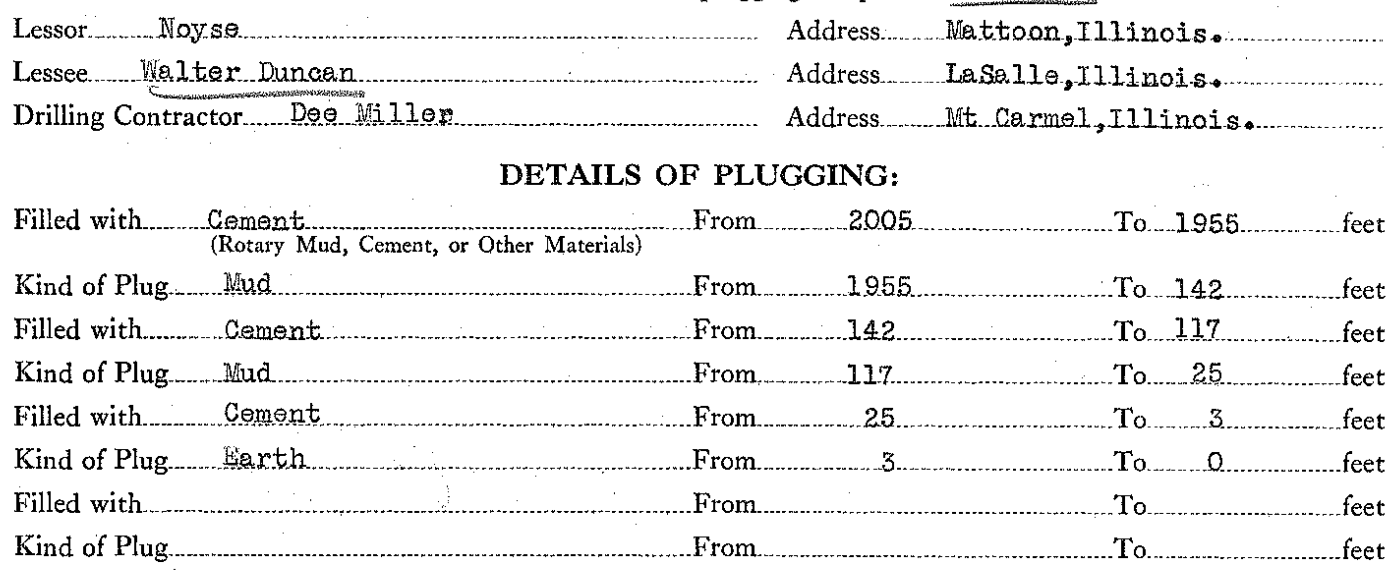

IF WORKABLE COAL BEDS WERE ENCOUNTERED IN THIS HOLE, DESCRIBE THE METHOD EMPLOYED TO PROTECT SAME. (A workable coal bed is thirty inches or more in thickness above 1,000 feet in depth). No coal encountered.

(1) Have pits, cellar and other excavations been filled?.....

(2) Have equipment, concrete bases and debris been removed?

(3) Has surface casing been cut off below plow depth?.....

$\begin{array}{ll}\text { Yes } & \text { No } \\ \text { Yes } & \text { No } \\ \square & \square \\ \text { Yes } & \text { No } \\ \text { Yes } & \square \\ \square & \text { No }\end{array}$

DPRTMENL

MINES AH MUERS

MES

(4) Has well-site been levelled?.

JAN 301951

If this was a producing well, give date and amount of last production.

2] DVason of

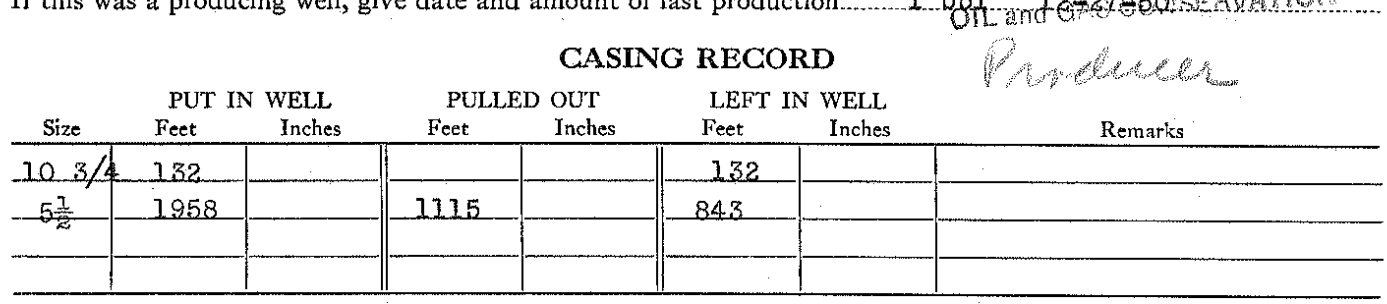

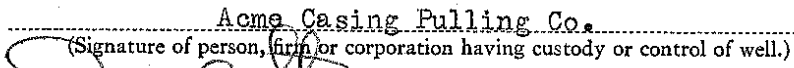

$$
\begin{aligned}
& \text { Per } 0 \text { C S } \\
& \text { Address Grayville, Illinois. }
\end{aligned}
$$

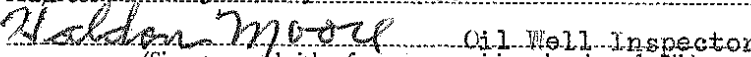

$$
\begin{aligned}
& \text { (Signature atd title of party supervising plugging of well.) } \\
& \text { Address Nowreaqua IIlinois. }
\end{aligned}
$$

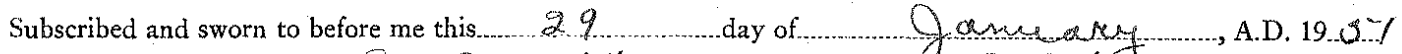
My commission expires. $\quad 2-24-34$ 
being first duly sworn do depose and do depose and say the following is a true and correct statement of the details of the plose

for. ol1 (Indicate whether for oil, gas, water or other purposes)

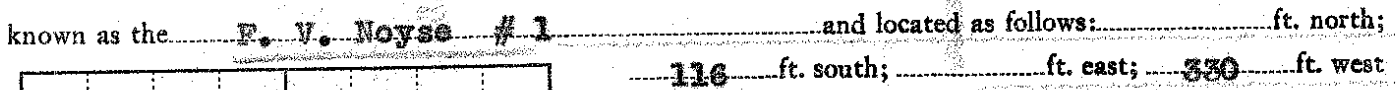

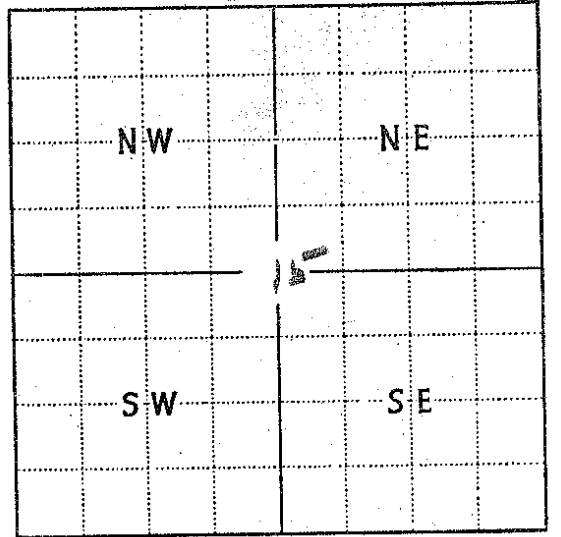

Locate well accurately on plat of section (Scale one inch-2,000 ft.)
126 - ft. south; corner of the

of the Qurter of the Quarter

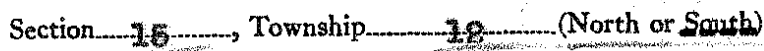

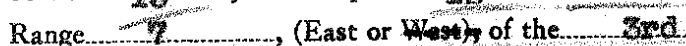

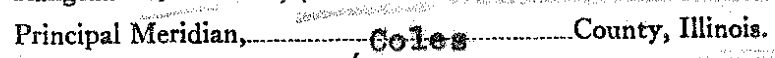

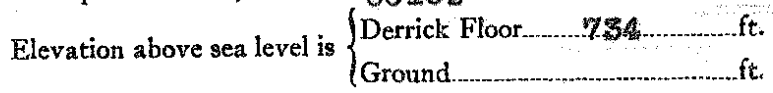

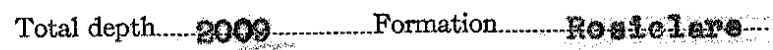
Date permit to drill issued _._....................

Permit issued to.-.....

Date drilling began - $1-6-46$

Date drilling completed.....1-23-46

Kind of drilling tools used-_..........-inotary

Date plugging began $-11-6-5 z$

Date plugging completed-1 $1-4-15$

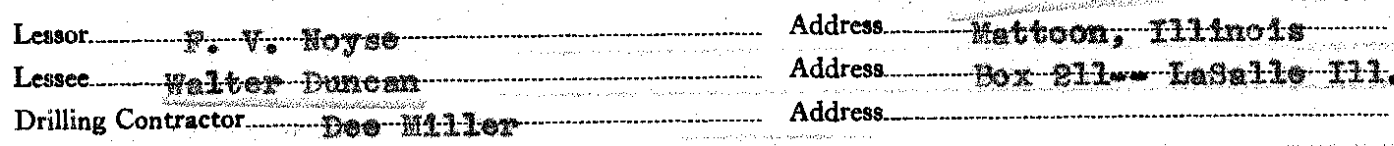

DETAILS OF PLUGGING:

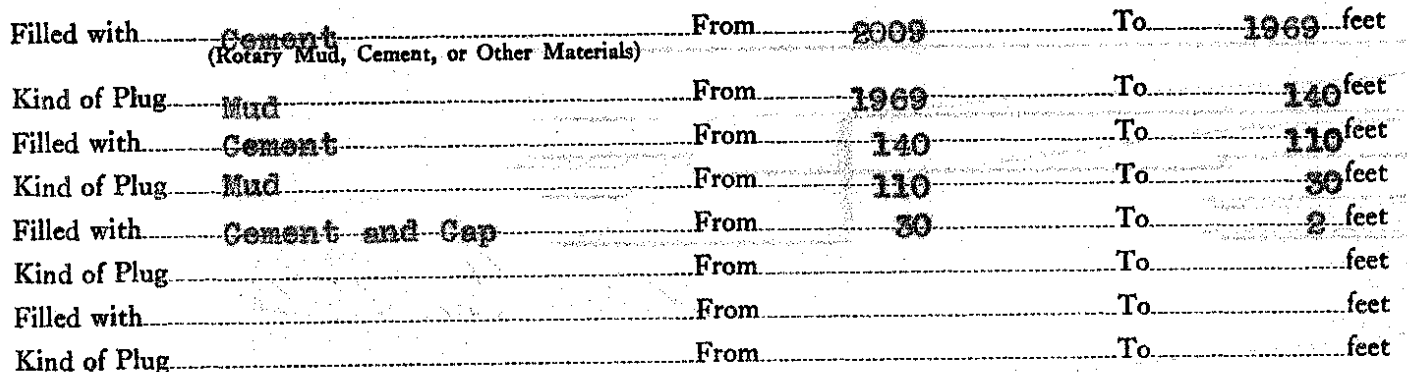

IF WORKABLE COAL BEDS WERE ENCOUNTERED IN THIS HOLE, DESCRIBE THE METHOD EMPLOYED TO PRO'TECT SAME. (A workable coal bed is thirty inches or more in thickness above 1,000 feet in depth) -

(1) Have pits and other excavations been filled?

(2) Have the following been removed?
Equipment
Concrete bases
$\stackrel{\text { Yes }}{\square}$ Debris $\stackrel{\text { Yes }}{\square}^{\text {No }}$

(3) Has surface casing been cut off three feet below ground surface?

(4) Has well-site been levelled?.

If this was a producing well, give date and amount of last production.
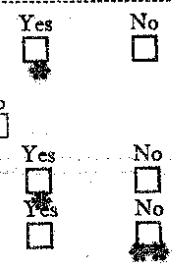

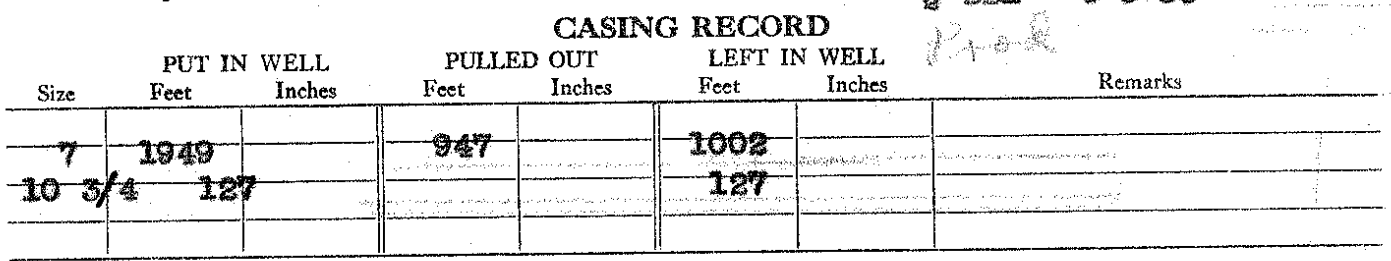

- Wrat (3)

Per $\times 2.22 \%(1,2024$

Address

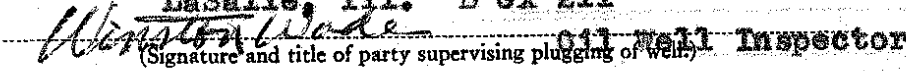

Address parts, Tlingle,

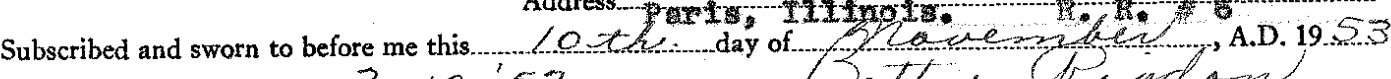

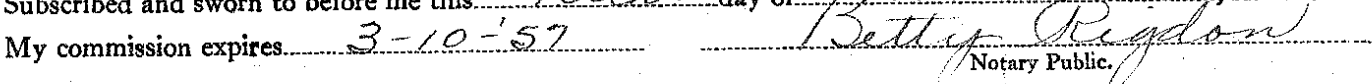


Lewrence Lindreth

being first duly ofrogn, do depose and say the following is a true and correct statement of the details' of the plugging a certalif well drilled for 011

known as the hotele

(Indicate whether for ail, gas, water or other purposes)
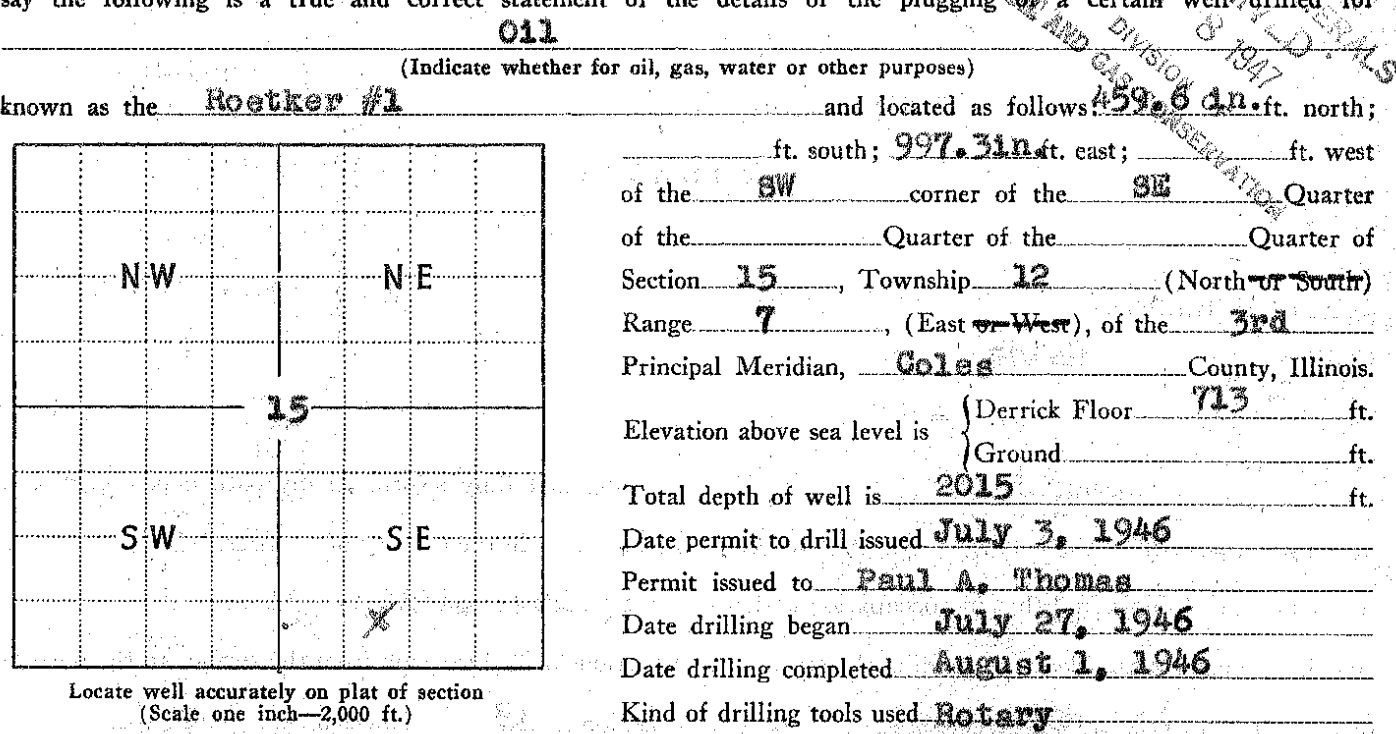

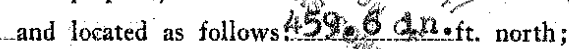

ft. south; $99 \% .31$ nft. east; st ft. west of the gV corner of the 32 ? of the Quarter of the Quarter of Section 15 ..., Township_ 12 (North चr Suttr) Range 7 , (East these), of the 3 ad

Principal Meridian, Colad County, Illinois. Elevation above sea level is $\{$ Derrick Floor 13 ft.

Total depth of well is 2015

Date permit to drill issued $1 \mathrm{u} 1 \mathrm{y} 3,1946$

Permit issued to faul A homa

Date drilling began Ju1y 27,1946

Date drilling completed Augus 1,1946

Kind of drilling tools used notary.

Date plugging began Novomber 2,1947

Date plugging completed Dreomber 2,1947

Lessor Roetkex

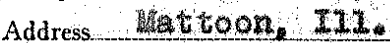

Lessee Pav A How

Drilling Contractor 3 . W Wenhal 1

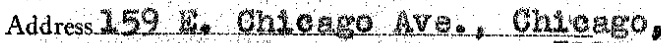
Addressenton. III. 121.

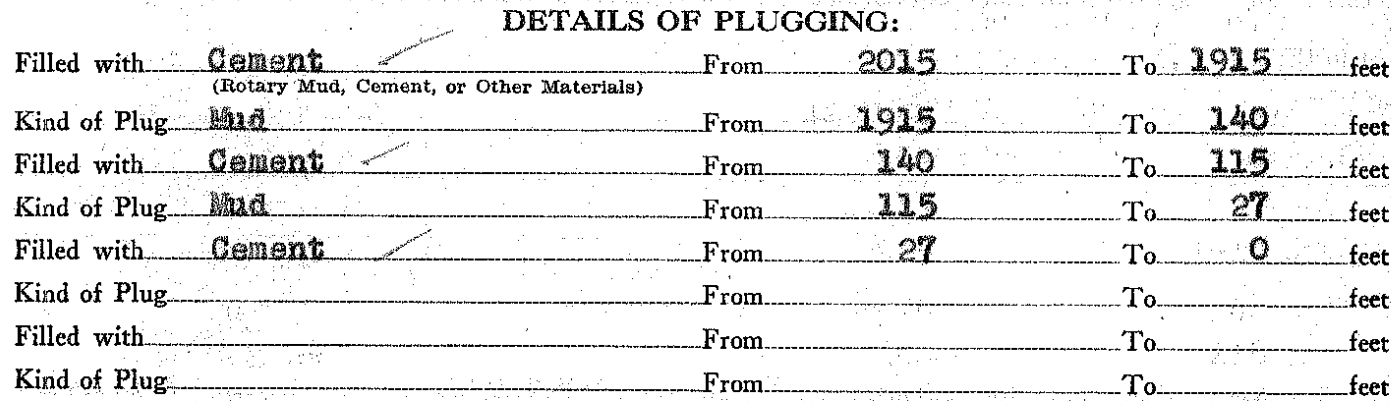

IF WORKABLE COAL BEDS WERE ENCOUNTERED IN THIS HOLE, DESCRIBE THE METHOD EMPLOYED TO PROTECT SAME. (A workable coal bed is thirty inches or more in thickness above 1,000 feet in depth) Arfart on back

(1) Have pits, cellar and other excavations been filled? .

(2) Have equipment, concrete bases and debris been removed?

(3) Has surface casing been cut off below plow depth?

(4) Has well-site been levelled?

$\begin{array}{cc}\text { Yes } & \text { No } \\ \text { Yes } & \square \\ \text { No } \\ \text { Yes } & \square \\ \square & \square \\ \text { Yes } & \text { No } \\ \square & \square\end{array}$

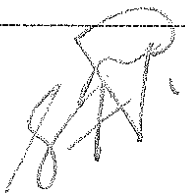

If this was a producing well, give date and amount of last production-mhy CASING RECORD ${ }^{4}-D_{1} \mathrm{Y}$.

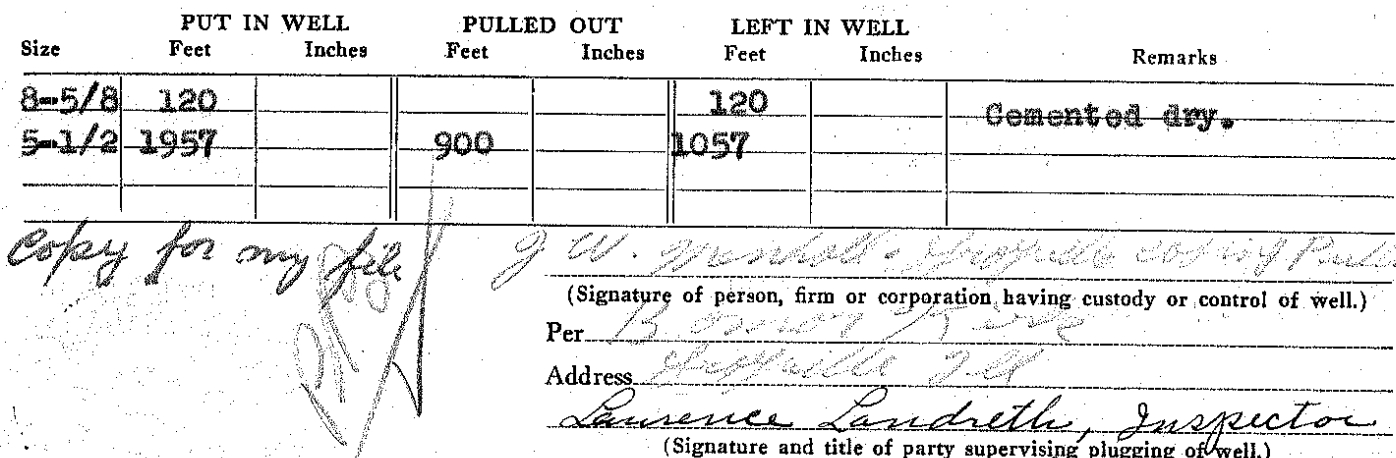

(Signature and title of party supervising plugging of well.) $^{2}$

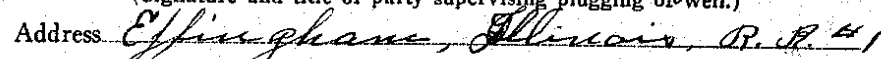

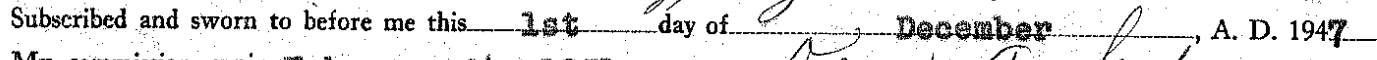
My commission expiresidobutazy 24,1951 
do depose and say the following is a true and correct statement of the details of the plugging of a certain well drilled for. Q11 and tas

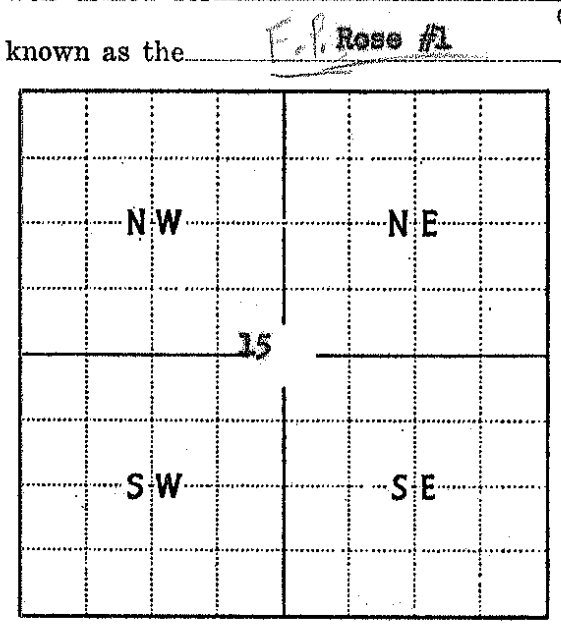

Locate well accurately on plat of section (Scale one Inch-2,000 ft.)

(Indicate whether for oil, gas, water or other purposes) and located as follows: 330 ft. south; ft. east; $330 \mathrm{ft}$. west of the SE - corner of the Sn of the ME Quarter of the Q Q Section $15 \quad$, Township 12 (North or s6hth) Range 1 , (East or $/(766)$, of the and

Principal Meridian, 6oles County, Illinois. Elevation above sea level is $\begin{cases}\text { Derrick Floor } & \mathrm{ft} . \\ \text { Ground } & \mathrm{ft} .\end{cases}$

Total depth $2175 \quad$ Formation Date permit to drill issued $9-17-56$ Permit No. 3440 Permit issued to o. $\mathbf{K}_{\text {. W Henson }}$ Date drilling began Septeribor 18,1956 Date drilling completed Septenlage 27,1956 Kind of drilling tools used Rotery

Date plugging began oetober 6,1956

Date plugging completed octobot 6,295

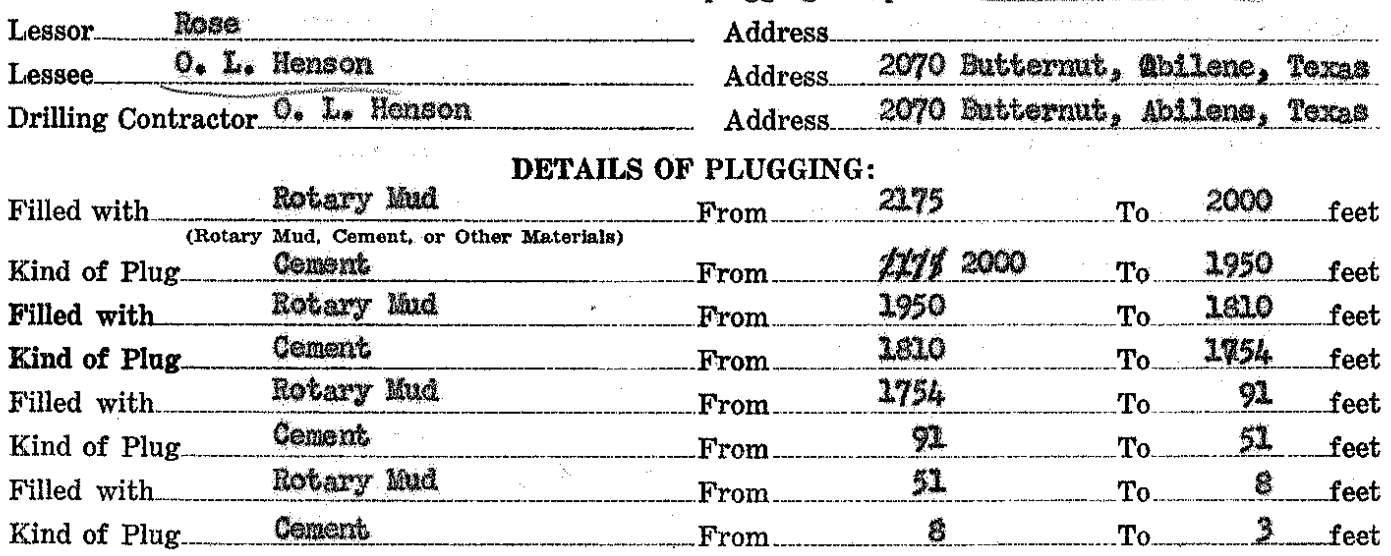

IF WORKABLE COAL BEDS WERE ENCOUNTERED IN THIS HOLE, DESCRIBE THE METHOD EMPLOYED TO PROTECT SAME. (A workable coal bed is thirty inches or more in thickness above 1,000 feet in depth) tone

(1) Have pits and other excavations been filled? $\ldots \ldots \ldots \ldots \ldots \ldots \square$

(2) Have the following been removed?

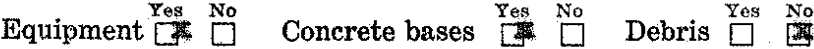

(3) Has surface casing been cut off three feet below ground surface?

(4) Has well-site been levelled?

If this was a producing well, give date and amount of last production

\begin{tabular}{|c|c|c|c|c|c|c|c|c|}
\hline \multirow[b]{2}{*}{ Size } & \multicolumn{2}{|c|}{ PUT IN WELL } & \multicolumn{4}{|c|}{ CASING RECORD } & & \\
\hline & Feet & Inches & Feet & Inches & Feet & Inches & Remárks & \\
\hline $55 / 8$ & 81 & & none & & 81 & & Cemented & \\
\hline & & & & & & & & \\
\hline & & & & & & & & \\
\hline
\end{tabular}

\section{L. Henson}

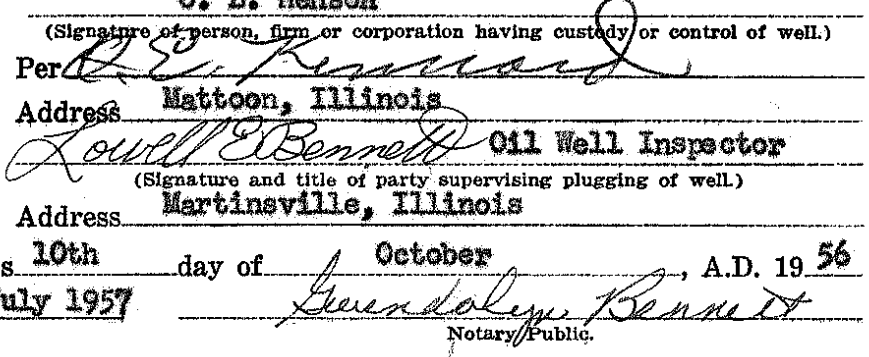


do depose and and $_{\text {the }}$ the fllowing is a true and correct statement of the details of the plugging of a first duly sworn, for 01 (Indicate whether for oil, gas, water or other purposes)

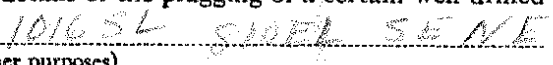

known as the nowtos

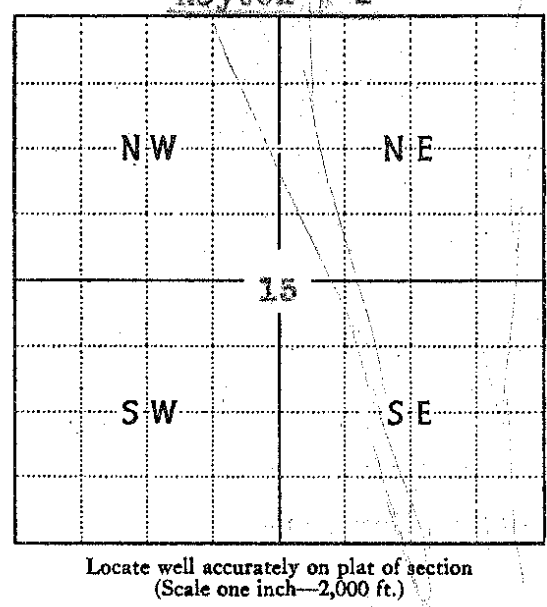

and located as follows: $\ldots$ fit. south; ft. east; .......- 310 ft. west

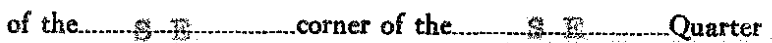
of the - Quarter of the Section.....

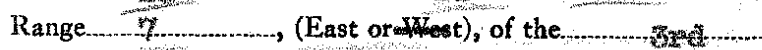

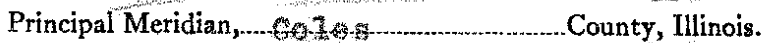
Elevation above sea level is $\left\{\begin{array}{l}\text { Derrick Floor } \\ \text { Ground }\end{array}\right.$

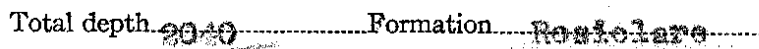
Date permit to drill issued._._... Permit No.

Permit issued to - -

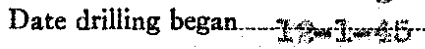

Date drilling completed

Kind of drilling tools used-

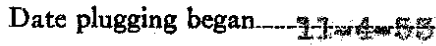

Date plugging completed.1.

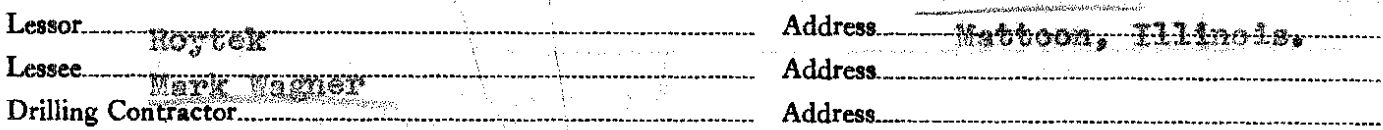

\section{DETAILS OF PLUGGING:}

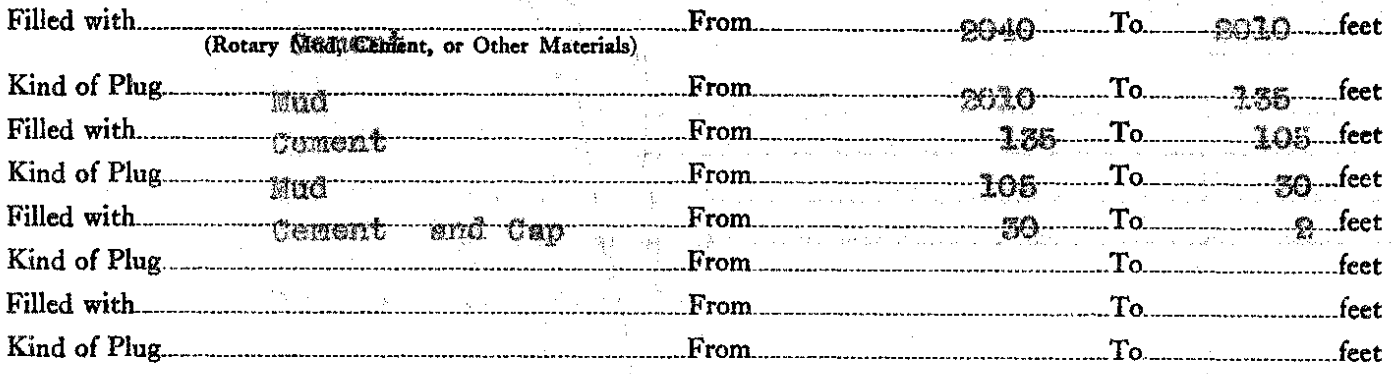

IF WORKABLE COAL BEDS WERE ENCOUNTERED IN THIS HOLE, DESCRIBE THE METHOD EMPLOYED TO PROTECT SAME. (A workable coal bed is thirty inches or more in thickness above 1,000 feet in depth).

Wo 60 a 1

(1) Have pits and other excavations been filled?

(2) Have the following been removed? Equipment $\square^{\text {Yes }}$ No

(3) Has surface casing been cut off three feet below ground surface?

(4) Has well-site been levelled?.

If this was a producing well, give date and amount of last production.

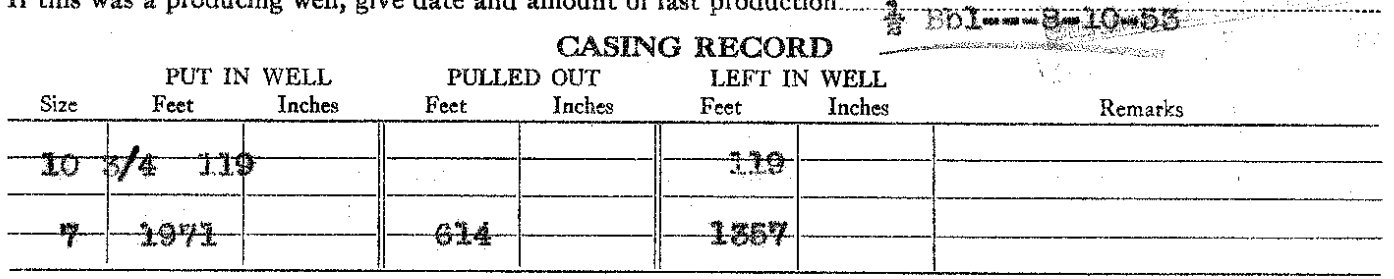

Address.

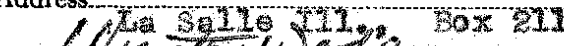

Address.

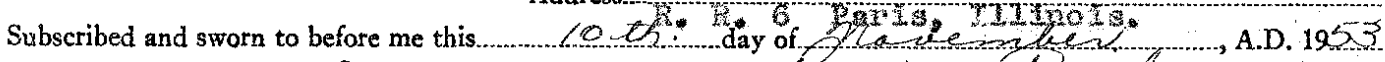

My commission expires $3-10-57$ 
County of Cold Ss.

\section{WELL PLUGGING AFFIDAVIT}

do depose and say the following is a true and correct statement of the details of the plugging of a certain well drilled for uil

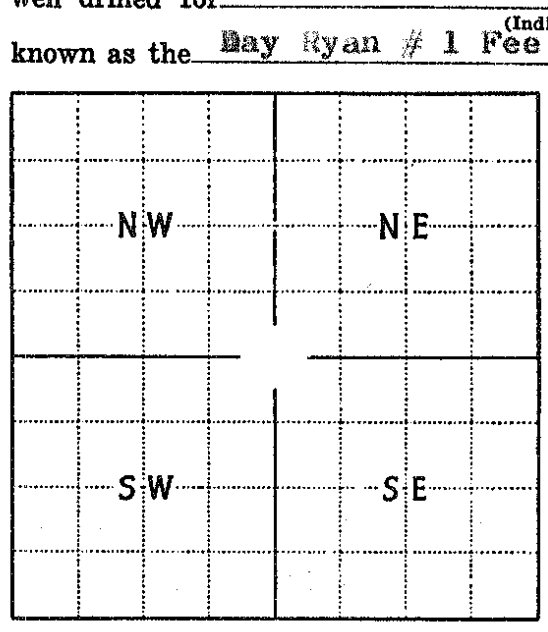

Locate well accurately on plat of section (Scale one inch-2,000 ft.)
(Indleate whether for oil, gas, water or other purposes) 951
and located as follows:

ft. north; ft. south;

ft. east: 193 ft. west of the 13 corner of the of the Quarter of the Quarter of

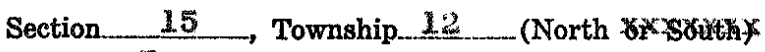
Range 7 , (East or West), of the Principal Meridian, Coles_County, Illinois. Elevation above sea level is $\left\{\begin{array}{l}\text { Derrick Floor } \\ \text { Ground }\end{array}\right.$ Total depth $1389 \quad$ Formation 30 solare Date permit to drill issued -17 . 4 Permit No. $<3$ Permit issued to glomwood $011 \mathrm{co}$. Date drilling began $3-3-46$

Date drilling completed $3-8-46$

Kind of drilling tools used Rotary

Date plugging began $1-18-73$

Date plugging completed $1-13-73$

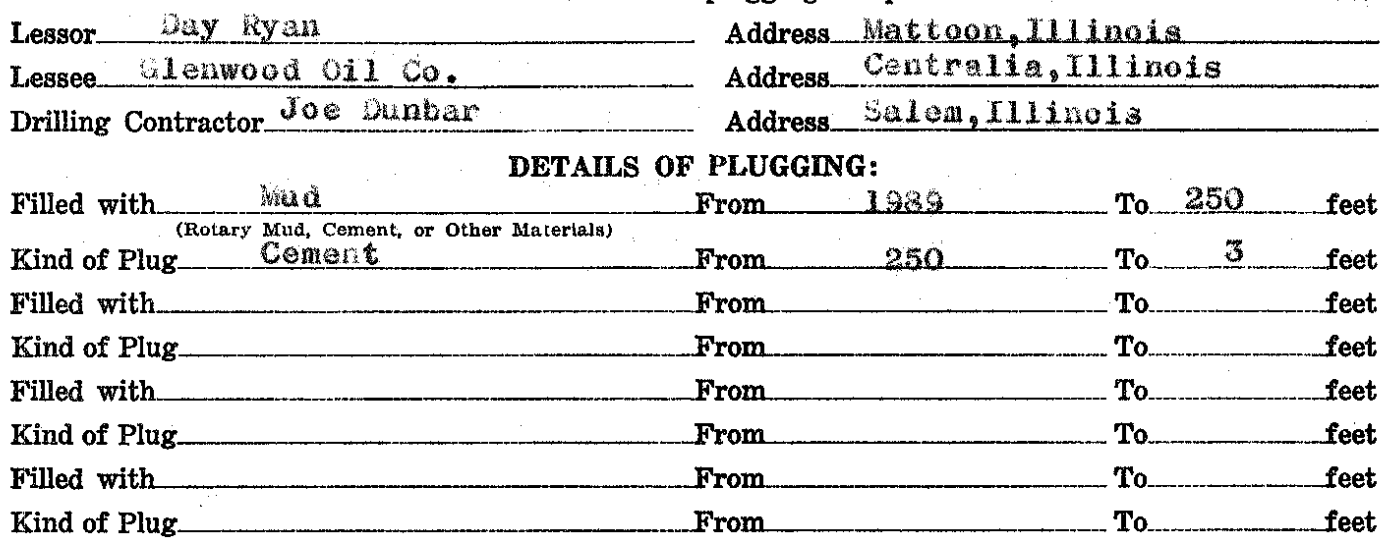

IF WORKABLE COAL BEDS WERE ENCOUNTERED IN THIS HOLE, DESCRIBE THE METHOD EMPLOYED TO PROTECT SAME. (A workable coal bed is thirty inches or more in thickness above 1,000 feet in depth)

(1) Have pits and other excavations been filled? $\ldots \ldots \ldots \ldots \ldots \ldots \ldots$

(2) Have the following been removed?

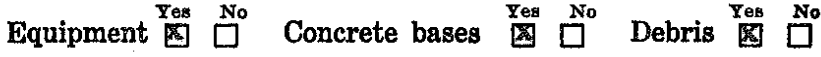

(3) Has surface casing been cut off three feet below ground surface?

If this was a producing well, give date and amount of last production Uniknowin

CASING RECORD

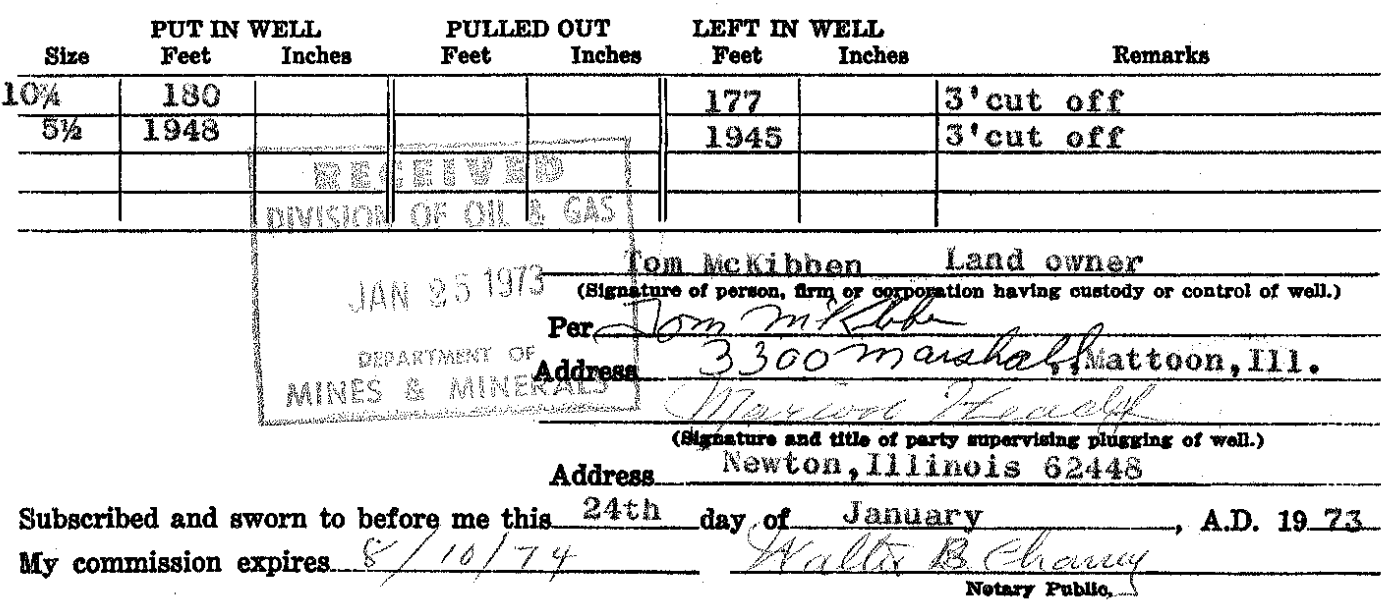




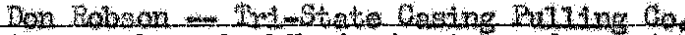

being first duly sworn, do depose and say the following is a true and correct statement of the details of the plugging of a certain well drilled for. (4)

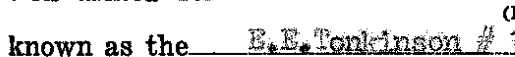
(Indlcate whether for oil, gas, water or other purposes)

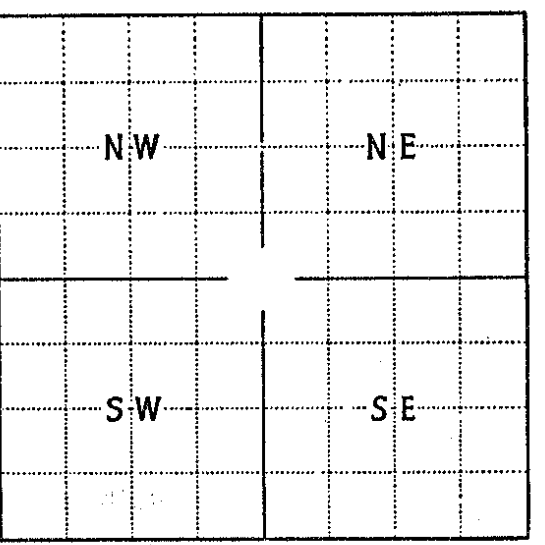

Locate well accurately on plat of section (Scale one inch-2,000 ft.) and located as follows

ft. north; 360 ft. south;____fft. east; 1040 ft. west

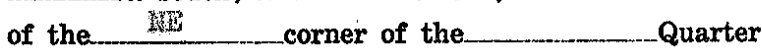
of the Q_Q Quarter of the Quarter of

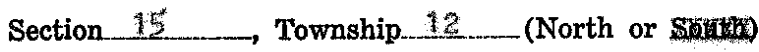
Range 1 , (East or Principal Meridian,__ Elevation above sea level is $\left\{\begin{array}{l}\text { Derrick Floor } \\ \text { Ground } 129\end{array}\right.$ Total depth $1806 \quad$ Formation Cypress Date permit to drill issued $6 / 23 / 50$ Permit No. 1107 Permit issued to W. W. Date drilling began $\quad 6 / 28 / 50$ Date drilling completed $7 / 3 / 50$ Kind of drilling tools used Date plugging began $\quad 2 / 24 / 68$ Date plugging completed $\quad 2 / 24 / 68$

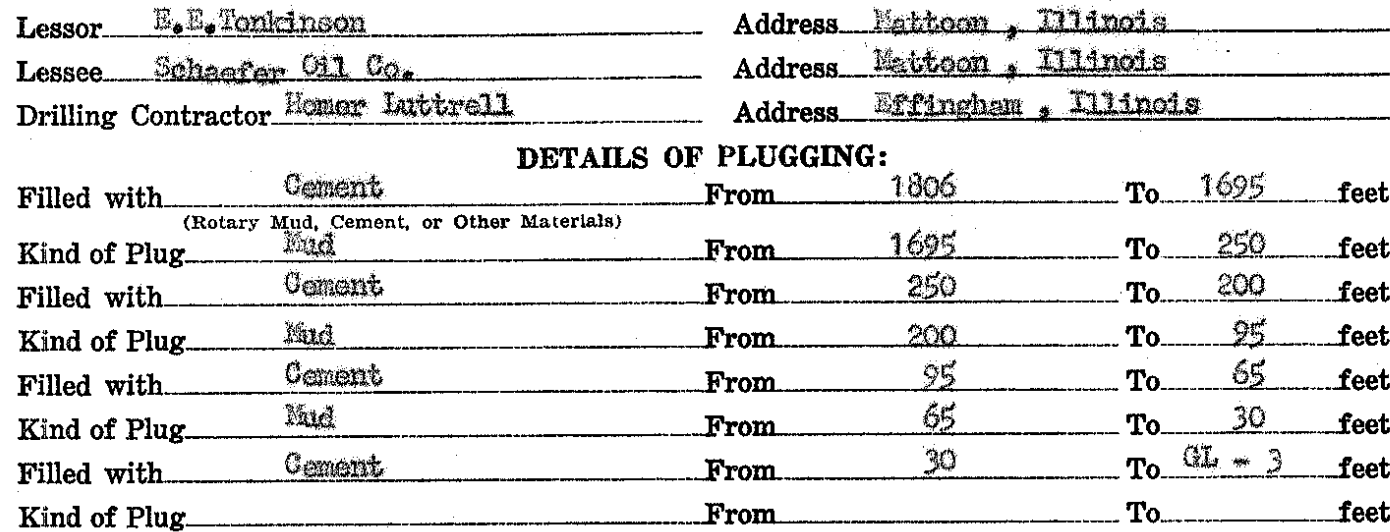

Kind of Plug _ IF WORKABLE COAL BEDS WERE

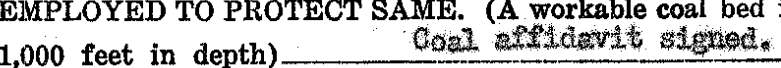

(1) Have pits and other excavations been filled? . . . . . . . . .

(2) Have the following been removed?

Equipment $\stackrel{\text { Yes }}{\square}$ No Concrete bases $\square^{\text {Yes }}$ No Debris $\square^{\text {Yes }}$ No

(3) Has surface casing been cut off three feet below ground surface? 国

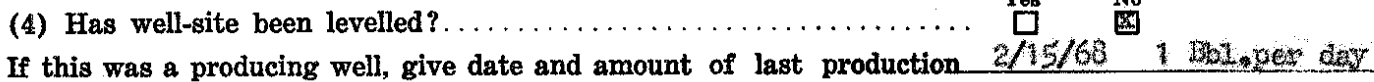
CASING RECORD

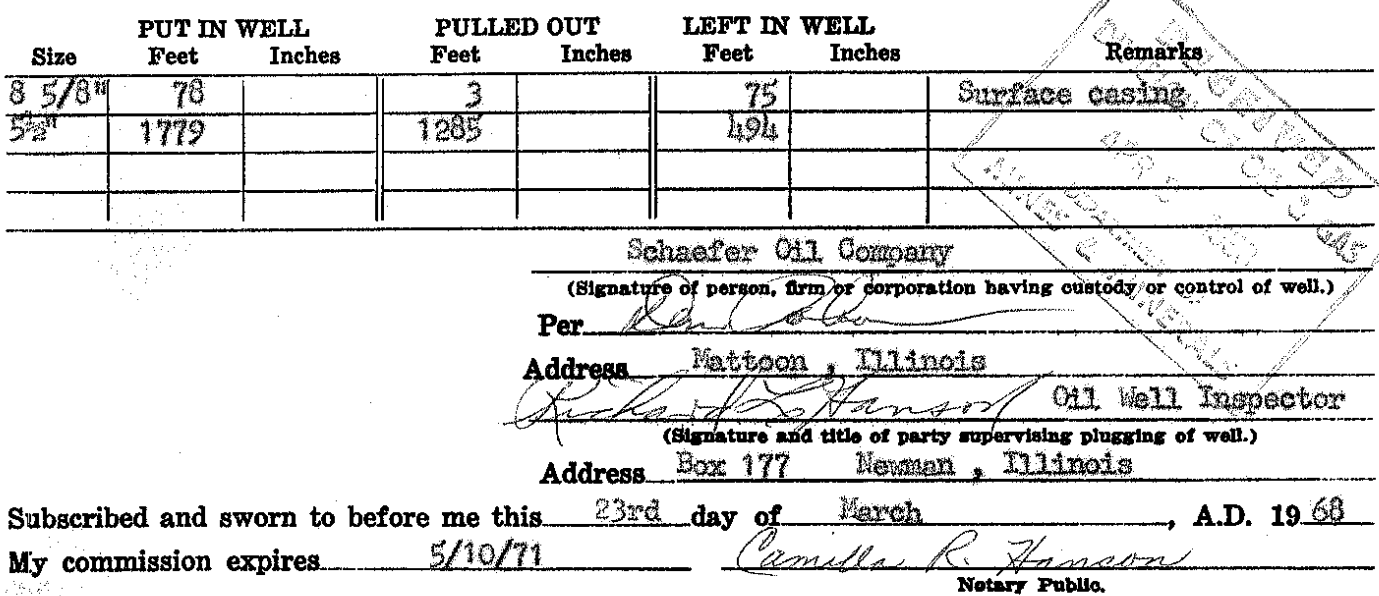


do depose and say the following is a true and correct statement of the details of the plugging of a certain well drilled for OIL

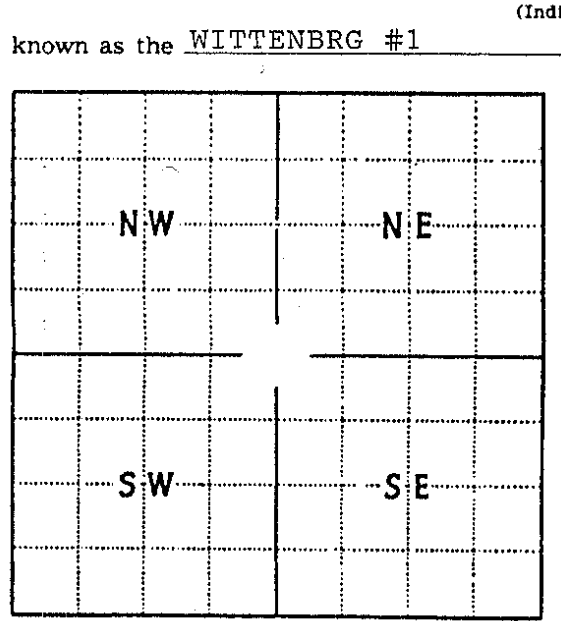

Locate well accurately on piat of section (Scale one inch-2,000 ft.) Indicate whether for ofl, gas, water or other purposes) and located as follows:

ft. north;

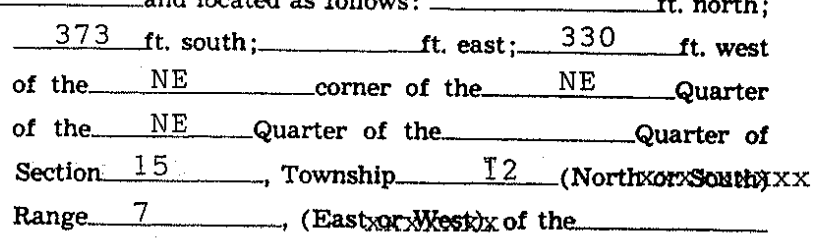

Principal Meridian, COLES

County, Illinols.

Elevation above sea level is $\begin{cases}\text { Derrick Floor } \underline{628} \mathrm{ft} . \\ \text { Ground }\end{cases}$

Total depth 2015 Formation

Date permit to drill issued $7-2-57$ Permit No. 1562

Permit issued to GORTON W TAYLOR

Date drilling began

Date drilling completed $7 / 13 / 57$

Kind of drilling tools used_ROTARY

Date plugging began $11 / 14 / 89$

Date plugging completed $11 / 15 / 89$

$\begin{array}{ll}\text { Lessor } & \text { WITTENBERG } \\ \text { Lessee } & \text { GORTON W TAYLOR } \\ \text { Drilling COYRERCtor EDISON DRLG }\end{array}$

Details of PLUGGing:

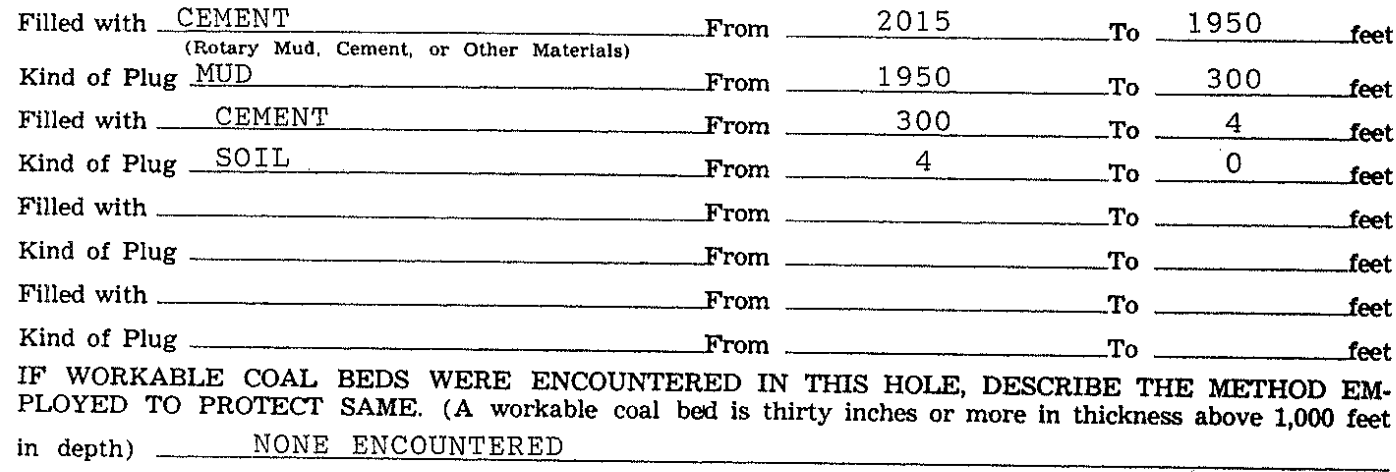

(1) Have pits and other excavations been flled? .............. No

(2) Have the following been removed?

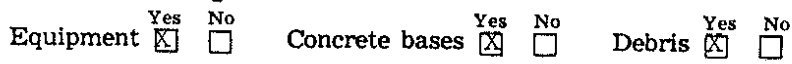

(3) Has surface casing been cut off three feet below ground surface?

(4) Has well-site been leveled? Address. MATTOON IL

Address.

Address Mt. VERNON IL.

If this was a producing well, give date and amount of last production

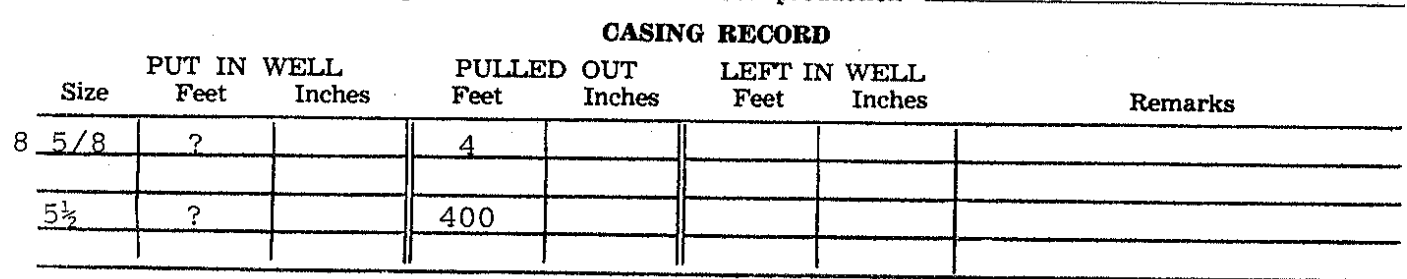

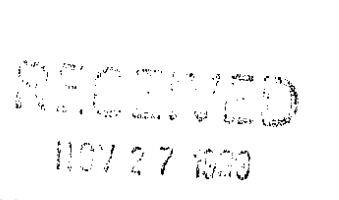

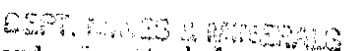

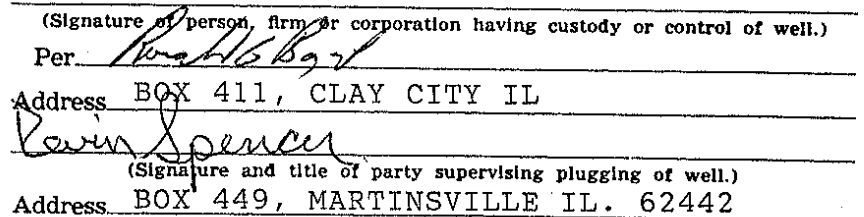

Address BOX 449, MARTINSVILLE IL. 62442 


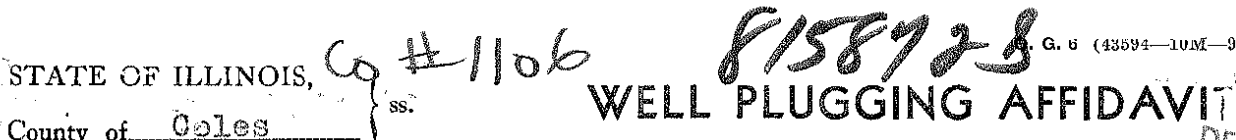

County of Ooles $\}^{\text {ss. }}$ Jim Gililiand

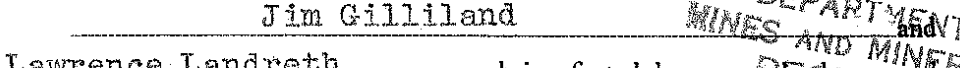

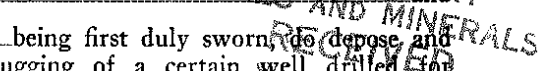

say the following is a true and correct statement of the details of the plugging of a certain O:1 known as the Zellers and located as follows

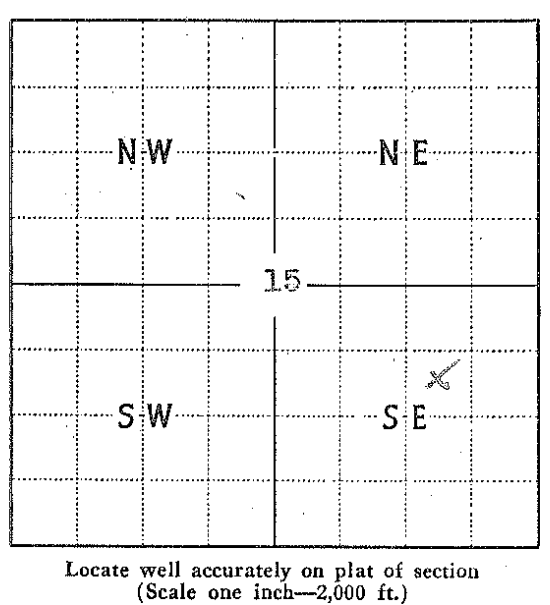

812 ft. south;

ft. east; 1015 - ft. west roto

of the $\quad$ HE $\quad$ corner of the $\quad S E$ Quarter

of the Quarter of the Quarter of

Section 15 , Township 12 (North or Busuthe)

Range 7 , (East $3 d$

Principal Meridian, _._. Coles County, Illinois.

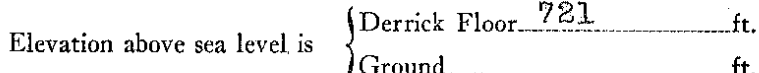

Total depth of well is $\quad 2015$

Date permit to drill issued $\quad 12-1-45 \quad 2007$

Permit issued to R. H. Troop \& Ray Sanders

Date drilling began Year 1345

Date drilling completed. $* 1945$

Kind of drilling tools used Rotary

Date plugging began $\quad 5-11-18$

Date plugging completed._- $\quad 5-13-48$

Lessor Ze11ers

Lessee R. H. Troop and Ray Sanders

Drilling Contractor $\mathrm{R} . \mathrm{H}$. Proop
Address Mattoon,IIInois

Address 219 S.19th St. Mt.Vernon, I1.I.

Address St. $\mathrm{EImo}, \mathrm{III}$.

DETAILS OF PLUGGING:

b

\begin{tabular}{|c|c|c|}
\hline Filled with Cement & From $\quad 2015$ & To $\quad 1965$ \\
\hline $\begin{array}{l}\text { (Rotary Mud, Cement, or Other Materials) } \\
\text { Kind of Plug Mud }\end{array}$ & 1965 & 435 \\
\hline Filled with Cement & From & To \\
\hline Kind of Plug Mud & 315 & 142 \\
\hline Filled with cement & From & 117 \\
\hline Kind of Plug Mud & From & To \\
\hline Filled with Cement & From & To \\
\hline Kind of Plug Fiarth & From & $T_{0}$ \\
\hline
\end{tabular}

IF WORKABLE COAL BEDS WERE ENCOUNTERED IN THIS HOLE, DESCRIBE THE METHOD EMPLOYLD TO PROTECT SAME. (A workable coal bed is thirty inches or more in thickness above 1,000 feet in depth) Affidavit on back

(1) Have pirs, cellar and other excavations been filled?...

If this was a producing well, give date and amount of last production March 1947, Iess than $1 / 2$ per day

CASING RECORD

\begin{tabular}{|c|c|c|c|c|c|c|c|}
\hline \multirow[b]{2}{*}{ Size } & \multicolumn{2}{|c|}{ PUT IN WELL } & \multicolumn{2}{|c|}{ PULLED OUT } & \multicolumn{2}{|c|}{ LEFT IN WELL } & \multirow[b]{2}{*}{ Remarks } \\
\hline & Feet & Inches & Feet & Inches & Feet & Inches & \\
\hline $10-3 / 4$ & 127 & & & & 129 & & Cenented \\
\hline 70 & 2015 & & 806 & & 1209 & & "n \\
\hline & & & & & & & \\
\hline & & & & & & & 4 \\
\hline
\end{tabular}

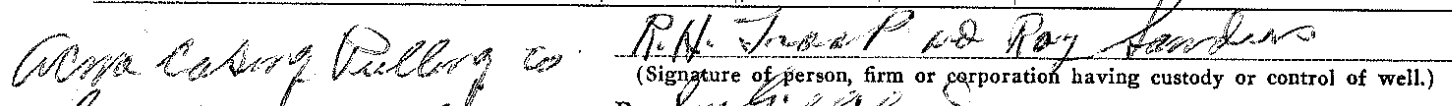


STATE OF ILLINOIS, County of Coles $\}^{\text {ss. }}$
Co 1105 WLL PLUGGING AFFIDAVIT

and

being first duly sworn, do depose and

Tawrence Jandreth say the following is a true and correct statement of the details of the plugging of a certain well drilled for OI 1 or ges

(Indicate whether for oil, gas, water or other purposes)

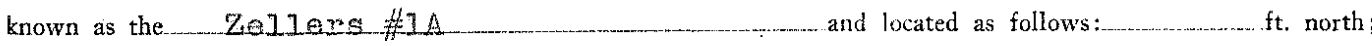

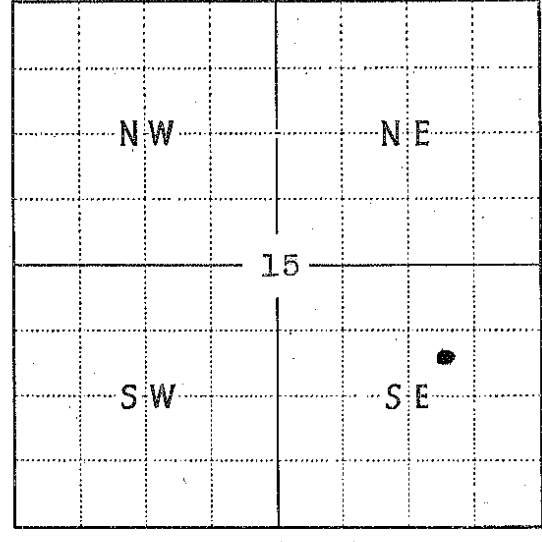

Locate well accurately on plat of section (Seale one inch-2,000 ft.)
866 ft. south;

of the NE

of the.

Section 15

Range 7

Principal Meridian,

Elevation above sea level is

corner of the

ft. east ; 990 ST:

Quarter of the

1.? (North

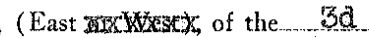

Ground..._.

Total depth of well is 1816 oles County, lllinois. J Derrick Floor $63 \mathrm{f} \quad \mathrm{ft}$. Date permit to drill issued $6-14-48$

Permit issued to F. Frank Hinklo

Date drilling began $6-1,6-48$

Date drilling completed $6-23-48$

Kind of drilling tools used Rotary

Date plugging began $6-23-48$

Date plugging completed $6-23-48$
Lessor Zellers

Lessee F. Frank Hinkle

Drilling Contractor Kuykendal1 DrLg. Co.
Address Mattoon, I11.

Address 459 standard B1dg. Decatur.

Address St Elmo, I1

DETAILS OF PLUGGING:

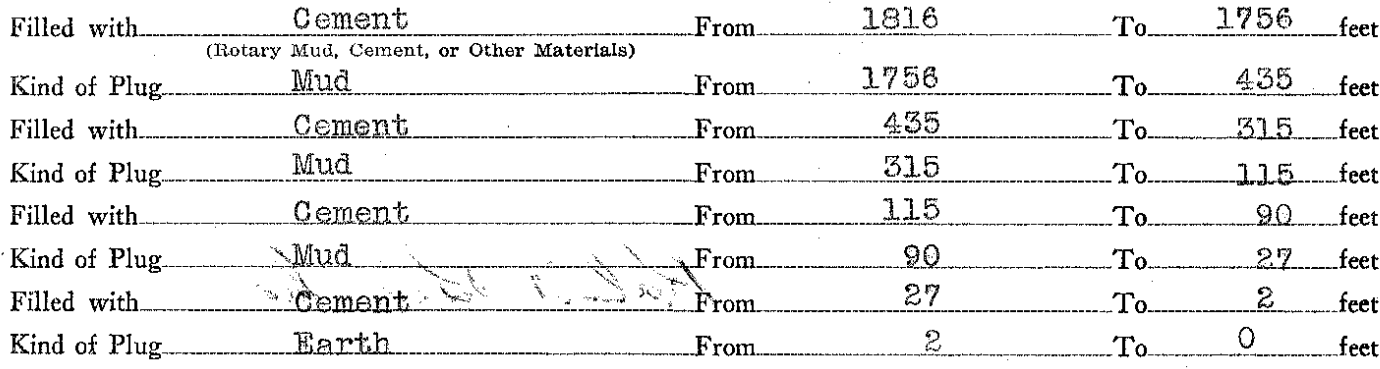

IF WORKABLE COAL BEDS WERE ENCOUNTERED IN THIS HOLE, DESCRIBE THE METHOD EMPLOYED TO PROTECT SAME. (A workable coal bed is thirty inches or more in thickness above 1,000 feet in depth) Affiderit on back

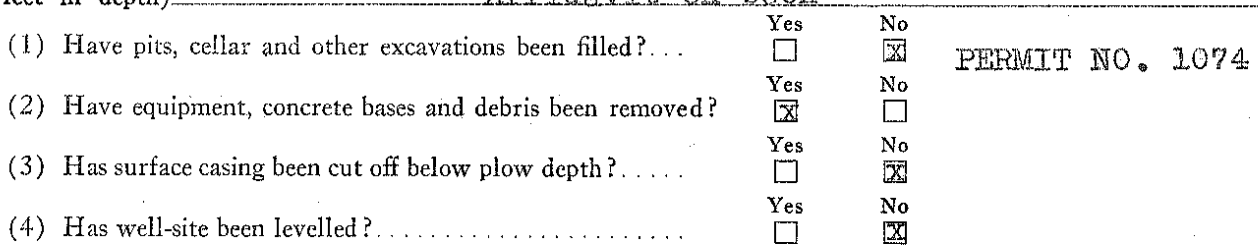

If this was a producing well, give date and amount of last production Dry hole

\section{CASING RECORD}

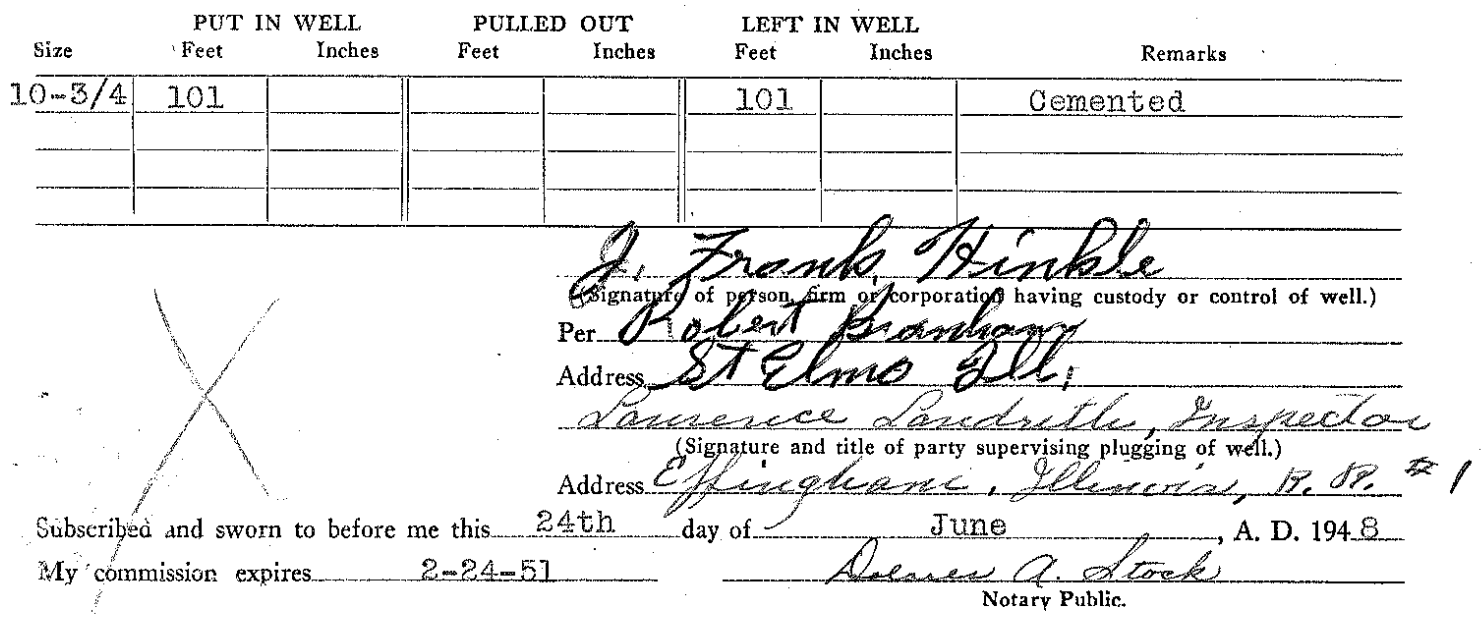


15-12N-7E-1 


\section{ILLINOIS DEPARTMENT OF NATURAL RESOURCES Office of Mines and Minerals}

Division of Oil and Gas _._. One Natural Resources Way

(217) 557-6379 COUNTY No. 1.756 \$ \$pringfield, llinois 62702/1271

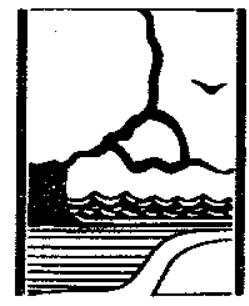

\section{OG-6 WELL PLUGGING REPORT}

PERMTTEE: Merle Reeves

PERMITTEE\#: $\quad 555$

well name: Frank Rose \#1

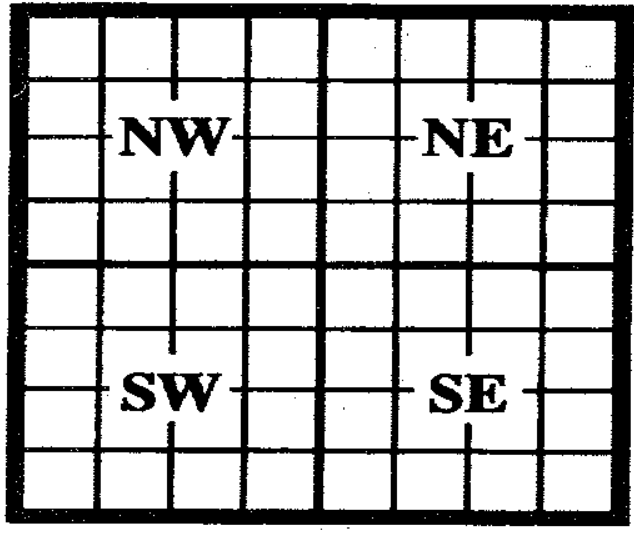

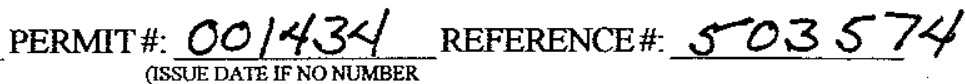

countr Coles

SECTION 15 TWP $12 N$ RANGE O O TE

LOCATION: FT. NORTH; OR 1065

FT. SOUTH, AND

FT. WEST OF THE $N E$ CORNER OF THE NE

QUARTER OF THE QUARTER OF THE

QUARTER OF THE

QUARTER.

WELL DATA:

\begin{tabular}{|c|c|c|}
\hline $\begin{array}{l}\text { SURFACE ELEVATION: } \\
\text { TOTAL DEPTH OF WELL }\end{array}$ & $\frac{700}{1832}$ & $\begin{array}{l}\text { PRODUCING / INJECTION INTERVALS } \\
\text { FROM } / 777 \text { TO } / 800\end{array}$ \\
\hline PLUGGED BACK TOTAL DEPTH & FT. & FROM 1821 \\
\hline BASE OF FRESHWATER ZONE & 150 & FROM \\
\hline WORKABLE COALS PRESENT AT & FT. & FROM \\
\hline DESCRIBE PREVIOUS PLUGBACK & PROCEDURE: & \\
\hline
\end{tabular}

DETALS OF PLUGGING:

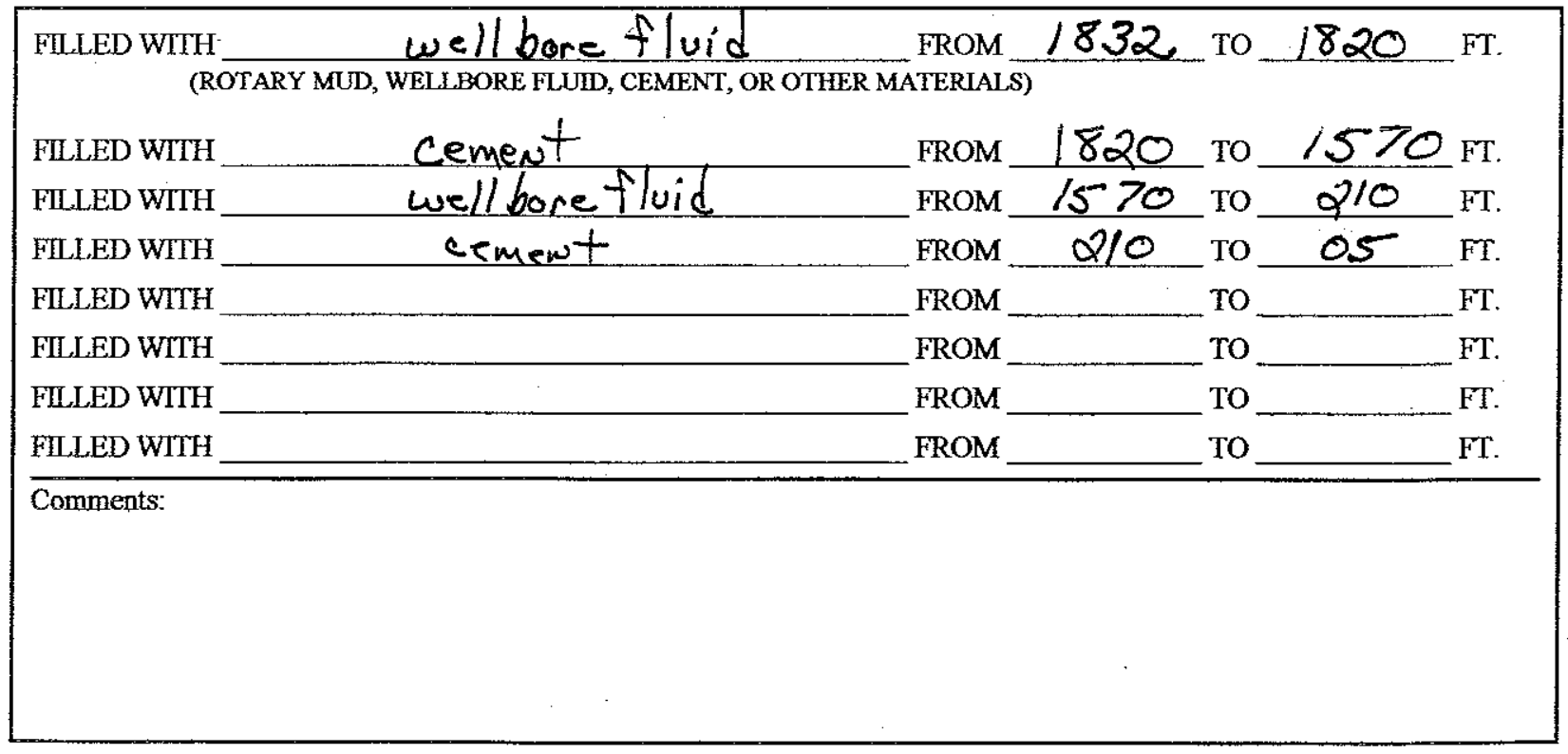


WELL DATA:

\begin{tabular}{|l|c|c|c|c|c|c|}
\hline \multicolumn{1}{|c|}{ CASING } & SIZE & $\begin{array}{c}\text { SETTING } \\
\text { DEPTH }\end{array}$ & $\begin{array}{c}\text { SACKS } \\
\text { CEMENT }\end{array}$ & $\begin{array}{c}\text { HOLE } \\
\text { SIZE }\end{array}$ & $\begin{array}{c}\text { EST. TOP } \\
\text { OF } \\
\text { CEMENT }\end{array}$ & $\begin{array}{c}\text { AMOUNT OF } \\
\text { CASING } \\
\text { REMOVED }\end{array}$ \\
\hline SURFACE & NO & SUR FRCe & & & & \\
\hline $\begin{array}{l}\text { INTERMEDIATEI } \\
\text { MINE } \\
\text { STRING/OR } \\
\text { LINER }\end{array}$ & & & & & & \\
\hline PRODUCTION & 4.50 & 1830 & 150 & 7.88 & 1208 & 300 \\
\hline
\end{tabular}

Under penalties of perjury, I declare that I have examined this form including accompanying statements and documents, and to the best of my knowledge, it is true, correct and complete.

mamice a pudy

Signature of Permittee or Desvnee

Address

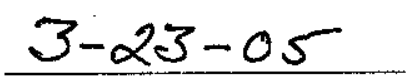

Date Plugging began

$3-24-05$

Date Plugging Completed

City, State, Zip

Inspector present during plugging operations

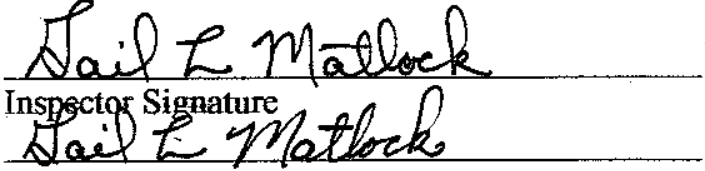

Inspector Signature

Inspector Signature

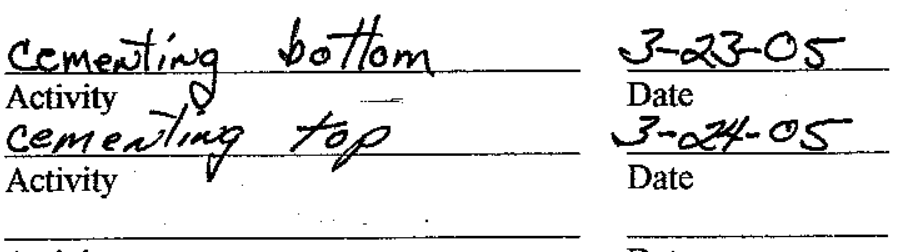

Activity

Date

Inspector not present during plugging operations

Authorization for Inspector not being present

Plugging information sent to District Office

$\square \quad$ Inspector site visit to pick up plugging information 


\section{ILLINOIS DEPARTMENT OF NATURAL RESOURCES Office of Mines and Minerals \\ Division of Oil and Gas One Natural Resources Way (217) 557-6379 COUNTY No. 190.4 Springfield, llinois 62702/1271}

\section{OG-6 WELL PLUGGING REPORT}

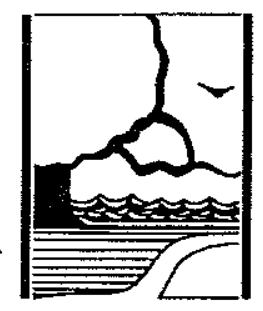

TYPE OF WELL: XPRODUCTION $\square$ CLASS II $\square$ GAS STORAGE $\square$ REPLUG $\square$ OTHER Permittee: Merke Reeves PERMITTEE\#: wellname: Frank Rose B-1. PERMIT \#: $\underset{\text { (ISSUE DATE IF NO NUMBER }}{000546}$ REFERENCE\#:S0,3575

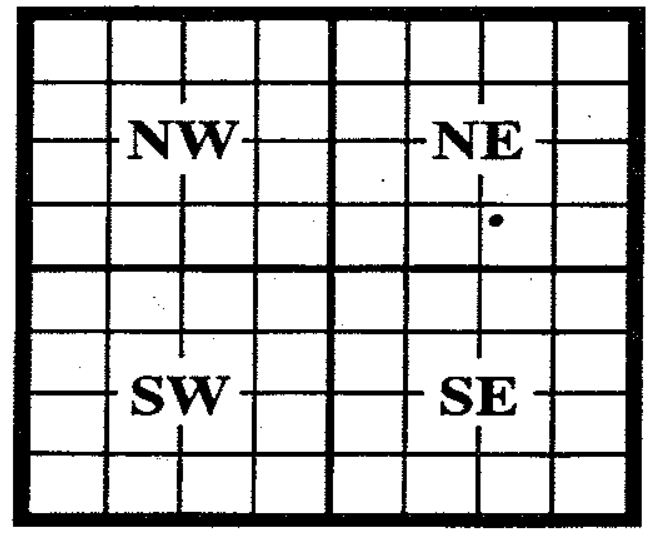

\section{COUNTY Coles}

SECTION 15 TWP $12 N$ RANGE $07 E$ LOCATION: FT. NORTH; OR $0 / 35$

FT. SOUTH, AND 0085 FT. EAST; OR FT. WEST OF THE $\bar{N}$ CORNER OF THE SW QUARTER OF THE $S \mathcal{E}$ QUARTER OF THE NE Quarter of THE QUARTER.

WELL DATA:

SURFACE ELEVATION:

TOTAL DEPTH OF WELL PLUGGED BACK TOTAL DEPTH BASE OF FRESHWATER ZONE WORKABLE COALS PRESENT AT DESCRIBE PREVIOUS PLUGBACK PROCEDURE:

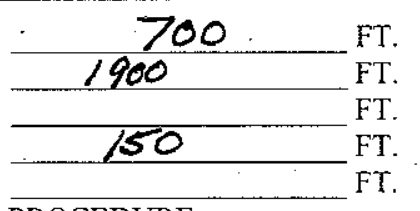

FT. FT. FT.

DETAILS OF PLUGGING:

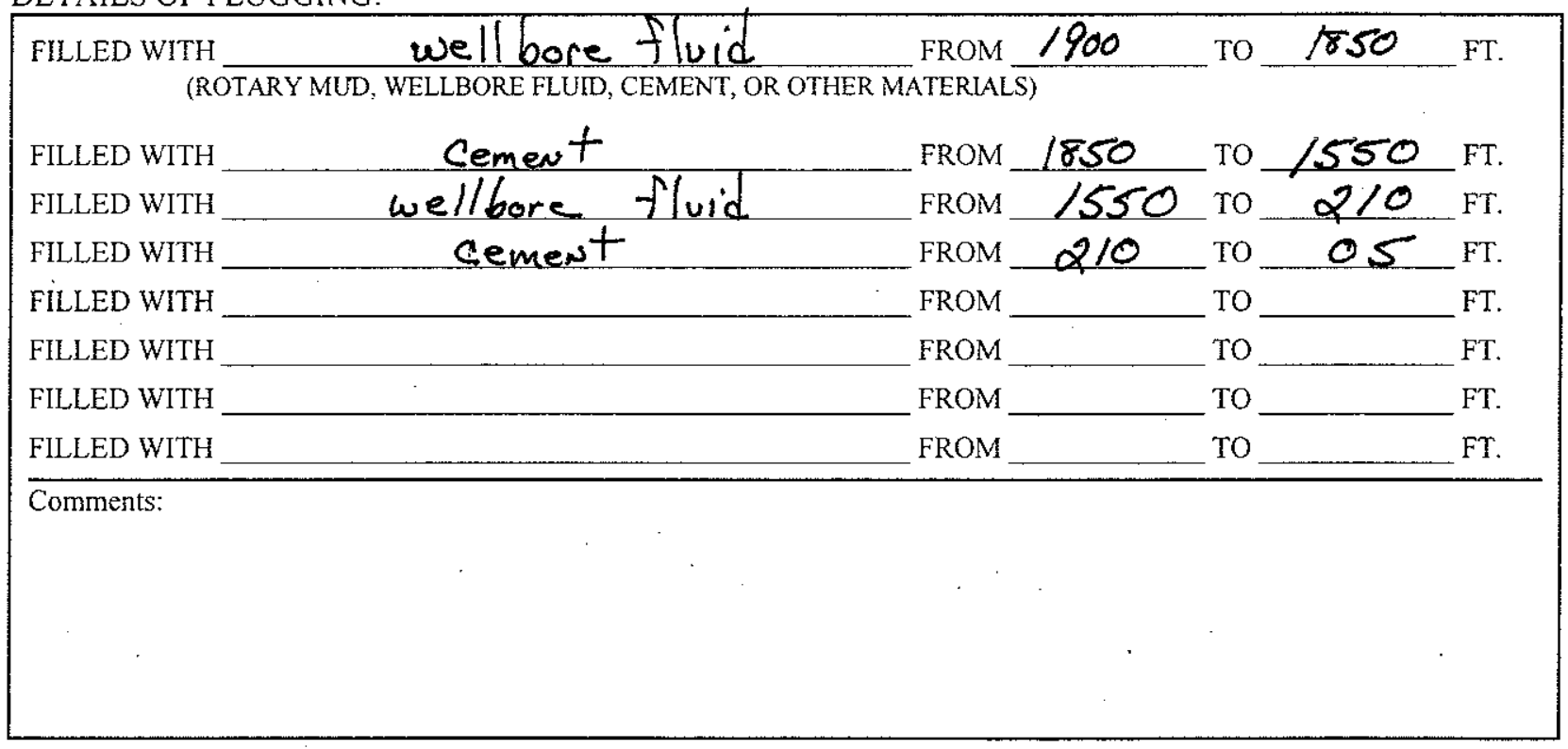

PRODUCING / INJECTION INTERVALS
FROM TO TO
FROM TO TO
FROM TO TOMOM TO


WELL DATA:

\begin{tabular}{|l|c|c|c|c|c|c|}
\hline \multicolumn{1}{|c|}{ CASING } & SIZE & $\begin{array}{c}\text { SETTING } \\
\text { DEPTH }\end{array}$ & $\begin{array}{c}\text { SACKS } \\
\text { CEMENT }\end{array}$ & $\begin{array}{c}\text { HOLE } \\
\text { SIZE }\end{array}$ & $\begin{array}{c}\text { EST. TOP } \\
\text { OF } \\
\text { CEMENT }\end{array}$ & $\begin{array}{c}\text { AMOUNT OF } \\
\text { CASING } \\
\text { REMOVED }\end{array}$ \\
\hline SURFACE & 10.75 & Not KNOWN & & & & 5 \\
\hline $\begin{array}{l}\text { INTERMEDIATE/ } \\
\text { MINE STRING/OR } \\
\text { LINER }\end{array}$ & & & & & & \\
\hline PRODUCTION & 4.50 & $/ 900-t$ & & 7.88 & & 600 \\
\hline
\end{tabular}

Under penalties of perjury, I declare that I have examined this form including accompanying statements and documents, and to the best of my knowledge, it is true, correct and complete.

Mavire C. Suld

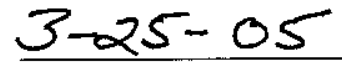

Date Plugging began

$3-28-05$

Date Plugging Completed

Address

City, State, Zip

Inspector present during plugging operations

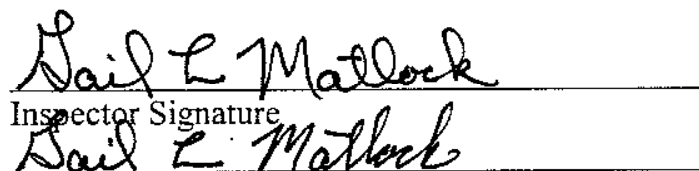

Inspector Signature

Inspector Signature

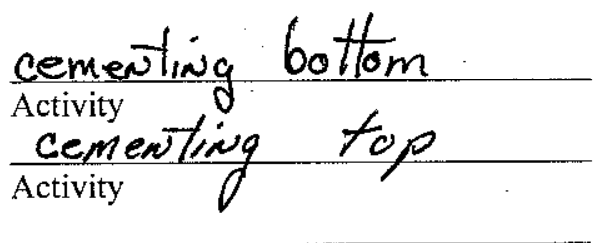

Activity
$3-25-05$ Date

$3-28-0.5$

Date

Date

Inspector not present during plugging operations

Authorization for Inspector not being present

Plugging information sent to District Office

Inspector site visit to pick up plugging information 
22-12N-7E 


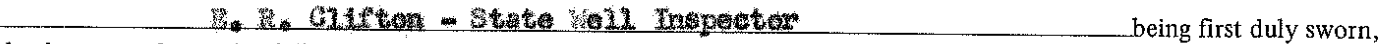
do depose and say the following is a true and correct statement of the details of the plugging of a certain well drilled for O1. 0

known as the_holdow (Indicate whether for oil, gas, water or other purposes)

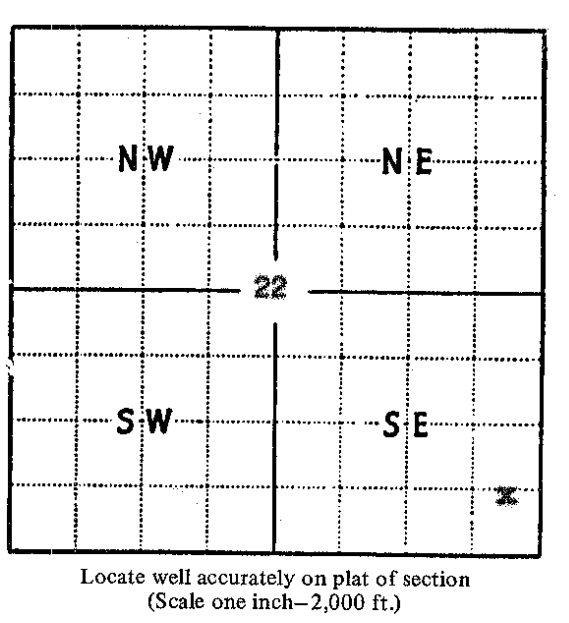

and located as follows: 660 ft. north; ft. south; $\mathrm{ft}$. east; $\quad 4 \quad 40$ ft. west

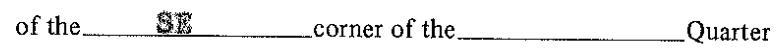
of the___ Quarter of the _____ Quarter of

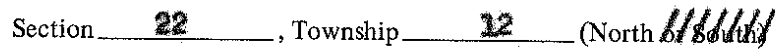

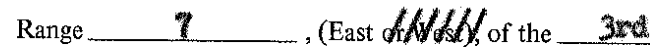

Principal Meridian, Wow Derrick Floor Elevation above sea level is $\{\quad$ Derrick Floor____ $\mathrm{ft}$.

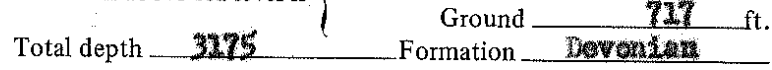
Date permit to drill issued $11 / 26 / 72$ Permit No. 1030 Permit issued to 算 Date drilling began $\quad \mathbf{1 1 - 1 9 - 7 2}$ Date drilling completed $\quad 1 x-29-7 x$

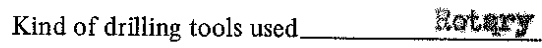

Date plugging began 8-2l-77

Date plugging completed $8 \times 27=77$

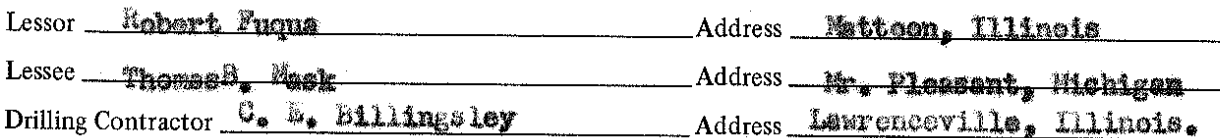
DETAILS OF PLUGGING:

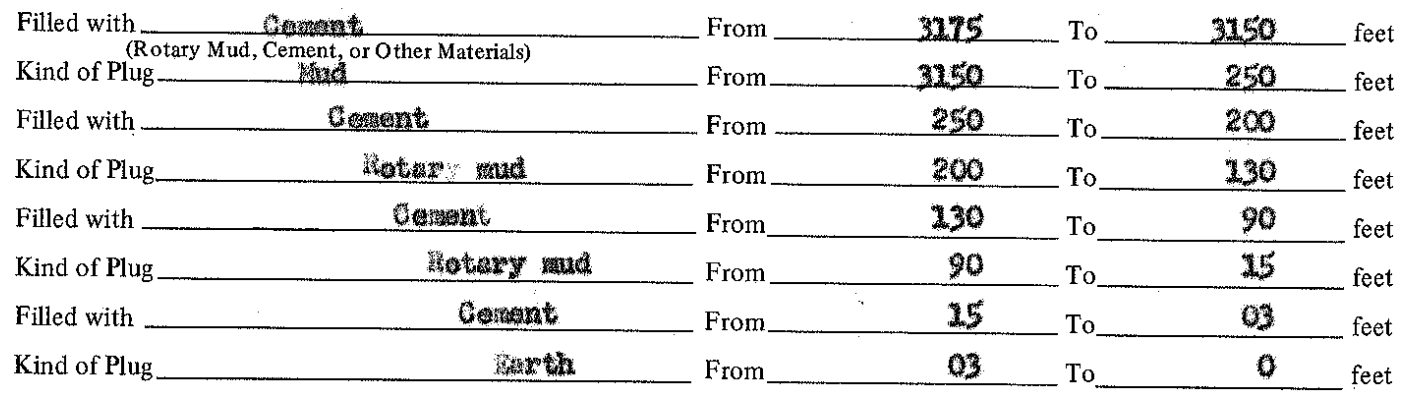

IF WORKABLE COAL BEDS WERE ENCOUNTERED IN THIS HOLE, DESCRIBE THE METHOD EMPLOYED TO PROTECT SAME. (A workable coal bed is thirty inches or more in thickness above 1,000 feet in depth)

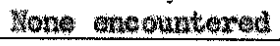

(1) Have pits and other excavations been filled? $\ldots \ldots \ldots \ldots \ldots \ldots \ldots \ldots$ Yes

(2) Have the following been removed?

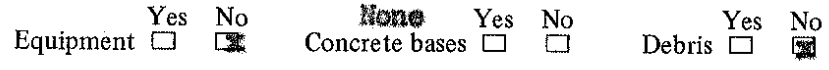

(3) Has surface casing been cut off three feet below ground surface?

(4) Has well-site been leveled? . . . . . . . . . . . . . . . . . . $\square^{\text {Yes }}$

$\begin{array}{ll}\text { Yes } & \text { No } \\ \text { Yes } & \text { No } \\ \square & \square\end{array}$

If this was a producing well, give date and amount of last production _

\section{CASING RECORD}

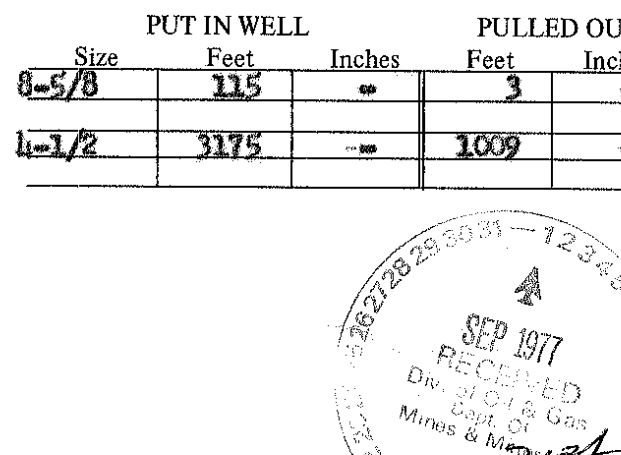

Subscribed and sworn to before me this $2 /$ is

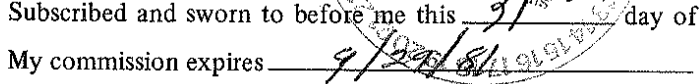
LEFT IN WELL Feet Inches

\begin{tabular}{l||c|c|c}
110 & $*$ & \\
\hline & 2166 & & \\
\hline
\end{tabular}

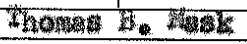

(Signature of person, firm or corporation having custody or control of well.)

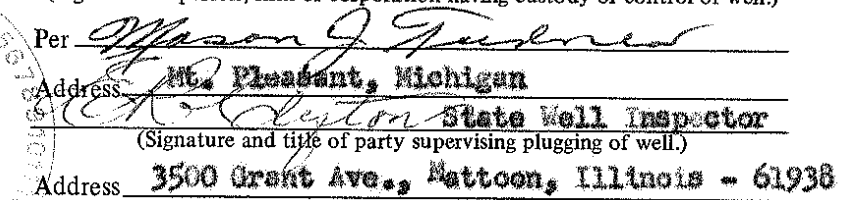
day of $\quad$ Cosecent? 

do depose and say the following is a true and correct statement of the details of the plugging of a certain well drilled for $011 / 0 \mathrm{as}$ (Indicate whether for oil, gas, water or other purposes)

known as the Ir Jones 2-A

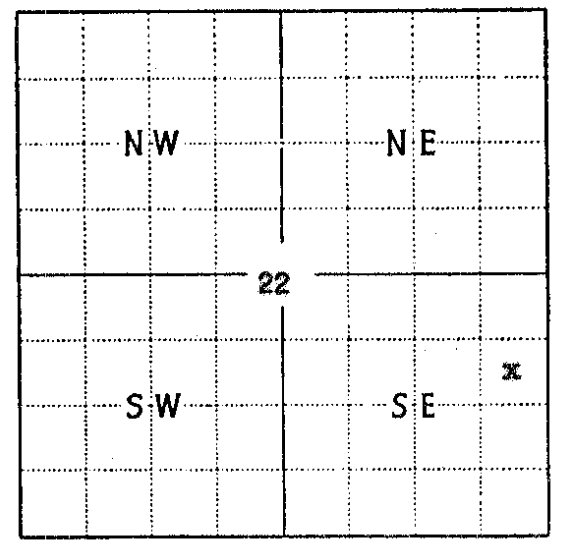

Locate well accurately on plat of section (Scale one inch-2, $2,000 \mathrm{ft}$,

and located as follows:

330 ft. north; ft. south ft. east; $\quad 330$ ft. west of the $\mathrm{SE}$. corner of the_NE Quarter of the S S Quarter of the_Quarter of

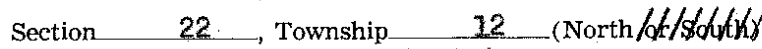
Range $\quad 1$, (East $d d / W /$ est $)$, of the 3 rd

Principal Meridian,_Coms County, Illinois. Elevation above sea level is $\begin{cases}\text { Derrick Floor } & \mathrm{ft} . \\ \text { Ground } \quad 717 & \mathrm{ft} .\end{cases}$ Total depth $3127 \quad$ Formation Trenton Date permit to drill issued 10/4/74 Permit No. 1001 Permit issued to Thonas B. Mask Date drilling began $10-5-74$ Date drilling completed $10-\quad-74$ Kind of drilling tools used Rotary Date plugging began $11-29-75$ Date plugging completed $\quad 12-2-75$

Lessor ‥ I nag

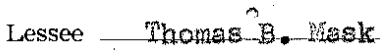

Drilling Contractor TIJinots Brilling $0_{0}$.
Address Hetwon, TIIino:s

Address.Mt. pleasant, Mloh.

DETAILS OF PLUGGING:

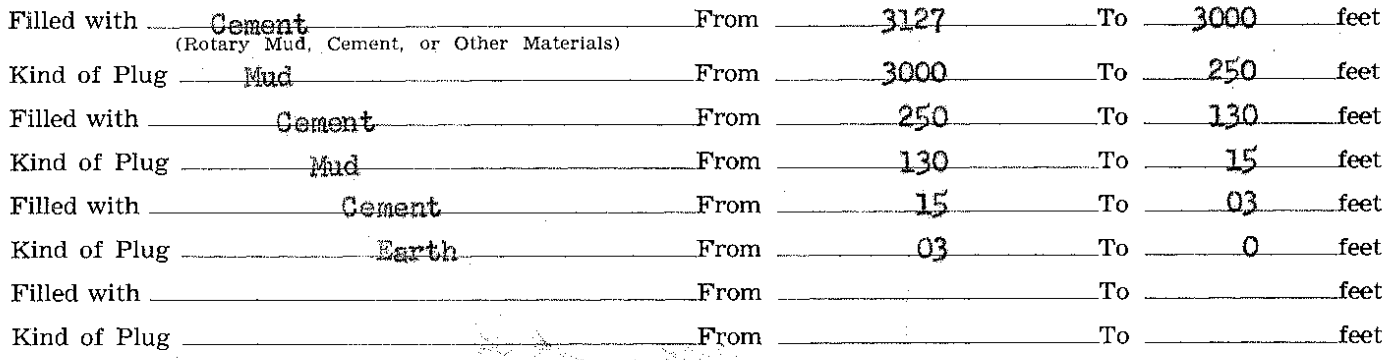

IF WORKABLE COAL BEDS WERE ENCOUNTERED IN THIS HOLE, DESCRIBE THE METHOD EMPLOYED TO PROTECT SAME. (A workable coal bed is thirty inches or more in thickness above 1,000 feet in 'depth) None oropuntered

(1) Have pits and other excavations been flled?

(2) Have the following been removed?

$$
\text { Equipment } \square\left[\begin{array}{l}
\text { Yes } \\
\square
\end{array} \text { Concrete bases } \square^{\text {Yes }} \square^{\text {No }} \text { Debris } \square^{\text {Yes }} \cdot{ }^{\text {No }}\right.
$$

(3) Has surface casing been cut off three feet below ground surface?

(4) Has well-site been levelled?

If this was a producing well, give date and amount of last production Unlanowm

\section{$\stackrel{\text { Yes }}{\square} \quad \stackrel{\text { No }}{\mathbb{x}}$}

No

赵

\begin{tabular}{|c|c|c|c|c|c|c|c|}
\hline \multicolumn{8}{|c|}{ CASING RECORD } \\
\hline Size & $\begin{array}{c}\text { PUT IN } \\
\text { Feet }\end{array}$ & $\begin{array}{l}\text { WELL } \\
\text { Inches }\end{array}$ & $\begin{array}{l}\text { PULLED } \\
\text { Feet }\end{array}$ & $\begin{array}{l}\text { OUT } \\
\text { Inches }\end{array}$ & $\begin{array}{l}\text { LEFT I } \\
\text { Feet }\end{array}$ & $\begin{array}{l}\text { WELL } \\
\text { Inches }\end{array}$ & Remarks \\
\hline $8.5 / 8 n$ & $14 h$ & - & 4 & $=$ & 140 & - & Cement citculated \\
\hline 12 & 3127 & & & & 887 & & Cemented wy \\
\hline
\end{tabular}

RECORD

Thomas B. Mask

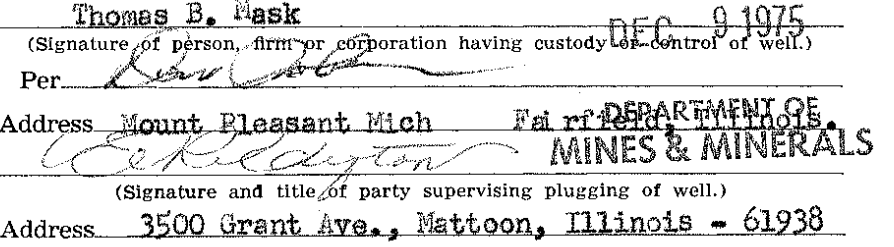

Subscribed and sworn to before me this

Address 3500 Grent Ave., Mattoon, I112nols - 61938

6 th day of Decomber

My commission expires 

$\left.\begin{array}{l}\text { STATE OF ILLINOIS } \\ \text { County of }\end{array}\right\}$ SS.

\section{County of} do depose and say the following is a true and correct statement of the details of the plugging first duly sworn, drilled for

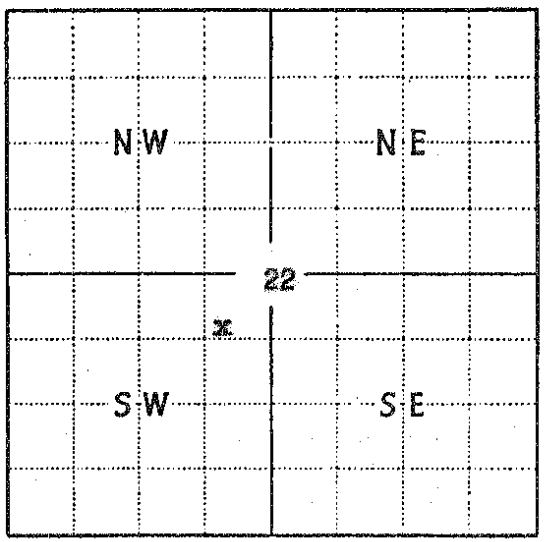

Locate well accurately on piat of section (Scale one inch- $-2,000 \mathrm{ft}$.) ft. south;

ft. east; 330 of the _ corner of the warter of the gus Quarter of the Quarter of Section 22 , Township 12 (North of A67fm) Range $\quad 7$, (East $6 / 66666 / 6 \mathrm{f}$ the $3 \mathrm{xa}$

Principal Meridian,__otas _ County, Illinois.

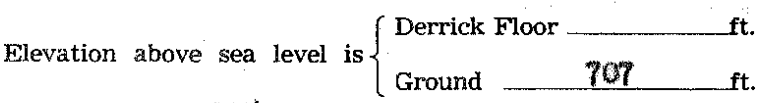
Total depth 3225 Formation Devonian Date permit to drill issued $1 / 21 / 72$ Permit No._ 736

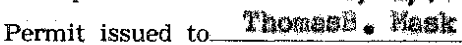

Date drilling began_ $\quad 3-23-72$

Date drilling completed $\quad 9-12-72$

Kind of drilling tools used The

Date plugging began $\quad 3-7-75$

Date plugging completed. $1-10-75$

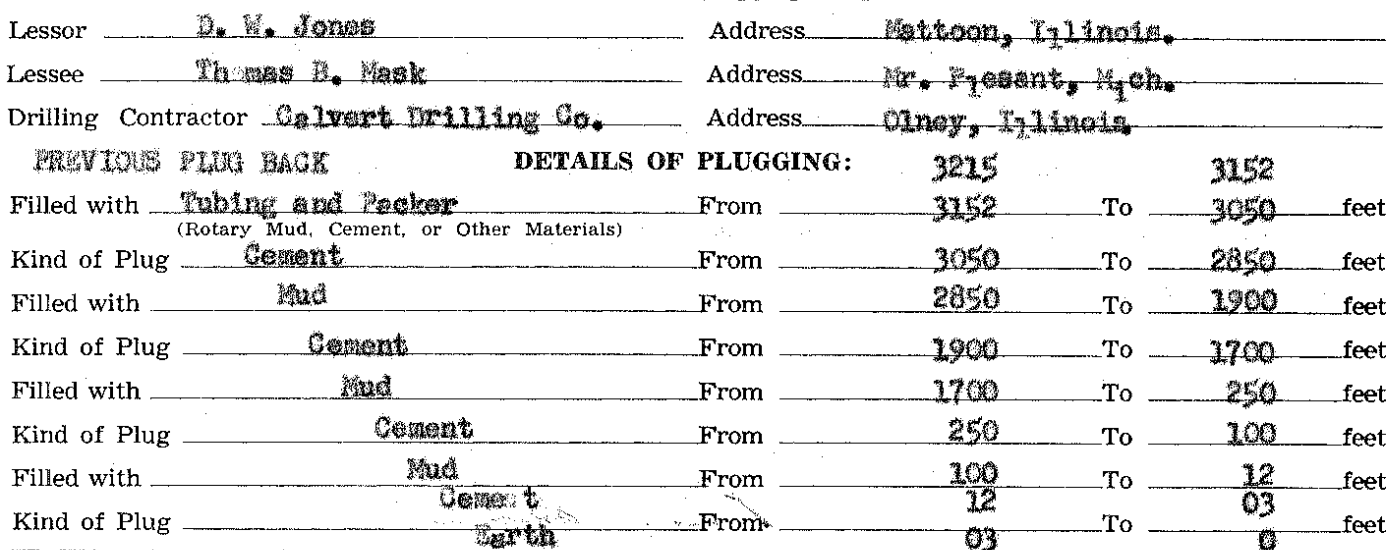
IF WORKABLE COAL BEDS WERE ENCOUNTERED IN THIS HOLE, DESCRIBE THE METHOD EMPLOYED TO PROTECT SAME. (A workable coal bed is thirty inches or more in thickness above 1,000 feet in depth)

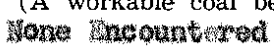

(1) Have pits and other excavations been filled?............... Yes

(2) Have the following been removed?

$$
\text { Equipment } \stackrel{\text { Yes }}{\square} \text { No } \quad \text { Concrete bases } \stackrel{\text { Yes }}{\square} \stackrel{\text { No }}{\square} \text { Debris } \square^{\square} \stackrel{\text { No }}{\square}
$$

(3) Has surface casing been cut off three feet below ground surface?

(4) Has well-site been leveled?

If this was a producing well, give date and amount of last production 1

CASING RECORD

\begin{tabular}{|c|c|c|c|c|c|c|c|}
\hline Size & $\begin{array}{c}\text { PUT IN } \\
\text { Feet }\end{array}$ & $\begin{array}{l}\text { WELL } \\
\text { Inches }\end{array}$ & $\begin{array}{l}\text { PULLED } \\
\text { Feet }\end{array}$ & $\begin{array}{l}\text { OUT } \\
\text { Inches }\end{array}$ & $\begin{array}{c}\text { LEFT } \\
\text { Feet }\end{array}$ & $\begin{array}{l}\text { WELL } \\
\text { Inches }\end{array}$ & Remarks \\
\hline $2-4 / 6$ & 180 & $\approx$ & 3 & & 135 & & 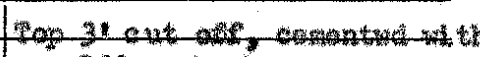 \\
\hline & & & & & & & 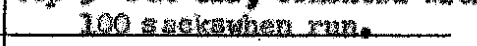 \\
\hline $1-1 / 2$ & 3225 & - & 2700 & $=$ & 2518 & $=$ & 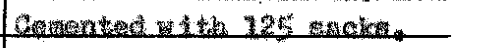 \\
\hline 2 & 102 & $=$ & & $=$ & 10 & $=$ & 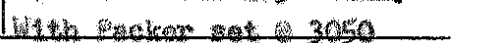 \\
\hline
\end{tabular}

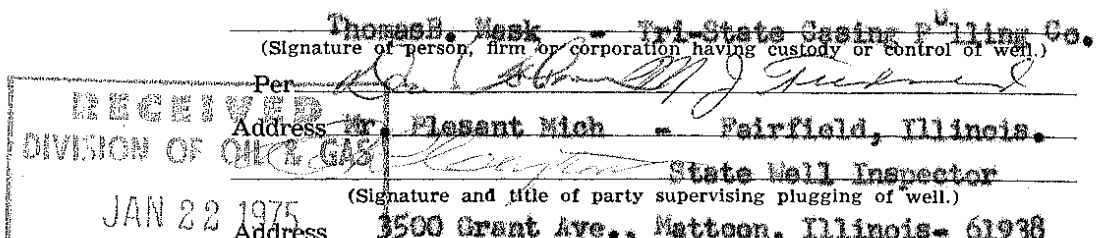

Subscribed and sworn to before me this 20 th day of A.D. 19,75

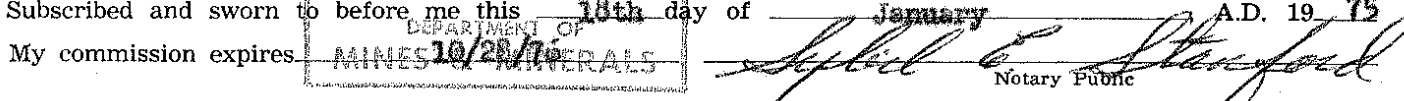


TTATE OF ILLINOIS

County of Colos

do depose and say the following is a true and correct statement of the details of the plugging of a certain well drilled for. Q11.

$$
\text { (Indicate whether for oil, gas, water or other purposes) }
$$

known as the Anna Strong if

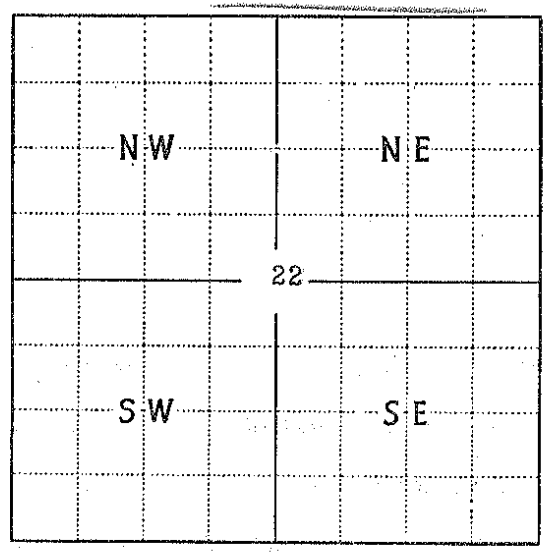

Locate well accurately on plat of section (Scale one inch-2,000 fr.)
Lessor Anna strong

Lessee...... Blake Di rekson

Drilling Contractor $\mathrm{S} . \mathrm{H}$. K Drilling Co. and located as follows: 3 . 350 f. fouth; 330 ft. east; 3242 ft. west

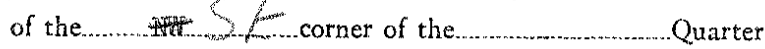
of the _.................. Quarter of the Quarter of Section.....22 ...., Township_......12 _......(North Range $7 \quad 7 \quad$ (East KarXast), of the 3

Principal Meridian, Coles County, Mllinois.

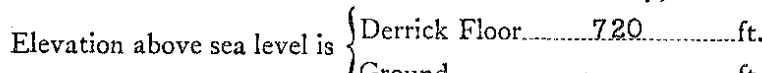

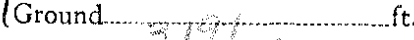

Total depth of well is $1480 \mathrm{ft}$ Date permit to drill issued $17-71=45$ Permit No 22 Permit issued to......... Blake Dixckson

Date drilling began $11-1.4-45$

Date drilling completed $I 1-21-45$

Kind of drilling tools used Rotary

Date plugging began $\quad 6-306 \pi x+6-1-51$

Date plugging completed.1. 6 a

DETAILS OF PLUGGING:

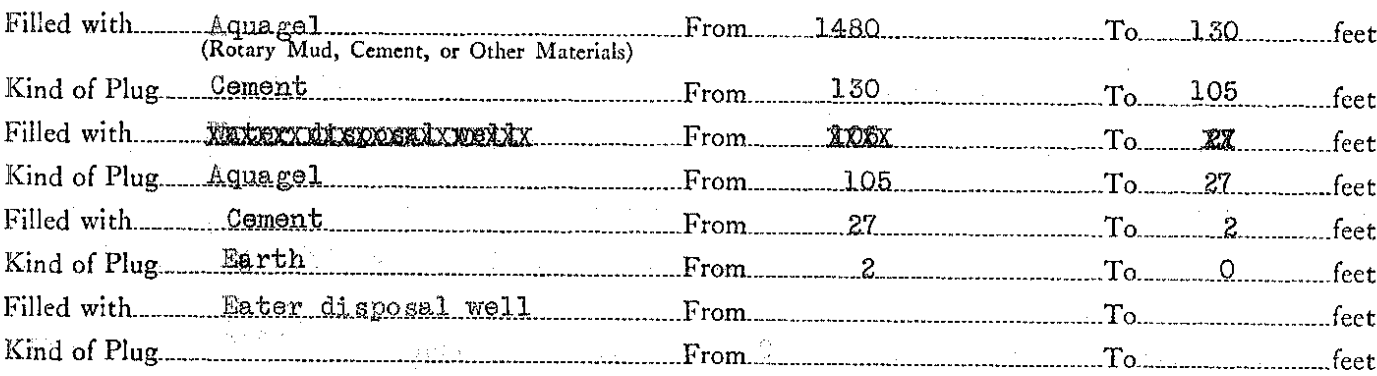

IF WORKABLE COAL BEDS WERE ENCOUNTERED IN THIS HOLE, DESCRIBE THE METHOD EMPLOYED TO PROTECT SAME. (A workable coal bed is thirty inches or more in thickness above 1,000 feet in depth) ...... No cor I encountered

(1) Have pits, cellar and other excavations been filled?....

(2) Have equipment, concrete bases and debris been removed?

(3) Has surface casing been cut off below plow depth?.....

Address Mattoon Ill

Address ...... Watoon.

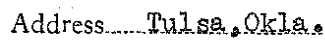

(4) Has well-site been levelled?.................

If this was a producing well, give date and amount of last production.

\section{CASING RECORD}

\begin{tabular}{|c|c|c|c|c|c|c|c|}
\hline \multirow[b]{2}{*}{ Size } & \multicolumn{2}{|c|}{ PUT IN WELL } & \multicolumn{2}{|c|}{ PULLED OUT } & \multicolumn{2}{|c|}{ LEFT IN WELL } & \multirow{2}{*}{ Remarks } \\
\hline & Feet & Inches & Feet & Inches & Feer & Inches & \\
\hline $103 / 4$ & 120 & & 0 & & 120 & & \\
\hline 7 & 1740 & & 715 & & 925 & & \\
\hline & & & & & & & \\
\hline & & & & & & & \\
\hline
\end{tabular}

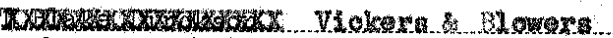
(Signature of person, firm or corporation having custody or control of well.)

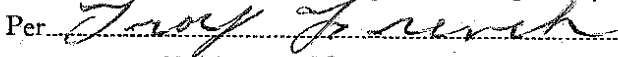

Address Mattoon, III.

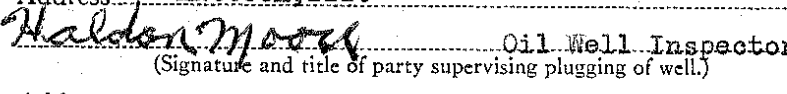

Address Signature and title of party supervising plugging of well.) My commission expires.

day of

Ilune 


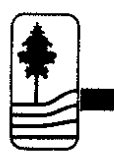

\section{ILLINOIS DEPARTMENT AEMANES AND MINERALS \\ OIL AND GAS DIVISTON (217) $782-7756$ \\ COUNTYNO 2175 \\ W. JEFFERSON - SUITE 300 \\ P.O. BOX 10140 \\ PRINGFIELD, IL 62791-0140}

\section{OG-6 WELL PLUGGING REPORT}

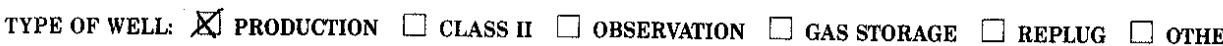
PERMITTE: $D \in L$ Developmeat Fued WELL NAME: TINisley t/RS $\not$, PERMIT No. 000575 PERMTTTE NO. 2226

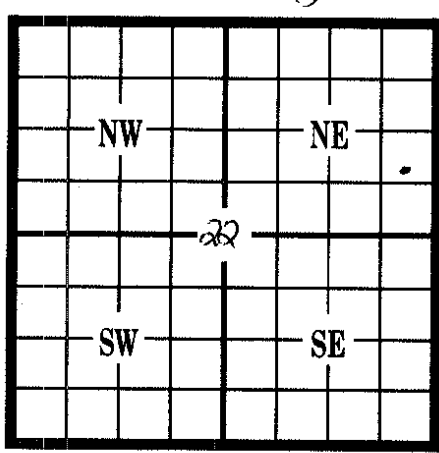
(ISSUE DATE IF NO NUMBER) REFERENCE NO. 121214

${ }_{\text {TOWNTH Coles }}^{\text {SOUNT }}$ SECTION $^{\text {RANGE }} \frac{22}{7 \varepsilon}$

LOCATION: 843 FT. NORTH; OR FT. SOUTH; AND FT. EAST; OR 3,30 FT. WEST OF THE SE CORNER OF THE NE QUARTER OF THE QUARTER OF THE__ QUARTER OF THE QUARTER. Mattoon WELL DATA:

SURFACE ELEVATION

TOTAL DEPTH OF WELL

PLUGGED BACK TOTAL DEPTH

BASE OF FRESHWATER ZONE

WORKABLE COALS PRESENT AT

DESCRIBE PREVIOUS PLUGBACK PROCEDURE:

\begin{tabular}{cc}
\hline 307 & FT \\
\hline 3200 & FT. \\
\hline$\frac{15}{157}$ & FT. \\
\hline FA & FT.
\end{tabular}

PRODUCING / INJECTION INTERVALS

FROM $\frac{2168}{2 / 25}$ To $2 / 83$
FROM To $3 / 235$
FROM To
FROM To

DETAILS OF PLUGGING:

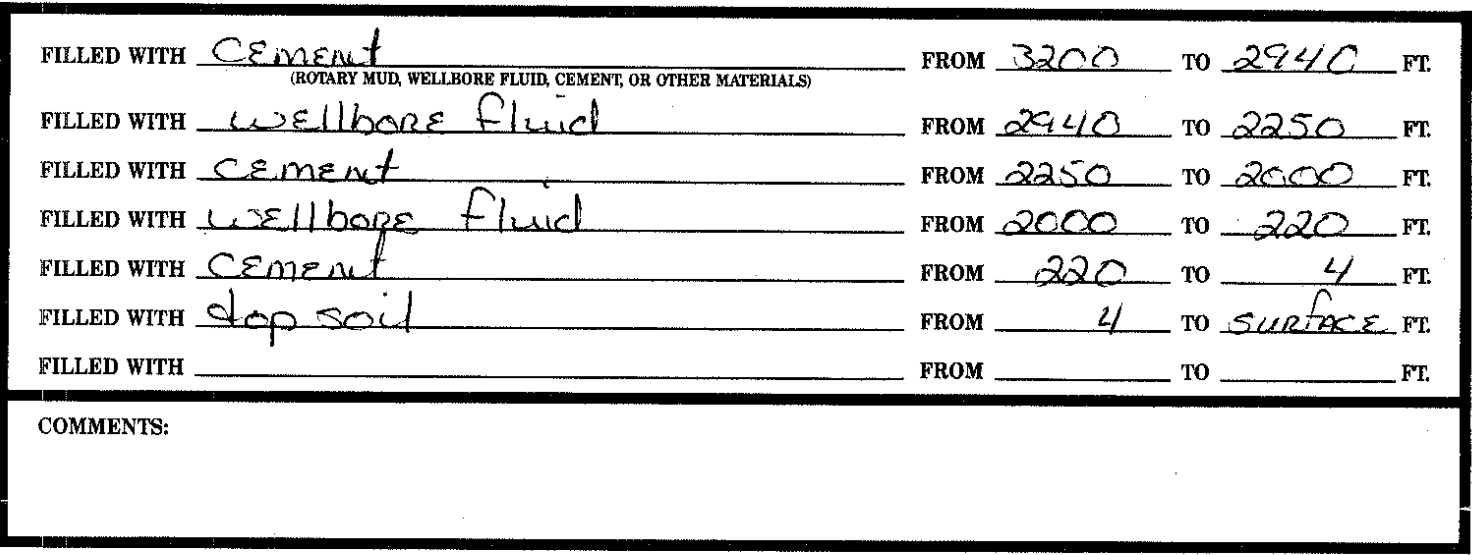

WELL DATA:

\begin{tabular}{|l|c|c|c|c|c|c|}
\hline \multicolumn{1}{|c|}{ CASING } & SIZE & $\begin{array}{c}\text { SETTING } \\
\text { DEPTH }\end{array}$ & $\begin{array}{c}\text { SACKS } \\
\text { CEMENT }\end{array}$ & $\begin{array}{c}\text { HOLE } \\
\text { SIZE }\end{array}$ & $\begin{array}{c}\text { EST. TOP OF } \\
\text { CEMENT }\end{array}$ & $\begin{array}{c}\text { AMOUNT OF } \\
\text { CASING REMOVED }\end{array}$ \\
\hline SURFACE & $8 \% / 8$ & 106 & NR & NR & $6 L$ & $4^{\prime}$ \\
\hline $\begin{array}{l}\text { INTERMEDIATE /MINE } \\
\text { STRING/OR LINER }\end{array}$ & & & & & & \\
\hline PRODUCTION & $4 / 2$ & 3200 & 500 & $N R$ & $?$ & 220 \\
\hline
\end{tabular}

UNDER PENALTIES OF PERJURY, I DECLARE THAT I HAVE EXAMINED THIS FORM INCLUDING ACCOMPANYING STATEMENTS AND DOCUMENTS, AND TO THE BEST OF MY KNOWLEDGE, IT IS/TRUE, CORRECT, AND COMPLETE.

SIGNATURE OF:

ADDRESS

$\overline{\text { CITY, STATE }}$

IL 472-0198 (Rev 8/93)
RECEIYED DEPT. OF NATQRALGESOOPHEETED SPRINGFIELD

$17 \operatorname{sep} 496$ MeterVE

SEP 301996 Printed on Recycled Paper (OVER)

OFFICE OF MINES \& MINERALU

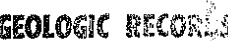



do depose and say the following is a true and correct statement of the details of the plugging of a certain well drilled for oi and for Gas (Indicate whether for oll, gas, water or other purposes)

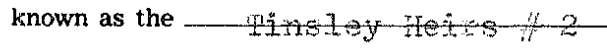

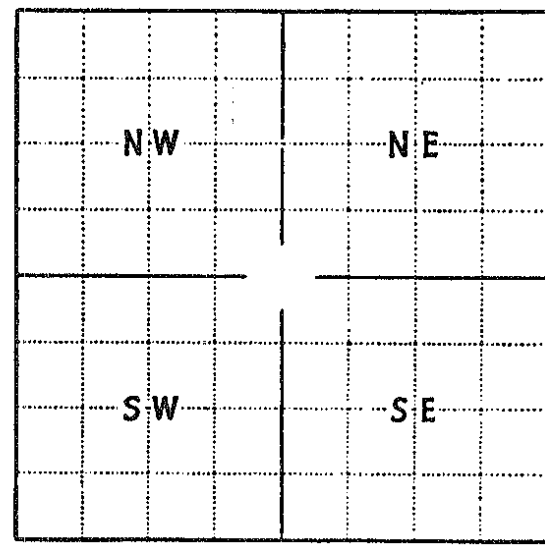

Locate well accurately on plat of section (Scale one inch-2,000 $\mathrm{ft}$.) and located as follows: ft. south; ft. east; $-380 \quad$ ft. west of the $\quad \mathrm{S} \quad$ comer of the WE Quarter of the Quarter of the_Quarter of Section 22 , Township I2 (North or Soythíy Range_ 7 , (East or Wegt $/ y$ of the Principal Meridian,__ Coles County, Illinois. Elevation above sea level is $\{$ Derrick Floor _ f ft. 3206 Ground $770.47 \mathrm{ft}$ Total depth 3206 Formation Devonjan Date permit to drill issued $2 / 2 / 73$ Permit No. 37 Permit issued to inton 1 . Botts

Date drilling began Date drilling completed ? Kind of drilling tools used lotary Date plugging began I/28/82 Date plugging completed $\quad 1 / 28 / 32$

Lessor _ Minsley reins Address ?

Lessee Btion Botis Address Mattoon, Til.

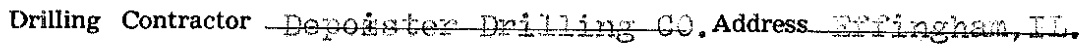

P.P.B. 2002 P.D.

Filled with $\frac{\text { Cement }}{\text { (Rotary Mud }}$

(Rotary Mud, Cement, or Other Materials)

Filled with Wud

\section{DETAILS OF PLUGGING:}

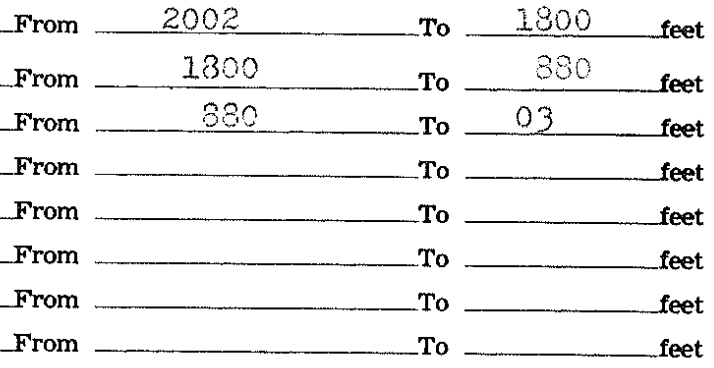

IF WORKABLE COAL BEDS WERE ENCOUNTERED IN THIS HOLE, DESCRIBE THE METHOD EMPLOYED TO PROTECT SAME. (A workable coal bed is thirty inches or more in thickness above 1,000 feet in depth) None

(1) Have pits and other excavations been filled? ................ Yes

(2) Have the following been removed?
Equipment $\stackrel{\text { Yes }}{\text { No }}$
Concrete bases
$\stackrel{\text { No }}{\square}$ Debris $\stackrel{\text { Yes }}{\square} \stackrel{\text { No }}{\square}$

(3) Has surface casing been cut off three feet below ground surface?

(4) Has well-site been leveled?

If this was a producing well, give date and amount of last production

CASING RECORD

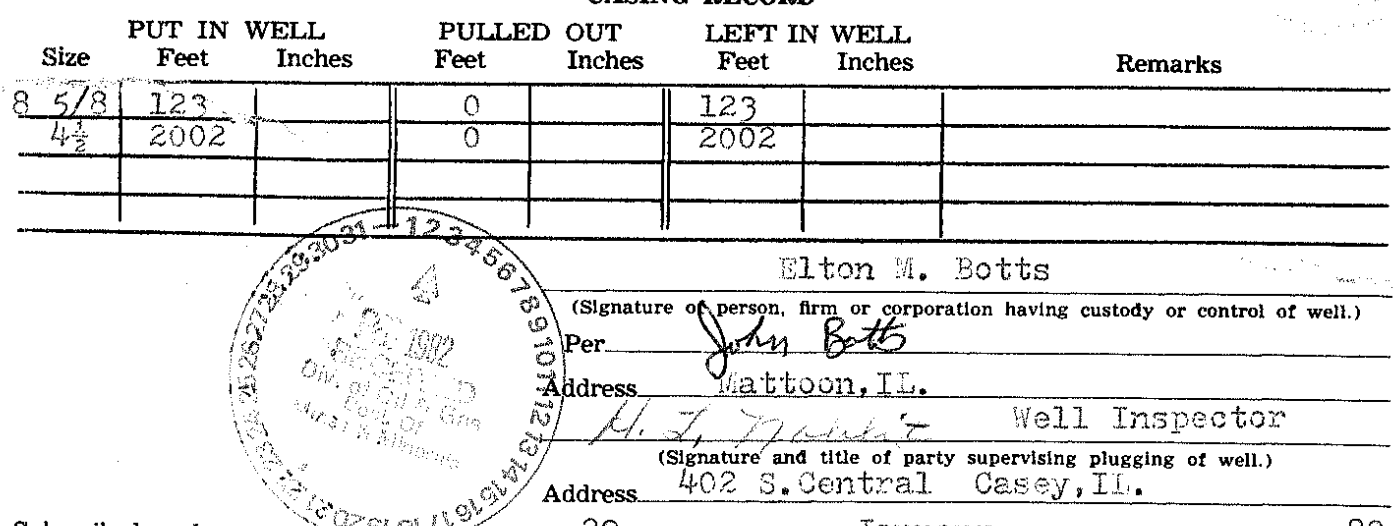

Subscribed and sworn to before me this 29 day of Jaruary

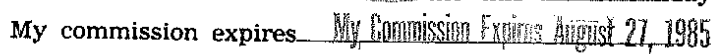


STATE OF ILLINOIS

County of Coles SS.

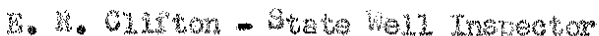

being first duly sworm do depose and say the following is a true and correct statement of the details of the plugging of a certain well drilled for $0 \mathrm{rg}$

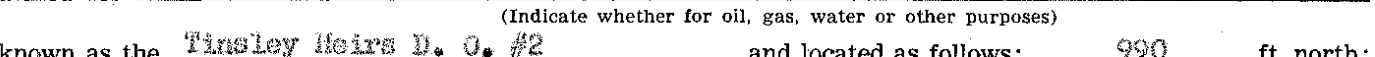

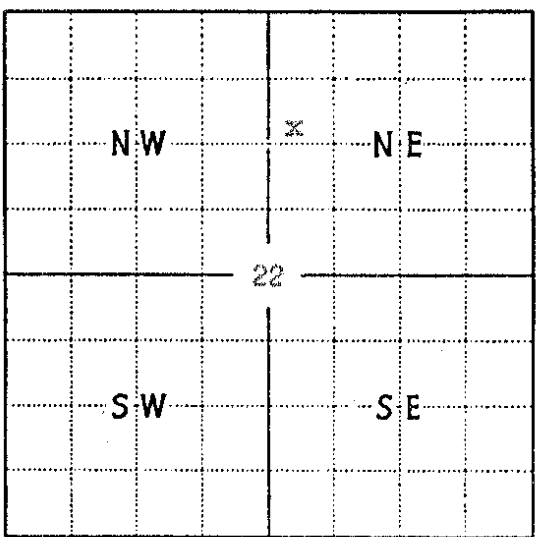

Locate well accurately on plat of section (Scale one inch-2,000 ft.)

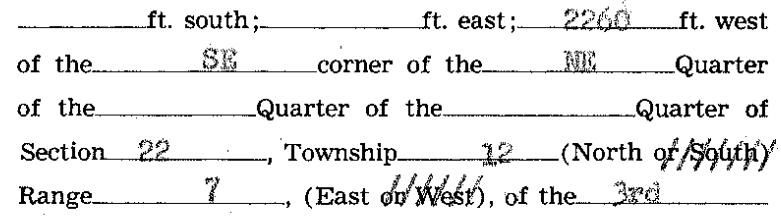

Principal Meridian,___ County, Illinois.

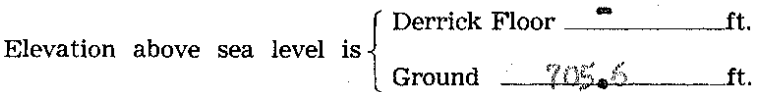
Total depth Date permit to drill issued $9 / 9 / 23$ Permit No. 732 Permit issued to Butow

Date drilling began__. $11-213-3$

Date drilling completed $12-6-79$

Kind of drilling tools used..... Luturisy

Date plugging began $12-6-73$

Date plugging completed $\quad 26-7-73$

Lessor

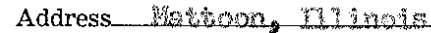

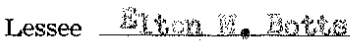

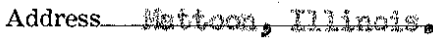
Drilling Contractor the DETAILS OF PLUGGING:

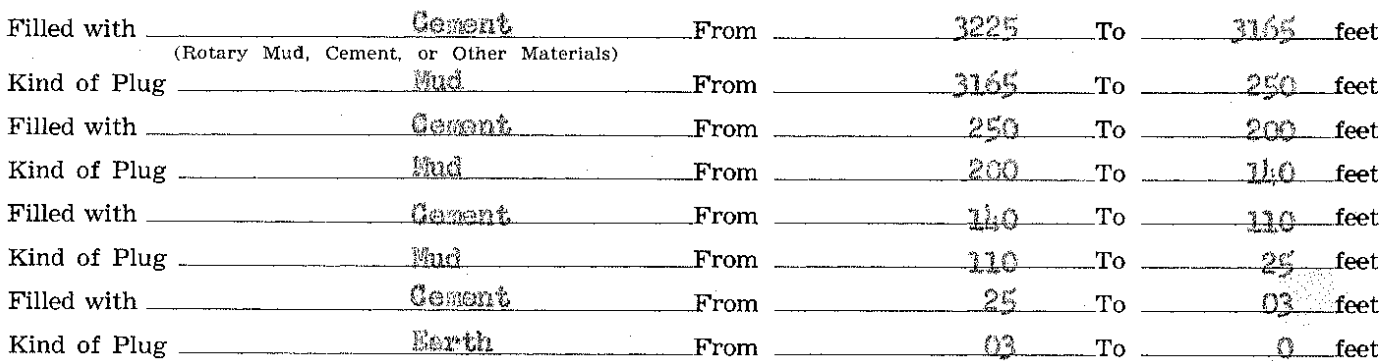

IF WORKABLE COAL BEDS WERE ENCOUNTERED IN THIS HOLE, DESCRIBE THE METHOD EMPLOYED TO PROTECT SAME. (A workable coal bed is thirty inches or more in thickness above 1,000 feet in depth) Woxse

(1) Have pits and other excavations been filled?................ Yes

(2) Have the following been removed? Equipment $\stackrel{\text { Yes }}{\square}$ No Concrete bases $\stackrel{\text { Yes }}{\square} \stackrel{\text { No }}{\square}$ Debris $\stackrel{\text { Yes }}{\square}$ No

(3) Has surface casing been cut off three feet below ground surface?

(4) Has well-site been levelled?

If this was a producing well, give date and amount of last production No ( 

do depose and say the following is a true and correct statement of the details of the plugging of a certain well drilled for O!

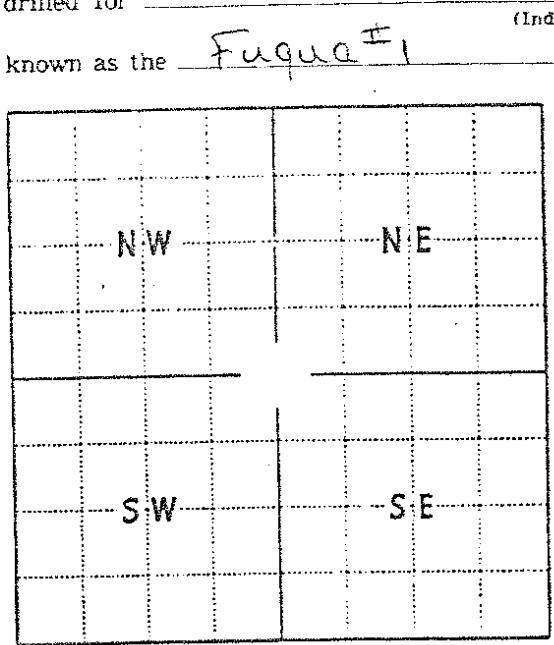

Lasste well sceurately on plat of section (Scale one inch- $-2,000 \mathrm{ft}$ : ridicate whether for oll. gas. water or other purposes;

and located as follows: $\quad 660$ ft. north: ft. south; $330 \mathrm{ft}$ east; _ ft. west of the SW corner of the $S E$ Quarter of the SE Quarter of the_____ Quarter of Section Z2, Township 12 (North Range $I$, (East whe of the Principal Meridian, Coles_County, minois. Elevation above sea level is $\left\{\begin{array}{l}\text { Derrick Floor } 719 \text { ft. } \\ \text { Ground } 715 \text { ft }\end{array}\right.$ Total depth 2393 Formation Date permit to drill issuediz/31/84Permit No 33287 Permit issued to $c$ harles Armantrout Date drilling began $1-2-85$ Date drilling completed $1-7-85$ Kind of drilling tools used Rotary Date plugging began $6 / 16 / 89$

Date plugging completed $6 / 19 / 89$

Lessor fuqua Lessee Clnarles Armantrout Add̀ress Drilling Contractor Depoister Drlg Address Mattoon Il DETAISS OF PLUGGING:

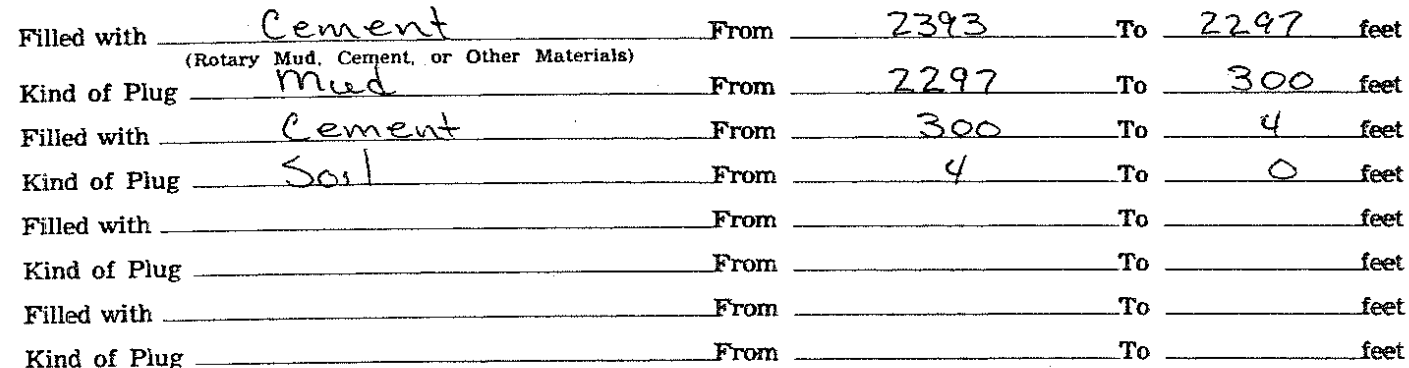

- IF WORKABLE COAL BEDS WERE ENCOUNTERED IN THIS HOLE, DESCRIBE THE METHOD EMPLOYED TO PROTECT SAME. (A workable coal bed is thirty inches or more in thickness above 1,000 feet in depth)

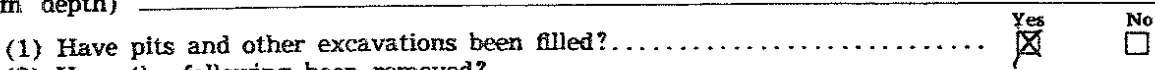

(2) Have the following been removed?

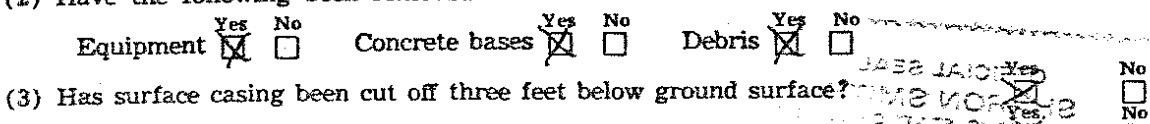

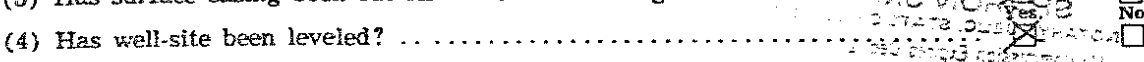

If this was a producing well, give date and amount of last production

CASENG ZEOOND

\begin{tabular}{|c|c|c|c|c|c|c|c|}
\hline Size & $\begin{array}{c}\text { PUT IN } \\
\text { Feet }\end{array}$ & $\begin{array}{l}\text { VELL } \\
\text { Inches }\end{array}$ & $\begin{array}{l}\text { PULLEE } \\
\text { Feet }\end{array}$ & $\begin{array}{l}\text { OUT } \\
\text { Inches }\end{array}$ & $\begin{array}{c}\text { LEFT I } \\
\text { Feet }\end{array}$ & $\begin{array}{l}\text { WELL } \\
\text { Inches }\end{array}$ & Remarks \\
\hline 858 & $164^{\circ}$ & & 4 & & 160 & & Zoo Sacks \\
\hline 412 & 2393 & & 1351 & & 1042 & & 225 Sacles \\
\hline
\end{tabular}

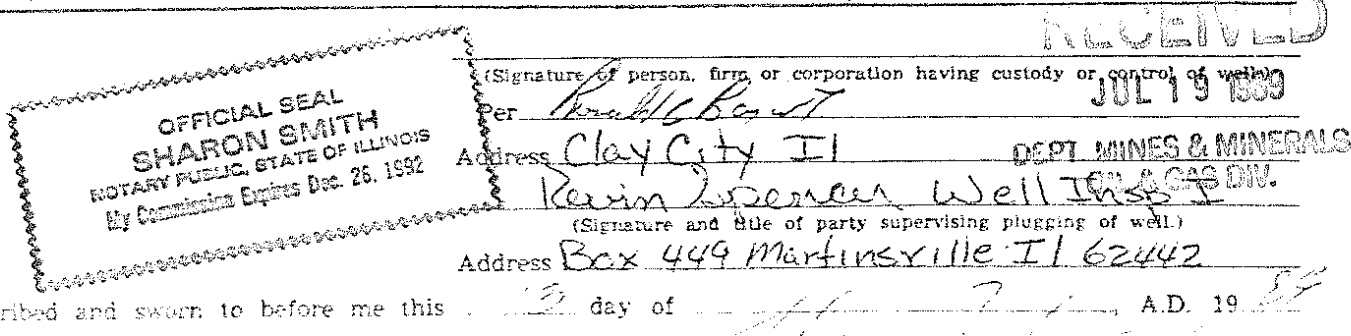


Wohoxa ary do depose and say the following is a true and correct statement of the details of the plugging of a certain well drilled for $\quad 0$ id

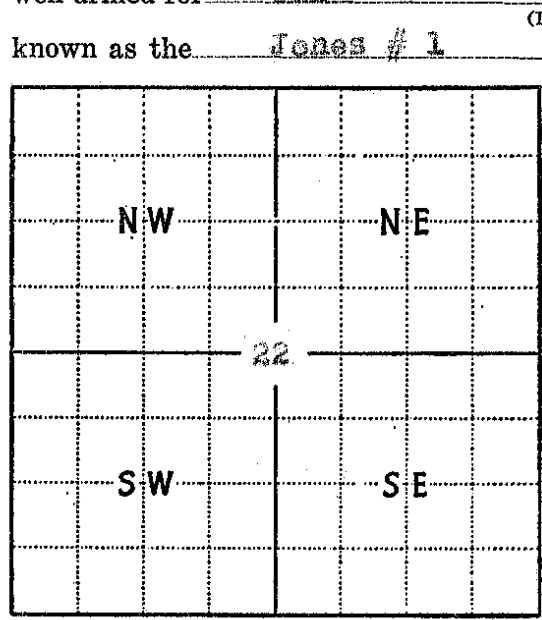

Locate well accurately on plat of section (Scale one inch $-2,000 \mathrm{ft}$ )

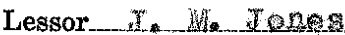
Wher for ofl, gas, water or other purpo and located as follows: 330 ft. north; ft. south; ft. east; 330 ft. west of the corner of the Qurer of the Quarter of the Quarter of Section 22 , Township_2 (North or-south) Range (East or West), of the Princiual Meridian, ot. County, Illinois.

Elevation above sea level is $\begin{cases}\text { Derrick Floor } & \mathrm{ft} . \\ \text { Ground } 70 & \mathrm{ft}\end{cases}$ Total depth 2001 Formation dasolore Date permit to drill issuea $20 / 59$ Permit No. 2207

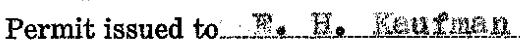

Date drilling began $\quad 12 / 5 / 59$

Date drilling completed $\quad 12 / 20 / 59$

Kind of dxilling tools used Kotares

Date plugging began _____ $\quad 10 / 2165$

Date plugging completed $\quad 10 / 24 / 65$

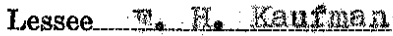

Address_r.

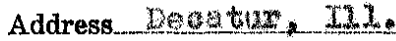

Drilling Contractor

Address_Dositur, 211.

\section{DETAILS OF PLUGGING:}

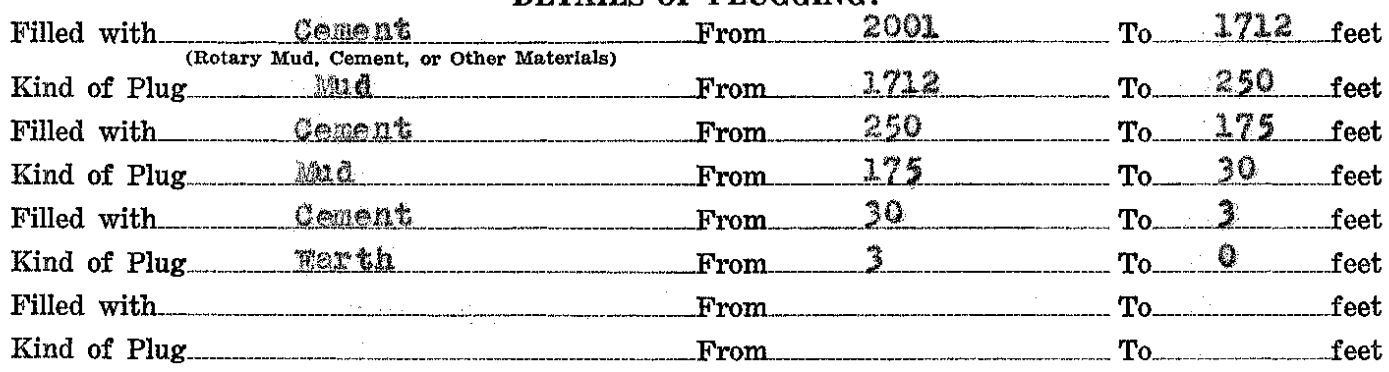

IF WORKABLE COAL BEDS WERE ENCOUNTERED IN THIS HOLE, DESCRIBE THE METHOD EMPLOYED TO PROTECT SAME. (A workable coal bed is thirty inches or more in thickness above 1,000 feet in depth) Wone

(1) Have pits and other excavations been filled?

(2) Have the following been removed?

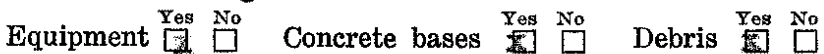

(3) Has surface casing been cut off three feet below ground surface?

(4) Has well-site been levelled?

If this was a producing well, give date and amount of last production

Yes $\quad$ No

\section{CASING RECORD}

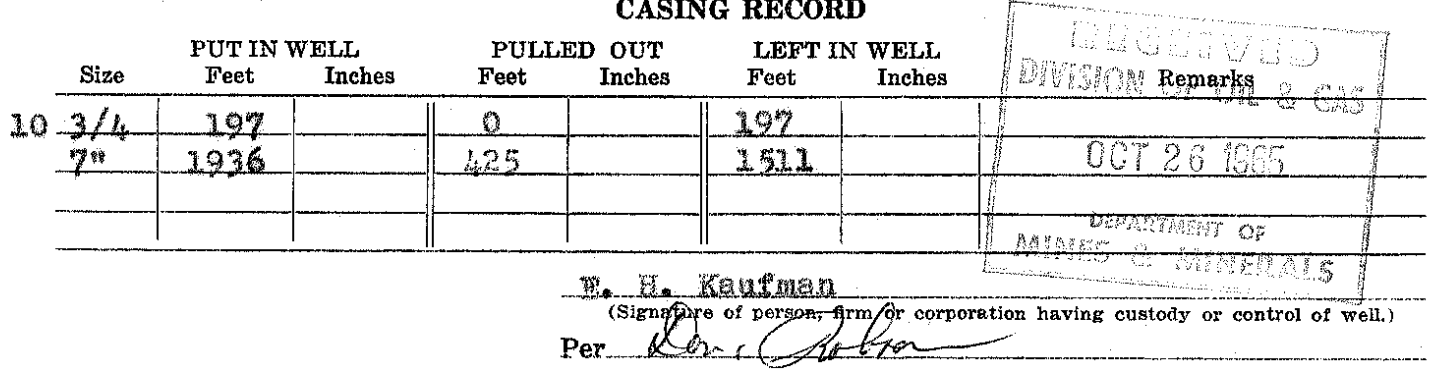

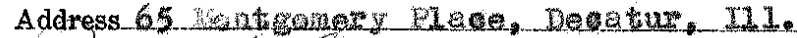

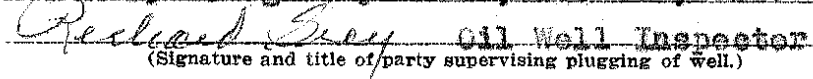

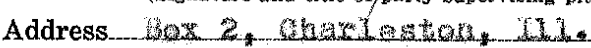

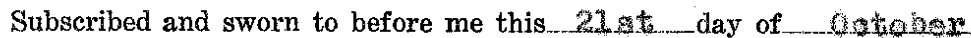
My commission expires $\quad$ - $16 / 69$ 


\section{程}

being first duly sworn do depose and say the following is a true and correct statement of the details of the plugging of a certain well drilled

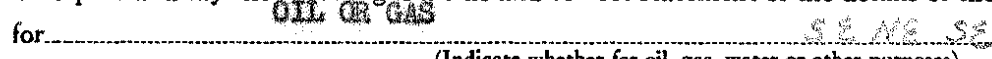

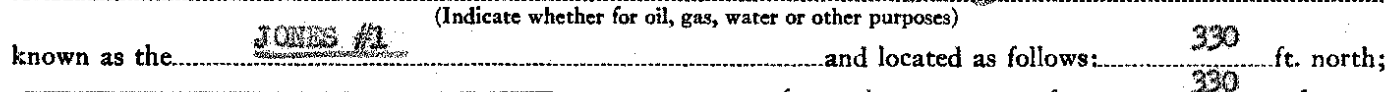

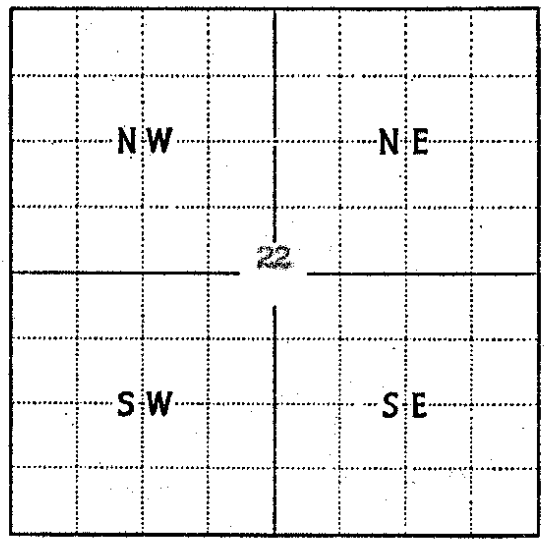

Locate well accurately on plat of section (Scale one inch-2,000 ft.)

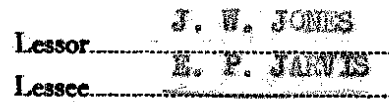

Drilling Contractor. ft. south; ft. east; - 320 ....ft. west of the 5 corner of the of the SE: Quarter of the Q Quarter of Section. $22 \quad$ Township. 12 (North 61666th) Range 7 (Eastof $(W 06)$, of the 3 at. Principal Meridian, - County, Illinois. Elevation above sea level is $\left\{\begin{array}{l}\text { Derrick Floor } \\ \text { Ground }\end{array}\right.$ Total depth 2983 Ground

Date permit to drill issued.

Permit issued to s. I. JALT:

Date drilling began.

Date drilling completed. $\quad 10-26+45$

Kind of drilling tools used

Date plugging began......... $7-2 / 44$

Date plugging completed $\quad 724=24$ thes

Address
Address

Address.

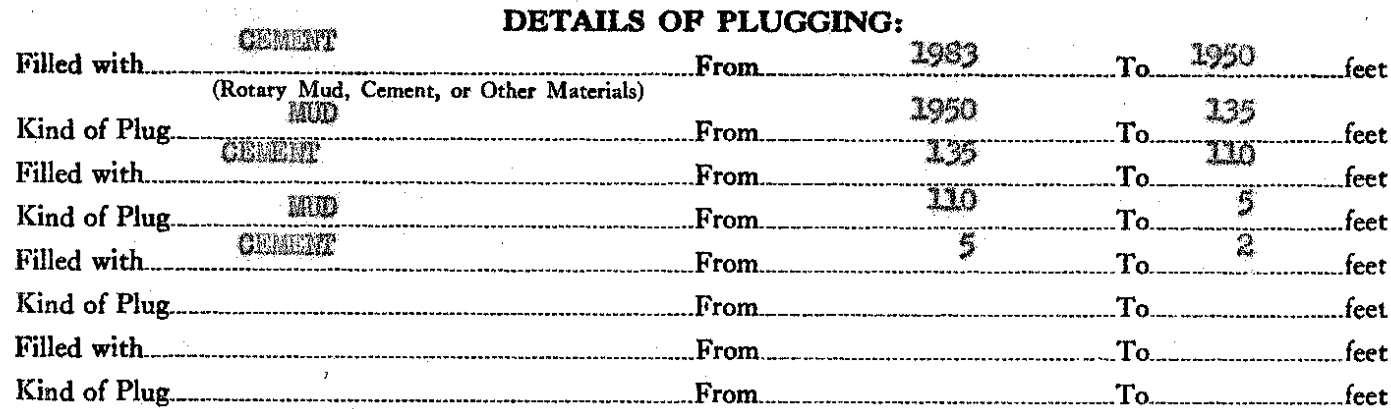

IF WORKABLE COAL BEDS WERE ENCOUNTERED IN THIS HOLE, DESCRIBE THE METHOD EMPLOYED TO PROTECT SAME. (A workable coal bed is thirty inches or more in thickness above 1,000 feet in depth)

feet in depth)...
(1) Have pits and other excavations been filled?.............
(2) Have the following been removed?

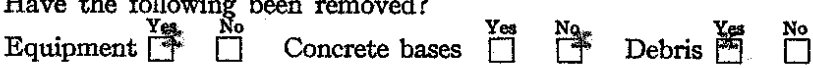

(3) Has surface casing been cut off three feet below ground surface?

(4) Has well-site been levelled?.

If this was a producing well, give date and amount of last production

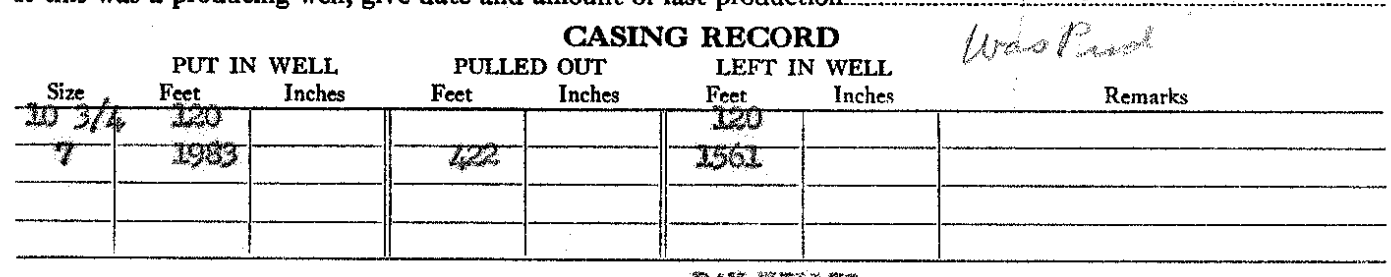

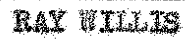

(Signagure of person, firm or corporation haying custodyor control of well.) Per $\angle 2+2=22$

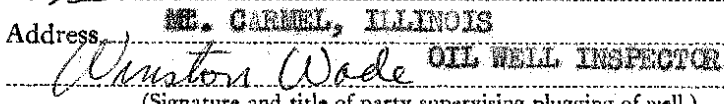
Address

(Signature and tithegharty supervising plygging of well.) 
STATE OF TLLINOIS, County of coles $\}^{\text {ss. }}$ cot $\$ 111$
8158938 WELL PLUGGING AFFIDAVIT

Lawrence Landreth Jim Gililiand say the following is a true and correct statement of the details of the plugging of a certain well adrilled for Salt Water Disposal

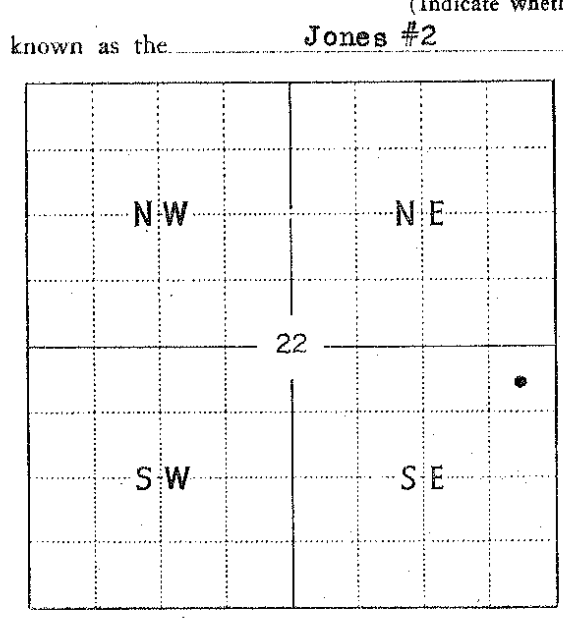

L.ocate well accurately on plat of section (Scale one inch $-2,000 \mathrm{ft}$.)

\section{liessor Jones \\ Lessee E. P. Jarvis}

Drilling Contractor E. D. Jarvis

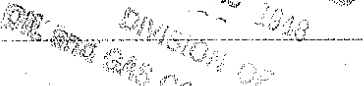
and located as follows: frot. north;

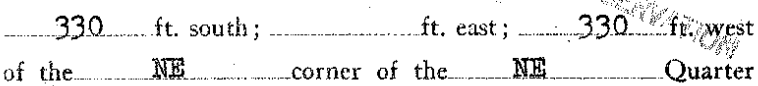
of the Quarter of the SE Quarter of Section 22 , Township I2 North (North or South) Range? East (East or West), of the $3 \mathrm{~d}$ Principal Meridian, Coles County, Illinois. Elevation above sea level is $\left\{\begin{array}{lll}\text { Derrick Floor } & 713 & \text { ft. } \\ \text { Ground } & 709 & \mathrm{ft} .\end{array}\right.$ Total depth of well is $6-2 \frac{189}{3-4} \ldots \mathrm{ft}$ Date permit to drill issued $11-10-45 \quad$ Permit No.197004 Permit issued to T. P. Jarvis

Date drilling began ......11-9-45

Date drilling completed $11-15-45$

Kind of drilling tools used Rotary

Date plugging began $11-27-48$

Date plugging completed $12-1-48$

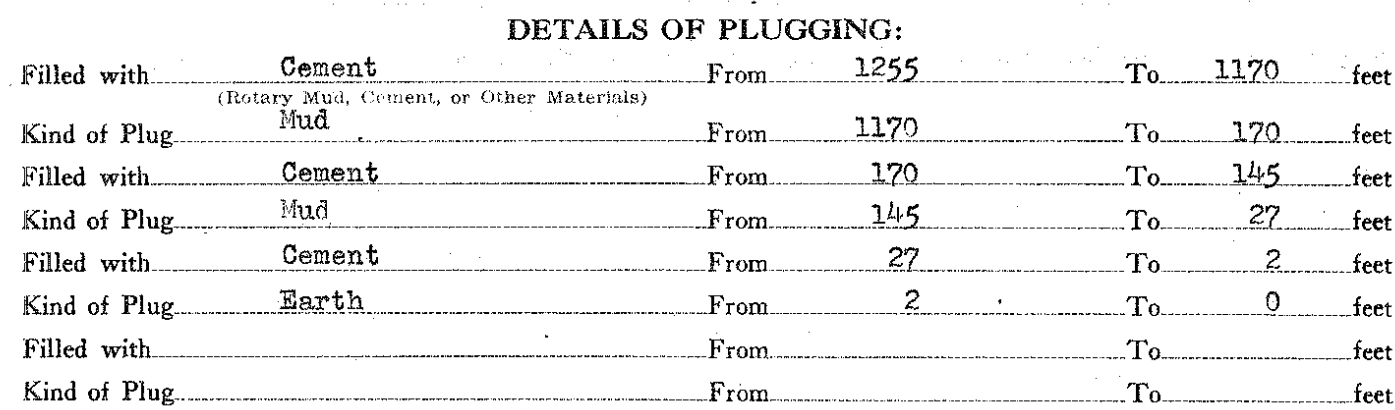

Address Mattoon, Illinois

Address 526 standard B1dg, Decatur, III. Address Decatur, IIl.

IF WORKABLE COAL BEDS WERE ENCOUNTERED IN THIS HOLE, DESCRIBE THE METHOD EMPLOYED TO PROTECT SAME. (A workable coal bed is thirty inches or more in thickness above 1,000 feet in depth) Affidarit on back
(1) Have pits, cellar and other excavations been filled?

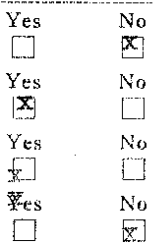
(2) Have equipment, concrete bases and debris been removed?
(3) Has surface casing been cut off below plow depth?
(4) Has well-site been levelled?
$\square$

If this was a producing well, give date and amount of last production

\section{CASING RECORD}

\begin{tabular}{|c|c|c|c|c|c|c|c|}
\hline Size & $\underset{\text { freet }}{P U}$ & $\begin{array}{l}\text { WELL } \\
\text { Inches }\end{array}$ & $\begin{array}{c}\text { PUr } \\
\text { Feet }\end{array}$ & $\begin{array}{l}\text { OUT } \\
\text { Inches }\end{array}$ & $\begin{array}{l}\text { LEFT } \\
\text { Feet }\end{array}$ & $\begin{array}{l}\text { NELL } \\
\text { Inches }\end{array}$ & Remarks \\
\hline $10-3 / 4$ & 160 & & & & 160 & . & Cemented \\
\hline 7 & 1936 & & 612 & & 1324 & & \\
\hline & & . & & & & & \\
\hline & & & & & & & \\
\hline
\end{tabular}

ACME CASING PULIING COMPANT

GRAYVILIE, ILLIHOIS

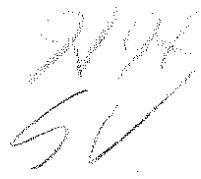

Subscribed and sworn to before me this My commission expires $2-24-51$

$$
\text { (Sigoature of pergof, firm or corporation having custody or control of well.) }
$$$$
\text { Per. } 1 \text { beteres }
$$

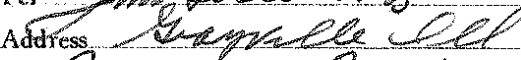

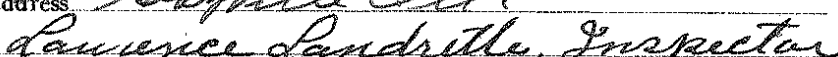
(Signayure and title of party supervising plugging of Reli.)

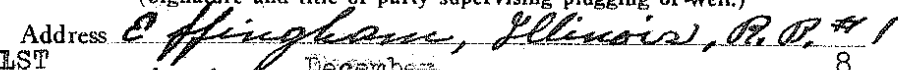

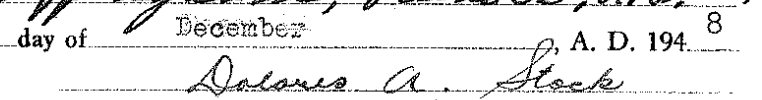
Notary Public. 
STATE OF ILLINOIS,

County of os as

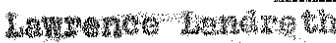

\title{
WELL PLUGGING AFFIDAVIT
}

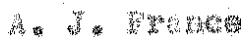

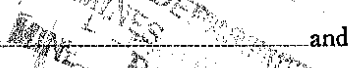

being frst duly sworn, do depose and say the following is a true and correct statement of the details of the plugging of 2 certain well drilled for

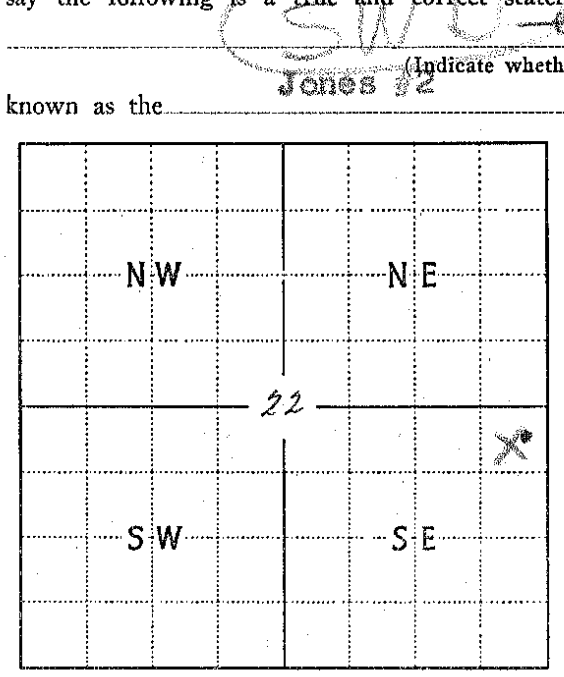

Locate well accurately on plat of section Scale one inch-2,000 ft.)

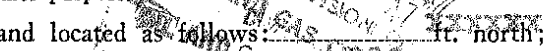

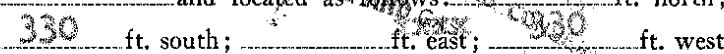
of the corner of the Quarter

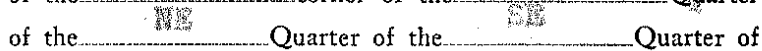
Section 2 . Township 12 (North or South) Range , (East of $W e s$ ), of the 3

Principal Meridian

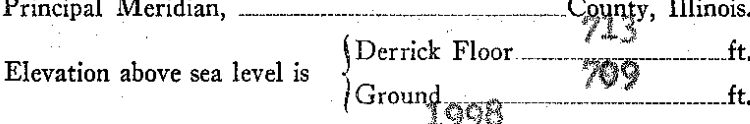

Total depth of well is . _ _

Date permit to drill isued

Permit issued to so wow

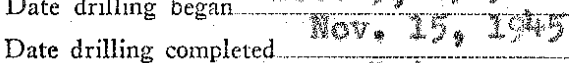

Kind of drilling tools used- $\quad$ ot

Date plugging began

Date plugging completed rut

\begin{tabular}{|c|c|}
\hline 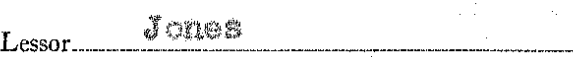 & 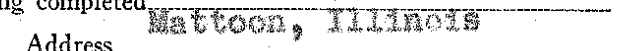 \\
\hline 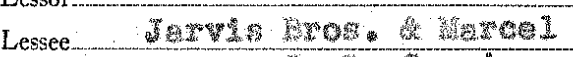 & 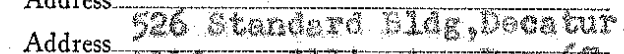 \\
\hline Drilling Contractor ton & Address \\
\hline
\end{tabular}

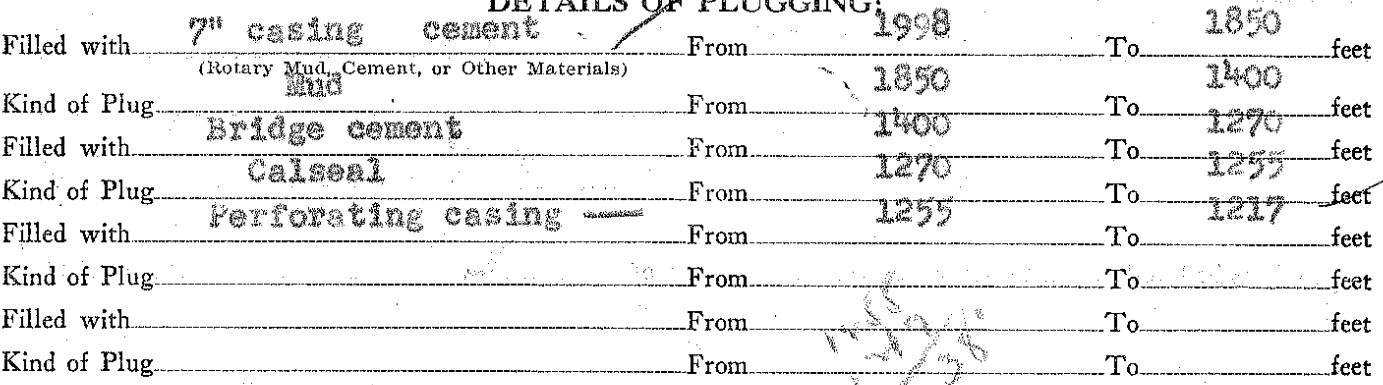

IF WORKABLE COAL BEDS WERE ENCOUNTERED IN THIS HOLE, DESCRIBE THE METHOD EMPLOYED TO PROTECT SAME. (A workable coal bed is thirty inches or more in thickness above 1,000 feet in depth........

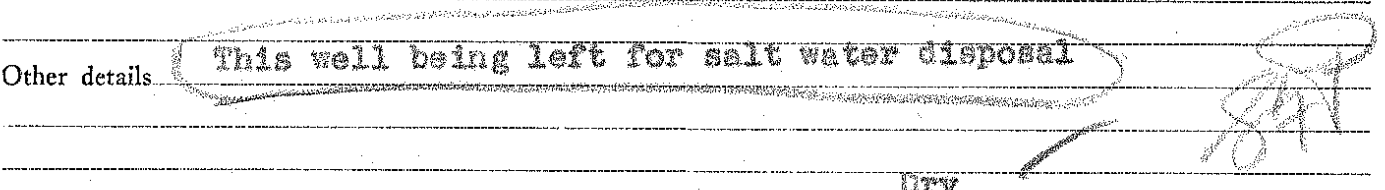

If this was a producing well, give date and amount of last production

CASING REGORD

Size
PUT IN WELL


Form OG-6

$\left.\begin{array}{l}\text { STATE OF ILLINOIS } \\ \text { County of.. } 100 \text { stigs }\end{array}\right\}$ ss.

WELL PLUGGHOHAFFIDAVIT

BOWHa

and

What

do depose and say the following is a true and correct statement of the details of the plugging of a certain well drilled for

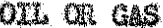
WW

(Indicate whether for oil, gas, water or other purposes)

known as the Jowness

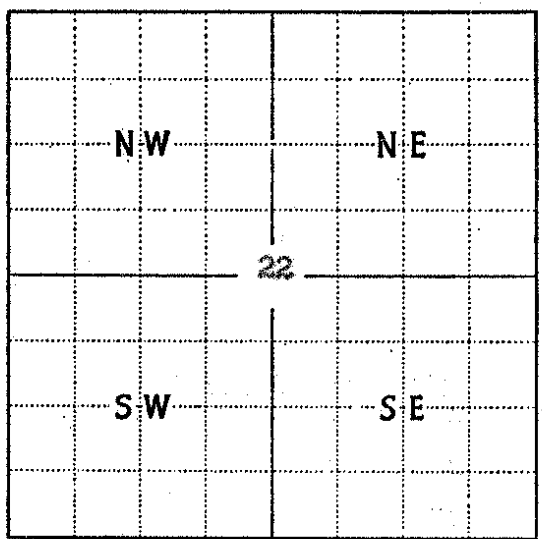

Locate well accurately on plat of section (Scale one inch-2,000 ft.)

and located as follows:

ft. north;

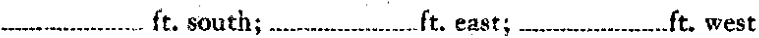
of the corner of the of the $\quad$ Q

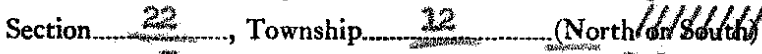

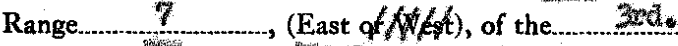
Principal Meridian, Gotess County, Illinois. Elevation above sea level is $\left\{\begin{array}{l}\text { Derrick Floor } \quad 711 \\ \text { Ground }\end{array}\right.$

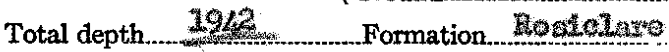

Date permit to drill issued.............................

Permit issued to....

Date drilling began

Date drilling completed. $\quad 12,52-45$

Kind of drilling tools used......

Date plugging began. $7-2-24$

Date plugging completed $7-22-5$

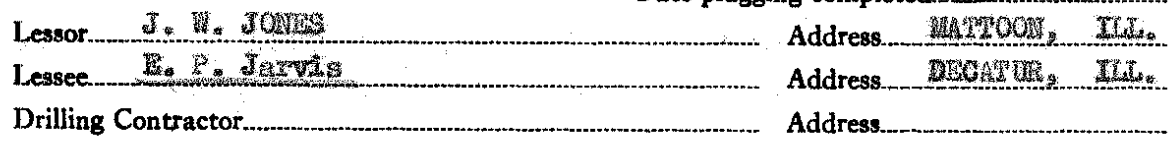

Drilling Contractor

DETAILS OF PLUGGING:

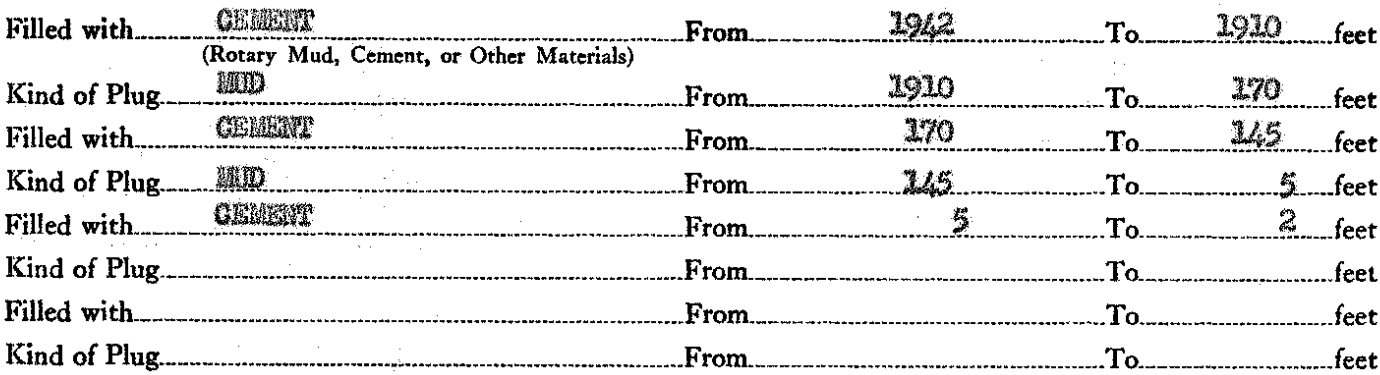

IF WORKABLE COAL BEDS WERE ENCOUNTERED IN THIS HOLE, DESCRIBE THE METHOD EMPLOYED TO PROTECT SAME. (A workable coal bed is thirty inches or more in thickness above 1,000 feet in depth) .....................

feet in depth)...
(1) Have pits and other excavations been filled?...............
(2) Have the following been removed?

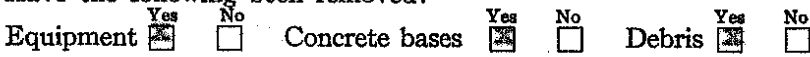

(3) Has surface casing been cut off three feet below ground surface?

(4) Has well-site been levelled?

If this was a producing well, give date and amount of last production

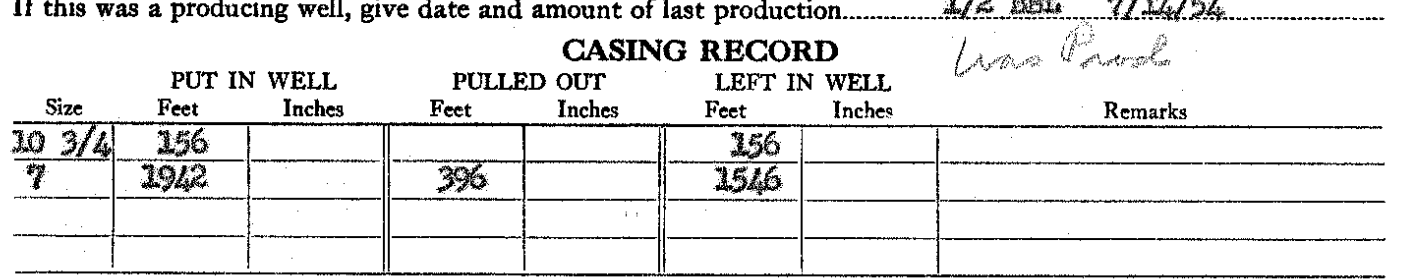

$\mathrm{Mu}: \mathrm{gr}$

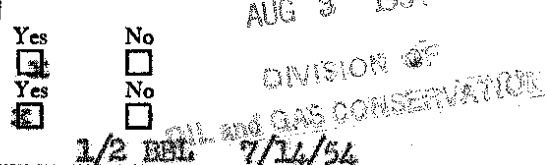

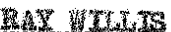

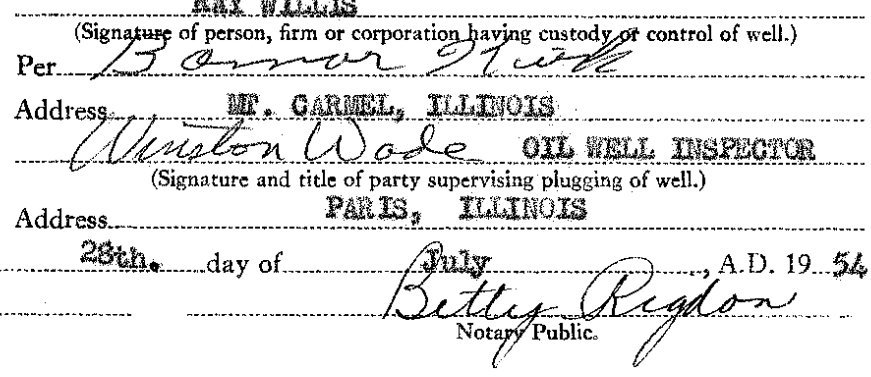




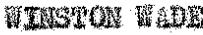

being first duly sworn do depose and say the following is a true and correct statement of the details of the plugging of a certain well drilled for.

known as the 30 are 4

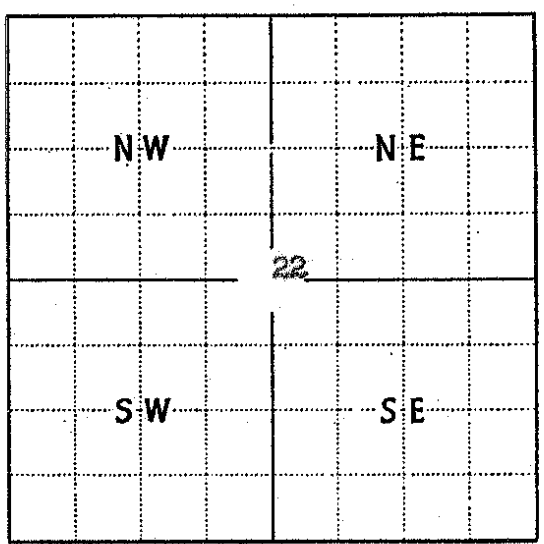
Locate well accurately on plat of section
(Scale one inch $-2,000 \mathrm{ft}$.)

\begin{tabular}{|c|c|}
\hline Lessor. & 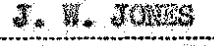 \\
\hline Lessee. & D. TANW S \\
\hline
\end{tabular}

Drilling Contractor

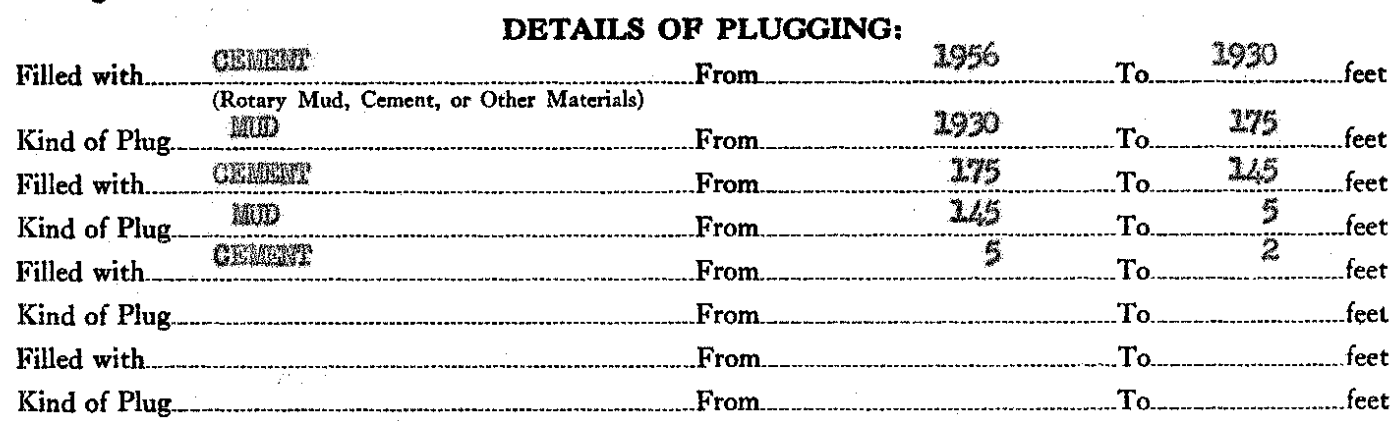

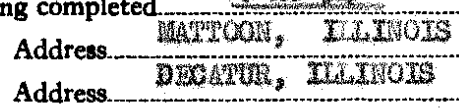
of the S. South; of the $22 \quad$ Quarter of the 12 Quarter of

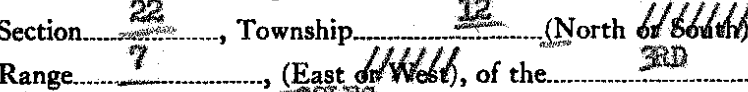
Principal Meridian, Elevation above sea level is $\left\{\begin{array}{l}\text { Derrick Floor } \\ \text { Ground }\end{array}\right.$

Total depth $1956 \quad$ Formation Date permit to drill issued. $\quad 2-29-15$ Permit No 1867 Permit issued to D. Sarts

Date drilling began

Date drilling completed. $12-3-13$

Kind of drilling tools used ......... Whot

Date plugging began $7-20-34$

Date plugging completed

$720=$ IF WORKABLE COAL BEDS WERE ENCOUNTERED IN THIS HOLE, DESCRIBE THE METHOD EMPLOYED TO PROTECT SAME. (A workable coal bed is thirty inches or more in thickness above 1,000 feet in depth) MO OOW

(1) Have pits and other excavations been filled?.............

(2) Have the following been removed?

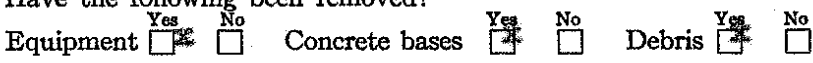

(3) Has surface casing been cut off three feet below ground surface?

(4) Has well-site been levelled?

If this was a producing well, give date and amount of last production

ft. east; 900 ft. north; 
being first duly sworn do depose and say the following is a true and correct statement of the details of the plugging of a certain well drilled for.

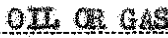

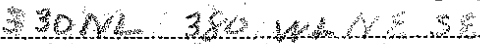

known as the Josing 3 (Indicate whether for oil, gas, water or other purposes)

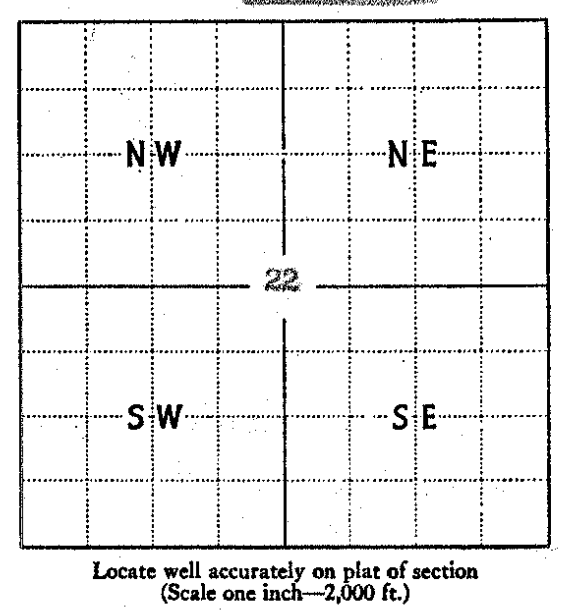

and located as follows:

ft. north;

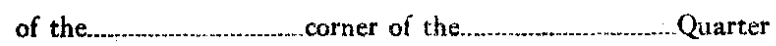
of the Quarter of the Quarter of

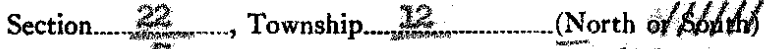

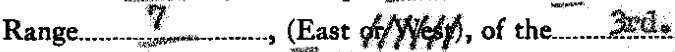

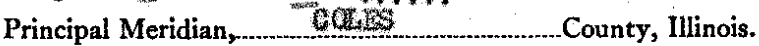

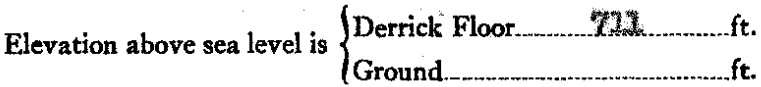

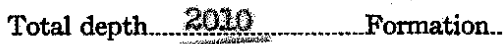
Date permit to drill issued $\quad$ Permit No.

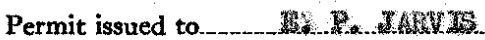

Date drilling began Date drilling completed $\quad 12-4-46$

Kind of drilling tools used.

Date plugging began $\quad 7-2 x-24$

Date plugging completed $7-21-54$

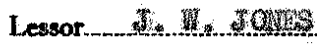

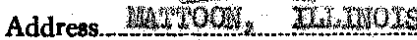

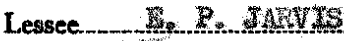

Drilling Contractor

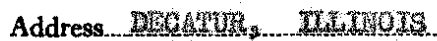

Address.

\section{DETAILS OF PLUGGING:}

\begin{tabular}{|c|c|c|}
\hline Filled with Ory & From. & To._tres \\
\hline $\begin{array}{l}\text { (Rotary Mud, Cement, or Other Materials) } \\
\text { Kind of Plug }\end{array}$ & 2462 & To $\quad 260$ \\
\hline Filled with & From & To 130 \\
\hline Kind of Plug & From & To. \\
\hline 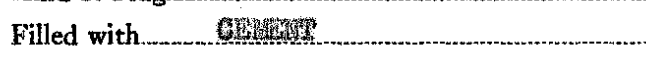 & From & To 2 \\
\hline Kind of Plug.-- & From & To \\
\hline Filled with & From & ... \\
\hline Kind of Plug & From & \\
\hline
\end{tabular}

IF WORKABLE COAL BEDS WERE ENCOUNTERED IN THIS HOLE, DESCRIBE THE METHOD EMPLOYED TO PROTECT SAME. (A workable coal bed is thirty inches or more in thickness above 1,000 feet in depth) 10.010

(1) Have pits and other excavations been filled?............

(2) Have the following been removed?

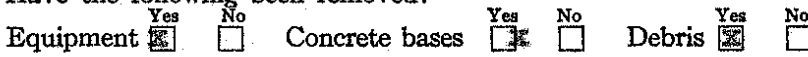

(3) Has surface casing been cut off three feet below ground surface?

(4) Has well-site been levelled?.

If this was a producing well, give date and amount of last production

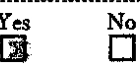

No
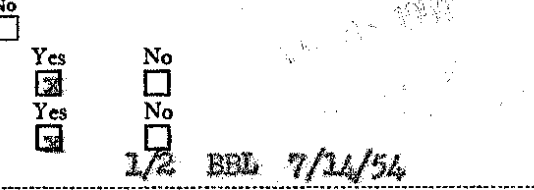

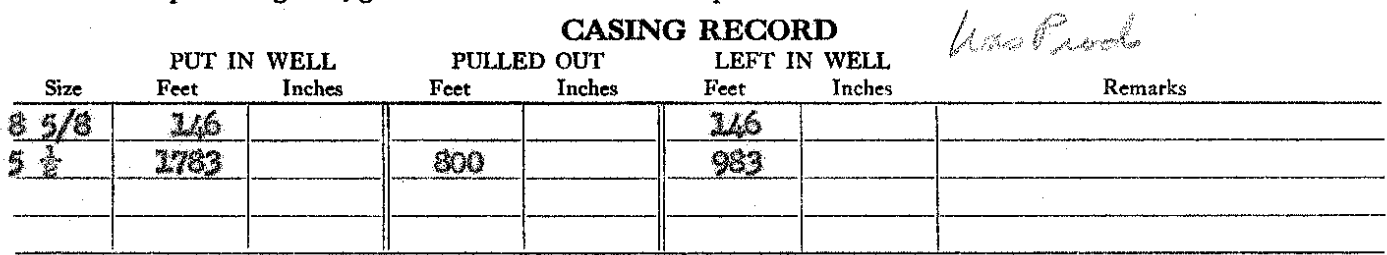

An wrass

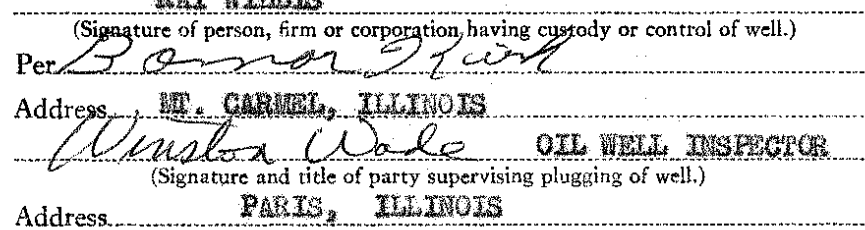

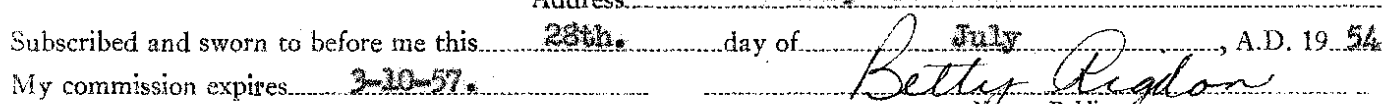


do depose and say the following is a true and correct statement of the details of the plugging of a certain well drilled for ox be qas

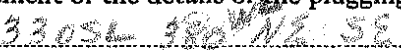
(Indicate whether for oil, gas, water or other purposes)

known as the Jor 4 and located as follows: ft. north;

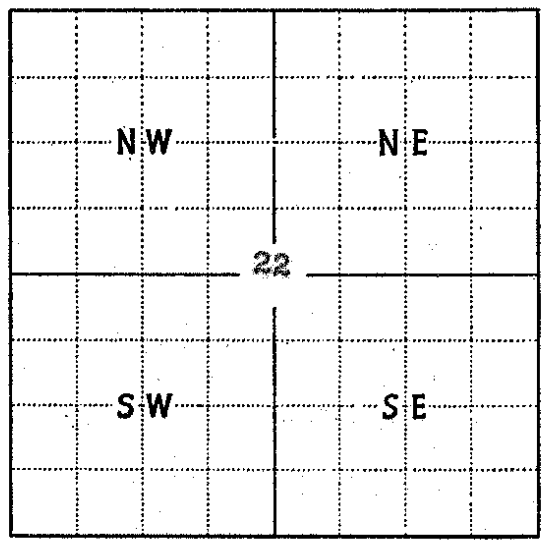

Locate well accurately on plat of section (Scale one inch-2,000 ft.) ft. south;

f...ft. east;

ft. west

of the $y^{2}$. of the 31 Quarter of the Quarter of

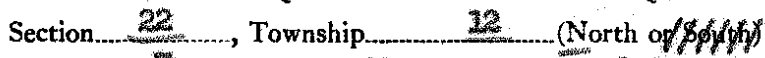
Range 7 , (Eas $/ 6 / \mathrm{W} \% \mathrm{~W})$, of the $3 \mathrm{xq}$. Principal Meridian, Gat County, Illinois.

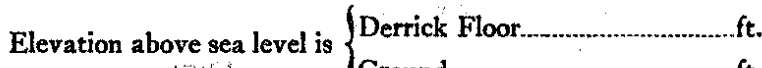

Total depth 2968 Ground

Date permit to drill issued........................ Permit No.

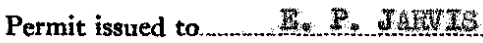

Date drilling began $\quad 2966$

Date drilling completed. 1946

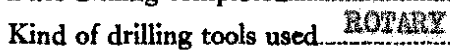

Date plugging began $7-19-54$

Date plugging completed $7-19-5$

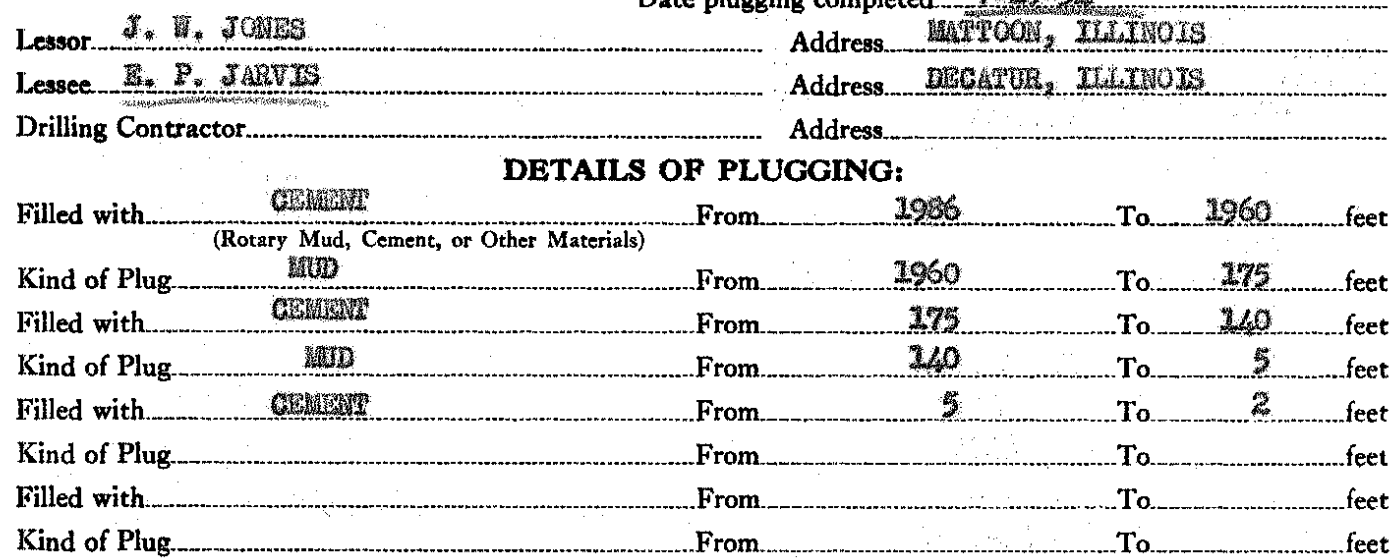

IF WORKABLE COAL BEDS WERE ENCOUNTERED IN THIS HOLE, DESCRIBE THE METHOD EMPLOYED TO PROTECT SAME. (A workable coal bed is thirty inches or more in thickness above 1,000 feet in depth)...

(1) Have pits and other excavations been filled?............

(2) Have the following been removed?

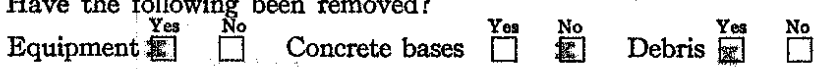

(3) Has surface casing been cut off three feet below ground surface?

(4) Has well-site been levelled?

Yes $\quad$ No

If this was a producing well, give date and amount of last production

\begin{tabular}{|c|c|c|c|c|c|c|c|}
\hline \multirow[b]{2}{*}{ Size } & \multirow{2}{*}{\multicolumn{2}{|c|}{ PUT IN WELL }} & \multicolumn{4}{|c|}{ CASING RECORD } & \\
\hline & & & \multicolumn{2}{|c|}{ PULLED OUT } & \multicolumn{2}{|c|}{ LEFT IN WELL } & \\
\hline $103 / 2$ & 258 & & & & 158 & & \\
\hline 5 & 1026 & & 527 & & 2459 & & \\
\hline & & & & & & & \\
\hline
\end{tabular}

Yes $1 / 234-26$

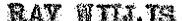

(Sigmature of person, firm or corpontion having custody or control of weil.)

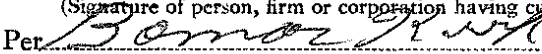

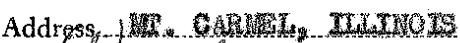

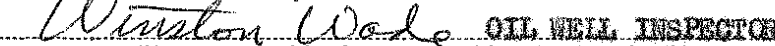

(Signature and ticle of party supervising plugging of well.)

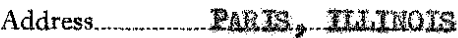

Subscribed and sworn to before me this......30th
My commission expires $3-10-57$. 
Form OG-6

STATE OF ILLINOIS

County of. coness

\section{WELL PLUGGUNG GNOAFHDAVIT}

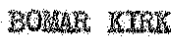

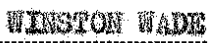
do depose and say the following is a true and correct statement of the details of the plugging of a certain well drilied

for OIL OR GR

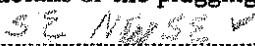
(Indicate whether for oil, gas, water or other purposes)

known as the Jandes

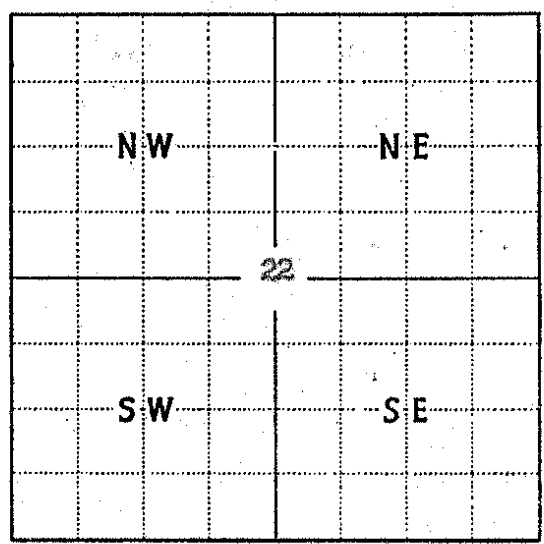

Locate well accurately on plat of section (Scale one inch-2,000 ft.)

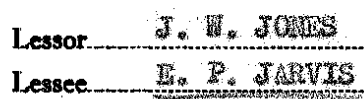

Drilling Contractor. and located as follows: $330 \quad \mathrm{ft}$. north;

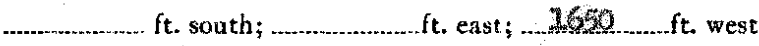
of the S1 corner of the Quarter of the $35 \quad$ Quarter of the Quarter of

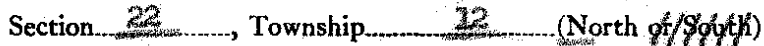

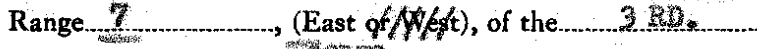
Principal Meridian, ot............. County, Illinois. Elevation above sea level is $\left\{\begin{array}{l}\text { Derrick Floor } 7 \mathrm{lo} \\ \text { Ground }\end{array}\right.$ Total depth $2002 \quad$ Formation 108 104ARS Date permit to drill issued $3-2-46 \quad$ Permit No. 1 Permit issued to s. B. Juth

Date drilling began

Date drilling completed $\quad 2-3-46$

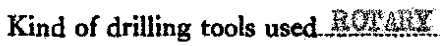

Date plugging began.........2-2

Date plugging completed $7+20$

\begin{tabular}{|c|c|c|}
\hline Add & (4) $100 \%$ & KLENOS \\
\hline Addr & odout & 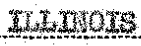 \\
\hline
\end{tabular}

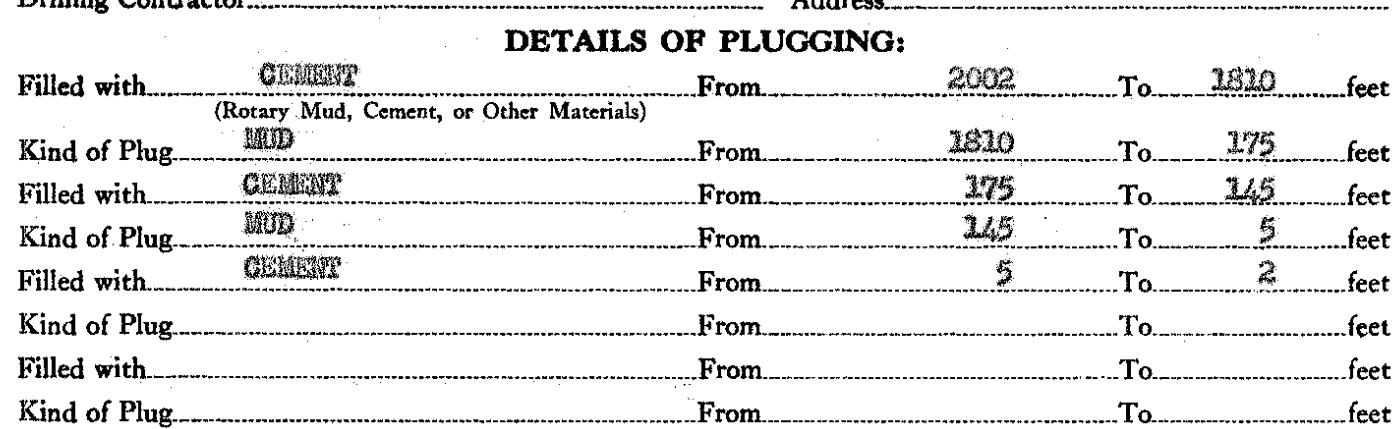

IF WORKABLE COAL BEDS WERE ENCOUNTERED IN THIS HOLE, DESCRIBE THE METHOD EMPLOYED TO PROTECT SAME. (A workable coal bed is thirty inches or more in thickness above 1,000 feet in depth) MO OOLY

(1) Have pits and other excavations been filled?............ Yes

(2) Have the following been removed?

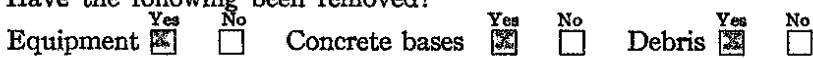

(3) Has surface casing been cut off three feet below ground surface?

(4) Has well-site been levelled?

If this was a producing well, give date and amount of last production $\quad 2 / 2,282,7-1 / 4,5$

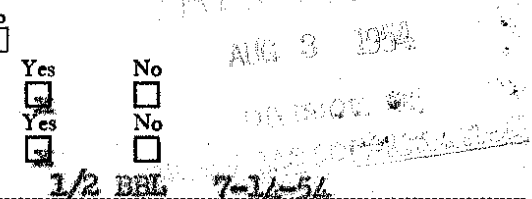

\begin{tabular}{|c|c|c|c|c|c|c|c|}
\hline \multirow{3}{*}{$\frac{\text { Size }}{103 / 4}$} & \multicolumn{2}{|c|}{ PUT IN WELL } & \multicolumn{4}{|c|}{ CASING RECORD } & \multirow{2}{*}{$\begin{array}{l}\text { Lrano } \\
\text { Remarks }\end{array}$} \\
\hline & Feet & Inches & Feet & Inches & Feet & Inches & \\
\hline & 758 & & & & 358 & & \\
\hline 7 & 2002 & & 428 & & 4574 & & \\
\hline & & & & & & & \\
\hline & & & & & & & \\
\hline
\end{tabular}

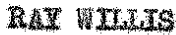

(Sigeatyare of person, firm or corporation having cuskgety or control of well.)

Per $202-202=102$

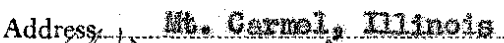

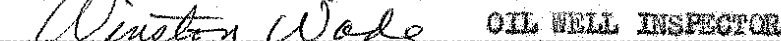

(Signature and title of party supervising plugging of well.)

Address

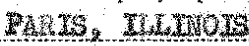

Subscribed and swom to before me this 28ta.
My commission expires.. $3-10-57$ 
STATE OF ILLINOIS, County of Colos ........

\section{Lewronce Landreth}

say the following is a true and correct statement of the details of the plugging of a certain well drilled tor

(Indicate whether for oil, gas, water or other purposes)

known as the J. U. Jones 16

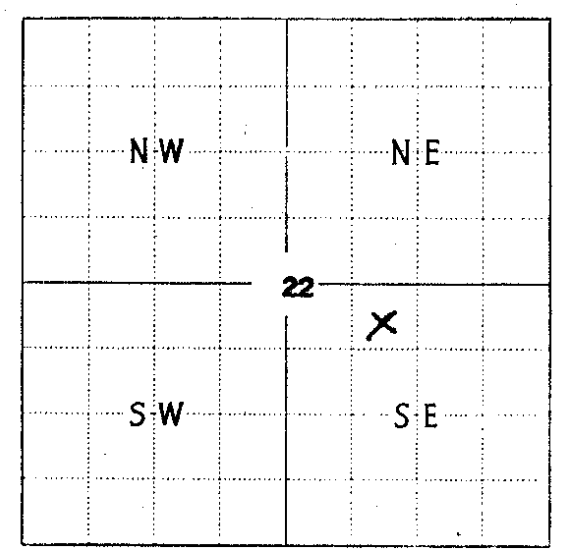

l.ocate well accurately on plat of yection
(Scale one inch $-2,000 \mathrm{ft}$.)

Lessor.

J. M. Jones

Lessee I. P. Jarrle A.J. I. Jones

Drilling Contractor

C. D. Darie

and located as follows:

ft. north; $330 \mathrm{ft}$ south; $\mathrm{m}$ corner of the $\mathbf{1 6 9 0}$. ft. west of the Quarter of the Q Quarter of Section ... 22 .., Township.12 Eoxth_... (North or South) Range 7 Bast (East or West), of the

Principal Meridian, Colee County, Illinois. Elevation above sea level is $\left\{\begin{array}{l}\text { Derrick Floor } \\ \text { Ground } 708\end{array}\right.$ Total depth of well is 1985 Date pernit to drill issued $\mathbf{1 - 2 - 4 6}$. Pernit No. 2 Permit issued to E. P. Jarrde A. J. Jonee Date drilling began 2-12-46 Date drilling completed 2-19-46 Kind of drilling tools used peter. Date plugging began P1Es bottan 12-27-46 Date plugging completed $11-29-48$

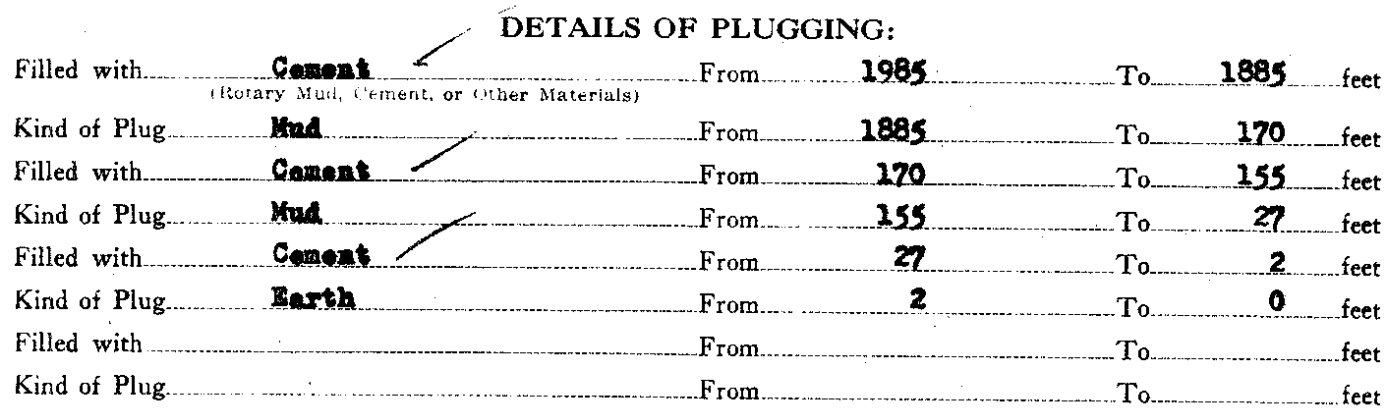

IF WORKABLE COAL BEDS WERE ENCOUNTERED IN THIS HOLE, DESCRIBE THE METHOD EMPLOYED TO PROTECT SAME. (A workable coal bed is thirty inches or more in-thickness above 1,000 feet in depth) Afriderit on baok

(1) Have pits, cellar and other excavations been filled?

(2) Have equipment, concrete bases and debris been removed?

(3) Has surface casing been cut off below plow depth?

Address Katteon, $\mathbf{1 1}$. Address 526 Mtandard BIds., Decatur, I11. Address Mattoon. TII.

(4) Has well-site been levelled?

$\begin{array}{cc}\text { Yes } & \text { No } \\ \mathbf{I} & \square \\ \text { Yes } & \text { No } \\ \mathbf{Z} & \square \\ \text { Yes } & \text { No } \\ \mathbf{Z} & \square \\ \text { Yes } & \text { No } \\ \mathbf{X} & \square\end{array}$

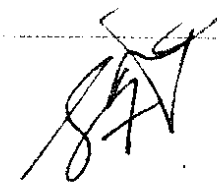

If this was a producing well, give date and amount of last production $1946-1 / 8 \mathrm{bbl}$. per dar

\section{CASING RECORD}

\begin{tabular}{l|c|c|} 
Sixe & \multicolumn{2}{c}{ PUT IN WELL } \\
Feet & Inches \\
\hline $8-3 / 4$ & 165 & \\
\hline 7 & 1928 & \\
\hline & & \\
\hline
\end{tabular}

PULLED OUT LEFT IN WELL.

\begin{tabular}{|c|c|c|c|c|}
\hline Feet & Inches & Feet & Inches & Remarks \\
\hline & & 165 & & \\
\hline 759 & & 1169 & & \\
\hline & & $\cdots$ & $\ldots$ & $\ldots \ldots$ \\
\hline
\end{tabular}

AGM CASING PULUING COMPANT

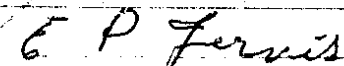

GRATILIA, ILLIWOIS

(Signatyre of person, firm or corporation having custody or control of weil.

Subscribed and sworn to before me this Per

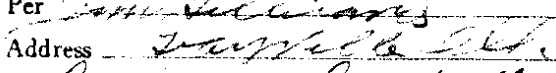
tamsece tondralle, quepectet

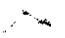

My commission expires

2-24-51

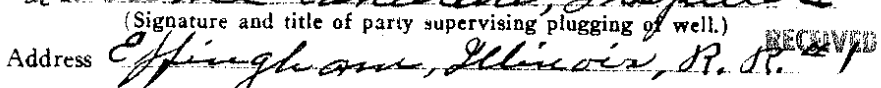

30 th Hotember 


\section{$10+1114$}

STATE OF ILLINOIS,

County of eles $\}$ ss.

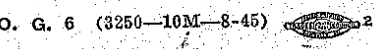

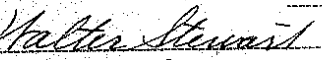

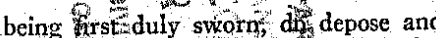
say the following is a true and correct statement of the details of the plugging of ${ }^{3}$ centall wellydrilled for Q2i

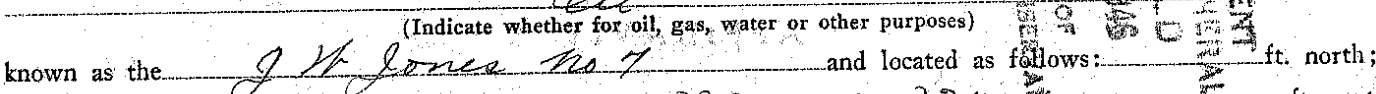

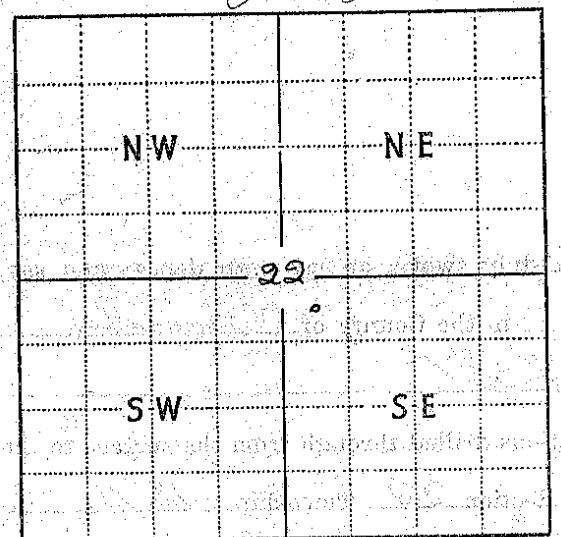

Locate well accurately on plat of section (Scale one inch-2,000 ft.) $330 \mathrm{ft}$ south; 330 ft. east ; west of the $\triangle \| K \quad$ corner of the $S E+$ Quarter of the Quarter of the Quarter of Section 22 , Township 22 (North of South) Range 4 , (East or West), of the 2 Principal Meridian, Coles County, Illinois. Elevation above sea level is $\left\{\begin{array}{l}\text { Derrick floor } 208 \mathrm{ft} . \\ \text { Ground }-20 \mathrm{ft}\end{array}\right.$ Total depth of well is $2003 \quad \mathrm{ft}$ Date permit to drill issued Thet $2 \&, 1946$

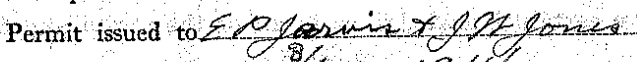
Date drilling began $8,1-1946$ Date drilling completed $3 / 6-\angle 9<6$ Kind of drilling tools used $p,-6 a n z$

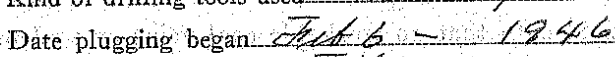
Date plugging completed $746 / 2<2<6$

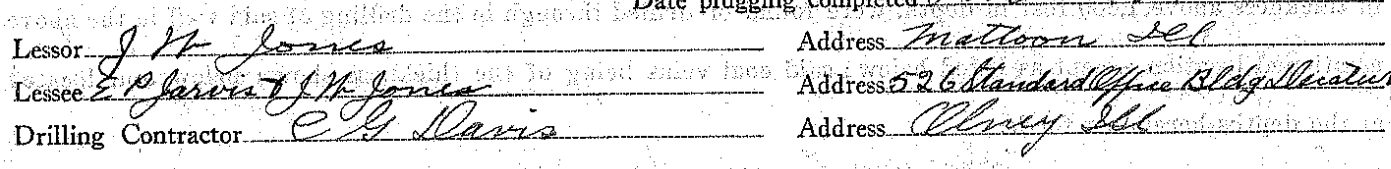

\section{DETAILS OF PLUGGING:}

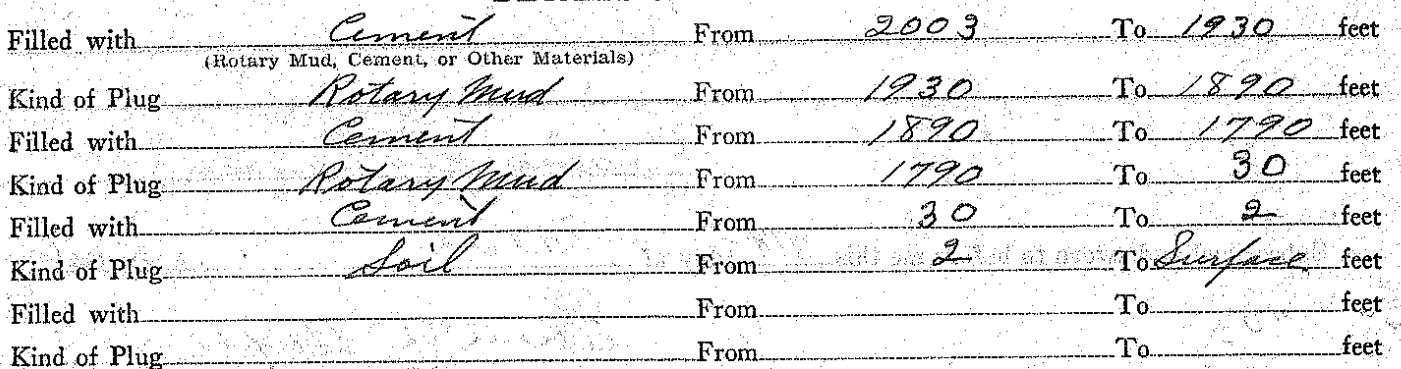

IF WORKABLE COAL BEDS WERE ENCOUNTERED IN THIS HOLE, DESCRIBE THE METHOD EMPLOYED TO PROTECT SAME. (A workable coal bed is thirty inches or more in thickness above 1,000 feet in depth zo edxe

Other details

If this was a producing well, give date and amount of last production.

CASING RECORD

\begin{tabular}{|c|c|c|c|c|c|c|c|}
\hline size & $\begin{array}{l}\text { PUT } \\
\text { Feet }\end{array}$ & $\begin{array}{l}\text { WELL } \\
\text { Inches }\end{array}$ & $\begin{array}{r}P 0 \\
\text { Feet }\end{array}$ & $\begin{array}{l}\text { OUT } \\
\text { Inches }\end{array}$ & $\begin{array}{l}\text { LEFT } \\
\text { Feet }\end{array}$ & $\begin{array}{l}\text { WELL } \\
\text { Inches }\end{array}$ & Remarks \\
\hline $10^{3} 4$ & 200 & 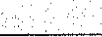 & 9 & & 188 & & 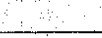 \\
\hline & & 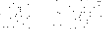 & & & & & \\
\hline & & $i$ & & & : & & \\
\hline$n$ & & & & & & & \\
\hline
\end{tabular}

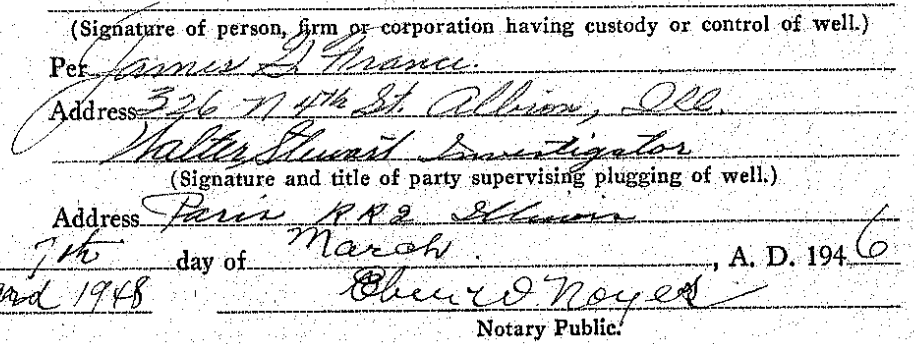


Form OG.6

MINSTON VADE do depose and say the following is a true and correct statement of the details of the plugging of a certain well drilled for OII OR GAS

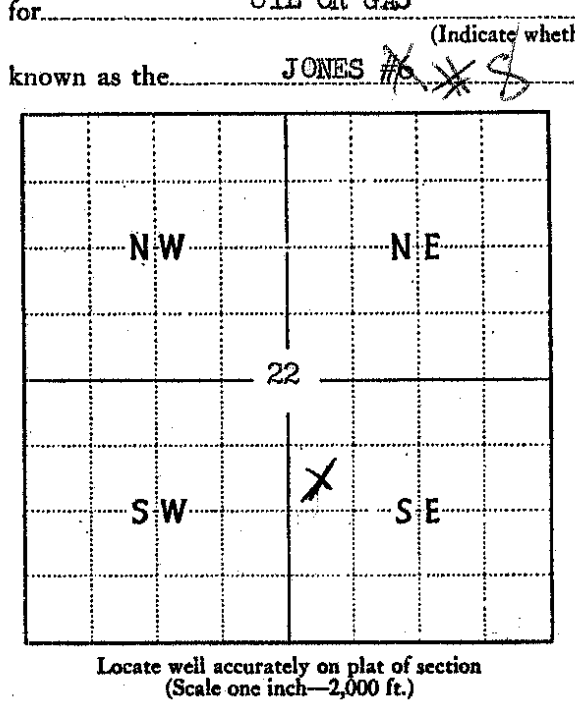

\section{for oil, gas, water or other purposes)}

and located as follows: 3

ft. north;

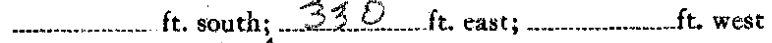
of the 514 corner of the Quarter of the $\mathrm{SE} \quad$ Quarter of the _.................... Quarter of Section........., Township 12 (North $\phi \downarrow \phi \phi \phi \phi \phi h)$

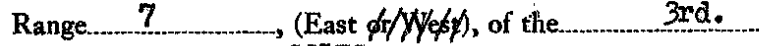
Principal Meridian, COLES County, Illinois.

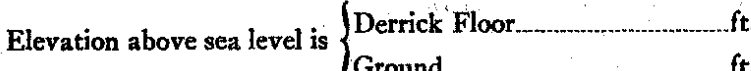
Total depth 1968 Formation Rogiclare Date permit to drill issued. $1-2-4 k$ Permit No

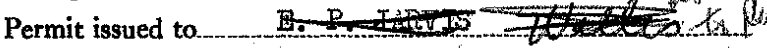
Date drilling began _........... 1946 Date drilling completed._.....1946 Kind of drilling tools used._._. ROTARY Date plugging began $\quad 7-23-54$

Date plugging completed... $7-23-54$

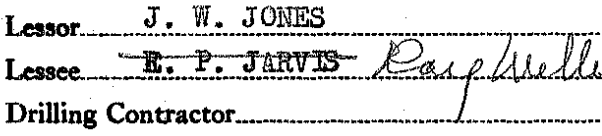
Address MIATTOOI, ILIINOIS Address DEC_._._._ER, TLEIHOTS

DETAILS OF PLUGGING:

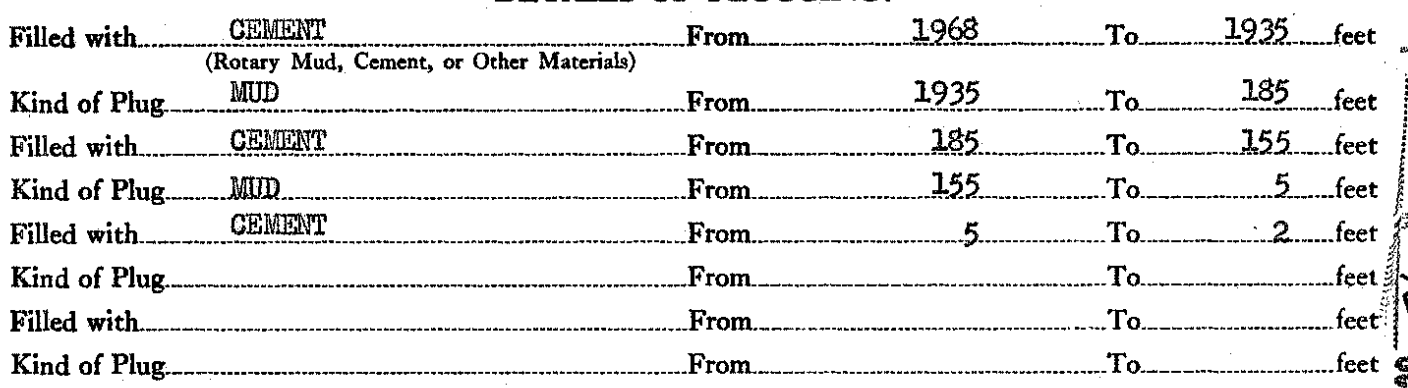

IF WORKABLE COAL BEDS WERE ENCOUNTERED IN THIS HOLE, DESCRIBE THE METHOD EMPLOYED TO PROTECT SAME. (A workable coal bed is thirty inches or more in thickness above 1,000 feet in depth) NO COAI

(1) Have pits and other excavations been filled?.............

(2) Have the following been removed?

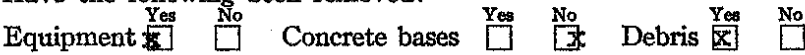

(3) Has surface casing been cut off three feet below ground surface?

(4) Has well-site been levelled?.

If this was a producing well, give date and amount of last production.

CASING RECORD

\begin{tabular}{|c|c|c|c|c|c|c|c|}
\hline \multirow[b]{3}{*}{ Size } & \multirow{2}{*}{\multicolumn{2}{|c|}{ PUT IN WELL. }} & \multicolumn{5}{|c|}{ CASING RECORD } \\
\hline & & & PUI & OUT & LEI & WELL. & \\
\hline & Feet & Inches & Feet & Inches & Feet & Inches & Remarks \\
\hline $103 / 4$ & 168 & & & & 168 & & \\
\hline 7 & 1965 & & 427 & & 1538 & & \\
\hline & & & & & & & \\
\hline & & & & & & & \\
\hline
\end{tabular}

Ray Nilize

(Sigzatyre of person, firm or corporation having custody/gr control of well.)

Per $>0202-20$

Address 1 MP. CARMTL, ILLINOIS

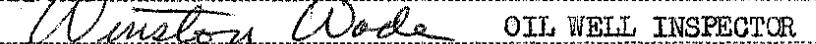

(Signature and title of party supervising plugging of well.)

Address. PARIS, ILIINOIS

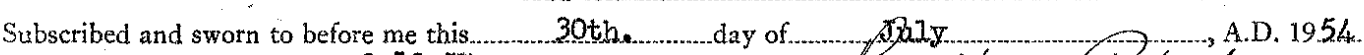

My commission expires $3-10-57$. 
$\left.\begin{array}{l}\text { Srate of illinols, } \\ \text { county of colea }\end{array}\right\}$ ss. 319 WELL PLUGGING AFFIDAYIT Heler Slewir If Casder say the following is a true and correct statement of the details of the plugging of aty certain welped dyolled for say the following is a true and correct statement of the

$\Varangle 40$ (Indicate whether for oil, gas, water or other purposes) 350 known as the 24 and located as follows: 3906 foft. north;

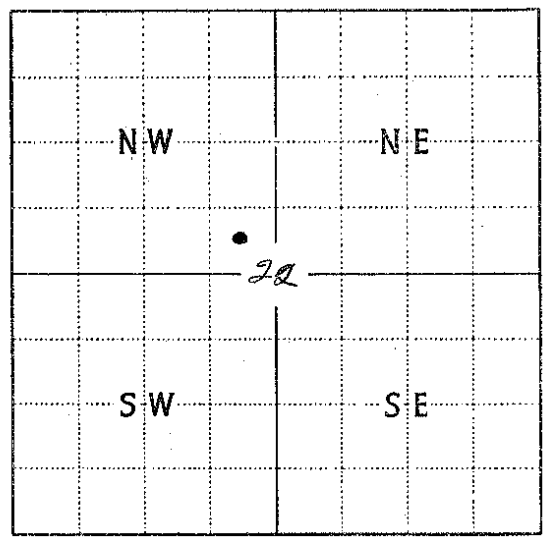

Locate well accurately on plat of section (Scale one inch-2,000 ft.) ft. south

of the $S E$

of the Quarter of the $\quad$ Quarter of

$\mathrm{ft}$ east ; $330 \quad \mathrm{ft}$. Range $Z$, (East or West), of the 3

Principal Meridian, Seles County, Illinois. Elevation above sea level is $\left\{\begin{array}{l}\text { Derrick Floor } 7 / 6 \\ \text { Pro...ft. }\end{array}\right.$ Ground 7 .

Total depth of well is $2 / 16$ Date permit to drill issued. Zat $28-7>\leq 5$

Permit issued to e encureal $2 i$

Date drilling begun 2 ee $3-<845$

Date driling completed 10

Date drilling completed $242<0-1943-$

Kind of drilling tools used Aozery Date plugging begun $\alpha f<<<1-1 \leq b$ Date plugging completed $\alpha 2 C, 2 \cdots 1943$
Lessor $\&$ Pedell

Lessee Lencerat CLL

Drilling Contractor Meculech Lleg eo

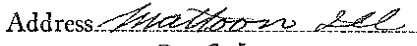

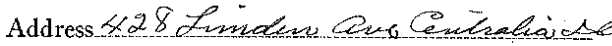
Address Tyes Texas

\section{DETAILS OF PLUGGING:}

Filled with

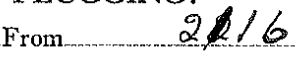

Kind of Plug (Rotary Mud, Cement, or Other Materials)

From $\quad 2056$
To $176 \quad$ feet

Filled with Cenuxt From 176 To 126 feet

Kind of Plug Polary bued

Filled with

Kind of Plug Lail. From 126 To 27 feet

Filled with From 27 To 2 feet

Kind of Plug From 2 To-fezface feet From. To. To feet

IF WORKABLE COAL BEDS WERE ENCOUNTERED IN THIS HOLE, DESCRIBE THE METHOD EMPLOYED TO PROTECT SAME. (A workable coal bed is thirty inches or more in thickness above 1,000 feet in depth and three feet or more in thickness below 1,000 feet in depth.) nos ohowivg of coel

Other details

If this was a producing well, give date and amount of last production

CASING REGORD

\begin{tabular}{l}
$\begin{array}{l}\text { PUT IN WELL } \\
\text { Size }\end{array}$ \\
\hline 898 \\
\hline 8
\end{tabular}

(Signature of person, firm or corporation having custody or control of well.) Per OL OO Lace

Address 7 hene

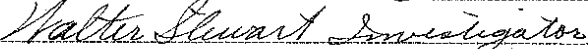
(Signature and title of party supervising plugging of well.)

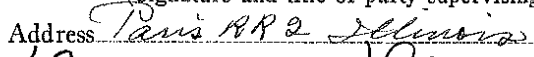

Subscribed and sworn to before me this day of My commision expires $100.30-1947$ 

do depose and say the following is a true and correct statement of the details of the plugging of a certain well drilled for

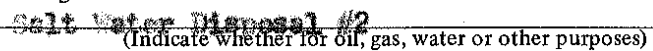

known as the

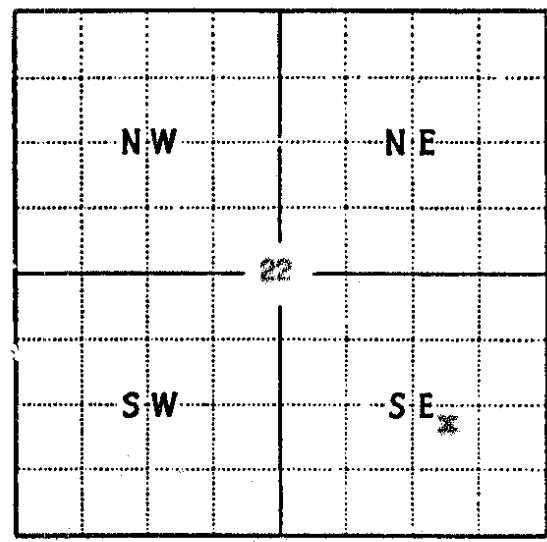

Locate well accurately on plat of section (Scale one inch-2,000 ft.)

and located as follows:

ft. north;

$330 \mathrm{ft}$. south; ft. east; $330 \mathrm{ft}$. west

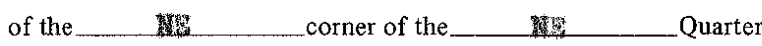
of the__ Quarter of the SE_ Q Q

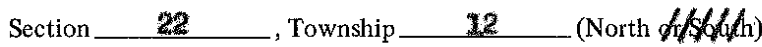
Range 7 , (East $(16 / 66)$, of the $3 x$ Principal Meridian, Cots 5 County, Illinois. Elevation above sea level is $\begin{cases}\text { Derrick Floor } & \\ \text { Ground ft. }\end{cases}$

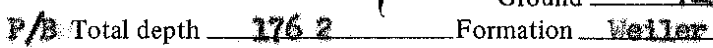

Date permit to drill issued $9 / 10 / 4$ Permit No. 54

Permit issued to

Date drilling began ___ $\quad 9-12-7 \mathbf{L}_{4}\left(\mathrm{~s}_{t}\right)$

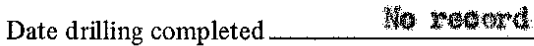

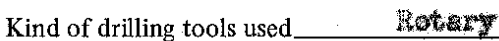

Date plugging began __ $-2-25$

Date plugging completed _ _ $3-17$

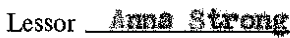

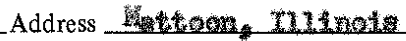

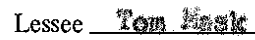

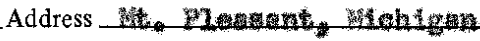

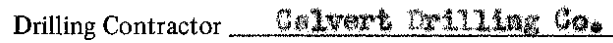
Address

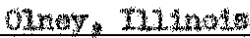

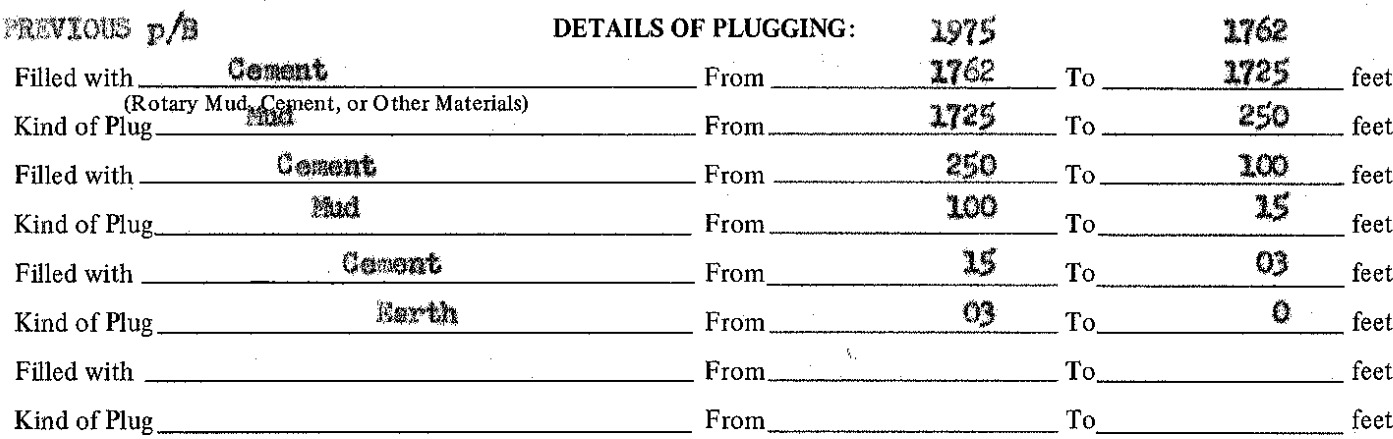

IF WORKABLE COAL BEDS WERE ENCOUNTERED IN THIS HOLE, DESCRIBE THE METHOD EMPLOYED TO PROTECT SAME. (A workable coal bed is thirty inches or more in thickness above 1,000 feet in depth) Wusta

(1) Have pits and other excavations been filled?

(2) Have the following been removed?

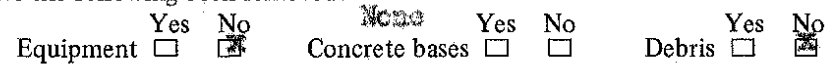

(3) Has surface casing been cut off three feet below ground surface?

(4) Has well-site been leveled? .

If this was a producing well, give date and amount of last production

Unimaxa

$\begin{array}{ll}\text { Yes } & \text { No } \\ \text { Yes } & \square \\ \square & \text { No }\end{array}$

\section{CASING RECORD}

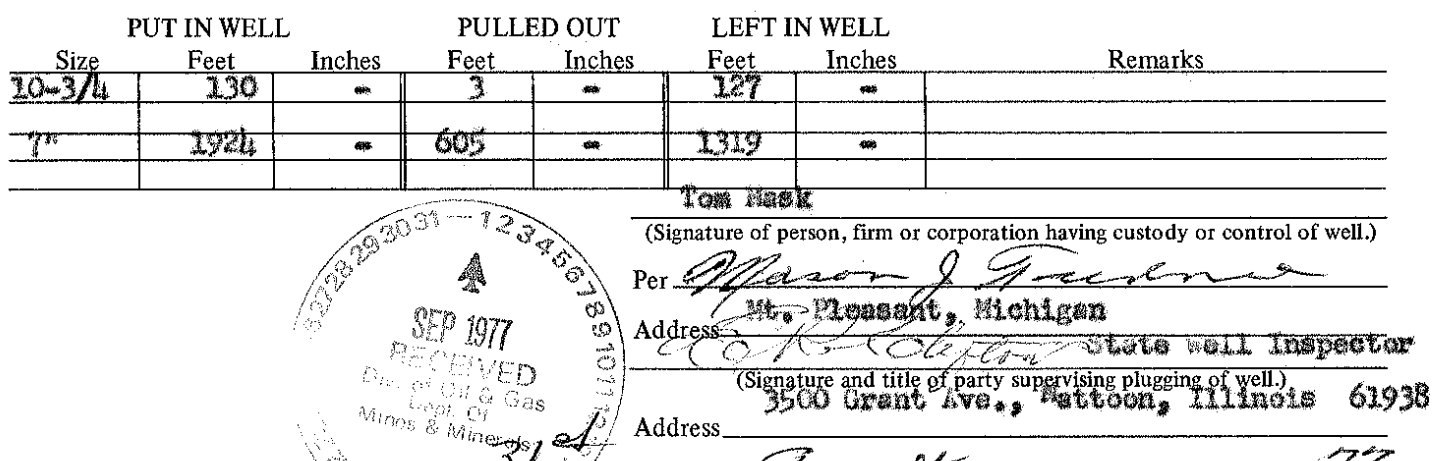

Subscribed and sworn to before me this j/

$8 / 20 / 580^{2}$, day of

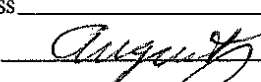

My commission expires $5 / 20 / 8 / 20^{\circ}$ 


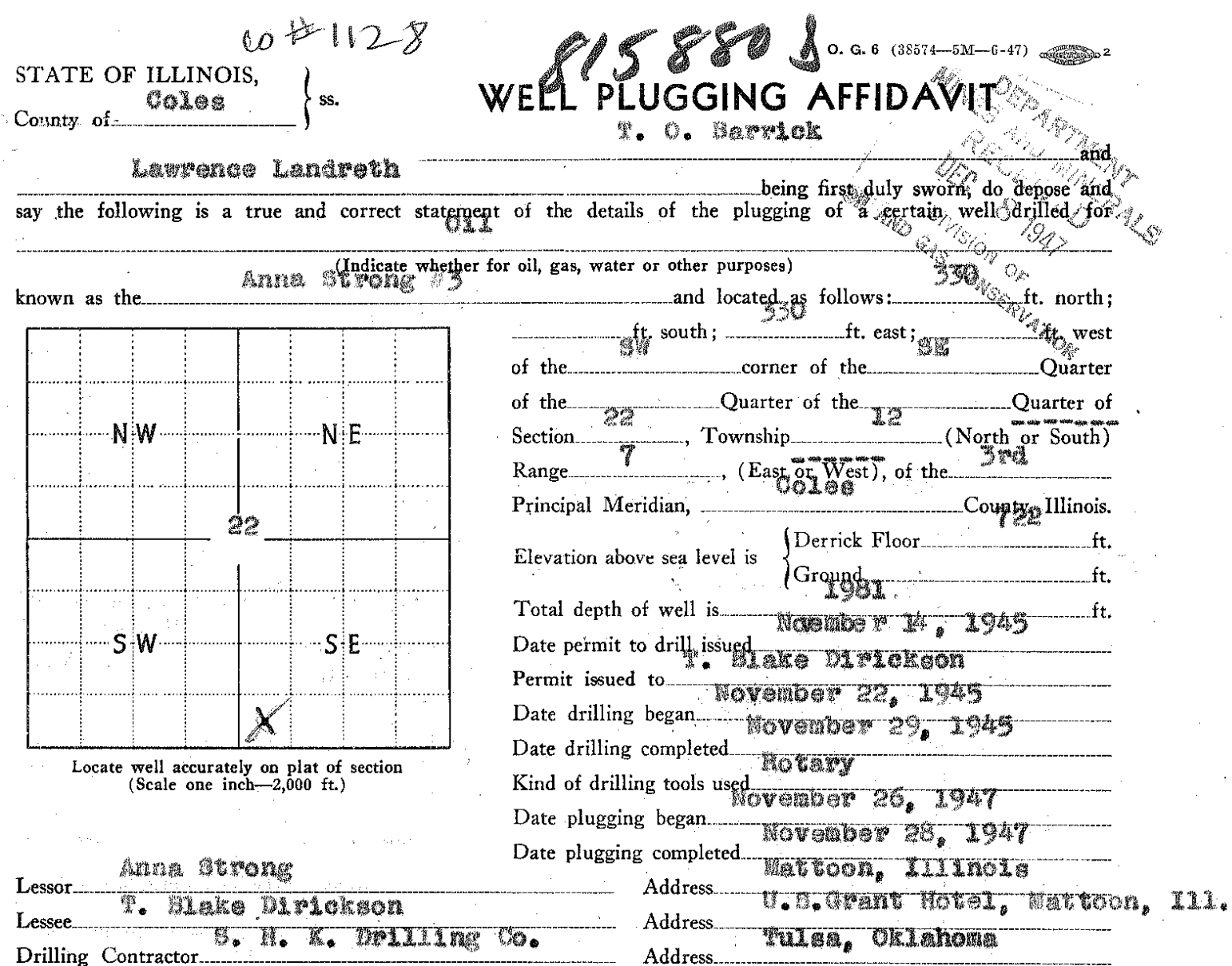

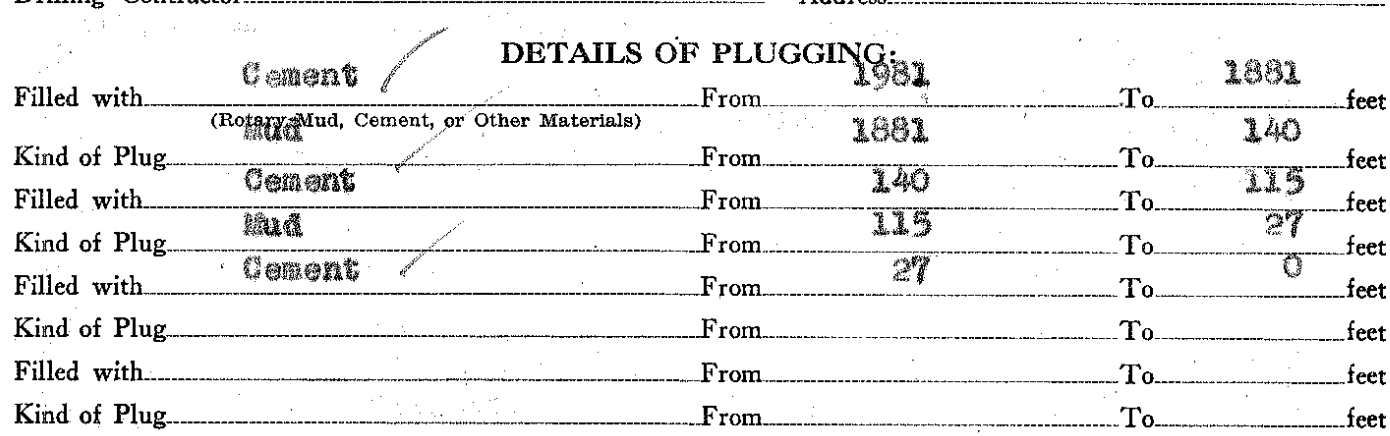

IF WORKABLE COAL BEDS WERE ENCOUNTERED IN THIS HOLE, DESCRIBE THE METHOD EMPLOYED TO PROTECT SAME. (A workable coal bed is thirty inches or more in thickness above 1,000 feet in depth)

(1) Have pits, cellar and other excavations been filled?..

(2) Have equipment, concrete bases and debris been removed?

(3) Has surface casing been cut off below plow depth?

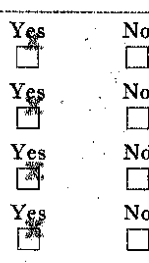

(4) Has well-site been levelled?

If this was a producing well, give date and amount of last production.

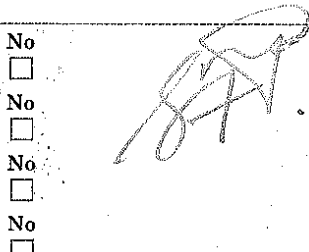

口.

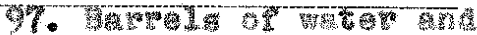

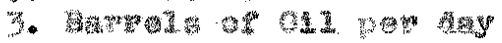

\section{CASING RECORD}

\begin{tabular}{c|c|c|c|c|} 
Size & \multicolumn{2}{c}{ PUT IN WELL } & \multicolumn{1}{c}{ PULLE } \\
\hline Feet
\end{tabular}

OUT : LEFT IN WELL

My commission expiresefelmenasy 24, 15

(Signature of person, firm or corporation having custody or control of well.)

Per

Address

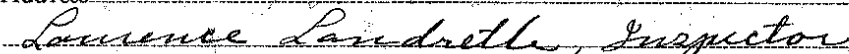
(Signature and title of party supervising plugging of well.)

Address $\varepsilon^{\prime} / \operatorname{los}^{\prime}$

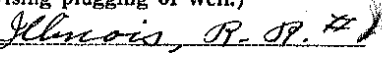

Subscribed and sworn to before me this. Le day of A. D. 194.7

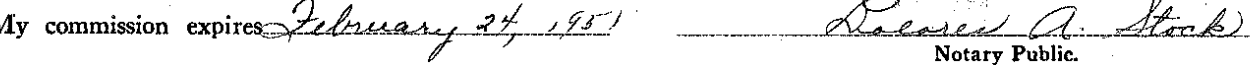


County of

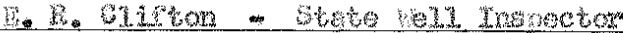

being first duly sworn, do depose and say the following is a true and correct statement of the details of the plugging of a certain well drilled for

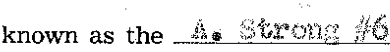

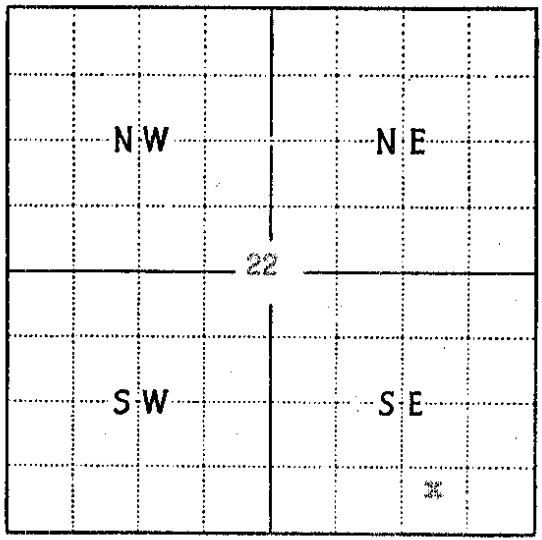

Locate well accurately on plat of section (Scale one inch-2,000 ft.)
(Indicate whether for oil, gas, water or other purposes) and located as follows: 330 ft. south; 330 ft. east;____ ft. west of the_corner of the w of the Q Quarter of the__ S

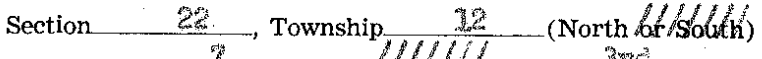
Range (East or $/$ West), of the $3 x^{2} e^{3}$

Principal Meridian,__ Coles County, Illinois. Elevation above sea level is $\left\{\begin{array}{l}\text { Derrick Floor } 7 \mathrm{mt} \\ \text { Ground } \mathrm{ft}\end{array}\right.$

* Total depth 1860 Formation $10010 \%$

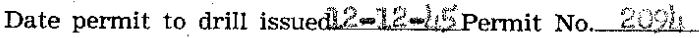

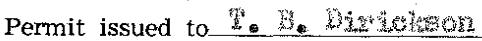

Date drilling began

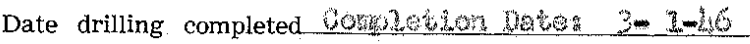
Kind of drilling tools used Xetsery Date plugging began__ $\quad 20-13$

Date plugging completed. $\quad 10-28+73$

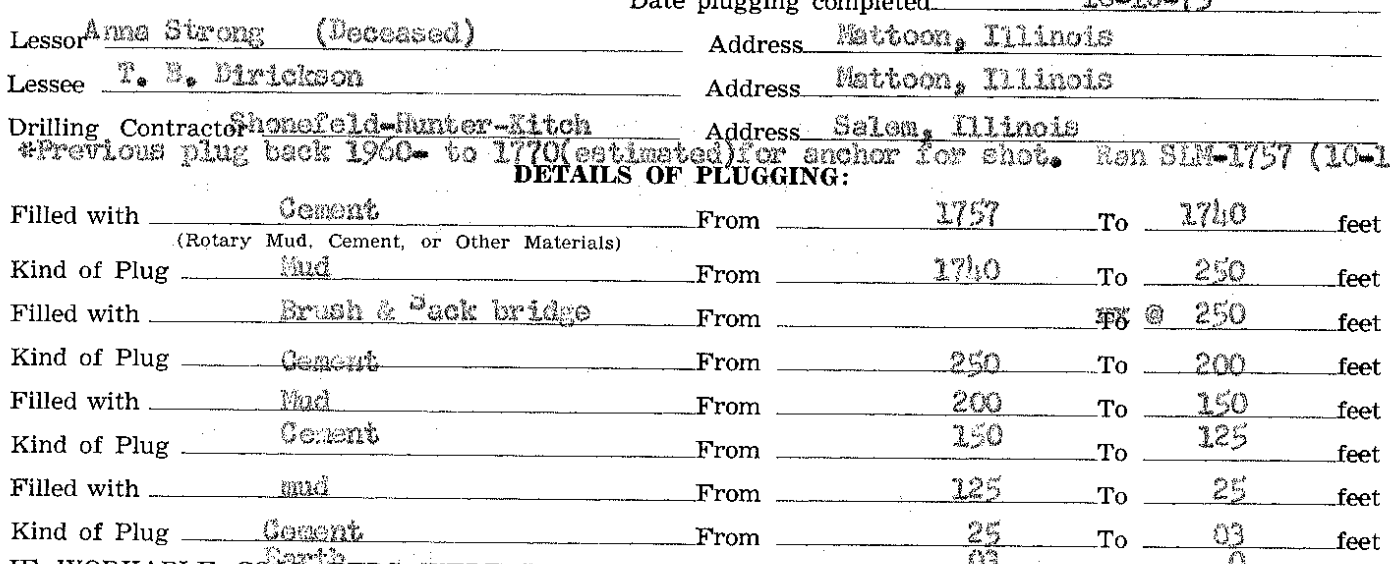
IF WORKABLE COAE BEDS WERE ENCOUNTERED IN THIS HOLE, TESCRIBE THE METHOD EM PLOYED TO PROTECT SAME. (A workable coal bed is thirty inches or more in thickness above 1,000 feet in depth)

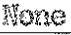

(1) Have pits and other excavations been filled?................ Yes $\square^{\text {No }}$

(2) Have the following been removed?

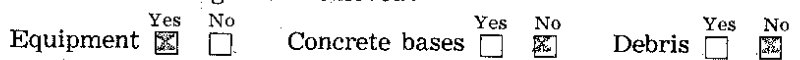

(3) Has surface casing been cut off three feet below ground surface?

(4) Has well-site been levelled?

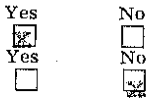

If this was a producing well, give date and amount of last production Lumagras

\section{CASING RECORD}

\begin{tabular}{|c|c|c|c|c|c|c|c|}
\hline Size & $\begin{array}{c}\text { PUT IN } \\
\text { Feet }\end{array}$ & $\begin{array}{l}\text { WELL } \\
\text { Inches }\end{array}$ & $\begin{array}{l}\text { PULLED } \\
\text { Feet }\end{array}$ & $\begin{array}{l}\text { OUT } \\
\text { Inches }\end{array}$ & $\begin{array}{c}\text { LEFT } \\
\text { Feet }\end{array}$ & $\begin{array}{l}\text { WELL } \\
\text { Inches }\end{array}$ & Remarks \\
\hline $10 \ln 3 / m^{2}$ & 110 & - & 3 & - & 43 & - & $\operatorname{lop}^{\circ}$ and pro \\
\hline ?" & 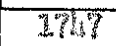 & - & 62 & $\infty$ & 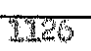 & - & \\
\hline & & & & & & & \\
\hline
\end{tabular}

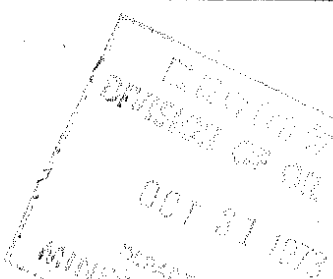

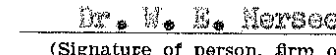

(Signature of person, firm or copporation having custody or control of well.) Per Tonuts 6 Downen

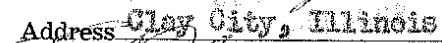

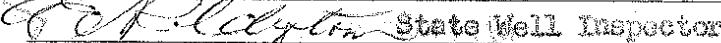

(Signature and title of party supervising plugging of well.

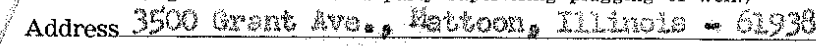

Subscribed and sworn to before me this 2 r day of Dewpow

My commission expires $10 / 28 / 76$

1973 
筷

being first duly sworn, do depose and say the following is a true and correct statement of the details of the plugging of a certain well drilled for ois

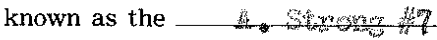

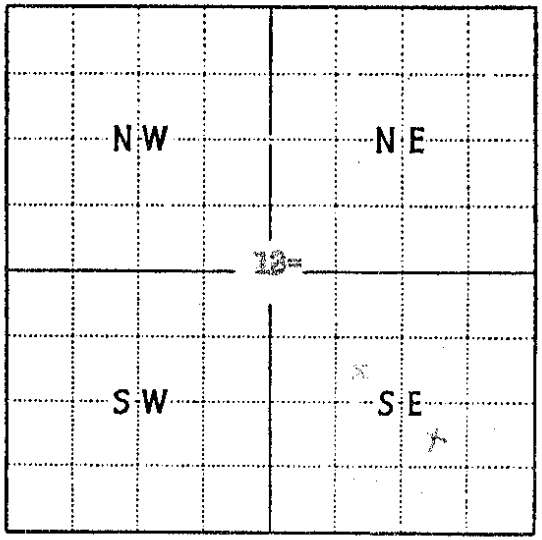

Locate well accurately on plat of section (Scale one inch $-2,000 \mathrm{ft}$.)

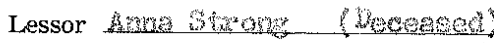
(Indicate whether for oil, gas, water or other purposes) and located as follows: ft. north; $3 \mathrm{st}$ ft. south; $\quad 390$ ft. east;___ : ft. west of the corner of the Q of the__ Q Q

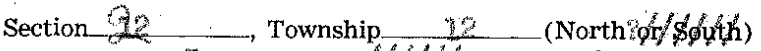

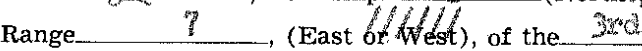

Principal Meridian, $60 \mathrm{leg}$ County, nllinois. Elevation above sea level is $\left\{\begin{array}{l}\text { Derrick Floor } 72 \quad \mathrm{ft} \\ \text { Ground } \quad \mathrm{ft}\end{array}\right.$

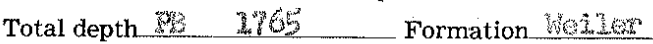

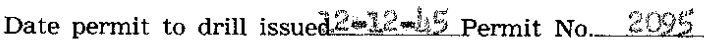

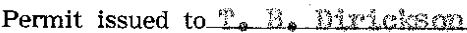

Date drilling began Date drilling completed Cortold

Kind of drilling tools used pudery Date plugging began $\quad 20-1643$

Date plugging completed_ $\quad 10-17-6$

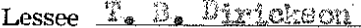

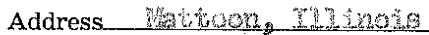

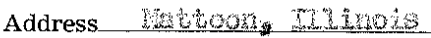

Drilling Contractor Soblown

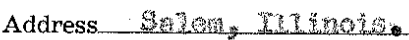

Details of PLUgGing:

Filled with __ cetions (Rotary Mud Cement or Other Materials)

From

Kind of Plug _..._.

From 376

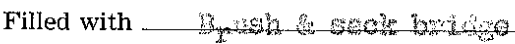

From

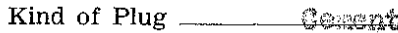

From

Filled with

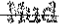

From

Kind of Plug

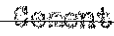

Filled with suc

From

From

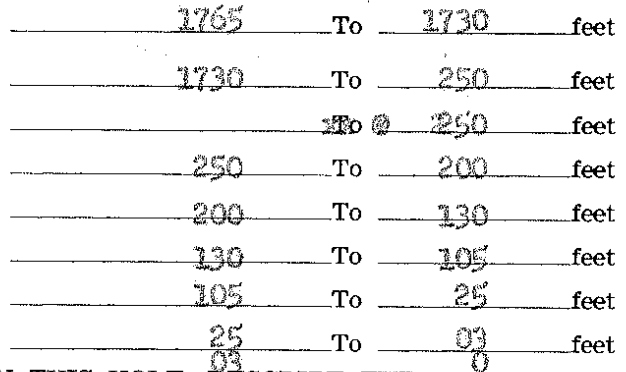

IF WORKABLE COAL PLOYED TO PROTECT SAME. (A workable coal bed is thirty inches or more in thickness above 1,000 feet in depth)

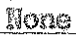

(1) Have pits and other excavations been filled?.

(2) Have the following been removed?
Equipment $\begin{array}{r}\text { Yes } \\ \text { No }\end{array}$
Concrete bases $\stackrel{\text { Yes }}{\square}$
Debris $\stackrel{\text { Yes }}{\square}$ No

(3) Has surface casing been cut off three feet below ground surface?

(4) Has well-site been levelled?

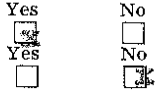

If this was a producing well, give date and amount of last production

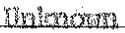

\section{CASING RECORD}

\begin{tabular}{|c|c|c|c|c|c|c|c|}
\hline Size & $\begin{array}{c}\text { PUT IN } \\
\text { Feet }\end{array}$ & $\begin{array}{l}\text { WELL } \\
\text { Inches }\end{array}$ & $\begin{array}{l}\text { PULALED } \\
\text { Feet }\end{array}$ & $\begin{array}{l}\text { OUT } \\
\text { Inches }\end{array}$ & $\begin{array}{c}\text { LEFT } \\
\text { Feet }\end{array}$ & $\begin{array}{l}N \text { WELL } \\
\text { Inches } \\
\end{array}$ & Remarks \\
\hline $10^{3}+4$ & 120 & $=$ & 3 & - & $2 \times$ & - & 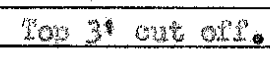 \\
\hline 78 & 2850 & - & 310 & $\infty$ & 432 & & \\
\hline & & & & & & & \\
\hline
\end{tabular}

We.

(Signature of peyson, frm or coyporation having custody or control of well.)

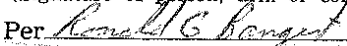

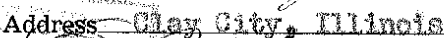

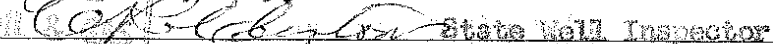
(Signature and tifle of party supervising plugging of well.)

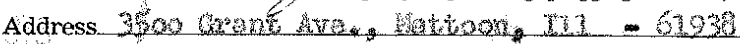

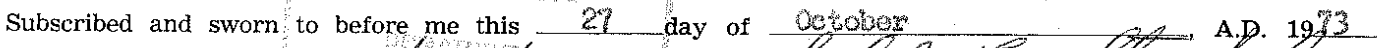
My commission expires $10 / 28 / \% 6$

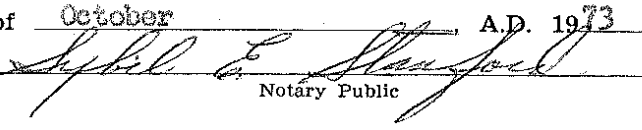


STATE OF ILLINOIS,

County of Coles $\}$ ss.
8158908 WELL PLUGGING AFFIDAVIT

Lavrence Landreth

\author{
T. O. Barrick
} Lawrence Landeeth
say the following is a true and correct statement of the details of the plugging of a certain well drilled and 011

(Indicate whether for oil, gas, water or other purposes)

known as the Anne Strong

and located as follows:

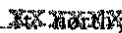

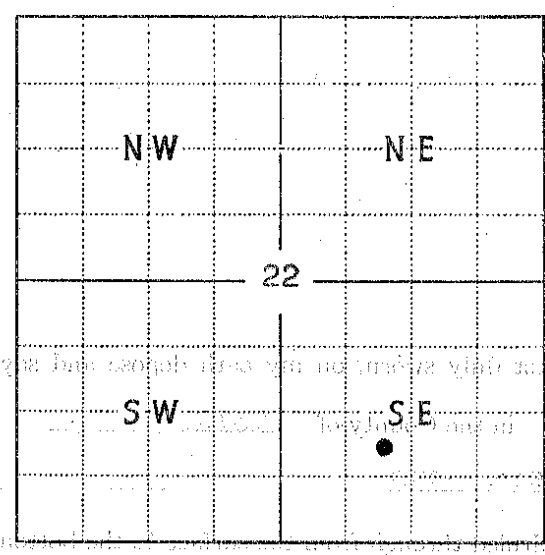

Locate well accurately on plat of section (Scile one inch-2,000 ft.)
330 ft. south;

Hext 330 fr. west of the $M E$ corner of the SW Quarter of the $\quad 3 \mathrm{SP} \quad$ Quarter of the $\quad$ Quarter of Section 22 , Township. 12 (North oxxoritu) Range $?$, (Eastrox Wuest), of the $3 d$

Principal Meridian, Coleg County, Hlinois Elevation above sea level is $\left\{\begin{array}{lcc}\text { Derrick Floor } & 713 & \mathrm{ft} \\ \text { Ground } & 719 & \mathrm{ft}\end{array}\right.$ Total depth of well is 1962 Date permit to drill issued $12-12-1945$

Permit issued to d, Blake Dirickson

Date drilling began 12-31-1945

Date drilling completed $1-10-2946$

Kind of drilling tools used Hotary

Date plugging began $12-5-1946$

Date plugging completed $12-5-1946$

\section{Lessor Anna Strong \\ Lessee T. Blake Dirlokrson \\ Drilling Contractor Schoenfeld Itunter KItch}

DETAILS OF PLUGGING:

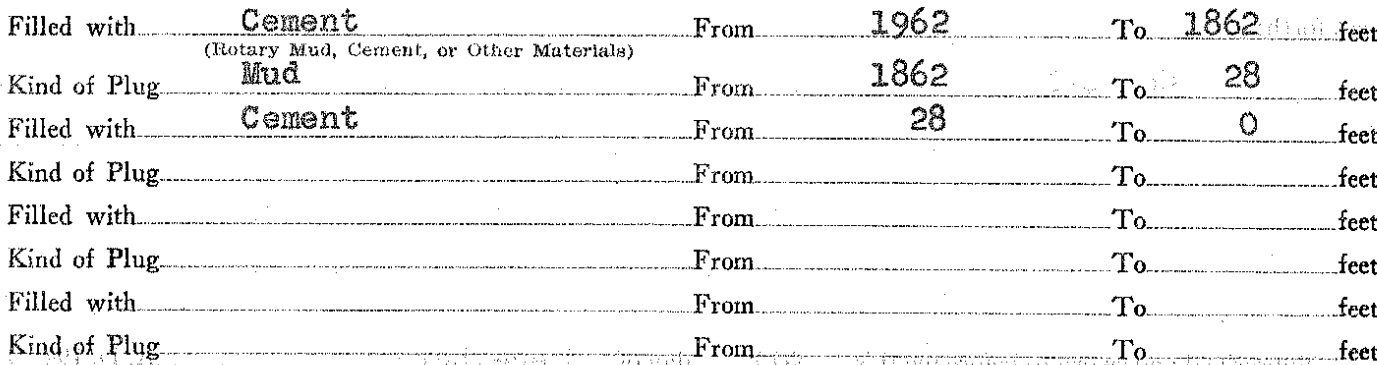

IF WORKABLE COAL BEDS WERE ENCOUNTERED IN THIS HOLE, DESCIRIBL THE METHOD EMPLOYED TO PROTECT SAME. (A workable coal bed is thirty inches or more in thickness above 1,000 feet in depth)
(1) Have pirs, cellar and other excavations been filled?

$\begin{array}{ll}\text { Yes } & \text { No } \\ \text { Yes } & \square \\ \text { Ne } & \text { No } \\ \text { Yes } & \text { No } \\ \mathbb{Z}] & \square \\ \text { Yes } & \text { No } \\ \square & \square\end{array}$
(2) Have equipment, concrete bases and debris been removed?
(3) Has surface casing been cut off below plow depth?....
(4) Has well-site been levelled?

No
$\square$
No
$\square]$
No
$\square$
No
$\square$

If this was a producing well, give date and amount of last production $9=10-1946 \quad 3 \quad b b 15.011$

\title{
GASING RECORD DYY
}

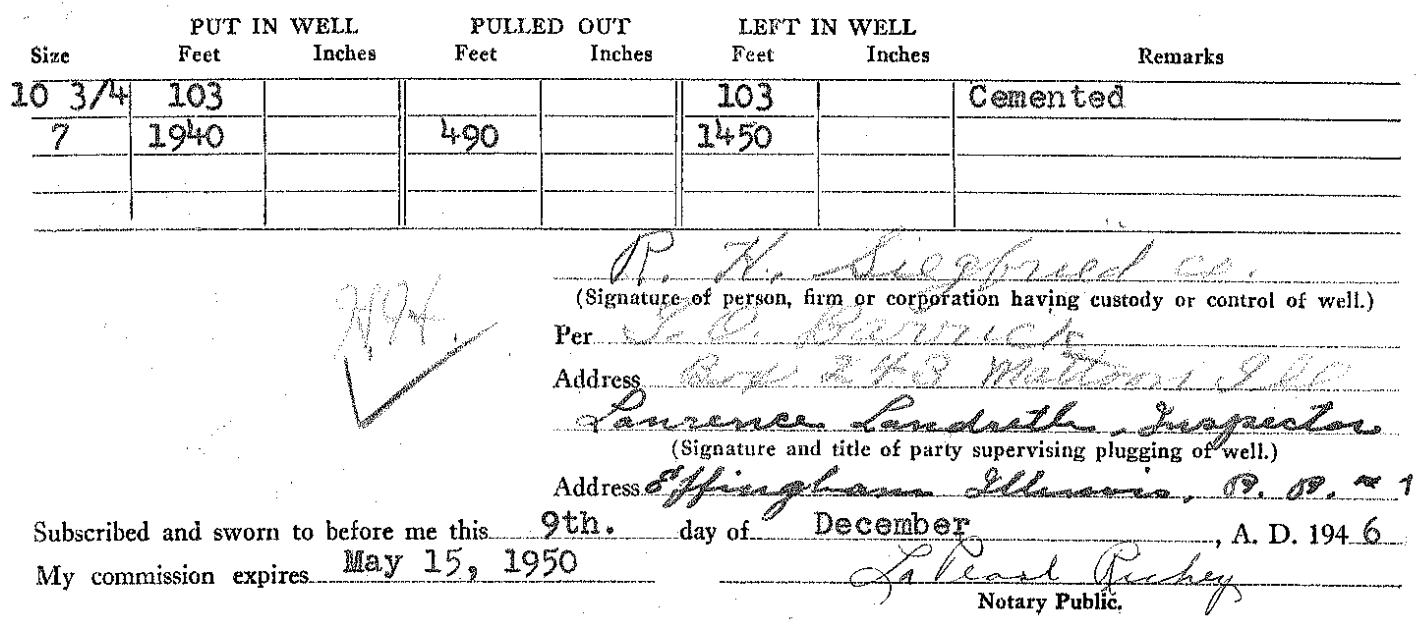


SFATE OF ILLINOIS

County of......coles. \} ss

Haldon Moore for. Oi1

known as the Anna strong 3 ndicate whether for oil, gas, water or other purposes)

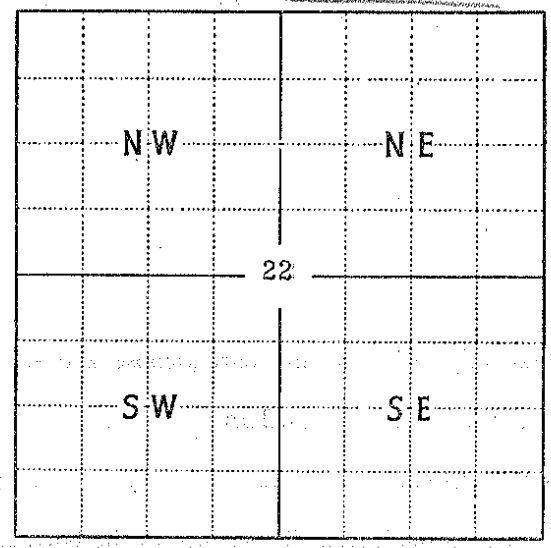

Locate well accurately on plat of section (Scule one inch-2,000 fr.)

and located as follows: ft. north; ............ south; $\quad 330 \quad$ ft. east; ft. west

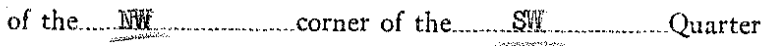

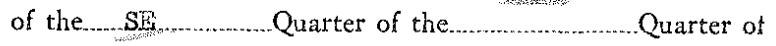

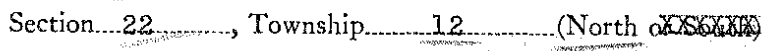
Range 7 . (East 1 , 3 Principal Meridian, Coles County, Illinois. Elevation above sea level is $\left\{\begin{array}{l}\text { Derrick Floor } 717 \ldots \mathrm{ft} . \\ \text { Ground }\end{array}\right.$

Total depth of well is 1981 f

Date permit to drill issued $11-31-46$... Permit No. 141

Permit issued to 1 - Btake Date drilling began $\quad 12-28-46,3 / 2$
Date drilling completed $\quad 2-2-47$

Kind of drilling tools used Rotary

Date plugging began $\quad 6-5-51$

Date plugging completed $6=7-51$

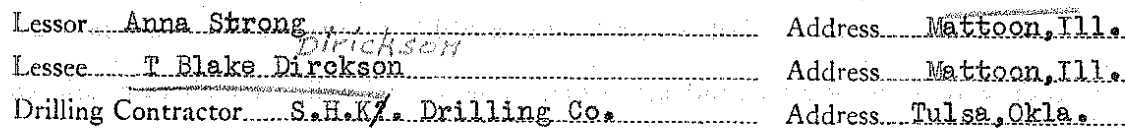

DETAILS OF PLUGGING:

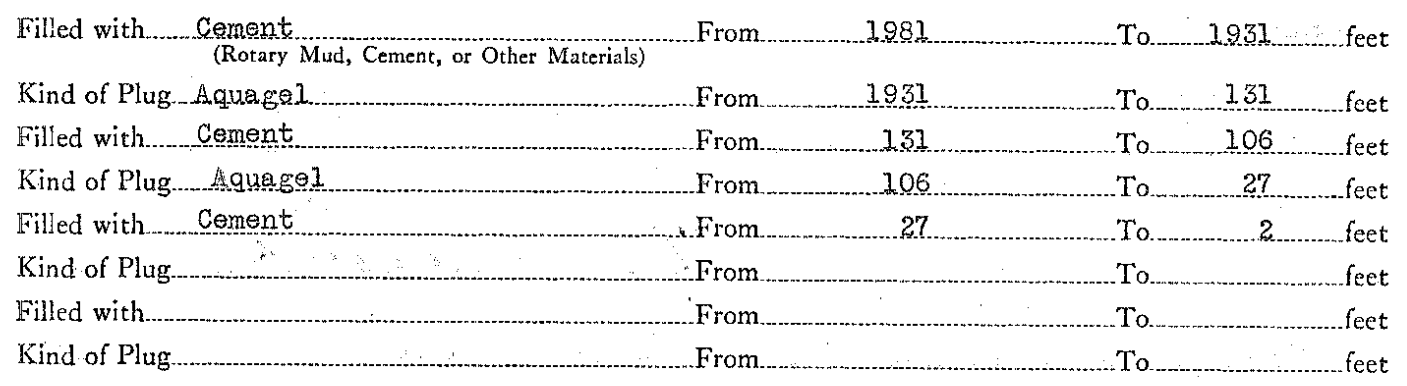

IF WORKABLE COAL BEDS WERE ENCOUNTERED IN THIS HOLE, DESCRIBE THE METHOD EMPLOYED TO PROTECT SAME. (A workable coal bed is thirty inches or more in thickness above 1,000 feet in depth) .......... No col encountered
(1) Have pits, cellar and other excavations been filled?.....
(2) Have equipment, concrete bases and debris been removed?
(3) Has surface casing been cut off below plow depth?.....

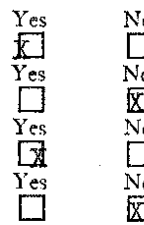
(4) Has well-site been levelled?..................

If this was a producing well, give date and amount of last production $\frac{1}{\mathrm{~b}} \mathrm{~b} \mathrm{l}$ per day

\section{CASING RECORD}

\begin{tabular}{|c|c|c|c|c|c|c|c|}
\hline \multirow{2}{*}{ Size } & \multicolumn{2}{|c|}{ PUT IN WELL } & \multicolumn{2}{|c|}{ PULLED OUT } & \multicolumn{2}{|c|}{ LEFT IN WELL } & \multirow[b]{2}{*}{ Remarks } \\
\hline & Feet & Inches & Feet & Inches & Feet & Inches & \\
\hline $103 / 4$ & 121 & & 0 & & 121 & & \\
\hline 7 & 1957 & & 847 & & 1110 & & \\
\hline & & & & & & & \\
\hline & & & & & & & \\
\hline
\end{tabular}

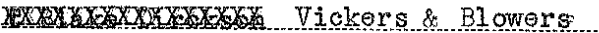
(Signature of person, firm or corpozation having custody or control of well.) Per $62+2$

Address . Nattoon, III

Maldon morel oil well Inspeator

(Signature and titie of party supervising plugging of well.)

Address Howeaqua, Ill.

Subscribed and sworn to before me this............

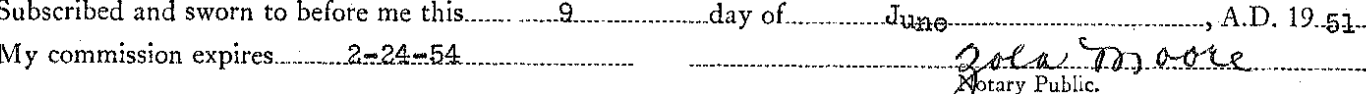


STATE OF ILLINOIS

County of WELL PLUGGING AFFIDAVIT

being first duly sworn do depose and say the following is a true and correct statement of the details of the plugging of a certain well drilled for. wis

(Indlcate whether for oll, gas, water or other purposes)

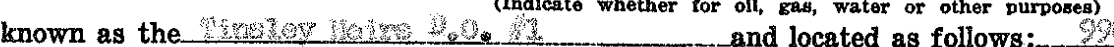

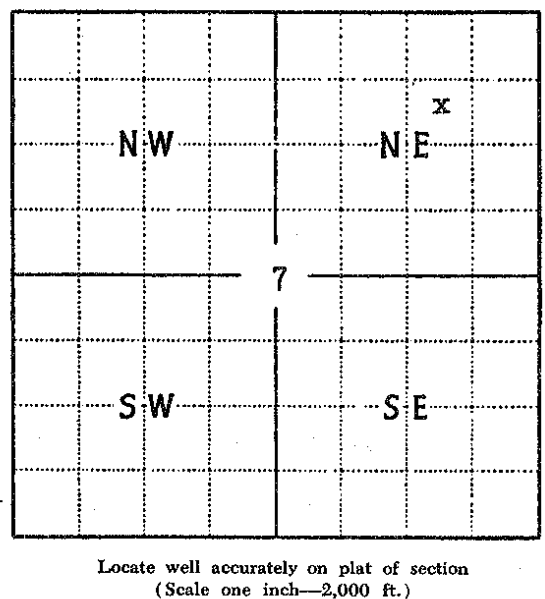

ft. south;

ft. east; - 1 wh

ft. north:

of the corner of the reserer of the Quarter of the Quarter of Section 2 , Township 12 (North /or sónth) Range (East or West), of the 3 ,

Principal Meridian, holes County, minois.

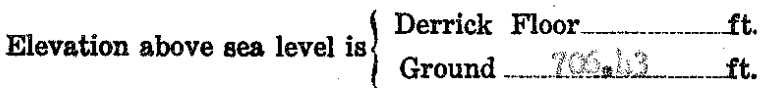

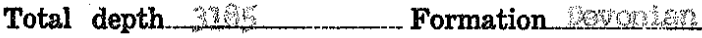

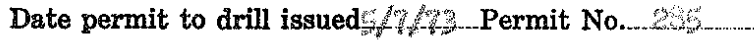

Permit issued to

Date drilling began _._._.

Date drilling completed o

Kind of drilling tools used. inters

Date plugging began ___._.

Date plugging completed

Lessor A b n

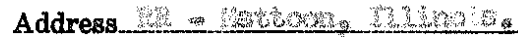

Lessee - L wora

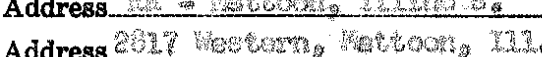

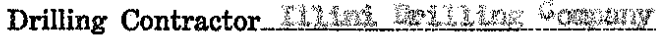

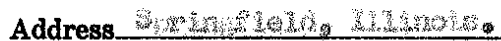
DETAILS OF PLUGGING:

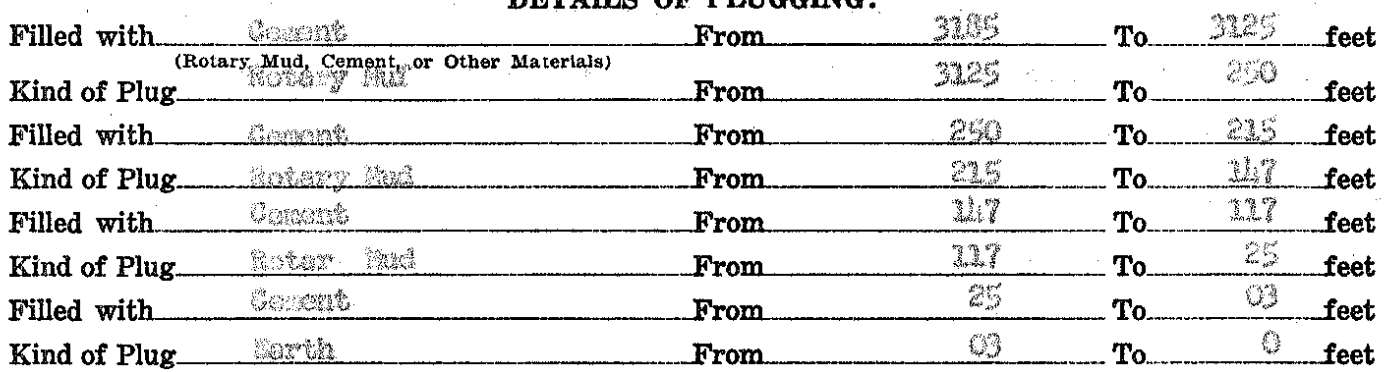

IF WORKABLE COAL BEDS WERE ENCOUNTERED IN THIS HOLE, DESCRIBE THE METHOD EMPLOYED TO PROTECT SAME. (A workable coal bed is thirty inches or more in thickness above

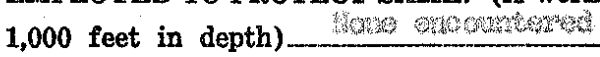

(1) Have pits and other excavations been filled?

(2) Have the following been removed?

Equipment $\stackrel{\text { Yes }}{\square} \square^{\text {No }}$ Concrete bases $\stackrel{\text { Yes }}{\square} \square^{\text {No }}$ Debris $\stackrel{\text { Yes }}{\square}$ o.

(3) Has surface casing been cut off three feet below ground surface?

(4) Has well-site been levelled?.

If this was a producing well, give date and amount of last production ar a

\section{CASING RECORD}

\begin{tabular}{|c|c|c|c|c|c|c|c|}
\hline \multirow[b]{2}{*}{ Size } & \multicolumn{2}{|c|}{ PUT IN WELL } & \multicolumn{2}{|c|}{ PULLED OUT } & \multicolumn{2}{|c|}{ LEF" IN WELAt } & \multirow[b]{2}{*}{ Remarks } \\
\hline & Feet & Inches & Feet & Inehes & Feet & Inches & \\
\hline 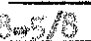 & $2 y^{4}$ & 繶 & 8 & 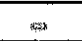 & n & 4 & 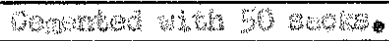 \\
\hline 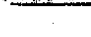 & & & & & & & \\
\hline & & & & & & & \\
\hline & & & & & & & \\
\hline
\end{tabular}

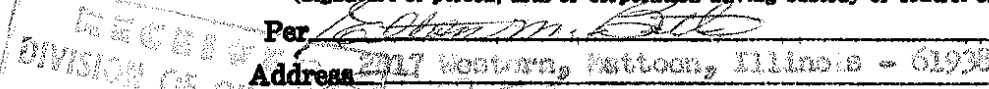

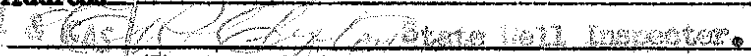

$$
\begin{aligned}
& \text { (Btemature and tillo of parts superviding plugreing of poll.) } \\
& 7 \text { Address }
\end{aligned}
$$

Subscribed and sworn to before me this 3 day of 3 ady commission expires 
Don Hixon - Ioxaco Ino

do depose and say the following is a true and correct statement of the details of the plugging of a certain well drilled for

osi

known as the A. Dinsley ${ }_{2}$

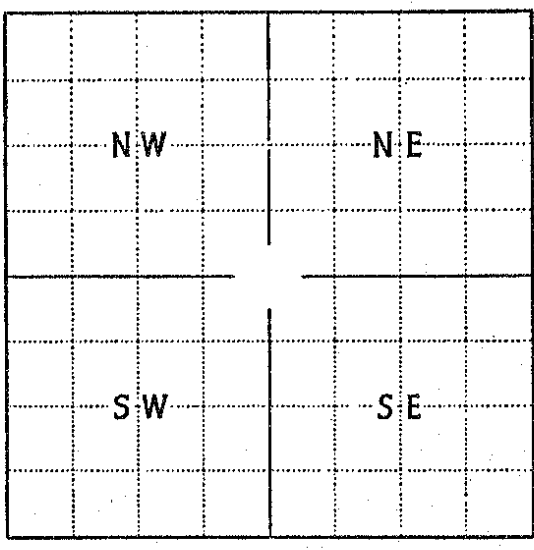

Locate well accurately on plat of section (Scale one inch-2,000 ft.) and located as follows: 330 ft. north; ft. south; 330 _. ft. east; ft. west

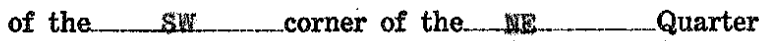
of the Quarter of the Quarter of Section 22, Township_12 (North or _tutho)

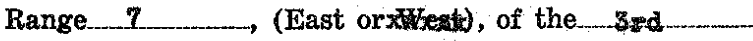
Principal Meridian, Colog County, Illinois. Elevation above sea level is $\left\{\begin{array}{l}\text { Derrick Floor } \\ \text { Ground } \mathrm{ft} .\end{array}\right.$

Total depth 1920 Formation Rosielare

Date permit to drill issuedl/22/46 Permit No.91 Permit issued to. The Texas Company Date drilling began $1 / 25 / 46$

Date drilling completed $3 / 2 / 46$

Kind of drilling tools used.... Rotary

Date plugging began__ $6 / 28 / 67$

Date plugging completed $8 / 29 / 62$

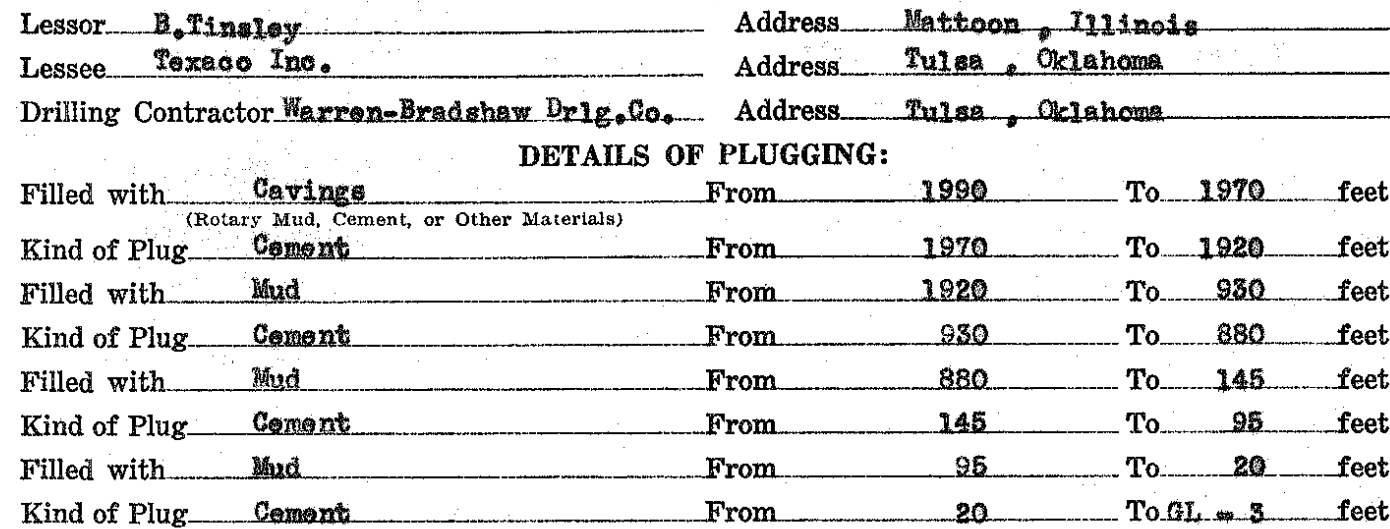

IF WORKABLE COAL BEDS WERE ENCOUNTERED IN THIS HOLE, DESCRIBE THE METHOD EMPLOYED TO PROTECT SAME. (A workable coal bed is thirty inches or more in thickness above 1,000 feet in depth)__Coal afeldavit signed

(1) Have pits and other excavations been filled?............

(2) Have the following been removed?

Equipment $\square^{\text {No }}$ Concrete bases $\square^{\text {No }}$ Debris $\stackrel{\text { Yes }}{\square} \square^{\text {No }}$

(3) Has surface casing been cut off three feet below ground surface?

If this was a producing well, give date and amount of last production 10/21/66 3 Bale. CASING RECORD

\begin{tabular}{|c|c|c|c|c|c|c|c|c|}
\hline \multirow{3}{*}{$\frac{\text { Size }}{10 / 4}$} & \multicolumn{2}{|c|}{ PUT IN WELL } & \multicolumn{2}{|c|}{ PULLED OUT } & \multicolumn{2}{|c|}{ LEFT IN WELL } & \multirow{2}{*}{\multicolumn{2}{|c|}{ Remarks }} \\
\hline & Feet & Inches & Feet & Inches & Feet & Inches & & \\
\hline & 120 & & 3 & & 217 & & Surtace & 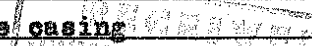 \\
\hline & & & & & & & & 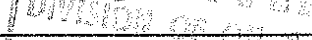 \\
\hline $7^{11}$ & -1930 & & 934 & & 996 & & & \\
\hline & & & & & & & 7 & W1:7\% \\
\hline
\end{tabular}

(Signature of person, firm of corporation having egstody, or cont trof of well;)

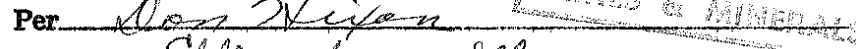

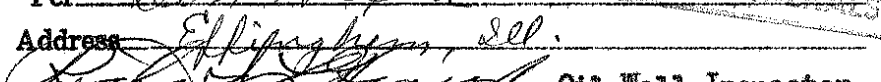
3 (signatare ine titlo of party supervising plugstng of well.)

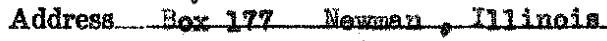

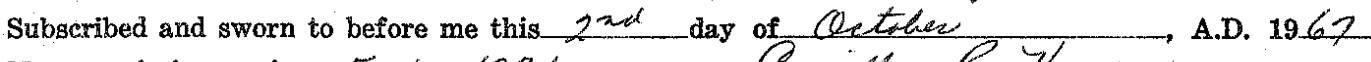
My commission expires $5-10-1971$ 
Don Hixon someco Ine. do depose and say the following is a true and correct statement of the details of the plugging of a certain well drilled for_._. $\quad 011$ (Indicate whether for oll, gas, water or other purposea) known as the A.B. insley and located as follows:

ft. north;

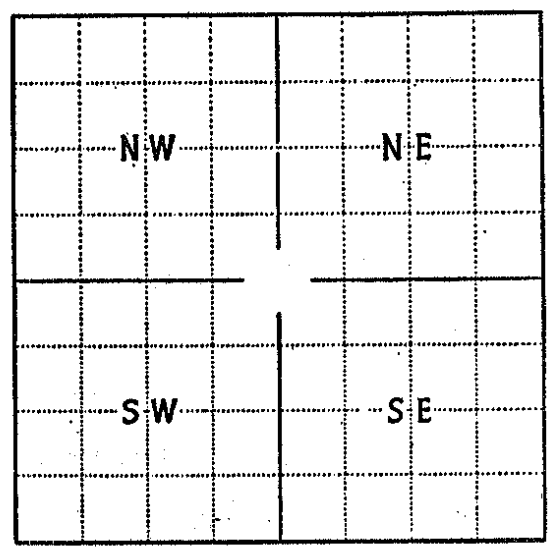

Locete well accurately on plat of section (Senlo one inch- $2,000 \mathrm{tt}$.)
_. ft. south;_______._. ft. east; $350 \quad$ ft. west of the $\quad 8 \mathrm{E}$ - corner of the _ _ Q Q of the__re Quarter of the_______uarter of

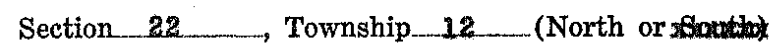
Range 7 , (East or

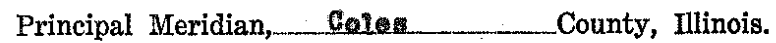

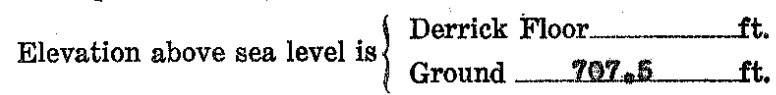
Total depth 1979 _____ormation Bosiolexe Date permit to drill issued/ $/ 23 / 46$ Permit No. 102 Permit issued to The Texa Company

Date drilling began $1 / 24 / 46$

Date drilling completed $2 / 18 / 46$

Kind of drilling tools used Rotary

Date plugging began $6 / 29 / 69$

Date plugging completed $2 / 2 / 67$

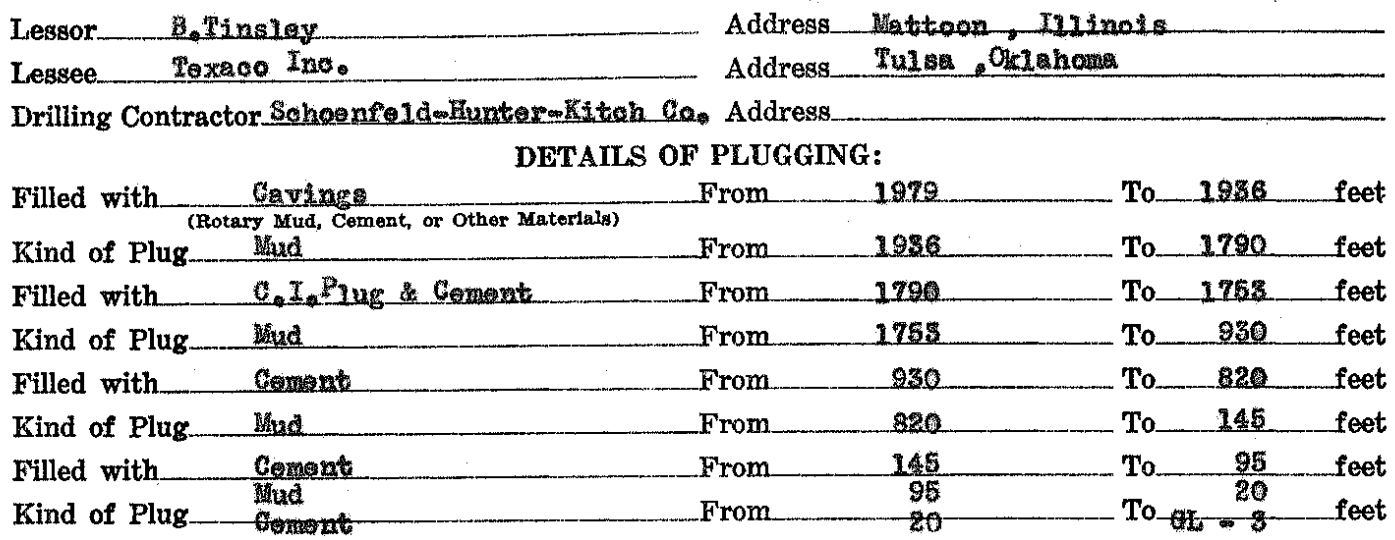

IF WORKABLE COAL BEDS WERE ENCOUNTERED IN THIS HOLE, DESCRIBE THE METHOD EMPLOYED TO PROTECT SAME. (A workable coal bed is thirty inches or more in thickness above 1,000 feet in depth) _ Coal afesdowit atgad

(1) Have pits and other excavations been filled?............ Yoe no

(2) Have the following been removed?

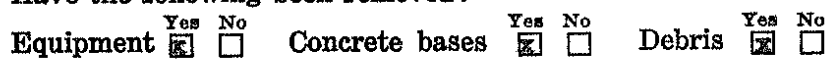

(3) Has surface casing been cut off three feet below ground surface?

(4) Has well-site been levelled $\ldots \ldots \ldots \ldots \ldots \ldots \ldots \ldots \ldots \ldots \ldots \ldots$

If this was a producing well, give date and amount of last production $4 / 3 / 64 \quad$ I Bbl.pes day.

CASING RECORD

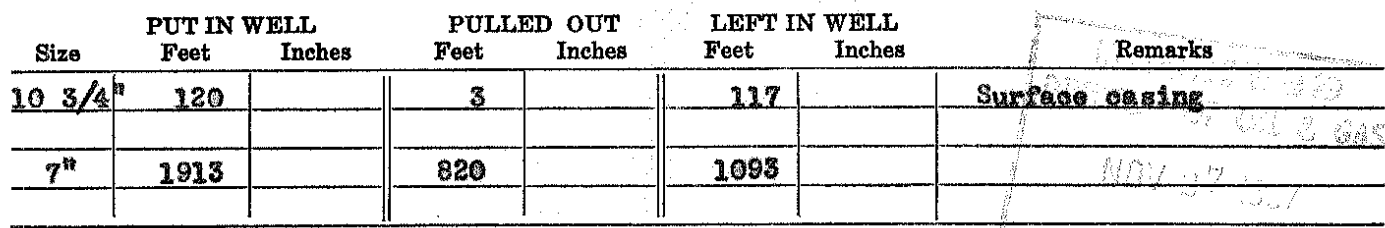

Texace Incorporated

(Gisnature of Derson, frm $6 \mathrm{r}$ corporation hevine oustody or control of woll,

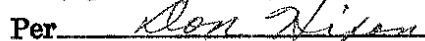

Address $\quad$ foling

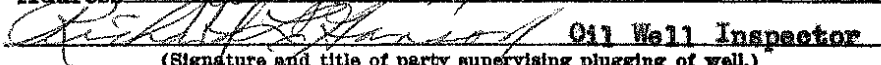

( 1 (Signdture and titis of perty supervising plugetng of vell.)

Address Box 177 Hownan. H11inois

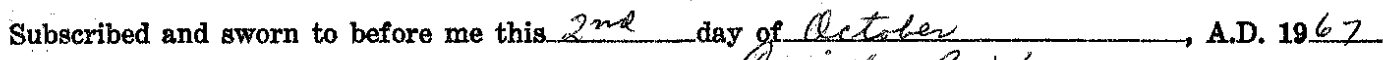
My commission expires $5-10-1924$ 
Don Hixon - Texace Inea being first duly sworn, do depose and say the following is a true and correct statement of the details of the plugging of a certain

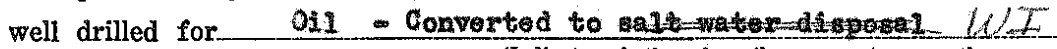

known as the B. Pinsloy \# 1 (Indicate whether for oll, gas, water or other purposes)

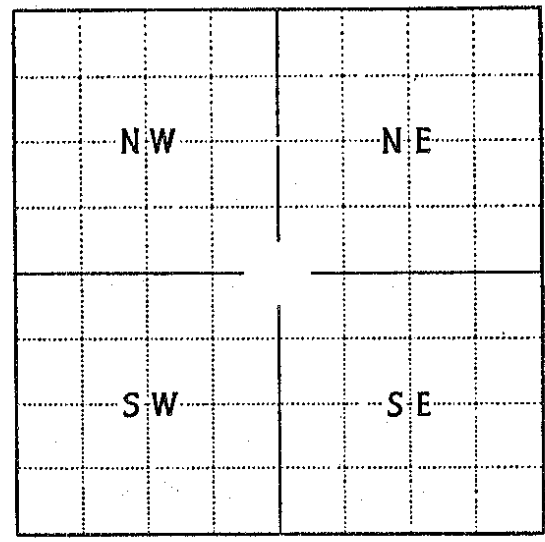

Locate well accurately on plat of section (Scale one inch-2, 2,000 $\mathrm{ft}_{1}$ )
330 ft. south; 330 ft. east;

of the WII corner of the of the Quarter of the Quarter of Section 28, Township 12 (North or Range 7 , (East or Principal Meridian,___Colos _ County, Illinois. Elevation above sea level is $\begin{cases}\text { Derrick Floor } & \mathrm{ft} . \\ \text { Ground } 709 & \mathrm{ft}\end{cases}$ Total depth 1990-PB-1955 Formation Rosjelfirg Date permit to drill jssued $4 / 12 / 64$ Permit No.460\% STD Permit issued to The Texas Company Date drilling began $12 / 26 / 45$

Date drilling completed $2 / 4 / 46$

Kind of drilling tools used Rotary

Date plugging began 6/26/67

Date plugging completed $9 / 5 / 67$

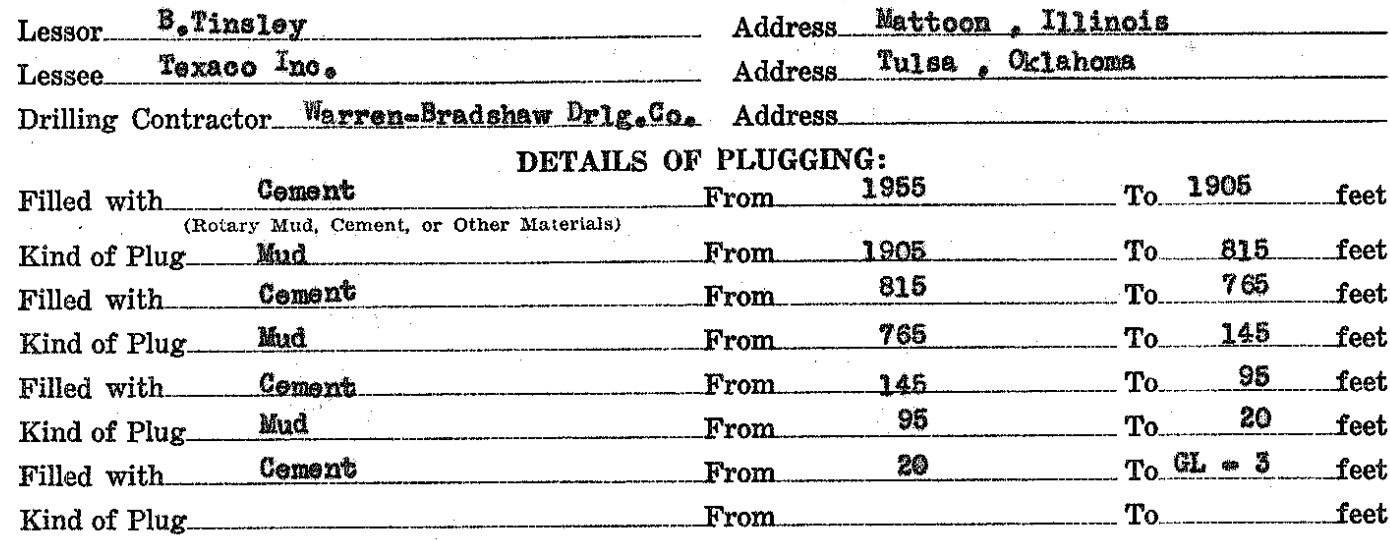

IF WORKABLE COAL BEDS WERE ENCOUNTERED IN THIS HOLE, DESCRIBE THE METHOD EMPLOYED TO PROTECT SAME. (A workable coal bed is thirty inches or more in thickness above 1,000 feet in depth) Con a cesdavit signed

(1) Have pits and other excavations been filled?

(2) Have the following been removed?

Equipment $\stackrel{\text { Yes }}{\square} \underset{\square}{\square}$ Concrete bases $\stackrel{\text { Yes }}{\square} \square^{\text {No }}$ Debris $\stackrel{\text { Yes }}{\square} \square^{\text {No }}$

(3) Has surface casing been cut off three feet below ground surface?

If this was a producing well, give date and amount of last production $3 / 18 / 54 \quad 2 \quad B b 15.06 \times$ day CASING RECORD

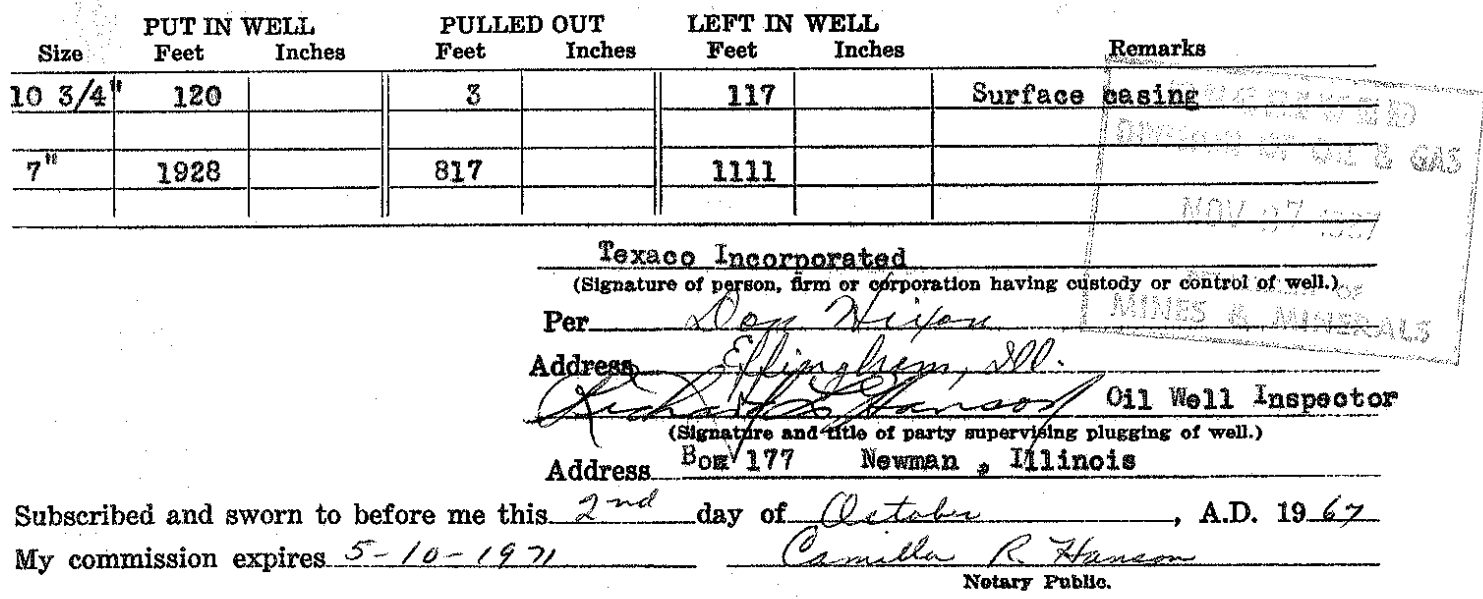


Konneth Chambers - - Aone Casing Pulling Co. and being first duly sworn, well drilled for os known as the B.Tinsiey F $_{4}$ (Indlcate whether for oil, gas, water or other purposes)
and located as follows:-_ ft. north;

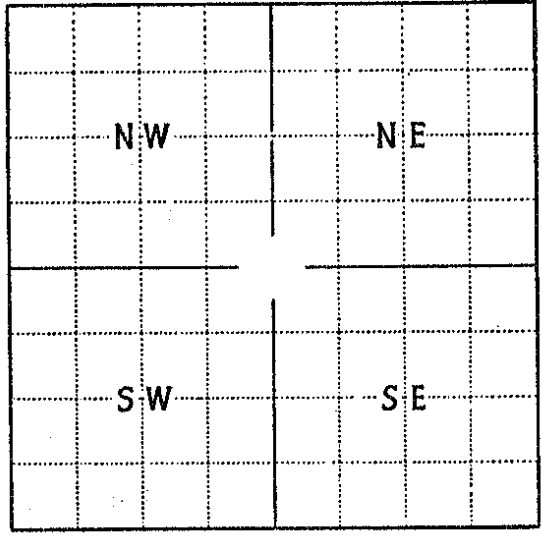

Locate well accurately on plat of section (Scale one inch-2,000 ft.)
830 ft. south;

ft. east; -330

ft. west of the $\quad$ corner of the N N _ _ _ Quarter of the NE Quarter of the ___ Quarter of Section_22_, Township_. 12 (North orxsutha) Range 7 , (East or west of the $3 x d$ Principal Meridian, Colos_County, nlinois.

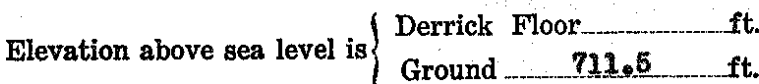

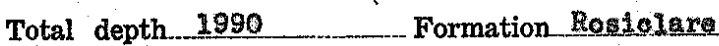
Date permit to drill issued2/13/46Permit No.204 Permit issued to The Texas Couneny Date drilling began $2 / 16 / 45$ Date drilling completed $3 / 15 / 46$ Kind of drilling tools used._._. Rotery Date plugging began $\quad \$ / 27 / 67$ Date plugging completed $6 / 28 / 67$

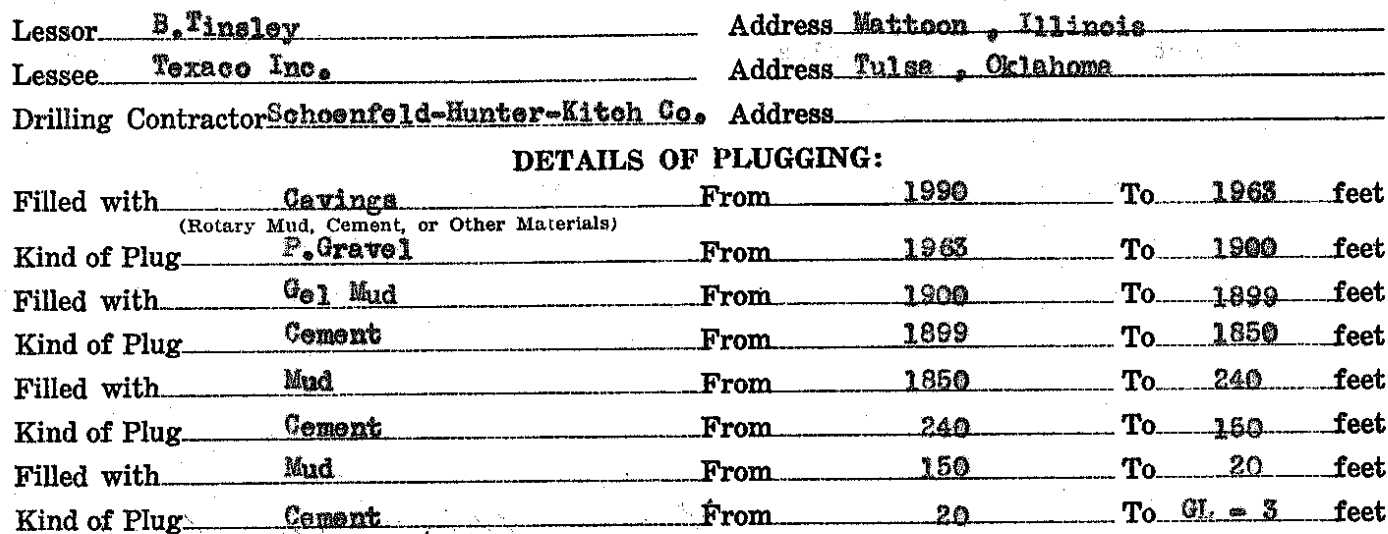
IF WORKABLE COAL BEDS WERE ENCOUNTERED IN THIS HOLE, DESCRIBE THE METHOD EMPLOYED TO PROTECT SAME. (A workable coal bed is thirty inches or more in thickness above 1,000 feet in depth) _.__. Coal affidevte signed

(1) Have pits and other excavations been filled $\ldots \ldots \ldots \ldots \ldots \ldots$ 羿

(2) Have the following been removed?

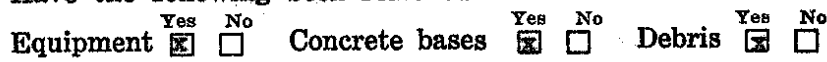

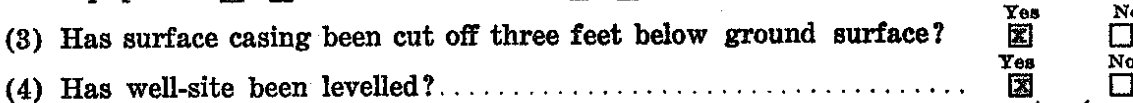

(4) Has well-site been levelled?............ CASING RECORD

\begin{tabular}{|c|c|c|c|c|c|c|c|}
\hline \multirow{2}{*}{ Size } & \multicolumn{2}{|c|}{ PUT IN WELL } & \multicolumn{2}{|c|}{ PULLED OUT } & \multicolumn{2}{|c|}{ LEFT IN WELL } & \multirow[t]{2}{*}{ Remarks } \\
\hline & Feet & Inches & Feet & Inches & & Inches & \\
\hline $20 \mathrm{~g} / 4^{14}$ & 177 & & 3 & & 174 & & Surface oastng \\
\hline & & & & & & & Henre $\quad-4 \times$ \\
\hline $7^{11}$ & 1920 & & 808 & & 1117 & & कीग \\
\hline & & & & & & & 02 \\
\hline
\end{tabular}

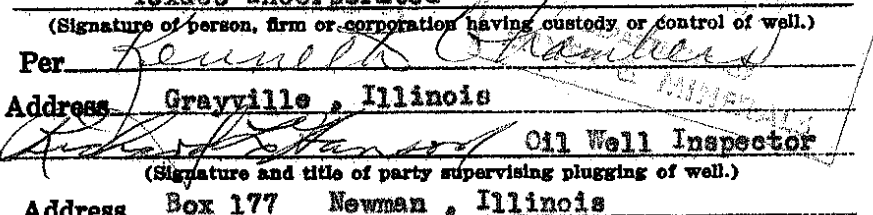

Address Box 177 Nowman. Illinots

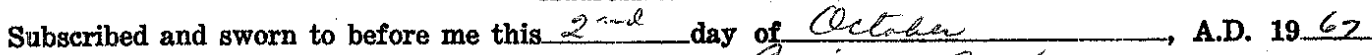
My commission expires $5-10-1921$ 
23-12N-7E-1 
STATE OF ILLINOIS, County of Celea ss. say the following is a true and correct statement of the details of the plugging of a certain well drofs (Indicate whether for oil, gas, water or other purposes)

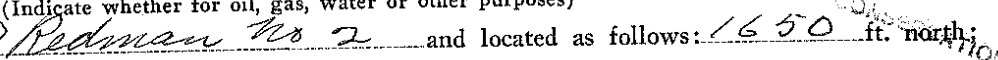

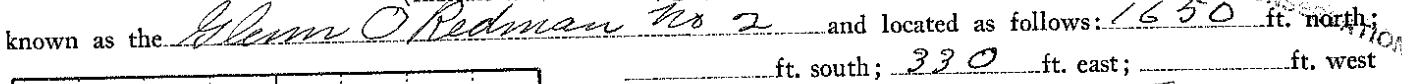

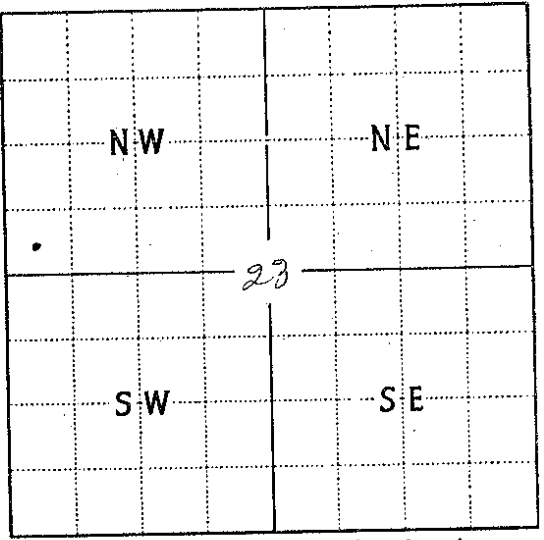

Locate well accurately on plat of section (Scale one inch $-2,000 \mathrm{ft}$.) of the SW corner of the ALENW Quarter of the $S W \quad$ Quarter of the Quarter of Section 23 .., Township $/ 2$ (North ov-South) Range $\quad$, (East or West), of the 3 Principal Meridian, Bese County, Illinois.

Elevation above sea level is Derrick Floor_____ft. ft. Ground $209 \quad$ fit. Total depth of well is...... 1984 Date permit to drill issued 20 ec $14-1945$ Permit issued to Lhelter Levrear Date drilling begun $2 \mathrm{Lec} 14-1945$ Date drilling completed. $20 \mathrm{Ce} 21 / 943^{-}$ Kind of drilling tools used Polary Date plugging begun $2 \mathrm{Cec}_{2} 2^{2}-245$

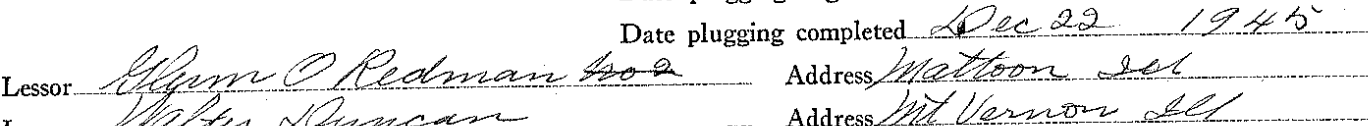

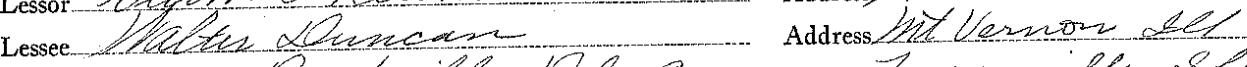

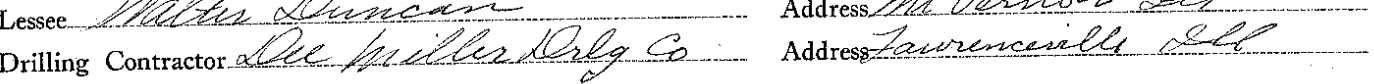
DETAILS OF PLUGGING:

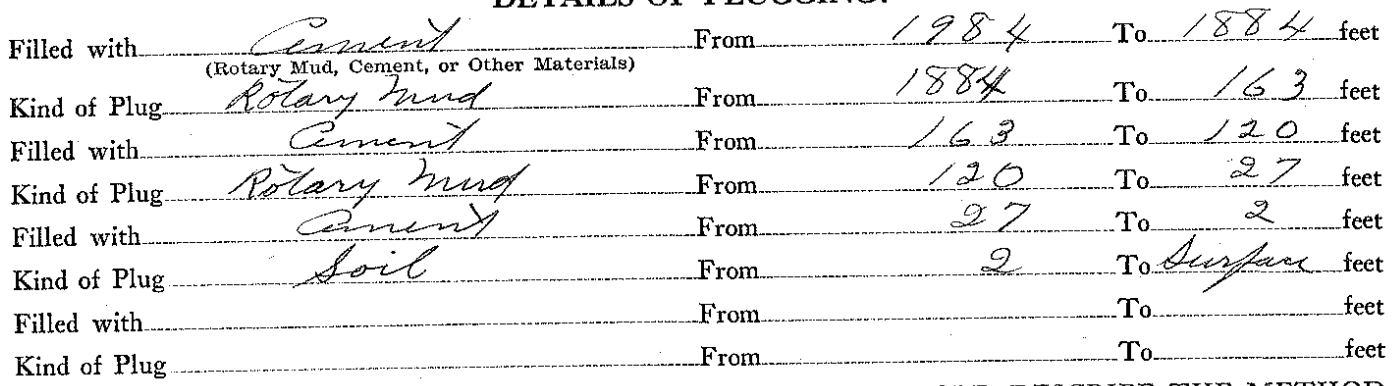

IF WORKABLE COAL BEDS WERE ENCOUNTERED IN THIS HOLE, DESCRIBE THE METHOD EMPLOYED TO PROTECT SAME. (A workable coal bed is thirty inches or more in thickness above 1,000 feet in depth and three feet or more in thickness below 1,000 feet in depth.)

Other details

If this was a producing well, give date and amount of last production

CASING RECORD

\begin{tabular}{l} 
Size $\begin{array}{c}\text { PUT IN WELL } \\
\text { Feet }\end{array}$ Inches \\
\hline $10^{3} / 4=160$ \\
\hline
\end{tabular}


26-13N-7E 

well drilled for 19.

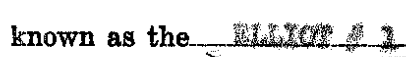
and located as follows.

ft. north;

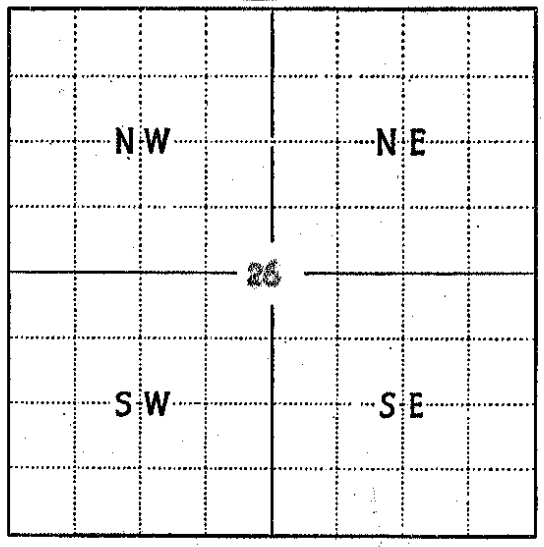

Locate well accurately on plat of section (Scale one inch-2,000 ft.)

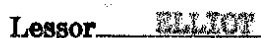

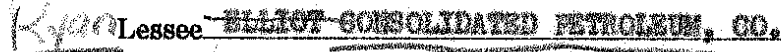
Drilling Contractor

- 330 ft. south; - 19to ft. east; of the corner of the Quarter of the of the Range $-\frac{7}{7}$ Township 7

Principal Meridian, conturas Elevation above sea level is $\{$ Derrick Floor Ground ft.

Total depth 2090 . Formation. Date permit to drill issued $10.25-5$ Permit No. $27 q$

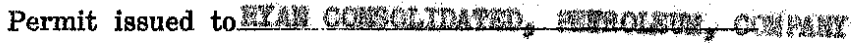

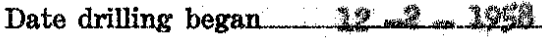
Date drilling completed $12-6-125$ Kind of drilling tools used

Date plugging began 22-6- -1 -

Date plugging completed $12+6-125$

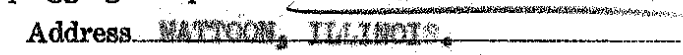

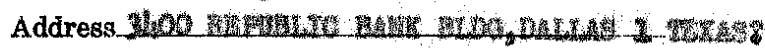
DETAMS OF PLUGGING:

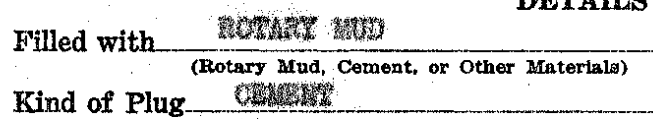

Filled with w From From. From From From From From From

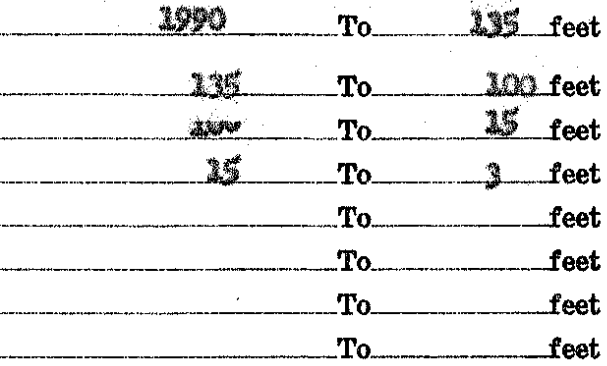

Tind of Plug IF WORKABLE COAL BEDS WERE ENCOUNTERED IN THIS HOLE, DESCRIBE THE METHOD
EMPLOYED TO PROTECT SAME. (A workable coal bed is thirty inches or more in thickness above 1,000 feet in depth)

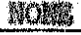

(1) Have pits and other excavations been filled?

(2) Have the following been removed? Equipment $\square$ Concrete bases $\square^{\text {Yes }}$ है Debris $\stackrel{\text { Yos }}{\square}$ No

(3) Has surface casing been cut off three feet below ground surface? Ye

(4) Has well-site been levelled?

If this was a producing well, give date and amount of last production.

\section{Yes

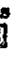

㖞

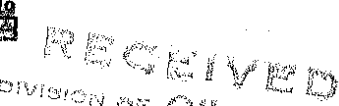

$$
\begin{aligned}
& \text { No } \\
& \mathrm{BED}-195 \mathrm{~s}
\end{aligned}
$$

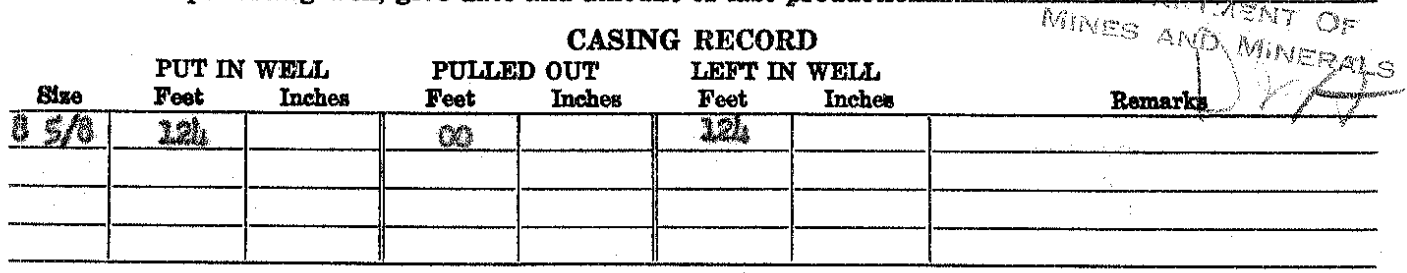

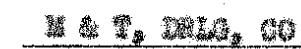

(Shgngture of person, firm or corporation hsving eustody of control of wall.)

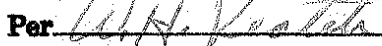

Address

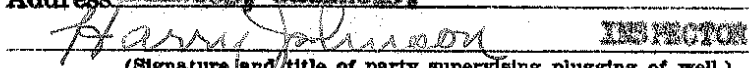

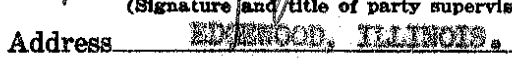

Subscribed and sworn to before me this 6 将壁 day of My commission expires $\quad 25.96$ 


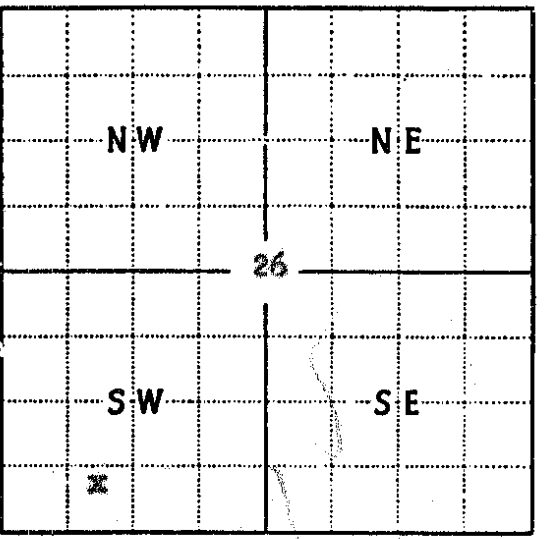

Locate well accurately on plat of section (Scale one inch-2,000 ft.)

ft. south;

$990 \mathrm{ft}$. east

of the c__ corner of the

of the Quarter of the

Section 26 Township

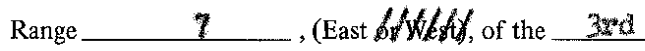

Principal Meridian, Cotitis Elevation above sea level is

Total depth 1980

Ground $673.6 \mathrm{ft}$.

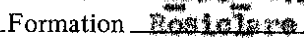

Date permit to drill issued $7 / 27 / 7 \%$ Permit No. 6060

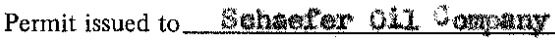

Date drilling began $\quad 9-7$

Date drilling completed $\quad-\mathbf{S}-\mathbf{l} \mathbf{l}=\mathbf{7 3}$

Kind of drilling tools used__ rotary

Date plugging began

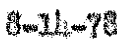

Date plugging completed

$8-11-76$

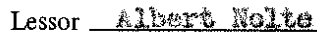

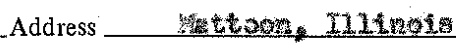

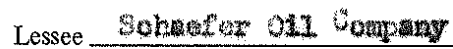
Address 路

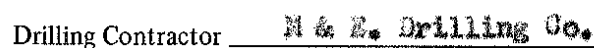
Address Gasey, IIInoì.

DETAILS OF PLUGGING:

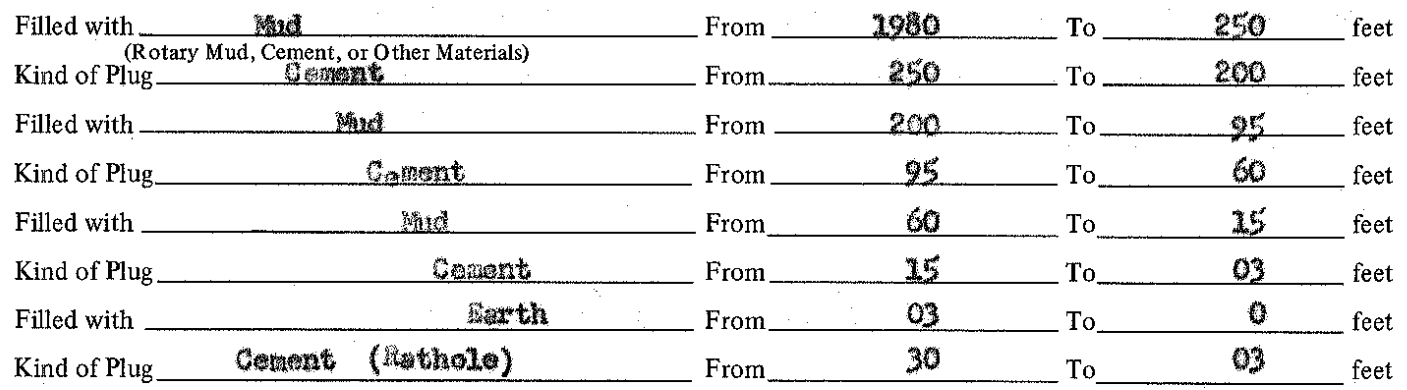

IF WORKABLE COAL BEDS WERE ENCOUNTERED IN THIS HOLE, DESCRIBE THE METHOD EMPLOYED TO PROTECT SAME. (A workable coal bed is thirty inches or more in thickness above 1,000 feet in depth)

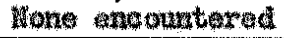

(1) Have pits and other excavations been filled? $\ldots \ldots \ldots \ldots \ldots \ldots \ldots \ldots$ Yes

(2) Have the following been removed?

$$
\text { Equipment } \stackrel{\text { Yes }}{\square} \text { No Concrete bases } \square \text { Co }
$$

(3) Has surface casing been cut off three feet below ground surface?

(4) Has well-site been leveled? . . . . . . . . . . . . . . .

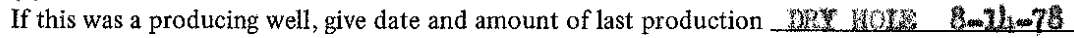

\section{CASING RECORD}

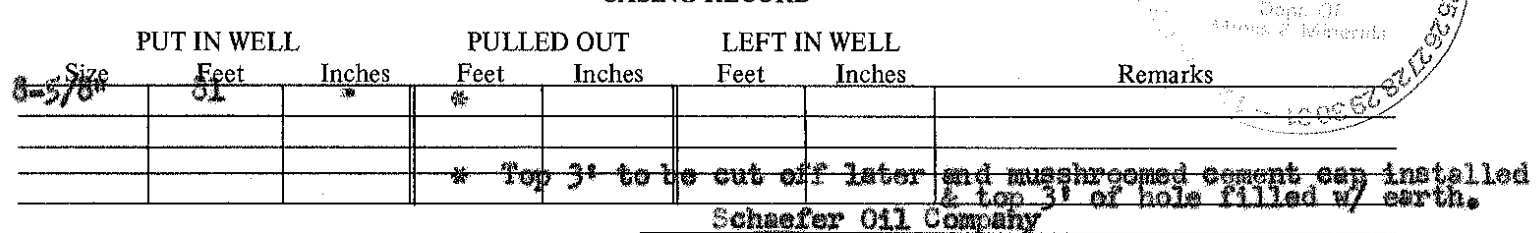

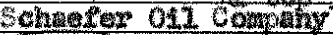

(Signafure of person, firith org gorpoyation having custody or control of well.)

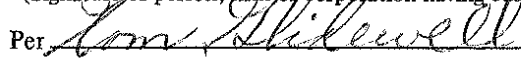

Address

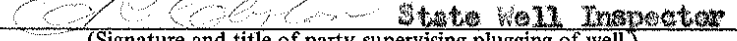

title of party supervising plugging of well.)

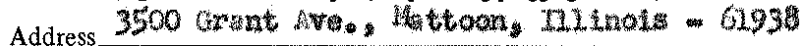

Subscribed and sworn to before me this $154 \mathrm{ta}$ day of 
STATE OF ILLINOIS,

County of $\}$ ss.

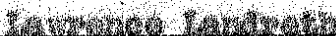

say the following is a true and correct statement of the details of the plugging of a certin weil drilled for.

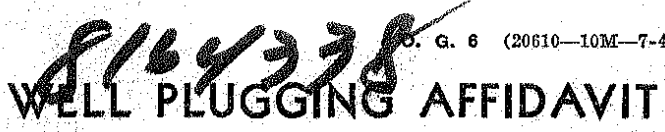

Hath

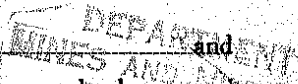

being first duly sworn, dos depose and 0 id

(Indicate whether for oil, gas, water or other purposes)

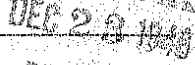

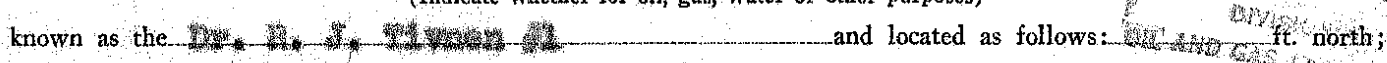

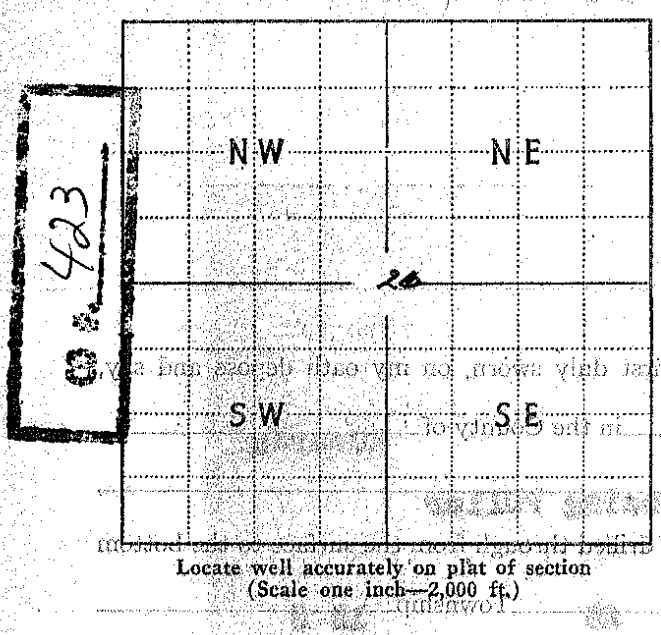

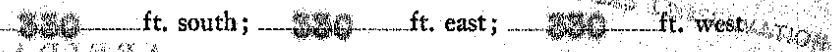

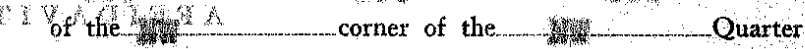
of the - Quarter of the - Quarter of Section a Range - (East or Westat, of the

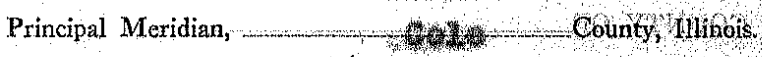

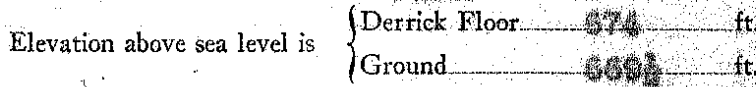
Total depth of well is Date permit to drill issued

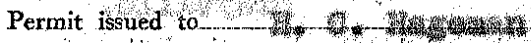

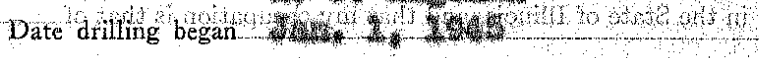

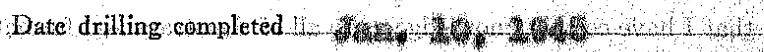
Kind of drilling tools used _ naty

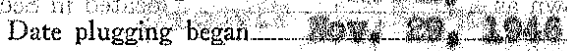

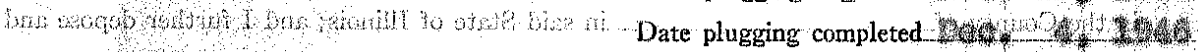

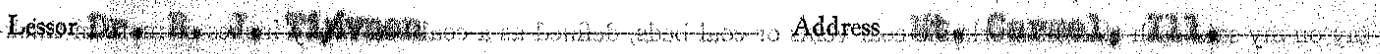

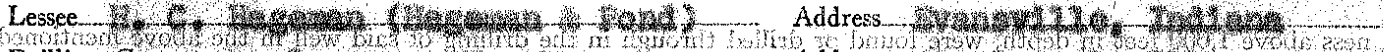

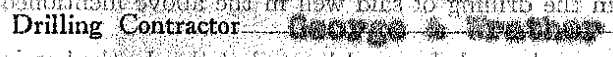

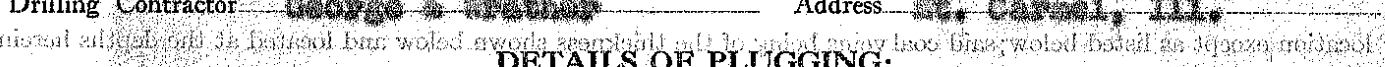

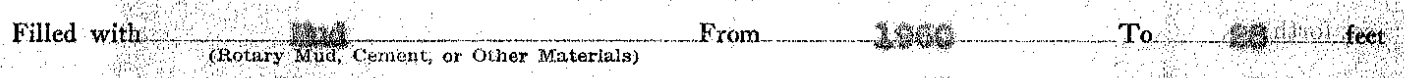

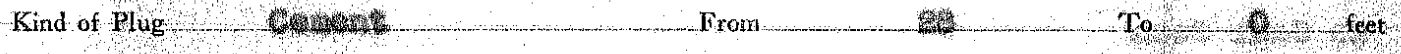
Filled with $\quad$ From $\quad \mathrm{To}_{\mathrm{r}} \quad$ feet Kind of Plug From $\quad$ To $\quad$ feet

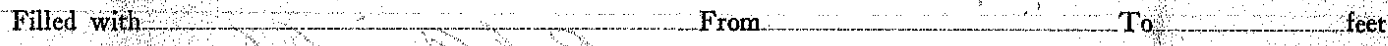

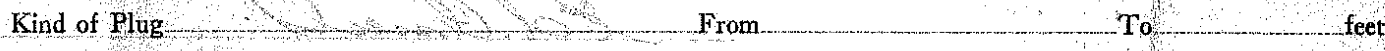
Filled with From for to fot Kind pt plug From foet To IF WORKABLE COAL BEDS WERE ENCOUNTERED IN THIS HOLE, DESCRIBE THE METHOD EMPLOYED TO PROTECT SAME. (A workable coal bed is thirty inches or more in thickness above 1,000 feet in depth)

(1) Have pits cellar and other excavations been filled?

(2) Iavegupincht, concrete bases and debris been removed?

$\begin{array}{cc}\text { Yes } & \text { No } \\ \square & \square \\ \text { Yes } & \text { No } \\ \square & \square \\ \text { Yess } & \text { No } \\ \square & \square \\ \text { Yes } & \text { No } \\ \square & \square\end{array}$

(3) Has surface casing been cut off below plow depth?....

(4) Has well-site been levelled?

If this was a producing well, give date and amount of last production.

\section{CASING RECORD}

\begin{tabular}{|c|c|c|c|c|c|c|c|}
\hline \multirow[b]{2}{*}{ Size } & \multicolumn{2}{|c|}{ PUT IN WELL } & \multicolumn{2}{|c|}{ PULXED OUT } & \multicolumn{2}{|c|}{ LEFT IN WELL } & \multirow[b]{2}{*}{ Remarks } \\
\hline & Feet & Inches & Feet & Inches & Feet & Inches & \\
\hline 10 & 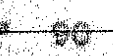 & & & & -4 & & ceanentid \\
\hline & $14 x$ & & W & & thet & & \\
\hline & 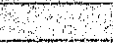 & & & & & & \\
\hline
\end{tabular}

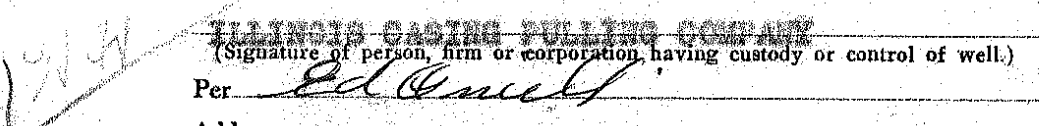

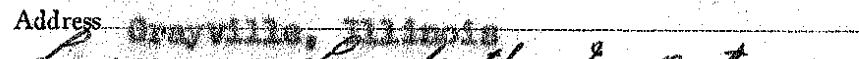

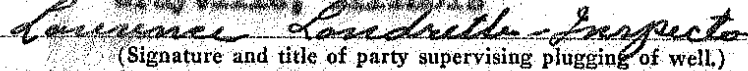

Adress \& f Subscribed and sworn to before me this 164 day of 2 cesmeer A. D. 1946 My commission expires $27,1,1,1,4$ $9: \frac{\mathbb{Q} 2}{\text { Notary Public. }}$ 
27-13N-7E 
do depose and say the following is a true and correct statement of the details of the plugging of a certain well drilled for. orb

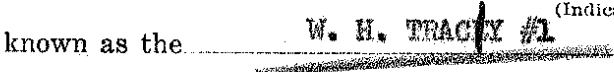

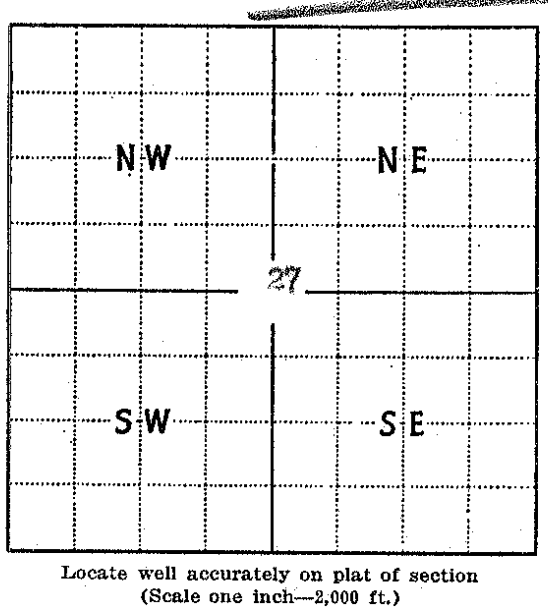
and located as follows: 330 ft. south; ft. east; $330 \mathrm{ft}$ west of the ST of the Qun Quarter of the Qu Section $\frac{27}{27}$, Township 13 (North/6r/\$othth)

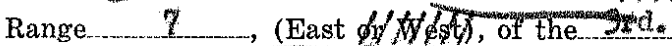
Principal Meridian, C...... CO Elevation above sea level is $\left\{\begin{array}{l}\text { Derrick Floor } \\ \text { Ground }\end{array} 672 \ldots \mathrm{ft}\right.$. Total depth $1960 \quad$ Formation Nodsosimer Date permit to drill issued $10-28-57$ ermit No. 2732

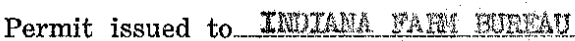
Date drilling began $\quad 10-3-37$ Date drilling completed $11-7-5 \%$ Kind of drilling tools used ow Date plugging began $\quad 31-1-57$

Date plugging completed $\quad 21-7-57$

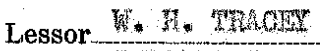

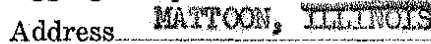

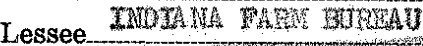

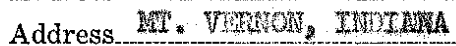

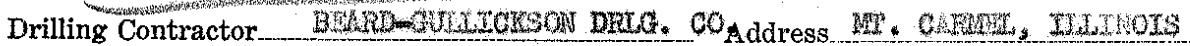

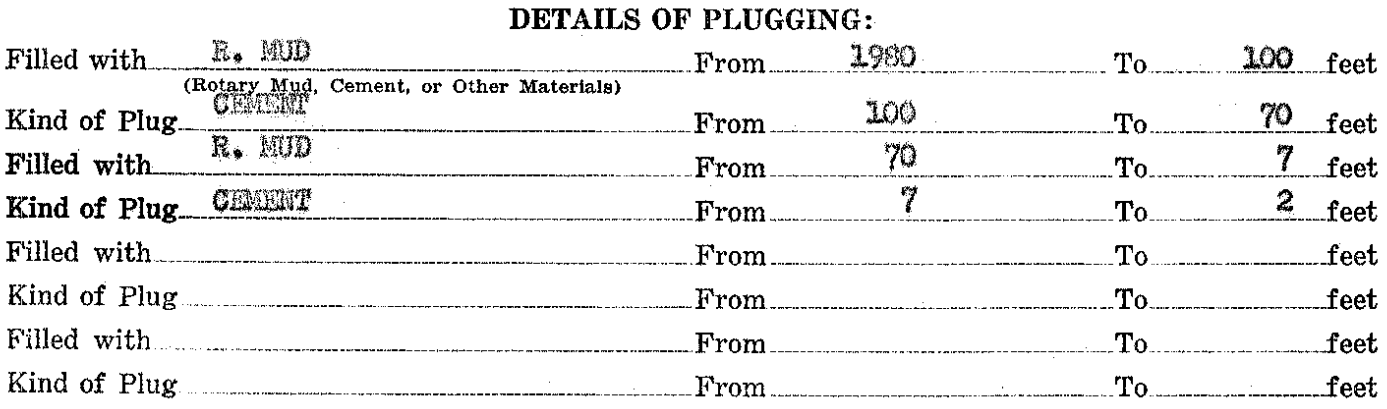

IF WORKABLE COAL BEDS WERE ENCOUNTERED IN THIS HOLE, DESCRIBE THE METHOD EMPLOYED TO PROTECT SAME. (A workable coal bed is thirty inches or more in thickness above 1,000 feet in depth) _ n

(1) Have pits and other excavations been filled?

(2) Have the following been removed?

Equipment $\stackrel{\text { Yes }}{\square}$ No Concrete bases $\stackrel{\text { Yes }}{\square} \stackrel{\text { No }}{\square}$ Debris $\stackrel{\text { Yes }}{\square}$

(3) Has surface casing been cut off three feet below ground surface? Yes

(4) Has well-site been levelled?

If this was a producing well, give date and amount of last production

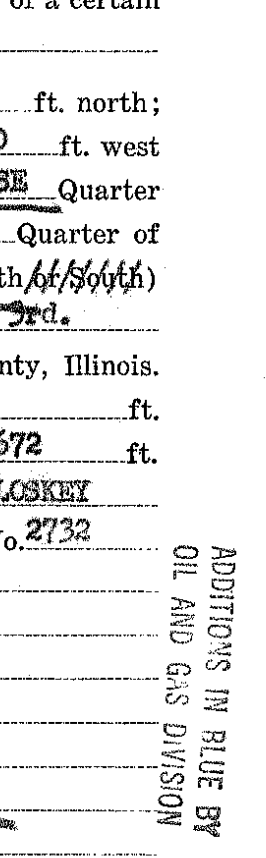

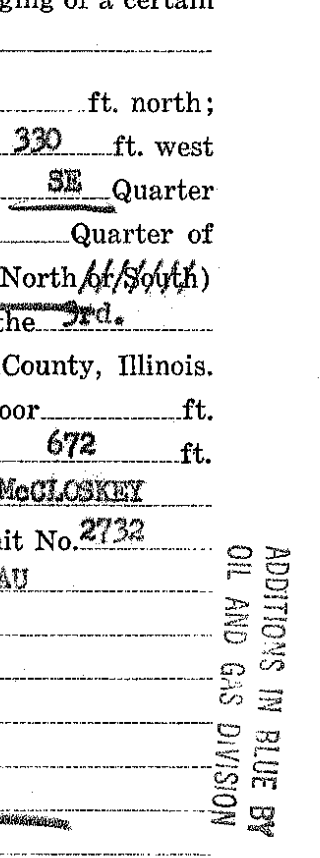

\section{Yes}

Yes No No
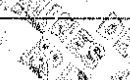
Form OG-6

STATE OF ILLINOIS

County of alsw ss. WELL PLUGGING AFFIDAVIT

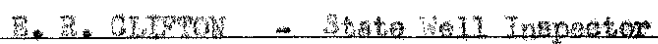

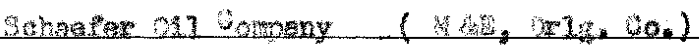
and being first duly sworn, do depose and say the following is a true and correct statement of the details of the plugging of a certain well drilled for mit

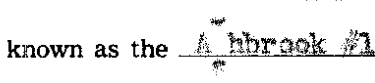

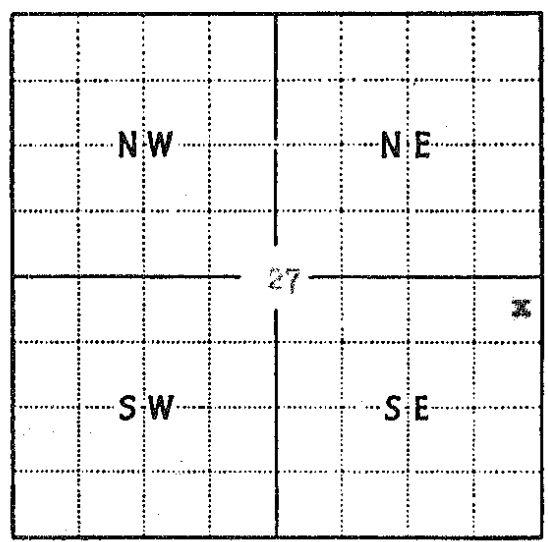

Locate well accurately on plat of section (Scale one inch-2,000 $\mathrm{ft}$.)

(Indicate whether for oil, gas, water or other purposes) and located as follows: $\quad 330 \mathrm{ft}$. north; ft. south;

ft. east $; \quad+30 \quad$ ft. west of the corner of the Un Quarter of the_suarter of the Q Q Q Q Q Section 27 Township 13 (North or Soluth) Range $\quad$, (East $6 / 6 /$ est), of the 3 , th

Principal Meridian, County, Illinois. Elevation above sea level is $\left\{\begin{array}{l}\text { Derrick Floor } \\ \text { Ground } f \mathrm{ft}\end{array}\right.$ Total depth $1953 \quad$ Formation Date permit to drill issued $5 / 3 / 79$ Permit No. 7300

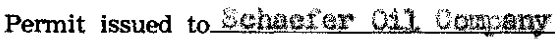
Date drilling began $\quad 5-11-79$ Date drilling completed $\quad 3 \times 16 \% 79$ Kind of drilling tools used notary Date plugging began $37-75$ Date plugging completed___ $\quad 3-14-79$

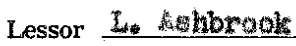

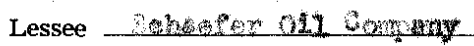

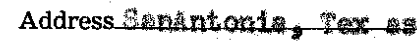

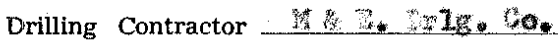

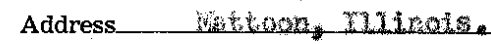
Address_Cu

Details of Plugging:

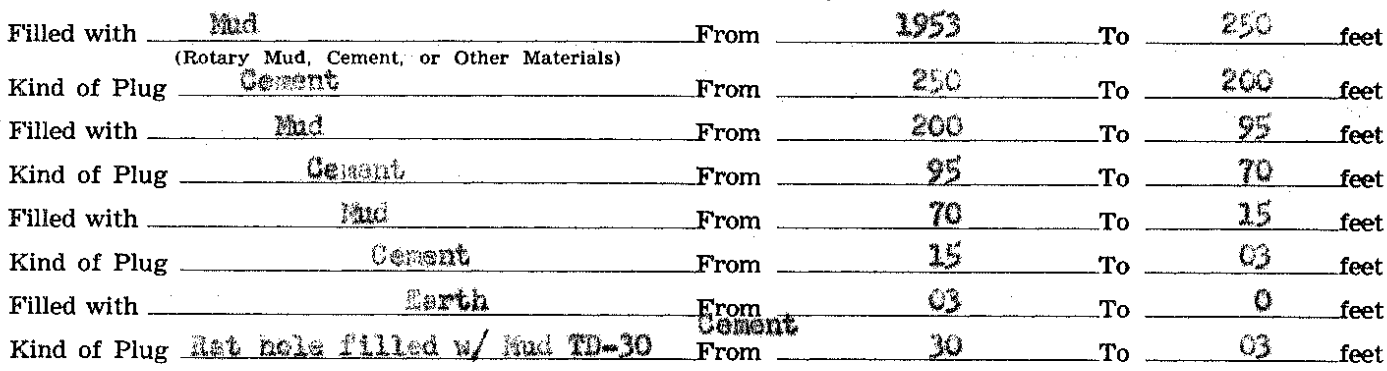
IF WORKABLE COAL BEDS WERE ENCOUNTERED IN THIS HOLE, DESCRIBE THE METHOD EMPLOYED TO PROTECT SAME. (A workable coal bed is thirty inches or more in thickness above 1,000 feet in depth) wone weowntertat

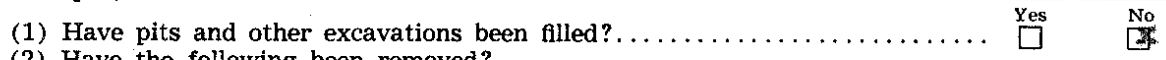

(2) Have the following been removed?

$$
\text { Equipment } \begin{array}{lllll}
\text { Yes } & \text { No } \\
\square & \text { Concrete bases } \square & \text { Yes } & \text { No } & \text { Debris } \stackrel{\text { Yes }}{\square} \text { ㅇo }
\end{array}
$$

(3) Has surface casing been cut off three feet below ground surface?

(4) Has well-site been leveled?

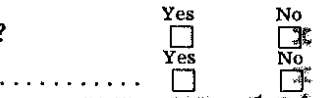

If this was a producing well, give date and amount of last production $12 x+160$

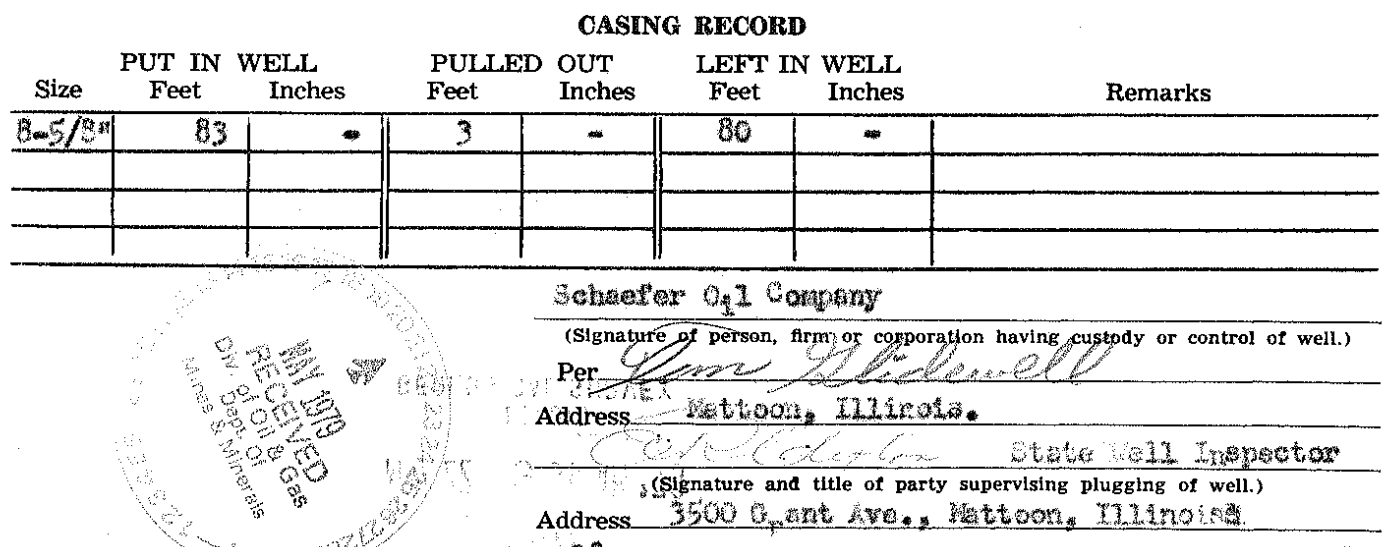

Subscribed and sworn to before me this 28 My commission expires $9-2-01$

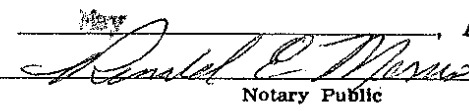


34-13N-7E 
STATE OF ILLINOIS,

County of asom $\}$ ss.

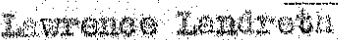

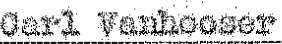

say the following is a true and correct statement of the details of the plugging of a certent drifed for $0,36,8$ (Indicate whether for oil, gas, water or other purposes)

known as the

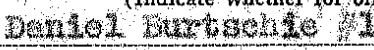

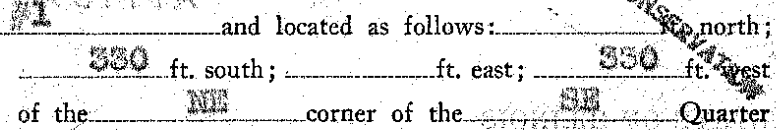

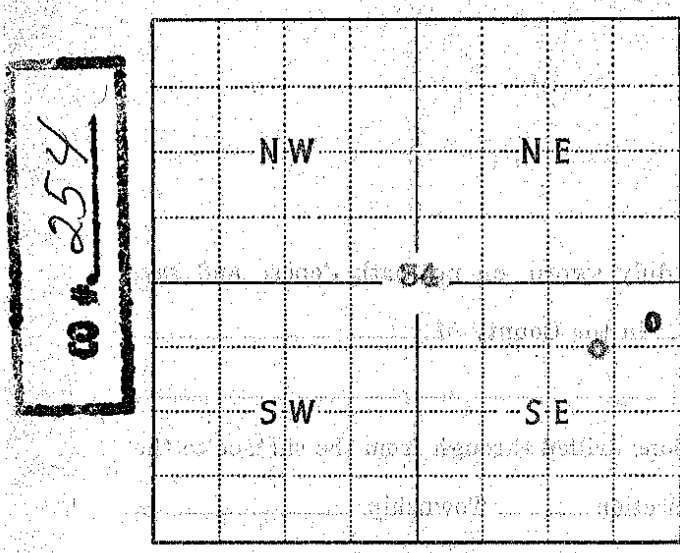

Locate well accurately on plat of sectio Scale one inch-2,000 ft.) of the Quarter of the Quarter of

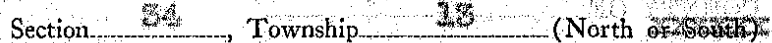
Range (East or West), of the obto Principal Meridian, Ot County, Illinois. Elevation above sea level is $\int$ Derrick Floor $\quad 0 / 2 \mathrm{ft}$ Total depth of well is fGround 2006 $\mathrm{ft}$. $\mathrm{ft}$

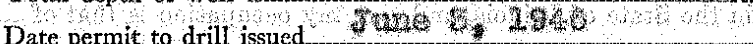

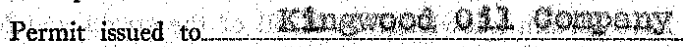
Date drilling began $40,2,2,4$ Date drilling completed $341, \quad 1946$

Kind of drilling tools used Wot the

Date plugging began $4 \mathrm{H}_{2}, \mathrm{~s}, \mathrm{H}, \mathrm{f}$

Date plugging completed $t 2, y, 306$

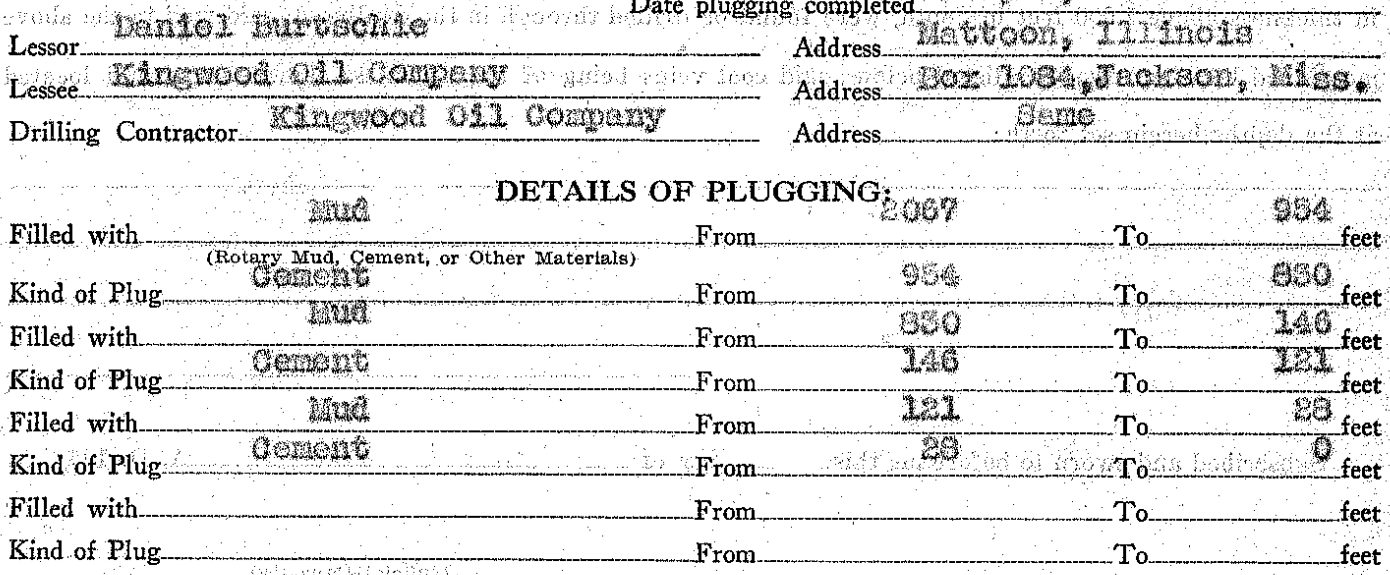

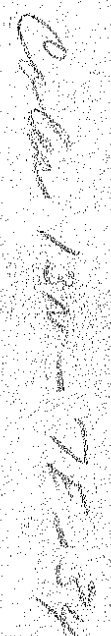

IF WORKABLE COAL BEDS WERE ENCOUNTERED IN THIS HOLE, DESCRIBE THE METHOD EMPLOYED TO PROTECT SAME (A workable coal bed is thirty inches or more in thickness above 1,000 feet in depth.

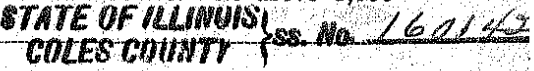

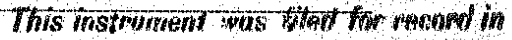

Other details

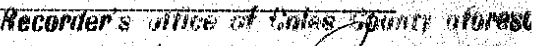

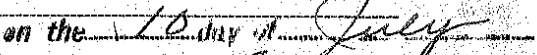

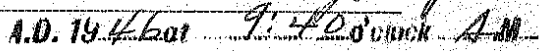

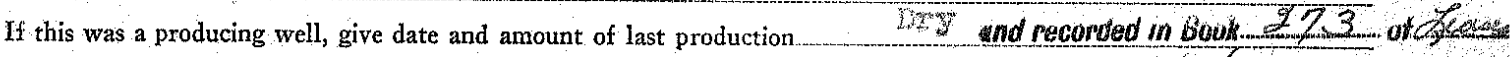

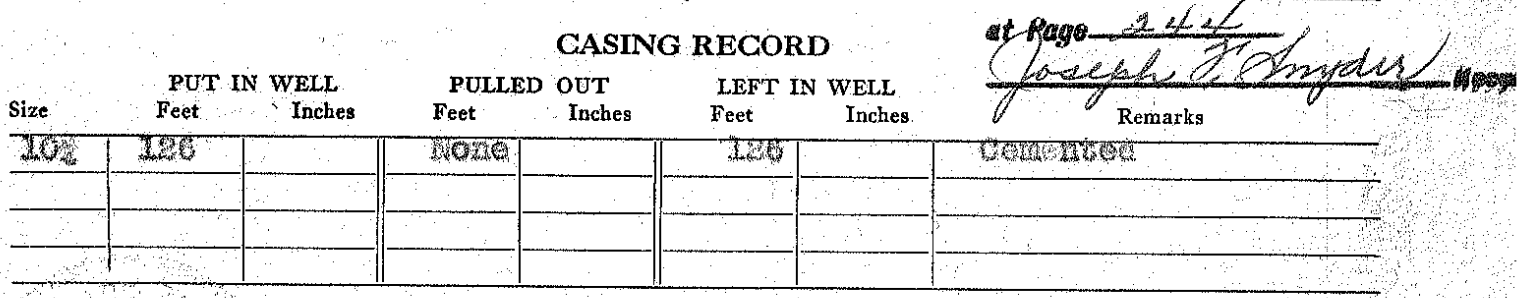

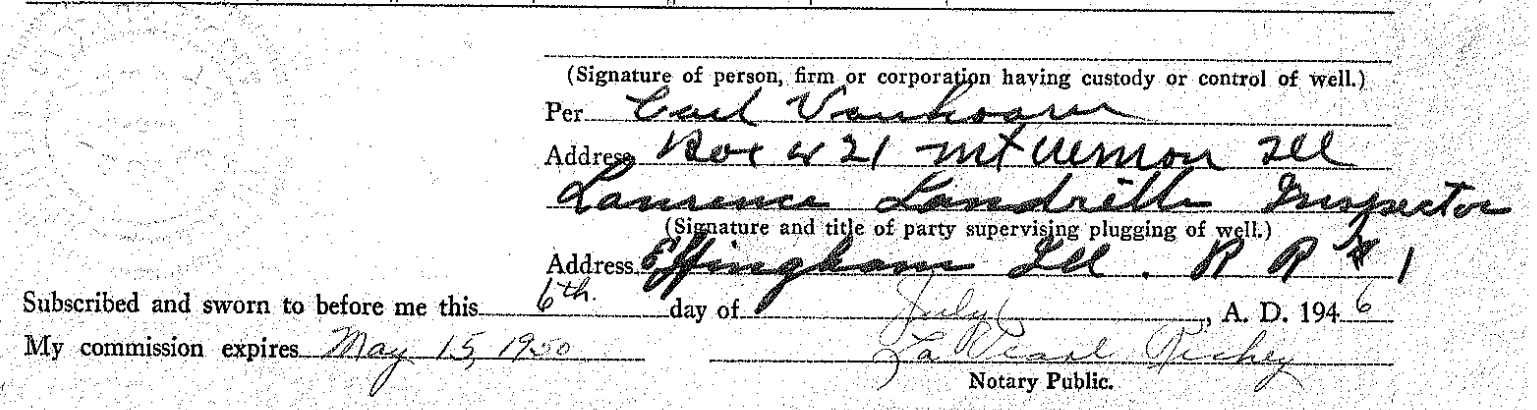




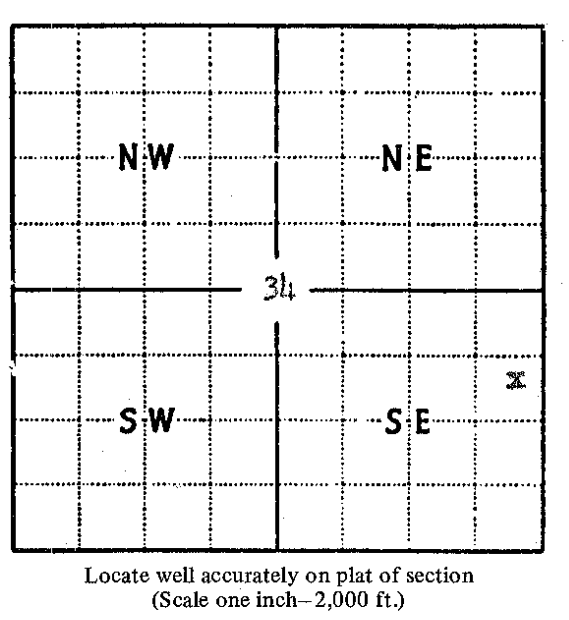

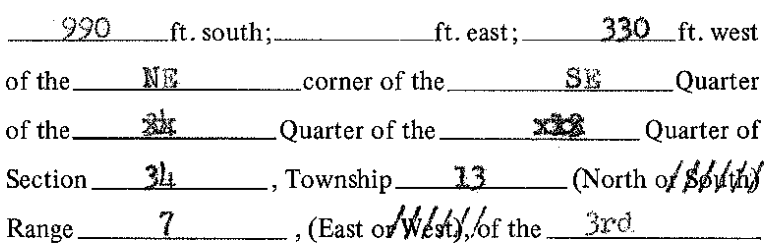

Principal Meridian, COTis County, Illinois. Elevation above sea level is $\left\{\begin{array}{l}\text { Derrick Floor } \\ \text { Ground }\end{array}\right.$ Total depth 1960 Formation Pos 107 tate

Date permit to drill issued $6 / 7 / 78$ Permit No. 5763

Permit issued to Sam olf Corapay

Date drilling began $6-9-78$

Date drilling completed $\quad 6 \operatorname{mom} 75-78$

Kind of drilling tools used___ Rotary

Date plugging began $\quad 6-15-78$

Date plugging completed _ $6-15-78$

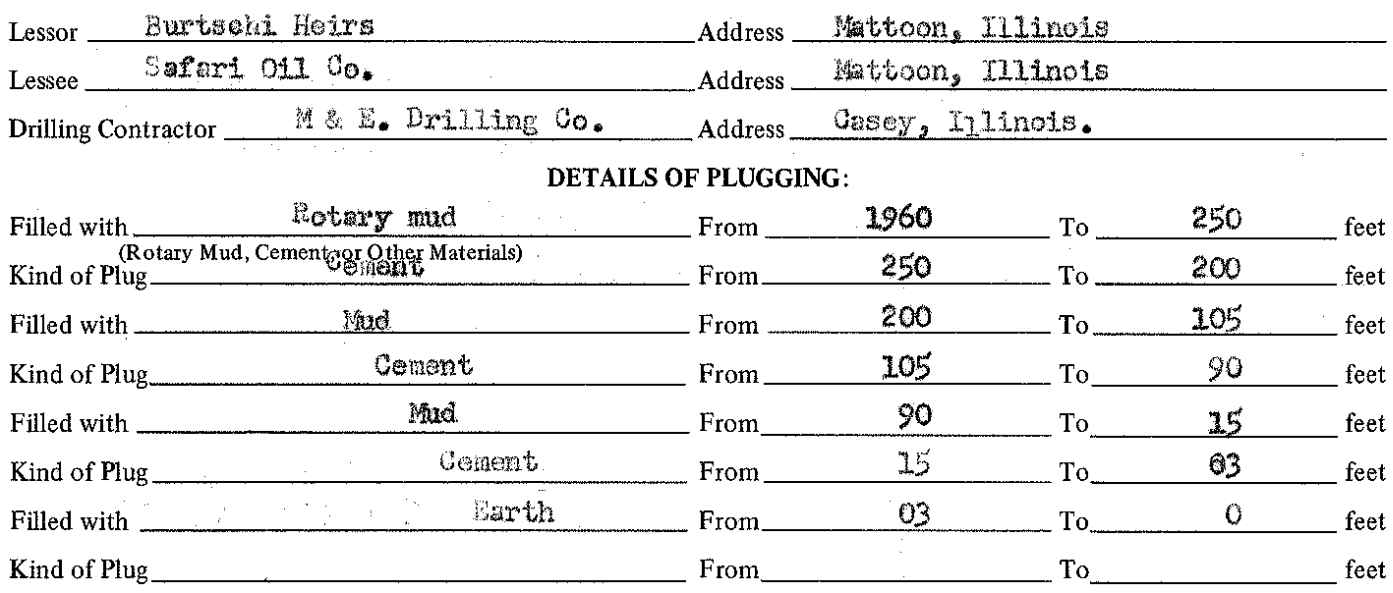

IF WORKABLE COAL BEDS WERE ENCOUNTERED IN THIS HOLE; DESCRIBE THE METHOD EMPLOYED TO PROTECT SAME. (A workable coal bed is thirty inches or more in thickness above 1,000 feet in depth) None encountered

(1) Have pits and other excavations been filled? $\ldots \ldots \ldots \ldots \ldots \ldots \ldots \ldots$ Yes

(2) Have the following been removed?

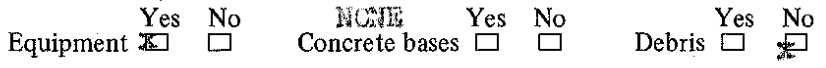

(3) Has surface casing been cut off three feet below ground surface?

(4) Has well-site been leveled? . .

If this was a producing well, give date and amount of last production

\section{CASING RECORD}

PUT IN WELL
Size
Feet

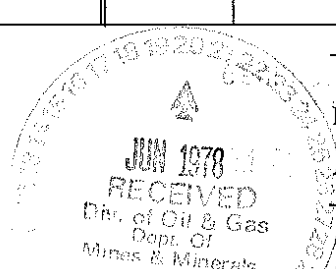

(Sighathre of person, firm or corporation haying custody or contról of well.) t 1 Aderess Sottoon, nilinois (Signature and titele of party supervising plugging of well.) Address 3500 Grant Ave. Whtoon, TlImois - 61938

Subscribed and sworn to before me this $17 \mathrm{th} /$ day of

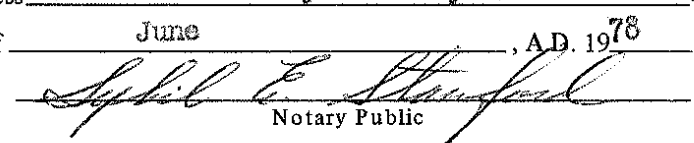


-

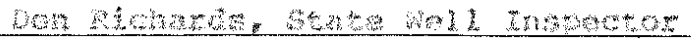
do depose and say the following is a true and correct statement of the detailsof being first duly sworn drilled for $\quad 0$ is

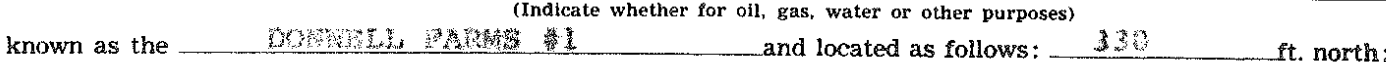

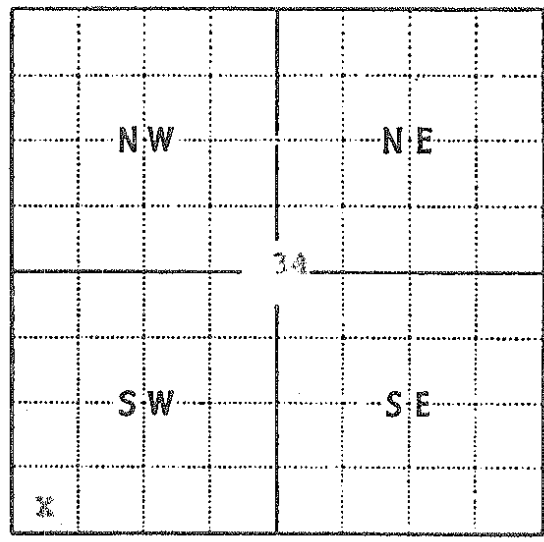

Locale well accurately on plat of section (Scale one inch-2, $2,000 \mathrm{ft}$.) ft. south; 3 in

ft. east: fit. west of the corner of the Q Q Cuarter of the________uarter of the________________erter of Section $\quad$ _t Township_ 13 (North or South) Range_ 7 , (East or West), of the $3 \quad \mathrm{~J}$ Principal Meridian,_._. County, Mlinois. Elevation above sea level is $\begin{cases}\text { Derrick Floor } & \text { ft. } \\ \text { Ground } & \text { ft. }\end{cases}$

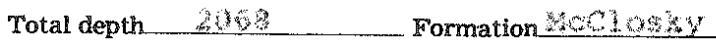
Date permit to drill issued-4 -47 Pemit No. 39923 Permit issued to

Date drilling began___

Date drilling completed

Kind of drilling tools used

Date plugging began $\quad 4-6-3$

Date plugging completed _ _ _ n

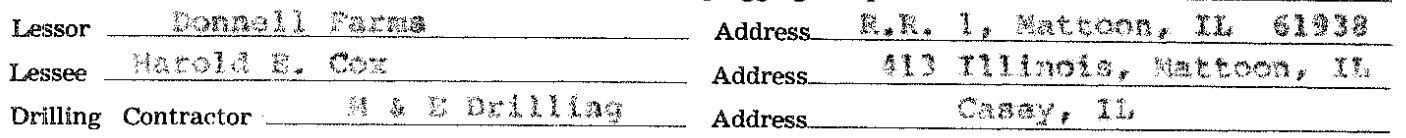

DETAILS OF PLUGGING:

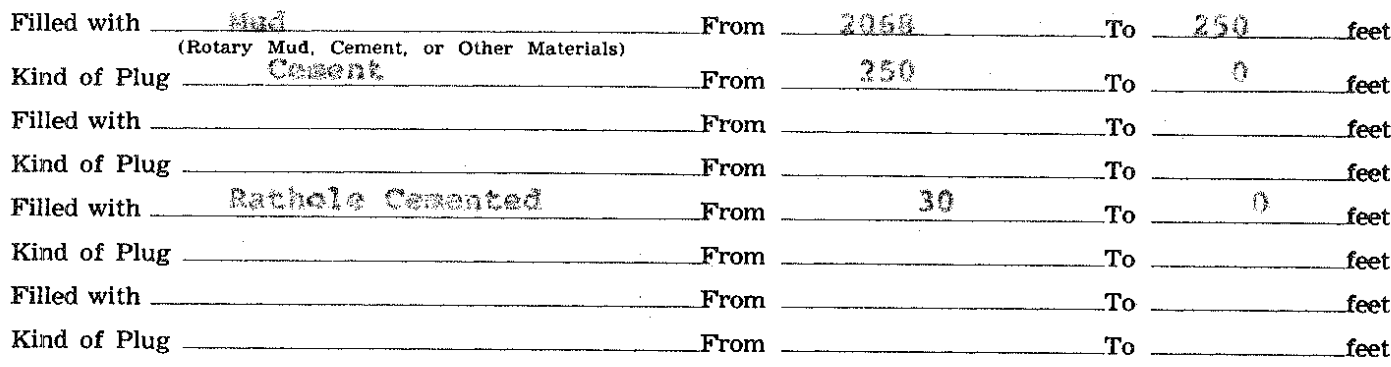

IF WORKABLE COAL BEDS WERE ENCOUNTERED IN THIS HOLE, DESCRIBE THE METHOD EMPLOYED TO PROTECT SAME. (A workable coal bed is thirty inches or more in thickness above 1,000 feet in depth) Qon 1 .

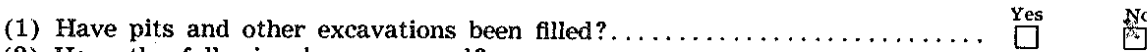

(2) Have the following been removed?

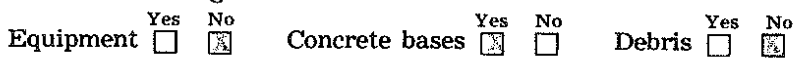

(3) Has surface casing been cut off three feet below ground surface?

(4) Has well-site been leveled?

If this was a producing well, give date and amount of last production

$$
\text { No }
$$
t

\section{CASING RECORD}

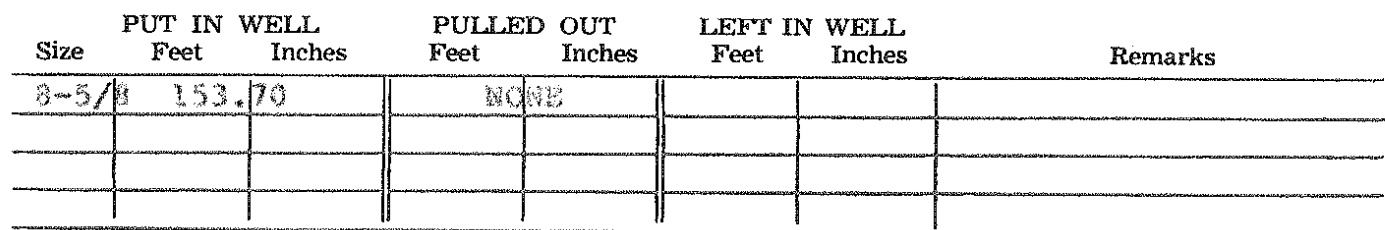

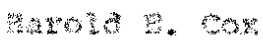

(Signature of pergong firm gregatog havgng custody or control of well.)

Address

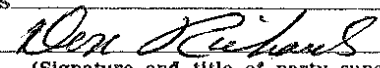

(Signature and title of party supervising plugging of well.)

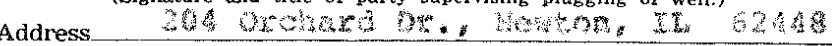
Subscribed and sworn to before me this btat day of My commission expires 

do depose and say the following is a true and correct statement of the details of the plugging of a certain well drilled for OL1

known as the $\quad$ andseh 1 Indicate whether for oil, gas, water or other purposes) and located as follows:

ft. north;

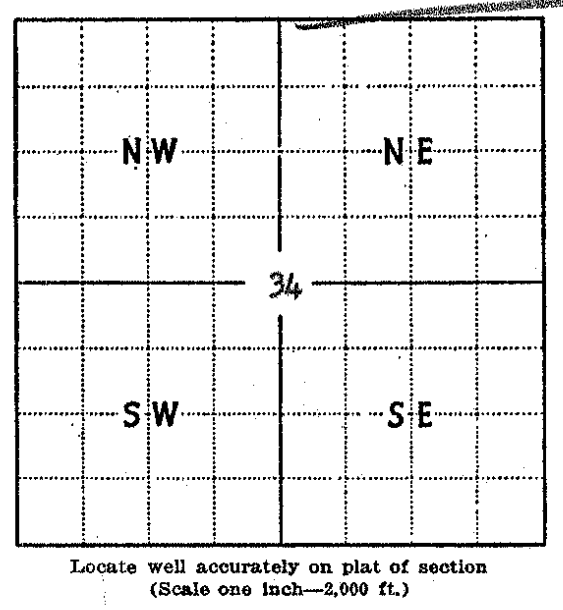
$330 \mathrm{ft}$. south; $332 \mathrm{ft}$. east;

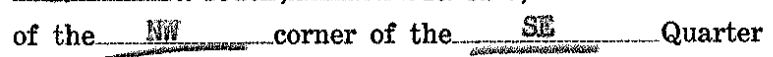
of the S2 Quarter of the Quarter of Section 34 , Township 13 (North or \$bthth) Range 7 , (East or Whest), of the

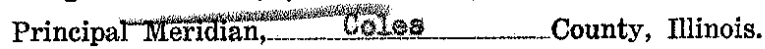
Elevation above sea level is $\begin{cases}\text { Derrick Floor } & \text { ft. } \\ \text { Ground } & \text { ft. }\end{cases}$

Total depth $1972 \quad$ Formation Date permit to drill issued $12-20-56$ permit No. 36 Permit issued to M. Nobinson Date drilling began Decerabo 13,2956 Date drilling completed December 24,1956 Kind of drilling tools used Date plugging began Novergbos 42.957

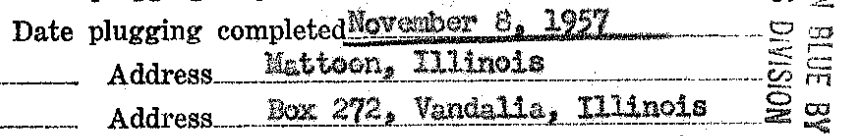

Lessor Danie I nuxtsent Lessee_H. Hobinson

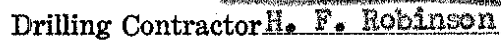

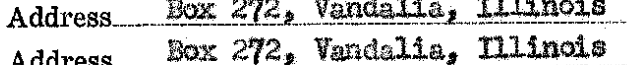

\section{DETAILS OF PLUGGING:}

Filled with

Kind of Plug

Filled with

Kind of Plug

Filled with

Kind of Plug

Filled with

Kind of Plug
From

From

From

From

From

From

From

From

$\begin{array}{rrrr} & \text { To } & & \text { feet } \\ 1972 & \text { To } & 189 & \text { feet } \\ 1289 & \text { To } & 60 & \text { feet } \\ 60 & \text { To } & 29 & \text { feet } \\ 29 & \text { To } & 8 & \text { feet } \\ 8 & \text { To } & 3 & \text { feet } \\ 3 & \text { To } & 0 & \text { feet } \\ & \text { To } & & \text { feet }\end{array}$

IF WORKABLE COAL BEDS WERE ENCOUNTERED IN THIS HOLE, DESCRIBE THE METHOD EMPLOYED TO PROTECT SAME. (A workable coal bed is thirty inches or more in thickness above 1,000 feet in depth) Nons

(1) Have pits and other excavations been filled? $\ldots \ldots \ldots \ldots \ldots \ldots$

(2) Have the following been removed?

Equipment $\stackrel{\text { Yes }}{\square}$ Concrete bases $\stackrel{\text { Tes }}{\square} \underset{\square}{\square}$ Debris $\stackrel{\text { Yes }}{\square} \underset{\square}{\square}$

(3) Has surface casing been cut off three feet below ground surface?

(4) Has well-site been levelled? ..................

If this was a producing well, give date and amount of last production

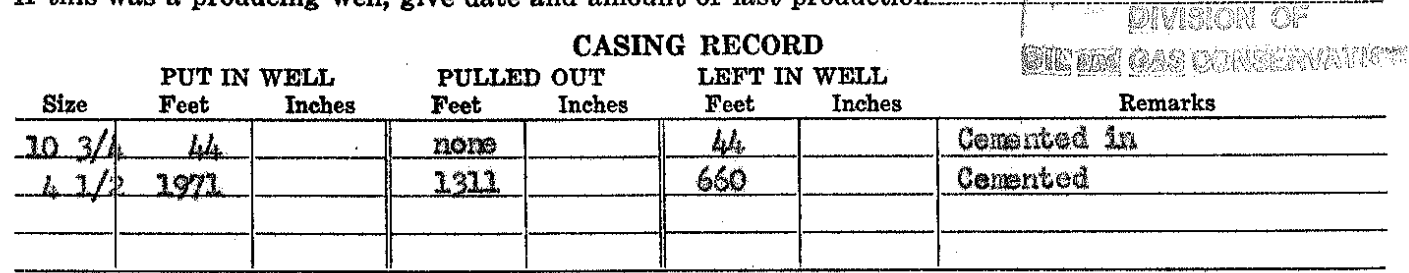

1. R. Roktinson

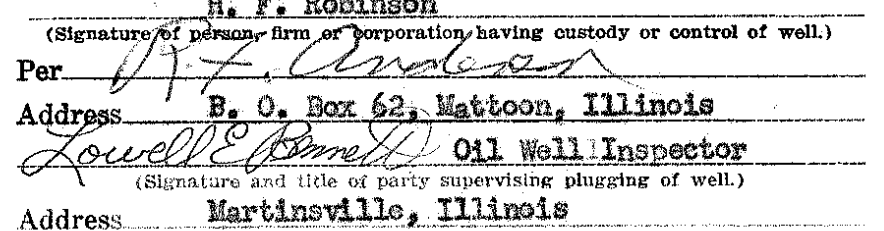

Subsemed and sworn to before me this $y$ day of row

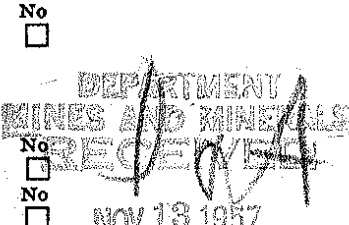




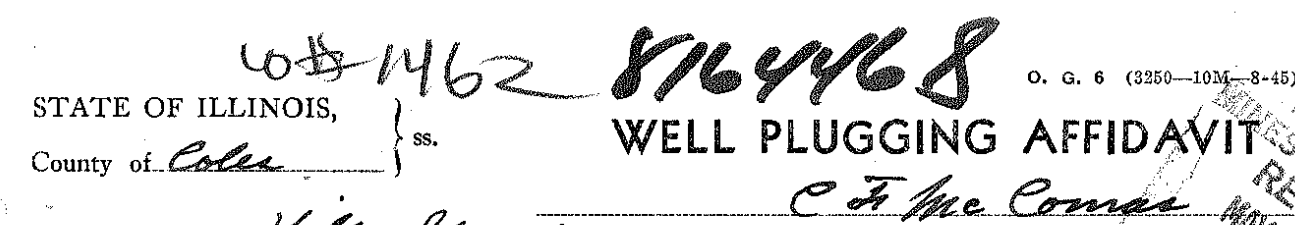

cots $146 z$ The
WELL PLUGGING AFFIDAVIT

Halters Stement

being first dexth sworn do depos and

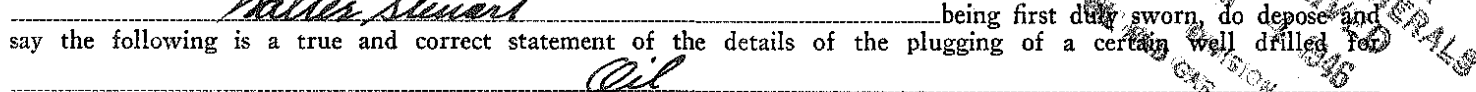

known as the (Indicate whether for oil, gas, water or other purposes)

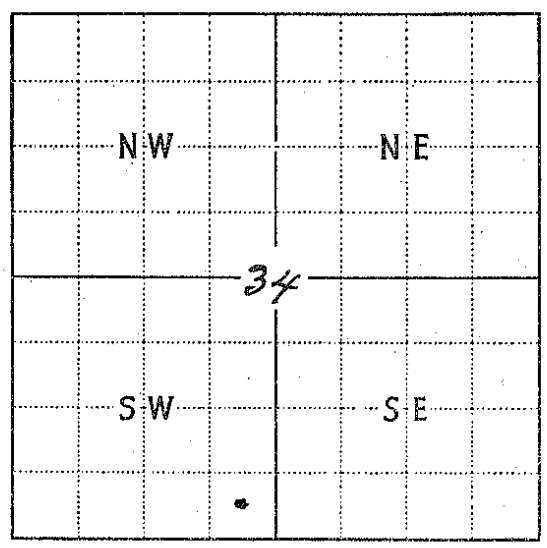

Locate well accurately on plat of section (Scale one inch-2,000 ft.) of the $S E$

ft. south;

$\mathrm{ft}$ east; $330 \quad \mathrm{ft}$. of the Quarter of the Quarter of Section 34 , Township_ > 3 (North or-South) Range $\quad$, (East ontwest), of the $?$

Principal Meridian, _. Cee County, Illinois. Elevation above sea level is $\left\{\begin{array}{l}\text { Derrick Floor } \\ \text { Ground } 69\end{array}\right.$ Total depth of well is 2002 Date permit to drill issued LlOeendest2-19\%6-

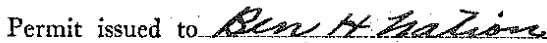
Date drilling began $0 \mathrm{Dec} 14-1845$

Date drilling completed $\angle Q \mathrm{Qee} 30-184 \mathrm{~s}^{\circ}$

Kind of drilling tools used Pyeses

Date plugging began Seyil $30-1946$

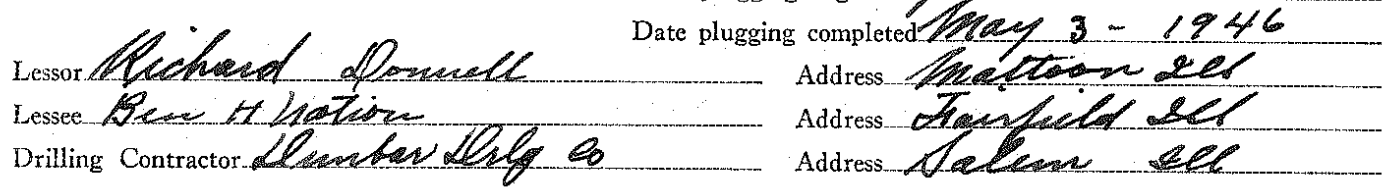

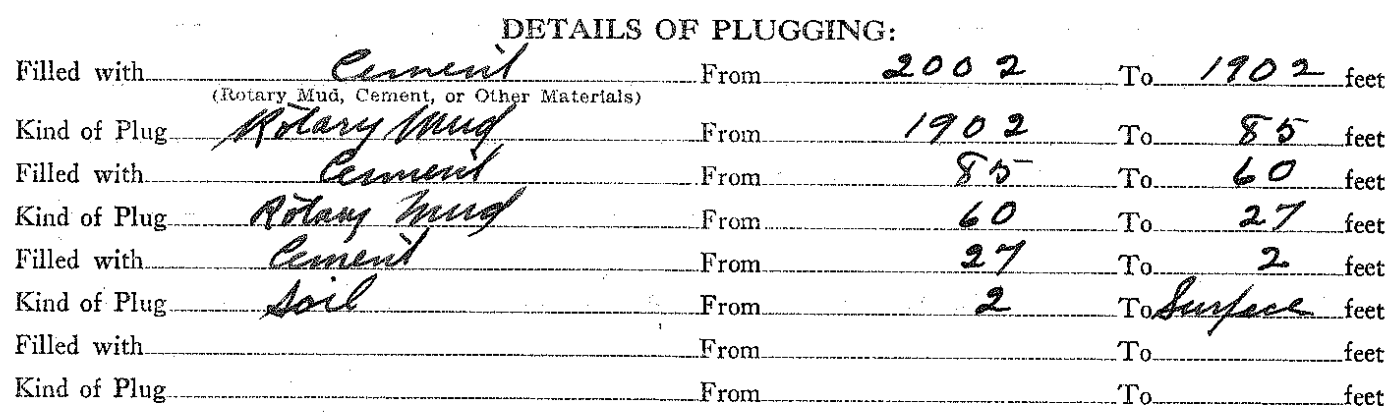
IF WORKABLE COAL BEDS WERE ENCOUNTERED IN THIS HOLE, DESCRIBE THE METHOD EMPLOYED TO PROTECT SAME. (A workable coal bed is thirty inches or more in thickness above 1,000 feet in depth.

Other details

If this was a producing well, give date and amount of last production

CASING RECORD

\begin{tabular}{|c|c|c|c|c|c|c|c|}
\hline \multirow[b]{2}{*}{ Size } & \multicolumn{2}{|c|}{ PUT IN WELL } & \multicolumn{2}{|c|}{ PULLED OUT } & \multicolumn{2}{|c|}{ LEFT IN WELL } & \multirow[b]{2}{*}{ Remarks } \\
\hline & Feet & Inches & Feet & Inches & Feet & Inches & \\
\hline 1034 & 51 & & 2 & & 79 & & \\
\hline \multirow[t]{3}{*}{22} & 1987 & & 1505 & & 482 & & \\
\hline & & & & & & & \\
\hline & & & & & & & \\
\hline
\end{tabular}

\footnotetext{
(Signature of person, firm or corporation having custody or control of well.) Per $\quad 1.72=6$ anes

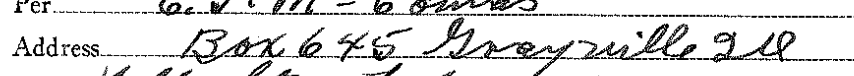

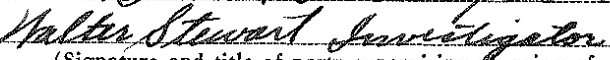

(Signature and title of party supervising piugging of well.)

Address Daxiz PR2

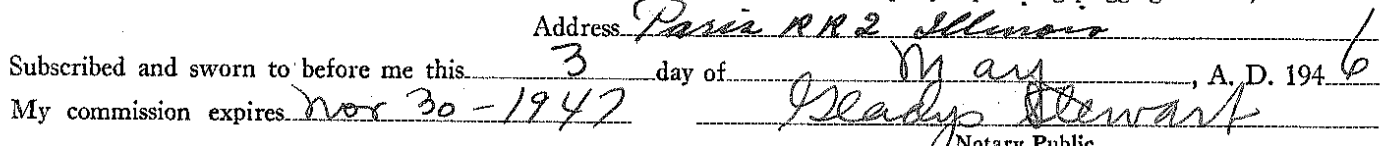


35-13N-7E 
STATE OF ILLINOIS,

County of Cole__ $\}$ ss. Lawrence Landreth
say the following is a true and correct statement of the details of the plughing of a certain well drilled fo 011

(Indicate whether for oil gasi water or other purposes)

known as the Bareithen \# 1
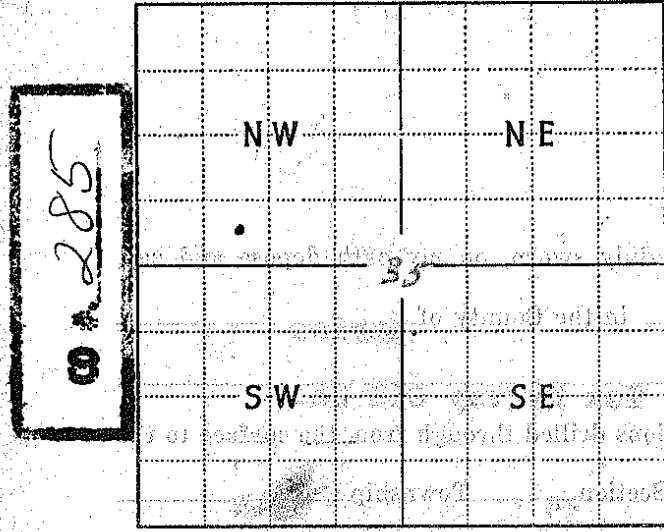

Locate well accurately on plat of section Scale one inch-2,000 ft.)

mint को

Barcither

Lessee Tex Haxey ol $1 \mathrm{Co}$

Drilling Contractor Company Tools

\section{WELL PLUGGING AFFIDAVHT}

\section{Foe-DIXo}

gging of a certain well drilled for

and located as follows: 330 ft. north ft. west

of the SW - corner of the N A Luarter

of the Quarter of the Quarter of

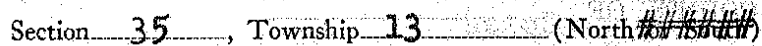

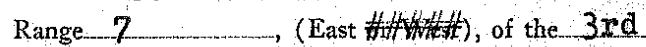

Principal Meridian, Cole County, Illinois. Elevation above sea level is $\left\{\begin{array}{l}\text { Derrick Floor } 692 \\ \text { Ground }-683\end{array}\right.$ Total depth of well is. 3193

Date permit to drill issued $8 / 16 / 46$

Permit issued to Tex Harvey $011 \mathrm{Co}$

Date drilling began $8 / 16 / 46$

Date drilling completed $8 / 26 / 46$

Kind of drilling tools used.

Rotary

Date plugging began $8 / 26 / 46$

Date plugging completed $8 / 26 / 46$

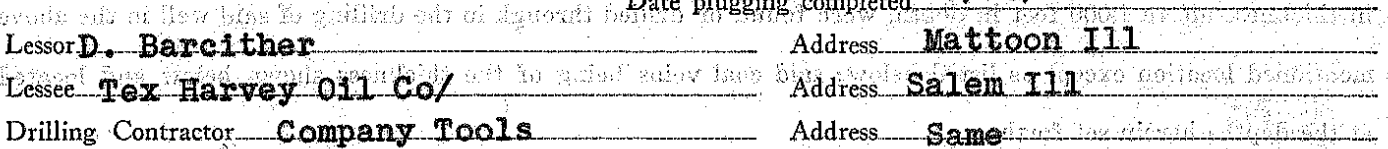

DETALS OF PLUGGING:

Filled with mud

Kind of Plug Cement

From Surface

To 3193 feet

Filled with Hud Cement From 309

From 3193

Filled with Mud

From $\quad \frac{145}{120}$

Kind of Plug Cement

From 120

28

From

From

From

To 3093 feet

To 145 feet

To 120 feet

To 28 feet

Filled with

Kind of Plug

IF WORKABLE COAI BEDS WERE ENCOUNTERED IN THIS HOLE, DESCRIBE THE METHCH EMPLOYED TO PROTECT SAME. (A workable coal bed is thirty inches or more in thickness above 1,000 feet in depth

Other details

If this was a producing well, give date and amount of last production

CASING RECORD

\begin{tabular}{|c|c|c|c|c|c|c|c|}
\hline \multirow{2}{*}{ Size } & \multicolumn{2}{|c|}{ PUT IN WELL } & \multicolumn{2}{|c|}{ PULLED OUT } & \multicolumn{2}{|c|}{ LEFT IN WELL } & \multirow{2}{*}{ Remarks } \\
\hline & Feet & Inches & Feet & Inches & Feet & Inches & \\
\hline $10 / 3 / 4$ & 120 & & & & 120 & & Cemented \\
\hline & & & 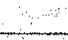 & & & & \\
\hline & & & & & & 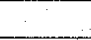 & \\
\hline & & & & & 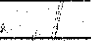 & & \\
\hline
\end{tabular}<smiles>COCCOC(C)C</smiles>

\section{Per \\ Address}

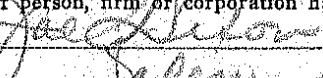

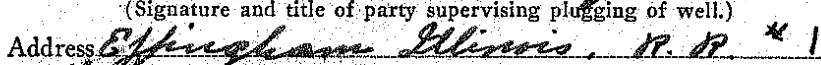
Subscribed and sworn to before me this 2842 day of
My commission expires $2-20-1930$ 
Form $0 G-6$

STATE OF ILLINOIS

SS.

WELL PLUGGING AFFIDAVIT

County of

Capitol Indemnity for R.H.B. \& issociates

being first duly sworn, do depose and say the following is a true and correct statement of the detalls of the plugging of a certain well drilled tor

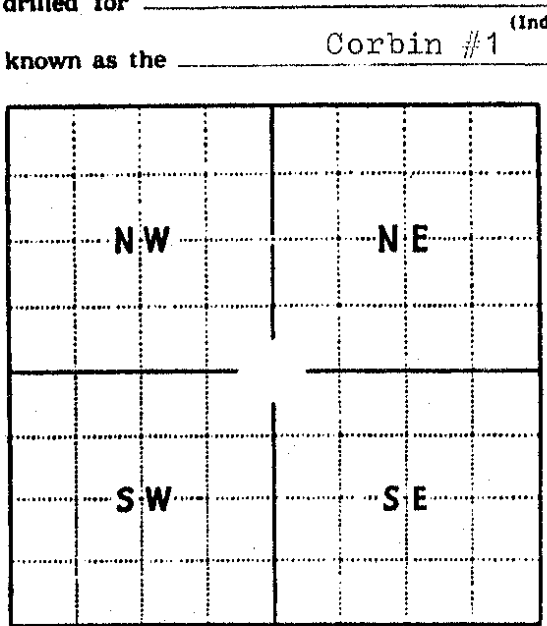

Locate well cocurately on plat of ecction (Scale one inch $-2,000$ ft.

(Indicate whether tor oll, gas, water or other purpowes) and located as follows: $330^{1}$ ft. north: of the ft. south; $\quad$ ft. east $;-\frac{990^{\prime}}{\mathrm{SW}} \mathrm{ft}$ west of the_Quarter of the_______arter of Section 35 . Township___ 13 (Noith or Soluth) Range___ 7 (East or Weat), of the

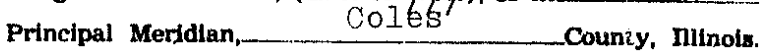

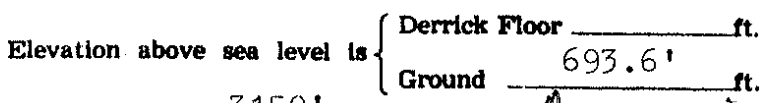

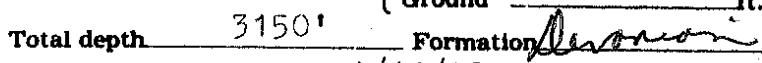
Date permit to drill issued $4 / 11 / 78$ ermit No. 5487 Permit issued to Lelef act $v$ Las Date drilling began._. $5 / 29 / 78$ Date drilling completed 11/14/78

Kind of drilling tools used Date plugging began $\quad 7 / 20 / 89$

Date plugging completed__ $\quad 7 / 21 / 89$

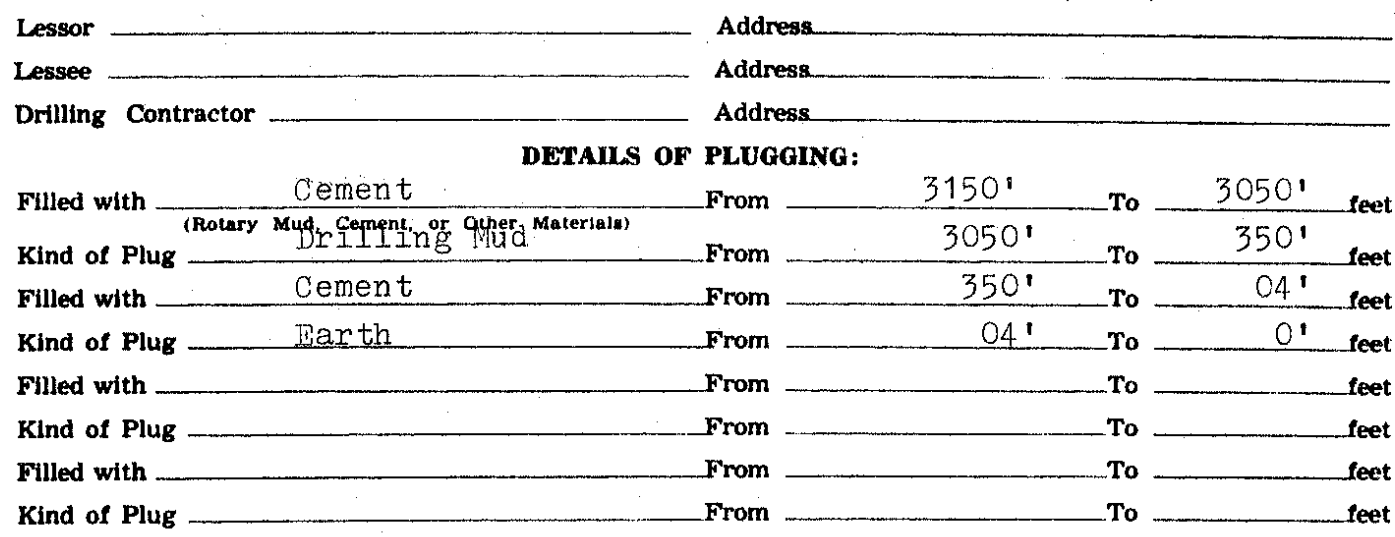

IF WORKABLE COAL BEDS WERE ENCOUNTERED IN THIS HOLE, DESCRIBE THE METHOD EMPLOYED TO PROTECT SAME. (A workable coal bed is thirty inches or more in thickness above 1,000 feet in depth)

(1) Have pits and other excavations been filled?

(2) Have the following been removed?
Equipment Yes No
Concrete bases Yeu

(3) Has surface casing been cut of three feet below ground surface?

(4) Has well-site been leveled? .

If this was a producing well, give date and amount of last production

CASING RECORD

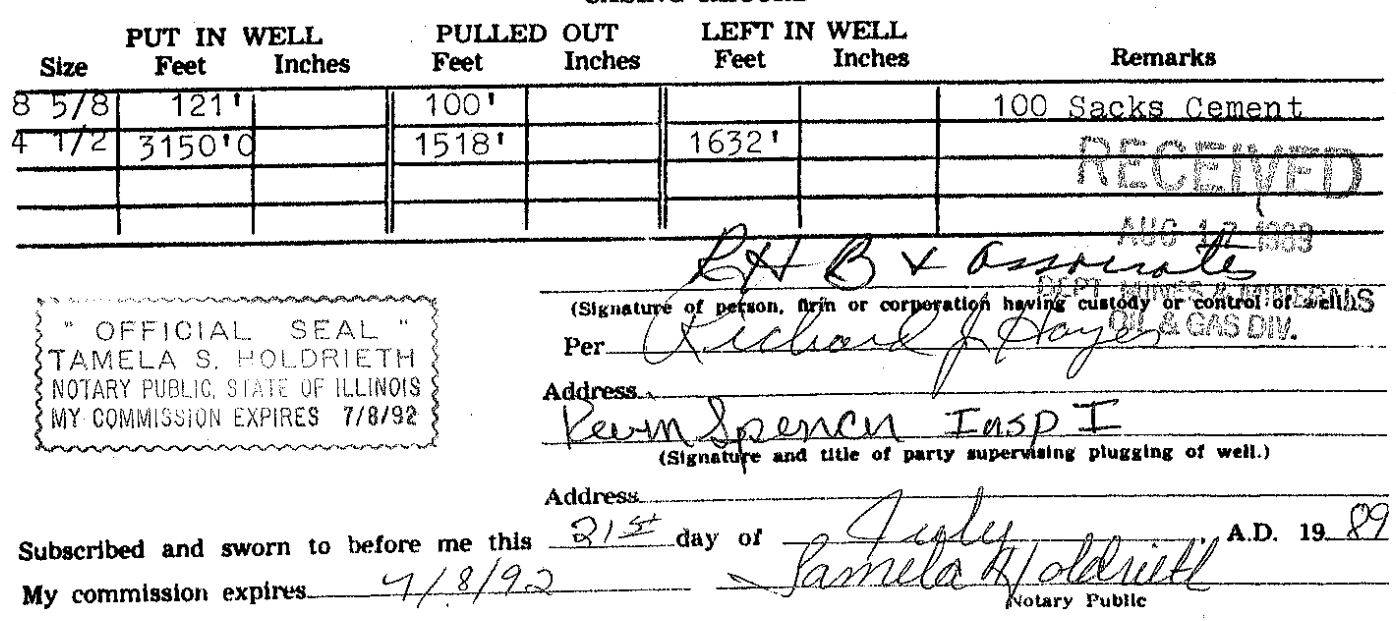


Form $09-6$

STATE OF ILLINOIS

County of Coles $\}$ ss.

$10+534$

WELL PLUGGING AFFIDAVIT

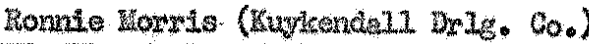

Lowe II. 32. Bencet

being first duly sworn,

do depose and say the following is a true and correct statement of the details of the plugging of a certain well drilled for

oti andona

known as the Dar Baxtether 1

Indicate whether tor oil gas, wa

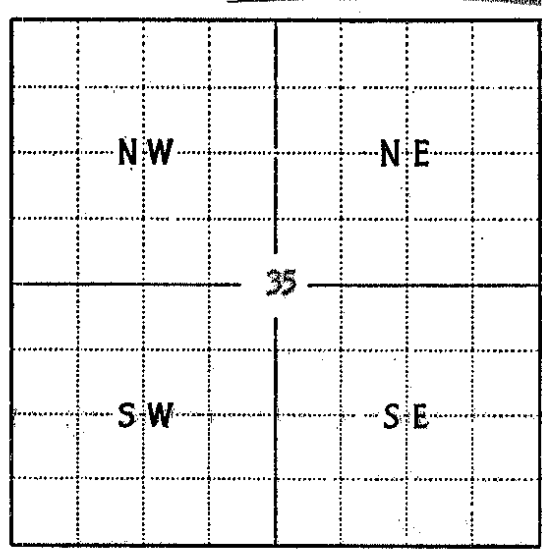

Locate well accurately on plat of section (Seale one inch $-2,000$ : th.)

Lessor Dan Bartether

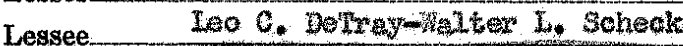

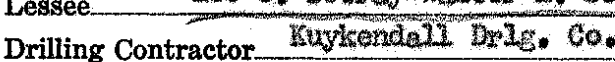
and located as follows: 330 ft. south; 330 ft. east; SU the of the W Quarter of the Quarter of Section 35 , Township 13 (North or Soluthy Range_ 7 , (East or West), of the and Principal Meridian, County, nlinois. Elevation above sea level is $\left\{\begin{array}{l}\text { Derrick Floor_aft. } \\ \text { ft. }\end{array}\right.$ Total depth 2010 Formation Date permit to drill issued $12-12-56$ Permit No. 44549 Permit issued to heo C. DeTray-helter L. Seheck Date drilling began Decenbes 13,1956 Date drilling completed Deconber 22,1956 Kind of drilling tools used otary Date plugging began Dember 20, 1956 Date plugging completed Decosas 20,1956 plugging completed

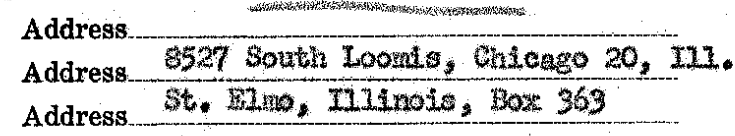

DETAILS OF PLUGGING:

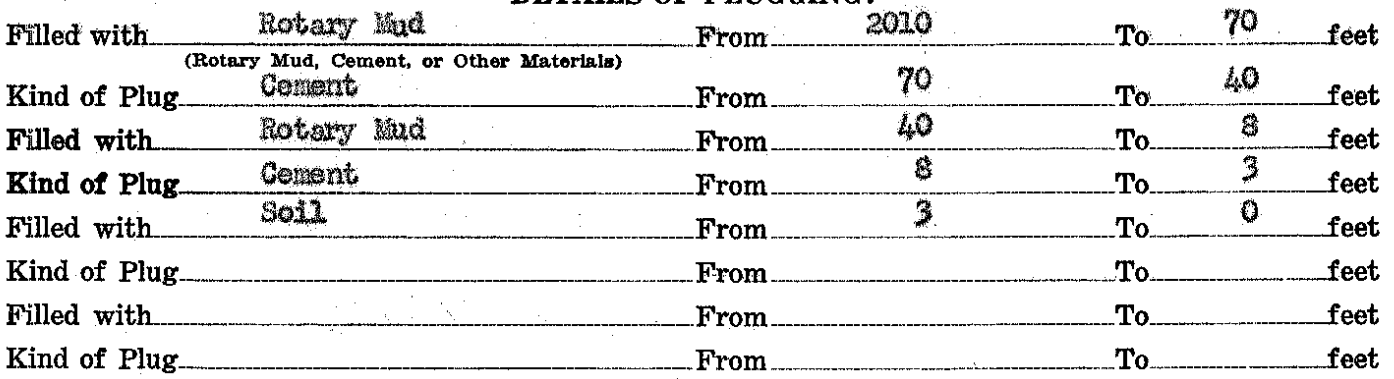

IF WORKABLE COAL BEDS WERE ENCOUNTERED IN THIS HOLE, DESCRIBE THE METHOD EMPLOYED TO PROTECT SAME. (A workable coal bed is thirty inches or more in thickness above 1,000 feet in depth) None

(1) Have pits and other excavations been filled?

(2) Have the following been removed?

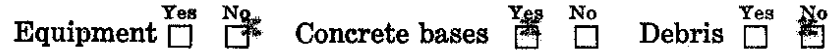

(3) Has surface casing been cut off three feet below ground surface?

(4) Has well-site been levelled?

If this was a producing well, give date and amount of last production
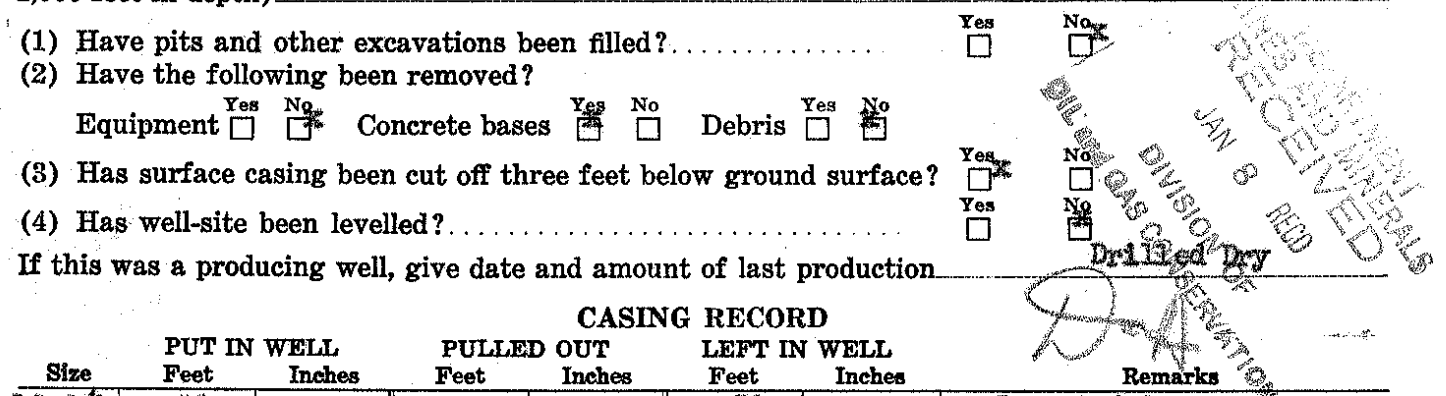

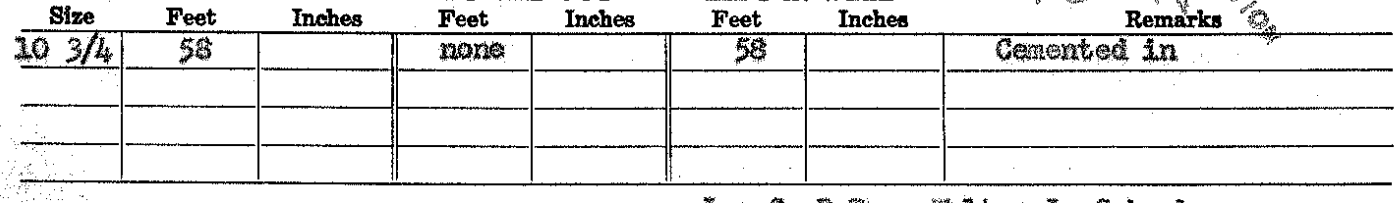

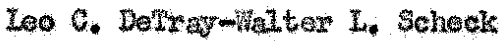

(SIgnaturs of person, firm or corporation having custody or control of well.)

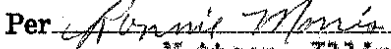

Address I I

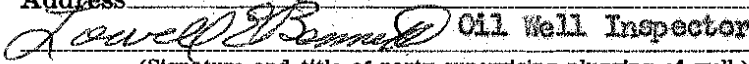

(Signature and titlo of party supervising plugging of well.)

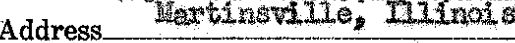

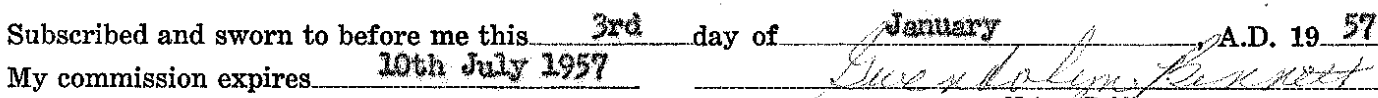




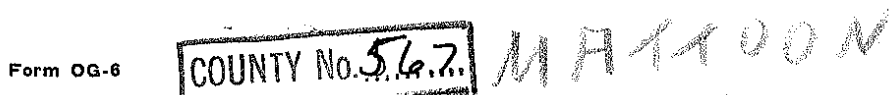

$\left.\begin{array}{l}\text { STATE OF ItITNOIS } \\ \text { County of couns }\end{array}\right\}$ ss. WELL PLUGGING AFFIDAVIT

of

Whencher do depose and say the following is a true and correct statement of the details of the plugging of a certain

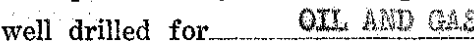

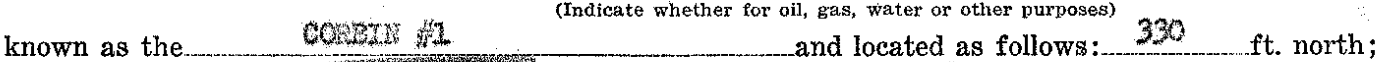

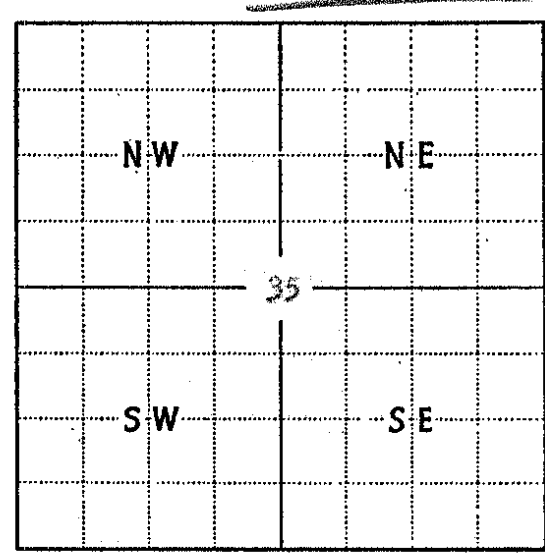

Locate well accurately on plat of section (Scale one inch-2,000 ft.)

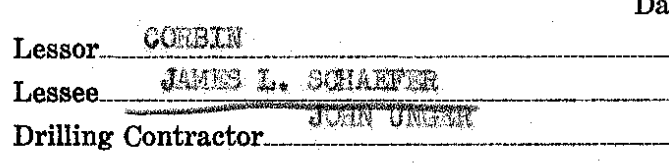

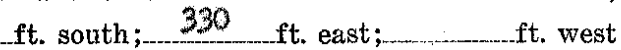

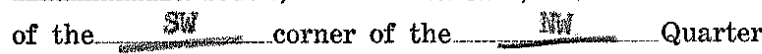
of the $\quad \mathrm{W}$ Quarter of the Quarter of

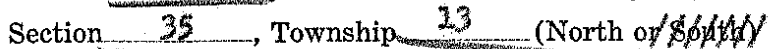
Range Principal Meridian, c..... County, Illinois. Elevation above sea level is $\left\{\begin{array}{l}\text { Derrick Floor } \\ \text { Ground }\end{array}\right.$ Total depth 977 Formation FOSICLAL Date permit to drill issued $3,20-57$ permit No. 646

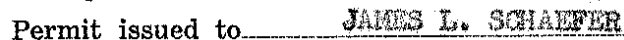
Date drilling began $\quad 3-21-57$ Date drilling completed $3-27-57$ Kind of drilling tools used $10 \mathrm{~m}$ WL Date plugging began $\quad 3-27-57$ Date plugging completed $3+37$

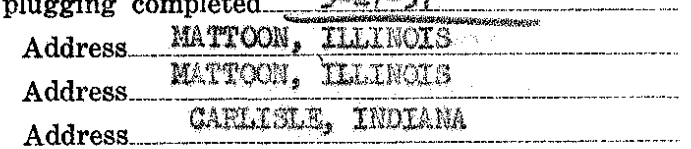

DETAILS OF PLUGGìn:

\begin{tabular}{|c|c|c|}
\hline 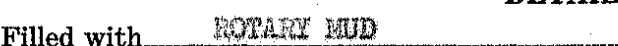 & Trom $\quad 197$ & feet \\
\hline 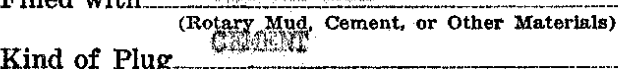 & From & 50 \\
\hline Filled with & From & feet \\
\hline Kind of Plug cy & From & To \\
\hline Filled with & From & To f feet \\
\hline Kind of Plug & From & To_____ feet \\
\hline Filled with & From & To feet \\
\hline Kind of Plug & From & To \\
\hline
\end{tabular}

IF WORKABLE COAL BEDS WERE ENCOUNTERED IN THYS HOLE, DESCRIBE THE METHOD EMPLOYED TO PROTECT SAME. (A workable coal bed is thirty inches or more in thickness above 1,000 feet in depth) Mo 004

(1) Have pits and other excavations been filled?

(2) Have the following been removed?

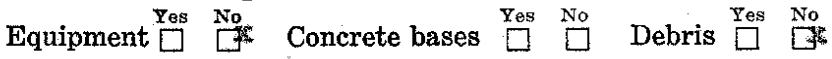

(3) Has surface casing been cut off three feet below ground surface? Yes

(4) Has well-site been levelled?

If this was a producing well, give date and amount of last production

Yes o

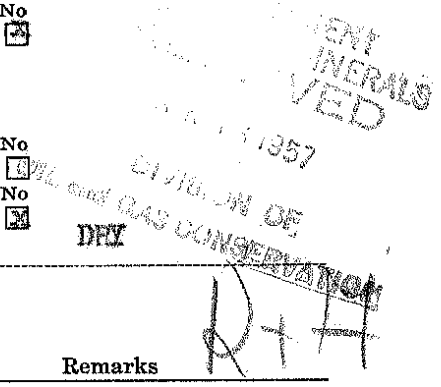

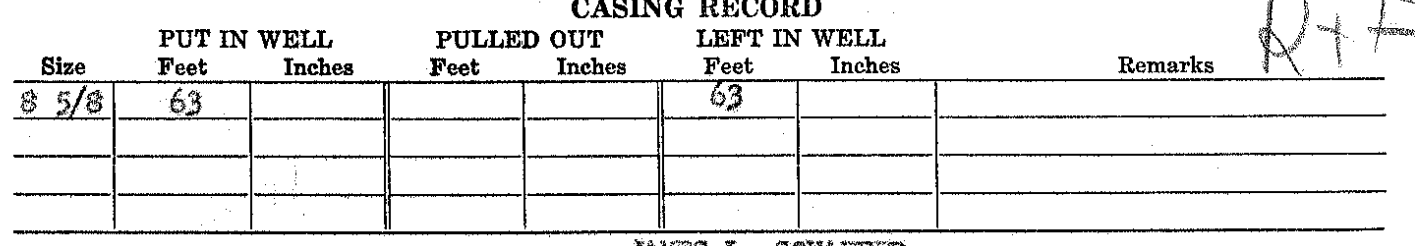

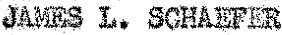

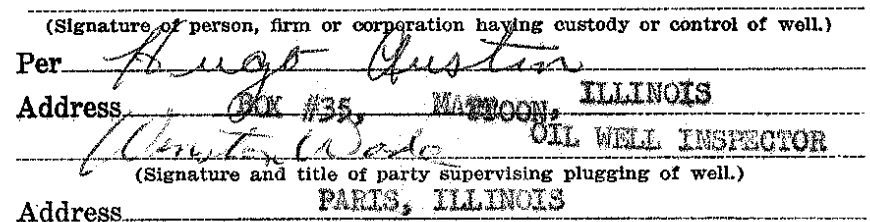

Subscribed and sworn to before me this 8 ta My commission expires $3-9+61$. 
do depose and say the following is a true and correct statement of the details of the plugging of a certain well drilled for oli andor cas

\section{(Indicate whether for oil, gas, water or other purposes)}

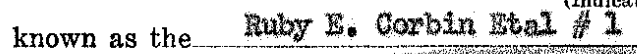

and located as follow:

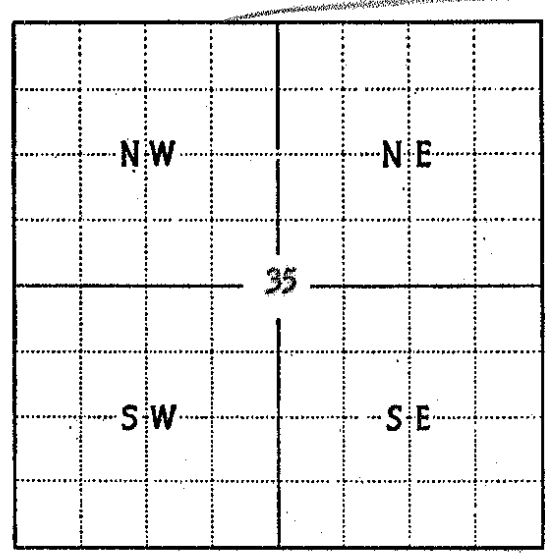

Locate well accurately on plat of section (Scale one tnch-2,000 ft.)

\section{0} ft. south;

ft. north:

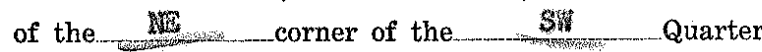
of the SW Quarter of the Q Quarter of

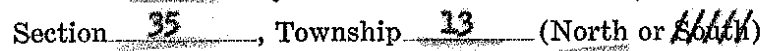
Range 7 , (East or $(W 66 t)$, of the 2 nd Principal Meridian, Coles County, Illinois. Elevation above sea level is $\left\{\begin{array}{l}\text { Derrick Floor } \\ \text { Ground } 683.1\end{array}\right.$ Total depth 1993 Formation Date permit to drill issued $10-22-5$ Permit No. 3899 Permit issued to Ashland Oal peftring Company Date drilling began October 22, 1956 Date drilling completed 0ctober 30,1956 Kind of drilling tools used Rotary Date plugging began Detobe 30,1956 Date plugging completed October 30,1956

\begin{tabular}{|c|c|c|}
\hline & $\sin$ & ress... \\
\hline & 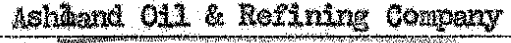 & 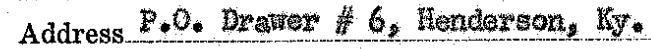 \\
\hline vill & Annett Dronlung Company & ess 3 inen, $I$ \\
\hline
\end{tabular}
DETAILS OF PLUGGING:

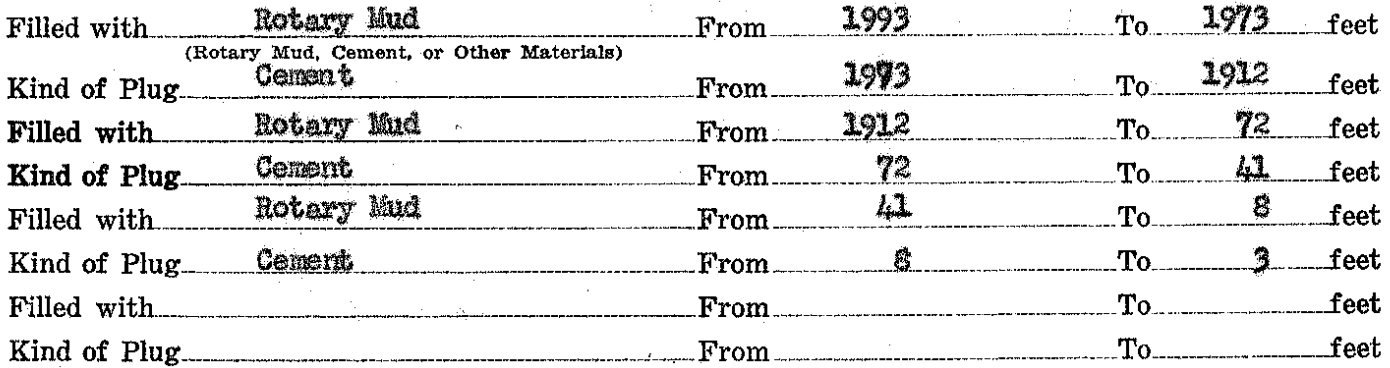

IF WORKABLE COAL BEDS WERE ENCOUNTERED IN THIS HOLE, DESCRIBE THE METHOD EMPLOYED TO PROTECT SAME. (A workable coal bed is thirty inches or more in thickness above 1,000 feet in depth) Hone

(1) Have pits and other excavations been filled?

(2) Have the following been removed?

Equipment $\stackrel{\text { № }}{\square}$ Concrete bases $\stackrel{\text { Yes }}{\square} \stackrel{\text { No }}{\square}$ Debris

(3) Has surface casing been cut off three feet below ground surface?

(4) Has well-site been levelled?.

If this was a producing well, give date and amount of last production

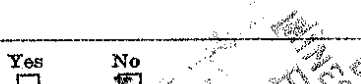

\section{Yes}

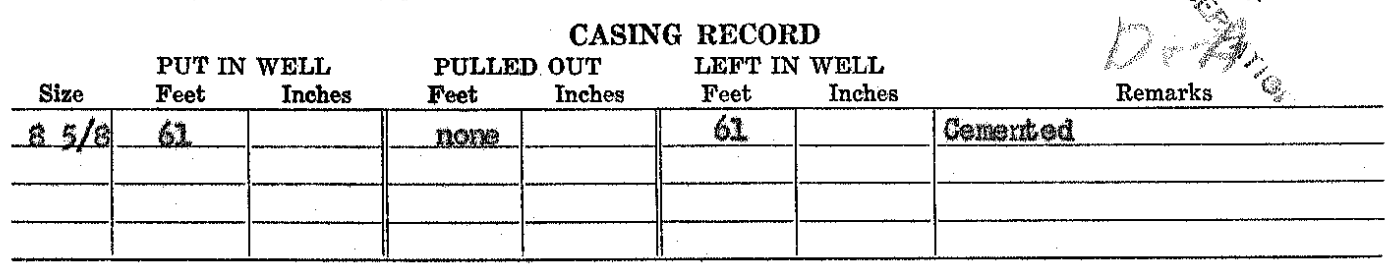

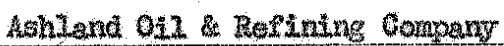

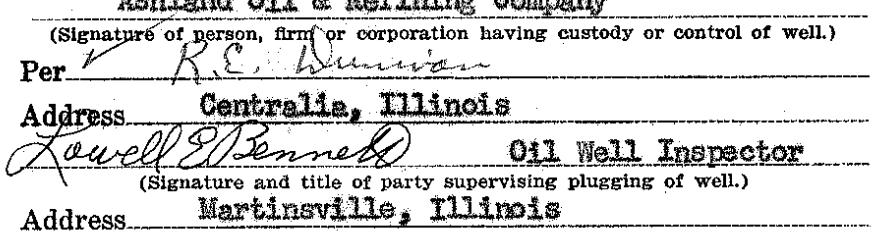

Subscribed and sworn to before me this 19 th day of f Wovember My commission expires 104h Juty 225 day of f tovenbe A.D. 19.56 
35-13N-7E-1 


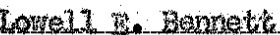
being first duly sworn, do depose and say the following is a true and correct statement of the details of the plugging of a certain well drilled for

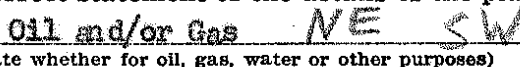

known as the and located as follows:

990 ft. north;

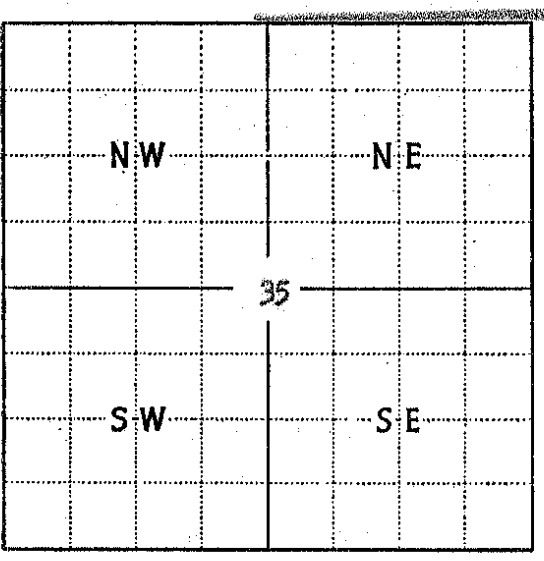

Locate well accurately on plat of section (Scale one Inch-2,000 ft.) ft. south; 990 ft. east; ft. west of the of the___ Quarter of the____ Quarter of Section 35 , Township 13 (North or S S/thly) Range 7 , (East or Wést), of the $2 n d$ Principal Meridian,_._coles__County, nlinois. Elevation above sea level is $\left\{\begin{array}{l}\text { Derrick Floor } 684 \ldots \ldots \mathrm{ft} . \\ \text { Ground }\end{array}\right.$ Total depth $1964 \quad$ Formation Date permit to drill issued $3-7=57$ Permit No

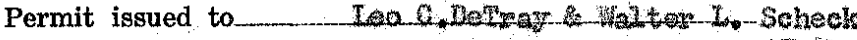

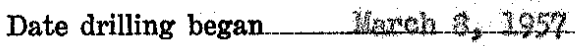
Date drilling completed tiatedi- 8,1957 Kind of drilling tools usedirovidy

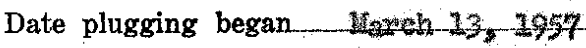

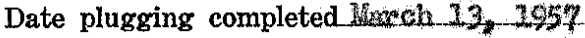

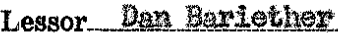
Address

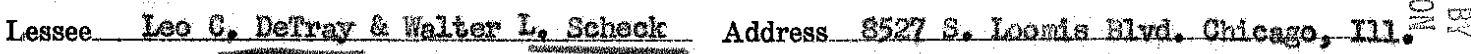

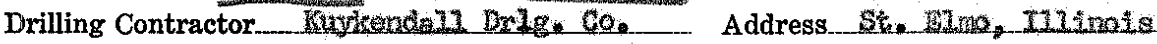
DETAILS OF PLUGGING:

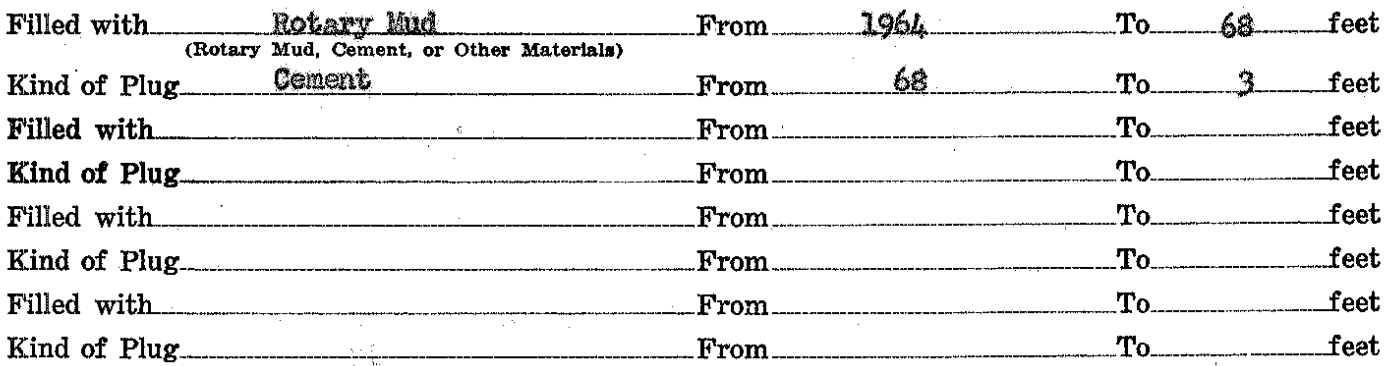

IF WORKABLE COAL BEDS WERE ENCOUNTERED IN THIS HOLE, DESCRIBE THE METHOD EMPLOYED TO PROTECT SAME. (A workable coal bed is thirty inches or more in thickness above 1,000 feet in depth) 期one

(1) Have pits and other excavations been filled?

(2) Have the following been removed?

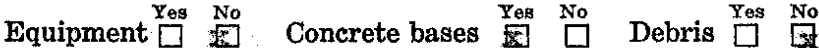

(3) Has surface casing been cut off three feet below ground surface?

(4) Has well-site been levelled?

If this was a producing well, give date and amount of last production

Yos No

\begin{tabular}{|c|c|c|c|c|c|c|c|}
\hline & & & & CAS & REC & & \\
\hline Size & $\begin{array}{l}\text { PUT } \\
\text { Feet }\end{array}$ & $\begin{array}{l}\text { WELLL } \\
\text { Inches }\end{array}$ & $\begin{array}{l}\text { PULI } \\
\text { Feet }\end{array}$ & $\begin{array}{l}\text { OUT } \\
\text { Inches }\end{array}$ & $\begin{array}{l}\text { LEFF } \\
\text { Feet }\end{array}$ & $\begin{array}{l}\text { WELL } \\
\text { Inches }\end{array}$ & Remarks \\
\hline $103 / 4$ & 58 & & none & & 50 & & Comentud in \\
\hline & & & & & & & \\
\hline & & & & & & & \\
\hline
\end{tabular}

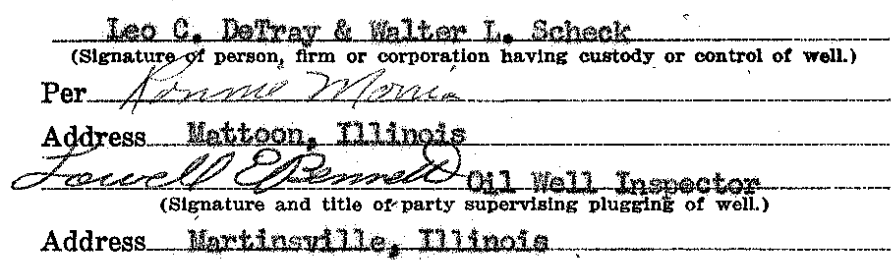

Subscribed and sworn to before me this. 4 th day of 2 - 


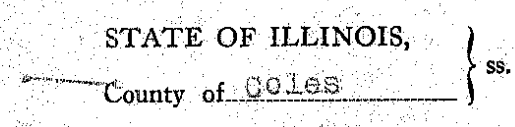

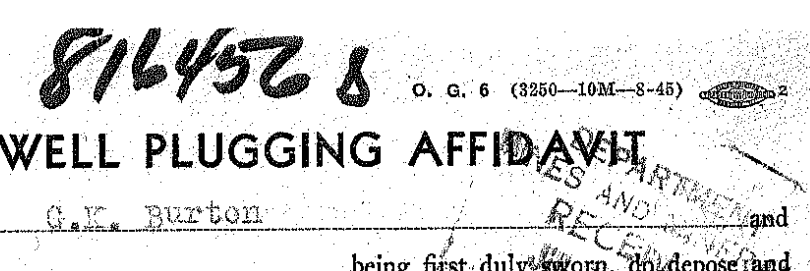

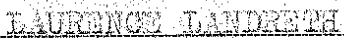

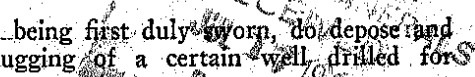

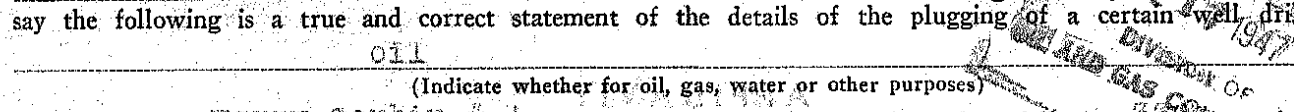

known as the arengengin
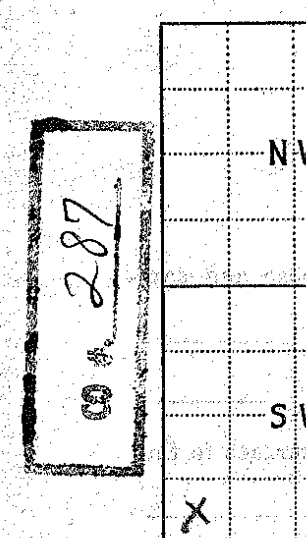

Locate well accurately on plat of section

(Scale one inch-2,000 ft.)

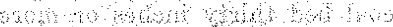

保

ft. south ; 350

of the 1 corner of the

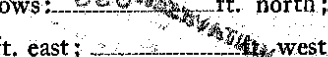

of the Quarter

of the Quarter of the Quarter of

Section 34 , Township 15 (North or Sonth)

Range $I$, (East ar West), of the

Principal Meridian, coles

County, Illinois.

Elevation above sea level is $\{$ Derrick Floor ft

Ground $68 \mathrm{e}$.

Total depth of well is 1906 ft.

Date permit to drill issued $00 t, 9,1948$

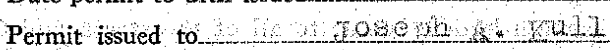

Date drilling began $20 / 6 / 46$

Date drilling completed $10 / 2 n / 40$

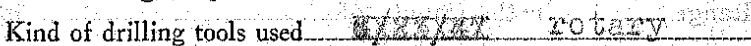

Date plugging began $\mathrm{C} / \mathrm{t} / \mathrm{s} / \mathrm{s}$

Date plugging completed $\quad 6 / 25 / 2 \%$

Lessor Han oorbin Address $15 \mathrm{t} 6002, \mathrm{LL}$

Lessee 10001,0 trd

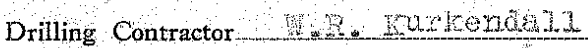

Address 30600,121

Address

\section{DETALL OF PLUGGNG:}

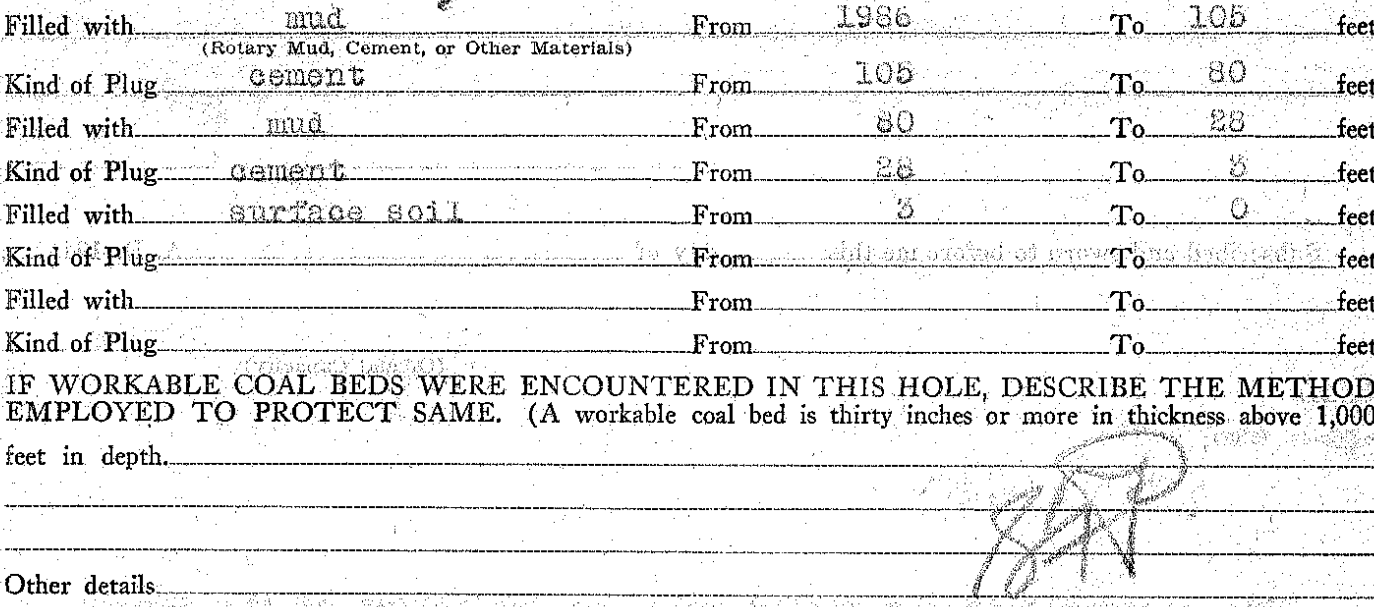

If this was a producing well, give date and amount of last production $10 y$

\section{CASING RECORD}

PUT IN WELL
Inches

(Signatuze of persop fyno or corporation laving custody or control of well.) Per $72,2+2<2$

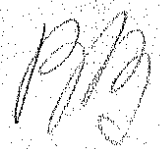

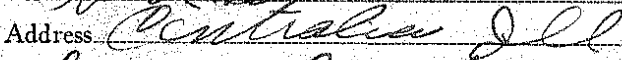

Signature and title of party supervising plugging of well.)
.

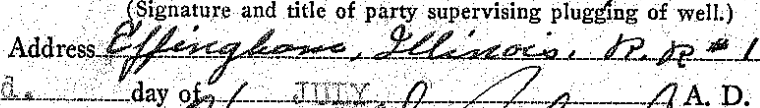
Subscribed and sworn to before me this $\mathrm{wh}_{\mathrm{S}} \mathrm{S} / \mathrm{S}$ 
Form OG-6

STATE OF ILLINOIS

County of. ss.

do depose and say the following is a true and correct statement of the details of the plugging of a certain well drilled for ois andor gas

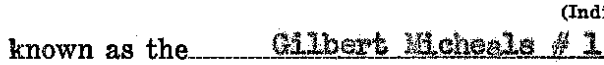
Indicate whether for oil, gas, water or other purposes)

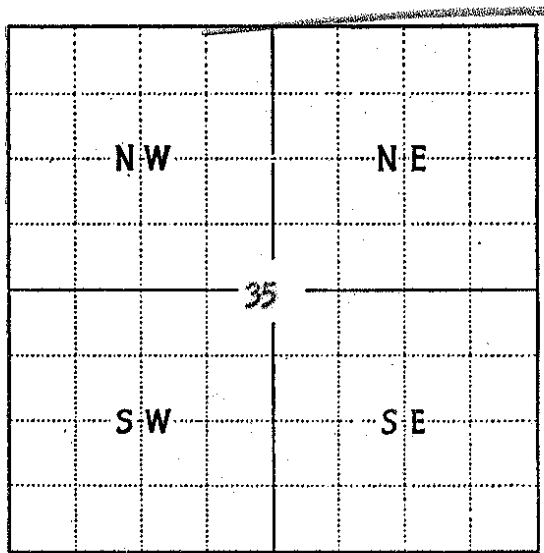

Locate well accurately on plat of section (Scale one inch-2,000 ft.) and located as follows: $320 \mathrm{ft}$ north; ft. south; 330 ft. east; _ ft. west

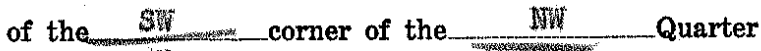
of the Quarter of the Quarter of Section 35 , Township 13 (North or \$66th) Range 7 , (East or Weaft), of the 2nd Principal Merian, County, Illinois. Elevation above sea level is $\left\{\begin{array}{l}\text { Derrick Floor } \\ \text { Ground } 681\end{array}\right.$

Total depth 1975 Formation Date permit to drill issued $-37-57$ Permit No.- 862

Permit issued to Robert Whature

Date drilling began ard 27,1957

Date drilling completed $4 x+23,2957$

Kind of drilling tools used Rot aty

Date plugging began 404212,1957

Date plugging completed Axp 1123,1957

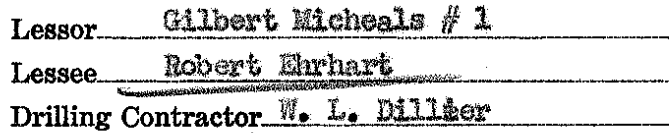

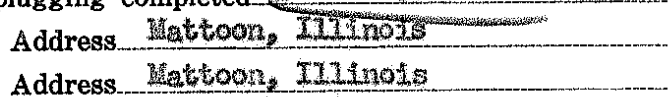
Address Caser, IIInols

DETAILS OF PLUGGING:

\begin{tabular}{|c|c|c|c|c|c|}
\hline Filled with & 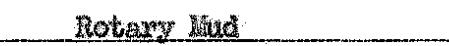 & From & 72 & To 90 & ee \\
\hline Kind of Plug & $\begin{array}{l}\text { (Rotary Mud Coment, or Other Materlals) } \\
\text { Cengut }\end{array}$ & From & 90 & To 42 & \\
\hline Filled with & Powary & From & 42 & To 32 & \\
\hline IKind of Plug & Centent & From & 32 & To 3 & \\
\hline Filled with & & From & & To & \\
\hline Kind of Plug & & From & & To & \\
\hline Filled with & & From & & To & \\
\hline Kind of Plug & & From & & To & \\
\hline
\end{tabular}

IF WORKABLE COAL BEDS WERE ENCOUNTERED IN THIS HOLE, DESCRIBE THE METHOD EMPLOYED TO PROTECT SAME. (A workable coal bed is thirty inches or more in thickness above 1,000 feet in depth). Mone

(1) Have pits and other excavations been filled? $\ldots \ldots \ldots \ldots \ldots \ldots \square$ ?os

(2) Have the following been removed?

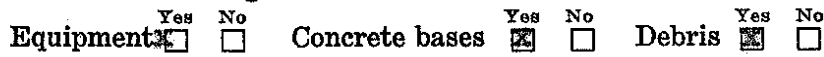

(3) Has surface casing been cut off three feet below ground surface?

(4) Has well-site been levelled?. . . . . . . . . . . . . . .

If this was a producing well, give date and amount of last production

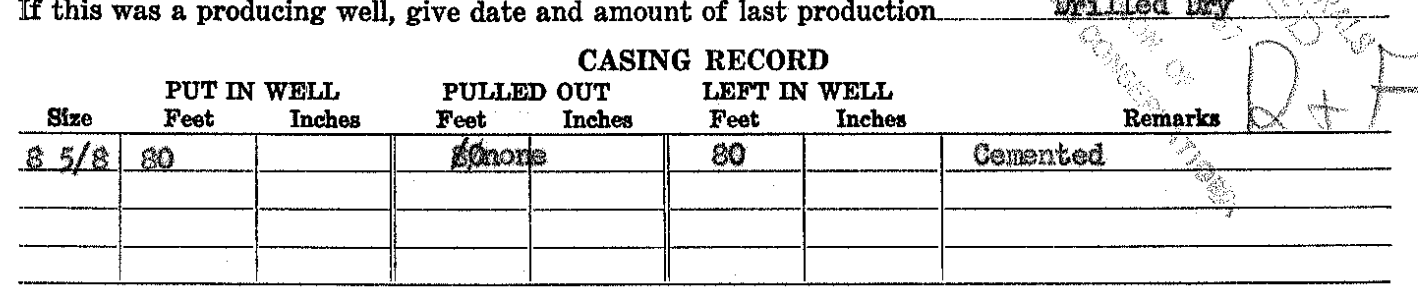

Whot wathat

(Signatuze of person form or corporation having custody or control of well.)

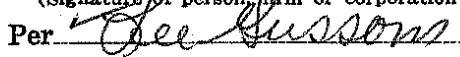

Address Gase Dutnols.

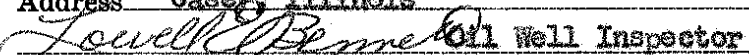

(Signature and title of party supervising plugging of well.)

Address Martinsville, Nulinois

Subscribed and sworn to before me this $3 \mathrm{rd}$ day of 2 , A.D. 1957

My commission expires 10 th Juty 1957 day of 1 tey 
36-13N-6E 
do depose and say the following is a true and correct statement of the details of the plugging of a certain well drilled for ort

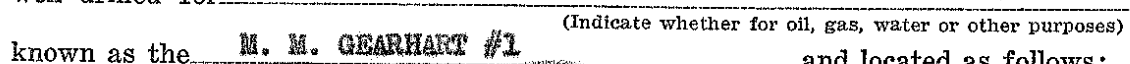

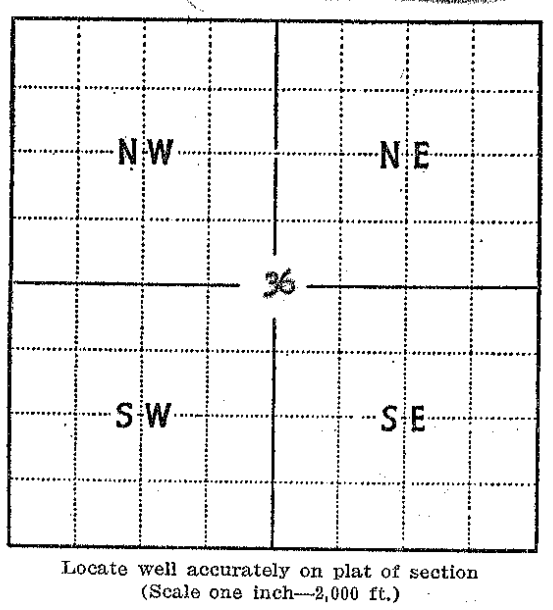

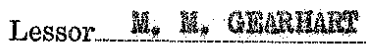

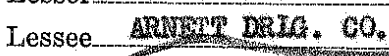

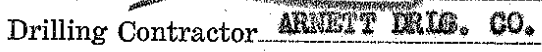
and located as follows: 330 ft. south; $\mathrm{ft}$. east; $330 \mathrm{ft}$. west ft. north; of the corner of the Q of the SI Quarter of the Quarter of Section 39 (North of Ahpth)

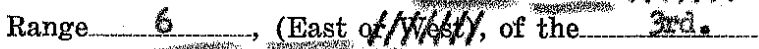
Principa Meridian, County, Mllinois. Elevation above sea level is $\left\{\begin{array}{l}\text { Derrick Floor } \\ \text { Ground }\end{array}\right.$ Total depth_230 Formation

Date permit to drill issued Permit No.

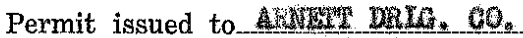

Date drilling began $\quad 5-31-56$

Date drilling completed $6-56$

Kind of drilling tools used Woghy

Date plugging began $6-9456$

Date plugging completed 6956

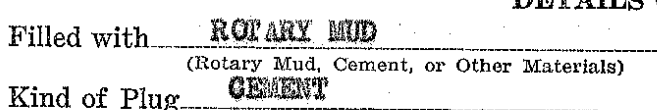

Filled with oon

Kind of Plug arda

Address

Address SALEH, HULOS

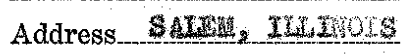

Filled with

Kind of Plug

Filled with.

PLUGGING:

Kind of Plug.

From 2250 To feet

From $\quad 75$

From

50

$\begin{array}{lrr}\text { To } & 50 & \text { feet } \\ \text { To } & \text { feet }\end{array}$

IF WORKABLE COAL BEDS WERE ENCOUNTERED IN THIS HOLE, DESCRIBE THE METHOD EMPLOYED TO PROTECT SAME. (A workable coal bed is thirty inches or more in thickness above 1,000 feet in depth) WO 004

(1) Have pits and other excavations been filled?

(2) Have the following been removed?

Equipment $\stackrel{\text { Yes }}{\square}$ 楼 Concrete bases $\stackrel{\text { Yes }}{\square} \stackrel{\text { No }}{\square}$ Debris $\stackrel{\text { Yes }}{\square}$

(3) Has surface casing been cut off three feet below ground surface?

(4) Has well-site been levelled?

If this was a producing well, give date and amount of last production

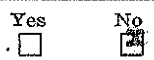

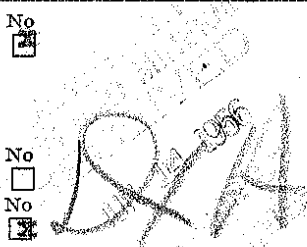

wax

\begin{tabular}{|c|c|c|c|c|c|c|c|}
\hline \multirow[b]{3}{*}{ Size } & \multirow{2}{*}{\multicolumn{2}{|c|}{ PUT IN WELL }} & \multicolumn{4}{|c|}{ CASING RECORD } & \multirow{3}{*}{ Remarks } \\
\hline & & & \multicolumn{2}{|c|}{ PULLED OUT } & \multicolumn{2}{|c|}{ LESTT IN WELL } & \\
\hline & Feet & Inches & Freet & Inches & Feet & Inches & \\
\hline $5 / 8$ & 63 & & & & 6. & & \\
\hline & & & & & & & \\
\hline & & & & & & & \\
\hline & & & & & & & \\
\hline
\end{tabular}

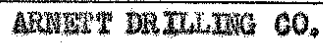

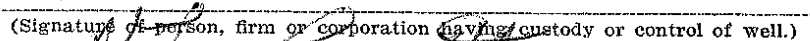

Per $11-2 \quad 02 a d 2$

Address, 1

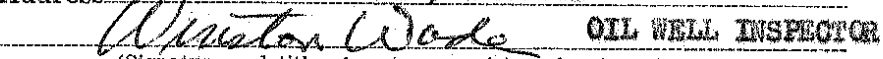

Address (Signature and title of party supervising plugging of well.) Subscribed and sworn to before me this who day of
My commission expires 3 mo-2.

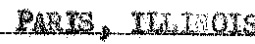




\section{$9-10.05$}

\section{ILLINOIS DEPARTMENT OF NATURAL RESOURCES Office of Mines and Minerals \\ Division of Oll and Gas COUNTY No.212/6 One Natural Resources Way (217) 557-6379 COUNTY No.2.2/6 Springfield, Illinois 62702/1271}

\section{OG-6 WELL PLUGGING REPORT}

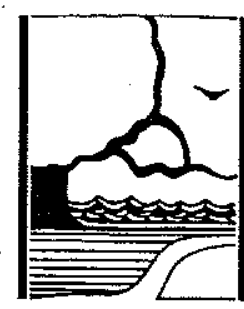

TYPE OF WELL: XPRODUCTION $\square$ CLASS II $\square$ GAS STORAGE $\square$ REPLUG $\square$ OTHER

Permittee: RK Petroleum Corp PERMITTEE\#:

WELl NAME:Bank Trust $\#$ PERMIT : 0.57022 REFERENCE\#: 209464

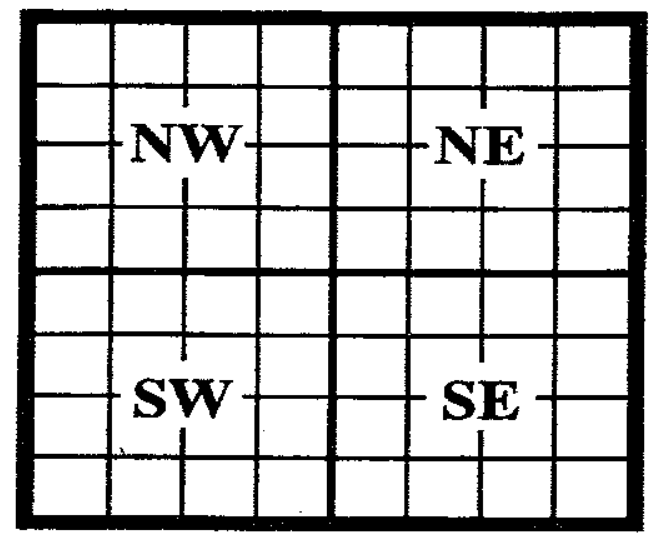

county Moultrié SECTION 36 TWP $13 \AA$ RANGE $06 E$ LOCATION: FT. NORTH; OR O.33O FT. SOUTH, AND 0.330 FT. EAST; OR FT. WEST OF THE $\overline{M W}$ CORNER OF THE $\overline{N E}$ QUARTER OF THE $\$ \Psi$ QUARTER OF THE QUARTER OF THE QUARTER.

WELL DATA:

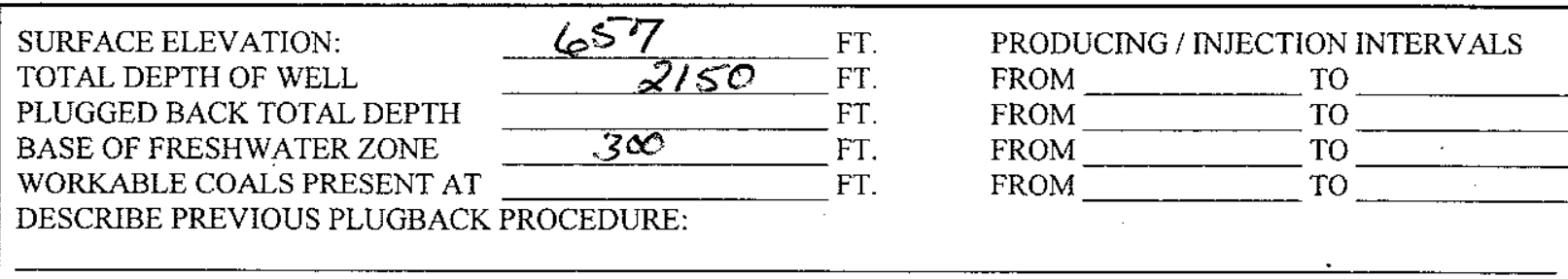

DETAILS OF PLUGGING:

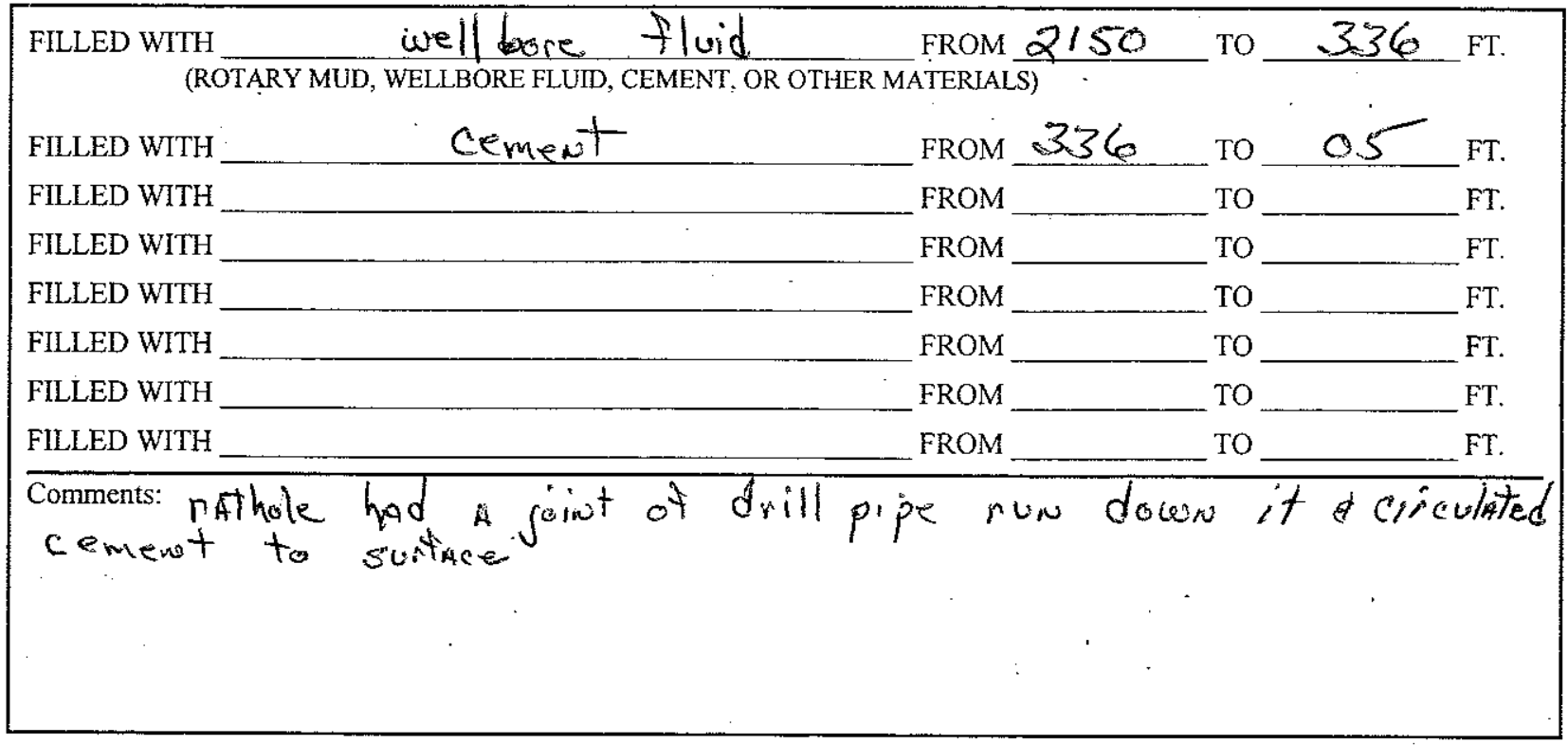


WELL DATA:

\begin{tabular}{|l|c|c|c|c|c|c|}
\hline \multicolumn{1}{|c|}{ CASING } & SIZE & $\begin{array}{c}\text { SETTING } \\
\text { DEPTH }\end{array}$ & $\begin{array}{c}\text { SACKS } \\
\text { CEMENT }\end{array}$ & $\begin{array}{c}\text { HOLE } \\
\text { SIZE }\end{array}$ & $\begin{array}{c}\text { EST. TOP } \\
\text { OF } \\
\text { CEMENT }\end{array}$ & $\begin{array}{c}\text { AMOUNT OF } \\
\text { CASING } \\
\text { REMOVED }\end{array}$ \\
\hline SURFACE & 8.6 .3 & 1306 & 22.5 & 12.25 & 0 & \\
\hline $\begin{array}{l}\text { INTERMEDIATE/ } \\
\text { MINE STRING/OR } \\
\text { LINER }\end{array}$ & & & & & & \\
\hline PRODUCTION & NA & & & & & \\
\hline
\end{tabular}

Under penalties of perjury, I declare that I have examined this form including accompanying statements and documents, and to the best of my knowledge, it is true, correct and complete.

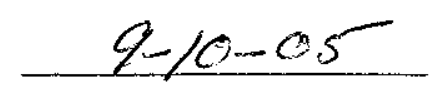

Signature of Permittee or Designee

Address

City, State, Zip
Date Plugging began

$9-10-05$

Date Plugging Completed

$\square$ Inspector present during plugging operations

\begin{tabular}{l} 
Inspector Signature \\
\hline Inspector Signature \\
\hline Inspector Signature
\end{tabular}

\begin{tabular}{l} 
Activity. \\
\hline Activity \\
\hline Activity
\end{tabular}

Date

Date

Date

Inspector not present during plugging operations

Authorization for Inspector not being present $\frac{\text { Mlauk. Wheter }}{\text { Manager Signature }}$

$\frac{9 / 15 / 05}{\text { Date }}$

Plugging information sent to District Office

$\square$ Inspector site visit to pick up plugging information 


\section{APPENDIX 6-1}

\section{Gauge Specifications}

Specifications for selected pressure and temperature instrumentation can be found at http://www.foxboro-eckardt.com/en-GB/products/

Specifications for the Weatherford well control system can be found at http://www.weatherford.com/Products/Production/FlowMeasurement/CS7XControlSystem/ fm_WFT067378 


\section{APPENDIX 6-2}

\section{Mechanical Integrity Testing Procedures}




\section{PRESSURE TEST OF ANNULUS INTEGRITY, TUBING AND PACKER (BASELINE)}

1. Notify the IL EPA of the plans to perform the annular pressure test and the schedule for the test.

2. Mount calibrated gauge on wellhead to monitor pressure of annular space (i.e., outside the tubing and inside the long casing).

3. Close in tubing valve and rig up to pressurize the annular space by connecting high pressure pump to wing valve corresponding to the described annular space.

4. Add fluid to the annular space to increase the pressure to no less than 100 psi above the maximum regulated pressure for the annular space.

5. Test the mechanical integrity of the annulus by recording the annulus pressure for 1 hour.

5. Reduce the inner annulus pressure back to atmospheric pressure and record the volume of fluid removed from the inner annulus.

6. Corrective action will be taken if any pressure test exceeded a $5 \%$ over a1 hour period.

7. Plot the data gathered (volume versus inner annulus pressure) and determine volume of fluid loss for pressure loss for the inner annulus space.

8. Receive approval from IL EPA that the well passed the annular pressure test.

Note: This procedure may be updated during or after drilling, characterization, and/or testing of the well to account for actual well completion details or site conditions. 


\section{PRESSURE TEST OF ANNULUS INTEGRITY, TUBING AND PACKER (DURING INJECTION)}

1. Notify the IL EPA of the plans to perform the annular pressure test and the schedule for the test.

2. Stop injection and allow the well to stabilize for 12 hours.

3. Prepare to monitor pressure of annular space (i.e., outside the tubing and inside the long casing) using the annular pressure monitoring system.

4. Close in tubing valve and rig up to pressurize the annular space by connecting high pressure pump to wing valve corresponding to the described annular space.

5. Add fluid to the annular space to increase the pressure to no less than 100 psi above the maximum regulated pressure for the annular space.

5. Test the mechanical integrity of the annulus by recording the annulus pressure for 1 hour.

5. Reduce the inner annulus pressure back to atmospheric pressure.

6. Corrective action will be taken if any pressure test exceeded a $5 \%$ over a1 hour period.

7. Receive approval from IL EPA that the well passed the annular pressure test.

Note: This procedure may be updated during or after drilling, characterization, and/or testing of the well to account for actual well completion details or site conditions. 


\section{PROCEDURE FOR RADIOACTIVE TRACER SURVEY}

1. Move in and rig up a wireline logging unit, mast unit, and wireline lubricator with grease injector pressure control equipment.

2. Install a Radio-Active Tracer survey (RAT) tool string with upper and lower gamma ray detectors, ejector, and a collar locator $(\mathrm{CL})$ on the wireline. Set up RAT tools and recorder according to the IL EPA guidelines. Note that the radioactive trace must be miscible in $\mathrm{CO}_{2}$.

3. Lower the RAT tools into the wellbore to total depth (TD). Run a depth correlation test and baseline gamma ray to from TD to approximately 1,000 feet above the packer to include the packer and collars.

4. Correct for any depth discrepancies.

5. Record background checks at desired depth.

6. Start injection of $\mathrm{CO}_{2}$ at typical rate during normal system operation.

7. Conduct a moving survey from 1,000 feet above the packer to the TD of the well.

- Move the RAT tool to 1,000 feet above the packer.

- Eject a slug of radioactive material at 1,000 feet above packer and verify ejection on the lower detector.

- After verification, lower the tool below the slug and monitor the movement of the slug by making and recording a series of passes across the slug until the slug is no longer detected. Note times and pass numbers on the log. Verify there is no upward movement above the base of the caprock.

8. Repeat the moving survey as above.

9. Conduct a stationary survey above the injection interval to check for upward fluid migration outside the cemented casing.

- Move the RAT tool to 1,000 feet above the location of the packer. Set the logging computer to record in time-drive mode.

- Maintain a constant injection rate.

10. Eject a slug of radioactive material at 1,000 feet above packer. Lower the RAT tool into the wellbore and set it at the base of the caprock. Verify the slug passing both detectors. Record on time-drive for an additional 30 minutes after passage of the slug. Verify no upward movement of injected fluid.

11. Stop injection and lower tool to TD. Run a final gamma ray/CL base log from TD to approximately 1,000 feet above the packer.

NOTE: A preliminary analysis of the RTS survey will be conducted on site by the logging company representative and, if present, the IL EPA representative.

12. Remove lubricator from well and prepare for routine injection.

Note: This procedure may be updated during or after drilling, characterization, and/or testing of the well to account for actual well completion details or site conditions. 


\section{PROCEDURE FOR PULSED NEUTRON CAPTURE LOGGING}

1. Shut down injection and allow well to equilibrate for 24 hours.

2. Move in rig and clear the wellbore of any material that would be corrosive to the logging tools. Remove any downhole equipment from the well and ensure that there are no obstructions that will prevent the passage of the pulsed neutron capture tool.

3. Rig up a blow-out preventer wireline logging unit, mast unit, and wireline lubricator with grease injector pressure control equipment.

4. The pulsed neutron capture log shall be conducted in the sigma mode and in tandem with a gamma-ray log.

5. Place tool in "standby" mode.

6. Run pulsed neutron capture tool to total depth (TD).

7. Turn on pulsed neutron capture tool. Pull tool out of the well and perform logging. The logging depth will be from TD to 1,000 feet above the depth of the packer. The data will be recorded by the logging company.

8. Pull logging tool out of well, and into tool catcher.

9. Obtain field copies of the logging data.

10. Remove blow-out preventer wireline logging unit, mast unit, and wireline lubricator from well.

11. Replace tubing, downhole equipment and wellhead.

12. Move rig off location

Note: This procedure may be updated during or after drilling, characterization, and/or testing of the well to account for actual well completion details or site conditions. 


\section{PROCEDURE FOR DIFFERENTIAL TEMPERATURE LOG (BASELINE)}

1. Move service rig onto site.

2. Clear the wellbore of any material that would be corrosive to the logging tools and ensure that there are no obstructions that will prevent the passage of the temperature tool.

3. The temperature log must be conducted through the injection tubing to obtain "real condition" data and to be protective of human health and the environment.

4. An appropriate scale for the temperature log must be selected. Frequent shifts in the log will be required if the scale selected is too small which makes the log difficult to interpret. If the scale is too large, the log is again difficult to interpret because temperature changes and gradients are difficult to discern. A scale range of $4^{\circ} \mathrm{F} /$ inch to $10^{\circ} \mathrm{F} / \mathrm{inch}$ is generally the best.

5. The temperature log shall be conducted in tandem with a collar locator log and a gamma-ray log. A differential temperature curve shall be included.

6. The temperature tool shall be sensitive to temperature changes of at least $0.1^{\circ} \mathrm{F}$.

7. The temperature log shall be run going into the well. The logging speed should be between 20-35 feet per minute. The logging speed shall be kept constant for all sequential passes. Stopping the tool during a log run should be avoided.

8. The well shall be shut-in for a minimum of 24 hours to reach "static" conditions prior to running the baseline log.

9. Run the baseline log from total depth to ground surface after the 24-hour shut-in period. Data will be recorded by the logging company.

10. Remove logging tool from well, and place wellhead back on well

11. Move service rig offsite.

12. Report results of differential temperature log to IL EPA.

Note: This procedure may be updated during or after drilling, characterization, and/or testing of the well to account for actual well completion details or site conditions. 


\section{ATTACHMENT 3}

FutureGen Design Basis Document 
Future Gen "m

A L L I A N C E

Clean Energy for a Secure Future

\section{FutureGen Design Data}

January 16, 2008

Revision D 


\section{SPECIFICATION REVISION PAGE}

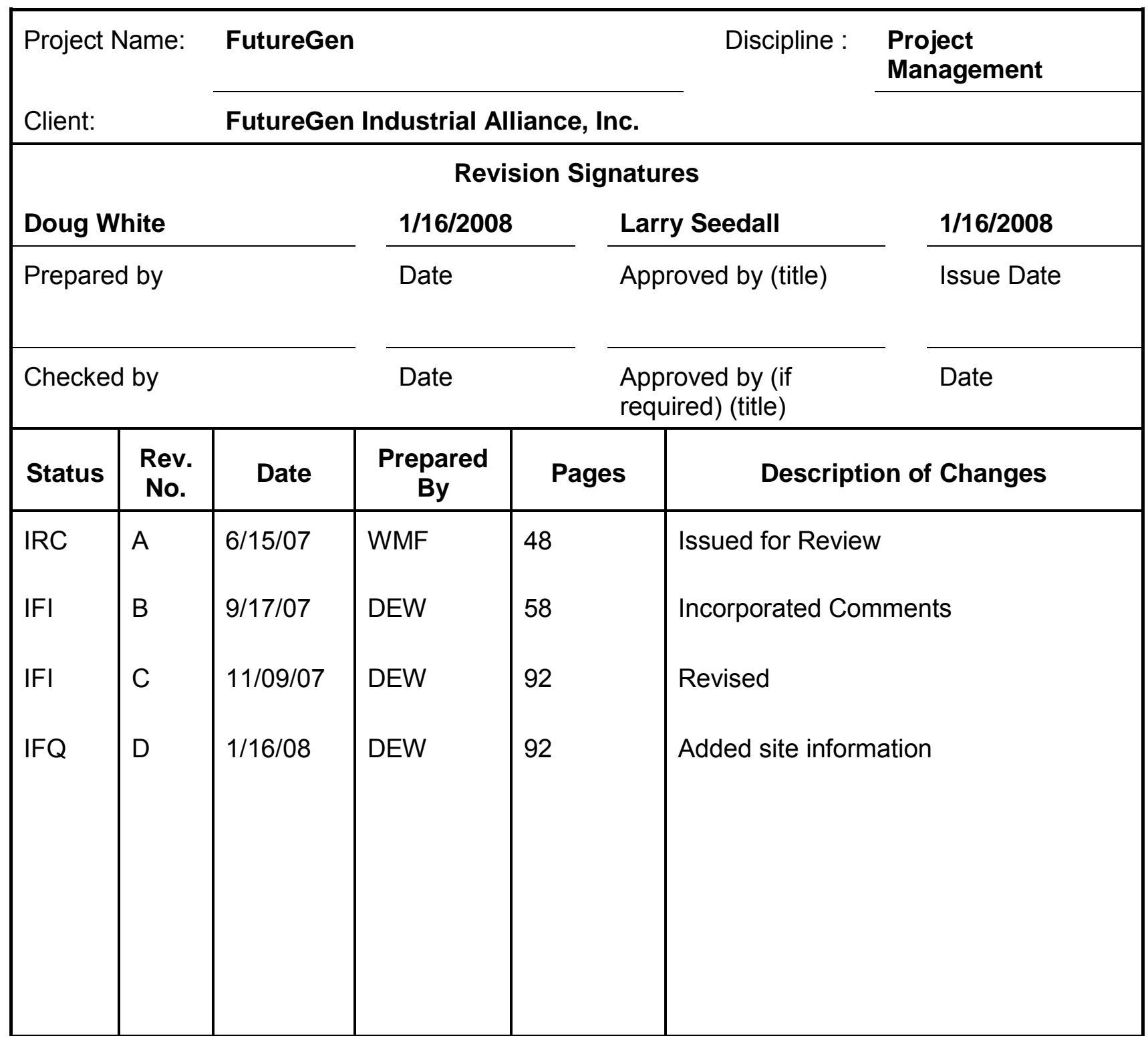




\section{TABLE OF CONTENTS}

\section{SECTION}

1. PROCESS DESIGN BASIS

1.1. Overall Project Objectives ................................................................................10

1.2. Plant Feed Basis .......................................................................................11

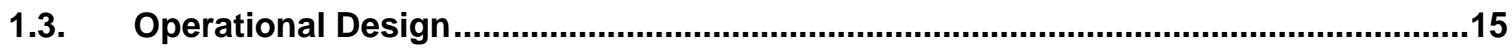

1.4. Product Specifications...................................................................................16

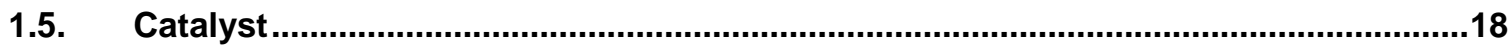

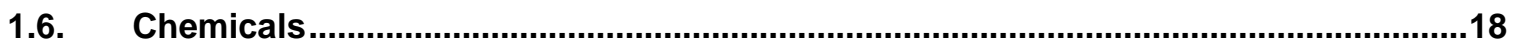

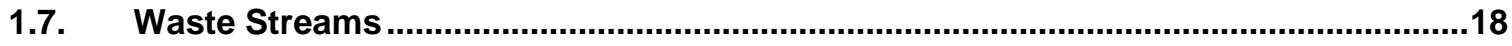

1.8. Sparing Philosophy ......................................................................................19

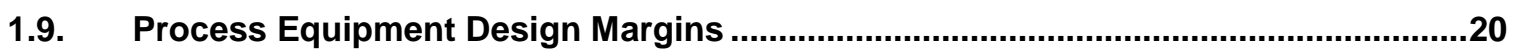

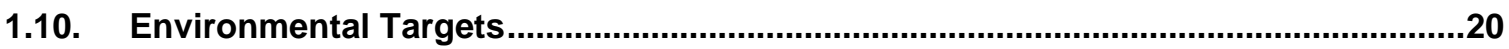

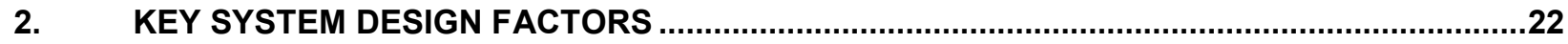

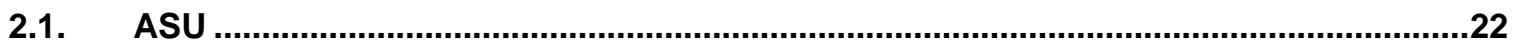

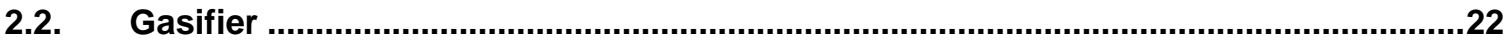

2.3. Shift Reactor System .....................................................................................23

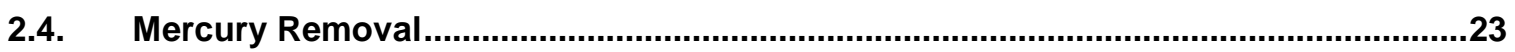

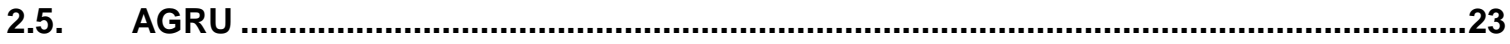

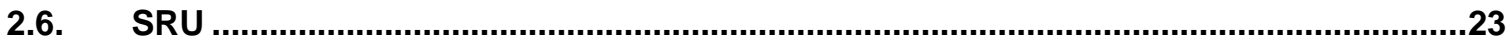

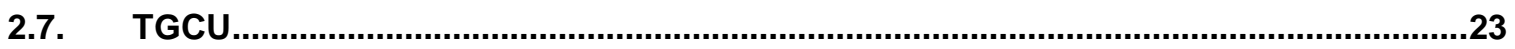

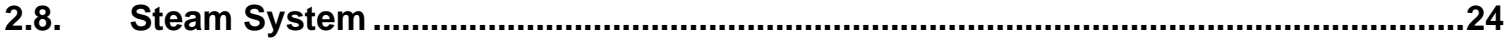

2.9. Coal Storage and Handling.................................................................................24

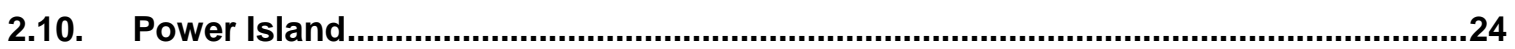

2.11. Water Treatment …...........................................................................................24

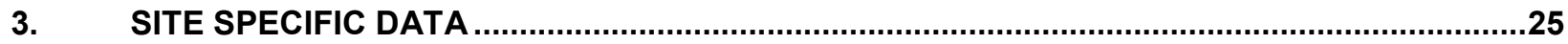

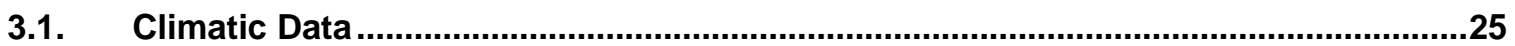

3.2. Seismic Design Parameters: ...........................................................................25

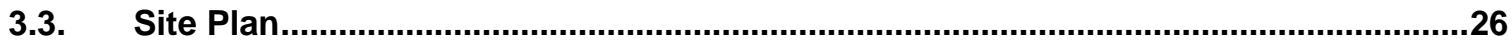

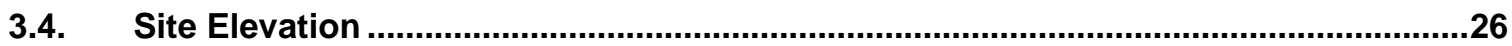

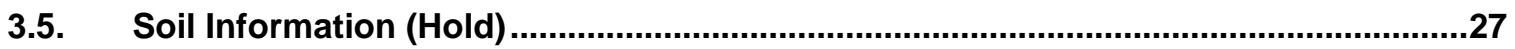

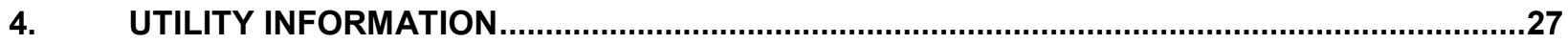

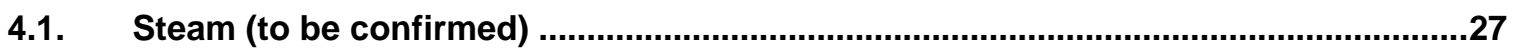

4.2. Steam Condensate …………….......................................................................28

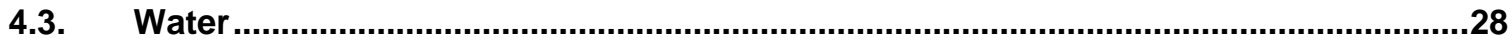

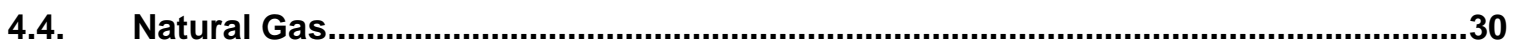

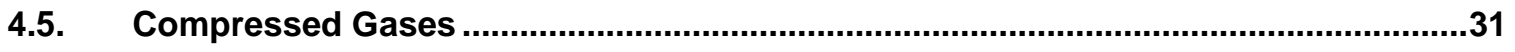

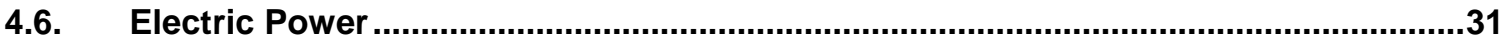

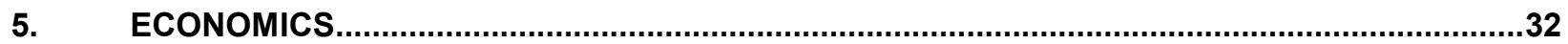


6. SPECIFICATIONS, ENGINEERING STANDARDS \& DESIGN REQUIREMENTS ......................34

7. CIVIL/STRUCTURAL ENGINEERING REQUIREMENTS ...............................................48

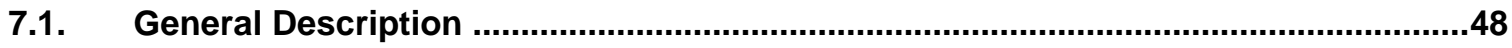

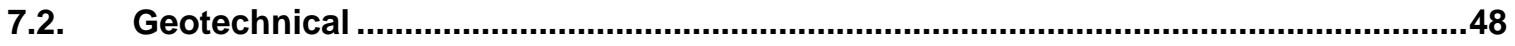

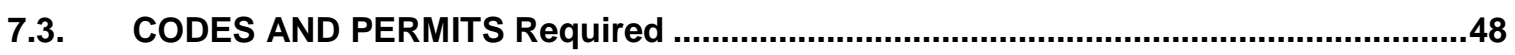

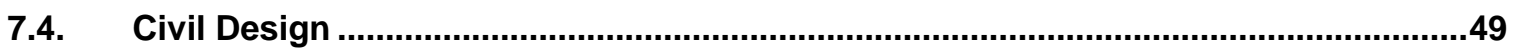

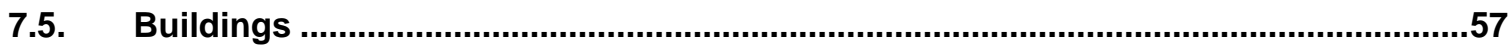

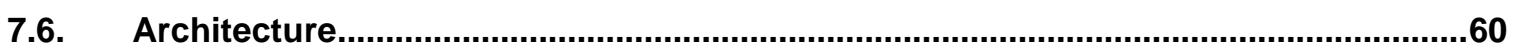

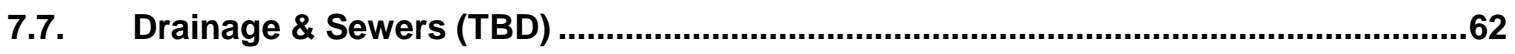

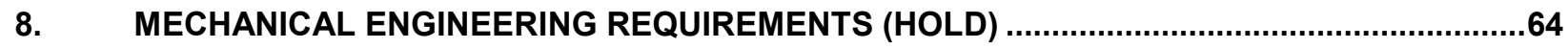

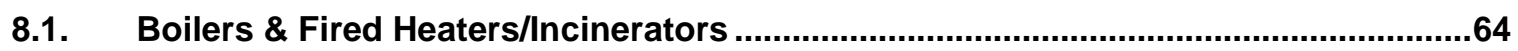

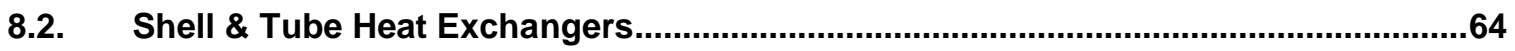

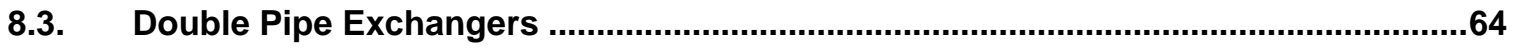

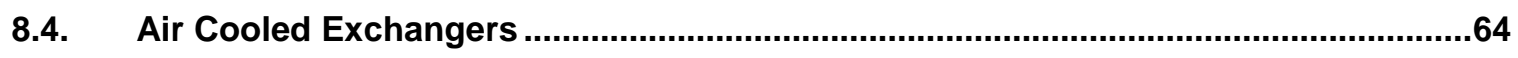

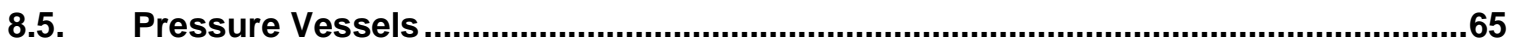

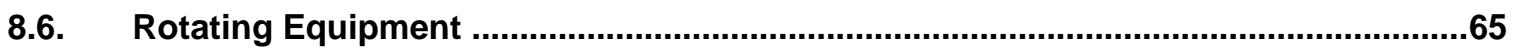

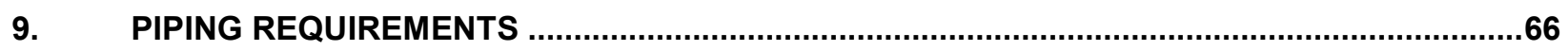

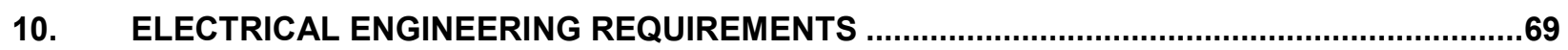

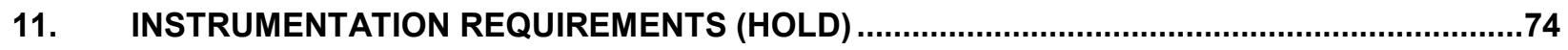

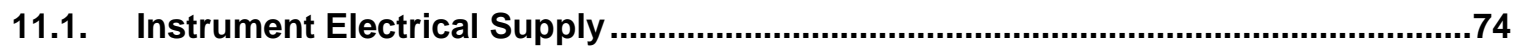

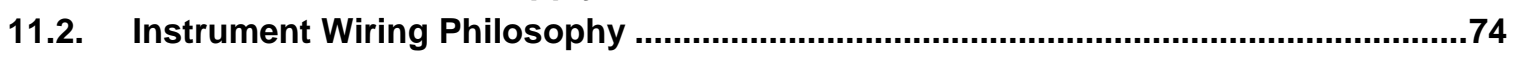

11.3. Instrument Specification ...............................................................................................

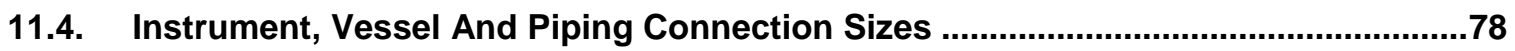

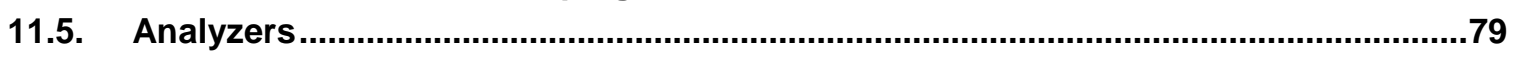

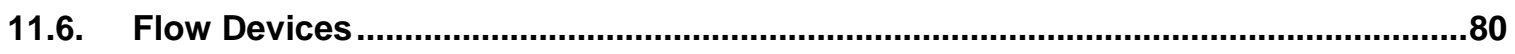

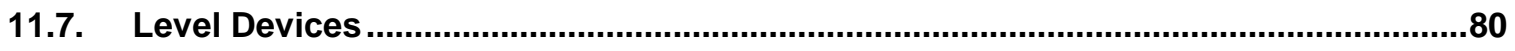

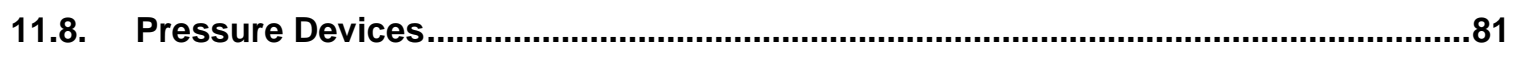

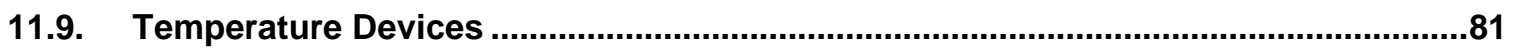

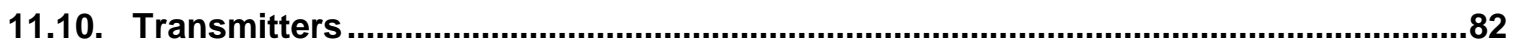

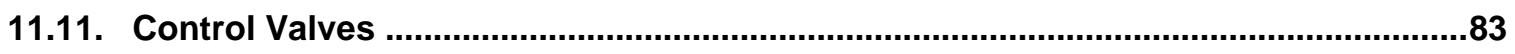

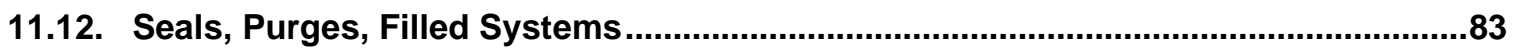

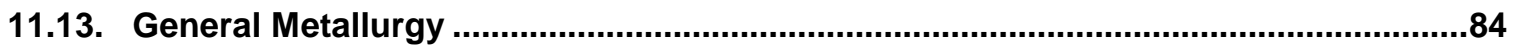

11.14. Distributed Control System (DCS) and Safety Instrumented Systems (SIS) ...........84

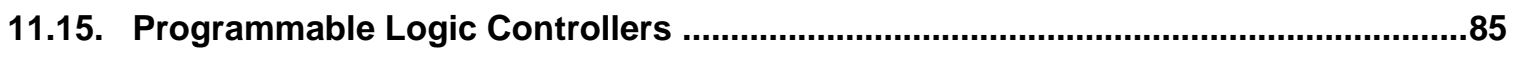

11.16. Instruments in Equipment Vendor Packaged Systems ..............................................85

11.17. Instruments in Equipment Vendor Packaged Systems ...........................................86

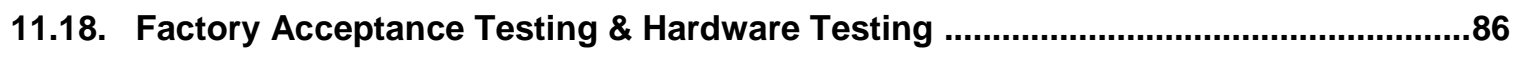

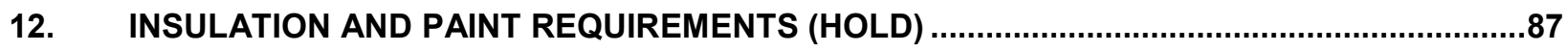

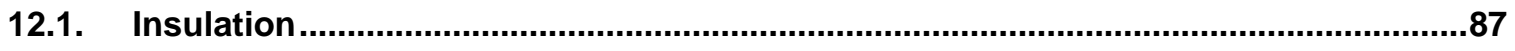




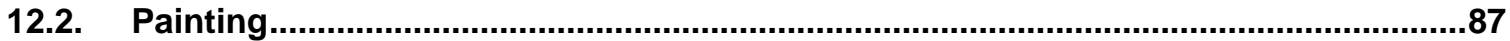

13. FLARE \& BLOWDOWN SYSTEM REQUIREMENTS ........................................................

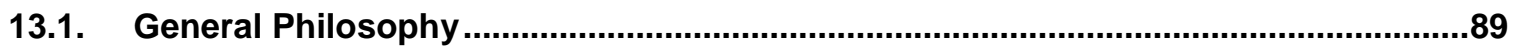

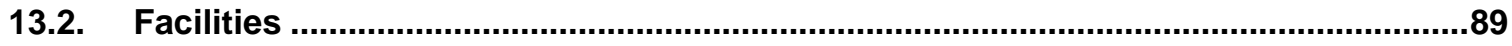

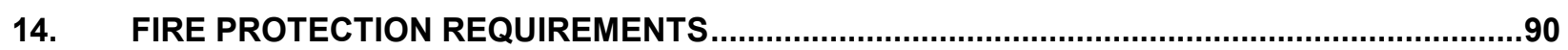

15. VENDORS, CONTRACTORS, SUBCONTRACTORS (HOLD) …..........................................92

\section{Abbreviations}

AASHTO American Association of State Highway and Transportation Officials

$A C$ alternating current

ACPA American Concrete Paving Association

ADA

American with Disabilities Act

AEIC

Association of Edison Illuminating Companies

AGRU acid gas removal unit

AISC American Institute of Steel Construction

ANSI American National Standards Institute

API American Petroleum Institute

AREA American Railway Engineering Association

ASCE

ASD

American Society of Civil Engineers

ASME

Allowable Stress Design

ASU

American Society of Mechanical Engineers

ATS air separation unit

AWG automatic transfer switch (for backup power)

AWS American Wire Gauge

BPCS

CCTV

American Welding Society

CMAA

Basic Process Control System

closed circuit television

CTG

Crane Manufacturers Association of America

CV combustion turbine generator

$\mathrm{CW}$

control valve

$\mathrm{D} / \mathrm{P}$

cooling water

$\mathrm{dBA}$

differential pressure

DCS

Decibels audible

distributed control system

\section{Page 5}




\begin{tabular}{|c|c|}
\hline Div. & division \\
\hline ECM & engineering construction management (contractor) \\
\hline ESD & emergency shut down \\
\hline FAT & factory acceptance test \\
\hline FCC & Federal Communications Commission \\
\hline FLA & full load amperes \\
\hline FM & Factory Mutual \\
\hline FPS & feet per second \\
\hline FW & fire water \\
\hline GT & gas turbine \\
\hline $\mathrm{H}$ & height \\
\hline HART & Highway Addressable Remote Transducer \\
\hline $\mathrm{HHV}$ & higher heating value \\
\hline $\mathrm{HOA}$ & hand - off - auto \\
\hline HP & high pressure \\
\hline hp & horsepower \\
\hline HRSG & heat recovery stream generator \\
\hline HS & hand switch \\
\hline I/O & input/output \\
\hline IBC & International Building Code \\
\hline ICDR & initial conceptual design report \\
\hline ICEA & Insulated Cable Engineers Association \\
\hline IEC & International Electrotechnical Commission \\
\hline IEEE & Institute of Electronics and Electrical Engineers \\
\hline IFC & International Fire Code \\
\hline IGCC & integrated gasification combined cycle \\
\hline IP & intermediate pressure \\
\hline ISA & Instrumentation, Systems and Automation Society \\
\hline ISO & International Standards Organization \\
\hline JB & junction box \\
\hline $\mathrm{k}$ & thousand \\
\hline $\mathrm{lb}$ & pound \\
\hline LEED & Leadership in Energy and Environmental Design \\
\hline LHV & lower heating value \\
\hline LP & low pressure \\
\hline LRFD & Load and Resistance Factor Design \\
\hline Max & maximum \\
\hline
\end{tabular}

\section{Page 6}




\begin{tabular}{|c|c|}
\hline MCC & motor control center \\
\hline Min & minimum \\
\hline $\mathrm{mm}$ & millimeter \\
\hline MM & million \\
\hline MMBtu & million British thermal units \\
\hline $\mathrm{mol} \%$ & molar percent \\
\hline MOV & motor operated valve \\
\hline MP & medium pressure \\
\hline $\mathrm{mph}$ & miles per hour \\
\hline MWe & megawatt \\
\hline $\mathrm{n} / \mathrm{r}$ & not reported \\
\hline NAAQS & National Ambient Air Quality Standards \\
\hline NACE & National Association of Corrosion Engineers \\
\hline NEC & National Electrical Code (NFPA 70) \\
\hline NEMA & National Electrical Manufacturer"s Association \\
\hline NFPA & National Fire Protection Association \\
\hline NPD & Nominal Flange Diameter \\
\hline NPT & National Pipe Thread \\
\hline OD & outside diameter \\
\hline OS & outside \\
\hline OSHA & Occupational Safety and Health Administration \\
\hline PB & push button \\
\hline PCA & Portland Cement Association \\
\hline PDC & power distribution center \\
\hline PDS & Plant Design System \\
\hline PDS & plant design system - Microstation 3D \\
\hline ph & phase \\
\hline PIP & Process Industry Practices \\
\hline PLC & programmable logic controller \\
\hline PM & particulate matter \\
\hline PMS & power management system \\
\hline ppmv & parts per million-volumetric basis \\
\hline ppmvd & parts per million-volumetric dry basis \\
\hline PRB & Power River Basin \\
\hline PSA & pressure swing adsorption \\
\hline PSD & prevention of significant deterioration \\
\hline psf & pounds per square foot \\
\hline
\end{tabular}




$\begin{array}{ll}\text { PSV } & \text { pressure safety valve } \\ \text { RF } & \text { raised face } \\ \text { RIE } & \text { remote instrument enclosure } \\ \text { RTD } & \text { resistance temperature detector } \\ \text { S\&T } & \text { shell and tube } \\ \text { SAMA } & \text { Scientific Apparatus Makers Association } \\ \text { SCF } & \text { standard cubic foot } \\ \text { Scfh } & \text { standard cubic feet per hour }\left(60^{\circ} \mathrm{F} \mathrm{\&} 14.696 \mathrm{psia}\right) \\ \text { Scfm } & \text { standard cubic feet per minute }\left(60^{\circ} \mathrm{F} \text { \& } 14.696 \text { psia) }\right. \\ \text { SEI } & \text { Structural Engineering Institute } \\ \text { SF } & \text { square foot } \\ \text { SIL } & \text { Safety Integrity Level } \\ \text { SIS } & \text { Safety Instrumented Systems } \\ \text { SJI } & \text { Steel Joist Institute } \\ \text { SRU } & \text { sulfur recovery unit } \\ \text { SS } & \text { stainless steel } \\ \text { STG } & \text { steam turbine generator } \\ \text { SWS } & \text { sour sater system } \\ \text { TBD } & \text { to be determined } \\ \text { TCP/IP } & \text { Transmission Control Protocol/Internet Protocol } \\ \text { te } & \text { metric ton (1 te=2204.62 lbs) } \\ \text { TGCU } & \text { tail gas cleanup unit } \\ \text { TPD } & \text { tons per day (1 ton=2000 lbs) } \\ \text { TPH } & \text { tons per hour (1 ton=2000 lbs) } \\ \text { TPY } & \text { tons per year (1 ton=2000 lbs) } \\ \text { UL } & \text { Underwriter"s Laboratory } \\ \text { UPS } & \text { Uninterruptible Power Supply } \\ \text { VAC } & \text { volts }- \text { alternating current } \\ \text { VDC } & \text { volts }- \text { direct current } \\ \text { W } & \text { width } \\ \text { WGINT } & \text { Washington Group International } \\ \text { WGS } & \text { water gas shift } \\ \text { ZLD } & \text { zero liquid discharge } \\ & \end{array}$


Client"s Name:

Plant Location:

Type Of Unit(s):
FutureGen Alliance

Illinois

IGCC (integrated gasification combined cycle) Power Plant Demonstration Unit and Research Facility with $\mathrm{CO}_{2}$ Sequestration

The system of engineering units for the project shall be in accordance with the following table:

\begin{tabular}{|c|c|}
\hline Process Variable & Engineering Units \\
\hline Temperature & Deg F \\
\hline $\begin{array}{l}\text { Pressure } \\
\qquad \begin{array}{l}\text { Near Atmosphere } \\
\text { Above Atmosphere } \\
\text { Below Atmosphere } \\
\text { Absolute }\end{array}\end{array}$ & $\begin{array}{l}\text { Inches of water } \\
\text { psig } \\
\text { Inches of water absolute } \\
\text { psia }\end{array}$ \\
\hline $\begin{array}{l}\text { Level } \\
\qquad \begin{array}{l}\text { Process } \\
\text { Storage tanks }\end{array}\end{array}$ & $\begin{array}{l}\text { Feet and inches } \\
\text { Feet and inches }\end{array}$ \\
\hline $\begin{array}{l}\text { Flow } \\
\text { Gas Volume } \\
\text { Gas Mass } \\
\text { Liquid Volume, Process flows } \\
\text { Liquid Volume, Utility flows } \\
\text { Liquid Mass } \\
\text { Steam }\end{array}$ & $\begin{array}{l}\text { scfm } \\
\mathrm{lb} / \mathrm{hr} \\
\mathrm{gpm} \\
\mathrm{gpm} \\
\mathrm{lb} / \mathrm{hr} \\
\mathrm{lb} / \mathrm{hr}\end{array}$ \\
\hline
\end{tabular}




\section{PROCESS DESIGN BASIS}

\subsection{Overall Project Objectives}

Facility-Related

1. IGCC configuration nominally rated at $275 \mathrm{MWe}$, with the capability to fully load a FClass gas turbine on at least one coal type

2. Maintain the capability to gasify a range of coal types from subbituminous to bituminous (High Vol Type A).

\section{Emission-Related}

3. Separate and capture at least $90 \%$ of the carbon in the sour syngas effluent from the gasifier on an instantaneous basis

4. Sequester at least $10^{6}$ Metric Tons $\mathrm{CO}_{2}$ per year in a deep saline geologic formation with the option for any $\mathrm{CO}_{2}$ captured beyond $10^{6}$ Metric Tons $\mathrm{CO}_{2}$ per year to be sent to an alternative use that avoids its release to the atmosphere

5. Remove greater than $90 \%$ mercury contained in the coal fed to the gasifier

6. Emit, at the HRSG stack, an amount of nitrogen oxides equal to or less than 0.05 pounds of nitrogen dioxide per million BTU of coal gasified

7. Emit, at the HRSG stack, an amount of particulate matter equal to or less than 0.005 pounds of particulate matter per million BTU of coal gasified

8. Emit, at the HRSG stack, an amount of sulfur equal to or less than $1 \%$ sulfur contained in the coal feed, or produce less than 15 ppmvd in the treated syngas fuel, whichever is greater.

9. Sulfur captured from the syngas shall be recovered as liquid elemental sulfur 


\subsection{Plant Feed Basis}

\subsubsection{Coal}

Capacity:

Coal will be supplied in sufficient quantity to provide1920 MMBTU/hr (LHV) of fuel to the combustion turbine for the base case coal (Illinois \#6)

Approximate feed rate: $\quad 210,000-340,000 \mathrm{lb} / \mathrm{hr}$

Exact feed rate: $\quad$ To be supplied by gasifier vendor

Coal analysis:

\begin{tabular}{|c|c|c|c|c|c|c|c|c|c|}
\hline & \multicolumn{3}{|c|}{$\begin{array}{c}\text { Northern Appalachia } \\
\text { Washed Pittsburgh } \\
\text { Seam Product Ranges }\end{array}$} & \multicolumn{3}{|c|}{$\begin{array}{c}\text { Illinois Basin Washed } \\
\text { Basis Seam III No.6 } \\
\text { State of Illinois }\end{array}$} & \multicolumn{3}{|c|}{$\begin{array}{c}\text { Powder River Basin } \\
\text { Raw Basis State of } \\
\text { Wyoming }\end{array}$} \\
\hline & Mean & Min & Max & Mean & Min & Max & Mean & Min & Max \\
\hline \multicolumn{10}{|l|}{$\begin{array}{l}\text { Proximate } \\
\text { Analysis, WT\% }\end{array}$} \\
\hline \multicolumn{10}{|l|}{ As Received } \\
\hline Total Moisture & 6.8 & 5.8 & 7.8 & 14.2 & 12.5 & 16.4 & 27.3 & 26.3 & 30.0 \\
\hline Ash & 7.62 & 6.39 & 8.76 & 9.5 & 7.6 & 11.5 & 4.5 & 4.0 & 6.0 \\
\hline Volatile Matter & 35.85 & 33.86 & 37.88 & 34.7 & 32.1 & 37.2 & 32.1 & 20.0 & 34.1 \\
\hline Fixed Carbon & 49.73 & 47.88 & 51.69 & 41.6 & 38.7 & 44.1 & 36.1 & 33.8 & 38.1 \\
\hline Sulfur & 2.87 & 2.12 & 3.47 & 3.11 & 2.5 & 4.0 & 0.21 & 0.18 & 0.3 \\
\hline Lb. SO2/MMBTU & $n / r$ & $n / r$ & $n / r$ & 5.75 & 4.8 & 7.2 & 0.48 & 0.4 & 0.8 \\
\hline $\begin{array}{l}\text { Equilibrium } \\
\text { Moisture }\end{array}$ & 2.00 & 1.50 & 2.90 & 10.4 & 8.5 & 12.00 & 26.3 & 25.2 & 27.4 \\
\hline \multicolumn{10}{|l|}{ Dry Basis } \\
\hline Ash & 8.17 & 6.86 & 9.4 & $n / r$ & $\mathrm{n} / \mathrm{r}$ & $\mathrm{n} / \mathrm{r}$ & $\mathrm{n} / \mathrm{r}$ & $n / r$ & $\mathrm{n} / \mathrm{r}$ \\
\hline Volatile Matter & 38.25 & 36.33 & 40.22 & $\mathrm{n} / \mathrm{r}$ & $\mathrm{n} / \mathrm{r}$ & $n / r$ & $\mathrm{n} / \mathrm{r}$ & $n / r$ & $n / r$ \\
\hline Fixed Carbon & 53.58 & 51.80 & 55.44 & $n / r$ & $\mathrm{n} / \mathrm{r}$ & $n / r$ & $n / r$ & $\mathrm{n} / \mathrm{r}$ & $n / r$ \\
\hline Mercury Hg ppm & 0.09 & 0.05 & 0.15 & $\mathrm{n} / \mathrm{r}$ & $\mathrm{n} / \mathrm{r}$ & $n / r$ & 0.06 & 0.03 & 0.09 \\
\hline
\end{tabular}




\begin{tabular}{|c|c|c|c|c|c|c|c|c|c|}
\hline & \multicolumn{3}{|c|}{$\begin{array}{l}\text { Northern Appalachia } \\
\text { Washed Pittsburgh } \\
\text { Seam Product Ranges }\end{array}$} & \multicolumn{3}{|c|}{$\begin{array}{c}\text { Illinois Basin Washed } \\
\text { Basis Seam III No.6 } \\
\text { State of Illinois }\end{array}$} & \multicolumn{3}{|c|}{$\begin{array}{c}\text { Powder River Basin } \\
\text { Raw Basis State of } \\
\text { Wyoming }\end{array}$} \\
\hline & Mean & Min & Max & Mean & Min & Max & Mean & Min & Max \\
\hline $\begin{array}{l}\text { Heating Value, } \\
\text { Btu/lb }\end{array}$ & & & & & & & & & \\
\hline As Received & 12968 & 12804 & 13198 & 10800 & 10400 & 11100 & 8800 & 8550 & 9000 \\
\hline Dry & 13914 & 13739 & 14160 & $n / r$ & $n / r$ & $\mathrm{n} / \mathrm{r}$ & $n / r$ & $n / r$ & $\mathrm{n} / \mathrm{r}$ \\
\hline MAFBTU & $n / r$ & $n / r$ & $n / r$ & 14158 & $n / r$ & $n / r$ & 12904 & $n / r$ & $n / r$ \\
\hline \multicolumn{10}{|l|}{$\begin{array}{l}\text { Ultimate Analysis } \\
\text { (Dry), WT\% }\end{array}$} \\
\hline Carbon, C & 76.87 & 75.33 & 78.41 & 70.0 & 67.4 & 72.9 & 70.5 & 69.0 & 72.5 \\
\hline Hydrogen, H & 5.10 & 4.85 & 5.35 & 4.9 & 4.3 & 5.6 & 4.8 & 4.2 & 5.4 \\
\hline Nitrogen, N & 1.44 & 1.33 & 1.55 & 1.3 & 0.8 & 1.5 & 0.9 & 0.8 & 1.0 \\
\hline Chlorine, $\mathrm{Cl}$ & 0.11 & 0.07 & 0.15 & 0.12 & 0.05 & 0.25 & $<0.01$ & $<0.01$ & 0.01 \\
\hline Sulfur, S & 3.08 & 2.27 & 3.72 & 3.62 & 2.9 & 4.7 & 0.29 & 0.24 & 0.43 \\
\hline Ash & 8.17 & 6.86 & 9.40 & 11.1 & 8.8 & 13.3 & 6.2 & 5.4 & 8.4 \\
\hline Oxygen, O & 5.23 & 3.88 & 6.58 & 8.96 & 7.0 & 11.7 & 17.31 & 15.8 & 18.8 \\
\hline \multicolumn{10}{|l|}{ Sulfur Forms (Dry) } \\
\hline Pyritic & $\mathrm{n} / \mathrm{r}$ & $\mathrm{n} / \mathrm{r}$ & $\mathrm{n} / \mathrm{r}$ & 1.12 & 0.53 & 1.79 & 0.01 & $<0.01$ & 0.03 \\
\hline Sulfate & $\mathrm{n} / \mathrm{r}$ & $\mathrm{n} / \mathrm{r}$ & $n / r$ & 0.05 & $<0.01$ & 0.10 & $<0.01$ & $<0.01$ & 0.01 \\
\hline Organic & $n / r$ & $n / r$ & $n / r$ & 2.45 & 1.80 & 3.20 & 0.28 & 0.21 & 0.41 \\
\hline \multicolumn{10}{|l|}{$\begin{array}{l}\text { Ash Fusion } \\
\text { Temperatures }\end{array}$} \\
\hline Reducing, deg F & & & & & & & & & \\
\hline Initial Deformation & 2058 & 1988 & 2128 & 2020 & 1920 & 2180 & 2155 & 2070 & 2240 \\
\hline Softening, $\mathrm{H}=\mathrm{W}$ & 2152 & 2093 & 2216 & 2110 & 1980 & 2265 & 2160 & 2075 & 2245 \\
\hline $\begin{array}{l}\text { Hemispherical, } \mathrm{H}=1 / 2 \\
\text { W }\end{array}$ & 2251 & 2205 & 2297 & 2165 & 2030 & 2350 & 2170 & 2085 & 2255 \\
\hline Fluid & 2349 & 2299 & 2394 & 2315 & 2170 & 2525 & 2175 & 2090 & 2260 \\
\hline Oxidizing, deg F & & & & & & & & & \\
\hline Initial Deformation & 2400 & 2294 & 2547 & 2325 & 2200 & 2450 & 2220 & 2135 & 2305 \\
\hline Softening, $\mathrm{H}=\mathrm{W}$ & 2452 & 2354 & 2611 & 2375 & 2250 & 2530 & 2225 & 2140 & 2310 \\
\hline $\begin{array}{l}\text { Hemispherical, } \\
\mathrm{H}=1 / 2 \mathrm{~W}\end{array}$ & 2497 & 2410 & 2638 & 2420 & 2300 & 2565 & 2230 & 2145 & 2315 \\
\hline
\end{tabular}




\begin{tabular}{|c|c|c|c|c|c|c|c|c|c|}
\hline & \multicolumn{3}{|c|}{$\begin{array}{l}\text { Northern Appalachia } \\
\text { Washed Pittsburgh } \\
\text { Seam Product Ranges }\end{array}$} & \multicolumn{3}{|c|}{$\begin{array}{l}\text { Illinois Basin Washed } \\
\text { Basis Seam III No.6 } \\
\text { State of Illinois }\end{array}$} & \multicolumn{3}{|c|}{$\begin{array}{c}\text { Powder River Basin } \\
\text { Raw Basis State of } \\
\text { Wyoming }\end{array}$} \\
\hline & Mean & Min & Max & Mean & Min & Max & Mean & Min & Max \\
\hline $\begin{array}{l}\text { Fluid } \\
\text { Ash composition, } \\
\text { WT\% }\end{array}$ & 2538 & 2445 & 2657 & 2510 & 2370 & 2695 & 2240 & 2155 & 2325 \\
\hline Silica, $\mathrm{SiO}_{2}$ & 43.58 & 38.86 & 49.56 & 49.6 & 43.2 & 55.4 & 32.7 & 28.2 & 38.5 \\
\hline Aluminia, $\mathrm{Al}_{2} \mathrm{O}_{3}$ & 22.36 & 20.20 & 26.10 & 19.3 & 16.4 & 22.2 & 16.7 & 14.2 & 19.4 \\
\hline Titania, $\mathrm{TiO}_{2}$ & 0.97 & 0.44 & 1.16 & 0.9 & 0.6 & 1.2 & 1.3 & 1.0 & 1.6 \\
\hline Ferric Oxide, $\mathrm{Fe}_{2} \mathrm{O}_{3}$ & 18.59 & 10.61 & 24.70 & 16.3 & 13.2 & 22.1 & 5.6 & 4.6 & 6.5 \\
\hline Lime, CaO & 5.11 & 3.71 & 7.54 & 5.2 & 2.6 & 7.2 & 24.7 & 19.0 & 28.7 \\
\hline Magnesia, MgO & 1.00 & 0.82 & 1.30 & 1.0 & 0.6 & 1.3 & 5.8 & 4.5 & 6.8 \\
\hline $\begin{array}{l}\text { Potassium Oxide, } \\
\mathrm{K}_{2} \mathrm{O}\end{array}$ & 1.33 & 1.00 & 1.66 & 2.1 & 1.5 & 2.5 & 0.3 & 0.2 & 0.5 \\
\hline Sodium Oxide, $\mathrm{Na}_{2} \mathrm{O}$ & 1.06 & 0.69 & 1.49 & 1.2 & 0.6 & 1.5 & 2.0 & 1.3 & 2.7 \\
\hline $\begin{array}{l}\text { Phosphorous } \\
\text { Pentoxide, } \mathrm{P}_{2} \mathrm{O}_{5}\end{array}$ & 0.39 & 0.14 & 0.77 & 0.2 & 0.1 & 0.3 & 1.2 & 0.8 & 1.6 \\
\hline Sulfur Trioxide, $\mathrm{SO}_{3}$ & 4.77 & 1.80 & 6.75 & 4.2 & 2.6 & 6.4 & 8.7 & 6.2 & 11.8 \\
\hline $\begin{array}{l}\text { Strontium Oxide, } \\
\text { SrO }\end{array}$ & $n / r$ & $\mathrm{n} / \mathrm{r}$ & $\mathrm{n} / \mathrm{r}$ & $<0.1$ & $<0.1$ & 0.1 & 0.3 & 0.2 & 0.4 \\
\hline Barium Oxide, $\mathrm{BaO}$ & $\mathrm{n} / \mathrm{r}$ & $\mathrm{n} / \mathrm{r}$ & $\mathrm{n} / \mathrm{r}$ & $<0.1$ & $<0.1$ & 0.1 & 0.7 & 0.5 & 0.9 \\
\hline $\begin{array}{l}\text { Manganese Dioxide, } \\
\mathrm{MnO}_{2}\end{array}$ & $\mathrm{n} / \mathrm{r}$ & $\mathrm{n} / \mathrm{r}$ & $\mathrm{n} / \mathrm{r}$ & $<0.1$ & $<0.1$ & 0.1 & $<0.1$ & $<0.1$ & 0.1 \\
\hline $\begin{array}{l}\text { Hardgrove } \\
\text { Grindability }\end{array}$ & & & & & & & & & \\
\hline $\mathrm{HGI}(\mathrm{A})(\mathrm{B})$ & 55 & 50 & 61 & 53 & 48 & 58 & 60 & 54 & 68 \\
\hline $\begin{array}{l}\text { Free Swelling } \\
\text { Index }\end{array}$ & & & & & & & & & \\
\hline FSI & 8 & 6 & 9 & 3.0 & 2.0 & 4.0 & 0.0 & 0.0 & 0.0 \\
\hline Calculated Values & & & & & & & & & \\
\hline $\begin{array}{l}\text { Slag Viscosity @ } \\
\text { T250 deg F (C) }\end{array}$ & 2417 & 2282 & 2625 & 2450 & 2290 & 2634 & 2175 & $<2150$ & 2275 \\
\hline $\begin{array}{l}\text { Silica Value } \\
\text { (fraction) }\end{array}$ & 0.64 & 0.56 & 0.76 & 0.688 & 0.62 & 0.75 & 0.475 & 0.415 & 0.566 \\
\hline
\end{tabular}




\begin{tabular}{|c|c|c|c|c|c|c|c|c|c|}
\hline & \multicolumn{3}{|c|}{$\begin{array}{l}\text { Northern Appalachia } \\
\text { Washed Pittsburgh } \\
\text { Seam Product Ranges }\end{array}$} & \multicolumn{3}{|c|}{$\begin{array}{c}\text { Illinois Basin Washed } \\
\text { Basis Seam III No.6 } \\
\text { State of Illinois }\end{array}$} & \multicolumn{3}{|c|}{$\begin{array}{c}\text { Powder River Basin } \\
\text { Raw Basis State of } \\
\text { Wyoming }\end{array}$} \\
\hline & Mean & Min & Max & Mean & Min & Max & Mean & Min & Max \\
\hline Base / Acid Ratio & 0.41 & 0.23 & 0.52 & 0.37 & 0.27 & 0.50 & 0.76 & 0.55 & 0.93 \\
\hline $\begin{array}{l}\text { Alkalis As } \mathrm{Na}_{2} \mathrm{O} \\
\text { Water Soluble } \\
\text { Alkalis (Dry) }\end{array}$ & $\mathrm{n} / \mathrm{r}$ & $\mathrm{n} / \mathrm{r}$ & $n / r$ & 0.29 & 0.16 & 0.39 & 0.14 & 0.09 & 0.18 \\
\hline Sodium Oxide & $n / r$ & $n / r$ & $n / r$ & 0.094 & 0.04 & 0.12 & 0.059 & 0.02 & 0.10 \\
\hline $\begin{array}{l}\text { Potassium Oxide } \\
\text { Trace Elements } \\
\text { (ppm, whole coal, } \\
\text { dry basis) }\end{array}$ & $n / r$ & $n / r$ & $n / r$ & 0.005 & $<0.01$ & 0.01 & 0.003 & $<0.01$ & 0.01 \\
\hline Arsenic - As & 4.30 & 1.79 & 11.20 & 3.00 & $<1$ & 9.00 & $<1$ & $n / r$ & 2.00 \\
\hline Antimony - Sb & 0.21 & 0.06 & 0.44 & $<1$ & $<1$ & 2.00 & $<1$ & $n / r$ & 1.00 \\
\hline Barium - Ba & 82.97 & 57.5 & 122.4 & 65.00 & 25.00 & 200.0 & 290.0 & 90.00 & 490.0 \\
\hline Beryllium - Be & 0.57 & 0.20 & 1.05 & 1.20 & 0.20 & 2.00 & $<0.2$ & $\mathrm{n} / \mathrm{r}$ & 0.50 \\
\hline Boron - B & $n / r$ & $\mathrm{n} / \mathrm{r}$ & $n / r$ & 175 & 35.00 & 300.0 & 34 & 10.00 & 60.00 \\
\hline Bromine - Br & $\mathrm{n} / \mathrm{r}$ & $\mathrm{n} / \mathrm{r}$ & $\mathrm{n} / \mathrm{r}$ & 25.00 & 1 & 50.0 & $<20$ & $\mathrm{n} / \mathrm{r}$ & $<20$ \\
\hline Cadmium - Cd & 0.07 & 0.02 & 0.20 & 0.50 & $<0.1$ & 2.20 & $<0.2$ & $n / r$ & 0.20 \\
\hline Chlorine - Cl & $\mathrm{n} / \mathrm{r}$ & $n / r$ & $n / r$ & 1000 & 400 & 2500 & $<50$ & $\mathrm{n} / \mathrm{r}$ & $<50$ \\
\hline Chromium - Cr & 13.15 & 8.52 & 23.20 & 28 & 10.00 & 50.00 & 4 & 2 & 6.00 \\
\hline Cobalt - Co & 2.37 & 1.80 & 4.40 & 3 & 1 & 5.00 & 2 & $<1$ & 5.00 \\
\hline Copper - Cu & 7.34 & 4.78 & 11.30 & 10 & 5 & 20.00 & 10 & 4 & 16.00 \\
\hline Fluorine - F & 79.06 & 36.00 & 207.0 & 130 & 30.00 & 500.0 & 65 & 35.00 & 95.00 \\
\hline Lead - Pb & 3.15 & 1.80 & 4.90 & 6 & 1.00 & 15.00 & 3 & $<1$ & 6.00 \\
\hline Lithium - Li & 8.82 & 6.10 & 11.48 & 8 & 4.00 & 18.00 & 3 & 1.00 & 6.00 \\
\hline Manganese - Mn & 16.57 & 10.70 & 27.34 & 40 & 15.00 & 80.00 & 11 & 5.00 & 40.00 \\
\hline Mercury - Hg & 0.09 & 0.05 & 0.15 & 0.07 & 0.04 & 0.14 & 0.06 & 0.03 & 0.09 \\
\hline Molybdenum - Mo & 1.13 & 0.72 & 5.00 & 7.00 & 2.00 & 17.00 & $<2$ & $n / r$ & 4.00 \\
\hline Nickel - Ni & 7.52 & 2.00 & 16.90 & 16 & 5.00 & 44.00 & 3 & $<1$ & 6.00 \\
\hline Selenium - Se & 1.30 & 0.71 & 2.13 & 3 & 1.00 & 9.00 & $<1$ & $n / r$ & 2.00 \\
\hline Silver - Ag & $n / r$ & $n / r$ & $n / r$ & $<0.2$ & $<0.2$ & 0.60 & $<0.2$ & $n / r$ & 0.20 \\
\hline Strontium - Sr & $\mathrm{n} / \mathrm{r}$ & $\mathrm{n} / \mathrm{r}$ & $\mathrm{n} / \mathrm{r}$ & 29 & 10.00 & 60.00 & 173 & 100.0 & 260.0 \\
\hline Thallium - TI & 0.18 & 0.01 & 0.31 & $<1$ & $<1$ & 1.00 & $<1$ & $\mathrm{n} / \mathrm{r}$ & $<1$ \\
\hline Tin - Sn & 0.57 & 0.31 & 1.31 & $<1$ & $<1$ & 1.00 & $<1$ & $n / r$ & $<1$ \\
\hline Thorium - Th & 1.40 & 1.10 & 1.84 & $\mathrm{n} / \mathrm{r}$ & $\mathrm{n} / \mathrm{r}$ & $\mathrm{n} / \mathrm{r}$ & $\mathrm{n} / \mathrm{r}$ & $\mathrm{n} / \mathrm{r}$ & $\mathrm{n} / \mathrm{r}$ \\
\hline
\end{tabular}




\begin{tabular}{|l|c|c|c|c|c|c|c|c|c|}
\hline & \multicolumn{3}{|c|}{$\begin{array}{c}\text { Northern Appalachia } \\
\text { Washed Pittsburgh } \\
\text { Seam Product Ranges }\end{array}$} & $\begin{array}{c}\text { Illinois Basin Washed } \\
\text { Basis Seam III No.6 } \\
\text { State of Illinois }\end{array}$ & \multicolumn{3}{c|}{$\begin{array}{c}\text { Powder River Basin } \\
\text { Raw Basis State of } \\
\text { Wyoming }\end{array}$} \\
\hline & Mean & Min & Max & Mean & Min & Max & Mean & Min & Max \\
\hline Uranium - U & 0.47 & 0.32 & 0.74 & $\mathrm{n} / \mathrm{r}$ & $\mathrm{n} / \mathrm{r}$ & $\mathrm{n} / \mathrm{r}$ & $\mathrm{n} / \mathrm{r}$ & $\mathrm{n} / \mathrm{r}$ & $\mathrm{n} / \mathrm{r}$ \\
\hline Vanadium - V & 15.17 & 9.29 & 28.37 & 35 & 15.00 & 100.0 & 13 & 2.00 & 23.00 \\
Zinc - Zn & 9.05 & 4.00 & 16.80 & 75 & 10.00 & 250.0 & 6 & 1.00 & 20.00 \\
Zirconium - Zr & $\mathrm{n} / \mathrm{r}$ & $\mathrm{n} / \mathrm{r}$ & $\mathrm{n} / \mathrm{r}$ & 18 & 12.00 & 43.00 & 9 & 5.00 & 13.00 \\
\hline
\end{tabular}

Notes: $\quad$ A. For Powder River Basin Coal HGI is reported at $26.6 \%$ moisture.

B. For Illinois \#6 Coal HGI is reported at $28.5 \%$ moisture.

C. Watt - Faraday Method

D. $n / r-$ not reported

\subsubsection{Acid Gas (returned from side stream process)}

Rate:

TBD

Composition:

TBD

Conditions:

TBD

\subsection{Operational Design}

1.3.1. Train Arrangement

Gasifier

Single Train

Gas clean-up

Single Train

ASU

Single Train

$\mathrm{CO}_{2}$ Compression

TBD

CTG/STG System:

1 on 1

\subsubsection{Fuel Flexibility}

Facility will be designed to handle each of the three listed coal types. The respective feed rates will be adjusted to Gasifier limitations when processing the PRB and Northern Appalachian coals.

\subsubsection{Capacity \\ Power (CTG+STG) 275 MWe nominal capacity}




\subsubsection{Composition}

Equipment will be designed to handle impurities based on the mean composition of the design base coal.

\subsubsection{Turndown}

Unit turndowns are based on the levels required to get $60 \%$ of plant power output with any feed.

$\begin{array}{ll}\text { Gasifier } & 60 \% \\ \text { Sour sift/gas cooling } & 60 \% \\ \text { AGRU } & 60 \% \\ \text { SRU/TGTU } & \text { TBD } \\ \text { ASU } & 60 \% \\ \mathrm{CO}_{2} \text { Compression } & 60 \% \\ \text { CTG/STG System: } & 60 \%\end{array}$

\subsubsection{Design Life}

Project life:

5 years at full operation

Equipment design life 25 years

\subsubsection{Availability}

TBD (Two 28 day outages per year are expected)

Must be consistent with $\mathrm{CO}_{2}$ sequestration of $1,000,000$ te/year

\subsubsection{Research and Development Philosophy}

Accommodate side stream R \& D (TBD)

Consider future installation of emerging technologies (TBD)

\subsection{Product Specifications}

\subsubsection{Power}

Delivery Voltage:

$345 \mathrm{kV}$ (to be confirmed)

Capacity:

The facility will be sized to provide1920 MMBTU/hr (LHV) of fuel to the combustion turbine for the base case coal (Illinois \#6)

\subsubsection{Hydrogen}

Possible high purity hydrogen co-production: TBD. Hydrogen product will increase syngas production commensurately

Product Purity: $\quad$ As produced from AGRU 
Product Rate:

TBD

Product Conditions:

As produced from AGRU

\subsubsection{Syngas production (for side stream process)}

Product composition:

As produced from gasifier

Product Rate:

TBD

Product Conditions:

TBD

\subsubsection{Carbon Dioxide}

$\mathrm{CO}_{2}$ Delivery Conditions:

Pressure

2200 psig at Plant limits

Temperature

$100{ }^{\circ} \mathrm{F}$ normal

$95^{\circ} \mathrm{F} \min$

Purity

$130{ }^{\circ} \mathrm{F}$ max

Moisture

$>95 \mathrm{~mol} \% \mathrm{CO}_{2}$

Nitrogen

$<100 \mathrm{ppmv}$

$\mathrm{H}_{2} \mathrm{~S}$

$<0.5 \mathrm{~mol} \%$

$<100$ ppmv

$\mathrm{CO}_{2}$ Recovery:

Specification

$>90 \%$ Removed on an instantaneous basis

Basis

$\mathrm{CO}_{2}$ Sequestration:

Carbon to $\mathrm{CO}_{2}$ pipeline/carbon in gasified coal

Minimum rate:

$1,000,000$ te/year

Peak send-out rate

Maximum instantaneous $\mathrm{CO} 2$ capture (approximately 7000 TPD )

\subsubsection{Sulfur}

Sulfur purity

$>99.9 w t \%$

Sulfur Recovery:

Specification

$>99 \%$ Removed or

$<15$ ppmvd in the treated, syngas fuel whichever is greater

Basis recovery: 1-(sulfur in fuel gas to the CTG /sulfur in coal feed)

syngas content:

Sulfur State

Syngas CTG feed excluding water and diluent Liquid 


\subsection{Catalyst}

Catalyst

Shift Catalyst

Mercury Removal Catalyst:

SRU Catalyst, Bed 1

SRU Catalyst, Bed 2, 3

TGCU Catalyst

Flue Gas Catalyst (SCR)

Ion Exchange Catalyst
Initial Charge

TBD

TBD

TBD

TBD

TBD

TBD

TBD

\section{Expected life}

TBD

TBD

TBD

TBD

TBD

TBD

TBD

\subsection{Chemicals}

Chemical

Water Treatment Chemicals

Solvent for AGRU

BFW/Steam System Chemicals

Flue Gas Treatment Chemicals (for SCR)
Initial Charge Consumption Rate

TBD

TBD

TBD

TBD

TBD

TBD

TBD

TBD

\subsection{Waste Streams}

\subsubsection{Air emissions}

Flue gas and vents to atmosphere: See Environmental Targets

\subsubsection{Liquid wastes}

No liquid waste. Residual wastewater including process runoff and other waste streams will be treated in a Zero Liquid Discharge (ZLD) facility

\subsubsection{Solid Wastes}

Slag:

$\begin{array}{ll}\text { Specification: } & \text { TBD } \\ \text { Rate: } & \text { TBD }\end{array}$

ZLD facility solids:

Specification: TBD

Rate: $\quad$ TBD 


\subsection{Sparing Philosophy}

\subsubsection{General Equipment Sparring}

Sparing philosophy and driver selection shall be as follows:

$$
\text { Equipment Sparing Philosophy }
$$

Prime Movers (Gas and Steam Turbine None Generators)

Heat Recovery Steam Generators

None

Step Up and auxiliary transformers

None

Boiler Feed Pumps

$2 \times 100 \%$

Condensate Pumps

$2 \times 100 \%$

Closed Cooling Water Pumps

$2 \times 100 \%$

Circulating Water Pumps

$2 \times 50 \%$

Miscellaneous other pumps

$2 \times 100 \%$

\subsubsection{Slurry Feed Gasifier}

Gasifier

$1 \times 100 \%$

Fuel feed coal/water slurry feed (up to $65 \%$ solids)

TBD by vendor

Slurry preparation mill (includes slag recycling if applicable)TBD by vendor

Syngas scrubbing tray (counter-flow)

$1 \times 100 \%$

Syngas cooling full quench section at the outlet

$1 \times 100 \%$

\subsubsection{Dry Feed Gasifier}

Gasifier

Fuel feed dry coal, inert gas pressurized injection

Fuel preparation milling and drying

Syngas wet scrubbing tray (counter-flow)

Dry solids removal cyclone, filter
$1 \times 100 \%$

$2 \times 60 \%$

$2 \times 60 \%$

$1 \times 100 \%$

$1 \times 100 \%$ 


\subsubsection{Gas Treating and Power Generation}

Air Separation Unit (ASU).

$1 \times 100 \%$

Water-gas shift fixed bed catalyst

$1 \times 100 \%$

Mercury removal sulfur Impregnated carbon bed

$1 \times 100 \%$

Acid Gas Removal Unit (AGRU)

$1 \times 100 \%$

Sulfur Recovery Unit (SRU)

$1 \times 100 \%$

Syngas reheat \& sweet gas expander (if applicable)

$1 \times 100 \%$

Flare system

$1 \times 100 \%$

Tail Gas Clean-up Unit (TGCU)

$1 \times 100 \%$

Combustion Turbine Generator (CTG)

$1 \times 100 \%$

Heat Recovery Steam Generator (HRSG)

$1 \times 100 \%$

Steam Turbine Generator (STG)

$1 \times 100 \%$

\subsection{Process Equipment Design Margins}

\subsubsection{Heat Exchangers}

The following design margins shall be applied unless specific process requirements demand different values

Exchangers are designed with $10 \%$ excess surface

\subsubsection{Process Pump}

Design at $10 \%$ above the maximum expected operating flow rates with dynamic head determined at this rate.

\subsubsection{Packed Towers}

Max Pressure drop $1 / 2$ " of water per foot of packing

\subsubsection{Trayed Towers}

Max $80 \%$ FRI flooding factor

Minimum $2 \mathrm{ft}$ tray spacing

\subsection{Environmental Targets}

\subsubsection{Air emissions}

Basis

$\mathrm{NO}_{x}$

Particulate matter (PM)

Mercury

$\mathrm{SO}_{2}$

Ammonia
Combustion turbine/HRSG stack to atmosphere $<0.05 \mathrm{lb} \mathrm{NO}_{2} / \mathrm{MMBTU}$ of coal gasified $<0.005 \mathrm{lb}$ PM/ MMBTU of coal gasified $<0.020 \mathrm{lb} \mathrm{Hg} / \mathrm{GW}-\mathrm{h}\left(0.611 \mathrm{lb} / 10^{12} \mathrm{Btu}\right)$ $<0.032 \mathrm{lb}$ S/ MMBTU of coal gasified TBD

\section{Page 20}


Mercury removal $\quad>90 \%$ (as per section 3.4 )

Sulfur removal $\quad>99 \%$ (as per section 2.4 .5 )

\subsubsection{Plant Liquid Effluent}

Facility Liquid Discharge Rate Zero discharge

\subsubsection{Noise Abatement}

Internal to the Plant all OSHA standards will be followed

Noise Impact on Surroundings:

TBD - Project shall meet all state and local noise criteria pertaining to the project site. 


\section{KEY SYSTEM DESIGN FACTORS}

\subsection{ASU}

Type:

Features:

Specifications:

Oxygen:

Pressure

Temperature

Oxygen

$\mathrm{mol} \% \mathrm{Ar}$

$\mathrm{mol} \% \mathrm{~N}_{2}$

Rate

Nitrogen:

Pressure

Temperature

$\mathrm{mol} \% \mathrm{Ar}$

$\mathrm{mol} \% \mathrm{~N}_{2}$

Rate

Compressor Driver Type

Storage (liquid):

Oxygen:

Storage capacity

Liquid rate to storage

Vaporization rate

Nitrogen:

Storage capacity

Liquid rate to storage

Vaporization rate
Cryogenic Air Separation Unit

ASU will also supply nitrogen rich purge gas, instrument/plant air and diluent for hydrogen rich gas turbine fuel. Nitrogen rich gas may also be supplied for coal transport and/or drying.

Gasifier technology supplier to advise

$80^{\circ} \mathrm{F}$ Minimum

95 mole \%

TBD

TBD

TBD

TBD

TBD

3.8 mole \% (Typical)

1.2 mole \% (Typical)

TBD

TBD

TBD

TBD

TBD

TBD

TBD

TBD

\subsection{Gasifier}

Type:

Features:

Performance

futureson
As determined by technology evaluation Must meet process requirement and fuel flexibility requirements

$>98 \%$ carbon conversion 
Storage

Slag/Ash silo capacity

\subsection{Shift Reactor System}

Type

Features

Performance

Actual conversion of $\mathrm{CO}$

\subsection{Mercury Removal}

Type

Performance

Basis

\subsection{AGRU}

Type

Features
(TBD) hours on slurry buffer capacity (if applicable)

72 hours of full operation (to be confirmed)

Multistage sour water gas shift reactors with heat recovery

Integrated heat recovery

Minimum $98 \%$ conversion of CO (to be confirmed)

TBD

TBD

$>90 \%$ mercury removal

1 -(mercury rejected to air/mercury in coal)

Minimum performance requirements are:

An integrated AGRU with high reliability and efficiency is desired

Must remove both $\mathrm{CO}_{2}$ and $\mathrm{H}_{2} \mathrm{~S}$ to meet sequestration, carbon capture and sulfur recovery requirements

Sulfur removal efficiency to support specification (section 2.4.4)

Product hydrogen from AGRU contains $<15$ ppmv of sulfur

Product hydrogen from AGRU contains $<$ TBD ppmv of arsenic

$\mathrm{CO}_{2}$ recovery to support specification (section 2.4.3)

$\mathrm{CO}_{2}$ purity to support specification (section 2.4.3)

Storage:

Solvent storage

TBD (based on system inventory and losses)

\subsection{SRU}

Type

Claus type unit

Sulfur recovery

TBD (based on once through)

\subsection{TGCU}

(need for this unit to be confirmed during Concept Design as function of return destination)

Type

Reduction method

Performance
$\mathrm{SO}_{2}$ reduction unit

TBD, catalytic

Nominal total conversion of $\mathrm{SO}_{2}$ 


\subsection{Steam System}

Type

Features
HP Gasifier Syngas cooler (if provided), Heat Recovery HP Steam Generator (HRSG) Horizontal gas flow, drum-type, multi-pressure design with deaerator and process integrated heat recovery (to be confirmed)

For steam levels see Section 5.

\subsection{Coal Storage and Handling}

Receipt Method

Rail/overland conveyor. Handling includes storage, conveying, drying, grinding and feeding TBD based on site selection and gasifier technology.

Unloading

Drying

TBD, approximately 150 rail cars with 100 tons/car

Grinding

TBD by gasifier technology

Storage

TBD by gasifier technology

Blending

$1 \times 30$ day storage piles

TBD

\subsection{Power Island}

Type

Reheat

Steam Turbine Generator (STG)/Combustion Turbine Generator (CTG)

Condenser type

TBD

Features

TBD

Combustion Turbine Generator (F class) modified for hydrogen rich fuel gas service. Natural gas or alternate fuel start up

Performance

TBD

\subsection{Water Treatment}

Performance:

Feed water to meet process requirement.

Waste water to meet zero liquid discharge (ZLD)

Storage:

Waste water

24 hours feed to ZLD unit.

For utility water storage requirements see Section 5 . 


\section{SITE SPECIFIC DATA}

The following data is specific site. All data shown are assumptions for design development only.

\subsection{Climatic Data}

Average Barometric Pressure

29.38 in $\mathrm{Hg}$

Relative Humidity

$72 \%$

Temperature

Minimum design temperature

$-22^{\circ} \mathrm{F}$

Maximum design temperature

$112^{\circ} \mathrm{F}$

Summer maximum design temperature (dry bulb)

$88^{\circ} \mathrm{F}$

Summer maximum design temperature (wet bulb)

$75^{\circ} \mathrm{F}$

Wind

Direction of prevailing wind (summer)

SSW - $8.01 \mathrm{mph}$

Direction of prevailing wind (winter)

$\mathrm{S}-11.2 \mathrm{mph}$

Maximum recorded velocity (sustained)

$61 \mathrm{mph}$ (2 minutes)

Maximum recorded velocity (gusts)

74 mph (5 seconds)

Structural designs shall be based on

$\mathrm{mph}$

Hurricane considerations are not required.

\section{Rainfall}

Maximum recorded in one hour

in

Maximum recorded in 12 hours

in

Maximum recorded in 24 hours

6.12 in

Maximum recorded in 24 hours (25 year frequency)

4.5 in

Snow

Maximum snow depth

16 in

Design snow loading factor

psf

\subsection{Seismic Design Parameters:}

Based on IBC 2006 and ASCE7-05, Site Class B 


\section{Design Basis \\ Rev. D \\ Doc. Number: 29207-700-51-ENG-00-000-001}

\subsection{Site Plan}

Site coordinates TBD

Natural drainage from site TBD.

Principal access to site by public road TBD

Nearest railroad siding approximately $600 \mathrm{ft}$.

Clearances to be provided to meet safety requirements, etc., at each boundary of the plot for:
$\mathrm{N}$
S
$\mathrm{E}$
W

Fired Heaters

Storage Tanks (inflammable)

Process Equipment

Buildings (non-hazardous)

Insurance or safety requirement affecting equipment spacing

TBD

Noise limits

Refer to Section 1.10.3

\subsection{Site Elevation}

Site is approximately 679 to $718 \mathrm{ft}$ above sea level.

Plant elevations are established with reference to (bench mark) (__ $)$ which is at elevation $\mathrm{ft}$ and is located 
Elevations of new unit with reference to above are:

Low point existing grade:

High point existing grade:

High point finished grade:

Low point finished grade:

Base line will be at high point of finished paving = elevation 100"-0".

The site (is) (is not) subject to possible flood condition; the maximum 100 year flood level is elevated $\mathrm{ft}$ and flood design (is) (is not) required.

Finished top of foundations and high point of floors will be at elevation (xx"-0") or ) .

\subsection{Soil Information (Hold)}

\section{UTILITY INFORMATION}

Initial data is for concept development only and not site specific. Data must be updated upon site selection

\subsection{Steam (to be confirmed)}

$\begin{array}{llll}\text { HP } & \text { MP Steam IP1 Steam IP2 Steam LP Steam } \\ \text { Steam } & & \end{array}$

At plant header

Normal pressure, psig $\quad 1800$

622

635

450

150

50

Saturated temperature, ${ }^{\circ} \mathrm{F}$

495

459

366

298

Minimum pressure, psig

Superheated temperature, ${ }^{\circ} \mathrm{F}$

1000

$550(1)$

TBD

TBD

TBD

Design Pressure, psig

2200

715

500

175

75

Design Temperature, ${ }^{\circ} \mathrm{F}$

TBD

650

TBD

TBD

TBD

Note 1. Superheat determined by process requirement 


\subsection{Steam Condensate}

Steam condensate return systems shall be provided if feasible

Deaerator pressure TBD

Disposition of recovered condensate from:

Turbine Condensers: $\quad$ Heated and returned to deaerator

Process Heaters: $\quad$ Returned to next lowest level

Building Heaters: Returned to deaerator

Tank Heaters:

Returned to deaerator

Steam Separators:

Returned to appropriate level

\subsection{Water}

\begin{tabular}{|c|c|c|c|c|c|}
\hline & $\begin{array}{l}\text { Potable } \\
\text { Water }\end{array}$ & $\begin{array}{l}\text { Raw } \\
\text { Water }\end{array}$ & $\begin{array}{l}\text { Cooling } \\
\text { Water }\end{array}$ & $\begin{array}{l}\text { Fire } \\
\text { Water }\end{array}$ & $\begin{array}{l}\text { Demin. } \\
\text { Water }\end{array}$ \\
\hline Source & & $B / L$ & $\begin{array}{l}\text { Cooling } \\
\text { Tower }\end{array}$ & $\begin{array}{l}\text { Site } \\
\text { Storage }\end{array}$ & Plant unit \\
\hline Return to & & NA & CT Basin & NA & NA \\
\hline Design Pressure, psig & & & 75 & & \\
\hline Design Temperature, ${ }^{\circ} \mathrm{F}$ & & & 200 & & \\
\hline Supply Press. at grade, psig & & & 30 & & \\
\hline $\begin{array}{l}\text { Return Pressure at grade, } \\
\text { psig }\end{array}$ & & & 20 & & \\
\hline Supply Temp, ${ }^{\circ} \mathrm{F}$ for design & & 60 & 85 & & \\
\hline Return Temp, ${ }^{\circ} \mathrm{F}$ for design & & & 125 & & \\
\hline $\begin{array}{l}\text { Quantity Available for this } \\
\text { project, Ib/hr }\end{array}$ & & & & & \\
\hline $\begin{array}{l}\text { Storage required (times and } \\
\text { basis to be confirmed) }\end{array}$ & 4 hours & 8 hours & $\begin{array}{c}4 \text { hours } \\
\text { based on } \\
\text { makeup }\end{array}$ & $\begin{array}{c}8 \text { hours } \\
\text { based on } \\
\text { max fire } \\
\text { case }\end{array}$ & $\begin{array}{l}12 \text { hours } \\
\text { minimum }\end{array}$ \\
\hline $\mathrm{pH}$ & & 7.64 & & & \\
\hline Conductivity ( $\mu \mathrm{mhos} / \mathrm{cm})$ & & 510 & & & $<0.1$ \\
\hline Analysis & & $\mathrm{mg} / \mathrm{l}$ & & & $\mathrm{ppb}$ \\
\hline
\end{tabular}




\begin{tabular}{|c|c|c|c|c|c|}
\hline & $\begin{array}{l}\text { Potable } \\
\text { Water }\end{array}$ & $\begin{array}{l}\text { Raw } \\
\text { Water }\end{array}$ & $\begin{array}{l}\text { Cooling } \\
\text { Water }\end{array}$ & $\begin{array}{c}\text { Fire } \\
\text { Water }\end{array}$ & $\begin{array}{l}\text { Demin. } \\
\text { Water }\end{array}$ \\
\hline Total Hardness as $\mathrm{CaCO}_{3}$ & & & & & \\
\hline Calcium as $\mathrm{Ca}^{++}$ & & 46 & & & \\
\hline Magnesium as $\mathrm{Mg}^{++}$ & & 12 & & & \\
\hline Total Alkalinity as $\mathrm{CaCO}_{3}$ & & & & & \\
\hline Sulfate as $\mathrm{SO}_{4}$ & & 29 & & & $<3$ \\
\hline Chloride as $\mathrm{Cl}^{-}$ & & 50 & & & $<3$ \\
\hline Nitrates as $\mathrm{NO}_{3}$ & & 12 & & & \\
\hline Silica as $\mathrm{SiO}_{2}$ & & 3.3 & & & $<10$ \\
\hline Bicarbonate as $\mathrm{HCO}_{3}$ & & 92 & & & \\
\hline Potassium as $\mathrm{K}$ & & 8.8 & & & \\
\hline Sodium as $\mathrm{Na}$ & & 33 & & & $<5$ \\
\hline Iron as Fe & & 0.16 & & & \\
\hline Manganese as Mn & & 0.018 & & & \\
\hline Phosphate as $\mathrm{PO}_{4}$ & & 12 & & & \\
\hline Oxygen as $\mathrm{O}_{2}$ & & & & & 8000 \\
\hline Carbon Dioxide & & & & & \\
\hline Total Organic Carbon & & 5.3 & & & $<300$ \\
\hline Total Dissolved Solids & & 320 & & & \\
\hline Total Suspended Solids & & 7 & & & \\
\hline
\end{tabular}




\subsection{Natural Gas}

Normal pressure, psig

Fuel Gas

Maximum pressure, psig

400

Minimum pressure, psig

450

Design Pressure, psig

250

Design Temperature, ${ }^{\circ} \mathrm{F}$

500

Gross (HHV) heating value,

200

Net (LHV) heating value,

$1038 \mathrm{Btu} / \mathrm{SCF}$

Specific gravity, (relative density

$936 \mathrm{Btu} / \mathrm{SCF}$

with respect to air)

Normal temperature, ${ }^{\circ} \mathrm{F}$

0.59

Total sulfur content, $\mathrm{gr} / 100 \mathrm{scf}(1)$

100

$\mathrm{H}_{2} \mathrm{~S}$ content, gr/100 scf(1)

4

Maximum available, SCFH

0.25

Analysis, Volume \%

Nitrogen

Carbon Dioxide

0.6

Methane

94.35

Ethane

Ethylene

0

Propane

0.96

Propylene

0

Isobutane

0.24

Normal Butane

0.2

Note (1) grains/100 standard cubic feet $\quad(7000$ grains $=1$ pound $)$ 


\subsection{Compressed Gases}

Operating Pressure, psig

Plant Air

100

100

Operating Temperature, ${ }^{\circ} \mathrm{F}$

Max. Oper. Pressure, psig

Min. Oper. Pressure, psig

Design Pressure, psig

Design Temperature, ${ }^{\circ} \mathrm{F}$

Capacity, SCFH

Source

$\begin{array}{cc}\text { Instrument Air } & \text { Utility Nitrogen } \\ 100 & 100 \\ 100 & 60 \\ & \\ 60 & 70 \\ 150 & 150 \\ 150 & 150\end{array}$

ASU with

Compressor

backup

ASU

Backup instrument air system must include air dryer. Instrument air dew point is $-40^{\circ} \mathrm{F}$. Maximum oxygen content of the nitrogen is $0.5 \mathrm{~mol} \%$ dry basis.

\subsection{Electric Power}

Electric power is generated internally for normal operation

Start-up power is available from the grid

Voltage:

$345 \mathrm{kV}$ (to be confirmed)

Import Capacity:

TBD MW 


\section{ECONOMICS}

Minimum rate of return for net present value calculations: TBD\%

Availability at $100 \%$ capacity for economic evaluation: $80 \%$.

Taxes shall not be included. Economic evaluations shall use the following pricing:

\begin{tabular}{|c|c|}
\hline Commodity & Price in $\$$ \\
\hline HP Steam, \$/1000 lb & $12.98 / 9.50(1,5)$ \\
\hline MP Steam, \$/1000 lb & $10.00 / 9.10(1,5)$ \\
\hline IP1 Steam, \$/1000 lb & NA/8.88(1,5) \\
\hline IP2 Steam, \$/1000 lb & $\mathrm{NA} / 6,42(1,5)$ \\
\hline LP Steam, \$/1000 lb & $\mathrm{NA} / 3,85(1,5)$ \\
\hline Condensate, $\$ / 1000 \mathrm{lb}$ & 1.20 \\
\hline Boiler Feed Water, \$/1000 lb & 4.60(HP)/TBD (LP) (2) \\
\hline Plant Water, $\$ / 1000 \mathrm{lb}$ & 0.20 \\
\hline Raw Water, \$/1000 lb & 0.14 \\
\hline Cooling Water, \$/1000 lb & 0.012 \\
\hline Fuel Gas, \$/MMBTU & 8.00 \\
\hline Diesel Fuel, \$/MMBTU & 11.00 \\
\hline Plant Air & \\
\hline LP Nitrogen & \\
\hline Diluent Nitrogen & $5.99(5)$ \\
\hline Diluent $\mathrm{H}_{2} \mathrm{O}$ vapor & $10.35(5)$ \\
\hline Inert Gas & \\
\hline Coal & \\
\hline WGS catalyst & \\
\hline AGRU solvent & \\
\hline Products & \\
\hline Electric Power, \$/kWh & $0.074(4)$ \\
\hline
\end{tabular}




\begin{tabular}{|l|c|}
\hline \multicolumn{1}{|c|}{ Commodity } & Price in $\$$ \\
\hline Sulfur & \\
$\mathrm{CO}_{2}$ & \\
\hline
\end{tabular}

Basis Notes:

(1) All steam levels (Superheated/saturated) include cost of condensate (deduct if returned)

(2) HP BFW includes power and heat to $627 \mathrm{~F}$ and $2000 \mathrm{psig}$

(3) Steam/Condensate values include capital cost components

(4) The value of power is for the nth commercial plant

(5) The values of steam and diluents are based on incremental power that can generated at power island interface conditions (section 5.1) as determined by Gate Cycle runs.

(6) On a circulating water basis 


\section{SPECIFICATIONS, ENGINEERING STANDARDS \& DESIGN REQUIREMENTS}

ASME Boiler \& Pressure Vessel Codes

ANSI Codes for Pressure Piping (B31.3 and 31.8)

ASTM Standards

ACI Standards

AISC Specifications

TEMA Standards

IEEE, NEMA \& ANSI Standards for Electrical Equipment

ISA Recommended Practices

API Standards, Specifications, and Recommended Practices

NFPA National Fire Codes

OIA Oil Insurance Association - General Recommendations for Spacing

\section{Specific Codes and Standards used}

\begin{tabular}{|l|l|l|}
\hline \multicolumn{2}{|l|}{ Title } & \multicolumn{2}{c|}{ Edition } \\
\hline Mechanical & $\begin{array}{l}\text { Axial and Centrifugal } \\
\text { Compressors }\end{array}$ & $7^{\text {th }}$ Edition 2000 \\
\hline API 617 & Special Purpose Gear Units & $5^{\text {th }}$ Edition 2003 \\
\hline API 613 & $\begin{array}{l}\text { Lubrication, Shaft Sealing and } \\
\text { Control Oil Systems }\end{array}$ & $4^{\text {th }}$ Edition 1999 \\
\hline API 614 & Machinery Protection Systems & $4^{\text {th }}$ Edition $2000 / 2003$ \\
\hline API 670 & Special Purpose Couplings & $3^{\text {rd }}$ Edition 1998 \\
\hline API 671 & Type One Performance Test & 1997 \\
\hline ASME PTC 10 & Centrifugal Pumps & $10^{\text {th }}$ Edition 2004 \\
\hline API 610 & Fired Heaters & $4^{\text {th }}$ Edition 2007 \\
\hline API 560 & $\begin{array}{l}\text { Shaft Sealing Systems for } \\
\text { Centrifugal and Rotary Pumps }\end{array}$ & $3^{\text {rd }}$ Edition 2004 \\
\hline API 682 & Div 1 \& 2 Pressure Vessels & 2004 Edition \\
\hline ASME Sec VIII & $\begin{array}{l}\text { Welded Steel Tanks for Oil } \\
\text { Storage }\end{array}$ & $11^{\text {th }}$ Edition 2007 \\
\hline API 650 & &
\end{tabular}


Doc. Number: 29207-700-51-ENG-00-000-001

\begin{tabular}{|c|c|c|}
\hline & Title & Edition \\
\hline API 620 & $\begin{array}{l}\text { Design and construction of } \\
\text { Large, Welded, Low Pressure } \\
\text { Storage Tanks }\end{array}$ & $10^{\text {th }}$ Edition 2002 \\
\hline API 660 & Shell \& Tube Heat Exchangers & $7^{\text {th }}$ Edition 2003 \\
\hline API 661 & Air Cooled Heat Exchangers & $6^{\text {th }}$ Edition 2006 \\
\hline API 686 & Machinery Installation & April 1996 \\
\hline IBC & International Building Code & 2006 Edition \\
\hline IFC & International Fire Code & 2006 Edition \\
\hline NFPA 10 & $\begin{array}{l}\text { Standard for Portable Fire } \\
\text { Extinguishers }\end{array}$ & 2007 Edition \\
\hline NFPA 12 & $\begin{array}{l}\text { Standard on Carbon Dioxide } \\
\text { Extinguishing Systems }\end{array}$ & 2005 Edition \\
\hline NFPA 13 & $\begin{array}{l}\text { Standard for the Installation of } \\
\text { Sprinkler Systems }\end{array}$ & 2007 Edition \\
\hline NFPA 14 & $\begin{array}{l}\text { Standard for the Installation of } \\
\text { Standpipe and Hose Systems }\end{array}$ & 2007 Edition \\
\hline NFPA 15 & $\begin{array}{l}\text { Standard for Water Spray Fixed } \\
\text { Systems for Fire Protection }\end{array}$ & 2007 Edition \\
\hline NFPA 18 & Standard on Wetting Agents & 2006 Edition \\
\hline NFPA 20 & $\begin{array}{l}\text { Standard for the Installation of } \\
\text { Stationary Pumps for Fire } \\
\text { Protection }\end{array}$ & 2007 Edition \\
\hline NFPA 22 & $\begin{array}{l}\text { Standard for Water Tanks for } \\
\text { Private Fire Protection }\end{array}$ & 2003 Edition \\
\hline NFPA 24 & $\begin{array}{l}\text { Standard for the Installation of } \\
\text { Private Fire Service Mains and } \\
\text { Their Appurtenances }\end{array}$ & 2007 Edition \\
\hline NFPA 30 & $\begin{array}{l}\text { Flammable and Combustible } \\
\text { Liquids Code }\end{array}$ & 2003 Edition \\
\hline NFPA 37 & $\begin{array}{l}\text { Standard for the Installation and } \\
\text { Use of Stationary Combustion } \\
\text { Engines and Gas Turbines }\end{array}$ & 2006 Edition \\
\hline NFPA 54 & National Fuel Gas Code & 2006 Edition \\
\hline NFPA 55 & $\begin{array}{l}\text { Standard for the Storage, Use, } \\
\text { and Handling of Compressed } \\
\text { Gases and Cryogenic Fluids in } \\
\text { Portable and Stationary }\end{array}$ & 2005 Edition \\
\hline
\end{tabular}

\section{Page 35}


Doc. Number: 29207-700-51-ENG-00-000-001

\begin{tabular}{|c|c|c|}
\hline & Title & Edition \\
\hline & $\begin{array}{l}\text { Containers, Cylinders, and } \\
\text { Tanks }\end{array}$ & \\
\hline NFPA 68 & $\begin{array}{l}\text { Guide for Venting of } \\
\text { Deflagrations }\end{array}$ & 2007 Edition \\
\hline NFPA 69 & $\begin{array}{l}\text { Standard on Explosion } \\
\text { Prevention Systems }\end{array}$ & 2007 Edition \\
\hline NFPA 70 & National Electrical Code & 2005 Edition \\
\hline NFPA $70 E$ & $\begin{array}{l}\text { Standard for Electrical Safety in } \\
\text { the Workplace }\end{array}$ & 2004 Edition \\
\hline NFPA 72 & National Fire Alarm Code & 2007 Edition \\
\hline NFPA 75 & $\begin{array}{l}\text { Standard for the Protection of } \\
\text { Information Technology } \\
\text { Equipment }\end{array}$ & 2003 Edition \\
\hline NFPA 80 & $\begin{array}{l}\text { Standard for Fire Doors and } \\
\text { Other Opening Protectives }\end{array}$ & 2007 Edition \\
\hline NFPA 85 & $\begin{array}{l}\text { Boiler and Combustion } \\
\text { Systems Hazards Code }\end{array}$ & 2004 Edition \\
\hline NFPA $90 A$ & $\begin{array}{l}\text { Standard for the Installation of } \\
\text { Air-Conditioning and Ventilating } \\
\text { Systems }\end{array}$ & 2002 Edition \\
\hline NFPA 110 & $\begin{array}{l}\text { Standard for Emergency and } \\
\text { Standby Power Systems }\end{array}$ & 2005 Edition \\
\hline NFPA 111 & $\begin{array}{l}\text { Standard on Stored Electrical } \\
\text { Energy Emergency and } \\
\text { Standby Power Systems }\end{array}$ & 2005 Edition \\
\hline NFPA 170 & $\begin{array}{l}\text { Standard for Fire Safety and } \\
\text { Emergency Symbols }\end{array}$ & 2006 Edition \\
\hline NFPA 214 & $\begin{array}{l}\text { Standard on Water-Cooling } \\
\text { Towers }\end{array}$ & 2005 Edition \\
\hline NFPA 220 & $\begin{array}{l}\text { Standard on Types of Building } \\
\text { Construction (Not applicable } \\
\text { where IBC is required) }\end{array}$ & 2006 Edition \\
\hline NFPA 497 & $\begin{array}{l}\text { Recommended Practice for the } \\
\text { Classification of Flammable } \\
\text { Liquids, Gases, or Vapors and } \\
\text { of Hazardous (Classified) } \\
\text { Locations for Electrical } \\
\text { Installations in Chemical }\end{array}$ & 2004 Edition \\
\hline
\end{tabular}




\begin{tabular}{|c|c|c|}
\hline & Title & Edition \\
\hline & Process Areas & \\
\hline NFPA 496 & $\begin{array}{l}\text { Standard for Purged and } \\
\text { Pressurized Enclosures for } \\
\text { Electrical Equipment }\end{array}$ & 2003 Edition \\
\hline NFPA 499 & $\begin{array}{l}\text { Recommended Practice for the } \\
\text { Classification of Combustible } \\
\text { Dusts and of Hazardous } \\
\text { (Classified) Locations for } \\
\text { Electrical Installations in } \\
\text { Chemical Process Areas }\end{array}$ & 2004 Edition \\
\hline NFPA 654 & $\begin{array}{l}\text { Standard for the Prevention of } \\
\text { Fire and Dust Explosions from } \\
\text { the Manufacturing, Processing, } \\
\text { and Handling of Combustible } \\
\text { Particulate Solids }\end{array}$ & 2006 Edition \\
\hline NFPA 655 & $\begin{array}{l}\text { Standard for Prevention of } \\
\text { Sulfur Fires and Explosions }\end{array}$ & 2007 Edition \\
\hline NFPA 750 & $\begin{array}{l}\text { Standard on Water Mist Fire } \\
\text { Protection Systems }\end{array}$ & 2006 Edition \\
\hline NFPA 850 & $\begin{array}{l}\text { Recommended Practice for Fire } \\
\text { Protection for Electric } \\
\text { Generating Plants and High } \\
\text { Voltage Direct Current } \\
\text { Converter Stations } \\
\end{array}$ & 2005 Edition \\
\hline NFPA 2001 & $\begin{array}{l}\text { Standard on Clean Agent Fire } \\
\text { Extinguishing Systems }\end{array}$ & 2004 Edition \\
\hline \multicolumn{3}{|c|}{ Instrumentation and Controls } \\
\hline IEC 60751 & $\begin{array}{l}\text { Industrial Platinum Resistance } \\
\text { Thermometer Sensors }\end{array}$ & \\
\hline IEC $61000-4-2,3, \& 4$ & $\begin{array}{l}\text { Electromagnetic Compatibility } \\
\text { (EMC) }\end{array}$ & \\
\hline IEC 61499-1 \& 2 & $\begin{array}{l}\text { Function Blocks for Industrial } \\
\text { Process Measurement and } \\
\text { Control Systems }\end{array}$ & \\
\hline IEC 61508 & $\begin{array}{l}\text { Functional Safety of } \\
\text { Electrical/Electronic/ } \\
\text { Programmable Electronic } \\
\text { Safety-Related Systems }\end{array}$ & \\
\hline IEC 61529 & Degree of Protection Provided & \\
\hline
\end{tabular}




\begin{tabular}{|l|l|l|}
\hline & \multicolumn{1}{|c|}{ Title } & Edition \\
\hline & By Enclosures (IP Codes) & \\
\hline IEC 61158-2 & $\begin{array}{l}\text { Foundation Fieldbus Standard } \\
\text { for Use in Industrial Control } \\
\text { Systems - Physical Layer } \\
\text { Specification and Service } \\
\text { Definition }\end{array}$ & \\
\hline IEC 61131-3 & PLC Programming Languages & \\
\hline ANSI C37.90 & $\begin{array}{l}\text { Relays and Relay Systems } \\
\text { Associated with Electric Power } \\
\text { Apparatus }\end{array}$ & \\
\hline ANSI C37.90a & $\begin{array}{l}\text { Guide for Surge Withstand } \\
\text { Capability (SWC) Tests }\end{array}$ & \\
\hline API 554 & $\begin{array}{l}\text { Process Instrumentation and } \\
\text { Control }\end{array}$ & \\
\hline IEEE 383 & $\begin{array}{l}\text { IEEE Standard for Type Test } \\
\text { for Class IE Electric Cables, } \\
\text { Field Splices, and Connections } \\
\text { for Nuclear Power Generating } \\
\text { Stations (Section 2.5, Flame } \\
\text { Test, only) }\end{array}$ & \\
\hline IEEE 1588 & $\begin{array}{l}\text { Standard for a Precision Clock } \\
\text { Synchronization Protocol for } \\
\text { Networked Measurement and } \\
\text { Control Systems }\end{array}$ & \\
\hline ISA 5.4 & $\begin{array}{l}\text { Flame Resisting Test (Section } \\
\text { 6.5) }\end{array}$ & \\
\hline ISA 5.5 & $\begin{array}{l}\text { Fiber Optic Outside Plant } \\
\text { Communications Cable }\end{array}$ & \\
\hline ISA RP12.4 & $\begin{array}{l}\text { Instrumentation Symbols and } \\
\text { Identification }\end{array}$ & \\
\hline ISA 50.02 & $\begin{array}{l}\text { Binary Logic Diagrams for } \\
\text { Process Operations }\end{array}$ & \\
\hline ICEA S-61-402 & Instrument Loop Diagrams & \\
\hline ISA 5.1 & $\begin{array}{l}\text { Graphic Symbols for Process } \\
\text { Diagrams }\end{array}$ & \\
\hline ISA 5.2 & Pressurized Enclosure & \\
\hline In-640 & $\begin{array}{l}\text { Fieldbus Standard for Use in } \\
\text { Industrial Control Systems }\end{array}$ & \\
\hline & \\
\hline
\end{tabular}

